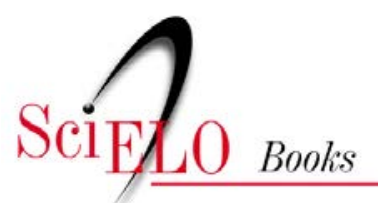

\title{
Leishmanioses do continente americano
}

\author{
Fátima Conceição-Silva \\ Carlos Roberto Alves \\ (orgs.)
}

CONCEIÇÃO-SILVA, F., and ALVES, C. R., comps. Leishmanioses do continente americano [online]. Rio de Janeiro: Editora FIOCRUZ, 2014, 511 p. ISBN 978-85-7541-568-9.

https://doi.org/10.7476/9788575415689.

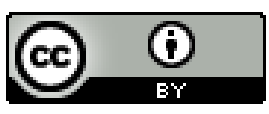

All the contents of this work, except where otherwise noted, is licensed under a Creative Commons Attribution 4.0 International license.

Todo o conteúdo deste trabalho, exceto quando houver ressalva, é publicado sob a licença Creative Commons Atribição 4.0. 


\section{LEISHMAMIOSES DO CONTINENTE AMERICANO}


FUNDAÇÃO OSWALDO CRUZ

Presidente

Paulo Gadelha

Vice-Presidente de Ensino, Informação e Comunicação

Nísia Trindade Lima

\section{EDITORA FIOCRUZ}

Diretora

Nísia Trindade Lima

Editor Executivo

João Carlos Canossa Mendes

Editores Científicos

Carlos Machado de Freitas

Gilberto Hochman

Conselho Editorial

Claudia Nunes Duarte dos Santos

Jane Russo

Ligia Maria Vieira da Silva

Maria Cecília de Souza Minayo

Marilia Santini de Oliveira

Moisés Goldbaum

Pedro Paulo Chieffi

Ricardo Lourenço de Oliveira

Ricardo Ventura Santos

Soraya Vargas Côrtes 
Fátima Conceição-Silva

Carlos Roberto Alves

organizadores

\section{LEISHMANIOSES DO CONTINENTE AMERICANO}

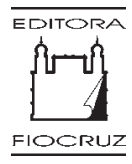


Copyright (C) 2014 dos organizadores

Todos os direitos desta edição reservados à

Fundação Oswaldo CRUz / Editora

Projeto gráfico, capa, editoração eletrônica e tratamento de imagens Adriana Carvalho Peixoto da Costa e Carlos Fernando Reis da Costa

Revisão e copidesque Marcionílio Cavalcanti de Paiva, Augusta Avalle, Myllena Paiva

Normalização de referências

Clarissa Bravo e Gislene Coimbra

Catalogação na fonte

Instituto de Comunicação e Informação Científica e Tecnológica

Biblioteca de Saúde Pública

C7441 Conceição-Silva, Fátima (Org.)

Leishmanioses do continente americano. / organizado por Fátima ConceiçãoSilva e Carlos Roberto Alves. - Rio de Janeiro: Editora Fiocruz, 2014.

512 p. : il. ; tab.

ISBN: 978-85-7541-439-2

1. Leishmaniose. I. Alves, Carlos Roberto (Org.). II. Título.

CDD - 22.ed. -616.9364

2014

EDITORA FIOCRUZ

Av. Brasil, 4036 - 1ำ andar - sala 112 - Manguinhos

21040-361 - Rio de Janeiro - RJ

Tels.: (21) 3882-9039 e 3882-9041

Telefax: (21) 3882-9006

editora@fiocruz.br

www.fiocruz.br/editora 
$\underline{\text { Autores }}$

\section{Adriano Gomes-Silva}

Biólogo, doutor em medicina tropical pelo Instituto Oswaldo Cruz (IOC/Fiocruz); pesquisador visitante, bolsista de produtividade em pesquisa pelo CNPq, Laboratório Interdisciplinar de Pesquisas Médicas do IOC/Fiocruz.

\section{Alda Maria Da-Cruz}

Médica-infectologista, doutora em medicina tropical pelo Instituto Oswaldo Cruz (IOC/Fiocruz), onde também é pesquisadora em saúde pública; professora associada da Faculdade de Ciências Médicas da Universidade do Estado do Rio de Janeiro (Uerj); membro titular da Academia de Medicina do Rio de Janeiro (AMRJ).

\section{Alexandre A. Peixoto (in memoriam)}

Biólogo, doutor em genética pela Universidade de Leicester, Reino Unido; pesquisador titular do Instituto Oswaldo Cruz/Fundação Oswaldo Cruz (IOC/Fiocruz).

\section{Aline Fagundes}

Bióloga, doutora em vigilância sanitária pelo Instituto Nacional de Controle de Qualidade em Saúde (INCQS/Fiocruz); tecnologista pleno do Instituto de Pesquisa Clínica Evandro Chagas/Fundação Oswaldo Cruz (Ipec/Fiocruz).

\section{Amanda dos Santos Cavalcanti}

Médica-veterinária, doutoranda do Programa de Pós-Graduação em Biologia Celular e Molecular pelo Instituto Oswaldo Cruz (IOC/Fiocruz), onde atua no Laboratório de Pesquisa em Leishmaniose.

\section{Ana Carolina Ramos Guimarães}

Bióloga, doutora em biologia celular e molecular pelo Instituto Oswaldo Cruz (IOC/Fiocruz), no qual atua como assistente de pesquisa.

\section{Ana Maria Jansen}

Médica-veterinária, doutora em microbiologia e imunologia, pós-doutorado pela Universidade de Nova York, EUA; pesquisadora titular do Laboratório de Biologia de Tripanosomatídeos (IOC/Fiocruz); bolsista de produtividade em pesquisa pelo CNPq e 'cientista do nosso estado' pela Faperj.

\section{André Luiz Rodrigues Roque}

Médico-veterinário, doutor em biologia parasitária; tecnologista em saúde pública do Laboratório de Biologia de Tripanosomatídeos (IOC/Fiocruz); 'jovem cientista do nosso estado' pela Faperj. 


\section{André N. Pitaluga}

Biólogo, doutor em biologia celular e molecular; pesquisador adjunto do Laboratório de Biologia Molecular de Parasitas e Vetores do Instituto Oswaldo Cruz (IOC/Fiocruz).

\section{Antonio J. Tempone}

Biólogo, doutor em biologia molecular pelo Instituto de Bioquímica Médica da Universidade Federal do Rio de Janeiro (IBqM/UFRJ); pesquisador em saúde pública do Instituto Oswaldo Cruz (IOC/Fiocruz).

\section{Armando 0. Schubach}

Médico, doutor em protozoologia; pesquisador titular do Instituto de Pesquisa Clínica Evandro Chagas (Ipec/Fiocruz); bolsista de produtividade em pesquisa pelo CNPq e 'cientista do nosso estado' pela Faperj.

\section{Beatriz Gomes Brazil}

Farmacêutica, doutora em biologia parasitária pelo Instituto Oswaldo Cruz (IOC/Fiocruz), pós-doutorado em medicina tropical pela Universidade de Liverpool, Reino Unido.

\section{Bernardo Acácio Santini Pereira}

Biólogo, doutor em ciências pelo Instituto Oswaldo Cruz (IOC/Fiocruz), pós-doutorando no Laboratório de Biologia Molecular e Doenças Endêmicas do mesmo instituto.

\section{Camila Guerra Silva}

Bióloga, doutora em ciências pelo Instituto Oswaldo Cruz (IOC/Fiocruz), pós-doutoranda no Laboratório de Biologia Estrutural do mesmo instituto.

\section{Carlos Henrique Nery Costa}

Médico, doutor em saúde pública tropical pela Universidade de Harvard, EUA; professor associado da Universidade Federal do Piauí (Ufpi).

\section{Carlos Roberto Alves (Organizador)}

Biólogo, doutor em ciências pelo Instituto Oswaldo Cruz (IOC/Fiocruz); pesquisador em saúde pública no mesmo instituto, bolsista de produtividade em pesquisa pelo CNPq e coordenador da área de pesquisa em leishmanioses do IOC/Fiocruz.

\section{Claude Pirmez}

Médica-patologista, doutora em ciências pela UFRJ; pesquisadora titular da Fundação Oswaldo Cruz, editora associada do periódico Memórias do Instituto Oswaldo Cruz; foi vice-diretora do IOC/Fiocruz e vice-presidente de pesquisa da Fiocruz.

\section{Constança Felicia De Paoli de Carvalho Britto}

Bióloga, doutora em ciências biológicas pela UFRJ; pesquisadora titular e chefe do Laboratório de Biologia Molecular e Doenças Endêmicas do IOC/Fiocruz; bolsista de produtividade em pesquisa pelo CNPq e 'cientista do nosso estado' pela Faperj.

\section{Daniela de Pita Pereira}

Médica-veterinária, doutora em biologia parasitária pelo Instituto Oswaldo Cruz (IOC/Fiocruz), pós-doutorado pelo Conselho Nacional de Desenvolvimento Científico e Tecnológico (CNPq); bolsista. 


\section{Daniela Leite Fabrino}

Bióloga, doutora em biologia celular e molecular pelo Instituto Oswaldo Cruz (IOC/Fiocruz); professora adjunta da Universidade Federal de São João del-Rei (UFSJ/MG) no Departamento de Química, Biotecnologia e Engenharia de Bioprocessos.

\section{Denise Barçante Castro-Pinto}

Bióloga, doutora em biologia celular e molecular pelo Instituto Oswaldo Cruz (IOC/Fiocruz); bolsista de pós-doutorado pela Faperj no Laboratório de Bioquímica de Tripanosomatídeos do IOC/Fiocruz.

\section{Dorcas Lamounier Costa}

Médica, doutora em ciências da saúde pela Universidade Federal de Minas Gerais (UFMG), com área de concentração em infectologia e medicina tropical; professora associada da Universidade Federal do Piaúi (Ufpi).

\section{Eduardo Caio Torres-Santos}

Farmacêutico, doutor em ciências biológicas pela Universidade Federal do Rio de Janeiro (UFRJ); pesquisador associado do Instituto Oswaldo Cruz (IOC/Fiocruz).

\section{Eduardo Fonseca Pinto}

Farmacêutico, doutor em ciências pela Universidade Federal do Rio de Janeiro (UFRJ); pesquisador em saúde pública do Instituto Oswaldo Cruz (IOC/Fiocruz).

\section{Elisa Cupolillo}

Bióloga, doutora em ciências pelo Instituto Oswaldo Cruz (IOC/Fiocruz), onde é pesquisadora titular em saúde pública do Laboratório de Pesquisa em Leishmaniose do IOC/Fiocruz; bolsista de produtividade em pesquisa pelo CNPq e bolsista pela Faperj.

\section{Elizabeth F. Rangel}

Bióloga, doutora em zoologia pela Universidade de São Paulo (USP), pós-doutorado pela Universidade de Yale, EUA; pesquisadora titular do Instituto Oswaldo Cruz (IOC/Fiocruz), onde é coordenadora do Serviço de Referência Nacional em Vigilância Entomológica, Taxonomia e Ecologia dos Vetores das Leishmanioses.

\section{Elmo Eduardo de Almeida-Amaral}

Farmacêutico, doutor em química biológica pela Universidade Federal do Rio de Janeiro (UFRJ); pesquisador adjunto do Instituto Oswaldo Cruz (IOC/Fiocruz).

\section{Fabiano Borges Figueiredo}

Médico-veterinário, doutor em ciências pelo Instituto de Pesquisa Clínica Evandro Chagas da Fundação Oswaldo Cruz (Ipec/Fiocruz), onde é pesquisador em saúde pública; bolsista de produtividade em pesquisa pelo CNPq.

\section{Fátima Conceição-Silva (Organizadora)}

Médica, doutora em ciências pelo Instituto Oswaldo Cruz (IOC/Fiocruz), pós-doutorado na WHO Immunology Research and Training Centre, Universidade de Lausanne, Suíça; pesquisadora titular em saúde pública no IOC/Fiocruz, professora e coordenadora de departamento da Escola de Medicina da Fundação Técnico-Educacional Souza Marques (FTESM); coordenadora da área de pesquisa em leishmanioses do IOC/Fiocruz. 


\section{Fernanda N. Morgado}

Médica-veterinária, doutora em ciências pelo Instituto de Pesquisa Clínica Evandro Chagas (Ipec/Fiocruz); tecnologista em saúde pública do Laboratório de Pesquisa em Leishmaniose (IOC/Fiocruz); professora da Escola de Medicina da Fundação Técnico-Educacional Souza Marques (FTESM).

\section{Filipe A. Carvalho-Costa}

Médico, doutor em medicina tropical pelo Instituto Oswaldo Cruz (IOC/Fiocruz); pesquisador em saúde pública do mesmo instituto.

\section{Franklin Souza da Silva}

Biólogo, doutorando em biologia parasitária pelo Instituto Oswaldo Cruz (IOC/Fiocruz); pesquisador do Laboratório de Biologia Molecular e Doenças Endêmicas do mesmo instituto.

\section{José Batista de Jesus}

Biólogo, doutor em microbiologia pela Universidade Federal do Rio de Janeiro (UFRJ); pesquisador conveniado IOC/ Fiocruz-Universidade Federal de São João del-Rei (UFSJ) e professor adjunto do Departamento de Engenharia de Biossistemas da UFSJ.

\section{Keyla Belízia Feldman Marzochi}

Médica, doutora em doenças infecciosas e parasitárias pela Universidade Federal do Rio de Janeiro (UFRJ); pesquisadora titular aposentada da Fundação Oswaldo Cruz e membro titular da Academia de Medicina do Rio de Janeiro (AMRJ).

\section{Leonor Leon}

Química, doutora em biologia celular e molecular pelo Instituto Oswaldo Cruz (IOC/Fiocruz); pesquisadora do Laboratório de Bioquímica de Tripanosomatídeos do mesmo instituto; bolsista de produtividade em pesquisa pelo CNPq.

\section{Luiz Guilherme S. R. Bauzer}

Biólogo, doutor em genética pela Universidade de Leicester, Reino Unido; bolsista da Coordenação de Aperfeiçoamento de Pessoal de Nível Superior (Capes).

\section{Luzia Monteiro de Castro Côrtes}

Bióloga, doutora em ciências pelo Instituto Oswaldo Cruz (IOC/Fiocruz); tecnologista em saúde pública no mesmo instituto.

\section{Marcelo Alves-Ferreira}

Farmacêutico, doutor em química biológica pelo Instituto de Bioquímica Médica da Universidade Federal do Rio de Janeiro (IBqM/UFRJ); pesquisador adjunto do Instituto Oswaldo Cruz (IOC/Fiocruz).

\section{Margarete M. Afonso}

Bióloga, doutoranda em saúde pública pela Escola Nacional de Saúde Pública Sergio Arouca (Ensp/Fiocruz); Laboratório de Transmissores de Leishmanioses do Instituto Oswaldo Cruz (IOC/Fiocruz).

\section{Maria de Fátima Madeira}

Bióloga, doutora em ciências pelo Instituto Oswaldo Cruz (IOC/Fiocruz); pesquisadora titular do Instituto de Pesquisa Clínica Evandro Chagas (Ipec/Fiocruz). 


\section{Mariana Côrtes Boité}

Médica-veterinária, doutoranda em biologia celular e molecular pelo Instituto Oswaldo Cruz (IOC/Fiocruz); tecnologista em saúde pública do Laboratório de Pesquisa em Leishmaniose do mesmo instituto.

\section{Mariana Silva de Almeida}

Médica-veterinária, doutoranda em biologia parasitária pelo Instituto Oswaldo Cruz (IOC/Fiocruz); Laboratório de Biologia Molecular e Doenças Endêmicas do mesmo instituto.

\section{Marilene Marcuzzo do Canto-Cavalheiro}

Química, doutora em biologia parasitária pelo Instituto Oswaldo Cruz (IOC/Fiocruz); pesquisadora titular do mesmo instituto.

\section{Márcia Pereira-Oliveira}

Bióloga, doutora em biologia parasitária pelo Instituto Oswaldo Cruz (IOC/Fiocruz); pesquisadora em saúde pública do mesmo instituto.

\section{Maurício L. Vilela}

Biólogo, doutor em biologia parasitária, pesquisador adjunto em saúde pública do Laboratório de Transmissores de Leishmanioses do Instituto Oswaldo Cruz (IOC/Fiocruz).

\section{Mauro Celio de Almeida Marzochi}

Médico, doutor e livre-docente em parasitologia aplicada; pesquisador titular aposentado da Fundação Oswaldo Cruz; pesquisador sênior do CNPq no Instituto de Pesquisa Clínica Evandro Chagas (Ipec/Fiocruz); membro titular da Academia de Medicina do Rio de Janeiro (ABMRJ).

\section{Paula Mello De Luca}

Bióloga, doutora em biologia parasitária pelo Instituto Oswaldo Cruz (IOC/Fiocruz), pós-doutorado pelo Vaccine Research Center do National Institute of Allergy and Infectious Diseases (VRC/NIH), EUA; pesquisadora em saúde pública do IOC/Fiocruz.

\section{Patricia Cuervo}

Microbiologista, doutora em biologia celular e molecular pelo Instituto Oswaldo Cruz (IOC/Fiocruz); pesquisadora adjunta do mesmo instituto, onde também é docente do Programa de Pós-Graduação em Biologia Celular e Molecular.

\section{Raquel S. Pacheco}

Farmacêutica-bioquímica, doutora em biologia celular e molecular pelo Instituto Oswaldo Cruz (IOC/Fiocruz); pesquisadora titular da Fiocruz e bolsista de produtividade em pesquisa pelo Conselho Nacional de Desenvolvimento Científico e Tecnológico (CNPq).

\section{Reginaldo Peçanha Brazil}

Farmacêutico, doutor em parasitologia pela Universidade de Liverpool, Reino Unido; pesquisador titular do Instituto Oswaldo Cruz (IOC/Fiocruz).

\section{Renata 0. de A. Soares}

Bióloga, doutora em biologia celular e molecular pelo Instituto Oswaldo Cruz (IOC/Fiocruz), pós-doutoranda com bolsa do Conselho Nacional de Desenvolvimento Científico e Tecnológico (CNPq). 


\section{Renato Porrozzi}

Biólogo, doutor em ciências pelo Instituto Oswaldo Cruz (IOC/Fiocruz); pesquisador titular em saúde pública do Laboratório de Pesquisa em Leishmaniose do mesmo instituto; bolsista de produtividade em pesquisa pelo CNPq.

\section{Ricardo Luiz de Azevedo Pereira}

Biomédico, doutor em ciências pela Universidade Federal do Rio de Janeiro (UFRJ), pós-doutorado pela Universidade Federal do Rio de Janeiro (UFRJ) e na Universidade de Stanford, Califórnia, EUA.

\section{Rilza Beatriz de Azeredo-Coutinho}

Médica-dermatologista, doutora em medicina tropical pelo Instituto Oswaldo Cruz (IOC/Fiocruz); dermatologista do Hospital Federal de Bonsucesso/Ministério da Saúde e da Secretaria Municipal de Saúde do Rio de Janeiro.

\section{Roger Magno Macedo Silva}

Biólogo, mestre em ciências pelo Programa de Biologia Parasitária do Instituto Oswaldo Cruz (IOC/Fiocruz); técnico em saúde pública da Plataforma de Microscopia Eletrônica Rudolph Barth do mesmo instituto.

\section{Salvatore Giovanni De Simone}

Biomédico, doutor em ciências pela Universidade Federal do Rio de Janeiro (UFRJ), pós-doutorado pela Universidade de New York, EUA, e pela European Molecular Biology, Alemanha; pesquisador titular e chefe do Laboratório de Bioquímica de Proteínas e Peptídeos do IOC/Fiocruz; pesquisador pelo CNPq, 'cientista do nosso estado' pela Faperj.

\section{Sergio C. F. Mendonça}

Médico, doutor em doenças infecciosas e parasitárias pela Universidade Federal do Rio de Janeiro (UFRJ), pósdoutorado pela Universidade de Lausanne, Suíça; bolsista de produtividade em pesquisa pelo CNPq, pesquisador titular e chefe do Laboratório de Imunoparasitologia do IOC/Fiocruz.

\section{Sergio G. Coutinho}

Médico, doutor em medicina tropical pelo Instituto Oswaldo Cruz (IOC/Fiocruz), pós-doutorado pela Organização Mundial da Saúde (OMS), Suíça; pesquisador titular aposentado da Fiocruz.

\section{Simone M. Costa}

Bióloga, mestre em entomologia pela Universidade Federal de Viçosa (UFV); tecnologista do Programa de Inovação Tecnológica (Inovatec) da Fundação Oswaldo Cruz/Fundação Carlos Chagas Filho de Amparo à Pesquisa do Estado do Rio de Janeiro (Fiocruz/Faperj).

\section{Suzana Côrte-Real}

Bióloga, doutora em patologia pela Universidade Federal Fluminense (UFF), especialista em microscopia eletrônica pelo Instituto Pasteur Lyon, França; pesquisadora titular em saúde pública do Laboratório de Biologia Estrutural do IOC/Fiocruz, bolsista de produtividade pelo CNPq, gerente da Plataforma de Microscopia Eletrônica Rudolph Barth do IOC/Fiocruz.

\section{Sylvio Celso Gonçalves da Costa}

Biólogo, doutor em medicina veterinária pela Universidade Federal Rural do Rio de Janeiro (UFRRJ); pesquisador titular da Fiocruz, bolsista de produtividade do CNPq e docente do curso de pós-graduação em biologia parasitária do Instituto Oswaldo Cruz (IOC/Fiocruz). 


\section{Tânia Zaverucha do Valle}

Bióloga, doutora em biologia parasitária pelo Instituto Oswaldo Cruz (IOC/Fiocruz), pós-doutorado em genética de camundongos pelo Instituto Pasteur de Paris, França; tecnologista em saúde pública na Fiocruz.

\section{Valter Viana de Andrade-Neto}

Farmacêutico, doutor em biologia celular e molecular pelo Instituto Oswaldo Cruz (IOC/Fiocruz); pós-doutorando do Laboratório de Bioquímica de Tripanosomatídeos do mesmo instituto.

\section{Vanessa Alvaro Diniz}

Bióloga, tecnologista bolsista da Fundação Carlos Chagas Filho de Amparo à Pesquisa do Estado do Rio de Janeiro (Faperj) no Laboratório de Biologia Estrutural do Instituto Oswaldo Cruz (IOC/Fiocruz).

\section{Wagner A. Costa}

Biólogo, doutorando em biodiversidade em saúde pelo Instituto Oswaldo Cruz (IOC/Fiocruz); bolsista em tecnologia do Laboratório de Transmissores de Leishmanioses do mesmo instituto.

\section{Yara M. Traub-Csekö}

Graduada em história natural, doutora em biologia molecular pela Universidade de Colúmbia, Estados Unidos; pesquisadora titular e chefe do Laboratório de Biologia Molecular de Parasitas e Vetores do Instituto Oswaldo Cruz (IOC/Fiocruz). 
Parte I - Questões Evolutivas, Taxonômicas e Ultraestruturais de Parasitos do Gênero Leishmania

1. Diversidade Genética em Parasitos do Gênero Leishmania: uma abordagem molecular Raquel S. Pacheco e Filipe A. Carvalho-Costa

2. Considerações sobre a Taxonomia do Gênero Leishmania Elisa Cupolillo, Mariana Côrtes Boité e Renato Porrozzi

3. Ultraestrutura de Parasitos do Gênero Leishmania

Camila Guerra Silva, Roger Magno Macedo Silva, Vanessa Alvaro Diniz e Suzana Côrte-Real

Parte il - Bioquímica e Metabolismo Energético dos Parasitos do Gênero Leishmania

4. Metabolismo de Carboidratos em Leishmania spp. Marcelo Alves-Ferreira

5. Lipídeos

Elmo Eduardo de Almeida-Amaral, Valter Viana de Andrade-Neto, Marilene Marcuzzo do Canto-Cavalheiro e Eduardo Caio Torres-Santos

6. Aminoácidos e Proteases

Salvatore Giovanni De Simone

7. A Importância de Radicais Livres Durante a Infecção por Protozoários do Gênero Leishmania

Denise Barçante Castro-Pinto, Daniela Leite Fabrino e Leonor Leon

Parte iII - Aspectos Bioquímicos e Moleculares na Interação Parasito-Hospedeiro-Vetor

8. Componentes de Superfície do Parasito e o Papel na Interação Parasito-Hospedeiro

Carlos Roberto Alves, Mariana Silva de Almeida, Franklin Souza da Silva, Bernardo Acácio Santini Pereira,

Ricardo Luiz de Azevedo Pereira e Luzia Monteiro de Castro Côrtes

9. Aspectos Moleculares da Interação Flebotomíneo-Leishmania 
Parte iv - Hospedeiros, Reservatórios e Manutenção dos Ciclos de Transmissão

10. Lutzomyia (Lutzomyia) longipalpis: fatores associados ao processo de expansão e urbanização da leishmaniose visceral americana 183

Maurício L. Vilela, Margarete M. Afonso, Simone M. Costa, Wagner A. Costa e Elizabeth F. Rangel

11. Vetores na Leishmaniose Tegumentar Americana

Reginaldo Peçanha Brazil e Beatriz Gomes Brazil

12. Marcadores Moleculares Empregados no Estudo do Complexo Lutzomyia longipalpis

(Diptera: Psychodidae: Phlebotominae)

Luiz Guilherme S. R. Bauzer e Alexandre A. Peixoto

13. Diagnóstico Molecular de Leishmania spp. em Flebótomos Provenientes de Áreas de Ocorrência

de Leishmanioses

Constança F. De Paoli de Carvalho Britto e Daniela de Pita Pereira

14. Hospedeiros e Reservatórios de Leishmania sp. e sua Importância na Manutenção

dos Ciclos de Transmissão nos Ambientes Silvestre e Sinantrópico

André Luiz Rodrigues Roque e Ana Maria Jansen

15. Os Parasitos e a Questão da Infecção em Animais Domésticos e Domiciliados

Fabiano Borges Figueiredo e Maria de Fátima Madeira

Parte v - Modelos Experimentais no Estudo das Leishmanioses do Continente Americano

16. Modelos Experimentais na Leishmaniose Visceral

Renato Porrozzi, Amanda dos Santos Cavalcanti e Elisa Cupolillo

17. Modelos Experimentais na Leishmaniose Tegumentar Americana

Sylvio Celso Gonçalves da Costa e Tânia Zaverucha do Valle

PARTe vi - Espectro Clínico das Leishmanioses

18. Formas Clínicas das Leishmanioses Tegumentares nas Américas

Rilza Beatriz de Azeredo-Coutinho e Sergio C. F. Mendonça

19. Leishmaniose Visceral

Dorcas Lamounier Costa e Carlos Henrique Nery Costa

Parte vil - Resposta Imune na Leishmaniose Tegumentar Americana

20. A Resposta Imune na Leishmaniose Tegumentar Americana Ativa 357

Fátima Conceição-Silva, Fernanda N. Morgado e Sergio G. Coutinho

21. Resposta Imune Celular no Processo de Cura da Leishmaniose Tegumentar Americana 381

Adriano Gomes-Silva, Alda Maria Da-Cruz, Claude Pirmez, Eduardo Fonseca Pinto e Márcia Pereira-Oliveira

Parte vili - Tratamento e Diagnóstico das Leishmanioses

22. Estado da Arte no Tratamento da Leishmaniose Tegumentar Americana no Brasil

Armando O. Schubach e Fátima Conceição-Silva

23. Modelos de Estudo para o Desenvolvimento de Drogas Anti-Leishmania 413

Renata O. de A. Soares e Leonor Leon 
Parte iX - Desafios para o Controle das Leishmanioses

24. A Questão do Controle das Leishmanioses no Brasil 431 Mauro C. A. Marzochi, Keyla B. Feldman Marzochi, Aline Fagundes e Fátima Conceição-Silva

25. Vacinas nas Leishmanioses 465 Paula Mello De Luca

26. Abordagens Genômicas, Transcriptômicas e Proteômicas Aplicadas ao Estudo de Leishmania spp. 491 Marcelo Alves-Ferreira, Ana Carolina Ramos Guimarães, Patricia Cuervo e José Batista de Jesus 


\section{Leishmanioses: uma apresentação}

$\mathrm{N}$ a 16a Assembleia Mundial de Saúde (2007) emitiu-se a resolução WHA60.13 sobre o controle das leishmanioses (WHA, 2007). No texto, foi reconhecido que a infecção por parasitos do gênero Leishmania causa uma das doenças tropicais mais negligenciadas no mundo. Já naquela época, mais de 12 milhões de indivíduos encontravam-se infectados, com pelo menos dois milhões de novos casos a cada ano e 350 milhões de pessoas consideradas em risco de contrair uma das formas clínicas da infecção, principalmente nas áreas de maior taxa de pobreza. Dentro de áreas endêmicas, o risco de infecção aumenta por meio de condições precárias de ocupação do espaço físico. Dessa forma, também contribuem para a manutenção do quadro de desigualdade social, já que representam forte entrave ao desenvolvimento dos países (Alvar, Yactayo \& Bern, 2006; Alvar et al., 2012; Chawala \& Madhubala, 2010). Nesse contexto, na reunião de 2007, as leishmanioses foram consideradas um problema de saúde pública substancial. Assim, algumas resoluções foram tomadas no sentido de reforçar os programas nacionais de controle, melhorar o diagnóstico e a prevenção, conduzir estudos epidemiológicos mais precisos e melhorar o intercâmbio de informações e ações entre países para promover a vigilância e controle da leishmaniose. Na ocasião, também foram indicadas algumas ações prioritárias como: desenvolvimento de novos medicamentos; reforço nas pesquisas para o controle de vetores, reservatórios e proteção do ser humano; melhoria dos métodos diagnósticos; e melhoria do acesso da população sob risco aos sistemas de saúde.

Muitos anos se passaram, no entanto ainda nos deparamos com os mesmos problemas. As leishmanioses, sobretudo a forma visceral (Leishmaniose Visceral - LV), têm se expandido para regiões antes consideradas indenes; e casos de lesão tegumentar (Leishmaniose Tegumentar - LT) e doença visceral têm sido diagnosticados em viajantes que retornam a seus países de origem, após visitas a regiões onde a transmissão da doença é relatada (Alvar et al., 2012).

Por que, apesar do grande número de grupos de pesquisas, instituições e países envolvidos no estudo das leishmanioses, ainda temos dificuldades para melhorar o diagnóstico, o tratamento e o controle da infecção? Pergunta difícil, respostas procuradas por muitos. Assim, organizar o conhecimento já existente, formular questões e propor meios para respondê-las é um exercício necessário e interessante. Nas páginas deste livro, algumas dessas questões são abordadas por especialistas da área. Mas, antes de fazer perguntas e procurar respostas, precisamos conhecer as leishmanioses e seus agentes etiológicos. É vasta a literatura sobre o assunto, e livros-texto podem ser 
consultados; por isso, aqui faremos apenas uma breve introdução ao assunto, de forma resumida. Cada parte será detalhada no(s) capítulo(s) correspondente(s).

As leishmanioses são doenças infecciosas causadas por diferentes espécies de protozoários intracelulares obrigatórios pertencentes ao gênero Leishmania, transmitidos por algumas espécies de insetos flebotomíneos (Brasil, 2010). Durante a hematofagia, as formas promastigotas presentes nas glândulas salivares dos flebótomos fêmeas são inoculadas na junção derme-epiderme do hospedeiro vertebrado. Nesse local ocorre a fagocitose dos parasitos, que irão se transformar em amastigotas no interior do vacúolo parasitóforo de células do sistema fagocítico mononuclear (SFM), entre elas o macrófago. No interior dessas células os amastigotas multiplicam-se por divisão binária e são responsáveis pelas infecções, que podem persistir por todo o tempo de vida do hospedeiro, com risco provável de acarretar as lesões cutâneas e viscerais.

O curso da infecção é definido por uma série de fatores do parasito (espécie, cepa, forma evolutiva, número inicial) e do hospedeiro (células do sistema imune inato e adaptativo, sistema complemento, quimiocinas etc.). A localização do parasito nas células do SFM, associada à resposta imune, estimulada pela presença do antígeno parasitário, produz uma reação inflamatória com predominância celular (processo inflamatório crônico do tipo granulomatoso). A interação entre a multiplicação parasitária e a resposta imune do hospedeiro poderá produzir infecção mais ou menos grave e, na dependência da espécie do parasito envolvida, podem surgir lesões teciduais acometendo o tegumento cutâneo e/ou mucoso (LT), ou órgãos viscerais (LV). Para a continuidade da transmissão, flebótomos fêmeas, durante o repasto sanguíneo, podem ingerir as formas amastigotas do hospedeiro infectado. No interior do inseto uma nova transformação ocorre, e após um período de divisão as formas denominadas promastigotas metacíclicas se instalam na região das glândulas salivares do inseto, o que permite a transmissão do protozoário para novo hospedeiro durante novo repasto sanguíneo (Figura 1).

Figura 1 - Esquema geral do ciclo biológico dos parasitos do gênero Leishmania

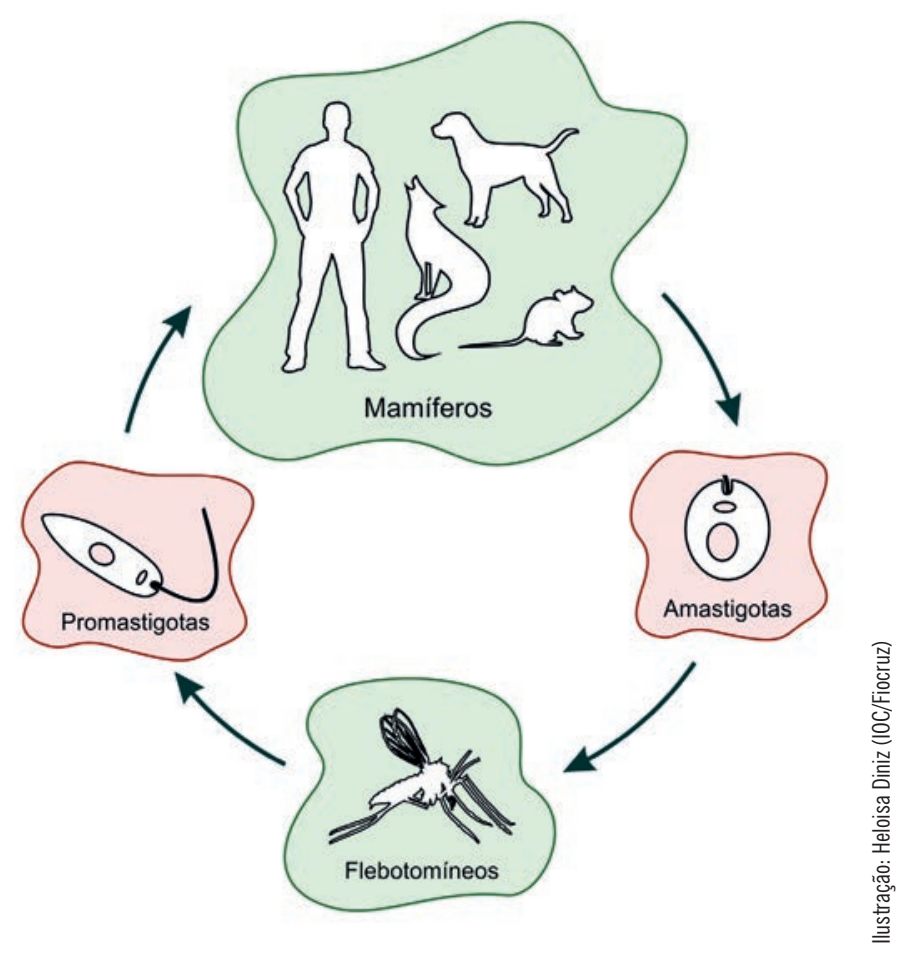


Pensar na vida biológica das Leishmania spp. é refletir que a sobrevivência de tais parasitos pode modificar a qualidade de vida de seus hospedeiros, uma vez que interfere na homeostasia destes. Provavelmente, isso se deve a uma adaptação genética associada à mudança de microambiente e à existência de dependência metabólica com vias redirecionadas às formas promastigotas e amastigotas do parasito - em ambos os casos, com expressão gênica regulada nas fases do ciclo de vida. O êxito do parasito vem também sendo explicado pela atuação direta dos componentes orgânicos das espécies de Leishmania. Nesse contexto, os componentes da superfície do parasito são traduzidos como um conjunto de fatores que influenciam no sucesso da vida parasitária, visto que sua superfície celular representa o primeiro contato com os diferentes microambientes de ambos os hospedeiros.

o ciclo biológico das espécies de Leishmania nos hospedeiros vertebrados vem sendo extensivamente estudado em modelos de infecção experimental, como roedores e primatas não humanos. Com base nos modelos são feitas inferências acerca de aspectos da doença humana, uma vez que reúnem uma série de vantagens para o estudo da rede de interações que se estabelece entre parasito-hospedeiro, como: (i) a possibilidade de infecção pelos mesmos parasitos que infectam o homem; (ii) a diversidade de linhagens híbridas ou mutantes de camundongos. Tais fatores permitem a escolha de características específicas (Foote \& Handman, 2005), dependendo do objetivo da pesquisa, e quando utilizadas linhagens suscetíveis, a infecção pode cursar com características similares às que ocorrem na doença humana (Pereira \& Alves, 2008). Assim, dentro das normas de uso ético da experimentação animal, esses animais são amplamente utilizados em estudos de quimioterapia e vacinação (Divanovic et al., 2011; Garg \& Dube, 2006).

A associação das formas clínicas da doença humana com as espécies de Leishmania é um capítulo largamente estudado e vem definindo o perfil das leishmanioses em nosso continente. Nas Américas, a forma visceral é causada por Leishmania infantum (estudos mais atualizados têm apontado para a semelhança entre L. chagasi e L. infantum, advindo daí a identificação do parasito causador da leishmaniose visceral americana como L. infantum. No entanto, ainda pode ser encontrado na literatura o uso de L. chagasi, L. infantum e L. infantum chagasi como sinonímias), e na forma tegumentar pelo menos 16 diferentes espécies de Leishmania foram identificadas como agentes causais de Leishmaniose Tegumentar Americana (LTA) em ambos os subgêneros: Leishmania e Viannia (Brasil, 2010; Baptista et al., 2009). No Brasil, as espécies causadoras de LTA mais comuns são: Leishmania amazonensis, Leishmania guyanensis e Leishmania braziliensis. Esta última tem ampla distribuição, do sul do Pará ao Nordeste, atingindo também o centro-sul do país e algumas áreas da Amazônia Oriental (Brasil, 2010), sendo o agente mais frequentemente encontrado em território nacional.

A LV é a forma de acometimento das leishmanioses que se localiza preferencialmente em órgãos e vísceras do sistema linfohematopoiético, como fígado, baço, gânglios e medula óssea, podendo também estar presente em outras regiões como rim, pulmão etc. É causada por parasitos como L. donovani, L. chagasi e L. infantum (as duas últimas hoje consideradas como sinonímias), mas alguns casos de infecção por L. tropica têm sido relatados (Brasil, 2011). A LV pode ser endêmica, esporádica ou epidêmica, com apresentações clínicas e sintomatologia variável. É infecção com distribuição mundial e a espécie envolvida depende de cada área endêmica, ocasionando pequenas diferenças entre as infecções que ocorrem nas Américas, Europa, África e Ásia. Nas duas últimas décadas, deu-se uma grande expansão dos casos detectados em muitas regiões do planeta e, apesar dos esforços no controle de vetores e reservatórios, a LV mantém-se em rápida expansão territorial, acometendo indivíduos de diferentes grupos de idades. No Brasil, epidemias urbanas foram observadas em várias cidades e a doença também tem sido verificada como infecção oportunista em pacientes com Aids, à semelhança do que se observa no sul da Europa (WHO, 2010). Em particular nos últimos dez anos, apesar dos recursos de tratamento intensivo e das rotinas estabelecidas para o tratamento específico da LV, constatou-se aumento na letalidade da doença em diversas regiões do Brasil. Um dos principais fatores que contribuem para o aumento dessa letalidade é o diagnóstico tardio (Campino \& Maia, 2010). Como ocorre acometimento sistêmico e a apresentação clínica é relacionada à sintomatologia comum a outras doenças infecciosas ou não, o diagnóstico nem sempre é feito rapidamente, colocando o paciente sob risco, já que a infecção 
tem letalidade potencial alta. Contudo, estudos longitudinais demonstram que parte da população da área endêmica permanece assintomática ou se recupera espontaneamente da infecção. Os fatores de riscos considerados mais importantes para a progressão da LV são: desnutrição, fatores genéticos e concomitância de outras doenças (Brasil, 2011; Griensven \& Diro, 2012). Nesse contexto, melhorar a rotina diagnóstica, dar ferramentas para o estadiamento da infecção e o correto manejo dos doentes pode fazer diferença na evolução da LV para casos graves ou para cura. Aliado a isso, melhorar o sistema de prevenção, o arsenal terapêutico e diminuir as taxas de transmissibilidade poderia diminuir a população em risco de infecção e controlar a expansão de LV.

A LTA é classificada em três formas clínicas básicas: leishmaniose cutânea localizada (LCL), leishmaniose mucosa (LM) e leishmaniose cutânea difusa (LCD). A LCL tem como principal manifestação uma lesão ulcerada que se desenvolve no local de inoculação do parasito. O indivíduo desenvolve úlcera de bordos elevados, fundo plano e superfície granulosa, geralmente autolimitada. Em algumas situações, a infecção pode se desenvolver de forma atípica, produzindo as formas disseminadas (LCDi) ou difusas (LCD). No primeiro caso ocorre a presença de inúmeras lesões, geralmente pequenas e distribuídas por várias regiões do tegumento cutâneo, que respondem bem ao tratamento antimonial. No segundo, advém também a disseminação das lesões, mas nesse caso as lesões tendem à forma tuberosa, sem ulceração, sendo por isso denominada difusa (LCD). Os parasitos são facilmente detectados e os pacientes de LCD respondem mal ao tratamento específico, levando à cronicidade da infecção e ao acometimento progressivo.

A LM geralmente apresenta destruição tecidual progressiva associada à intensa resposta inflamatória nas vias aerodigestivas superiores, abrangendo mucosa nasal, oral, faringe e laringe (Brasil, 2010; Amato, Andrade \& Duarte, 2003; Marsden, 1986; Lessa et al., 2007). Essa lesão geralmente surge semanas ou anos após o desaparecimento da lesão cutânea inicial, por disseminação hematogênica ou linfática, a partir do foco primário. Trabalhos experimentais em hamsters parecem corroborar tal hipótese (Kanan \& Ryan, 1975). Mais raramente, a lesão mucosa pode aparecer na vigência de úlcera cutânea em atividade, sendo então denominada leishmaniose mucocutânea (LMC). Parte dos pacientes de LM relata história de ausência de tratamento ou tratamento inadequado da lesão cutânea inicial, o que leva a concluir que as curas espontâneas e os tratamentos curtos e irregulares constituem um forte risco para o aparecimento da forma mucosa (Brasil, 2010). Dados da frequência da doença na forma mucosa são variáveis, de acordo com a região. A maior parte dos casos atendidos ocorre em hospitais, aos quais os portadores da LTA são atraídos pela extensão e cronicidade da doença.

Os pacientes de LM apresentam resposta positiva à intradermorreação de Montenegro (IDRM) e à resposta linfoproliferativa específica, in vitro, de células do sangue periférico. A magnitude dessa resposta é geralmente maior que aquela verificada na forma localizada (Amato, Andrade \& Duarte, 2003; Carvalho et al., 1985; Castes, Verde \& Rondón, 1983; Conceição-Silva et al., 1990). O mecanismo exato da formação da lesão mucosa, como e onde as leishmânias sobrevivem em latência no organismo humano durante anos e os fatores que desencadeiam a doença ainda permanecem obscuros (Brasil, 2010). De modo geral, qualquer região da mucosa nasal, oral ou faríngea pode apresentar lesões de LTA. No entanto, a maioria dos pacientes acometidos tem envolvimento nasal isolado ou em associação com outras áreas de mucosa. Em 42\% dos pacientes de LM, ocorre perfuração do septo nasal (Amato, Andrade \& Duarte, 2003). A boca geralmente tem lesões em associação com o acometimento nasal, mas é possível o encontro de uma ou mais lesões apenas na mucosa oral. Mais frequentemente, tais lesões ocorrem no lábio e no palato, embora já tenham sido identificadas lesões de úvula, gengiva, tonsilas e língua. Quando ocorre o acometimento da laringe, este costuma ser bastante intenso, com a presença de granulações vegetantes, recobertas com uma tênue camada de fibrina envolvendo a mucosa da epiglote e estendendo-se para a mucosa do vestíbulo laríngeo e pregas vocais. Pode ocorrer odinofagia e disfonia (Marsden, 1986; Lessa et al., 2007; observações não publicadas do Laboratório de Vigilância em Leishmanioses/Instituto de Pesquisa Clínica Evandro Chagas - LAB-VigiLeish/Ipec/Fiocruz). 
A complexidade das leishmanioses impõe que o diagnóstico considere vários parâmetros clínicos, epidemiológicos e laboratoriais que consistem basicamente na evidenciação do parasito e em provas imunológicas. Assim, o diagnóstico laboratorial pode ser obtido por meio de ferramentas parasitológicas (exames diretos e cultura), imunológicas (sorologia e IDRM) e histológicas (HE, imuno-histoquímica). De acordo com a infraestrutura, ainda podem ser empregadas ferramentas moleculares baseadas na reação em cadeia da polimerase (Polymerase Chain Reaction - PCR), que constitui uma técnica com elevada sensibilidade, tornando possível o diagnóstico, principalmente nos casos não resolvidos pelos métodos clássicos (Andrade et al., 2005).

Os espécimes clínicos coletados para o diagnóstico parasitológico dependem da apresentação clínica da doença (Andrade et al., 2005). Na LT podem ser obtidos tendo como base a escarificação ou biópsia de lesão (Mello et al., 2011). Também pode ser feita a punção aspirativa, quando houver necessidade de investigação de comprometimento ganglionar primário. Já na LV os espécimes são comumente obtidos por amostras de sangue periférico, punção aspirativa de medula óssea ou punção biópsia de fígado ou baço. No exame parasitológico direto, é realizada a pesquisa de formas amastigotas em lâminas de impressão por aposição ou material proveniente de escarificação, biópsia e punção aspirativa, corados pela técnica de Giemsa ou Leishman. O exame parasitológico indireto visa ao isolamento do agente infeccioso em meios de cultivo apropriados, como, por exemplo, o meio semissólido Novy, McNeal e Nicolle (NNN) e os meios líquidos Schneider's ou infusão de coração e cérebro (Brain and Heart Infusion BHI). Outro método de diagnóstico indireto é a inoculação em animais de laboratório, sendo o hamster o animal de escolha. No entanto, em razão da dificuldade de manuseio e manutenção, a inoculação em animais tem utilização restrita, não sendo usada em exames de rotina diagnóstica (Brasil, 2010).

A análise histopatológica dos fragmentos de biópsia também é de fundamental importância no diagnóstico da LTA, pois pode identificar as formas parasitárias e, ao mesmo tempo, contribuir para o diagnóstico diferencial. Alguns estudos e esforços têm sido realizados com o objetivo de implantação de outras metodologias auxiliares, como a imuno-histoquímica e o PCR (Kenner et al., 1999).

A detecção de resposta imune específica pode ser feita através da intradermorreação de Montenegro (IDRM), imunofluorescência indireta (IFI) e/ou ensaio imunoenzimático (Enzyme-Linked Immunosorbent Assay - Elisa), além de resposta proliferativa primária de linfócitos (RPL), sendo esta última pouco utilizada na prática (Brasil, 2010).

Sabe-se que as manifestações clínicas de determinados agravos, assim como a resposta terapêutica, podem estar parcialmente relacionadas à espécie de parasito envolvido na infecção. Nas leishmanioses, este é um assunto bastante explorado, buscando-se, principalmente, estabelecer possíveis associações dos padrões clínicos e/ou da resposta terapêutica com a diversidade genética dos parasitos (Baptista et al., 2009).

A ampla diversidade genética dos parasitos do gênero Leishmania, sobretudo L. brazilensis, é bastante conhecida (Lessa et al., 2007; Pacheco et al., 1990; Cupolillo et al., 2003; Ishikawa et al., 2002). Tal diversidade pode estar relacionada ao genoma nuclear desses organismos, que mostram uma considerável plasticidade inter e intraespécies em termos de número e tamanho dos cromossomos (cariótipo molecular) e, também, no genoma mitocondrial, que pode variar principalmente no tamanho e organização dos maxicírculos. Entretanto, aspectos concernentes aos padrões epidemiológicos também podem ter influência na diversidade desses parasitos. Estudo com amostras de L. braziliensis isoladas da região amazônica revelaram elevada heterogeneidade genética, fato que foi relacionado ao grande número de espécie de vetores e animais que atuam nos ciclos de transmissão nessa região, ao contrário do que ocorre na costa atlântica do Brasil, onde as amostras estudadas indicaram baixo nível de heterogeneidade (Pacheco et al., 1990).

Mesmo com grande prevalência e com os conhecimentos atuais sobre a relação entre o parasito e seu hospedeiro, poucos avanços foram obtidos no tratamento dessa parasitose. O gênero Leishmania foi descrito em 1903, e em 1912 Gaspar Vianna demonstrou o uso do tártaro emético (tartarato de potássio e antimônio trivalente) no tratamento de 
pacientes com LTA. Entretanto, em razão dos graves efeitos secundários provocados por esse fármaco, outros compostos, baseados nos antimoniais, foram testados, chegando-se ao antimonial pentavalente, que passou a ser utilizado, a partir da década de 40 do século XX, como fármaco de primeira escolha para o tratamento das leishmanioses. Apesar de eficaz, na maioria dos casos os antimoniais estão associados à considerável toxicidade hepática e renal. Por essa razão, naqueles casos em que há impedimento da utilização dos antimoniais, outros fármacos podem ser utilizados como tratamento alternativo, sendo os mais usados a anfotericina b e a pentamidina (Brasil, 2010; Oliveira et al., 2011). No entanto, todos os fármacos empregados no tratamento das leishmanioses, seja o antimônio pentavalente, a anfotericina B ou a pentamidina, têm limitações quanto ao seu emprego, tais como custo elevado, dificuldade de administração, toxicidade ou ainda o desenvolvimento de possível resistência, o que representa grande obstáculo para o sucesso da terapia (Ameen, 2010).

Embora os antimoniais pentavalentes sejam usados há mais de sessenta anos, seu mecanismo de ação ainda não foi esclarecido. Falta elucidar detalhes da ação leishmanicida dos antimoniais pentavalentes na forma orgânica, como pró-fármacos (Goodwin \& Page, 1943), ou na forma iônica $\left(\mathrm{Sb}^{5+} \mathrm{ou} \mathrm{Sb}{ }^{3+}\right.$ ), após sua conversão in vivo (Roberts, Berman \& Rainey, 1995). O esclarecimento desses detalhes pode ser útil à compreensão do mecanismo de toxicidade do antimônio, que é influenciada pela natureza química do composto, seguindo o pressuposto de que espécies químicas distintas de um mesmo elemento químico podem seguir caminhos metabólicos diferentes. Estudos nessa área podem ser proveitosos no desenvolvimento de formulações à base de derivados do antimônio mais eficazes e menos tóxicos, melhorando o tratamento das leishmanioses.

Ainda com relação aos antimoniais, observa-se grande variabilidade de respostas terapêuticas, cujas razões específicas não são totalmente esclarecidas. Sugere-se que fatores imunológicos dos hospedeiros, variabilidade genética do parasito, assim como a farmacocinética do antimonial no organismo, possam interferir no processo de resposta terapêutica. A Organização Mundial da Saúde (OMS) recomenda que os antimoniais pentavalentes sejam usados nas doses de $10-20 \mathrm{mg} / \mathrm{kg} /$ dia, por um período mínimo de vinte dias, para tratamento da LTA. Contudo, outras doses e outros esquemas terapêuticos são utilizados, não havendo um consenso de qual seria o melhor esquema (Ameen, 2010).

O Ministério da Saúde do Brasil (Brasil, 2010) preconiza a utilização do antimonial pentavalente (antimoniato$\mathrm{N}$-metil-glucamina - $\mathrm{Sb}^{v}$ ) na dose de $10-20 \mathrm{mg} \mathrm{Sb} / \mathrm{kg} / \mathrm{dia}$ durante vinte dias consecutivos. A dose dependeria do tipo de apresentação clínica e da idade dos pacientes. No entanto, dependendo da região e da experiência dos médicos responsáveis, o esquema pode variar não só em relação à dose, mas também em relação ao tempo e à forma de administração.

Apesar dos intensos estudos já realizados, muito pouco ainda se sabe sobre possíveis fatores que podem estar envolvidos na evolução das leishmanioses para a cura clínica e a proteção contra recidivas e reinfecções (Mishra, Saxena \& Singh, 2007). Estudos sistemáticos avaliando vários aspectos (clínicos e laboratoriais) poderiam trazer subsídios para o conhecimento da dinâmica desse processo infeccioso.

Entre os fatores ligados à cura das lesões de LTA, a discussão sobre a erradicação do parasito após a cura clínica foi motivo de controvérsia durante muitos anos. Com o estudo sistemático de cicatrizes e com a possibilidade de utilização de técnicas de grande sensibilidade, a evidenciação de parasitos pode ser feita com a detecção de antígenos ou DNA parasitários em lesões de LTA em cicatrização (Oliveira et al., 2011; Schubach et al., 1998a, 1998b; Mendonça et al., 2004). Schubach e colaboradores (2001) demonstraram a existência de antígenos de Leishmania no tecido cicatricial e sugeriram que tal fato poderia estar relacionado a mecanismos de manutenção da resposta imune, levando à imunoproteção. Por sua vez, como foi possível o isolamento de parasitos em culturas de amostras de cicatriz, também foi sugerido que a persistência do agente infeccioso poderia estar relacionada ao desenvolvimento de lesões tardias ou 
ao aparecimento de reativações no local da lesão primária. Também é fato hoje reconhecido a manutenção de infecção latente em casos de LV, o que pode ser verificado pelo surgimento de casos de LV em população adulta acometida de HIV-Aids em regiões sem história atual de infecção nos residentes hígidos, como tem ocorrido em países da região do Mediterrâneo Europeu (Brasil, 2011; Campino \& Maia, 2010; Griensven \& Diro, 2012). Todos esses dados sugerem a tendência ao equilíbrio dinâmico entre o parasito e o sistema imune. Assim, o estudo de resposta imune nos tecidos e órgãos normalmente acometidos pela infecção, e a identificação dos mecanismos modulatórios envolvidos no equilíbrio da relação parasito-hospedeiro, podem ser uma boa ferramenta na compreensão dos fatores que mantêm ou alteram tal equilíbrio. Além disso, outros fatores como doenças concomitantes, o uso de determinadas drogas, idade, localização etc. também poderiam influenciar a evolução da infecção para o controle ou a manutenção de atividade. Um conhecido fato é a dificuldade de cicatrização de lesões da LTA nas pernas, em razão das dificuldades de drenagem local. Por último, fatores pertencentes a variações genéticas do parasito, assim como a carga parasitária, poderiam estar envolvidos na manutenção da atividade inflamatória e consequentemente na ocorrência de falha terapêutica precoce ou tardia.

As leishmanioses permanecem como uma das doenças parasitárias de grande impacto para a humanidade. Podemos afirmar que ainda temos muitas questões não respondidas, e pensar sobre elas, além de ser um bom exercício, é acima de tudo uma necessidade. Neste livro, especialistas se debruçaram sobre algumas dessas questões, o que, em determinadas situações, fez surgir novas questões. Nem todas têm resposta fácil, mas pensar sobre elas é nosso trabalho.

Ao longo das páginas desta publicação, o leitor perceberá que cinco tópicos do tema leishmânia vão conseguir prendê-lo à leitura: o parasito, sua estrutura e sua composição bioquímica; os hospedeiros e os diversos modelos experimentais; a clínica e a resposta imune associada; o passado e o presente do tratamento; e os desafios para o controle da doença. Os organizadores desta obra entendem que essa pluralidade de temas, reunida em um único volume, oferece ao leitor uma visão única e multifacetária do assunto leishmanioses, ou seja, abordando os aspectos relevantes para uma visão crítica das leishmanioses nos dias de hoje. Seguindo a opção por organizar uma coletânea de informações e ideias não necessariamente homogêneas, cada autor teve independência para escrever sobre as informações constantes na literatura e sobre sua experiência e hipóteses acerca do tema, não havendo obrigatoriedade de sequência ou cerceamento de conteúdo pelos organizadores.

O primeiro grupo de ideias desenvolvidas pelos autores, aqui, é composto por capítulos que relatam o estado da arte das Questões Evolutivas, Taxonômicas e Ultraestruturais de Parasitos do Gênero Leishmania $(1,2,3)$ e da composição Bioquímica e o Metabolismo Energético dos Parasitos do Gênero Leishmania (4 a 7), além dos Aspectos Bioquímicos e Moleculares na Interação Parasito-Hospedeiro-Vetor (8 e 9). O segundo grupo de ideias contemplada na obra reúne capítulos que dissertam sobre temas como Hospedeiros, Reservatórios e a Manutenção dos Ciclos de Transmissão (10 a 15) e Modelos Experimentais no Estudo das Leishmanioses do Continente Americano (16, 17). O terceiro grupo é dedicado a temas da clínica e do status imunológico dos pacientes com leishmaniose, relatando sobre Espectro Clínico das Leishmanioses $(18,19)$ e sobre a Resposta Imune na Leishmaniose Tegumentar Americana (20, 21). O Tratamento e Diagnóstico das Leishmanioses são abordados no relato do Estado da Arte no Tratamento da LTA no Brasil (22) e na descrição dos Modelos de Estudo para o Desenvolvimento de Drogas Anti-Leishmania (23). Finalmente, reservou-se espaço nesta publicação para informar aos leitores sobre os Desafios para o Controle das Leishmanioses, descrevendo A Questão do Controle das Leishmanioses (24), as Vacinas nas Leishmanioses (25) e, ainda, questões relacionadas às Abordagens Genômicas, Transcriptômicas e Proteômicas Aplicadas ao Estudo de Leishmania spp. (26).

Uma publicação como esta não poderia ter sido concretizada sem a participação e o auxílio de muitas pessoas, a quem gostaríamos de agradecer. Mesmo incorrendo na possibilidade de esquecermos alguém (a quem, de antemão, pedimos desculpas), não poderíamos deixar de mencionar o grupo de pesquisadores da Área de Pesquisa em Leishmanioses 
do Instituto Oswaldo Cruz (IOC/Fiocruz), que junto conosco participou da primeira etapa de discussão sobre a ideia deste livro: drs. Sergio Coutinho Furtado de Mendonça, Maurício Luiz Vilela, Renato Porrozzi de Almeida e Salvatore Giovanni De Simone, além do entusiasmo do trabalho da analista de pesquisa, desenvolvimento e inovação (PDI) do Instituto, Andréa Silva de Souto, que nos prestou assistência durante a organização inicial deste livro. Agradecemos também às analistas de PDI Helenice Andrade e Claudia Kamel, assim como à jornalista Elisandra de Araújo Galvão (BioManguinhos/Fiocruz), que auxiliaram na organização da parte documental e/ou nos contatos iniciais com a Editora Fiocruz; e às dras. Mariza Morgado e Mariza Conde, que propiciaram as condições para a aglutinação dos pesquisadores da Área de Pesquisa em Leishmanioses do IOC/Fiocruz em torno deste projeto.

Esta obra também não teria sido possível sem a participação da equipe do Setor de Produção e Tratamento de Imagens do IOC/Fiocruz, em especial Genilton José Vieira, Heloisa Maria Nogueira Diniz e Rodrigo Mexas, e sem o aval e o suporte da Editora Fiocruz, a quem agradecemos nas pessoas do editor executivo João Canossa e do revisor Marcionílio Cavalcanti de Paiva, além de Augusta Avalle e Myllena Paiva, que auxiliaram na finalização da revisão, e de Clarissa Bravo e Gislene Coimbra, normalizadoras das referências. Também foram fundamentais na composição do livro os programadores visuais Adriana Carvalho e Carlos Fernando Reis.

Tudo isso seria muito mais difícil sem o suporte dado pela Fiocruz e em particular pela atual Direção do IOC (na pessoa do diretor dr. Wilson Savino) e à passada, representada aqui pela ex-diretora dra. Tânia Cremonini de Araújo-Jorge.

Por fim, este trabalho seria inviável sem a adesão maciça e entusiasmada dos profissionais autores desta coletânea. Este livro é um reflexo do comprometimento dos pesquisadores com a qualidade da ciência e informação que produzem para a sociedade.

A todos, nossos sinceros agradecimentos.

Os organizadores

\section{REFERÊNCIAS}

ALVAR, J.; YACTAYO, S. \& BERN, C. Leishmaniasis and poverty. Trends in Parasitology, 22: 552-557, 2006.

ALVAR, J. et al. Leishmaniasis worldwide and global estimates of its incidence. Plos One, 7(5): e35.671, 2012.

AMATO, V. S.; ANDRADE, H. F. \& DUARTE, M. I. Mucosal leishmaniasis: in situ characterization of the host inflamatory response, before and after treatment. Acta Tropica, 85: 39-49, 2003.

AMEEN, M. Cutaneous leishmaniasis: advances in disease pathogenesis, diagnostics and therapeutics. Clinical and Experimental Dermatology, 35: 699-705, 2010.

ANDRADE, B. B. et al. Métodos diagnósticos da Leishmaniose tegumentar: fatos, falácias e perspectivas. Gazeta Médica da Bahia, 75: 75-82, 2005.

BAPTISTA, C. et al. Leishmania (Viannia) braziliensis genotypes identified in lesions of patients with atypical or typical manifestations of tegumentary leishmaniasis: evaluation by two molecular markers. Experimental Parasitology, 42: 317-322, 2009.

BRASIL. Ministério da Saúde. Secretaria de Vigilância em Saúde. Manual de Vigilância da Leismaniose Tegumentar Americana. 2. ed. Brasília: Ministério da Saúde, 2010.

BRASIL. Ministério da Saúde. Leishmaniose Visceral: recomendações clínicas para redução da mortalidade. Brasília: SVS, Departamento de Vigilância Epidemiológica, 2011. (Serie A: Normas e Manuais Técnicos).

CAMPINO, L. \& MAIA, C. Epidemiology of leishmaniases in Portugal. Acta Médica Portuguesa, 23: 859-864, 2010. 
CARVALHO, E. M. et al. Cell mediated immunity in American cutaneous and mucosal leishmaniasis. The Journal of Immunology, 135(6): 414-418, 1985.

CASTES, M.; VERDE, O. \& RONDÓN, A. J. Characterization of the cellular immune response in American cutaneous leishmaniasis. Clinical Immunology and Immunopathology, 27: 176-186, 1983.

CHAWALA, B. \& MADHUBALA, R. Drug targets in Leishmania. Journal of Parasitic Diseases, 34:1-13, 2010.

CONCEIÇÃO-SILVA, F. et al. Quantitative study of Leishmania braziliensis reactive T cells in peripheral blood and in the lesions of patients with american mucocutaneous leishmaniasis. Clinical and Experimental Immunology, 79: 221-226, 1990.

CUPOLILLO, E. et al. Genetic polymorphism and molecular epidemiology of Leishmania (Viannia) braziliensis from different hosts and geographic areas in Brazil. Journal of Clinical Microbiology, 41: 3.126-3.132, 2003.

DIVANOVIC, S. et al. Therapeutic enhancement of protective immunity during experimental leishmaniasis. PLoS Neglected Tropical Diseases, 5(9): e1.316, 2011.

FOOTE, S. J. \& HANDMAN, E. Genetics of murine leishmaniasis. Briefings in Functional Genomics and Proteomics, 4(3): 270-276, 2005.

GARG, R. \& DUBE, A. Animal models for vaccine studies for visceral leishmaniasis. The Indian Journal of Medical Research, 123(3): 439-454, 2006.

GoodWIN, L. G. \& PAGE, J. E. A. Study of the excretion of organic antimonials using a polarographic procedure. The Biochemical Journal, 37: 198-209, 1943.

GRIENSVEN, J. \& DIRO, E. Visceral leishmaniasis. Infectious Disease Clinics of North America, 26: 309-322, 2012.

ISHIKAWA, E. A. et al. Genetic variation in populations of Leishmania species in Brazil. Transactions of the Royal Society of Tropical Medicine and Hygiene, 96, supl. 1: S111-121, 2002.

KANAN, M. W. \& RYAN, T. J. Endonasal localization of blood borne viable and non viable particulate matter. The British Journal of Dermatology, 92(4): 663-673, 1975.

KENNER, J. R. I. et al. Immunohistochemistry to identify Leishmania parasites in fixed tissues. Journal of Cutaneous Pathology, 26(3): 130-136, 1999.

LESSA, M. M. et al. Mucosal Leishmaniasis: epidemiological and clinical aspects. Revista Brasileira de Otorrinolaringologia, 73: 843-847, 2007.

MARSDEN, P. D. Mucosal leishmaniasis (Espundia Escomel, 1911). Transactions of the Royal Society of Tropical Medicine and Hygiene, 80: 859-887, 1986.

MELLO, C. X. et al. Comparison of the sensitivity of imprint and scraping techniques in the diagnosis of American tegumentary leishmaniasis in a referral centre in Rio de Janeiro, Brazil. Parasitology Research, 109(3): 927-933, 2011.

MENDONÇA, M. G. et al. Persistence of Leishmania parasites in scars after clinical cure of American cutaneous leishmaniasis: is there a sterile cure? The Journal of Infectious Diseases, 189(6): 1.018-1.023, 2004.

MISHRA, J.; SAXENA, A. \& SINGH, S. Chemotherapy of leishmaniasis: past, present and future. Current Medicinal Chemistry, 14: 1.153-1.169, 2007.

OLIVEIRA, L. F. et al. Systematic review of the adverse effects of cutaneous leishmaniasis treatment in the New World. Acta Tropica, 118(2): 87-96, 2011.

PACHECO, R. S. et al. Population heterogeneity among clones of New World Leishmania species. Parasitology, 100(3): 393398, 1990.

PEREIRA, B. A. S. \& ALVES, C. R. Immunological characteristics of experimental murine infection with Leishmania (Leishmania) amazonensis. Veterinary Parasitology, 158: 239-255, 2008.

ROBERTS, W. L.; BERMAN, J. D. \& RAINEY, P. M. In vitro antileishmanial properties of tri- and pentavalent antimonial preparations. Antimicrobial Agents Chemotherapy, 39(6): 1.234-1.239, 1995. 
SCHUBACH, A. et al. Detection of Leishmania DNA Polymerase Chain Reaction in Scars of Treated Human Patiens. The Journal of Infection Disease, 178: 911-914, 1998a.

SCHUBACH, A. et al. Cutaneous scars in american tegumentary leishmaniasis patients: a site of Leishmania (viannia) braziliensis persistence and viability eleven years after antomonial therapy and clinical cure. The American Journal of Tropical Medicine and Hygiene, 58(6): 824-827, 1998b.

SCHUBACH, A. et al. Leishmanial antigens in the diagnosis of active lesions and ancient scars of American tegumentary leishmaniasis patients. Memórias do Instituto Oswaldo Cruz, 96(7): 987-996, 2001.

WORLD HEALTH ASSEMBLY (WHA). Resolution from the 16º . World Health Assembly, 21 maio 2007. Disponível em: <www. who.int/neglected_diseases/mediacentre/WHA_60.13_Eng.pdf > . Acesso em: 11 mai. 2012.

WORLD HEALTH ORGANIZATION (WHO). Control of leishmaniasis. In: REPORT OF A MEETING OF THE WHO EXPERT COMMITTEE ON THE CONTROL OF LEISHMANIASES, 22-26 mar. 2010, Geneva. (WHO Tecnichal Report Series, 949). 
parte I

\section{Questões Evolutivas, Taxonômicas e Ultraestruturais de Parasitos do Gênero Leishmania}




\section{1 \\ Diversidade Genética em Parasitos do Gênero Leishmania:}

uma abordagem molecular

Raquel S. Pacheco I Filipe A. Carvalho-Costa

\section{DIVERSIDADE GENÉTICA INTER E INTRAESPECÍFICA EM LEISHMANIA}

$\mathrm{D}$ entre os gêneros de protozoários parasitas do homem, Leishmania (Ross, 1903) é provavelmente aquele que abrange o maior número de espécies patogênicas. Espécies diferentes de Leishmania foram identificadas inicialmente com base em apresentações clínicas distintas (visceral, cutânea, cutânea difusa, mucocutânea), em situações epidemiológicas particulares, em características biológicas e em distribuições geográficas específicas. Dois subgêneros (Leishmania e Viannia) foram definidos pelas diferenças observadas em relação aos sítios anatômicos de desenvolvimento dos parasitos no tubo digestivo dos insetos vetores (Lainson \& Shaw, 1987). Nesse sentido, o subgênero Viannia é restrito ao Novo Mundo, enquanto Leishmania (Leishmania) circula no Novo Mundo e no Velho Mundo (Kerr, 2000).

Verificar se todas as espécies de Leishmania descritas representam realmente unidades taxonômicas discretas (DTUs - sigla em inglês para Discrete Typing Unity), terminologia introduzida por Michel Tibayrenc no fim dos anos 90 (Tibayrenc, 1998), ou seja, conjuntos de isolados mais geneticamente relacionados entre si do que a quaisquer outros - identificáveis por meio de marcadores genéticos específicos, aplicados em estudos de abordagem interespecífica - é ainda um dos desafios em genética das leishmanioses. Como segundo desafio, este em nível intraespecífico, está a caracterização de DTUs capazes de subdividir determinado táxon, demonstrando as possibilidades de uma determinada espécie de Leishmania ser 'estruturada' ou 'não estruturada'. A estruturação de DTUs capazes de subdividir espécies de Leishmania poderia ser explicada por dois mecanismos: evolução clonal e especiação críptica.

Como revisto por Bañuls, Hide e Tibayrenc (1999), as ferramentas utilizadas para identificar DTUs (ou para rejeitar sua existência) são: (i) a genética populacional, capaz de avaliar, em um corte pontual no tempo, a individualização de populações e a presença de fluxo gênico entre elas; e (ii) a análise filogenética, que tem como objetivo reconstruir o passado evolutivo (ou microevolutivo, como normalmente realizado em epidemiologia molecular e genética evolutiva de patógenos) de uma espécie. Nesse sentido, estudos iniciais (Tibayrenc, Kjellberg \& Ayala, 1990; Jimenez, Alvar \& Tibayrenc, 1997) utilizando como metodologia a eletroforese de multilocos enzimáticos testaram as seguintes hipóteses: (i) os genótipos determinados pela análise dos padrões de migração eletroforética de isoenzimas seriam 'instáveis' (ou seja, não se propagariam) devido à recombinação genética não 
podendo, portanto, ser usados como marcadores genéticos; (ii) os genótipos se propagariam como 'cópias' genéticas e, dessa forma, poderiam ser usados como marcadores genéticos. Como marcadores genéticos, entendemos quaisquer diferenças detectáveis ao nível do DNA cujo padrão de transmissão de geração para geração possa ser identificado. Confrontadas, tais hipóteses estão na base do debate sobre sexualidade versus clonalidade em genética evolutiva de microrganismos, de forma que, na primeira hipótese, estaríamos diante de uma espécie com comportamento sexual, 'praticando fluxo gênico' e, na segunda, perante um patógeno que se propagaria sob a forma de clones que são cópias daquele que lhes originou. Neste último caso, encontraríamo-nos diante da estruturação da população de parasitos e a espécie poderia ser subdividida em DTUs entre as quais não ocorrem trocas genéticas, ou ocorreriam como eventos esporádicos e raros (Tibayrenc \& Ayala, 2002).

Cabe ressaltar que a segunda possibilidade é a que tem prevalecido nos estudos em taxonomia molecular do gênero Leishmania (Tibayrenc \& Ayala, 2002). Tais discussões despertaram grande interesse dos pesquisadores envolvidos com a epidemiologia molecular e a genética em leishmanioses, uma vez que a diversidade das populações parasitárias poderia influenciar a evolução e a distribuição de caracteres relacionados à virulência, à resistência às drogas e à infectividade (Miles et al., 2009). Novas técnicas para estudo da variabilidade genética inter e intraespecífica no gênero Leishmania têm sido capazes de identificar (ou agrupar) diferentes espécies e distintos genótipos para determinadas espécies. Em comum entre essas metodologias está o emprego de técnicas baseadas na reação em cadeia da polimerase (PCR) (Saiki et al., 1995). A PCR tem representado, também, importante ferramenta diagnóstica para as leishmanioses, com crescente aplicabilidade clínica e epidemiológica.

Partindo-se das observações sobre diversidade genética intraespecífica, podemos admitir que os parasitos do gênero Leishmania circulem em humanos, reservatórios e vetores como um conjunto de subpopulações heterogêneas (Tibayrenc, Kjellberg \& Ayala, 1990). Dessa forma, tem sido proposto que determinados clones poderiam propagar-se com maior ou menor sucesso em áreas endêmicas e que distintos graus de endemicidade poderiam estar associados a uma maior ou menor diversidade de clones circulando na natureza, refletindo situações epidemiológicas mais simples ou de maior complexidade (Pacheco et al., 1986). Alguns clones, naturalmente, obteriam vantagens evolutivas ao serem selecionados por 'filtros' biológicos em reservatórios e vetores. Desses filtros emerge a geração endógena de novos polimorfismos, em um mecanismo adaptativo constante e dinâmico relacionado às pressões seletivas (Pacheco et al., 1995), podendo ser reversível (Lee, Tarn \& Chang, 1993). A circulação, na natureza, de subpopulações parasitárias heterogêneas, traz a possibilidade de infecção por inóculos policlonais que estarão submetidos à pressão imune exercida pelo hospedeiro, em um processo que poderá levar à seleção clonal. Dentro desse contexto, a heterogeneidade clonal em isolados humanos e reservatórios silvestres foi evidenciada (Pacheco et al., 1990; Saravia et al., 1990).

Cenários ecoepidemiológicos distintos possivelmente são também capazes de influenciar a variabilidade genética de populações de Leishmania. Em regiões hiperendêmicas, situações epidemiológicas mais complexas podem possibilitar a circulação das populações parasitárias em um maior número de espécies de vetores e reservatórios, que representariam fontes de heterogeneidade, dentro da dinâmica da interação parasito-hospedeiro.

\section{MARCADORES MOLECULARES EMPREGADOS NA AVALIAÇÃO DA DIVERSIDADE GENÉTICA EM LEISHMANIA}

\section{Eletroforese de multilocos enzimáticos (MLEE, sigla em inglês para Multilocus Enzyme Electrophoresis)}

O estudo de polimorfismos em enzimas que atuam nas vias metabólicas foi, como relatado anteriormente, a primeira metodologia empregada para caracterizar isolados de Leishmania (Momen, 1984). Por meio dessa técnica, graus variáveis de diversidade têm sido demonstrados entre as diferentes espécies do gênero. Deve-se ter em mente que a análise de padrões eletroforéticos de enzimas reflete de maneira indireta variações (polimorfismos) ao nível genômico. Isolados distintos de parasitos que apresentam padrões semelhantes são agrupados em zimodemas. A sensibilidade da técnica 
em identificar a diversidade genética existente entre cepas de Leishmania pode ser aumentada utilizando-se um maior número de enzimas. Entre as enzimas mais frequentemente utilizadas nas análises isoenzimáticas, podemos citar aconitato hidratase, glicose-6-fosfato-desidrogenase, glicose-fosfato-isomerase, isocitrato desidrogenase, malato desidrogenase, enzima málica, nucleotidase, peptidase (L-prolina), aldolase fosfoglicomutase e 6-fosfoglico-desidrogenase. As diferenças nas posições das bandas produzidas nos géis de eletroforese são resultado das mobilidades distintas apresentadas pelas enzimas, ocasionadas por polimorfismos nos genes que as codificam. As bandas podem então ser numeradas e os perfis (eletromorfos) submetidos à análise numérica com o intuito de se agrupar as amostras em zimodemas. Embora permaneça sendo considerado o método padrão para a identificação de espécies no gênero Leishmania (Rioux et al., 1990; Momen et al.,1985; Grimaldi et al., 1991; Thomaz-Soccol et al., 1993; Cupolillo, Grimaldi \& Momen, 1994; Cupolillo et al., 2000), a técnica apresenta como principal fator limitador a necessidade de que os parasitos sejam previamente cultivados, procedimento que em muitas ocasiões não é factível. Além disso, embora as isoenzimas sejam consideradas marcadores seletivamente neutros, o grau de polimorfismo enzimático é limitado, pois tais enzimas desempenham funções metabólicas cujas características não poderiam ser alteradas sob risco de inviabilização das atividades de respiração celular. Sendo assim, além do número de loci examinados ser limitado, pode-se não identificar polimorfismos para um ou mesmo vários dos loci isoenzimáticos disponíveis. Isso pode limitar ainda mais o poder discriminatório da metodologia. Não obstante, a vantagem da MLEE reside no fato de que os alelos isoenzimáticos são codominantes, isto é, genótipos homozigóticos e heterozigóticos de um determinado lócus são facilmente identificados. Essa vantagem permite estimar parâmetros tais como frequências genotípicas, frequências alélicas e, com base nestes, desvios do equilíbrio de Hardy-Weinberg em um lócus ou do equilíbrio de ligação gamética entre loci (Weir, 1990).

Como revisto recentemente (Schönian, Kuhls \& Mauricio, 2011), por intermédio da MLEE, os parasitos do gênero Leishmania puderam ser classificados em complexos dentro do subgênero Leishmania: (i) complexo L. donovani, que inclui $L$. (L.) donovani, L. (L.) archibaldi e L. (L.) infantum (syn. L. (L.) chagasi); (ii) complexo L. tropica, que inclui L. (L.) tropica, L. (L.) killicki e L. (L.) aethiopica; (iii) complexo L. major, que inclui L. (L.) major, L. (L.) gerbilli, $L$. (L.) arabica e $L$. (L.) turanica; e (iv) complexo L. mexicana que inclui $L$. (L.) mexicana, $L$. (L.) amazonensis, $L$. (L.) aristidesi, $L$. (L.) venezuelensis e $L$. (L.) forattinii, além de $L$. (L.) enriettii fora destes complexos. Dentro do subgênero Viannia, distinguem-se (i) complexo L. braziliensis incluindo L. (V.) braziliensis e L. (V.) peruviana e (ii) complexo $L$. guyanensis, incluindo L. (V.) guyanensis, L. (V.) panamensis e $L$. (V.) shawi, além das espécies $L$. (V.) naiffi, L. (V.) lainsoni, $L$. (V.) lindenbergi e L. (V.) utingensis, não pertencentes a estes complexos. Não classificadas em nenhum dos dois subgêneros, estariam L. colombiensis, L. equatorensis, L. hertigi, L. herreri e L. deanei.

\section{Polimorfismo de tamanho de fragmentos de restrição (RFLP, sigla em inglês para Restriction Fragment Length Polymorphism)}

A técnica RFLP baseia-se na digestão do DNA parasitário pelas denominadas 'enzimas de restrição', que são capazes de reconhecer e clivar a fita dupla da molécula de DNA em sítios específicos. Essas endonucleases identificam sequências nucleotídicas específicas, clivando a dupla fita de DNA nos sítios palindrômicos de reconhecimento (Nathans \& Smith, 1975). Como produto da digestão do material genético, fragmentos de DNA de tamanhos distintos serão obtidos e visualizados através de eletroforese. Na presença de polimorfismos nas sequências nucleotídicas (e, portanto, de diversidade genética entre os isolados), as enzimas de restrição deixarão de reconhecer alguns sítios de clivagem gerando-se assim perfis eletroforéticos diferentes. A técnica de RFLP, quando comparada à MLEE, apresenta como vantagem o potencial de avaliar todo o genoma do organismo estudado. Os marcadores baseados em RFLP possuem expressão codominante, de forma que permite discriminar genótipos homozigotos e heterozigotos. A técnica aumenta, portanto, a probabilidade de se identificar associações entre marcadores e genes que controlam determinada característica de interesse (Tanksley et al., 1992). 
Como aplicações práticas da técnica de RFLP do kDNA (DNA do cinetoplasto) em epidemiologia molecular e taxonomia em leishmanioses podemos citar, entre outras: (i) o rastreamento de cepas circulantes em humanos, reservatórios domésticos e silvestres, definindo-se situações epidemiológicas mais simples e mais complexas em áreas endêmicas (Pacheco et al., 1986); (ii) a identificação de infecção mista por $L$ (L.) chagasi e L (V.) braziliensis em um paciente do Rio de Janeiro (Oliveira-Neto et al., 1986); (iii) a deteç̧ão de infecção concomitante cutânea, visceral e ocular por $L$ (V.) braziliensis em paciente transplantado renal e em uso de imunossupressores (Gontijo et al., 2002); e (iv) a descrição de Leishmania (Leishmania) forattinii, nova espécie de Leishmania infectando gambás e roedores no Brasil (Yoshida et al., 1993).

Caso as enzimas de restrição sejam aplicadas a segmentos de DNA previamente amplificados por PCR específica para determinada região do genoma, teremos a técnica RFLP-PCR. Essa metodologia, baseada na PCR, é capaz também de avaliar a diversidade genética intra e interespecífica de espécies de Leishmania do Novo e do Velho Mundo (Marfurt et al., 2003; Rotureau et al., 2006). No Brasil, foi utilizada para a discriminação de amostras de L. (L.) braziliensis e $L$. (V.) amazonensis obtidas a partir de lesões cutâneas (Volpini et al., 2004). A avaliação da variabilidade interespecífica entre $L$. (L.) infantum e $L$. (L.) chagasi sugeriu que estes taxa fossem considerados uma única espécie (Mauricio et al., 2001), corroborando análise prévias por MLEE. Alguns estudos que utilizaram a técnica RFLP-PCR na epidemiologia molecular de Leishmania elegeram o gene que codifica a proteína gp63, e os produtos dessa amplificação como substrato para a digestão por enzimas de restrição (Mauricio et al., 2001).

Recentemente, foi demonstrado que os perfis eletroforéticos obtidos com base na digestão por enzimas de restrição do segmento genômico que codifica a proteína de choque térmico de $70 \mathrm{kDa}$ (hsp70, sigla em inglês para heat shock protein) é capaz de discriminar muitas espécies de Leishmania de importância médica: L. (L.) infantum, L. (L.) donovani, L. (L.) tropica, L. (L.) aethiopica, L. (L.) major, L. (V.) lainsoni, L. (V.) naiffi, L. (V.) braziliensis, L. (V.) peruviana, L. (V.) guyanensis e L. (V) panamensis (Montalvo et al., 2010). Da mesma forma, a técnica RFLP-PCR direcionada ao gene de mini-exon foi capaz de gerar padrões de bandas espécie-específicos em Leishmania do Novo e do Velho Mundo (Marfurt et al., 2003).

\section{Polimorfismo de DNA amplificado ao acaso (RAPD, sigla em inglês para Random Amplified Polymorphic DNA)}

Esta técnica consiste na amplificação aleatória de fragmentos de DNA parasitário utilizando-se oligonucleotídeos inespecíficos que reconhecem sequências curtas no genoma. A presença de polimorfismos irá alterar o padrão de reconhecimento desses sítios pelos iniciadores, gerando, após a amplificação, um padrão de bandas distinto para as amostras geneticamente divergentes. A quantidade de bandas não compartilhadas entre amostras pareadas será tanto maior quanto mais polimorfismos existam no genoma destas. Diferentes perfis podem então ser submetidos à análise numérica em softwares específicos.

Assim como a MLEE, o RAPD é uma ferramenta disponível para avaliar a presença de variabilidade genética intra e interespecífica em Leishmania, possibilitando inferências sobre a estrutura de populações parasitárias. A técnica RAPD apresenta como vantagem o fato de não requerer a constituição prévia de uma biblioteca de iniciadores específicos para o organismo de interesse. Um grupo 'polivalente' de oligonucleotídeos pode ser usado para quaisquer organismos. A técnica conjuga, portanto, a simplicidade da visualização direta dos marcadores isoenzimáticos com a resolutividade dos marcadores de DNA.

A principal limitação da técnica é o relativamente baixo conteúdo de informação genética por lócus - apenas um alelo é detectado -, o que define a dominância dos marcadores RAPD (Grattapaglia \& Sederoff, 1994). Dessa forma, genótipos heterozigotos não podem ser discriminados dos homozigotos pela técnica do RAPD. Idealmente, o RAPD deve complementar a MLEE com o objetivo de corroborar (ou não) o agrupamento em zimodemas obtido por meio desta. Estudos com marcador RAPD (Schriefer et al., 2004) possibilitaram avaliar a diversidade genética intraespecífica 
de L. (V.) braziliensis, evidenciando-se a multiclonalidade das populações parasitárias em uma área endêmica no Nordeste brasileiro; os parasitos identificados em lesões cutâneas eram geneticamente distintos daqueles detectados em lesões mucosas. Entretanto, clones geneticamente relacionados de L. (V.) braziliensis nas lesões inicial e reativada de um mesmo paciente, no Rio de Janeiro (Baptista et al., 2009). No Sudão, a variabilidade genética intraespecífica de amostras de $L$. (L.) donovani identificadas em pacientes com leishmaniose visceral foi avaliada, demonstrando-se a presença de três genótipos entre os parasitos resistentes ao estibogluconato de sódio e apenas um entre os isolados sensíveis a essa droga (Hamad et al., 2010). Os marcadores RAPD auxiliaram também a comparação de Leishmania isolada de lesões cutâneas no Brasil com cepas de referência da Organização Mundial da Saúde (OMS), demonstrando a similaridade daquelas com L. (L.) major (Silva et al., 2009).

\section{PCR de iniciador único em condições de baixa estringência (LSSP-PCR, sigla em inglês para Low-Stringency Single Specific Primer-PCR)}

Esta técnica baseia-se na amplificação prévia de um segmento genômico parasitário por meio de PCR específica. Os produtos desta primeira PCR são então submetidos a uma segunda amplificação utilizando-se iniciador único e condições de baixa estringência, como aquelas obtidas ao se utilizar baixas temperaturas de anelamento. Isso permite um reconhecimento menos específico de sequências nucleotídicas pelo iniciador único, que será um daqueles do par específico utilizado na primeira amplificação. Com base em tal procedimento, podem ser gerados produtos de diferentes tamanhos que serão discriminados por eletroforese, constituindo-se em padrões complexos formados por várias bandas. O padrão de bandas obtido pode ser alterado por polimorfismos de base única (Pena et al., 1994), sendo a técnica capaz de discriminar variantes genéticas intraespecíficas de L. (V.) braziliensis (Ferreira et al., 2007; Baptista et al., 2009).

Por meio da técnica LSSP-PCR, foram demonstrados polimorfismos intraespecíficos nos minicírculos do kDNA de L. (V.) braziliensis recuperadas de lesões de mucosa oral e nasal, detectando-se perfis divergentes em lesões de um mesmo paciente obtidas em um intervalo de um ano (Oliveira et al., 2010).

\section{PCR ancorada a repetições de sequências simples (SSR-PCR, sigla em inglês para Simple Sequence Repeats-PCR)}

Os genomas eucariotos apresentam grande quantidade de sequências repetidas, algumas mais complexas (minissatélites) e outras mais simples (microssatélites), sendo altamente polimórficos e portanto úteis para utilização como marcadores genéticos. Regiões que contêm sequências simples repetidas podem ser amplificadas individualmente por meio de PCR utilizando-se iniciadores específicos, complementares a sequências que as flanqueiam. Tais segmentos apresentam um polimorfismo resultante da presença de quantidades variáveis de elementos simples repetidos. Dessa forma, 'ilhas' microssatélites com quaisquer repetições simples podem ser consideradas um lócus alélico. Os polimorfismos são observados após eletroforese em gel de agarose ou poliacrilamida. Os loci SSR são codominantes. Como vantagem da técnica, pode-se citar o elevado conteúdo de polimorfismos. Por serem frequentes e distribuídos ao acaso, possibilitam uma ampla cobertura do genoma. Como limitação está a necessidade de desenvolvimento prévio dos marcadores, que envolve a construção de uma biblioteca de fragmentos genômicos pequenos para o organismo de interesse.

Embora já tenham sido identificados microssatélites contendo todas as combinações de bases, as repetições (CA)n parecem ser as mais comuns (Rossi et al., 1994). A técnica demonstrou também ser capaz de discriminar cepas de referência de L. (L.) amazonensis, L. (L.) chagasi, L. (V.) braziliensis e L. (V.) guyanensis, por intermédio da geração de perfis distintos. Os autores relataram uma sensibilidade comparável àquela observada para RAPD, porém com maior reprodutibilidade. Isolados asiáticos e africanos de L. (L.) tropica puderam ser avaliados quanto à variabilidade genética mediante tal técnica, demonstrando-se o agrupamento das amostras por área geográfica (Schwenkenbecher 
et al., 2006). A técnica SSR-PCR, aplicada a estudos em epidemiologia molecular de L.(L.) infantum exibiu também capacidade de discriminar genótipos dessa espécie identificados em cães e humanos (Bulle et al., 2002).

\section{Sequenciamento de DNA, tipagem por sequenciamento de multilocos (MLST, sigla em inglês para Multilocus Sequence Typing) e tipagem por multilocos de microssatélites (MLMT, sigla em inglês para Multilocus Microsatellite Typing)}

Para estudos em epidemiologia molecular e genética evolutiva de patógenos, alvos genéticos específicos são inicialmente amplificados por PCR e posteriormente submetidos a sequenciamento. Sequências genômicas de ambos os espaçadores transcritos internos (ITS, sigla em inglês para Internal Transcribed Spacers) e da subunidade 5.8S do DNA ribossomal depositadas no GenBan foram analisadas (Dávila \& Momen, 2000), demonstrando (i) a separação dos subgêneros L. (Leishmania) e L. (Viannia); (ii) dentro de L. (Leishmania) a discriminação entre espécies do Velho Mundo e aquelas pertencentes ao complexo L. mexicana; (iii) a separação dos complexos de espécies do Velho Mundo; (iv) separação de espécies dentro dos complexos. Os resultados não divergiram da classificação proposta por meio de MLEE.

Recentemente, sequências nucleotídicas de um fragmento de 1.380 pares de bases do gene que codifica a proteína hsp70 foram determinadas com o intuito de se avaliar a variabilidade genética de isolados de Leishmania. Essas, combinadas a sequências previamente obtidas, permitiram o estudo de 52 amostras de 17 espécies distintas. Os resultados permitiram o reconhecimento de apenas oito espécies, em vez das 17 previamente definidas por MLEE: $L$. (L.) donovani, L. (L.) major, L. (L.) tropica, L. (L.) mexicana, L. (V.) lainsoni, L. (V.) naiffi, L. (V.) guyanensis e L. (V.) braziliensis (Fraga et al., 2010).

A técnica MLST mensura diretamente variações na sequência de nucleotídeos do DNA parasitário, em um grupo de genes específicos, denominados genes housekeeping (genes constitutivos, necessários para a manutenção das funções celulares basais), caracterizando isolados distintos segundo seus perfis alélicos particulares. A técnica envolve a realização de PCR, seguida de sequenciamento do DNA. Diferenças em nucleotídeos entre as amostras podem ser avaliadas para um número variável de genes, dependendo do grau de discriminação desejado. Ferramentas de biologia computacional são utilizadas para manejar, analisar e interpretar os dados obtidos.

A técnica MLST, entretanto, pode ser dificultada quando a espécie sob análise contém variação genética muito reduzida para diferenciar os isolados, como é o caso em alguns eucariotos. Nesses casos, é possível que os níveis de diversidade genética observados nos loci não sejam suficientes para permitir a discriminação de isolados por MLST.

Como alternativa para o problema, podem ser utilizados os marcadores MLMT. Essa técnica tem como loci-alvos repetições de dois, três ou quatro nucleotídeos (as repetições de microssatélites citadas anteriormente no item SSR-PCR). Tais repetições são bem mais variáveis do que os genes constitutivos, devido ao acúmulo progressivo de polimorfismos de tamanho ocasionados em consequência de erros da DNA polimerase durante a replicação do genoma. Os alelos de cada lócus são amplificados e estudados por sequenciamento, caracterizando-se os polimorfismos de tamanho.

Essa mesma técnica foi empregada para estudos de epidemiologia molecular na Índia, os quais incluíram a caracterização de 132 isolados de L. (L.) donovani obtidos de pacientes com calazar, leishmaniose cutânea pós-calazar e leishmaniose cutânea, revelando-se a similaridade de 125 cepas de origens geográficas e manifestações clínicas distintas, ou de sua sensibilidade aos antimoniais. A circulação de uma população estruturada (geneticamente homogênea) de parasitos na região sugeriu a introdução recente do patógeno e sua difusão epidêmica (Alam et al., 2009).

A técnica MLMT foi também empregada para a caracterização de isolados de L. (V.) braziliensis, L. (V.) guyanensis e L. (V.) peruviana, tendo sido capaz de discriminar as diferentes espécies de acordo com a área geográfica e de detectar a estruturação populacional (Oddone et al., 2009). 


\section{CONSIDERAÇÕES FINAIS}

Diversas técnicas de biologia molecular têm sido empregadas em estudos epidemiológicos das leishmanioses tegumentar e visceral, do Novo e do Velho Mundo. Vários marcadores genéticos, com características distintas e graus de resolução variáveis têm sido empregados na detecção de diversidade genética intra e interespecífica, no intuito de se elucidar questões taxonômicas, evolutivas, epidemiológicas e mesmo clínicas, relacionadas à resistência aos antimoniais, à imunossupressão e às diferentes formas de apresentação da doença. Investigações nesse campo necessitam de uma abordagem que considere, de forma integrada, polimorfismos genéticos do patógeno, do hospedeiro e do vetor, incluindo suas interações (Tibayrenc, 1998).

Cabe ressaltar que, mesmo a despeito de questionamentos sobre distintos relógios moleculares ou características sinapomórficas dos marcadores moleculares, polimorfismos continuam sendo detectados em um ou ambos os genomas, nuclear e mitocondrial (Pacheco et al., 2000). Enfatizamos ainda que a plasticidade genotípica dos parasitos e vetores das leishmanioses, que possibilita a adaptação a condições adversas, pode estar associada à obtenção de vantagem seletivas em condições de estresse nos ciclos de transmissão. A esse ponto, duas questões emergem (Pacheco \& Brito, 1999): estariam as populações (ou clones) de Leishmania evoluindo em direção a um aumento ou a uma redução nos níveis de heterogeneidade? Existiria uma evolução paralela dos genomas nuclear e mitocondrial ou uma possível interação entre ambos os elementos no parasito? Um ponto fundamental que emerge desse cenário está relacionado à relação parasito-hospedeiro. Se a entidade biológica em evolução é a linhagem clonal (Ayala, 1993), pode-se imaginar clones com diferentes características biológicas sendo misturados com a população total circulante, compartilhando diferentes fatores de virulência ou competindo por vantagens seletivas tais como distintas taxas de crescimento e tropismo.

Embora muito se tenha caminhado no sentido de uma melhor compreensão da história natural das leishmanioses, o horizonte à nossa frente está repleto de possibilidades para estudos genéticos de Leishmania. As leishmanioses são, em grande parte do planeta, doenças negligenciadas que afetam grupos populacionais de pequena visibilidade e o desenvolvimento de novas e mais eficazes possibilidades terapêuticas é uma necessidade evidente. A doença está também associada ao desflorestamento, apresentando taxas de incidência crescentes em regiões de expansão das fronteiras econômicas no Brasil, principalmente na Amazônia. As alterações climáticas determinadas pelo aquecimento global são fatores que poderão influenciar a distribuição de vetores e o surgimento de novos focos da doença. A pandemia de HIV/Aids leva à possibilidade de que as leishmanioses representem desafios crescentes em saúde pública em diversos países. Nesse contexto, várias questões necessitarão ser respondidas, muitas delas valendo-se da epidemiologia molecular. Mais recentemente, o sequenciamento dos genomas completos de L. (L.) infantum e $L$ (V.) braziliensis (Peacock et al., 2007) contribui com a identificação de genes que são espécie-específicos ou estão sob pressão seletiva, fornecendo recursos para direcionar esforços na identificação de fatores intrínsecos do parasito que influenciam a infecção. Da mesma forma, elementos únicos ao gênero Leishmania poderão ser utilizados como alvos potenciais de novas drogas ou no desenvolvimento de vacinas.

\section{REFERÊNCIAS}

ALAM, M. Z. et al. Multilocus microsatellite typing (MLMT) reveals genetic homogeneity of Leishmania donovani strains in the Indian subcontinent. Infection, Genetics and Evolution, 9: 24-31, 2009.

AYALA, F. J. Trypanosoma and Leishmania have clonal population structures of epidemiological significance. Biological Research, 23: 47-63, 1993.

BAÑULS, A. L.; HIDE, M. \& TIBAYRENC, M. Epidemiology and evolutionary genetics of Leishmania parasites. International Journal for Parasitology, 29: 1.137-1.147, 1999. 
BAPTISTA, C. et al. Leishmania (Viannia) braziliensis genotypes identified in lesions of patients with atypical or typical manifestations of tegumentary leishmaniasis: Evaluation by two molecular markers. Experimental Parasitology, 121: 317-322, 2009.

BULLE, B. et al. Practical approach for typing strains of Leishmania infantum by microsatellite analysis. Journal of Clinical Microbiology, 40: 3.391-3.397, 2002.

CUPOLILLO, E.; GRIMALDI JR., G. \& MOMEN, H. A general classification of New World Leishmania using numerical zymotaxonomy. The American Journal of Tropical Medicine and Hygiene, 50: 296-311, 1994.

CUPOLILLO, E. et al. A revised classification for Leishmania and Endotrypanum. Parasitology Today, 16: 142-144, 2000.

DÁVILA, A. M. \& MOMEN, H. Internal-transcribed-spacer (ITS) sequences used to explore phylogenetic relationships within Leishmania. Annals of Tropical Medicine and Parasitology, 94: 651-654, 2000.

FERREIRA, G. A. et al. Discrimination of Leishmania braziliensis variants by kDNA signatures produced by LSSP-PCR. The Journal of Parasitology, 93: 712-714, 2007.

FRAGA, J. et al. Phylogeny of Leishmania species based on the heat-shock protein 70 gene. Infection, Genetics and Evolution, 10: 238-245, 2010.

GONTIJO, C. M. F. et al. Concurrent cutaneous, visceral and ocular leishmaniasis by Leishmania (Viannia) brasiliensis in a kidney transplant patient. Memórias do Instituto Oswaldo Cruz, 97: 751-753, 2002.

GRATTAPAGLIA, D. \& SEDEROFF, R. Genetic linkage maps of Eucalyptus grandis and Eucalyptus urophylla using a pseudotestcross: mapping strategy and RAPD markers. Genetics, 137: 1.121-1.137, 1994.

GRIMALDI JR., G. et al.characterization and classification of leishmanial parasites from humans, wild mammals, and sand flies in the Amazon region of Brazil. The American Journal of Tropical Medicine and Hygiene, 44: 645-661, 1991.

HAMAD, S. H. et al. Leishmania donovani: Genetic diversity of isolates from Sudan characterized by PCR-based RAPD. Experimental Parasitology, 125: 389-393, 2010.

JIMENEZ, M.; ALVAR, J. \& TIBAYRENC, M. Leishmania infantum is clonal in Aids patients too; epidemiological implications. Aids, 11: 569-573, 1997.

KERR, S. F. Palaearctic origin of Leishmania. Memórias do Instituto Oswaldo Cruz, 95: 75-80, 2000.

LAINSON, R. \& SHAW, J. Evolution, classification and geographical distribution. In: PETERS, W. \& KILLICK-KENDRICK, R. (Eds.). The Leishmaniases in Biology and Medicine, Biology and Epidemiology. v. 1. London: Academic Press, 1987.

LEE, S. T.; TARN, C. \& CHANG, K. P. Characterization of the switch of kinetoplast DNA minicircle dominance during development and reversion of drug resistence in Leishmania. Molecular and Biochemical Parasitology, 58: 187-204, 1993.

MARFURT, J. et al. Diagnostic genotyping of Old and New World Leishmania species by PCR-RFLP. Diagnostic Microbiology and Infectious Disease, 46: 115-124, 2003.

MAURICIO, I. L. et al. Genetic typing and phylogeny of the Leishmania donovani complex by restriction analysis of PCR amplified gp63 intergenic regions. Parasitology, 122: 393-403, 2001.

MILES, M. A. et al. The molecular epidemiology and phylogeography of Trypanosoma cruzi and parallel research on Leishmania: looking back and to the future. Parasitology, 136: 1.509-1.528, 2009.

MOMEN, H. Parasite characterization by zimodeme analysis. In: MOREL, C. (Ed.). Genes and Antigens of Parasites: a laboratory manual. Geneva: UNDP, World Bank, WHO, 1984. (Special Programme for Research and Training in Tropical Diseases / FINEP / CNPq / Fundação Oswaldo Cruz, Rio de Janeiro, Brasil).

MOMEN, H. et al. Brazilian Leishmania stocks phenotypically indistiguishble from L. major. The American Journal of Tropical Medicine and Hygiene, 34: 1.076-1.084, 1985.

MONTALVO, A. M. et al. Heat-shock protein 70 PCR-RFLP: a universal simple tool for Leishmania species discrimination in the New and Old World. Parasitology, 137: 1.159-1.168, 2010. 
NATHANS, D. \& SMITH, H. O. Restriction endonucleases in the analysis and restructuring of DNS molecules. Annual Review of Biochemistry, 44: 273-293, 1975.

ODDONE, R. et al. Development of a multilocus microsatellite typing approach for discriminating strains of Leishmania (Viannia) species. Journal of Clinical Microbiology, 47: 2.818-2.825, 2009.

OLIVEIRA, F. S. et al. KDNA minicircle signatures of Leishmania (Viannia) braziliensis in oral and nasal mucosa from mucosal leishmaniasis patients. Diagnostic Microbiology and Infectious Disease, 66: 361-365, 2010.

OLIVEIRA-NETO, M. P. et al. Concurrent human infection with Leishmania donovani chagasi and Leishmania braziliensis braziliensis. Annals of Tropical Medicine and Parasitology, 80: 587-592, 1986.

PACHECO, R. S. \& BRITO, C. M. Reflections on the population dynamics of Trypanosoma cruzi: heterogeneity versus plasticity. Memórias do Instituto Oswaldo Cruz, 94: 199-201, 1999.

PACHECO, R. S. et al. Schizodeme analysis of Leishmania isolates and comparison with some phenotypic techniques. In: RIOUX, J. A. (Ed.). Leishmania Taxonomie et Phylogenése: applications éco-épidémiologiques. Montpellier: IMEEE, 1986.

PACHECO, R. S. et al. Population heterogeneity among clones of New World Leishmania species. Parasitology, 100: 393-398, 1990.

PACHECO, R. S. et al. Genotypic polymorphisms in experimental metastatic dermal leishmaniasis. Molecular and Biochemical Parasitology, 69: 197-209, 1995.

PACHECO, R. S. et al. Intraspecific heterogeneity in the mini-exon gene localization of Leishmania (Viannia) panamensis and Leishmania (Viannia) guyanensis from Colombia. The Journal of Parasitology, 86: 1.250-1-253, 2000.

PEACOCK, C. S. et al. Comparative genomic analysis of three Leishmania species that cause diverse human disease. Nature Genetics, 39: 839-847, 2007.

PENA, S. D. et al. Sequence-specific "gene signatures" can be obtained by PCR with single specific primers at low stringency. Proceedings of the National Academy of Sciences of the USA, 91: 1.946-1.949, 1994.

RIOUX, J. A. et al. Taxonomy of Leishmania. Use of isoenzymes. Suggestions for a new classification. Annales de Parasitologie Humaine et Comparée, 65: 111-125, 1990.

ROSS, R. Note on the bodies recently described by Leishman and Donovan. British Medical Journal, 2: 1.261-1.262, 1903.

ROSSI, V. et al. Structural organisation of microsatellite families in the Leishmania genome and polymorphisms at two (CA) n loci. Molecular and Biochemical Parasitology, 65: 271-282, 1994.

ROTUREAU, B. et al. Use of PCR - Restriction Fragment Length Polymorphism analysis to identify the main New World Leishmania species and analyze their taxonomic properties and polymorphism by application of the assay to clinical samples. Journal of Clinical Microbiology, 44: 459-467, 2006.

SAIKI, R. K. et al. Enzimatic amplification of beta globin genomic sequences and restriction site analysis for diagnosis od sickle cell anemia. Science, 230: 1.350-1.354, 1995.

SARAVIA, N. G. et al. Recurrent lesions in human Leishmania braziliensis infection - reactivation or reinfection? The Lancet, 336: 398-402, 1990.

SCHÖNIAN, G.; KUHLS, K. \& MAURICIO, I. L. Molecular approaches for a better understanding of epidemiology and population genetics of Leishmania. Parasitology, 138: 405-425, 2011.

SCHRIEFER, A. et al. Multiclonal Leishmania braziliensis population structure and its clinical implication in a region of endemicity for American Tegumentary Leishmaniasis. Infection and Immunity, 72: 508-514, 2004.

SCHWENKENBECHER, J. M. et al. Microsatellite analysis reveals genetic structure of Leishmania tropica. International Journal for Parasitology, 36: 237-246, 2006.

SILVA, S. O. et al.Leishmania sp. isolated from human cases of cutaneous leishmaniasis in Brazil characterized as Leishmania major-like. Acta Tropica, 112: 239-248, 2009. 
TANKSLEY, S. D. et al. High density molecular linkage maps of the tomato and potato genomes. Genetics, 132: 1.141-1.160, 1992.

THOMAZ-SOCCOL, V. et al. Phylogenetic taxonomy of New-World Leishmania. Annales de Parasitologie Humaine et Comparée, 68: 104-106, 1993.

TIBAYRENC, M. Genetic epidemiology of parasitic protozoa and other infectious agents: the need for an integrated approach. International Journal for Parasitology, 28: 85-104, 1998.

TIBAYRENC, M. \& AYALA, M. J. The clonal theory of parasitic protozoa: 12 years on Trends in Parasitology, 18: 405-410, 2002.

TIBAYRENC, M.; KJELLBERG, F. \& AYALA, F. J. A clonal theory of parasitic protozoa: the population structure of Entamoeba, Giardia, Leishmania, Naegleria, Plasmodium, Trichomonas and Trypanosoma, and its medical and taxonomical consequences. Proceedings of the National Academy of Sciences of the USA, 87: 2.414-2.418, 1990.

VOLPINI, A. C. et al. PCR-RFLP to identify Leishmania (Viannia) braziliensis and L. (Leishmania) amazonensis causing American cutaneous leishmaniasis. Acta Tropica, 90: 31-37, 2004.

WEIR, B. S. Genetic Data Analysis: methods for discrete population genetic data. Sunderland: Sinauer Associates, 1990.

YOSHIDA, E. L. A. et al. Description of Leishmania (Leishmania forattinii) sp. $n$, a new parasite infecting opossuns and rodents in Brazil. Memórias do Instituto Oswaldo Cruz, 88: 397-406, 1993. 


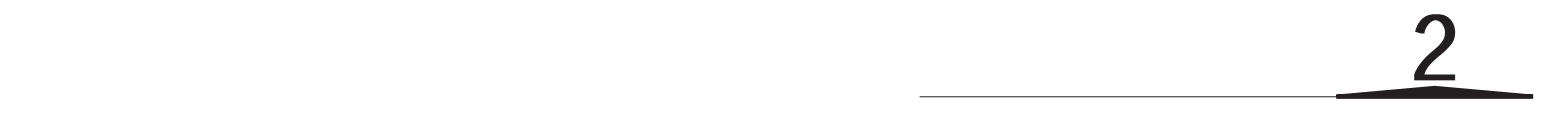

\title{
Considerações sobre a Taxonomia do Gênero Leishmania
}

\author{
Elisa Cupolillo I Mariana Côrtes Boité I Renato Porrozzi
}

\begin{abstract}
A taxonomia reúne organismos em grupos definidos, promove nomenclatura apropriada para os grupos formados e sistematiza a identificação de organismos previamente desconhecidos. O termo tem sua origem na palavra grega táxis - que significa ordem, arranjo - e nomos (lei, ciência). Assim, a taxonomia de um organismo é a prática e a ciência da classificação, usando unidades taxonômicas, chamadas taxa, para analisar e formular uma estrutura hierárquica. Tipicamente, tal formulação obedece a relações de tipo e subtipo, que por definição devem apresentar as mesmas propriedades e comportamentos. Como se trata de uma abordagem criada pelo homem, e não uma regra natural, deve ser constantemente revista e submetida à validação.
\end{abstract}

Leishmania é um gênero de protozoários parasitas, notável pelo grande número de espécies descritas. Estudos empregando métodos moleculares para análises filogenéticas têm sugerido que realmente existe uma variabilidade elevada para esse gênero. Entretanto, a validade taxonômica de várias espécies de Leishmania tem sido constantemente discutida. Um estudo recente de análise filogenética do gene que codifica a proteína de choque térmico de $70 \mathrm{kDa}$ (hsp70) analisou 17 espécies definidas por eletroforese de enzimas (análise de zimodemas), tendo os resultados obtidos suportado a existência de apenas oito dessas espécies (Fraga et al., 2010). Portanto, uma revisão da nomenclatura desse gênero se mostra de fundamental importância. Neste capítulo apresentaremos a situação atual da nomenclatura utilizada para o gênero Leishmania, as controvérsias a respeito do tema e aspectos que indicam a importância de estudos taxonômicos focando esse grupo de parasitos.

O gênero Leishmania foi descrito primeiramente por Ross em 1903, após sir William Boog Leishman atender, no hospital em que trabalhava, a um paciente proveniente da Índia. O mesmo apresentava febre, esplenomegalia e anemia. Sir Leishman já havia desenvolvido anteriormente um método de coloração (coloração de Leishman), e então, entre outros exames, ele optou por realizar uma punção do baço e submeter o material à coloração. Após observação em lâmina, identificou um grande número de corpúsculos ovais nas células do baço e do sangue. Meses depois ele observou as mesmas formas em fígado e baço de um rato com tripanossomíase. Após a publicação de tais achados, outro médico, Charles Donovan, confirmou essas observações, e os corpúsculos ficaram conhecidos como corpúsculos Leishman-Donovan. Entretanto, foi Ronald Ross (1903) quem propôs que tais corpúsculos representavam estágio intracelular de um novo parasito, o qual ele nomeou como Leishmania donovani. A partir daí várias espécies de 
Leishmania foram descritas e diversos sistemas de classificação foram adotados, usando categorias taxonômicas como a classificação em subespécie (Pessôa, 1961), ou classificações em complexos (Shaw \& Lainson, 1972) e seções (Cupolillo et al., 2000). Uma excelente revisão histórica sobre a descrição das espécies neotropicais de Leishmania foi recentemente publicada (Lainson, 2010). No entanto, tal revisão não considera alguns trabalhos mais recentes que usam metodologias bioquímicas e moleculares em estudos de taxonomia de Leishmania e, portanto, a manutenção de algumas classificações antigas pode estar equivocada.

A classificação de Leishmania foi inicialmente baseada em critérios clínicos, bioecoepidemiológicos, tais como relação com vetores, distribuição geográfica, tropismo tissular, propriedades antigênicas e as manifestações clínicas (Bray, 1974; Lumsden, 1974; Pratt \& David, 1981; Shaw et al., 1987). Contudo, análises imunológicas, bioquímicas e moleculares mostraram que tais critérios eram muitas vezes insuficientes. Assim, outros aspectos, tais como análises por reatividade com anticorpos monoclonais (análise de serodemas), padrões observados por eletroforese de isoenzimas (análise de zimodemas) e padrões de polimorfismo observados, tendo por base a digestão do DNA do cinetoplasto (kDNA) por enzimas de restrição, foram bastante utilizados para contribuir com a classificação de Leishmania (Chance, Peters \& Shchory, 1974; Kreutzer \& Christensen, 1980; Arnot \& Barker, 1981; Miles et al., 1981; Pratt \& David, 1981; Handman \& Curtis, 1982; Wirth \& Pratt, 1982; Anthony et al., 1985; Saravia et al., 1985; Barker et al., 1986).

Representantes do gênero Leishmania causam uma variedade de síndromes clínicas que incluem a forma visceral da doença, assim como lesões cutâneas com cura autorresolutiva ou que podem evoluir para formas metastáticas, envolvendo a infecção da mucosa orofaríngea. A gravidade do quadro clínico em pessoas imunocompetentes depende da resposta do hospedeiro e também da espécie de Leishmania responsável pela infecção. Distinguir entre as espécies é, portanto, crucial para o correto diagnóstico e prognóstico da doença, bem como para a tomada de decisões a respeito do tratamento e medidas de controle. Desde a primeira descrição do gênero Leishmania, o número de espécies tem variado, com muitas sendo descritas e algumas sendo consideradas como sinonímias.

Todos os membros do gênero Leishmania são parasitos heteroxênicos, sendo os flebotomíneos os hospedeiros invertebrados e tendo como hospedeiros vertebrados diversos répteis e mamíferos. Esse grupo de parasitos encontrase então dividido em três subgêneros. O subgênero L. (Sauroleishmania) inclui apenas as espécies parasitas de répteis, que embora para alguns autores seja considerado como outro gênero (Lainson et al., 1987), estudos moleculares corroboram sua classificação como subgênero (Saf'janova, 1982). As espécies de Leishmania de mamíferos são classificadas em dois subgêneros, L. (Leishmania) e L. (Viannia). De maneira geral, as espécies classificadas no subgênero L. (Viannia) apresentam desenvolvimento pobre em meio de cultura, desenvolvimento lento em hamsters experimentalmente infectados e desenvolvem-se no intestino posterior do flebotomíneo, ficando os parasitos aderidos à parede, na região do piloro; este grupo inclui apenas espécies que são encontradas nas Américas e por isso correspondem à maioria das espécies referidas como do Novo Mundo. Já as espécies do subgênero L. (Leishmania) geralmente crescem facilmente em cultura, provocam grandes lesões nodulares em hamsters, com metástase para as extremidades, e se desenvolvem no intestino médio e anterior de flebotomíneos; estão incluídas neste grupo espécies que circulam nas Américas, África, Ásia e Europa, o que justifica as referências às espécies desse subgênero como do Novo e do Velho mundos, dependendo da região geográfica onde são observadas.

Um conceito ainda bastante utilizado, e que por isso merece destaque, é o da classificação das espécies de Leishmania em complexos. Com base em critérios extrínsecos, tais como comportamento do parasito em cultura e em hamster, Shaw e Lainson (1972) reuniram as espécies de Leishmania em três complexos: complexo Leishmania braziliensis, Leishmania mexicana e Leishmania donovani. Tal classificação pôde ser validada pelo 'método-ouro' atual para tipagem de Leishmania: o ensaio isoenzimático, ou eletroforese de isoenzimas. 
A aplicação de taxonomia numérica a partir dos dados obtidos pela eletroforese de isoenzimas e análise por marcadores moleculares, associadas aos conceitos que foram utilizados para descrição de cada espécie, resulta no sistema atual de classificação das leishmânias (Figura 1). Por análise de isoenzimas, por exemplo, foram definidos complexos de espécies dentro dos subgêneros (Cupolillo, Grimaldi \& Momen, 1994). Além disso, análises de isoenzimas, corroboradas por análises de filogenia molecular, foram utilizadas para organizar esses parasitos em duas seções: Euleishmania, que inclui todas as espécies classificadas nos subgêneros mencionados anteriormente, e Paraleishmania, na qual estão agrupadas espécies que não podem ser classificadas nestes subgêneros e que são filogeneticamente próximas a outro gênero da família Trypanosomatidea, o gênero Endotrypanum (Cupolillo et al., 2000).

A descrição de algumas espécies antes do advento de técnicas moleculares, tendo como base apenas critérios extrínsecos, é marcante. Por exemplo, a localização geográfica foi determinante para descrever L. guyanensis e L. peruviana, ambas causando leishmaniose cutânea, mas representando um novo relato da presença do parasito na Guiana e na região dos Andes, no Peru, respectivamente. L. infantum foi isolada de uma criança na Tunísia e, embora associada com leishmaniose visceral, a sua história de isolamento foi determinante para sua descrição. Da mesma forma, foi denominada de L. chagasi o parasito associado à leishmaniose visceral isolado pela primeira vez no Brasil.

Hoje, são conhecidas cerca de trinta espécies de Leishmania, das quais em torno de vinte são patogênicas para seres humanos. É importante destacar que o gênero Leishmania é caracterizado por uma grande diversidade genética inter e intraespecífica. Sabe-se que as espécies descritas no subgênero L. (Viannia) variam enormemente em seu grau de diversidade: enquanto L. braziliensis, assim como L. naiffi, apresenta um alto grau de polimorfismo isoenzimático intraespecífico (ou seja, com diversos zimodemas), L. guyanensis é notavelmente homogênea.

Em contraste com taxonomistas que trabalham com protozoários como, por exemplo, o Trypanosoma cruzi, aqueles que trabalham com Leishmania tendem a não ser conservadores no que se refere à descrição de novas espécies. Usando o mesmo método de identificação (no caso, Random Amplified Polymorphic DNA - RAPD), a distância observada entre cepas de T. cruzi é, algumas vezes, maior do que aquela observada entre espécies de Leishmania (Bañuls et al., 1999a). Qual seria então a razão para a descrição de tantas espécies em Leishmania? As diversas espécies de Leishmania geralmente apresentam diferenças epidemiológicas e clínicas. No entanto, a validade de algumas espécies e dos esquemas de classificação de Leishmania tem sido questionada por vários autores. Alguns exemplos clássicos se referem à validade de L. panamensis, L. peruviana, L. shawi, L. chagasi, L. infantum, L. archibaldi, L. garnhami, L. pifanoi, L. venezuelensis e L. forattinii (Bañuls et al., 1999b; 2000; Mauricio, Stothard \& Miles, 2000; Mauricio et al., 2001; Cupolillo et al., 2001). Dentre essas, a sinonímia de L. chagasi e L. infantum está bem evidenciada e tem sido aceita por vários autores (Mauricio, Stothard \& Miles, 2000; Lukes et al., 2007), embora L. chagasi ainda seja uma nomenclatura utilizada. o caso das demais espécies é ainda mais complexo. Por exemplo, por meio de análises bioquímicas e moleculares, L. peruviana foi validada como espécie (Bañuls et al., 2000), embora estudo de filogenia molecular indique que esta deva ser considerada como uma subespécie de L. braziliensis (Fraga et al., 2010). 
Figura 1 - Esquema da classificação taxonômica atual de espécies de Leishmania, considerando a descrição original das espécies e classificações propostas com base em critérios extrínsecos e a partir dos resultados obtidos por métodos bioquímicos e moleculares

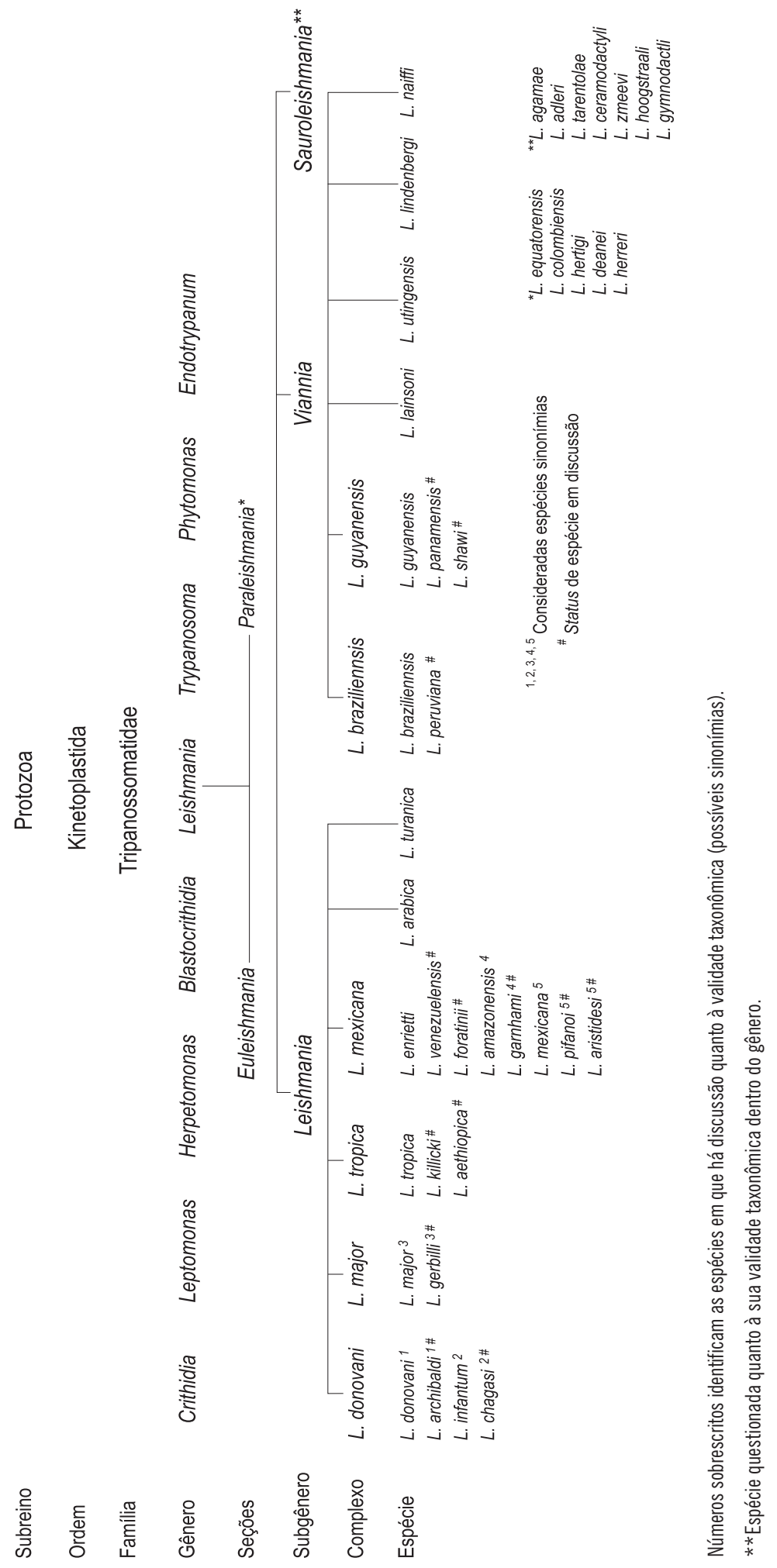




\section{AS ESPÉCIES DE LEISHMANIA, SUA DISTRIBUIÇÃO GEOGRÁFICA E A DIVERSIDADE DOS CICLOS DE TRANSMISSÃO}

As leishmanioses, em geral, são antropozoonoses. Os ciclos de transmissão podem ser silvestres e, neste caso, a infecção humana em geral é acidental, como ainda acontece em algumas infecções por L. guyanensis e L. braziliensis em áreas como a região amazônica. Muitas espécies já estão adaptadas a ciclos secundários ou peridomésticos, com animais sinantrópicos ou domésticos participando do ciclo de transmissão, que envolve flebotomíneos antropofílicos; este é o caso, por exemplo, do ciclo de transmissão de L. braziliensis em algumas áreas endêmicas de colonização humana antiga e também de $L$. infantum. Como mencionado anteriormente, $L$. donovani é transmitida em um ciclo antroponótico, sem aparente participação de um animal doméstico ou silvestre e envolvendo flebotomíneos totalmente antropofílicos.

Uma das características do ciclo de transmissão de Leishmania spp. é sua associação com vários ecótopos. Apesar de não haver indícios diretos de associação estrita entre espécie e ambiente específico, algumas espécies eram descritas em regiões cobertas pela Floresta Amazônica, como é o caso de L. lainsoni e L. naiffi. Espécies como L. infantum, L. braziliensis e L. guyanensis são observadas em vários ambientes e, logo, podem ser transmitidas por diferentes espécies de flebotomíneos, embora possa existir uma restrição em virtude de um ambiente propício ao vetor. Por exemplo, o principal vetor de L. infantum nas Américas é Lutzomyia longipalpis. Da mesma forma, na região amazônica brasileira existe uma forte associação entre L. guyanensis e Lutzomyia umbratilis, embora na região andina do Peru esse parasito pareça ser transmitido por Lutzomyia peruensis. O caso de L. braziliensis é ainda mais interessante, já que em uma mesma área observa-se a participação de diversas espécies de flebotomíneos no ciclo de transmissão dessa espécie do parasito (Souza Rocha et al., 2010). Tais informações apontam para o fato da adaptação do vetor a um ecótopo determinar a distribuição de algumas espécies de Leishmania. São observadas espécies do parasito com aparente adaptação a uma espécie de vetor, porém outras são capazes de infectar diversas espécies de flebotomíneos. Exemplo ilustrativo pode ser citado para L. naiffi. Até recentemente essa espécie havia sido descrita em áreas cobertas pela Floresta Amazônica (Naiff et al., 1991; Pratlong et al., 2002; Figueira et al., 2008; Van der Snoek et al., 2009), com pelo menos três espécies de flebótomos como vetor. Em estudo recente (Azpurua et al., 2010), parasito bastante semelhante à $L$. naiffi foi isolado pela primeira vez na região do canal do Panamá, em Lu. trapidoi e Lu. gomezi. Tais observações indicam que o parasito apresenta plasticidade quanto ao ambiente, e que a distribuição geográfica observada está mais relacionada à adaptação aos vetores e hospedeiros presentes no local do que ao bioma. Por isso a ocorrência de espécies de Leishmania deve ser tratada como dinâmica, e não restrita às informações existentes sobre alguns isolados.

A dispersão das espécies de Leishmania em vários ambientes também favorece a adaptação deste parasito a diferentes mamíferos (Rotureau, 2006a; 2006b). É conhecido que o mesmo parasito se comporta diferentemente em regiões distintas, isso não só em termos de relação parasito-hospedeiro, mas também no que diz respeito à sensibilidade a fármacos (Laurent et al., 2007).

Em um mesmo ambiente podemos encontrar espécies de Leishmania distintas, infectando os mesmos hospedeiros vertebrados e invertebrados (Lucas et al., 1988; Saravia et al., 1998; Martinez et al., 2002; Antoniou et al., 2004; Madeira et al., 2006; Rotureau, 2006a; Azpurua et al., 2010). Essas características certamente têm um importante papel na diversidade de Leishmania, assim como em um possível processo de especiação destes organismos (Shaw, 1997).

\section{AS ESPÉCIES DE LEISHMANIA E AS MANIFESTAÇÕES CLÍNICAS}

Independentemente da espécie de Leishmania, a infecção por este parasito em humanos pode ser assintomática, assim como pode produzir um amplo espectro de manifestações clínicas, como: leishmaniose cutânea, cutâneo 
difusa, cutâneo-mucosa e visceral. Tais manifestações podem ser causadas por diversas espécies, no entanto, algumas relações podem ser feitas. Por exemplo, a forma mucosa é comumente observada em infecções causadas por L. (Viannia), mais frequentemente por L. braziliensis; esta espécie também apresenta forte associação com a forma disseminada, caracterizada clinicamente pela presença de múltiplas lesões. No caso da manifestação difusa, forma distinta da disseminada, caracterizada pela presença de múltiplas lesões nodulares ricas em parasitos e que produz uma resposta anérgica, as infecções são causadas pelas espécies L. mexicana e L. amazonensis. No caso da leishmaniose visceral, observa-se uma alta relação entre esta manifestação clínica e infecções por espécies do complexo L. donovani.

Uma característica comum em infecções causadas pelas diversas espécies é a ocorrência de cura espontânea em lesões cutâneas, sugerindo que as diversas espécies devem compartilhar moléculas envolvidas em processos de virulência e patogênese (Chang \& McGwire, 2002). Entretanto, a despeito de vários estudos tentando associar espécies e cepas com manifestações clínicas produzidas, pouco se tem concluído.

\section{CARACTERÍSTICAS GENÔMICAS DAS ESPÉCIES DE LEISHMANIA}

Considerando as informações existentes para algumas espécies de Leishmania, sabemos que as espécies do Velho Mundo apresentam 36 cromossomas (Wincker et al., 1996), enquanto as do Novo Mundo têm 34 ou 35, com os cromossomas 8 e 29, e 20 e 36 fundidos no grupo L. mexicana e os cromossomas 20 e 34 em L. braziliensis (Britto et al., 1998).

Sabe-se que a organização dos genes é conservada entre as espécies de Leishmania (Ravel et al., 1999). Contudo, observa-se um alto nível de polimorfismo nas sequências de DNA (Ravel et al., 1999; Beverley, Ismach \& Pratt, 1987).

Uma análise comparativa dos genomas de três espécies, L. major, L. infantum e L. braziliensis, indicou relativa conservação no que tange ao conteúdo de genes, sintenia e arquitetura, embora tenham sido identificadas aproximadamente duzentas diferenças em nível de conteúdo de genes ou pseudogenes, incluindo 78 genes que estavam restritos a uma determinada espécie (Peacock et al., 2007). Até o presente, apenas um lócus foi diretamente relacionado com o tropismo de Leishmania spp. No caso de L. donovani, a expressão dos produtos do gene A2 é fundamental para a sobrevivência do parasito nas vísceras. Sabe-se que L. major contém apenas pseudogenes A2. A despeito das diferenças observadas com relação ao fenótipo de manifestações clínicas causadas pelas diversas espécies, poucos genes parecem ser espécie-específicos: cinco genes são específicos de L. major, 26 de L. infantum e aproximadamente 47 de $L$. braziliensis, o que corrobora o fato de que esta é a espécie mais divergente dentre as três estudadas. Análises com outras espécies deveriam ser realizadas para determinarmos, por exemplo, se os genes específicos de L. braziliensis são observados entre as outras espécies do subgênero L. (Viannia).

A comparação do genoma de L. major, L. braziliensis e L. infantum também indicou que aproximadamente $8 \%$ dos genes apresentam taxas evolutivas distintas e estão envolvidos em um espectro de processos essenciais, incluindo transporte, e metabolismo de diversas moléculas, que podem influenciar na sobrevivência do parasito no hospedeiro e também na produção da doença.

Uma das diferenças marcantes está relacionada com o fato de que apenas em L. braziliensis foram observadas evidências da existência de maquinaria de RNA de interferência (RNAi) e elementos transponíveis (Smith, Peacock \& Cruz, 2007). Logo, parece que poucos genes espécie-específicos devem ser importantes na patogênese. A observação contrassensual da variedade de sinais clínicos causados perante a conservação de genótipos entre as espécies de Leishmania e a ausência de genes específicos relacionados ao fenótipo apontam para uma regulação gênica baseada predominantemente em número de cópias dos genes e em modificações pós-traducionais (Scheltema, 2010). 


\section{ABORDAGENS DE FILOGENIA MOLECULAR E GENÉTICA DE POPULAÇÕES APLICADAS À TAXONOMIA DE LEISHMANIA}

Durante as últimas décadas, estudos de filogenia molecular de Leishmania por meio da análise de sequências de DNA de diversos genes têm sido conduzidos, servindo como parâmetros importantes na taxonomia desses parasitos. Sequências inteiras ou parciais de vários genes têm sido utilizadas, incluindo genes que codificam para DNA polymerase a (polA), a subunidade maior da RNA polimerase II (rpollLS) (Talmi-Frank, 2010) e 7SL RNA (Azmi, 2010), espaçadores internos transcritos do rDNA (ITS) (Gelanew et al., 2010) e genes mitocondriais como citocromo b (cytb).

Mais recentemente, sequências do gene hsp70 foram analisadas (Fraga et al., 2010; Da Silva et al., 2010) e os resultados obtidos corroboram a divisão em subgêneros, assim como as evidências de que L. (Sauroleishmania) deve ser considerada como um subgênero de Leishmania e não como outro gênero da família Trypanosomatidae. Esses estudos indicam que algumas espécies de Leishmania não são válidas filogeneticamente, considerando as sequências analisadas. De acordo com o conceito filogenético, espécie deve constituir um grupo monofilético, sendo este um grupo basal de organismos, diagnosticavelmente diferente de outros grupos, e intimamente ligado a um modelo parental de ancestralidade e descendência. Isso assumido, tendo por base estudos analisando sequências de hsp70, não é possível validar espécies como, por exemplo, L. infantum, L. archibaldi, L. aethiopica, L. amazonensis, L. panamensis, L. shawi e L. peruviana. É evidente que não se pode fazer uma revisão taxonômica de um grupo com base em apenas um marcador. No caso de considerarmos hsp70 como alvo, por exemplo, é esperado que a filogenia resolva apenas os maiores grupos (como subgêneros e complexos) e não auxilie nas conclusões acerca de espécies, em razão da alta similaridade desse gene entre as diversas espécies (Schonian, Mauricio \& Cupolillo, 2010). No entanto, a validade taxonômica de $L$. archibaldi, L. panamensis, L. shawi e L. peruviana também tem sido discutida com base em resultados obtidos por marcadores que apresentam taxa evolutiva mais rápida e, logo, maior divergência entre as sequências.

Análises de filogenia molecular têm indicado a necessidade de revisão da nomenclatura do complexo L. donovani . Estudos mais recentes mostram que apenas $L$. donovani e $L$. infantum devem ser incluídas neste complexo, não sendo $L$. archibaldi uma espécie válida. Além disso, foi reforçada a ideia de que os parasitos do complexo $L$. donovani que causam leishmaniose visceral na Europa e nas Américas devem ser classificados como L. infantum (Lukes et al., 2007). De fato, talvez esse seja um bom exemplo para o uso do conceito de subespécie em Leishmania, já que estes parasitos, hoje denominados como espécies distintas, têm diferentes vetores e, possivelmente, reservatórios, bem como circulam em diferentes áreas geográficas. Com base nesses argumentos é que os nomes subespecíficos $L$. (L.) infantum infantum e L. (L.) infantum chagasi foram propostos (Shaw, 2002).

Porém, se a definição de espécies em Leishmania é problemática, imagine a de subespécie. Se monofilia é um pré-requisito para definir qualquer grupo taxonômico, todos os grupos monofiléticos distinguíveis dentro de uma espécie deveriam ser considerados como subespécie.

Ao aplicarmos análises de filogenia molecular em taxonomia de Leishmania, é fundamental que o conceito filogenético de espécie seja aceito. Mais ainda, a filogenia molecular deve ser associada a estudos de genética de população (Tibayrenc \& Ayala, 1999). De fato, a associação dessas abordagens, hoje essenciais para estudos epidemiológicos, tem contribuído muito para elucidar diversas questões relacionadas à taxonomia de Leishmania. A diversidade intraespecífica observada nesse grupo é marcante e, logo, é difícil chegar a conclusões quando apenas um ou poucos representantes de uma espécie são analisados. Vale ressaltar que a distância genética observada entre isolados de uma mesma espécie às vezes é maior do que aquela detectada entre espécies distintas (Cupolillo et al., 2001).

O uso de ferramentas moleculares e a interpretação dos dados por abordagens evolutivas auxiliaram, por exemplo, a entender a diversidade do complexo $L$. donovani, definindo L. chagasi como isolados provenientes de regiões das 
Américas, associados principalmente a leishmaniose visceral e que corresponde a uma sinonímia de L. infantum. Abordagem multilocus, seja por sequenciamento de genes de interesse ou por análise de microssatélites, certamente estão entre as abordagens que recentemente mais contribuíram para a compreensão da complexidade do gênero Leishmania. Tais estudos têm discutido a validade de espécies e a presença de populações e subpopulações de Leishmania spp. em algumas áreas endêmicas (Mauricio et al., 2006; Zemanova et al., 2007; Schwenkenbecher et al., 2006; Kuhls et al., 2008; Al Jawabreh et al., 2008; Tsukayama, Lucas \& Bacon, 2009).

Ferramentas moleculares associadas à interpretação dos dados por métodos filogenéticos e de análises de populações têm sido também bastante valiosas para a compreensão do mecanismo de reprodução de Leishmania, o que certamente tem fortes implicações com a definição de espécies nesse grupo de parasitos. Classicamente, tais organismos são considerados como apresentando um modo de propagação clonal (Tibayrenc, Kjellberg \& Ayala, 1990). No entanto, além de observações de possíveis híbridos entre espécies de Leishmania por eletroforese de enzimas, assim como por outros métodos, foi demonstrado que algumas espécies de Leishmania são potencialmente automíticas, com frequente troca genética. Ao que tudo indica, após recombinação esses possíveis híbridos se propagam por clonalidade (Bastien, Blaineau \& Pages, 1992; Rougeron et al., 2009; Schwenkenbecher et al., 2006; Bañuls et al., 1997; Belli, Miles \& Kelly, 1994; Dujardin et al., 1995a; 1995b; Delgado et al., 1997). É interessante ressaltar que as linhagens híbridas são possivelmente resultado de troca genética dentro da mesma espécie ou entre espécies bastante relacionadas filogeneticamente.

\section{DEFINIÇÃOO DE ESPÉCIES E 0 GÊNERO LEISHMANIA}

O conceito de espécie é certamente um ponto muito debatido e longe de ser completamente definido. Embora as classificações taxonômicas sejam esquemas propostos pelos cientistas e por isso não representam fielmente eventos da natureza, a classificação dos organismos em categorias taxonômicas é de fundamental importância.

Eventos de recombinação genética acontecem em Leishmania spp. (Akopyants et al., 2009), mas o processo de clonalidade é essencial para a propagação desses parasitos (Tibayrenc, Kjellberg \& Ayala, 1990). Dessa forma, é evidente que não se podem definir espécies nesse grupo de organismos com base no conceito biológico de espécies.

Existem vários outros conceitos de espécie (Futuyama, 1998), mas no caso de Leishmania é difícil identificar qual conceito está sendo ou deve ser seguido. Desse modo, a definição de espécies é muito arbitrária, baseada em uma diversidade de caracteres extrínsecos e intrínsecos, na maioria das vezes considerados em conjunto. Isso certamente acarreta controvérsias e falta de consenso no que diz respeito à definição de espécies, levando a um número exagerado daquelas que são descritas e muitas classificações propostas.

Segundo Dobzhansky (1937), a classificação biológica dos organismos é, simultaneamente, um sistema de escaninhos concebido pelo homem com a proposta pragmática de registrar as observações de uma maneira conveniente e de reconhecer um fato de descontinuidade biológica. Não só no caso de Leishmania, debates acerca de conceitos de espécie em microrganismos têm sido muito frequentes e é consenso que critérios filogenéticos devem ser enfatizados. o fato é que fatores implicados no processo de especiação estão presentes em Leishmania, como propagação por clonalidade e por mecanismos de recombinação genética, restrição geográfica e ecológica e diferenças em propriedades genéticas.

Apesar da descrição de diversos métodos que se propõem a auxiliar a taxonomia de microrganismos, a definição de espécies continua, muitas vezes, arbitrária e artificial (Staley, 1997). Para muitos microrganismos é também pragmática, operacional e universalmente aplicável: uma espécie é uma categoria que circunscreve um grupo de isolados/cepas genomicamente coerente, que compartilham um alto nível de similaridade em características distintas. 
Pelo que foi exposto nos tópicos anteriores, fica evidente que não é simples definir o conceito de espécie e um sistema de classificação para ser adotado em organismos que apresentem características semelhantes às que observamos no gênero Leishmania. Por isso, os estudos de sistemática desses organismos são tão essenciais. Destacamos a importância dos estudos de biologia evolutiva, associando as informações obtidas pelos estudos filogenéticos e de genética de populações. Não podemos deixar de transcrever uma colocação de Avise e Wollenberg (1997), adaptada de uma observação feita por Dobzhansky (1937: 7748): "population genetics has so profound a bearing on the problem of the mechanisms of speciation that any speciation theory that disregards established population genetic principles is faulty at its source".

Dessa forma fica evidente que, mais do que apresentar uma definição de espécie mais apropriada para o gênero Leishmania, é fundamental definir uma metodologia-consenso que permita identificar Leishmania, e que seja comparável interlaboratorialmente, além de fornecer resultados que possam servir nas investigações epidemiológicas, usando como base as análises de genética populacional e de filogenia. Nesse sentido, assim como já proposto para outros microrganismos patógenos (Baldo et al., 2006; Maiden, 2006), uma abordagem sistemática incluindo análises multilocus contribuirá de forma ímpar com estudos taxonômicos de Leishmania.

\section{REFERÊNCIAS}

AKOPYANTS, N. S. et al. Demonstration of genetic exchange during cyclical development of Leishmania in the sand fly vector. Science, 324(5.924): 265-268, 2009.

AL-JAWABREH, A. et al. Identification of geographically distributed sub-populations of Leishmania (Leishmania) major by microsatellite analysis. BMC Evolutionary Biology, 8: 183, 2008.

ANTHONY, R. L. et al. Subcellular and taxonomic specificity of monoclonal antibodies to new world Leishmania. The American Journal of Tropical Medicine and Hygiene, 1985; 34(6):1085-1094.

ANTONIOU, M. et al. Short report: treatment failure due to mixed infection by different strains of the parasite Leishmania infantum. The American Journal of Tropical Medicine and Hygiene, 71(1): 71-72, 2004.

ARNOT, D. E. \& BARKER, D. C. Biochemical identification of cutaneous Leishmanias by analysis of Kinetoplast DNA. II. Sequence homologies in Leishmania Kdna. Molecular and Biochemical Parasitology, 3(1): 47-56, 1981.

AVISE, J. C. \& WOLLENBERG, K. Phylogenetics and the origin of species. Proceedings of the National Academy of Sciences of the USA, 94(15): 7.748-7.755, 1997.

AZMI, K. et al. Identification of Old World Leishmania species by PCR-RFLP of the 7 spliced leader RNA gene and reverse dot blot assay. Tropical Medicine and International Health, 15(8): 872-880, 2010.

AZPURUA, J. et al. Lutzomyia sand fly diversity and rates of infection by Wolbachia and an Exotic Leishmania species on Barro Colorado Island, Panama. PLoS Neglected Tropical Diseases, 4(3): e627, 2010.

BALDO, L. et al. Multilocus sequence typing system for the endosymbiont Wolbachia pipientis. Applied and Environmental Microbiology, 72(11): 7.098-7.110, 2006.

BAÑULS, A. L. et al. Evidence for hybridization by multilocus enzyme electrophoresis and random amplified polymorphic DNA between Leishmania braziliensis and Leishmania panamensis/guyanensis in Ecuador. The Journal of Eukaryotic Microbiology, 44(5): 408-411, 1997.

BAÑULS, A. L. et al. A phylogenetic analysis by multilocus enzyme electrophoresis and multiprimer random amplified polymorphic DNA fingerprinting of the Leishmania genome project Friedlin reference strain. Folia Parasitologiva (Praha), 46(1): 10-14, 1999a.

BAÑULS, A. L. et al. Genetic analysis of leishmania parasites in Ecuador: are Leishmania (Viannia) panamensis and Leishmania (V.) Guyanensis distinct taxa? The American Journal of Tropical Medicine and Hygiene, 61(5): 838-845, $1999 \mathrm{~b}$. 
BAÑULS, A. L. et al. Is Leishmania (Viannia) peruviana a distinct species? A MLEE/RAPD evolutionary genetics answer. The Journal of Eukaryotic Microbiology, 47(3): 197-207, 2000.

BARKER, D. C. et al. The Potential of using recombinant DNA species specific probes for the identification of tropical Leishmania. Parasitology, 92: S139-S174, 1986.

BASTIEN, P.; BLAINEAU, C. \& PAGES, M. Leishmania: sex, lies and karyotype. Parasitology Today, 8(5): 174-177, 1992.

BELLI, A. A.; MILES, M. A. \& KELLY, J. M. A putative Leishmania panamensis/Leishmania braziliensis hybrid is a causative agent of human cutaneous leishmaniasis in Nicaragua. Parasitology, 109(Pt 4): 435-442, 1994.

BEVERLEY, S. M.; ISMACH, R. B. \& PRATT, D. M. Evolution of the genus Leishmania as revealed by comparisons of nuclear DNA restriction fragment patterns. Proceedings of the National Academy of Sciences of the USA, 84(2): 484-488, 1987.

BRAY, R. S. Leishmania. Annual Review of Microbiology, 28: 189-217, 1974.

BRITTO, C. et al. Conserved linkage groups associated with large-scale chromosomal rearrangements between Old World and New World Leishmania genomes. Gene, 222(1): 107-117, 1998.

CHANCE, M. L.; PETERS, W. \& SHCHORY, L. Biochemical taxonomy of Leishmania. I. Observations on DNA. Annals of Tropical Medicine and Parasitology, 68(3): 307-316, 1974.

CHANG, K. P. \& MCGWIRE, B. S. Molecular determinants and regulation of Leishmania virulence. Kinetoplastid Biology and Disease, 1(1): 1, 2002.

CUPOLILLO, E. et al. A revised classification for Leishmania and Endotrypanum. Parasitology Today, 16(4): 142-144, 2000.

CUPOLILLO, E. et al. Recent advances in the taxonomy of the New World leishmanial parasites. Medical Microbiology and Immunology, 190(1-2): 57-60, 2001.

CUPOLILLO, E.; GRIMALDI, G. \& MOMEN, H. A general classification of new world Leishmania using numerical zymotaxonomy. The American Journal of Tropical Medicine and Hygiene, 50(3): 296-311, 1994.

DA SILVA, L. A. et al. Sequence analysis and PCR-RFLP profiling of the hsp70 gene as a valuable tool for identifying Leishmania species associated with human leishmaniasis in Brazil. Infection, Genetics and Evolution, 10(1): 77-83, 2010.

DELGADO, O. et al. Cutaneous leishmaniasis in Venezuela caused by infection with a new hybrid between Leishmania (Viannia) braziliensis and L. (V.) guyanensis. Memórias do Instituto Oswaldo Cruz, 92(5): 581-582, 1997.

DOBZHANSKY, T. Genetics and the Origin of Species. New York: Columbia University Press 1937.

DUJARDIN, J. C. et al. From population to genome: ecogenetics of Leishmania (Viannia) braziliensis and L. (V.) peruviana. Annals of Tropical Medicine and Parasitology, 89, supl. 1: 45-53, 1995a.

DUJARDIN, J. C. et al. Putative Leishmania hybrids in the Eastern Andean valley of Huanuco, Peru. Acta Tropica, 59(4): 293307, 1995b.

FIGUEIRA, L. P. et al. Isoenzymatic characterization of human isolates of Leishmania sp. (Kinetoplastida: Trypanosomatidae) from the municipalities of Rio Preto da Eva and Manaus, State of Amazonas. Revista da Sociedade Brasileira de Medicina Tropical, 41(5): 512-514, 2008.

FRAGA, J. et al. Phylogeny of Leishmania species based on the heat-shock protein 70 gene. Infection, Genetics and Evolution, 10(2): 238-245, 2010.

FUTUYMA, J. D. Evolutionary Biology. 3. ed. Sunderland: Sinauer Associates, 1998.

GELANEW, T. et al. A clinical isolate of Leishmania donovani with ITS1 sequence polymorphism as a cause of para-kala-azar dermal leishmaniasis in an Ethiopian human immunodeficiency virus-positive patient on highly active antiretroviral therapy. The British Journal of Dermatology, 163(4):870-874, 2010.

HANDMAN, E. \& CURTIS, J. M. Leishmania tropica surface antigens of intracellular and flagellate forms. Experimental Parasitology, 54(2): 243-249, 1982. 
KREUTZER, R. D. \& CHRISTENSEN, H. A. Characterization of Leishmania Spp by Isoenzyme Electrophoresis. The American Journal of Tropical Medicine and Hygiene, 29(2): 199-208, 1980.

KUHLS, K. et al. Differentiation and gene flow among European populations of Leishmania infantum MON-1. PLoS Neglected Tropical Diseases, 2(7): e261, 2008.

LAINSON, R. The Neotropical Leishmania species: a brief historical review of their dicovery, ecology and taxonomy. Revista Pan-Amazônica de Saúde, 1(2): 13-38, 2010.

LAINSON, R. et al. American visceral Leishmaniasis: on the origin of Leishmania (Leishmania) chagasi. Transactions of the Royal Society of Tropical Medicine and Hygiene, 81(3): 517, 1987.

LAURENT, T. et al. Epidemiological dynamics of antimonial resistance in Leishmania donovani: genotyping reveals a polyclonal population structure among naturally resistant clinical isolates from Nepal. Infection, Genetics and Evolution, $7(2): 206-212,2007$.

LUCAS, C. M. et al. Geographic distribution and clinical description of leishmaniasis cases in Peru. The American Journal of Tropical Medicine and Hygiene, 59(2): 312-317, 1998.

LUKES, J. et al. Evolutionary and geographical history of the Leishmania donovani complex with a revision of current taxonomy. Proceedings of the National Academy of Sciences of the USA, 104(22): 9.375-9.380, 2007.

LUMSDEN, W. H. R. Biochemical taxonomy of Leishmania. Transactions of the Royal Society of Tropical Medicine and Hygiene, 68(1): 74-75, 1974.

MADEIRA, M. F. et al. Mixed infection with Leishmania (Viannia) braziliensis and Leishmania (Leishmania) chagasi in a naturally infected dog from Rio de Janeiro, Brazil. Transactions of the Royal Society of Tropical Medicine and Hygiene, 100(5): 442-445, 2006.

MAIDEN, M. C. Multilocus sequence typing of bacteria. Annual Review of Microbiology, 60: 561-588, 2006.

MARTINEZ, E. et al. Co-infection by Leishmania amazonensis and L. infantum/L. chagasi in a case of diffuse cutaneous leishmaniasis in Bolivia. Transactions of the Royal Society of Tropical Medicine and Hygiene, 96(5): 529-532, 2002.

MAURICIO, I. L.; STOTHARD, J. R. \& MILES, M. A. The strange case of Leishmania chagasi. Parasitology Today, 16(5): 188189, 2000.

MAURICIO, I. L. et al. Genetic typing and phylogeny of the Leishmania donovani complex by restriction analysis of PCR amplified gp63 intergenic regions. Parasitology, 122: 393-403, 2001.

MAURICIO, I. L. et al. Towards multilocus sequence typing of the Leishmania donovani complex: resolving genotypes and haplotypes for five polymorphic metabolic enzymes (ASAT, GPI, NH1, NH2, PGD). International Journal for Parasitology, 36(7): 757-769, 2006.

MILES, M. A. et al. Leishmaniasis in Brazil. XV. Biochemical distinction of Leishmania mexicana amazonensis, 1 braziliensis braziliensis and 1 braziliensis guyanensis aetiological agents of cutaneous Leishmaniasis in the Amazon basin of Brazil. Transactions of the Royal Society of Tropical Medicine and Hygiene, 75(4): 524-529, 1981.

NAIFF, R. D. et al. Epidemiological and nosological aspects of Leishmania naiffi Lainson \& Shaw, 1989. Memórias do Instituto Oswaldo Cruz, 86(3): 317-321, 1991.

PEACOCK, C. S. et al. Comparative genomic analysis of three Leishmania species that cause diverse human disease. Nature Genetics, 39(7): 839-847, 2007.

PESSÔA, S. B. Classificação das leishmanioses e das espécies do gênero Leishmania. Arquivo de Higiene em Saúde Pública, 26: 41-50, 1961.

PRATLONG, F. et al. Human cutaneous leishmaniasis caused by Leishmania naiffi is wide-spread in South America. Annals of Tropical Medicine and Parasitology, 96(8): 781-785, 2002.

PRATT, D. M. \& DAVID, J. R. Monoclonal antibodies that distinguish between new world species of Leishmania. Nature, 291(5.816): 581-583, 1981. 
RAVEL, C. et al. High conservation of the fine-scale organisation of chromosome 5 between two pathogenic Leishmania species. Nucleic Acids Research, 27(12): 2.473-2.477, 1999.

ROTUREAU, B. Trypanosomatid (Protozoa, Kinetoplastida) parasites of sloths (Mannmalia, Xenarthra). Bulletin de la Société de Pathologie Exotique, 99(3): 171-175, 2006a.

ROTUREAU, B. Are new world leishmaniases becoming anthroponoses? Medical Hypotheses, 67(5): 1.235-1.241, $2006 \mathrm{~b}$.

ROUGERON, V. et al. Extreme inbreeding in Leishmania braziliensis. Proceedings of the National Academy of Sciences of the USA, 106(25): 10.224-10.229, 2009.

SAF'JANOVA, V. Classification of the genus Leishmania ross. In: The Leishmaniasis Lennigrad: Academy of Sciences, USSR All Union Society of Protozoologists, 1982.

SARAVIA, N. G. et al. Mucocutaneous Leishmaniasis in Colombia. Leishmania-braziliensis subspecies diversity. The American Journal of Tropical Medicine and Hygiene, 34(4): 714-720, 1985.

SARAVIA, N. G. et al. Epidemiologic, genetic, and clinical associations among phenotypically distinct populations of Leishmania (Viannia) in Colombia. The American Journal of Tropical Medicine and Hygiene, 59(1): 86-94, 1998.

SCHELTEMA, R. A. et al. The potential of metabolomics for Leishmania research in the post-genomics era. Parasitology, 137(9): 1.291-1.302, 2010.

SCHONIAN, G.; MAURICIO, I. \& CUPOLILLO, E. Is it time to revise the nomenclature of Leishmania? Trends in Parasitology, 26(10): 466-469, 2010.

SCHWENKENBECHER, J. M. et al. Microsatellite analysis reveals genetic structure of Leishmania tropica. International Journal for Parasitology, 36(2): 237-246, 2006.

SHAW, J. J. RAPD for the differentiation of Leishmania. Transactions of the Royal Society of Tropical Medicine and Hygiene, 91(1): 93-94, 1997.

SHAW, J. J. New World leishmaniasis: the ecology of leishmaniasis and the diversity of leishmanial species in Central and South America. In: FARRELL, J. P. (Ed.). Leishmania. Boston, Dordrech, London: Kluwer Academics, 2002.

SHAW, J. J. \& LAINSON, R. Leishmaniasis in Brazil .6. Observations on seasonal variations of Lutzomyia flaviscutellata in different types of forest and its relationship to enzootic rodent Leishmaniasis (Leishmania mexicana amazonensis). Transactions of the Royal Society of Tropical Medicine and Hygiene, 66(5): 709, 1972.

SHAW, J. J. et al. Leishmaniasis in Brazil: XXIII. The identification of Leishmania braziliensis braziliensis in wild-caught neotropical sandflies using monoclonal antibodies. Transactions of the Royal Society of Tropical Medicine and Hygiene, 81(1): 69-72, 1987.

SMITH, D. F.; PEACOCK, C. S. \& CRUZ, A. K. Comparative genomics: from genotype to disease phenotype in the leishmaniases. International Journal for Parasitology, 37(11): 1.173-1.186, 2007.

SOUZA ROCHA, L. et al. Molecular biological identification of monoxenous trypanosomatids and Leishmania from antropophilic sand flies (Diptera: Psychodidae) in Southeast Brazil. Parasitology Research, 107(2): 465-468, 2010.

STALEY, J. T. Biodiversity: are microbial species threatened? Current Opinion in Biotechnology, 8(3): 340-345, 1997.

TALMI-FRANK, D. et al. Detection and identification of old world Leishmania by high resolution melt analysis. PLoS Neglected Tropical Diseases, 4(1): e581, 2010.

TIBAYRENC, M. \& AYALA, F. J. Evolutionary genetics of Trypanosoma and Leishmania. Microbes and Infection, 1(6): 465$472,1999$.

TIBAYRENC, M.; KJELLBERG, F. \& AYALA, F. J. A clonal theory of parasitic protozoa: the population structures of Entamoeba, Giardia, Leishmania, Naegleria, Plasmodium, Trichomonas, and Trypanosoma and their medical and taxonomical consequences. Proceedings of the National Academy of Sciences of the USA, 87(7): 2.414-2.418, 1990.

TSUKAYAMA, P.; LUCAS, C. \& BACON, D. J. Typing of four genetic loci discriminates among closely related species of New World Leishmania. International Journal for Parasitology, 39(3): 355-362, 2009. 
VAN DER SNOEK, E. M. et al. Spontaneous cure of American cutaneous leishmaniasis due to Leishmania naiffi in two Dutch infantry soldiers. Clin Exp Dermatol, 34(8): e889-e891, 2009.

WINCKER, P. et al. The Leishmania genome comprises 36 chromosomes conserved across widely divergent human pathogenic species. Nucleic Acids Research, 24(9): 1.688-1.694, 1996.

WIRTH, D. F. \& PRATT, D. M. Rapid identification of Leishmania species by specific hybridization of kinetoplast DNA in cutaneous lesions. Proceedings of the National Academy of Sciences of the USA, 79(22): 6.999-7.003, 1982.

ZEMANOVA, E. et al. The Leishmania donovani complex: genotypes of five metabolic enzymes (ICD, ME, MPI, G6PDH, and FH), new targets for multilocus sequence typing. International Journal for Parasitology, 37(2): 149-160, 2007. 


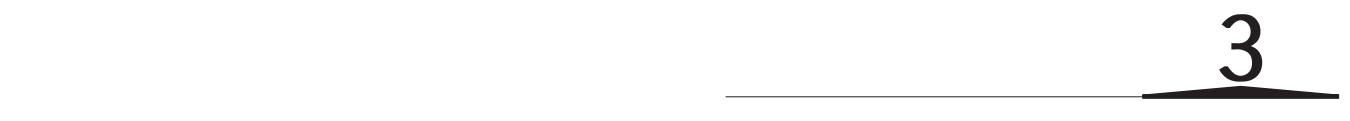

\title{
Ultraestrutura de Parasitos do Gênero Leishmania
}

\author{
Camila Guerra Silva I Roger Magno Macedo Silva I Vanessa Alvaro Diniz I Suzana Côrte-Real
}

$\mathrm{O}$ S protozoários do gênero Leishmania são parasitos digenéticos pertencentes à ordem Kinetoplastida e à família Trypanosomatidae. Esse parasito tem duas formas principais distintas: promastigota, encontrada no trato digestório do inseto vetor (Família - Phlebotominae) e amastigota, parasito intracelular obrigatório encontrado em hospedeiros vertebrados. Promastigotas são alongados, apresentando longo flagelo livre emergindo da região anterior do parasito e extremidade posterior mais afilada. Seu tamanho é variável, medindo entre 1,5-3 $\mu \mathrm{m}$ de largura x 16-40 $\mu \mathrm{m}$ de comprimento, incluindo o flagelo que normalmente tem tamanho igual ou superior ao corpo do parasito (Figura 1A). O núcleo é arredondado ou oval e está localizado na região mediana da célula, enquanto o cinetoplasto está situado entre a extremidade anterior e o núcleo, próximo à bolsa flagelar (Figura 1B). Entretanto, os amastigotas são ovoides ou esféricos, com flagelo curto e interiorizado na bolsa flagelar. O tamanho dos amastigotas varia de acordo com a espécie do parasito, medindo entre 1,5-3 $\mu \mathrm{m}$ x 3-6,5 $\mu \mathrm{m}$ de diâmetro. $\mathrm{O}$ núcleo é arredondado, ocupando cerca de um terço do corpo do parasito, estando o cinetoplasto localizado próximo à bolsa flagelar (Figura 2).

Figura 1A - Microscopia eletrônica de varredura: promastigota de Leishmania (L.) amazonensis mostrando sua forma afilada e os longos flagelos emergindo da bolsa flagelar

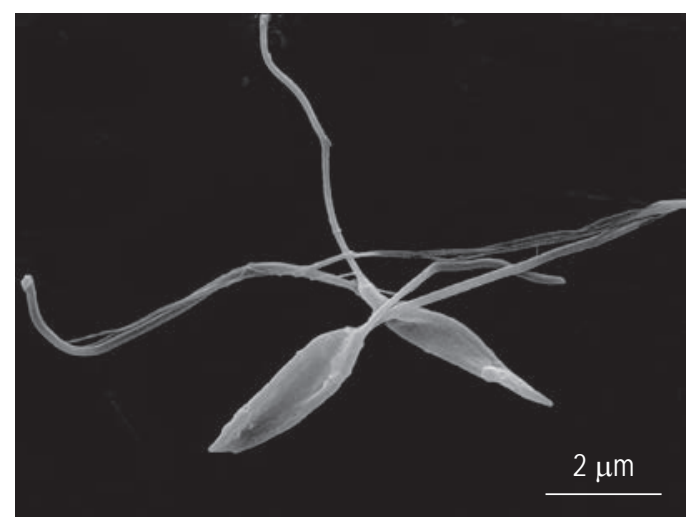


Figura 1B - Microscopia eletrônica de transmissão: promastigotas de Leishmania (V.) braziliensis formando a tradicional roseta em cultura axênica. Uma delas apresenta dois núcleos (N), indicando o início da divisão celular

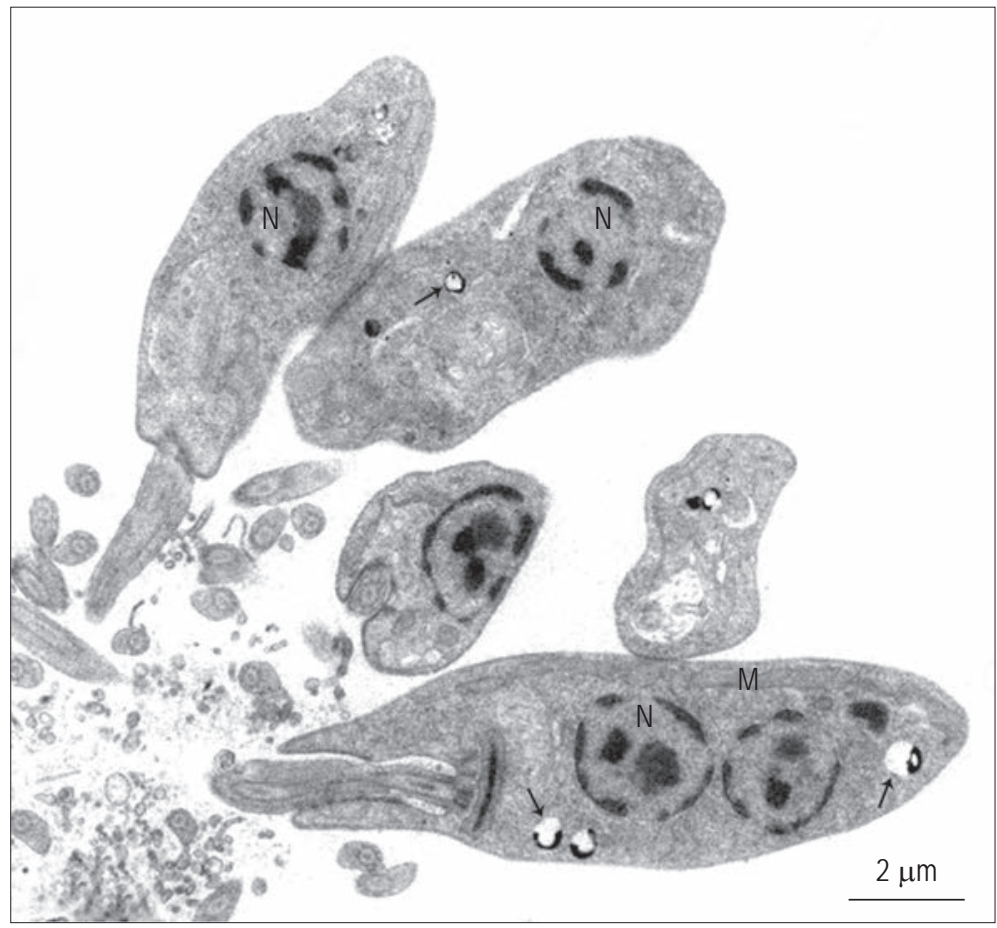

Figura 2 - Microscopia eletrônica de transmissão: amastigotas (*) de Leishmania (L.) amazonensis intracelulares com morfologia arredondada, flagelo (F) curto localizado na bolsa flagelar, núcleo (N) e cinetoplasto (K)

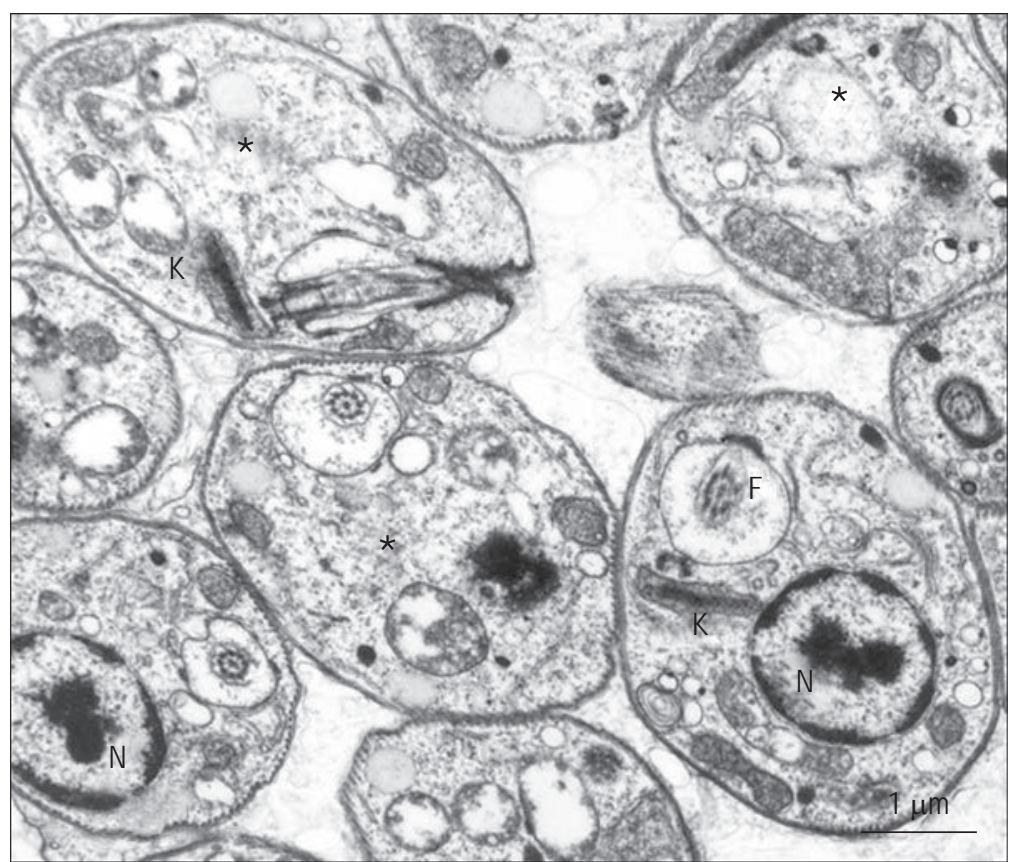


o estudo da estrutura das formas evolutivas da Leishmania, desde sua descoberta, tem sido feito com a utilização de colorações (segundo o método Romanowsky: Leishman, May-Grunwald, Giemsa e Wright; e o método Panótico) e posterior observação em microscópio óptico, pela qual é possível distinguir as duas formas evolutivas - promastigota e amastigota - basicamente pela presença ou não de flagelo aparente, e a forma do corpo do parasito - alongado ou ovalado, respectivamente (Nacy \& Diggs, 1981; Naderer \& McConville, 2008; Chang, 1978).

\section{ASPECTOS ULTRAESTRUTURAIS DA LEISHMANIA}

\section{Membrana plasmática}

As células dos seres vivos são envolvidas pela membrana plasmática. Esta desempenha importante papel de separação entre o ambiente extracelular e o intracelular, e atua de forma seletiva e específica interligando esses dois compartimentos.

Os parasitos do gênero Leishmania apresentam um denso glicocálix composto por várias moléculas localizadas na superfície externa da membrana plasmática, presas por meio de uma âncora de glicosilfosfatidilinositol (GPI). Dentre elas estão as lipofosfoglicanas (LPG) (McNeely \& Turco, 1990; Lang et al., 1991); as proteofosfoglicanas (PPGs) (Ilg, Handman \& Stierhof, 1999); as glicoproteínas 63 (gp63) (Chaudhuri \& Chang, 1988; Chaudhuri et al., 1989); e os glicosilinositolfosfolipídeos (GIPLS) (Orlandi \& Turco, 1987), sendo a gp63 e a LPG as moléculas mais estudadas. Quando ocorre a conversão para a mudança de promastigota para amastigota, essas moléculas apresentam perfil de permanência na membrana.

A LPG é o principal glicoconjugado presente na superfície de parasitos do gênero Leishmania (Ilg, 2001). Os promastigotas expressam uma grande quantidade de LPG em sua superfície (cerca de 1-5x106 cópias por célula), estando distribuídos por toda a superfície do parasito, incluindo flagelo. Entretanto, os amastigotas expressam um número significativamente menor, cerca de 100-1.000 cópias por célula (Turco, 1990). A gp63 é uma metaloproteinase ancorada por GPI, distribuída de forma homogênea na superfície dos promastigotas e concentrada majoritariamente na bolsa flagelar dos amastigotas (Medina-Acosta et al., 1989).

Enzimas presentes na membrana plasmática são amplamente estudadas, seja por métodos bioquímicos ou por citoquímica ultraestrutural. Dentre elas, destacamos a 3'- e 5'-nucleotidase (Figura 3), que são enzimas utilizadas por esses parasitos na obtenção de nucleotídeos, uma vez que não fazem "síntese 'de novo'” (Dwyer \& Gottlieb, 1984; Côrte-Real et al., 1993). Também é possível detectar a $\mathrm{Mg}^{++} \mathrm{ATPase}$ e a $\mathrm{Ca}^{++} \mathrm{ATPase}$, sendo esta última importante na obtenção do cálcio do meio externo, seja ele oriundo do meio axênico ou do trato digestório (promastigotas) ou da célula hospedeira, quando os amastigotas estão localizados no vacúolo parasitóforo (Côrte-Real, Santos \& Meirelles, 1995). A ATP difosfohidrolase também está presente na membrana de Leishmania (V.) braziliensis e Leishmania (L.) amazonensis (Rezende-Soares et al., 2010; Coimbra et al., 2002).

Por meio da técnica de criofratura foi possível observar diferenças na distribuição de proteínas integrais, denominadas como partículas intramembranosas, e a agregação destas partículas em regiões especializadas na membrana da Leishmania (Benchimol \& De Souza, 1980). A diferença na distribuição de tais partículas reflete a variação da composição e função das proteínas de membrana. A densidade de tais partículas pode variar de acordo com a forma evolutiva do parasito (Pimenta \& De Souza, 1987), sendo possível observar que a membrana que recobre os promastigotas é mais rica em proteínas integrais que a membrana dos amastigotas. Além disso, foi possível verificar que a bolsa flagelar e a membrana do flagelo apresentam uma quantidade menor de partículas intramembranosas quando comparadas ao corpo do parasito. A presença de grupos de partículas intramembranares, descritas como regiões especializadas da membrana, foram observadas na área de adesão do flagelo ao corpo do parasito, formando as zonas de adesão flagelar (Pimenta \& De Souza, 1987). No entanto, na região da membrana 
próxima à abertura da bolsa flagelar foi encontrado um domínio especializado com alta concentração de proteínas integrais (Snapp \& Landfear, 1999).

Figura 3 - Citoquímica ultraestrutural: promastigota de Leishmania (L.) mexicana apresentando material eletrondenso na superfície da membrana plasmática, indicando reação positiva para a enzima 5' -nucleotidase

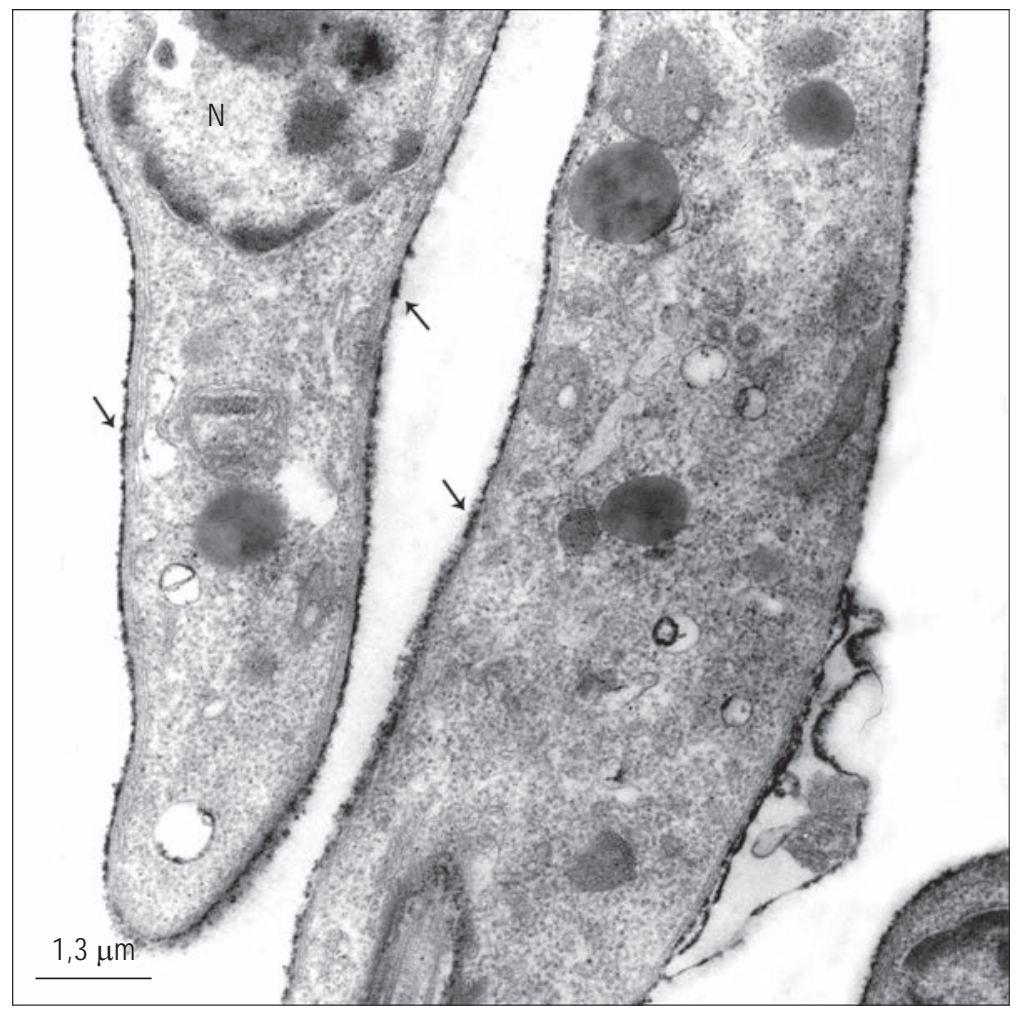

\section{Citoesqueleto}

O citoesqueleto da Leishmania apresenta um arranjo de microtúbulos subpeliculares (MT) que correm paralelamente ao longo do eixo do corpo (Figura 4), sendo responsáveis pela manutenção da forma do parasito durante as fases de diferenciação no seu ciclo de vida (Woods, Baines \& Gull, 1992; Kohl \& Gull, 1998). Esses microtúbulos medem cerca de 150-200 Å de diâmetro, são constituídos de heterodímeros de $\alpha$ e $\beta$-tubulina repetidos, ligados uns aos outros por proteínas associadas a microtúbulos - MAPs (Sasse \& Gull, 1988).

Além dos microtúbulos subpeliculares, a Leishmania apresenta outros componentes do citoesqueleto, entre eles a actina. Ela está distribuída de maneira uniforme no corpo do parasito, estando presente no flagelo, na bolsa flagelar, no núcleo (lâmina nuclear) e no cinetoplasto, mas também na face citoplasmática da membrana plasmática. Essa proteína está principalmente associada ao polo apical do corpo do parasito e no ponto de fixação do flagelo com o corpo basal (Sahasrabuddhe, Bajpai \& Gupta, 2004).

\section{Bolsa flagelar e flagelo}

A porção anterior do corpo da Leishmania apresenta uma invaginação da membrana plasmática conhecida como bolsa flagelar (BF), e desta emerge o flagelo. A membrana plasmática presente no corpo do parasito estabelece 
continuidade com a membrana do flagelo, mantendo características proteicas próprias de ambas. A membrana que reveste a bolsa flagelar é especializada, sendo o local onde ocorre o processo de endocitose de nutrientes desses parasitos, já que é a única região do corpo onde não são encontrados microtúbulos subpeliculares (Field et al., 1998). Próximo ao cinetoplasto (K) está localizado o corpúsculo basal (CB), formado somente por nove pares de microtúbulos periféricos e intimamente ligado à base dos microtúbulos do flagelo. (Figura 5). Todavia, o flagelo da Leishmania é constituído por um axonema formado por nove pares de microtúbulos concêntricos e um par central. Ao longo do flagelo pode ser observada uma estrutura complexa conhecida como estrutura paraflagelar ou corpo paraxial (Figura 6). O corpo paraxial é formado por um arranjo de filamentos proteicos conectados aos pares de microtúbulos 4 e 7 do axonema (De Souza, 1995; Foth et al., 2002). O flagelo desses parasitos está envolvido em diversas funções, como motilidade e adesão às células-alvo. A Leishmania é um parasito extremamente móvel, sendo capaz de mover-se cerca de 10-30 $\mu \mathrm{m}$ por segundo em meio de cultura, através do movimento de onda realizado pelo flagelo (sempre da ponta para base), puxando desta forma o corpo do parasito (Santrich et al., 1997).

Figura 4 - Promastigota de Leishmania (V.) braziliensis mostrando microtúbulos subpeliculares (MT) localizados abaixo da membrana plasmática

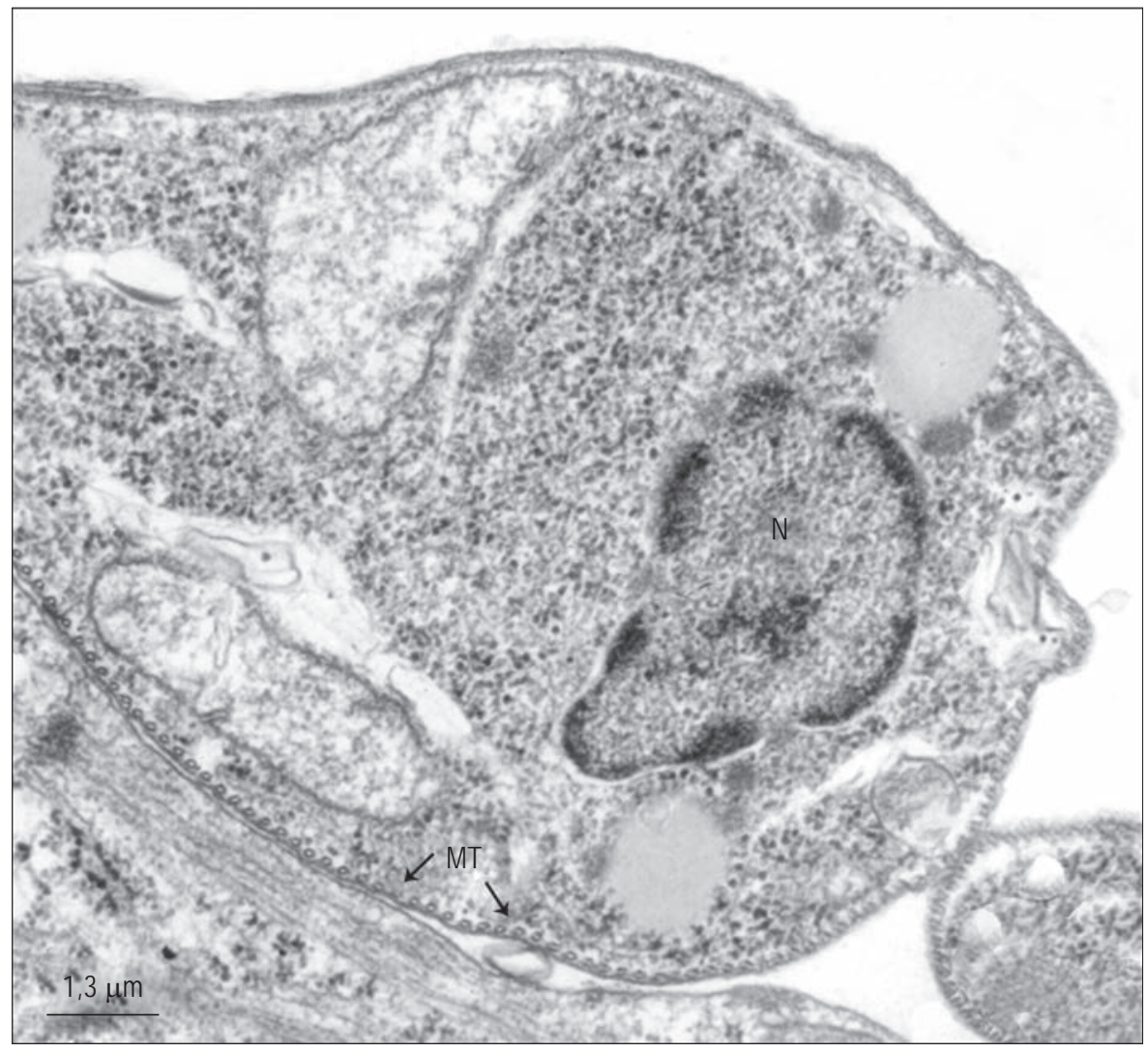


Figura 5 - Corpúsculo basal (CB) pode ser visualizado próximo à base da bolsa flagelar (BF). Ao longo do flagelo (F) podem ser vistos os microtúbulos e a formação do axonema formado por nove pares de microtúbulos concêntricos e um par central (insert)

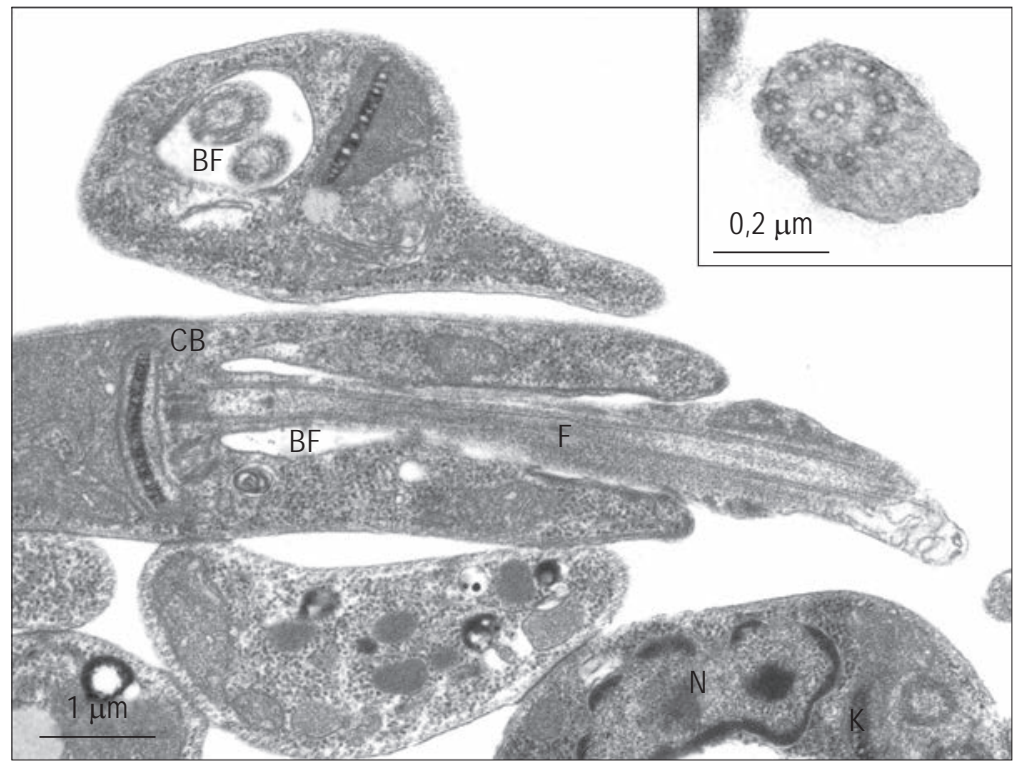

Figura 6 - No corte transversal do flagelo (F) observamos uma estrutura complexa conhecida como estrutura paraflagelar ou corpo paraxial $\left({ }^{*}\right)$

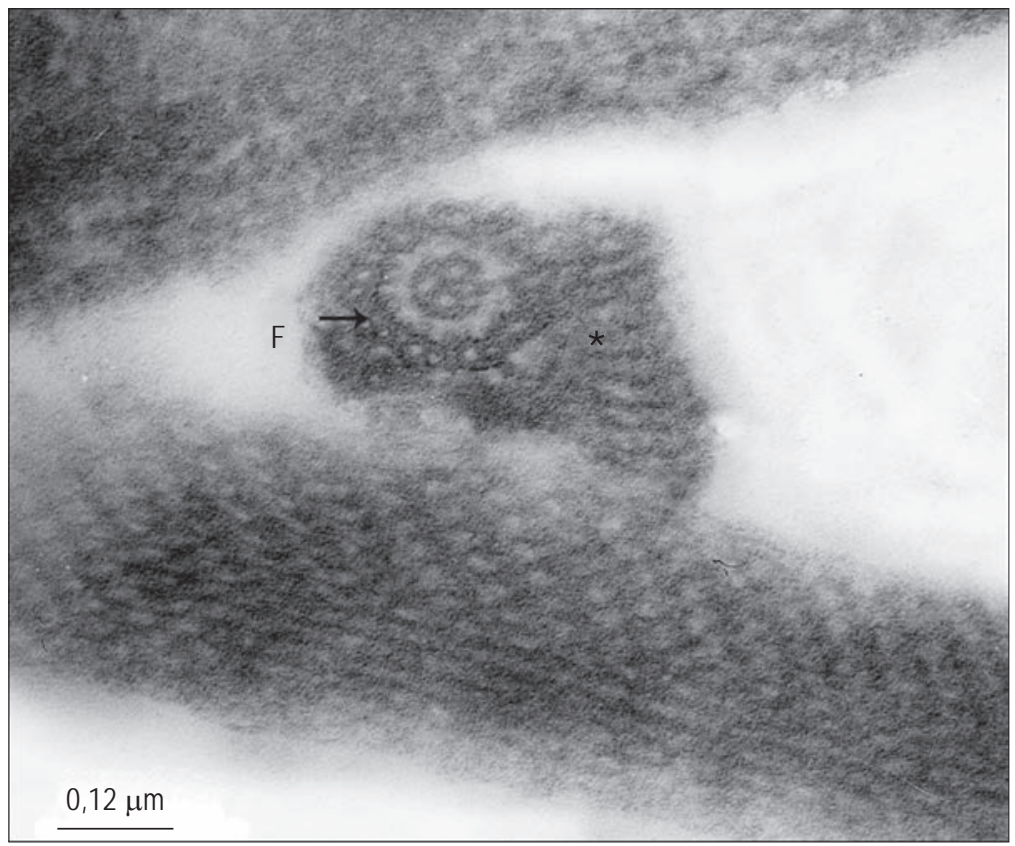

Retículo endoplasmático e complexo de Golgi

Por todo o corpo dos parasitos do gênero Leishmania são encontrados perfis tubulares do retículo endoplasmático (RE). Entretanto, ele é por vezes visualizado logo abaixo dos microtúbulos subpeliculares (Pimenta \& De Souza, 1985), formando assim uma tríade, juntamente com a membrana plasmática (Figura 7). 
Figura 7 - Micrografia eletrônica mostrando perfis tubulares do retículo endoplasmático (RE) próximo aos microtúbulos subpeliculares

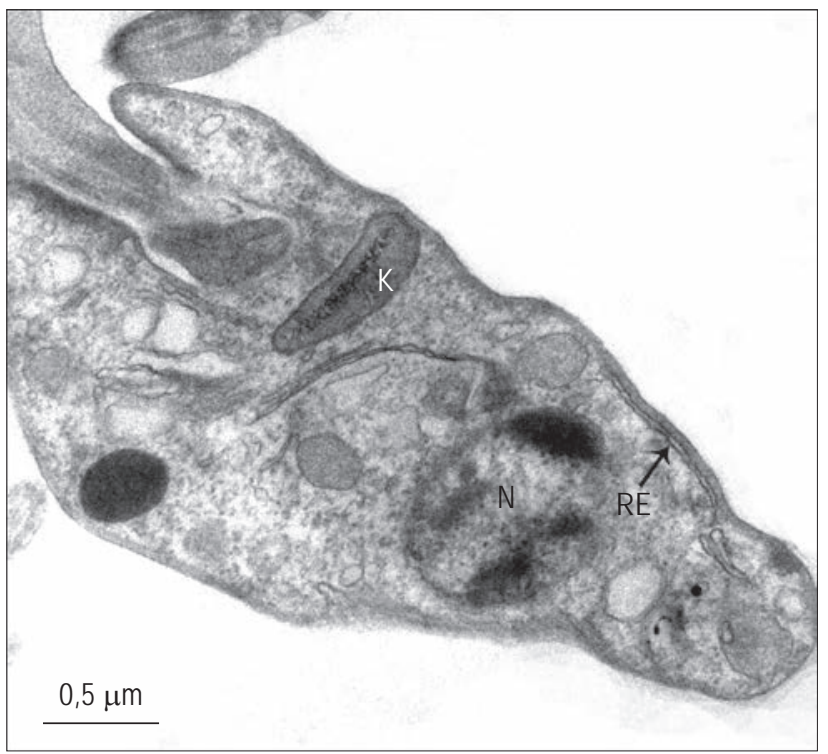

As organelas envolvidas no transporte de moléculas do retículo endoplasmático para a bolsa flagelar são encontradas agrupadas na extremidade anterior da célula, enquanto as regiões do retículo endoplasmático que apresentam intenso brotamento de vesículas ficam localizadas próximas ao complexo de Golgi (CG). Na Leishmania, ele tem estrutura similar à observada em células de mamíferos, sendo encontrado entre o núcleo e cinetoplasto na região anterior do parasito (Figura 8). Estudos citoquímicos têm demonstrado a participação do complexo de Golgi no processo de glicosilação de glicoconjugados (Clayton, Häusler \& Blattner, 1995).

Figura 8 - Nos parasitos do gênero Leishmania, o complexo de Golgi (CG) é formado por cisternas e está entre o núcleo e cinetoplasto na região anterior do parasito

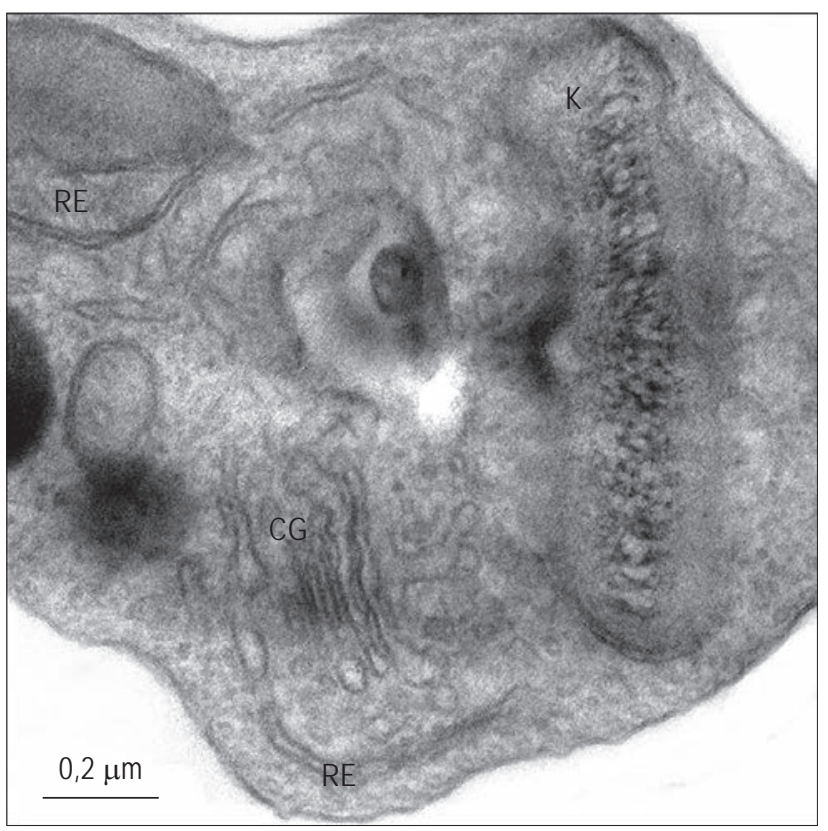




\section{Via endocítica}

A endocitose em Leishmania pode ser observada tanto em promastigotas quanto em amastigotas, no processo de nutrição e evasão do sistema imune. o processo de endocitose/exocitose de macromoléculas ocorre na região da bolsa flagelar, que não apresenta microtúbulos subpeliculares. Proteínas de membrana são endocitadas e posteriormente encaminhadas ao sistema endolisossomal, por meio de um processo dependente de clatrina (Weise et al., 2000). A presença de proteínas que participam da via endocítica como a clatrina, Rab5, receptores de transferrina e de hemoglobina indicam que o processo de endocitose é mediado por receptores em Leishmania (Voyiatzaki \& Soteriadou, 1992; Singh et al., 2003).

Diversas estruturas da via endocítica foram identificadas em promastigotas de Leishmania, dentre elas: corpos multivesiculares, estruturas tubulares e túbulos multivesiculares (Figura 9). Os corpos multivesiculares são estruturas com cerca de 200-300 nm de diâmetro, arredondadas, limitados por membrana e com conteúdo elétron-lucentes. As estruturas tubulares são constituídas de aglomerados de túbulos regulares conectados uns aos outros com 60 nm de diâmetro, localizadas próximo ao complexo de Golgi e da bolsa flagelar (Weise et al., 2000). Os túbulos multivesiculares são observados desde a região anterior até a região posterior do corpo do parasito, sendo a organela final da via endocítica. São caracterizados como grandes túbulos limitados por membrana contendo uma série de pequenas vesículas de tamanho e formas distintos, medindo cerca de 100-200 nm de diâmetro (Weise et al., 2000; Ghedin et al., 2001). Além de ser o compartimento final da via endocítica de promastigotas e Leishmania, os túbulos multivesiculares são o local de acúmulo de proteínas e lipídeos ingeridos pelo parasito. No citoplasma da Leishmania são observadas organelas contendo lipídeos, estando dispersas por todo o citoplasma (Figura 10).

Figura 9 - Estruturas tubulares e vesículas (setas) participando no processo de endocitose podem ser visualizadas na bolsa flagelar (BF) de amastigotas de Leishmania (L.) amazonensis

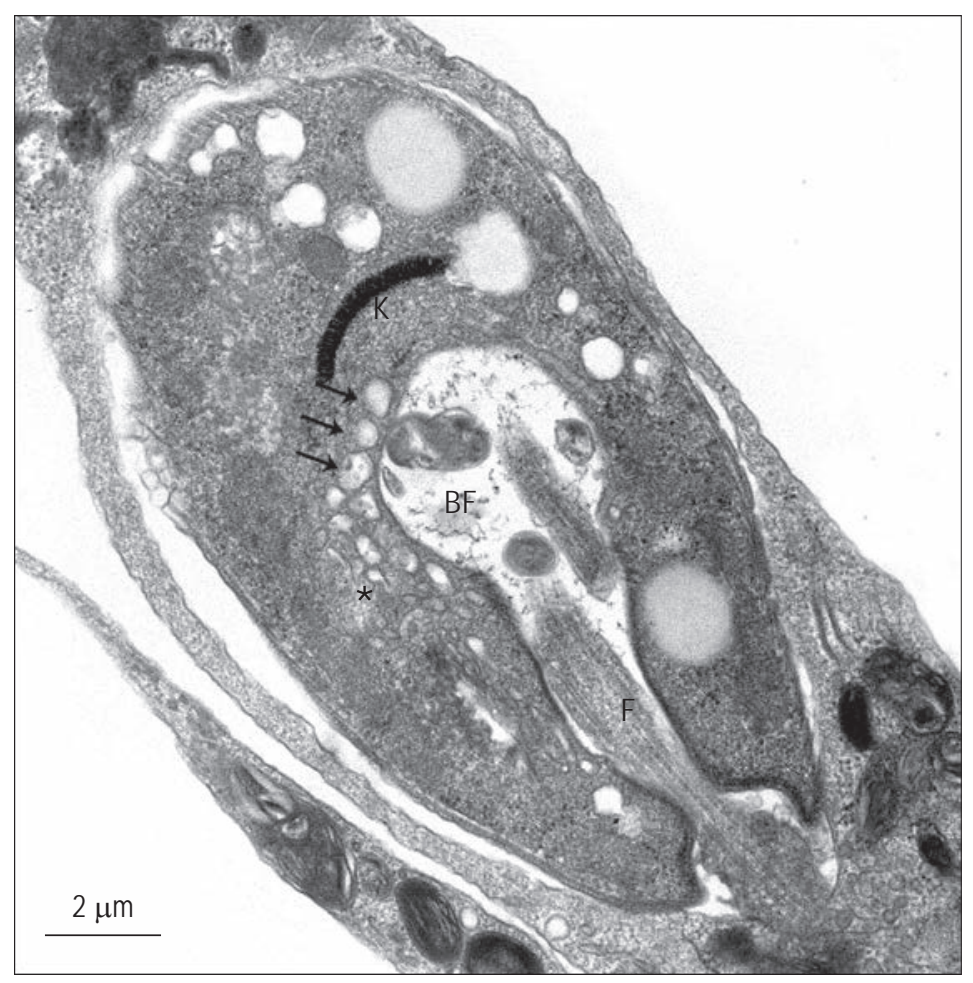


Figura 10 - Micrografia eletrônica de Leishmania (V.) braziliensis mostra organelas eletrondensas, contendo lipídeos (L), dispersas no citoplasma

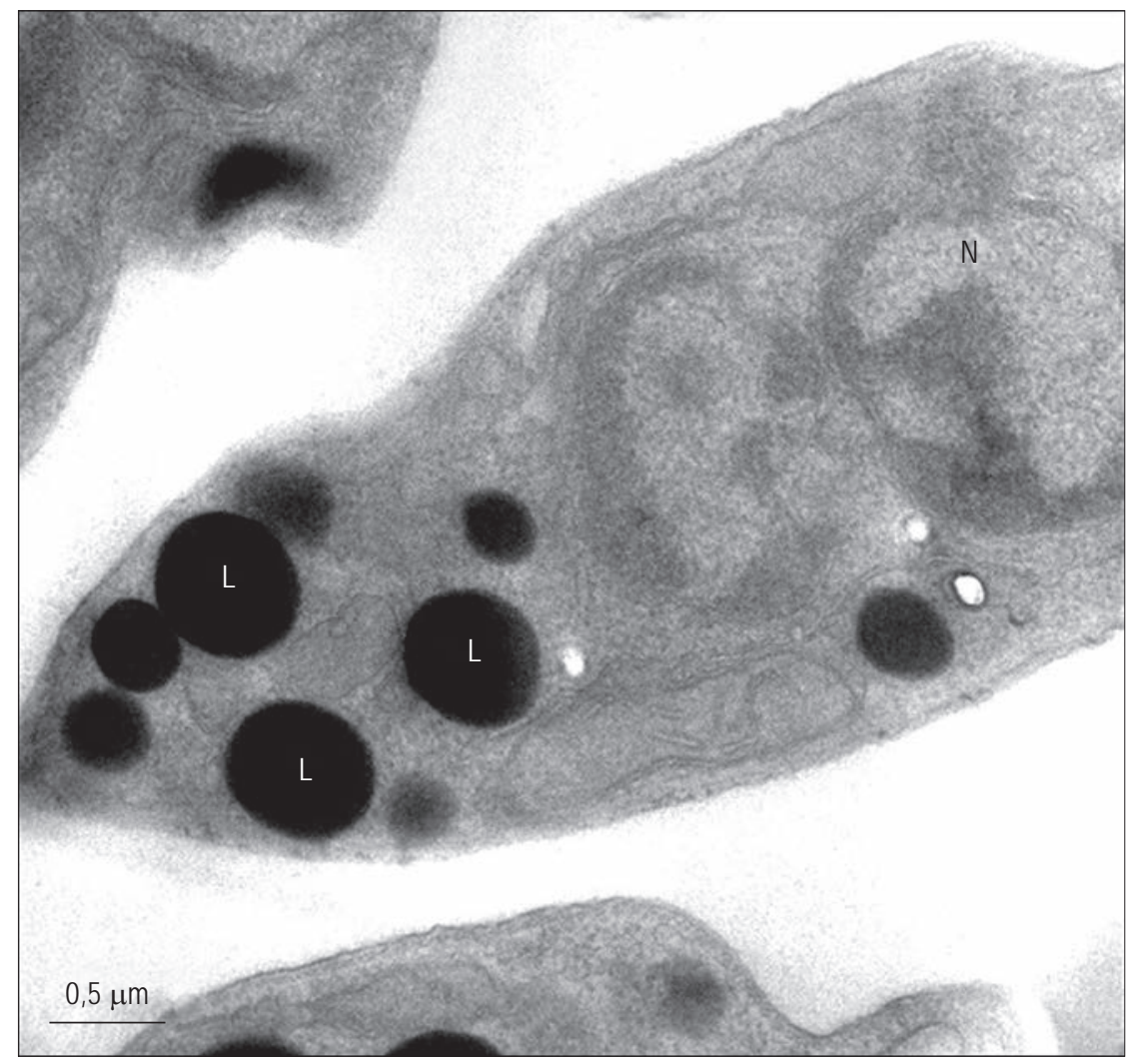

Em amastigotas, a via endocítica é utilizada como mecanismo de escape do sistema imune do hospedeiro, mediante a ingestão e degradação de moléculas como MHC Classe II e cofatores, evitando assim a apresentação antigênica (Antoine et al., 1999). As moléculas endocitadas por meio da bolsa flagelar são encaminhadas aos megassomos (MG), organela final da via endocítica em amastigotas (Alexander \& Vickerman, 1975).

\section{Megassomos}

Formas amastigotas de Leishmania apresentam uma organela circundada por uma membrana, contendo em seu interior vesículas eletrondensas imersas em uma matriz heterogênea, o megassomo (Figura 11). Ela pode variar em tamanho e número, podendo ser maior que o núcleo. o megassomo tem como característica a presença de enzimas, fosfatase ácida e cisteína-proteinase em suas vesículas (De Souza, Sant'Anna \& Cunha-e-Silva, 2009). Em promastigotas metacíclicas de Leishmania (L.) chagasi foram descritas estruturas tubulares e multivesiculares, apresentando enzimas características de lisossomos (Alberio et al., 2004). 
Figura 11 - Megassomos (MG), organelas da via endocítica (cabeça de seta) são observadas em amastigotas Leishmania (L.) amazonensis. Estas organelas apresentam em seu interior vesículas eletrondensas (seta) imersas na matriz (insert)

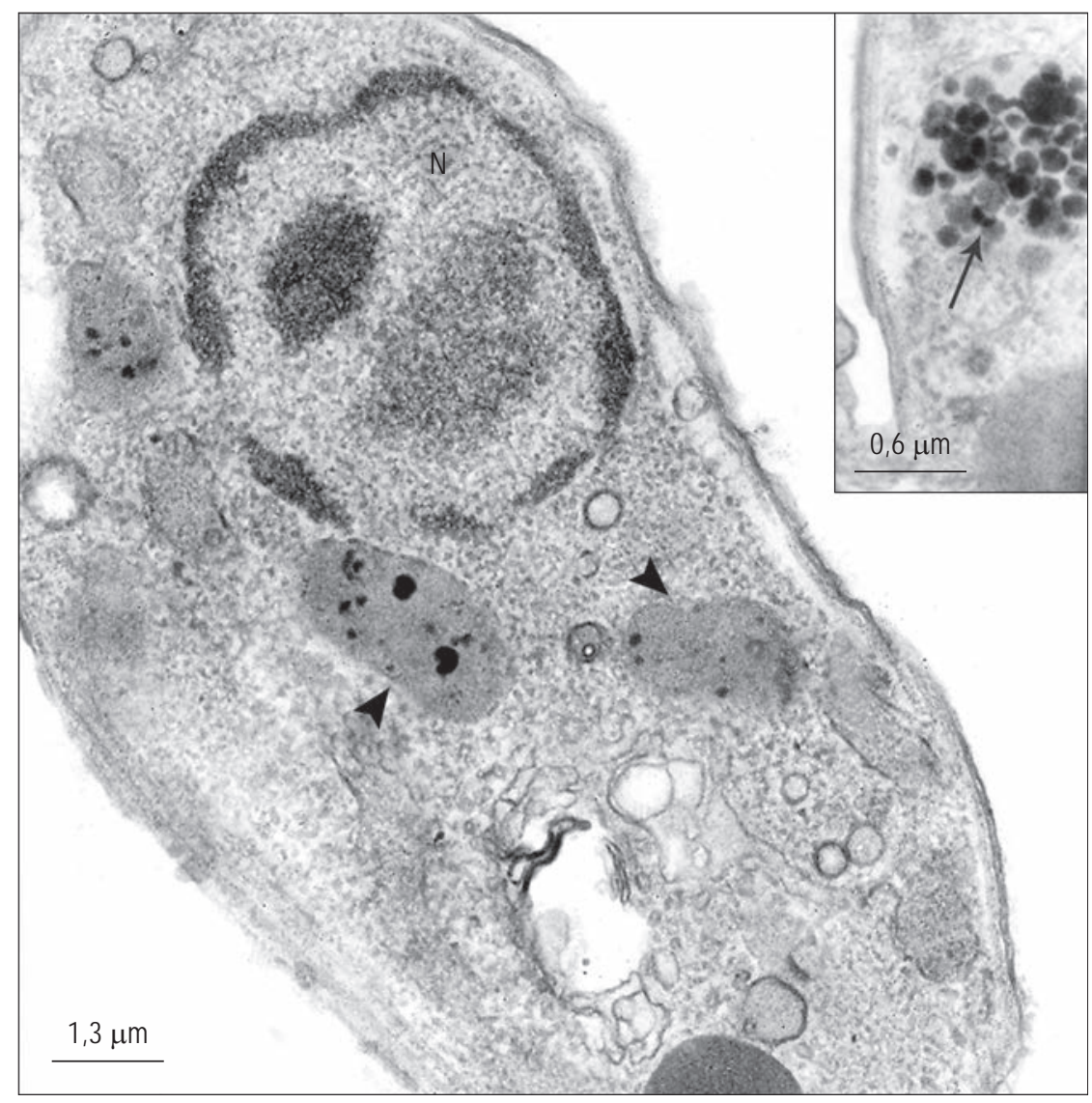

\section{Glicossomas}

Inicialmente, organelas presentes em alguns tipos celulares, contendo dois tipos de enzimas - catalase e $\mathrm{H}_{2} \mathrm{O}_{2}-$ produzindo oxidases, foram denominadas peroxissomos. Entretanto, em tripanossomatídeos também foi descrito, no citoplasma desses parasitos, uma organela esférica circundada por uma membrana, com diâmetro aproximado de $0.7 \mu \mathrm{m}$, com matriz pouco densa e homogênea e contendo um cristaloide no seu interior, sendo então denominada de glicossoma (De Souza, 2002).

\section{Acidocalcissoma}

Há quase cem anos, organelas com conteúdo ácido e contendo grande quantidade de cálcio foram identificadas como grânulos de volutina (Vercesi, Moreno \& Docampo, 1994). Essas organelas, quando estudadas em tripanossomatídeos e Apicomplexa, receberam uma nova denominação, sendo então chamadas de acidocalcissomas (Docampo \& Moreno, 1999). Elas foram caracterizadas como organelas ácidas que armazenam cálcio, apresentando alta densidade de elétrons e alto teor de polifosfatos, além de magnésio e outros elementos (Docampo \& Moreno, 1999; Scott et al., 1997; Vannier-Santos et al., 1999). Os acidocalcissomas são delimitados por uma única membrana, podendo apresentar morfologia esférica, alongada ou polimórfica, e estão distribuídos randomicamente pela célula (Figuras 1B e 12). Ele apresenta conteúdo eletrondenso que varia de acordo com o procedimento utilizado nas preparações das amostras 
por métodos convencionais. O material eletrondenso pode ser removido, deixando um fino anel abaixo da membrana ou dando-lhes a aparência de vacúolos vazios. Em alguns tripanossomatídeos, o material denso aparece em um dos lados da membrana como uma inclusão, o que levou à sua denominação como vacúolos de inclusão (Docampo et al., 2005; Moreno \& Docampo, 2009; Vickerman \& Tetley, 1977). Em promastigotas de Leishmania (L.) amazonensis, os acidocalcissomas foram observados distribuídos por todo o corpo, apresentando as características mencionadas anteriormente (Figura 12). Entretanto, a melhor preservação do material eletrondenso do acidocalcissoma é obtida por congelamento e ultracriomicrotomia, no qual todos os acidocalcissomas parecem ser completamente preenchidos (Scott, Docampo \& Dvorak, 1997).

Figura 12 - Por microscopia eletrônica de transmissão podemos visualizar organelas com conteúdo eletrondenso, distribuídas no citoplasma de Leishmania (L.) amazonensis

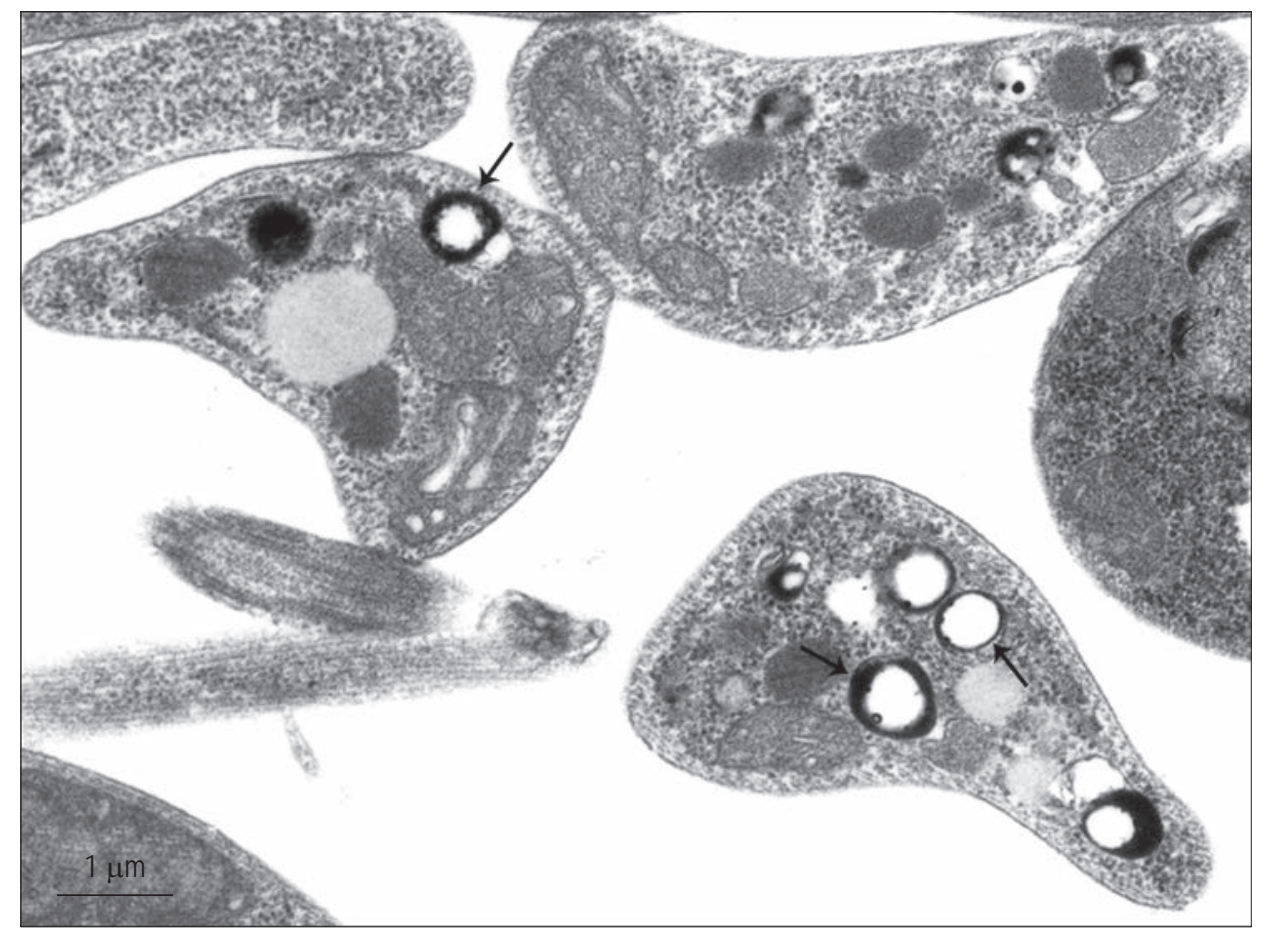

\section{Mitocôndria e cinetoplasto}

Os parasitos do gênero Leishmania têm mitocôndria única, que percorre todo o corpo do parasito, apresentando dupla membrana, sendo a membrana interna formadora das cristas mitocondriais geralmente paralela à membrana externa. Na porção mitocondrial próxima à base do flagelo está presente o cinetoplasto (Figura 13). O cinetoplasto é a região que possui o mais complexo DNA mitocondrial encontrado na natureza. Ele está presente em flagelados unicelulares da ordem Kinetoplastida. Ele é conhecido como uma rede de milhares de DNAs circulares catenados, o k-DNA. Os círculos de k-DNA são de dois tipos, maxicírculos que geralmente têm tamanho de intervalo entre 20-40 kb, dependendo da espécie, e estão presentes em algumas dezenas de cópias idênticas por rede e, minicírculos, presentes aos milhares de exemplares por rede, geralmente são quase idênticos em tamanho - 0,5 a $10 \mathrm{~kb}$, dependendo da espécie, mas são heterogêneos na sequência. Os maxicírculos codificam produtos de genes mitocondriais típicos (r-RNAs) e subunidades complexas da cadeia respiratória, mas, curiosamente, alguns dos genes codificadores de proteínas são criptografados (Lukes et al., 2002). 
Figura 13 - Micrografia eletrônica mostrando mitocôndria única apresentando dupla membrana, com cristas mitocondriais formadas pela membrana interna. Na porção mitocondrial próxima à base do flagelo observamos o cinetoplasto (complexo DNA mitocondrial) em forma de bastão

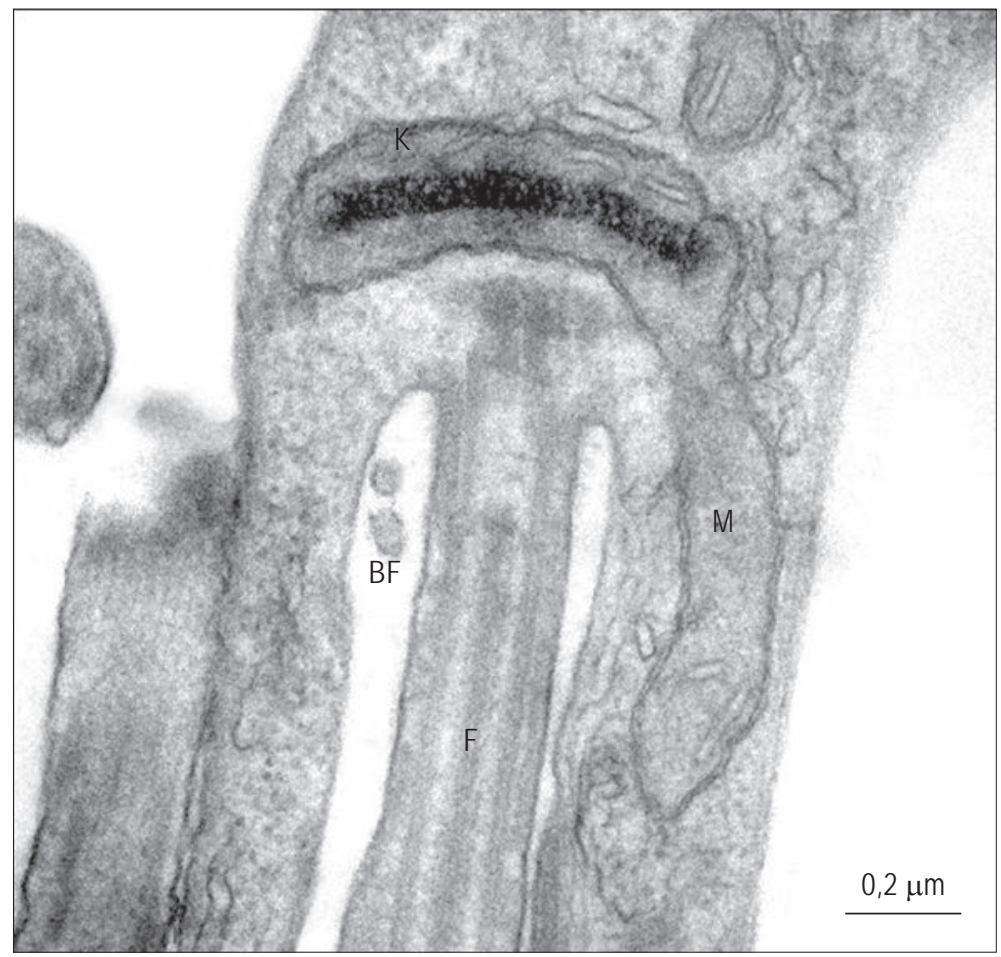

Núcleo

Os protozoários do gênero Leishmania apresentam núcleo arredondado, ocupando a região central do corpo do parasito e nucléolo central, com uma organização estrutural similar ao de outras células eucarióticas. A heterocromatina forma uma rede, conectando-se com a lâmina nuclear e esta com a membrana interna do envoltório. A membrana externa é proveniente do retículo endoplasmático e apresenta polirribossomos aderidos. O envelope nuclear contém inúmeros complexos do poro nuclear, que abrangem as membranas interna e externa e são morfologicamente indistinguíveis do envelope nuclear de outros eucariotos. O tamanho e o número de cromossomos é variável, conforme a espécie da Leishmania (Pagès et al., 1989).

\section{CONCLUSÃO E PERSPECTIVAS}

A observação desses parasitos, utilizando metodologias que preservassem suas organelas e estruturas e que pudessem ser visualizados na amplitude de seus detalhes, levou ao estudo ultraestrutural utilizando a microscopia eletrônica. Para isso, são utilizadas técnicas convencionais de inclusão e/ou técnicas avançadas de congelamento e criofratura, citoquímica e imunocitoquímica. Essas demonstram a organização de componentes celulares, a presença de moléculas importantes para o ciclo de vida da Leishmania e a presença de receptores de superfície utilizados no reconhecimento da célula-alvo (Benchimol \& De Souza, 1980; Weise et al., 2000; De Souza, 2002).

o estudo morfológico ultraestrutural da Leishmania tem sido amplamente avaliado com o objetivo de detectar mudanças expressivas, principalmente quando acontece a conversão da forma promastigota para amastigota, 
a divisão celular de ambas, o momento fugaz da troca genética (Sousa, Pereira \& Côrte-Real, 1997), ocorrendo a formação de híbridos, o estudo das organelas e a participação da membrana plasmática na interação com as célulaalvo (Hespanhol et al., 2005; Guerra et al., 2010), sejam elas do inseto vetor ou de mamíferos.

\section{REFERÊNCIAS}

ALBERIO, S. O. et al. Ultrastructural and cytochemical identification of megasome in Leishmania (Leishmania) chagasi. Parasitology Research, 92(3): 246-254, 2004.

ALEXANDER, J. \& VICKERMAN, K. Fusion of host cell secondary lysosomes with the parasitophorous vacuoles of Leishmania mexicana - infected macrophages. The Journal of Protozoology, 22: 502-508, 1975.

ANTOINE, J. C. et al. H-2M molecules, like MHC classII molecules, are targeted to parasitephorous vacuoles of Leishmaniainfected macrophages and internalized by amastigotes of L. amazonensis and L. mexicana. Journal of Cell Science, 112: 2.559-2.570, 1999 .

BENCHIMOL, M. \& SOUZA, W. Freeze-fracture study of the plasma membrane of Leishmania mexicana amazonensis. The Journal of Parasitology, 66(6): 941-947, 1980.

CHANG, K. P. Leishmania infection of human skin fibroblasts in vitro: absence of phagolysosomal fusion after induced phagocytosis of promastigotes, and their intracellular transformation. The American Journal of Tropical Medicine and Hygiene, 27(6): 1.084-1.096, 1978.

CHAUDHURI, G. \& CHANG, K. P. Acid protease activity of a major surface membrane glycoprotein (gp63) from Leishmania mexicana promastigotes. Molecular and Biochemical Parasitology, 27(1): 43-52, 1988.

CHAUDHURI, G. et al. Surface acid proteinase (gp63) of Leishmania mexicana. A metalloenzyme capable of protecting liposome-encapsulated proteins from phagolysosomal degradation by macrophages. The Journal of Biological Chemistry, 264(13): 7.483-7.489, 1989.

CLAYTON, C.; HÄUSLER, T. \& BLATTNER, J. Protein trafficking in kinetoplastid protozoa. Microbiological Reviews, 59(3): 325-344, 1995.

COIMBRA, E. S. et al. Characterization and cytochemical localization of an ATP diphosphohydrolase from Leishmania amazonensis promastigotes. Parasitology, 124(Pt 2): 137-143, 2002.

CÔRTE-REAL, S.; SANTOS, C. B. \& MEIRELLES, M. N. Differential expression of the plasma membrane Mg2+ ATPase and $\mathrm{Ca} 2+$ ATPase activity during adhesion and interiorization of Leishmania amazonensis in fibroblasts in vitro. Journal of Submicroscopic Cytology and Pathology, 27(3): 359-366, 1995.

CÔRTE-REAL, S. et al. Immunogold labeling and cerium cytochemistry of the enzyme ecto-5'-nucleotidase in promastigote forms of Leishmania species. Memórias do Instituto Oswaldo Cruz, 88(3): 407-412, 1993.

DOCAMPO, R. \& MORENO, S. N. J. Acidocalcisome: a novel Ca2+ storage compartment in trypanosomatids and apicomplexan parasites. Parasitology Today, 15: 443-448, 1999.

DOCAMPO, R. et al. Acidocalcisomes -conserved from bacteria to man. Nature Reviews. Microbiology, 3(3): 251-261, 2005.

DWYER, D. M. \& GOTTLIEB, M. Surface membrane localization of 3'- and 5'-nucleotidaseactivities in Leishmania donovani promastigotes. Molecular and Biochemical Parasitology, 10(2): 139-150, 1984.

FIELD, H. et al. Complexity of trypanosomatid endocytosis pathways revealed by Rab4 and Rab5 isoforms in Trypanosoma brucei. The Journal of Biological Chemistry, 273(48): 32.102-32.110, 1998.

FOTH, B. et al. Leishmania major proteophosphoglycans exist as membrane-bound and soluble forms and localise to the cell membrane, the flagellar pocket and the lysosome. International Journal for Parasitology, 32(14): 1.701-1.708, 2002.

GHEDIN, E. et al. Secretory and endocytic pathways converge in a dynamic endosomal system in a primitive protozoan. Traffic, 2(3): 175-188, 2001. 
GUERRA, C. S. et al. Histopathological analysis of initial cellular response in TLR-2 deficient miceexperimentally infected by Leishmania (L.) amazonensis. International Journal of Experimental Pathology, 91(5): 451-459 2010.

HESPANHOL, R. C. et al. The expression of mannose receptors in skin fibroblast and theirinvolvement in Leishmania (L.) amazonensis invasion. The Journal of Histochemistry and Cytochemistry, 53(1): 35-44, 2005.

ILG, T. Lipophosphoglycan of the protozoan parasite Leishmania: stage and species specific importance for colonization of the sandfly vector, transmission and virulence to mammals. Medical Microbiology and Immunology, 190(1-2): 13-17, 2001.

ILG, T.; HANDMAN, E. \& STIERHOF, Y. D. Proteophosphoglycans from Leishmania promastigotes and amastigotes. Biochemical Society Transactions, 27(4): 518-525, 1999.

KOHL, L. \& GULL, K. Molecular architecture of the trypanosome cytoskeleton. Molecular and Biochemical Parasitology, 93(1): 1-9, 1998.

LANG, T. et al. Transmission and scanning EM-immunogold labeling of Leishmania major lipophosphoglycan in the sandfly Phlebotomus papatasi. European Journal of Cell Biology, 55(2): 362-372, 1991.

LUKES, J. et al. Kinetoplast DNA network: evolution of an improbable structure. Eukaryotic Cell, 1(4): 495-502, 2002.

MCNEELY, T. B. \& TURCO, S. J. Requirement of lipophosphoglycan for intracellular survival of Leishmania donovani within human monocytes. The Journal of Immunology, 144(7): 2.745-2.750, 1990.

MEDINA-ACOSTA, E. et al. The promastigote surface protease (gp63) of Leishmania is expressed but differentially processed and localized in the amastigote stage. Molecular and Biochemical Parasitology, 37(2): 263-273, 1989.

MORENO, S. N. \& DOCAMPO, R.The role of acidocalcisomes in parasitic protists. The Journal of Eukaryotic Microbiology, 56(3): 208-213, 2009.

NACY, C. A. \& DIGGS, C. L. Intracellular replication of Leishmania tropica in mouse peritoneal macrophages: comparison of amastigote replication in adherent and nonadherent macrophages. Infection and Immunity, 34(1): 310-313, 1981.

NADERER, T. \& MCCONVILLE, M. J. The Leishmania-macrophage interaction: a metabolic perspective. Cellular Microbiology, 10(2): 301-308, 2008.

ORLANDI JR., P. A. \& TURCO, S. J. Structure of the lipid moiety of the Leishmania donovani lipophosphoglycan. The Journal of Biological Chemistry, 262 (21): 10.384-10.391, 1987.

PAGÈS, M. et al. Chromosome size and number polymorphisms in Leishmania infantum suggest amplification/deletion and possible genetic exchange. Molecular and Biochemical Parasitology, 36(2): 161-168, 1989.

PIMENTA, P. F. \& SOUZA, W. Fine structure and cytochemistry of the endoplasmic reticulum and its association with the plasma membrane of Leishmania mexicana amazonensis. Journal of Submicroscopic Cytology, 17(3): 413-419, 1985.

PIMENTA, P. F. \& SOUZA, W. Leishmania mexicana: distribution of intramembranous particles and filipin sterol complexes in amastigotes and promastigotes. Experimental Parasitology, 63(2): 117-135, 1987.

REZENDE-SOARES, F. A. et al. Cytochemical localization of ATP diphosphohydrolase from Leishmania (Viannia) braziliensis promastigotes and identification of an antigenic and catalytically active isoform. Parasitology, 137(5): 773-783, 2010.

SAHASRABUDDHE, A. A.; BAJPAI, V. K. \& GUPTA, C. M. A novel form of actin in Leishmania: molecular characterisation, subcellular localisation and association with subpellicular microtubules. Molecular and Biochemical Parasitology, 134(1): 105-114, 2004.

SANTRICH, C. et al. A motility function for the paraflagellar rod of Leishmania parasites revealed by PFR-2 gene knockouts. Molecular and Biochemical Parasitology, 90(1): 95-109, 1997.

SASSE, R. \& GULL, K. Tubulin post-translational modifications and the construction of microtubular organelles in Trypanosoma brucei. Journal of Cell Science, 90(Pt4): 577-589, 1988.

SCOTT, D. A. et al. In situ compositional analysis of acidocalcisomes in Trypanosoma cruzi. The Journal of Biological Chemistry, 272(44): 28.020-28.029, 1997. 
SINGH, S. B. et al. Rab5-mediated endosome-endosome fusion regulates hemoglobin endocytosis in Leishmania donovani. The Embo Journal, 22(21): 5.712-5.722, 2003.

SNAPP, E. L. \& LANDFEAR, S. M. Characterization of a targeting motif for a flagellar membrane protein in Leishmania enriettii. The Journal of Biological Chemistry. 1999; 274(41): 29.543-29.548. Erratum in: The Journal of Biological Chemistry, 277(14): 12.486, 2002.

SOUSA, M. A.; PEREIRA, M. C. S. \& CÔRTE-REAL, S. Leishmania major: parasite interactions suggesting sexuality. Memórias do Instituto Oswaldo Cruz, 92(6): 761-766, 1997.

SOUZA, W. Structural organization of the cell surface of pathogenic protozoa. Micron: the international research and review journal for microscopy, 26(5): 405-430, 1995.

SOUZA, W. Special organelles of some pathogenic protozoa. Parasitology Research, 88(12): 1.013-1.125, 2002.

SOUZA, W.; SANT'ANNA, C. \& CUNHA-E-SILVA, N. L. Electron microscopy and cytochemistry analysis of the endocytic pathway of pathogenic protozoa. Progress in Histochemistry and Cytochemistry, 44(2): 67-124, 2009.

TURCO, S. J. The leishmanial lipophosphoglycan: a multifunctional molecule. Experimental Parasitology, 70(2): 241-245, 1990.

VANNIER-SANTOS, M. A. et al. Impairment of sterol biosynthesis leads to phosphorus and calcium accumulation in Leishmania acidocalcisomes. Microbiology, 145(11): 3.213-3.220, 1999.

VERCESI, A. E.; MORENO, S. N. J. \& DOCAMPO, R. Ca2+/H+ exchange in acidic vacuoles of Trypanosoma brucei. The Biochemical Journal, 304: 227-233, 1994.

VICKERMAN, K. \& TETLEY, L. Recent ultrastructural studies on trypanosomes. Annales de la Société Belge de Médecine Tropicale, 57: 441-455, 1977.

VOYIATZAKI, C. S. \& SOTERIADOU, K. P. Identification and isolation of the Leishmania transferrin receptor. The Journal of Biological Chemistry, 267(13): 9.112-9.117, 1992.

WEISE, F. et al. Distribution of GPI-anchored proteins in the protozoan parasite Leishmania, based on an improved ultrastructural description using high-pressure frozen cells. Journal of Cell Science, 113(24): 4.587-4.603, 2000.

WOODS, A.; BAINES, A. J. \& GULL, K. A high molecular mass phosphoprotein defined by a novel monoclonal antibody is closely associated with the intermicrotubule cross bridges in the Trypanosoma brucei cytoskeleton. Journal of Cell Science, 103(Pt 3): 665-675, 1992. 
parte II

Bioquímica e Metabolismo

Energético dos Parasitos do

Gênero Leishmania 


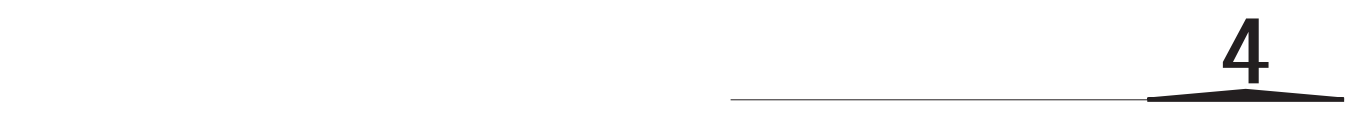

\section{Metabolismo de Carboidratos em Leishmania spp.}

Marcelo Alves-Ferreira

$\mathrm{O}$

metabolismo de carboidratos corresponde ao núcleo central de produção de energia na maioria dos organismos

vivos, sejam procariontes ou eucariontes. Esse conjunto de vias metabólicas possibilita a geração de energia, a qual é vital para os mais diferentes processos celulares, incluindo os mecanismos de replicação, transcrição, tradução, equilíbrio hidroeletrolítico, transdução de sinal, dentre outros. Em Leishmania spp., o metabolismo de carboidratos vem sendo estudado desde a década de 1960 (Voller, Shaw \& Bryant, 1963; Mancilla, Naquira \& Lanas, 1965, 1969; Poorman \& Janovy, 1969). Os primeiros trabalhos visavam à caracterização de diferentes vias, utilizando principalmente as técnicas de marcação radioativa, assim como a possibilidade de identificação do mecanismo de ação de drogas utilizadas no tratamento das leishmanioses. Atualmente, com o desenvolvimento das técnicas de biologia molecular, de biologia estrutural e da disponibilização dos dados genômicos de diferentes espécies de Leishmania, o conhecimento sobre o metabolismo de carboidratos nesses organismos tem evoluído significativamente. Porém, ainda existem lacunas a serem preenchidas.

A abordagem deste capítulo consistirá na subdivisão entre as principais vias metabólicas: glicólise, ciclo de Krebs, fosforilação oxidativa e a via das pentoses, além de serem abordadas diferentes metodologias de análise do metabolismo nos protozoários patogênicos.

\section{GLICÓLISE}

A via glicolítica vem sendo estudada desde o início do estudo relacionado ao metabolismo de carboidratos em Leishmania spp. (Voller, Shaw \& Bryant, 1963; Mancilla, Naquira \& Lanas, 1965, 1969; Poorman \& Janovy, 1969). Porém, mesmo após as publicações dos genomas de três espécies: Leishmania major (Ivens et al., 2005), Leishmania braziliensis e Leishmania infantum (Peacock et al., 2007), ainda existem detalhes a ser desvendados para o completo entendimento do mecanismo de ação das enzimas glicolíticas, como os relacionados à regulação da glicólise nas diferentes espécies e nas diferentes formas evolutivas desses protozoários.

Antes de serem metabolizados, os açúcares devem ser captados do meio externo por intermédio de transportadores, que são proteínas integrais presentes nas membranas plasmáticas das diferentes espécies de Leishmania. Esses transportadores são do tipo que realizam o transporte ativo portanto, são dependentes de ATP (Landfear, 2008; 
Tetaud et al., 1997). Algumas peculiaridades têm sido descritas em relação às características desses transportadores, incluindo atribuições distintas da função primária de transporte. Em L. mexicana foi demonstrado que existem três isoformas de transportadores de glicose, os quais são codificados pelo gene LmGT (Burchmore et al., 2003). Recentemente foram realizados diversos estudos que possibilitaram a caracterização genética, a identificação de modificações metabólicas e a caracterização fenotípica de transportadores de glicose em diversas cepas de L. mexicana (Burchmore et al., 2003; Rodríguez-Contreras \& Landfear, 2006; Rodríguez-Contreras et al., 2007).

Esses microrganismos têm uma organela especializada, existente nos outros membros da família Trypanosomatidae, denominada glicossomo. Do ponto de vista evolutivo, estudos moleculares indicam que os glicossomos são derivados de uma organela ancestral relacionada aos peroxissomos (Opperdoes \& Borst, 1977; Michels et al., 2006). Essa organela é especializada em uma série de vias metabólicas, de lipídeos, nucleotídeos e carboidratos. No caso da via glicolítica nas Leishmania spp., os glicossomos apresentam sete enzimas envolvidas nesta via, o que implica uma semicompartimentalização de uma via metabólica (Figura 1). Esse tipo de estratégia metabólica é semelhante ao que ocorrre com o ciclo da ureia em mamíferos, porém utilizando a mitocôndria em vez dos peroxissomos. O restante das reações ocorre no citoplasma, gerando fosfoenolpiruvato, o qual pode ser convertido em piruvato ou ocorrer uma reentrada desse intermediário no glicossomo, gerando piruvato ou succinato no interior dessa organela (Saunders et al., 2010). A glicólise apresenta como produtos finais principais os seguintes compostos: acetato, L-alanina, succinato e $\mathrm{CO}_{2}$, tanto em promastigota quanto em amastigota, e também lactato, este produzido somente pela forma promastigota (Figura 1) (Saunders et al., 2010; Bringaud, Rivière \& Coustou, 2006). As enzimas envolvidas nas etapas glicossomais da via glicolítica, assim como a maioria das enzimas que ocorrem nesta organela, apresentam um dos dois tipos de peptídeo sinal em suas estruturas proteicas, denominados PTS1 e PTS2 (Hannaert et al., 2006). Na forma sanguínea do Trypanossoma brucei, as enzimas glicolíticas representam 90\% do conteúdo proteico presentes em seus glicossomos (Michels et al., 2006).

As etapas da via glicolítica no interior dos glicossomos converte glicose em gliceraldeído-3-fosfato, gerando adenosina-trifosfato (ATP) e nicotimanida-adenina-dinocleotídeo (NADH). Entretanto, o consumo de ATP nas reações de fosforilação equivale à produção dos mesmos dentro dessa organela. Isto significa que a produção de ATP nessa etapa está voltada para o consumo intraglicossomal, tanto por conta da estequiometria entre síntese e consumo, como em razão da dificuldade de transporte do ATP através da sua membrana unilamenar (Saunders et al., 2010).

A primeira enzima da glicólise em leishmânias é a hexocinase, mas também pode ser glicocinase, que promove a conversão de glicose em glicose-6-fosfato, à custa de uma molécula de ATP. Essas enzimas já foram caracterizadas em L. mexicana (Pabón et al., 2007) e em L. major (Cáceres et al., 2007), respectivamente. Entretanto, foi descrito que a hexocinase pode ser inibida por pirofosfato inorgânico (Pabón et al., 2007), fato este que não ocorre com a glicocinase (Cáceres et al., 2007). Após a sua formação, a glicose-6-fosfato é convertida à frutose-6-fosfato através da ação da glicose-6-fosfato isomerase. Essa enzima, assim como a hexocinase, já foi caracterizada e ambas tiveram as suas localizações celulares correlacionadas ao glicossomo (Mottram \& Coombs, 1985).

Posteriormente, a frutose-6-fosfato é convertida em frutose-1,6-difosfato, via enzima fosfofrutocinase 1 (PFK1). Essa enzima catalisa passo limitante da via glicolítica em mamíferos, porém, este mecanismo parece estar ausente na glicólise realizada pelas leishmânias. Entretanto, foi descrito que a PFK1 de Leishmania também é ativada por AMP, mediante um mecanismo alostérico, possibilitando assim uma característica regulatória dessa enzima sobre a via glicolítica (Berens \& Marr, 1977a; López et al., 2002).

A frutose-1,6-difosfato é clivada em gliceraldeído-3-fosfato e dihidroxicetona-fosfato, via aldolase. Essa enzima foi caracterizada cineticamente em $L$. donovani e, posteriormente, foi clonada e caracterizada em L. mexicana (Ghosh \& Datta, 1970; De Walque, Opperdoes \& Michels, 1999). Posteriormente, ocorre a interconversão entre esses 
compostos por intermédio de atividade enzimática da triose fosfato isomerase, possibilitando assim a continuidade da via glicolítica. Essa enzima de L. mexicana teve a sua estrutura determinada por cristalografia e difração de Raios X em 1999 (Williams et al., 1999), possibilitando posteriormente o estudo comparativo entre as estruturas de enzimas homólogas de Trypanosoma cruzi, T. brucei, seres humanos, levedura, galo, Plasmodium falciparum e Entamoeba histolytica (Olivares-Illana et al., 2006). Esse trabalho demonstrou a importância da região central entre as subunidades, assim como mostrou a ação inibitória do composto 6,6'-bisbenzotiazol-2,2' diamina, a qual foi específica para as enzimas de tripanossomatídeos (Olivares-Illana et al., 2006).

A reação seguinte é de fundamental importância, pois é constituída por fosforilação oxidativa, que produz 1,3-bifosfoglicerato e NADH a partir do gliceraldeído-3-fosfato e $\mathrm{NAD}^{+}$. A enzima responsável por essa catálise é a gliceraldeído-3-fosfato desidrogenase. Essa enzima de L. mexicana teve a sua estrutura molecular resolvida, a qual apresentou uma estrutura tetramérica (Kim et al., 1995; Kim \& Hol, 1998). Devido a sua semelhança com as enzimas homólogas de T. cruzi e de T. brucei, sua estrutura tem sido utilizada visando a busca por um candidato a inibidor, além da sua posição central na via glicolítica (Kim et al., 1995; Kim \& Hol, 1998; Suresh et al., 2001).

Na última reação da via glicolítica tradicional, que ocorre nos glicossomos em tripanossomatídeos, é a catalisada pela enzima fosfoglicerato cinase glicossomal. Tal enzima catalisa a reação que promove a conversão de 1,3-bifosfoglicerato em 3-fosfoglicerato, com a produção de uma molécula de ATP. Alguns trabalhos descreveram as características dessa enzima em L. major e em L. mexicana, tais como a presença de duas isoformas, sendo uma citossólica e a outra glicossomal, as quais apresentam homologia com as enzimas de Trypanosoma e de Crithidia (McKoy et al., 1998; Adjé, Opperdoes \& Michels, 1997).

Os níveis glicossomais de $\mathrm{NAD}^{+}$e de NADH são balanceados em razão da ação da lançadeira do glicerol-3-fosfato, acoplada ao metabolismo mitocondrial (Figura 1). O sistema de lançadeiras atua durante a glicólise, através de moléculas citossólicas que agem lançando para o interior da mitocôndria elétrons e $\mathrm{H}^{+}$liberados pelo NADH, que por si mesmo não consegue penetrar na organela. Tal sistema inicia-se com a conversão de di-hidroxicetona fosfato em glicerol-3-fosfato, pela ação da enzima glicerol-3-fosfato desidrogenase com a regeneração do $\mathrm{NAD}^{+}$, possibilitando assim a manutenção do fluxo glicolítico glicossomal. o glicerol-3-fosfato é reoxidado pela enzima mitocondrial glicerol-3-fosfato desidrogenase FAD dependente, regenerando a di-hidroxicetona fosfato (Guerra et al., 2006).

As etapas realizadas no citoplasma envolvem as enzimas fosfoglicerato mutase, enolase e piruvato cinase (Figura 1). A enzima enolase de L. mexicana foi recentemente clonada e a sua atividade foi então caracterizada. Entretanto, a sua localização celular apresentou uma peculiaridade: além de ser localizada na fração citossólica, ela também foi encontrada associada a membranas e na face externa da membrana plasmática (Quiñones et al., 2007). Mais tarde, esse mesmo grupo identificou uma atividade alternativa da enolase: ela atua como receptor de plasminogênios em L. mexicana, aumentando a possibilidade de essa enzima ser um bom alvo para o desenvolvimento de novas abordagens terapêuticas (Vanegas et al., 2007).

A piruvato cinase de Leishmania spp. é uma das enzimas glicolíticas mais estudadas e tem sido analisada desde a década de 1970 (Berens \& Marr, 1977b). Identificou-se que essa enzima apresenta duas isoformas, as quais são reguladas alostericamente pela frutose-2,6-bifosfato e de forma distinta entre as mesmas (Ponte-Sucre \& Ramirez, 1993; Ponte-Sucre et al., 1993). As características cinéticas e estruturais foram determinadas com o auxílio de técnicas bioquímicas, por mutação sítio-dirigidas e por cristalização (Ernest et al., 1994; Fothergill-Gillmore et al., 2000; Rigden et al., 1999; Hannaert et al., 2002). Mais recentemente foram publicados novos dados correlacionados com a regulação alostérica por frutose-2,6-bifosfato e com um novo modelo molecular, assim como foram desenhados e testados compostos-líderes como inibidores dessa enzima, objetivando o desenvolvimento de novos fármacos (Sandoval et al., 2008; Nowicki et al., 2008; Morgan et al., 2010a, 2010b). 
Figura 1 - Metabolismo de carbono em Leishmania spp.

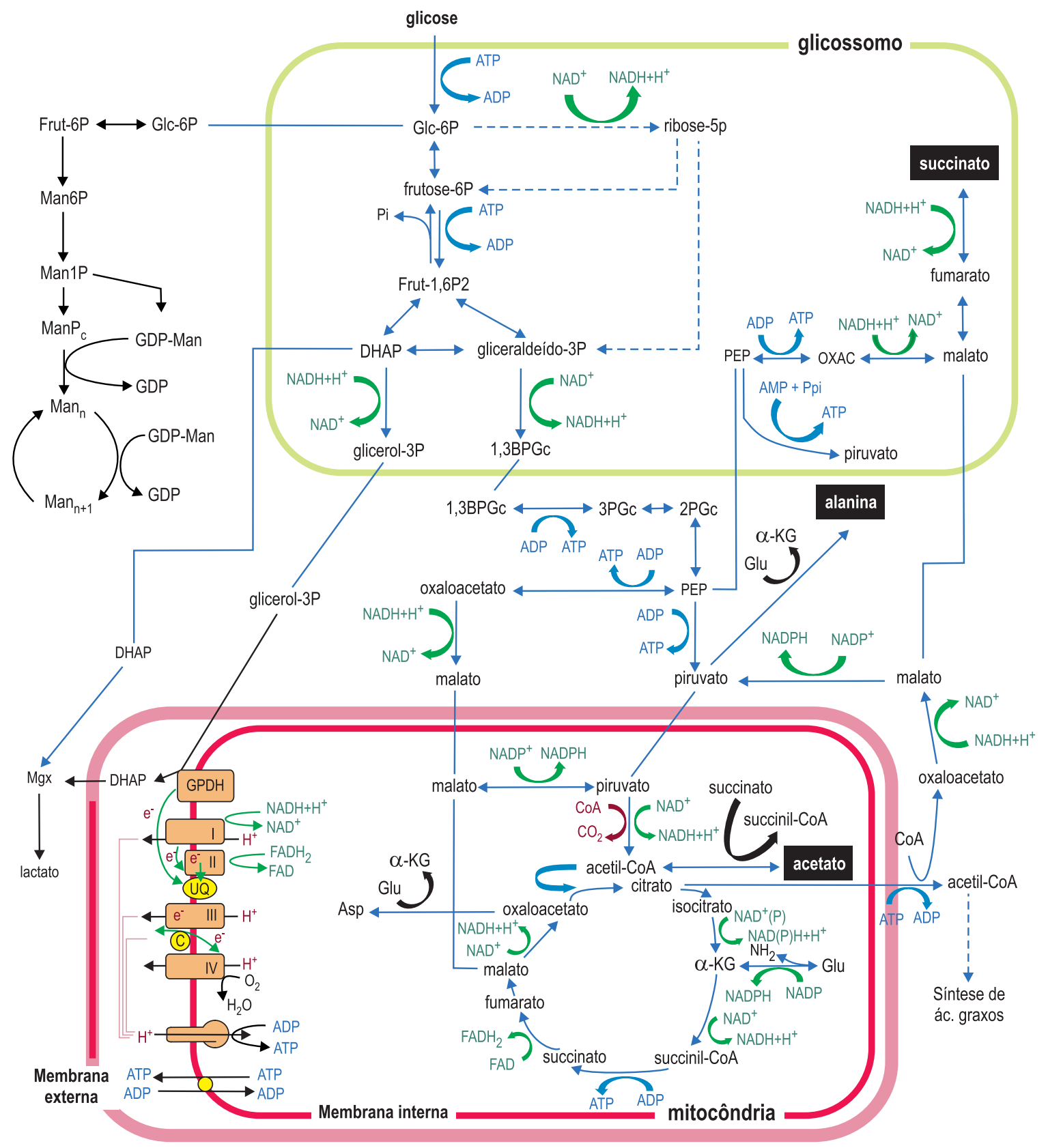

Representação esquemática do metabolismo central de carbono por promastigotas cultivados em meio rico em glicose. Os principais produtos finais (succinato, L-alanina e acetato) estão demonstrados em caixas com o fundo preto. Algumas enzimas envolvidas na via glicolítica, na via das pentoses-fosfato e da fermentação do succinato podem ser parcialmente presentes no citoplasma ou exclusivamente localizadas nos glicossomos. As flechas pontilhadas referem-se a paços multienzimáticos, os quais não estão demonstrados.

Abreviações: I-IV, complexos da cadeia respiratória; $\alpha$ KG, $\alpha$-cetoglutarato; 1,3BPGP, 1,3-bifosfoglicerato; DHAP, dihidroxicetona fosfato; Fru1,6P2, frutose-1,6-bifosfato; Glu, glutamato; GPDH, glicerol-3-fosfato desidrogenase FAD-dependente; Glc6P, glicose-6-fosfato; Man6P, manose-6-fosfato; ManPc, Man 1,4-fosfato cíclico; Man , manogênios oligoméricos (Manß1,2Man) ${ }_{n}$; PEP, fosfoenolpiruvato; 2PGc, 2-fosfoglicerato; 3PGc, 3-fosfoglicerato; ADP, adenosina-difosfato; ATP, adenosina-trifosfato; NADH, nicotinamidaadenina-dinucleotídeo (forma reduzida); $\mathrm{NAD}^{+}$, nicotinamida-adenina-dinucleotídeo (forma oxidada); $\mathrm{FADH}_{2}$, flavina-adenina-dinucleotídeo (forma reduzida); FAD, flavinaadenina-dinucleotídeo (forma oxidada); Mgx, metilglioxal; Asp, aspartato; OXA, oxalato; $\mathrm{CoA}$, coenzima A; $\mathrm{H}^{+}$, ín hidreto; e- elétrons transportados por reações de oxidorredução; C, citocromo C; UQ, ubiquinona; NADPH, NADH fosforilado.

Fonte: adaptado de Saunders et al., 2010. 
O catabolismo de glicose em Leishmania spp. gera como produtos finais principalmente succinato, alanina, acetato, $\mathrm{CO}_{2}$ e, em determinadas condições, lactato (Figura 1) (Saunders et al., 2010; Bringaud, Rivière \& Coustou, 2006; Opperdoes \& Coombs, 2007). No entanto, o metabolismo energético sofre alterações de acordo com a forma evolutiva em questão, que por sua vez encontra-se em diferentes ambientes nutricionais e, consequentemente, necessita adaptar-se a essas condições. Nesse contexto, as leishmânias apresentam a maquinaria enzimática capaz de realizar a gliconeogênese, utilizando como fonte de carbono sobretudo aminoácidos (Ivens et al., 2005; Peacock et al., 2007; Naderer et al., 2006). Intermediários do ciclo de Krebs podem ser utilizados nessa via, por intermédio da ação da fosfoenolpiruvato carboxicinase. Posteriormente, a reação irreversível catalisada pela PFK1 é ultrapassada pela ação da enzima frutose-1,6-bifosfatase (FBP). Essas duas enzimas gliconeogênicas são constitutivamente expressas e ativas em Leishmania spp. (Naderer et al., 2006).

\section{CICLO DE KREBS E FOSFORILAÇÃO OXIDATIVA}

O funcionamento do ciclo de Krebs ainda não foi efetivamente descrito em Leishmania spp., pois apesar de Hart e Coombs (1982) terem demonstrado a expressão de todas as enzimas desse ciclo, as respectivas atividades ainda não foram estudadas como um todo. Mais recentemente, análises proteômicas em $L$. donovani, por cromatografia multidimensional acoplada a espectrometria de massas, demonstraram que durante a diferenciação de promastigota para amastigota ocorre um aumento na maioria das enzimas do ciclo de Krebs (Rosenzweig et al., 2008). Tais dados provavelmente relacionam-se às mudanças no metabolismo energético, as quais ocorrem em razão dos diferentes ambientes e, portanto, de diferentes nutrientes, permitindo que essas formas evolutivas de Leishmania spp. sobrevivam. Foi descrito que nas formas procíclicas de T. brucei as enzimas do ciclo de Krebs não funcionam como um ciclo, proporcionando a continuidade do metabolismo de carboidratos e de outros compostos, tais como de aminoácidos (Van Weelden et al., 2005) (Quadro 1). Nesse contexto, como as Leishmania spp. expressam duas isoformas de fosfoenolpiruvato carboxicinase que podem contribuir para a formação de malato, associado à ação da enzima málica que também produz malato a partir de piruvato, consequentemente a produção do malato poderia contribuir na viabilidade do ciclo de Krebs em razão de tais reações serem anapleróticas, também denominadas reações de preenchimento (Saunders et al., 2010).

As Leishmania spp. apresentam uma cadeia transportadora de elétrons convencional contendo os complexos I, II, III e IV, este último dependente de citocromo C, contudo, não apresentando a oxidase alternativa descrita em T. brucei (Bringaud, Rivière \& Coustou, 2006; Tielens \& Van Hellemond, 1998). O complexo IV é o aceptor final de elétrons que possibilita a reoxidação do NADH e do succinato pela cadeia transportadora de elétrons, propiciando a formação do gradiente de $\mathrm{H}^{+}$, que é fundamental para a geração de ATP via ATP sintase. A inibição desse complexo com cianeto ou condições de crescimento em anaerobiose induz a uma rápida paralisação do metabolismo, entretanto de forma reversível (Van Hellemond \& Tielens, 1997). Essas informações sugerem uma incapacidade de manutenção do crescimento baseada na produção de energia apenas por fosforilação ao nível do substrato, ou seja, produção de ATP apenas via glicólise e na ausência de $\mathrm{O}_{2}$, mesmo em condições de crescimento com alta concentração de glicose (Van Hellemond \& Tielens, 1997). 
Quadro 1 - Produtos finais do metabolismo das fontes de carbono por tripanossomatídeos cultivados em meio rico em glicose

\begin{tabular}{|c|c|c|c|c|c|}
\hline Parasito & $\begin{array}{c}\text { Forma } \\
\text { evolutiva }\end{array}$ & Hospedeiro & $\begin{array}{l}\text { Fonte(s) de } \\
\text { carbono }^{b}\end{array}$ & $\begin{array}{l}\text { Produtos finais secretados em condições } \\
\text { ricas em glicose }\end{array}$ & Referências \\
\hline T. brucei & $B T^{d}$ & Vertebrado & Glicose & Piruvato & (Fairlamb \& Opperdoes, 1986) \\
\hline \multirow[t]{3}{*}{ T. brucei } & PT & Inseto ${ }^{e}$ & Glicose & $\mathrm{CO}_{2}$, Succinato, Acetato, L-Lactato & (Van Weelden et al., 2003; Besteiro et al., 2002) \\
\hline & & & L-Prolina ${ }^{f}$ & Acetato, Succinato, Acetato & (Van Weelden et al., 2005; Van Weelden et al., 2003) \\
\hline & & & L-Treonina & Acetato, Glicina & (Cross, Klein \& Linstead, 1975) \\
\hline T. cruzi & $\mathrm{T}$ & Vertebrado & Glicose & $\mathrm{CO}_{2}$, Succinato, Acetato & (Cannata \& Cazzulo, 1984) \\
\hline T. cruzi & A & Vertebrado & Glicose & $\mathrm{CO}_{2}$, Acetato, Glicina, Piruvato, Succinato & (Sanchez-Moreno et al., 1995) \\
\hline \multirow[t]{2}{*}{ T. cruzi } & $\mathrm{E}$ & Inseto & Glicose & $\mathrm{CO}_{2}$, Succinato, L-Alanina, Acetato & (Cannata \& Cazzulo, 1984) \\
\hline & & & Aminoácidos ${ }^{\dagger}$ & $n d^{h}$ & (Cannata \& Cazzulo, 1984; Cazzulo, 1984; Cazzulo, 1994) \\
\hline \multirow[t]{2}{*}{ Leishmania spp. } & A & Vertebrado & Ácidos graxos & $\mathrm{Nd}$ & (Hart \& Coombs, 1982; Berman et al., 1987) \\
\hline & & & Glicose & $\mathrm{CO}_{2}$, L-Alanina, Acetato, Succinato & (Rainey \& Mackenzie, 1991) \\
\hline \multirow[t]{2}{*}{ Leishmania spp. } & $P$ & Insetog & Aminoácido & $\mathrm{Nd}$ & (Marr \& Berens, 1977; Cazzulo et al., 1985) \\
\hline & & & Glicose & $\mathrm{CO}_{2}$, Succinato, L-Alanina, Acetato, D-Lactato & (Rainey \& Mackenzie,1991; Darling et al., 1987) \\
\hline \multirow[t]{2}{*}{ Crithidia spp. } & Ch & Inseto ${ }^{e}$ & Glicose & $\mathrm{CO}_{2}$, Succinato, Etanol, Acetato & (Marr \& Berens, 1977; Gilroy et al., 1988) \\
\hline & & & Aminoácidos & $\mathrm{Nd}$ & (Marr \& Berens, 1977) \\
\hline Phytomonas spp. & P & Vegetal & Glicose & $\mathrm{CO}_{2}$, Acetato, Etanol & (Chaumont et al., 1994) \\
\hline
\end{tabular}

a BT - tripomastigota sanguíneo; PT - tripomastigota procíclico; T - tripomastigota; A - amastigota; E - epimastigota; P - promastigota; Ch - coanomastigota.

b Preferências de fonte de carbono em meio rico em glicose.

' Somente são mencionados os produtos finais principais, de acordo com as respectivas referências.

${ }^{d}$ As formas tripomastigota sanguíneo são cultivadas em aerobiose.

e Somente insetos hematófagos.

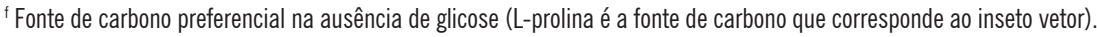

${ }^{\mathrm{g}}$ Insetos hematófagos e sugadores de plantas.

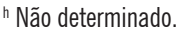

Fonte: adaptada de Bringaud, Rivière \& Coustou, 2006.

\section{VIA DAS PENTOSES-FOSFATO}

Esta via metabólica apresenta uma distribuição na maioria dos reinos e pode ser dividida entre o ramo oxidativo, cujas principais funções são a produção de NADPH e de ribose-5-fosfato, e o ramo não oxidativo, que possibilita a recuperação de alguns produtos finais do ramo oxidativo (gliceraldeído-3-fosfato e frutose-6-fosfato) por intermédio da glicólise, visando à produção de ATP. Pode funcionar também de forma invertida para gerar ribose-5-fosfato, fundamental na síntese de nucleotídeos.

Já está bem estabelecida a existência da via das pentoses-fosfato em Leishmania spp., tanto o ramo oxidativo quanto o não oxidativo, pois esta via já vem sendo estudada nesses protozoários desde a década de 1970 (Barrett, 1997). Foi demonstrada em $L$. donovani a utilização de ribose como substrato energético, assim como foram identificadas as enzimas ribose-fosfato isomerase, transcetolase e transaldolase, e, provavelmente, a glicose-6-fosfato desidrogenase (6PGDH) (Ghosh \& Datta, 1971). Posteriormente, foi demonstrada a presença da 6PGDH em L. donovani e em L. tarentolae (Ghosh \& Honigberg, 1976; Janovy, 1972). 
O ramo oxidativo dessa via metabólica é o principal produtor de NADPH. Esta molécula apresenta uma função de fundamental importância na redução da proteína tripanotiona, que tem atuação como antioxidante nesses organismos. A tripanotiona é mantida no estado reduzido pela tripanotiona redutase, a qual utiliza NADPH como cofator (Doyle et al., 2009). Esses dados, assim como a produção de ribose-5-fosfato, conforme descrito anteriormente, explicam o grande fluxo de glicose através da via das pentoses nas formas promastigotas nesses microrganismos.

Nosso grupo vem estudando a enzima ribose-5-fosfato isomerase de L. major e de T. brucei, fundamental para a produção desse açúcar precursor de nucleotídeos, a qual apresenta uma característica importante: a enzima do protozoário é análoga à enzima humana (Schwarz, 2010). Isso significa dizer que, apesar de catalisarem a mesma reação, apresentam estruturas diferentes, como observado, em razão das suas origens evolutivas distintas (dados não publicados). A compreensão das nuances estruturais e bioquímicas dessas enzimas estão sendo estudadas, utilizando-se técnicas de dinâmica molecular e docking, visando à caracterização de mais um possível alvo para o desenvolvimento de novos fármacos.

A via das pentoses-fosfato já foi bem descrita em L. donovani (Ghosh \& Datta, 1971) e em L. mexicana (Figura 2) (Fairlamb \& Cerami, 1992). Todavia, ainda perduram algumas questões relativas ao compartimento celular no qual ocorre essa via. Apesar de a maioria das enzimas apresentarem o peptídeo sinal que direciona essas proteínas para o glicossomo, já foi descrito que boa parte dessas enzimas se encontra no citoplasma (Barrett, 1997; Maugeri et al., 2003). A presença dessa via no citoplasma justifica-se em virtude do metabolismo da tripanotiona via NADPH.

Figura 2 - Via das pentoses-fosfato alternativa em promastigotas de L. mexicana. Esta via converge para a síntese de ribose-5-fosfato tendo como objetivo a síntese de nucleotídeos

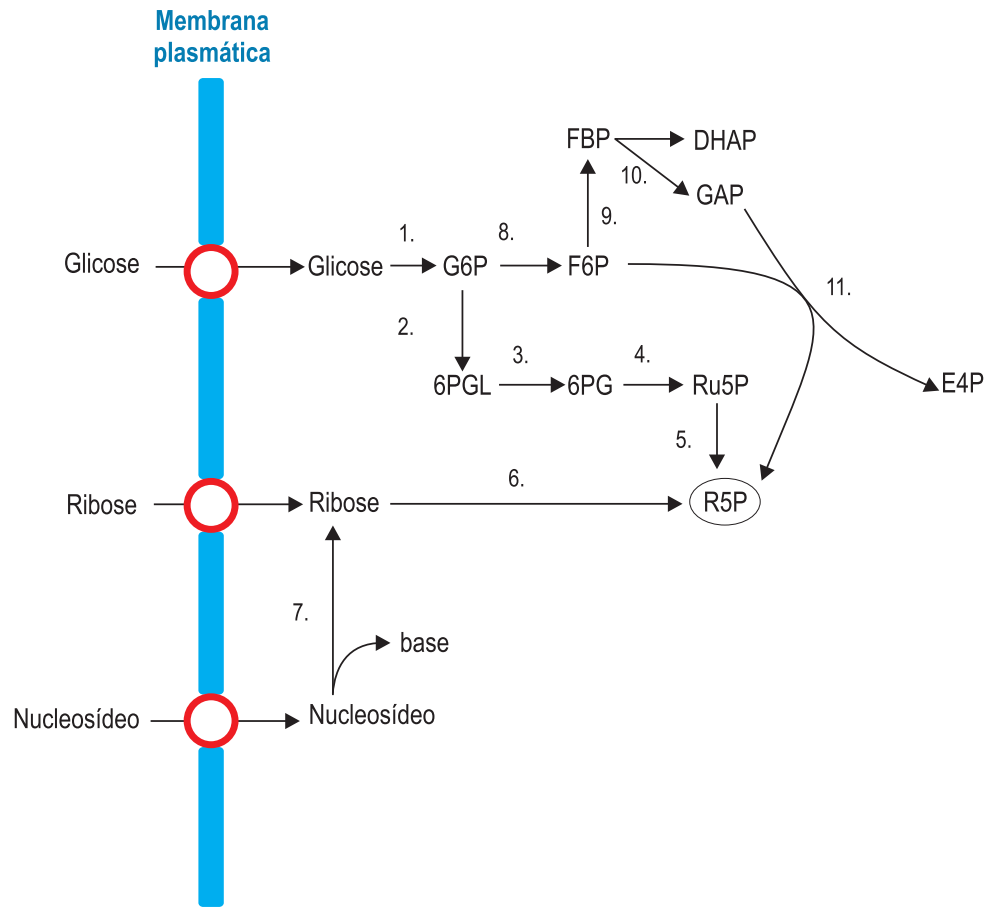

Abreviações: G6P, glicose-6-fosfato; F6P, frutose-6-fosfato; FBP, frutose-1,6-bofosfato; DHAP, dihidroxicetona fosfato; GAP, gliceraldeído-3-fosfato; E4P, eritrose-4-fosfato; 6PGL, 6-fosfogliconolactona; 6PG, 6-fosfogliconato; Ru5P, ribulose-5-fosfato; R5P, ribose-5-fosfato. Enzimas: (1) hexocinase; (2) glicose-6-fosfato desidrogenase; (3) 6-fofogliconolactonase; (4) 6-fosfogliconato desidrogenase; (5) ribose-5-fosfato isomerase; (6) ribocinase; (7) nucleosídeo hidrolase; (8) fosfoglicose isomerase; (9) fosfofrutocinase; (10) aldolase; (11) transcetolase. São demonstrados também os transportadores de glicose, ribose e nucleosídeos. 


\section{CONCLUSÕES}

O metabolismo de carboidratos em Leishmania spp. tem sido muito estudado nas últimas décadas, tanto com o objetivo de se obter conhecimento básico sobre como funciona a produção de energia nesses protozoários, como visando a identificar e caracterizar novos alvos terapêuticos em potencial. Nesse contexto, foram mencionadas ao longo deste capítulo diversas enzimas que apresentam tal potencial. Contudo, ainda existe a necessidade de se permanecer estudando essas vias/enzimas até se obter uma evolução para a terapêutica das leishmanioses.

Assim, têm sido realizados novos estudos utilizando-se diferentes técnicas dotadas de maior poder de análise em larga escala. Uma delas é a cromatografia gasosa e líquida, que, acoplada à espectrometria de massas e associada ao desenvolvimento de novos bancos de dados e novos algoritmos de análise, têm por fim a modelagem metabólica via biologia de sistemas, por exemplo. Esses novos estudos envolvem áreas como a metabolômica (Maugeri et al., 2003), a transcriptômica e a proteômica (Bringaud, Rivière \& Coustou, 2006), bem como a bioinformática (Doyle et al., 2009). Nesta última área, desenvolveu-se um aplicativo que possibilita a identificação de enzimas análogas (Otto et al., 2008) constituídas de proteínas que apresentam a mesma função enzimática, porém com estruturas distintas, as quais podem futuramente ser utilizadas em novos alvos terapêuticos. Outra abordagem nessa mesma área foi o desenvolvimento do banco de dados curado, denominado Leishcyc (Creek et al., 2012), que consiste em um banco de dados de vias bioquímicas em L. major. Ambos os sistemas de informações descritos apresentam uma série de aplicativos e estão livremente disponíveis no ambiente web, para que possam ser utilizados por qualquer pesquisador ou interessado.

\section{REFERÊNCIAS}

ADJÉ, C. A.; OPPERDOES, F. R. \& MICHELS, P. A. Organization, sequence and stage-specific expression of the phosphoglycerate kinase genes of Leishmania mexicana mexicana. Molecular and Biochemical Parasitology, 90(1): 155-168, 1997.

BARRETT, M. P. The pentose phosphate pathway and parasitic protozoa. Parasitology Today, 13(1): 11-16, 1997.

BERENS, R. L. \& MARR, J. J. Leishmania donovani and L. braziliensis: function of pyruvate kinase. Experimental Parasitology, 43(2): 407-413, 1977 a.

BERENS, R. L. \& MARR, J. J. Phosphofructokinase of Leishmania donovani and Leishmania braziliensis and its role in glycolysis. The Journal of Protozoology, 24(2): 340-344, $1977 \mathrm{~b}$.

BERMAN, J. D. et al. Uptake, distribution, and oxidation of fatty acids by Leishmania mexicana amastigotes. The Journal of Parasitology, 73: 555-560, 1987.

BESTEIRO, S. et al. Succinate secreted by Trypanosoma brucei is produced by a novel and unique glycosomal enzyme. NADHdependent fumarate reductase. Journal of Chemical Biology, 277: 38.001-38.012, 2002.

BRINGAUD, F.; RIVIÈRE, L. \& COUSTOU, V. Energy metabolism of trypanosomatids: adaptation to available carbon sources. Molecular and Biochemical Parasitology, 149(1): 1-9, 2006.

BURCHMORE, R. J. et al. Genetic characterization of glucose transporter function in Leishmania mexicana. Proceedings of the National Academy of Sciences of the USA, 100(7): 3.901-3.906, 2003.

CÁCERES, A. J. et al. Molecular and biochemical characterization of novel glucokinases from Trypanosoma cruzi and Leishmania spp. Molecular and Biochemical Parasitology, 156(2): 235-245, 2007.

CANNATA, J. J. \& CAZZULO, J. J. The aerobic fermentation of glucose by Trypanosoma cruzi. Comparative Biochemistry and Physiology B, 79: 297-308, 1984.

CAZZULO, J. J. Protein and amino acid catabolism in Trypanosoma cruzi. Comparative Biochemistry and Physiology B, 79: 309-320, 1984. 
CAZZULO, J. J. Intermediate metabolism in Trypanosoma cruzi. Journal of Bioenergetics and Biomembranes, 26: 157 165,1994

CAZZULO, J. J. et al. End products and enzyme levels of aerobic glucose fermentation in trypanosomatids. Molecular and Biochemical Parasitology, 16: 329-343, 1985.

CHAUMONT, F. et al. Aerobic and anaerobic glucose metabolism of Phytomonas sp. isolated from Euphorbia characias. Molecular and Biochemical Parasitology, 67: 321-331, 1994.

CREEK, D. J. et al. Metabolomic analysis of trypanosomatid protozoa. Molecular and Biochemical Parasitology, 181(2): 73-84, 2012.

CROSS, G. A.; KLEIN, R. A. \& LINSTEAD, D. J. Utilization of amino acids by Trypanosoma brucei in culture: 1-threonine as a precursor for acetate. Parasitology, 71: 311-326, 1975.

DARLING, T. N. et al. Products of Leishmania braziliensis glucose catabolism: release of d-lactate and, under anaerobic conditions, glycerol. Proceedings of the National Academy of Sciences of the USA, 84: 7.129-7.133, 1987.

DE WALQUE, S.; OPPERDOES, F. R. \& MICHELS, P. A. Cloning and characterization of Leishmania mexicana fructose-1,6bisphosphate aldolase. Molecular and Biochemical Parasitology, 103(2): 279-283, 1999.

DOYLE, M. A. et al. LeishCyc: a biochemical pathways database for Leishmania major. BMC Systems Biology, 3: 57, 2009.

ERNEST, I. et al. Pyruvate kinase of Leishmania mexicana mexicana. Cloning and analysis of the gene, overexpression in Escherichia coli and characterization of the enzyme. Molecular and Biochemical Parasitology, 64(1): 43-54, 1994.

FAIRLAmB, A. H. \& CERAMI, A. Metabolism and functions of trypanothione in the Kinetoplastida. Annual Review of Microbiology, 46: 695-729, 1992.

FAIRLAmB, A. H. \& OPPERDoes, F. R. Carbohydrate metabolism in African trypanosomes, with special reference to the glycosome. In: MORGAN, M. J. (Ed.). Carbohydrate Metabolism in Cultured Cells. New York: Plenum Publishing Corporation, 1986.

FOTHERGILL-GILLMORE, L. A. et al. Leishmania pyruvate kinase: the crystal structure reveals the structural basis of its unique regulatory properties. Biochemical Society Transactions, 28(2): 186-190, 2000.

GHOSH, D. K. \& DATTA, A. G. Aldolase activity in the cell-free extract of the protozoan Leishmania donovani. Canadian Journal of Biochemistry, 48(1): 151-153, 1970.

GHOSH, D. K. \& DATTA, A. G. Leishmania donovani: assay for a functional pentose phosphate pathway. Experimental Parasitology, 29(1): 103-109, 1971.

GHOSH, D. K. \& HONIGBERG, B. M. Activities of glucose-6-phosphate, 6-phosphogluconate, and isocitrate dehydrogenases from Leishmania donovani cultivated at 25 and 37 C. The Journal of Protozoology, 23(3): 450-455, 1976.

GILROY, F. V. et al. Metabolic studies of the protozoan parasite, Crithidia luciliae, using proton nuclear magnetic resonance spectroscopy. Molecular and Biochemical Parasitology, 31: 107-115, 1988.

GUERRA, D. G. et al. The mitochondrial FAD-dependent glycerol-3-phosphate dehydrogenase of Trypanosomatidae and the glycosomal redox balance of insect stages of Trypanosoma brucei and Leishmania spp. Molecular and Biochemical Parasitology, 149(2): 155-169, 2006.

HANNAERT, V. et al. The putative effector-binding site of Leishmania mexicana pyruvate kinase studied by site-directed mutagenesis. FEBS Letters, 514(2-3): 255-259, 2002.

HANNAERT, V. et al. Evolution of energy metabolism and its compartimentation in Kinetoplastida. Kinetoplastid Biology and Disease, 2: 11, 2006. Disponível em: <www.kinetoplastids.com/content/2/1/11>. Acesso em: 17 mar. 2012.

HART, D. T. \& COOMBS, G. H. Leishmania mexicana: energy metabolism of amastigotes and promastigotes. Experimental Parasitology, 54(3): 397-409, 1982.

IVENS, A. C. et al. The genome of the kinetoplastid parasite, Leishmania major. Science, 309(5.733): 436-442, 2005. 
JANOVY JR., J. Temperature and metabolism in Leishmania. 3. Some dehydrogenases of L. donovani, L. mexicana, and L. tarentolae. Experimental Parasitology, 32(2): 196-205, 1972.

KIM, H. \& HOL, W. G. Crystal structure of Leishmania mexicana glycosomal glyceraldehyde-3-phosphate dehydrogenase in a new crystal form confirms the putative physiological active site structure. Journal of Molecular Biology, 278(1): 5-11, 1998.

KIM, H. et al. Crystal structure of glycosomal glyceraldehyde-3-phosphate dehydrogenase from Leishmania mexicana: implications for structure-based drug design and a new position for the inorganic phosphate binding site. Biochemistry, 34(46): 14.975-14.986, 1995.

LANDFEAR, S. M. Drugs and transporters in kinetoplastid protozoa. Advances in Experimental Medicine and Biology, 625: 22-32, 2008.

LÓPEZ, C. et al. Leishmania donovani phosphofructokinase. Gene characterization, biochemical properties and structuremodeling studies. European Journal of Biochemistry, 269(16): 3.978-3.989, 2002.

MANCILLA, R.; NAQUIRA, C. \& LANAS, C. Metabolism of glucose qlabeled with carbon-14 in Leishmania enriettii. Nature, 206: 27-28, 1965.

MANCILLA, R.; NAQUIRA, C. \& LANAS, C. Metabolism of glucose-C14 in Leishmania brasiliensis. Comparative Biochemistry and Physiology, 28(1): 227-232, 1969.

MARR, J. J. \& BERENS, R. L. Regulation of aerobic fermentation in protozoans. VI. Comparative biochemistry of pathogenic and nonpathogenic protozoans. Acta Tropica, 34: 143-155, 1977.

MAUGERI, D. A. et al. Pentose phosphate metabolism in Leishmania mexicana. Molecular and Biochemical Parasitology, $130(2): 117-125,2003$

MCKOY, G. et al. Characterisation of phosphoglycerate kinase genes in Leishmania major and evidence for the absence of a third closely related gene or isoenzyme. Molecular and Biochemical Parasitology, 90(1):169-181,1997. Erratum em: *Molecular and Biochemical Parasitology 93(1):161, 1998.

MICHELS, P. A. et al. Metabolic functions of glycosomes in trypanosomatids. Biochimica et Biophysica Acta, 1.763(12): 1.463-1.477, 2006.

MORGAN, H. P. et al. An improved strategy for the crystallization of Leishmania mexicana pyruvate kinase. Acta Crystallographica. Section F, Structural Biology and Crystallization Communications, 66(3): 215-218, 2010 a.

MORGAN, H. P. et al. Allosteric mechanism of pyruvate kinase from Leishmania mexicana uses a rock and lock model. Journal of Chemical Biology, 285(17): 12.892-12.898, 2010b.

MOTTRAM, J. C. \& COOMBS, G. H. Leishmania mexicana: subcellular distribution of enzymes in amastigotes and promastigotes. Experimental Parasitology, 59(3): 265-274, 1985.

NADERER, T. et al. Virulence of $L$. major in macrophages and mice requires the gluconeogenesis enzyme frutose-1,6bisphosphatase. Proceedings of the National Academy of Sciences of the USA, 103: 5.502-5.507, 2006.

NOWICKI, M. W. et al. Design, synthesis and trypanocidal activity of lead compounds based on inhibitors of parasite glycolysis. Bioorganic \& Medicinal Chemistry, 16(9): 5.050-5.061, 2008.

OLIVARES-ILLANA, V. et al. Structural differences in triosephosphate isomerase from different species and discovery of a multitrypanosomatid inhibitor. Biochemistry, 45(8): 2.556-2.560, 2006.

OPPERDOES, F. R. \& BORST, P. Localization of nine glycolytic enzymes in a microbody-like organelle in Trypanosoma brucei: the glycosome. FEBS Letters, 80: 360-364, 1977.

opperdoes, F. R. \& CoOMBS, G. H. Proven and predicted metabolism in Leishmania. Trends in Parasitology, 23: 149158, 2007.

OTTO, T. D. et al. AnEnPi: identification and annotation of analogous enzymes. BMC Bioinformatics, 9: 544, 2008. 
PABÓN, M. A. et al. Purification and characterization of hexokinase from Leishmania mexicana. Parasitology Research, 100(4): 803-810, 2007.

PEACOCK, C. S. et al. Comparative genomic analysis of three Leishmania species that cause diverse human disease. Nature Genetics, 39(7): 839-847, 2007.

PONTE-SUCRE, A. \& RAMIREZ, J. L. Fructose 2,6 bisphosphate promotes the monomer-tetramer conservation of Leishmania mexicana amazonensis pyruvate kinase type two. Biological Research, 26(1-2): 131-134, 1993.

PONTE-SUCRE, A. et al. Isolation of two pyruvate kinase activities in the parasitic protozoan Leishmania mexicana amazonensis. Archives of Biochemistry and Biophysics, 300(1): 466-471, 1993.

POoRMAN, A. E. \& JANOVY JR., J. Temperature and metabolism in Leishmania. II. Aldolase in L. adleri, L. donovani, L. mexicana, and L. tarentolae. Experimental Parasitology, 26(3): 329-335, 1969.

QUIÑONES, W. et al. Leishmania mexicana: molecular cloning and characterization of enolase. Experimental Parasitology, 116(3): 241-251, 2007.

RAINEY, P. M. \& MACKENZIE, N. E. A carbon-13 nuclear magnetic resonance analysis of the products of glucose metabolism in Leishmania pifanoi amastigotes and promastigotes. Molecular and Biochemical Parasitology, 45: 307-315, 1991.

RIGDEN, D. J. et al. The structure of pyruvate kinase from Leishmania mexicana reveals details of the allosteric transition and unusual effector specificity. Journal of Molecular Biology, 293(3): 745-749, 1999.

RODRÍGUEZ-CONTRERAS, D. \& LANDFEAR, S. M. Metabolic changes in glucose transporter-deficient Leishmania mexicana and parasite virulence. Journal of Chemical Biology, 281(29): 20.068-20.076, 2006.

RODRIGUEZ-CONTRERAS, D. et al. Phenotypic characterization of a glucose transporter null mutant in Leishmania mexicana. Molecular and Biochemical Parasitology, 153(1): 9-18, 2007.

ROSENZWEIG, D. et al. Retooling Leishmania metabolism: from sand fly gut to human macrophage. Faseb Journal, 22(2): 590-602, 2008.

SANCHEZ-MORENO, M. et al. Metabolic studies by 1H NMR of different forms of Trypanosoma cruzi as obtained by 'in vitro' culture. FEMS Microbiology Letters, 133: 119-125, 1995.

SANDOVAL, W. et al. A biochemical and genetic study of Leishmania donovani pyruvate kinase. Gene, 424(1-2): 25-32, 2008.

SAUNDERS, E. C. et al. Central carbon metabolism of Leishmania parasites. Parasitology, 137(9): 1.303-1.313, 2010.

SCHWARZ, M. G. A. Identificação, Clonagem, Expressão Heteróloga e Localização da Ribose-5-Fosfato Isomerase de Leishmania major, 2010. Monografia em Ciências Biológicas, Rio de Janeiro: Instituto de Biologia, Universidade Federal Rio de Janeiro.

SURESH, S. et al. Conformational changes in Leishmania mexicana glyceraldehyde-3-phosphate dehydrogenase induced by designed inhibitors. Journal of Molecular Biology, 309(2): 423-435, 2001.

TETAUD, E. et al. Kinetoplastid glucose transporters. The Biochemical Journal, 325(3): 569-580, 1997.

TIELENS, A. G. \& HELLEMOND, J. J. Differences in energy metabolism between trypanosomatidae. Parasitology Today, 14(7): 265-272, 1998.

VANEGAS, G. et al. Enolase as a plasminogen binding protein in Leishmania mexicana. Parasitology Research, 101(6): 1.511-1.516, 2007.

VAN HELLEMOND, J. J. \& TIELENS, A. G. Inhibition of the respiratory chain results in a reversible metabolic arrest in Leishmania promastigotes. Molecular and Biochemical Parasitology, 85(1): 135-138, 1997.

VAN WEELDEN, S. W. et al. Procyclic Trypanosoma brucei do not use Krebs cycle activity for energy generation. Journal of Chemical Biology, 278: 12.854-12.863, 2003.

VAN WEELDEN, S. W. et al. New functions for parts of the Krebs cycle in procyclic Trypanosoma brucei, a cycle not operating as a cycle. Journal of Chemical Biology, 280(13): 12.451-12.460, 2005. 
VOLLER, A.; SHAW, J. J. \& BRYANT, C. The effect of two antimony drugs on the in vitro metabolism of radioactive glucose by culture forms of Leishmania tropica (Wright, 1903). Annals of Tropical Medicine and Parasitology, 57: 404-408, 1963.

WILLIAMS, J. C. et al. Structural and mutagenesis studies of leishmania triosephosphate isomerase: a point mutation can convert a mesophilic enzyme into a superstable enzyme without losing catalytic power. Protein Engineering, 12 (3): 243-250, 1999. 


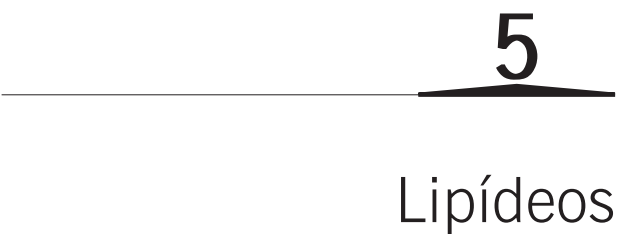

Elmo Eduardo de Almeida-Amaral I Valter Viana de Andrade-Neto

Marilene Marcuzzo do Canto-Cavalheiro I Eduardo Caio Torres-Santos

$P_{c}^{o}$ or definição, lipídeos são biomoléculas insolúveis em água e solúveis em solventes orgânicos. Dessa forma, constituem um grupo de substâncias estruturalmente bastante diversificadas, que se originam por meio de rotas metabólicas distintas. Apresentam várias funções biológicas: servem como armazenamento de energia, moléculas sinalizadoras e mensageiras em vias de transmissão de sinais e, ainda, como componentes de membranas (Berg, Tymoczko \& Stryer, 2008). São os principais constituintes das membranas celulares na maioria dos organismos, incluindo os tripanossomatídeos.

Os fosfolipídeos são elementos estruturais de grande importância, sendo considerados os principais componentes das membranas biológicas de Leishmania. Como exemplo da importância dos fosfolipídeos, podemos citar a degradação de glicerofosfolípideos gerando uma infinidade de moléculas sinalizadoras, incluindo inositol 1,4,5-trifosfato e 1,2-diacilglicerol. Além disso, os fosfolipídeos como fosfatidilinositol (PI) podem ser modificados por um grupo de cinases (PI3K, PI4K e PIPKs) em fosfoinosídeos bioativos (PIP, PIP2 e PIP3) (Zhang \& Beverley, 2010).

Outros importantes lipídeos presentes em Leishmania são os ácidos graxos. São ácidos carboxílicos com cadeias de hidrocarboneto variando de 4 a 36 átomos de carbono. Quase todos os ácidos graxos apresentam número par de átomos de carbono, podendo ser saturados ou insaturados, com ligação dupla quase sempre na configuração cis (Nelson \& Cox, 2006). Em Leishmania, encontramos tanto ácidos graxos saturados (como, por exemplo, o ácido esteárico, com 18 átomos de carbono) como os ácidos graxos insaturados, como o ácido araquidônico, com vinte átomos de carbono com quatro ligações duplas cis (Lee, Stephens \& Englund, 2007; Livore, Tripodi \& Uttaro, 2007; Tripodi et al., 2006).

Ainda dentro da classificação de lipídeos, encontram-se os esteróis, que desempenham importante papel na regulação da fluidez das membranas biológicas e outras funções metabólicas menos estudadas, como controle do ciclo celular e estabilização de receptores. Os esteróis têm muito destaque nos tripanossomatídeos porque a via biossintética desses parasitos divergiu durante a evolução da via dos mamíferos, fazendo com que determinadas etapas sejam consideradas bons alvos para o desenvolvimento de novos fármacos.

Neste capítulo, em razão da grande diversidade química e biológica dos lipídeos, centraremos nossa atenção nas principais vias metabólicas envolvendo ácidos graxos e esteróis, realçando as similaridades e diferenças entre os mamíferos e Leishmania spp., à luz do conhecimento atual. 


\section{ÁCIDOS GRAXOS}

O sistema enzimático que catalisa a síntese de ácidos graxos é denominado ácido graxo sintase (AGS) e, apesar de ser similar em diversos organismos, apresenta algumas diferenças estruturais significativas. Pode, assim, ser classificado em ácido graxo sintase do tipo I (AGS1) e ácido graxo sintase do tipo II (AGS2) (Smith, 1994; Witkowski et al., 2004).

As enzimas que compõem a AGS1 estão localizadas no citoplasma das células de mamíferos e de fungos, organizadas em múltiplos sítios catalíticos, unidas em uma grande cadeia polipeptídica, formando um dímero com subunidades idênticas de $272 \mathrm{kd}$. Cada cadeia envolve-se em três domínios unidos por regiões flexíveis, que permitem movimento aos domínios que são necessários para a cooperação entre os centros ativos da enzima (Smith, 1994; Witkowski et al., 2004). No entanto, a AGS2, encontrada em bactérias e plantas, apresenta cada enzima em polipeptídios individuais, mas unidos formando um complexo, que se dissociam em enzimas individuais quando a célula é rompida (Rock \& Jackowski, 2002).

As reações bioquímicas fundamentais na síntese de ácidos graxos são muito semelhantes em ambos os complexos. Os intermediários na síntese de ácidos graxos são ligados a uma proteína carreadora de acilas (ACP - Acyl Carrier Domain Protein). Ao final de cada ciclo de síntese, temos como resultado o aumento do ácido graxo em unidade de dois carbonos, estes que são doados por meio do grupamento malonil, que é transferido do malonil-CoA para o acetilCoA que está ligado ao ACP. Para a adição de dois carbonos no ácido graxo que está sendo formado são necessárias quatro reações: condensação, redução do grupo carbonila, desidratação e redução da ligação dupla, catalisadas pelas enzimas: acetil-CoA-ACP transacetilase, malonil-CoA-ACP transacetilase, $\beta$-cetoacil-ACP sintase, $\beta$-cetoacil-ACP redutase, $\beta$-hidroxiacil-ACP desidrogenase e enoil-ACP redutase, respectivamente. Nas etapas de redução utiliza-se o NADPH como redutor (Berg \& Stryer, 2008; Nelson, 2006; Smith, 1994; Witkowski et al., 2004).

A síntese dos ácidos graxos nos tripanossomatídeos é essencial para a sua sobrevivência. Promastigotas de Leishmania spp. podem crescer em meio quimicamente definido que carece de lipídeos (Steiger \& Steiger, 1977). Portanto, esses organismos têm a capacidade de sintetizar ácidos graxos de novo. Estudando o genoma de Leishmania encontraram-se enzimas que caracterizam a presença da AGS2 como, por exemplo, $\beta$-cetoacil-ACP redutase, $\beta$-cetoacilACP sintase e enoil-ACP redutase, estando essas enzimas presentes na sua mitocôndria única (Lee, Stephens $\&$ Englund, 2007; Gurvitz, 2009; Paul et al., 2001). Contudo, AGS2 contribui com apenas uma pequena fração dos ácidos graxos sintetizados pela célula, existindo outra via não convencional para a síntese da grande parte dos ácidos graxos necessários para Leishmania.

Entretanto, estudos mais recentes revelaram que os parasitos do gênero Leishmania fazem a maior parte da síntese dos ácidos graxos por um mecanismo novo e inesperado, envolvendo enzimas chamadas elongases (ELOs), presentes no retículo endoplasmático. Genes implicados no alongamento dos ácidos graxos foram descobertos em leveduras em 1996, embora a cadeia de atividade de alongamento dessa via tenha sido inicialmente documentada em 1970 (Toke \& Martin, 1996).

As ELOs utilizam reações bioquímicas semelhantes às utilizadas na AGS1 e AGS2, exceto pelo fato de que o malonil-CoA não está ligado ao ACP, sendo utilizado como inicializador da síntese o butiril-CoA, em vez do acetil-CoA. Além disso, as enzimas da via são proteínas integrais da membrana do retículo endoplasmático (Lee et al., 2006). As ELOs condensam o malonil-CoA na cadeia acila em crescimento, aumentando-o em dois átomos de carbono. O $\beta$-cetoacil-CoA formado é então reduzido ( $\beta$-cetoacil-ACP redutase), desidratado ( $\beta$-hidroxiacil-ACP desidrogenase) e reduzido novamente (trans-2-enoil-CoA redutase), produzindo um longo e saturado acil-CoA. As duas etapas de redução requerem NADPH (Lee et al., 2006).

Como produto final da reação das ELOs temos ácidos graxos contendo de oito a 18 carbonos, que serão utilizados por Leishmania para síntese de, por exemplo, glicosilfosfatidilinositol (Ferguson, 1999). 
Uma característica notável das ELOs de Leishmania é a utilização de acil-CoA de cadeia curta como inicializador da síntese. Essa característica distingue as ELOs dos tripanossomatídeos do sistema de alongamento dos ácidos graxos presente nas células de mamíferos, que utiliza o palmitoil-CoA (ácido graxo de 16 carbonos) como inicializador (Lee, Stephens \& Englund, 2007; Paul et al., 2001; Lee et al., 2006).

Em Leishmania também temos a síntese dos ácidos graxos poli-insaturados (PUFAs, do inglês Polyinsaturated Fatty-Acid). As PUFAs são sintetizadas pela ação das ELOs e das dessaturases. Em Leishmania, assim como em outros tripanossomatídeos, o ácido esteárico sintetizado pela via das elongases é dessaturado, formando ácido oleico (ácido graxo com 18 átomos de carbono e uma ligação dupla) e o ácido linoleico (ácido graxo com 18 átomos de carbono e duas ligações duplas). Contudo, Leishmania spp. podem sintetizar PUFAs ainda maiores, apresentando de vinte átomos de carbono com quatro ligações duplas, como o ácido araquidônico, até ácidos graxos com 22 átomos de carbono, com até seis ligações duplas (Livore, Tripodi \& Uttaro, 2007; Tripodi et al., 2006).

\section{Oxidação dos ácidos graxos}

A oxidação dos ácidos graxos em acetil-CoA é uma via central que libera energia em muitos organismos. Nos mamíferos, a oxidação dos ácidos graxos fornece próximo de 80\% das necessidades energéticas de órgãos como o fígado e o coração (Berg, Tymoczko \& Stryer, 2008; Nelson, 2006). Embora o papel biológico da oxidação dos ácidos graxos seja diferente de organismo para organismo, seu mecanismo é essencialmente o mesmo (Berg, Tymoczko \& Stryer, 2008). Neste tópico iremos abordar a $\beta$-oxidação (processo constituído de quatro passos reacionais), meio pelo qual os ácidos graxos são oxidados em Leishmania.

O primeiro relato da utilização dos ácidos graxos como fonte de energia em Leishmania foi feito por Hart e Coombs em 1982 (Hart \& Coombs, 1982). Nesse clássico trabalho, foi demonstrado que Leishmania mexicana, tanto na forma promastigota quanto na forma amastigota, é capaz de utilizar os ácidos graxos como fonte de energia. Uma diferença marcante entre as formas promastigota e amastigota está na velocidade de oxidação dos ácidos graxos. A forma promastigota não oxida rapidamente os ácidos graxos; na sua maior parte, eles são utilizados para a síntese de outros lipídeos como, por exemplo, fosfatidilinositol e glicosilfosfatidilinositol (Hart \& Coombs, 1982). No entanto, as formas amastigotas apresentam uma alta capacidade de utilização dos ácidos graxos como fonte de energia. Por exemplo, uma mistura equimolar de estearato, palmitato e oleato é oxidada dez vezes mais rapidamente em amastigotas quando comparado a promastigotas (Hart \& Coombs, 1982). Essa alta oxidação dos ácidos graxos observada na forma amastigota reflete uma adaptação ao substrato encontrado intracelularmente nos macrófagos (Hart \& Coombs, 1982; Glew et al., 1988). Blum (1987) comparou a oxidação de ácidos graxos entre promastigotas e amastigotas, obtidos mediante o aquecimento da cultura de promastigotas de Leishmania braziliensis de $26^{\circ} \mathrm{C}$ a $34^{\circ} \mathrm{C}$ por doze horas (Darling \& Blum, 1987). Assim como a L. mexicana, as formas promastigotas e amastigotas de L. braziliensis foram capazes de oxidar completamente os ácidos graxos a $\mathrm{CO}_{2}$. Similarmente às amastigotas de L. mexicana oriundas de macrófagos, as amastigotas de L. braziliensis oxidaram mais rapidamente ácidos graxos em comparação com a forma promastigota. Porém, a oxidação observada nas amastigotas obtidas por meio do aquecimento da cultura de promastigotas de $26^{\circ} \mathrm{C}$ a $34^{\circ} \mathrm{C}$ por doze horas foi apenas três vezes mais rápida (Glew et al., 1988; Blum, 1987).

A oxidação dos ácidos graxos em células de mamíferos ocorre na matriz mitocondrial, por meio de uma série de reações chamada de $\beta$-oxidação. A $\beta$-oxidação é uma sequência de reações catalisadas por quatro enzimas: acil-CoA desidrogenase; enoil-CoA hidratase; $\beta$-hidroxiacil-CoA desidrogenase e acil-CoA acetiltransferase (Lopaschuk et al., 2010; Eaton, Bartlett \& Pourfarzam, 1996).

A $\beta$-oxidação começa com uma desidrogenação, produzindo uma ligação dupla entre os átomos de carbono $\alpha$ e $\beta$ do ácido graxo (na forma de acil-CoA), liberando um trans- $\Delta^{2}$-enoil-CoA. Essa reação é catalisada pela acil-CoA 
desidrogenase. No segundo passo, uma molécula de água é adicionada à ligação dupla do trans- $\Delta^{2}$-enoil-CoA para formar o $\beta$-hidroxiacil-CoA pela ação da enoil-CoA hidratase. No terceiro passo, o $\beta$-hidroxiacil-CoA é desidrogenado para formar o $\beta$-cetoacil-CoA, sob a ação catalítica da $\beta$-hidroxiacil-CoA desidrogenase. $O$ quarto e último passo da $\beta$-oxidação é catalisado pela acil-CoA acetiltransferase, que promove a reação do $\beta$-cetoacil-CoA com uma molécula de coenzima A livre ( $\mathrm{COA}$ ) para romper o fragmento carboxila terminal de dois átomos de carbono do ácido graxo original na forma de acetil-CoA. O outro produto é um tioéster de coenzima A com o ácido graxo original, diminuído em dois átomos de carbono. Por analogia com as reações de hidrólise, tal reação também é chamada de tiólise e a acil-CoA acetiltransferase, de tiolase (Berg, Tymoczko \& Stryer, 2008; Nelson, 2006; Lopaschuk et al., 2010; Eaton, Bartlett \& Pourfarzam, 1996).

Em várias espécies de Leishmania foram encontradas enzimas que realizam $\beta$-oxidação, como a acil-CoA desidrogenase, uma proteína bifuncional enoil-CoA hidratase/ $\beta$-hidroxiacil-CoA desidrogenase, e a acil-CoA acetiltransferase (Hart \& Coombs, 1982; Berman et al., 1987; Coombs, Craft \& Hart, 1982; Opperdoes \& Szikora, 2006; Hart \& Opperdoes, 1984). Como acontece nas células de mamíferos, a $\beta$-oxidação em Leishmania ocorre pelos mesmos quatro passos reacionais descritos anteriormente, culminando com a diminuição do ácido graxo original em dois átomos de carbono, gerando acetil-CoA e $\mathrm{FADH}_{2}$ (Michels et al., 2006).

Nas células de mamíferos, as enzimas da oxidação dos ácidos graxos estão localizadas na matriz mitocondrial. Ácidos graxos de 12 carbonos ou menores podem adentrar a mitocôndria sem o auxílio de transportadores de membrana. Aqueles que dispõem de uma cadeia carbônica maior, os quais constituem a maioria dos ácidos graxos livres, são transportados para o interior da mitocôndria por meio do transportador acil-carnitina translocase (Lopaschuk et al., 2010).

Em Leishmania, o local onde ocorre a $\beta$-oxidação é bastante controverso. Na década de 1980, mediante estudos utilizando fracionamento subcelular, acreditou-se que a $\beta$-oxidação ocorria nos glicossomos (Coombs, Craft \& Hart, 1982). Com o advento dos estudos da genômica e da proteômica, não foram encontrados direcionadores que comprovassem que as enzimas presentes em Leishmania responsáveis pela $\beta$-oxidação estariam realmente nos glicossomos, não havendo consenso da real localização desse sistema (Opperdoes \& Szikora, 2006; Michels et al., 2006).

Para Leishmania, a $\beta$-oxidação é uma importante via de obtenção de energia, principalmente para a forma amastigota, que reside no vacúolo parasitóforo no interior dos macrófagos, sendo também demonstrada a necessidade de um meio rico em ácidos graxos para que ocorra a transformação da forma promastigota em amastigota (Hart \& Coombs, 1982). Inibição da $\beta$-oxidação também foi descrita como sendo um dos prováveis mecanismos de ação de um dos fármacos mais utilizados para o tratamento da leishmaniose, o estibogluconato de sódio (Pentostam ${ }^{\circledR}$ ) (Berman et al., 1987; Berman, Gallalee \& Best, 1987), reafirmando a importância metabólica da $\beta$-oxidação para Leishmania.

\section{ESTERÓIS}

Os esteróis constituem o mais abundante grupo de isoprenoides da natureza, ocorrendo em procariotos e eucariotos. Apresentam como núcleo característico o ciclopentanoperidrofenantreno, constituído por quatro anéis hidrocarbonados fundidos, três com seis carbonos e um com cinco que, em virtude da presença de uma ligação dupla, se torna quase planar e relativamente rígido. Apresentam diferentes papéis na biologia celular dos eucariotos. O mais conhecido é a manutenção da arquitetura da membrana, no qual os esteróis livres interagem com a cadeia de ácidos graxos de fosfolipídeos para controlar a fluidez de membrana. Menos conhecidos são os efeitos dos esteróis na regulação do ciclo celular (Fernandez et al., 2004). Sua característica anfipática, em razão da polaridade conferida pela hidroxila no carbono 3, é muito importante na orientação da molécula nas membranas biológicas e é responsável por boa parte de suas funções. 
O colesterol é o esterol mais abundante em seres humanos e, por esse motivo, suas funções têm sido extensivamente estudadas desde o último século. Entretanto, os fungos e os tripanossomatídeos distinguiram sua via biossintética e seus esteróis diferem do colesterol, apresentando o esqueleto ergostano, caracterizado pela presença de ramificações na posição 24 (Figura 1).

Figura 1 - Estrutura do ergosterol

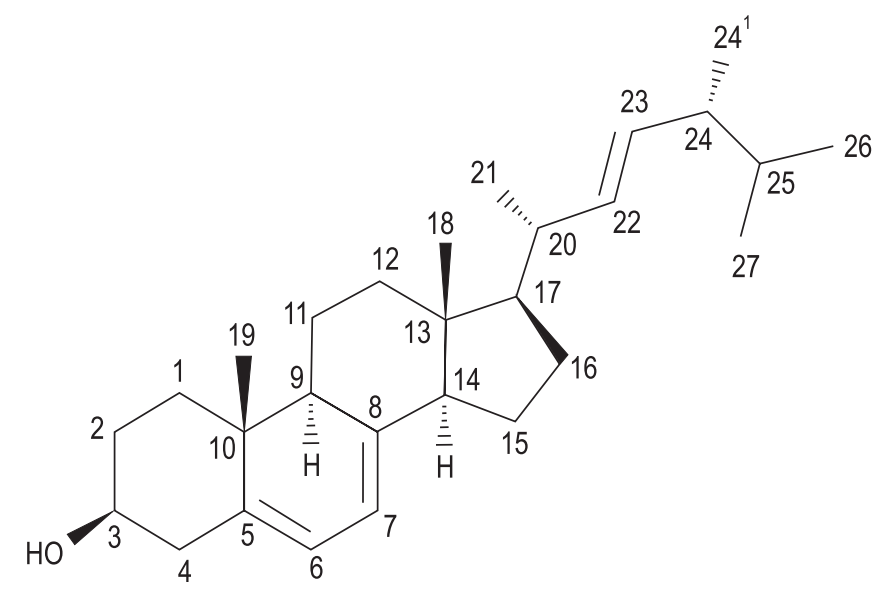

Durante muito tempo, os esteróis foram reconhecidos apenas por suas funções estruturais, mas, atualmente, sabe-se que o colesterol desempenha papéis cruciais na organização, dinâmica e funcionalidade das membranas celulares, como a estabilização de receptores transdutores de sinais (Paila, Tiwari \& Chattopadhyay, 2009; Lagane et al., 2000; Kalipatnapu \& Chattopadhyay, 2007; Pucadyil \& Chattopadhyay, 2006; Gaibelet et al., 2008). Está envolvido também na entrada de microrganismos patogênicos intracelulares, como Leishmania (Pucadyil et al., 2004; Pucadyil \& Chattopadhyay, 2007) e T. cruzi (Fernandes et al., 2007).

Como a maior parte do conhecimento foi adquirido por meio de estudos sobre o colesterol, tomaremos como base a rota biossintética dessa molécula, destacando as diferenças já encontradas em relação à biossíntese dos esteróis de tripanossomatídeos, especialmente Leishmania. A biossíntese dos esteróis pode ser dividida didaticamente em quatro estágios: no estágio 1, ocorre a síntese de um intermediário com seis átomos de carbono, o ácido mevalônico; o estágio 2 envolve a conversão do ácido mevalônico em unidades de isopreno ativadas; o estágio 3 consiste na polimerização de seis unidades isoprênicas com cinco átomos de carbono para formar a estrutura linear do esqualeno, com trinta átomos de carbono; no estágio 4 ocorre a ciclização do esqualeno, formando os quatro anéis do núcleo de esteróis, além de uma série de mudanças posteriores (oxirreduções e remoção ou migração de grupos metila) que levam aos produtos finais (Nelson \& Cox, 2006). A biossíntese dos esteróis dos tripanossomatídeos se dá de acordo com essa mesma linha geral, diferindo em alguns pontos específicos a serem discutidos a seguir.

- Estágio 1 - Síntese do ácido mevalônico

Em mamíferos, todos os átomos para a síntese de esteróis são fornecidos pelo acetato. Duas moléculas de acetilCoA formam acetoacetil-CoA, que se condensa com uma terceira molécula de acetil-CoA, originando a $\beta$-hidroxi- $\beta$ metilglutaril-CoA (HMG-CoA), com seis átomos de carbono. Essas reações são catalisadas pela tiolase e pela HMGCoA sintase, respectivamente. Porém, interessantemente, Ginger e colaboradores demonstraram que, ao incubarem promastigotas e amastigotas axênicas de L. mexicana com diversos substratos marcados $\operatorname{com}{ }^{14} \mathrm{C} \mathrm{ou}{ }^{3} \mathrm{H}$, a principal fonte de carbono para a síntese de esteróis nesses organismos foi a leucina, respondendo por $50 \%$ a $60 \%$ da radioatividade incorporada, enquanto o acetato dado exogenamente respondeu por cerca de apenas $2 \%$ (Ginger, Chance \& Goad, 
1999). Nesse estudo, o acetato foi incorporado majoritariamente em triacilgliceróis e fosfolipídeos. Aparentemente a leucina, um aminoácido com seis átomos de carbono, é convertida diretamente em HMG-CoA por uma série de reações que envolvem desaminação e descarboxilação, para a ativação por conjugação com a coenzima A e posterior reincorporação do átomo de carbono perdido.

A via metabólica da biossíntese de esteróis a partir da leucina, proposta pelos autores, é apresentada na Figura 2.

Figura 2 - Proposta de via metabólica para a conversão de leucina em ácido mevalônico em Leishmania<smiles>CCC(C)CC(=O)C(=O)O</smiles>

Leucina

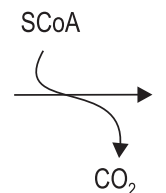

$\mathrm{CO}_{2}$<smiles>C=CC(=O)C=C(C)C=CC(=O)OC</smiles>

Dimetilcrotonil CoA<smiles>CC(C)CC(=O)O</smiles>

Isovaleril CoA

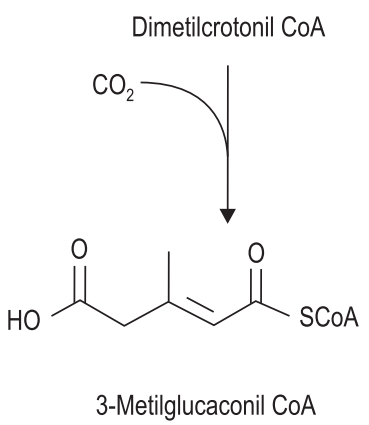

Fonte: adaptada de Ginger, Chance \& Goad, 1999.

Após a formação da HMG-CoA, as vias de mamíferos e tripanossomatídeos têm em comum uma primeira etapa limitante: a redução da HMG-CoA em ácido mevalônico, pela enzima HMG-CoA redutase. Essa é uma enzimachave, responsável pelo principal ponto de regulação na biossíntese de isoprenoides, tanto em mamíferos, quanto nos tripanossomatídeos. Em mamíferos, a HMG-CoA redutase é uma proteína integral de membrana do retículo endoplasmático liso, sendo inibida pela quantidade de colesterol intracelular (Nelson \& Cox, 2006). No entanto, Peña-Diaz e colaboradores (2004) demonstraram que em tripanossomatídeos tal enzima, apesar de apresentar alta homologia nos sítios catalíticos com as enzimas de mamíferos, não dispõe de uma sequência aminoterminal direcionadora para retículo endoplasmático, concentrando-se sobretudo na mitocôndria única desses parasitos (PeñaDiaz et al., 2004). Esses autores demonstraram, ainda, que a enzima dos parasitos tem uma sequência direcionadora para a mitocôndria, que, ao ser removida, provoca o acúmulo no compartimento citossólico.

- Estágio 2 - Conversão do ácido mevalônico em duas unidades de isopreno ativadas

No estágio 2, três grupos fosfato são transferidos de três moléculas do ATP para o ácido mevalônico. O fosfato ligado ao grupo hidroxila no C-3 do ácido mevalônico no intermediário 3-fosfo-5-pirofosfomevalonato é um bom grupo abandonador; no próximo passo, esse fosfato e o grupo carboxila próximo saem, deixando uma ligação dupla no produto de cinco átomos de carbono, o $\Delta^{3}$-isopentenilpirofosfato. Esse é o primeiro de dois isoprenos ativados centrais na formação do colesterol. A isomerização do $\Delta^{3}$-isopentenilpirofosfato gera o segundo isopreno ativado, o dimetilalilpirofosfato (Figura 3, adiante).

- Estágio 3 - Síntese do esqualeno

$\mathrm{Na}$ etapa seguinte, o isopentenilpirofosfato e o dimetilalilpirofosfato sofrem condensação 'cabeça-cauda', na qual um grupo pirofosfato é removido para a formação de uma cadeia de dez carbonos, o geranilpirofosfato. Então, 
a farnesilpirofosfato sintase, uma enzima citoplasmática em Leishmania (Ortiz-Gomez et al., 2006), catalisa a condensação 'cabeça-cauda' do geranilpirofosfato com o isopentenilpirofosfato, gerando o farnesilpirofosfato, com 15 carbonos. Finalmente, a esqualeno sintase catalisa a reação 'cauda-cauda' entre duas moléculas de farnesilpirofosfato, na primeira etapa comprometida com a síntese de esteróis, levando à formação do esqualeno (Figura 3, adiante).

- Estágio 4 - Formação do núcleo ciclopentanoperidrofenantreno

A ação da esqualeno epoxidase acrescenta um átomo de oxigênio do $\mathrm{O}_{2}$ na extremidade da cadeia do esqualeno, formando um epóxido, em uma reação de oxirredução dependente de NADPH-citocromo P450 redutase. As ligações duplas do produto, 2,3-epóxido de esqualeno são posicionadas de tal forma que uma reação concertada pode converter o epóxido de esqualeno linear em uma estrutura cíclica, originando o primeiro esterol da via, o lanosterol. Após esse ponto, as vias biossintéticas se especializam de acordo com os organismos, levando à formação de esteróis estruturalmente distintos em plantas, mamíferos, fungos e tripanossomatídeos, em uma série de aproximadamente vinte reações (Nelson \& Cox, 2006).

\section{Composição esteroídica dos tripanossomatídeos}

Os tripanossomatídeos já foram extensivamente estudados em relação à composição de esteróis. Em 1984, identificaram-se esqualeno, lanosterol (4,4,14 $\alpha$-trimetilcolesta-8,24-dieno-3 $\beta$-ol, 1$)$ e dimetilzimosterol $(4 \alpha, 14 \alpha$ dimetilcolesta-8,24-dieno-3ß-ol, 3) em várias espécies de Leishmania (Figura 3) (Goad, Holz \& Beach, 1984). A descoberta dessas substâncias sugeriu que a biossíntese de esterol ocorria de maneira similar à dos fungos, oferecendo uma oportunidade para o desenvolvimento de quimioterapia com alvo na via biossintética dos esteróis. A maior parte dos esteróis dos tripanossomatídeos apresentam esqueleto $\Delta^{5,7} \mathrm{C} 28$-ergostano (com metila em 24) ou C29-estigmastano (com etila em 24). A ausência de 24-metil derivados de esteróis 4,4 dimetilados sugere que a metilação em 24 ocorre de forma tardia na via e parece que o zimosterol (colesta-8,24-dieno-3 $\beta$-ol, 7 ) pode ser o maior substrato para essa reação (Figura 3) (Coombs \& North, 1991). Em espécies de Leishmania, os esteróis baseados no esqueleto ergostano são os mais abundantes em amastigotas e promastigotas, predominando o 5-desidroepisterol (ergosta-5,7,24(241)trieno-3 $\beta$-ol, 12) (Goad, Holz \& Beach, 1984), embora o ergosterol (ergosta-5,7,22-trieno-3 $\beta$-ol, 13) predominante nos fungos esteja presente em pequenas quantidades. Os esteróis de esqueleto relacionados ao estigmastano (14, $15,17)$ representam $5 \%$ do total de esteróis de promastigotas de Leishmania spp., mas, na forma amastigota, em algumas espécies, podem chegar a $20 \%$ do total, sugerindo que tais esteróis podem ter um importante papel quando os parasitos estão na célula hospedeira (Roberts et al., 2003).

Os esteróis de amastigotas de L. mexicana crescidas em células J-774 são diferentes dos esteróis de promastigotas. o principal esterol é o episterol (ergosta-7,24(241)-dieno-3 $\beta$-ol, 10), em vez de desidroepisterol (12), enquanto

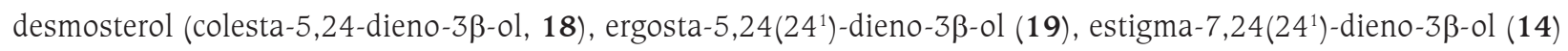
e estigma-5,7,24(241)-trieno-3 $\beta$-ol (15) são adicionais ao perfil de esteróis das formas promastigotas. A presença do esterol 19 (Figura 3) nas amastigotas é interessante, uma vez que a ocorrência de esteróis $\Delta^{5}$ não é vista em promastigotas porque possivelmente não são capazes de dessaturar a ligação $\Delta^{7}$, tendo somente $\Delta^{5,7}$ e $\Delta^{7}$, assim como nos fungos. Tal informação sugere que os esteróis $\Delta^{5}$ são produzidos em amastigotas a partir do desmosterol, absorvido de células do hospedeiro (Haughan \& Goad, 1991). O mesmo esterol foi identificado em amastigotas de $L$. braziliensis (Holz et al., 1986).

As quantidades de esteróis predominantes diferem entre os tripanossomatídeos. A via de biossíntese de epimastigotas e tripomastigotas de T. cruzi é sugerida de maneira similar à descrita para Leishmania spp., usando estrutura de esteróis conhecidos da biossíntese de fungos e estrutura de esteróis acumulados pela adição de inibidores. O modelo de biossíntese é diferente das etapas iniciais observados em Leishmania spp., como por exemplo metilação em 24 do lanosterol (1). A metilação em Leishmania spp. ocorre em uma etapa mais tardia. As formas epimastigotas de T. cruzi 
contêm ergosterol e ergosta-5,7-dieno-3 $\beta$-ol que, juntos, formam aproximadamente $40 \%$ do total de esteróis. Além disso, uma apreciável quantidade, aproximadamente $30 \%$, de estigma-5,7-dieno-3 $\beta$-ol (16) e 7 -desidroporiferasterol (estigma-5,7,22-trieno-3ß-ol, 17) é observada nessa forma. Formas tripomastigotas de T. cruzi, de maneira similar à descrita para L. mexicana, são capazes de converter desmosterol do hospedeiro (Roberts et al., 2003).

Nas espécies de Leishmania, o 7-desidroporiferasterol é observado em pequenas quantidades, indicando que esse organismo tem uma capacidade limitada para reação de transmetilação secundária, no qual um precursor 24-metilado, tal como episterol (10) e desidroepisterol (12), é convertido em esteróis com o esqueleto estigmastano C-29. Tal reação é típica de algas e plantas superiores e é ausente em muitos fungos (Goad, Holz \& Beach, 1984). As formas amastigotas de T. cruzi apresentam diferenças em relação às Leishmania spp. Formas amastigotas de T. cruzi aparentemente não produzem esteróis $\Delta^{5,7}$, mas, em vez disso, contêm episterol (ergosta-7,24(241)-dieno-3 $\beta$-ol, 10), ergosta-7-eno-3 $\beta$-ol e 24-etildinocolesta-7-eno-3 $\beta$-ol (14), indicando ausência de atividade da $\Delta^{5}$ dessaturase (Roberts et al., 2003; Liendo et al., 1999). A via de biossíntese dos esteróis em Leishmania spp. e T. cruzi, proposta por Roberts e colaboradores (2003), está sintetizada na Figura 3.

Em adição aos esteróis endógenos, os tripanossomatídeos contêm quantidades variáveis de colesterol, que são derivados do meio de cultura ou da célula hospedeira. Esses parasitos dispõem de receptor para LDL, que é conservado em toda ordem kinetoplastidae (Bastin et al., 1996), localizado na bolsa flagelar, o que indica que o colesterol obtido seja proveniente da captação e metabolização da LDL.

Surpreendentemente, o T. brucei apresenta um comportamento dual em relação à utilização de esteróis. Quando está no inseto vetor ou é cultivado em sua forma procíclica, é capaz de prover todas suas necessidades com a síntese endógena de ergosterol. Porém, quando está na forma sanguínea, torna-se dependente da captação de colesterol exógeno, sugerindo que esses esteróis podem ter funções complementares no parasito (Coppens, Levade \& Courtoy, 1995). Dessa forma, o processo de aquisição de colesterol por T. brucei tem sido bastante estudado, em virtude do seu potencial como alvo farmacológico, e o receptor de LDL desempenha um papel fundamental nesse processo. Após a endocitose, que ocorre na bolsa flagelar, as partículas de LDL se acumulam em estruturas endocíticas e a apolipoproteína é rapidamente degradada por tiol proteases em pH ácido. Acredita-se que processo semelhante ocorra em T. cruzi e Leishmania spp. A captação ávida e seletiva e a degradação da LDL, combinada com a reciclagem do receptor, conduz a uma utilização eficiente de lipídeos derivados do hospedeiro. Formas procíclicas de T. brucei, que realizam biossíntese de novo de esteróis, também demonstraram endocitose de LDL mediada por receptor (Lee et al., 1999; Liu et al., 2000). Os insetos têm uma liproproteína chamada lipoforina, que apresenta notável similaridade com a estrutura tridimensional da apoproteína E. No entanto, ainda não está claro se o mesmo receptor de LDL pode reconhecer lipoforinas (Lee et al., 1999).

Fosfolipídeos (ex., esfingomielina) e ésteres de colesterila (ex., oleato de colesterila) também são obtidos pela endocitose e degradação da LDL. A esfingomielina e o oleato de colesterila são liberados e podem ser metabolizados sob a degradação lisossomal da apoB-100. Tais lipídeos permanecem intactos quando os parasitos são incubados com leupeptina e cloroquina, que previnem a proteólise da LDL. A esfingomielina é clivada pela esfingomielinase (hidrolase ácida lisossomal), que produz ceramida sendo esta dividida em esfingosina e ácidos graxos. Os dois produtos formados podem ser incorporados em fosfatidilcolina, em triacilgliceróis, ou em ésteres de colesterila. Similarmente, o oleato de colesterila pode ser hidrolisado (lipase lipossomal) em colesterol livre, o qual é capaz de atravessar a membrana do lisossomo (Coppens \& Courtoy, 2000). O colesterol obtido da LDL pode ser reesterificado com ácidos graxos, como oleato, sugerindo que existe nas formas sanguíneas do T. brucei uma acil-coenzima A:colesterol aciltransferase, em que o substrato é fornecido pela LDL-colesterol. Tanto nas formas sanguíneas como nas procíclicas, quando a exigência de síntese de membrana é totalmente preenchida, o excesso de colesterol é estocado na forma de ésteres. Essas formas de T. brucei comportam-se de forma semelhante às células de mamífero, em que a ligação de LDL no seu receptor inicia e regula um processo celular que leva à esterificação do colesterol derivado de LDL exógena para estocagem (Coppens \& Courtoy, 2000). 
Figura 3 - Biossíntese de esteróis em tripanossomatídeos

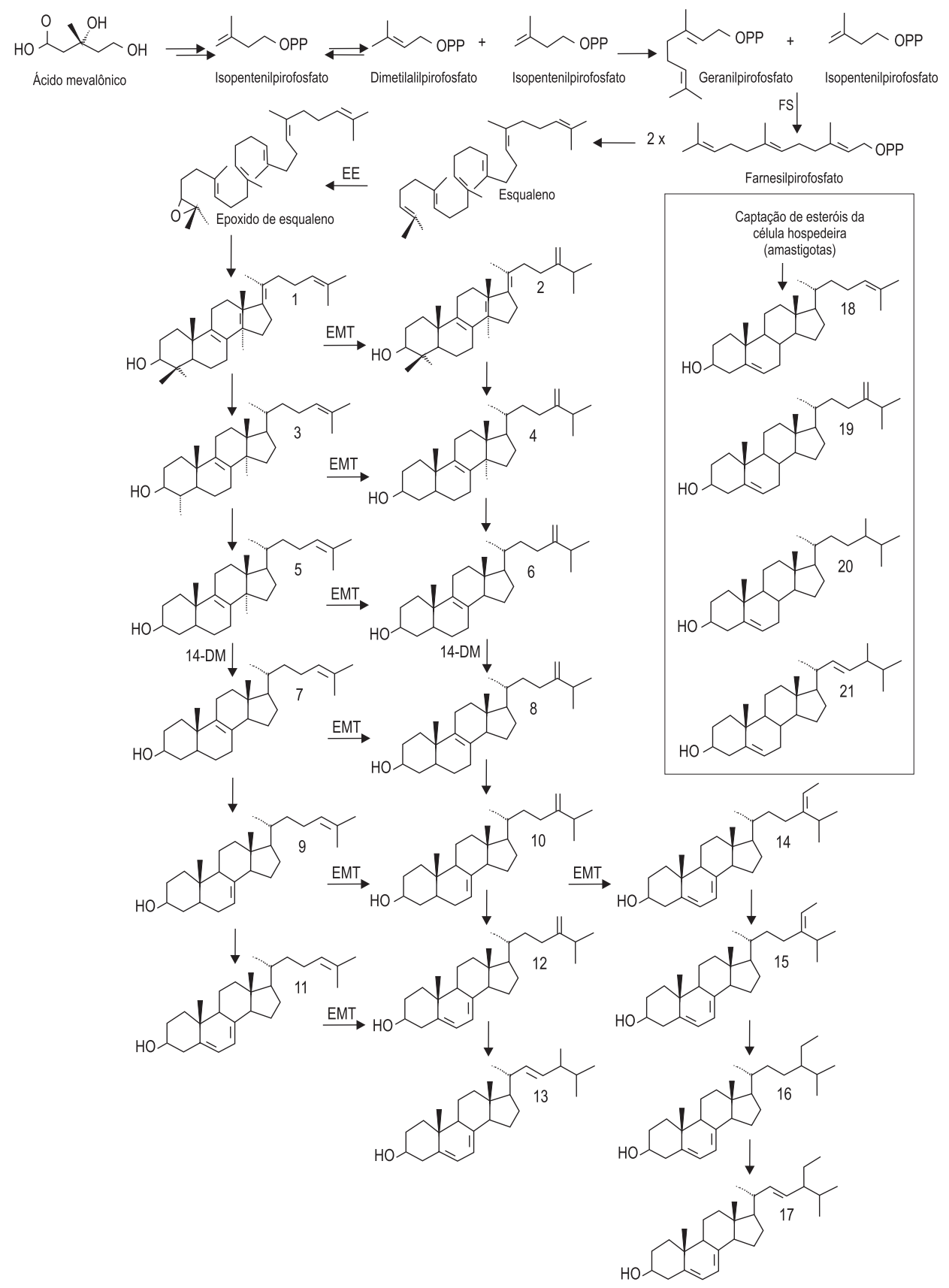

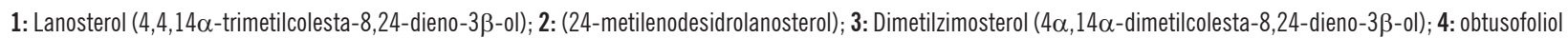

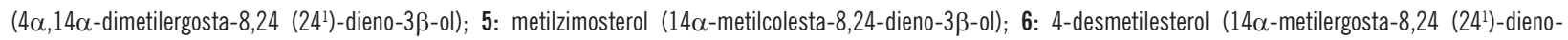

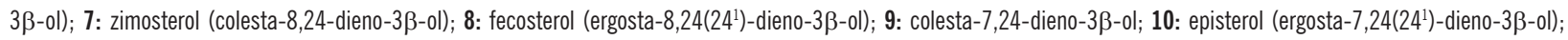

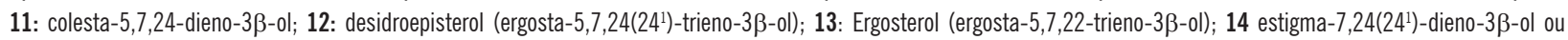

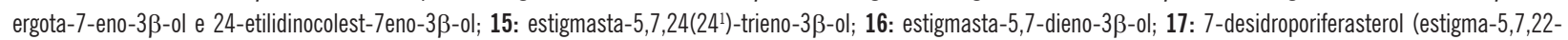

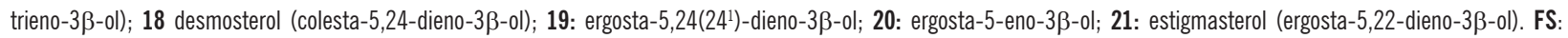
Farnesilpirofosfato sintase - Inibida por bisfosfonatos; EE: esqualeno 2,3 epoxidase - Inibida por alilaminas; 14-DM: C-14 desmetilase - Inibida por azóis; EMT: $\Delta^{24}$ esterol metiltransferase - Inibida por azasteróis (Haughan \& Goad, 1991; Roberts et al., 2003; Holz et al., 1986).

Fonte: adaptação do modelo proposto por Roberts et al. (2003) para a biossíntese dos esteróis em Leishmania spp. e T. cruzi. 
Apesar de em certas situações o colesterol aparecer como esterol majoritário em Leishmania spp. (Rakotomanga et al., 2007), poucos esforços têm sido envidados para investigar o processo de endocitose e aproveitamento de lipídeos exógenos nesses parasitos. É provável que muitos dos processos descritos para o T. brucei sejam semelhantes em Leishmania e T. cruzi, e pode ser que desempenhem papéis metabólicos ainda desconhecidos ou, ainda, interfiram na atividade de fármacos inibidores da biossíntese de esteróis. Andrade-Neto e colaboradores (2011) demonstraram que promastigotas de L. amazonensis aumentam a endocitose de LDL sob pressão farmacológica, com consequente aumento no conteúdo intracelular de colesterol, e que esses parasitos cultivados em meio sem fonte exógena de colesterol se tornam mais sensíveis aos inibidores da biossíntese de esteróis.

\section{Inibidores da biossíntese do ergosterol}

Fármacos que atuam na biossíntese dos esteróis apresentam interessante atividade leishmanicida e tripanossomicida ao inibir diversas enzimas da via como, por exemplo, a HMG-CoA redutase, a esqualeno epoxidase, a C-14 desmetilase e a C-24 metiltransferase, que são inibidas pelas estatinas (sinvastatina, lovastatina), alilaminas (terbinafina), azóis (cetoconazol, miconazol, itraconazol e fluconazol) e azasteróis, respectivamente (Rodrigues et al., 2002; Haughan, Chance \& Goad, 1992; Beach, Goad \& Holz, 1988; Berman, Holz \& Beach, 1984).

Martin e colaboradores (2001) demonstraram que os bisfosfonatos têm atividade contra T. cruzi, T. brucei e L. donovani, por inibirem a enzima farnesilpirofosfato sintase (Martin et al., 2001). De fato, bisfosfonatos utilizados no tratamento de desordens ósseas, como o risedronato e o pamidronato, foram ativos nos modelos de leishmaniose experimental cutânea e visceral (Rodrigues, 2002; Martin et al., 2001).

A alilamina terbinafina é um potente inibidor da esqualeno-2,3-epoxidase e tem efeito em Leishmania spp. e T. cruzi (Vannier-Santos et al., 1995; Urbina, 1997). O tratamento de promastigotas e amastigotas de L. mexicana com terbinafina resulta no acúmulo de três a quatro vezes de esqualeno e uma diminuição na quantidade de esteróis C-29 e C-28 endógenos (Roberts et al., 2003). Foi demonstrada a atividade desse fármaco em L. major e L. donovani (Zakai \& Zimmo, 2000). O efeito sobre o crescimento tem sido atribuído pelo efeito na diminuição de esteróis das estruturas de membrana celulares e parece não estar relacionado ao excesso de esqualeno (Roberts et al., 2003).

Os antifúngicos imidazólicos e triazólicos apresentam uma alta atividade na inibição da biossíntese de esteróis e no crescimento de várias espécies de Leishmania (Beach, Goad \& Holz, 1988; Ramos et al., 1994; Goad, Holz \& Beach, 1985; Berman et al., 1986; Goad, 1994) e T. cruzi (Liendo et al., 1999; Beach, Goad \& Holz, 1986). Eles atuam na enzima citocromo P450 C-14 desmetilase (CYP51), essencial na biossíntese de esteróis do fim da via, em promastigotas e amastigotas, ocasionando a diminuição de esteróis C-28 e C-29 e acúmulo de vários esteróis metilados em $14 \alpha$. Novas isoformas de CYP51 foram encontradas em T. brucei, T. vivax, T. cruzi e Leishmania spp. A sequência de aminoácidos dessa enzima apresenta 74-86\% de identidade entre eles e de 22-33\% com C-14 desmetilase de outros reinos biológicos. Há homologia também com a CYP51 de Mycobacterium tuberculosis (28\%), tomate (28\%) e humana (27\%) (Lepesheva \& Waterman, 2004). A identidade proteica da CYP51 e da HMGCo-A redutase das diferentes espécies de Leishmania com as de humano foi comparada por P-BLAST (Andrade-Neto, dados não publicados). Em relação a C-14 desmetilase, L. major, L. braziliensis e L. infantum apresentam 34\% de homologia proteica e L. amazonensis tem $33 \%$. No caso da HMG-CoA redutase, L. braziliensis, L. infantum, L. major apresentam 53\%, 52\% e 51\%, respectivamente, de identidade proteica com a enzima de humanos.

O primeiro esterol da via de biossíntese que acumula após o tratamento com os azóis em promastigotas de Leishmania spp. é o dimetilzimosterol (3). No entanto, durante uma longa exposição, os esteróis podem ser metabolizados em esteróis alquilados (4) ou desmetilados no C-5 (5) para produzir finalmente um 4-desmetilesterol (6) (Roberts et al., 2003). Amastigotas cultivadas em linhagem de macrófagos (J774) e promastigotas de L. mexicana em cultura, quando 
expostos ao cetoconazol, têm a biossíntese de 5-desidroepisterol (12), ergosterol (13) e episterol (10) prejudicada, ocorrendo acúmulo de dimetilzimosterol (3) e obtusofoliol (4) (Goad, Holz \& Beach, 1985; Berman et al., 1986). O efeito de itraconazol, cetoconazol e fluconazol sobre a biossíntese de esteróis de promastigotas de várias espécies também foi avaliado. Esse trabalho mostrou que promastigotas de L. aethiopica, L. donovani e subespécies de L. mexicana crescidas por longo período na presença de concentrações de azóis causam a diminuição dos esteróis majoritários reduzidos, e a substituição desses por $14 \alpha$-metilesteróis endógenos e colesterol exógeno em grande quantidade (Beach, Goad \& Holz, 1988). A perturbação da biossíntese de esteróis pelo itraconazol e cetoconazol também foi analisada em amastigotas de L. mexicana. Mostrou-se que as amastigotas são consideravelmente mais sensíveis a essas moléculas que os macrófagos da linhagem J774. Observou-se também que as amastigotas tratadas apresentaram grande quantidade de colesterol exógeno, como foi visto em formas promastigotas (Hart et al., 1989). Em epimastigotas e amastigotas de T. cruzi tratadas com os azóis, o acúmulo de 14 $\alpha$-metilesteróis foi de lanosterol (1) e, particularmente, do produto de alquilação no C-24, o 24-metilenodesidrolanosterol (2). Além disso, em comparação com Leishmania spp., a quantidade total de esteróis acumulada e a proporção de colesterol não diferem significativamente entre tripomastigotas e epimastigotas de T. cruzi tratadas e não tratadas com cetoconazol, sugerindo alguma diferença no processo regulatório comparado à situação de Leishmania spp. (Roberts et al., 2003). O tratamento com miconazol causou a diminuição de esteróis $\Delta^{5,7}$ de epimastigotas de T. cruzi (Haughan \& Goad, 1991). O miconazol e um inibidor da HMG CoA redutase (Stancu \& Sima, 2001) - a lovastatina - foram usadas em combinação para avaliar sua potência como agentes leishmanicidas. A combinação foi considerada sinérgica, inibindo promastigotas e amastigotas de Leishmania spp. Nas formas promastigotas o efeito foi maior em L. amazonensis que em L. donovani. Análises da composição de esteróis de ambos, promastigotas e amastigotas, revelaram inibição da C-14 desmetilase pelo miconazol e mostraram evidências da inibição da biossíntese de esteróis pela lovastatina (Haughan, Chance \& Goad, 1992).

O efeito do azasterol, um inibidor da $\Delta^{24}$ - esterol metiltransferase, que inibe a alquilação do C-24, tem sido estudado em Leishmania spp. e T. cruzi (Rodrigues et al., 2011; Haughan, Chance \& Goad, 1995; Jimenez-Jimenez et al., 2008; Lorente et al., 2004; Gros et al., 2006). A atividade do azasterol sobre o crescimento, e sobre a composição de esteróis, foi avaliada em $L$. donovani. Os experimentos revelaram o declínio de 24-alquil esteróis e acúmulo de colesta-5,7,24-

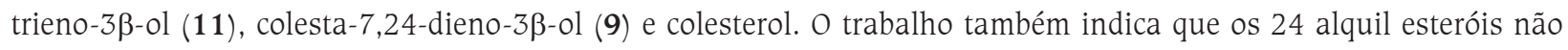
são absolutamente necessários para a sobrevivência e crescimento de $L$. donovani e que o parasito pode ser capaz de usar os esteróis endógenos acumulados e o colesterol captado do meio de cultura (Haughan, Chance \& Goad, 1995).

Os inibidores da esqualeno sintase têm sido utilizados como alvo para quimioterapia em Leishmania spp. e T. cruzi, inibindo assim a formação do esqualeno e o seu crescimento (Granthon et al., 2007). Os experimentos com tais inibidores também demonstram um aumento na quantidade de colesterol, que pode significar uma tentativa de manter sua membrana e outras funções (Urbina et al., 2002; Lorente et al., 2005).

Outras classes de substâncias leishmanicidas parecem interferir na biossíntese de esteróis. A 2',6'-diidroxi-4'metoxichalcona (DMC), por exemplo, é um protótipo com atividade contra L. amazonensis in vitro (Torres-Santos et al., 1999a) e in vivo (Torres-Santos et al., 1999b), que provoca alterações não usuais no perfil de esteróis do parasito (Torres-Santos et al., 2009).

\section{CONCLUSÕES E PERSPECTIVAS}

Entre as distintas vias metabólicas de lipídeos em Leishmania spp., as rotas biossintéticas de esteróis e de ácidos graxos têm sido até agora as mais intensamente estudadas.

A síntese dos ácidos graxos nos tripanossomatídeos é essencial para sua sobrevivência. No entanto, apesar da presença do sistema enzimático AGS2 em Leishmania, possibilidades de estudos de novos alvos surgiram nos últimos 
anos, pois outra rota não convencional, utilizando enzimas ELOs e PUFAs, tem sido implicada como a principal responsável pela síntese dos ácidos graxos nesse tipo celular. Ainda que pouco estudada, a $\beta$-oxidação dos ácidos graxos é uma importante fonte de energia em Leishmania, principalmente na forma amastigota. Interessantemente, a inibição da $\beta$-oxidação já foi descrita como sendo um dos prováveis mecanismos de ação do estibogluconato de sódio (Pentostam ${ }^{\circledR}$ ). Com a descrição do genoma desses parasitos, novas moléculas podem ser desenhadas especificamente como inibidoras das diferentes enzimas dessa via.

A descoberta, na década de 1980, de que os tripanossomatídeos apresentam similaridade com os fungos em relação à biossíntese dos esteróis, estimulou uma intensa investigação da atividade leishmanicida dos fármacos antifúngicos utilizados na clínica. O estudo desses inibidores, baseado nas diferenças com as células dos mamíferos, tem oferecido grandes contribuições tanto no conhecimento da própria via como na busca racional para o desenvolvimento de novos fármacos. Em adição aos esteróis endógenos, em certas situações o colesterol pode aparecer como esterol majoritário em Leishmania spp.. Esses parasitos contam com receptor para LDL, que é conservado em toda ordem kinetoplastidae, localizado na bolsa flagelar, o que indica que o colesterol obtido seja proveniente da captação e metabolização da LDL. Entretanto, poucos esforços têm sido feitos para investigar o processo de endocitose e aproveitamento de lipídeos exógenos em tais parasitos.

É importante ressaltar que, apesar dos avanços no conhecimento da bioquímica e da biologia celular de Leishmania spp., todos os fármacos reportados neste capítulo foram desenvolvidos para outras finalidades distintas do tratamento da leishmaniose. O estudo das vias metabólicas lipídicas e de funções biológicas até então desconhecidas em Leishmania spp., em conjunto com as poderosas ferramentas de biologia computacional e química medicinal, poderá levar ao desenvolvimento de uma nova geração de fármacos específicos e realmente seletivos para a leishmaniose, fármacos estes que não sejam um simples aproveitamento de moléculas projetadas para outros fins e que, casualmente, tenham demonstrado atividade leishmanicida.

\section{REFERÊNCIAS}

ANDRADE-NETO, V. V. et al. The pharmacological inhibition of sterol biosynthesis in Leishmania is counteracted by enhancement of LDL endocytosis. Acta Tropica, 119: 194-198, 2011.

BASTIN, P. et al. An M(r) 145000 low-density lipoprotein (LDL)-binding protein is conserved throughout the Kinetoplastida order. Molecular and Biochemical Parasitology, 76(1-2): 43-56, 1996.

BEACH, D. H.; GOAD, L. J. \& HOLZ, G. G. Effects of ketoconazole on sterol biosynthesis by Trypanosoma cruzi epimastigotes. Biochemical and Biophysical Research Communications, 136(3): 851-856, 1986.

BEACH, D. H.; GOAD, L. J. \& HOLZ, G. G. Effects of antimycotic azoles on growth and sterol biosynthesis of Leishmania promastigotes. Molecular and Biochemical Parasitology, 31(2): 149-162, 1988.

BERG, J. M. T.; TYMOCZKO, J. L. \& STRYER, L. Bioquímica. 6 ed. Rio de Janeiro: Guanabara Koogan, 2008.

BERMAN, J. D.; GALLALEE, J. V. \& BEST, J. M. Sodium stibogluconate (Pentostam) inhibition of glucose catabolism via the glycolytic pathway, and fatty-acid beta-oxidation in Leishmania mexicana amastigotes. Biochemical Pharmacology, 36(2): 197-201, 1987.

BERMAN, J. D.; HOLZ, G. G. \& BEACH, D. H. Effects of ketoconazole on growth and sterol biosynthesis of Leishmania mexicana promastigotes in culture. Molecular and Biochemical Parasitology, 12(1): 1-13, 1984.

BERMAN, J. D. et al. Effects of ketoconazole on sterol biosynthesis by Leishmania mexicana amastigotes in murine macrophage tumor-cells. Molecular and Biochemical Parasitology, 20(1): 85-92, 1986.

BERMAN, J. D. et al. Uptake, distribution, and oxidation of fatty acids by Leishmania mexicana amastigotes. Journal of Parasitology, 73(3): 555-560, 1987. 
BLUM, J. J. Oxidation of fatty acids by Leishmania braziliensis panamensis. Journal of Protozoology, 34(2): 169-174, 1987.

COOMBS, G. H. \& NORTH, M. D. Lipid biochemistry of trypanosomatids. Biochemical Protozoology, 312-328, 1991.

COOMBS, G. H.; CRAFT, J. A. \& HART, D. T. A Comparative Study of Leishmania mexicana amastigotes and promastigotes enzyme activities and sub cellular locations. Molecular and Biochemical Parasitology, 5(3): 199-211, 1982.

COPPENS, I. \& COURTOY, P. J. The adaptative mechanisms of Trypanosoma brucei for sterol homeostasis in its different lifecycle environments. Annual Review of Microbiology, 54: 129-156, 2000.

COPPENS, I.; LEVADE, T. \& COURTOY, P. J. Host plasma low density lipoprotein particles as an essential source of lipids for the blood stream forms of Trypanosoma brucei. Journal of Biological Chemistry, 270(11): 5.736-5.741, 1995.

DARLING, T. N. \& BLUM, J. J. Invitro reversible transformation of Leishmania braziliensis panamensis between promastigote and ellipsoidal forms. Journal of Protozoology, 34(2): 166-168, 1987.

EATON, S.; BARTLETT, K. \& POURFARZAM, M. Mammalian mitochondrial beta-oxidation. Biochemical Journal, 320: 345$357,1996$.

FERGUSON, M. A. J. The structure, biosynthesis and functions of glycosylphosphatidylinositol anchors, and the contributions of trypanosome research. Journal of Cell Science, 112(17): 2.799-2.809, 1999.

FERNANDES, M. C. et al. Novel strategy in Trypanosoma cruzi cell invasion: implication of cholesterol and host cell microdomains. International Journal for Parasitology, 37(13): 1.431-1.441, 2007.

FERNANDEZ, C. et al. Cholesterol is essential for mitosis progression and its deficiency induces polyploid cell formation. Experimental Cell Research, 300(1): 109-120, 2004.

GAIBELET, G. et al. Cholesterol content drives distinct pharmacological behaviours of mu-opioid receptor in different microdomains of the CHO plasma membrane. Molecular Membrane Biology, 25(5): 423-435, 2008.

GINGER, M. L.; CHANCE, M. L. \& GOAD, L. J. Elucidation of carbon sources used for the biosynthesis of fatty acids and sterols in the trypanosomatid Leishmania mexicana. Biochemical Journal, 342: 397-405, 1999.

GLEW, R. H. et al. Biochemistry of the Leishmania species. Microbiological Reviews, 52(4): 412-432, 1988.

GOAD, L. J. The effects of antifungal compounds on growth and sterol metabolism in plants and protozoa. Biochemical Society Transactions, 22(3): 629-635, 1994.

GOAD, L. J.; HOLZ, G. G. \& BEACH, D. H. Sterols of Leishmania species: implications for biosynthesis. Molecular and Biochemical Parasitology, 10(2): 161-170, 1984.

GOAD, L. J.; HOLZ, G. G. \& BEACH, D. H. Sterols of ketoconazole-inhibited Leishmania mexicana mexicana promastigotes. Molecular and Biochemical Parasitology, 15(3): 257-279, 1985.

GRANTHON, A. C. et al. Alterations on the growth and ultrastructure of Leishmania chagasi induced by squalene synthase inhibitors. Veterinary Parasitology, 146(1-2): 25-34, 2007.

GROS, L. et al. Evaluation of azasterols as anti-parasitics. Journal of Medicinal Chemistry, 49(20): 6.094-6.103, 2006.

GURVITZ, A. Identification of the Leishmania major Proteins LmjF07.0430, LmjF07.0440, and LmjF27.2440 as components of fatty acid synthase II. Journal of Biomedicine and Biotechnology, 2009.

HART, D. T. \& COOMBS, G. H. Leishmania mexicana: energy metabolism of amastigotes and promastigotes. Experimental Parasitology, 54(3): 397-409, 1982.

HART, D. T. \& OPPERDOES, F. R. The occurrence of glycosomes (micro bodies) in the promastigote stage of four major Leishmania species. Molecular and Biochemical Parasitology, 13(2): 159-172, 1984.

HART, D. T. et al. Perturbation of sterol biosynthesis by itraconazole and ketoconazole in Leishmania mexicana mexicana infected macrophages. Molecular and Biochemical Parasitology, 33(2): 123-134, 1989.

HAUGHAN, P. A. \& GOAD, L. J. Lipid biochemistry of trypanosomatids. In: COOMBS, G. H \& NORTH, M. D. (Eds.). Biochemical Protozoology. London: Taylor and Francis, 1991. 
HAUGHAN, P. A.; CHANCE, M. L. \& GOAD, L. J. Synergism invitro of lovastatin and miconazole as antileishmanial agents. Biochemical Pharmacology, 44(11): 2.199-2.206, 1992.

HAUGHAN, P. A.; CHANCE, M. L. \& GOAD, L. J. Effects of an azasterol inhibitor of sterol 24-transmethylation on sterol biosynthesis and growth of Leishmania donovani promastigotes. Biochemical Journal, 308: 31-38, 1995.

HOLZ, G. G. et al. Leishmania amastigotes incorporate and transform macrophage host-cell sterols. Journal of Cellular Biochemistry, 62(Sup. 10A): 162, 1986.

JIMENEZ-JIMENEZ, C. et al. Delta(24(25))-sterol methenyltransferase: intracellular localization and azasterol sensitivity in Leishmania major promastigotes over expressing the enzyme. Molecular and Biochemical Parasitology, 160(1): $52-59,2008$.

KALIPATNAPU, S. \& CHATTOPADHYAY, A. Membrane organization and function of the serotonin(1A) receptor. Cellular and Molecular Neurobiology, 27(8): 1.097-1.116, 2007.

LAGANE, B. et al. Role of sterols in modulating the human mu-opioid receptor function in Saccharomyces cerevisiae. Journal of Biological Chemistry, 275(43): 33.197-33.200, 2000.

LEE, M. G. S. et al. Acquisition of lipoproteins in the procyclic form of Trypanosoma brucei. Molecular and Biochemical Parasitology, 100(2): 153-162, 1999.

LEE, S. H.; STEPHENS, J. L. \& ENGLUND, P. T. A fatty-acid synthesis mechanism specialized for parasitism. Nature Reviews Microbiology, 5(4): 287-297, 2007.

LEE, S. H. et al. Fatty acid synthesis by elongases in trypanosomes. Cell, 126(4): 691-699, 2006.

LEPESHEVA, G. I. \& WATERMAN, M. R. CYP51 - the omnipotent P450. Molecular and Cellular Endocrinology, 215(1-2): 165170, 2004.

LIENDO, A. et al. Sterol composition and biosynthesis in Tryanosoma cruzi amastigotes. Molecular and Biochemical Parasitology, 104(1): 81-91, 1999.

LIU, J. Y. et al. Receptor-mediated endocytosis in the procyclic form of Trypanosoma brucei. Journal of Biological Chemistry, 275(16): 12.032-12.040, 2000.

LIVORE, V. I.; TRIPODI, K. E. J. \& UTTARO, A. D. Elongation of polyunsaturated fatty acids in trypanosomatids. Febs Journal, 274(1): 264-274, 2007.

LOPASCHUK, G. D. et al. Myocardial fatty acid metabolism in health and disease. Physiological Reviews, 90(1): 207-258, 2010.

LORENTE, S. O. et al. Novel azasterols as potential agents for treatment of leishmaniasis and trypanosomiasis. Antimicrobial Agents and Chemotherapy, 48(8): 2.937-2.950, 2004.

LORENTE, S. O. et al. Biphenylquinuclidines as inhibitors of squalene synthase and growth of parasitic protozoa. Bioorganic \& Medicinal Chemistry, 13(10): 3.519-3.529, 2005.

MARTIN, M. B. et al. Bisphosphonates inhibit the growth of Trypanosoma brucei, Trypanosoma cruzi, Leishmania donovani, Toxoplasma gondii, and Plasmodium falciparum: a potential route to chemotherapy. Journal of Medicinal Chemistry, 44(6): 909-916, 2001.

MICHELS, P. A. M. et al. Metabolic functions of glycosornes in trypanosomatids. Biochimica et Biophysica Acta-Molecular Cell Research, 1763(12): 1.463-1.477, 2006.

NELSON, D. L. C. \& COX, M. M. Lehninger: princípios de bioquímica. 4. ed. São Paulo: Sarvier, 2006.

OPPERDOES, F. R. \& SZIKORA, J. P. In silico prediction of the glycosomal enzymes of Leishmania major and trypanosomes. Molecular and Biochemical Parasitology, 147(2): 193-206, 2006.

ORTIZ-GOMEZ, A. et al. Farnesyl diphosphate synthase is a cytosolic enzyme in Leishmania major promastigotes and its overexpression confers resistance to risedronate. Eukaryotic Cell, 5(7): 1.057-1.064, 2006. 
PAILA, Y. D.; TIWARI, S. \& CHATTOPADHYAY, A. Are specific nonannular cholesterol binding sites present in G-protein coupled receptors? Biochimica et Biophysica Acta-Biomembranes, 1.788(2): 295-302, 2009.

PAUL, K. S. et al. Fatty acid synthesis in African trypanosomes: a solution to the myristate mystery. Trends in Parasitology, 17(8): 381-387, 2001.

PEÑA-DIAZ, J. et al. Mitochondrial localization of the mevalonate pathway enzyme 3-hydroxy-3-methyl-glutaryl-CoA reductase in the trypanosomatidae. Molecular Biology of the Cell, 15(3): 1.356-1.363, 2004.

PUCADYIL, T. J. \& CHATTOPADHYAY, A. Role of cholesterol in the function and organization of G-protein coupled receptors. Progress in Lipid Research, 45(4): 295-333, 2006.

PUCADYIL, T. J. \& CHATTOPADHYAY, A. Cholesterol depletion induces dynamic confinement of the G-protein coupled serotonin(1A) receptor in the plasma membrane of living cells. Biochimica et Biophysica Acta-Biomembranes, 1.768(3): 655-668, 2007.

PUCADYIL, T. J. et al. Cholesterol is required for Leishmania donovani infection: implications in leishmaniasis. Molecular and Biochemical Parasitology, 133(2): 145-152, 2004.

RAKOTOMANGA, M. et al. Miltefosine afects lipid metabolism in Leishmania donovani promastigotes. Antimicrobial Agents and Chemotherapy, 51(4): 1.425-1.430, 2007.

RAMOS, H. et al. Effect of ketoconazole on lethal action of amphotericin B on Leishmania mexicana promastigotes. Antimicrobial Agents and Chemotherapy, 38(5): 1.079-1.084, 1994.

ROBERTS, C. W. et al. Fatty acid and sterol metabolism: potential antimicrobial targets in apicomplexan and trypanosomatid parasitic protozoa. Molecular and Biochemical Parasitology, 126(2): 129-142, 2003.

ROCK, C. O. \& JACKOWSKI, S. Forty years of bacterial fatty acid synthesis. Biochemical and Biophysical Research Communications, 292(5): 1.155-1.166, 2002.

RODRIGUES, J. C. F. et al. Ultrastructural and biochemical alterations induced by 22,26-azasterol, a Delta(24(25))-sterol methyltransferase inhibitor, on promastigote and amastigote forms of Leishmania amazonensis. Antimicrobial Agents and Chemotherapy, 46(2): 487-499, 2002.

SMITH, S. The animal fatty acid synthase: one gene, one polypeptide, seven enzymes. Faseb Journal, 8(15): 1.248-1.259, 1994.

STANCU, C. \& SIMA, A. Statins: mechanism of action and effects. Journal of Cellular and Molecular Medicine, 5(4): $378-$ $387,2001$.

STEIGER, R. F. \& STEIGER, E. Cultivation of Leishmania donovani and Leishmania braziliensis in defined media: nutritional requirements. Journal of Protozoology, 24(3): 437-441, 1977.

TOKE, D. A. \& MARTIN, C. E. Isolation and characterization of a gene affecting fatty acid elongation in Saccharomyces cerevisiae. Journal of Biological Chemistry, 271(31): 18.413-18.422, 1996.

TORRES-SANTOS, E. C. et al. Improvement of in vitro and in vivo antileishmanial activities of 2',6 '-dihydroxy-4 '-methoxychalcone by entrapment in poly(D,L-lactide) nanoparticles. Antimicrobial Agents and Chemotherapy, 43(7): 1.776-1.778, 1999a.

TORRES-SANTOS, E. C. et al. Selective effect of 2 ',6 '-dihydroxy-4 'methoxychalcone isolated from Piper aduncum on Leishmania amazonensis. Antimicrobial Agents and Chemotherapy, 43(5): 1.234-1.241, 1999b.

TORRES-SANTOS, E. C. et al. Altered sterol profile induced in Leishmania amazonensis by a natural dihydroxymethoxylated chalcone. Journal of Antimicrobial Chemotherapy, 63(3): 469-472, 2009.

TRIPODI, K. E. J. et al. Functional characterization of front-end desaturases from trypanosomatids depicts the first polyunsaturated fatty acid biosynthetic pathway from a parasitic protozoan. Febs Journal, 273(2): 271-280, 2006.

URBINA, J. A. Lipid biosynthesis pathways as chemotherapeutic targets in kinetoplastid parasites. Parasitology, 114: S91S99, 1997.

URBINA, J. A. et al. Squalene synthase as a chemotherapeutic target in Trypanosoma cruzi and Leishmania mexicana. Molecular and Biochemical Parasitology, 125(1-2): 35-45, 2002. 
VANNIER-SANTOS, M. A. et al. Alterations induced by the antifungal compounds ketoconazole and terbinafine in Leishmania. Journal of Eukaryotic Microbiology, 42(4): 337-346, 1995.

WITKOWSKI, A. et al. Head-to-head coiled arrangement of the subunits of the animal fatty acid synthase. Chemistry \& Biology, 11(12): 1.667-1.676, 2004.

ZAKAI, H. A. \& ZIMMO, S. K. Effects of itraconazole and terbinafine on Leishmania major lesions in BALB/c mice. Annals of Tropical Medicine and Parasitology, 94(8): 787-791, 2000.

ZHANG, K. \& BEVERLEY, S. M. Phospholipid and sphingolipid metabolism in Leishmania. Molecular and Biochemical Parasitology, $170(2)$ : 55-64, 2010. 


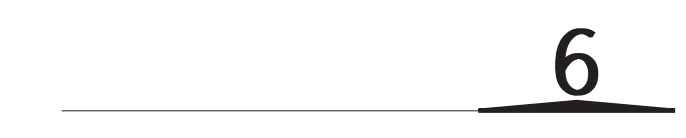

Aminoácidos e Proteases

Salvatore Giovanni De Simone

$\mathrm{O}^{3}$

aminoácidos são indispensáveis para todos os organismos vivos e operam como blocos de construção de proteínas. Seu mecanismo de captação e suas vias metabólicas estão organizados diferentemente na biosfera e podem ser únicas para cada aminoácido e organismos. Contudo, a identificação das enzimas envolvidas e a construção da organização das diversas vias metabólica podem se constituir uma tarefa árdua e muitas vezes demorada. Nesse aspecto, os projetos de sequenciamento e anotação genômica de protozoários patogênicos concluídos como Leishmania sp. estão contribuindo significativamente para a identificação da capacidade enzimática dos parasitos, fato que nos permite realizar a reconstrução funcional das suas vias metabólicas.

A maioria dos microrganismos e as plantas produzem praticamente todos os vinte aminoácidos conhecidos de que necessitam para sua sobrevivência. Entretanto, mamíferos, incluídos os seres humanos, e os parasitos, de maneira geral, podem produzi-los parcialmente. As diferenças entre os diversos organismos vão desde o modo de captação exógena desses substratos proteicos (que pode ser distinto em seus vários estágios de desenvolvimento) até a capacidade metabólica intracelular de assimilação, utilização, interconversão e síntese de aminoácidos. Neste capítulo, procuramos descrever o conjunto de ações integradas do metabolismo de aminoácidos essenciais à sobrevivência dos diversos estágios de desenvolvimento de Leishmania sp. Tais estágios vão desde a assimilação, transporte e ação de proteases até a oferta intracelular de aminoácidos para sua sobrevivência e multiplicação.

\section{ASSIMILAÇÃO E TRANSPORTE DE AMINOÁCIDOS}

Os aminoácidos e os lipídeos são as principais fontes de carbono para os amastigotas. Tomando-se como base o conhecimento das necessidades dos estágios cultiváveis in vitro e a reconstrução do metaboloma utilizando ferramentas computacionais (Ivens et al., 2005; Opperdoes \& Coombs, 2007), é possível hoje inferirmos que além dos outros nutrientes, os amastigotas captam pelo menos dez dos aminoácidos essenciais do fagolisossoma dos macrófagos (McConville et al., 2007).

Os aminoácidos existentes no interior dos fagolisossomas são obtidos pelos macrófagos, por meio de proteólise de proteínas exógenas e de autofagia, sendo captadas pelos amastigotas por intermédio de transportadores específicos. 
Os aminoácidos essenciais e os não essenciais, mais ornitina, aldometionina e treonina, são transportados especificamente e distintamente (essenciais versus não essenciais) por transportadores denominados de permeases existentes em sua membrana plasmática. O transportador AAP3 para a arginina, e AAP7 para a lisina, foi recentemente clonado (Shaked-Mishan et al., 2006).

A interface entre os amastigotas e os fagolisossomas são o lúmen e a membrana limitante dos fagolisossomas. Portanto, durante seu estágio intracelular as amastigotas de Leishmanias utilizam esse caminho para assimilar seus aminoácidos (Figura 1).

Em promastigota, existem pelas menos duas hipóteses, entretanto a maioria das opiniões aponta para o caminho lisossomal e envolvimento do tráfego de membrana de constituintes proteicos. Contudo, diversas enzimas das classes cisteína e serina-proteases intracelulares não lisossomais foram purificadas de sobrenadantes de cultura, e embora a função biológica não tenha ainda sido esclarecida, observações indicam uma ação sobre substratos proteicos que aumentariam o pool de aminoácidos para fins nutricionais.

Figura 1 - Assimilação de aminoácidos por amastigotas intracelulares

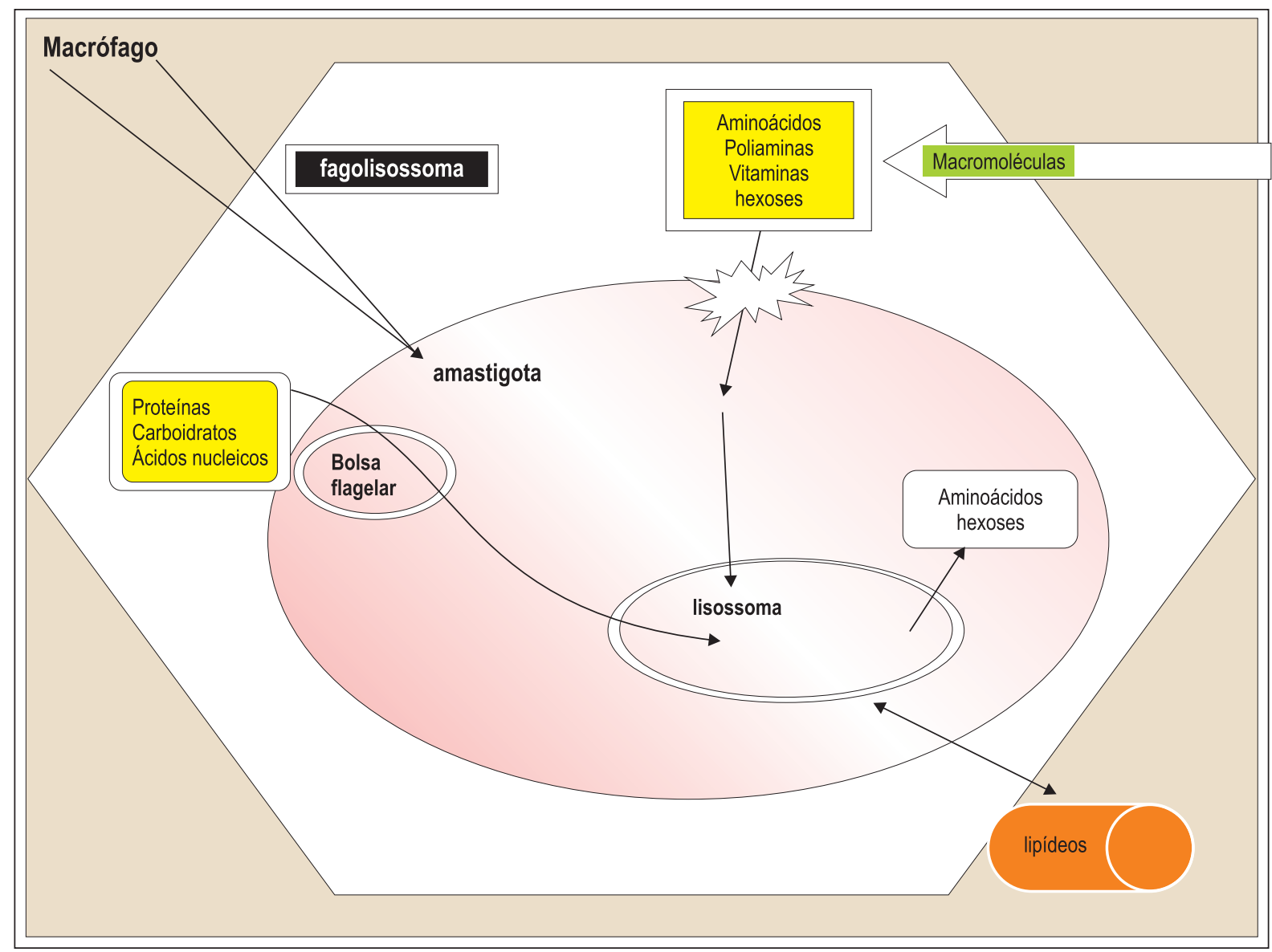

Os nutrientes essenciais, cátions e outras fontes de carbono chegam ao fagolisossomas valendo-se da via endocítica ou pelo citosol dos macrógafos. A captação de aminoácidos por amastigotas é feita mediante permeases, proteínas transportadoras específicas da membrana do parasito. Outro mecanismo existente envolve a captação de macromoléculas (proteínas, DNA, carboidratos) e é realizado por endocitose.

Fonte:adaptada de McConville et al., 2007. 


\section{Transportadores de aminoácidos}

As Leishmanias sintetizam um subconjunto de aminoácidos (não essenciais), mas outros devem ser importados. As proteínas que realizam tal função são denominadas de permeases. Essas proteínas membranares estão amplamente distribuídas em células eucarióticas e, além de ter a função de assimilar aminoácidos necessários às múltiplas funções biológicas, assimilam aminoácidos como precursores para a biossíntese de proteínas e outras vias biossintéticas, como poliaminas e pirimidinas.

Mesmo para aminoácidos sintetizados por uma célula, podem existir permeases que complementam o abastecimento necessário para a biossíntese. Transportadores de aminoácidos representam uma das maiores famílias de permeases codificadas dentro do genoma de muitos eucariotos, e estão distribuídas em muitas classes e superfamílias (<www. bioparadigms.org/slc/menu.asp>). Na verdade, entre os parasitos cujos genomas foram sequenciados (L. major, T. brucei e T. cruzi), o maior grupo de transportadores de aminoácidos são as permeases (3-40 genes), com a possível exceção dos transportadores ABC. Vários transportadores de aminoácidos têm sido extensivamente estudados em alguns microrganismos como leveduras e em mamíferos, mas há escassez de conhecimento a respeito dessa família de proteínas entre os protozoários parasitários.

o primeiro gene transportador de aminoácidos de Leishmania sp. clonado e funcionalmente caracterizado foi o transportador de arginina AAP3 de L. donovani (LdAAP3) (Shaked-Mishan et al., 2006). A proteína pertence à superfamília auxina aminoácido permease (AAP), no entanto os membros desta família em Leishmania são bastante divergentes e representam um clã em separado. A arginina é um aminoácido essencial e deve ser assimilado do meio onde o parasito estiver. Este aminoácido é usado apenas para a síntese de proteínas e como precursor para a síntese de poliaminas. O transporte e os níveis de RNAm da proteína transportadora LdAAP3 aumentaram cerca de cinco vezes quando parasitos deficientes em Arg foram colocados em contato com o aminoácido (Darlyuk et al., 2009). Da mesma forma, o aumento da expressão da proteína LdAAP3 foi abolida, quando o equilíbrio intracelular foi atingido. Tais observações sugerem que o parasito, diante das necessidades intracelulares, aumenta ou diminui o transporte de Arg para manter a homeostase. Recentemente, um gene transportador de lisina de L. donovani (LdAAP7) e seu ortólogo em T. cruzi (TcAAP7) foram clonados e funcionalmente expressos. A incapacidade de suprimir o gene LdAAP7 sugere que este seja o único transportador de lisina em $L$. donovani e que tal permease é essencial para promover a captação deste aminoácido.

\section{OFERTA INTRACELULAR DE AMINOÁCIDOS}

\section{Construindo vias metabólicas na era genômica}

Pelo menos três projetos de sequenciamentos genômicos de Leishmania e outros tantos de tripanossomatídeos e protozoários patogênicos foram concluídos, e as informações geradas estão nos fornecendo dados para uma reconstrução metabólica. A anotação de genomas e reconstrução metabólica é um esforço complementar necessário que requer subsequente isolamento das enzimas e caracterização de suas funções/atividades enzimáticas.

Quando um genoma é totalmente sequenciado e necessário ajustar os genes identificados ao seu contexto funcional. Essa etapa é limitada pela exatidão da anotação dos genes. A procura para o reconhecimento do produto do gene começa com a identificação de quadros de leitura abertas, seguida pela identificação das proteínas codificadas. Algoritmos computacionais são então utilizados para permitir diferentes níveis de automação do processo, entretanto tais algoritmos apresentam desempenho variável perante diferentes genomas ao tentar identificar genes. Portanto, as previsões mais confiáveis são as daqueles que utilizam uma inspeção manual. A identificação final do produto do gene, porém, só é alcançada pela caracterização bioquímica e molecular. Contudo, uma vez que a anotação dos genes 
esteja disponível, podemos classificar seu produto (de acordo com o seu papel inferido) e realizar a reconstrução de aspectos da biologia do organismo.

Leishmania e Trypanosoma evoluíram de um ancestral comum e compartilham muitas características. Assim, era de se esperar que muitos dos genes de diferentes tripanossomatídeos fossem ortólogos, como já foi comprovado (El-Sayed et al., 2005). No entanto, existem algumas diferenças biológicas substanciais entre tripanossomatídeos, e estas podem ser ilustradas considerando-se suas estratégias de história de vida. Notavelmente, as leishmânias se desenvolvem dentro de um vacúolo parasitóforo presente em células mononucleares de um mamífero hospedeiro, portanto adaptado para alcançar esse nicho apropriado metabolicamente à sua sobrevivência. Desse modo, acreditase que a capacidade metabólica de amastigotas evoluiu para garantir que tal estágio estivesse totalmente adaptado para a sua existência intracelular.

Da mesma forma, promastigotas estão adaptados à vida em diferentes partes das glândulas salivares do inseto vetor (exceto para o complexo de L. braziliensis). Além disso, flebotomíneos diferem dos vetores de tripanossomos em sua biologia (ex., sua fonte de alimento), acarrentando implicações para o parasito do gênero Leishmania dentro deles. Há agora informações completas sobre os genes de Leishmania e isso deve ajudar os pesquisadores a deduzir as suas adaptações para cada uma das fases do seu ciclo de vida. Todavia, ainda não se sabe quando, no ciclo de vida de muitos dos genes, são funcionalmente importantes. Presumivelmente, essas análises serão concluídas em breve, embora seja duvidoso que as análises globais de transcriptomas e proteômas possam fornecer todas as respostas, tornando-se necessário um estudo detalhado de grupos de genes por longos anos. Além disso, o conhecimento dos ambientes em que as diferentes formas do parasito residem, como o vacúolo parasitóforo, continua pobre, fato que limita a capacidade dos pesquisadores para imitar essas condições experimentalmente. É sabido que existe uma variação de pH entre o amastigota que reside em um ambiente ácido, enquanto acredita-se ser o hábitat de promastigotas mais próximo de neutro. Isso tem implicações na aquisição de nutrientes (Burchmore \& Barrett, 2001), embora o pH interno de ambas as formas do parasito deva girar em torno de neutro. Outro aspecto que nos parece ser importante na definição das rotas/vias metabólicas é a disponibilidade de $\mathrm{O}_{2}$ e $\mathrm{CO}_{2}$. Amastigotas e promastigotas respondem, metabolicamente, de forma diferente diante da disponibilidade de gás (Hart \& Coombs, 1981; Darling et al., 1989) e das diferenças dos ambientes em que residem.

\section{Genômica e metabolismo de aminoácidos}

Os resultados das análises de bioinformática do genoma de Leishmania braziliensis, Leishmania infantum, Leishmania amazonensis e Leishmania major podem ser encontrados em bases de dados genômicos. O genoma de L. major apresenta 36 cromossomos (32,8 megabase, 911 genes RNA, 39 pseudogenes) que comportam 8.272 genes codificadores de proteínas (3.083 cluster e 662 famílias). Apenas 36\% desses genes puderam ser relacionados à sua possível função biológica e um pouco menos de $2 \%$ corresponde a proteases (El-Sayed et al., 2005). As sequências de $L$. infantum e $L$. amazonensis ainda não estão concluídas. Nessa fase, a base de dados Merops (<www.merops. ac.uk>) aponta para 56-84 genes de proteases identificadas nas três primeiras espécies de Leishmania e 18 genes para enzimas do metabolismo de aminoácidos (L. infantum), entretanto uma análise mais aprofundada das sequências de nucleotídeos necessitará ser realizada e revista ao longo dos próximos anos. Como as proteases estão diretamente envolvidas na manutenção do pool intracelular de aminoácidos, será apresentada a seguir uma breve descrição das principais proteases caracterizadas em Leishmania sp. até o momento.

\section{Proteases}

A clivagem proteolítica de ligações peptídicas é uma das mais frequentes e importantes modificações póstraducionais de proteínas. As peptidases (proteases) recebem o prefixo 'endo' quando clivam ligações no meio de 
cadeias polipeptídicas, podendo neste caso serem chamadas também de proteinases, e o prefixo 'exo' quando clivam ligações em uma das extremidades da cadeia polipeptídica, compreendendo as chamadas 'amino' e carboxipeptidases. Provavelmente, o maior progresso no estudo de proteases tenha sido o estabelecimento de uma classificação racional baseada na comparação dos sítios ativos, mecanismo de ação e estrutura tridimensional. As seis classes reconhecidas pela International Union of Biochemistry and Molecular Biology (IUBMB) são: serina, cisteína, aspártico, metaloprotease e mais recentemente glutâmico e treonina. Posteriormente, foram definidas famílias para agrupar proteases que teriam descendido de um ancestral comum por evolução divergente.

\section{CISTEÍNA-PEPTIDASES}

As cisteína-peptidases formam um grupo de enzimas que contém um resíduo de $\mathrm{Cys}^{25}$ localizado no sítio ativo. A catálise ocorre via um intermediário tiol-éster e é facilitada pelas cadeias laterais de $\operatorname{His}^{159}$ e Asp ${ }^{158}$ (Asn). Em geral, estão localizadas no citosol e em compartimentos lisossomais/megassomas.

Uma análise detalhada do recém-concluído genoma de L. major revelou a presença de genes que codificam um total de 65 cisteína-peptidases, que podem ser agrupadas em quatro clãs e 13 famílias. Muitas dessas enzimas do parasito são suscetíveis de desempenhar papéis cruciais no hospedeiro. No entanto, a maioria dos estudos tem-se concentrado em apenas três tipos de cisteína-peptidases, designadas como: (i) cisteína-peptidases A (CPA), CPB e CPC, pertencentes ao Clan CA da Família C1 (papaína-símile); (ii) calpain-símile, pertencente à família C2; e (iii) metacaspase, da família C14, que tem alta atividade peptidásica (Robertson \& Coombs, 1990) (Figura 2).

As catepsinas L-símiles correspondem à maioria da atividade detectada e assim designada peptidases cisteínaTipo I. Essas enzimas são encontradas em L. major e em L. mexicana e são codificadas por genes multicópia (oito na primeira e 19 na segunda), apresentando uma extensão C-terminal incomum. Embora o maior nível de atividade tenha sido identificado nas formas amastigotas, os dois primeiros genes são predominantemente transcritos em promastigotas metacíclicos. Uma organização genômica similar de genes catepsina-L, como foi descrito em L. pifanoi, ocorre em L. donovani (Mottram, Coombs \& Alexander, 1994). Peptidases CPA (Tipo II) também apresentam homologia com a catepsina L, uma enzima codificada por um único gene exemplar, e têm sido detectadas nas formas infectantes (amastigotas e promastigotas metacíclicos) de L. mexicana e L. major.

Cisteína-peptidase C (CPC) ou peptidase Tipo III é uma enzima catepsina B-símile expressa por um gene único em todas as fases de desenvolvimento de L. mexicana e de L. major (Mottram, Coombs \& Alexander, 1994; Coombs \& Mottram, 1997; Mottram et al., 1989). Cisteína-peptidases parecem ser relevantes para os vários aspectos do ciclo de vida de Leishmania e da relação parasito-hospedeiro. Entre outros, as cisteína-peptidases participam da nutrição do parasito, desempenham um papel essencial na bem-sucedida invasão de macrófagos e participam dos mecanismos de escape do sistema imune (Mundodi et al., 2002).

Além disso, parece que as CPBs são importantes fatores de virulência que modulam a resposta imune do hospedeiro, facilitando o crescimento intracelular do parasito. A multiplicidade dos genes pode atuar como um mecanismo que garanta a síntese de grandes quantidades da enzima. As isoenzimas CPB caracterizadas até agora são altamente conservadas, mas algumas diferenças de atividade são evidentes, demonstrando que as poucas variações de aminoácidos nas posições estratégicas são realmente importantes na modificação das especificidades de substrato das isoenzimas, os quais podem fornecer ao parasito uma ampla gama de atividades hidrolíticas (Juliano et al., 2004).

As CPBs de L. mexicana estão confinadas nos lisossomas das formas amastigotas, sendo também encontradas no compartimento multivesicular túbulo-lisossoma de promastigotas. Entretanto, a rota do tráfego das cisteínapeptidases de Leishmania parece envolver, além dos lisossomas, a bolsa flagelar e o caminho endosomal (Brooks et al., 2000; McConville et al., 2002). Um modelo de processamento e tráfego é apresentado na Figura 3. Estudos sobre 
o efeito de inibidores de cisteína-peptidase apontaram que, independentemente da química do inibidor, as alterações morfológicas produzidas no parasito foram semelhantes, mesmo sem se levar em conta a eficácia e os inibidores testados (Selzer et al., 1999).

Figura 2 - Clãs e famílias de proteases em Leishmania sp. Os números entre parênteses correspondem ao número de espécies moleculares de cada família

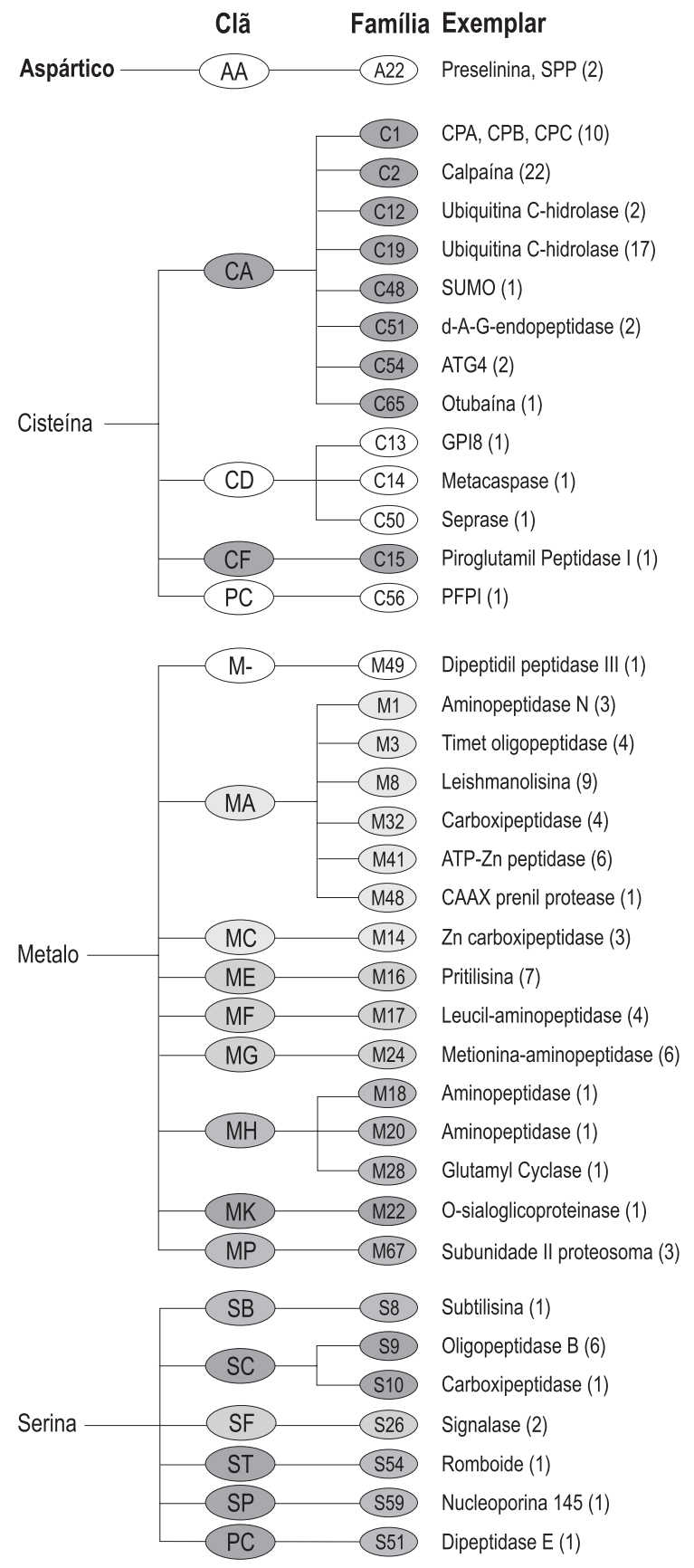


Figura 3 - Modelo de processamento de cisteína-proteases e tráfego, sobreposto a uma micrografia eletrônica de transmissão de amastigotas de Leishmania

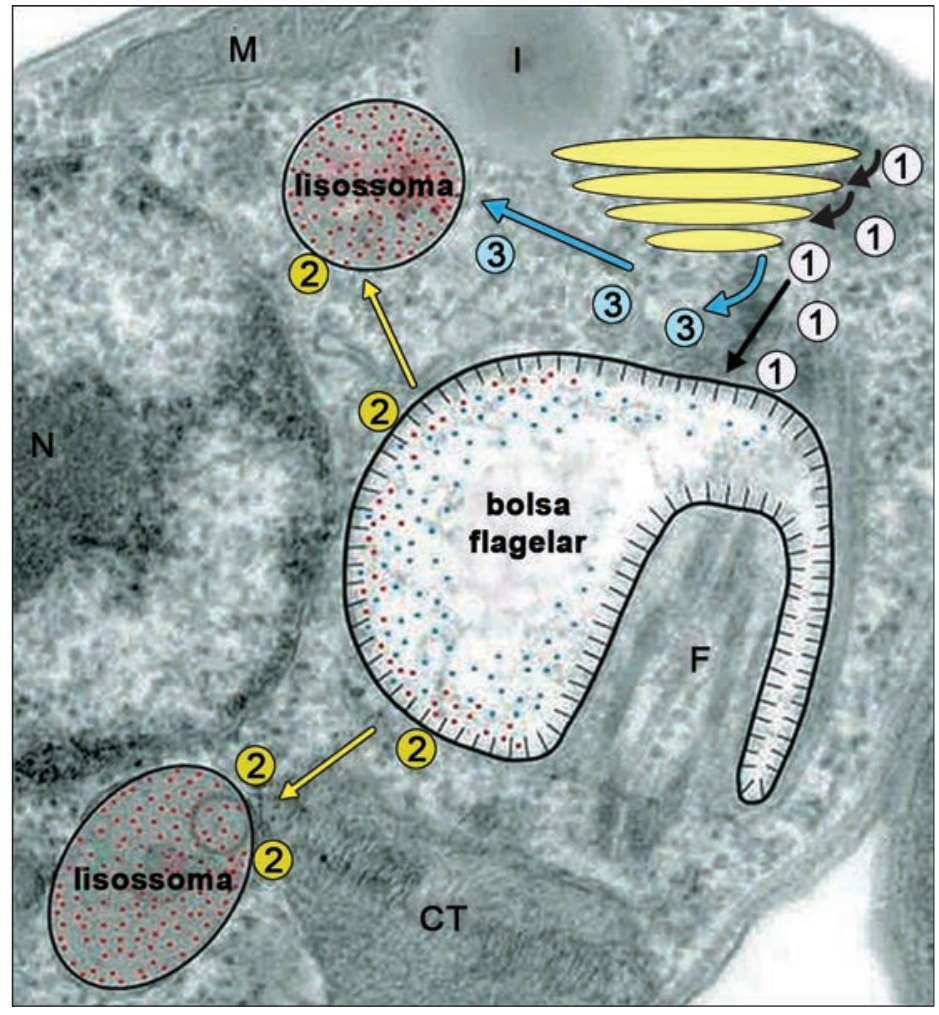

A rota principal do tráfego proposta envolve zimogênio (3) em vesículas produzidas a partir do complexo de Golgi (amarelo) que se move para fusão com a bolsa flagelar. Após a ligação a um possível receptor da bolsa flagelar (representado por linhas pretas que se estendem desde a membrana da bolsa flagelar), a protease cisteína é ativada para a forma madura (1) e, em seguida, transportada para o lisossoma/megassoma (2). Um segundo possível caminho (indicado com um ponto de interrogação) envolve 0 tráfego direto de vesículas (3) do lisossomo com a ativação do zimogênio.

Abreviações: F - flagelo; I - corpo de inclusão (lipídeos); CT - cinetoplasto; M - mitocôndria; N - o núcleo

Fonte: adaptada de Brooks, 2000.

Calpaínas são peptidases neutras da família C2 presentes em uma variedade de organismos, incluindo Leishmania spp., e estão envolvidas em diversos processos celulares, como: apoptose, transdução de sinal, diferenciação celular e remodelação do citoesqueleto. Sao enzimas não lisossomais ativadas alostericamente por $\mathrm{Ca}^{2+}$. Cerca de 27 genes que codificam para calpaínas-símiles foram identificados nos genomas de Leishmania spp. (L. major, L. infatum e L. braziliensis) finalizados ou em progresso, entretanto, em sua maioria suas funções biológicas permanecem desconhecidas.

SERINA-PEPTIDASES (EC 3.4.21)

A maior família de peptidases corresponde à família da quimiotripsina (S1). O marco central do sítio ativo destas enzimas é a tríade catalítica Asp ${ }^{102}$, His $^{57}$ e $\operatorname{Ser}^{195}$ (baseado na numeração da quimiotripsina). A catálise procede via um intermediário de estado de transição tetraédrico durante os estágios de acilação e deacilação. O mesmo tipo de mecanismo está envolvido em todas as reações de serina-proteases. Nosso entendimento atual do mecanismo de ação dessas enzimas é ilustrativo de todo o grupo de enzimas envolvidas na transferência de fragmentos, apesar de que, nesse caso, a transferência é para a água. A transferência intermediária da porção acila de um substrato para formar uma ligação covalente com um grupo funcional da enzima é um aspecto comum entre as serina-proteases e outras transferases (Figura 4). 
Figura 4 - Mecanismo catalítico das serina-proteases

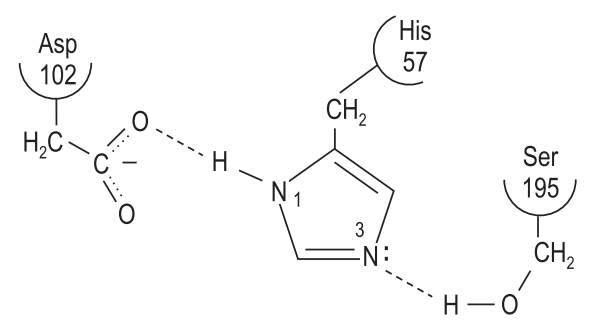

Os genomas de Leishmania sp. concluídos até o momento estimam que esses parasitos apresentam cerca de 13 diferentes serina-proteases, distribuídas pelas famílias S8, S9, S10, S26, S51, S54 e S59 (Figura 2). Foram identificados genes que codificam para uma família de subtilisina-símile, prolil oligopeptidase, uma peptidase sinal tipo I, uma subunidade reguladora do proteassoma 26S, uma serina carboxipeptidase, uma nucleoporina homóloga e uma família serina-peptidase intramembranares (romboidas-símiles ortólogas). A família prolil oligopeptidase (Peptidase família S9) inclui a prolil oligopeptidase B (subfamília Peptidase S9a), dipeptidil peptidase IV (Peptidase S9b subfamília), peptidase acilaminoacil (subfamília Peptidase S9c) e glutamil peptidase (subfamília Peptidase S9D) (Rawlings, Morton \& Barrett, 2006). Essa família de enzimas é diferente da clássica família de proteases serina, tripsina e subtilisina, em que as enzimas clivam substratos peptídicos, excluindo-se apenas as proteínas de grande porte (Gerczei, Keseru \& Naray-Szabo, 2000). As enzimas consistem em um domínio peptidase com uma hidrolase b/enovelada e sete domínios $\beta$-hélice (Fülöp, Böcskei \& Polgár, 1998; Gerczei, Keseru \& Naray-Szabo, 2000; Rea \& Fülöp, 2006).

O genoma de L. major codifica para uma prolil oligopeptidase (Q4Q080, família S9a), duas oligopeptidases B (Q4QHU7 e Q4QJ45, família S9a) e duas serina-peptidases (Q4Q4J7 e Q4QGF5, família S9D). Nenhum dos componentes da subfamília S9c foi encontrado. As oligopeptidases B clivam em resíduos de arginina e lisina (Pacaud \& Richaud, 1975; Polgár, 2002), embora apresentem maior eficiência catalítica em substratos dibásico (Ashall et al., 1990; Polgár, 1997; Morty, Fülöp \& Andrews, 2002; Hemerly et al., 2003).

Apesar de as serina-peptidases serem o maior grupo de proteases investigadas, apenas alguns membros dessa classe de peptidase foram bem caracterizadas em Leishmania sp. (Silva-Lopez \& De-Simone, 2004b). Destas, apenas duas têm sido mais bem estudadas: oligopeptidase B (OpB) e PoP-Tc80, enzimas citoplasmáticas e membros da família das prolil oligopeptidases (PoP) (CE 3.4.21.83; clã SC, família S9).

No genoma de L. major foram identificadas também duas oligopeptidases B. OpB de L. major foi a primeira a ser identificada (Rafati et al., 2004) e, em seguida, reanotada no banco de dados genômicos (Ivens et al., 2005). As outras oligopeptidases B identificadas apresentam diferenças significativas em relação à primeira e, assim, foram denominado OpB-símile.

Os componentes dessa família apresentam atividade proteolítica sobre peptídeos de baixa massa molecular, além de especificidade do tipo tripsina-símile, isto é, atuam clivando ligações peptídicas carboxila terminal de resíduos básicos (Morty et al., 1999). Duas OpB (OpB-símile e OpB-2) foram identificadas no genoma de L. major e confirmadas experimentalmente mediante clonagem por nosso grupo (Guedes et al., 2008; Guedes et al., 2010). Em T. cruzi, a oligopeptidase B (PoP-TC) está diretamente envolvida no estabelecimento da infecção, modulando a atividade de cálcio a partir de uma molécula precursora citosólica (Tardieux et al., 1992).

Outra enzima identificada foi a S26-peptidase sinal (EC 3.4.21.89) tipo I, (26-Spase-I), membro da família de proteases associadas à membrana, cuja função é clivar o peptídeo sinal N-terminal das proteínas que são translocadas através das membranas biológicas. O gene que codifica essa proteína foi identificado em $L$. infatum, L. major e L. donovani, 
entretanto tem sido classificada como aspártico-protease (Rafati et al., 2004). As Spases-I são proteases únicas, que utilizam uma serina no lugar da lisina e um mecanismo de díade catalítica no lugar da clássica tríade catalítica Asp/His/Ser das serina-proteases. Compare o mecanismo catalítico das serina e aspártico-proteases descrito neste capítulo (Figura 4) para verificar a diferença. Portanto, estamos descrevendo tal enzima como uma possível serina-protease, mas existe a possibilidade de pertencer à classe aspartil protease pelas observações dos autores (Taheri et al., 2010). Porém, devido à sua homologia e o novo conhecimento desse grupo de proteases, acreditamos que em breve deverá ser reclassificada.

Embora a Spase-I bacteriana seja monomérica, peptidases-sinal de células eucarióticas comumente funcionam como complexos oligoméricos contendo duas cópias divergentes do monômero catalítico. Estes são denominados de peptidases-sinal IMP1 e IMP2 da membrana mitocondrial interna, os quais removem peptídeos-sinal de proteínas codificadas para as membranas nucleares e mitocondriais. Além disso, dois componentes da peptidase-sinal do retículo endoplasmático (RE) em mamíferos (18-kDa e 21-kDa) pertencem a essa família e processam muitas proteínas que penetram o RE para retenção ou exportação para o Golgi, vesículas secretoras, membrana plasmática ou vacúolo. Um membro atípico da família Spase tipo S26-I é a peptidase Traf, que tem a notável atividade de produzir uma proteína cíclica do sistema pilina de Pseudomonas.

Até o momento três serina-proteases (Silva-Lopez \& De-Simone, 2004a, 2004b; Silva-Lopez, Pinto Coelho \& DeSimone, 2005), que diferem de outras serina-proteases isoladas de Leishmania (Ribeiro de Andrade et al., 1998), foram caracterizadas enzimaticamente. Uma serina-protease solúvel em detergente (LSP-I) apresenta atividade máxima em $28^{\circ} \mathrm{C}$ e pH7, sendo sensível a variações de temperatura. Essa enzima tem características de uma 26-Spase-I e está associada a membranas celulares (Silva-Lopez \& De-Simone, 2004a), entretanto a sua função celular não está clara. Uma segunda serina-protease solúvel (LSP-II) também com atividade ótima a $28^{\circ} \mathrm{C}$, porém com distinta localização celular, foi isolada (Morgado-Díaz et al., 2005). A localização entre o núcleo e a bolsa flagelar sugere sua associação a processos endocíticos/exocíticos (McConville et al., 2002; Webster \& Fish, 1989). A terceira serina-protease (LSP-III) foi purificada do sobrenadante de cultura de promastigotas e apresenta uma boa estabilidade térmica. Anticorpos anti-LSPIII reagiram contra LSP-I sugerindo similaridade estrutural e de localização celular. Em amastigotas, a enzima também foi encontrada em estruturas eletrodensas correspondendo a megassomos, sítios de atividade proteolítica em Leishmania envolvidos em processos de diferenciação e sobrevivência intracelular (Ueda-Nakamura et al., 2002). Podemos então concluir que a LSP-III é uma enzima secretada, podendo estar, portanto, associada à virulência e/ou patogenicidade. Além disso, o fato de essa enzima estar colocalizada em megassomas com outras proteases poderá possibilitar a compreensão do tráfego intracelular de material proteico, evento fundamental para manter o ciclo de vida do parasito (Silva-Lopez \& De-Simone, 2004a). Outro fato de extrema importância, comum entre as novas serina-proteases caracterizadas, é a modulação negativa da atividade enzimática por $\mathrm{Ca}^{2+}$, o que contrasta com o efeito modulador de serina-proteases de mamíferos, como tripsina e quimiotripsina pancreáticas que requerem $\mathrm{Ca}^{2+}$ para sua atividade.

\section{MetalopePTIDASES (CE 3.4.24)}

Metaloproteases são endopeptidases que possuem como componente ativo um átomo de metal de transição, normalmente zinco. Cerca de 16 famílias de metaloproteases foram identificadas nos genomas de Leishmania sp., dentre estas encontra-se a dipeptidil-peptidase II (família M49), enzima que aparentemente está ausente em tripanossomas, aminopeptiases, carboxipeptidases e dipeptidases, enzimas muito pouco estudadas. A gp63 é a enzima de Leishmania sp. melhor caracterizada e tem recebido distintos nomes ao longo de sua caracterização; PSP (peptidase superfície promastigota) e leishmanolisina, embora a denominação 'principal peptidase de superfície' (MSP) tenha sido escolhida por estar em conformidade com as recomendações da nomenclatura de genes e proteínas de tripanossomatídeos (Clayton et al., 1998). A MSP (EC 3.4.24.36) é um metalopeptidase com uma sequência de ligação de Zn His-Glu-XX-His (motivo HEXXH, código de letra única) e mais um resíduo C-terminal - o terceiro 
ligante de zinco. Essa endopeptidase pertence à família M8 e sua estrutura terciária coloca esta família no clã MA, subclã das metzincinas, MA(M) (Schlagenhauf, Etges \& Metcalf, 1998). O mecanismo de ação e a especificidade de substrato dessa peptidase são semelhantes aos outros membros da família, sendo ativa em uma ampla faixa de $\mathrm{pH}$. Todas as MSPs de Leishmania sp. estudadas até esta data apresentam alta similaridade (Yao, Donelson \& Wilson, 2003) e em promastigotas estão ancoradas por meio de glicosilfosfatidilinositol (GPI).

A expressão da enzima encontra-se aumentada em promastigotas metacíclicos e pode ser um ligante envolvido na interação do parasito com os sistemas de defesa do hospedeiro, incluindo os componentes do sistema complemento e macrófagos. Uma quantidade significativa de MSP está presente no meio extracelular por procedimento autoproteolítico (McGwire et al., 2002) ou secreção (Ellis et al., 2002).

Duas aminopeptidases, a leucilaminopeptidase (LAP) e a metionina aminopeptidase-2 (MetAP2), foram identificadas em Leishmania sp.. A primeira foi clonada e caracterizada bioquimicamente de L. amazonensis, L. donovani e L. major (Morty et al., 1999). A enzima está localizada no citosol de todas as fases do ciclo de vida do parasito e catalisa a remoção de resíduos N-terminais de peptídeos e proteínas. Filogeneticamente é a mais divergente evolutivamente da família M17, incluindo os homólogos de organismos procarióticos e eucarióticos. Além da indicação de que o zinco é o cofator, sua atividade foi demonstrada exclusivamente em substratos sintéticos contendo resíduos leucina, metionina e cisteína, que representam a especificidade de substrato para qualquer LAP conhecida.

Metionina aminopeptidase-2 (MetAP2) é uma enzima monomérica, contendo cobalto. Ela é responsável pela hidrólise do resíduo de metionina iniciador da maioria das proteínas recém-sintetizadas. Essa enzima é fundamental para o crescimento celular e está presente em todos os organismos. A impossibilidade da remoção da Met N-terminal das proteínas recém-sintetizadas acarreta um produto normalmente inativo, fato que leva a um crescimento mais lento ou à letalidade (Lowther \& Matthews, 2000). A caracterização fina da enzima MetAP2 e aminopeptidase-básica de tripanossomatídeos ainda não foi realizada, embora sua presença tenha sido detectadas por meio de inibidores específicos.

\section{AsPÁRTICO-PROTEASES (EC 3.4.23)}

Em geral, aspártico-proteases (EC 3.4.23) (EC number = número de classificação da função enzimática, conferido pela Comissão Internacional de Enzimas) são enzimas bilobuladas homólogas com seu centro ativo, constituído de dois resíduos de ácido aspártico (32 e 215; numeração da pepsina suína) distribuídos geometricamente e unitariamente em cada lóbulo. A maioria dessa classe de enzimas pertence à família da pepsina que inclui enzimas digestivas (pepsina, quimosima, catepsinas lisossomais D) e de processamento (renina) e algumas proteases fúngicas (penicillopepsin, rhizopuspepsin, endothiapepsin). A segunda família compreende proteases virais, como a retropsina do vírus causador da síndrome da imunodeficiência adquirida (HIV/Aids). As retropepsinas, quando sintetizadas, são monoméricas; entretanto, durante a maturação, se dimerizam formando a enzima ativa. Esta família de proteases tem sido muito pouco estudada em tripanossomatídeos e outros agentes parasitários, principalmente por conta de sua pouca relação estrutural. No entanto, felizmente, mais recentemente, tem suscitado um renovado interesse em razão da possibilidade de serem alvos para o desenvolvimento de novos fármacos.

Contrastando com a serina e a cisteína-proteases, a catálise por aspártico-proteases não envolve um intermediário covalente, mas um intermediário tetraédrico. O ataque nucleofílico é atingido pela transferência simultânea de dois prótons: um de uma molécula de água para a díade dos dois grupos carboxilas e um segundo da díade ao oxigênio da carbonila do substrato. Essa catálise ácida-base geral pode ser denominada de mecanismo push-pull e leva à formação não covalente de um intermediário tetraédrico.

Em humanos essa classe de proteases está envolvida em diferentes processos celulares, desde a clivagem de proteínas com finalidade nutricional até processamento e maturação de proteínas intracelulares e intramembranares. 
O genoma de L. infantum, L. major e L. amazonensis (dados não mostrados) prevê a sequência gênica de duas aspartil-proteases. Contudo, até o momento somente uma única atividade enzimática foi detectada em sobrenadantes de extratos celulares usando inibidores enzimáticos (Alves et al., 2005). Nosso grupo, entretanto, identificou, isolou e caracterizou bioquímica e estruturalmente duas distintas aspartil-proteases, uma associada à membrana celular e outra a organelas intracelulares que apresentam distintas especificidades de clivagem [dados do autor não publicados]. Da mesma forma duas distintas atividades foram recentemente descritas em T. cruzi, uma solúvel e outra associada a estruturas membranares (Pinho et al., 2009).

Existe, porém, a possibilidade da existência em Leishmania sp. de uma terceira aspartil protease denominada de peptidase peptídeo sinal (PPS) (Rafati et al., 2004; Taheri et al., 2010).

Tais enzimas são conservadas evolutivamente, apresentando representantes em eucariotos superiores, fungos, protozoários, arachea e plantas. As PPSs têm uma relação funcional com a família das presenilinas (PS) aspartilprotease, mas diferem entre si estruturalmente e em vários outros aspectos fundamentais. Tanto as PSs quanto as PPSs clivam proteínas transmembranares, sendo que as PSs clivam proteínas transmembrares tipo-1 enquanto as PPSs clivam proteínas transmembrana tipo-2. Essa classificação corresponde ao sentido de exposição estrutural do domínio catalítico (Figura 5).

Figura 5 - Representação esquemática da localização membranar das possíveis estruturas (A) e sentido hidrolítico (B) das presenilina (PS) e peptidase peptídeo-sinal (PPs) de Leishmania sp.
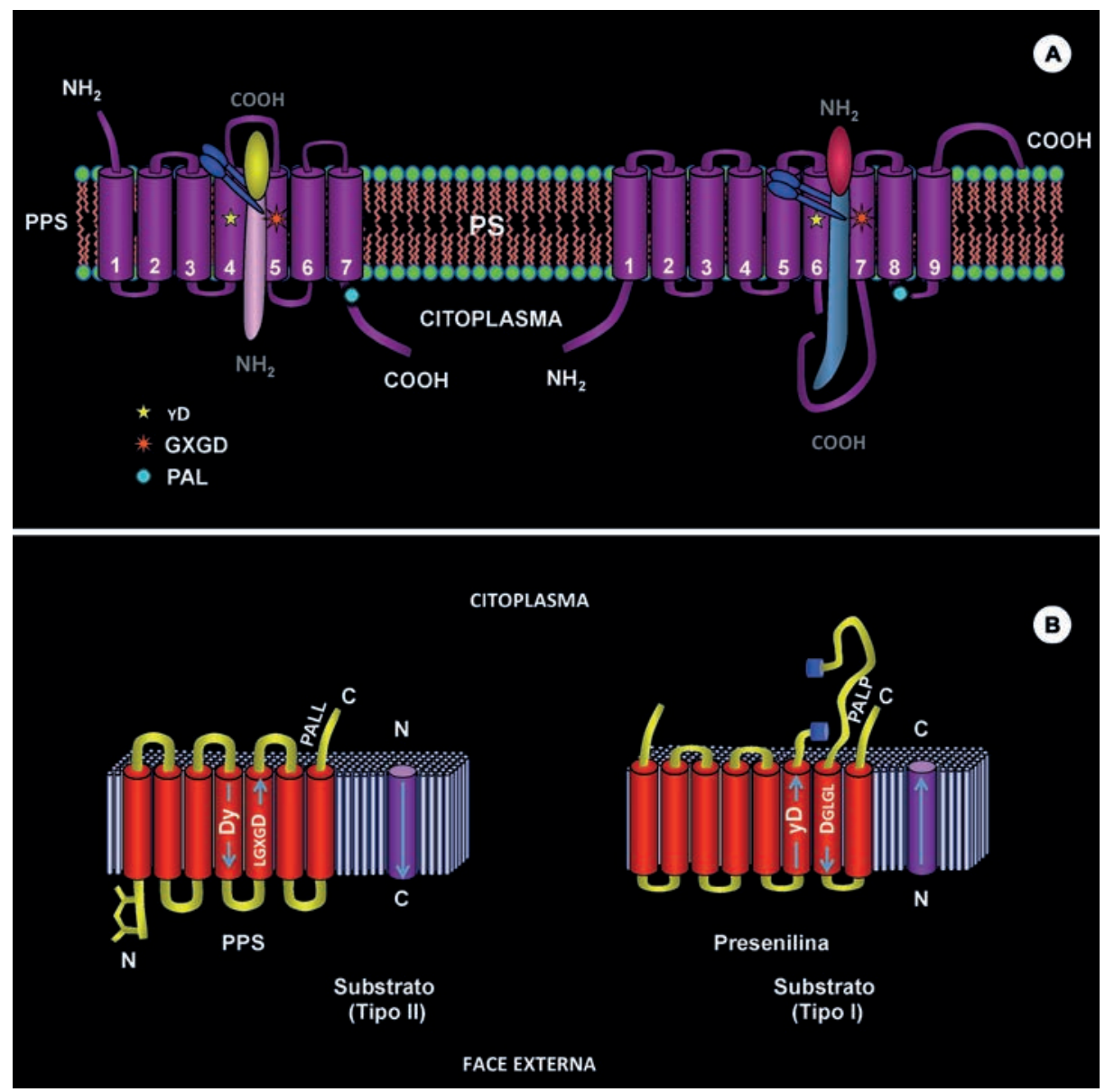
A homologia global entre as PPSs e as PSs é quase nula, todavia as PSs parecem ser proteínas membranares de passo único, enquanto as PPSs de multipasso. As PSs contêm YD e as PPSs GxGD adjacente às membranas e um motivo PAL perto do $\mathrm{COOH}$-terminal conservado de função desconhecida. Diferem quanto à orientação dos domínios transmembrana do sítio ativo (YD e GxGD). Nas PPSs o sítio está invertido em relação às PSs, fato diretamente relacionado à topologia e ao acesso aos substratos (Figura 5).

As PSs atuam como proteases somente quando associadas ao complexo gama-secretase. Tanto em Leishmania sp. quanto em humanos o papel biológico das PPSs é desconhecido, e apenas alguns substratos endógenos foram identificados em humanos. No entanto, há evidências de que os membros dessa família possam regular processos essenciais tanto fisiologicamente como fisiopatologicamente.

\section{COMPLEXOS PROTEICOS ASSOCIADOS À TRANSFORMAÇÃO PROTEICA E METABOLISMO DE AMINOÁCIDOS}

\section{Proteassoma}

É um complexo proteico multienzimático abundante e solúvel presente no citoplasma celular e em outros compartimentos celulares. Tem a função básica de hidrolisar proteínas selecionadas ou anormalmente formadas, a pequenos peptídeos de 3-20 resíduos, os quais são posteriormente transformados em aminoácidos simples por outras enzimas metabólicas. Esse complexo corresponde a aproximadamente $1 \%$ do conteúdo total das proteínas celulares e forma subpopulações com composições diferentes de acordo com a fonte de isolamento ou localização.

Tem sido apontado que os proteassomas podem também estar envolvidos na regulação de importantes processos celulares, incluindo a expressão gênica, a progressão do ciclo celular, diferenciação celular e infectividade (Kisselev \& Goldberg, 2001).

A proteína que vai ser fragmentada necessita ser reconhecida e direcionada ao sítio da clivagem. O processo de marcação é denominado de ubiquitinação. Nesse processo, as proteínas celulares alvo de degradação são marcadas com a ubiquitina, uma proteína composta por 76 aminoácidos. Essa ligação é iniciada entre a glicina carbóxi-terminal da ubiquitina e o grupo $\varepsilon$-amino da lisina na proteína-alvo que deve ser eliminada. Posteriormente, outras ligações similares entre o carbóxi-terminal da ubiquitina com o grupo $\varepsilon$-amino da lisina de outra molécula de ubiquitina ocorre para formar cadeias poliubiquitinadas. Em algumas proteínas (por exemplo, quando há falta de lisina em proteínas), a poliubiquitinação pode ocorrer no resíduo amino terminal. Além disso, o resíduo de lisina onde ocorre poliubiquitinação é importante porque pode atuar como um sinal de degradação mediada pelo proteassoma. A ubiquitinação em outros resíduos de lisina (Lys-63, por exemplo) pode atuar como um sinal para reparo do DNA, ativação de fatores de transcrição etc. Contudo, a monoubiquitinação de proteínas pode ter outras funções, como por exemplo, endocitose.

No gênero Leishmania, o proteassoma tem sido estudado em L. mexicana (Robertson, 1999), L. donovani (Christensen et al., 2000) e L. chagasi (González et al., 1996; Silva-Jardim, Orta \& Ramalho-Pinto, 2004). O proteassoma de L. mexicana se assemelha em tamanho ao de outras espécies, mas parece diferir estruturalmente dos proteassomas de vertebrados.

Apresenta um coeficiente de sedimentação de 20S, massa molecular de $670 \mathrm{kDa}$ (Robertson, 1999) e é composto de pelo menos dez subunidades distintas de $32 \mathrm{kDa}$. Na presença de adenosina-trifosfato (ATP), sua massa molecular aumenta para $1.200 \mathrm{kDa}$. O proteassoma $20 \mathrm{~S}$ purificado de formas promastigotas de L. chagasi apresenta seis proteínas com massas moleculares de 22-35 kDa semelhantes às encontradas para as subunidades de L. mexicana (Robertson, 1999), T. Cruzi (Christensen et al., 2000) e T. brucei (El-Sayed et al., 2005). Tal comportamento se assemelha à de outras espécies eucarióticas, no entanto o proteassoma de L. mexicana tem uma especificidade de substrato mais parecida com a dos proteassomas de eucariontes. 
O proteassoma de L. chagasi, assim como outros proteassomas 20S, exibe maior atividade de tripsina em comparação com a atividade quimiotripsina-símile e hidrolisam, substratos com resíduos volumosos na posição P1 (Figura 6). Em L. mexicana essa posição é ocupada por resíduos hidrofóbicos, básicos e ácidos. Diferentemente, o proteassoma de $L$. mexicana tem maior atividade quimiotríptica (Robertson, 1999). Tal hipótese é apoiada por experimentos realizados com inibidores específicos da atividade proteassômica, como N-carbobenzoxil-Leu-Leu-leucinal (MG132) e lactacistina (Rock \& Goldberg, 1999).

Figura 6 - Representação esquemática do proteassoma 26S de Leishmania sp.
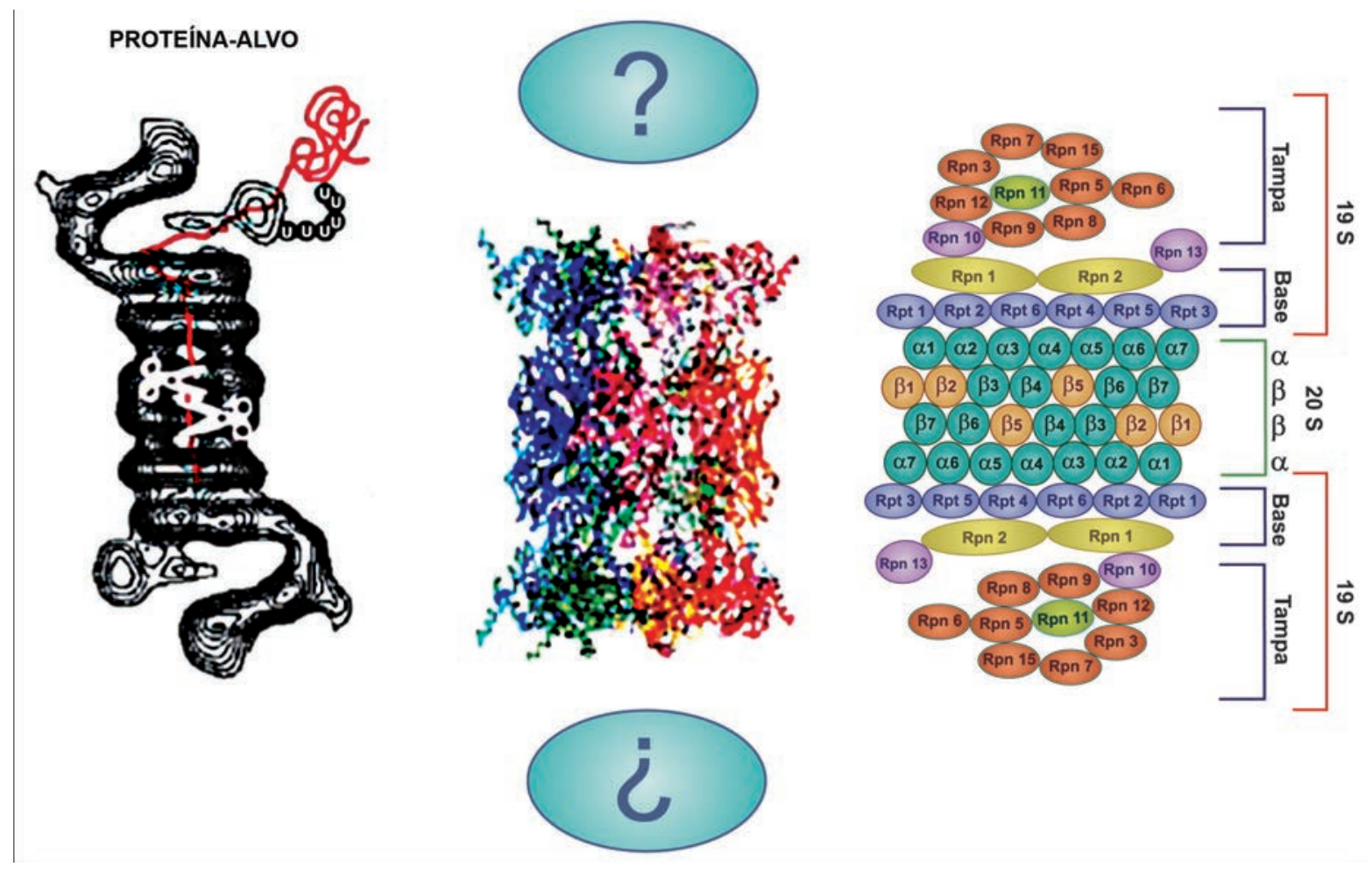

Complexo gama-secretase

O complexo gama-secretase tem características multiproteicas e se encontra presente nas membranas de todos os tipos celulares (desde bactérias até células eucariontes superiores). Tem a função de realizar o processamento seletivo e a maturação de um conjunto de proteínas, em eucariotos superiores denominadas tipo I, endereçadas à membrana plasmática. A composição qualitativa e quantitativa das proteínas do complexo é variável na escala evolutiva. Em eucariotos esse complexo é composto pelas proteínas presenilinas (PSs), nicastrin (Nic), Aph-1 e Pen-2 (detalhes sobre estas duas últimas, ver legenda da Figura 7). A PS apresenta os dois aspartatos que formam o sítio catalítico. Ela é sintetizada como uma holoproteína que é clivada pós-traducionalmente em um fragmento N-terminal (FNT) e em um FCT, os quais permanecem vinculados como um heterodímero.

Discute-se muito como o processamento proteolítico pode ocorrer em um ambiente hidrofóbico como a membrana celular, entretanto o conhecimento hoje existente desse complexo advém dos estudos realizados até então com C. elegans e células humanas. Esta última está relacionada à doença de Alzheimer e a eventos de transducção de sinal. Nosso grupo tem-se dedicado ao conhecimento e ao mecanismo de ação dessa classe de proteases há alguns 
anos e, recentemente, conseguiu identificar a presença e a localização celular de todas as proteínas Aph1B, PS-1, PS-2, Nic, Pen-2 que compõem o complexo gama-secretase em Leishmania sp. [dados do autor não publicados]. No momento, estamos solicitando a reanotação das sequências no banco de dados. A grande dificuldade inicial foi a baixa homologia existente entre os componentes dessa classe de proteases, todavia, a descoberta de alguns domínios específicos na estrutura permitiram sua identificação inequivocadamente. Apesar da grande importância fisiológica e na relação parasito-hospedeiro que esse conjunto de proteínas possa ter, uma discussão aprofundada desse complexo foge ao escopo deste capítulo, uma vez que o conhecimento em Leishmania é muito pouco.

Figura 7 - Modelo da possível organização das proteínas membranares que compõem o complexo gama-secretase de Leishmania sp.
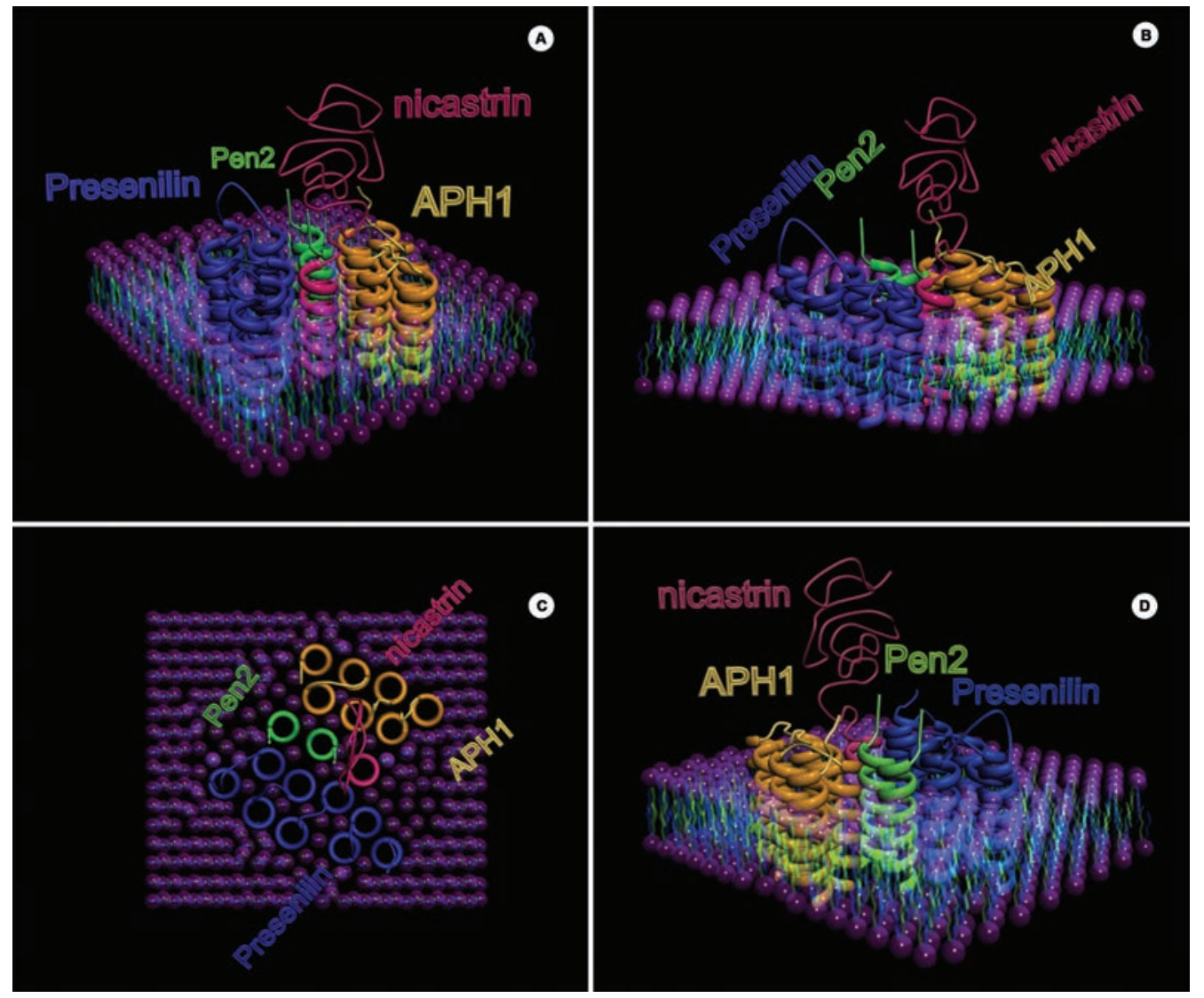

A, C, D - vista lateral; e C - vista de cima.

Aph-1 (faringe-anterior defeituosa 1) - produto do gene da proteína originalmente identificado na via de sinalização Notch em Caenorhabditis elegans como um regulador da localização celular da nicastrina.

Pen-2 (intensificador de presenilina 2) - proteína componente de regulação do complexo gama-secretase.

\section{OXIDAÇÃO DE AMINOÁCIDOS}

Classicamente, a degradação metabólica dos $\alpha$-aminoácidos inicia-se com a remoção do grupo $\alpha$-amino, como amônia ou acetato, e pode ser excretado por peixes e outros animais aquáticos. Organismos terrestres, contudo, convertem amônia em componentes não tóxicos como ureia (mamíferos) ou ácido úrico (pássaros e répteis). O esqueleto de carbono remanescente do aminoácido é frequentemente o $\alpha$-cetoácido, que é então convertido em intermediário capaz de ser assimilado pelo ciclo de Krebs. Entretanto, organismos inferiores, como as Leishmanias, apresentam 
particularidades em seu metabolismo oxidativo de aminoácidos quando comparados a esses organismos e a outros tripanossomatídeos. Para fins didáticos, discutiremos individualmente os principais aminoácidos que sofrem oxidação, estando demonstrada na Figura 8 a inter-relação metabólica.

- Prolina - as enzimas-chave prolina-oxidase e D-1-pirrolina-5-carboxilato desidrogenase foram identificadas nas três espécies de Leishmania cujo genoma foi completado. Como essas enzimas foram também identificadas em T. cruzi e em T. brucei, podemos afirmar que a oxidação da prolina ocorre de maneira semelhante nos três tripanossomatídeos.

- Metionina - as enzimas mitocondriais metilmalonil epimerase-CoA (MME-CoA) e metilmalonil mutase-CoA (MMM-CoA) são necessárias para oxidar o 2-cetobutirato (CB) a succinil-CoA. Estas enzimas estão ausentes em T. cruzi e T. brucei, porém foram identificadas em Leishmania major, fato que sugere que a oxidação completa da metionina ocorre somente em Leishmania sp.

- Treonina - Leishmania dispõe de duas rotas para metabolizar a treonina. Na primeira, pode converter treonina THF por uma via dependente de glicina usando a enzima serina hydroximetiltransferase (SHMT) (também conhecida como treonina aldolase). Além da desmetilação da serina, a SHMT também é capaz de desfazer a ligação $\mathrm{Ca}-\mathrm{Cb}$ da treonina. A glicina resultante pode ser convertida a piruvato por THF-dependente do sistema de clivagem da glicina SCG), seguido por uma serina/treonina desidratase (STD). Alternativamente, pode converter desidratase treonina para 2-cetobutirato, que depois é oxidado a succinil-CoA (Figura 9).

O T. brucei não dispõe de desidratase e SHMT. Ele parece metabolizar a treonina usando o caminho alternativa da aminoacetone, que envolve uma treonina desidrogenase (TDH) mitocondrial e um sintase aminoacetone (2-amino-3CoA ligase cetobutirato). Esta é também a principal via de degradação de treonina em mamíferos, mas não é operacional em Leishmania por causa da ausência do TDH mitocondrial.

- Leucina - este aminoácido pode sofrer tanto transaminação a 2-cetoisocaproato por uma aminotransferase citoplasmática quanto pode ser oxidado por uma acil-CoA desidrogenase de cadeia-curta-ramificada mitocondrial, uma carboxilase e uma hidratase para hidroximetilglutaril-CoA (HMG-CoA).

A enzima seguinte (liase HMGCoA) da via oxidativa clássica não está presente em L. major. Sendo assim, a HMG-CoA é utilizada preferencialmente pela via de síntese de isoprenoides. A presença dessa via metabólica foi demonstrada experimentalmente em L. major (Ginger et al., 2000, 2001). Em T. cruzi e T. brucei, a HMG-CoA segue a via clássica de oxidação, sendo a Leu clivada em acetil-CoA e acetoacetato.

- Aminoácidos não comuns/ciclo da ureia - a presença de um ciclo da ureia totalmente funcional em Leishmania sp. está descartada, entretanto várias enzimas deste ciclo foram identificadas em L. major. A primeira enzima, carbamoilfosfato-sintetase está presente tanto em L. major, quanto em T. cruzi e em T. brucei, mas a sintase e a arginase foram identificadas apenas em L. major. Este fato indica que a arginina, a ornitina e a ureia podem ser formadas apenas pela Leishmania, e não por T. brucei e por T. cruzi.

Tais observações esclarecem uma antiga discussão sobre a excreção de ureia/amoníaco por espécies de tripanossomatídeos (Yoshida \& Camargo, 1978). Entretanto, esse fato pode ter relação com a presença do estágio do parasito no vacúolo parasitóforo, que apresenta um ambiente ácido e consequentemente incompatível com a liberação de amônia, os quais poderiam afetar o pH de hidrólise de certas enzimas proteolíticas. Isso também pode refletir a utilização de aminoácidos do vacúolo por amastigotas.

A ornitina descarboxilase, alvo da droga antitripanossoma - difluorometilornitina -, encontra-se presente tanto em L. major quanto em T. brucei (mas não em T. cruzi). Entretanto, a falta de eficácia da droga contra a Leishmania parece estar relacionada tanto com o transportador do parasito quanto com o ambiente em que vivem, em vez da ausência da enzima-alvo (Müller et al., 2001). 
Figura 8 - Metabolismo de aminoácidos de L. major, T. brucei e T. cruzi

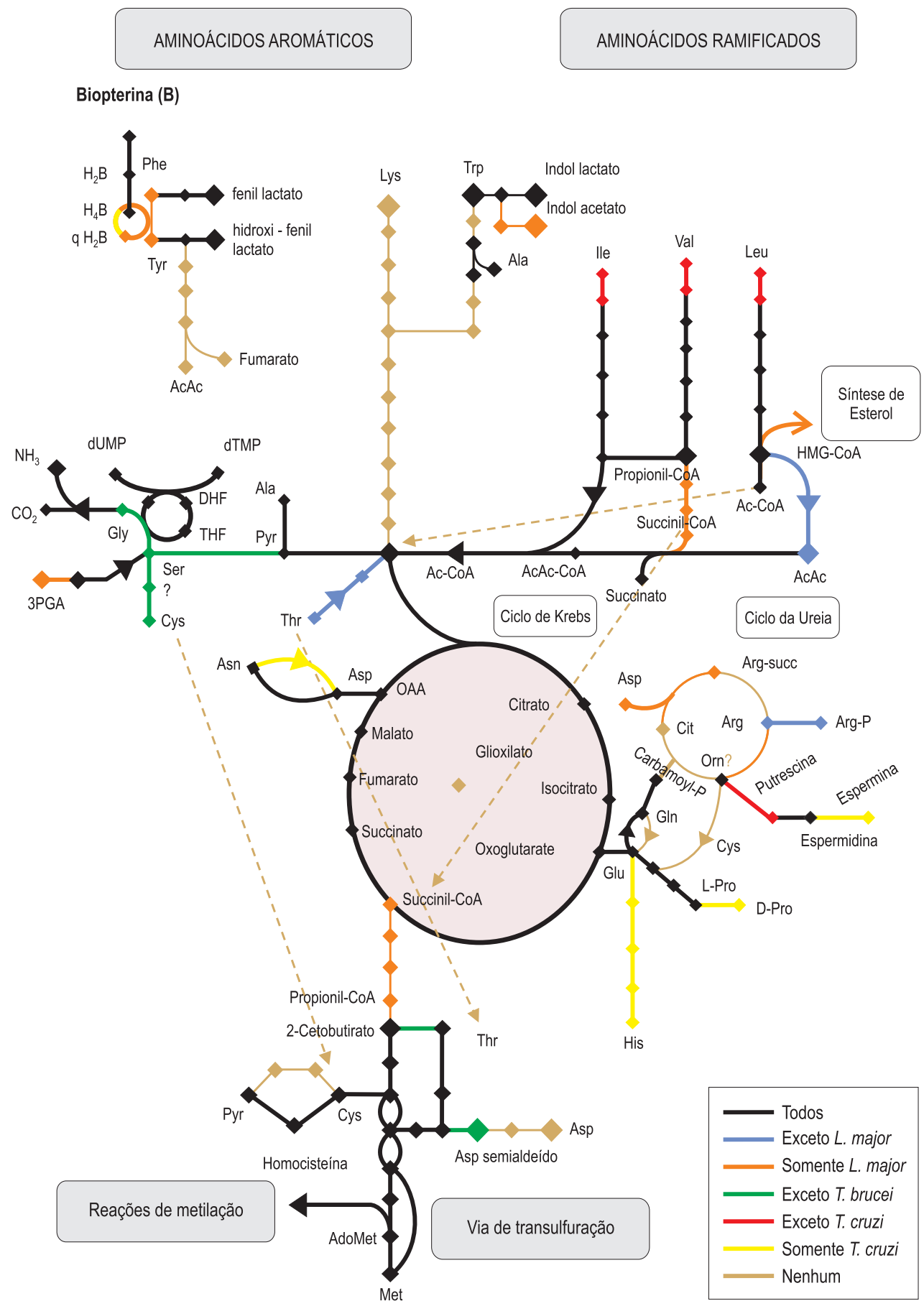

Em preto, estão assinadas as rotas compartilhadas pelos três tripanossomatídeos. Em cinza, estão anotadas tanto as enzimas ausentes do metabolismo de aminoácidos como as do ciclo do glioxilato e ureia (estão presentes na maioria dos outros eucariotos). A chave indica as diferenças entre L. major, T. brucei e T. cruzi. Os pontos de interrogação representam os passos em que não houve uma identificação inequívoca do gene.

Abreviações: Acac - acetoacetato; AdoMet - adenosilmetionina; B - biopterina; Cit - citrulina; FHD - diidrofolato; HMGCOA - CoA hidroximetilglutaril; OAA - ácido oxalacético; Orn - ornitina; PGA - ácido fosfoglicérico; forma - qH2B quinoide de diidrobiopterina; THF - tetraidrofolato.

Fonte: adaptada de Opperdoes \& Coombs, 2007. 
Figura 9 - Metabolismo da treonina em L. major comparada ao metabolismo em T. cruzi e em T. brucei

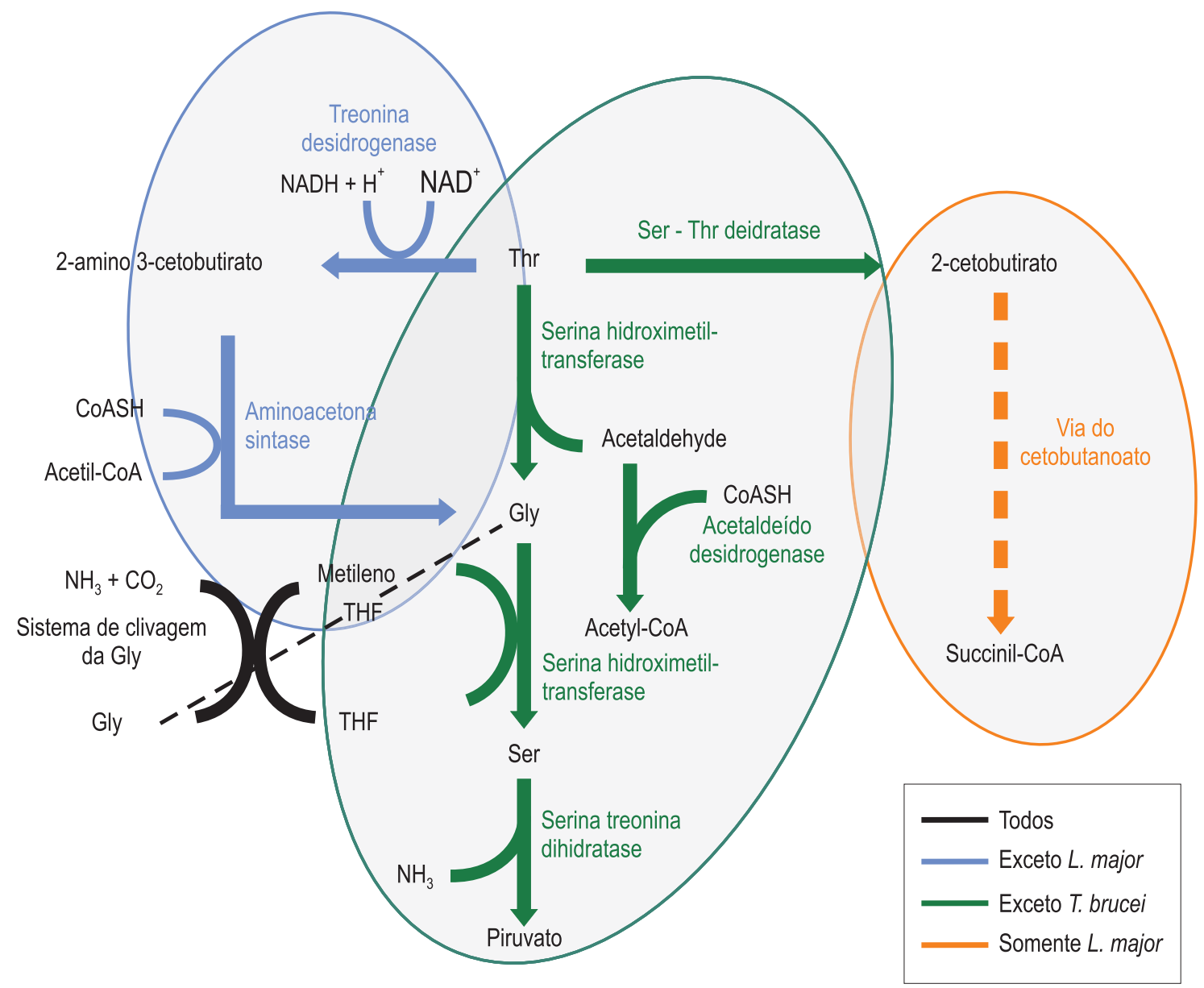

Destacamos a rota do cetobutanoato (verde) em L. major, enquanto em T. brucei e em T. cruzi (laranja) ocorrem à via do aminoacetona. Nota-se também, em T. brucei, a ausência de enzimas necessárias ao metabolismo da treonina (violeta).

\section{SÍNTESE DE AMINOÁCIDOS}

Humanos são capazes de sintetizar 11 dos 20 aminoácidos, ao passo que as leishmânias 13 dos 20 aminoácidos. Portanto, os outros 7-9 aminoácidos necessitam ser assimilados por meio da nutrição. A capacidade de síntese de aminoácidos por Leishmania sp. está limitada aos não essenciais, mais a treonina e a metionina. A maioria dos genes que codificam as enzimas envolvidas na síntese desses aminoácidos foram claramente identificadas nos genomas completados até então.

- Serina - ${ }_{\mathrm{D}}$-3-fosfoglicerato desidrogenase é a primeira enzima da síntese da serina. Está presente em L. major, mas ausente em T. cruzi e em T. brucei, fato que indica diferenças em sua capacidade de sintetizar este aminoácido.

- Cisteína - a cisteína pode ser produzida pela cisteína-sintase, com a eventual participação da 3-sulfotransferase mercaptopiruvato (STMP). Ambas as enzimas foram identificadas em L. major e seus genes estão também presentes em T. cruzi. Além disso, a cisteína pode ser gerada a partir da homocisteína pela rota da transulfuração, presente tanto em T. cruzi quanto em T. brucei. 
Em L. major e T. cruzi, a glicina e a serina podem ser convertidas pela ação do STMP, conforme detalhado anteriormente.

- Alanina/Aspártico/Asparagina - a alanina é formada com base no piruvato, pela alanina-aminotransferase citosólica. Já o aspartato e a asparagina podem ser formados, respectivamente, tendo por base o oxaloacetato, pela enzima aspartato aminotransferase mitocondrial e uma asparagina sintetase. Essas enzimas estão presentes também em T. cruzi e em T. brucei. No entanto, a conversão da asparagina para aspartato não ocorre em T. brucei.

- Prolina/Glutâmico - a capacidade de Leishmania sp. sintetizar prolina difere substancialmente dos outros tripanossomatídeos. A síntese da ${ }_{L}$-prolina $e_{L}$-glutamato ocorrem por meio de $\gamma$-glutamil-fosfato e ${ }_{D}$-1-pirrolina-5carboxilato, pelas enzimas $\gamma$-glutamil quinase, $\gamma$-glutamil fosfato redutase $\mathrm{e}_{\mathrm{D}}$-pirrolina-5-carboxilato redutase.

Em eucariotos superiores, as duas primeiras reações são realizadas normalmente pela enzima bifuncional pirrolina-5-carboxilato sintetase. No entanto, em procariontes, tais atividades são codificadas por distintos genes. 0 gene correspondente é encontrado em L. major (e em T. cruzi, mas não em T. brucei).

A terceira atividade é catalisada por uma enzima independente e seu gene está presente em todos os três tripanossomatídeos. Dessa forma, Leishmania e T. cruzi são capazes de sintetizar prolina a partir do glutamato, ao passo que T. brucei não terá tal capacidade.

Curiosamente, os genes que codificam as enzimas $\gamma$-glutamil quinase e $\gamma$-glutamil-fosfato redutase também estão presentes em L. major, mas não em T. cruzi e em T. brucei. A reconstrução filogenética indicou que essas duas enzimas têm origem bacteriana, enquanto a pirrolina-5-carboxilato sintetase bifuncional é de origem eucariótica.

- Lisina/Treonina/Metionina/Aspártico - a síntese dos aminoácidos essenciais lisina, treonina e metionina, com base no ácido aspártico, como ocorre em alguns organismos, parece não existir ou é incompleta em todos os três tripanossomatídeos. Os genes que codificam a aspartato-quinase (AK) e a aspartato-semialdeído desidrogenase (AAD) não foram detectados em Leismania sp. Sendo assim, a síntese 'de novo' de aspartato parece não ocorrer. $L$. major parece ser capaz de sintetizar tanto a metionina quanto a treonina a partir de semialdeído aspartato, mas tal conversão parece estar ausente nos dois outros tripanossomatídeos.

- Aminoácidos aromáticos/ramificados/Lisina/Histidina - os aminoácidos aromáticos (Phe, Tyr ou Trp), os aminoácidos ramificados (Leu, Ile e Val) e a Lys e His não são sintetizados tanto por Leshmania sp. quanto T. cruzi e T. Brucei, por conta da ausência dos respectivos genes. Portanto, para serem utilizados em suas proteínas, necessitam ser assimilados do meio externo.

\section{CONCLUSÕES E PERSPECTIVAS}

A conclusão dos vários genomas de Leishmania sp. e de outros parasitos tem trazido avanços importantes no conhecimento do metabolismo geral dos diversos organismos. Entretanto, a anotação de genomas de parasitos não é simples por conta da sua grande divergência e viés de composição e, portanto, suscetíveis a pequenas modificações à medida que são determinadas as funções dos genes não identificados nas primeiras rodadas/análises.

Para alguns procariotos de interesse industrial significativo, a reconstrução de redes metabólicas já provou ser útil, por exemplo, no aumento da produção de um produto metabólico desejado. No contexto de um organismo patogênico como Leishmania sp., a reconstrução metabólica teria o potencial de desempenhar um importante papel para se entender a biologia do parasito e na descoberta de alvos ou estratégias para o desenvolvimento de novos medicamentos.

Deu-se início ao sequenciamento de projetos genômicos de Leishmania sp., os quais necessitam ser incrementados em razão da grande variabilidade de espécies. Além disso, os genomas de Leishmania existentes hoje nos bancos 
de dados foram feitos com o uso de espécies isoladas de invertebrados. Agora, os esforços em curso direcionam-se para dar sentido a essa massa de informações em termos de produtos codificados e suas interações no crescimento, desenvolvimento e sobrevivência. Em relação ao metabolismo proteico geral, em Leishmania evidenciam-se três distintos mecanismos proteolíticos de processamento de proteínas: os eventos que ocorrem no interior dos fagolisossomas; os dependentes dos proteassomas; e agora, os dependentes do complexo gama-secretase. Embora cada um tenha especificidade funcional, todos estão interligados por meio de blocos de construção das proteínas, os aminoácidos. Tais elementos tem enorme importância tanto para a síntese de proteínas endógenas, quanto para poliaminas e outros compostos essenciais à sobrevivência do parasito, além de funcionarem como osmólitos.

Como já apresentado, parece que existe uma constância qualitativa das enzimas transportadoras e de oxidação e síntese de aminoácidos identificadas, entre as três espécies de Leishmania e variações importantes com outros flagelados. Da mesma forma, esse fato ocorre também com proteases, proteassomas e com os complexos membranares proteicos. Contudo, diferenças estruturais são evidentes em quase todas essas proteínas, que, de certa forma, podem funcionar como alvos para o desenvolvimento de novos fármacos. Além disso, como as propriedades funcionais desses grupos especiais de proteínas são estritamente dependentes de sua estrutura, a função biológica final, em termos de atividade, pode estar aumentada ou diminuída entre as várias espécies. Consequentemente, tal circunstância pode ocasionar modulação de comportamento - isto é, maior ou menor agressividade ou patogenicidade, quer seja no invertebrado vetor, quer no hospedeiro definitivo -, expressa ou evidenciada na relação hospedeiro-parasito e, por conseguinte, na forma ou no fenótipo da doença.

\section{REFERÊNCIAS}

ALVES, C. R. et al. Leishmnaia amazonensis: early proteinase activities during promastigote-amastigote differentiation in vitro. Experimental Parasitology, 109: 38-48, 2005.

ASHALL, F. et al. Substrate specificity and inhibitor sensitivity of a trypanosomatid alkaline peptidase. Biochimica et Biophysica Acta, 1.035: 293-299, 1990.

BROOKS, D. R. et al. Processing and trafficking of cysteine proteases in Leishmania mexicana. Journal of Cell Science, 13 : 4.035-4.041, 2000.

BURCHMORE, R. J. \& BARRETT, M. P. Life in vacuoles-nutrient acquisition by Leishmania amastigotes. International Journal for Parasitology, 31: 1.311-1.320, 2001.

CHRISTENSEN, C. B. et al. Molecular characterization of a Leishmania donovani cDNA clone with similarity to human $20 \mathrm{~S}$ proteasome a-type subunit. Biochimica et Biophysica Acta, 1.500: 77-87, 2000.

CLAYTON, C. et al. Genetic nomenclature for Trypanosoma and Leishmania. Molecular and Biochemical Parasitology, 97 : 221-224, 1998.

COOMBS, G. H. \& MOTTRAM, J. C. Parasite proteinases and amino acid metabolism: possibilities for chemotherapeutic exploitation. Parasitology, 114, supl.: S61-S80, 1997.

DARLING, T. N. et al. Carbon dioxide abolishes the reverse Pasteur effect in Leishmania major promastigotes. Molecular and Biochemical Parasitology, 33: 191-202, 1989.

DARLYUK, I. et al. Arginine homeostasis and transport in the human pathogen Leishmania donovani. The Journal of Biological Chemistry, 284: 19.800-19.807, 2009.

ELLIS, M. et al. Processing and trafficking of Leishmania mexicana GP63: analysis using GPI8 mutants deficient in glycosylphoaphatidylinositol protein anchoring. The Journal of Biological Chemistry, 277: 27.968-27.974, 2002.

EL-SAYED, N. M. et al. Comparative genomics of trypanosomatid parasitic protozoa. Science, 309: 404-409, 2005. 
FÜLÖP, V.; BÖCSKEI, Z. \& POLGÁR, L. Prolyl oligopeptidase: an unusual â-propeller domain regulates proteolysis. Cell, 94: $161-170,1998$.

GERCZEI, T.; KESERU, G. M. \& NARAY-SZABO, G. Construction of a 3D model of oligopeptidase B, a potential processing enzyme in prokaryotes. Journal of Molecular Graphics and Modelling, 18: 7-17, 2000.

GINGER, M. L. et al. Utilization of leucine and acetate as carbon sources for sterol and fatty acid biosynthesis by Old and New World Leishmania species, Endotrypanum monterogeii and Trypanosoma cruzi. European Journal of Biochemistry, 267: 2.555-2.566, 2000 .

GINGER, M. L. et al. The biosynthetic incorporation of the intact leucine skeleton into sterol by the trypanosomatid Leishmania mexicana. The Journal of Biological Chemistry, 276: 11.674-11.682, 2001.

GONZÁLEZ, J. et al. Proteasome activity is required for the stage-specific transformation of a protozoan parasite. The Journal of Experimental Medicine, 184: 1.909-1.918, 1996.

GUEDES, H. L. M. et al. Oligopeptidase B-2 from Leishmania amazonensis with an usual C-terminal extension. Acta Parasitology, 53: 197-204, 2008.

GUEDES, H. L. M. et al. Serine proteases of Leishmania amazonensis as immunomodulatory and disease-aggravating components of the crude LaAg. Vaccine, 28: 5.491-5.495, 2010.

HART, D. T. \& COOMBS, G. H. The effects of carbon dioxide and oxygen upon the growth and in vitro transformation of Leishmania mexicana mexicana. Molecular and Biochemical Parasitology, 4: 1.117-1.174, 1981.

HEMERLY, J. P. et al. Subsite specificity (S3, S2, S1', S2' and S3') of oligopeptidase B from Trypanosoma cruzi and Trypanosoma brucei using fluorescent quenched peptides: comparative study and identification of specific carboxypeptidase activity. The Biochemical Journal, 373: 933-939, 2003.

IVENS, A. C. et al. The genome of the Kinetoplastid parasite, Leishmania major. Science, 309: 436-442, 2005.

JULIANO, M. A. et al. Differences in substrate specificities between cysteine protease CPB isoforms of Leishmania mexicana are mediated by a few amino acid changes. European Journal of Biochemistry, 271: 3.704-3.714, 2004.

KISSElEV, A. F. \& GOLDBERG, A. L. Proteasome inhibitors: from research tools to drug candidates. Chemistry and Biology, 8: 739-758, 2001.

LOWTHER, W. \& MATTHEWS, B. W. Structure and function of the methionine aminopeptidases. Biochimica et Biophysica Acta, 1.477: 157-167, 2000.

McConVILLE, M. J. et al. Secretory patway of trypanosomatid parasite. Microbiology and Molecular Biology Reviews, 66: 122-154, 2002.

McConVILLE, M. J. et al. Living in a phagolysosome; metabolism of Leishmania amastigote. Trends in Parasitology, 23: $368-375,2007$.

McGWIRE, B. S. et al. Extracellular release of the glycosylphosphatidylinositol (GPI)-linked Leishmania surface metalloprotease, gp63, is independent of GPI phospholipolysis: implications for parasite virulence. Journal of Biological Chemistry, 277(11): 8.802-8.809, 2002.

MORGADO-DÍAZ, J. A. et al. Subcellular localization of an intracellular serine protease of $68 \mathrm{kDa}$ in Leishmania (Leishmania) amazonensis promastigotes. Memórias do Instituto Oswaldo Cruz, 100: 377-383, 2005.

MORTY, R. E.; FÜLÖP, V. \& ANDREWS, N. W. Substrate recognition properties of oligopeptidase B from Salmonella enterica serovar Typhimurium. Journal of Bacteriology, 184: 3.329-3.337, 2002.

MORTY, R. E. et al. Oligopeptidase B from Trypanosoma brucei, a new member of an emerging subgroup of serine oligopeptidases. The Journal of Biological Chemistry, 274: 26.149-26.156, 1999.

MOTTRAM, J. C.; COOMBS, G. H. \& ALEXANDER, J. Cysteine peptidases as virulence factors of Leishmania. Current Opinion in Microbiology, 7: 375-381, 2004. 
MOTTRAM, J. C. et al. A cysteine proteinase cDNA from Trypanosoma brucei predicts an enzyme with an unusual C-terminal extension. Febs Letter, 258: 211-215, 1989.

MÜLLER, S. et al. Targeting polyamines of parasitic protozoa in chemotherapy. Trends in Parasitology, 17: 242-249, 2001.

MUNDODI, V. et al. Genomic organization and functional expression of differentially regulated cysteine protease genes of Leishmania donovani complex. Gene, 282: 257-265, 2002.

OPPERDOES, F. R. \& COOMBS, G. H. Metabolism of Leishmania: proven and predicted. Trends in Parasitology, 23: 150$158,2007$.

PACAUD, M. \& RICHAUD, C. Protease II from Escherichia coli. The Journal of Biological Chemistry, 250: 7.771-7.779, 1975.

PINHO, R. T. et al. Trypanosoma cruzi: isolation and characterization of aspartyl proteases. Experimental Parasitology, 122: 128-133, 2009.

POLGÁR, L. A potential processing enzyme in prokaryotes: oligopeptidase B, a new type of serine peptidase. Proteins, 28: 375-379, 1997.

POLGÁR, L. The prolyl oligopeptidase family. Cellular and Molecular Life Sciences, 59: 349-362, 2002.

RAFATI, S. et al. Type I signal peptidase from Leishmania is a target of the immune response in human cutaneous and visceral leishmaniosis. Molecular \& Biochemical Parasitology, 135: 13-20, 2004.

RAWLingS, N. D.; MORTON, F. R. \& BARRETT, A. J. MEROPS: the peptidase database. Nucleic Acids Research, 34: D270D272, 2006.

REA, D. \& FÜLÖP, V. Structure-function properties of prolyl oligopeptidase family enzymes. Cell Biochemistry and Biophysics, 44: 349-365, 2006.

RIBEIRO DE ANDRADE, A. et al. Leishmania (Leishmania) amazonensis: purification and enzymatic characterization of a soluble serine oligopeptidase from promastigotes. Experimental Parasitology, 89: 153-160, 1998.

ROBERTSON, C. D. The Leishmania mexicana proteasome. Molecular and Biochemical Parasitology, 103: 49-60, 1999.

ROBERTSON, C. D. \& COOMBS, G. H. Characterization of three groups of cysteine proteinases in the amastigotes of Leishmania mexicana mexicana. Molecular and Biochemical Parasitology, 42: 269-276, 1990.

ROCK, K. L. \& GOLDBERG, A. L. Degradation of cell proteins and the generation of MHC class I-presented peptides. Annual Review of Immunology, 17: 739-779, 1999.

SCHLAGENHAUF, E.; ETGES, R. \& METCALF, P. The crystal structure of the Leishmania major surface proteinase leishmanolysin (gp63). Structure, 6: 1.035-1.046, 1998.

SELZER, P. M. et al. Cysteine protease inhibitors as chemotherapy: lessons from a parasite target. Proceedings of the National Academy of Sciences of the USA, 96: 11.015-11.022, 1999.

SHAKED-MISHAN, P. et al. A novel high-affinity arginine transporter from the human parasitic protozoan Leishmania donovani. Molecular Microbiology, 60: 30-38, 2006.

SILVA-JARDIM, I.; ORTA, M. F. \& RAMALHO-PINTO, F. J. The Leishmania chagasi proteasome: role in promastigotes growth and amastigotes survival within murine macrophages. Acta Tropica, 91: 121-130, 2004.

SILVA-LOPEZ, R. E. \& DE-SIMONE, S. G. A serine protease from detergent soluble extract of Leishmania (Leishmania) amazonensis. Zeitschrift für Naturforschung. C, 59c: 590-598, 2004a.

SILVA-LOPEZ, R. E. \& DE-SIMONE, S. G. Leishmania (Leishmania) amazonensis: Purification and characterization of a promastigote serine protease. Experimental Parasitology, 107: 173-182, 2004b.

SILVA-LOPEZ, R. E.; PINTO COELHO, M. G. \& DE-SimONE, S. G. Purification of an extracellular serine protease from Leishmania (Leishmania) amazonensis. Parasitology, 130: 1-13, 2005.

TAHERI, T. et al. Leishmania major: disruption of signal peptidase type I and its consequences on survival, growth and infectivity. Experimental Parasitology, 126: 135-145, 2010. 
TARDIEUX, L. et al. Lysosome recruitment and fusion are early events required for trypanosome invasion of mammalian cells. Cell, 71: 1.117-1.130, 1992.

UEDA-NAKAMURA, T. et al. Expression and processing of megasome cysteine proteinases during Leishmania amazonensis differentiation. Parasitology Research, 88: 332-337, 2002.

WEBSTER, P. \& FISH, W. R. Endocytosis by African trypanosomes. II. Occurrence in different life-cycle stages and intracellular sorting. European Journal of Cell Biology, 49: 303-310, 1989.

YAO, C.; DONELSON, J. E. \& WILSON, M. E. The major surface protease (MSP or GP63) of Leishmania sp. Biosynthesis, regulation of expression, and function. Molecular and Biochemical Parasitology, 132: 1-16, 2003.

YOSHIDA, N. \& CAMARGO, E. P. Ureotelism and ammonotelism in trypanosomatids. Journal of Bacteriology, 136: 1.184$1.186,1978$. 


\title{
$\underline{7}$ \\ A Importância de Radicais Livres Durante a Infecção por Protozoários do Gênero Leishmania
}

\author{
Denise Barçante Castro-Pinto I Daniela Leite Fabrino I Leonor Leon
}

$\mathrm{N}$ as últimas décadas, foram realizados inúmeros estudos no sentido de esclarecer o papel dos radicais livres em processos fisiopatológicos. A presença desses radicais foi descoberta há pouco mais de cinquenta anos, sendo imediatamente relacionada com processos prejudiciais ao organismo, tais como intenso dano celular, mutagênese e envelhecimento celular. Na década de 1980, surgiram na literatura trabalhos demonstrando o papel benéfico dos radicais livres e sua importância nos processos de sinalização celular. Esses radicais foram reconhecidos como segundos mensageiros, ou mesmo como moléculas efetoras, em importantes processos fisiológicos tais como a resposta imune (Droge, 2002).

Em qualquer organismo vivo, a homeostasia celular é afetada por um excesso de espécies reativas oxigenadas (ROS, da sigla em inglês), assim como de espécies reativas nitrogenadas (RNS, da sigla em inglês). Os tripanossomatídeos, de uma maneira geral, quando dentro dos macrófagos e como consequência da explosão respiratória, são expostos a intermediários oxigenados tóxicos, como: ânion superóxido $\left(\mathrm{O}_{2}^{-}\right)$, peróxido de hidrogênio $\left(\mathrm{H}_{2} \mathrm{O}_{2}\right)$ e o radical hidroxila $\left(\mathrm{OH}^{-}\right)$. Com relação aos radicais nitrogenados produzidos pela célula fagocítica, o principal é o óxido nítrico (NO). Esse radical é biossintetizado a partir da L-arginina pela enzima óxido nítrico sintase (NOS) (Stamler, Singel \& Loscalzo, 1992). Essas espécies intermediárias são tóxicas individualmente e, pelas suas características químicas, são altamente reativas, levando à formação de outros radicais ou moléculas com toxicidade potencializada, como a formação do peroxinitrito (ONOO). Os tripanossomatídeos têm um eficiente sistema de defesa antioxidante constituído de um tiol, a tripanotiona (T) e da tripanotiona redutase (TR), assim como tem a capacidade de liberar NO através da enzima óxido nítrico sintase constitutiva (CNOS). Tais fatos permitem ao parasito sua sobrevivência no interior da célula hospedeira.

Deve-se ressaltar que a formação desses radicais ocorre não somente na célula hospedeira como também nesses parasitos, em processos inter-relacionados, que irão definir o estabelecimento ou não de infecção.

\section{A L-ARGININA}

Conhecida há mais de um século, a L-arginina é um aminoácido envolvido em múltiplos processos metabólicos, fisiológicos e patológicos. Esse aminoácido foi definido há alguns anos como essencial para o crescimento de parasitos do gênero Leishmania, que eram incapazes de se multiplicar em meio deficiente em L-arginina, sugerindo um mecanismo 
de captação e utilização dessa molécula (Camargo et al., 1978; Krassner \& Flory, 1971). Tal mecanismo de transporte da L-arginina é realizado por um aminoácido permease (LdAAP3), descrito em L. donovani (Shaked-Mishan et al., 2006).

A L-arginina tem sido muito estudada em mamíferos, por sua participação no ciclo da ureia, através da enzima arginase e na produção do NO, mediada pela NOS. A NOS oxida a L-arginina em duas etapas que inicialmente envolve uma hidroxilação resultando na $\mathrm{N}^{\omega}$-hidroxi-L-arginina (NOHA), a qual é posteriormente oxidada a L-citrulina, levando à formação do NO. Todavia, a arginase hidrolisa a L-arginina em L-ornitina e ureia. Tais dados demonstram que esses parasitos, assim com as células de mamíferos, utilizam a L-arginina por meio de um sistema de transportadores (LdAAP3) e de enzimas (NOS e arginase). Existe uma importante inter-relação entre essas vias, uma vez que a ornitina é utilizada pela ornitina descarboxilase (ODC) para síntese de poliaminas, entre elas a espermidina, esta diretamente relacionada à produção da tripanotiona, que é o equivalente da glutationa do sistema de mamíferos, importante para a manutenção intracelular do sistema redox em tripanossomatídeos (Figura 1).

Figura 1 - Inter-relação das vias do NO e das poliaminas/tripanotiona, tendo a L-arginina como substrato para a NOS e a Arginase

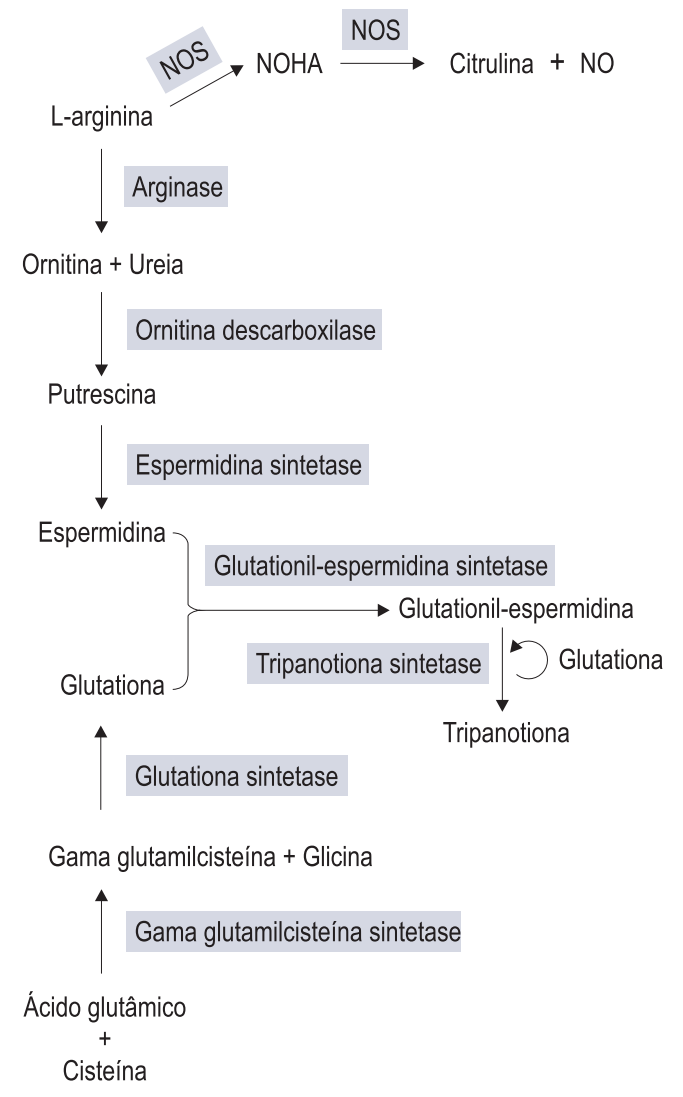

Fonte: Castro-Pinto, 2010.

\section{ESPÉCIES REATIVAS NITROGENADAS}

Durante a infecção por parasitos do gênero Leishmania ocorre a produção de NO, tanto pela célula hospedeira, quanto pelo parasito. NO é um importante e versátil mediador gasoso nos sistemas biológicos, sendo relevante na regulação de uma ampla gama de processos fisiológicos e patológicos, bem como na ação do sistema imune (Martinez \& Andriantsitohaina, 2009). 
Embora tenha sido descrita pela primeira vez e extensamente estudada em mamíferos, a síntese de NO, via NOS, não é restrita a essas células. Em mamíferos há três isoformas diferentes da NOS, as quais representam produtos gênicos distintos e constituem uma família enzimática de NOSs (Alderton, Cooper \& Knowles, 2001; James, 1994). Duas de suas isoformas são constitutivas (CNOS), sendo (1) descrita em células neuronais (nNOS ou NOS I) e (2) descrita em endoteliais (eNOS ou NOS III) e uma isoforma induzível (iNOS ou NOS II). A síntese de NO também tem sido observada em invertebrados (Johansson \& Carlberg, 1995), sempre através da enzima NOS. A primeira demonstração da existência da via do NO em um eucarioto unicelular foi feita em 1995 por Paveto e colaboradores, em Trypanosoma cruzi, que descreveram a presença de uma NOS constitutiva (CNOS). A mesma via de cNOS foi também evidenciada em $L$. donovani, causadora da leishmaniose visceral, mas o significado biológico, assim como a relação com a via existente no macrófago (induzida e nociva para esses microrganismos), continua sendo uma incógnita (Basu et al., 1997).

As isoformas descritas em Leishmania se assemelham à isoforma constitutiva de mamíferos, inclusive quanto à sua requisição de cofatores e dependência de $\mathrm{Ca}^{2+}$. Em 1997, quando foi descrita a presença de cNOS e consequentemente a produção de NO em $L$. donovani, suas funções eram totalmente desconhecidas. Mais recentemente, nosso grupo demonstrou a relação da ocorrência de uma cNOS em L. amazonensis com sua capacidade de infecção, visto que o tratamento com a L-nitro-arginina-metil-ester (L-NAME), um inibidor de cNOS, afeta intensamente a capacidade infectiva desse parasito (Genestra et al., 2003a; Genestra et al., 2006). Anteriormente, nosso grupo também estudou a importância do NO produzido pelo parasito na sua sobrevivência dentro do macrófago, além da caracterização de uma CNOS e a produção de NO em Leishmania sp. Observou-se também o efeito de diferentes inibidores e de um agente quelante de $\mathrm{Ca}^{2+}$ na produção desse radical (Genestra et al., 2003a, 2003b; Geigel, 2000; Geigel \& Leon, 2003).

Quanto à capacidade tóxica do No, diversos mecanismos de ação são descritos. Por exemplo, a inativação de enzimas ferro-dependentes pode ocorrer em virtude da associação do NO ao grupo prostético, ferro e enxofre (Fe-S), ocasionando nitrosilação do seu sítio ativo (Martinez \& Andriantsitohaina, 2009; James, 1994; Oswald et al., 1994), assim como a formação do radical peroxinitrito (ONOO), numa reação entre o NO e o radical superóxido $\left(\mathrm{O}_{2}{ }^{-}\right)$, que é tóxico para diversos tipos celulares (Denicola et al., 1993; Genestra, 2007; Peluffo et al., 2004). Dependendo do tempo de contato e da situação sob a qual ele foi produzido, o No pode se tornar uma molécula altamente tóxica. Entretanto, ainda não está claro, na literatura, exatamente qual concentração de No é considerada tóxica para uma célula (Martinez \& Andriantsitohaina, 2009; Brunet, 2001; Kroncke, Fehsel \& Kolb-Bachofen, 1997). O limite de concentração de NO entre a não toxicidade às células do hospedeiro e a toxicidade necessária para ação microbicida, é muito tênue (Nagy et al., 2007). É importante lembrar que cada tipo celular/tecidual tem um limiar próprio de resistência ao NO (Kroncke, Fehsel \& Kolb-Bachofen, 1997).

Além disso, todos os organismos que têm a capacidade de produzir No dispõem também do potencial para regular sua produção, bem como para desenvolver vias de detoxificação e resistência a essa molécula. Em mamíferos, o mais importante antioxidante intracelular talvez seja a glutationa, que reage com o No gerando S-nitrosoglutationa, levando o NO a perder seu potencial oxidativo. A depleção dessa molécula em culturas de células mostra um aumento na suscetibilidade aos danos causados pelo NO, sugerindo que pools de glutationa funcionem como 'varredores' de NO (NO scavenger) (Kroncke, Fehsel \& Kolb-Bachofen, 1997; Genestra et al., 2008). Em se tratando de protozoários, em especial os da ordem Kinetoplastida, como a Leishmania sp., ainda não foi feita a identificação de uma enzima estritamente ligada à neutralização de espécies reativas nitrogenadas.

Embora o NO tenha grande importância nos processos de sinalização celular e seja usado por diferentes organismos para tal finalidade, essa molécula recebe grande destaque na literatura como relevante composto microbicida com papel reconhecido principalmente na imunidade inata, inclusive contra Leishmania sp. No que se refere a esse parasito, 
o NO é considerado, por diversos autores, como uma molécula-chave da resposta imune do hospedeiro (Assreuy et al., 1994; Awasthi, Mathur \& Saha, 2004; Evans et al., 1993; Green et al., 1990a, 1990b; Murray \& Nathan, 1999). Entretanto, diferentes trabalhos revelam que esse parasito tem notável capacidade de driblar a resposta imune do hospedeiro e estabelecer uma infecção crônica. Os mais diversos patógenos, incluindo Leishmania sp., iniciam sua interação com o hospedeiro vertebrado através dos macrófagos, células componentes do sistema imune inato, as quais exibem diversos mecanismos de defesa, entre eles o No.

Tais células, contudo, exercem muitas vezes um duplo papel na 'batalha' imunológica travada pelos hospedeiros contra infecções. Por um lado, são consideradas importantes células efetoras no controle e morte de microrganismos por meio de mecanismos oxidativos e não oxidativos. Porém, podem também servir de local de hospedagem e multiplicação para os mesmos, protegendo-os de substâncias adversas do meio extracelular ou oferecendo condições microambientais favoráveis para sua sobrevivência (Bogdan \& Rollinghoff, 1999; Burchmore \& Barrett, 2001; McConville et al., 2007). A forma amastigota tem especial habilidade em enfrentar o ambiente hostil do compartimento endossomal dos macrófagos e permanecer, ainda que de modo subpatente, em número diminuto, silenciosamente e viável por muito tempo (anos) nas células de seus hospedeiros vertebrados (Zambrano-Villa et al., 2002). Uma vez dentro dos vacúolos do compartimento endossomal, um dos principais componentes tóxicos dos fagossomos, além dos compostos oxigenados, é o NO. No entanto, a forma amastigota desse parasito demonstra particular habilidade de sobrevivência em seus hospedeiros, seja suprimindo sua produção, seja resistindo à sua ação direta ou, ainda, produzindo seu próprio NO (Genestra et al., 2003a, 2003b; Kima, 2007).

Em uma análise comparativa de suscetibilidade ao NO, nosso grupo mostrou que, in vitro, as duas formas evolutivas de L. amazonensis são resistentes a altas concentrações de NO. Utilizando formas promastigotas e amastigotas (axênicas) em presença de diferentes concentrações de nitroprussiato de sódio (SNP), um doador químico de NO, verificou-se que embora esse composto exerça uma toxicidade dose dependente nesses parasitos, as formas amastigotas, que enfrentam o ambiente hostil fagossomal dentro da célula hospedeira e são responsáveis pela manutenção da infecção, são significativamente mais resistentes ao NO do que os promastigotas (Geigel, 2000; Genestra et al., 2008).

Além disso, a Leishmania age sobre a via metabólica da L-arginina, aminoácido que tem posição crucial em duas vias metabólicas antagônicas na célula hospedeira e é de grande importância metabólica para o próprio parasito (Kropf et al., 2005; Reguera et al., 2009; Vincendeau et al., 2003). Esses parasitos possuem um transportador independente, de alta afinidade por sódio $\left(\mathrm{Na}^{+}\right)$para a L-arginina (Shaked-Mishan et al., 2006; Kandpal et al., 1995). É possível que o parasito esteja reduzindo a quantidade de substrato para a iNos da célula hospedeira, uma vez que ele está 'roubando' o substrato da enzima da célula hospedeira. Isso levaria a uma diminuição dos níveis de No produzidos pela via induzida da NOS. Como resultado, o parasito não só diminuiria os níveis nocivos de NO produzidos por essa via, como se beneficiaria com o substrato para produzir seu próprio No e também com um gerador de guanosina monofosfato cíclico (GMPc) (Peluffo et al., 2004).

A infecção murina por L. major é um modelo bem estudado no que concerne ao estabelecimento de resistência ou suscetibilidade do hospedeiro à infecção, especialmente em macrófagos. Nessas células, fica claro que a estimulação por citocinas componentes do perfil Th1, principalmente o IFN $\gamma$, leva à síntese de NO, o que viria a ser tóxico para o parasito. Entretanto, o perfil de citocinas Th2 é capaz de inibir a produção de NO e estimular a via bioquímica da arginase, que usa o mesmo substrato usado na produção de NO. Desse modo, a síntese do No é regulada negativamente, enquanto paralelamente a L-arginina produzirá como metabólitos finais poliaminas usadas para multiplicação e crescimento do parasito (Peluffo et al., 2004; Vincendeau et al., 2003) (Figura 2). 
Figura 2 - Balanço entre as enzimas óxido nítrico sintase e arginase no macrófago e seu efeito em tripanossomatídeos

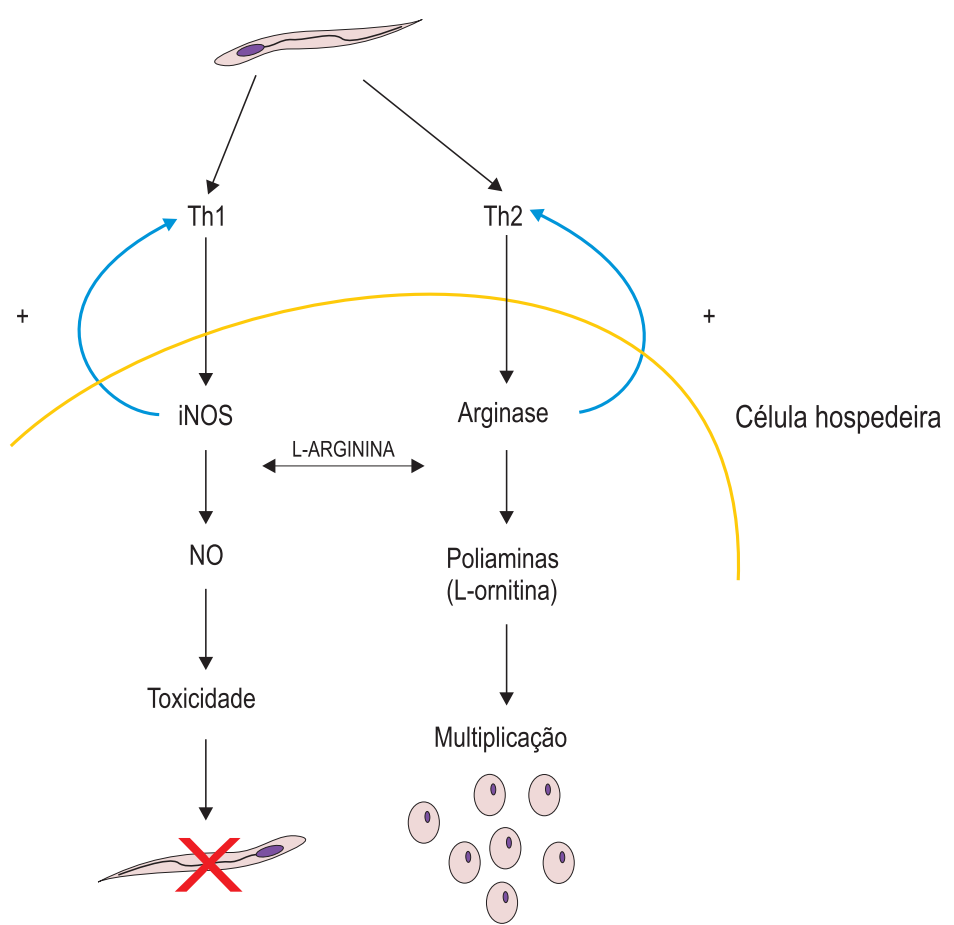

Fonte: Fabrino, 2010, adaptado de Vincendeau et al., 2003.

Em se tratando da via metabólica do NO, o parasito pode estar interferindo em etapas distintas da mesma, resultando na diminuição da produção dessa molécula ou mesmo usando-a a seu favor (James, 1994; Peluffo et al., 2004; Brunet, 2001; Vincendeau et al., 2003; Bogdan, Rollinghoff \& Solbach, 1990; Clark \& Rockett, 1996).

Recentemente demostrou-se que amastigotas de L. amazonensis induzem um estado de ativação celular no hospedeiro pelo qual há aumento dos níveis de L-arginina no citosol, mas não induz nem a ativação da iNOS, nem a inibição da arginase da célula hospedeira. Desse modo, o parasito dirige o metabolismo da célula hospedeira para que ele possa se beneficiar tanto da L-arginina disponível quanto da poliamina produzida pelo hospedeiro (Naderer \& McConville, 2008).

A complexidade dos mecanismos de ação da via bioquímica do NO nos leva a pensar em estudos mais detalhados sobre as interações entre esse protozoário e essa via metabólica, tais como: (i) avaliação da produção de No em presença de diferentes quantidades de substrato; (ii) avaliação da produção de No combinada com a adição de um análogo inerte da L-arginina como o L- NAME, que compete com o substrato pela ligação do sítio ativo da enzima; e (iii) pela regulação da produção de NO por meio do uso de RNA de interferência (RNAi), que pode, assim, ser silenciada em nível transcricional (Rivero, 2006).

Outra possibilidade para avaliar a via do No é testando-se a suscetibilidade das diferentes formas evolutivas e cepas in vitro tendo por base o uso de compostos doadores desse radical livre, como por exemplo, o S-nitrosoN-acetilpenicilamina (SNAP) e o nitroprussiato de sódio (SNP) (Geigel, 2000; Genestra et al., 2008). O SNP $\left(\mathrm{Na}_{2}\left[\mathrm{Fe}(\mathrm{CN})_{5}(\mathrm{NO})\right]\right)$ merece especial atenção, pois é um doador de $\mathrm{NO}$ bastante usado tanto em ensaios in vivo quanto in vitro, uma vez que sua ação é baseada na produção e liberação de No de forma semelhante à ação dos nitratos orgânicos (Bates et al., 1991; Yamamoto \& Bing, 2000). 
Tendo em vista que seis mil dos mais de oito mil genes desses protozoários são ortólogos, e que os kinetoplastidas estão entre os mais antigos eucariotos, é natural que eles apresentem várias vias bioquímicas semelhantes, assim como é muito provável que eles compartilhem a semelhança de algumas vias com seus hospedeiros (Rivero, 2006; Donelson, Gardner \& El-Sayed, 1999; Stuart et al., 2008). Como apresentado anteriormente neste capítulo, em se tratando da via metabólica do No, tal hipótese já está sendo bem documentada na literatura.

\section{ESPÉCIES REATIVAS OXIGENADAS}

Os tripanossomatídeos, de maneira geral, quando dentro dos macrófagos e como consequência da explosão respiratória, são expostos a intermediários oxigenados tóxicos, como: ânion superóxido $\left(\mathrm{O}_{2}^{-}\right)$, peróxido de hidrogênio $\left(\mathrm{H}_{2} \mathrm{O}_{2}\right)$ e o radical hidroxila $\left(\mathrm{OH}^{-}\right)$.

A primeira linha de defesa envolvendo a remoção desses radicais está associada à enzima superóxido dismutase (SOD), que transforma o ânion superóxido em $\mathrm{H}_{2} \mathrm{O}_{2}$. Existem diversas isoformas de SOD presentes em diferentes organismos e em diversos compartimentos intracelulares. Essas enzimas se caracterizam pela presença de íon(s) metálico(S) (Mn, Fe, Cu e Zn) no seu sítio ativo. De modo geral, todos os eucariotos contêm SOD/Mn, SOD/Fe ou SOD/ Cu-Zn. Tripanossomatídeos contêm uma isoforma de SOD que compreende Fe (James, 1994; Fairlamb \& Cerami, 1992).

A segunda linha de defesa envolve a remoção do $\mathrm{H}_{2} \mathrm{O}_{2}$ formado e essa etapa é realizada nos mamíferos por meio de catalases e várias peroxidases. Além disso, as células de mamíferos possuem um sistema antioxidante extremamente eficiente constituído da glutationa e da enzima glutationa redutase (GR). A glutationa reduzida (GSH, L-glutamilL-cisteinil-glicina) está presente na maioria das células e é o tiol mais abundante no meio intracelular, sendo sua capacidade redutora determinada pelo grupamento-SH presente na cisteína.

Todas as células eucariotas contêm duas importantes classes de metabólitos: os tióis e as poliaminas (Walsh, Bradley \& Nadeau, 1991). Grupos tiólicos ativos em proteínas têm um papel tamponador-chave que contrabalança qualquer possível alteração do estado reduzido intracelular. Após exposição da GSH a um agente oxidante, ocorre sua oxidação a GSSG, sendo feita a recuperação da GSH pela GR, numa etapa essencial para manter íntegro o sistema de proteção celular. Na inativação de um agente oxidante não ocorre produção de GSSG e depleção de GSH.

Em situações em que o sistema de oxidorredução está íntegro, haverá recuperação da GSH, entretanto, sob condições de excesso de agentes oxidantes e/ou deficiência do sistema protetor, haverá desequilíbrio entre o consumo de GSH e a produção de GSSG, o que caracteriza o estresse oxidativo. Assim, a magnitude do estresse oxidativo pode ser monitorada pela razão GSSG/GSH.

O excesso de GSSG resulta em ambiente mais oxidante, que favorece a formação de pontes dissulfeto (-SS-) nas proteínas portadoras de grupamento tiol (-SH). As pontes dissulfeto oxidam essas proteínas, com prejuízo de suas funções. Tal oxidação é reversível como resultante da ação de compostos antioxidantes, como a GSH. Essa defesa atribuída a glutationa em sua forma reduzida (GSH) é caracterizada tanto pela remoção não enzimática de radicais livres, como pela neutralização de peróxidos, através de catalase e peroxidases glutationa-dependentes (Walsh, Bradley \& Nadeau, 1991; Fairlamb, 1989; Krauth-Siegel \& Coombs, 1999). Em praticamente todos os organismos, a glutationa e a GR estão envolvidas na manutenção de um ambiente intracelular adequado, como a redução de dissulfetos e a neutralização de hidroperóxidos.

Com relação às poliaminas, são moléculas de natureza policatiônica presentes em plantas, animais e microrganismos. As poliaminas predominantes nesses sistemas biológicos são: a diamina putrescina, a triamina espermidina e a tetramina espermina. Devido à natureza policatiônica, podem unir-se e estabilizar polímeros ricos em cargas negativas como é o DNA, mas também a fosfolipídeos e proteínas. A maioria das células eucariotas conta com um sistema de transporte de poliaminas localizado na membrana plasmática que facilita a captação de poliaminas 
exógenas. O mencionado sistema, de vital importância em tecidos animais que se encontram em proliferação, é um alvo farmacológico no desenvolvimento de novos compostos quimioterapêuticos. A espermidina, assim como outras poliaminas (putrescina e espermina) é derivada da metionina e da ornitina. A primeira etapa da biossíntese das poliaminas é a descarboxilação da ornitina, através da enzima L-ornitina decarboxilase (ODC), resultando na formação da putrescina, ou seja, da ornitina descarboxilada. Uma etapa paralela é a descarboxilação da S-adenosil-metionina, pela ação da enzima S-adenosil-metionina-descarboxilase (S-AdoMet). A etapa final consiste na conjugação da ornitina descarboxilada e S-adenosina-metionina descarboxilada, que pela transferência de um grupamento propilamino dessa última e pela ação da enzima propilaminotransferase I, vai formar a espermidina.

Os tripanossomatídeos não contêm níveis detectáveis de catalase e de glutationa peroxidase (GP), contêm GSH, mas não contêm GR - a responsável, na maioria das células, pela manutenção da glutationa em sua forma reduzida. Nesses parasitos, o equivalente a glutationa é um ditiol de baixo peso molecular que foi descoberto como resultado de estudos com Trypanosoma brucei (Fairlamb \& Cerami, 1985), em que se observou que extrato dialisado desse parasito não reduzia GSSG em presença de NADPH (cofator da reação). Em estudos subsequentes, Fairlamb e colaboradores (1985) purificaram um composto de baixo peso molecular que, após caracterização química, foi definido como $\mathrm{N}^{1}$, $\mathrm{N}^{8}$-bis (glutationil)-espermidina, $[\mathrm{T}(\mathrm{S})]_{2}$, e como só tinha sido observado em protozoários tripanossomatídeos, recebeu o nome de tripanotiona. Assim, a tripanotiona é composta do tripeptídeo glutationa, acoplado a uma poliamina, que na maioria dos casos é a espermidina. A tripanotiona é mantida intracelularmente como um ditiol, em virtude da ação de uma enzima única, a tripanotiona redutase (TR). Assim, a etapa de neutralização do peróxido de hidrogênio em tripanossomatídeos é realizada pelo sistema tripanotiona e da enzima TR - um sistema semelhante ao glutationa-GR de mamíferos. A TR tem sido identificada em todas as espécies de tripanossomatídeos estudadas até agora: Crithidia fasciculata (Henderson, Fairlamb \& Cerami, 1987; Shames et al., 1986), T. cruzi (Carnieri, Moreno \& Docampo, 1993; Jockers-Scherubl, Schirmer \& Krauth-Siegel, 1989; Krauth-Siegel et al., 1987), T. brucei (Fairlamb \& Cerami, 1992; Henderson et al., 1987), L. donovani (Taylor et al., 1994), L. tarentolae (Mukhopadhyay et al., 1996) e L. amazonensis (Mukhopadhyay et al., 1996; Castro-Pinto et al., 2004, 2007).

Genes que codificam para TR têm sido clonados e sequenciados de T. congolense (Shames et al., 1988), T. cruzi (Sullivan \& Walsh, 1991), C. fasciculata e T. brucei (Aboagye-Kwarteng, Smith \& Fairlamb, 1992; Field, Cerami \& Henderson, 1992), L. donovani (uma cepa da Etiópia e outra da Índia) (Taylor et al., 1994; Cunningham \& Fairlamb, 1995), L. guyanensis (Keithly, 1989) e L. amazonensis (Castro-Pinto et al., 2008). Tripanossomatídeos que sofreram knock-out do gene associado a TR apresentaram redução de 90\% na atividade da enzima em relação à cepa selvagem e, em consequência, aumento na suscetibilidade ao peróxido de hidrogênio (Fairlamb, Henderson \& Cerami, 1989; Krieger et al., 2000). Dumas e colaboradores (1997) obtiveram mutantes de L. donovani e L. major, nas quais o gene de TR foi eliminado, tendo observado que esses parasitos tiveram sua infectividade diminuída e foram incapazes de sobreviver no interior dos macrófagos. Tais parasitos se tornaram avirulentos e apresentaram um aumento na sensibilidade ao estresse oxidativo. Castro-Pinto e colaboradores (2004) demonstraram que a atividade de TR de L. amazonensis em promastigotas não infectantes (sem formas metacíclicas detectáveis) foi significantemente menor quando comparada com promastigotas infectantes (contendo $73 \%$ de formas metacíclicas) e com as formas amastigotas, tanto as axênicas quanto aquelas obtidas de lesão de camundongos infectados. É de se esperar que promastigotas infectantes tenham um eficiente sistema de neutralização dos componentes tóxicos liberados pelo macrófago no momento da infeçãa. Entretanto, formas não infectantes têm esse sistema expresso em níveis basais. Quanto às formas amastigotas, a atividade ainda mais aumentada da TR mostra que nessas formas o sistema tripanotiona / TR precisa estar mais ativo para a manutenção da infecção.

Por outro lado, estudos relacionados ao papel da TR em L. donovani e T. cruzi, usando parasitos transfectados que apresentavam expressão aumentada de TR, revelaram que esses parasitos foram tão suscetíveis à ação da $\mathrm{H}_{2} \mathrm{O}_{2}$ quanto os parasitos originais (não transfectados) (Kelly et al., 1993). Corroborando tal resultado, experimentos 
preliminares do nosso grupo (dados não publicados), usando uma cepa de L. infantum transfectada (cedida pela dra. Ana Thomas, da Universidade do Porto, Portugal) para expressar TR, não mostraram um aumento no consumo de NADPH, sugerindo que, apesar de a molécula de TR estar sendo expressa em níveis maiores que na cepa selvagem, isto não significa obrigatoriamente que a enzima esteja ativa.

Além da tripanotiona e tripanotiona redutase (TR), uma cascata composta de triparedoxina (Tpx) que transfere elétrons do NADPH para a ribonucleotídeo redutase (RiboR) que catalisa a redução do nucleosídeo difosfato (NDP) a deoxinucleosídeo difosfato (dNDP), precursores da síntese de DNA, bem como de várias triparedoxina peroxidases (TpxPx), participam da detoxificação de hidroperóxidos (ROOH) (Castro et al., 2008; Castro \& Thomas, 2008; KrauthSiegel, Comini \& Schlecker, 2007).

Em células de mamíferos, a glutationa, a GR e a glutationa peroxidase estão localizadas na mitocôndria, que protege essa organela de danos oxidativos (Griffith \& Meister, 1985; Mbemba et al., 1985; Taniguchi, Hara \& Honda, 1986). Sendo o sistema glutationa / GR essencial para as funções mitocondriais em todos os eucariotos, se pensou que o sistema tripanotiona / TR tivesse um padrão de localização intracelular semelhante. Meziane-Cherif e colaboradores (1994) estudaram, por meio de imunofluorescência e imunoeletromicroscopia, a localização intracelular de TR em $T$. cruzi (epimastigotas, tripomastigotas e amastigotas) e L. infantum (promastigotas), usando anticorpos contra um peptídeo sintético de uma sequência de 24 aminoácidos de TR (pTR24). Os resultados desse trabalho mostraram que a TR estava presente em todos os estágios evolutivos de T. cruzi (discreta em tripomastigotas) e promastigotas de $L$. infantum. Os autores confirmaram, por imunoeletromicroscopia, a presença de TR na mitocôndria de T. cruzi, mais especificamente no k-DNA (sem maiores referências a L. infantum), sugerindo que a sua localização seria semelhante à de GR em mamíferos.

Entretanto, demostrou-se que a TR é encontrada exclusivamente no citosol, nos dois diferentes estágios evolutivos de tripanossomas africanos, sugerindo que essa enzima não está associada aos mecanismos de detoxificação da mitocôndria. Sabendo-se que a mitocôndria conta com um sistema de transporte eficiente para captar a glutationa sintetizada no citosol, os autores supõem que tanto a GSH como a $\mathrm{T}(\mathrm{SH})_{2}$ seriam deslocadas do citosol para a mitocôndria, onde atuariam removendo os radicais livres oxigenados de forma não enzimática (Smith, Opperdoes \& Fairlamb, 1991).

Considerando-se que um pequeno número de proteínas é codificado pelo DNA do cinetoplasto (Souza, 1984) e que a TR tem sido descrita como sendo codificada pelo DNA nuclear e sintetizada no citosol, é de se esperar que a enzima seja importada do citosol para a mitocôndria. Entretanto, faltam dados suficientes na literatura que possam esclarecer como funciona esse sistema de importação. Porém, em formas tripomastigotas de T. brucei, após fracionamento celular, a atividade de TR foi observada somente na fração citosólica, sem nenhuma associação com os demais componentes subcelulares (Smith, Opperdoes \& Fairlamb, 1991). Em experimentos do nosso grupo, quando foram analisadas frações enriquecidas de membrana de promastigotas de L. amazonensis, praticamente não se observou atividade de TR, corroborando a maioria dos dados da literatura com outros tripanossomatídeos, de que a presença da TR seria no citosol. Além disso, a análise por imunofluorescência revelou que a TR de L. amazonensis é citosólica, com marcação evidente nas extremidades anterior e posterior do corpo do parasito (Castro-Pinto et al., 2004).

Shames e colaboradores (1986) estabeleceram uma similaridade de estrutura e de mecanismo entre GR e TR, mas observaram que as enzimas de mamíferos e de parasitos apresentam uma exclusiva especificidade com relação aos seus respectivos substratos. A composição bioquímica dos tripanossomatídeos difere em numerosos aspectos das células de mamíferos. Dessa forma, os processos específicos dos parasitos podem providenciar alvos seletivos para o desenvolvimento de drogas. Apesar da identidade de cerca de 40\% na sequência de aminoácidos entre GR e TR (Walsh, Bradley \& Nadeau, 1991), essas enzimas possuem um alto grau de especificidade para seus respectivos substratos dissulfetos. Castro-Pinto e colaboradores (2004) confirmaram tais dados, mostrando que a presença de GSSG na concentração de $100 \mu \mathrm{M}$ não levou a um aumento do consumo do NADPH, isto é, que a enzima do parasito (TR) não 
foi capaz de usar GSSG como substrato. Como já citado anteriormente, GSSG é mantido intracelularmente como GSH de forma não enzimática, uma vez que o parasito não contém GR.

Evidência de que o consumo de NADPH no ensaio da atividade de TR é devido ao sistema do parasito [T(S) 2 /TR], além das condições ideais para a atividade da TR, como pH, temperatura e força iônica, é o fato de que um excesso de GSSG (500 a $1.000 \mu \mathrm{M}$ ) reagir com o T(SH) formado e reverter a reação, aumentando a concentração de $\mathrm{T}(\mathrm{S})_{2}$ (de forma não enzimática), teve como resultado um aumento do consumo de NADPH. Ao mesmo tempo que se forma $\mathrm{T}(\mathrm{S})_{2}$, há também a produção de GSH, mantendo o ambiente celular na forma reduzida ideal (Fairlamb et al., 1985; Castro-Pinto et al., 2004; Krauth-Siegel, Jacoby \& Schirmer, 1995).

Dados da literatura relacionados ao metabolismo dos tripanossomatídeos têm levado ao estudo de diversos agentes quimioterápicos, que exploram o conhecimento das diferenças bioquímicas entre esses parasitos e seus hospedeiros. Para que ocorra a síntese de tripanotiona são necessárias concentrações adequadas de glutationa e espermidina. Assim, uma estratégia quimioterápica seria a inibição da síntese da glutationa e/ou da síntese da espermidina, ou a prevenção da ligação glutationa e espermidina. A síntese da glutationa envolve duas enzimas - a $\gamma$-glutamil cisteína sintetase e a glutationa sintetase -, enquanto a síntese de poliaminas envolve basicamente S-adenosil-metionina descarboxilase e ornitina descarboxilase, além de propilaminotransferases (I e II) (Lehningher, Nelson \& Cox, 1993).

O desenvolvimento de inibidores para essas vias metabólicas como alvo de drogas talvez não seja uma boa abordagem, uma vez que as mesmas ocorrem no hospedeiro vertebrado. Pentamidina e Berenil@, diamidinas aromáticas usadas como agentes terapêuticos contra, respectivamente, leishmanioses e mal de cadeiras (esta última causada por T. evansi), tem sido relatados como inibidores de uma etapa de descarboxilação da S-adenosil-metionina da síntese de poliaminas (Brun et al., 1996) e difluormetilornitina (DFMO), da descarboxilação da ornitina. A ornitina descarboxilase (ODC) do parasito não é menos suscetível ao DFMO que a ODC do hospedeiro, mas diferenças relevantes entre o metabolismo de ambos têm sido relatadas. Por exemplo, o parasito não tem capacidade de obter poliaminas exogenamente em quantidades suficientes, além do relativamente baixo turnover da ODC (horas em comparação com 15 minutos da ODC de mamíferos). Por outro lado, ODC de mamíferos é uma das proteínas celulares mais lábeis, enquanto a ODC de tripanossomatídeos como T. brucei e L. donovani (T. cruzi não contém ODC) são metabolicamente estáveis.

Dentre os inibidores da síntese da glutationa inclui-se a L-butionina-sulfoximina (BSO), que interfere na etapa de ligação do ácido glutâmico e da cisteína e que não se mostrou tóxica para células de mamíferos (Arrick, Griffith \& Cerami, 1981), provavelmente pelo fato de o parasito e o hospedeiro apresentarem importantes diferenças em suas necessidades de GSH. A inibição da via de síntese das poliaminas tem sido relacionada a diferentes classes de compostos, incluindo análogos fluorados da ornitina (difluorometilornitina / DFMO) (Bitonti et al., 1985; Fairlamb et al., 1987; Giffin et al., 1986; Phillips, Coffino \& Wang, 1987) e diamidinas (pentamidina, Berenilß), entre outros (Fairlamb, Henderson \& Cerami, 1989; Brun et al., 1996; Basselin, Lawrence \& Robert-Gero, 1996; Byers et al., 1991).

A inibição da ODC de T. brucei tem efeito pronunciado na proliferação celular. Infecções usando esse parasito em modelo murino foram curadas pela administração de DFMO, que inibe irreversivelmente a ODC (Bacchi et al., 1983, 1980). Além disso, a DFMO foi usada com sucesso no tratamento de tripanossomíases humanas, apesar da necessidade de altas doses (Sjoerdsma \& Schechter, 1984). Inibidores da S-AdoMet DC também tem sido descritos como potentes agentes contra tripanossomas africanos (Brun et al., 1996; Byers et al., 1991; Bitonti, Dumont \& McCann, 1986). Entre os inibidores usados estão o Berenil@ e a pentamidina. Foi demonstrado que tal enzima era inibida irreversivelmente pelo Berenil@ e de forma reversível pela pentamidina. Os mesmos autores observaram, em experimentos in vivo, que o Berenil@ inibia em cerca de $70 \%$ a atividade da enzima quando injetado quatro horas após o inóculo do parasito (T. brucei), resultando no aumento da concentração de putrescina nos tripanossomas. Afora isso, quando se injetavam espermidina e espermina em camundongos infectados com T. brucei e tratados com Berenil@, se observou que havia um bloqueio no efeito curativo do inibidor (Bitonti, Dumont \& McCann, 1986). 
A biossíntese da glutationa, tomada como alvo das drogas, representaria um potencial dano para o hospedeiro. Entretanto, estratégias para inibição da síntese da glutationa têm sido elaboradas usando como modelo L. donovani. A L-butionina-sulfoximina (BSO) é um inibidor de glutationa e não apresenta toxicidade para o hospedeiro, como foi demonstrado também em experimentos com T. cruzi usando camundongos suíços (Arrick, Griffith \& Cerami, 1981). Estudos adicionais mostraram que os requerimentos de glutationa do parasito e do hospedeiro diferem marcadamente. Assim, a utilização de análogos da glutationa pode ser uma excelente estratégia no sentido de inibir a posterior síntese da tripanotiona (glutationa + poliamina) (Castro-Pinto et al., 2007).

A biossíntese da tripanotiona envolve a glutationil espermidina sintetase (GSS) e a tripanotiona sintetase (TS). A primeira enzima catalisa a conjugação de uma molécula de glutationa com um dos grupos amino terminais da espermidina, produzindo tanto $\mathrm{N}^{1}$ - quanto $\mathrm{N}^{8}$ glutationil espermidina, enquanto TS catalisa a conjugação de uma segunda molécula da glutationa ao grupo amino-residual dos intermediários formados na primeira etapa, produzindo a bis-glutationil-espermidina ou tripanotiona. Estudos relacionados à biossíntese da tripanotiona indicaram que o resíduo glutamato é essencial para o reconhecimento do substrato, pois qualquer modificação nessa parte da glutationa resulta em perda total de sua capacidade como substrato. Porém, alterações na estrutura da molécula, como a alquilação do grupamento tiol da cisteína com grupos metila, etila ou propila, resultam em análogos que mostram eficiência equivalente ou maior como substratos, quando comparados com a própria glutationa, que é o substrato natural nesta reação (De Craecker et al., 1997). Em trabalho recente, Castro-Pinto e colaboradores (2004) relataram que derivados amidínicos (metoxiamidina e pentamidina) são excelentes inibidores da atividade da TR.

A tripanotiona também tem sido associada à resistência a drogas. Extrusão ou sequestro de conjugados tioldrogas tem sido estudado em Leishmania, mas este assunto não é totalmente entendido. Os parasitos resistentes a arsênico e antimônio trivalentes apresentam o gene da PgpA (P-glicoproteína A) amplificado e essa glicoproteína pertence à família dos transportadores $\mathrm{ABC}$ envolvidos na resistência a drogas em mamíferos (Borst et al., 2000) e protozoários parasitos (Borst \& Ouellette, 1995). Esses transportadores ABC têm sido associados à expulsão do conjugado glutationa-arsênico em Leishmania (Legare et al., 2001). A tripanotiona forma complexos com arseniato e antimoniato em $L$. tarentolae, sendo provavelmente o tiol fisiológico conjugado a tais drogas transportadas pela Pgp A (Mukhopadhyay et al., 1996). Apesar do uso excessivo de compostos antimoniais no tratamento das leishmanioses, seu modo de ação permanece incerto. Sabe-se mais sobre o mecanismo de resistência ao antimonial trivalente ( $\mathrm{Sb}^{\text {III }}$ ) do que sobre seu modo de ação. Foi demonstrado que o modo de ação de antimoniais em Leishmania é um fato intimamente ligado ao mecanismo de resistência, por promoverem a perda da tripanotiona e da glutationa (complexadas e efluxadas), alterando profundamente o potencial redox da célula.

\section{CONCLUSÃO}

Os protozoários do gênero Leishmania desenvolveram diversas estratégias de evasão do sistema de defesa do hospedeiro, e alguns pontos são cruciais para que tal evasão seja favorecida. Parasitos do gênero Leishmania sendo eucariotos como suas células hospedeiras, compartilham diversas vias metabólicas. Desse modo, é da maior importância um estudo comparativo dessas vias, numa tentativa de definir um alvo molecular para compostos usados na quimioterapia (ou ainda sob pesquisa) das leishmanioses. Esse alvo seria uma molécula/via que ocorra somente no parasito e que seja essencial para seu desenvolvimento. Quanto mais específico esse alvo, menor será a ocorrência de efeitos secundários danosos no hospedeiro. No caso de radicais livres (nitrogenados ou oxigenados), está bem documentado na literatura que o parasito tem capacidade de se 'defender' da célula hospedeira, por meio dessas vias metabólicas que permitem ao mesmo tempo tanto a neutralização de radicais oxigenados, via seu sistema de oxidorredução (T/TR), como a capacidade de sobreviver em altas concentrações de radicais nitrogenados (NO). 
De fato, a L-arginina está na intersecção de rotas bioquímicas divergentes, produzindo metabólitos que podem ter efeitos contrastantes quando avaliados numa relação parasito/hospedeiro (Peluffo et al., 2004). As rotas bioquímicas que utilizam a L-arginina como substrato facilitam de forma direta (produção de NO) ou indireta por meio da arginase, levando à síntese de poliaminas, e consequentemente da tripanotiona, o desenvolvimento do parasito dentro da célula hospedeira.

A presença de uma cNOS nesse protozoário, que compartilha diversas rotas bioquímicas com as células hospedeiras, nos faz pensar sobre sua função nos mesmos e desperta o interesse sobre a toxicidade do No no mesmo. Embora a literatura pontue o NO como uma molécula tóxica para Leishmania, há ainda certa discussão acerca desse tema. Considerada uma molécula fundamental em ações microbicidas da resposta imune inata, na década de 1980 e início de 1990, resultados recentes ressaltam outras possíveis atividades funcionais do No, como fazer parte do metabolismo do parasito ou mesmo contribuir para mecanismos de sobrevivência do mesmo em células do hospedeiro. o entendimento da função dessa molécula é, portanto, crucial para o estabelecimento de estratégias para o controle de diferentes doenças infecciosas.

Além disso, a presença de um eficiente sistema de oxidorredução, representado pela T/TR, se constitui em uma excelente fonte de trabalho quando se pretende definir um alvo promissor para drogas anti-Leishmania.

\section{REFERÊNCIAS}

ABOAGYE-KWARTENG, T.; SMITH, K. \& FAIRLAMB, A. H. Molecular characterization of the trypanothione reductase gene from Crithidia fasciculata and Trypanosoma brucei: comparison with other flavoprotein disulphide oxidoreductases with respect to substrate specificity and catalytic mechanism. Molecular Microbiology, 6(21): 3.089-3.099, 1992.

ALDERTON, W. K.; COOPER, C. E. \& KNOWLES, R. G. Nitric oxide synthases: structure, function and inhibition. The Biochemical Journal, 357(3): 593-615, 2001.

ARRICK, B. A.; GRIFFITH, O. W. \& CERAMI, A. Inhibition of glutathione synthesis as a chemotherapeutic strategy for trypanosomiasis. The Journal of Experimental Medicine, 153(3): 720-725, 1981.

ASSREUY, J. et al. Production of nitric oxide and superoxide by activated macrophages and killing of Leishmania major. European Journal of Immunology, 24(3): 672-676, 1994.

AWASTHI, A.; MATHUR, R. K. \& SAHA, B. Immune response to Leishmania infection. The Indian Journal of Medical Research, 119(6): 238-258, 2004.

BACCHI, C. J. et al. Polyamine metabolism: a potential therapeutic target in trypanosomes. Science, 210(4.467): 332-334, 1980.

BACCHI, C. J. et al. In vivo effects of alpha-DL-difluoromethylornithine on the metabolism and morphology of Trypanosoma brucei brucei. Molecular and Biochemical Parasitology, 7(3): 209-225, 1983.

BASSELIN, M.; LAWRENCE, F. \& ROBERT-GERO, M. Pentamidine uptake in Leishmania donovani and Leishmania amazonensis promastigotes and axenic amastigotes. The Biochemical Journal, 315(2): 631-634, 1996.

BASU, N. K. et al. Isolation of a nitric oxide synthase from the protozoan parasite, Leishmania donovani. Fems Microbiology Letters, 156(1): 43-47, 1997.

BATES, J. N. et al. Nitric oxide generation from nitroprusside by vascular tissue. Evidence that reduction of the nitroprusside anion and cyanide loss are required. Biochemistry and Pharmacology, 42, supl: S157-S165, 1991.

BITONTI, A. J.; DUMONT, J. A. \& MCCANN, P. P. Characterization of Trypanosoma brucei brucei S-adenosyl-L-methionine decarboxylase and its inhibition by Berenil, pentamidine and methylglyoxal bis(guanylhydrazone). The Biochemical Journal, 237(3): 685-689, 1986.

BITONTI, A. J. et al. Catalytic irreversible inhibition of Trypanosoma brucei brucei ornithine decarboxylase by substrate and product analogs and their effects on murine trypanosomiasis. Biochemistry and Pharmacology, 34(10): 1.773-1.777, 1985. 
BOGDAN, C. \& ROLLINGHOFF, M. How do protozoan parasites survive inside macrophages? Parasitology Today, 15(1): 2228, 1999.

BOGDAN, C.; ROLLINGHOFF, M. \& SOLBACH, W. Evasion strategies of Leishmania parasites. Parasitology Today, 6(6): 183187, 1990.

BORST, P. \& OUELLETTE, M. New mechanisms of drug resistance in parasitic protozoa. Annual Review of Microbiology, 49: 427-460, 1995.

BORST, P. et al. A family of drug transporters: the multidrug resistance-associated proteins. Journal of the National Cancer Institute, 92(16): 1.295-1.302, 2000.

BRUN, R. et al. In vitro trypanocidal activities of new S-adenosylmethionine decarboxylase inhibitors. Antimicrobial Agents and Chemotherapy, 40(6): 1.442-1.447, 1996.

BRUNET, L. R. Nitric oxide in parasitic infections. International Immunopharmacology, 1(8): 1.457-1.467, 2001.

BURCHMORE, R. J. \& BARRETT, M. P. Life in vacuoles--nutrient acquisition by Leishmania amastigotes. International Journal for Parasitology, 31(12): 1.311-1.320, 2001.

BYERS, T. L. et al. Antitrypanosomal effects of polyamine biosynthesis inhibitors correlate with increases in Trypanosoma brucei brucei S-adenosyl-L-methionine. The Biochemical Journal, 274(2): 527-533, 1991.

CAMARGO, E. P. et al. Trypanosoma spp., Leishmania spp. and Leptomonas spp.: enzymes of ornithine-arginine metabolism. Experimental Parasitology, 46(2): 141-144, 1978.

CARNIERI, E. G.; MORENO, S. N. \& DOCAMPO, R. Trypanothione-dependent peroxide metabolism in Trypanosoma cruzi different stages. Molecular and Biochemical Parasitology, 61(1): 79-86, 1993.

CASTRO, H. \& TOMAS, A. M. Peroxidases of trypanosomatids. Antioxidants and Redox Signaling, 10(9): 1.593-1.606, 2008.

CASTRO, H. et al. Leishmania infantum: provision of reducing equivalents to the mitochondrial tryparedoxin/tryparedoxin peroxidase system. Experimental Parasitology, 120(4): 421-423, 2008.

CASTRO-PINTO, D. B. et al. Trypanothione reductase activity is prominent in metacyclic promastigotes and axenic amastigotes of Leishmania amazonensis. Evaluation of its potential as a therapeutic target. Journal of Enzyme Inhibition and Medicinal Chemistry, 19(1): 57-63, 2004.

CASTRO-PINTO, D. B. et al. Leishmania amazonensis trypanothione reductase: evaluation of the effect of glutathione analogs on parasite growth, infectivity and enzyme activity. Journal of Enzyme Inhibition and Medicinal Chemistry, 22(1): 71-75, 2007.

CASTRO-PINTO, D. B. et al. Cloning and expression of trypanothione reductase from a New World Leishmania species. Archives of Microbiology, 189(4): 375-384, 2008.

CLARK, I. A. \& ROCKETT, K. A. Nitric oxide and parasitic disease. Advances in Parasitology, 37: 1-56, 1996.

CUNNINGHAM, M. L. \& FAIRLAMB, A. H. Trypanothione reductase from Leishmania donovani. Purification, characterisation and inhibition by trivalent antimonials. European Journal of Biochemistry, 230(2): 460-468, 1995.

DE CRAECKER, S. et al. Characterization of the peptide substrate specificity of glutathionylspermidine synthetase from Crithidia fasciculata. Molecular and Biochemical Parasitology, 84(1): 25-32, 1997.

DENiCOLA, A. et al. Peroxynitrite-mediated cytotoxicity to Trypanosoma cruzi. Archives of Biochemistry and Biophysics, 304(1): 279-286, 1993.

DONELSON, J. E.; GARDNER, M. J. \& EL-SAYED, N. M. More surprises from Kinetoplastida. Proceedings of the National Academy of Sciences of the USA, 96(6): 2.579-2.581, 1999.

DROGE, W. Free radicals in the physiological control of cell function. Physiological Reviews, 82 (1): 47-95, 2002.

DUMAS, C. et al. Disruption of the trypanothione reductase gene of Leishmania decreases its ability to survive oxidative stress in macrophages. The Embo Journal, 16(10): 2.590-2.598, 1997. 
EVANS, T. G. et al. Effect of in vivo inhibition of nitric oxide production in murine leishmaniasis. The Journal of Immunology, 151(2): 907-915, 1993.

FAIRLAMB, A. H. Novel biochemical pathways in parasitic protozoa. Parasitology, 99, supl.: S93-S112, 1989.

FAIRLAMB, A. H. \& CERAMI, A. Identification of a novel, thiol-containing co-factor essential for glutathione reductase enzyme activity in trypanosomatids. Molecular and Biochemical Parasitology, 14(2): 187-198, 1985.

FAIRLAMB, A. H. \& CERAMI, A. Metabolism and functions of trypanothione in the Kinetoplastida. Annual Review of Microbiology, 46: 695-729, 1992.

FAIRLAMB, A. H.; HENDERSON, G. B. \& CERAMI, A. Trypanothione is the primary target for arsenical drugs against African trypanosomes. Proceedings of the National Academy of Sciences of the USA, 86(8): 2.607-2.611, 1989.

FAIRLAMB, A. H. et al. Trypanothione: a novel bis(glutathionyl)spermidine cofactor for glutathione reductase in trypanosomatids. Science, 227(4.693): 1.485-1.487, 1985.

FAIRLAMB, A. H. et al. In vivo effects of difluoromethylornithine on trypanothione and polyamine levels in bloodstream forms of Trypanosoma brucei. Molecular and Biochemical Parasitology, 24(2): 185-191, 1987.

FIELD, H.; CERAMI, A. \& HENDERSON, G. B. Cloning, sequencing, and demonstration of polymorphism in trypanothione reductase from Crithidia fasciculata. Molecular and Biochemical Parasitology, 50(1): 47-56, 1992.

GEIGEL, L. F. Estudo da Via do Óxido Nítrico em Leishmania amazonensis, 2000. Dissertação de Mestrado, Rio de Janeiro: Instituto Oswaldo Cruz, Fundação Oswaldo Cruz.

GEIGEL, L. F. \& LEON, L. L. Cyclic 3'-5' guanosine monophosphate-dependent activity in Leishmania amazonensis. Memórias do Instituto Oswaldo Cruz, 98(4): 499-500, 2003.

GENESTRA, M. Oxyl radicals, redox-sensitive signalling cascades and antioxidants. Cellular Signalling, 19(9): 1.807$1.819,2007$.

GENESTRA, M. et al. Comparative analysis of the nitric oxide production by Leishmania sp. Medical Microbiology and Immunology, 192(4): 217-223, 2003a.

GENESTRA, M. et al. Effect of L-arginine analogs and a calcium chelator on nitric oxide (NO) production by Leishmania sp. Journal of Enzyme Inhibition and Medicinal Chemistry, 18(5): 445-452, 2003b.

GENESTRA, M. et al. Nitric oxide synthase (NOS) characterization in Leishmania amazonensis axenic amastigotes. Archives of Medical Research, 37(3): 328-333, 2006.

GENESTRA, M. et al. In vitro sodium nitroprusside-mediated toxicity towards Leishmania amazonensis promastigotes and axenic amastigotes. Cell Biochemistry and Function, 26(6): 709-717, 2008.

GIFFIN, B. F. et al. Polyamine depletion following exposure to DL-alpha-difluoromethylornithine both in vivo and in vitro initiates morphological alterations and mitochondrial activation in a monomorphic strain of Trypanosoma brucei brucei. The Journal of Protozoology, 33(2): 238-243, 1986.

GREEN, S. J. et al. Activated macrophages destroy intracellular Leishmania major amastigotes by an L-arginine-dependent killing mechanism. The Journal of Immunology, 144(1): 278-283, $1990 \mathrm{a}$.

GREEN, S. J. et al. Leishmania major amastigotes initiate the L-arginine-dependent killing mechanism in IFN-gamma-stimulated macrophages by induction of tumor necrosis factor-alpha. The Journal of Immunology, 145(12): 4.290-4.297, 1990b.

GRIFFITH, O. W. \& MEISTER, A. Origin and turnover of mitochondrial glutathione. Proceedings of the National Academy of Sciences of the USA, 82(14): 4.668-4.672, 1985.

HENDERSON, G. B. et al. Substrate specificity of the flavoprotein trypanothione disulfide reductase from Crithidia fasciculata. Biochemistry, 26(11): 3.023-3.027, 1987.

HENDERSON, G. B.; FAIRLAMB, A. H. \& CERAMI, A. Trypanothione dependent peroxide metabolism in Crithidia fasciculata and Trypanosoma brucei. Molecular and Biochemical Parasitology, 24(1): 39-45, 1987. 
JAMES, E. R. Superoxide dismutase. Parasitology Today, 10(12): 481-484, 1994.

JOCKERS-SCHERUBL, M. C.; SCHIRMER, R. H. \& KRAUTH-SIEGEL, R. L. Trypanothione reductase from Trypanosoma cruzi. Catalytic properties of the enzyme and inhibition studies with trypanocidal compounds. European Journal of Biochemistry, $180(2): 267-272,1989$.

JOHANSSON, K. U. \& CARLBERG, M. NO-synthase: what can research on invertebrates add to what is already known? Advances in Neuroimmunology, 5(4): 431-442, 1995.

KANDPAL, M. et al. Kinetics and molecular characteristics of arginine transport by Leishmania donovani promastigotes. Molecular and Biochemical Parasitology, 71(2): 193-201, 1995.

KEITHLY, J. S. Ornithine decarboxylase and trypanothione reductase genes in Leishmania braziliensis guyanensis. The Journal of Protozoology, 36(5): 498-501, 1989.

KELLY, J. M. et al. Phenotype of recombinant Leishmania donovani and Trypanosoma cruzi which over-express trypanothione reductase. Sensitivity towards agents that are thought to induce oxidative stress. European Journal of Biochemistry, 218(1): 29-37, 1993.

KIMA, P. E. The amastigote forms of Leishmania are experts at exploiting host cell processes to establish infection and persist. International Journal for Parasitology, 37(10): 1.087-1.096, 2007.

KRASSNER, S. M. \& FLORY, B. Essential amino acids in the culture of Leishmania tarentolae. The Journal of Parasitology, 57(4): 917-920, 1971.

KRAUTH-SIEGEL, R. L. \& COOMBS, G. H. Enzymes of parasite thiol metabolism as drug targets. Parasitology Today, 15(10): 404-409, 1999

KRAUTH-SIEGEL, L. R.; COMINI, M. A. \& SCHLECKER, T. The trypanothione system. Sub-cellular Biochemistry, 44: 231251, 2007.

KRAUTH-SIEGEL, R. L.; JACOBY, E. M. \& SCHIRMER, R. H. Trypanothione and N1-glutathionylspermidine: isolation and determination. Methods in Enzymology, 251: 287-294, 1995.

KRAUTH-SIEGEL, R. L. et al. Trypanothione reductase from Trypanosoma cruzi. Purification and characterization of the crystalline enzyme. European Journal of Biochemistry, 164(1): 123-128, 1987.

KRIEGER, S. et al. Trypanosomes lacking trypanothione reductase are avirulent and show increased sensitivity to oxidative stress. Molecular Microbiology, 35(3): 542-552, 2000.

KRONCKE, K. D.; FEHSEL, K. \& KOLB-BACHOFEN, V. Nitric oxide: cytotoxicity versus cytoprotection--how, why, when, and where? Nitric Oxide, 1(2): 107-120, 1997.

KROPF, P. et al. Arginase and polyamine synthesis are key factors in the regulation of experimental leishmaniasis in vivo. Faseb Journal, 19(8): 1.000-1.002, 2005.

LEGARE, D. et al. ABC proteins of Leishmania. Journal of Bioenergetics and Biomembranes, 33(6): 469-474, 2001.

LEHningher, A. L.; NELSON, D. L. \& COX, M. M. Principles of Biochemistry. 2. ed. New York: Worth Publishers, 1993.

MARTINEZ, M. C. \& ANDRIANTSITOHAINA, R. Reactive nitrogen species: molecular mechanisms and potential significance in health and disease. Antioxidants and Redox Signaling, 11(3):669-702, 2009.

MBEMBA, F. et al. Subcellular localization and modification with ageing of glutathione, glutathione peroxidase and glutathione reductase activities in human fibroblasts. Biochimica et Biophysica Acta, 838(2): 211-220, 1985.

McCONVILLE, M. J. et al. Living in a phagolysosome; metabolism of Leishmania amastigotes. Trends in Parasitology, 23(8): 368-375, 2007.

MEZIANE-CHERIF, D. et al. Trypanosoma cruzi: immunolocalization of trypanothione reductase. Experimental Parasitology, $79(4): 536-541,1994$. 
MUKHOPADHYAY, R. et al. Trypanothione overproduction and resistance to antimonials and arsenicals in Leishmania. Proceedings of the National Academy of Sciences of the USA, 93(19): 10.383-10.387, 1996.

MURRAY, H. W. \& NATHAN, C. F. Macrophage microbicidal mechanisms in vivo: reactive nitrogen versus oxygen intermediates in the killing of intracellular visceral Leishmania donovani. The Journal of Experimental Medicine, 189(4): 741-746, 1999.

NADERER, T. \& McCONVILLE, M. J. The Leishmania-macrophage interaction: a metabolic perspective. Cellular Microbiology, 10(2): 301-308, 2008.

NAGY, G. et al. Nitric oxide, chronic inflammation and autoimmunity. Immunology Letters, 111(1): 1-5, 2007.

OSWALD, I. P. et al. NO as an effector molecule of parasite killing: modulation of its synthesis by cytokines. Comparative Biochemistry and Physiology. Pharmacology, Toxicology and Endocrinology, 108(1): 11-18, 1994.

PELUFFO, G. et al. L-arginine metabolism during interaction of Trypanosoma cruzi with host cells. Trends in Parasitology, 20(8): 363-369, 2004.

PHILLIPS, M. A.; COFFINO, P. \& WANG, C. C. Cloning and sequencing of the ornithine decarboxylase gene from Trypanosoma brucei. Implications for enzyme turnover and selective difluoromethylornithine inhibition. Journal of Chemical Biology, 262(18): 8.721-8.727, 1987.

REGUERA, R. M. et al. Leishmania major lacking arginase (ARG) are auxotrophic for polyamines but retain infectivity to susceptible BALB/c mice. Molecular and Biochemical Parasitology, 165(1): 48-56, 2009.

RIVERO, A. Nitric oxide: an antiparasitic molecule of invertebrates. Trends in Parasitology, 22 (5): 219-225, 2006.

SHAKED-MISHAN, P. et al. A novel high-affinity arginine transporter from the human parasitic protozoan Leishmania donovani. Molecular Microbiology, 60(1): 30-38, 2006.

SHAMES, S. L. et al. Purification and characterization of trypanothione reductase from Crithidia fasciculata, a newly discovered member of the family of disulfide-containing flavoprotein reductases. Biochemistry, 25(12): 3.519-3.526, 1986.

SHAMES, S. L. et al. Trypanothione reductase of Trypanosoma congolense: gene isolation, primary sequence determination, and comparison to glutathione reductase. Biochemistry, 27(14): 5.014-5.019, 1988.

SJOERDSMA, A. \& SCHECHTER, P. J. Chemotherapeutic implications of polyamine biosynthesis inhibition. Clinical Pharmacology and Therapeutics, 35(3): 287-300, 1984.

SMITH, K.; OPPERDOES, F. R. \& FAIRLAMB, A. H. Subcellular distribution of trypanothione reductase in bloodstream and procyclic forms of Trypanosoma brucei. Molecular and Biochemical Parasitology, 48(1): 109-112, 1991.

SOUZA, W. Cell biology of Trypanosoma cruzi. International Review of Cytology, 86: 197-283, 1984.

STAMLER, J. S.; SINGEL, D. J. \& LOSCALZO, J. Biochemistry of nitric oxide and its redox-activated forms. Science, 258(5.090): 1.898-1.902, 1992.

STUART, K. et al. Kinetoplastids: related protozoan pathogens, different diseases. The Journal of Clinical Investigation, 118(4): 1.301-1.310, 2008.

SULLIVAN, F. X. \& WALSH, C. T. Cloning, sequencing, overproduction and purification of trypanothione reductase from Trypanosoma cruzi. Molecular and Biochemical Parasitology, 44(1): 145-147, 1991.

TANIGUCHI, M.; HARA, T. \& HONDA, H. Similarities between rat liver mitochondrial and cytosolic glutathione reductases and their apoenzyme accumulation in riboflavin deficiency. Biochemistry International, 13(3): 447-454, 1986.

TAYLOR, M. C. et al. The structure, organization, and expression of the Leishmania donovani gene encoding trypanothione reductase. Molecular and Biochemical Parasitology, 64(2): 293-301, 1994.

VINCENDEAU, P. et al. Arginases in parasitic diseases. Trends in Parasitology, 19(1): 9-12, 2003.

WALSH, C.; BRADLEY, M. \& NADEAU, K. Molecular studies on trypanothione reductase, a target for antiparasitic drugs. Trends in Biochemical Sciences, 16(8): 305-309, 1991. 
YAMAMOTO, T. \& BING, R. J. Nitric oxide donors. Proceedings of the Society for Experimental Biology and Medicine, 225(3): 200-206, 2000.

ZAMBRANO-VILlA, S. et al. How protozoan parasites evade the immune response. Trends in Parasitology, 18(6): 272$278,2002$. 
parte III

Aspectos Bioquímicos e Moleculares na Interação

Parasito-Hospedeiro-Vetor 


\title{
8 \\ Componentes de Superfície do Parasito e o Papel na Interação Parasito-Hospedeiro
}

\author{
Carlos Roberto Alves I Mariana Silva de Almeida I Franklin Souza da Silva \\ Bernardo Acácio Santini Pereira I Ricardo Luiz de Azevedo Pereira I Luzia Monteiro de Castro Côrtes
}

$\mathrm{P}$ rotozoários, como os parasitos pertencentes ao gênero Leishmania, apresentam sua superfície recoberta por uma complexa membrana celular, que é a responsável pela manutenção da integridade do meio intracelular, mantendo-o distinto do meio extracelular. Dessa forma, a membrana celular também rege a interação do protozoário com o meio extracelular, atuando na captação de nutrientes e vias de sinalizações que definem mecanismos de adaptação do protozoário.

Como a superfície celular desses protozoários representa o primeiro contato com os diferentes microambientes dos seus hospedeiros (invertebrados e vertebrados), a expressão regulada de componentes de superfície está diretamente relacionada ao sucesso da infecção. Desse modo, os componentes de superfície dos promastigotas e amastigotas são os determinantes da interação parasito/hospedeiro nas leishmanioses e podem significar alvos de ação sobre a cadeia de transmissão da doença em ambos os hospedeiros.

A membrana plasmática desses protozoários apresenta ainda uma camada mais externa, constituída por uma rede entrelaçada de carboidratos ligados covalentemente aos lipídeos e proteínas - o glicocálice ou glicocálix (glykys = glicídios e calyx = envoltório). Esse envoltório é secretado pela membrana plasmática, por vesículas secretoras, e se mantém aderido a ela, atuando nas interações entre os protozoários e as células dos hospedeiros. Uma vez que a constituição do glicocálice pode variar entre diferentes espécies e entre as formas evolutivas de uma mesma espécie, esta pode ser utilizada para a caracterização de espécies e para o acompanhamento da mudança das formas evolutivas. De maneira geral, o glicocálice dos protozoários Leishmania é rico em glicosilfosfatidilinositol (glycosylphosphatidylinositol GPI), lipofosfoglicanos (lipophosphoglycan - LPG), glicoinositolfosfolipídeos (glycoinositolphospholipids - GIPLS), proteínas e enzimas.

Ao longo deste capítulo será relatada a composição da membrana de superfície de Leishmania, com enfoque na atuação desses componentes no ciclo de vida do protozoário. o capítulo pretende apresentar o estado da arte desses componentes nos subgêneros Leishmania e Viannia, principalmente nas espécies que ocorrem no continente americano. 


\section{LIPOFOSFOGLICANO}

O lipofosfoglicano (LPG) é um dos principais componentes da superfície dos promastigotas de Leishmania sp., participando na constituição do glicocálice desses parasitos (Moody et al., 1993). Foi identificado inicialmente em promastigotas por meio de anticorpos monoclonais, sendo caracterizado como um lipopolissacarídeo com propriedades anfipáticas (Handman, Greenblatt \& Goding, 1984). A estrutura e a expressão do LPG variam entre as diferentes espécies e estágios evolutivos do protozoário, mostrando-se uma importante ferramenta na adaptação do parasito ante os diferentes microambientes dos hospedeiros (Pimenta, Saraiva \& Sacks, 1991; Saraiva et al., 1995; Olivier, Gregory \& Forget, 2005; Assis et al., 2012). Estudos in vitro utilizando Leishmania (Leishmania) major indicaram que a forma específica de LPG de amastigota desaparece após 48 horas da transformação amastigota-promastigota, enquanto durante a transformação promastigota-amastigota, a forma específica de LPG de amastigota foi detectada 12 horas após a infecção (Glaser et al., 1991). Em outras espécies, como Leishmania (Leishmania) donovani, a forma específica de amastigota não é detectada (McConville \& Blackwell, 1991).

O tipo de ancoramento do LPG à superfície da membrana plasmática é realizado por um grupamento GPI [1-O-alquil2-lisofosfatidil(mio)inositol] presente em todas as espécies de Leishmania analisadas até o momento (McConville \& Ralton, 1997; Turco \& Descoteaux, 1992). O GPI apresenta um núcleo fosfossacarídico com galactofuranose (Galf) interna. Uma das características do gênero Leishmania é o fato de o GPI dispor de um esqueleto formado por unidades repetitivas de fosfodissacarídeos e na região mais extrema, uma cobertura de oligossacarídeos (Turco et al., 1987; Ilg et al., 1992; McConville \& Homans, 1992). Variações dessas estruturas podem ser detectadas dentro de uma mesma espécie e entre espécies de Leishmania, revelando um polimorfismo dos oligossacarídeos que as constituem, servindo, assim, como marcador específico de espécies ou do estágio em que se encontra o parasito, como proposto para Leishmania (Leishmania) mexicana e L. (L.) major.

A presença de resíduos de Gluß1,3 nas ramificações das unidades repetitivas de Galß1,4 Mana1-PO4 é um dos aspectos que distingue o LPG das formas promastigotas procíclicas de Leishmania (Leishmania) infantum das metacíclicas. Tais modificações são significativas na interação desse parasito com seu vetor, o flebotomíneo Lutzomya longipalpis, visto que, em contraste às formas procíclicas, as formas metacíclicas não são capazes de se ligar ao intestino do inseto vetor (Soares et al., 2002).

O LPG das formas procíclicas de Leishmania (Viannia) braziliensis foi caracterizado por não conter cadeias laterais de açúcares. Diferente das espécies do subgênero Leishmania, as formas metacíclicas de L. (V.) braziliensis produzem menos

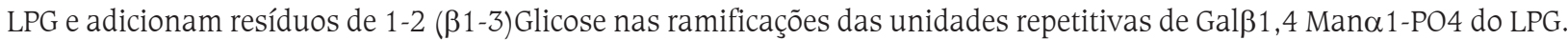
Essa modificação foi descrita como um novo mecanismo na regulação da estrutura do LPG durante a metaciclogênese (Soares et al., 2005).

No hospedeiro invertebrado, o LPG é importante para a fixação de promastigotas procíclicos ao epitélio intestinal, o que representa uma etapa essencial à manutenção do ciclo de vida do parasito no inseto vetor (Mahoney et al., 1999; Sacks et al., 1995; Pimenta et al., 1992). A L. (V.) braziliensis apresenta um padrão de adesão ao epitélio intestinal de Lutzomyia (Nyssomyia) whitmani, que caracteriza-se como um vetor bastante competente, diferente do observado em Lu. (N.) intermedia, sendo que neste último, o LPG parece ter uma importância menor no processo de adesão (Soares et al., 2010). Estudos recentes avaliando a permanência de uma linhagem mutante para LPG de L. (L.) major (null para o gene lpg1 que codifica para enzima transferase da galactofuranose) (Spath et al., 2000) no intestino de Phlebotomus duboscqi evidenciaram que a ausência da expressão de LPG reduz expressivamente a presença de parasitos 72 horas após a infecção, sendo que após 15 a 21 dias não se detecta a presença de parasitos (Secundino et al., 2010). É interessante notar que a infecção com a cepa mutante em Lu. longipalpis, vetor não natural desse parasito, mostrou-se 
mais efetiva do que com a cepa selvagem, indicando que o LPG não é necessário para infecções em vetores não naturais, fato também observado em outros estudos (Secundino et al., 2010; Myskova et al., 2007).

Um polipeptídeo de $65 \mathrm{kDa}$ no epitélio do trato digestório de Phlebotomus papatasi foi descrito como ligante de LPG das formas procíclicas $L$. (L.) major (Dillon \& Lane, 1999). Posteriormente, em uma série de experimentos, a PpGalec, uma galectina expressa no epitélio intestinal de $P$. papatasi, demonstrou ser crucial para sobrevivência e transmissão de L. (L.) major por meio de sua ligação com LPG (Kamhawi et al., 2004). No inseto vetor - após o escape da matriz peritrófica -, os promastigotas necessitam aderir ao epitélio intestinal. Essa adesão evita a excreção dos promastigotas do interior da luz do intestino, assim como permite a sua multiplicação e posterior diferenciação, sendo um fenômeno essencial à manutenção do ciclo de vida.

No hospedeiro vertebrado, o LPG é um importante ligante de macrófagos, estando diretamente envolvido nas etapas iniciais da infecção. A utilização de uma cepa mutante de L. (L.) major, deficiente no gene lpg1 (lpg1-), revelou que o parasito apresenta uma atenuação de sua virulência nas infecções de macrófagos de camundongo. Os promastigotas lpg1- se mostraram altamente suscetíveis à ação do sistema complemento, além de terem sido afetados por agentes oxidantes produzidos pelas células do hospedeiro e perderem a capacidade de inibir a fusão do fagolisossoma (Spath, 2000; Handman \& Goding, 1985; Spath et al., 2003).

Sabe-se também que o LPG de Leishmania spp. exerce uma ação inibitória sobre a atividade da proteína quinase C (PKC) de macrófagos, favorecendo o estabelecimento e manutenção da infecção, uma vez que essa enzima é um componente-chave do processo de ativação de tais células (Turco, 1999; Delgado-Domínguez et al., 2010). Embora esse efeito do LPG seja um fato estabelecido, o mecanismo de sinalização intracelular envolvido na resposta oxidativa que lesa o parasito ainda não foi esclarecido. Um avanço na compreensão da via de ação do LPG foi a descrição de que na infecção murina por $L$. (L.) donovani há uma ação seletiva sobre a isoforma PKC $\beta$ dependente de cálcio, com diminuição da expressão e atividade dessa enzima (Bhattacharyya et al., 2001). Além disso, estudo avaliando ação de três tipos de LPG de $L$. (L.) infantum indicou que apenas uma variante é capaz de estimular a produção de óxido nítrico em macrófagos murinos (Coelho-Finamore et al., 2011).

Em relação ao sistema complemento, o LPG de promastigotas metacíclicas de L.(L.) major inibe a formação do complexo de ataque à membrana em virtude de suas longas cadeias de açúcar. As modificações que ocorrem na superfície dos promastigotas durante a transição entre o estágio não infectivo (forma procíclica) ao infectivo (forma metacíclica) obstruem a inserção do componente lítico C5b-9 na membrana dos promastigotas infectivos (Puentes et al., 1990; Puentes et al., 1988; Sacks, 1992). Por sua vez, LPG também pode atuar na ativação do complemento, com deposição de $\mathrm{C} 3 \mathrm{~b}$ covalentemente ligado à membrana celular, o que proporciona a ligação dos promastigotas ao macrófago via receptor C3bi, com a posterior endocitose das formas metacíclicas do parasito e lise das formas não infectivas (Puentes et al., 1988; Mosser, Springer \& Diamond, 1992).

Além de atuar sobre macrófagos, o LPG de L. (L.) major promove também a ativação da resposta imune inata com a participação de linfócitos natural killer (NK) e de células dendríticas por intermédio do receptor toll-like 2 (Becker et al., 2003; Brandonisio, Spinelli \& Pepe, 2004; Soong, 2008). Em linfócitos NK, esta interação do LPG com o receptor toll-like 2 leva a um aumento da síntese de interferon gama (INF- $\gamma$ ) e fator de necrose tumoral alfa (tumor necrosis factor alfa - TNF- $\alpha$ ), estimulando subpopulações de linfócitos T, o que conferiu certo grau de imunidade à infecção em animais de experimentação (Becker et al., 2003).

Além dessas características indicarem o LPG como um dos possíveis candidatos à vacina contra as leishmanioses (Moody et al., 1993; Tonui et al., 2001), estudos em camundongos infectados previamente com cepas mutantes de L. (L.) major, deficientes nos genes lpg, indicaram uma resposta imune protetora contra infecção de cepas virulentas na ausência de uma forte resposta Th1 (Uzonna et al., 2004). 


\section{GLICOINOSITOLFOSFOLIPÍDEOS}

Os glicolipídeos majoritariamente estudados em Leishmania são os glicoinositolfosfolipídeos (GIPLs). Também denominados GPIs livres, são glicolipídeos de baixo peso molecular e altamente expressos na superfície do parasito tanto nas formas promastigotas como nas amastigotas. Os GILPs de L. (L.) major contêm de quatro a seis resíduos de açúcar ligados ao lipídeo liso-alquil-fosfatidilinositol (McConville et al., 1990).

Estudos vêm demonstrando que os GIPLs auxiliam na sobrevivência de L. (L.) major dentro de macrófagos, inibindo a síntese de óxido nítrico principalmente pela região alquil-acil-glicerol (Proudfoot, O’Donnell \& Liew, 1995; Zuffery et al., 2003). Além disso, os GILPs, de modo semelhante ao LPG, provavelmente pela porção GPI comum aos dois, atuam na inibição da atividade de PKC (Zufferey et al., 2003). Diferenças na estrutura do GILPs sugerem que sejam espécieespecífica, cepa-específica e estágio-específico (McConville \& Blacwell, 1991; McConville et al., 1994).

A taxa de infecção de macrófagos por L. (V.) braziliensis tem sido relacionada com microdomínios de lipídeos da membrana externa (detergent-resistant membranes - DRMs) de promastigotas contendo GILPs. A desestruturação desses domínios é capaz de induzir a uma diminuição na taxa de infecção de macrófagos por L. (V.) braziliensis, sugerindo uma relação entre os microdomínios contendo GILPs e a infectividade desses parasitos (Yoneyama et al., 2006).

\section{PROTEÍNAS E ENZIMAS}

Inúmeras proteínas têm sido verificadas na superfície das formas amastigotas e promastigotas de espécies de Leishmania, com base em estudos com marcações radioativas associadas às técnicas de imunoprecipitação, ou Western blotting, utilizando anticorpos monoclonais e soro imune de paciente e animais. Assim, uma faixa muito ampla de proteínas, com massa molecular relativa de $10 \mathrm{kDa}$ até $120 \mathrm{kDa}$, tem sido encontrada. Poucas dessas proteínas têm sua função conhecida, sendo uma notável exceção a proteína ligante de laminina com $67 \mathrm{kDa}$, identificada na superfície de promastigota e amastigota de L. (L.) donovani (Bandyopadhyay et al., 2001). Assim como o observado para as diferentes formas de LPG e GILPs, muitas das proteínas encontradas parecem ser estágio-específicas, como é o caso da proteína de $116 \mathrm{kDa}$ presente em promastigotas infectivas de L. (L.) major (Sacks, Hieny \& Sher, 1985) e das proteínas de $23 \mathrm{kDa}, 52 \mathrm{kDa}$ e $68 \mathrm{kDa}$ em promastigotas e $38 \mathrm{kDa}, 70 \mathrm{kDa}$ e $74 \mathrm{kDa}$ em amastigotas de L. (L.) pifanoi (Pan, 1986).

Um dos primeiros estudos sobre as proteínas de superfície de L. (V.) braziliensis, realizado em 1985, foi uma simples comparação entre a superfície celular dos promastigotas patogênicos e os não patogênicos. Nesse estudo foi constatado que a superfície celular desses promastigotas é diferente quanto aos receptores de lectinas e quanto às cargas (Ayesta, Arguello \& Hernandez, 1985). Nesse mesmo ano foi descrita outra estratégia para a análise das proteínas de superfície desse parasito, a qual inclui a iodinação da superfície celular seguida do procedimento fracionamento com detergente não iônico e cromatografia de troca iônica, para isolar uma proteína de $65 \mathrm{kDa}$ de promastigotas infectivos (Misle, Márquez \& Hernandez, 1985). No ano seguinte foram isoladas duas glicoproteínas da membrana celular de promastigotas de L. (V.) braziliensis, uma de $53 \mathrm{kDa}$ com afinidade de ligação à concanavalina $\mathrm{A}$ e à Ricinus communis e outra de $47 \mathrm{kDa}$ com afinidade de ligação a Dolichos biflorus (Nagakura et al., 1986).

A proteína de $11 \mathrm{kDa}$ de cinetoplastídeos (Kinetoplastid membrane protein of $11 \mathrm{kDa}-\mathrm{KMP}-11$ ) e as hidrofílicas aciladas (hydrophilic acylated surface protein - HASP) também estão localizadas na membrana plasmática de Leishmania spp.. Tais proteínas não apresentam domínio transmembrana, peptídeo sinal e nem âncora de GPI, e são isoladas por solventes orgânicos juntamente com o LPG. A KMP-11 apresenta fortes características hidrofóbicas e está associada ao LPG na superfície celular do parasito (Jardim et al., 1995). Já foi descrita em diversos gêneros de tripanossomatídeos (Stebeck et al., 1995), contudo suas propriedades imunorregulatórias foram confirmadas somente em pacientes com leishmaniose cutânea e mucosa, uma vez que induzem a expressão de interleucina-10 
(Carvalho et al., 2005). Um estudo recente demonstrou sua presença em amastigotas e promastigotas de Leishmania (Leishmania) amazonensis e também que sua expressão aumenta na superfície dos parasitos durante a metaciclogênese (Matos et al., 2010).

As proteínas hidrofóbicas aciladas de superfície (hydrophobic acylated surface proteins - HASPs) têm características hidrofílicas além de serem distintamente reguladas nas formas evolutivas do parasito e encontradas com predominância em amastigotas e em abundância na superfície de formas infectivas de L. (L.) major (Flinn, Rangarajan \& Smith, 1994). Estas proteínas são expressas em genes em uma mesma região cromossômica nas espécies do gênero Leishmania (Depledge et al., 2010). Provavelmente a dupla acilação que apresentam deve mediar a associação com a membrana, agindo como uma âncora de superfície. Entre 70\% a 80\% das HASPs são observadas na face citosólica da membrana celular (Denny et al., 2000). Já foi proposto que em pacientes com leishmaniose visceral causada pela Leishmania (Leishmania) chagasi, as HASPs estariam atuando na imunomodulação da infecção (Vinhas et al., 1994).

A caracterização de genes por meio de métodos moleculares tem possibilitado a associação de sequências de nucleotídeos com proteínas presentes em tripanossomatídeos. É o caso de uma sequência de nucleotídeos obtida de L. (L.) donovani, a qual codifica para uma proteína com 198 aminoácidos, que apresentou 36\% de identidade com a proteína amastina da superfície de Trypanosoma cruzi (Wu et al., 2000). No T. cruzi a amastina foi caracterizada com glicoproteína e atua na invasão e proliferação intracelular desse parasito (Jackson, 2010). Em razão de ausência de estudos sobre a funcionalidade dessa proteína em Leishmania spp., não se pode afirmar que tenha a mesma função da amastina de T. cruzi. Porém, sabe-se que o gene dessa proteína, semelhante à amastina, é mais expresso na fase estacionária e principalmente em amastigotas de L. (L.) donovani, podendo, dessa forma, estar relacionado à sobrevivência de amastigotas dentro do fagolisossomo (Wu et al., 2000).

Certas proteínas presentes na superfície do parasito parecem ter um papel na via de sinalização que leva à mudança de estágio dentro do ciclo de vida dos mesmos, como os receptores de adenilato ciclase (receptor AC). Essa enzima cataliza a conversão de adenosida trifosfato (ATP) a adenosina monofosfato cíclico (AMPc) e, assim, participam de uma via de sinalização do AMPc já descrita em protozoários kinetoplastida (Seebeck, Schaub \& Johner, 2004). Esses receptores foram descritos em $L$. (L.) donovani e podem induzir a mudanças de estágio pela elevação de AMPc intracelular, fato observado em T. cruzi (Sanchez et al., 1995; Biswas, Bhattacharya \& Das, 2011).

A glicoproteína de 46 kDa, chamada de gp46/M-2, descrita na superfície de L. (L.) amazonensis (Kahl \& McMahonPratt, 1987), apresenta notável resistência à digestão proteolítica. Sua estrutura contém uma sequência repetitiva de 24 aminoácidos, a qual corresponde a $22 \%$ do total da proteína madura, e um teor glicídico de $7 \%$, correspondente a $3 \mathrm{kDa}$, além de ser ligada à membrana pela âncora de GPI (Lohhman, Langer \& McMahon-Pratt, 1990). A gp46/M-2 é codificada pela mesma família de genes polimórficos do complexo de antígenos-2 de superfície de promastigotas, descrito previamente em $L$. (L.) major, e observa-se em sua estrutura regiões conservadas com esses antígenos (Murray, Spithill \& Handman, 1989).

Dentre todas as espécies de Leishmania já estudadas, os genes que codificam gp46/M-2 não foram encontrados em somente duas espécies: L. (V.) braziliensis e Leishmania (Leishmania) enrittii (Hanekamp \& Langer, 1991; McMahon-Pratt et al., 1992). Além disso, a expressão de RNA mensageiro (mRNA) da gp46/M-2 de L. (L.) chagasi apresenta indícios de ser mais elevada em promastigotas de fase estacionária de cultura, levando a crer que seria um fator de virulência desse estágio evolutivo do parasito (Beetham et al., 1997). Outro fato importante é que gp46/M-2 de L. (L.) amazonensis proporciona uma proteção contra a infecção dessa espécie em camundongos susceptíveis (Champsi \& McMahon-Pratt, 1988; McMahon-Pratt et al., 1993). Tal observação sugere que a gp46/M-2 seria outro antígeno candidato a vacina contra a leishmaniose (Liew \& O’Donnell, 1993). 
As espécies de Leishmania têm várias proteínas reconhecidas como membros de famílias conservadas durante a evolução (Requena, Alonso \& Soto, 2000). Dentre essas, se destacam os proteofosfoglicanos (proteophosphoglycan - PPG), caracterizados como polipeptídeos altamente glicosilados. São proteínas que apresentam ligação de fosfossacarídeos à cadeia peptídica por O-glicosilação. Os PPGs podem ser encontrados na membrana celular do parasito ancoradas por GPI, sendo dessa forma denominadas mPPGs (Ilg et al., 1999). A função dos mPPGs ainda não está totalmente clara, porém especula-se que, em razão da sua longa cadeia cobrindo a membrana plasmática dos parasitos, tenha papel importante como ligante a receptores de macrófagos e de células do trato digestório do inseto vetor (Ilg, 2000).

Em promastigotas, um PPG secretado e filamentoso (fPPG) forma um agregado viscoso, estabelecendo uma rede de filamentos fibrosos como um gel. O fPPG é secretado pela bolsa flagelar (Stierhof et al., 1994) com 95\% de sua composição de fosfoglicanos e a porção peptídica apresentando abundância de serina, alanina e prolina. Sua extensiva glicosilação potencialmente confere capacidade de resistir à ação de proteinases, embora ainda não existam claras evidências nesse sentido. Além disso, sua participação parece ser importante no bloqueio do intestino anterior do inseto vetor, o que impede a ingestão de alimento e leva o inseto a sucessivas tentativas de se alimentar, aumentando as chances de infecção dos hospedeiros vertebrados por Leishmania spp. (Ilg, 2000; Walters et al., 1989).

Amastigotas secretam dentro do vacúolo parasitófaro outro tipo de PPG, que estruturalmente são definidos como uma cadeia polipeptídica modificada com fosfoglicanos ligados a resíduos de serina (Ilg, 2000) e contêm açúcares semelhantes aos encontrados em LPG e nas fosfatases ácidas. A secreção deste PPG modificado dentro de macrófagos parece contribuir para manutenção do vacúolo parasitóforo (Peters, Stierhof \& Ilg, 1997). Adicionalmente, essa molécula também é capaz de ativar o complemento via proteína ligadora de manose (Peters et al., 1997), podendo assim contribuir para ligação da Leishmania spp. à célula hospedeira.

Várias espécies de Leishmania estudadas revelaram a expressão de fosfatases ácidas (acid phosphatase - AcP) durante seu ciclo biológico (Shakarian \& Dwyer, 2000). Três destas AcP foram descritas na membrana de L. (L.) donovani com 128, 132 e 108 kDa e pH ótimo de atividade próximo a 5,5 (Remaley et al., 1985). O genes de Leishmania para as fosfatases ácidas secretadas (SAcP) e de membrana (MAcP) mostraram-se homólogos tanto em espécies viscerotrópicas como dermotrópicas (Shakarian \& Dwyer, 2000; Shakarian et al., 2002).

Tanto as MAcPs (que apresentam peso molecular $120 \mathrm{kDa}$ e $134 \mathrm{kDa}$ ) quanto as SAcPs podem ser apontadas como uma das estratégias de sobrevivência do parasito no trato alimentar do inseto vetor, e também no interior do macrófago, uma vez que interferem na produção de metabólitos oxidativos $\left(\mathrm{H}_{2} \mathrm{O}_{2}, \mathrm{OH}^{-}, \mathrm{O}^{2-}\right)$ tóxicos ao protozoário (Buchmuller-Rouiller \& Mauel, 1987; Glew et al., 1988). Essas ectoenzimas são monoesterases capazes de hidrolisar uma variedade de substratos fosforilados, principalmente fosfolipídeos e fosfoproteínas e, dessa forma, interferem na produção de radicais livres pelos macrófagos (Glew et al., 1988). Contudo, seu papel na resposta imunológica ainda não está completamente elucidado. Estudos com amostras de soro de pacientes com leishmaniose visceral (Ellis, Shakarian \& Dwyer, 1998) detectaram anticorpos contra SAcPs de L. (L.) donovani, sugerindo que sua expressão em amastigotas induz a um estímulo da resposta imune humoral.

Outras classes de enzimas presentes na membrana plasmática, no flagelo e na bolsa flagelar de diversas espécies de Leishmania são as 3'-nucleotidases ( $43 \mathrm{kDa}$ ) (Côrte-Real et al., 1993) e 5'-nucleotidases ( $70 \mathrm{kDa}$ ) (Campbell et al., 1991). Essas enzimas hidrolisam nucleotídeos a ácidos nucléicos 3'-AMP e 5'-AMP, respectivamente (Farajnia et al., 2004; Gottlieb \& Dwyer, 1983; Hansen et al., 1982). As nucleotidases teriam papel nutricional importante, já que esses parasitos não são capazes de sintetizar purina via síntese de novo (Debrabrant, Gottlieb \& Dwyer, 1995). A identificação de genes homólogos dessa enzima em várias espécies de Leishmania confirma que a 3’-nucleotidase é conservada nesse gênero (Debrabant, Gottlieb \& Dwyer, 1995), corroborando o seu papel crítico na captação de purinas. A remoção de porção C-terminal da enzima causa sua liberação da membrana plasmática de L. (L.) donovani, demonstrando que 
esse domínio é responsável por seu ancoramento. Ainda assim, sua atividade enzimática não sofre interferência com a remoção desse domínio e nem com a remoção de suas $N$-glicosilações (Debrabant, Ghedin \& Dwyer, 2000). Como a 3'-nucleotidase não foi detectada em células de mamíferos, ela surge como outra possibilidade de alvo para ação de quimioterápios mais seletivos (Farajnia et al., 2004; Gbenle \& Dwyer, 1992).

As enzimas transportadoras de íons $\mathrm{Ca}^{2+}\left(\mathrm{Ca}^{2+}\right.$-ATPase) também foram descritas na membrana de superfície da Leishmania spp. e atuam como uma bomba de $\mathrm{Ca}^{2+}$. Tais enzimas apresentam alta afinidade com esse íon e sua atividade está estritamente relacionada com a calmodulina, visto que antagonistas da calmodulina bloqueiam completamente sua atividade (Banerjee, Sarkar \& Bhaduri, 1999; Benaim et al., 1993). Com duas subunidades (51 kDa e $57 \mathrm{kDa}$ ) fortemente associadas à membrana plasmática (Ghosh et al., 1990), conta com um sítio aloestérico ao $\mathrm{Mg}^{2+}$ capaz de modular sua atividade cinética (Mazumder et al., 1992).

A homeostase da concentração submicromolar de $\mathrm{Ca}^{2+}$ intracelular de L. (V.) braziliensis, L. (L.) mexicana, T. cruzi e Trypanosoma brucei é mantida pela atividade da $\mathrm{Ca}^{2+}$-ATPase presente na membrana plasmática desses parasitos (Benaim \& Romero, 1990). Também foi proposto que o aumento da atividade da $\mathrm{Ca}^{2}+$ ATPase presente na membrana plasmática de $L$. (L.) amazonensis pode determinar a regulação dos níveis de cálcio no interior do fagossomo (CôrteReal, Santos \& Meirelles, 1995).

Enzimas transportadoras de íons $\mathrm{Mg}^{2+}$ também foram descritas na membrana celular de Leishmania spp., sendo denominadas $\mathrm{Mg}^{2+}$-ATPases. As $\mathrm{Mg}^{2+}$-ATPases de $L$. (L) donovani têm sua atividade modulada pela fluidez da membrana (Dutta et al., 1990). Tais enzimas parecem ter uma função de bomba de extrusão de $\mathrm{H}^{+}$, além de ter um possível papel na acumulação de glicose e potássio no meio intracelular (Dutta et al., 1990; Mukherjee, Mandal \& Bhaduri, 2001). Alterações na atividade dessas proteínas podem estar relacionadas com a virulência do parasito, participando da pré-adaptação dos promastigotas para sobrevivência dentro dos macrófagos (Berredo-Pinho et al., 2001; Lu et al., 1997).

As proteinases consistem em outra categoria de proteínas descrita na membrana celular de Leishmania spp. Entre as quatro classes de proteinase descritas nesse parasito (Alves et al., 2005; Silva-Lopez et al., 2004; Bouvier, Etges \& Bordier, 1985; Silva-Lopez \& Giovanni-De-Simone, 2004), somente as metaloproteinases e as cisteína-proteinases foram localizadas na membrana plasmática de várias espécies de Leishmania, até o momento.

A gp63 é uma das principais glicoproteínas encontradas na superfície de promastigotas de Leishmania spp., com massa molecular aproximada de $63 \mathrm{kDa}$. É uma zinco-metaloproteinase e está fixada à membrana plasmática por meio de âncora de GPI, evidenciando polimorfismo entre espécies, além de ter uma expressão reduzida em amastigotas (Olivier \& Hassani, 2010; Davies et al., 1990; Muskus \& Marin, 2002). Nos últimos anos, tem sido demonstrado que a massa molecular das metaloproteinases de Leishmania spp. não é muito homogênea, podendo ser detectadas enzimas desde 50 kDa e mesmo acima de 63 kDa (Alves, Mendonça-Lima \& Alves, 2004; Yao et al., 2004; Cuervo et al., 2006).

Não obstante as metaloproteinases terem sido descritas como proteinases de membrana em espécies de Leishmania, estudos recentes indicam que isoformas dessas enzimas têm localização intracelular em L. (L.) mexicana e em L. (L.) chagasi (Weise et al., 2000; Yao et al., 2005). Também uma análise por microscopia confocal sobre a distribuição dessas enzimas em $L$. (V.) braziliensis demonstrou a existência intracelular de metaloproteinases com domínios homólogos a gp63, localizados próximos à bolsa flagelar (Cuervo et al., 2008).

A importância das metaloproteinases no ciclo biológico da Leishmania spp. ainda é alvo de muitos estudos. As metaloproteinases têm atividade proteolítica sobre numerosos substratos, podendo estar envolvidas na degradação de macromoléculas do hospedeiro. Essas enzimas estão associadas à hidrólise e inativação de imunoglobulinas $\mathrm{G}$ (Etges, Bouvier \& Bordier, 1986; Mendonça-Lima \& Atta, 1992) e têm propriedade de inativar o fator C3b, em C3bi, do complemento (Bogdan \& Rollinghoff, 1998; Chaudhuri \& Chang, 1988). Essa última atividade pode auxiliar a 
internalização dos promastigotas no macrófago, tendo como consequência C3bi atuar como opsonina, ligando ao LPG ou à própria gp63 (Bogdan \& Rollinghoff, 1998).

Protótipos de vacina oral usando Salmonella typhimurium atenuada contendo o gene da gp63 induziram um fenótipo Th1 de proteção, com linfócitos $\mathrm{T} \mathrm{CD}^{+}$, para infecção por $L$. (L.) major em camundongos BALB/c (Xu et al., 1995). O êxito de vacinas de cDNa também foi observado no controle da infecção de BALB/c por L. (L.) mexicana com indução de linfócitos T citotóxicos (Ali et al., 2009). Também camundongos BALB/c vacinados com gp63 em lipossomos catiônicos induz proteção contra infecção por L. (L.) donovani (Bhowmick, Ravindran \& Ali, 2008). Por sua vez, a vacinação de cães com plasmídeos de DNA codificante da gp63, e outras proteínas de Leishmania, não induziu proteção desses animais contra a infecção experimental por L. (L.) infantum (Rodriguez-Cortes et al., 2007). Mesmo sem uma clara definição do perfil de proteção que a gp63 pode induzir, ainda é plausível o uso dessa proteína na construção de vacinas para as leishmanioses.

Estudos in silico, com sequência da L. (V.) braziliensis, indicaram que regiões do sítio catalítico da metaloproteinases apresentam sequências conservadas e que regiões que codificam os domínios de superfície estão possivelmente envolvidas nas interações parasito-hospedeiro: sítios de adesão a macrófago e epitopos de linfócitos $\mathrm{T}$ e $\mathrm{B}$ imunodominantes (Victoir et al., 2005).

Além disso, já foi proposta uma função protetora da gp63 contra a ação de tripsina e quimiotripsina do inseto vetor, enzimas cuja expressão aumente após o repasto sanguíneo e, dessa forma, podem interferir no desenvolvimento de parasitos no intestino do inseto. Observou-se que a atividade de tripsina e quimiotripsina acarreta a diminuição da subpopulação de promastigotas com expressão menor de gp63 no intestino do vetor, quando este se encontra repleto de sangue (Pimenta et al., 1997).

Várias cisteína-proteinases (CPs) foram descritas em espécies de Leishmania que causam a forma tegumentar e visceral da doença. Inicialmente essas enzimas foram descritas em amastigotas de L. (L.) mexicana, que são particularmente ricas em CPs, principalmente encontrada em megassomas, com possível papel na virulência no hospedeiro vertebrado (Pupkis \& Coombs, 1984; Robertson \& Coombs, 1990).

Posteriormente verificou-se que essa enzima poderia ser detectada em outras espécies de Leishmania e que a mesma não estaria exclusivamente relacionada às formas infectivas do parasito (Alves, Marzochi \& Giovanni-de-Simone, 1993; Omara-Opyene \& Gedamu, 1997). Com a descrição do genoma de L. (L.) major, foi observada a existência de genes que codificam um total de $65 \mathrm{CPs}$, agrupadas em quatro clãs e 13 famílias (Mottram, Coombs \& Alexander, 2004).

A possibilidade de CPs na superfície celular foi inicialmente demonstrada utilizando-se o método de extração com o detergente Triton X-114 (Alves, Marzochi \& Giovanni-de-Simone, 1993). Nesse trabalho, os autores demonstraram que promastigotas não infectivos de L. (L.) major apresentam uma proteína hidrofóbica (20 kDa) com atividade enzimática sensível à presença de um inibidor de cisteína-proteinases [L-trans-epoxisuccinil-leucilamida-(4-guanidino) butano]. Estudos posteriores, nos quais foi utilizado soro de coelho antipapaína, uma CP de Caryca papaia, demonstraram a presença de proteínas reconhecidas por esse antissoro na superfície da membrana celular e na bolsa flagelar de L. (L.) amazonensis (Alves et al., 2005; Mottram, Coombs \& Alexander, 2004). Hoje, sabe-se que algumas isoformas de CP estão presentes na membrana de superfície de promastigotas de L. (V.) braziliensis associadas a âncoras GPI (Rebello et al., 2009).

A maioria dos estudos sobre a atividade das CPs está centrada nos grupos das enzimas denominadas CPA, CPB e CPC, e cada um deles apresenta características que lhes são próprias: CPA - constituído por enzimas da subfamília das catepsinas L. Esse grupo caracteriza-se por ser codificado por um gene de cópia única e pela ausência de uma longa extensão COOH-terminal antes de seu processamento final (Mottram et al., 1992; Mottram \& Coombs, 1998); CPB - constituído por enzimas da subfamília das catepsinas L. Esse grupo caracteriza-se por uma longa extensão 
COOH-terminal nas formas das enzimas antes de seu processamento final. Além disso, as enzimas CPB são expressas por genes com múltiplas cópias, organizados em sequências em tandem. Essas isoformas apresentam variações entre suas especificidades por substratos e propriedades catalíticas (Brooks et al., 2001); CPC - constituído por enzimas da subfamília das catepsinas B. Esse grupo, de forma similar ao grupo CPA, é codificado por um gene em cópia única e não apresenta uma extensão COOH-terminal como as enzimas CPB (Bart, Coombs \& Mottram, 1995).

As CPs de Leishmania spp. podem atuar como moduladores da resposta imune nas infecções tegumentares. Nesse particular, é válido ressaltar que sequências peptídicas da região COOH-terminal das CPBs têm potencial imunorregulador na resposta imune celular para casos humanos de LTA causados por L. (V.) braziliensis (Alves et al., 2001) e no desenvolvimento da infecção experimental murina por L. (L.) amazonensis (Alves et al., 2004, Pereira et al., 2011).

Existem evidências da ação de CPs de Leishmania atuando na regulação do sistema imune do hospedeiro, tanto induzindo este a apresentar uma resposta tipo Th2 quanto inibindo uma resposta do tipo Th1. As CPs de L. (L.) mexicana e de L. (L.) amazonesis são capazes inibir a apresentação de antígenos pela degradação da molécula do complexo principal de histocompatibilidade classe II no vacúolo parasitóforo do hospedeiro (Souza Leão et al., 1995).

A geração de mutantes deficientes nos genes das CPB $(\triangle c p b)$ permitiu a obtenção de informações sobre a importância dessas CPs na interação parasito-hospedeiro. Mutantes de L. (L.) mexicana $\Delta c p b$ apresentaram virulência reduzida e pouca capacidade de promover lesões em camundongos BALB/c (Alexander, Coombs \& Mottram, 1998) e somente a reinserção de múltiplos genes CPB nesses mutantes por um cosmídeo foi capaz de efetivamente restaurar sua virulência, sugerindo que tais genes têm funções complementares (Denise et al., 2003).

Além disso, existem indícios de que a enzima CPB de L. (L.) mexicana ativa é capaz de clivar os receptores de IL-2 e de IgE e de induzir à expressão de IL-4 em camundongos, promovendo a resposta Th2. Camundongos infectados com parasitos mutantes $\Delta c p b$ foram capazes de apresentar uma resposta do tipo Th1 e, dessa forma, debelar a infecção (Pollock et al., 2003). Também já foi descrita a capacidade de diferentes espécies de Leishmania, inclusive da L. (L.) mexicana, de inibir a produção de IL-12 em macrófagos e células dentríticas (Weinheber et al., 1998). Esse processo é, ao menos em parte, dependente da CPB, uma vez que parasitos do tipo selvagem contam com uma capacidade maior de inibir a produção de IL-12 do que mutantes $\Delta c p b$, e inibidores de CPB são capazes de impedir essa ação dos parasitos. É possível que tal capacidade seja resultado da clivagem proteolítica tanto do fator de transcrição kappa B do hospedeiro quanto de seu inibidor IкB pela CPB (Cameron et al., 2004).

Não obstante homólogos de CPB terem sido detectados na membrana celular de promastigotas de L. (V.) braziliensis (Rebello et al., 2009), assim como outras cisteína-proteinases em L. (L.) amazonensis (Alves et al., 2000), essas enzimas estão presentes nos grandes lisossomos do estágio amastigota e também podem ser liberadas na matriz extracelular, o que pode facilitar alguns de seus efeitos (Mottram, Brooks \& Coombs, 1998).

Proteínas que ligam à heparina (PLHS) também foram descritas na superfície de Leishmania spp. (Butcher et al., 1990; Azevedo-Pereira et al., 2007; Mukhopadhyay et al., 1989) e outros tripanossomatídeos (Kock et al., 1997; Ortega-Barria \& Pereira, 1991). A maior parte dos estudos com PLHs de Leishmania spp. tem sido desenvolvida $\operatorname{com} L$. (L.) donovani, L. (L.) major e L. (L.) amazonensis, e só recentemente foi proposto o estudo dessa proteína em L. (V.) braziliensis. Nesta espécie, a PLH sinalizou uma possível participação na interação com proteínas do intestino de Lu. intermedia e de Lu. Whitmani (Azevedo-Pereira et al., 2007).

Nos parasitos nos quais as PLHs foram estudadas, verificou-se que essas moléculas agem como proteínas de adesão e podem promover a interiorização dos mesmos com as células hospedeiras. Experimentos realizados com promastigotas de L. (L.) donovani demonstraram que em torno de 860 mil moléculas de PLHs são encontradas na 
superfície do parasito, mais precisamente na porção flagelar dos promastigotas, e que por meio de ligação com heparina pudesse induzir a inibição da atividade de PKCs sobre a superfície celular do parasito (Butcher et al., 1990; Mukhopadhyay et al., 1989).

As PLHs estariam relacionadas às formas infectivas de L. (L.) donovani, já que estas predominam em promastigotas de fase estacionária de cultivo e que sucessivas passagens desses parasitos em meio de cultivo levam à perda da capacidade de os mesmos se ligarem à heparina (Kock et al., 1997; Butcher et al., 1992). Amastigotas de $L$. (L.) amazonensis e de L. (L.) major têm maior capacidade de se ligar à heparina do que promastigotas das mesmas espécies (Volf, Svobodova \& Dvorakova, 2001). Além disso, glicosaminoglicanos como heparina influenciam o desenvolvimento de $L$. (L.) major no intestino do inseto vetor, aumentando a carga parasitária dos insetos experimentalmente infectados.

Uma recente discussão alerta para o fato de que as PLHs, assim como o LPG, estariam participando dos fenômenos moleculares de ligação entre promastigotas de L. (V.) braziliensis e o trato digestório de espécies de Lutzomyia que atuam como vetores na leishmaniose tegumentar americana (Alves, Côrtes \& Brazil, 2010). Assim, outros componentes da superfície dos promastigotas de L. (V.) braziliensis, como as proteínas, podem estar envolvidos nas etapas de ligação desse parasito ao intestino do vetor. A habilidade de os promastigotas estarem aderidos às microvilosidades do trato digestório dos flebotomíneos é um passo essencial para manutenção do ciclo de vida do parasito, sendo um fator que distingue parasitos infectivos dos não infectivos.

Demonstrou-se, em ensaios in vitro, que a heparina e o sulfato de heparan são os principais GAGs envolvidos no fenômeno de inibição da ligação de promastigotas e amastigotas de Leishmania spp. às células hospedeiras (Butcher et al., 1992; Volf, Svobodova \& Dvorakova et al., 2001). Curiosamente, também demonstrou-se que a heparina pode aumentar a ligação de promastigotas aos macrófagos (Butcher et al., 1992). Tal fato é um indicativo de que a heparina poderia influenciar duas atividades distintas sobre a infecção celular por Leishmania spp., sendo também uma sugestão para heterogeneidade funcional das proteínas que ligam a heparina presente na superfície do parasito.

Embora certas proteínas e proteinases de Leishmania spp. sejam ancoradas por GPI e têm ações definidas no ciclo de vida do parasito, ressalta-se que nem todas as proteínas ancoradas por GPI são essenciais ao crescimento ou infectividade no hospedeiro vertebrado. Mutantes $\triangle G P I 8$ de L. (L.) mexicana foram capazes de promover a infecção em camundongos (Hilley et al., 2000). Esses mutantes não têm o gene GPI8 que codifica a enzima transamidase, a qual é responsável pela adição da porção proteica à ancora de GPI.

\section{CONCLUSÕES}

Os parasitos do gênero Leishmania apresentam uma série de peculiaridades adaptativas nas diferentes fases de seu ciclo biológico. Como as superfícies celulares dos promastigotas e amastigotas estão em contato direto com tecidos e células dos hospedeiros, é razoável que a organização destas seja uma das estratégias para aumentar as chances de sucesso do parasitismo.

Ao fazer uma síntese do conhecimento atual sobre o papel funcional dos componentes do parasito é possível indicar o envolvimento desses componentes nos eventos iniciais da dinâmica de interação finas e vitais que se estabelecem entre os protozoários Leishmania e os seus hospedeiros (Tabela 1). Assim, quando os promastigotas ou amastigotas mudam de hospedeiro ocorre ativação de receptores presentes na superfície celular, que sinalizam para transformação do parasito (receptor de adenilciclase). Nessa mudança de hospedeiros, permanecem ativas nos parasitos enzimas que favorecem o equilíbrio e a adaptação às condições iônicas $\left(\mathrm{Ca}^{2+}\right.$ - e $\mathrm{Mg}^{2+}$ - ATPases) e a captação de nutrientes essenciais (3'-nucleotidase e 5'-nucleotidase). 
Tabela 1 - Principais componentes da membrana de superfície das espécies de Leishmania e suas atuações nos hospedeiros

\begin{tabular}{|c|c|c|}
\hline \multirow{2}{*}{ Componentes } & \multicolumn{2}{|l|}{ Função } \\
\hline & Hospedeiro Vertebrado & Hospedeiro Invertebrado \\
\hline LPG & $\begin{array}{l}\text { Ligante de macrófagos; } \\
\text { Inibe a atividade da PKC de macrófagos; } \\
\text { Em metacíclicos: (a) inibe a formação do complexo de ataque à membrana; e (b) } \\
\text { ativa complemento proporcionando a ligação ao macrófago via C3bi; } \\
\text { Atua na resposta imune inata via células NK e célula dendríticas por meio de } \\
\text { receptor toll-like } 2 \text { e pelo aumento de INF- } \gamma \text { e TNF- } \alpha\end{array}$ & Fixa promastigotas procíclicos ao epitélio intestinal \\
\hline GIPLS & $\begin{array}{l}\text { Inibe síntese de óxido nítrico em macrófagos; } \\
\text { Inibe atividade de PKC; } \\
\text { Influencia a taxa de infecção de macrófagos; }\end{array}$ & FNd \\
\hline \multicolumn{3}{|l|}{ Proteínas e enzimas: } \\
\hline KMP-11 & Imunomodulação & FNd \\
\hline HASP & Imunomodulação & FNd \\
\hline Amastina & Invasão e multiplicação intracelular & FNd \\
\hline $\begin{array}{l}\text { Receptor de } \\
\text { adenilciclase }\end{array}$ & Induz a mudança de estágio de promastigota a amastigota & $\begin{array}{l}\text { Induz à mudança de estágio amastigota a } \\
\text { promastigota }\end{array}$ \\
\hline gp46/M-2 & FNd & FNd \\
\hline \multirow{4}{*}{ PPG } & mPPG - ligante de receptores de macrófagos & mPPG - ligante de células do tubo digestório \\
\hline & aPPG - contribuir para manutenção do vacúolo parasitóforo & FNd \\
\hline & aPPG - ativa complemento via proteína ligadora de manose & FNd \\
\hline & FNd & fPPG - dificulta ingestão de alimento do flebótomo \\
\hline AcPs & MAcPs/SAcPs - interferem na produção de metabólitos oxidativos $\left(\mathrm{H}_{2} \mathrm{O}_{2}, \mathrm{OH}^{-}, \mathrm{O}^{2-}\right)$ & Idem \\
\hline $\begin{array}{l}\text { 3'-nucleotidase e } \\
\text { 5'-nucleotidase }\end{array}$ & Papel nutricional - hidrólise de nucleotídeos a ácidos nucleicos (3'-AMP e 5'-AMP) & Idem \\
\hline $\mathrm{Ca}^{2+}$ - ATPase & Manutenção dos níveis de $\mathrm{Ca}^{2+}$ citoplasmático e do fagossomo & Manutenção dos níveis de $\mathrm{Ca}^{2+}$ citoplasmático \\
\hline $\mathrm{Mg}^{2+}$ - ATPases & $\begin{array}{l}\text { Função de bomba de extrusão de } \mathrm{H}^{+} \\
\text {Acumulação de glicose e potássio } \\
\text { Pré-adaptação dos promastigotas no macrófago }\end{array}$ & FNd \\
\hline Metaloproteinases & $\begin{array}{l}\text { Hidrólise e inativação de imunoglobulinas G; } \\
\text { Inativação do fator C3b em C3bi do complemento; } \\
\text { Adesão interiorização nos macrófagos }\end{array}$ & $\begin{array}{l}\text { Protege os promastigotas da ação da tripsina e } \\
\text { quimiotripsina do intestino do inseto; }\end{array}$ \\
\hline $\begin{array}{l}\text { Cisteína- } \\
\text { proteinases }\end{array}$ & $\begin{array}{l}\text { Imunorregulador na leishmaniose cutânea: com atividade enzimática sobre } \\
\text { componentes do sistema imune e pela atuação da região C-terminal na indução } \\
\text { resposta Th2 }\end{array}$ & FNd \\
\hline PLH & Ligação dos promastigotas aos macrófagos & $\begin{array}{l}\text { Ligação dos promastigotas ao trato digestório de } \\
\text { flebótomos }\end{array}$ \\
\hline
\end{tabular}

Obs: FNd (função não determinada). 
A superfície celular desses protozoários é capaz de controlar atividades específicas para viverem em um ou outro hospedeiro. Até o presente momento, a maioria dos componentes de superfície dos parasitos, já descritos anteriormente, tem o papel biológico relacionado ao hospedeiro mamífero, enquanto apenas um escasso número voltado à interação com o inseto vetor foi estudado. Nesse cenário, o LPG é o componente de superfície mais diversificado em funções direcionadas à manutenção do ciclo de vida do parasito, com atuação no vertebrado (influenciando na resposta imune inata e adquirida e subvertendo as funções do macrófago) e no inseto vetor (realizando a fixação do promastigota ao trato digestório).

No hospedeiro vertebrado, o parasito tem a capacidade de controlar ou subverter a ação de diversos componentes do sistema imune. A superfície celular reúne fatores como proteínas, enzimas e/ou glicoconjugados voltados à imunomodulação da resposta imune do hospedeiro vertebrado, favorecendo assim a sobrevivência do parasito.

Também as proteínas de superfície, como metaloproteinases e proteínas que ligam à heparina, têm ações no vertebrado (nas funções do macrófago), mas somente as metaloproteinases atuam no inseto vetor (protege os promastigotas da ação de proteinase do inseto); e é nítido o papel das cisteína-proteinases na resposta imune da leishmaniose cutânea do hospedeiro vertebrado, como enzima e como indutor de resposta imune celular.

Mesmo com os conhecimentos aqui reunidos sobre a os componentes de Leishmania spp., para uma real compreensão dos fenômenos de interação entre os parasitos e seus hospedeiros faz-se necessário levar em consideração a ação de todos os componentes de superfície - aqueles já descritos e os que ainda estão em estudo, uma vez que uma categorização artificial da importância destes pode acarretar uma interpretação incorreta de tais fenômenos.

\section{REFERÊNCIAS}

ALEXANDER, J.; COOMBS, G. H. \& MOTTRAM, J. C. Leishmania mexicana cysteine proteinase-deficient mutants have attenuated virulence for mice and potentiate a Th1 response. The Journal of Immunology, 161(12): 6.794-6.801, 1998.

ALI, S. A. et al. CTL responses to Leishmania mexicana gp63-cDNA vaccine in a murine model. Parasite Immunology, 31(7): 373-383, 2009.

ALVES, C. R., CÔRTES, L. M. \& BRAZIL, R. P. The vectorial potential of Lutzomyia (Nyssomyia) intermedia and Lutzomyia (N.) whitmani in the transmission of Leishmania (V.) braziliensis can also be related to proteins attaching. Journal of Biomedicine \& Biotechnology, 2010.

ALVES, C. R.; MARZOCHI, M. C. \& GIOVANNI-DE-SIMONE, S. Heterogeneity of cysteine proteinases in Leishmania braziliensis and Leishmania major. Brazilian Journal of Medical and Biological Research, 26(2): 167-171, 1993.

ALVES, C. R. et al. Detection of cysteine-proteinases in Leishmania amazonensis promastigotes using a cross-reactive antiserum. FEMS Microbiology Letters, 186(2): 263-267, 2000.

ALVES, C. R. et al. A strategy for the identification of T-cell epitopes on Leishmania cysteine proteinases. Cytobios, 104(405): 33-41, 2001.

ALVES, C. R. et al. Th1 and Th2 immunological profile induced by cysteine proteinase in murine Leishmaniasis. Parasite Immunology, 26(3): 127-135, 2004.

ALVES, C. R. et al. Leishmania amazonensis: early proteinase activities during promastigote-amastigote differentiation in vitro. Experimental Parasitology, 109(1): 38-48, 2005.

ALVES, J. L.; MENDONÇA-LIMA, F. W. \& ALVES, C. R. The use of metal chelate affinity chromatography on the isolation of Leishmania chagasi promastigote hydrophobic proteinases. Veterinary Parasitology, 119(2-3): 137-145, 2004.

ASSIS, R. R. et al. Glycoconjugates in New World species of Leishmania: polymorphisms in lipophosphoglycan and glycoinositolphospholipids and interaction with hosts. Biochimica et Biophysica Acta, 1820(9):1.354-1.365, 2012. 
AYESTA, C.; ARGUELLO, C. \& HERNANDEZ, A. G. Leishmania braziliensis: cell surface differences in promastigotes of pathogenic and nonpathogenic strains. Experimental Parasitology, 59(2): 185-191, 1985.

AZEVEDO-PEREIRA, R. L. et al. Heparin binding proteins from Leishmania (Viannia) braziliensis promastigotes. Veterinary Parasitology, 145(3-4): 234-239, 2007.

BANDYOPADHYAY, K. et al. Role of $67 \mathrm{kDa}$ cell surface laminin binding protein of Leishmania donovani in pathogenesis. Journal of Biochemistry, 130(1): 141-148, 2001.

BANERJEE, C.; SARKAR, D. \& BHADURI, A. Ca2 + and calmodulin-dependent protein phosphatase from Leishmania donovani. Parasitology, 118(6): 567-573, 1999.

BART, G.; COOMBS, G. H. \& MOTTRAM, J. C. Isolation of $1 \mathrm{mcpc}$, a gene encoding a Leishmania mexicana cathepsin-B-like cysteine proteinase. Molecular and Biochemical Parasitology, 73(1-2): 271-274, 1995.

BECKER, I. et al. Leishmania lipophosphoglycan (LPG) activates NK cells through toll-like receptor-2. Molecular and Biochemical Parasitology, 130(2): 65-74, 2003.

BEETHAM, J. K. et al. Glycoprotein 46 mRNA abundance is post-transcriptionally regulated during development of Leishmania chagasi promastigotes to an infectious form. The Journal of Biological Chemistry, 272(28): 17.360-17.366, 1997.

BENAIM, G. \& ROMERO, P. J. A calcium pump in plasma membrane vesicles from Leishmania braziliensis. Biochimica et Biophysica Acta, 1.027(1): 79-84, 1990.

BENAIM, G. et al. Intracellular calcium homeostasis in Leishmania mexicana. Identification and characterization of a plasma membrane calmodulin-dependent Ca(2+)-ATPase. Biological Research, 26(1-2): 141-150, 1993.

BERREDO-PINHO, M. et al. A Mg-dependent ecto-ATPase in Leishmania amazonensis and its possible role in adenosine acquisition and virulence. Archives of Biochemistry and Biophysics, 391(1): 16-24, 2001.

BHATTACHARYYA, S. et al. Selective impairment of protein kinase C isotypes in murine macrophage by Leishmania donovani. Molecular and Cellular Biochemistry, 216(1-2): 47-57, 2001.

BHOWMICK, S.; RAVINDRAN, R. \& ALI, N. gp63 in stable cationic liposomes confers sustained vaccine immunity to susceptible BALB/c mice infected with Leishmania donovani. Infection and Immunity, 76(3): 1.003-1.015, 2008.

BISWAS, A.; BHATTACHARYA, A. \& DAS, P. K. Role of cAMP Signaling in the Survival and Infectivity of the Protozoan Parasite, Leishmania donovani. Molecular Biology International, 2.011: 1-9, 2011.

BOGDAN, C. \& ROLLINGHOFF, M. The immune response to Leishmania: mechanisms of parasite control and evasion. International Journal for Parasitology, 28(1): 121-134, 1998.

BOUVIER, J.; ETGES, R. J. \& BORDIER, C. Identification and purification of membrane and soluble forms of the major surface protein of Leishmania promastigotes. The Journal of Biological Chemistry, 260(29): 15.504-15.509, 1985.

BRANDONISIO, O.; SPINELLI, R. \& PEPE, M. Dendritic cells in Leishmania infection. Microbes and infection, 6(15): 1.4021.409, 2004.

BROOKS, D. R. et al. The stage-regulated expression of Leishmania mexicana CPB cysteine proteases is mediated by an intercistronic sequence element. The Journal of Biological Chemistry, 276(50): 47.061-47.069, 2001.

BUCHMULLER-ROUILLER, Y. \& MAUEL, J. Impairment of the oxidative metabolism of mouse peritoneal macrophages by intracellular Leishmania spp. Infection and Immunity, 55(3): 587-593, 1987.

BUTCHER, B. A. et al. Leishmania donovani: cell-surface heparin receptors of promastigotes are recruited from an internal pool after trypsinization. Experimental Parasitology, 71(1): 49-59, 1990.

BUTCHER, B. A. et al. Heparin enhances the interaction of infective Leishmania donovani promastigotes with mouse peritoneal macrophages. A fluorescence flow cytometric analysis. The Journal of Immunology, 148(9): 2.879-2.886, 1992.

CAMERON, P. et al. Inhibition of lipopolysaccharide-induced macrophage IL-12 production by Leishmania mexicana amastigotes: the role of cysteine peptidases and the NF-kappaB signaling pathway. The Journal of Immunology, 173(5): 3.297-3.304, 2004. 
CAMPBELL, T. A. et al. Purification and characterization of the 3'-nucleotidase/nuclease from promastigotes of Leishmania donovani. Molecular and Biochemical Parasitology, 47(1): 109-117, 1991.

CARVALHO, L. P. et al. Effect of LACK and KMP11 on IFN-gamma production by peripheral blood mononuclear cells from cutaneous and mucosal Leishmaniasis patients. Scandinavian Journal of Immunology, 61 (4): 337-342, 2005.

CHAMPSI, J. \& MCMAHON-PRATT, D. Membrane glycoprotein M-2 protects against Leishmania amazonensis infection. Infection and Immunity, 56(12): 3.272-3.279, 1988.

CHAUDHURI, G. \& CHANG, K. P. Acid protease activity of a major surface membrane glycoprotein (gp63) from Leishmania mexicana promastigotes. Molecular and Biochemical Parasitology, 27(1): 43-52, 1988.

COELHO-FINAMORE, J. M. et al. Leishmania infantum: Lipophosphoglycan intraspecific variation and interaction with vertebrate and invertebrate hosts. The Journal of Parasitology, 41(3-4): 333-342, 2011.

CÔRTE-REAL, S. et al. Immunogold labeling and cerium cytochemistry of the enzyme ecto-5'-nucleotidase in promastigote forms of Leishmania species. Memórias do Instituto Oswaldo Cruz, 88(3): 407-412, 1993.

CÔRTE-REAL, S.; SANTOS, C. B. \& MEIRELLES, M. N. Differential expression of the plasma membrane Mg2+ ATPase and $\mathrm{Ca} 2+$ ATPase activity during adhesion and interiorization of Leishmania amazonensis in fibroblasts in vitro. Journal of Submicroscopic Cytology and Pathology, 27(3): 359-366, 1995.

CUERVO, P. et al. A zymographic study of metalloprotease activities in extracts and extracellular secretions of Leishmania (Viannia) braziliensis strains. Parasitology, 132(2): 177-185, 2006.

CUERVO, P. et al. Cellular localization and expression of gp63 homologous metalloproteases in Leishmania (Viannia) braziliensis strains. Acta Tropica, 106(3): 143-148, 2008.

DAVIES, C. R. et al. Expression of LPG and GP63 by different developmental stages of Leishmania major in the sandfly Phlebotomus papatasi. Parasitology, 101(3): 337-343, 1990.

DEBRABANT, A.; GHEDIN, E. \& DWYER, D. M. Dissection of the functional domains of the Leishmania surface membrane 3'-nucleotidase/nuclease, a unique member of the class I nuclease family. The Journal of Biological Chemistry, 275(21): 16.366-16.372, 2000.

DEBRABANT, A.; GOTTLIEB, M. \& DWYER, D. M. Isolation and characterization of the gene encoding the surface membrane 3'-nucleotidase/nuclease of Leishmania donovani. Molecular and Biochemical Parasitology, 71(1): 51-63, 1995.

DELGADO-DOMínGUEZ, J. et al. Leishmania mexicana lipophosphoglycan differentially regulates PKCalpha-induced oxidative burst in macrophages of BALB/c and C57BL/6 mice. Parasite Immunology, 32 (6): 440-449, 2010.

DENISE, H. et al. Expression of multiple CPB genes encoding cysteine proteases is required for Leishmania mexicana virulence in vivo. Infection and Immunity, 71(6): 3.190-3.195, 2003.

DENNY, P. W. et al. Acylation-dependent protein export in Leishmania. The Journal of Biological Chemistry, 275(15): 11.017$11.025,2000$.

DEPLEDGE, D. P. et al. Leishmania-specific surface antigens show sub-genus sequence variation and immune recognition. PLoS Neglected Tropical Diseases, 4(9): e829, 2010.

DILLON, R. J. \& LANE, R. P. Detection of Leishmania lipophosphoglycan binding proteins in the gut of the sandfly vector. Parasitology, 118(1): 27-32, 1999.

DUTTA, M. et al. Fluidity-dependent Mg2(+)-ATPase activity in membranes from Leishmania donovani promastigotes. The Biochemical Journal, 265(3): 923-926, 1990.

ELLIS, S. L.; SHAKARIAN, A. M. \& DWYER, D. M. Leishmania: amastigotes synthesize conserved secretory acid phosphatases during human infection. Experimental Parasitology, 89(2): 161-168, 1998.

ETGES, R.; BOUVIER, J. \& BORDIER, C. The major surface protein of Leishmania promastigotes is a protease. The Journal of Biological Chemistry, 261(20): 9.098-9.101, 1986. 
FARAJNIA, S. et al. Molecular characterization of a novel amastigote stage specific Class I nuclease from Leishmania major. International journal for Parasitology, 34(8): 899-908, 2004.

FLINN, H. M.; RANGARAJAN, D. \& SMITH, D. F. Expression of a hydrophilic surface protein in infective stages of Leishmania major. Molecular and Biochemical Parasitology, 65(2): 259-270, 1994.

GBENLE, G. O. \& DWYER, D. M. Purification and properties of 3'-nucleotidase of Leishmania donovani. The Biochemical Journal, 285(1): 41-46, 1992.

GHOSH, J. et al. A high affinity Ca2(+)-ATPase on the surface membrane of Leishmania donovani promastigote. The Journal of Biological Chemistry, 265(19): 11.345-11.351, 1990.

GLASER, T. A. et al. An antigenically distinct lipophosphoglycan on amastigotes of Leishmania major. Molecular and Biochemical Parasitology, 45(2): 337-344, 1991.

GLEW, R. H. et al. Biochemistry of the Leishmania species. Microbiological Reviews, 52(4): 412-432, 1988.

GOTTLIEB, M. \& DWYER, D. M. Evidence for distinct 5'- and 3'-nucleotidase activities in the surface membrane fraction of Leishmania donovani promastigotes. Molecular and Biochemical Parasitology, 7(4): 303-317, 1983.

HANDMAN, E. \& GODING, J. W. The Leishmania receptor for macrophages is a lipid-containing glycoconjugate. The Embo Journal, 4(2): 329-336, 1985.

HANDMAN, E.; GREENBLATT, C. L. \& GODING, J. W. An amphipathic sulphated glycoconjugate of Leishmania: characterization with monoclonal antibodies. The Embo Journal, 3(10): 2.301-2.306, 1984.

HANEKAMP, T. \& LANGER, P. J. Molecular karyotype and chromosomal localization of genes encoding two major surface glycoproteins, gp63 and gp46/M2, hsp70, and beta-tubulin in cloned strains of several Leishmania species. Molecular and Biochemical Parasitology, 48(1): 27-37, 1991.

HANSEN, B. D. et al. The specificity of purine base and nucleoside uptake in promastigotes of Leishmania braziliensis panamensis. Parasitology, 85(2): 271-282, 1982.

HILLEY et al. Leishmania mexicana mutants lacking glycosylphosphatidylinositol (GPI): protein transamidase provide insights into the biosynthesis and functions of GPI-anchored proteins. Molecular Biology of the Cell, 11(4): 1.183-1.195, 2000.

ILG, T. Proteophosphoglycans of Leishmania. Parasitology Today, 16(11): 489-497, 2000.

ILG, T. et al. Structure of Leishmania mexicana lipophosphoglycan. The Journal of Biological Chemistry, 267(10): 6.8346.840, 1992.

ILG, T. et al. Molecular cloning and characterization of a novel repeat-containing Leishmania major gene, ppg1, that encodes a membrane-associated form of proteophosphoglycan with a putative glycosylphosphatidylinositol anchor. The Journal of Biological Chemistry, 274(44): 31.410-31.420, 1999.

JACKSON, A. P. The evolution of amastin surface glycoproteins in trypanosomatid parasites. Molecular Biology and Evolution, 27(1): 33-45, 2010.

JARDIM, A. et al. Isolation and structural characterization of the Leishmania donovani kinetoplastid membrane protein-11, a major immunoreactive membrane glycoprotein. The Biochemical Journal, 305(1): 307-313, 1995.

KAHL, L. P. \& MCMAHON-PRATT, D. Structural and antigenic characterization of a species- and promastigote-specific Leishmania mexicana amazonensis membrane protein. The Journal of Immunology, 138(5): 1.587-1.595, 1987.

KAMHAWI, S. et al. A role for insect galectins in parasite survival. Cell, 119(3): 329-341, 2004.

KOCK, N. P. et al. Receptors for carbohydrate ligands including heparin on the cell surface of Leishmania and other trypanosomatids. Tropical Medicine \& International Health, 2(9): 863-874, 1997.

LIEW, F. Y. \& O’DONNELL, C. A. Immunology of Leishmaniasis. Advances in Parasitology, 32: 161-259, 1993.

LU, H. G. et al. Intracellular Ca2+ pool content and signaling and expression of a calcium pump are linked to virulence in Leishmania mexicana amazonesis amastigotes. The Journal of Biological Chemistry, 272(14): 9.464-9.473, 1997. 
MAHONEY, A. B. et al. Intra-species and stage-specific polymorphisms in lipophosphoglycan structure control Leishmania donovani-sand fly interactions. Biochemistry, 38(31): 9.813-9.823, 1999.

MATOS, D. C. et al. Kinetoplastid membrane protein-11 is present in promastigotes and amastigotes of Leishmania amazonensis and its surface expression increases during metacyclogenesis. Memórias do Instituto Oswaldo Cruz, 105(3): 341-347, 2010.

MAZUMDER, S. et al. Allosteric modulation of Leishmania donovani plasma membrane $\mathrm{Ca}(2+)$-ATPase by endogenous calmodulin. The Journal of Biological Chemistry, 267(26): 18.440-18.446, 1992.

McCONVILLE, M. J. \& BLACKWELL, J. M. Developmental changes in the glycosylated phosphatidylinositols of Leishmania donovani. Characterization of the promastigote and amastigote glycolipids. The Journal of Biological Chemistry, 266(23): 15.170-15.179, 1991.

McCONVILLE, M. J. \& HOMANS, S. W. Identification of the defect in lipophosphoglycan biosynthesis in a non-pathogenic strain of Leishmania major. The Journal of Biological Chemistry, 267(9): 5.855-5.861, 1992.

McCONVILLE, M. J. \& RALTON, J. E. Developmentally regulated changes in the cell surface architecture of Leishmania parasites. Behring Institute Mitteilungen, 99: 34-43, 1997.

McCONVILLE, M. J. et al. Structures of the glycoinositolphospholipids from Leishmania major. A family of novel galactofuranose-containing glycolipids. The Journal of Biological Chemistry, 265(13): 7.385-7.394, 1990.

McCONVILLE, M. J. et al. The developmental regulation and biosynthesis of GPI-related structures in Leishmania parasites. Brazilian Journal of Medical and Biological Research, 27(2): 139-144, 1994.

MCMAHON-PRATT, D. et al. Loss of the GP46/M-2 surface membrane glycoprotein gene family in the Leishmania braziliensis complex. Molecular and Biochemical Parasitology, 50(1): 151-160, 1992.

MCMAHON-PRATT, D. et al. Recombinant vaccinia viruses expressing GP46/M-2 protect against Leishmania infection. Infection and Immunity, 61(8): 3.351-3.359, 1993.

MENDONCA-LIMA, F. W. \& ATTA, A. M. Partial characterization of Leishmania chagasi promastigote peptidases. Memórias do Instituto Oswaldo Cruz, 87(2): 307-308, 1992.

MISLE, J. A.; MARQUEZ, M. E. \& HERNANDEZ, A. G. Solubilization and partial purification of a cell surface component of Leishmania braziliensis. Zeitschrift für Parasitenkunde, 71(4): 419-428, 1985.

MOODY, S. F. et al. The structure of Leishmania major amastigote lipophosphoglycan. The Journal of Biological Chemistry, 268(25): 18.457-18.466, 1993.

MOSSER, D. M.; SPRINGER, T. A. \& DIAMOND, M. S. Leishmania promastigotes require opsonic complement to bind to the human leukocyte integrin Mac-1 (CD11b/CD18). The Journal of Cell Biology, 116(2): 511-520, 1992.

MOTTRAM, J. C. \& COOMBS, G. H. Leishmania cysteine proteinases: virulence factors in quest of a function-reply. Parasitology Today, 14(6): 251-252, 1998.

MOTTRAM, J. C.; BROOKS, D. R. \& COOMBS, G. H. Roles of cysteine proteinases of trypanosomes and Leishmania in hostparasite interactions. Current Opinion in Microbiology, 1(4): 455-460, 1998.

MOTTRAM, J. C.; COOMBS, G. H. \& ALEXANDER, J. Cysteine peptidases as virulence factors of Leishmania. Current Opinion in Microbiology, 7(4): 375-381, 2004.

MOTTRAM, J. C. et al. A developmentally regulated cysteine proteinase gene of Leishmania mexicana. Molecular Microbiology, 6(14): 1.925-1.932, 1992.

MUKHERJEE, T.; MANDAL, D. \& BHADURI, A. Leishmania plasma membrane Mg2+-ATPase is a $\mathrm{H}+/ \mathrm{K}+$-antiporter involved in glucose symport. Studies with sealed ghosts and vesicles of opposite polarity. The Journal of Biological Chemistry, 276(8): 5.563-5.569, 2001.

MUKHOPADHYAY, N. K. et al. Heparin binds to Leishmania donovani promastigotes and inhibits protein phosphorylation. The Biochemical Journal, 264(2): 517-525, 1989. 
MURRAY, P. J.; SPITHILL, T. W. \& HANDMAN, E. The PSA-2 glycoprotein complex of Leishmania major is a glycosylphosphatidylinositol-linked promastigote surface antigen. The Journal of Immunology, 143(12): 4.221-4.226, 1989.

MUSKUS, C. E. \& MARIN VILLA, M. Metacyclogenesis: a basic process in the biology of Leishmania. Biomedica, 22(2): 167177, 2002.

MYSKOVA, J. et al. A lipophosphoglycan-independent development of Leishmania in permissive sand flies. Microbes and Infection, 9(3): 317-324, 2007.

NAGAKURA, K. et al. Leishmania braziliensis: localization of glycoproteins in promastigotes. Experimental Parasitology, 61(3): 335-342, 1986.

OLIVIER, M. \& HASSANI, K. Protease inhibitors as prophylaxis against Leishmaniasis: new hope from the major surface protease gp63. Future Medicinal Chemistry, 2(4): 539-542, 2010.

OLIVIER, M.; GREGORY, D. J. \& FORGET, G. Subversion mechanisms by which Leishmania parasites can escape the host immune response: a signaling point of view. Clinical Microbiology Reviews, 18(2): 293-305, 2005.

OMARA-OPYENE, A. L. \& GEDAMU, L. Molecular cloning, characterization and overexpression of two distinct cysteine protease cDNAs from Leishmania donovani chagasi. Molecular and Biochemical Parasitology, 90(1): 247-267, 1997.

ORTEGA-BARRIA, E. \& PEREIRA, M. E. A novel T. cruzi heparin-binding protein promotes fibroblast adhesion and penetration of engineered bacteria and trypanosomes into mammalian cells. Cell, 67: 411-421, 1991.

PAN, A. A. Leishmania mexicana pifanoi: analysis of the antigenic relationships between promastigotes and amastigotes by gel diffusion, immunoelectrophoresis, and immunoprecipitation. The Journal of Protozoology, 33(2): 192-197, 1986.

PEREIRA, B. A. et al. In silico predicted epitopes from the $\mathrm{COOH}$-terminal extension of cysteine proteinase B inducing distinct immune responses during Leishmania (Leishmania) amazonensis experimental murine infection. BMC Immunology, 8(12): 44, 2011.]

PETERS, C.; STIERHOF, Y. D. \& ILG, T. Proteophosphoglycan secreted by Leishmania mexicana amastigotes causes vacuole formation in macrophages. Infection and Immunity, 65(2): 783-786, 1997.

PETERS, C. et al. Secreted proteophosphoglycan of Leishmania mexicana amastigotes activates complement by triggering the mannan binding lectin pathway. European Journal of Immunology, 27(10): 2.666-2.672, 1997.

PIMENTA, P. F.; SARAIVA, E. M. \& SACKS, D. L. The comparative fine structure and surface glycoconjugate expression of three life stages of Leishmania major. Experimental Parasitology, 72 (2): 191-204, 1991.

PIMENTA, P. F. et al. Stage-specific adhesion of Leishmania promastigotes to the sandfly midgut. Science, 256(5.065): 1.8121.815, 1992.

PIMENTA, P. F. et al. A novel role for the peritrophic matrix in protecting Leishmania from the hydrolytic activities of the sand fly midgut. Parasitology, 115(4): 359-369, 1997.

POLLOCK, K. G. et al. The Leishmania mexicana cysteine protease, CPB2.8, induces potent Th2 responses. The Journal of Immunology, 170(4): 1.746-1.753, 2003.

PROUDFOOT, L.; O'DONNELL, C. A. \& LIEW, F. Y. Glycoinositolphospholipids of Leishmania major inhibit nitric oxide synthesis and reduce leishmanicidal activity in murine macrophages. European Journal of Immunology, 25(3): 745-750, 1995.

PUENTES, S. M. et al. Complement binding by two developmental stages of Leishmania major promastigotes varying in expression of a surface lipophosphoglycan. The Journal of Experimental Medicine, 167(3): 887-902, 1988.

PUENTES, S. M. et al. Serum resistance of metacyclic stage Leishmania major promastigotes is due to release of C5b-9. The Journal of Immunology, 145(12): 4.311-4.316, 1990.

PUPKIS, M. F. \& COOMBS, G. H. Purification and characterization of proteolytic enzymes of Leishmania mexicana mexicana amastigotes and promastigotes. Journal of General Microbiology, 130(9): 2.375-2.383, 1984.

REBELLO, K. M. et al. Cysteine proteinases from promastigotes of Leishmania (Viannia) braziliensis. Parasitology Research, 106(1): 95-104, 2009. 
REMALEY, A. T. et al. Characterization of Leishmania donovani acid phosphatases. The Journal of Biological Chemistry, 260(2): 880-886, 1985.

REQUENA, J. M.; ALONSO, C. \& SOTO, M. Evolutionarily conserved proteins as prominent immunogens during Leishmania infections. Parasitology Today, 16(6): 246-250, 2000.

ROBERTSON, C. D. \& COOMBS, G. H. Characterisation of three groups of cysteine proteinases in the amastigotes of Leishmania mexicana mexicana. Molecular and Biochemical Parasitology, 42 (2): 269-276, 1990.

RODRIGUEZ-CORTES, A. et al. Vaccination with plasmid DNA encoding KMPII, TRYP, LACK and GP63 does not protect dogs against Leishmania infantum experimental challenge. Vaccine, 25(46): 7.962-7.971, 2007.

SACKS, D. L. The structure and function of the surface lipophosphoglycan on different developmental stages of Leishmania promastigotes. Infectious Agents and Disease, 1(4): 200-206, 1992.

SACKS, D. L.; HIENY, S. \& SHER, A. Identification of cell surface carbohydrate and antigenic changes between noninfective and infective developmental stages of Leishmania major promastigotes. The Journal of Immunology, 135(1): 564-569, 1985.

SACKS, D. L. et al. Stage-specific binding of Leishmania donovani to the sand fly vector midgut is regulated by conformational changes in the abundant surface lipophosphoglycan. The Journal of Experimental Medicine, 181(2): 685-697, 1995.

SANCHEZ, M. A. et al. A family of putative receptor-adenylate cyclases from Leishmania donovani. The Journal of Biological Chemistry, 270(29): 17.551-17.558, 1995.

SARAIVA, E. M. et al. Changes in lipophosphoglycan and gene expression associated with the development of Leishmania major in Phlebotomus papatasi. Parasitology, 111(3): 275-287, 1995.

SECUNDINO, N. et al. Proteophosphoglycan confers resistance of Leishmania major to midgut digestive enzymes induced by blood feeding in vector sand flies. Cellular Microbiology, 12(7): 906-918, 2010.

SEEBECK, T.; SCHAUB, R. \& JOHNER, A. cAMP signalling in the kinetoplastid protozoa. Current Molecular Medicine, 4(6): 585-599, 2004.

SHAKARIAN, A. M. \& DWYER, D. M. Structurally conserved soluble acid phosphatases are synthesized and released by Leishmania major promastigotes. Experimental Parasitology, 95(2): 79-84, 2000.

SHAKARIAN, A. M. et al. Molecular dissection of the functional domains of a unique, tartrate-resistant, surface membrane acid phosphatase in the primitive human pathogen Leishmania donovani. The Journal of Biological Chemistry, 277(20): 17.994-18.001, 2002.

SILVA-LOPEZ, R. E. \& GIOVANNI-DE-SIMONE, S. Leishmania (Leishmania) amazonensis: purification and characterization of a promastigote serine protease. Experimental Parasitology, 107(3-4): 173-182, 2004.

SILVA-LOPEZ, R. E. et al. Subcellular localization of an extracellular serine protease in Leishmania (Leishmania) amazonensis. Parasitology Research, 93(4): 328-331, 2004.

SOARES, R. P. et al. Leishmania chagasi: lipophosphoglycan characterization and binding to the midgut of the sand fly vector Lutzomyia longipalpis. Molecular and Biochemical Parasitology, 121(2): 213-224, 2002.

SOARES, R. P. et al. Leishmania braziliensis: a novel mechanism in the lipophosphoglycan regulation during metacyclogenesis. International Journal for Parasitology, 35(3): 245-253, 2005.

SOARES, R. P. et al. Differential midgut attachment of Leishmania (Viannia) braziliensis in the sand flies Lutzomyia (Nyssomyia) whitmani and Lutzomyia (Nyssomyia) intermedia. Journal of Biomedicine \& Biotechnology, 2.010: 1-7, 2010.

SOONG, L. Modulation of dendritic cell function by Leishmania parasites. The Journal of Immunology, 180(7): 4.355$4.360,2008$.

SOUZA LEÃO, S. et al. Intracellular Leishmania amazonensis amastigotes internalize and degrade MHC class II molecules of their host cells. Journal of Cell Science, 108(10): 3.219-3.231, 1995.

SPATH, G. F. et al. Lipophosphoglycan is a virulence factor distinct from related glycoconjugates in the protozoan parasite Leishmania major. Proceedings of the National Academy of Sciences of the USA, 97(16): 9.258-9.263, 2000. 
SPATH, G. F. et al. The role(s) of lipophosphoglycan (LPG) in the establishment of Leishmania major infections in mammalian hosts. Proceedings of the National Academy of Sciences of the USA, 100(16): 9.536-9.541, 2003.

STEBECK, C. E. et al. Kinetoplastid membrane protein-11 (KMP-11) is differentially expressed during the life cycle of African trypanosomes and is found in a wide variety of kinetoplastid parasites. Molecular and Biochemical Parasitology, 71(1): 1-13, 1995.

STIERHOF, Y. D. et al. Characterization of polymer release from the flagellar pocket of Leishmania mexicana promastigotes. The Journal of Cell Biology, 125(2): 321-331, 1994.

TONUI, W. K. et al. Transmission blocking vaccine studies in Leishmaniasis: II. Effect of immunization using Leishmania major derived 63 kilodalton glycoprotein, lipophosphoglycan and whole parasite antigens on the course of L. major infection in BALB/c mice. East African Medical Journal, 78(2): 90-92, 2001.

TURCO, S. J. Adversarial relationship between the Leishmania lipophosphoglycan and protein kinase C of host macrophages. Parasite Immunology, 21(12): 597-600, 1999.

TURCO, S. J. \& DESCOTEAUX, A. The lipophosphoglycan of Leishmania parasites. Annual Review of Microbiology, 46: 65-94, 1992.

TURCO, S. J. et al. Structure of the major carbohydrate fragment of the Leishmania donovani lipophosphoglycan. Biochemistry, 26(19): 6.233-6.238, 1987.

UZONNA, J. E. et al. Vaccination with phosphoglycan-deficient Leishmania major protects highly susceptible mice from virulent challenge without inducing a strong Th1 response. The Journal of Immunology, 172 (6): 3.793-3.797, 2004.

VICTOIR, K. et al. Complexity of the major surface protease (msp) gene organization in Leishmania (Viannia) braziliensis: evolutionary and functional implications. Parasitology, 131(2): 207-214, 2005.

VINHAS, V. et al. Characterization of T cell responses to purified Leishmania antigens in subjects infected with Leishmania chagasi. Brazilian Journal of Medical and Biological Research, 27(5): 1.199-1.205, 1994.

VOLF, P. et al. Bloodmeal digestion and Leishmania major infections in Phlebotomus duboscqi: effect of carbohydrates inhibiting midgut lectin activity. Medical and Veterinary Entomology, 15(3): 281-286, 2001.

WALTERS, L. L. et al. Ultrastructural development of Leishmania chagasi in its vector, Lutzomyia longipalpis (Diptera: Psychodidae). The American Journal of Tropical Medicine and Hygiene, 41(3): 295-317, 1989.

WEINHEBER, N. et al. Phagocytosis of Leishmania mexicana amastigotes by macrophages leads to a sustained suppression of IL-12 production. European Journal of Immunology, 28(8): 2.467-2.477, 1998.

WEISE, F. et al. Distribution of GPI-anchored proteins in the protozoan parasite Leishmania, based on an improved ultrastructural description using high-pressure frozen cells. Journal of Cell Science, 113(24): 4.587-4.603, 2000.

WU, Y. et al. A new developmentally regulated gene family in Leishmania amastigotes encoding a homolog of amastin surface proteins. Molecular and Biochemical Parasitology, 110(2): 345-357, 2000.

XU, D. et al. Protection against Leishmania major infection in genetically susceptible BALB/c mice by gp63 delivered orally in attenuated Salmonella typhimurium (AroA-AroD-). Immunology, 85(1): 1-7, 1995.

YAO, C. et al. Multiple products of the Leishmania chagasi major surface protease (MSP or GP63) gene family. Molecular and Biochemical Parasitology, 135(2): 171-183, 2004.

YAO, C. et al. Internal and surface subpopulations of the major surface protease (MSP) of Leishmania chagasi. Molecular and Biochemical Parasitology, 139(2): 173-183, 2005.

YONEYAMA, K. A. et al. Characterization of Leishmania (Viannia) braziliensis membrane microdomains, and their role in macrophage infectivity. Journal of Lipid Research, 47(10): 2.171-2.178, 2006.

ZUFFEREY, R. et al. Ether phospholipids and glycosylinositolphospholipids are not required for amastigote virulence or for inhibition of macrophage activation by Leishmania major. The Journal of Biological Chemistry, 278(45): 44.70844.718, 2003. 


\section{$\underline{9}$ \\ Aspectos Moleculares da Interação Flebotomíneo-Leishmania}

Antonio J. Tempone I André N. Pitaluga I Yara M. Traub-Csekö

Tnsetos flebotomíneos são os principais vetores naturais das leishmanioses. Apesar de já terem sido descritas algumas centenas de espécies desses dípteros, apenas uma pequena fração delas foi associada à transmissão das leishmanioses (Killick-Kendrick, 1999). Doenças infecciosas veiculadas por artrópodes vetores têm como um dos alvos de controle o vetor. O controle de vetores pelo uso de inseticidas, além de afetar outros organismos no ambiente, também pode acarretar o desenvolvimento de resistência, com consequências de ordem ambiental, social e econômica. Dessa forma, faz-se necessário o desenvolvimento de novas abordagens para o controle de vetores, sendo o conhecimento da biologia e fisiologia de vetores e de sua interação com os parasitos de fundamental importância nesse processo. No caso de mosquitos transmissores da malária, vários estudos têm focado na identificação e função das moléculas envolvidas na interação entre mosquitos e plasmódios, de forma que até insetos transgênicos incapazes de transmitir a malária já foram desenvolvidos (Sperança \& Capurro, 2007).

Com relação às leishmanioses, constata-se que a maioria dos dados a respeito dos mecanismos de transmissão e interação patógeno-hospedeiro-vetor referem-se a estudos realizados entre leishmânias e flebotomíneos do Velho Mundo, existindo uma lacuna de conhecimento no que tange às leishmanioses do Novo Mundo. Durante seu desenvolvimento no interior do inseto vetor, a Leishmania está exposta a vários desafios e barreiras. O flebotomíneo, por sua vez, também é afetado pela presença do parasito. A chave para o desenvolvimento de ferramentas que interfiram na transmissão das leishmanioses está na compreensão dos mecanismos envolvidos no equilíbrio desse relacionamento desenvolvido ao longo de uma coevolução antiga e bem-sucedida. Aspectos moleculares envolvidos na interação flebotomíneo-Leishmania são discutidos a seguir.

\section{ASPECTOS GERAIS}

\section{Distribuição geográfica de flebotomíneos}

Existem atualmente oitocentas espécies de flebotomíneos identificadas no mundo, $60 \%$ destas localizadas em regiões neotropicais. No Brasil, até o momento, foram identificadas 229 espécies, que representam $28,6 \%$ do total de espécies conhecidas. A Região Norte tem 166 espécies (64 endêmicas), a Sudeste 106 (19 endêmicas), a Região Centro- 
Oeste 98 (quatro endêmicas), a Nordeste 94 (quatro endêmicas) e a Região Sul apresenta 42 espécies (uma endêmica) (Aguiar \& Medeiros, 2003). Até o momento, 19 espécies de flebotomíneos são consideradas vetores de leishmaniose para homens e animais no Brasil (Young \& Duncan, 1994; Dos Santos et al., 1998). Destas, Lutzomyia intermedia, Lutzomyia migonei e Lutzomyia whitmani são encontradas em todas as cinco regiões brasileiras. Lutzomyia longipalpis (Lutz \& Neiva, 1912) é encontrada em todo o continente americano, do México à Argentina, e está presente em todas as regiões do território brasileiro, com exceção do Sul. Essa tem sido a principal transmissora em todos os focos ativos de leishmaniose, picando o homem, cães e raposas (Deane \& Deane 1955), e, por ser considerada um vetor permissivo, tem grande importância epidemiológica.

Em função da ampla distribuição de L. longipalpis, é provável a existência de barreiras entre diferentes populações gerando variações dentro da espécie. Essas variações foram identificadas inicialmente por Mangabeira, em 1969, ao analisar um padrão de pigmentação no terceiro e quarto segmento abdominal de machos (fenótipo uma ou duas manchas) de L. longipalpis provenientes do Pará e Ceará. Posteriormente, Ward e colaboradores (1983) também observaram essas mesmas diferenças de pigmentação, levando a propor a existência de dois taxa distintos. Atualmente, fortes indícios indicam que L. longipalpis é um complexo de espécies crípticas que diferem geneticamente, além de apresentarem diferentes sons de corte e ferormônios (Bauzer et al., 2007; Araki et al., 2009).

\section{Biologia e ciclo de vida dos flebotomíneos}

Os flebotomíneos são insetos da ordem Diptera da família Psychodidae, caracterizados pelo pequeno porte (2-3 mm) em relação a outros insetos vetores, como os mosquitos, e por apresentarem corpo muito piloso.

São insetos holometábolos e seu ciclo de vida consiste numa fase de ovo seguida por quatro estágios larvares (L1 a L4), uma fase pupal e uma fase adulta. Os ovos têm uma forma elipsóide e medem, dependendo da espécie, de 300 a $500 \mu \mathrm{m}$ de comprimento por 70 a $150 \mu \mathrm{m}$ de largura. Algumas horas após a postura os ovos perdem a coloração branco-amarelada, devido ao amadurecimento da casca, e passam a apresentar uma coloração castanhoescura. As larvas são pequenas, brancas e vermiformes. Logo após a eclosão, se alimentam das cascas dos ovos, dos corpos em decomposição dos adultos e de outras fontes de matéria orgânica disponíveis. As larvas têm 12 segmentos além da cabeça, sendo três torácicos e nove abdominais. A cabeça é bem desenvolvida, com coloração escura e peças bucais tipo triturador. Os apêndices cefálicos são as antenas que variam em número e comprimento, dependendo do estágio larvar e da espécie. No gênero Lutzomyia, as larvas de primeira fase apresentam um par de cerdas caudais, enquanto as demais fases apresentam dois pares. As pupas são claras e se tornam escuras progressivamente ao se aproximar da eclosão do adulto. São compostas pelo cefalotórax formado pela fusão dos quatro primeiros segmentos e pelo abdômen formado pela fusão dos nove segmentos seguintes. Na fase adulta, os flebotomíneos apresentam um dimorfismo sexual evidente não apenas na morfologia, mas também nos hábitos alimentares, sendo a fêmea hematofágica. A distinção sexual se dá em diferentes partes do corpo. A probóscide da fêmea é mais longa e adaptada à alimentação sanguínea e, ainda nas fêmeas, são encontrados os cibários, estruturas relacionadas com a ingestão sanguínea. Outra diferença muito usada na separação de machos e fêmeas em laboratório é a morfologia do último segmento abdominal, onde está localizada a genitália. No macho existe um grupo de apêndices desenvolvidos e ornamentados, enquanto na fêmea esses apêndices são menores, conferindo um aspecto arredondado à genitália.

Os ovos levam em torno de seis a nove dias para eclodir, e a maturação das larvas dura entre 14 e 19 dias. A transição de pupa para a fase adulta leva entre oito e nove dias. O tempo total de desenvolvimento, desde a alimentação sanguínea até o surgimento de formas adultas, usando sangue de hamster, é de aproximadamente 35 dias (Rangel et al., 1986). 


\section{Infecção de flebotomíneos por Leishmania}

Protozoários do gênero Leishmania têm um ciclo de vida digenético com duas fases distintas, uma no hospedeiro vertebrado e outra no hospedeiro-vetor invertebrado flebotomíneo. As formas amastigotas ingeridas juntamente com o sangue do vertebrado são direcionadas ao intestino médio, onde os protozoários se diferenciam em formas promastigotas procíclicas. Essas formas pequenas, flageladas e ovoides apresentam alta taxa de multiplicação dentro do bolo alimentar. Entre o $2^{\circ}$. e o $5^{\circ}$. dia após a alimentação infectada, as formas procíclicas sofrem uma série de divisões que originam uma nova forma de promastigota, as nectomonas. Estas são majoritárias no tubo digestivo dos insetos nos primeiros dias após a alimentação infectada, até a passagem do bolo alimentar. Já no final da digestão, por volta de 72 horas após o repasto sanguíneo, com a degradação da matriz peritrófica, as formas nectomonas ocupam o intestino médio na porção abdominal e se ligam às microvilosidades do epitélio intestinal pelo flagelo. Após quatro a cinco dias da alimentação, as formas nectomonas migram para a porção torácica do intestino médio e se transformam em formas haptomonas e paramastigotas. Paralelamente, surgem também no intestino do vetor os promastigotas metacíclicos, as formas infectivas ao hospedeiro vertebrado (Lainson, Ryan \& Shaw, 1987) (Figura 1). Essas formas, delgadas e com flagelo extenso, são ativas e responsáveis pela continuação do ciclo de vida do parasito. Os metacíclicos estabelecem uma massiva infecção da válvula estomodeal que, em alguns casos, é acompanhada de invasão do intestino anterior, incluindo a faringe, o cibário e a probóscide. As formas metacíclicas danificam a válvula estomodeal impedindo o correto bombeamento do sangue e estimulando a regurgitação das formas metacíclicas presentes nas porções anteriores do intestino (Schlein, Jacobson \& Messer, 1992). Além disso, o parasito secreta um gel (parasite secretory gel - PSG) que, ao formar uma verdadeira tampa na parte anterior do tubo digestivo, reduz a eficiência da entrada de sangue pela alimentação (Rogers, Chance \& Bates, 2002; Stierhof et al., 1999). Dessa maneira, a Leishmania parece ser capaz de alterar o comportamento de alimentação dos flebotomíneos para aumentar a eficiência da transmissão (Rogers et al., 2004). É sugerido que entre cem e mil parasitos sejam liberados por um flebótomo infectado durante o repasto sanguíneo (Warburg \& Schlein, 1986; Schlein, Jacobson \& Messer, 1992).

A adesão ao epitélio após a degradação da matriz peritrófica é uma etapa crucial na infecção dos flebotomíneos pelas leishmânias. Os parasitos incapazes de aderir ao epitélio intestinal do flebotomíneo serão eliminados quando da excreção do bolo alimentar. A adesão à parede intestinal possibilita a multiplicação e diferenciação das leishmânias e está relacionada à permissividade do vetor.

Ensaios ex vivo, nos quais Leishmania de várias epécies em diferentes estágios de desenvolvimento foram incubadas com o intestino de diferentes espécies de flebotomíneos, mostraram que as formas promastigotas, leptomonas e nectomonas são as que apresentaram os maiores índices de fixação ao intestino desses insetos, quando comparadas às formas procíclicas e metacíclicas. Os autores, curiosamente, também observaram que algumas espécies de Leishmania não consideradas como pares naturais de L. longipalpis, como L. major e $L$. tropica, foram aparentemente mais eficientes ao se ligar ao intestino do inseto do que L. infantum, considerada o par natural desse flebotomíneo (Wilson et al., 2010). Interessantemente, foi descrito recentemente um isolado de Leishmania (Viannia) braziliensis aflagelar obtido de paciente (Zauli et al., 2012). Este isolado não somente foi capaz de infectar macrófagos in vitro e gerar lesões em camundongos como ainda se mostrou eficaz na infecção do flebotomíneo L. longipalpis de maneira estável mesmo após a digestão sanguínea e de maneira semelhante à linhagem selvagem de L. (V) braziliensis.

Tais observações, aparentemente contraditórias, levantam indícios sobre a existência de componentes ainda não caracterizados, provavelmente presentes em ambos, patógenos e hospedeiros vetores, que são de suma importância para a sobrevivência, infectividade das leishmânias e a especificidade da relação leishmânia-flebotomíneo. 
Figura 1 - Estágios do desenvolvimento de Leishmania sp. no tubo digestivo do flebotomíneo

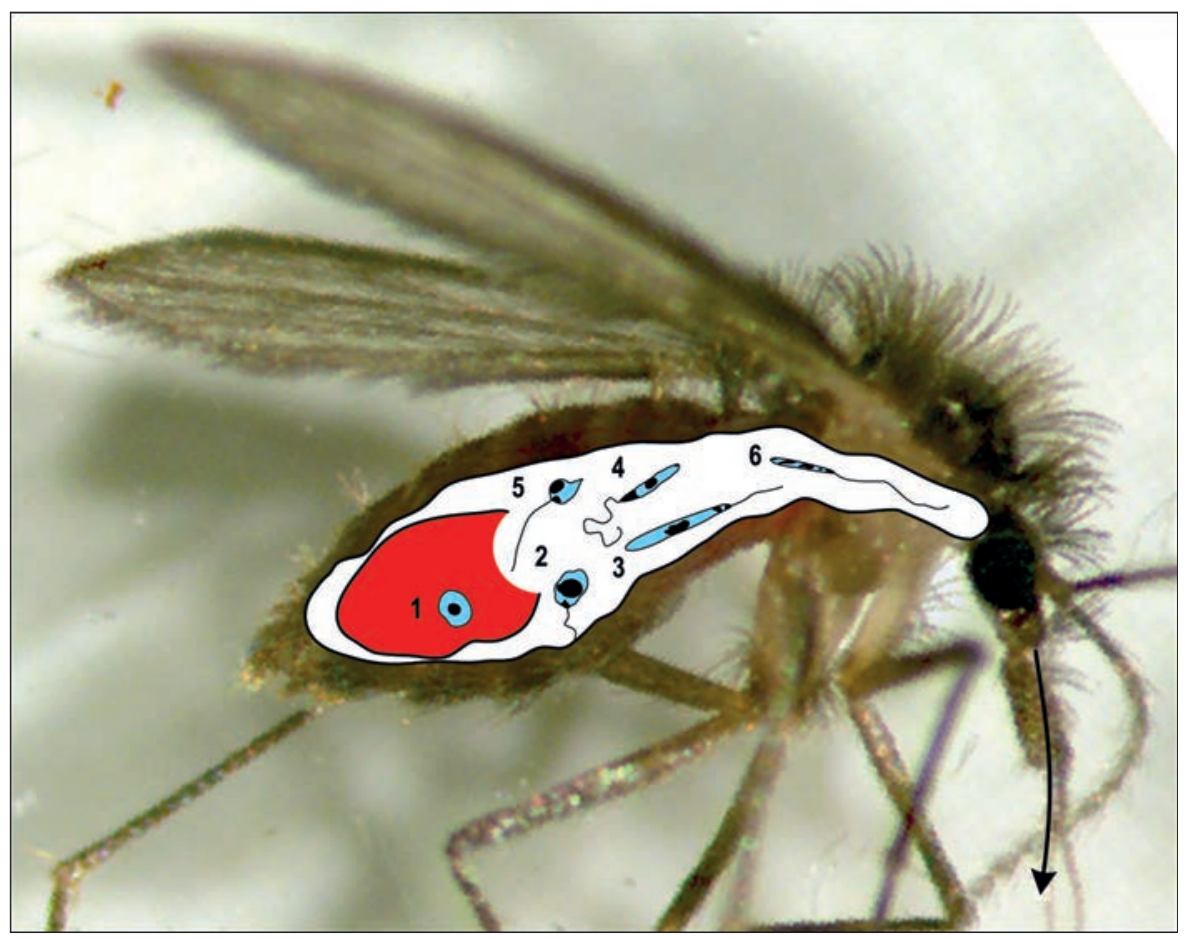

As formas amastigotas (1) ingeridas no repasto sanguíneo necessitam sobreviver à ação das proteases digestivas secretadas logo após a ingestão sanguínea. De dois a três dias após a alimentação sanguínea, essas formas, já diferenciadas em promastigotas, entram em contato com o tubo digestivo depois da degradação da matriz peritrófica. Neste período são geralmente observadas as formas procíclicas (2) e, posteriormente, as nectomonas (3). A partir do segundo dia surgem as formas haptomonas (4), que se tornam majoritárias no tubo digestivo do quarto dia em diante. No terceiro dia as formas paramastigotas (5) surgem e se mantêm em baixa concentração. Entre 0 quinto e 0 sétimo dias após infecção, os parasitos migram para as partes bucais do flebotomíneo. As formas metacíclicas (6), consideradas infectivas, surgem no quarto dia após a infecção e se mantêm sempre em baixa concentração em relação às demais formas de promastigotas. Porém, tais formas serão encontradas principalmente na região anterior do inseto, formando um plug composto de um gel secretado de promastigotas (promastigote secretory gel - PSG) na válvula estomodeal. Este plug afeta a eficiência do repasto sanguíneo, forçando o inseto a regurgitar o plug contendo formas metacíclicas na pele do hospedeiro vertebrado antes de se alimentar.

A identificação das moléculas necessárias à fixação das leishmânias em seus respectivos vetores é de fundamental importância para o conhecimento das relações parasito/vetor e poderá ser de grande auxílio no desenvolvimento de estratégias de bloqueio de transmissão. A adesão das leishmânias ao tubo digestivo e algumas moléculas envolvidas nesse processo serão discutidas a seguir.

\section{ALIMENTAÇÃO SANGUIINEA}

\section{0 tubo digestivo}

O tubo digestivo dos flebotomíneos é especialmente importante não somente para a fisiologia do inseto, mas também no aspecto vetorial da transmissão da leishmaniose e de outros patógenos. Os flebotomíneos apresentam partes bucais curtas $(0.2-0.4 \mathrm{~mm})$, o que impede uma penetração profunda na pele dos hospedeiros. A laceração da pele e dos capilares superficiais leva ao surgimento de uma hemorragia subcutânea pequena e localizada de onde o sangue é sugado. A quantidade de sangue ingerido varia entre indivíduos e entre espécies, mas de maneira geral esses são capazes de ingerir seu próprio peso (0,1 mg a 0,6 mg) em sangue (Chaniotis, 1967). Como em outros dípteros anautógenos, a alimentação sanguínea nos flebotomíneos é necessária para o desenvolvimento dos ovos, e a 
quantidade destes é proporcional ao volume de sangue ingerido (Ready, 1979; Lehane, 1991). Em relação a hospedeiros preferenciais, as espécies neotropicais que se alimentam de sangue quente são bastante ecléticas, sendo capazes de se alimentar em diferentes hospedeiros tais como humanos, cães e aves, entre outros (Brazil, Morton \& Ward, 1991).

o tubo digestivo se inicia na probóscide e vai até o intestino, que é dividido em três partes: anterior, médio e posterior. A válvula do cibário separa o cibário da faringe e a válvula cardíaca separa a faringe da porção anterior do intestino. O bombeamento simultâneo das válvulas é importante para a sucção do repasto sanguíneo. Como na maioria dos insetos, digestão e absorção de nutrientes ocorrem no intestino médio, sendo as fezes e a urina passadas ao intestino posterior onde a água e os sais ainda serão absorvidos (Chapman, 1985).

\section{Matriz peritrófica}

Durante a digestão, o sangue é envolvido pela matriz peritrófica (MP) produzida pelas células do epitélio intestinal. Esta matriz começa a se formar entre uma e quatro horas após a ingestão sanguínea e em 24 horas está completamente formada. A MP é sintetizada como uma bainha de formato cilíndrico que envolve o sangue ingerido dentro do tubo digestivo (Pimenta et al., 1997). A matriz é formada por material fibroso constituído por quitina e várias proteínas associadas (Moskalyk, Oo \& Jacobs-Lorena, 1996). A MP desempenha importantes funções durante o processo de digestão sanguínea. Sua estrutura física protege o epitélio intestinal contra a ação de radicais livres e danos causados por cristais de heme produzidos pela degradação da hemoglobina (Richards \& Richards, 1977). Em mosquitos, viu-se que uma proteína da matriz interage diretamente com heme, tendo provavelmente um papel detoxificador (Devenport et al., 2006). Mecanismos similares ainda não foram identificados em flebotomíneos.

Um dos desafios aos quais as leishmânias estão submetidas nas fases iniciais da infecção do inseto é a exposição às enzimas digestivas. A matriz permite a formação lenta de um gradiente de tripsinas do epitélio do intestino até a parte central do bolo digestivo contendo parasitos. Isso permite que os parasitos se desenvolvam em formas mais resistentes a essas hidrolases (Pimenta, Secundino \& Nieves Blanco, 2003). Em flebotomíneos do Velho Mundo o papel relevante da MP na infecção do inseto pelas leishmânias foi demonstrado por Pimenta e colaboradores, em 1997: grupos de fêmeas tratadas com quitinase exógena, que impediu a formação da matriz, apresentaramse mais refratárias à infecção por Leishmania sp. quando comparados aos grupos-controle. A importância da MP no processo infectivo desses insetos pelas leishmânias foi corroborada em um estudo mais recente, em que o silenciamento do gene PpChit1 de Phlebotomous papatasi, que codifica para uma quitinase induzida por sangue e envolvida na maturação e degradação da MP, resultou em uma significativa redução na infecção por L. major em relação aos controles (Coutinho-Abreu et al., 2010).

\section{Digestão}

O evento inicial que irá determinar a competência vetorial de um inseto é a capacidade de sobrevivência do parasito no microambiente intestinal rico em proteases, com pico de atividade entre 18 e 48 horas após alimentação sanguínea (Sacks \& Kamhawi, 2001; Volf, Svobodová \& Dvoráková, 2001; Telleria et al., 2007). Mesmo num sistema vetor-parasito compatível como P. papatasi-L. major a diferenciação de amastigota para promastigota é altamente sensível à proteólise, com até $50 \%$ de morte dos parasitos nas primeiras 48 horas após alimentação sanguínea. Considerando-se o possível papel dessas enzimas na sobrevivência do parasito no vetor, atividades enzimáticas foram investigadas em relação à infecção por Leishmania. A presença de Leishmania foi relacionada aos níveis de enzimas proteolíticas em P. papatasi (Schlein \& Jacobson, 1998; Borovsky \& Schlein, 1987), e foi sugerido que algum componente específico da atividade tipo-tripsina impedia a sobrevivência de $L$. donovani nesse 
vetor, ao contrário de L. major, cuja sobrevivência provavelmente estava correlacionada à modulação da atividade (Borovsky \& Schlein, 1987). Inibidores de tripsina permitiram a sobrevivência de L. donovani em P. papatasi (Schlein \& Jacobson, 1998; Borovsky \& Schlein, 1987; Pimenta et al., 1997). Apenas $5 \%$ de L. donovani sobreviveu no intestino de $P$. papatasi quando sangue total foi usado em alimentação artificial (Schlein \& Jacobson, 1998). Entretanto, quando esse sangue foi misturado a inibidores de tripsina ou quando os insetos foram alimentados com eritrócitos em salina, esse número aumentou em $70 \%$.

Enquanto resultados similares foram vistos em P. papatasi infectada por L. major (Dillon \& Lane, 1993), no par não natural $P$. langeroni-L. major houve um aparente atraso da digestão e níveis altos persistentes de enzimas digestivas, com um possível efeito na sobrevivência dos parasitos. Uma vez que já foram identificados inibidores de serina-proteases de L. major com efeito sobre enzimas de macrófagos (Eschenlauer et al., 2009), levantou-se a hipótese de tais inibidores terem uma função na atividade enzimática no tubo digestivo do vetor, hipótese esta ainda a ser demonstrada. Em L. longipalpis, evidências recentes sugerem uma diminuição de atividade de tripsinas em insetos infectados por L. i. chagasi (Telleria et al. 2010). Além disso, a inibição da expressão de tripsina em $L$. longipalpis por injeções por RNAi resultou em uma sobrevivência aumentada de Leishmania no vetor (Sant'anna et al., 2009). A proteção natural de Leishmania ao ataque proteolítico foi atribuída a moléculas contendo fosfoglicanas (revisto por Sacks \& Kamhawi, 2001), que serão discutidas posteriormente.

Diversos genes que desempenham importante papel na digestão sanguínea foram identificados em trabalhos de sequenciamento de ESTs de tubo digestivo de L. longipalpis (Dillon et al., 2006; Jochim et al., 2008; Pitaluga et al., 2009) e P. papatasi (Ramalho-Ortigão et al., 2007a). Entre esses, genes de L. longipalpis que atuam no processo de digestão sanguínea e infecção, como tripsina (Telleria et al., 2007, 2010), V-ATPase (Ramalho-Ortigão et al., 2007b) e quitinase (Ramalho-Ortigão \& Traub-Csekö, 2003) foram recentemente identificados.

\section{Tripsinas}

As tripsinas constituem a mais abundante classe de proteases digestivas presentes nos insetos hematófagos (Lehane, 1991). Além de seu óbvio papel na digestão, essas enzimas também estão relacionadas com a capacidade de certos patógenos infectarem seus vetores naturais. Em L. longipalpis foram identificados dois genes de tripsinas - Lltryp1 e Lltryp2 -, que são diferencialmente expressos em fases distintas do processo digestivo e no desenvolvimento do inseto (Telleria et al., 2007). A expressão de Lltryp1 em fêmeas adultas é modulada pela alimentação sanguínea e alcança um pico após 12 horas do repasto. Lltryp2, por sua vez, é expresso constitutivamente em insetos adultos e também em larvas. Resultados de Western blot usando anticorpos específicos para as duas tripsinas (Telleria et al., 2010) confirmaram a modulação de Lltryp 1 pela ingestão de sangue. A presença de Lltryp 2 em fases imaturas do inseto está sendo investigada. Atividade enzimática foi também investigada em L. longipalpis, por meio de zimografia. A atividade foi compatível com resultados obtidos por estudos de expressão gênica e Western blot, com bandas proteolíticas mais intensas aparecendo após alimentação sanguínea (Telleria et al., 2010).

Uma vez que inibição de serina-proteases intestinais de flebotomíneos foi anteriormente associada à infecção por Leishmania (Borovsky \& Schlein, 1987; Dillon \& Lane, 1993; Sant'Anna et al., 2009), investigou-se isso também em $L$. longipalpis usando-se subtratos específicos. Houve uma diminuição significativa nesta atividade em insetos infectados por L. chagasi, principalmente 12 e 48 horas após a alimentação (Telleria et al., 2010).

\section{Lectinas e peptídios mioinibidores}

A ingestão sanguínea induz a produção de lectinas, identificadas em diversos tecidos dos flebotomíneos e associada tanto à digestão quanto a mecanismos de defesa, incluindo aglutinação de parasitos. Após a ingestão sanguínea, a 
atividade de lectinas no tubo digestivo aumenta de duas a 16 vezes, dependendo da espécie de flebotomíneo e do conteúdo proteico da alimentação (Grubhoffer, Hypsa \& Volf, 1997). Demonstrou-se a aglutinação de diferentes espécies de Leishmania usando-se lisados de flebotomíneos, mesmo nas combinações naturais de parasito-vetor (Svobodová et al., 1997). Além disso, a inibição da atividade de lectinas aumentou a infecção de L. major em Phlebotomus duboscqi, indicando que as lectinas secretadas têm uma importante função na sobrevivência inicial da Leishmania no tubo digestivo do flebotomíneo (Volf, Kienvegová \& Svobodová, 1998).

Outra interferência direta do parasito no metabolismo digestivo do vetor está relacionada aos movimentos peristálticos do tubo digestivo. Identificou-se um neuropeptídeo mioinibitório secretado de L. major que interrompe o peristaltismo do tubo digestivo de P. papatasi e em menor escala em L. longipalpis (Vaidyanathan, 2004; Vaidyanathan, 2005). Além disso, um lisado de $L$. major causa a inibição total do movimento peristáltico do seu vetor natural $P$. papatasi, enquanto chega a $50 \%$ e $20 \%$ de inibição quando são utilizados os parasitos incompatíveis L. braziliensis e $L$. donovani, respectivamente (Vaidyanathan, 2004). Uma linhagem indiana de $L$. donovani não produziu efeito negativo nos movimentos peristálticos de $P$. papatasi, sugerindo que esses inibidores sejam espécie-específicos. A principal vantagem da interrupção dos movimentos peristálticos para a Leishmania está no relaxamento do tubo digestivo, dificultando a digestão sanguínea e diminuindo a chance de os parasitos serem expelidos.

\section{V-ATPases}

V-ATPases de insetos são responsáveis pela energização de membranas (Klein, 1992) e acidificação de compartimentos, e até mesmo de todo o tubo digestivo como ocorre no inseto Bombyx mori (Wieczorek et al., 2000). Essas proteínas, que podem desempenhar uma grande variedade de funções e são encontradas em todos os eucariotos (Nelson, 2003), funcionam geralmente como bombas de próton compostas por várias subunidades. Em L. longipalpis sugeriu-se uma relação entre a reacidificação do tubo digestivo após a digestão sanguínea e o processo de metaciclogênese (Gontijo et al., 1998).

De fato, a V-ATPase de L. longipalpis aparenta ser regulada positivamente pela presença de sangue no tubo digestivo, com duas vezes mais RNAs após seis horas da alimentação sanguínea (Ramalho-Ortigão et al., 2007b). A análise da expressão durante o desenvolvimento indica uma regulação estágio-específica (Ramalho-Ortigão et al., 2007b). Além disso, vários transcritos relacionados com acidificação ou alcalinização de tubo digestivo de L. longipalpis foram identificados (Pitaluga et al., 2009). Os principais componentes detectados dessa via foram o transportador antiporte de $\mathrm{Na}+/ \mathrm{H}+$, bomba de $\mathrm{Na}+/ \mathrm{Ca}++$ dependente de potássio e o transportador simporte $\mathrm{Na}+/$ prolina. Como já mencionado anteriormente, a interferência do parasito na atividade de diversas enzimas digestivas foi observada em $P$. papatasi e em Phlebotomus langeroni quando infectados com L. major (Dillon \& Lane, 1993) e em L. longipalis infectada com L. chagasi (Telleria et al., 2010). Isso poderia estar relacionado à produção de inibidores pelos parasitos. Uma hipótese alternativa para tal evento seria a interferência do parasito na via catiônica do vetor durante o processo digestivo, que resultaria em variações no pH ótimo para as enzimas digestivas.

\section{IDENTIFICAÇÃO DE GENES DE FLEBOTOMÍNEOS MODULADOS PELA INFECÇÃO POR LEISHMANIA POR SEQUENCIAMENTO DE ESTS}

Atualmente, há poucos dados sobre a resposta de flebotomíneos à infecção por Leishmania. O funcionamento do sistema imune desses insetos é geralmente inferido tendo por base estudos em drosófila e mosquitos. Com a ausência de dados completos do genoma de flebotomíneos, a identificação de componentes da resposta imune desses insetos depende quase que exclusivamente de dados obtidos a partir de projetos de sequenciamento de Expressed Sequence TagS (ESTs). Contudo, os dados disponíveis são recentes e em número consideravelmente inferior quando comparados a outros vetores de importância médica. 
Em 2001, Ramalho-Ortigão e colaboradores publicaram o primeiro sequenciamento de ESTs de L. longipalpis, seguidos por Dillon e colaboradores em 2006, Jochim e colaboradores em 2008 e Pitaluga e colaboradores em 2009. Tais trabalhos tiveram como foco, sobretudo, a identificação de transcritos modulados pela infecção por Leishmania sp. Dillon e colaboradores (2006) buscaram uma resposta sistêmica à infecção por L. infantum e Leishmania mexicana com o sequenciamento de ESTs do inseto inteiro. Os trabalhos de Jochim e Pitaluga enfocaram o tubo digestivo, devido ao seu importante papel tanto na transmissão da leishmaniose como na fisiologia do inseto. Embora utilizando populações distintas de L. longipalpis (Jacobina e Belém, respectivamente), ambos os trabalhos buscaram identificar transcritos relacionados tanto à infecção por L. chagasi quanto à digestão sanguínea, a partir do sequenciamento de ESTs oriundos de bibliotecas de cDNA do tubo digestivo, após diferentes tempos de alimentação sanguínea e infecção. Deu-se grande importância às bibliotecas produzidas com cDNAs obtidos a partir de insetos infectados ou não após 72 horas de alimentação. Este é um momento crítico, quando as leishmânias se ligam às microvilosidades do epitélio intestinal do flebotomíneo, passo este necessário para o sucesso da infecção do inseto, da metaciclogênese e, portanto, da manutenção do ciclo da leishmaniose.

Por meio dessa abordagem foram identificados em L. longipalpis genes modulados pela presença de L. chagasi, conforme havia sido descrito em trabalhos semelhantes utilizando flebotomíneos do Velho Mundo (P. papatasi) infectados com L. major (Ramalho-Ortigão et al., 2007a). Entre os genes modulados negativamente estão os que codificam para proteínas de microvilosidades (Jochim et al., 2008). Há pouca informação sobre a função dessas proteínas, que, em geral, têm domínio de alergeno de insetos (pfam 06757) e são bastante conservadas em diversas espécies.

Diversos genes ligados à digestão sanguínea foram também modulados negativamente pela infecção de L. longipalpis por L. chagasi, como a tripsina 2, a quimiotripsina $1 \mathrm{~A}$, a astacina e a carboxipeptidase A1. Jochim e colaboradores (2008) indicaram que transcritos de Lltryp1, que codifica para uma tripsina modulada pela ingestão de sangue, tinham a produção diminuida após infecção, enquanto o trancrito de Lltryp2, que codifica para uma tripsina constitutiva, era mais abundante em bibliotecas de L. longipalpis infectadas. Pitaluga e colaboradores (2009) encontraram resultados similares para Lltryp2, mas não para Lltryp1 quando da análise de bibliotecas de cDNA preparadas de intestino médio de insetos infectados ou não. Outro gene modulado negativamente pela infecção de L. longipalpis por Leishmania foi o da actina (Jochim et al., 2008).

A modulação de genes que codificam para peritrofinas em relação à infecção por Leishmania é bastante diferente em flebotomíneos do Novo Mundo e Velho Mundo. A expressão de peritrofina 1 de L. longipalpis é aumentada durante a infecção por L. chagasi, enquanto se encontra diminuída em P. papatasi infectada por L. major. Outro gene de MP modulado positivamente em L. longipalpis, em relação à infecção, foi de uma molécula ligadora de quitina (Jochim et al., 2008).

Existem algumas evidências de que flebotomíneos são capazes de reconhecer e responder à infecção por Leishmania. Em $P$. duboscqi a infecção por L. major levou à produção do peptídeo antimicrobiano defensina (Boulanger et al., 2004). Isso mostra que tal vetor responde à infecção pelo parasito pelas vias clássicas de imunidade inata de insetos: Toll, IMD e JAK-Stat. Diversos genes dessas vias foram identificados nos sequenciamentos de ESTs de L. longipalpis (Dillon et al., 2006; Jochim et al., 2008; Pitaluga et al., 2009).

\section{MICROBIOTA E IMUNIDADE}

Diversos microrganismos residem nos insetos, preferencialmente no tubo digestivo (Dillon \& Dillon, 2004), onde desempenham papel fundamental na ativação do sistema imune e na inibição do desenvolvimento de patógenos. Em mosquitos, alguns desses microrganismos têm sido associados à inibição do desenvolvimento do plasmódio no tubo digestivo do vetor (Pumpuni et al., 1996; Gonzalez-Ceron et al., 2003; Cirimotich, Ramirez \& Dimopoulo, 2011). 
A microbiota intestinal pode afetar o parasito diretamente, ainda durante a alimentação sanguínea, mediante a produção de enzimas e toxinas ou até mesmo servindo de barreira física para dificultar a interação com o epitélio intestinal. Os diversos microrganismos que compõem a microbiota são capazes de modular a capacidade vetorial em diversos vetores (Azambuja, Garcia \& Ratcliffe, 2005). Observou-se, por exemplo, que a microbiota do mosquito vetor da malária $A$. gambiae é capaz de modular a presença do $P$. falciparum no inseto, e que a eliminação da microbiota por antibióticos causa um significativo aumento na infecção pelo parasito (Dong, Manfredini \& Dimopoulo, 2009). Há ainda evidências da influência da microbiota no ciclo de vida de parasitos em outros insetos como a mosca tsé-tsé (Weiss \& Aksoy, 2011), que transmite a doença do sono, e também em flebotomíneos (Schlein, Polacheck \& Yuval, 1985). Nestes, alguns microrganismos presentes no tubo digestivo foram recentemente caracterizados (Gouveia et al., 2008). Em L. longipalpis provenientes da gruta da Lapinha (Lagoa Santa, Minas Gerais) foram isoladas diversas espécies de bactérias como: Acinetobacter lowffii, Stenotrophomonas malthophilia, Pseudomonas putida, Flavimonas orizihabitans, Enterobacter cloacae, Klebsiella ozaenae, Bacillus thuringiensis e Staphylococcus spp. (Oliveira et al., 2000). A presença da microbiota em flebotomíneos é potencialmente importante, pois, como observado em P. papatasi, esta pode interferir na transmissão da leishmaniose (Schlein, Polacheck \& Yuval, 1985).

Uma melhor identificação dos microrganismos presentes na microbiota pode, ainda, possibilitar uma nova estratégia no controle da disseminação da leishmaniose. Os microrganismos identificados poderiam ser manipulados geneticamente para produzir algum componente leishmanicida. E também poderiam ser utilizados como potenciais vetores de uma vacina de bloqueio da transmissão da doença (Pidiyar, Polacheck \& Yuval, 2004).

\section{A INTERAÇÃO FLEBOTOMÍNEO-LEISHMANIA}

\section{Adesão da Leishmania ao tubo digestivo do flebotomíneo}

Após o término da digestão e a degradação da MP, para uma infecção efetiva do inseto, a Leishmania necessita aderir às microvilosidades do epitélio intestinal. Algumas moléculas envolvidas nessa adesão já foram identificadas. As formas promastigotas procíclicas apresentam uma intensa cobertura de lipofosfoglicanas (LPGS) com amplas funções (Descoteaux \& Turco, 1999). LPG é uma das moléculas utilizadas como ligante ao epitélio intestinal dos vetores do Velho Mundo (Descoteaux \& Turco; 1999, Kamhawi et al., 2000; Kamhawi et al., 2004). Uma proteína ligadora de galactose (PpGalec) foi identificada como o receptor para L. major em P. papatasi e caracterizada. Essa galectina, presente na superfície do epitélio intestinal voltada para o lúmen, se liga especificamente a resíduos de galactose do LPG de $L$. major, o que contribui para a competência vetorial espécie-específica (Kamhawi et al., 2004). Curiosamente, apenas alguns transcritos dessa galectina, presente em abundância em P. papatasi, foram descritos em L. longipalpis (Jochim et al., 2008; Pitaluga et al., 2009). Isso leva a crer que possam existir outros receptores de L. chagasi em L. longipalpis, considerada permissiva na transmissão de diferentes espécies de Leishmania (Sacks \& Kamhawi, 2001). De fato, demonstrou-se que LPG não é necessária ao desenvolvimento de infecções em vetores permissivos como L. longipalpis e P. arabicus, utilizando infecções com Leishmania mutantes deficientes de LPG (Myskova et al., 2007). Diferentemente dos vetores espécie-específicos, a ligação ao epitélio intestinal dos vetores permissivos parece estar relacionada à presença de glicoproteínas com terminação N-acetil-galactosamina do vetor, possivelmente ligando a algum tipo de lectina na superfície do parasito e permitindo, assim, a ligação com diferentes espécies de leishmânia (Myskova et al., 2007).

\section{Sobrevivência da Leishmania no flebotomíneo}

Como já mencionado, as leishmânias são organismos unicelulares heteroxenos cujo ciclo ocorre em dois diferentes hospedeiros, um mamífero e um inseto flebotomíneo. No mamífero, as leishmânias evoluíram para o parasitismo 
intracelular, em que as formas aflageladas amastigotas habitam e proliferam no interior das estruturas fagolisossomais de macrófagos (Handman \& Bullen, 2002). No inseto vetor, formas flageladas promastigotas colonizam e se multiplicam no interior do trato digestivo. Em ambos os hospedeiros, as leishmânias têm de ser capazes de sobrepujar as barreiras que a fisiologia de cada ambiente opõe à sua colonização. A identificação de moléculas que possibilitem às leishmânias sobreviverem nesses ambientes hostis aos invasores constitui um importante componente para 0 melhor entendimento da biologia do patógeno, da sua relação com cada um dos hospedeiros e para o desenvolvimento de abordagens profiláticas e terapêuticas dessas parasitoses.

Entre as modificações associadas à sobrevivência da Leishmania nos seus vetores artrópodes está a formação de um organizado e denso glicocálice composto por diversos glicoconjugados que formam uma espécie de escudo protetor. A composição molecular desses glicocompostos varia de acordo com a espécie e o estágio de desenvolvimento do parasito (Moody et al., 1993; Guha-Niyogi, Sullivan \& Turco, 2001), sendo que algumas dessas macromoléculas, incluindo vários fosfoglicanos, têm sido relacionadas à virulência de algumas espécies de Leishmania (Turco \& Descoteaux, 1992; Späth et al., 2003).

Os glicofosfoconjugados tanto podem ser secretados como estar presentes na superfície das leishmânias. Os fosfoglicanos têm em comum a presença de unidades dissacarídicas repetidas de Gal(beta1,4)Man(alfa1)- $\mathrm{PO}_{4}$, que podem ser secretados como cadeias fosfoglicanas livres (PG) (Greis et al., 1992) ligados diretamente à superfície da célula por âncoras de glicosilfosfatidilinositol (GPI), como nos LPGs ou ligados a regiões ricas em Ser/Thr de proteínas como a fosfatase ácida secretada (SAP) e os proteofosfoglicanos (PPG) secretados ou de superfície (Ilg, 2000).

Estudos têm evidenciado a participação dos fosfoglicanos na interação entre os patógenos e os seus hospedeiros. o grande número desses compostos nas secreções e superfície dos parasitos sugere que essas moléculas têm relevante papel para a sobrevivência, fixação e posterior colonização dos distintos ambientes por eles habitados.

\section{Interação Leishmania-vetor mediada por lipofosfoglicanos e lectinas}

LPG foi identificado como uma molécula majoritária presente na superfície, incluindo o flagelo, de promastigotas de todas as espécies de Leishmania. Ele se apresenta como um glicocálice filamentoso densamente empacotado. É uma molécula formada por três subunidades: um domínio fosfoglicano (PG) ligado por um hexassacarídeo Glycan core Gal(alfa1,6)Gal(alfa1,3)Galf(beta1,3)[Glc(alfa1)-PO4]Man(alfa1,3)Man(alfa1,4)GlcN(alfa1) a uma âncora lipídica de 1-O-alcil-2-liso-fosfatidilinositol. As moléculas de LPG de Leishmania apresentam polimorfismos intra e interespecíficos relacionados a variações no número de repetições das unidades dissacarídicas de Gal(beta1,4) $\operatorname{Man}\left(\right.$ alfa1) $-\mathrm{PO}_{4}$, presença de ramificações glicídicas e a composição do oligassacarídeo terminal não fosforilado - 0 cap (Turco \& Descoteaux, 1992; McConville \& Ferguson, 1993; Killick-Kendrick, Molineux \& Ashford, 1974).

Com relação à interação entre Leishmania e os seus vetores artrópodes, sabe-se que estudos bioquímicos e genéticos têm associado o LPG à capacidade de adesão seletiva ao epitélio intestinal dos flebotomíneos, de forma a evitar que os parasitos sejam eliminados durante a ejeção do bolo fecal (Sacks \& Kamhawi, 2001; Kamhawi, 2006). Experimentos utilizando L. major e P. papatasi revelaram que a adesão do protozoário ao epitélio intestinal do inseto é controlada por modificações nas moléculas de LPG da superfície dos promastigotas (Pimenta et al., 1994, 1992; Butcher et al., 1996). A liberação dos parasitos ocorrida durante a metaciclogênese é consequência de alterações na composição das moléculas de LPG, as quais se tornam incapazes de se ligar à galectina intestinal (Kamhawi et al., 2004).

A capacidade dos flebotomíneos de suportarem ou não o desenvolvimento de determinadas espécies de Leishmania fez com que os mesmos fossem classificados em dois grupos: os restritos e os permissivos. Vetores restritos são aqueles que permitem somente o desenvolvimento das espécies por eles transmitidas na natureza, como, por exemplo, 
P. papatasi e P. sergenti, que somente transmitem L. major e L. tropica, respectivamente (Kamhawi et al., 2000). Já os permissivos são capazes de transmitir uma ampla gama de espécies de Leishmania. Entre esses podemos relacionar o Phlebotomus halepensis (Sádlová, Hajmová \& Volf, 2003), Phlebotomus argentipes e L. longipalpis (Kamhawi et al., 2000; Pinto-da-Silva et al., 2002; Soares \& Turco, 2003; Pinto-da-Silva et al., 2005). Os mecanismos envolvidos na 'permissividade' de alguns vetores flebotomíneos ainda não foram elucidados e outras moléculas, além do LPG, têm sido propostas como mediadoras desse processo.

L. major mutantes para LPG1, gene codificante para uma glicosiltransferase responsável pela adição de unidades monossacarídicas de galactofuranosil para a cadeia lipofosfoglicana emergente, não apresentam LPG na sua superfície, mas têm níveis normais dos demais glicoconjugados. Como esperado, esses mutantes foram incapazes de se desenvolver no interior de vetores restritos, mas sua capacidade de se estabelecer em vetores permissivos revelou que a colonização do trato digestivo desses vetores não era mediada pela ligação de LPG às lectinas dos flebotomíneos (Secundino et al., 2010; Svárovská et al., 2010). Nesse caso, a adesão de Leishmania ao epitélio intestinal de vetores permissivos parece ser mediada pela presença de glicoproteínas O-ligadas na superfície do epitélio. Essas moléculas se ligariam a compostos semelhantes a lectinas presentes na superfície do parasito (Myskova et al., 2007; Volf \& Myskova, 2007).

o paradigma da aderência descrito para a interação entre L.major e P. papatasi parece estar invertido em espécies permissivas: glicoproteínas de flebotomíneos contendo N-acetil-galactosamina (GalNAc) interagem com moléculas do tipo lectina presentes na superfície do parasito. Entre os candidatos potenciais estão proteínas ligadoras de heparina e as supramencionadas moléculas tipo lectinas, já descritas em várias espécies de Leishmania (Hernandez et al., 1986; Mukhopadhyay et al., 1989; Kock et al., 1997; Svobodová, Bates \& Volf, 1997).

A presença conservada em flebotomíneos permissivos de $\mathrm{N}$-acetil-galactosaminas capazes de se ligar a moléculas da superfície dos parasitos explica o sucesso que algumas espécies de Leishmania têm em colonizar vetores diferentes daqueles que normalmente as transmitem. Um relevante exemplo é a introdução de L. infantum da Europa para a América Latina (L. i. chagasi) (Killick-Kendrick et al., 1980; Maurício, Stothard \& Miles, 2000). No sul da Europa, esse parasito é transmitido para cães e humanos pelo vetor permissivo P. perniciosus. Quando os colonizadores europeus chegaram à América Latina com seus cães infectados, o parasito foi capaz de se desenvolver em L. longipalpis, outro vetor permissivo (Killick-Kendrick, 1999; Killick-Kendrick et al., 1980).

\section{Proteofosfoglicanos}

Como citado anteriormente, a ingestão de sangue pelos vetores das leishmanioses gera respostas fisiológicas no intestino destes organismos, que incluem a síntese da matriz peritrófica, diurese e secreção de enzimas digestivas. No entanto, o parasito tem que sobreviver a vários desafios/insultos no interior do intestino alimentado com sangue. Estudos recentes com mutantes de L. major defectivos para os genes LPG2 ou LPG5A e LPG5B, que codificam para os respectivos transportadores de GDP-Manose e UDP-Galactose, e que são incapazes de sintetizar qualquer um dos compostos glicofosfoconjugados (Späth et al., 2003; 2007), têm evidenciado a participação dessas moléculas na evasão à ação das enzimas digestivas dos vetores flebotomíneos, sejam eles específicos e/ou permissivos. Mutantes LPG1 $1^{-}$de L. major que não expressam LPG foram capazes de resistir à ação das enzimas digestivas dos flebotomíneos, ao passo que os outros mutantes, que não expressam fosfoglicanos, foram incapazes de sobreviver no interior do intestino dos insetos. Esses trabalhos revelaram que moléculas de LPG são incapazes de garantir a sobrevivência de Leishmania no intestino dos flebotomíneos, sendo que a proteção dos parasitos contra as enzimas digestivas é aparentemente mediada por moléculas de proteofosfoglicanos depositados na superfície dos protozoários (Secundino et al., 2010; Svárovská et al., 2010). Fosfoglicanos secretados por promastigotas têm importante papel na transmissão dos patógenos. Essas moléculas se acumulam na porção superior do trato digestivo dos insetos vetores formando uma 
matriz gelatinosa (Rogers, Chance \& Bates, 2002; Bates e Rogers, 2004; Rogers et al., 2004), composta principalmente por proteofosfoglicano filamentoso (fPPG), que preenche o lúmen do intestino torácico, dificultando a ingestão de sangue pelo inseto. Essa dificuldade faz com que o vetor procure se alimentar mais vezes, aumentando as chances de transmissão do parasito.

\section{GP63}

A glicoproteína gp63, também conhecida como leishmaniolisina, é uma metalopeptidase dependente de Zinco localizada em secreções e na superfície das leishmânias. Essa protease foi identificada como um importante fator de virulência, estando relacionada ao sucesso da infecção do hospedeiro vertebrado através de vários mecanismos (Yao, Donelson \& Wilson, 2003). Apesar de a grande maioria dos estudos sobre essa glicoproteína majoritária da superfície de Leishmania se referir à sua ação no hospedeiro vertebrado, pouco se sabe sobre o seu papel na infecção do hospedeiro artrópode pelas formas promastigotas, nas quais a concentração dessa metaloproteinase é maior. Os dados disponíveis até o momento são inconclusivos. Infecções de $P$. dubosqui com mutantes de L. major defectivos em gp63 não apresentaram diferenças na taxa de sobrevivência quando comparadas ao grupo-controle (Joshi et al., 2002). Já estudos com L. amazonensis-L. longipalpis demonstraram que os protozoários que subexpressavam a glicoproteína tiveram menores taxas de infectividade e um menor número de parasitos nos instantes iniciais da infecção, quando comparados ao controle. Entretanto, esse efeito se dissipou em momentos mais tardios da infecção, sugerindo que o papel protetor ocorra no início da infecção (Hajmová et al., 2004). Tais resultados apontam para a necessidade de novos estudos, utilizando-se diferentes pares de patógenos-vetores.

\section{Saliva de Insetos}

Para a obtenção do sangue necessário à sua reprodução, as fêmeas de flebotomíneos introduzem várias vezes a probóscide na pele do hospedeiro, causando lacerações de tecidos e capilares que levam à formação de eritemas de onde as mesmas se alimentam. Nesse processo, a saliva dos insetos, injetada conjuntamente com as leishmânias durante a sucção do sangue, tem relevante papel na aquisição de alimento e na transmissão do parasito. A saliva de insetos hematófagos é constituída por uma rica mistura de moléculas com propriedades farmacológicas capazes de alterar as respostas fisiológicas dos hospedeiros vertebrados às injúrias das picadas.

Processos hemostáticos como a cascata de coagulação sanguínea, vasoconstrição, fibrinólise e agregação plaquetária, que deveriam ser desencadeados em consequência das lesões provocadas pelas picadas dos flebotomíneos, são inibidos pela presença de moléculas anticoagulantes, vasodilatadoras e de inibidores de agregação plaquetária, que garantem a manutenção do fluxo sanguíneo, necessário para que o inseto obtenha alimento suficiente para amadurecer os seus ovos (Valenzuela, Rowton \& Ribeiro, 1999; Ribeiro, 1995). Além de substâncias anticoagulantes, a saliva também apresenta moléculas capazes de modular as respostas inflamatórias e imunológicas do hospedeiro (Kamhawi, 2000; Ribeiro \& Francischetti, 2003). Essas propriedades da saliva alteram a fisiologia local do hospedeiro e criam um microambiente propício à alimentação do inseto e à infecção pela Leishmania.

\section{A saliva como potencializador da infecção por Leishmania}

A importância da saliva na transmissão das leishmanioses foi evidenciada por Titus e Ribeiro em 1988, quando camundongos infectados conjuntamente com L. major e extrato salivar de L. longipalpis apresentaram lesões mais extensas e com maior número de parasitos quando comparadas aos controles infectados sem saliva. Resultados semelhantes foram observados com camundongos inoculados com L. major na presença de extrato salivar de P. papatasi 
(Mbow et al., 1998; Belkaid et al., 1998). Recentemente, Laurenti e colaboradores (2009) estudaram o efeito da saliva de duas populações distintas de L. longipalpis sobre o desenvolvimento da infecção por $L$. amazonensis. Camundongos $\mathrm{BALB} / \mathrm{c}$ infectados na presença de extrato salivar de L. longipalpis capturados no campo ou oriundos de colônias mantidas em laboratório foram comparados com animais infectados sem saliva. O resultado demonstrou que ambos os extratos salivares foram capazes de estimular a infecção por L. amazonensis quando comparados ao controle, sendo que os camundongos que foram infectados na presença da saliva das fêmeas colonizadas apresentaram as lesões mais extensas e com maior número de patógenos.

Estudos histopatológicos e morfométricos indicaram diferenças na dinâmica do processo inflamatório das lesões cutâneas dos camundongos infectados com Leishmania na presença e ausência dos extratos salivares. As lesões das cobaias infectadas sem o extrato salivar apresentaram um maior recrutamento de neutrófilos, quando comparadas às cobaias infectadas concomitantemente aos extratos salivares. As lesões dos camundongos infectados com saliva de animais colonizados foram as que apresentaram o maior percentual de macrófagos. Sabe-se que durante as primeiras horas após a inoculação da Leishmania ocorre um afluxo leucocitário ao local da picada, com o predomínio de neutrófilos. Com o transcorrer da infecção os neutrófilos são progressivamente substituídos por células mononucleares, ocasionando o estabelecimento de um infiltrado mononuclear por volta do sétimo dia. O maior afluxo de macrófagos para a lesão potencializa o estabelecimento da infecção, uma vez que Leishmania é capaz de parasitar essas células. O fracionamento eletroforético das proteínas presentes na saliva dessas populações revelou diferenças qualitativas e quantitativas entre os extratos de insetos selvagens e de insetos colonizados. Essa diferença na composição molecular da saliva desses grupos provavelmente deve-se à isogenia da população, decorrente do isolamento e da seleção dos indivíduos melhor adaptados ao cativeiro. Isso sugere que, na população selvagem, a composição da saliva e a capacidade de veiculação de Leishmania variam entre os indivíduos de uma mesma população.

\section{A saliva como indutor de resistência à infecção por Leishmania}

De forma aparentemente contraditória, observa-se que a saliva também apresenta propriedades imunorregulatórias que levam à resistência do hospedeiro contra os parasitos. Trabalhos demonstraram que a exposição a picadas de flebotomíneos não infectados influenciam na epidemiologia das leishmanioses devido à ativação do sistema imune celular e humoral do hospedeiro (Barral et al., 2000; Valenzuela et al., 2001; Rohousová et al., 2005; Gomes et al., 2007). Estudos epidemiológicos mostraram que habitantes de áreas não endêmicas, que nunca haviam sido expostos a picadas de flebotomíneos, apresentavam um maior risco de desenvolver formas clínicas mais severas de leishmanioses. Estudos imunológicos em área endêmica de leishmaniose visceral (LV) revelaram que seus habitantes apresentavam anticorpos do tipo IgG contra antígenos presentes na saliva de L. longipalpis (Barral et al., 2000). Outros autores demonstraram que indivíduos com resposta humoral contra antígenos salivares também apresentavam resposta celular contra L. chagasi (Gomes et al., 2002). Trabalhos têm evidenciado que a repetida exposição a picadas de flebotomíneos, ou ao homogenato de glândulas salivares desses insetos, protege os camundongos contra a infecção por L. major (Belkaid et al., 1998; Kamhawi et al., 2000). Interessantemente, a alimentação de L. longipalpis em animais previamente imunizados com picadas ou tecidos de tubo digestivo desse inseto levaram a vários efeitos biológicos nos próprios insetos, como diminuição de oviposição e mortalidade precoce (Vilela et al., 2006).

A resposta imune aos antígenos salivares de flebotomíneos é espécie-específica. O soro de animais picados por P. papatasi não reage com antígenos de outras espécies de Phlebotomus (Volf \& Rohousová, 2001) e o soro de humanos picados por $P$. papatasi não reage contra antígenos da saliva de L. longipalpis (Rohousová, Volf \& Lipoldová, 2005). Dessa forma, podemos supor que anticorpos contra antígenos salivares de flebotomíneos possam servir como um importante marcador epidemiológico de exposição aos vetores em áreas endêmicas. Nessas regiões o grau de exposição do hospedeiro ao inseto é um importante fator epidemiológico que pode ser usado para estimar o 
risco de transmissão dos parasitos, bem como o efeito que medidas de controle como o uso de inseticidas estão tendo sobre o tamanho da população de vetores.

A ação dos componentes da saliva de flebotomíneos durante o início da interação entre o parasito e o sistema imunológico do hospedeiro está intimamente relacionada à evolução da doença e à proteção contra o parasito. Desse modo, a caracterização dos componentes salivares é essencial para o melhor entendimento da patogênese da doença e para o desenvolvimento de novas estratégias que impossibilitem a transmissão do parasito.

Entre as principais moléculas identificadas na saliva de L. longipalpis está um peptídeo de 6,8 KDa com potente atividade vasodilatadora que também apresenta propriedades imunomodulatórias: o fator indutor de eritema (EIF), conhecido como maxadilan (Ribeiro et al., 1989). A participação de maxadilan na transmissão das leishmanioses foi demonstrada quando camundongos inoculados com L. major, na presença de saliva ou de maxadilan recombinante, tiveram a infecção exacerbada em relação aos controles. Além disso, camundongos vacinados contra maxadilan ficaram protegidos da infecção com L. major (Morris et al., 2001).

Vários antígenos presentes na saliva dos flebotomíneos têm sido testados na busca de vacinas que protejam os hospedeiros contra a infecção por Leishmania. Gomes e colaboradores, em 2008, imunizaram camundongos com um plasmídeo que codificava para um peptídeo de $11 \mathrm{KDa}$ presente na saliva de L. longipalpis, induzindo proteção contra a coinoculação de $L$. chagasi e extrato salivar. A necessidade de melhor caracterizar os antígenos salivares de flebotomíneos fica evidente ao observarmos os resultados obtidos com a imunização de camundongos com duas proteínas salivares de P. papatasi - PpSP15 e PpSP44. Os camundongos imunizados com a proteína PpSP15 apresentaram proteção contra a infecção por L. major, enquanto os imunizados com a proteína PpSP44 tiveram o agravamento da infecção (Oliveira et al., 2008). O soro de indivíduos expostos a picadas de L. longipalpis reconhecem vários antígenos imunogênicos (Gomes et al., 2002).

\section{TROCA DE MATERIAL GENÉTICO ENTRE LEISHMÂNIAS}

Desde a descoberta dos agentes etiológicos das leishmanioses debate-se se a origem das populações de Leishmania poderia ser clonal ou se poderiam existir mecanismos de intercâmbio genético. Trocas de material genético já foram descritas em outros tripanossomatídeos. Genótipos híbridos foram observados em moscas tsé-tsé durante a cotransmissão de duas variedades de Trypanosoma brucei (Jenni et al., 1986) e em células de mamíferos após coinfecção com dois clones de Trypanosoma cruzi (Gaunt et al., 2003). Alguns estudos têm registrado a ocorrência de populações hibrídas de Leishmania na natureza. Foram isolados de pacientes imunodeprimidos parasitos apresentando material genético de duas espécies divergentes, $L$. infantum e L. major, transmitidas por vetores diferentes e que apresentam distinta distribuição geográfica (Ravel et al., 2006).

Recentemente, Akopyants e colaboradores (2009) demonstraram de forma inequívoca o intercâmbio genético entre distintas populações de leishmânias. Fêmeas de $P$. duboscqi foram infectadas com pares de diferentes parasitos transgênicos de L. major, cada um deles resistente a uma única droga. Posteriormente, as fêmeas coinfectadas se alimentaram diretamente em camundongos. Após o período de desenvolvimento, os parasitos foram reisolados e os que apresentavam resistência a duas drogas foram selecionados. As leishmânias transmitidas aos camundongos pelos insetos também foram isoladas e selecionadas para dupla resistência. Ao final, 18 clones com dupla resistência foram isolados em ambas as culturas. $\mathrm{O}$ fato de a Leishmania poder promover trocas gênicas tem relevante importância epidemiológica, principalmente a potencial capacidade que organismos híbridos teriam de infectar diferentes vetores, o que aumentaria a sua capacidade de dispersão e transmissão. Além disso, faz-se necessário investigar a participação do inseto nesse processo. Para tanto, dados a respeito do genoma desses vetores são de fundamental importância na busca de moléculas que participem de tal processo. 


\section{CONCLUSÃO E PERSPECTIVAS}

Assim como para outros artrópodes transmissores de doenças, existe um grande interesse no desenvolvimento de abordagens alternativas para o controle das leishmanioses que envolvam o controle de vetores ou a interferência na interação vetor-parasito.

Uma das abordagens alternativas propostas é o uso de vacinas bloqueadoras de transmissão. Em vetores da malária vários alvos para o desenvolvimento dessas vacinas, tanto no mosquito como no parasito, já foram identificados (Saul, 2007; Lavazec \& Bourgouin, 2008) e testados, com resultados promissores (Miura et al., 2007; Mlambo, Maciel \& Kumar, 2007; Wu et al., 2008). Poucos estudos similares existem em leishmaniose. Num desses estudos, $P$. dubosqi foram alimentados em camundongos previamente imunizados com gp63, lisados de parasitos ou LPG, e em seguida alimentados em animais infectados com L. major. Observou-se que os parasitos tinham uma sobrevivência e metaciclogênese diminuídas em insetos previamente alimentados em animais imunizados, mais acentuadamente com LPG (Tonui et al., 2001a, 2001b). Quando tais insetos foram usados para infectar novos camundongos, verificouse uma infecção mais leve em animais infectados com insetos previamente imunizados (Tonui et al., 2001b), demonstrando assim o potencial de bloqueio de transmissão dessas moléculas.

Mais recentemente, a capacidade potencial de bloquear transmissão de uma vacina desenvolvida contra leishmaniose visceral canina foi investigada. Tanto em estudos de inibição de adesão a intestinos médio de $L$. longipalpis dissecados, como em estudos de alimentação artificial de insetos na presença ou não do antígeno, ou de soro de cães vacinados, viu-se uma significativa diminuição de infecção dos insetos por L. donovani e L. chagasi (Saraiva et al., 2006). Isso indica a viabilidade da inclusão de antígenos focados na inibição da transmissão da leishmaniose em vacinas que visem a proteção contra a doença, seja em humanos ou em cães.

Para a identificação de genes-alvo no vetor de interesse, para o potencial desenvolvimento de estratégias de intervenção na transmissão das leishmanioses, estudos funcionais são essenciais. Flebotomíneos transgênicos ainda não foram obtidos, em grande parte, devido ao seu pequeno porte e fragilidade. Uma alternativa em largo uso na caracterização funcional de vários genes em outros vetores como mosquitos, é o silenciamento gênico por mecanismos de RNA de interferência (RNAi). Uma vez mais, em flebotomíneos essa abordagem é dificultada pelo pequeno tamanho dos insetos e sua fragilidade. Entretanto, resultados recentes são promissores. O primeiro estudo publicado eliminou a expressão de um gene de xantina deshidrogenase em L. longipalpis, levando a uma significativa redução da produção de urato e a uma sobrevivência diminuída dos insetos (Sant'anna et al., 2008). Uma segunda publicação pelo mesmo grupo (2009) mostrou que o silenciamento de um gene de tripsina, levando à diminuição de sua transcrição e atividade enzimática, causou um aumento da sobrevivência de L. mexicana neste vetor. Recentemente também um gene de quitinase foi silenciado em P. papatasi e implicado no sucesso da infecção deste vetor por L. major (Coutinho -Abreu et al., 2010). E, finalmente, nosso grupo demonstrou a participação da via de imunidade inata IMD na infecção de L. longipalpis por Leishmania, mediante o silenciamento do regulador negativo Caspar (Telleria et al., 2012). A expectativa é de grandes avanços nessa área num futuro próximo.

Outro fator significativo para o avanço dos estudos moleculares da interação flebotomíneo-Leishmania é o progresso dos trabalhos de sequenciamento dos genomas de vetores do Velho Mundo e de L. longipalpis, que deverão estar completos num curto espaço de tempo. Estas e outras abordagens de ponta deverão levar nossos conhecimentos sobre essa interação a outros níveis. 


\section{REFERÊNCIAS}

AGUIAR, G. M. \& MEDEIROS, W. M. Distribuição regional e habitats das espécie flebotomíneos do Brasil. In: RANGEL, E. F. \& LAINSON, R. (Orgs.). Flebotomíneos do Brasil. Rio de Janeiro: Editora Fiocruz, 2003.

AKOPYANTS, N. S. et al. Demonstration of genetic exchange during cyclical development of Leishmania in the sand fly vector. Science, 324: 265-268, 2009.

ARAKI, A. S. et al. Molecular and behavioral differentiation among Brazilian populations of Lutzomyia longipalpis (Diptera: Psychodidae: Phlebotominae). PLoS Neglected Tropical Diseases, 3: e365, 2009.

AZAMBUJA, P.; GARCIA, E. S. \& RATCLIFFE, N. A. Gut microbiota and parasite transmission by insect vectors. Trends in Parasitology, 21: 568-572, 2005.

BARRAL, A. et al. Human immune response to sand fly salivary gland antigens: a useful epidemiological marker? The American Journal of Tropical Medicine and Hygiene, 62: 740-745, 2000.

BATES, P. A. \& ROGERS, M. E. New Insights into the Developmental Biology and Transmission Mechanisms of Leishmania. Current Molecular Medicine, 4: 601-609, 2004.

BAUZER, L. G. et al. Lutzomyia longipalpis in Brazil: a complex or a single species? Memórias do Instituto Oswaldo Cruz, 102: 1-12, 2007.

BELKAID, Y. et al. Development of a natural model of cutaneous leishmaniasis: powerful effects of vector saliva and saliva preexposure on the long-term outcome of Leishmania major infection in the mouse ear dermis. The Journal of Experimental Medicine, 188: 1.941-1.953, 1998.

BOROVSKY, D. \& SCHLEIN, Y. Trypsin and chymotrypsin-like enzymes of the sandfly Phlebotomus papatasi infected with Leishmania and their possible role in vector competence. Medical and Veterinary Entomology, 1:235-242, 1987.

BOULANGER, N. et al. Characterization of a defensin from the sand fly Phlebotomus duboscqi induced by challenge with bacteria or the protozoan parasite Leishmania major. Infection and Immunity, 72: 7.140-7.146, 2004.

BRAZIL, R. P.; MORTON, I. E. \& WARD, R. D. Notes of the feeding habits of Lutzomyia (Nyssomyia) whitmani (Diptera Psychodidae) in Ceara State, northeast Brazil. Memórias do Instituto Oswaldo Cruz, 86: 497-498, 1991.

BUTCHER, B. A. et al. Deficiency in beta 1,3-galactosyltransferase of a Leishmania major lipophosphoglycan mutant adversely influences the Leishmania-sandfly interaction. The Journal of Biological Chemistry, 271: 20.573-20.579, 1996.

CHANiotiS, B. N. The biology of California Phlebotomus (Diptera: Psychodidae) under laboratory conditions. Journal of Medical Entomology, 4: 221-233, 1967.

CHAPMAN, R. F. Structure of the digestive system. In: KERKUT, G. A. \& GILBERT, L. I. (Eds.). Comprehensive Insect Physiology, Biochemistry and Pharmacology. Oxford: Pergamon Press, 1985.

CIRIMOTICH, C. M.; RAMIREZ, J. L. \& DIMOPOULOS, G. Native microbiota shape insect vector competence for human pathogens. Cell Host and Microbe, 10: 307-310, 2011.

COUTINHO-ABREU, I. V. et al. Targeting the midgut secreted PpChit1 reduces Leishmania major development in its natural vector, the sand fly Phlebotomus papatasi. PLoS Neglected Tropical Diseases, 4: e901, 2010.

DEANE, L. M. \& DEANE, M. P. Sobre a biologia do Phlebotomus longipalpis, transmissor da leishmaniose visceral, em uma zona endêmica do Estado do Ceará. I. distribuição, predominância e variação estacional. Revista Brasileira de Biologia, 15: 83-95, 1955.

DESCOTEAUX, A. \& TURCO, S. J. Glycoconjugates in Leishmania infectivity. Biochimica et Biophysica Acta, 1.455: 341-352, 1999.

DEVENPORT, M. et al. Identification of the Aedes aegypti peritrophic matrix protein AeIMUCI as a heme-binding protein. Biochemistry, 45: 9.540-9.549, 2006.

DILLON, R. J. \& DILLON, V. M. The gut bacteria of insects: nonpathogenic interactions. Annual Review of Entomology, 49: 71-92, 2004. 
DILLON, R. J. \& LANE, R. P. Influence of Leishmania infection on blood-meal digestion in the sandflies Phlebotomus papatasi and P. langeroni. Parasitology Research, 79: 492-496, 1993.

DILLON, R. J. et al. Analysis of ESTs from Lutzomyia longipalpis sand flies and their contribution toward understanding the insect-parasite relationship. Genomics, 88: 831-840, 2006.

DONG, Y.; MANFREDINI, F. \& DIMOPOULOS, G. Implication of the mosquito midgut microbiota in the defense against malaria parasites. PLoS Pathogens, 5(5): 1-10, 2009.

DOS SANTOS, S. O. et al. Incrimination of Lutzomyia cruzi as a vector of American visceral leishmaniasis. Medical and Veterinary Entomology, 12: 315-317, 1998.

ESCHENLAUER, S. et al. Influence of parasite encoded inhibitors of serine peptidases in early infection of macrophages with Leishmania major. Cellular Microbiology, 11: 106-120, 2009.

GAUNT, M. W. et al. Mechanism of genetic exchange in American trypanosomes. Nature, 421: 936-939, 2003.

GOMES, R. B. et al. Seroconversion against Lutzomyia longipalpis saliva concurrent with the development of anti-Leishmania chagasi delayed-type hypersensitivity. The Journal of Infectious Diseases, 186: 1.530-1.534, 2002.

GOMES, R. B. et al. Antibodies against Lutzomyia longipalpis saliva in the fox Cerdocyon thous and the sylvatic cycle of Leishmania chagasi. Transactions of the Royal Society of Tropical Medicine and Hygiene, 101: 127-133, 2007.

GOMES, R. B. et al. Immunity to a salivary protein of a sand fly vector protects against the fatal outcome of visceral leishmaniasis in a hamster model. Proceedings of the National Academy of Sciences of the USA, 105: 7.845-7.850, 2008.

GONTIJO, N. F. et al. Lutzomyia longipalpis: pH in the gut, digestive glycosidases, and some speculations upon Leishmania development. Experimental Parasitology, 90: 212-219, 1998.

GONZALEZ-CERON, L. et al. Bacteria in midgutsof field-collected Anopheles albimanus block Plasmodium vivax sporogonic development. Journal of Medical Entomology, 40: 371-374, 2003.

GOUVEIA, C. et al. Study on the bacterial midgut microbiota associated to different Brazilian populations of Lutzomyia longipalpis (Lutz \& Neiva) (Diptera: Psychodidae). Neotropical Entomology, 37: 597-601, 2008.

GREIS, K. D. et al. Purification and characterization of an extracellular phosphoglycan from Leishmania donovani. Journal of Biological Chemistry, 267: 5.876-5.881, 1992.

GRUBHOFFER, L.; HYPSA, V. \& VOLF, P. Lectins (hemagglutinins) in the gut of the important disease vectors. Parasite, 4: 203-216, 1997.

GUHA-NIYOGI, A.; SULLIVAN, D. R. \& TURCO, S. J. Glycoconjugate structures of parasitic protozoa. Glycobiology, 11: 45R-59R, 2001.

HAJMOVÁ, M. et al. Down-regulation of gp63 in Leishmania amazonensis reduces its early development in Lutzomyia longipalpis. Microbes and Infection, 6: 646-649, 2004.

HANDMAN, E. \& BULLEN, D. V. R. Interaction of Leishmania with the host macrophage. Trends in Parasitology, 18: 332-334, 2002.

HERnANDEZ, A. G. et al. The localization of a lectin-like component on the Leishmania cell surface. Molecular Biology Reports, 11: 149-153, 1986.

ILG, T. Proteophosphoglycans of Leishmania. Parasitology Today, 16: 489-497, 2000.

JENNI, L. et al. Hybrid formation between African trypanosomes during cyclical transmission. Nature, 1986 322:173-5.

JOCHIM, R. C. et al. The midgut transcriptome of Lutzomyia longipalpis: comparative analysis of cDNA libraries from sugarfed, blood-fed, post-digested and Leishmania infantum chagasi-infected sand flies. BMC Genomics, 9: 15, 2008.

JOSHI, P. B. et al. Targeted gene deletion in Leishmania major identifies leishmanolysin (GP63) as a virulence factor. Molecular and Biochemical Parasitology, 120: 33-40, 2002. 
KAMHAWI, S. The biological and immunomodulatory properties of sand fly saliva and its role in the establishment of Leishmania infections. Microbes and Infection, 2: 1.765-1.773, 2000.

KAMHAWI, S. Phlebotomine sand flies and Leishmania parasites: friends or foes? Trends in Parasitology, 22: 439-445, 2006.

KAMHAWI, S. et al. The vectorial competence of Phlebotomus sergenti is specific for Leishmania tropica and is controlled by species-specific, lipophosphoglycan-mediated midgut attachment. Parasitology, 121: 25-33, 2000.

KAMHAWI, S. et al. A role for insect galectins in parasite survival. Cell, 119: 329-341, 2004.

KILLICK-KENDRICK, R. The biology and control of phlebotomine sandflies. Clinics in Dermatology, 17: 279-289, 1999.

KILLICK-KENDRICK, R.; MOLYNEUX, D. H. \& ASHFORD, R. W. Ultrastructural observations on the attachment of Leishmania in the sandfly. Transactions of the Royal Society of Tropical Medicine and Hygiene, 68: 269, 1974.

KILLICK-KENDRICK, R. et al. Possible origins of Leishmania chagasi. Annals of Tropical Medicine and Parasitology, 74: 563$565,1980$.

KLEIN, U. The insect V-ATPase, a plasma membrane proton pump energizing secondary active transporting epithelia. The Journal of Experimental Biology, 172: 345-354, 1992.

KOCK, N. P. et al. Receptors for carbohydrate ligands incuding heparin on the cell surface of Leishmania and other trypanosomatids. Tropical Medicine and International Health, 2: 863-874, 1997.

LAINSON, R.; RYAN, L. \& SHAW, J. J. Infective stages of Leishmania in the sandfly vector and some observations on the mechanism of transmission. Memórias do Instituto Oswaldo Cruz, 82: 421-424, 1987.

LAURENTI, M. D. et al. Effects of salivary gland homogenate from wild-caught and laboratory-reared Lutzomyia longipalpis on the evolution and immunomodulation of Leishmania (Leishmania) amazonensis infection. Scandinavian Journal of Immunology, 70: 389-395, 2009.

LEHANE, M. Biology of Blood-Sucking Insects. London: Haper-Collins Academic, 1991.

MAURÍCIO, I. L.; STOTHARD, J. R. \& MILES, M. A. The strange case of Leishmania chagasi. Parasitology Today, 16: 188-189, 2000.

MBOW, M. L. et al. Phlebotomus papatasi sand fly salivary gland lysate down-regulates a Th1, but up-regulates a Th2, response in mice infected with Leishmania major. The Journal of Immunology, 161: 5.571-5.577, 1998.

McCONVILLE, M. J. \& FERGUSON, M. A. The structure, biosynthesis and function of glycosylated phosphatidylinositols in the parasitic protozoa and higher eukaryotes. The Biochemical Journal, 294: 305-324, 1993.

MIURA, K. et al. Transmission-blocking activity induced by malaria vaccine candidates Pfs25/Pvs25 is a direct and predictable function of antibody titer. Malaria Journal, 6: 107, 2007.

MLAMBO, G.; MACIEL, J. \& KUMAR, N. Murine model for assessment of Plasmodium falciparum transmission-blocking vaccine using transgenic Plasmodium berghei parasites expressing the target antigen Pfs25 2008. Infection and Immunity, 76: 2.018-2.024, 2007.

MOODY, S. F. et al. The structure of Leishmania major amastigote lipophosphoglycan. The Journal of Biological Chemistry, 268: 18.457-18.466, 1993.

MORRIS, R. V. et al. Sandfly maxadilan exacerbates infection with Leishmania major and vaccinating against it protects against L. major infection. The Journal of Immunology, 167: 5.226-5.230, 2001.

MOSKALYK, L. A.; OO, M. M. \& JACOBS-LORENA, M. Peritrophic matrix proteins of Anopheles gambiae and Aedes aegypti. Insect Molecular Biology, 5: 261-268, 1996.

MUKHOPADHYAY, N. K. et al. Heparin binds to Leishmania donovani promastigotes na inhibtis protein phosphorylation. The Biochemical Journal, 264: 517-525, 1989.

MYSKOVA, J. et al. A lipophosphoglycan-independent development of Leishmania in permissive sand flies. Microbes and Infection, 9: 317-324, 2007. 
NELSON, N. A journey from mammals to yeast with vacuolar H+ATPase (V-ATPase). Journal of Bioenergetics and Biomembranes, 35: 281-289, 2003.

OLIVEIRA, F. et al. Immunity to distinct sand fly salivary proteins primes the anti-Leishmania immune response towards protection or exacerbation of disease. PLoS Neglected Tropical Diseases, 2: e226, 2008.

OLIVEIRA, S. M. et al. Prevalence of microbiota in the digestive tract of wild females of Lutzomyia longipalpis (Lutz \& Neiva, 1912) (Diptera: Psychodidae). Revista da Sociedade Brasileira de Medicina Tropical, 33: 319-322, 2000.

PIDIYAR, V. J. et al. Studies on cultured and uncultured microbiota of wild Culex quinquefasciatus mosquito midgut based on 16s ribosomal RNA gene analysis. The American Journal of Tropical Medicine and Hygiene, 70: 597-603, 2004.

PIMENTA, P. F. P.; SECUNDINO, N. F. C. \& NIEVES BLANCO, E. Interação da Leishmania: hospedeiro invertebrado. In: RANGEL, E. F. \& LAINSON, R. (Orgs.). Flebotomíneos do Brasil. 1. ed. Rio de Janeiro: Editora Fiocruz, 2003.

PIMENTA, P. F. et al. Stage-specific adhesion of Leishmania promastigotes to the sandfly midgut. Science, 256: 1812-1815, 1992.

PIMENTA, P. F. et al. Evidence that the vectorial competence PF phlebotomine sanflies for different species of Leishmania is controled by structural polymorphisms in the surface lipophosphoglycan. Proceedings of the National Academy of Sciences of the USA, 91: 9.155-9.159, 1994.

PIMENTA, P. F. et al. A novel role for the peritrophic matrix in protecting Leishmania from the hydrolytic activities of the sand fly midgut. Parasitology, 115: 359-369, 1997.

PINTO-DA-SILVA, L. H. et al. Leishmania (Viannia) braziliensis metacyclic promastigotes purified using Bauhinia purpurea lectin are complement resistant and highly infective for macrophages in vitro and hamsters in vivo. International Journal for Parasitology, 32: 1.371-1.377, 2002.

PINTO-DA-SILVA, L. H. et al. The 3A1-La monoclonal antibody reveals key features of Leishmania (L) amazonensis metacyclic promastigotes and inhibits procyclics attachment to the sand fly midgut. International Journal for Parasitology, 35: 757 $764,2005$.

PITALUGA, A. N. et al. EST sequencing of blood-fed and Leishmania-infected midgut of Lutzomyia longipalpis, the principal visceral leishmaniasis vector in the Americas. Mol Genet Genomics, 282: 307-317, 2009.

PUMPUNI, C. B. et al. Bacterial population dynamics in three anopheline species: the impact on Plasmodium sporogonic development. The American Journal of Tropical Medicine and Hygiene, 54: 214-218, 1996.

RAMALHO-ORTIGÃO, J. M. \& TRAUB-CSEKÖ, Y. M. Molecular characterization of Llchit1, a midgut chitinase cDNA from the leishmaniasis vector Lutzomyia longipalpis. Insect Biochemistry and Molecular Biology, 33: 279-287, 2003.

RAMALHO-ORTIGÃO, J. M. et al. Characterization of constitutive and putative differentially expressed mRNAs by means of expressed sequence tags, differential display reverse transcriptase-PCR and randomly amplified polymorphic DNA-PCR from the sand fly vector Lutzomyia longipalpis. Memórias do Instituto Oswaldo Cruz, 96: 105-111, 2001.

RAMALHO-ORTIGÃO, J. M. et al. Exploring the midgut transcriptome of Phlebotomus papatasi: comparative analysis of expression profiles of sugar-fed, blood-fed and Leishmania-major-infected sandflies. BMC Genomics, 8: 300, 2007 a.

RAMALHO-ORTIGÃO, J. M. et al. Cloning and characterization of a V-ATPase subunit C from the American visceral leishmaniasis vector Lutzomyia longipalpis modulated during development and blood ingestion. Memórias do Instituto Oswaldo Cruz, 102: 509-515, 2007b.

RANGEL, E. F. et al. Biology of Lutzomyia intermedia Lutz \& Neiva, 1912 and Lutzomyia longipalpis Lutz \& Neiva, 1912 (Diptera, Psychodidae), under experimental conditions. I. Feeding aspects of larvae and adults. Memórias do Instituto Oswaldo Cruz, 81: 431-438, 1986.

RAVEL, C. et al. First report of genetic hybrids between two very divergent Leishmania species: Leishmania infantum and Leishmania major. International Journal for Parasitology, 36: 1.383-1.388, 2006.

READY, P. D. Factors affecting egg production of laboratory-bred Lutzomyia longipalpis (Diptera: Psychodidae). Journal of Medical Entomology, 16: 413-423, 1979. 
RIBEIRO, J. M. Blood-feeding arthropods: live syringes or invertebrate pharmacologists? Infectious Agents and Disease, 4: 143-152, 1995.

RIBEIRO, J. M. \& FRANCISCHETTI, I. M. Role of arthropod saliva in blood feeding: sialome and post-sialome perspectives. Annual Review of Entomology, 48: 73-88, 2003.

RIBEIRO, J. M. et al. Anovel vasodilatory peptide from the salivary glands of the sand fly Lutzomyia longipalpis. Science, 243: 212-214, 1989.

RICHARDS, A. G. \& RICHARDS, P. A. The peritrophic membranes of insects. Annual Review of Entomology, 22: 219-240, 1977.

ROGERS, M. E.; CHANCE, M. L. \& BATES, P. A. The role of promastigote secretory gel in the origin and transmission of the infective stage of Leishmania mexicana by the sandfly Lutzomyia longipalpis. Parasitology, 124: 495-507, 2002.

ROGERS, M. E. et al. Transmission of cutaneous leishmaniasis by sand flies is enhanced by regurgitation of fPPG. Nature, 430: 463-467, 2004.

ROHOUSOVÁ, I.; VOLF, P. \& LIPOLDOVÁ, M. Modulation of murine cellular immune response and cytokine production by salivary gland lysate of three sand fly species. Parasite Immunology, 27: 469-473, 2005.

ROHOUSOVÁ, I. et al. Detection of species-specific antibody response of humans and mice bitten by sand flies. Parasitology, 30: 493-499, 2005.

SACKS, D. \& KAMHAWI, S. Molecular aspects of parasite-vector and vector-host interactions in leishmaniasis. Annual Review of Microbiology, 55: 453-483, 2001.

SÁdLOVÁ, J.; HAJMOVÁ, M. \& VOLF, P. Phlebotomus (Adlerius) halepensis vector competence for Leishmania major and Le. tropica. Medical and Veterinary Entomology, 17: 244-250, 2003.

SANT'ANNA, M. R. et al. Gene silencing in phlebotomine sand flies: Xanthine dehydrogenase knock down by dsRNA microinjections. Insect Biochemistry and Molecular Biology, 38: 652-660, 2008.

SANT'ANNA, M. R. et al. Inhibition of trypsin expression in Lutzomyia longipalpis using RNAi enhances the survival of Leishmania. Parasites and Vectors, 2: 62, 2009.

SARAIVA, E. M. et al. The FML-vaccine (Leishmune) against canine visceral leishmaniasis: a transmission blocking vaccine. Vaccine, 24: 2.423-2.431, 2006.

SAUL, A. Mosquito stage, transmission blocking vaccines for malaria. Current Opinion in Infectious Diseases, 20: 476481, 2007.

SCHLEIN, Y. \& JACOBSON, R. L. Resistance of Phlebotomus papatasi to infection with Leishmania donovani is modulated by components of the infective bloodmeal. Parasitology, 117: 467-473, 1998.

SCHLEIN, Y.; JACOBSON, R. L. \& MESSER, G. Leishmania infections damage the feeding mechanism of the sandfly vector and implement parasite transmission by bite. Proceedings of the National Academy of Sciences of the USA, 89: 9.944$9.948,1992$.

SCHLEIN, Y.; POLACHECK, I. \& YUVAL, B. Mycoses, bacterial infections and antibacterial activity in sandflies (Psychodidae) and their possible role in the transmission of leishmaniasis. Parasitology, 90: 57-66, 1985.

SCHLEIN, Y. et al. Vector compatibility of Phlebotomus papatasi dependent on differentially induced digestion. Acta Tropica, 40: 65-70, 1983.

SECUNDINO, N. et al. Proteophosphoglycan confers resistance of Leishmania major to midgut digestive enzymes induced by blood feeding in vector sand flies. Cellular Microbiology, 12: 906-918, 2010.

SOARES, R. P. \& TURCO, S. J. Lutzomyia longipalpis (Diptera: Psychodidae: Phlebotominae): a review. Anais da Academia Brasileira de Ciências, 75(3): 301-330, 2003.

SPÄTH, G. F. et al. Persistence without pathology in phosphoglycan-deficient Leishmania major. Science, 301: 1.241-1.243, 2003. 
SPÄTH, G. F. et al. Two functionally divergent UDP-Gal nucleotide sugar transporters participate in phsphoglycan synthesis in Leishmania major. The Journal of Biological Chemistry, 282: 14.006-14.017, 2007.

SPERANÇA, M. A. \& CAPURRO, M. L. Perspectives in the control of infectious diseases by transgenic mosquitoes in the postgenomic era: a review. Memórias do Instituto Oswaldo Cruz, 102: 425-433, 2007.

STIERHOF, Y. D. et al. Filamentous proteophosphoglycan secreted by Leishmania promastigotes forms gel-like threedimensional networks that obstruct the digestive tract of infected sandfly vectors. European Journal of Cell Biology, 78(10): 675-689, 1999.

SVÁROVSKÁ, A. et al. Leishmania major glycosylation mutants require phosphoglycans (lpg2-) but not lipophosphoglycan (lpg1-) for survival in permissive sand fly vectors. PLoS Neglected Tropical Diseases, 4: e580, 2010.

SVOBODOVÁ, M.; BATES, P. A. \& VOLF, P. Detection of lectin activity in Leishmania promastigotes and amastigotes. Acta Tropica, 68: 23-35, 1997.

TELLERIA, E. L. et al. Constitutive and blood meal-induced trypsin genes in Lutzomyia longipalpis. Archives of Insect Biochemistry and Physiology, 66: 53-63, 2007.

TELLERIA, E. L. et al. Trypsin-like serine proteases in Lutzomyia longipalpis-expression, activity and possible modulation by Leishmania infantum chagasi. PLoS One, 5: e10.697, 2010.

TELLERIA, E. L. et al. Caspar-like gene depletion reduces Leishmania infection in the sand fly host Lutzomyia longipalpis. The Journal of Biological Chemistry, 287(16):12.985-12.993, 2012.

TITUS, R. G. \& RIBEIRO, J. M. Salivary gland lysates from the sand fly Lutzomyia longipalpis enhance Leishmania infectivity. Science, 239: 1.306-1.308, 1988.

TONUI, W. K. et al. Transmission blocking vaccine studies in leishmaniasis: II. Effect of immunisation using Leishmania major derived 63 kilodalton glycoprotein, lipophosphoglycan and whole parasite antigens on the course of L. major infection in BALB/c mice. East African Medical Journal, 78: 90-92, $2001 \mathrm{a}$.

TONUI, W. K. et al. Transmission blocking vaccine studies in leishmaniasis: I. Lipophosphoglycan is a promising transmission blocking vaccine molecule against cutaneous leishmaniasis. East African Medical Journal, 78: 84-89, 2001b.

TURCO, S. J. \& DESCOTEAUX, A. The lipophosphoglycan of Leishmania parasites. Annual Review of Microbiology, 46: 65-94, 1992.

VAIDYANATHAN, R. Leishmania parasites (Kinetoplastida: Trypanosomatidae) reversibly inhibit visceral muscle contractions in hemimetabolous and holometabolous insects. Journal of Invertebrate Pathology, 87: 123-128, 2004.

VAIDYANATHAN, R. Isolation of a myoinhibitory peptide from Leishmania major (Kinetoplastida: Trypanosomatidae) and its function in the vector sand fly Phlebotomus papatasi (Diptera: Psychodidae). Journal of Medical Entomology, 42: 142$152,2005$.

VALENZUELA, J. G.; ROWTON, E. D. \& RIBEIRO, J. M. Toward an understanding of the biochemical and pharmacological complexity of the saliva of a hematophagous sand fly Lutzomyia longipalpis. Proceedings of the National Academy of Sciences of the USA, 96: 15.155-15.160, 1999.

VALENZUELA, J. G. et al. Toward a defined anti-Leishmania vaccine targeting vector antigens: characterization of a protective salivary protein. The Journal of Experimental Medicine, 194: 331-342, 2001.

VILELA, M. L. et al. Considerations on the effect of anti-sandfly antibodies on biological parameters of Lutzomyia longipalpis (Lutz \& Neiva, 1912) (Diptera: Psychodidae: Phlebotominae). Brazilian Journal of Biology, 66: 175-183, 2006.

VOLF, P. \& MYSKOVA, J. Sand flies and Leishmania: specif versus permissive vectors. Trends in Parasitology, 23: 91-92, 2007.

VOLF, P. \& ROHOUSOVÁ, I. Species-specific antigens in salivary glands of phlebotomine sandflies. Parasitology, 122(1): $37-41,2001$.

VOLF, P.; KIEWEGOVÁ, A. \& SVOBODOVÁ, M. Sandfly midgut lectin: effect of galactosamine on Leishmania major infections. Medical and Veterinary Entomology, 12: 151-154, 1998. 
VOLF, P.; SVOBODOVÁ, M. \& DVORÁKOVÁ, E. Bloodmeal digestion and Leishmania major infections in Phlebotomus duboscqi: effect of carbohydrates inhibiting midgut lectin activity. Medical and Veterinary Entomology, 15: 281-286, 2001.

WARBURG, A. \& SCHLEIN, Y. The effect of post-bloodmeal nutrition of Phlebotomus papatasi on the transmission of Leishmania major. The American Journal of Tropical Medicine and Hygiene, 35: 926-930, 1986.

WARD, R. D. et al. Reproductive isolation between different forms of Lutzomyia longipalpis (Lutz \& Neiva), (Diptera: Psychodidae), the vector of Leishmania donovani chagasi Cunha \& Chagas and its significance to kala-azar distribution in South America. Memórias do Instituto Oswaldo Cruz, 78: 269-280, 1983.

WEISS, B. \& AKSOY, S. Microbiome influences on insect host vector competence. Trends in Parasitology, 27: 514-522, 2011.

WIECZOREK, H. et al. Structure and regulation of insect plasma membrane H+-V-ATPase. The Journal of Experimental Biology, 203: 127-135, 2000.

WILSON, R. et al. Stage-specific adhesion of Leishmania promastigotes to sand fly midguts assessed using an improved comparative binding assay. PLoS Neglected Tropical Diseases, 4: e816, 2010.

WU, Y. et al. Phase 1 trial of malaria transmission blocking vaccine candidates Pfs 25 and Pvs25 formulated with montanide ISA 51. PLoS One, 3: e2636, 2008.

YAO, C.; DONELSON, J. E. \& WILSON, M. E. The major surface protease (MSP or GP63) of Leishmania sp. Biosynthesis, regulation of expression, and function. Molecular and Biochemical Parasitology, 132: 1-16, 2003.

YOUNG, D. G. \& DUNCAN, M. A. Guide to identification and geographic distribution of Lutzomyia sandflies in Mexico, the West Indies Central and South America (Diptera, Psychodidae). Memoirs of the American Entomological Institute, 54: $1-881,1994$.

ZAULI, R. C. et al. A dysflagellar mutant of Leishmania (Viannia) braziliensis isolated from a cutaneous leishmaniasis patient. Parasites and Vectors, 5: 11, 2012. 


\section{parte IV \\ Hospedeiros, Reservatórios e \\ Manutenção dos Ciclos \\ de Transmissão}




\title{
Lutzomyia (Lutzomyia) longipalpis: fatores associados ao processo de expansão e urbanização da leishmaniose visceral americana
}

Maurício L. Vilela I Margarete M. Afonso I Simone M. Costa

Wagner A. Costa I Elizabeth F. Rangel

\begin{abstract}
A leishmaniose visceral americana (LVA) tornou-se uma das doenças mais importantes no Brasil no atual contexto, em razão da sua incidência com caráter de evolução crônica e envolvimento sistêmico que resulta em alta letalidade, sobretudo em indivíduos não tratados e em crianças desnutridas por conta da baixa condição socioeconômica. Além disso, é considerada emergente em indivíduos portadores de infecção pelo vírus da imunodeficiência adquirida (Brasil, 2003).

Outro fator preponderante para o agravamento da situação da LVA no Brasil está relacionado ao processo de urbanização que a doença começou a apresentar no início da década de 1980 , situação distinta do padrão dito clássico, em que os elementos estavam fortemente associados aos aspectos socioeconômicos das populações acometidas pelo agravo. Como consequência, nesse novo cenário tornou-se necessário incorporar outras abordagens para o enfrentamento da situação, no qual os aspectos referentes à vigilância entomológica ganharam destacado papel ante essa realidade. Vale destacar que diante do novo padrão de transmissão, as ações focadas para o controle da LVA no ambiente urbano tornaram-se problemas de premente necessidade em sua resolução. A maioria dos casos humanos ocorre em municípios de médio e grande porte do país, envolvendo diferentes aspectos que contribuem para o surgimento de novos casos - como áreas submetidas a desordens ambientais, em consequência da ocupação do espaço - relativos às invasões em áreas periurbanas, com o estabelecimento de moradias precárias. É importante frisar que a mobilidade das populações humanas pode ser um relevante fator no contexto das doenças transmitidas por vetores, uma vez que pode modular a exposição aos vetores e, consequentemente, a transmissão de patógenos. Tal aspecto transcende a relação espaço e tempo, resultando em interferências sobre a dinâmica de doenças, tendo como exemplo a dengue, mas que pode ser inferido no tocante à LVA (Stoddard et al., 2009). É digno de destaque que além das potenciais situações citadas, o contexto ambiental favorece o estabelecimento dos elos da cadeia epidemiológica.
\end{abstract}

\section{DESENVOLVIMENTO}

A LVA é uma grave doença, que tem revelado expressiva expansão geográfica no Brasil. Há décadas passadas seu foco era voltado principalmente para os estados das Regiões Nordeste e Norte do país. Atualmente, em virtude de vários fatores, ganha importância nas regiões Sudeste e Centro-Oeste, além da recente situação de registros de casos 
humanos na fronteira do Brasil com a Argentina - no município de São Borja, estado do Rio Grande do Sul (Brasil, 2003). Na América Latina já foi descrita em 12 países, e o Brasil está entre os que mais contribui para o crescimento do número de casos humanos no mundo (Brasil, 2003).

O agente etiológico da LVA no continente americano é a Leishmania (Leishmania) infantum chagasi; o principal vetor é Lutzomyia (Lutzomyia) longipalpis (Lutz \& Neiva, 1912), espécie que reúne fortes evidências quanto à sua competência vetorial, assim como está intimamente ligada ao processo de expansão da doença, já que revela ampla distribuição geográfica nas Américas (Lainson \& Rangel, 2005). No Brasil, até o momento, não foi registrado nos estados do Acre, Amazonas, Amapá e Santa Catarina (Figura 1), constituindo-se em um flebotomíneo que apresenta forte adaptação aos ambientes modificados pela ação antrópica.

As primeiras contribuições relevantes para o estudo da epidemiologia da LVA no Brasil, relativas ao vetor, foram obtidas em pesquisas conduzidas no estado do Ceará: o achado de 'leptomonas', possivelmente L. (L.) infantum chagasi, em espécimes de $L$. (L.) longipalpis; a constatação de que a distribuição espacial do vetor coincidia com os sítios de transmissão da doença, já que esse flebotomíneo correspondia a 97\% dos exemplares capturados, com elevada incidência nos domicílios das áreas de transmissão (Deane \& Deane, 1954).

Estudos pioneiros sobre a epidemiologia da LVA no Ceará descreveram raposas infectadas com amastigotas, além da forte atração que exerciam sobre os flebotomíneos, que se tornavam infectados, sugerindo serem esses mamíferos reservatórios primários da LVA. Demonstrou-se ainda que L. (L.) longipalpis picava avidamente cães, por meio de xenodiagnóstico, observando-se que cerca de 30\% dos flebotomíneos se infectaram, sendo tal aspecto relevante para sugerir o cão como importante fonte de infecção para o vetor no ambiente domiciliar (Deane, 1956).

Figura 1 - Distribuição geográfica de Lutzomyia (Lutzomyia) Iongipalpis no Brasil

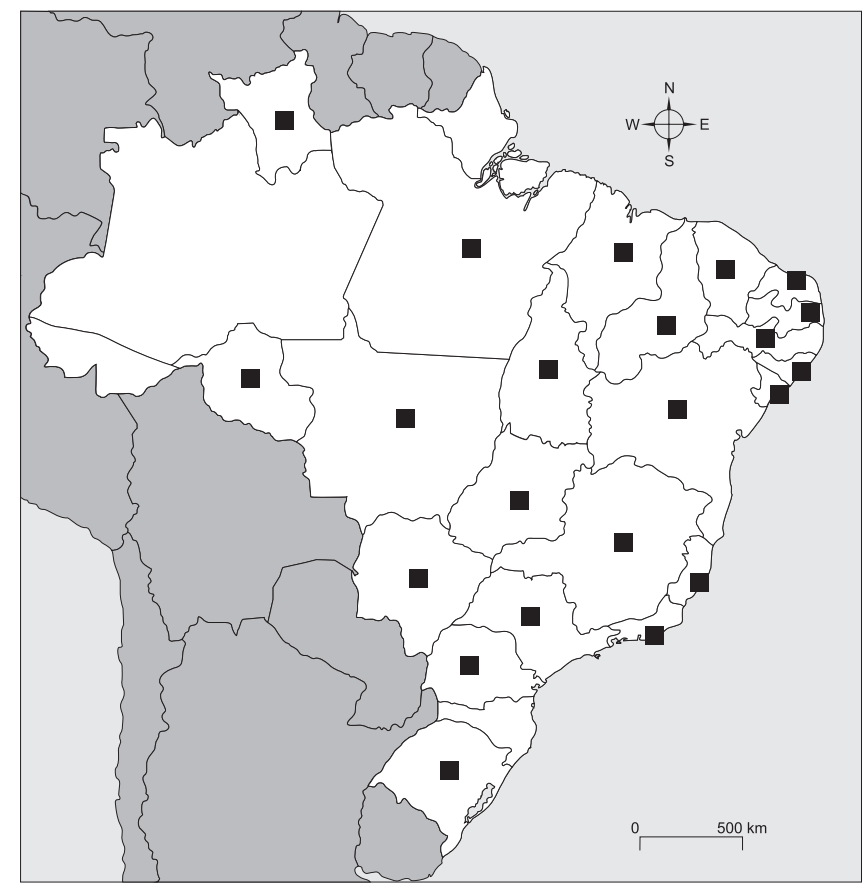

Fonte: LTL/IOC/Fiocruz. 
Posteriormente, evidências reforçaram a competência vetorial de L. (L.) longipalpis, por meio da transmissão experimental de L. (L.) infantum chagasi, pela picada (hamster a hamster) (Lainson, Ward \& Shaw, 1977). No estado do Pará detectaram taxa de infecção natural de flebotomíneos variando entre $7 \%$ a $14 \%$, sendo os exemplares de $L$. longipalpis capturados nas moradias onde residiam pessoas e cães doentes (Lainson et al., 1985).

No Brasil, L. (L.) longipalpis é também o principal vetor de LVA em todas as regiões, sendo registrado nos seguintes estados: Alagoas, Bahia, Ceará, Distrito Federal, Espírito Santo, Goiás, Maranhão, Mato Grosso, Mato Grosso do Sul, Minas Gerais, Pará, Paraíba, Pernambuco, Piauí, Rio de Janeiro, Rio Grande do Norte, Rio Grande do Sul, Rondônia, Roraima, São Paulo e Tocantins (Brasil, 2003). Investigações recentes desenvolvidas no estado do Paraná registraram o encontro do vetor na área urbana do município de Foz do Iguaçu (Santos, Ferreira \& Bisetto, 2012).

A LVA, no Brasil, tem apresentado importantes mudanças no padrão de transmissão, em virtude das alterações ambientais não apenas decorrentes dos impactos naturais, mas também como consequência de ações antrópicas e intenso fluxo migratório de populações, um componente socioeconômico importante nesse contexto, o que ocasionou transformações e degradação nos ecossistemas.

Inicialmente a doença tinha um caráter eminentemente rural, mas a partir da década de 1980 deflagrou um processo de expansão para áreas urbanas de médio e grande porte (Costa, 2008; Maia-Elkhoury et al., 2008; Rangel \& Vilela, 2008). Nos anos 80, surtos de LVA em Teresina e São Luís motivaram o desenvolvimento de estudos epidemiológicos, em parte focados para L. (L.) longipalpis. No estado do Piauí, com a propagação da doença, a área urbana de Teresina registrou um grande número de casos em humanos, confirmando em seguida a concentração da doença dentro dos limites da cidade. L. (L.) longipalpis foi registrado dentro das habitações humanas, o que suscitou a hipótese de uma correlação positiva entre o número de casos humanos e o índice de infestação do vetor. Em 1994, espécimes de L. (L.) longipalpis infectados naturalmente foram capturados em Teresina, no ambiente urbano (Costa, Pereira \& Araújo, 1990; Costa, 1993). Posteriormente, L. (L.) longipalpis pôde ser capturado em habitações humanas em várias regiões do Piauí, demonstrando claramente sua adaptação ao ambiente urbano (Andrade-Filho, Silva \& Falcão, 2001).

O surto de LVA em São Luís, Maranhão, em 1983, incrementou as pesquisas sobre o vetor, demonstrando a antropofilia de $L$. (L.) longipalpis bem como o registro de espécimes naturalmente infectados com promastigotas do tipo Suprapylaria, sugeridas como Leishmania sp. Desde então, vários estudos voltados para o vetor de LVA indicaram que L. (L.) longipalpis encontrava-se adaptado ao ambiente domiciliar (Soares et al., 2006; Penha et al., 2006).

Certamente, Mato Grosso do Sul é um dos estados onde a LVA representa um sério problema de saúde pública, denotando um caráter endêmico desde 1980 em algumas cidades classificadas como de transmissão intensa (Nunes, 1988). Os primeiros relatos de casos humanos autóctones em Campo Grande se deram em 2002, com um aumento gradual no número de casos notificados. Recentemente, estudos sobre a fauna flebotomínica na área urbana de Campo Grande demonstraram claramente que L. (L.) longipalpis foi o flebotomíneo mais abundante (92,22\%) no ambiente domiciliar, apontando para um aumento de seis vezes na densidade em comparação com estudos realizados no período de 1999-2000. O estudo sugere que a elevada densidade desse vetor é o principal fator de risco para transmissão da LVA na área urbana (Oliveira et al., 2006).

Os dados epidemiológicos das últimas décadas revelam a periurbanização e a urbanização da leishmaniose visceral, destacando surtos em Santarém (Pará), Corumbá, Três Lagoas e Campo Grande (Mato Grosso do Sul), Natal (Rio Grande do Norte), São Luís, Caxias e Imperatriz (Maranhão), Teresina (Piauí), Belo Horizonte e Monte Claros (Minas Gerais), Araçatuba, Bauru e Piracicaba (São Paulo), Rio de Janeiro (Rio de Janeiro), Fortaleza (Ceará), Aracaju (Sergipe), Jequié e Camaçari (Bahia), Palmas e Araguaína (Tocantins), Brasília (Distrito Federal), Várzea Grande (Mato 
Grosso), com cerca de 1.600 municípios apresentando transmissão autóctone (Costa et al., 1995; Jerônimo et al., 1994; Silva et al., 2001; Brasil, 2010a).

Entre 1980 e 2005, o Brasil registrou 59.129 casos de LVA, sendo 82,5\% na Região Nordeste. Gradativamente, a doença expandiu-se para as Regiões Centro-Oeste, Norte e Sudeste, onde houve um incremento de $15 \%$ dos casos em 1998 para 44\% em 2005. Durante o mesmo período foram registrados casos autóctones em 1.904 diferentes municípios brasileiros (34,2\%) (Costa, 2008). A estratificação no período entre 2006-2008 revela que os casos humanos estão concentrados atualmente em 3,9\% dos municípios brasileiros, dentre os quais 129 são classificados como áreas de transmissão intensa, 88 como áreas de transmissão moderada, 1.040 como áreas de transmissão esporádica e 4.308 não registraram casos no período (Brasil, 2010a).

Até fins da década de 1970 a doença apresentava um perfil de transmissão conhecido como clássico intimamente associado ao ambiente rural, onde a composição fisiogeográfica era formada por vales e montanhas, popularmente chamados de 'boqueirões' e 'pés de serra'. Nessa situação é importante considerar o nível socioeconômico de baixa qualidade, fortemente associado aos bolsões de miséria e pobreza. Tal cenário esteve por muitos anos relacionado às cidades de médio e pequeno porte do Nordeste brasileiro, onde se concentrava a quase totalidade dos casos humanos. Com a mudança de padrão de transmissão, e consequentemente a presença da LVA no ambiente urbano, hoje verificamos que a doença se dispersou da Região Nordeste para as Regiões Centro-Oeste e Sudeste e continua se expandindo para outras regiões geográficas. Um dado recente aponta de forma categórica a expansão territorial da LVA, quando casos humanos foram registrados na Região Sul do Brasil, no município de São Borja, fronteira com a Argentina. Em fins de 2008 foram registrados os primeiros casos suspeitos de leishmaniose visceral canina no município, posteriormente confirmados sorologicamente como Leishmania Leishmania infantum chagasi e autóctones. No início de 2009 foi confirmado o primeiro caso humano de LVA. Um ano após, esse número se elevou para cinco, dos quais quatro evoluíram para cura e um para óbito registrado. A investigação e o levantamento entomológico revelaram a presença de $L$. (L.) longipalpis no município, assim como em Itaqui e Uruguaiana, localizados na mesma região (Brasil, 2010b).

Analisando espacialmente a LVA, é evidente a heterogeneidade de ambientes onde a doença ocorre, em associação com a distribuição do vetor e outros fatores biológicos, fisiogeográficos e sociais, determinantes no processo de instalação e manutenção da doença.

De forma inequívoca, a história da epidemiologia da LVA no Brasil revelou o importante papel desempenhado pelo vetor, a $L$. (L.) longipalpis. A habilidade de se alimentar frequentemente em animais domésticos e sinantrópicos, assim como sua notável antropofilia, favoreceu sua adaptação aos ambientes modificados, permitindo a manutenção do ciclo de transmissão no ambiente rural e, ao mesmo tempo, a dispersão da doença.

Os primeiros estudos sobre LVA no Brasil negligenciaram a origem silvestre de L. (L.) longipalpis. Pesquisas desenvolvidas na Amazônia demonstraram que esse flebotomíneo é primordialmente silvestre, podendo mesmo ser capturado em áreas bem afastadas das habitações humanas. Evidências acumuladas em estudos epidemiológicos no Pará davam conta da natureza silvestre do vetor, mas ao mesmo tempo revelavam sua capacidade de se adaptar ao ambiente domiciliar (Lainson \& Rangel, 2005).

A literatura tem registrado, com base em trabalhos de campo, o ecletismo de $L$. (L.) longipalpis em se alimentar em uma variada gama de mamíferos e aves, que inclui cães, porcos, equinos, gado e galinhas (Deane, 1956; Rosabal \& Trejos, 1965; Zeledon, Murillo \& Guitierrez, 1984; Rangel \& Lainson, 2003). Recentes estudos de identificação de fontes alimentares na Região Nordeste foram capazes de demonstrar a elevada plasticidade alimentar desse flebotomíneo, onde foram coletados exemplares que haviam se alimentado em aves, canídeos, caprinos, didelfídeos, equídeos, felídeos, humanos, ovinos e roedores, sendo a maior positividade encontrada para o antissoro de ave. 
Confirmando seu marcante papel no processo de adaptação ao ambiente doméstico, as análises demonstraram ainda a frequência da alimentação de L. (L.) longipalpis em cães, os reservatórios domésticos da doença (Afonso, Duarte \& Rangel, 2010). Os resultados revelaram a associação entre essa espécie de flebotomíneo e didelfídeos, situação também apontada em estudos anteriores no estado da Bahia, em áreas de transmissão de LVA, onde é sugerida a importância desses animais como reservatórios secundários (Sherlock et al., 1984, 1988), o que reforça a necessidade de avaliações aprofundadas sobre a ação desses mamíferos sinantrópicos na cadeia de transmissão da LVA.

A aptidão de $L$. (L.) longipalpis em se alimentar em mais de uma fonte sanguínea confirma o ecletismo da espécie, fator que possivelmente favorece sua adaptação a diferentes hábitats, a ambientes modificados, com tendência a ter sua atividade ligada ao ambiente domiciliar, notadamente àqueles relacionados aos abrigos de animais domésticos, fato que sustenta a transmissão da LVA no ambiente rural e a expansão da doença para áreas urbanizadas, determinando os dois perfis de transmissão encontrados no Brasil.

As doenças de transmissão vetorial, frequentes nos países de clima tropical, aparecem como um dos principais problemas de saúde pública e, diante do fenômeno do aquecimento global, pode merecer uma destacada relevância no cenário mundial. o cenário de mudanças climáticas e ambientais globais, em que as incertezas sobre a natureza de seu impacto na escala dos ecossistemas locais se somam às complexidades das novas realidades de um Brasil urbano, sugere novas questões no enfrentamento do problema das doenças transmitidas por artrópodes, no contexto da saúde pública. A sinergia existente entre os processos sociais e os ecossistemas sobre os quais eles se desenvolvem, associada à persistência de condições inadequadas de vida, tem possibilitado a proliferação dessas doenças em novos ambientes, tendo como exemplo a ocorrência da LVA em grandes cidades brasileiras, observando-se aí características peculiares a cada uma (Brasil, 2008).

Em relação ao futuro impacto das mudanças climáticas na saúde, espera-se em todo o mundo que tais fenômenos venham a significar um agravante às situações-problema já existentes, podendo aumentar sua intensidade, gravidade, duração ou ampliação da sua distribuição no espaço geográfico. Dessa forma, estima-se para o Brasil impactos adicionais em relação às doenças infecciosas endêmicas (Confalonieri \& Marinho, 2007).

Sistemas ecológicos, nos quais se encontram estabelecidos focos naturais de doenças infecciosas, quando sob forte pressão antrópica, se tornam um risco para a saúde humana. Por isso, um dos principais indicadores de ocorrência de patologia de um ecossistema é a elevada prevalência de doenças infecciosas.

o impacto das drásticas alterações ambientais, determinadas pela ação humana, vem alterando a ecologia de algumas espécies de leishmânias e flebotomíneos e, consequentemente, o padrão epidemiológico das leishmanioses. Nesse modelo, que emerge do desmatamento, algumas espécies de mamíferos silvestres, hospedeiros do parasito, podem passar a frequentar áreas habitadas pela população humana, especialmente as peridomiciliares, o que possibilita que os flebotomíneos vetores, dotados de plasticidade alimentar, possam facilmente sustentar uma curva populacional ascendente.

Ao correlacionar propriedades dos ecossistemas com surtos e epidemias, é possível identificar pontos de risco e realizar sua previsibilidade e controle. No caso da LVA, um sistema ecológico saudável estaria relacionado com as inter-relações entre os vetores, parasito e reservatórios no ambiente silvestre. Nesse contexto, avaliar os elos da cadeia epidemiológica da LVA, em associação com a pressão antrópica, permite entender o processo de evolução do sistema ecológico.

A construção de usinas hidrelétricas são exemplos de obras de grande porte, as quais geram mobilidade humana por meio do fluxo migratório que se estabelece; posteriormente, no curso da execução do empreendimento, ocorre o desmatamento, o surgimento do lago após o represamento do rio, potencializando impactos ambientais que podem favorecer o estabelecimento de surtos epidêmicos de doenças de transmissão vetorial, como por exemplo, as leishmanioses. 
Tal cenário foi observado no município de Porto Nacional (caracterizado como área de transmissão intensa de LVA), no centro-sul do estado do Tocantins, um dos municípios diretamente impactados pela Usina Hidrelétrica Luis Eduardo Magalhães (UHE Lajeado), concluída em 2002. Estudos posteriores realizados nesse município, avaliando a fauna flebotomínica e buscando associar o perfil de $L$. (L.) longipalpis com fatores determinantes no processo de expansão da LVA, relacionou análise espacial com variáveis ambientais, demonstrando que $L$. (L.) longipalpis foi a espécie de maior abundância na zona urbana quando comparada à zona rural. Quanto aos aspectos climáticos, observou-se fraca correlação positiva entre a abundância do vetor com temperatura $(r=0,099)$ e umidade $(r=0,071)$, e correlação negativa insignificante com precipitação ( $\mathrm{r}=$ - 0,039) (Figura 2) (Carvalho, 2008; Vilela et al., 2011).

Figura 2 - Correlação entre Lutzomyia (L.) Iongipalpis com a temperatura (A), umidade relativa (B) e precipitação (C) em Porto Nacional, Tocantins
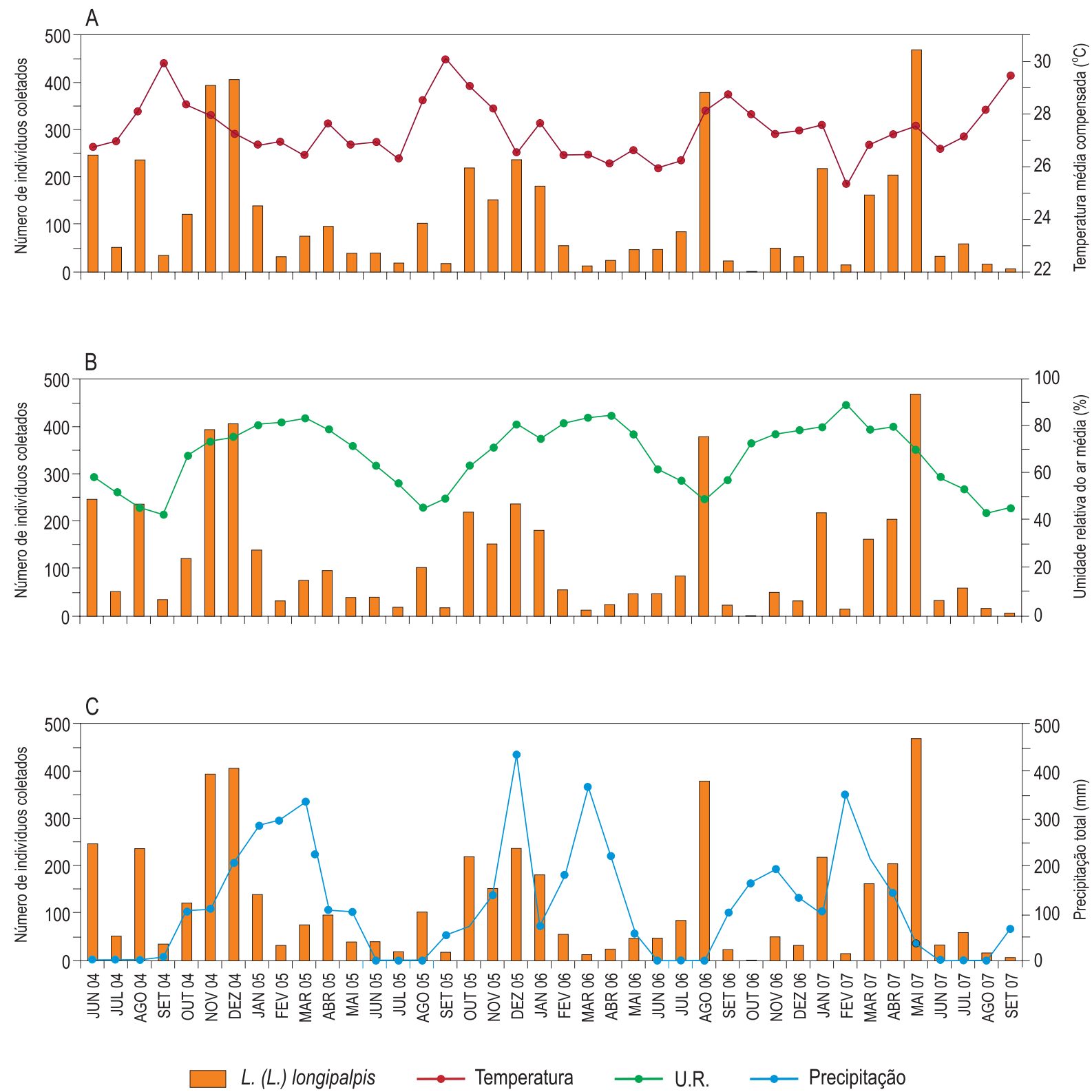

Fonte: LTL/IOC/Fiocruz, Inmet. 
No que se refere à análise espacial do solo, nos pontos de coleta da zona rural estão presentes principalmente no mesmo tipo de solo - o latossolo vermelho-amarelo -, enquanto os pontos da zona urbana, no gleissolo háplico; em relação à vegetação, todos os pontos de registro do vetor relacionaram-se com elementos do ambiente do Cerrado (Afonso et al., 2010) (Figura 3).

Figura 3 - Correlação entre Lutzomyia (L.) longipalpis entre o tipo de vegetação (A) e solo (B) em Porto Nacional, Tocantins
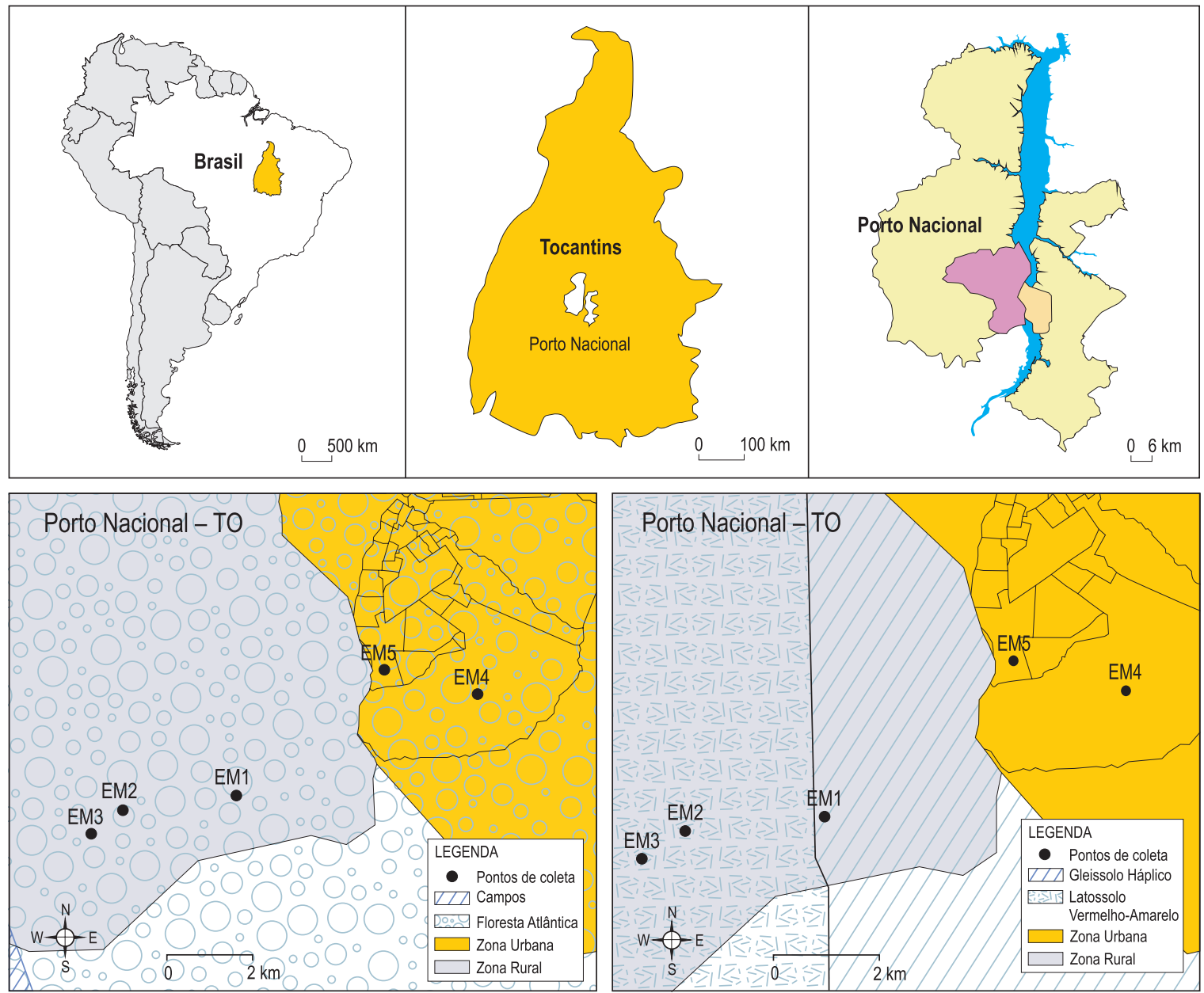

Estruturação do mapa: Labgeo/LIS/Icict/Fiocruz.

Fonte: IBGE, LTL/IOC/Fiocruz.

Estudos empregados no estado da Bahia, associados após o fenômeno El Niño, revelaram um significativo aumento na densidade de flebotomíneos e nos números de casos de LVA humana e canina no período entre 1989 e 1995, sendo constatada a correlação positiva entre tal fenômeno e a incidência anual da leishmaniose visceral (Bavia et al., 2005). Nesse mesmo contexto foi sugerido, ainda, que no estado do Maranhão a ocorrência de LVA nos limites do Parque Estadual de Lençóis Maranhenses, em áreas rurais e urbanas, teria relação com o impacto das atividades turísticas desenvolvidas sem o devido planejamento, aliado à degradação ambiental (Resende et al., 2006). Estudos realizados em área urbana de Bonito, Mato Grosso do Sul, região que sofreu intensa alteração ambiental, revelou um aumento da densidade de L. (L.) longipalpis junto às populações humanas (frequência de 90,4\% no ambiente domiciliar) e um progressivo processo de introdução de LVA na área urbana (Nunes et al., 2008). 
Embora outros flebotomíneos sejam considerados como potenciais vetores de LVA, tais como Lutzomyia cruzi e Lutzomyia migonei (Santos et al., 1998; Salomon et al., 2010; Carvalho et al., 2010), nitidamente a espécie L. (L.) longipalpis se apresenta como o elo mais importante da cadeia de transmissão da LVA, sendo sem dúvida, um fator biológico de risco absolutamente essencial no processo de transformação do perfil epidemiológico e no incremento da urbanização da doença. O melhor entendimento de fatores de risco ambiental para a adaptação do vetor permitirá uma avaliação mais apurada sobre a urbanização da LVA, bem como traçar estratégias e ações preventivas.

\section{CONCLUSÕES E PERSPECTIVAS}

O processo de urbanização da LVA no Brasil nos remete a reflexões de diferentes ordens, no sentido de adquirirmos conhecimento para o enfrentamento do agravo. Para isso, é necessário o emprego de ferramentas, abordagens e análises distintas no tocante aos aspectos relacionados à vigilância entomológica de vetores da doença. Tais medidas serão de fundamental importância para detectar e compreender possíveis alterações que possam ocorrer na biologia e no comportamento das espécies envolvidas nos ciclos de transmissão, primordialmente aqueles focados no principal vetor da LVA nas Américas, Lutzomyia (Lutzomyia) longipalpis.

No atual cenário, em que mudanças globais e de grande magnitude se delineam no mundo, potencializando implicações na saúde das populações, é imprescindível que se intensifiquem os estudos voltados para as doenças relacionadas ao ambiente como as de transmissão vetorial, tendo por exemplo a LVA. Assim, há extrema urgência em se avançar no conhecimento sobre os atuais e potenciais vetores em uma conjuntura de modificações climáticas e ambientais. Isso no sentido de se detectar alterações comportamentais desses artrópodes e, consequentemente, a localização de onde possam ocorrer os ciclos de transmissão. Desse modo, poder-se-á adquirir conhecimentos que gerem valiosos subsídios e estratégias destinadas a controlar e, fundamentalmente, diminuir a incidência de casos humanos.

\section{REFERÊNCIAS}

AFONSO, M. M. S.; DUARTE, R. \& RANGEL, E. F. Diversidade alimentar de Lutzomyia (Lutzomyia) longipalpis (Lutz \& Neiva, 1912) (Diptera: Psychodidade: Phebotominae), procedente de áreas endêmicas de leishmaniose visceral americana no nordeste do Brasil. In: CONGRESSO DA SOCIEDADE BRASILEIRA DE MEDICINA TROPICAL, XLVI, 14-18 mar. 2010, Foz do Iguaçu.

AFONSO, M. M. S. et al. Lutzomyia (Lutzomyia) longipalpis (Lutz \& Neiva, 1912) (Diptera: Psychodidade: Phebotominae), frente à expansão da Leishmaniose Visceral Americana, no Município de Porto Nacional, Estado do Tocantins: dados preliminares. In: CONGRESSO DA SOCIEDADE BRASILEIRA DE MEDICINA TROPICAL, XLVI, 14-18 mar. 2010, Foz do Iguaçu.

ANDRADE-FILHO, J. D.; SILVA, A. C. L. \& FALCÃO, A. L. Phlebotomine sand flies in the State of Piauí, Brazil (Diptera: Psychodidae: Phlebotominae). Memórias do Instituto Oswaldo Cruz, 96: 1.085-1.087, 2001.

BAVIA, M. E. et al. Remote sensing and geographic information systems and risk of America visceral leishmaniasis in Bahia, Brazil. Parassitologia, 47:165-169, 2005.

BRASIL. Ministério da Saúde. Departamento de Vigilância Epidemiológica, Secretaria de Vigilância em Saúde. Manual de Vigilância e Controle da Leishmaniose Visceral. Brasília: Ministério da Saúde, 2003.

BRASIL. Ministério da Saúde. Organização Pan-Americana da Saúde. Mudanças Climáticas e Ambientais e seus Efeitos na Saúde: cenários e incertezas para o Brasil. Brasília: Ministério da Saúde, 2008.

BRASIL. Ministério da Saúde. Secretaria de Vigilância em Saúde. Sistema de informação de agravos de notificação, 2009.

BRASIL. Ministério da Saúde. Tópicos de saúde: leishmaniose visceral. Disponível em: <http://portal.saude.gov.br/portal/ saude/visualizar_texto.cfm?idtxt=22141>. Acesso em: 02 set. 2010a. 
BRASIL. Ministério da Saúde. Secretaria de Vigilância em Saúde, Departamento de Vigilância Epidemiológica, Coordenação Geral de Doenças Transmissíveis \& Centro Estadual de Vigilância em Saúde, Secretaria da Saúde do Estado do Rio Grande do Sul. Nota Técnica conjunta sobre a situação da leishmaniose visceral na fronteira do Estado do Rio Grande do Sul com a Argentina, 2010b.

CARVAlHo, B. M. Estudo Sobre os Flebotomíneos (Diptera: Psychodidae: Phlebotominae) do Município de Porto Nacional, Estado de Tocantins, 2008. Monografia, Rio de Janeiro: Universidade Estácio de Sá.

CARVALHO, M. R. et al. Natural Leishmania infantum infection in Migonemyia migonei (França, 1920) (Diptera:Psychodidae: Phlebotominae) the putative vector of visceral leishmaniasis in Pernambuco State, Brazil. Acta Tropica, 116: 108-110, 2010.

CONFALONIERI, U. E. C. \& MARINHO, D. M. Mudança climática global e saúde: perspectivas para o Brasil. Revista Multiciência, 8: 48-64, 2007.

COSTA, C. H. N. Characterization and speculations on the urbanization of visceral leishmaniasis in Brazil. Cadernos de Saúde Pública, 24(12): 2.959-2.963, 2008.

COSTA, C. H. N. Urbanization of kala-azar in Brazil: kala-azar in Teresina, Piauí, Brazil. In: RESEARCH AND CONTROL OF LEISHMANIASIS IN BRAZIL. 1993, Rio de Janeiro. Proceedings of a National Workshop... Rio de Janeiro: Fiocruz, 1993.

CostA, C. H.; PEREIRA, H. F. \& ARAújo, M. V. Epidemia de leishmaniose visceral no Estado do Piauí, Brasil 1980-1986. Revista de Saúde Pública, 24: 361-72, 1990.

CosTA, J. M. L. et al. Leishmaniose visceral no Estado do Maranhão, Brasil. A evolução de uma epidemia. Cadernos de Saúde Pública, 11: 321-324, 1995.

DEANE, L. M. Leishmaniose Visceral no Brasil: estudos sobre reservatórios e transmissores realizados no Estado do Ceará, 1956. Tese, Rio de Janeiro: Serviço Nacional de Educação Sanitária.

DEANE, M. P. \& DEANE, L. M. Infecção natural do Phlebotomus longipalpis por leptomonas, provavelmente de Leishmania donovani, em foco de calazar, no Ceará. O Hospital, 45: 697-702, 1954.

JERONIMO, S. M. et al. An urban outbreak of visceral leishmaniasis in Natal, Brazil. Transactions of the Royal Society of Tropical Medicine and Hygiene, 88: 386-388, 1994.

LAINSON, R. \& RANGEL, E. F. Lutzomyia longipalpis and the eco-epidemiology of American visceral leishmaniasis, with particular reference to Brazil. Memórias do Instituto Oswaldo Cruz, 100: 811-27, 2005.

LAINSON, R.; WARD, R. D. \& SHAW, J. J. Experimental transmission of Leishmania chagasi causative agent of neotropical visceral leishmaniasis, by the sandfly Lutzomyia longipalpis. Nature (London), 266: 628-630, 1977.

LAINSON, R. et al. Leishmaniasis in Brazil XXI. Visceral leishmaniasis in the Amazon Region and further observations on the role of Lutzomyia longipalpis (Lutz \& Neiva, 1912) as the vector. Transactions of the Royal Society of Tropical Medicine and Hygiene, 79: 223-226, 1985.

MAIA-ELKHOURY, N. A. et al. Visceral leishmaniasis in Brazil: trends and challenges. Cadernos de Saúde Pública, 24(12): 2.941-2.947, 2008.

NUNES, V. L. B. et al. Estudo de flebotomíneos (Diptera, Psychodidae) em área urbana do município de Bonito, Mato Grosso do Sul, Brasil. Revista Brasileira de Entomologia, 52(3): 446-451, 2008.

NUNES, V. L. B. et al. Aspectos epidemiológicos da leishmaniose visceral em cães de Corumbá, Mato Grosso do Sul. Pesquisa Veterinária Brasileira: Revista do Colégio Brasileiro de Patologia Animal, 8: 17-21, 1988.

OLIVEIRA, A. G. et al. Abundance of Lutzomyia longipalpis (Diptera: Psychodidae: Phlebotominae) and urban transmission of visceral leishmaniasis in Campo Grande, state of Mato Grosso do Sul, Brazil. Memórias do Instituto Oswaldo Cruz, 101: 869-74, 2006.

PENHA, T. A. et al. Flebotomíneos em área endêmica de leishmaniose visceral canina no Município de São Luís Maranhão. Revista da Sociedade Brasileira de Medicina Tropical, 39, supl. 1: 77, 2006. 
RANGEL, E. F. \& LAINSON, R. Ecologia das leishmanioses. Lutzomyia longipalpis e a eco-epidemiologia da leishmaniose visceral americana. In: RANGEL, E. F. \& LAINSON, R. (Eds.). Flebotomíneos do Brasil. Rio de Janeiro: Editora Fiocruz, 2003.

RANGEL, E. F. \& VILELA, M. L. Lutzomyia longipalpis (Diptera, Psychodidae, Phlebotominae) and urbanization of visceral leishmaniasis in Brazil. Cadernos de Saúde Pública, 24(12): 2.948-2.952, 2008.

RESENDE, M. C. et al. Seasonal variation of Lutzomyia longipalpis in Belo Horizonte, State of Minas Gerais. Revista da Sociedade Brasileira de Medicina Tropical, 39: 51-55, 2006.

ROSABAL, R. \& TREJOS, A. Phebotomus de El Salvador (Diptera: Psychodidae). II. Observaciones sobre su biologia con especial referencia a P. longipalpis. Revista de Biologia Tropical, 13: 219-228, 1965.

SALOMON, O. D. et al. Lutzomyia migonei as putative vector of visceral leishmaniasis in La Banda, Argentina. Acta Tropica, 113: 84-87, 2010.

SANTOS, D. R.; FERREIRA, A. C. \& BISETTO JUNIOR, A. The first record of Lutzomyia longipalpis (Lutz \& Neiva, 1912) (Diptera: Psychodidae: Phlebotominae) in the State of Paraná, Brasil. Revista da Sociedade Brasileira de Medicina Tropical, 45(5): 643-645, 2012.

SANTOS, S. O. et al. Incrimination of Lutzomyia cruzi as a vector of American visceral leishmaniasis. Medical and Veterinary Entomology, 12: 315-317, 1998.

SHERLOCK, I. A. et al. Natural infection of the opossum Didelphis albiventris (Marsupialia: Didelphidae) with Leishmania donovani in Brazil. Memórias do Instituto Oswaldo Cruz, 79: 511, 1984.

SHERLOCK, I. A. et al. Observações sobre calazar em Jacobina, Bahia. VI. Investigações sobre reservatórios silvestres e comensais. Revista da Sociedade Brasileira de Medicina Tropical, 21: 23-27, 1988.

SILVA, E. S. et al. Visceral leishmaniasis in the metropolitan Region of Belo Horizonte, State of Minas Gerais, Brazil. Memórias do Instituto Oswaldo Cruz, 96: 285-291, 2001.

SOARES, M. R. A. et al. Flebotomíneos (Diptera: Psychodidae) identificados de duas áreas endêmicas de leishmaniose visceral americana na Ilha de São Luís - MA. Revista da Sociedade Brasileira de Medicina Tropical, 39, supl. 1: $77,2006$.

STODDARD, S. T. et al. The role of human movement in the transmission of vector-borne pathogens. Plos Neglected Tropical Diseases, 3(7): e481, 2009.

VILELA, M. L. et al. Phlebotomine fauna (Diptera: Psychodidae) and putative vectors of leishmaniases in impacted area by hydroelectric plant, state of Tocantins, Brazil. PLoS One, 6(12): e27721, 2011.

ZELEDON, R.; MURILLO, J. \& GUITIERREZ, H. Ecology of Lutzomyia longipalpis (Lutz \& Neiva, 1912) and possibilities of the existence of visceral leishmaniasis in Costa Rica. Memórias do Instituto Oswaldo Cruz, 79: 455-459, 1984. 


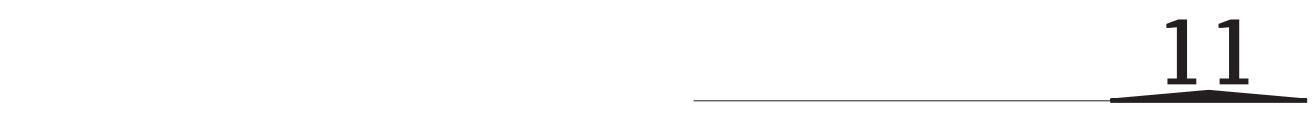

\section{Vetores na Leishmaniose Tegumentar Americana}

Reginaldo Peçanha Brazil I Beatriz Gomes Brazil

$\mathrm{O}$ flebotomíneos (Diptera: Psychodidae: Phlebotominae) são hospedeiros naturais de vários microrganismos, entre os quais alguns agentes etiológicos de doenças de importância médica e veterinária como vírus, bactérias e protozoários. Três gêneros de protozoários tripanossomatídeos são encontrados parasitando esses dípteros: Endotrypanum, Trypanosoma e Leishmania. Apenas neste último gênero encontram-se flagelados patogênicos para o homem que têm como vetores os flebotomíneos, fato que confere a esses insetos grande importância pela transmissão das leishmanioses nas mais diversas regiões do mundo (Lainson \& Shaw, 1987).

Os flebotomíneos constituem um grupo de insetos relativamente primitivo, havendo hipóteses de que provavelmente tenha aparecido no Cretáceo Inferior (Lewis, 1982; Andrade \& Brazil, 2003). Esse grupo, bem definido dentro da ordem Diptera, tem provavelmente origem monofilética (Aransay et al., 2000). Embora ele seja encontrado em regiões temperadas, a maioria das espécies apresenta distribuição tropical e subtropical.

Os adultos, machos e fêmeas, são reconhecidos pelo seu tamanho diminuto, pelo corpo bastante piloso, pelas asas mantidas eretas sobre o corpo - quando pousados - e pelo voo saltitante. As fêmeas são hematófagas e, em geral, costumam picar durante a noite ou nos crepúsculos, mas podem picar também durante o dia (Brazil \& Brazil, 2003).

Atualmente, existem dois sistemas de classificação sendo utilizados na identificação das espécies de flebotomíneos americanos (Young \& Duncan, 1994). Por ser a mais atual, de maior amplitude metodológica e maior abrangência do número de espécies classificadas, a classificação de Galati (Galati, 2003) é a utilizada neste capítulo.

\section{DESENVOLVIMENTO DE LEISHMANIA SPP. NO VETOR}

Hoje, existem cerca de novecentas espécies de flebotomíneos descritas no mundo, dentre as quais mais de quatrocentas são encontradas nas Américas. Dentre estas, pouco mais de vinte espécies são consideradas vetores comprovados das leishmanioses no Novo Mundo. Esse número relativamente pequeno de vetores se dá em razão de uma série de fatores fisiológicos e bioquímicos inerentes tanto aos insetos quanto aos parasitos. Tais fatores influenciam a sobrevivência dos parasitos no tubo digestório do inseto, sua multiplicação e transformações que 
resultarão no aparecimento de formas infectantes, influenciando ainda a transmissão para o hospedeiro vertebrado (Pimenta et al., 1992; Bates \& Rogers, 2004).

O desenvolvimento das diferentes espécies de Leishmania nas espécies suscetíveis de flebotomíneos apresenta variações quanto à localização da infecção no tubo digestório do inseto, o que permite dividi-las em três diferentes grupos (Lainson \& Shaw, 1987). Essa característica fisiológica das leishmânias serviu como base para a atual classificação do gênero Leishmania em dois subgêneros: Leishmania e Viannia, separando-se o gênero Sauroleishmania, o que foi posteriormente confirmado por meio de estudos bioquímicos e moleculares. O último gênero inclui espécies parasitos de lacertídeos e não são patogênicas para o homem, mas tem também os flebotomíneos como vetores (Killick-Kendrick et al., 1984; Shaw, 1963).

A pesquisa da infecção natural de flebotomíneos por Leishmania é feita pela dissecção das fêmeas e a observação das formas flageladas no trato digestório do inseto. Embora laboriosa, essa técnica permite estabelecer o índice de infecção, observar a atividade, o desenvolvimento e a localização dos flagelados no inseto, o que auxilia a identificação do parasito ao nível subgênero, além de permitir o isolamento do flagelado para posterior confirmação e comparação com isolados humanos (Ward, Lainson \& Shaw, 1973; Killick-Kendrick, 1990).

Nos últimos anos, as técnicas moleculares baseadas em PCR têm sido aplicadas na detecção de DNA de Leishmania em flebotomíneos em variados estudos de transmissão em diferentes regiões. Em razão da sua alta sensibilidade tem-se encontrado um alto número de flebotomíneos com 'infecções naturais', mas que na realidade, na maioria dos casos, não atendem aos critérios básicos para sua incriminação como vetor, uma vez que a presença de DNA apenas indica que o inseto se alimentou em fonte infectada com aquele DNA, sem, no entanto, caracterizar se houve multiplicação ou adesão da espécie de Leishmania ao tubo digestório do inseto.

\section{BIOLOGIA DOS FLEBOTOMÍNEOS E TRANSMISSÃO DA LT}

A ampla distribuição geográfica da leishmaniose tegumentar nas Américas está associada à presença das fêmeas de diferentes espécies de flebotomíneos com fortes tendências antropofílicas, e em densidade suficiente para manter a infecção circulando em diferentes ecótopos. Soma-se a isso uma série de características biológicas inerentes ao próprio vetor, as quais influenciam sua capacidade vetorial e, consequentemente, a disseminação da doença.

Desse modo, fatores que têm importância na transmissão: a distribuição do inseto; a abundância da espécie em uma determinada área; os hábitos alimentares (zoofilia, antropofilia ou ecletismo); a concordância gonotrófica (necessidade de múltiplos repastos para a reprodução); a suscetibilidade à infecção pela espécie de Leishmania na área de ocorrência dos casos, além da capacidade de algumas espécies de adentrar os ambientes antrópicos (sinantropia) (Brazil \& Brazil, 2003; Forattini, 1973).

A incriminação de um flebotomíneo como vetor de uma determinada espécie de Leishmania, para o homem, leva em consideração características da biologia do inseto e de sua relação com os hospedeiros das leishmânias. Sabe-se que, para que ocorra a transmissão, há a necessidade de uma fonte infectada, da espécie de flebotomíneos suscetível à infecção pela espécie do protozoário e potenciais novos hospedeiros.

Embora em sua maioria sejam oportunistas, algumas espécies picam preferencialmente o homem, sendo a característica da antropofilia um dos principais fatores na sua incriminação. Outro fator diz respeito ao repetido encontro de infecção natural na espécie antropofílica por formas flageladas da mesma espécie de Leishmania, isolada e caracterizada dos casos de leishmanioses em uma mesma área. Por fim, a comprovação pela infecção experimental do flebotomíneo e a transmissão pela picada, embora geralmente negligenciados pelos pesquisadores, são considerados pela Organização Mundial da Saúde (OMS) como fatores determinantes na incriminação do vetor. 


\section{VETORES NAS AMÉRICAS}

Como já salientado em outros capítulos, a leishmaniose tegumentar americana (LTA) é doença infecciosa autóctone, crônica, causada por diferentes espécies de Leishmania (Ross, 1903). Sob o ponto de vista epidemiológico, trata-se de uma zoonose na qual animais silvestres e domésticos apresentam papéis fundamentais na manutenção do ciclo. Embora a transmissão clássica de todas as formas da LTA se dê a partir da penetração do homem em área enzoótica, a variedade de espécies de Leishmania e flebotomíneos envolvidas determina algumas particularidades epidemiológicas, incluindo a adaptação para um aspecto mais periurbano na transmissão (Figura 1).

Figura 1 - Ciclo de transmissão das leishmanioses no Brasil

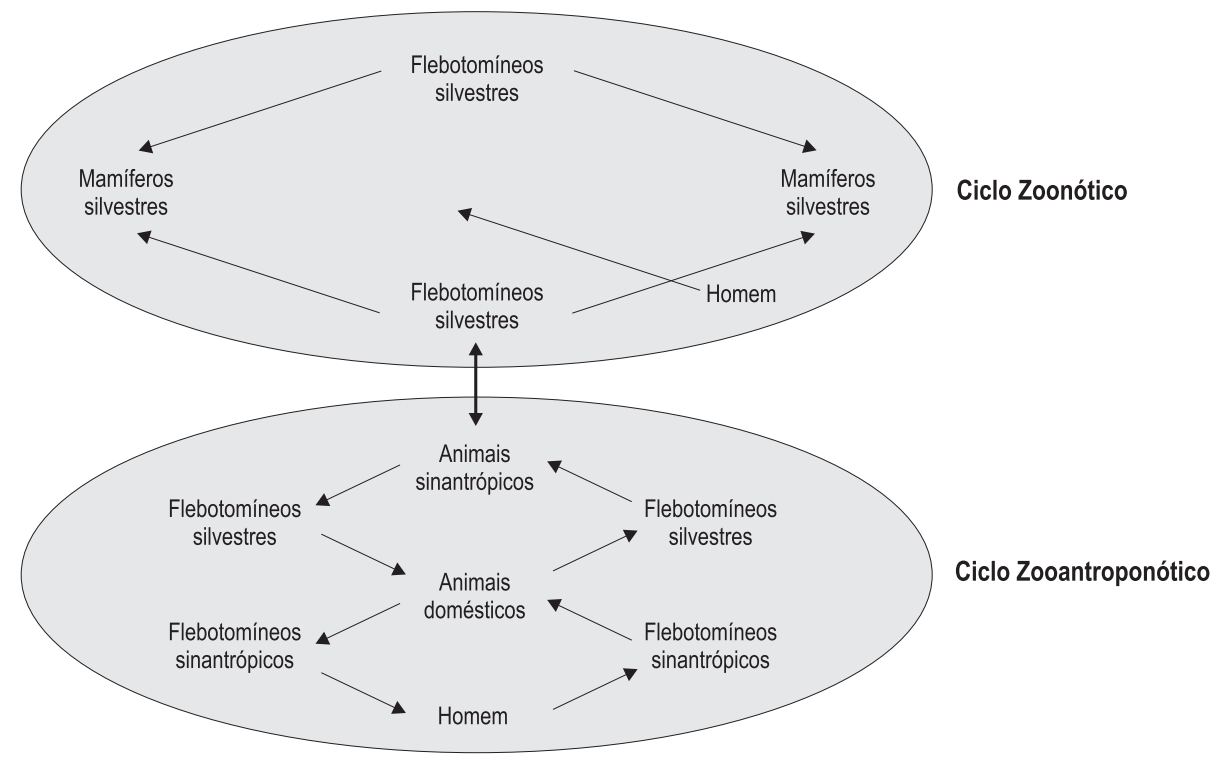

Sabemos, até o momento, que pelo menos 12 espécies de Leishmania são responsáveis pela leishmaniose cutânea nas Américas (Deane \& Grimaldi, 1985; Lainson, 2010), das quais somente três pertencem ao subgênero Leishmania e nove ao subgênero Viannia. Em virtude da grande variedade de espécies envolvidas e da ampla distribuição geográfica onde estes parasitos circulam, encontramos também um variável número de vetores (Quadro 1).

Quadro 1 - Vetores de Leishmania spp. causadora de leishmaniose cutânea no homem nas Américas

\begin{tabular}{|l|l|c|l|}
\hline Espécie de Leishmania & \multicolumn{1}{|c|}{ Distribuição geográfica } & Forma clínica & \multicolumn{1}{|c|}{ Vetor(es) } \\
\hline L.(V.) braziliensis & Américas do Sul e América Central & LC/LMUC & $\begin{array}{l}\text { Ny. intermedia, Ny. neivai, Ny. whitmani, } \\
\text { Mi. migonei, Psy. wellcomei, Psy. complexus }\end{array}$ \\
\hline L. (V.) guyanensis & Norte do Brasil, Guiana Francesa e Suriname & LC/LMUC & Ny. umbratilis \\
\hline L. (V.) panamensis & Norte da América do Sul e América Central & LC & $\begin{array}{l}\text { Ny. trapidoi, Ny. ylephiletor, Lu. gomezi, } \\
\text { Psy. panamensis }\end{array}$ \\
\hline L. (V.) peruviana & Peru & LC & Lu. peruensis, Lu. verrucarum \\
\hline L. (V.) lainsoni & Norte do Brasil, Bolívia e Peru & LC & Tr. ubiquitalis, Lu. nuneztovari anglesi, Tr. velascoi \\
\hline L. (V.) naiffi & Norte do Brasil e Guiana Francesa & LC & Psy. ayrozai
\end{tabular}


Quadro 1 - Vetores de Leishmania spp. causadora de leishmaniose cutânea no homem nas Américas (continuação)

\begin{tabular}{|l|l|c|l|}
\hline Espécie de Leishmania & \multicolumn{1}{|c|}{ Distribuição geográfica } & Forma clínica & \multicolumn{1}{|c|}{ Vetor(es) } \\
\hline L. (V.) shawi & Norte do Brasil & LC & Ny. whitmani s.I \\
\hline L (V.) colombiensis & Colômbia e Panamá & LC & Lu. hartmanni, Lu. gomezi, Psy. panamensis \\
\hline L. (V.) lindenbergi & Brasil (Pará) & LC & Nyssomyia antunesi \\
\hline L. (L.) amazonensis & América do Sul e América Central & LC/LAD & Bi. flaviscutellata, Pi. nuneztovari \\
\hline L. (L.) mexicana & Sul dos Estados Unidos, México e América Central & LC/LAD & Bi. olmeca olmeca \\
\hline L. (L.) venezuelensis & Venezuela & LC & Bi. olmeca bicolor \\
\hline
\end{tabular}

Abreviações: LC - Leishmaniose cutânea; LMUC - Leishmaniose mucocutânea; LAD - Leishmaniose anérgica difusa.

Em alguns casos, uma mesma Leishmania pode ter mais de um vetor comprovado, dependendo da região (Rangel \& Lainson, 2009).

- Leishmania (L.) mexicana Biagi, 1953

Também conhecida como úlcera de los chicleros, apresenta uma distribuição limitada do sul dos Estados Unidos, México e países da América Central, onde Bichromomyia olmeca olmeca (Vargas \& Díaz-Nájera, 1959) é um vetor comprovado. Esse vetor, embora seja antropofílico, apresenta alguma preferência por animais silvestres. Daí as características enzooóticas desta Leishmania. Outro flebotomíneo de importância é a Lutzomyia (Tricholateralis) cruciata (Coquillett, 1907), que pode ter importância epidemiológica em razão de seu comportamento antropofílico nas regiões endêmicas de LT, mas seu papel como vetor ainda requer comprovação.

- Leishmania (L.) amazonensis Lainson \& Shaw, 1972

Este parasito apresenta uma ampla distribuição em vários países da América do Sul e América Central; seu ciclo vital é tipicamente o de uma zoonose entre animais silvestres. Até 1975, os casos humanos de leishmaniose cutânea associada a essa espécie apresentavam distribuição restrita à bacia Amazônica, onde o vetor Bichromomyia flaviscutellata (Mangabeira, 1942), de hábitos zoofílicos, restringia-se ao ambiente florestal. Assim, na Região Norte a transmissão só ocorre quando o homem penetra na floresta, levando a infecção humana a ser pouco frequente. Além dos estados na Região Norte, esse flebotomíneo já foi encontrado no Maranhão, Ceará, Bahia, Espírito Santo, Rio de Janeiro, Minas Gerais, Mato Grosso, Mato Grosso do Sul e Goiás. Embora pouco comum nas capturas com armadilhas luminosas, nas diversas regiões brasileiras, seu papel como vetor da Leishmania amazonensis é incontestável no Brasil e em outros países da América do Sul.

Um provável segundo vetor é a Pintomyia (Pifanomyia) nuneztovari (Ortiz, 1954), que, além da sua antropofilia, já foi encontrado naturalmente infectado por L. amazonensis na região subandina da Bolívia. Tais características a colocam como suspeita de transmitir a LT nessa região da Bolívia (Martinez et al., 1999).

- Leishmania (Leishmania) venezuelensis Bonfante-Garrido, 1980

Até o presente momento, este parasito só foi identificado em isolados de poucos casos de leishmaniose cutânea em humanos e animais domésticos na Venezuela, sendo o possível vetor ainda desconhecido. Existem fortes indicações de que a Bichromomyia olmeca bicolor (Fairchild \& Theodor, 1971) seja o vetor na Venezuela. Esta espécie, que tem uma distribuição bastante ampla no norte da América do Sul, incluído o Brasil, o Panamá e a Costa Rica, apresenta uma acentuada atração por roedores, mas ocasionalmente pica o homem. 


\section{- Leishmania (Viannia) braziliensis Vianna, 1911}

A exata distribuição geográfica da L. braziliensis lato sensu ainda é incerta, embora o parasito já tenha sido identificado desde a América Central até a Argentina. Ele é responsável pela forma cutânea, que pode evoluir para a forma mucocutânea. No Brasil o parasito tem sido identificado em praticamente todos os estados, o que faz com que várias espécies de flebotomíneos possam estar envolvidas na transmissão.

Os dois maiores vetores são Nyssomyia intermedia (Lutz \& Neiva, 1912) e Ny. whitmani (Antunes \& Coutinho, 1939), com distribuição ampla nas áreas periurbanas e urbanas das Regiões Nordeste, Sudeste, Sul e Centro-Oeste. Em algumas áreas de Minas Gerais, São Paulo e Sul do Brasil, Ny. intermedia é simpátrica com a espécie irmã Ny. neivai (Pinto, 1926). Esta é a mais comum em algumas regiões do Sul do Brasil, e o recente encontro de espécimes naturalmente infectados em Santa Catarina e Rio Grande do Sul reforça seu papel como vetor de L. braziliensis nessa específica região do país e, possivelmente, na Argentina (Marcondes et al., 2009; Pita-Pereira et al., 2009). No que diz respeito a Ny. whitmani, é possível que se trate de um complexo de espécies. Sua importância como vetor de Leishmania spp. tem que ser reavaliada nas diversas regiões do Brasil. São fortes as indicações de que tal espécie seja silvestre onde as matas primárias seriam seu ecótopo natural. Entretanto, observações no Nordeste, Sudeste e Sul do território nacional indicam sua profunda tendência em habitar as matas já alteradas pelo homem, com igualmente grande tendência a se adaptar ao peridomicílio (Rangel \& Lainson, 2009). Tem sido observado o grande ecletismo da espécie quanto a seus hábitos alimentares, com grande avidez para picar o homem. Sua importância como vetor de Leishmania braziliensis no Nordeste e no Sudeste, e possivelmente em outras regiões do Brasil, é inegável. É provável que tenha significância como vetor da LT também na Argentina e no Paraguai.

Migonemyia (Migonemyia) migonei (França, 1920) é um flebotomíneo com distribuição bastante ampla em quase toda a América do Sul. Em razão da sua antropofilia e de sua adaptação ao ambiente modificado pelo homem, tem sido sempre considerada um vetor suspeito tanto no Brasil como na Venezuela, onde foi encontrado diversas vezes com infecção natural por Leishmania (Pita-Pereira et al., 2005). É uma espécie que ataca, além do homem, aves, cães e equinos com bastante avidez no peridomicílio, tendo sido recentemente incriminada de transmitir a L. braziliensis no Rio de Janeiro e em Pernambuco.

Na Região Norte o Psychodopygus wellcomei Fraiha, Shaw \& Lainson, 1971 é considerado um importante vetor de L. braziliensis. Este flebotomíneo, primariamente silvestre e altamente antropofílico, pica o homem tanto durante o dia quanto à noite. No Maranhão, Ceará e Pernambuco tem sido encontrado em áreas de floresta, pouco sabendose sobre seu envolvimento na transmissão da Leishmania nesses estados. Psychodopygus complexus (Mangabeira, 1941) é também considerado vetor de L. braziliensis na Serra dos Carajás, no estado do Pará, onde esta espécie, altamente antropofilica, foi encontrada naturalmente infectada. PSy. complexus tem sido encontrada na Zona da Mata em Pernambuco, área endêmica para leishmaniose cutânea, mas ainda sem comprovação do seu envolvimento na transmissão. As fêmeas de Psy. wellcomei e de Psy. complexus são morfologicamente semelhantes, sendo por isso necessária a identificação do macho para separar as espécies em áreas em que ocorrem em simpatria (Galati, 2003).

- Leishmania (Viannia) guyanensis Floch, 1954

É bastante comum esta Leishmania ser encontrada infectando o homem na Região Norte do Brasil, sobretudo ao norte do rio Amazonas. É igualmente comum na Guiana Francesa e no Suriname. O vetor principal desta espécie é a Nyssomyia umbratilis (Ward \& Fraiha, 1977), que pica o homem com certa avidez. Nos casos humanos de LT causados por tal espécie, é habitual a multiciplicidade das lesões cutâneas em razão do grande número de flebotomíneos que picam o homem quando perturbados pela penetração deste na floresta. O ataque das fêmeas de Ny. umbratilis pode ocorrer durante o dia, na 'penumbra' da floresta, daí tendo se originado o nome da espécie. A presença de promastigotas no trato digestório de $\mathrm{Ny}$. umbratilis é mais corriqueiro do que geralmente em outras espécies de flebotomíneos, já que 
esta espécie também é vetor de parasitos do gênero Endotrypanum, o que muitas vezes dificulta o diagnóstico de Leishmania. Ny. umbratilis já foi encontrada em matas primárias do Ceará e de Pernambuco, mas ainda é desconhecida sua importância epidemiológica na transmissão de Leishmania nesses estados.

- Leishmania (Viannia) peruviana Velez, 1913

Este parasito é responsável pela 'uta', forma de leishmaniose cutânea com lesão geralmente única e de cura espontânea. Tem sido isolado de casos humanos e de cães, especialmente na encosta ocidental dos Andes peruanos a 1.300 metros acima do nível do mar. Nessa área, de vegetação xerófila, a Lutzomyia (Helcocyrtomyia) peruensis (Shannon, 1929) e a Lutzomyia verrucarum (Townsend, 1913) são os vetores suspeitos na região. Ambas as espécies podem ser encontradas tanto no intradomicílio como no peridomicílio, mas sobretudo nos abrigos de animais; entretanto, Lu. peruensis, embora possa picar o homem, não é tão antropofílica quanto a Lu. verrucarum.

- Leishmania (Viannia) panamensis Lainson \& Shaw, 1972

Este parasito é responsável pela LT no norte da América do Sul e América Central, apresentando distribuição geográfica relativamente ampla, tendo sido isolado na América do Sul (Equador, Venezuela e Colômbia) e América Central (Panamá, Costa Rica e Nicarágua). Sua transmissão ocorre, em geral, nas matas primárias e secundárias desses países, onde os vetores suspeitos são: Nyssomyia trapidoi (Fairchild \& Hertig, 1952) na Colômbia, Panamá e Costa Rica; Nyssomyia ylephiletor (Fairchild \& Hertig, 1952) na Costa Rica e Panamá; Lutzomyia (Tricholateralis) gomezi (Nitzulescu, 1931) no Panamá; e Psy. panamensis (Shannon, 1926) no Panamá.

- Leishmania (Viannia) lainsoni Silveira et al., 1987

Até pouco tempo esta espécie só tinha sido isolada no estado do Pará, onde a paca (Agouti paca) seria o reservatório silvestre e onde haveria infecção ocasional do homem. No momento, o parasito já foi registrado no Peru e na Bolívia. Também no estado do Pará e provavelmente em outra área da região amazônica. Trichophoromyia ubiquitalis (Mangabeira, 1942) é o vetor principal, mas sua pouca antropofilia certamente determina os poucos casos humanos existentes. Duas outras espécies podem ser responsáveis pela transmissão da L. lainsoni na região subandina da Bolívia: Lu. nuneztovari anglesi Le Pont \& Desjeux, 1984 e Trichophoromyia velascoi (Le Pont \& Desjeux, 1992). Estudos mais aprofundados fazem-se necessários para determinar realmente o principal vetor nessa região.

- Leishmania (Viannia) naiffi Lainson \& Shaw, 1989

Raros casos de leishmaniose cutânea por este parasito já foram registrados na região amazônica (Pará e Amazonas) e também na Guiana Francesa, mas é provável que sua distribuição seja mais ampla. É uma espécie que infecta o tatu (Dasypus novemcintus), sendo seu provável vetor o Psychodopygus ayrozai (Barretto \& Coutinho, 1940), que nessa região é pouco antropofílica, decorrendo disso os poucos casos humanos conhecidos. É possível que outras duas espécies - Psy. squamiventris (Lutz \& Neiva, 1912) e Pys. Paraenses (Costa Lima, 1941) -, bastante antropofílicas, possam estar envolvidas na transmissão do parasito na região amazônica.

- Leishmania (Viannia) shawi Lainson et al., 1989

Este parasito ocorre na região amazônica, onde é responsável pela infecção cutânea no homem e em uma variedade de animais silvestres. O único flebotomíneo incriminado até o momento é a Nyssomyia whitmani s.l., que nas florestas primárias da região é bastante zoofílico e que raramente pica o homem.

- Leishmania (Viannia) colombiensis Kreutzer et al., 1991

Esta Leishmania, embora pouco comum, já foi isolada de casos humanos na Colômbia e no Panamá. Os vetores são Lutzomyia (Helcocyrtomyia) hartmanni (Fairchild \& Hertig, 1957) na Colômbia, e Lutzomyia (Tricholateralis) gomezi e Psychodopygus panamensis, no Panamá. 
- Leishmania (Viannia) lindenbergi Silveira et al., 2002

Esta Leishmania foi isolada e descrita após um surto de leishmaniose cutânea entre soldados em treinamento em mata secundária nos arredores de Belém, Pará. Embora não se tenha certeza quanto ao seu real vetor, a Nyssomyia antunesi (Coutinho, 1939) é a principal suspeita de transmitir o parasito entre os soldados. Esta espécie é bastante antropofílica e com ampla distribuição na região amazônica.

\section{CONCLUSÕES}

Apesar do grande número de pesquisadores dedicados ao estudo do complexo problema da LT nas Américas, muito ainda há que ser estudado em relação a esta protozoose, particularmente no tocante às espécies vetoras. Há um grande número de espécies de flebotomíneos suspeitas e com fortes indícios de serem os vetores das diferentes espécies de Leishmania causadoras das distintas formas clínicas da LT. Ainda faltam estudos relacionados à biologia da grande maioria dessas espécies, além de conhecimentos laboratoriais que possibilitem comprovar seu status vetorial.

Por sua vez, medidas profiláticas satisfatórias em uma doença transmissível por vetores envolvem o controle vetorial, ou ainda, outras estratégias que contribuam para diminuir o contato do parasito com o homem e seus animais domésticos, impedindo assim a transmissão.

A falta de recursos de imunização da população e de seus animais domésticos na prevenção da leishmaniose tegumentar confere ainda mais importância ao estudo das espécies incriminadas como vetoras. Estudo este que possa viabilizar o estabelecimento de paradigmas no controle da doença. Desse modo, além dos estudos de ecologia das espécies, a observação da biologia em colônias laboratoriais poderá trazer subsídios que permitam clarificar o papel vetorial das diferentes espécies. Além disso, há que se propiciar a realização de estudos de infecção e transmissão experimentais, os quais poderão comprovar o papel vetorial de várias espécies que hoje são conhecidas como prováveis vetores, mas que permanecem sem evidência. Tais estudos poderão possibilitar ainda a comparação entre espécies suspeitas de serem vetoras em uma mesma área, definindo assim, juntamente com estudos de sazonalidade e longevidade, qual o vetor principal e o secundário, o que poderá auxiliar no controle vetorial das espécies envolvidas.

Além da necessidade de se ampliar os estudos de biologia, há que se buscar novos modos de captura e coleta dos flebotomíneos, uma vez que há espécies que apesar de saber-se estarem presentes e com potencial de serem transmissoras de Leishmania em uma determinada área, ainda assim são capturados em pequeno número pelas armadilhas luminosas tradicionais. Isso torna necessário o uso daquelas de mais difícil manuseio, exigindo iscas animais ou prolongado trabalho de captura manual. Ainda nesse caso, a tentativa de colonização das espécies poderia contribuir para os estudos de comportamento e de resposta a diferentes estímulos, que serviriam como base para o desenvolvimento de armadilhas mais eficazes.

Com relação à pesquisa de infecção natural, apesar de laboriosa a dissecção dos espécimes, é ainda o único meio de se detectar uma infecção ativa e de propiciar a observação do desenvolvimento do parasito no inseto, além de permitir o isolamento da cepa para comparações e estudos posteriores.

\section{REFERÊNCIAS}

ANDRADE FILHO, J. D. \& BRAZIL, R. P. Relationships of new word phlebotomine sand flies (Diptera: Psychodidae) based on fossil evidence. Memórias do Instituto Oswaldo Cruz, 98, supl. 1: 145-149, 2003.

ARANSAY, A. M. et al. Phylogenetic relationships of phlebotomine sandflies inferred from small subunit nuclear ribosomal DNA. Insect Molecular Biology, 9: 157-168, 2000. 
BATES, P. A. \& ROGERS, M. E, New insights into the developmental biology and transmission mechanisms of Leishmania. Current Molecular Medicine, 4(6): 601-609, 2004.

BRAZIL, R. P. \& BRAZIL, B. G. Biologia de flebotomíneos neotropicais. In: RANGEL, E. \& LAINSON, R. (Orgs.). Flebotomíneos do Brasil. Rio de Janeiro: Editora Fiocruz, 2003.

DEANE, L. M. \& GRIMALDI, G. Leishmaniasis in Brazil. In: CHANG, K. P. \& BRAY, R. S. (Ed.). Leishmaniasis. New York: Elsevier, 1985.

FORATTINI, O. Entomologia Médica. São Paulo: Edgard Blucher, Edusp, 1973.

GALATI, E. A. B. Classificação de Phlebotominae. In: RANGEL, E. \& LAINSON, R. (Eds.). Flebotomíneos do Brasil. Rio de Janeiro: Editora Fiocruz, 2003.

KILLICK-KENDRICK, R. The life-cycle of Leishmania in the sandfly with special reference to the form infective to the vertebrate host. Annales de Parasitologie Humaine et Comparée, 65, supl. 1: 37-42, 1990.

KILLICK-KENDRICK, R. et al. The taxonomy of Leishmania-like parasites of reptiles. In: RIOUX, J.-A. (Ed.). Leishmania. Taxonomie et phylogenèse. Applications eco-épidemiologiques. COLLOQUE INTERNATIONAL CENTRE NATIONAL DE LA RECHERCHE SCIENTIFIQUE, INSTITUT NATIONAL DE LA SANTÉ ET DE LA RECHERCHE MÉDICALE (CNRS INSERM), 2-6 jul. 1984, Montpellier. Anais... Montpellier: L'Institut Méditerranéen d'Etudes Epidémiologiques et Ecologiques (IMEEE), 1986.

LAINSON, R. Espécies neotropicais de Leishmania: uma breve revisão histórica sobre sua descoberta, ecologia e taxonomia. Revista Pan-Amazônica de Saúde, 1(2): 40-50, 2010.

LAINSON, R. \& SHAW, J. J. Evolution, classification and geographical distribution. In: PETERS, W. \& KILLICK-KENDRICK, R. (Eds.). The Leishmaniases in Biology and Medicine. London: Academic Press, 1987.

LEWIS, D. J. A Taxonomic review of the genus Phlebotomus (Diptera: Psychodidae). Bulletin of the British Museum, 45(2): 121-209, 1982.

MARCONDES, C. B. et al. Natural infection of Nyssomyia neivai (Pinto, 1926) (Diptera: Psychodidae, Phlebotominae) by Leishmania (Viannia) spp. in Brazil. Transactions of the Royal Society of Tropical Medicine and Hygiene, 103(11): 1.093-1.094, 2009.

MARTINEZ, E. et al. Lutzomyia nuneztovari anglesi (Le Pont and Desjeux 1984) as a vector of Leishmania amazonensis in a sub-Andean leishmaniasis focus of Bolivia. The American Journal of Tropical Medicine and Hygiene, 61(5): 846-849, 1999.

PIMENTA, P. F. et al. Stage-specific adhesion of Leishmania promastigotes to the sandfly midgut. Science, 256(5.065): $1.812-1.815,1992$.

PITA-PEREIRA, D. et al. Identification of naturally infected Lutzomyia intermedia and Lutzomyia migonei with Leishmania (Viannia) braziliensis in Rio de Janeiro (Brazil) revealed by a PCR multiplex non-isotopic hybridization assay. Transactions of the Royal Society of Tropical Medicine and Hygiene, 99: 905-913, 2005.

PITA-PEREIRA, D. et al. First Report of Lutzomyia (Nyssomyia) neivai (Diptera: Psychodidae: Phlebotominae). Naturally infected by Leishmania (Viannia) braziliensis in a Periurban area of South Brazil using a multiplex polymerase chain reaction assay. The American Journal of Tropical Medicine and Hygiene, 80(4): 593-595, 2009.

RANGEL, E. F. \& LAINSON, R. Proven and putative vectors of American cutaneous leishmaniasis in Brazil: aspects of their biology and vectorial competence. Memórias do Instituto Oswaldo Cruz, 104(7): 937-954, 2009.

SHAW, J. J. A possible vector of Endotrypanum schaudinni of the Sloth, Chlloepus hoffmanni, in Panama. Nature, 201: 417-418, 1963.

WARD, R. D.; LAINSON, R. \& SHAW, J. J. Further evidence of the role of Lutzomyia flaviscutellata (Mangabeira) as the vector of Leishmania mexicana amazonensis in Brazil. Transactions of the Royal Society of Tropical Medicine and Hygiene, 67(4): 608-609, 1973.

YOUNG, D. G. \& DUNCAN, M. A. Guide to the identification and geographic distribution of Lutzomyia sand flies in Mexico, West Indies, Central and South America. The American Entomology Society, 54: 881, 1994. 


\title{
Marcadores Moleculares Empregados no Estudo do Complexo Lutzomyia longipalpis (Diptera: Psychodidae: Phlebotominae)
}

\author{
Luiz Guilherme S. R. Bauzer I Alexandre A. Peixoto
}

\begin{abstract}
A distribuição geográfica do flebotomíneo Lutzomyia longipalpis s.l. (Lutz \& Neiva, 1912), principal vetor de Leishmania infantum (considerada como sinônimo de Leishmania chagast) nas Américas, compreende uma área que se estende do sul do México até o norte da Argentina, cobrindo assim uma variedade de hábitats (Martins, Willians \& Falcão, 1978; Young \& Duncan, 1994; Soares \& Turco, 2003; Lainson \& Rangel, 2005). Algumas populações desse vetor estão, portanto, separadas por cadeias montanhosas e inúmeras outras possíveis barreiras geográficas, climáticas e ecológicas que podem estar associadas a padrões de divergência populacional. E ainda, estudos de soltura e recaptura indicaram que o fluxo genético entre populações de Lu. longipalpis s.l. talvez seja limitado pela distância, já que os espécimes marcados revelaram um curto alcance de voo (Dye, Davies \& Lainson, 1991; Morrison et al., 1993). Portanto, existe um considerável grau de isolamento entre certas populações de Lu. longipalpis s.l., o qual possivelmente resultou em um processo de divergência genética com potencial surgimento de novas espécies dentro desse complexo (Lanzaro et al., 1993; Alexander et al., 1998). E mais: populações locais podem ter experimentado diferentes padrões evolutivos, com possíveis implicações na capacidade de transmitir leishmaniose (Lanzaro \& Warburg, 1995).

Nos mais diversos organismos, o processo de especiação não é necessariamente acompanhado por mudanças morfológicas. Assim, são comuns casos onde duas ou mais espécies morfologicamente idênticas (espécies crípticas) recebem o mesmo nome, apesar de satisfazerem o conceito biológico de espécies (Mayr, 1963). O desafio taxonômico imposto pelas espécies crípticas foi reconhecido há mais de trezentos anos (Winker, 2005), e o advento de técnicas moleculares permitiu o desenvolvimento de novas ferramentas para a deteção e diferenciação de espécies com similaridades morfológicas (Bickford et al., 2007).

Uma variedade de marcadores genéticos já foi empregada em populações de Lu. longipalpis s.l. de distintos países da América Latina, para melhor compreensão taxonômica desse importante inseto vetor. Entretanto, não há ainda um consenso quanto ao número e distribuição dos membros desse complexo de espécies, já que os trabalhos que empregam diferentes marcadores moleculares apresentam conclusões divergentes - revisão feita por Bauzer e colaboradores (2007). Isso sugere fortemente a ocorrência de eventos recentes, ou incipientes, de especiação dentro do complexo, com uma provável associação com introgressão (Araki et al., 2009). Muitos dados gerados até o momento indicam um nível de complexidade que se assemelha ao observado no complexo Anopheles gambiae s.l. e An. gambiae s.s. (Ayala \&
\end{abstract}


Coluzzi, 2005). Divergência genética entre populações do complexo Lu. longipalpis já foi estudada com base no emprego de diferentes técnicas e marcadores moleculares, tais como isoenzimas, Single Strand Conformation Polymorphism (SSCP) de DNA mitocondrial, Random Amplification of Polymorphic DNA (RAPD), microssatélites e sequenciamento de DNA nuclear e mitocondrial. Tais técnicas diferem em termos de sensibilidade, custo, reprodutibilidade e tempo de execução. Marcadores moleculares baseados em DNA são ferramentas particularmente úteis para o estudo de complexos de espécies, já que a variabilidade observada é normalmente maior do que aquela produzida por marcadores isoenzimáticos (Loxdale \& Lushai, 1998).

Neste capítulo, procuramos revisar mais detalhadamente apenas os trabalhos que utilizaram DNA como ferramenta molecular para a elucidação do status taxonômico de Lu. longipalpis s.l.. Portanto, não fizemos uma revisão dos trabalhos que empregaram marcadores isoenzimáticos, embora muitos sejam citados ao longo do texto. Dentre as técnicas que utilizam DNA, também não discutimos os trabalhos envolvendo RAPD (Williams et al., 1990). Essa técnica foi bastante empregada, no passado, em muitos organismos e já foi também utilizada em Lu. longipalpis s.l. (Dias et al., 1998; Queiroz Balbino et al., 2006). Contudo, tem sido cada vez menos empregada nos dias atuais, por conta da sua reputação em relação a dois fatores: baixa reprodutibilidade - o que causa sérios problemas na comparação de resultados de diferentes estudos - e sua desvantagem em revelar somente marcadores dominantes.

Os tópicos seguintes apresentam resultados e conclusões obtidos com o emprego de alguns tipos de marcadores moleculares (DNA mitocondrial, genes envolvidos no controle do comportamento e microssatélites) em estudos de diferenciação genética do complexo Lu. longipalpis.

\section{DNA MITOCONDRIAL (mtDNA)}

Um dos primeiros trabalhos a utilizar mtDNA como marcador molecular para o estudo do complexo Lu. longipalpis foi publicado por Soto e colaboradores (2001), tendo empregado um fragmento que consistia da metade 3' do gene mitocondrial ND4 (subunidade quatro da NADH desidrogenase). Segundo os autores, o objetivo primário do estudo foi utilizar uma fonte adicional não relacionada às técnicas previamente empregadas para inferir divergência e especiação em Lu. longipalpis s.l., tais como isoenzimas (Lanzaro et al., 1993; Soto et al., 2001), morfometria (Dujardin et al., 1997), cariotipagem e bandeamento cromossômico (Yin et al., 1999). Foram utilizados espécimes de campo da Colômbia, Guatemala e Honduras, assim como espécimes de colônia do Brasil, Colômbia, Costa Rica e Venezuela (Quadro 1).

Quadro 1 - Alguns dos principais marcadores moleculares empregados em estudos de diferenciação genética entre espécies do complexo Lu. longipa/pis, com as respectivas localidades e referências

\begin{tabular}{|c|c|c|c|}
\hline Classe & Marcador & Localidades & Referências \\
\hline mtDNA & ND4 & $\begin{array}{l}\text { Lutzomyia Iongipalpis } \\
\text { Tulumajillo (El Progreso) - Guatemala } \\
\text { Rancho Grande (La Paz) - Honduras } \\
\text { San Francisco de Coray (Valle) - Honduras } \\
\text { Los Guatales (Valle) - Honduras } \\
\text { Isla El Tigre (Valle) - Honduras } \\
\text { Pavana (Choluteca) - Honduras } \\
\text { Liberia (Guanacaste) - Costa Rica } \\
\text { Girón (Santander) - Colômbia } \\
\text { El Callejon (Cundinamarca) - Colômbia } \\
\text { Neiva (Huila) - Colômbia } \\
\text { El Batatillo (Trujillo) - Venezuela } \\
\text { Sobral (Ceará) - Brasil } \\
\text { Jacobina (Bahia) - Brasil } \\
\text { Lapinha (Minas Gerais) - Brasil }\end{array}$ & (Soto et al., 2001) \\
\hline
\end{tabular}


Quadro 1 - Alguns dos principais marcadores moleculares empregados em estudos de diferenciação genética entre espécies do complexo Lu. Iongipalpis, com as respectivas localidades e referências (continuação)

\begin{tabular}{|c|c|c|c|}
\hline Classe & Marcador & Localidades & Referências \\
\hline mtDNA & $\mathrm{COI}$ & $\begin{array}{l}\text { Lutzomyia longipalpis } \\
\text { Bucaramanga (Santander) - Colômbia } \\
\text { Neiva (Huila) - Colômbia } \\
\text { Liberia (Guanacaste) - Costa Rica } \\
\text { Pavana (Choluteca) - Honduras } \\
\text { Trujillo (Trujillo) - Venezuela } \\
\text { Jacobina (Bahia) - Brasil } \\
\text { Baturité (Ceará) - Brasil } \\
\text { Santarém (Pará) - Brasil } \\
\text { Salvaterra, Ilha de Marajó (Pará) - Brasil } \\
\text { Lapinha (Minas Gerais) - Brasil } \\
\text { Pacaraima (Roraima) - Brasil } \\
\text { Lutzomyia pseudolongipalpis } \\
\text { Curarigua (Lara) - Venezuela } \\
\text { El Paso (Lara) - Venezuela }\end{array}$ & (Arrivillaga et al., 2002, 2003) \\
\hline mtDNA & Subunidade ribossomal $12 S$ & $\begin{array}{l}\text { Lutzomyia longipalpis } \\
\text { Bucaramanga (Santander) - Colômbia } \\
\text { Neiva (Huila) - Colômbia } \\
\text { Liberia (Guanacaste) - Costa Rica } \\
\text { Pavana (Choluteca) - Honduras } \\
\text { Trujillo (Trujillo) - Venezuela } \\
\text { Jacobina (Bahia) - Brasil } \\
\text { Baturité (Ceará) - Brasil } \\
\text { Lapinha (Minas Gerais) - Brasil } \\
\text { Pacaraima (Roraima) - Brasil } \\
\text { Lutzomyia pseudolongipalpis } \\
\text { Curarigua (Lara) - Venezuela } \\
\text { El Paso (Lara) - Venezuela }\end{array}$ & (Arrivillaga et al., 2003) \\
\hline mtDNA & Subunidade ribossomal $16 S$ & $\begin{array}{l}\text { Lutzomyia Iongipalpis } \\
\text { Bucaramanga (Santander) - Colômbia } \\
\text { Neiva (Huila) - Colômbia } \\
\text { Liberia (Guanacaste) - Costa Rica } \\
\text { Pavana (Choluteca) - Honduras } \\
\text { Trujillo (Trujillo) - Venezuela } \\
\text { Jacobina (Bahia) - Brasil } \\
\text { Baturité (Ceará) - Brasil } \\
\text { Lapinha (Minas Gerais) - Brasil } \\
\text { Pacaraima (Roraima) - Brasil } \\
\text { Lutzomyia pseudolongipalpis } \\
\text { Curarigua (Lara) - Venezuela }\end{array}$ & (Arrivillaga et al., 2003) \\
\hline mtDNA & Citocromo b & $\begin{array}{l}\text { Lutzomyia Iongipalpis } \\
\text { Natal (Rio Grande do Norte) - Brasil } \\
\text { Patos (Paraíba) - Brasil } \\
\text { João Pessoa (Paraíba) - Brasil } \\
\text { Itamaracá (Pernambuco) - Brasil } \\
\text { Calumbi (Pernambuco) - Brasil } \\
\text { Juazeiro (Bahia) - Brasil } \\
\text { Monte Santo (Bahia) - Brasil } \\
\text { Feira de Santana (Bahia) - Brasil } \\
\text { Pancas (Espírito Santo) - Brasil }\end{array}$ & $\begin{array}{l}\text { (Hodgkinson et al., 2002, 2003; } \\
\text { Coutinho-Abreu et al., 2008) }\end{array}$ \\
\hline
\end{tabular}


Quadro 1 - Alguns dos principais marcadores moleculares empregados em estudos de diferenciação genética entre espécies do complexo Lu. longipalpis, com as respectivas localidades e referências (continuação)

\begin{tabular}{|c|c|c|c|}
\hline Classe & Marcador & Localidades & Referências \\
\hline Gene nuclear & period & $\begin{array}{l}\text { Lutzomyia Iongipalpis } \\
\text { Marajó (Pará) - Brasil } \\
\text { Sobral (Ceará) - Brasil* } \\
\text { Natal (Rio Grande do Norte) - Brasil } \\
\text { Teresina (Piauí) - Brasil } \\
\text { Estrela de Alagoas (Alagoas) - Brasil* } \\
\text { Jacobina (Bahia) - Brasil } \\
\text { Jaíba (Minas Gerais) - Brasil* } \\
\text { Lapinha (Minas Gerais) - Brasil } \\
\text { Pancas (Espírito Santo) - Brasil } \\
\text { Barra de Guaratiba (Rio de Janeiro) - Brasil } \\
\text { Mesquita (Rio de Janeiro) - Brasil } \\
\text { Lutzomyia cruzi } \\
\text { Corumbá (Mato Grosso do Sul) - Brasil }\end{array}$ & $\begin{array}{l}\text { (Araki et al., 2009; } \\
\text { Bauzer et al., 2002a, 2002b; } \\
\text { Vigoder et al., 2010) }\end{array}$ \\
\hline Gene nuclear & cacophony & $\begin{array}{l}\text { Lutzomyia longipalpis } \\
\text { Sobral (Ceará) - Brasil** } \\
\text { Natal (Rio Grande do Norte) - Brasil } \\
\text { Jacobina (Bahia) - Brasil } \\
\text { Lapinha (Minas Gerais) - Brasil }\end{array}$ & (Bottecchia et al., 2004) \\
\hline Gene nuclear & paralytic & $\begin{array}{l}\text { Lutzomyia longipalpis } \\
\text { Sobral (Ceará) - Brasil* }\end{array}$ & (Lins, Souza \& Peixoto, 2008) \\
\hline Microssatélites & $\begin{array}{l}\text { LIST6 } 002^{\text {(a) }} \\
\text { LIST6 } 004^{\text {(a) }} \\
\text { LIST6 } 006^{\text {(a) }} \\
\text { LIST6 } 012^{\text {(a) }} \\
\text { LIST6 029 (a) }\end{array}$ & $\begin{array}{l}\text { Lutzomyia Iongipalpis } \\
\text { Altagracia (Guárico) - Venezuela } \\
\text { El Layero (Guárico) - Venezuela } \\
\text { Guayabita (Aragua) - Venezuela } \\
\text { Las Cabreras (Nueva Esparta) - Venezuela } \\
\text { Sobral (Ceará) - Brasil* } \\
\text { Marajó (Pará) - Brasil } \\
\text { Natal (Rio Grande do Norte) - Brasil } \\
\text { Jacobina (Bahia) - Brasil } \\
\text { Lapinha (Minas Gerais) - Brasil } \\
\text { Lutzomyia pseudolongipalpis } \\
\text { La Rinconada, Curarigua (Lara) - Venezuela } \\
\text { Lutzomyia cruzi } \\
\text { Corumbá (Mato Grosso do Sul) - Brasil } \\
\text { Ladário (Mato Grosso do Sul) - Brasil }\end{array}$ & $\begin{array}{l}\text { (Watts et al., 2005; } \\
\text { Maingon et al., 2003) }\end{array}$ \\
\hline
\end{tabular}

* Localidades com ocorrência de espécies simpátricas.

(a) Pares de iniciadores que flanqueiam cinco loci de microssatélites dinucletotídicos (CA), não ligados.

As análises foram feitas com um fragmento de 618 pares de base e a diferenciação entre as populações foi estimada principalmente pelo índice de fixação Fst (Hudson, Slatkin \& Maddison, 1992). Os resultados indicaram que algumas populações alopátricas eram suficientemente divergentes para representar espécies diferentes, segundo os autores. Cálculos feitos apenas para os espécimes de campo da América Central apontaram um efeito altamente significativo da distância geográfica na diferenciação do gene ND4. Contudo, uma alta diferenciação genética foi observada entre a população da Guatemala e as de Honduras, sugerindo ausência de fluxo gênico entre as populações relativamente próximas. 
De todo modo os autores concluem que, com a possível exceção da população da Guatemala, a divergência entre as sequências das populações da América Central foi consistente com a existência de uma espécie única, porém estruturada. Análise de máxima parcimônia detectou quatro clados correspondentes ao norte da América do Sul, à América Central, ao Brasil e a uma população colombiana (Girón), que se mostrou mais relacionada com as populações brasileiras do que com as demais populações da América do Sul. Dentro do clado do norte da América do Sul, as sequências oriundas de El Batatillo (Venezuela) e aquelas de duas localidades da Colômbia central (El Callejon e Neiva) apresentaram valores suficientemente altos para sugerir que barreiras ao fluxo gênico pudessem existir entre elas, levando assim ao questionamento da coespecificidade dessas populações. Já na linhagem brasileira, houve grande diferenciação dos espécimes da colônia de Sobral quando comparados aos das colônias de Jacobina e Lapinha, o que levou os autores a também questionar a natureza coespecífica das populações brasileiras de Lu. longipalpis s.l..

Nos dois anos subsequentes, novos trabalhos foram publicados por Arrivillaga e colaboradores $(2002,2003)$ utilizando mtDNA como marcador molecular no estudo do complexo Lu. longipalpis. Nestes, sequências do gene citocromo c oxidase I (COI) foram empregadas na análise filogeográfica de populações de Lu. longipalpis s.l. de cinco países da América Latina (ver Quadro 1). No total, 19 haplótipos foram revelados por análise de SSCP e confirmados por sequenciamento. Árvores construídas com base nos métodos de neighbor-joining e máxima parcimônia revelaram quatro clados entre as populações estudadas, que, de acordo com os autores, definem quatro diferentes espécies: espécie A (clado brasileiro, representado pelas populações de Lapinha, Salvaterra, Santarém, Jacobina e Baturité), espécie B (clado de Lara, representado pelas populações venezuelanas de Curarigua e El Paso), espécie C (clado cisandino, representado pelas populações de Trujillo, Bucaramanga, Neiva e Roraima) e espécie D (clado transandino, representado pelas populações de Pavana, Liberia, Bucaramanga e Trujillo). No entanto, esses dois últimos clados não foram tão fortemente apoiados pelos valores de bootstrap, e a ocorrência em simpatria de haplótipos próximos entre amostras de Bucaramanga e Trujillo também não deu apoio à monofilia dos clados trans e cisandinos.

Lanzaro e colaboradores (1993) já haviam demonstrado barreiras reprodutivas, com formação de machos híbridos estéreis, em cruzamentos recíprocos entre membros desses dois clados. Além disso, a noção de que os clados cis e transandinos representam espécies biológicas é apoiada por estudos de isoenzimas entre essas populações, em que foram revelados níveis de distância genética consistentes com o observado em espécies do gênero Lutzomyia (Lanzaro \& Warburg, 1995; Arrivillaga et al., 2003; Lanzaro et al., 1998; Mutebi et al., 1998). Análise filogenética das sequências do gene COI, por máxima parcimônia, revelou relações próximas entre as populações brasileiras. Tais resultados concordaram com análises baseadas em variação de isoenzimas aplicadas às mesmas populações, com exceção da de Roraima, que não foi incluída nos estudos isoenzimáticos (Mukhopadhyay et al., 1998; Arrivillaga et al., 2003; Mutebi et al., 1999; Azevedo et al., 2000).

Apesar da caracterização de um clado brasileiro, o gene COI indicou a existência de pelo menos duas espécies no Brasil, visto que a população brasileira de Roraima está agrupada com a população de Neiva (Colômbia), formando o clado cisandino. A análise indicou também que a separação do clado de Lara dos demais é a mais antiga, já que ambos os métodos de neighbor-joining e máxima parcimônia o colocam em uma posição mais basal. Na verdade, a espécie que representa esse clado já tinha sido descrita morfologicamente, sendo chamada de Lutzomyia pseudolongipalpis (Arrivillaga \& Feliciangeli, 2001).

Variações nos genes mitocondriais ribossomais $12 S$ e $16 S$ também foram utilizadas por Arrivillaga e colaboradores (2003), para esclarecer relações filogenéticas e taxonômicas entre algumas das 13 populações de Lu. longipalpis estudadas com o gene COI (ver Quadro 1). Para os dois marcadores ribossomais, o polimorfismo foi detectado tanto por análise de SSCP quanto por sequenciamento. As análises filogenéticas das sequências de mtDNA ribossomal revelaram alto grau de homogeneidade entre amostras representativas de uma vasta área geográfica, contrastando 
com os resultados apontados com o marcador COI. Os autores sugerem que os resultados obtidos com a análise dos genes ribossômicos mitocondriais se devem à sua lenta taxa de evolução.

Outro marcador mitocondrial empregado nos estudos de genética de populações de Lu. longipalpis s.l. foi o gene citocromo b (cyt b), primeiramente utilizado por Hodgkinson e colaboradores (2003) em uma análise combinada de SSCP e de sequenciamento da sua porção 3'. O objetivo foi testar a confiabilidade da técnica SSCP aplicada ao cyt b na caracterização da variabilidade genética desse inseto vetor. Para tal, iniciadores de PCR foram desenhados com base na sequência consenso de táxons bem separados. Espécimes brasileiros de flebotomíneos foram coletados em Juazeiro e Natal (ver Quadro 1), localidades com diferentes altitudes e características de vegetação, separadas por aproximadamente 715 quilômetros.

Comparações entre os haplótipos identificados por SSPC e suas respectivas sequências confirmaram a confiabilidade da técnica. Isso por que, além da detecção de diferenças nucleotídicas únicas em variantes SSPC, não houve variação nas sequências de espécimes com a mesma mobilidade. O alinhamento de sequências de 261 pares de base de 36 indivíduos identificou 16 sítios segregantes em um total de 21 haplótipos, revelando ainda seis haplótipos compartilhados pelas populações.

Uma vez confirmada a possibilidade do emprego desse marcador para o estabelecimento de padrões de variação genética entre populações de Lu. longipalpis s.l., o mesmo foi empregado em outro estudo feito por Hodgkinson e colaboradores (2003) com amostras de campo das populações de Natal, Itamaracá, Juazeiro, Monte Santo, Feira de Santana e Pancas (ver Quadro 1), que representam um transecto geográfico da região leste do Brasil. Fragmentos de 261 pares de base, correspondentes à porção 3' terminal do DNA mitocrondrial cyt b, foram alinhados e trinta haplótipos foram observados, de um total de 78 espécimes. Os autores notaram uma transição geográfica, a $10^{\circ}$ de latitude sul, que marcou uma estruturação das populações analisadas. Somente as três populações ao norte do paralelo $10^{\circ} \mathrm{S}$ foram suficientemente homogêneas para indicar uma alta probabilidade de fluxo genético entre elas. Os autores concluíram ainda que, com exceção da população de Pancas, o padrão filogeográfico das populações amostradas não pôde ser atribuído ao isolamento simples por distância. A comparação par a par entre três populações ao sul do paralelo $10^{\circ} \mathrm{S}$ (Pancas, Monte Santo e Feira de Santana) apontou uma diferenciação não somente entre elas próprias, mas também entre cada uma destas e as populações do norte, indicando um fluxo genético limitado entre as amostras analisadas. Entretanto, os autores concluíram que a divergência genética entre as sequências representativas dos clados do norte e as do sul foi pequena, apontando para uma diferenciação geográfica intraespecífica.

Finalmente, uma recente análise de polimorfismos do gene mitocondrial cyt $b$ foi feita por Coutinho-Abreu e colaboradores (2008) em um trabalho que teve como objetivo investigar o possível papel do rio São Francisco na definição da atual distribuição das espécies crípticas de Lu. longipalpis s.l. do leste do Brasil. A análise de variabilidade genética incluiu 29 haplótipos descritos anteriormente por Hodgkinson e colaboradores (2002, 2003) e mais cinco novos obtidos de amostras selvagens das populações de Calumbi, João Pessoa e Patos, no Nordeste do Brasil (ver Quadro 1). Uma árvore neighbor-joining de distância genética baseada em valores de Fst (Hudson, Slatkin \& Maddison, 1992) revelou dois clados: o primeiro incluiu as populações de Natal, Patos, Juazeiro, João Pessoa e Itamaracá; o segundo incluiu populações de Calumbi, Pancas, Monte Santo e Feira de Santana. O paralelo $10^{\circ} \mathrm{S}$ é a latitude aproximada do trecho onde o rio São Francisco deixou de correr no sentido sul-norte, desviando-se para leste durante a glaciação Mindel. Os resultados indicaram que todas as populações do primeiro clado se encontram ao norte do paralelo $10^{\circ} \mathrm{S}$ e as populações do segundo clado, com exceção da população de Calumbi, são encontradas ao sul do paralelo $10^{\circ} \mathrm{S}$. Baseados no relógio molecular do cyt $b$, os autores estimaram um tempo de divergência entre os grupos de aproximadamente 0,45 milhão de anos, tempo este que coincide com o período em que o rio São Francisco mudou a direção de seu curso. 


\section{GENES NUCLEARES ENVOLVIDOS NO CONTROLE DO COMPORTAMENTO}

Em um grande número de insetos, sinais acústicos emitidos durante a corte/cópula atuam de forma importante no isolamento reprodutivo entre espécies próximas, um processo bem caracterizado em Drosophila (Kyriacou \& Hall, 1980, 1982, 1986; Ritchie, Halsey \& Gleason, 1999; Sakai \& Ishida, 2001). Neste inseto modelo, period (per), um dos genes envolvidos com tal aspecto do comportamento reprodutivo se revelou um marcador molecular interessante para o estudo do processo de especiação (Peixoto et al., 1992; Hilton \& Hey, 1996; Wang \& Hey, 1996; Gleason \& Powell, 1997; Lachaise et al., 2000). Esse gene, um dos componentes do relógio circadiano de Drosophila, foi identificado com base em mutações que alteravam os ritmos de emergência de pupas e atividade locomotora de moscas adultas (Konopka \& Benzer, 1971). Como o gene per também controla diferenças espécie-específicas nos ritmos de som de corte entre D. melanogaster e suas espécies irmãs (Kyriacou \& Hall, 1980, 1982, 1986; Ritchie, Halsey \& Gleason, 1999), foi considerado um exemplo de gene de especiação (Coyne, 1992).

A comunicação acústica também é um aspecto do comportamento sexual de Lu. longipalpis s.l. (Araki et al., 2009; Ward et al., 1988; Souza et al., 2002, 2004) e, por isso, genes potencialmente envolvidos no controle desse sinal são marcadores moleculares promissores para o estudo da diferenciação genética de populações desse complexo de espécies de insetos vetores. Assim, Peixoto e colaboradores (2001) isolaram e clonaram um fragmento de cerca de 900 pares de bases de Lu. longipalpis s.l., homólogo ao gene per de Drosophila. Esse foi o primeiro marcador molecular associado ao comportamento sexual empregado para estudos do processo de especiação desse complexo. No primeiro estudo feito por Bauzer e colaboradores (2002a), foram analisadas três populações brasileiras, separadas por distâncias superiores a 800 quilômetros (Lapinha, Jacobina e Natal) (ver Quadro 1). Para tal, a variação molecular em um fragmento de per de 266 pares de base, contendo um íntron de 54 pares de base, foi analisada e empregada no cálculo do índice de fixação Fst (Hudson, Slatkin \& Maddison, 1992). Uma alta divergência genética entre as amostras dessas três localidades foi detectada. Juntamente com dados de feromônios (Ward et al., 1988; Hamilton, Dawson \& Pickett; 1996a, 1996b) e de som de cópula (Souza et al., 2002) obtidos para essas mesmas populações, os resultados indicaram que elas provavelmente representam três espécies crípticas. Na verdade, dados isoenzimáticos já tinham sugerido a existência de tais grupos, embora a divergência observada não tenha sido considerada alta o suficiente para indicar a existência de um complexo de espécies (Mukhopadhyay et al., 1998).

Em um segundo estudo, Bauzer e colaboradores (2002b) empregaram o mesmo fragmento de per para analisar amostras de Sobral, estado do Ceará (ver Quadro 1). Lu. longipalpis s.l. apresenta um polimorfismo de manchas abdominais (Mangabeira, 1969) e, em Sobral, os machos podem apresentar um único par de manchas esbranquiçadas no quarto tergito abdominal ou podem apresentar também um par adicional de manchas no terceiro tergito (Ward et al., 1983). Esses fenótipos de manchas abdominais são denominados uma pinta (1P) e duas pintas (2P), respectivamente, e já foram amplamente analisados em estudos que procuravam demonstrar se esse era ou não um caráter espécieespecífico. Por exemplo, cruzamentos em laboratório foram realizados entre colônias oriundas de populações brasileiras simpátricas e alopátricas com diferentes padrões de pintas abdominais (Ward et al., 1983, 1988; Souza et al., 2008). Taxas de inseminação muito reduzidas foram observadas em cruzamentos entre duas colônias representativas dos dois tipos morfológicos de Sobral, sugerindo que elas poderiam representar espécies simpátricas. Contudo, foram também obtidas baixas taxas de inseminação entre amostras de populações que compartilhavam o mesmo fenótipo e taxas normais entre algumas colônias que diferiam no fenótipo de pintas, indicando que o padrão de pintas não era um caráter espécie-específico. Além disso, nos cruzamentos entre as formas 1P e 2P observaram-se machos carregando um fenótipo intermediário, no qual a mancha do terceiro tergito é menor e de tamanho variável.

Esse fenótipo intermediário foi encontrado em alta frequência em algumas localidades, apontando um polimorfismo intraespecífico (Ward et al., 1988, 1985). Entretanto, embora as pintas não possam ser normalmente usadas como 
um caráter espécie-específico, os mesmos estudos já citados indicaram que tal fenótipo podia ser útil para identificar espécies simpátricas em localidades onde fenótipos intermediários eram raros - por exemplo, em Sobral -, onde machos com fenótipo 1P e 2P produzem diferentes tipos de feromônios (Ward et al., 1988). A análise do gene per realizada por Bauzer e colaboradores (2002b) indicou uma grande diferenciação genética entre as amostras de Sobral, confirmando os dados prévios de cruzamentos e feromônios.

Além disso, estimativas de diferenciação genética par a par entre essa população e as de Jacobina, Lapinha e Natal revelaram que Sobral fenótipo $2 \mathrm{P}$ e Natal eram essencialmente o mesmo pool genético, e que Sobral fenótipo 1P era distinta de todas as outras analisadas até aquele momento, sendo um pouco mais próxima à de Lapinha, com a qual compartilhava o mesmo tipo de feromônio. Dois anos mais tarde, publicou-se um estudo com a caracterização do som de cópula dos machos fenótipo 1P e fenótipo 2P de Sobral (Souza et al., 2004), tendo os resultados concordado com o padrão de estruturação indicado pelos dados de per e feromônios.

Araki e colaboradores (2009) estenderam a análise desse fragmento do gene per para amostras de mais sete localidades brasileiras: Marajó, Teresina, Pancas, Mesquita, Barra de Guaratiba, Estrela de Alagoas e Jaíba (ver Quadro 1); nestas duas últimas foram coletados machos com uma e duas pintas, sendo o fenótipo intermediário raro, tal qual observado em Sobral. Portanto, as amostras com fenótipo 1P e 2P de Estrela de Alagoas e Jaíba foram analisadas separadamente. Os valores dos índices de fixação Fst (Hudson, Slatkin \& Maddison, 1992) computados indicaram uma diferenciação genética alta e significativa entre os machos 1P e 2P que ocorrem em Jaíba e Estrela de Alagoas (Araki et al., 2009). Genealogias foram construídas com as amostras de cada uma dessas localidades, revelando dois clados distintos que separavam a maioria das sequências das amostras de fenótipo 1P das de fenótipo 2P. Algumas poucas sequências de um fenótipo se misturavam ao segundo fenótipo e vice-versa, fornecendo possível evidência de retenção de polimorfismo ancestral ou introgressão entre as duas formas simpátricas.

Uma análise global com a inclusão das populações analisadas por Bauzer e colaboradores (2002a, 2002b) revelou que os machos com fenótipo 2P em Jaíba, Estrela de Alagoas e Sobral, assim como as amostras de Natal, Pancas e Marajó, são muito próximos geneticamente, com todos os valores de Fst computados par a par baixos ou não significativos. Os resultados indicaram ainda que as populações de Lapinha, Sobral 1P, Teresina e Jaíba 1P apresentam uma diferenciação genética entre elas que varia de baixa a moderada. Finalmente, as populações de Jacobina e Estrela 1P não só mostraram grande diferenciação genética entre elas próprias como também com todas as outras populações analisadas até aquele momento com o gene per (Araki et al., 2009; Bauzer et al., 2002a, 2002b).

Araki e colaboradores (2009) também compararam os resultados obtidos com o gene per com dados novos e previamente publicados acerca dos diferentes tipos de som de cópula e feromônios sexuais produzidos pelos machos (Araki et al., 2009; Souza et al., 2002, 2004; Hamilton, Dawson \& Pickett, 1996a, 1996b; Hamilton, Brazil \& Maingon, 2004; Hamilton et al., 2005). Essa análise integrativa revelou que as populações analisadas poderiam ser divididas em dois grandes grupos. O primeiro deles, que inclui as populações de Marajó, Sobral 2P, Natal, Estrela 2S, Jaíba 2P e Pancas, representaria uma das espécies do complexo que está distribuída principalmente ao longo da costa norte e nordeste do Brasil, atingindo o sudeste em regiões mais afastadas da costa. Além da proximidade genética revelada pelo gene per, essas populações compartilham o mesmo tipo de som de cópula (burst) e de feromônio (cembreno-1). As demais populações apresentam diferentes níveis de divergência genética e produzem diferentes tipos de feromônios e subtipos do som de cópula 'pulsado' (com padrão bem distinto do som tipo burst). Tais populações, portanto, são muito mais heterogêneas e representam provavelmente cinco espécies incipientes (Araki et al., 2009).

Finalmente, per foi recentemente empregado como marcador molecular por Vigoder e colaboradores (2010) em um estudo que integrou padrões de polimorfismo genético com diferenciação fenotípica de som de cópula em Lutzomyia cruzi (Mangabeira, 1938), uma espécie muito próxima a Lu. longipalpis s.l., também associada com a transmissão da 
leishmaniose visceral americana (Santos et al., 1998; Pita-Pereira et al., 2008). A análise do som de cópula revelou que machos de $L u$. cruzi produzem som do tipo burst, similar àquele previamente caracterizado em seis populações de Lu. longipalpis s.l. (Natal, Marajó, Sobral 2P, Jaíba 2P, Estrela 2P e Pancas) (Araki et al., 2009; Souza et al., 2004). Contudo, Lu. cruzi produz o feromônio 9-metil-germacreno-B (Brazil \& Hamilton, 2002), diferente do feromônio cembreno-1 encontrado nestas populações com som do tipo burst. A análise da diferenciação genética no gene per revelou uma divergência maior entre algumas populações de Lu. longipalpis s.l. que a observada entre algumas destas e Lu. cruzi, indicando que esta última é na verdade um membro do complexo Lu. longipalpis, confirmando resultados prévios obtidos em um estudo com microssatélites (Watts et al., 2005), a ser descrito na próxima sessão.

Diversos outros genes também envolvidos no controle do som de corte em $D$. melanogaster já foram identificados (Peixoto \& Hall, 1998; Gleason, 2005). Dentre eles destacam-se cacophony (cac) e paralytic (para), que codificam canais iônicos dependentes de voltagem. O gene cac codifica um canal de cálcio (Smith et al., 1998) e já foi empregado como marcador molecular em estudo de diferenciação entre linhagens derivadas de uma população natural de $D$. melanogaster (Peixoto, Costa \& Hall, 2000). Já o gene para codifica um canal de sódio (Loughney, Kreber \& Ganetzky, 1989; Littleton \& Ganetzky, 2000) e seus homólogos em outros insetos são sítios de mutações associadas com resistência a inseticidas (Loughney, Kreber \& Ganetzky, 1989; Milani, 1956; Pittendrigh et al., 1997). Ambos os genes foram empregados como marcadores moleculares em estudos de diferenciação entre populações de Lu. longipalpis s.l. no Brasil. Bottecchia e colaboradores (2004) sequenciaram um pequeno íntron ( $100 \mathrm{pb})$ do gene cac de indivíduos das populações alopátricas de Lapinha, Jacobina e Natal e das populações simpátricas de Sobral (ver Quadro 1).

Esse íntron mostrou-se altamente polimórfico, incluindo eventos de inserção e deleção (indels). Observou-se uma grande diferenciação entre as amostras, num padrão similar ao observado anteriormente com o gene per (Bauzer et al., 2002a, 2002b). Comparação feita com o teste de Mantel apresentou significante correlação ( $r=0,85)$ entre as estimativas de Fst baseadas nos dois loci entre as cinco populações analisadas em comum. Entretanto, o fluxo genético estimado entre as espécies crípticas de Sobral com o gene cac foi sete vezes maior do que aquele estimado com o gene per, indicando que o primeiro marcador é mais sujeito a introgressão do que o segundo. Já o outro marcador, para, foi utilizado por Lins, Souza e Peixoto (2008) para estudar a divergência entre as duas espécies simpátricas de Sobral. Os resultados indicaram este como o primeiro marcador a apresentar diferenças fixas entre as duas espécies. Comparados aos outros dois marcadores associados ao som, empregados no estudo de diferenciação genética desses insetos vetores (Bauzer et al., 2002a, 2002b; Bottecchia et al., 2004), para foi o que apresentou o menor nível de polimorfismo em Sobral. No entanto, o valor de Fst foi o mais alto até o momento, indicando o maior grau de diferenciação genética dentre esses três marcadores. A presença de diferenças fixas em para sinaliza que esse gene pode ser futuramente utilizado como um locus diagnóstico para identificar as fêmeas das duas espécies crípticas em Sobral, em estudos que se destinem a determinar possíveis diferenças na capacidade vetorial entre elas.

\section{MICROSSATÉLITES}

Maingon e colaboradores (2003) utilizaram microssatélites, previamente isolados de Lu. longipalpis s.l. (Watts et al., 2001), para estudar a diferenciação das duas espécies simpátricas do complexo que ocorre na localidade brasileira de Sobral. Como mencionado antes, os machos dessa localidade produzem diferentes tipos de feromônios. Aqueles de fenótipo 1P produzem o feromônio 9-metil-germacreno-B e aqueles de fenótipo $2 \mathrm{P}$ produzem o feromônio do tipo cembreno-1 (Ward et al., 1988). Utilizando cinco loci de microssatélites, os autores genotiparam 190 indivíduos das duas espécies simpátricas do complexo Lu. longipalpis. Dois índices de fixação foram utilizados, $R_{S T}$ (Slatkin et al., 1995) e $\theta_{\text {ST }}$ (Weir \& Cockerham, 1984). Frequências alélicas altamente divergentes em dois dos cinco loci de microssatélites determinaram uma diferenciação genética significante para as comparações entre amostras com diferentes feromônios, 
independentemente do índice utilizado. o fato de que somente dois dos cinco loci de microssatélites analisados nas populações simpátricas de Sobral apontaram intensa diferenciação sugere que introgressão envolvendo os outros três loci pode ter ocorrido. Tais resultados se assemelharam aos obtidos com o complexo Anopheles gambiae, que indicaram taxas diferenciais de introgressão pelo genoma (Besansky et al., 2003; Stump et al., 2005) e concordam com as evidências de introgressão reveladas pelos genes nucleares envolvidos no comportamento (Bauzer et al., 2002b; Bottecchia et al., 2004).

Os resultados obtidos por Maingon e colaboradores (2003), portanto, confirmaram a existência de duas espécies crípticas naquela localidade. Além disso, a diferenciação genética observada nesses loci de microssatélites pôde ser usada na genotipagem não só de machos como também das fêmeas, que são morfologicamente idênticas, permitindo a identificação da espécie que produz 9-metil-germacreno-B com um grau de confiança de 100\%, e para a espécie que produz cembreno-1, um grau de confiança de $86 \%$. Os autores comentam que, com mais marcadores de microssatélites e uma amostra maior, tal genotipagem poderia ser explorada em outras populações ou espécies de Lu. longipalpis S. l.. Isso forneceria uma base para uma identificação molecular de fêmeas, o que facilitaria a abordagem de questões sobre possíveis consequências epidemiológicas associadas à subestruturação de Lu. longipalpis.

Um outro estudo que empregou microssatélites como marcadores moleculares foi conduzido por Watts e colaboradores (Watts et al., 2005), em que se investigou o padrão filogeográfico e possíveis relações com diferentes tipos de feromônios produzidos em 11 populações do Brasil e da Venezuela (ver Quadro 1). Além das amostras de Lu. longipalpis, foram incluídas amostras de Lu. pseudolongipalpis e Lu. cruzi. Dados genotípicos individuais foram obtidos de 493 indivíduos, gerando 89 alelos entre todos os cinco loci de microssatélites empregados. Diferenciação genética entre as amostras, investigada mediante o índice de fixação $\theta_{\text {ST }}$ (Weir \& Cockerham, 1984), foi acentuada para a maior parte das comparações par a par. Houve uma fraca relação entre a diferenciação genética e a distância geográfica, e somente quando as amostras que produzem o mesmo tipo de feromônio foram analisadas individualmente é que a separação geográfica passou a explicar uma porcentagem maior de diferença genética entre as populações.

A diferenciação genética entre as duas amostras de Sobral que produzem feromônios distintos foi maior do que muitas comparações entre amostras separadas por distâncias consideráveis. Uma árvore neighbor-joining, construída com base na análise de $\theta_{\mathrm{sT}}$, separou as amostras em cinco clados. Dois destes foram representados pelas espécies Lutzomyia cruzi (Brasil) e Lu. pseudolongipalpis (Venezuela), isoladamente. Um terceiro clado foi constituído por populações venezuelanas (Altagracia, Guayabita, El Layero, Las Cabreras), caracterizadas majoritariamente pela produção do feromônio 9-metil-germacreno-B. Um quarto clado agrupou as populações brasileiras de Jacobina, Lapinha e Sobral 1P, onde a primeira é a única caracterizada pelo feromônio 3-metil- $\alpha$-himacaleno, enquanto as outras duas compartilham o feromônio 9-metil-germacreno-B. Finalmente, um quinto e bem distinto grupo foi composto de populações brasileiras que produzem feromônio do tipo cembreno-1 (Natal, Marajó e Sobral 2P).

Os autores concluíram que não somente há uma diferenciação genética entre as populações brasileiras, mas também que os tipos de feromônio moldam a estruturação genética dessas populações. Mencionaram ainda que os dados concordam com diferenças previamente descritas em som de cópula de machos, um outro fenótipo com potencial envolvimento na seleção sexual de Lu. longipalpis s.l. (Souza et al., 2002, 2004).

\section{COMENTÁRIOS FINAIS}

Os marcadores moleculares utilizados nos estudos evolutivos do complexo Lu. longipalpis apontaram, de forma geral, um grau elevado de diferenciação genética entre as espécies crípticas. É provável que também existam diferenças em aspectos da capacidade vetorial. Nesse sentido, estudos de genética de populações utilizando marcadores moleculares envolvidos com os aspectos da biologia desses vetores que influenciam a transmissão da L. infantum são 
particularmente importantes. Um exemplo desse tipo de estudo, já realizado em Lu. longipalpis s.l., são os trabalhos envolvendo o peptídio maxadilan, um potente vasodilatador encontrado na saliva desses insetos (Lanzaro \& Warburg, 1995; Warburg et al., 1994; Lanzaro et al., 1999; Yin, Norris \& Lanzaro, 2000). Outros estudos evolutivos envolvendo genes que controlam a competência vetorial, escolha de hospedeiro (por exemplo, receptores olfativos) e a adaptação a ambientes modificados pelo homem são particularmente promissores.

Outra abordagem promissora será a utilização da genômica de populações e de análises multilócus no complexo Lu. longipalpis (Black et al., 2001; Luikart et al., 2003; Stinchocombe \& Hoekstra, 2007; Mazzoni et al., 2008; Thomson, Wang \& Johnson, 2010). A análise simultânea de um grande número de loci torna possível a separação de efeitos locus específicos (por exemplo, seleção natural) dos efeitos pangenômicos (por exemplo, deriva genética). o ponto crucial dessa separação é que os efeitos genômicos fornecem informações mais confiáveis acerca de eventos históricos e demográficos como, por exemplo, vicariância e gargalos populacionais. Já os efeitos locus específicos ajudam a identificar sinais de seleção natural em genes envolvidos com os mais variados processos de adaptabilidade, podendo incluir aqueles envolvidos na capacidade vetorial.

\section{REFERÊNCIAS}

ALEXANDER, B. et al. Current status of the L. longipalpis species complex. Memórias do Instituto Oswaldo Cruz, 93: 31-33, 1998.

ARAKI, A. et al. Molecular and behavioral differentiation among Brazilian populations of Lutzomyia longipalpis (Diptera: Psychodidae: Phlebotominae). PLoS Neglected Tropical Diseases, 3: e365, 2009.

ARRIVILLAGA, J. \& FELICIANGELI, M. Lutzomyia pseudolongipalpis: the first new species within the longipalpis (Diptera: Psychodidae: Phlebotominae) complex from La Rinconada, Curarigua, Lara State, Venezuela. Journal of Medical Entomology, 38: 783-790, 2001.

ARRIVILLAGA, J. et al. Phylogeography of the neotropical sand fly Lutzomyia longipalpis inferred from mitochondrial DNA sequences. Infection, Genetics and Evolution, 2: 83-95, 2002.

ARRIVILLAGA, J. et al. The taxonomic status of genetically divergent populations of Lutzomyia longipalpis (Diptera: Psychodidae) based on the distribution of mitochondrial and isozyme variation. Journal of Medical Entomology, 40: 615627, 2003.

AYALA, F. \& COLUZZI, M. Chromosome speciation: humans, Drosophila, and mosquitoes. Proceedings of the National Academy of Sciences of the USA, 102, supl. 1: 6.535-6.542, 2005.

AZEVEDO, A. et al. Studies on populations of Lutzomyia longipalpis (Lutz \& Neiva, 1912) (Diptera: Psychodidae: Phlebotominae) in Brazil. Memórias do Instituto Oswaldo Cruz, 95: 305-322, 2000.

BAUZER, L. et al. The period gene and genetic differentiation between three Brazilian populations of Lutzomyia longipalpis. Insect Molecular Biology, 11: 315-323, 2002a.

BAUZER, L. et al. Molecular divergence in the period gene between two putative sympatric species of the Lutzomyia longipalpis complex. Molecular Biology and Evolution, 19: 1.624-1.627, 2002b.

BAUZER, L. et al. Lutzomyia longipalpis in Brazil: a complex or a single species? A mini-review. Memórias do Instituto Oswaldo Cruz, 102: 1-12, 2007.

BESANSKY, N. et al. Semipermeable species boundaries between Anopheles gambiae and Anopheles arabiensis: evidence from multilocus DNA sequence variation. Proceedings of the National Academy of Sciences of the USA, 100: 10.818$10.823,2003$.

BICKFORD, D. et al. Cryptic species as a window on diversity and conservation. Trends in Ecology \& Evolution, 22: 148-155, 2007.

BLACK, W. et al. Population genomics: genome-wide sampling of insect populations. Annual Review of Entomology, 46: 441469, 2001. 
BOTTECCHIA, M. et al. Genetic divergence in the cacophony IVS6 intron among five Brazilian populations of Lutzomyia longipalpis. Journal of Molecular Evolution, 58: 754-761, 2004.

BRAZIL, R. \& HAMILTON, J. Isolation and identification of 9-methylgermacrene-B as the putative sex pheromone of Lutzomyia cruzi (Mangabeira, 1938) (Diptera: Psychodidae). Memórias do Instituto Oswaldo Cruz, 97: 435-436, 2002.

COUTINHO-ABREU, I. et al. Lutzomyia longipalpis s.l. in Brazil and the impact of the Sao Francisco River in the speciation of this sand fly vector. Parasits \& Vectors, 1: 37, 2008.

COYNE, J. Genetics and speciation. Nature, 355: 511-515, 1992.

DIAS, E. et al. Random amplified polymorphic DNA (RAPD) analysis of Lutzomyia longipalpis laboratory populations. Revista do Instituto de Medicina Tropical de São Paulo, 40: 49-53, 1998.

DUJARDIN, J. et al. Isozymic and metric variation in the Lutzomyia longipalpis complex. Medical and Veterinary Entomology, 11: 394-400, 1997.

DYE, C.; DAVIES, C. \& LAINSON, R. Communication among phlebotomine sandflies: a field study of domesticated Lutzomyia longipalpis populations in Amazonian Brazil. Animal Behaviour, 42: 183-192, 1991.

GLEASON, J. Mutations and natural genetic variation in the courtship song of Drosophila. Behavior Genetics, 35: 265-277, 2005.

GLEASON, J. \& POWELL, J. Interspecific and intraspecific comparisons of the period locus in the Drosophila willistoni sibling species. Molecular Biology and Evolution, 14: 741-753, 1997.

HAMILTON, J.; BRAZIL, R. \& MAINGON, R. A fourth chemotype of Lutzomyia longipalpis (Diptera: Psychodidae) from Jaibas, Minas Gerais State, Brazil. Journal of Medical Entomology, 41: 1.021-1.026, 2004.

HAMILTON, J.; DAWSON, G. \& PICKETT, J. 9-Methylgermacrene-B: proposed structure for novel homosesquiterpene sex pheromone glands of Lutzomyia longipalpis (Diptera: Psychodidae) from Lapinha, Brazil. Journal of Chemical Ecology, 22: 1.477-1.491, 1996a.

HAMILTON, J.; DAWSON, G. \& PICKETT, J. 3-Methyl-Himachalene: proposed structure for novel homosesquiterpene sex pheromone of Lutzomyia longipalpis (Diptera: Psychodidae) from Jacobina, Brazil. Journal of Chemical Ecology, 22: 2.331-2.340, 1996b.

HAMiLTon, J. et al. Analysis of the sex pheromone extract of individual male Lutzomyia longipalpis sandflies from six regions in Brazil. Medical and Veterinary Entomology, 19: 480-488, 2005.

HILTON, H. \& HEY, J. DNA sequence variation at the period locus reveals the history of species and speciation events in the Drosophila virilis group. Genetics, 144: 1.015-1.025, 1996.

HODGKINSON, V. et al. Rapid identification of mitochondrial cytochrome B haplotypes by single strand conformation polymorphism in Lutzomyia longipalpis (Diptera: Psychodidae) populations. Journal of Medical Entomology, 39: 689694, 2002.

HODGKINSON, V. et al. Mitochondrial cytochrome b variation in populations of the visceral leishmaniasis vector Lutzomyia longipalpis across eastern Brazil. The American Journal of Tropical Medicine and Hygiene, 69: 386-392, 2003.

HUDSON, R.; SLATKIN, M. \& MADDISON, W. Estimation of levels of gene flow from DNA sequence data. Genetics, 132: 583589, 1992.

KONOPKA, R. \& BENZER, S. Clock mutants of Drosophila melanogaster. Proceedings of the National Academy of Sciences of the USA, 68: 2.112-2.116, 1971.

KYRIACOU, C. \& HALL, J. Circadian rhythm mutations in Drosophila melanogaster affect short-term fluctuations in the male's courtship song. Proceedings of the National Academy of Sciences of the USA, 77: 6.729-6.733, 1980.

KYRIACOU, C. \& HALL, J. The function of courtship song rhythms in Drosophila. Animal Behaviour, 30: 784-801, 1982.

KYRIACOU, C. \& HALL, J. Interspecific genetic control of courtship song production and reception in Drosophila. Science, 232: 494-497, 1986. 
LACHAISE, D. et al. Evolutionary novelties in islands: Drosophila santomea, a new melanogaster sister species from São Tomé. Proceedings. Biological Sciences, 267: 1.487-1.495, 2000.

LAINSON, R. \& RANGEL, E. Lutzomyia longipalpis and the eco-epidemiology of American visceral leishmaniasis, with particular reference to Brazil: a review. Memórias do Instituto Oswaldo Cruz, 100: 811-827, 2005.

LANZARO, G. \& WARBURG, A. Genetic variability in phlebotomine sandflies: possible implicatioins for leishmaniasis epidemiology. Parasitology Today, 4: 151, 1995.

LANZARO, G. et al. Lutzomyia longipalpis is a species complex: genetic divergence and interspecific hybrid sterility among three populations. The American Journal of Tropical Medicine and Hygiene, 48: 839-847, 1993.

LANZARO, G. et al. Genetic variation among natural and laboratory colony populations of Lutzomyia longipalpis (Lutz \& Neiva, 1912) (Diptera: Psychodidae) from Colombia. Memórias do Instituto Oswaldo Cruz, 93: 65-69, 1998.

LANZARO, G. et al. Variation in the salivary peptide, maxadilan, from species in the Lutzomyia longipalpis complex. Insect Molecular Biology, 8: 1-9, 1999.

LINS, R.; SOUZA, N. \& PEIXOTO, A. Genetic divergence between two sympatric species of the Lutzomyia longipalpis complex in the paralytic gene, a locus associated with insecticide resistance and lovesong production. Memórias do Instituto Oswaldo Cruz, 103: 736-740, 2008.

LITTLETON, J. \& GANETZKY, B. Ion channels and synaptic organization: analysis of the Drosophila genome. Neuron, 26(1): 35-43, 2000.

LOUGHNEY, K.; KREBER, R. \& GANETZKY, B. Molecular analysis of the para locus, a sodium channel gene in Drosophila. Cell, 58: 1.143-1.154, 1989.

LOXDALE, H. \& LUSHAI, G. Molecular markers in entomology. Bulletin of Entomological Research, 88: 577-600, 1998.

LUIKART, G. et al. The power and promise of population genomics: from genotyping to genome typing. Nature Reviews Genetics, 4: 981-994, 2003.

MAINGON, R. et al. Genetic identification of two sibling species of Lutzomyia longipalpis (Diptera: Psychodidae) that produce distinct male sex pheromones in Sobral, Ceará State, Brazil. Molecular Ecology, 12: 1.879-1.894, 2003.

MANGABEIRA, O. Sobre a sistemática e biologia dos flebótomos do Ceará. Revista Brasileira de Malariologia e Doenças Tropicais, 21: 3-26, 1969.

MARTINS, A.; WILliAnS, P. \& FALCÃO, A. American Sand Flies (Diptera: Psychodidae, Phlebotominae). Rio de Janeiro: Academia Brasileira de Ciências, 1978.

MAYR, E. Animal Species and Evolution. Cambridge: Belknap Press of Harvard University Press, 1963.

MAZZONI, C. et al. Multilocus analysis of introgression between two sand fly vectors of leishmaniasis. BMC Evolutionary Biology, 8: 141, 2008.

MILANI, R. Mendelian behavior of resistance to the knock-down action of DDT and correlation between knock-down and mortality in Musca domestica L. Rendiconti - Istituto Superiore di Sanità, 19: 1.107-1.143, 1956.

MORRISON, A. et al. Dispersal of the sand fly Lutzomyia longipalpis (Diptera: Psychodidae) at an endemic focus of visceral leishmaniasis in Colombia. Journal of Medical Entomology, 30: 427-435, 1993.

MUKHOPADHYAY, J. et al. Genetic variability in biochemical characters of Brazilian field populations of the Leishmania vector, Lutzomyia longipalpis (Diptera: Psychodidae). The American Journal of Tropical Medicine and Hygiene, 59: 893-901, 1998.

MUTEBI, J. et al. Genetic variability among populations of the sand fly Lutzomyia (Lutzomyia) longipalpis (Diptera: Psychodidae) from Central America. Journal of Medical Entomology, 35: 169-174, 1998.

MUTEBI, J. et al. Breeding structure of the sand fly Lutzomyia longipalpis (Lutz \& Neiva) in Brazil. The American Journal of Tropical Medicine and Hygiene, 61: 149-157, 1999.

PEIXOTO, A. Evolutionary behavioral genetics in Drosophila. Advances in Genetics, 47: 117-150, 2002. 
PEIXOTO, A. \& HALL, J. Analysis of temperature-sensitive mutants reveals new genes involved in the courtship song of Drosophila. Genetics, 148: 827-838, 1998.

PEIXOTO, A.; COSTA, R. \& HALL, J. Molecular and behavioral analysis of sex-linked courtship song variation in a natural population of Drosophila melanogaster. Journal of Neurogenetics, 14: 245-256, 2000.

PEIXOTO, A. et al. Evolution of the threonine-glycine repeat region of the period gene in the melanogaster species subgroup of Drosophila. Journal of Molecular Evolution, 35: 411-419, 1992.

PEIXOTO, A. et al. New molecular markers for phlebotomine sand flies. International Journal for Parasitology, 31: 635-639, 2001.

PITA-PEREIRA, D. et al. Detection of natural infection in Lutzomyia cruzi and Lutzomyia forattinii (Diptera: Psychodidae: Phlebotominae) by Leishmania infantum chagasi in an endemic area of visceral leishmaniasis in Brazil using a PCR multiplex assay. Acta Tropica, 107: 66-69, 2008.

PITTENDRIGH, B. et al. Point mutations in the Drosophila sodium channel gene para associated with resistance to DDT and pyrethroid insecticides. Molecular and General Genetics, 256: 602-610, 1997.

QUEIROZ BALBINO, V. et al. Genetic structure of natural populations of the sand fly Lutzomyia longipalpis (Diptera: Psychodidae) from the Brazilian northeastern region. Acta Tropica, 98: 15-24, 2006.

RITCHIE, M.; HALSEY, E. \& GLEASON, J. Drosophila song as a species-specific mating signal and the behavioural importance of Kyriacou \& Hall cycles in D. melanogaster song. Animal Behaviour, 58: 649-657, 1999.

SAKAI, T. \& ISHIDA, N. Circadian rhythms of female mating activity governed by clock genes in Drosophila. Proceedings of the National Academy of Sciences of the USA, 98: 9.221-9.225, 2001.

SANTOS, S. et al. Incrimination of Lutzomyia cruzi as a vector of American visceral leishmaniasis. Medical and Veterinary Entomology, 12: 315-317, 1998.

SLATKIN, M. A measure of population subdivision based on microsatellite allele frequencies. Genetics, 139: 457-462, 1995.

SMITH, L. et al. Courtship and visual defects of cacophony mutants reveal functional complexity of a calcium-channel alpha1 subunit in Drosophila. Genetics, 149: 1.407-1.426, 1998.

SOARES, R. \& TURCO, S. Lutzomyia longipalpis (Diptera: Psychodidae: Phlebotominae): a review. Anais da Academia Brasileira de Ciências, 75: 301-330, 2003.

SOTO, S. et al. Speciation and population structure in the morphospecies Lutzomyia longipalpis (Lutz \& Neiva) as derived from the mitochondrial ND4 gene. Molecular Phylogenetics and Evolution, 18: 84-93, 2001.

SOUZA, N. et al. Copulation songs in three siblings of Lutzomyia longipalpis (Diptera: Psychodidae). Transactions of the Royal Society of Tropical Medicine and Hygiene, 96: 102-103, 2002.

SOUZA, N. et al. Analysis of the copulatory courtship songs of Lutzomyia longipalpis in six populations from Brazil. Journal of Medical Entomology, 41: 906-913, 2004.

SOUZA, N. et al. Reproductive isolation between sympatric and allopatric Brazilian populations of Lutzomyia longipalpis s.l. (Diptera: Psychodidae). Memórias do Instituto Oswaldo Cruz, 103: 216-219, 2008.

STINCHCOMBE, J. \& HOEKSTRA, H. Combining population genomics and quantitative genetics: finding the genes underlying ecologically important traits. Heredity, 100: 158-170, 2007.

STUMP, A. et al. Centromere-proximal differentiation and speciation in Anopheles gambiae. Proceedings of the National Academy of Sciences of the USA, 102: 15.930-15.935, 2005.

THOMSON, R.; WANG, I. \& JOHNSON, J. Genome-enabled development of DNA markers for ecology, evolution and conservation. Molecular Ecology, 19: 2.184-2.195, 2010.

VIGODER, F. et al. Lovesongs and period gene polymorphisms indicate Lutzomyia cruzi (Mangabeira, 1938) as a sibling species of the Lutzomyia longipalpis (Lutz and Neiva, 1912) complex. Infection, Genetics and Evolution, 10: 734-739, 2010.

WANG, R. \& HEY, J. The speciation history of Drosophila pseudoobscura and close relatives: inferences from DNA sequence variation at the period locus. Genetics, 144: 1.113-1.126, 1996. 
WARBURG, A. et al. Saliva of Lutzomyia longipalpis sibling species differs in its composition and capacity to enhance leishmaniasis. Philosophical Transactions of the Royal Society of London. Series B, Biological Sciences, 345: 223-230, 1994.

WARD, R. et al. Reproductive isolation between different forms of Lutzomyia longipalpis (Lutz \& Neiva), (Diptera: Psychodidae), the vector of Leishmania donovani chagasi (Cunha \& Chagas) and its significance to kala-azar distribution in South America. Memórias do Instituto Oswaldo Cruz, 78: 269-280, 1983.

WARD, R. et al. The distribution of two morphological forms of Lutzomyia longipalpis (Lutz \& Neiva) (Diptera: Psychodidae). Memórias do Instituto Oswaldo Cruz, 80: 145-148, 1985.

WARD, R. et al. The Lutzomyia longipalpis complex: reproduction and distribution. In: SERVICE, M. W. (Ed.). Biosystematics of Haematophagous Insects. Oxford: Oxford University Press, 1988.

WATTS, P. et al. Polymorphic dinucleotide microsatellite loci in the sandfly Lutzomyia longipalpis (Diptera: Phlebotominae). Molecular Ecology Notes, 2: 60-61, 2001.

WATTS, P. et al. Male sex pheromones and the phylogeographic structure of the Lutzomyia longipalpis species complex (Diptera: Psychodidae) from Brazil and Venezuela. The American Journal of Tropical Medicine and Hygiene, 73: 734-743, 2005.

WEIR, B. \& COCKERHAM, C. Estimating F-statistics for the analysis of population structure. Evolution, 38: 1.358-1.370, 1984.

WILLIAMS, J. et al. DNA polymorphisms amplified by arbitrary primers are useful as genetic markers. Nucleic Acids Research, 18: 6.531-6.535, 1990.

WINKER, K. Sibling species were first recognized by William Derham (1718). The Auk, 122(2): 706-707, 2005.

YIN, H.; NORRIS, D. \& LANZARO, G. Sibling species in the Lutzomyia longipalpis complex differ in levels of mRNA expression for the salivary peptide, maxadilan. Insect Molecular Biology, 9: 309-314, 2000.

YIN, H. et al. Metaphase karyotypes and G-banding in sandflies of the Lutzomyia longipalpis complex. Medical and Veterinary Entomology, 13: 72-77, 1999.

YOUNG, D. \& DUNCAN, M. Guide to the identification and geographic distribution of Lutzomyia sand flies in Mexico, the West Indies, Central and South America (Diptera: Psychodidae). Memoirs of American Entomological Institute, 54: 1-881, 1994. 


\title{
Diagnóstico Molecular de Leishmania spp. em Flebótomos Provenientes de Áreas de Ocorrência de Leishmanioses
}

\author{
Constança F. De Paoli de Carvalho Britto I Daniela de Pita Pereira
}

\begin{abstract}
A s leishmanioses são doenças com significativa diversidade clínica e epidemiológica, de ampla faixa de distribuição

geográfica no Velho e no Novo Mundo, envolvendo várias espécies de vetores flebotomíneos proximamente associadas com diferentes parasitos do gênero Leishmania e hospedeiros reservatórios, que propiciam ciclos de transmissão distintos (Lainson \& Shaw, 1987, 2005). A capacidade de um flebotomíneo em atuar como vetor é primeiramente determinada pela habilidade de sobrevivência, multiplicação e diferenciação do parasito no interior do trato digestório do inseto (Lainson \& Rangel, 2005). Consequentemente, a observação e a correta identificação das formas do parasito presentes no intestino do vetor constituem passos importantes para a incriminação de vetores de Leishmania e a caracterização da doença. Embora as diversas espécies de Leishmania sejam morfologicamente semelhantes, elas apresentam graus variáveis de especificidade em relação aos seus hospedeiros invertebrados (Shaw, 1994).

o Brasil representa o país com maior número de espécies de flebotomíneos, totalizando aproximadamente trezentas espécies e subespécies de Lutzomyia distribuídas por todo o território brasileiro, entre as 470 espécies descritas no Novo Mundo (Galati, 2003); sem considerar que novas espécies de vetores ainda estão sendo encontradas e descritas no país nos últimos anos.

Para a definição de fatores de risco e controle epidemiológico das leishmanioses, é importante a vigilância contínua das espécies de Leishmania e flebotomíneos prevalentes em áreas endêmicas, assim como a identificação de reservatórios. Algumas espécies de flebotomíneos têm sido sugeridas ou incriminadas como transmissoras de leishmanioses, por meio de observações epidemiológicas e/ou experimentais, tendo principalmente como base o grau de antropofilia, distribuição espacial coincidente com a doença e a incidência de infecção natural por Leishmania spp. o conhecimento sobre a ecologia do vetor é essencial quando se busca avaliar a capacidade vetorial de uma espécie particular de flebotomíneo, e os estudos de prevalência da infecção por Leishmania nesses insetos contribuem como indicadores funcionais da intensidade de transmissão da doença nas áreas endêmicas. A endemicidade da doença em uma dada localidade está, em parte, associada com a distribuição e a abundância das espécies de insetos vetores na área de investigação.
\end{abstract}




\section{MÉTODOS UTILIZADOS PARA A DETECÇÃO DE LEISHMANA SPP. EM INSETOS FLEBOTOMÍNEOS}

A maioria das investigações epidemiológicas tem objetivado a pesquisa de flagelados no trato digestório de flebótomos e o entendimento da associação entre o vetor e o parasito na natureza. Estudos da prevalência de infecção no vetor flebotomíneo podem ser usados como indicadores de mudanças na intensidade de transmissão de Leishmania em determinado foco endêmico. Entretanto, deve ser ressaltado que a prevalência no vetor é geralmente baixa e sua estimativa requer a dissecção de um grande número de espécimes (Martín-Sánchez et al., 2006).

A correta identificação das espécies de vetores em áreas de ocorrência de leishmanioses, bem como a estimativa das taxas de infecção natural pelas diferentes espécies de Leishmania, auxiliam na compreensão da epidemiologia da doença e também na adoção de medidas de prevenção e controle dessa parasitose. Com esse cenário, estudos têm sido conduzidos mediante dissecção de insetos fêmeas e identificação dos parasitos in situ ou por intermédio da aplicação de técnicas moleculares para a detecção do DNA de Leishmania em espécimes individuais ou em pools constituídos por grupos de flebotomíneos da mesma espécie e área de origem.

A metodologia mais comumente utilizada para a identificação das formas do parasito encontradas no intestino do flebótomo fêmea tem sido a dissecção do aparelho digestório do díptero, seguido de exame de microscópio direto entre lâmina e lamínula. Nesse caso a positividade das amostras deve ser confirmada posteriormente, com o isolamento do parasito em meio de cultura - frequentemente suscetível à contaminação, e/ou por meio de inoculação em animais de laboratório. Tal confirmação é essencial, uma vez que os flebótomos são também hospedeiros de outros flagelados dos gêneros Trypanosoma e Endotrypanum, sendo que neste último, os parasitos passam por um estágio de promastigota indistinguível das leishmânias, complicando, sobremaneira, o diagnóstico microscópico e o isolamento em cultura (Rodríguez et al., 1994; Tesh \& Modi, 1984). Além de se constituir em laborioso procedimento, outros fatores podem limitar o uso da metodologia clássica de dissecção, como por exemplo, sua baixa sensibilidade, especialmente quando se considera a baixa prevalência de infecção encontrada na maioria dos focos endêmicos (Ashford, Desjeux \& De Raadt, 1991), associada à dificuldade de processamento de um grande número de amostras, necessário nas investigações epidemiológicas. A dissecção do inseto, seguida da observação direta do parasito consome tempo, requer grande habilidade técnica por conta principalmente do tamanho reduzido dos insetos flebotomíneos, além da necessidade de se trabalhar com insetos vivos. Apesar de que esses também podem ser criopreservados em nitrogênio líquido para posterior dissecção.

A investigação de infecção natural por Leishmania valendo-se de metodologia convencional tem gerado taxas que variam de 0 a 9\% (Arias et al., 1985; Ryan \& Brazil, 1984; Santos et al., 1998), mas em geral esses índices se situam abaixo de $1 \%$ nas distintas áreas investigadas tanto no Brasil quanto em outros países da América do Sul (Galati et al., 1996; Luz et al., 2000; Perez et al., 1994). Índices de infecção relativamente altos podem ser observados em flebotomíneos capturados em florestas primárias, como a região amazônica, a qual apresenta uma fauna flebotomínica diversificada e abundante (Lainson et al., 1985; Arias \& Freitas, 1978; Lainson, Ward \& Shaw, 1976; Silveira et al., 1991).

Com o intuito de se elevar a frequência do encontro de flebótomos naturalmente infectados, outras estratégias foram introduzidas. O uso de anticorpos monoclonais específicos em radioimunoensaios e ensaios de imunofluorescência indireta mostrou ser um teste rápido para a identificação imediata da espécie de Leishmania que está infectando o vetor, além de a abordagem possibilitar a avaliação simultânea de um grande número de exemplares (Adini et al., 1998). Da mesma forma, sondas moleculares específicas baseadas no DNA do cinetoplasto ou kDNA de Leishmania foram usadas em ensaios de hibridização para a deteç̧ão e identificação dos parasitos em vetores flebotomíneos (Ready, Smith \& Killick-Kendrick, 1988). Contudo, ambas as metodologias não demonstraram boa sensibilidade para serem adotadas em investigações epidemiológicas. 
Nos últimos vinte anos, métodos moleculares baseados na reação em cadeia da polimerase ou PCR foram desenvolvidos para a identificação de algumas espécies de Leishmania isoladas de culturas ou de casos humanos. Os primeiros trabalhos de aplicação da PCR na fauna flebotomínica foram descritos no Novo Mundo (Bruijn \& Barker, 1992) e na Índia (Mukherjee et al., 1997). A tecnologia de PCR representa um método alternativo para a detecção e identificação de Leishmania spp. em estudos de campo destinados a avaliar a competência vetorial de insetos flebotomíneos e tem revelado valores distintos de sensibilidade e especificidade (Rodríguez et al., 1999; Silva \& Grunewald, 1999; Aransay, Scoulica \& Tselentis, 2000; Córdoba-Lanús et al., 2006; Paiva et al., 2006, 2010; Pita-Pereira et al., 2008, 2009, 2011; Marcondes et al., 2009). Apesar de sua ampla aplicação na análise de amostras entomológicas provenientes de distintas regiões geográficas, em geral, outros métodos ainda se fazem necessários para a posterior caracterização molecular das espécies de Leishmania detectadas nos flebótomos. Assim, produtos amplificados contendo DNA de Leishmania podem ser submetidos a diversos procedimentos para genotipagem molecular do parasito, tais como análises de polimorfismos de tamanho dos fragmentos de restrição (RFLP), hibridização com sondas específicas para subgênero/complexo/espécie, sequenciamento ou até mesmo a realização de um segundo ensaio de PCR com iniciadores específicos para complexos ou espécies (Azizi et al., 2006; Azizi, Rassi \& Moemenbellah-Fard, 2010; Garcia et al., 2007; Pita-Pereira et al., 2005; Jorquera et al., 2005; MartínSanchez et al., 2006) (ver Quadro 1, adiante).

As principais vantagens do uso da PCR consistem na sua maior sensibilidade, possibilitando a identificação de material genético de Leishmania mesmo em quantidades mínimas como 50 fg de DNA (Fu, Perona-Wright \& Barker, 1998), além de a técnica não depender do isolamento e cultivo do parasito, levando a uma maior rapidez do diagnóstico quando uma grande amostragem de flebótomos precisa ser avaliada (Barker, 1989; Michalsky et al., 2002). A possibilidade de se poder trabalhar com insetos mantidos a seco, congelados ou conservados em álcool, sem afetar o desempenho da reação, implica outra vantagem da técnica. Ressalta-se também que a eficiência de detecção pelo ensaio molecular independe do número, estágio de desenvolvimento e localização dos parasitos no trato digestório do vetor (Perez et al., 1994). Entretanto, é reconhecido que fatores adicionais influenciam na sensibilidade da PCR, como por exemplo, o método empregado para extração de DNA, o número de cópias do DNA alvo da amplificação, assim como a variabilidade genética do alvo selecionado. Existem evidências que diferenças na eficiência de métodos de extração influenciam significativamente a sensibilidade do ensaio molecular. Além disso, o processo de 'otimização' de um protocolo de PCR deve resultar em uma combinação perfeita entre o DNA extraído (e consequentemente o método de extração) e as condições de reação (Bastien, Procop \& Reischl, 2008).

o processo de armazenamento de insetos constitui-se em um passo prévio importante, de modo a tornar essa ferramenta molecular ainda mais sensível e específica. Recomendam-se, assim, a padronização de procedimentos para conservação dos insetos pós-captura e a adequação de protocolos para extração de DNA. A facilidade de transporte das amostras com a adequada preservação do DNA que possibilite manter a sua integridade por longos períodos é um item relevante a ser considerado. Para tanto, devem ser avaliadas as temperaturas de transporte e as condições de conservação. Insetos mantidos secos a $4^{\circ} \mathrm{C}$ ou em temperaturas mais baixas, ou conservados à temperatura ambiente em isopropanol ou etanol 70\% têm se mostrado eficientes quanto à preservação do DNA (Cabrera et al., 2002; Paiva et al., 2007).

É reconhecido que os insetos apresentam inibidores em seus tecidos que podem diminuir a eficiência da reação de PCR, majoritariamente em seu exoesqueleto, cabeça e tórax (Higgins \& Azard, 1995; Siridewa, Karunanayake \& Chandrasekharan, 1996). Independentemente da presença de inibidores nos tecidos dos flebótomos, alguns reagentes empregados na extração de DNA, tais como, fenol, clorofórmio, proteinase K ou excesso de EDTA, podem também inibir a atividade da enzima DNA polimerase e consequentemente fornecer resultados diagnósticos falso-negativos. 
Em vista disso, recomenda-se o emprego de um gene constitutivo (endógeno) de flebotomíneo no ensaio de PCR, a fim de controlar a qualidade do DNA extraído e verificar a possibilidade da presença de inibidores nas amostras a serem analisadas (Pita-Pereira et al., 2005).

Tem sido demonstrado que o método de PCR é mais eficiente do que as técnicas de dissecção para o processamento e identificação da presença de Leishmania, em se tratando de uma ampla amostragem de flebótomos. Entretanto, a metodologia molecular aplicada a insetos individuais não se torna prática quando centenas ou milhares de exemplares precisam ser processados. Para contornar tais dificuldades, estudos têm sido conduzidos por meio da aplicação da PCR em pools ou grupos de insetos, gerando como resultados taxas estimadas de infecção (Silva \& Grunewald, 1999; Miranda et al., 2002; Martín-Sánchez et al., 2006; Jorquera et al., 2005; Pita-Pereira et al., 2005, 2008; Paiva et al., 2010; Nascimento et al., 2007; Soares et al., 2010). Além disso, o ensaio molecular tem contribuído para a identificação de espécies suspeitas de atuarem como vetores, eliminando o erro que pode ser gerado pela pesquisa do parasito por microscopia, quando se considera que flagelados que se movimentam no interior do trato digestório do flebótomo possam indicar infecção por Leishmania (Perez et al., 1994; Rodríguez et al., 1999).

O uso da PCR tem permitido a estimativa de taxas de infecção de flebótomos em distintas áreas de ocorrência de leishmanioses em vários países, incluindo: Sucre - Venezuela, com taxa de infecção de 1,3\% (Jorquera et al., 2005); Urana e Puerto Cabello - Venezuela, com 1,1\% (Feliciangeli et al., 1994); Chaute e Nambuque/Padregual (regiões andinas) - Peru, com 1,1\% (Perez et al., 1994) e 2,6\% (Kato et al., 2011); Chanchan e Alausi - regiões andinas do Equador, com 3,3\% (Kato et al., 2005); Panamá, 0,46\% (Miranda et al., 2009); Cidade de Chetumal - México, 1,95\% (Sánchez-García et al., 2010); no Brasil - estado da Bahia, com 1,5\% (Miranda et al., 2002); município do Rio de Janeiro, 2\% (Pita-Pereira et al., 2005); estado de Pernambuco (Zona da Mata) com 4\% (Carvalho et al., 2010); Maranhão, 1,56\% (Felipe et al., 2011); Mato Grosso com 0,71\% (Missawa et al., 2010) e Mato Grosso do Sul com 1,1\% e 1,6\% (Pita-Pereira et al., 2008; Paiva et al., 2010); município de Porto Alegre (regiões periurbanas) 1,1\% (Pita-Pereira et al., 2009) e 0,3\% (Pita-Pereira et al., 2011); Minas Gerais, 3,9\% (Michalsky et al., 2011); Paraná, 0,22\% (Oliveira et al., 2011) e no Espírito Santo, índice de 0,46\% (Rocha et al., 2010). Taxas superiores de positividade, de 8,3\% de infecção por Leishmania infantum (Syn. L. chagasi) em Phlebotomus papatasi na Grécia foram reveladas com o emprego de um ensaio de PCR seminested (Aransay, Scoulica \& Tselentis, 2000); de 9,1\% para infecção por L. (Viannia) em Lutzomyia neivai capturados nas províncias de Tucumán e Salta, na Argentina (Córdoba-Lanús et al., 2006) e de 6,7\% de Phlebotomus argentipes infectados por Leishmania spp. no Nepal (Pandey et al., 2008).

A metodologia de PCR também pode ser usada com a finalidade de medir a quantidade de uma determinada sequência-alvo presente em amostras biológicas, por intermédio de sistemas fechados que empregam corantes fluorescentes e que permitem monitorar a reação durante a sua ocorrência em tempo real. Além de possibilitar a quantificação de amostras, outra vantagem dos ensaios de PCR em tempo real reside no menor tempo necessário para o resultado final, considerando que a etapa de visualização dos produtos amplificados em gel pode ser eliminada, o que também evita a possibilidade de contaminação do ambiente e de amostras decorrente da manipulação pós-PCR.

Em 2005 foi descrito o primeiro trabalho com PCR em tempo real utilizando o sistema de deteç̧ão por sonda TaqMan, para o diagnóstico de infecção natural em flebotomíneos (Gómez-Saladín, Doud \& Maroli, 2005). Aplicando iniciadores gênero-específicos para amplificação do gene da subunidade menor do RNA ribossomal de Leishmania, os autores revelaram uma positividade de 2,9\% em flebótomos coletados em duas províncias da Sicília, Itália. Contudo, nesse trabalho, a metodologia foi aplicada apenas como uma ferramenta qualitativa. Mais recentemente, desenvolveu-se um outro ensaio, baseado no sistema TaqMan, direcionado para o gene de cópia única da DNA polimerase $\alpha$, que possibilitou a quantificação de L. infantum chagasi em espécimes de Lutzomyia longipalpis infectados experimentalmente (Ranasinghe 
et al., 2008). Outros alvos moleculares podem ser empregados para quantificação da carga parasitária em flebotomíneos, entre eles o kDNA, como foi descrito em 2011, no qual os autores avaliaram diferentes alvos para quantificação de leishmânias em Lu. Longipalpis (Bezerra-Vasconcelos et al., 2011).

A quantificação de Leishmania em flebotomíneos é importante para avaliar a eficiência do desenvolvimento do parasito nas distintas espécies de vetores que possam estar envolvidas com a transmissão de uma mesma espécie de Leishmania. Nesse contexto, as diferenças relacionadas com a adaptação e colonização do parasito no trato digestório do inseto podem justificar as diferenças quanto à capacidade vetorial do mesmo, as quais por sua vez poderão contribuir para a definição do grau de endemicidade de áreas com notificações de casos de leishmanioses. Isso pôde ser observado em um estudo de comparação da competência vetorial de Lutzomyia evansi e Lu. longipalpis para transmissão de L. infantum chagasi em duas áreas na Colômbia e Venezuela (Montoya-Lerma et al., 2003). Tal metodologia pode também ser utilizada para simples detecção do DNA do parasito nos insetos flebotomíneos (Coleman et al., 2009) e para identificação da Leishmania pela temperatura de dissociação dos produtos amplificados (Talmi-Frank et al., 2010; Pita-Pereira et al., 2012).

\section{CONTRIBUIÇÃO DA METODOLOGIA DE PCR PARA A IDENTIFICAÇÃO DE NOVAS ESPÉCIES DE VETORES}

Tendo como base a extensa diversidade de espécies de insetos flebotomíneos, com cerca de 470 espécies descritas no Novo Mundo, ainda há muito a se estudar sobre o potencial destas na transmissão da doença. Cerca de $10 \%$ das espécies foram confirmadas ou suspeitas de atuarem como vetores de Leishmania, mediante relatos de infecção natural ou experimental (Lainson \& Shaw, 2005). O sucesso do completo desenvolvimento do parasito no interior dos vetores depende de sua habilidade em superar as barreiras existentes no intestino médio do flebotomíneo, tais como, resistir à ação de enzimas digestivas, sua capacidade em atravessar a membrana peritrófica, assim como de adesão às células epiteliais. Por sua vez, o desempenho de determinadas espécies em relação à sua incriminação como vetor implica não apenas a sua habilidade de completar a metaciclogênese do parasito, mas também de ser capaz de realizar a sua transmissão (Killick-Kendrick, 1990).

O encontro de DNA de Leishmania no trato digestório de flebotomíneos não é uma evidência conclusiva para estabelecer que determinadas espécies estejam atuando como vetores. Um resultado de PCR positivo não permite distinguir entre as formas amastigotas (estágio encontrado no interior de macrófagos) adquiridas pela alimentação do inseto no sangue de um mamífero infectado e as formas promastigotas, as quais realmente representam a colonização no intestino do vetor (Aransay, Scoulica \& Tselentis, 2000). Ressalta-se que entre os flebótomos que são PCR positivos, podem estar incluídos aqueles que carregam fragmentos de DNA do parasito resultantes de infecções não estabelecidas (abortivas) ou provenientes do sangue alimentado. Nesse cenário, insetos experimentalmente infectados devem ser usados em ensaios de transmissão, objetivando demonstrar a capacidade vetorial das espécies suspeitas e a investigar possíveis ciclos de transmissão (Killick-Kendrick, 1999). Em razão dessa particularidade dos ensaios moleculares, uma alternativa seria a avaliação de infecção apenas utilizando fêmeas que não apresentem sangue no trato digestório (Pita-Pereira, 2008; Pita-Pereira et al., 2009, 2011; Carvalho et al., 2010).

Mesmo assim, o encontro de insetos infectados entre espécimes de fêmeas capturadas é uma condição que deve ser considerada na definição do risco de transmissão para o homem e outros hospedeiros que possam atuar como reservatórios na natureza, contribuindo para o entendimento da epidemiologia das leishmanioses em áreas endêmicas. A aplicação da PCR para o rastreamento de infecção natural em flebótomos tem possibilitado incriminar outras espécies que estariam envolvidas com a transmissão de ambas as formas da doença - leishmaniose tegumentar (LT) e leishmaniose visceral (LV) - em diferentes áreas geográficas (Silva \& Grunewald, 1999; Aransay, Scoulica \& 
Tselentis, 2000; Miranda et al., 2002; Pita-Pereira et al., 2005; Pita-Pereira et al., 2008; Pita-Pereira et al., 2009; Córdoba-Lanús et al., 2006; Saraiva et al., 2009; Perez et al., 2007; Savani et al., 2009; Pita-Pereira et al., 2011).

Como exemplo, por mais de cinquenta anos Lu. longipalpis foi considerada a única espécie vetora de $L$. (L.) infantum chagasi por toda a extensão geográfica de leishmaniose visceral (Lainson \& Rangel, 2005) nas Américas Central e do Sul. Atualmente já existem relatos na Região Centro-Oeste do Brasil, do papel de Lutzomyia cruzi atuando como importante espécie vetorial de LV no município de Corumbá - Mato Grosso do Sul, área endêmica com aumento da notificação da doença nas últimas duas décadas (Santos et al., 1998). Mais recentemente, com o auxílio de ferramentas moleculares, esses dados foram corroborados por meio da deteç̧ão de kDNA de L. infantum chagasi em exemplares de Lu. cruzi capturados nos municípios de Corumbá, no Mato Grosso do Sul e Jaciara, estado de Mato Grosso (Pita-Pereira et al., 2008; Missawa et al., 2011). Alguns autores sugeriram Lutzomyia forattinii como vetor secundário de LV na região de Corumbá (Pita-Pereira et al., 2008). Investigações concernentes à fauna flebotomínica em Corumbá revelaram a predominância de Lu. cruzi e Lu. forattinii (Galati et al., 1985) e o caráter antropofílico de ambas as espécies, sugerindo a possível participação destas na transmissão de leishmaniose visceral em Corumbá (Galati et al., 1997).

Um estudo recente realizado em área endêmica de LV no estado de Pernambuco - São Vicente Férrer (Zona da Mata), relatou pela primeira vez infecção natural por L. (L.) infantum (Syn. L. chagasi) em Lutzomyia (Migonemyia) migonei, com uma taxa de infecção estimada de $4 \%$ nos insetos analisados (Carvalho et al., 2010). Estudos anteriores na mesma localidade demonstraram a predominância dessa espécie de flebotomíneo em residências e abrigos de animais no ambiente peridomiciliar (90\%) e ausência de Lu. longipalpis (Carvalho et al., 2007). O conjunto destes dados sugere que Lu. migonei possa estar atuando na transmissão de L. infantum (Syn. L. chagasi) no ciclo doméstico zoonótico em Pernambuco, em áreas de leishmaniose visceral onde o vetor primário - Lu. longipalpis esteja ausente.

Infecção natural de Lu. migonei por L. (V.) braziliensis foi demonstrada por PCR seguida de hibridização em uma área de leishmaniose tegumentar no Rio de Janeiro (Pita-Pereira et al., 2005), sendo este um resultado até então não evidenciado em áreas endêmicas desse município. Em outras regiões do Brasil, essa espécie de flebotomíneo tem sido incriminada como vetor de LT (Queiroz et al., 1994).

Em um estudo entomológico realizado no município de Bonito - Mato Grosso do Sul, observou-se pela primeira vez Lutzomyia almerioi infectada com L. infantum chagasi e L. (Viannia) spp., mediante o uso de PCR direcionada para a subunidade menor do RNA ribossomal de Leishmania (Savani et al., 2009). Nesse trabalho também foi identificada infecção por L. (Viannia) spp. em Lu. longipalpis (taxa de 2,76\%). A observação de que as duas espécies de flebotomíneos encontravam-se naturalmente infectadas por agentes de ambas as leishmanioses, tegumentar e visceral, sugere que elas poderiam estar atuando na transmissão dessas doenças na área estudada. Vale a pena enfatizar que Lu. almerioi pertence ao mesmo grupo monofilético que Lu. longipalpis, Lu. cruzi e Lu. forattinii, sendo as duas últimas incriminadas como potenciais transmissores de leishmaniose visceral no estado do Mato Grosso do Sul (Galati et al., 1997; Pita-Pereira et al., 2008). Entretanto, investigações adicionais se fazem necessárias para confirmar, por exemplo, se Lu. longipalpis é de fato um vetor de espécies do subgênero Viannia, considerando que esta espécie de flebotomíneo é a principal responsável pela transmissão de $L$. (L.) infantum chagasi, agente etiológico da leishmaniose visceral americana.

Outro exemplo refere-se à identificação, por PCR, de Lutzomyia whitmani naturalmente infectada com L. (Viannia) spp. no município de Santa Luzia - Minas Gerais, considerada área endêmica de leishmaniose tegumentar. Esses dados, associados à abundância dos insetos capturados, dão suporte à hipótese de que essa espécie deva estar contribuindo 
para a transmissão de LT no Brasil (Carvalho et al., 2008). Estudos prévios realizados no estado do Ceará já tinham possibilitado incriminar Lu. whitmani como vetor de L. (V.) braziliensis no município de Baturité (Queiroz et al., 1994).

Em uma área endêmica de LT na Argentina, 440 espécimes de fêmeas de Lu. (Nyssomyia) neivai foram analisadas para a detecção dos subgêneros L. (Viannia) e L. (Leishmania). Das amostras coletadas, 9,1\% apresentaram resultados para infecção apenas com parasitos do subgênero Viannia, sendo esta a primeira descrição de flebótomos naturalmente infectados na Argentina servindo-se do uso de abordagens moleculares, além de reportar pela primeira vez infecção senso estrito de Lu. neivai (Córdoba-Lanús et al., 2006). Tais resultados contribuíram para incriminar essa espécie como vetor de leishmaniose na região e para a identificação do principal parasito circulante como pertencente ao subgênero Viannia.

No município de Porto Alegre - Rio Grande do Sul, em uma área periurbana com descrição recente de leishmaniose tegumentar, estimou-se taxa de infecção de 1,1\% por L. (V.) braziliensis em Lu. (N.) neivai valendo-se de um ensaio de PCR seguido de hibridização (Pita-Pereira et al., 2009). A associação desses dados aos estudos entomológicos que demonstraram ser essa espécie a mais frequente na área estudada (94,9\%), sem a ocorrência de Lutzomyia intermedia (Gonçalves, 2003) - espécie proximamente relacionada à $L u$. (N.) neivai -, indica a importância desta última no ciclo epidemiológico de LT em Porto Alegre, além de sugerir esta espécie como vetor adicional de $L$. $(V$.) braziliensis nas Regiões Sudeste e Sul do Brasil. Espécimes de $L$ u. (N.) neivai infectados com L. (V.) braziliensis também foram encontrados em um foco de LT no estado de Santa Catarina pelo emprego de PCR e hibridização (Marcondes et al., 2009). Os autores relataram a abundância e predominância de Lu. (N.) neivai entre as espécies capturadas (98,5\%), indicando ser este o vetor dominante de $L$. (Viannia) na localidade investigada. Em Porto Alegre, na mesma região onde foi registrada infecção natural em Lu. (N.) neivai, Lu. (Pintomyia) fischeri foi detectada infectada por Leishmania (V.) braziliensis (Pita-Pereira et al., 2011). Os autores sugeriram que esta espécie poderia estar atuando como um vetor secundário de LT na área estudada.

Também se observou infecção natural por L. (V.) braziliensis em Lu. intermedia em áreas de ocorrência de leishmaniose tegumentar no estado do Rio de Janeiro (Rangel et al., 1984; Pita-Pereira et al., 2005), reforçando achados prévios experimentais de demonstração do desenvolvimento dessa espécie de parasito em Lu. intermedia (Rangel et al., 1992).

\section{DIAGNÓSTICO MOLECULAR PELA REAÇÃO EM CADEIA DA POLIMERASE: ALVOS UTILIZADOS}

A PCR tem sido aplicada com êxito em trabalhos de campo para estudos da competência vetorial de insetos flebotomíneos, até mesmo em áreas apresentando baixas taxas de infecção. Teoricamente o ensaio possibilita a deteç̧ão da presença de um único parasito por flebótomo (Bruijn \& Barker, 1992), sem que elementos do trato digestório do inseto ou o conteúdo do sangue alimentado possam inibir ou interferir na reação de amplificação (Michalsky et al., 2002).

Ensaios diagnósticos da fauna flebotomínica pela PCR têm sido desenvolvidos com iniciadores ou primers desenhados para diferentes alvos moleculares do genoma de Leishmania, tais como: minicírculos do kDNA, genes da subunidade menor do ribossomo (SSU rDNA), sequências espaçadoras do gene de miniexon, sequências subteloméricas, microssatélites, regiões espaçadoras transcritas (ITS), além de sequências nucleares de cópia única como o gene de citocromo b (cyt b), da DNA polimerase $\alpha$, hsp70 e cisteína-proteinase b $(c p b)$. No Quadro 1 encontramse exemplificados distintos alvos e os tipos de protocolos de PCR que vêm sendo empregados por vários grupos, com as respectivas sequências dos iniciadores e sondas para hibridização. 
Quadro 1 - Protocolos de PCR e sequências de iniciadores e sondas empregadas para a detecção de DNA de Leishmania spp. em flebotomíneos vetores das leishmanioses

\begin{tabular}{|c|c|c|c|c|c|c|c|c|}
\hline \multirow[b]{2}{*}{$\begin{array}{c}\text { Alvos } \\
\text { moleculares }\end{array}$} & \multirow[b]{2}{*}{ Sequências de iniciadores e sondas } & \multicolumn{6}{|c|}{ Protocolos de PCR } & \multirow[b]{2}{*}{ Referências } \\
\hline & & Singleplex & $\begin{array}{l}\text { Acoplado à } \\
\text { Hibridização }\end{array}$ & Multiplex & $\begin{array}{c}\text { Acoplado à } \\
\text { RFLP ou } \\
\text { Sequenciamento }\end{array}$ & $\begin{array}{l}\text { Nested ou } \\
\text { Seminested }\end{array}$ & $\begin{array}{l}\text { Tempo } \\
\text { real }\end{array}$ & \\
\hline \multirow{21}{*}{ 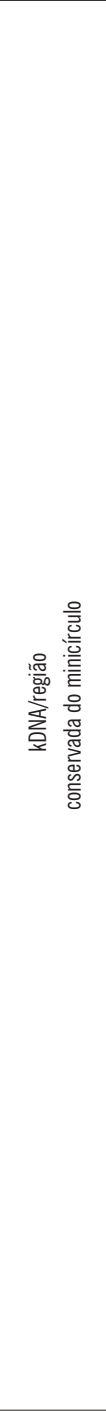 } & \multirow{5}{*}{$\begin{array}{l}\text { Iniciadores: gênero Leishmania } \\
\text { A: 5' (G/C)(G/C)(C/G)CC(A/C)CTAT(A/T)TTACACCAACCCC } \\
\text { B: 5' GGGGAGGGGGCGTTCTGCGAA }\end{array}$} & & $x$ & & & & & $\begin{array}{l}\text { (Miranda et al., 2002; } \\
\text { Pita-Pereira et al., 2005, 2008, 2009, 2011; } \\
\text { Marcondes et al., 2009; } \\
\text { Carvalho et al., 2010) }\end{array}$ \\
\hline & & $x$ & & & & & & $\begin{array}{l}\text { (Michalsky et al., 2002; Felipe et al., 2011; } \\
\text { Córdoba-Lanús et al., 2006; } \\
\text { Oliveira-Pereira et al., 2006) }\end{array}$ \\
\hline & & & & & $x$ & & & $\begin{array}{l}\text { (Miranda et al., 2009; } \\
\text { Missawa et al., 2010, 2011; } \\
\text { Rocha et al., 2010) }\end{array}$ \\
\hline & & & & $x$ & $x$ & & & (Michalsky et al., 2011) \\
\hline & & & & & & $x$ & & (Carvalho et al., 2008) \\
\hline & \multirow{2}{*}{$\begin{array}{l}\text { Iniciadores: complexo L. braziliensis } \\
\text { MP1-L: 5' GAACGGGGTTCTGTATGC } \\
\text { MP3-H: 5' TACTCCCCGACATGCCTCTG }\end{array}$} & $x$ & & & & & & (Perez et al., 1994, 2007) \\
\hline & & & & $X$ & & & & (Oliveira et al., 2011) \\
\hline & \multirow{3}{*}{$\begin{array}{l}\text { Iniciadores: complexo L. braziliensis } \\
\text { B1: 5' GGGGTTGGTGTAATATAGTGG } \\
\text { B2: 5' CTAATTGTGCAGGGGGAGG }\end{array}$} & $x$ & & & & & & (Michalsky et al., 2002) \\
\hline & & & & & & $x$ & & (Carvalho et al., 2008) \\
\hline & & $x$ & & & & & & (Córdoba-Lanús et al., 2006) \\
\hline & \multirow{3}{*}{$\begin{array}{l}\text { Iniciadores: complexo L. mexicana } \\
\text { M1: 5' CCAGTTTCGAGCCCCGGAG } \\
\text { M2: 5' GGTGTAAAATAGGGGCGGATGCTCTG }\end{array}$} & $x$ & & & & & & (Michalsky et al., 2002) \\
\hline & & & & & & $x$ & & (Carvalho et al., 2008) \\
\hline & & $x$ & & & & & & (Córdoba-Lanús et al., 2006) \\
\hline & Iniciadores: L. infantum chagasi & & & & & \multirow{2}{*}{$x$} & & \multirow{2}{*}{ (Carvalho et al., 2008) } \\
\hline & MC2: 5' CACCCATTTTTCCGATTTTG & & & & & & & \\
\hline & Iniciadores: L. infantum chagasi & \multirow{3}{*}{$x$} & & & & & & \multirow{3}{*}{ (Soares et al., 2010) } \\
\hline & RV1: 5' CTTTTCTGGTCCCGCGGGTAGG & & & & & & & \\
\hline & RV2: 5' CCACCTGGCCTATTTTACACCA & & & & & & & \\
\hline & $\begin{array}{l}\text { Iniciadores: L. major } \\
\text { JW11: 5' CCTATTTTACACCAACCCCCAGT } \\
\text { JW12: 5' GGGTAGGGGCGTTCTGCGAAA }\end{array}$ & $x$ & & & & & & (Ranasinghe et al., 2008) \\
\hline & $\begin{array}{l}\text { Sonda: subgênero Viannia } \\
\text { 5' TAATTGTGCACGGGGAGGCCA }\end{array}$ & & $x$ & & & & & $\begin{array}{l}\text { (Miranda et al., 2002; } \\
\text { Pita-Pereira et al., 2005, 2009 2011; } \\
\text { Marcondes et al., 2009) }\end{array}$ \\
\hline & $\begin{array}{l}\text { Sonda: L. infantum chagasi } \\
\text { 5' AAAAATGGGTGCAGAAAT }\end{array}$ & & $x$ & & & & & $\begin{array}{l}\text { (Pita-Pereira et al., 2008; } \\
\text { Carvalho et al., 2010) }\end{array}$ \\
\hline \multirow{4}{*}{ 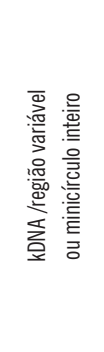 } & \multirow{2}{*}{$\begin{array}{l}\text { Iniciadores: gênero Leishmania } \\
\text { LINR4: 5' GGGGTTGGTGTAAATAGGG } \\
\text { LIN17: 5' TTTGAACGGGATTTCTG } \\
\text { LIN19: 5' CAGAACGCCCCTACCCG }\end{array}$} & & & & & $x$ & & $\begin{array}{l}\text { (Aransay et al., 2000) } \\
\text { (Azizi et al., 2010) }\end{array}$ \\
\hline & & & & & $x$ & & & (Pandey et al., 2008) \\
\hline & $\begin{array}{l}\text { Iniciadores: gênero Leishmania } \\
\text { L.MC-1S: 5' CTRGGGGTTGTGTAAAATAG } \\
\text { L.MC-1R: 5' TWTGAACGGGRTTTCTG }\end{array}$ & & & & $x$ & & & (Kato et al., 2005) \\
\hline & $\begin{array}{l}\text { Iniciadores: complexo L. donovani } \\
\text { MC1: 5' GTTAGCCGATGGTGGTCTTG } \\
\text { MC2: 5' CACCCATTTTTCCGATTTTG }\end{array}$ & & & & $x$ & & & (Maia et al., 2009) \\
\hline
\end{tabular}


Quadro 1 - Protocolos de PCR e sequências de iniciadores e sondas empregadas para a detecção de DNA de Leishmania spp. em flebotomíneos vetores das leishmanioses (continuação)

\begin{tabular}{|c|c|c|c|c|c|c|c|c|}
\hline \multirow[b]{2}{*}{$\begin{array}{c}\text { Alvos } \\
\text { moleculares }\end{array}$} & \multirow[b]{2}{*}{ Sequências de iniciadores e sondas } & \multicolumn{6}{|c|}{ Protocolos de PCR } & \multirow[b]{2}{*}{ Referências } \\
\hline & & Singleplex & $\begin{array}{c}\text { Acoplado à } \\
\text { Hibridização }\end{array}$ & Multiplex & \begin{tabular}{|c|} 
Acoplado à \\
RFLP ou \\
Sequenciamento
\end{tabular} & $\begin{array}{l}\text { Nested ou } \\
\text { Seminested }\end{array}$ & $\begin{array}{c}\text { Tempo } \\
\text { real }\end{array}$ & \\
\hline \multirow[b]{5}{*}{ 亳 } & $\begin{array}{l}\text { Iniciadores: gênero Leishmania } \\
\text { PG1: 5' TTATTGGTATGCGAAACTTCC }\end{array}$ & $x$ & & & & & & $\begin{array}{c}\text { (Paiva et al., 2006) } \\
\text { (Nascimento et al., 2007) }\end{array}$ \\
\hline & PG2: 5' GAAACTGATACTTATATA & & & & $x$ & & & (Paiva et al., 2010) \\
\hline & $\begin{array}{l}\text { Iniciadores: subgênero Viannia } \\
\text { PV1: 5' CGTCTTCCGGCAACATTT }\end{array}$ & $x$ & & & & & & (Paiva et al., 2006) \\
\hline & PV2: 5' CGTTAGTTGGAAGCCCAAGG & & & & $x$ & & & (Paiva et al., 2010) \\
\hline & $\begin{array}{l}\text { Iniciador: gênero Leishmania } \\
\text { LU-5A: 5' TTTATTGGTATGCGAAACTTC } \\
\text { Iniciador: subgênero Leishmania } \\
\text { LM-3A: 5' GCACCGCACCGG(A/G)CCAC } \\
\text { Iniciador: subgênero Viannia } \\
\text { LB-3C: 5' CGT(C/G)CCGAACCCCGTGTC } \\
\text { Iniciador: L. infantum chagasi } \\
\text { LC-3L: 5' GCCCGCG(C/T)GTCACCACCAT }\end{array}$ & & & $x$ & & & & (Jorquera et al., 2005) \\
\hline 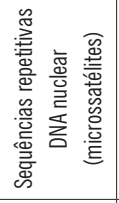 & $\begin{array}{l}\text { Iniciadores e sonda: L. (V.) braziliensis } \\
\text { 3J1: 5' TACCTGATGACTCCAC } \\
\text { 3J2: 5' CCTCATCATACCGTTGATC } \\
\text { Sonda LbJ38 - região repetitiva do DNA nuclear }\end{array}$ & & $x$ & & & & & (Rodríguez et al., 1999, 2002) \\
\hline \multirow{4}{*}{ 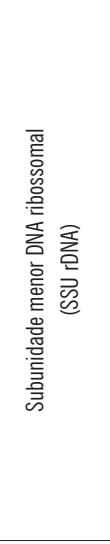 } & $\begin{array}{l}\text { Iniciadores e sonda TaqMan: gênero Leishmania } \\
\text { LEISU1: 5' AAGTGCTTCCCATCGCAACT } \\
\text { LEISL1: 5' GACGCACTAAACCCCTCCAA } \\
\text { Sonda LEISP1: 5' FAM-CGGTTCGGTGTGTGGCGCC-TAMRA } \\
\end{array}$ & & & & & & $x$ & (Gómez-Saladín, Doud \& Maroli, 2005) \\
\hline & $\begin{array}{l}\text { Iniciadores: gênero Leishmania } \\
\text { S4: 5' GATCCAGCTGCAGGTTCACC } \\
\text { S12: 5' GGTGATTCCGTCAA CGGAC } \\
\text { S17: 5' CCAAGCTGCCCAGTAGAAT }\end{array}$ & $x$ & & & & & & $\begin{array}{l}\text { (Paiva et al., 2006; } \\
\text { Nascimento et al., 2007) }\end{array}$ \\
\hline & S18: 5' TCGGGCGGATAAAACCC & & & & $x$ & $x$ & & (Savani et al., 2009) \\
\hline & $\begin{array}{l}\text { Iniciadores: ordem Kinetoplastida } \\
\text { R221: 5' GGTTCCTTTCCTGATTTACG } \\
\text { R332: 5' GGCCGGTAAAGGCCGAATAG } \\
\text { Iniciadores: gênero Leishmania } \\
\text { R223: 5' TCCCATCGCAACCTCGGTT } \\
\text { R333: 5' AAAGCGGGCGCGGTGCTG } \\
\end{array}$ & & & & & $x$ & & (Rossi et al., 2008) \\
\hline 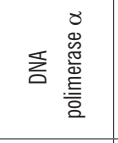 & \begin{tabular}{|l|} 
Iniciadores e sonda TaqMan: L. infantum chagasi \\
Senso: 5' TGTCGCTTGCAGACCAGATG \\
Anti-senso: 5' GCATCGCAGGTGTGAGCAC \\
Sonda: 5' FAM-CAGCAACAACTTCGAGCCTGGCACC-TAMRA
\end{tabular} & & & & & & $x$ & (Ranasinghe, S. et al., 2008) \\
\hline \multirow{2}{*}{ 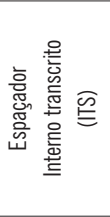 } & $\begin{array}{l}\text { Iniciadores: gênero Leishmania } \\
\text { LITSR: 5' CTGGATCATTTCCGATG } \\
\text { L5.8S: 5' TGATACCACTTATCGCACTT }\end{array}$ & & & & $x$ & & & (Maia et al., 2009) \\
\hline & $\begin{array}{l}\text { Iniciadores : complexo L. (L.) mexicana } \\
\text { IR1: 5'GCTGTAGGTGAACCTGCAGCAGCTGGATCATT } \\
\text { LM17: 5'CCCCTCTCCTCCTCCCC }\end{array}$ & & & $x$ & & & & (Sánchez-García et al., 2010) \\
\hline 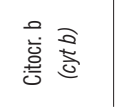 & $\begin{array}{l}\text { Iniciadores: gênero Leishmania } \\
\text { L.cyt-S: 5' GGTGTAGGTTTAGTYTAGG } \\
\text { L.cyt-R: 5' CTACAATAAACAAATCATAATATRCAATT }\end{array}$ & & & & $x$ & & & (Kato et al., 2005, 2008, 2011) \\
\hline
\end{tabular}


Quadro 1 - Protocolos de PCR e sequências de iniciadores e sondas empregadas para a detecção de DNA de Leishmania spp. em flebotomíneos vetores das leishmanioses (continuação)

\begin{tabular}{|c|c|c|c|c|c|c|c|c|}
\hline \multirow[b]{2}{*}{$\begin{array}{c}\text { Alvos } \\
\text { moleculares }\end{array}$} & \multirow[b]{2}{*}{ Sequências de iniciadores e sondas } & \multicolumn{6}{|c|}{ Protocolos de PCR } & \multirow[b]{2}{*}{ Referências } \\
\hline & & Singleplex & $\begin{array}{c}\text { Acoplado à } \\
\text { Hibridizaçãa }\end{array}$ & Multiplex & $\begin{array}{c}\text { Acoplado à } \\
\text { RFLP ou } \\
\text { Sequenciamento }\end{array}$ & $\begin{array}{l}\text { Nested ou } \\
\text { Seminested }\end{array}$ & $\begin{array}{c}\text { Tempo } \\
\text { real }\end{array}$ & \\
\hline 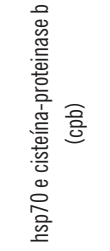 & $\begin{array}{l}\text { Iniciadores: L. (V.) braziliensis e L. (L.) mexicana } \\
\text { Hsp70sen: 5' GACGGTGCCTGCCTACTTCAA } \\
\text { Hsp70ant: 5' CCGCCCATGCTCTGGTACATC } \\
\text { Iniciadores: L. (V.) braziliensis } \\
\text { Cpbsen: 5' TGTGCTATT CGAGGAGTTCAA } \\
\text { Cpbant: 5' TTACCCTCAGGAATCACTTTGT }\end{array}$ & & & & $x$ & & & (Perez et al., 2007) \\
\hline
\end{tabular}

Singleplex - PCR com um único par de iniciadores por reação (alvo único); Acoplado à Hibridização - uso de sondas moleculares pós-PCR; Multiplex - PCR com distintos iniciadores desenhados para regiões não sobrepostas do alvo molecular ou para alvos moleculares diferenciados (alvos múltiplos); Acoplado à RFLP ou Sequenciamento - PCR seguido de uma etapa posterior de clivagem dos produtos amplificados com enzimas de restrição ou sequenciamento dos produtos; Nested ou Seminested - PCR com distintos iniciadores desenhados para o mesmo alvo molecular, podendo ser realizado em uma única reação ou em duas etapas de amplificação. Nesse caso, o produto amplificado na primeira reação servirá como molde para a segunda PCR utilizando iniciadores para uma sequência interna do produto gerado na primeira reação; Tempo real - PCR que emprega um par de iniciadores e uma sonda fluorescente desenhada para uma região interna do fragmento que está sendo amplificado (sistema Taqman). Alternativamente, a PCR pode ser usada com um par de iniciadores na presença de um corante que emite fluorescência (SYBR Green); nesse caso, não é necessário o desenho de sonda TaqMan para a sequência interna amplificada. A PCR em Tempo Real pode ser usada como ensaio qualitativo ou quantitativo medido em tempo real.

A sensibilidade desses sistemas pode ser aumentada quando, como alvo de detecção do parasito, são utilizadas sequências representadas em múltiplas cópias no genoma. A escolha de regiões conservadas ou variáveis presentes em tais alvos permite adaptar a especificidade da PCR em nível de gênero, complexo, espécie ou até mesmo o isolado individual. Muitas vezes faz-se necessário o acoplamento de outras ferramentas moleculares para a caracterização do parasito.

Os minicírculos que constituem a rede de DNA do cinetoplasto de protozoários da ordem Kinetoplastida têm sido amplamente usados para a detecção do DNA de Leishmania (Degrave et al., 1994). Tais moléculas estão representadas em aproximadamente dez mil cópias por célula, distribuídas em cerca de dez classes de diferentes sequências com tamanhos que podem variar de 0,75 a $1 \mathrm{~kb}$, sendo estas sequências conhecidas para a maioria das espécies de Leishmania (Rogers \& Wirth, 1988; Breniere et al., 1999; Brewster \& Barker, 2002). Os minicírculos apresentam uma região de sequência conservada, de aproximadamente 120 pb, comum a todas as espécies do gênero Leishmania, e uma região de sequência altamente variável que permite discriminar as diferentes espécies. Nesse caso, após a amplificação da região de sequência variável, são empregadas outras metodologias como RFLP, hibridização com sondas específicas ou sequenciamento para a identificação do parasito em nível de complexo ou espécie.

Outro alvo que tem sido explorado para fins de diagnóstico e tipagem molecular de protozoários Kinetoplastida corresponde aos genes de miniexon. Tais genes estão presentes em cem a duzentas cópias de repetições em tandem no genoma nuclear e são divididos em regiões transcritas e não transcritas. A região transcrita é constituída por um exon altamente conservado de 39 nucleotídeos e um íntron moderadamente conservado entre espécies de tripanossomatídeos de um mesmo gênero ou subgênero. A região não transcrita consiste de uma região intergênica variável entre as espécies de Leishmania e tem se mostrado útil para a identificação de subgênero ou espécie (Fernandes et al., 1994).

Apesar do avanço no desenvolvimento de marcadores moleculares para caracterização de Leishmania, ainda se faz necessária a busca de novos alvos do parasito, os quais possibilitem, por si só ou em associação com outros já descritos, a correta identificação de espécies e complexos desses protozoários. 


\section{CONSIDERAÇÕES FINAIS}

A principal estratégia para o controle das leishmanioses inclui a ação combinada do encontro de casos da doença em humanos e tratamento, o controle vetorial e, em focos zoonóticos, o controle de reservatórios animais. As medidas de prevenção e controle devem ser avaliadas em termos de custo-benefício nas diferentes situações epidemiológicas nas quais tais medidas serão contempladas. Estimativas da prevalência de infecção na população de vetores tornamse importantes para avaliar o resultado dos programas de controle na transmissão das leishmanioses. Também tem sido sugerido que mudanças ambientais e, em particular, as alterações climáticas podem influenciar os padrões de veiculação de doenças transmitidas por insetos vetores. Contudo, não temos conhecimento de como, ou em qual extensão, tais mudanças irão afetar a distribuição geográfica de flebotomíneos ou a transmissão de Leishmania por esses vetores. Mais informações concernentes à distribuição de Leishmania spp. na fauna flebotomínica são essenciais para o melhor conhecimento da epidemiologia das leishmanioses e para o desenvolvimento de ações efetivas de controle da doença. Nesse contexto, a metodologia de PCR tem se mostrado de grande valor para análises que requerem uma ampla amostragem de flebótomos e que têm como propósito avaliar taxas de infecção natural nas populações de insetos, contribuindo assim para a identificação de potenciais espécies envolvidas na transmissão das leishmanioses, concomitante à correta identificação de seu agente contagioso.

\section{REFERÊNCIAS}

ADINI, I. et al. Species-specific detection of Leishmania in sandflies using an enzyme-linked immunosorbent assay. Transactions of the Royal Society of Tropical Medicine and Hygiene, 92: 35-37, 1998.

ARANSAY, A. M.; SCOULICA, E. \& TSELENTIS, Y. Detection and identification of Leishmania DNA within naturally infected sand flies by seminested PCR on minicircle kinetoplastic DNA. Applied and Environmental Microbiology, 66: 1.933-1.938, 2000.

ARIAS, J. R. \& FREITAS, R. A. Sobre os vetores de leishmaniose cutânea na Amazônia central do Brasil. 2: Incidência de flagelados em flebótomos selváticos. Acta Amazônica, 8: 387-396, 1978.

ARIAS, J. R. et al. Flagellate infections of Brazilian sand flies (Diptera: Psychodidae): isolation in vitro and biochemical identification of Endotrypanum and Leishmania. The American Journal of Tropical Medicine and Hygiene, 34(6): 1.098$1.108,1985$.

ASHFORD, R. W.; DESJEUX, P. \& DE RAADT, P. Estimation of population at risk of infection with leishmaniasis. Immunology Today, 8: 104-105, 1991.

AZIZI, K. ; RASSI, Y. \& MOEMENBELLAH-FARD, M. D. PCR-based detection of Leishmania major kDNA within naturally infected Phlebotomus papatasi in southern Iran. Transactions of the Royal Society of Tropical Medicine and Hygiene, 104(6): 440-442, 2010.

AZIZI, K. et al. Phlebotomus (Paraphlebotomus) alexandri: a probable vector of Leishmania infantum in Iran. Annals of Tropical Medicine and Parasitology, 100: 63-68, 2006.

BARKER, D. C. Molecular approaches to DNA diagnosis. Parasitology, 99: 125-146, 1989.

BASTIEN, P.; PROCOP, G. W. \& REISCHL, U. Quantitative real-time PCR is not more sensitive than "conventional” PCR. Journal of Clinical Microbiology, 46(6): 1.897-1.900, 2008.

BEZERRA-VASCONCELOS, D. R. et al. Real-time PCR to assess the Leishmania load in Lutzomyia longipalpis sand flies: screening of target genes and assessment of quantitative methods. Experimental Parasitology, 129(3): 234-239, 2011.

BRENIERE, S. F. et al. Polymerase chain reaction-based identification of New World Leishmania species complexes by specific kDNA probes. Acta Tropica, 73: 283-293, 1999.

BREWSTER, S. \& BARKER, D. C. Analysis of minicircle classes in Leishmania (Viannia) species. Transactions of the Royal Society of Tropical Medicine and Hygiene, 96: 55-63, 2002. 
BRUIJN, M. H. \& BARKER, D. C. Diagnosis of New World leishmaniasis: specific detection of species of the Leishmania braziliensis complex by amplification of kinetoplast DNA. Acta Tropica, 52: 45-58, 1992.

CABRERA, O. L. et al. Definition of appropriate temperature and storage conditions in the detection of Leishmania DNA with PCR in phlebotomine flies. Biomedica (Bogota), 22: 296-302, 2002.

CARVALHO, G. M. et al. Naturally infected Lutzomyia sand flies in a Leishmania-endemic area of Brazil. Vector Borne and Zoonotic Diseases, 8(3): 407-414, 2008.

CARVALHO, M. R. et al. Phlebotomine sandflies species from American visceral leishmaniasis in the North Rainforest region of Pernambuco State, Brazil. Cadernos de Saúde Pública, 23: 1.227-1.232, 2007.

CARVALHO, M. R. et al. Natural Leishmania infantum infection in Migonemyia migonei (França, 1920) (Diptera: Psychodidae: Phlebotominae) the putative vector of visceral leishmaniasis in Pernambuco State, Brazil. Acta Tropica, 116(1): 108-110, 2010.

COLEMAN, R. E. et al. U.S. Military operations at Tallil Air Base, Iraq: Detection and identification of Leishmania parasites in sand flies. Journal of Medical Entomology, 46(3): 649-663, 2009.

CÓRDOBA-LANÚS, E. et al. Natural infection of Lutzomyia neivai with Leishmania spp. in northwestern Argentina. Acta Tropica, 98(1): 1-5, 2006.

DEGRAVE, W. et al. Use of molecular probes and PCR for detection and typing of Leishmania: a mini review. Memórias do Instituto Oswaldo Cruz, 89: 463-469, 1994.

FELICIANGELI, M. D. et al. Vectors of cutaneous leishmaniasis in north-central Venezuela. Medical and Veterinary Entomology, 8(4): 317-324, 1994.

FELIPE, I. M. A. et al. Leishmania infection in humans, dogs and sandflies in a visceral leishmaniasis endemic area in Maranhão, Brazil. Memórias do Instituto Oswaldo Cruz, 106(2): 207-211, 2011.

FERNANDES, O. et al. Mini-exon gene variation in human pathogenic Leishmania species. Molecular and Biochemical Parasitology, 66(2): 261-271, 1994.

FU, G.; PERONA-WRIGHT, G. \& BARKER, D. C. Leishmania braziliensis: characterisation of a complex specific subtelomeric repeat sequence and its use in the detection of parasites. Experimental Parasitology, 90: 236-243, 1998.

GALATI, E. A. B. Morfologia e taxonomia. Morfologia, terminologia de adultos e identificação dos táxons da América. In: RANGEL, E. F. \& LAINSON, R. (Eds.). Flebotomíneos do Brasil. Rio de Janeiro: Editora Fiocruz, 2003.

GALATI, E. A. B. et al. Fauna flebotomínica do Município de Corumbá, Mato Grosso do Sul, Brasil e descrição de Lutzomyia forattinii, sp. n. (Diptera, Psychodidae, Phlebotominae). Revista Brasileira de Entomologia, 29: 261-266, 1985.

GALATI, E. A. B. et al. Study of the phlebotomines (Diptera: Psychodidae), in area of cutaneous leishmaniasis in the State of Mato Grosso do Sul, Brazil. Revista de Saúde Pública, 30(2): 115-128, 1996.

GALATI, E. A. B. et al. Estudo de flebotomíneos (Diptera: Psychodidae) em foco de leishmaniose visceral no Estado de Mato Grosso do Sul, Brasil. Revista de Saúde Pública, 31(4): 378-390, 1997.

GARCIA, A. L. et al. Epidemiological monitoring of American tegumentary leishmaniasis: molecular characterization of a periodomestic transmission cycle in the Amazonian lowlands of Bolivia. Transactions of the Royal Society of Tropical Medicine and Hygiene, 101: 1.208-1.213, 2007.

GÓMEZ-SALADíN, E.; DOUD, C. W. \& MAROLI, M. Short report: surveillance of Leishmania spp. among sand flies in Sicily (Italy) using a fluorogenic real-time polymerase chain reaction. The American Journal of Tropical Medicine and Hygiene, $72(2): 138-141,2005$.

GONÇALVES, B. R. D. Identificação da fauna de flebotomíneos em função de casos autóctones de LTA. Boletim Epidemiológico, Secretaria Municipal de Saúde de Porto Alegre, 21: 5, 2003.

HIGGINS, J. A. \& AZARD, A. F. Use of polymerase chain reaction to detect bacteria in Arthropods: a review. Journal of Medical Entomology, 32: 213-222, 1995. 
JORQUERA, A. et al. Multiplex-PCR for detection of Leishmania infection in Lutzomyia spp captured in an endemic region for cutaneous leishmaniasis in State of Venezuela. Memórias do Instituto Oswaldo Cruz, 100(1): 43-46, 2005.

KATO, H. et al. Detection and identification of Leishmania species within naturally infected sand flies in the andean areas of Ecuador by a polymerase chain reaction. The American Journal of Tropical Medicine and Hygiene, 72 (1): 87-93, 2005.

KATO, H. et al. Natural infection of Lutzomyia tortura with Leishmania (Viannia) naiffi in an Amazonian area of Ecuador. The American Journal of Tropical Medicine and Hygiene, 79(3): 438-440, 2008.

KATO, H. et al. Natural infections of man-biting sand flies by Leishmania and Trypanosoma species in the northern Peruvian Andes. Vector Borne and Zoonotic Diseases, 11(5): 515-521, 2011.

KILLICK-KENDRICK, R. Phlebotomine vectors of the leishmaniasis: a review. Medical and Veterinary Entomology, 4: 1-24, 1990.

KILLICK-KENDRICK, R. The biology and control of phlebotomine sand flies. Clinics in Dermatology, 17: 279-289, 1999.

LAINSON, R. \& RANGEL, E. F. Lutzomyia longipalpis and the eco-epidemiology of american visceral leishmaniasis, with particular reference to Brazil: a review. Memórias do Instituto Oswaldo Cruz, 100(8): 811-827, 2005.

LAINSON, R. \& SHAW, J. J. Evolution, classification and geographical distribution. In: PETERS, W. \& KILLICK-KENDRICK, R. (Eds.). The Leishmaniases in Biology and Medicine. v. 1. Biology and epidemiology. London: Academic Press, 1987.

LAINSON, R. \& SHAW, J. J. New world leishmaniasis. In: COX, F. E. G.; KREIER, J. P. \& WAKELIN, D. (Eds.). Microbiology and Microbial Infections, Parasitology. London, Sydney, Auckland: Topley \& Wilson's Arnold, 2005.

LAINSON, R.; WARD, R. D. \& SHAW, J. J. Cutaneous leishmaniasis in North Brazil: Lutzomyia anduzei as a major vector. Transactions of the Royal Society of Tropical Medicine and Hygiene, 70: 171-172, 1976.

LAINSON, R. et al. Leishmaniasis in Brazil. XXI. Visceral leishmaniasis in the Amazon Region and further observations on the role of Lutzomyia longipalpis (Lutz \& Neiva, 1912) as the vector. Transactions of the Royal Society of Tropical Medicine and Hygiene, 79: 223-226, 1985.

LUZ, E. et al. Lutzomyia whitmani (Diptera: Psychodidae) as vector of Leishmania (V.) braziliensis in Paraná state, southern Brazil. Annals of Tropical Medicine and Parasitology, 94(6): 623-631, 2000.

MAIA, C. et al. Molecular detection of Leishmania infantum in naturally infected Phlebotomus perniciosus from Algarve Region, Portugal. Journal of Vector Borne Diseases, 46: 268-272, 2009.

MARCONDES, C. B. et al. Natural infection of Nyssomyia neivai (Pinto, 1926) (Diptera: Psychodidae, Phlebotominae) by Leishmania (Viannia) spp. in Brazil. Transactions of the Royal Society of Tropical Medicine and Hygiene, 103: 1.0931.097, 2009.

MARTíN-SÁNCHEZ, J. et al. Pool screen PCR for estimating the prevalence of Leishmania infantum infection in sandflies (Diptera: Nematocera Phlebotomidae). Transactions of the Royal Society of Tropical Medicine and Hygiene, 100(6): 527-532, 2006.

MICHALSKY, E. M. et al. Assessment of PCR in the detection of Leishmania spp in experimentally infected individual phlebotomine sandflies (Diptera: Psychodidae: Phlebotominae). Revista do Instituto de Medicina Tropical de São Paulo, $44(5): 255-259,2002$.

MICHALSKY, E. M. et al. Natural infection with Leishmania infantum chagasi in Lutzomyia (Lutzomyia) longipalpis (Diptera: Psychodidae) sandflies captured in the municipality of Janaúba, State of Minas Gerais, Brazil. Revista da Sociedade Brasileira de Medicina Tropical, 44(1): 58-62, 2011.

MIRANDA, A. et al. Molecular epidemiology of American tegumentary leishmaniasis in Panama. The American Journal of Tropical Medicine and Hygiene, 81(4): 565-571, 2009.

MIRANDA, J. C. et al. Frequency of infection of Lutzomyia phlebotomines with Leishmania braziliensis in a Brazilian endemic area assessed by pinpoint capture and polymerase chain reaction. Memórias do Instituto Oswaldo Cruz, 97: 185-188, 2002.

MISSAWA, N. A. et al. Lutzomyia longipalpis naturally infected by Leishmania (L.) chagasi in Várzea Grande, Mato Grosso State, Brazil, an area of intense transmission of visceral leishmaniasis. Cadernos de Saúde Pública, 26(12): 2.414-2.419, 2010. 
MISSAWA, N. A. et al. Evidence of transmission of visceral leishmaniasis by Lutzomyia cruzi in the municipality of Jaciara, State of Mato Grosso, Brazil. Revista da Sociedade Brasileira de Medicina Tropical, 44(1): 76-78, 2011.

MONTOYA-LERMA, J. et al. Comparative vectorial efficiency of Lutzomyia evansi and Lu. longipalpis for transmitting Leishmania chagasi. Acta Tropica, 85: 19-29, 2003.

MUKHERJEE, S. et al. Short report: Leishmania DNA in Phlebotomus and Sergentomyia species during a kala-azar epidemic. The American Journal of Tropical Medicine and Hygiene, 57: 423-425, 1997.

NASCIMENTO, J. C. et al. Natural infection of phlebotomines (Diptera: Psychodidae) in a visceral-leishmaniasis focus in Mato Grosso do Sul, Brazil. Revista do Instituto de Medicina Tropical de São Paulo, 49: 119-122, 2007.

OLIVEIRA, D. M. et al. Natural infection of Nyssomyia neivai by Leishmania (Viannia) spp. in the state of Paraná, southern Brazil, detected by multiplex polymerase chain reaction. Vector Borne and Zoonotic Diseases, 11(2): 137-143, 2011.

OLIVEIRA-PEREIRA, Y. N. et al. Molecular diagnosis of the natural infection rate due to Leishmania sp in sandflies (Psychodidae, Lutzomyia) in the Amazon region of Maranhão, Brazil. Revista da Sociedade Brasileira de Medicina Tropical, 39(6): 540-543, 2006.

PAIVA, B. R. et al. Detection and identification of Leishmania species in field-captured phlebotomine sandflies based on miniexon gene PCR. Acta Tropica, 99: 252-259, 2006.

PAIVA, B. R. et al. Padronização de condições para detecção de DNA de Leishmania spp. em flebotomíneos (Díptera, Psychodidae) pela reação em cadeia da polimerase. Cadernos de Saúde Pública, 23: 87-94, 2007.

PAIVA, B. R. et al. Species-specific identification of Leishmania in naturally infected sand flies captured in Mato Grosso do Sul State, Brazil. Acta Tropica, 115: 126-130, 2010.

PANDEY, K. et al. Molecular detection of Leishmania parasites from whole bodies of sandflies collected in Nepal. Parasitology Research, 103(2): 293-297, 2008.

PEREZ, J. E. et al. Natural Leishmania infection of Lutzomyia spp. in Peru. Transactions of the Royal Society of Tropical Medicine and Hygiene, 88: 161-164, 1994.

PEREZ, J. E. et al. Isolation and molecular identification of Leishmania (Viannia) peruviana from naturally infected Lutzomyia peruensis (Diptera:Psychodidae) in the Peruvian Andes. Memórias do Instituto Oswaldo Cruz, 102(5): 655-658, 2007.

PITA-PEREIRA, D. et al. Identification of naturally infected Lutzomyia intermedia and Lutzomyia migonei with Leishmania (Viannia) braziliensis in Rio de Janeiro (Brazil) revealed by a PCR multiplex non-isotopic hybridisation assay. Transactions of the Royal Society of Tropical Medicine and Hygiene, 99(12): 905-913, 2005.

PITA-PEREIRA, D. et al. Detection of natural infection in Lutzomyia cruzi and Lutzomyia forattinii (Diptera: Psychodidae: Phlebotominae) by Leishmania infantum chagasi in an endemic area of visceral leishmaniasis in Brazil using a PCR multiplex assay. Acta Tropica, 107: 66-69, 2008.

PITA-PEREIRA, D. et al. First report of Lutzomyia (Nyssomyia) neivai (Diptera: Psychodidae: Phlebotominae) naturally infected by Leishmania (Viannia) braziliensis in a periurban area of south Brazil using a multiplex polymerase chain reaction assay. The American Journal of Tropical Medicine and Hygiene, 80(4): 593-595, 2009.

PITA-PEREIRA, D. et al. Lutzomyia (Pintomyia) fischeri (Diptera: Psychodidae: Phlebotominae), a probable vector of American cutaneous leishmaniasis: detection of natural infection by Leishmania (Viannia) DNA in specimens from the municipality of Porto Alegre (RS), Brazil, using multiplex PCR assay. Acta Tropica, 120(3): 273-275, 2011.

PITA-PEREIRA, D. et al. SYBR Green-based Real-Time PCR targeting kinetoplast DNA can be used to discriminate between the main etiologic agents of Brazilian cutaneous and visceral leishmaniases. Parasites \& Vectors, 5: 15, 2012.

QUEIROZ, R. G. et al. Cutaneous leishmaniasis in Ceará state in Northeastern Brazil: incrimination of Lutzomyia whitmani (Diptera:Psychodidae) as a vector of Leishmania braziliensis in Baturité municipality. The American Journal of Tropical Medicine and Hygiene, 50: 693-698, 1994.

RANASINGHE, S. et al. A real-time PCR assay to estimate Leishmania chagasi load in its natural sand fly vector Lutzomyia longipalpis. Transactions of the Royal Society of Tropical Medicine and Hygiene, 102: 875-882, 2008. 
RANGEL, E. F. et al. Infecção natural de Lutzomyia intermedia Lutz \& Neiva, 1912, em área endêmica de leishmaniose tegumentar no Estado do Rio de Janeiro. Memórias do Instituto Oswaldo Cruz, 79: 395-396, 1984.

RANGEL, E. F. et al. Development of Leishmania (Viannia) braziliensis Vianna, 1911 in Lutzomyia intermedia (Lutz \& Neiva, 1912) (Diptera: Psychodidae: Phlebotominae) under experimental conditions. Memórias do Instituto Oswaldo Cruz, 87: 235-238, 1992.

READY, P. D.; SMITH, D. F. \& KILLICK-KENDRICK, R. DNA hybridizations on squash-blotted sandflies to identify both Phlebotomus papatasi and infecting Leishmania major. Medical and Veterinary Entomology, 2: 109-116, 1988.

ROCHA, L. S. et al. Survey of natural infection by Leishmania in sand fly species collected in southeastern Brazil. Transactions of the Royal Society of Tropical Medicine and Hygiene, 104(7): 461-466, 2010.

RODRÍGUEZ, N. et al. Diagnosis of cutaneous leishmaniasis and species discrimination of parasites by PCR and hybridization. Journal of Clinical Microbiologyiol, 9: 2.246-2.252, 1994.

RODRÍGUEZ, N. et al. Detection of Leishmania braziliensis in naturally infected individual sandflies by the polymerase chain reaction. Transactions of the Royal Society of Tropical Medicine and Hygiene, 93: 47-49, 1999.

ROGERS, W. O. \& WIRTH, D. F. Generation of sequence diversity in the kinetoplast DNA minicircles of Leishmania mexicana amazonensis. Molecular and Biochemical Parasitology, 30: 1-8, 1988.

ROSSI, E. et al. Seasonal phenology, host-blood feeding preferences and natural Leishmania infection of Phlebotomus perniciosus (Diptera, Psychodidae) in a high-endemic focus of canine leishmaniasis in Rome province, Italy. Acta Tropica, 105(2): 158-165, 2008.

RYAN, L. \& BRAZIL, R. P. Leishmania infentions in Lutzomyia longipalpis on the Island of S. Luis, Maranhão State. Memórias do Instituto Oswaldo Cruz, 79(3): 383-384, 1984.

SÁNCHEZ-GARCÍA, L. et al. Sand flies naturally infected by Leishmania (L.) mexicana in the peri-urban area of Chetumal city, Quintana Roo, México. Transactions of the Royal Society of Tropical Medicine and Hygiene, 104(6): 406-411, 2010.

SANTOS, S. O. et al. Incrimination of Lutzomyia cruzi as a vector of American visceral leishmaniasis. Medical and Veterinary Entomology, 12(3): 315-317, 1998.

SARAIVA, L. et al. Natural infection of Lutzomyia neivai and Lutzomyia sallesi (Diptera: Psychodidae) by Leishmania infantum chagasi in Brazil. Journal of Medical Entomology, 46(5): 1.159-1.163, 2009.

SAVANI, E. S. M. M. et al. The finding of Lutzomyia almerioi and Lutzomyia longipalpis naturally infected by Leishmania spp. in a cutaneous and canine visceral leishmaniases focus in Serra da Bodoquena, Brazil. Vet Parasitol, 160: 18-24, 2009.

SHAW, J. J. Taxonomy of the genus Leishmania: present and future trends and their implications. Memórias do Instituto Oswaldo Cruz, 89: 471-478, 1994.

SILVA, O. S. \& GRUNEWALD, J. Contribution to the sand fly fauna (Diptera: Phlebotominae) of Rio Grande do Sul, Brazil, and Leishmania (Viannia) infections. Memórias do Instituto Oswaldo Cruz, 94: 579-582, 1999.

SILVEIRA, F. T. et al. Cutaneous leishmaniasis in the Amazon Region: natural infection of the sandfly Lutzomyia ubiquitalis (Psychodidae: Phlebotomine) by Leishmania (Viannia) lainsoni in Pará State, Brazil. Memórias do Instituto Oswaldo Cruz, 86: 127-130, 1991.

SIRIDEWA, K.; KARUNANAYAKE, E. H. \& CHANDRASEKHARAN, N. V. Polymerase chain reaction-based technique for the detection of Wuchereria bancrofti in human blood samples hydrocele fluid, and mosquito vector. The American Journal of Tropical Medicine and Hygiene, 54: 72-76, 1996.

SOARES, M. R. et al. Molecular analysis of natural infection of Lutzomyia longipalpis in an endemic area for visceral leishmaniasis in Brazil. Cadernos de Saúde Pública, 26(12): 2.409-2.413, 2010.

TALMI-FRANK, D. et al. Detection and identification of Old World Leishmania by high resolution melt analysis. PLoS Negl Trop Dis, 4(1): e581, 2010.

TESH, R. B. \& MODI, G. B. A simple method for experimental infection of phlebotomine sand flies with Leishmania. The American Journal of Tropical Medicine and Hygiene, 33: 41-46, 1984. 


\title{
14 \\ Hospedeiros e Reservatórios de Leishmania sp. e sua Importância na Manutenção dos Ciclos de Transmissão nos Ambientes Silvestre e Sinantrópico
}

\author{
André Luiz Rodrigues Roque I Ana Maria Jansen
}

$\mathrm{O}$

contato do homem com o ambiente silvestre e sua fauna e, portanto, com os ciclos de transmissão das diversas espécies de seus parasitos, sempre ocorreu e continua ocorrendo. Atualmente, a expansão de fronteiras agrícolas e sua consequente destruição de hábitats naturais, o aquecimento global e a popularização do ecoturismo são apenas alguns exemplos de fatores que têm levado o homem a um contato maior com esses ciclos de transmissão, permitindo o intercâmbio de parasitos entre animais silvestres, domésticos e o homem (Daszak et al., 2007; Jones et al., 2008; Swan, Coetzer \& Terblanche, 2009).

Vários fatores associados às alterações ambientais, naturais ou não, corroboram para acelerar esse processo, promovendo a dispersão dos parasitos para novas áreas e proporcionando o contato destes com novos hospedeiros, os quais poderão atuar como reservatórios amplificando, desse modo, a área de ocorrência da espécie do parasito em questão (Aguirre \& Tabor, 2008; Rhyan \& Spraker, 2010; Slenning, 2010).

Tais fenômenos são especialmente importantes quando ocorrem com parasitos multi-hospedeiros, isto é, capazes de infectar uma ampla gama de espécies. Esse é o caso de algumas espécies inseridas no gênero Leishmania, dentre as quais aquelas de maior importância em saúde pública no continente americano: L. infantum (=L. chagasi), $L$. braziliensis e L. amazonensis. Esses tripanossomatídeos se caracterizam por apresentar uma grande heterogeneidade genética e ecletismo biológico no que se refere às diferentes ordens de mamíferos que são capazes de infectar. Tal ecletismo resulta em que esses protozoários sejam encontrados em ciclos de transmissão com características e particularidades regionalizadas, o que converte-se em uma epidemiologia complexa e peculiar nas áreas de sua ocorrência (Ashord, 1996; Rotureau, 2006). A complexidade da ecoepidemiologia das leishmanioses tem como consequência o desconhecimento de muitos aspectos do seu ciclo enzoótico. Entretanto, a magnitude do problema sanitário que as leishmanioses representam impõe a necessidade de esclarecer os elos da cadeia epidemiológica em todos os níveis, como pré-requisito de definir efetivas estratégias de controle que se fazem necessárias (Rotureau, 2006; Tesh, 1995; Shaw, 2007).

Apesar do conceito e dos métodos envolvidos no estudo de reservatórios de parasitos terem se modificado significativamente ao longo do tempo (Ashford, 1997; Haydon et al., 2002; Chaves et al., 2007), ainda hoje, o conceito do que é um reservatório é permeado por uma visão antropocêntrica, uma vez que reservatório é frequentemente 
referido como "a espécie animal que é fonte de infecção de um determinado parasito para o homem”. Além de antropocêntrico, esse conceito é fixista por não considerar o caráter dinâmico e, portanto, mutável das associações parasito-hospedeiro. Tomando como base principalmente os trabalhos de Ashford (1997) e de Haydon e colaboradores (2002), consideramos como 'reservatório' não apenas uma única espécie de mamífero infectado por uma espécie de parasito que potencialmente infecta o homem e animais domésticos em determinada localidade, mas como um sistema que pode incluir uma ou mais espécies de animais responsáveis pela manutenção de uma dada espécie de parasito na natureza. Em cada sistema reservatório, as espécies desempenham diferentes papéis na manutenção da parasitose, o que significa que o papel de cada componente deve ser sempre considerado único dentro de uma determinada escala espaço-temporal (Roque \& Jansen, 2010). A complexidade da interação hospedeiro/reservatório-parasito se dá sobretudo em razão do caráter dinâmico e imprevisível dessa unidade biológica em constante mudança, em virtude das alterações do meio ambiente e do processo coevolutivo dos componentes dessa interação (Roque, 2009). É nesse contexto que apresentamos e discutimos a conceituação de reservatórios para Leishmania spp., sua importância na manutenção dos ciclos de transmissão desses parasitos na natureza e seu papel na epidemiologia dessa zoonose no continente americano.

\section{DESENVOLVIMENTO}

\section{Reservatórios: conceituação}

O encontro de um animal infectado não é suficiente para o considerarmos como um reservatório. Um animal infectado é um hospedeiro do parasito, mas sua importância na manutenção do ciclo de transmissão numa dada área dependerá das peculiaridades da interação parasito-hospedeiro; é esta que vai determinar a competência da espécie animal em questão na manutenção e/ou transmissão do parasito e que, portanto, definirá seu papel (ou não) como reservatório. Cada interação parasito-hospedeiro apresenta particularidades determinadas por fatores relacionados ao hospedeiro (sexo, idade, padrão comportamental, competência imunológica, coinfecções), ao parasito (tempo de geração, potencial reprodutivo, estratégias de transmissão), ao vetor (hábitos, comportamento, dispersão) e ao ambiente onde ocorre. Isso mostra que as espécies não desempenham o mesmo papel no ciclo de transmissão de um parasito nos diferentes recortes tempo-espaciais. As diferentes características epidemiológicas e padrões de infecção se modificam de uma região para outra em consequência de padrões ecológicos das áreas de ocorrência, incluindo variações na vegetação, clima, diversidade e abundância relativa das espécies de animais silvestres; fatores demográficos como migração de pessoas e animais domésticos; alteração do hábitat original por causas naturais (fenômenos como o El Niño, atividades vulcânicas ou combustão espontânea de turfas) ou por ação antrópica (crescimento das cidades e expansão das atividades agrícolas); alteração nos hábitos alimentares dos vetores; condição socioeconômica e cultural da população; diferentes subpopulações de parasitos e espécies de vetores; e presença ou ausência de hospedeiros e reservatórios, domésticos e/ou silvestres (Guerin et al., 2002; Desjeux et al., 2004; Cerbino, Weneck \& Costa, 2009).

Para definir uma determinada espécie animal como reservatório de um dado parasito, faz-se necessário a determinação dos seguintes parâmetros:

- Distribuição geográfica do hospedeiro: define a área máxima de ocorrência da parasitose (Mills \& Childs, 1998). Assim, é importante definir a composição faunística e a representatividade de cada espécie dentro da comunidade de potenciais reservatórios (abundância relativa), bem como sua distribuição pelos estratos florestais. Nesse caso, vale lembrar que a maioria das espécies não está restrita apenas ao estrato florestal onde são mais comumente encontradas, e seu deslocamento de um a outro estrato implica na possibilidade de dispersão de seus parasitos, contribuindo para o estabelecimento de novos focos de transmissão (Jansen et al., 1999). Além disso, em alguns cenários, uma espécie infectada que apresente alta abundância relativa pode 
ter maior competência como reservatório em um determinado local do que em outro, no qual seu número e biomassa sejam pouco expressivos (Jansen \& Cortez, 2007).

- Identificação taxonômica dos hospedeiros: a correta identificação dos hospedeiros é fundamental, uma vez que mesmo espécies crípticas podem apresentar padrões de infecção distintos e, portanto, ter diferentes papéis na manutenção e dispersão de um parasito na natureza (Roque et al., 2005). Interpretações epidemiológicas equivocadas podem surgir tomando-se por base dados taxonômicos imprecisos dos hospedeiros (Mills \& Childs, 1998).

- Prevalência e distribuição da parasitose nas diferentes populações de hospedeiros: a prevalência da infecção numa mesma espécie de hospedeiro pode ser muito alta em algumas localidades e muito baixa em outras áreas, que podem até mesmo estar bem próximas. Fica assim evidente que em diferentes localidades uma mesma espécie de mamífero pode desempenhar distintos papéis na manutenção do parasito na natureza (Herrera et al., 2005). É possível, e até provável, que parasitos sejam extintos periodicamente em uma determinada população de hospedeiros e sejam reintroduzidos algum tempo mais tarde (Mills \& Childs, 1998).

- Análise regional do parasito e reservatórios em distintos ecossistemas dentro de um mesmo bioma: essa informação permite avaliar onde está acontecendo a transmissão, onde há maior risco de spillover da parasitose. Observa-se com frequência que a transmissão de parasitos é focal, ou seja, às vezes restritos a hot spots (zonas 'quentes'), em que a transmissão do parasito é extremamente bem-sucedida, ao lado de outras onde a transmissão não acontece (Jones et al., 2008; Weiss \& McMichael, 2004). Adicionalmente, há que se lembrar de uma importante lei em ecologia que comprovadamente cabe no universo de estudo da parasitologia, este também um fenômeno ecológico: "as espécies não se distribuem homogeneamente num dado ambiente" (Bush et al., 2001: 322). O mesmo se aplica a seus parasitos, sendo fundamental que estudos de reservatórios sejam realizados de modo abrangente e sob uma perspectiva multidisciplinar.

- Estimativa da prevalência da infecção entre distintas categorias demográficas das subpopulações de hospedeiros, a saber - machos e fêmeas, adultos e jovens: de posse de tal informação é possível determinar se a transmissão ainda está acontecendo (caso a prevalência da parasitose seja elevada na população de animais jovens) ou há possibilidade de dispersão do parasito. Tomando como exemplo: gambás são descritos como animais nômades, no entanto, os machos têm comportamento nômade muito mais acentuado que as fêmeas e são, assim, melhores dispersores de parasitos; primatas vivem em grupos, têm comportamento territorialista e, assim, são mais suscetíveis a parasitoses transmitidas de forma direta quando um dos componentes do grupo está infectado. Diferenças demográficas apontam para a dinâmica das subpopulações de hospedeiros no tempo e espaço e podem nos ajudam a prever oscilações na transmissão baseada nas flutuações sazonais populacionais dos principais hospedeiros (Noireau, Diosque \& Jansen, 2009).

- Dinâmica das populações de hospedeiros no tempo: as redes de transmissão de parasitos variam no tempo e espaço. Os ambientes estão em constantes mudanças e estas se refletem, necessariamente, nas possibilidades de encontro entre parasitos e hospedeiros. Assim, alterações ambientais tanto podem favorecer o encontro do parasito com novas espécies animais suscetíveis - o que pode levar a uma expansão dos focos de transmissão - quanto podem resultar, em especial, na extrema destruição de hábitats e na perda da diversidade de ambos parasitos e hospedeiros. Isso significa que um sistema reservatório onde um dado parasito é mantido caracterizase por ser um cenário dinâmico sempre sujeito à participação de novos atores (hospedeiros) (Haydon et al., 2002; Noireau, Diosque \& Jansen, 2009). Zoonoses ocorrem frequentemente em focos descontínuos tanto no tempo quanto no espaço, o que torna essencial que programas de vigilância epidemiológica sejam, além de constantes, regionais (muitas vezes até microrregionais).

Um ponto controverso quando se discute reservatórios silvestres é que a sempre citada ausência de sintomatologia nesses animais seria uma condição essencial para a caracterização de reservatórios e indicaria antiguidade na 
relação parasitária (Lainson \& Shaw, 1979; WHO, 1990). Sabe-se, entretanto, que uma antiga relação parasitohospedeiro não necessariamente evolui para uma interação harmônica (sem danos ao hospedeiro), mas sim para uma que favoreça a maior transmissibilidade do parasito, sendo esta dependente de sua estratégia reprodutiva (Giorgio, 1995; Woolhouse, Taylor \& Haydon, 2001). Além disso, detectar sintomas clínicos em animais silvestres ainda é tarefa para alguns poucos especialistas. Outro aspecto importante é que uma vez definida uma determinada espécie como reservatório, há que se considerar que um táxon não é um conjunto homogêneo de animais. Ao contrário, muitas espécies apresentam uma expressiva variedade de morfotipos, raças, e/ou subpopulações. Essa variedade intraespecífica reflete-se também em peculiaridades na interação parasito-hospedeiro, como observado, por exemplo, nos diferentes padrões de resposta imune e da consequente resistência ou suscetibilidade das diferentes linhagens de camundongos ante a infecção experimental por Leishmania sp. (Sakthianandeswaren, Foote \& Handman, 2009). Também no homem a infecção por Leishmania spp. pode resultar em um espectro de manifestações que variam de processos benignos, auto-resolutivos, até formas graves - disseminadas, anérgicas ou hiperérgicas.

Além do componente genético, infecções parasitárias concomitantes, gestação e outros fatores são responsáveis por tornar um animal mais ou menos suscetível ou resistente. Uma das grandes dificuldades no estudo de mamíferos silvestres e sinantrópicos é exatamente distinguir os suscetíveis (os que apresentam alta infectividade ao vetor e, portanto, estão relacionados com a dispersão do parasito) dos resistentes, que apresentam baixa infectividade/ transmissibilidade. $\mathrm{O}$ fato é que o curso de uma infecção é o resultado de variáveis inerentes não só ao parasito, mas também ao hospedeiro, às particularidades de sua exposição ao parasito (via de infecção, tamanho do inóculo e reinfecções), ao ambiente e ao vetor. Assim, a importância de uma espécie animal como reservatório depende: de sua estratégia de vida e ciclo reprodutivo; do hábitat e clima locais; da presença, hábitos e capacidade vetorial do hospedeiro invertebrado; e das peculiaridades da interação parasito-hospedeiro, todos interligados num mesmo intervalo de tempo (Ashford, 1996; Roque et al., 2005; Herrera et al., 2005).

\section{Perfil da Infecção e Abordagem Metodológica em Mamíferos Não Humanos}

Causador no homem de diferentes manifestações clínicas de leishmanioses, o gênero Leishmania é composto de mais de vinte espécies de flagelados digenéticos cujos hospedeiros vertebrados incluem mamíferos de pelo menos sete diferentes ordens (Lainson \& Shaw, 1979) e cujos hospedeiros invertebrados nas Américas são flebotomíneos (Diptera: Psychodidae) do gênero Lutzomyia (WHO, 2010). As espécies de Leishmania mais comumente associadas à doença humana no continente americano são zoonoses e podem infectar um amplo espectro de espécies de mamíferos silvestres. Apesar disso, ainda são restritos os estudos sobre o papel desempenhado pelas diferentes espécies de mamíferos nos ciclos de transmissão de Leishmania spp., sendo as descrições de reservatório, muitas vezes, restritas apenas a achados pontuais da infecção (Ashford, 1996; WHO, 1990).

Em humanos, as diferentes formas clínicas que as leishmanioses podem assumir foram compartimentalizadas, para melhor compreensão, em tegumentar (cutânea, cutâneo-mucosa e cutâneo-difusa) e visceral. Essa mesma categorização, no entanto, não pode ser extrapolada à infecção em outros mamíferos domésticos, silvestres ou sinantrópicos. Cães infectados com L. infantum, espécie relacionada à forma visceral da doença humana, podem apresentar ulcerações de pele em que é possível o isolamento de parasitos (Madeira, 2009). Por sua vez, visceralização de espécies de Leishmania relacionadas a formas tegumentares da doença humana é observada em roedores desde a década de 1950 (Nery Guimarães, 1951a, 1951b). Várias espécies de mamíferos silvestres já foram encontradas infectadas pelas diferentes espécies de Leishmania que circulam nas Américas. Ainda assim, estudos da dinâmica da infecção desses parasitos nos hospedeiros silvestres ainda são escassos ou inexistentes (Travi et al., 2002; Raymond et al., 2003; Roque et al., 2010). A maioria dos trabalhos ainda se restringe a apontar os reservatórios baseando-se em prevalência de achados pontuais de infecção, muitas vezes diagnosticados apenas por meio de ferramentas moleculares (PCR, do inglês Polymerase 
Chain Reaction) de alta sensibilidade, mas que não definem a real importância epidemiológica daquele achado e nem a participação desse hospedeiro no ciclo de transmissão do parasito (Roque, 2009). Nesse sentido, entender o papel que as espécies de hospedeiros/reservatórios mamíferos desempenham na manutenção e expansão dos ciclos de transmissão de Leishmania spp. na natureza demanda estudos de campo, os quais são essenciais na definição de medidas efetivas de controle dessa parasitose. Adicionalmente, estudos experimentais com espécies consideradas possíveis reservatórios silvestres devem ser realizados como forma de auxiliar a interpretação dos dados obtidos nessas investigações (Roque et al., 2010).

Tanto em humanos quanto em outros mamíferos, o exame direto e/ou cultura de sangue são muito pouco efetivos para, respectivamente, diagnóstico e isolamento de Leishmania spp. Nesse caso, as culturas de punções ou fragmentos de tecidos hematopoiéticos constituem o padrão-ouro da abordagem metodológica, mas não necessariamente refletem transmissibilidade do parasito. Esta será indicada pela origem do material cultivado de onde se isolou o parasito. Assim, culturas de pele ou sangue e/ou xenodiagnóstico positivo indicam potencial de infectividade do mamífero ao vetor, ou seja, apontam para a transmissibilidade do parasito. A visualização direta do parasito em fragmentos de pele tem menor sensibilidade; mas, associada à confirmação do agente etiológico neste tecido, também atestam sua transmissibilidade. Já a cultura positiva obtida apenas de órgãos internos (baço, fígado, medula óssea, linfonodos e outros) demonstra a presença de parasitos vivos e viáveis, mas não atestam sua infectividade ao vetor (Roque, 2009).

Testes sorológicos, dentre os quais os mais utilizados são a Reação de Imunofluorescência Indireta (Rifi) e o Ensaio Imunoenzimático (Elisa), apontam para a exposição daquele mamífero ao agente etiológico. O animal foi exposto ao parasito em algum momento da sua vida, mas isso não significa que ele represente uma importante fonte de infecção para o vetor ou mesmo que continue mantendo esse parasito. Um animal positivo apenas em testes sorológicos demonstra ter sido exposto ao ciclo de transmissão, é um hospedeiro do parasito, mas seu potencial de transmissibilidade ao vetor é baixo. Diagnóstico molecular por PCR qualitativos são amplamente utilizados e considerados exames parasitológicos diretos enriquecidos, uma vez que detectam partes constitutivas, no caso fragmentos de DNA, dos parasitos. Apesar de demonstrarem a presença do parasito, a alta sensibilidade desses testes não nos permite atestar a sua viabilidade nem definir se a carga parasitária detectada seria suficiente para garantir a transmissibilidade daquele tripanossomatídeo. o potencial de transmissibilidade do hospedeiro não pode ser definido nem pelas reações quantitativas por PCR em tempo real, que, apesar de efetivas para calcular a carga parasitária, não são capazes de avaliar a viabilidade daquele parasito (Silva, Gontijo \& Melo, 2005; Britto, 2009). Vale mencionar que, mesmo sendo extremamente sensível, a utilização da PCR como padrão-ouro para diagnóstico ou controle de cura da infecção do homem ainda se constitui em assunto em pleno debate (Salam et al., 2010; Mendonça et al., 2004). Já em relação à infecção nos animais silvestres e sinantrópicos, o diagnóstico por PCR ainda é um desafio, carecendo de padronização de técnicas e alvos moleculares espécie-específicos, tanto em relação ao parasito quanto ao hospedeiro.

\section{Reservatórios Mantenedores e Amplificadores}

Consideramos como reservatórios mantenedores aqueles mamíferos capazes de se infectar e manter infecções estáveis por uma determinada espécie de parasito. Reservatórios amplificadores são aqueles que, além de manter, apresentam um perfil de infecção que garante a transmissibilidade desse parasito (Roque et al., 2010). Essa conceituação deve ser considerada para cada espécie investigada, em cada localidade e num dado recorte de tempo. Para exemplificar, tomemos os gambás (Didelphis spp.), frequentemente citados como principal reservatório de outro tripanossomatídeo - T. cruzi. Como veremos adiante, os escassos estudos em reservatórios de Leishmania sp. não nos possibilitam utilizar um exemplo para tais parasitos. Gambás podem ser excelentes reservatórios amplificadores do T. cruzi em algumas áreas (Roque et al., 2008), mas esta peculiaridade não se repete em todos os ecossistemas. 
No Pantanal sul mato-grossense, estudos evidenciam a importância dos quatis (Nasua nasua) como reservatórios (Herrera et al., 2008), enquanto em alguns fragmentos de Mata Atlântica essa função é desempenhada por primatas Calitriquídeos (Lisboa et al., 2006). Outro importante aspecto é que reservatórios mantenedores podem se transformar em amplificadores em situações especiais, como quando sofrem doenças outras debilitantes, por exemplo, que podem alterar o perfil da infecção e favorecer o aumento da população parasitária no organismo. Com isso, aumentam também as chances de transmissão, ou seja, a transmissibilidade do parasito.

\section{Hospedeiros Mamíferos Apontados como Reservatórios: considerações}

De modo geral, o estudo da interação de mamíferos silvestres e sinantrópicos com parasitos, e especialmente com Leishmania spp., é dificultado por condições entre as quais destacamos a dificuldade em obter colônias de espécies de mamíferos silvestres em cativeiro e a complexidade de realizar trabalhos de campo de longo curso e dentro de um enfoque ecológico. Como será visto ao longo deste capítulo, os termos 'hospedeiro' e 'reservatório' muitas vezes são apresentados como sinônimos nos artigos citados. Nosso intuito, aqui, foi o de realizar uma revisão reinterpretando os dados existentes na literatura sob o enfoque ecológico proposto pelos mais recentes estudos em reservatório e modelagem ambiental, relacionando-os, sempre que possível, ao potencial de transmissibilidade do vetor. Nem sempre tal abordagem foi possível, tendo em vista que em alguns dos estudos citados não conseguimos ter acesso completo ao texto ou a informações complementares. Outro problema encontrado foi na identificação do agente etiológico envolvido. Além das periódicas revisões taxonômicas propostas para Leishmania spp., a nomenclatura de muitas espécies foram modificadas ao longo do tempo e as diversas metodologias de identificação do agente envolvido impossibilitava-nos, muitas vezes, de definir o agente etiológico com base na atual taxonomia do gênero Leishmania.

Nesse contexto, discutimos algumas espécies de mamíferos silvestres e sinantrópicos já encontrados infectados por Leishmania spp. como 'hospedeiros do parasito' ou 'potenciais reservatórios', quando demonstrada a manutenção e/ou potencial de transmissão do parasito ao vetor. Como já dito, a condição de reservatório irá variar nos diferentes ambientes e apenas um estudo local da enzootia poderá definir se um desses 'potenciais reservatórios' está ou não atuando como reservatório num determinado ambiente e num dado momento, uma vez que essa condição também pode se modificar no decorrer do tempo.

\section{- Ordem Marsupialia}

Representante da nossa fauna autóctone, a ordem Marsupialia apresenta sua maior diversidade de espécies no continente australiano, enquanto apenas uma família é reconhecida nas Américas, a Didelmorphidae. O gênero Didelphis (Figura 1) é aquele com maior dispersão no continente, ocorrendo do sudeste do Canadá ao sul da Argentina, sendo, provavelmente por seu caráter sinantrópico, um dos mamíferos mais investigados no que diz respeito à infecção por Leishmania sp., ainda que sejam escassos os estudos de acompanhamento de infecções naturais e/ou experimentais (Travi et al., 1994; Schallig et al., 2007; Quinnell \& Courtenay, 2009).

A ampla distribuição dos didelfídeos se deve principalmente a sua impressionante adaptabilidade a diferentes nichos ecológicos, principalmente a ambientes com elevado grau de ação antrópica. Esses animais podem colonizar forros das casas e outros abrigos do domicílio e peridomicílio, e sobrevivem nutrindo-se de restos alimentares do homem. Tais características fizeram com que os Didelphis sp. sejam atualmente indicadores de degradação ambiental por influência humana (Olifiers, Gentile \& Fiszon, 2005). Didelphis sp. são nômades, solitários (principalmente os machos), excelentes escaladores e seu refúgio principal são buracos e folhagens de árvores (Austad, 1988).

Didelphis marsupialis, espécie encontrada desde o México até a região amazônica, já foi descoberta naturalmente infectada por pelo menos cinco diferentes espécies de Leishmania sp. Sua importância como potencial reservatório 
de L. infantum foi demonstrada em uma comunidade rural na Colômbia, onde esses animais apresentavam a maior abundância relativa na área (68,5\% dos animais capturados), elevada prevalência de culturas positivas $(32,4 \%)$ e altas cargas parasitárias nos imprints, ambos em material de baço (Corredor, 1989). Estudos posteriores ainda confirmariam a infecção desse didelfídeo em outras regiões na Colômbia e Venezuela (Travi et al., 1994; Quinnell \& Courtenay, 2009). Outras espécies de Leishmania já isoladas de D. marsupialis são L. braziliensis (Lainson \& Shaw, 1998; Grimaldi Jr. \& Tesh, 1993), L. amazonensis (Arias et al., 1981; Grimaldi Jr. et al., 1991), L. guyanensis (Arias et al., 1981; Grimaldi Jr. et al., 1991; Dedet, Gay \& Chatenay, 1989) e L. panamensis (Ashford, 1996).

Figura 1 - Gambá Didelphis albiventris proveniente de São Borja, Rio Grande do Sul

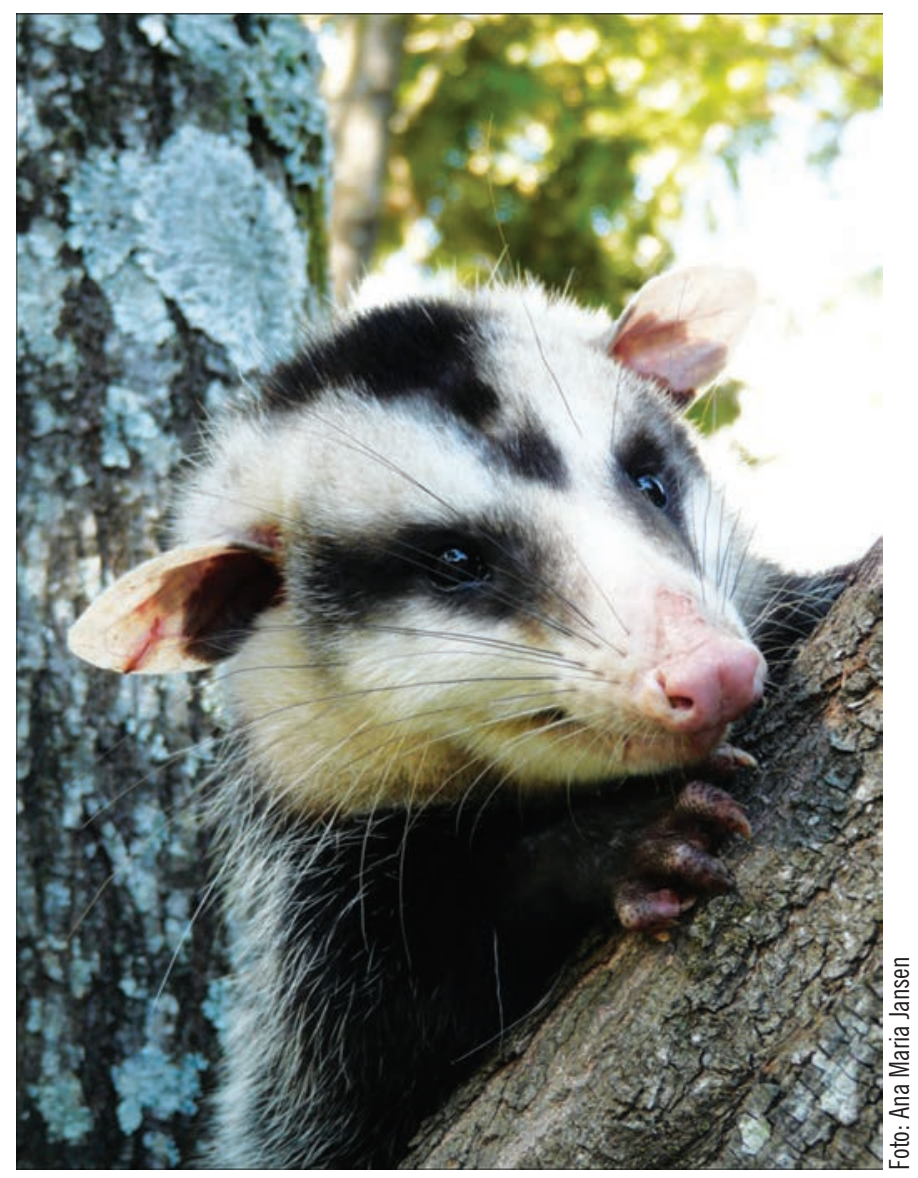

Didelphis albiventris tem sua maior distribuição na parte central da América do Sul, da Colômbia ao norte da Argentina, sendo bastante abundante nas Regiões Nordeste, Central e Sul do Brasil. O isolamento de L. infantum nesta espécie de marsupial foi primeiramente realizado no estado da Bahia, em 1984 (Sherlock et al., 1984), sendo posteriormente diagnosticado por PCR em Pernambuco (Brandão-Filho et al., 2003) e Rio Grande do Sul (Roque ALR e colaboradores, dados não publicados). A infectividade ao vetor foi ainda demonstrada por xenodiagnóstico, o que confirma que essa espécie pode desempenhar o papel de reservatório (Sherlock, 1996). Outras espécies de Leishmania já diagnosticadas em D. albiventris são L. peruviana e L. amazonensis (Grimaldi Jr. \& Tesh, 1993).

Recentemente, no município de Bauru, interior do estado de São Paulo, uma investigação por PCR de aspirado de medula óssea em 112 gambás, sendo 102 D. albiventris e 10 D. aurita, demonstrou uma elevada prevalência de 
infecção por Leishmania spp. (91,6\%), embora nesse estudo não se tenha conseguido caracterizar as espécies do parasito envolvidas (Santiago et al., 2007). O estudo não incluiu imprint ou isolamento de parasitos em pele, ou seja, comprova a competência desse táxon em manter o gênero Leishmania, mas não sua competência em infectar o vetor.

Marmosa sp. já foram encontradas naturalmente infectadas por L. amazonensis (Arias et al., 1981) e por $L$. braziliensis (Brandão-Filho et al., 2003). Metachirus nuticaudatus, marsupial terrestre de médio-porte e ampla distribuição na América do Sul, já foi encontrado infectado por L. braziliensis (Lainson \& Shaw, 1998), L. amazonensis e L. panamensis (Ashford, 1996). Já a cuíca-de-quatro-olhos Philander opossum, marsupial noturno encontrado forrageando tanto no solo quanto em árvores, já foi identificado infectado por L. braziliensis (Lainson \& Shaw, 1998) e por L. amazonensis (Grimaldi Jr. \& Tesh, 1993).

Até o momento, apenas um trabalho de infecção experimental de marsupiais por Leishmania sp. foi publicado (Travi et al., 1998a). Nesse trabalho, dos cinco D. marsupialis utilizados, apenas uma fêmea jovem apresentou sintomatologia que, apesar de inespecífica, os autores descrevem como sugestiva de leishmaniose visceral (apatia, prostração, desidratação e descamação de pele) dois meses após a infecção experimental por L. infantum. Na necropsia foram observadas inúmeras formas amastigotas do parasito no baço, fígado e linfonodos. Análises histológicas demonstraram histiócitos parasitados, necrose esplênica e esteatose hepática. Os demais gambás, mesmo sem clínica aparente, também apresentaram alterações histológicas - discretos infiltrados inflamatórios no fígado, linfonodos e baço. A infectividade ao vetor foi ainda confirmada por xenodiagnóstico, embora a taxa de infecção dos vetores tenha sido considerada pelos autores como bastante baixa em relação a relatos em outros mamíferos (Travi et al., 1998a). Vale mencionar que esse é um ensaio laboratorial, com flebotomíneos de colônia de laboratório e, portanto, em um sistema distante das condições na natureza. O fato importante é que o trabalho demonstrou inequivocamente a possibilidade de gambás infectados com L. infantum atuarem como fonte de infecção para Lu. longipalpis (Travi et al., 1998a).

\section{- Superordem Xenarthra}

Mamíferos da superordem Xenarthra foram previamente classificados em uma ordem denominada Edentata, recentemente descrita como polifilética, que incluía também os pangolins (Manis spp.) africanos e asiáticos. Com a nova classificação dos pangolins na ordem Pholidota, os mamíferos das ordens Cingulata (tatus) e Pilosa (tamanduás e preguiças) foram juntamente classificados na superordem Xenarthra (Moller-Krull et al., 2007; De Esteban-Trivigno, Mendoza \& Renzi, 2008). Mamíferos dessa superordem apresentam peculiaridades biológicas fascinantes como ossos pélvicos fundidos, ossos de reforço na coluna e uma estrutura peculiar de circulação sanguínea que os permite poupar energia, com uma taxa metabólica extremamente baixa (Bugge, 1979; Gaudin \& Biewener, 1992). Essas adaptações, no entanto, não impediram a massiva extinção de um grande número de representantes desse táxon, sendo os gêneros atuais existentes apenas uma pequena representação da fauna existente no período Terciário (Moller-Krull et al., 2007). Ainda hoje, a destruição de seus nichos específicos, resultante sobretudo da ação humana, certamente contribui expressivamente para a acentuada redução das populações desses mamíferos na natureza.

Tatus, preguiças e tamanduás, atualmente os principais representantes dessa superordem, têm uma longa história coevolutiva com tripanossomatídeos e representam um grupo de mamíferos em que já foi encontrada grande diversidade de espécies de Leishmania sp. Outros tripanossomatídeos também descritos nesses mamíferos incluem várias espécies do gênero Trypanosoma, além do ainda pouco estudado gênero Endotrypanum (Ashford, 1996; Rotureau, 2006). Importante notar que, apesar dessa diversidade de espécies de tripanossomatídeos, não há descrição da infecção desse grupo de mamíferos por L. infantum e L. braziliensis, espécies de grande importância em saúde pública no Brasil. Ainda assim, há duas descrições de isolamento de Leishmania sp. de preguiças no Panamá e na Costa Rica, os quais foram caracterizados como Leishmania braziliensis s.l. Nesse caso, trata-se de espécies do complexo L. braziliensis, cuja taxonomia à época não incluía as ferramentas atuais e, portanto, difere bastante daquela atualmente aceita. 
Analisando os trabalhos mais recentes da mesma região, podemos sugerir que provavelmente se tratava de outras espécies do subgênero Viannia (Dedet, Gay \& Chatenay, 1989).

Os tatus representam um dos mais antigos grupos de mamíferos e o mais primitivo de Xenarthra. São caracterizados por terem o corpo coberto por placas ósseas articuladas e flexíveis, que correspondem a 16\% do seu peso vivo e lhes confere proteção. Os membros desta família - Dasypodidae - são encontrados desde o Sul dos Estados Unidos até o estreito de Magalhães (Miranda \& Costa, 2006). Até o momento, o tatu-galinha (Dasypus novemcinctus) foi o único hospedeiro não humano encontrado infectado por $L$. (V.) naiffi, obtendo-se o isolamento do parasito de amostras de sangue e órgãos internos (fígado e baço) desses animais (Lainson \& Shaw, 1989; Naiff et al., 1991). Também neste caso são necessários estudos complementares que avaliem o potencial de infectividade desse táxon para o vetor. Vale ressaltar que a distribuição geográfica de L. naiffi parece ser bem maior que se supunha anteriormente, sendo possível encontrar esse parasito no Peru, Equador e Martinica, além de no Brasil (Pratlong et al., 2002). Apesar de haver relatos de infecção patogênica em humanos por L. naiffi (Naiff et al., 1991), atualmente esta espécie não parece ser um importante agente etiológico de leishmaniose humana (Van der Snoek et al., 2009). L. (V.) guyanensis é a outra espécie de Leishmania já diagnosticada em tatus, e também em D. novemcinctus no estado brasileiro do Pará (Rotureau, 2006; Lainson et al., 1979).

Os tamanduás constituem uma só família (Myrmecophagidae) com características anatômicas, fisiológicas e comportamentais similares, apesar da grande discrepância de peso que pode ocorrer entre diferentes espécies, variando desde $200 \mathrm{~g}$ até $50 \mathrm{~kg}$. Têm conformação compacta, destacando-se um focinho longo e cônico e uma língua extensa e viscosa, adaptada especialmente ao seu hábito alimentar composto de térmitas e formigas. São dotados de membros superiores fortes e providos de poderosas garras que eles utilizam para defesa própria e como ferramenta alimentar (Miranda \& Costa, 2006). Em apenas uma espécie de tamanduá, o tamanduá-mirim (Tamandua tetradactyla), foi possível obter o isolamento de Leishmania sp., sendo duas diferentes espécies - L. (V.) guyanensis e L. (L.) amazonensis, no Brasil e Equador, respectivamente (Rotureau, 2006; Lainson, Shaw \& Povoa, 1981; Mimori et al., 1989).

As preguiças são habitantes arborícolas das regiões de clima tropical e subtropical das Américas Central e do Sul e são representadas por dois gêneros: Bradypus (família Bradypodidae) e Choloepus (família Magalonichidae). As preguiças têm corpo com reduzida massa muscular, membros anteriores curtos e posteriores longos, ambos providos de garras imprescindíveis à sua locomoção, defesa e acesso aos alimentos. Movimentam-se lentamente, passando de uma a outra árvore diretamente pelo extrato arbóreo e descendo ao solo apenas uma vez por semana para defecar (Miranda \& Costa, 2006). Diferentes espécies de Leishmania já foram diagnosticadas em preguiças. A preguiça-dedois-dedos (Choloepus didactylus) pode ser considerada um potencial reservatório de L. guyanensis, como apontam os estudos que demonstraram elevada prevalência de infecção por isolamento em pele íntegra e órgãos do sistema linfático, os quais variam de 35\% a 47\% na Guiana Francesa (Dedet, Gay \& Chatenay, 1989; Gentile et al., 1981) e de até 46\% no Brasil (Lainson, Shaw \& Povoa, 1981).

L. shawi já foi diagnosticada em duas espécies de preguiças, a preguiça-de-dois-dedos e a preguiça-de-bentinho (Bradypus tridactylus), ambas no Brasil (Lainson et al., 1989). No Panamá, L. colombiensis foi encontrada em vísceras de preguiça-real (Choloepus hoffmanni) (Grimaldi Jr. \& Tesh, 1993; Kreutzer et al., 1991), enquanto L. equatorensis foi descrita infectando esta mesma espécie no Equador (Grimaldi Jr. et al., 1992). Por fim, L. (V.) panamensis, espécie fortemente relacionada a L. guyanensis, já foi descrita em Choloepus hoffmanni e Bradypus variegatus no Panamá (Grimaldi Jr. \& Tesh, 1993; Ashford, 2000).

A interação do homem com Xenarthra merece ser enfatizada: em áreas rurais, é comum observar tatus invadindo galinheiros à procura de ovos e/ou animais, aproximando-se dessa forma do ambiente peridomiciliar, onde podem servir de fonte de infecção aos flebotomíneos que ali se encontrem. A importância epidemiológica dos mamíferos da 
superordem Xenarthra é ainda maior se considerarmos que preguiças, tamanduás e tatus são caçados e consumidos em algumas áreas do Brasil, como na região amazônica. Não é raro observar pessoas criando filhotes desses mamíferos no quintal de casa, após terem matado as mães durante uma caçada. Esses filhotes são mantidos até se tornarem adultos, e nesse período podem se infectar e servir de fonte de infecção a flebotomíneos que frequentam o ambiente peridomiciliar.

\section{- Ordem Rodentia}

Os roedores talvez representem o grupo de mamífero mais diversificado e com ampla dispersão no mundo todo, e sua característica comum é o crescimento contínuo de seu único par de dentes incisivos. A diversidade morfológica neste táxon é exemplificada pelo contraste existente entre um pequeno rato pigmeu (Oligoryzomys sp.) de $10 \mathrm{~g}$ e a imensa capivara (Hydrochoerus hydrochaeris), que pode chegar a $70 \mathrm{~kg}$ (Lange \& Schmidt, 2007). A grande diversidade de espécies de roedores faz com que ainda existam vários grupos cuja posição taxonômica ainda é discutível, e cujos indivíduos só podem ser separados por cariotipagem (Bonvicino et al., 1996; Bonvicino, Otazu \& D’Andrea, 2002). Estratégias e sazonalidade de reprodução, tempo de gestação e número de filhotes são outras características que diferem significativamente entre os gêneros dessa ordem (Wilson \& Reeder, 2005).

Roedores não são autóctones das Américas e os primeiros representantes desse táxon (Hystricognathi caviomorfos) chegaram juntamente com os primeiros primatas oriundos da África há cerca de 45 milhões de anos. A segunda onda de migração de roedores para o nosso continente (Sciurognathi - cricetídeos) é bem mais recente. Parece estar relacionada à diversificação dos roedores murídeos e cricetídeos na África e à chegada por uma rota de migração que incluía um estabelecimento inicial na América do Norte (Flynn \& Wyss, 1998). Desde sua chegada, os roedores adaptaram-se bem, diversificaram-se em um grande número de espécies e passaram a colonizar os mais diversos tipos de hábitat, das florestas tropicais aos desertos, dos planaltos de elevadas altitudes às planícies alagadas, do ambiente silvestre ao ambiente urbano. Os roedores são ainda encontrados nos mais diversos estratos naturais, sendo reconhecidas desde espécies fossoriais, capazes de cavar longos e interligados túneis sob a terra, até espécies de hábitos semiaquáticos e arborícolas (Wilson \& Reeder, 2005).

Esse táxon de mamíferos é provavelmente o mais estudado no que se refere à infecção por Leishmania spp., em condições tanto naturais quanto experimentais. Dentro deste, a espécie Mus musculus é exaustivamente estudada em todo o mundo, com diversos objetivos que incluem desde estudos de subpopulações celulares envolvidas na resposta imune e nas lesões, até avaliações como modelo da doença humana. A maioria de tais estudos foi e é realizado em linhagens de Mus musculus de laboratório, e não de animais de vida livre. Para este capítulo, no entanto, iremos nos ater àquelas espécies silvestres e sinantrópicas, potenciais reservatórios desses parasitos, os quais já foram estudados em condições experimentais.

A diversidade desse grupo de mamíferos, com representantes ocupando diversos e distintos nichos ecológicos, reflete-se também na grande diversidade de espécies de Leishmania já diagnosticadas nesse táxon. Embora seja indiscutível a importância dos roedores na manutenção de diversas espécies de Leishmania, há numerosas lacunas que necessitam ser preenchidas no conhecimento do papel que as espécies desempenham na dispersão desses parasitos. Roedores da subordem Caviomorpha provavelmente desempenham um importante papel no ciclo de transmissão das leishmanioses desde sua entrada nas Américas. A entrada desse grupo de roedores, há 37 milhões de anos, está relacionada à entrada de novas espécies do subgênero Leishmania no continente, provavelmente introduzidas por roedores infectados que, ao colonizar com sucesso as Américas, estabeleceram novos ciclos de transmissão (ThomazSoccol et al., 1993).

Um dos gêneros mais estudados em relação à infecção por Leishmania são os roedores caviomorfos do gênero Proechimys, já encontrados infectados por diferentes espécies do parasito. Esses roedores se caracterizam por sua 
longevidade (mais de três anos em cativeiro) e elevada abundância na maioria das localidades onde são encontrados, em florestas tropicais das Américas Central e do Sul (Ashford, 1996). Diferentes espécies de Proechimys já foram apontadas como potenciais reservatórios de L. amazonensis no Brasil e Guiana Francesa (Arias et al., 1981; Dedet, Gay \& Chatenay, 1989), com base em frequente parasitismo de pele, confirmado por cultura de tecido. Outras espécies de Leishmania já diagnosticadas neste gênero de roedor são L. infantum na Colômbia (Travi et al., 1998b), L. guyanensis na Guiana Francesa e Brasil (Rotureau, 2006; Dedet, Gay \& Chatenay, 1989), L. braziliensis (Grimaldi Jr. \& Tesh, 1993) e L. panamensis (Ashford, 1996).

Outro gênero de roedor caviomorfo encontrado naturalmente infectado éo Thrichomys, cuja infecção por Leishmania sp. dos complexos L. mexicana e $L$. donovani foi demonstrado por PCR numa área endêmica de leishmaniose cutânea e visceral em Minas Gerais, Brasil (Oliveira et al., 2005). Esse gênero de roedor compreende ao menos cinco espécies crípticas distribuídas no Pantanal, Cerrado e Caatinga brasileiros (Bonvicino, Otazu \& D’Andrea, 2002; Borodin et al., 2006). A competência desse caviomorfo na manutenção e seu potencial como reservatório de $L$. infantum e $L$. braziliensis foi ainda confirmada através da infecção experimental de T. laurentius (Roque et al., 2010).

Além de Proechimys canicollis na Colômbia, e Thrichomys apereoides no Brasil, L. infantum já foi diagnosticada em Nectomys squamipes no Brasil e Rattus rattus no Brasil e Venezuela (Quinnell \& Courtenay, 2009; Dantas-Torres \& Brandão-Filho, 2006). Em cativeiro, a infecção já foi parasitologicamente confirmada também em fígado e baço de Coendu prehensilis, utilizados como sentinelas na Bolívia (Le Pount, Mouchet \& Desjeux, 1989).

Com relação à L. braziliensis, infecções naturais já foram reportadas em roedores dos gêneros Akodon, Bolomys, Dasyprocta, Hollochilus, Neacomys, Nectomys, Oryzomys, Proechimys, Rattus, Rhipidomys e Sigmodon (Rotureau, 2006; Grimaldi Jr. \& Tesh, 1993). A grande maioria dessas descrições, no entanto, reflete diagnósticos pontuais, baseados em técnicas com alta sensibilidade (PCR), muitas vezes apenas de vísceras, que são insuficientes para definir uma dada espécie como reservatório e esclarecer o potencial de transmissibilidade desses roedores. Destes, apenas nos roedores dos gêneros Rattus e Sigmodon na Venezuela, e Nectomys, Bolomys e Rattus no Brasil é que foi possível o isolamento e a caracterização bioquímica dos parasitos (Brandão-Filho et al., 2003; Vasconcelos et al., 1994; Lima et al., 2002).

Roedores também são frequentemente apontados como os principais reservatórios das espécies do complexo $L$. mexicana - L. mexicana e L. amazonensis. De fato, vários trabalhos já diagnosticaram a infecção por L. amazonensis em diferentes espécies de roedores, dentre as quais, espécies dos gêneros Akodon, Dasyprocta, Oligoryzomys, Oryzomys, Proechimys e Sciurus (Ashford, 1996; Rotureau, 2006; Dedet, Gay \& Chatenay, 1989; Kerr et al., 2006). Na Guiana Francesa, por exemplo, a infecção por L. amazonensis já foi observada em duas espécies simpátricas de Proechimys P. cuvieri e P. guyanensis (Rotureau, 2006). No entanto, a manutenção do parasito por longo tempo e/ou seu potencial de transmissibilidade ao vetor não foi demonstrado em nenhum desses estudos.

Em relação à infecção pela L. mexicana, só no estado americano do Texas, esse parasito já foi isolado de Neotoma micropus, $N$. albigula e $N$. floridana, sendo este último capturado com extensa lesão na orelha causada pelo parasito (Kerr, McHugh \& Dronen, 1995). Esse é um achado bastante informativo e indica essa espécie como sendo muito possivelmente infectiva para o vetor e, portanto, importante na dispersão da L. mexicana. Ototylomys phyllotis e Heteromys desmarestianus também já foram encontrados infectados em Belize (Ashford, 1996). Outras espécies de roedores já encontradas infectadas por L. mexicana foram Heteromys gaumeri, Nyctomys sumichrasti, Oryzomys melanotis, Peromyscus yucatanis, Rattus rattus, Reithrodontomys gracilis e Sigmodon hispidus (Ashford, 1996; Lima et al., 2002; Van et al., 2009). A persistência da infecção por L. mexicana em roedores foi demonstrada em duas oportunidades: no Texas, em um trabalho de marcação-recaptura de Neotoma micropus, uma espécie de cricetídeo endêmica da América do Norte que mostrou por PCR a persistência da infecção por até um ano (Raymond et al., 2003); e no México, mantendo-se 
em cativeiro 29 exemplares de quatro espécies de roedor (Sigmodon hispidus, Oryzomys melanotis, Ototylomys phillotis e Peromyscus yucatanis) naturalmente infectados por até dois anos, sendo a persistência de tais infecções demonstrada parasitologicamente (Van Wynsberghe et al., 2000). Vale ressaltar que nesse último trabalho, úlceras semelhantes às apresentadas em humanos infectados por essa mesma espécie de Leishmania foram ainda observadas em um Sigmodon hispidus, e que Oryzomys melanotis também é descrito como apresentando sinais clínicos de leishmaniose (Van Wynsberghe et al., 2000).

A paca (Agouti paca), um dos maiores roedores americanos, cujo peso corpóreo pode ultrapassar $10 \mathrm{~kg}$, foi a única espécie silvestre até o momento encontrada infectada por Leishmania (V.) lainsoni, no estado brasileiro do Pará (Silveira et al., 1991). L. panamensis já foi diagnosticada em roedores dos gêneros Heteromys, Akodon, Rattus e Coendu (Ashford, 1996), enquanto esquilos (Scirus granatensis) já foram encontrados naturalmente infectados por L. equatorensis (Grimaldi Jr. et al., 1992). Já a infecção por L. deanei e L. enrietti, espécies taxonomicamente mais próximas de Endotrypanum do que de Leishmania, são descritas, respectivamente, no ouriço Coendu sp. e no porquinho da Índia Cavia porcellus (Rotureau, 2006; Machado et al., 1994).

Em relação às infecções experimentais em diferentes espécies de roedores silvestres criados em cativeiro, até o momento, foram poucos os estudos e alguns sequer conseguiram obter a infecção, como Henry Disney, utilizando Ototylomys phyllotis e L. mexicana, em Honduras (Ashford, 1996), e Lainson e colaboradores utilizando Proechimys guyanensis e L. infantum, no Brasil (Lainson, Ishikawa \& Silveira, 2002). Esse insucesso pode ser devido a numerosas variáveis relacionadas tanto ao parasito quanto ao hospedeiro, como por exemplo, a heterogeneidade intraespecífica de ambos os taxa e o tamanho do inóculo e via de inoculação. Dessa forma, baseado apenas nesses estudos, não há ainda como excluir a hipótese de tais roedores estarem envolvidos na manutenção e/ou dispersão de espécies de Leishmania na natureza. Os poucos estudos experimentais realizados incluíram Proechimys semispinosus (Travi et al., 2002), Galea spixii (Barbosa et al., 2008) e Thrichomys laurentius (Roque et al., 2010). Destes, apenas em Galea spixii experimentalmente infectado por $L$. infantum não foi possível o reisolamento dos parasitos (Barbosa et al., 2008).

Proechimys semispinosus, provenientes da Colômbia e experimentalmente infectados por L. panamensis, desenvolveram lesões não ulceradas que desapareceram após sete semanas, tornando-os mais resistentes a novas infecções. $\mathrm{Na}$ fase inicial da infecção, esses animais mostraram-se infectivos ao vetor durante xenodiagnóstico e foi possível o reisolamento de parasitos no local do inóculo (Travi et al., 2002). Roedores dessa mesma espécie experimentalmente infectados por $L$. infantum desenvolveram infecção apenas subclínica, não sendo possível demonstrar a infectividade ao vetor, apesar de os autores terem conseguido reisolar o parasito no baço de alguns roedores durante a necropsia (Travi et al., 2002).

Thrichomys laurentius (Figura 2), experimentalmente infectados por L. infantum e por L. braziliensis, foram capazes de manter a infecção por longo tempo, sendo possível a recuperação de parasitos até 12 meses após a infecção. DNA dos parasitos foi detectado em todos os grupos experimentais e em todos os tecidos amostrados, independentemente da espécie de Leishmania inoculada. Amostras positivas de baço também foram diagnosticadas em outra espécie do mesmo gênero, T. pachyurus. Vale ressaltar que L. braziliensis, espécie descrita como dermotrópica e associada apenas a formas cutâneas da doença humana, foi capaz de visceralizar e se multiplicar em órgãos internos nessa espécie de roedor (Roque et al., 2010). A eficácia de testes sorológicos (Rifi e Elisa) foi demonstrada até mesmo para os roedores infectados por L. braziliensis, um parasito geralmente não associado a uma importante resposta humoral. Tais dados enfatizam a importância de se considerar todas as possibilidades de perfis de infecção e a necessidade de incluir uma vasta gama de métodos diagnósticos, independentemente do que atualmente se sabe sobre a infecção em outros hospedeiros durante a investigação de reservatórios de Leishmania sp. (Roque et al., 2010). 
Figura 2 - Ratos punaré Thrichomys laurentius nascidos em cativeiro no biotério de roedores silvestres do Laboratório de Biologia e Parasitologia de Mamíferos Silvestres Reservatórios, IOC/Fiocruz

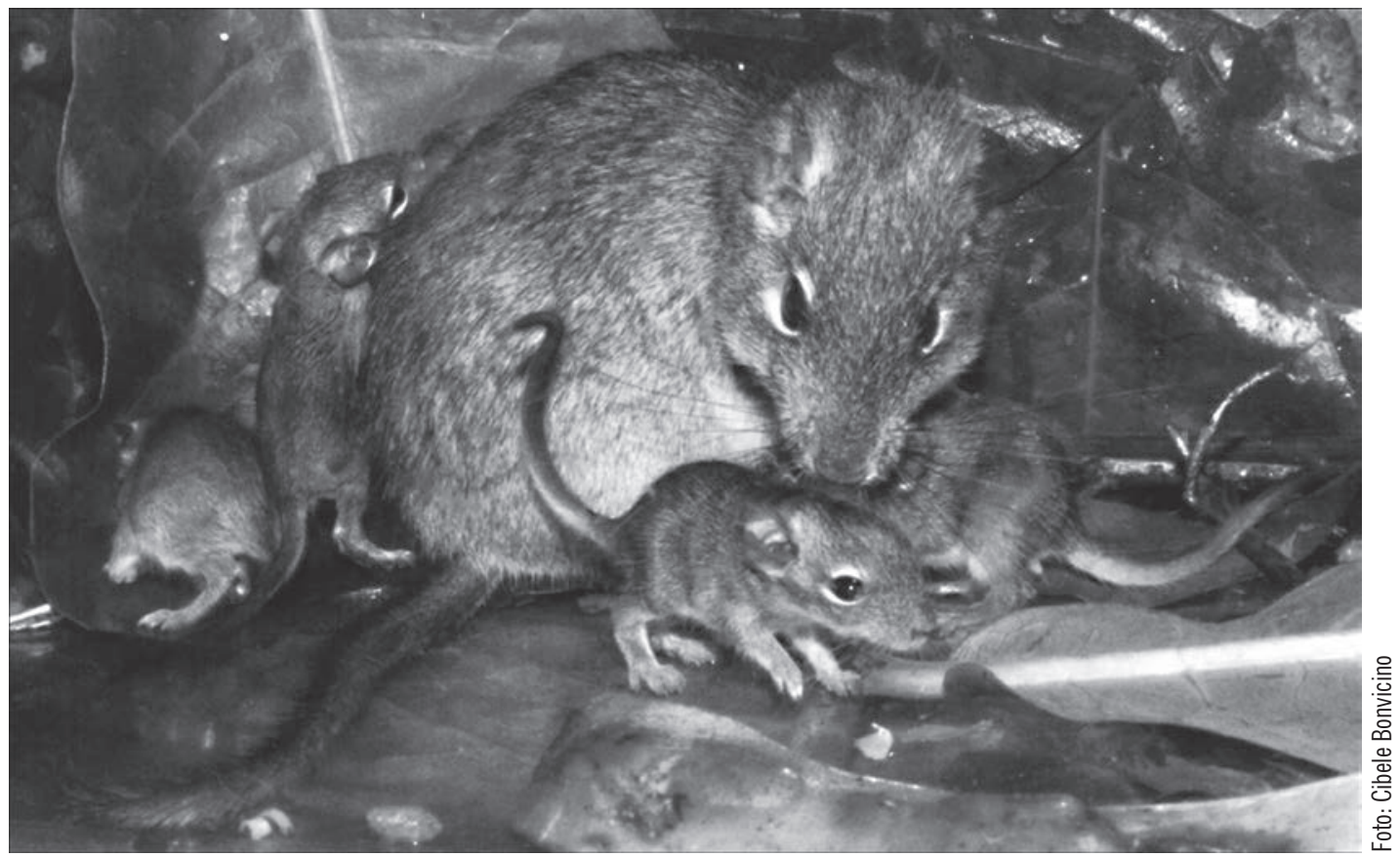

É provável que dentro desse táxon de mamíferos tão heterogêneos haja um espectro de competência na manutenção e amplificação de espécies do gênero Leishmania que inclua desde espécies tolerantes com alta infectividade para o vetor, até espécies que controlam e resolvem rapidamente a infecção. Estudos experimentais como os mencionados são essenciais para o melhor entendimento dos mecanismos de manutenção dessa parasitose em seus hospedeiros naturais, e enfatizam a necessidade de estudos mais aprofundados dos ciclos silvestres de transmissão. Nos trabalhos de campo, é essencial investir em estudos que não se limitem apenas a descrever os hospedeiros infectados, mas que sejam realizados sob um enfoque ecológico para entender o papel de cada espécie na manutenção e amplificação das populações parasitárias de Leishmania spp. e, assim, auxiliar na predição de fatores que possam resultar na reemergência de casos humanos.

\section{• Ordem Carnívora}

Os mamíferos desta ordem também compreendem um grupo muito heterogêneo que inclui desde carnívoros quase estritos, como a jaguatirica (Leopardus pardalis) e a irara (Eira barbara), até outras espécies que complementam sua dieta alimentar com insetos e frutos, como os quatis (Nasua nasua) e os lobos-guará (Chrysocyon brachyurus). A característica comum desse grupo é a presença de um quinto dedo nas patas traseiras e a presença de garras e dentes adaptados para rasgar as presas. Muitos desses mamíferos apresentam uma importante biomassa corporal e grande área de deslocamento, aspectos importantes para a dispersão de parasitos. Além disso, algumas espécies como quatis e iraras são encontrados tanto no solo quanto em copa de árvores, o que favorece a dispersão de parasitos entre diferentes estratos arbóreos. Por sua vez, carnívoros são altamente dependentes de uma grande área de vida e muito caçados em razão de seu potencial de predação a animais de criação, como galinhas e gado, fazendo com que muitas espécies de carnívoros, especialmente as de grande porte, estejam sob risco de extinção (Silva \& Adania, 2007). 
Dentre os mamíferos dessa ordem, dois estão intimamente ligados ao homem - o cão e o gato. A domesticação de cães e gatos data de dez e cinco mil anos, respectivamente, e a utilização destes, principalmente para fins de companhia, estende-se por todas as partes do globo (Sá, 2002). A infecção do cão doméstico por L. infantum é bastante descrita e, de fato, esses animais podem atuar como importantes reservatórios do parasito e exercer papel fundamental na transmissão em áreas endêmicas (Dantas-Torres, 2007). A própria entrada de cães infectados durante os primeiros anos de colonização das Américas é apontada como a responsável pela entrada dessa espécie de Leishmania nas Américas (Killick-Kendrick et al., 1980; Mauricio, Stothard \& Miles, 2000). Apesar dos relatos serem mais escassos, a participação dos gatos nos ciclos de transmissão de L. infantum também já foi sugerida (Savani et al., 2004; Silva et al., 2008). Além de L. infantum, os cães também são hospedeiros de outras espécies, como $L$. braziliensis, L. amazonensis, L. peruviana, L. panamensis, L. mexicana, L. pifanoi e L. colombiensis (Dantas-Torres, 2009). A importância dos carnívoros domésticos e seu papel na epidemiologia das leishmanioses serão discutidos no capítulo 15.

Em relação aos carnívoros silvestres hospedeiros de L. infantum, foi no cachorro-do-mato Cerdocyon thous (Figura 3) a primeira descrição da infecção, embora à época os autores tenham erroneamente reportado o hospedeiro como Lycalopex vetulus (Deane \& Deane, 1955; Courtenay et al., 1996). Desde então, diversos trabalhos confirmaram parasitologicamente, sorologicamente e/ou por PCR tais infecções, sendo esses animais encontrados, algumas vezes, apresentando sintomatologia avançada da doença (Quinnell \& Courtenay, 2009; Lainson et al., 1990; Silva et al., 2000). Este canídeo pode apresentar prevalências de infecção de até $42 \%$ por isolamento e de até $78 \%$ por sorologia (Lainson et al., 1990; Courtenay et al., 2002). A infectividade ao vetor já foi comprovada por xenodiagnóstico, embora a taxa de infecção dos vetores seja reportada como bem menor quando comparada à taxa obtida em cães domésticos (Quinnell \& Courtenay, 2009; Courtenay et al., 2002; Gomes et al., 2007).

Figura 3 - Cachorro-do-mato Cerdocyon thous proveniente do Parque Nacional da Serra da Canastra, Minas Gerais

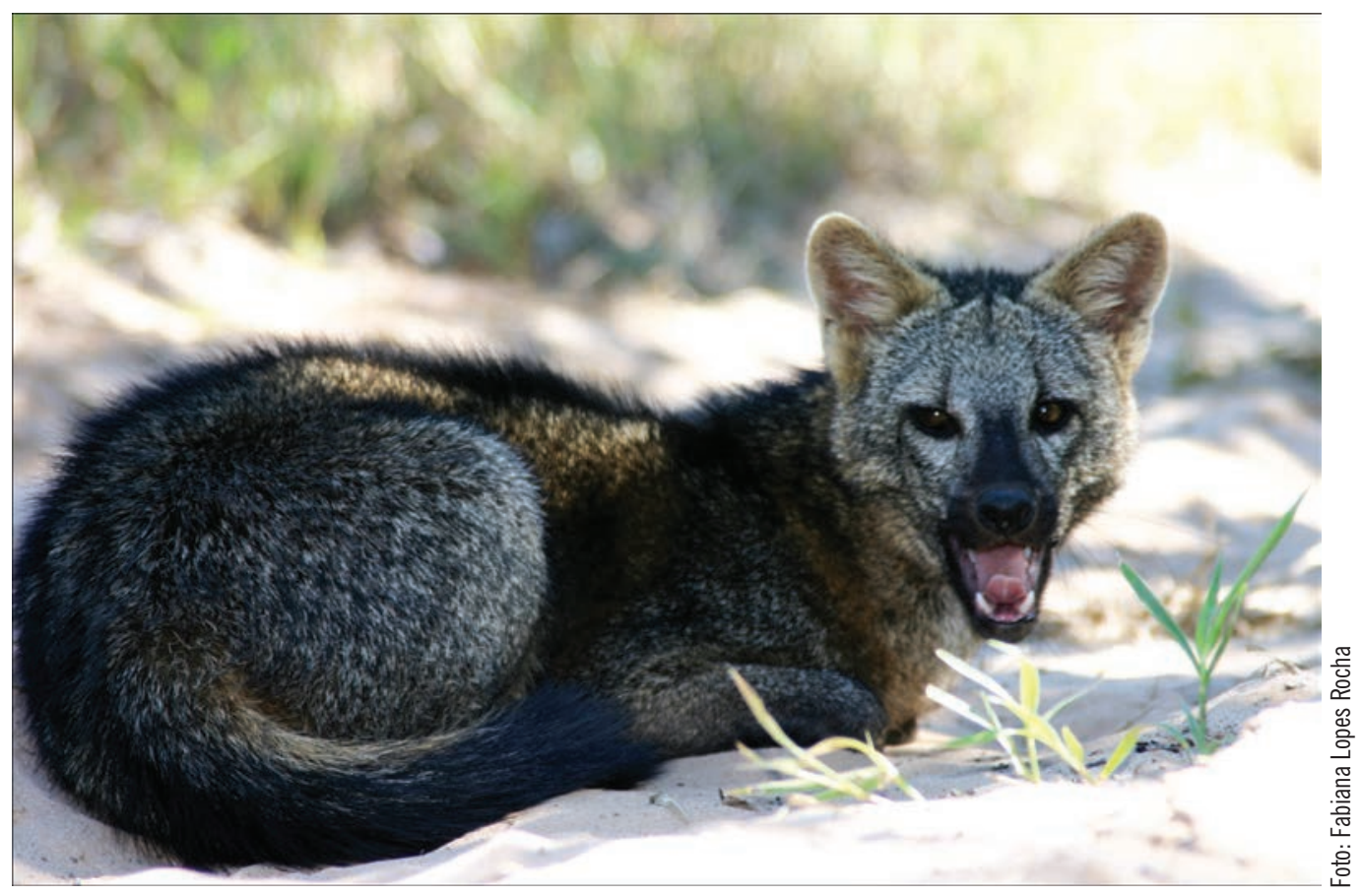


Além de $C$. thous, outro carnívoro silvestre que pode ser considerado um potencial reservatório de $L$. infantum é o cachorro-vinagre Speothos venaticus. Um exemplar dessa espécie mantido em um zoológico no Rio de Janeiro, Brasil, é o único carnívoro silvestre, à exceção do $C$. thous, cujo isolamento de L. infantum já foi obtido (Figueiredo et al., 2008). A infecção em cachorro-vinagre foi também confirmada por visualização direta, PCR e sorologia em duas fêmeas mantidas em Ilha Solteira/SP, que apresentaram sinais clínicos de leishmaniose visceral (Lima et al., 2009). Outros canídeos diagnosticados apenas por PCR e/ou sorologia foram a raposinha Pseudalopex vetulus e o lobo-guará Chrysocyon brachyurus (Curi, Miranda \& Talamoni, 2006).

A partir de muitos desses relatos, ao menos dois estudos investigaram a prevalência e o perfil de infecção em canídeos e felinos silvestres mantidos em cativeiro (Luppi et al., 2008; Dahroug et al., 2010). Cinco de 15 canídeos pertencentes às quatro espécies citadas antes foram positivos tanto por sorologia quanto por PCR, sendo que destes, um cachorro-vinagre e uma raposinha apresentaram sinais clínicos semelhantes aos encontrados na leishmaniose visceral canina em Minas Gerais, Brasil. Esses sintomas incluíam, dentre outros, hiperplasia de linfonodos, baço e fígado, anemia, prostração e, em P. vetulus, lesões ulceradas na pele (Luppi et al., 2008).

Há ainda muito que estudar em relação ao papel das diferentes espécies de canídeos silvestres na manutenção e dispersão das leishmanioses. Certamente, assim como acontece em outras ordens de mamíferos, o padrão de infecção desses taxa apresentam peculiaridades regionais e mesmo individuais. Se for considerado que em algumas áreas (Pantanal, Pampa Gaúcho e Região Nordeste do país) esses canídeos são abundantes e representam elevada biomassa, qualquer estudo terá que incluir uma avaliação do tamanho e estrutura populacional da espécie-alvo, de modo a incluir amostras realmente representativas. O estudo de canídeos silvestres, principalmente em áreas onde a abundância relativa desses animais é expressiva, é fundamental, mesmo que bastante difícil de ser realizado, e com certeza trará importantes informações para o estudo da ecologia das leishmanioses.

Em relação aos felinos silvestres, cinco onças-pardas, ou suçuaranas (Puma concolor), e uma onça-pintada (Panthera onca) em Mato Grosso do Sul, Brasil, foram positivas por PCR em material de punção de linfonodo, sendo confirmada a infecção por L. infantum através da digestão dos produtos amplificados por enzimas de restrição (Dahroug et al., 2010).

Além de L. infantum, outras quatro espécies do parasito já foram descritas em carnívoros silvestres: L. shawi em quatis Nasua nasua (Lainson et al., 1989); L. guyanensis no jupará Potos flavus (Pajot et al., 1982); L. amazonensis no cachorro-do-mato e em juparás (Rotureau, 2006; Kreutzer et al., 1991); e L. panamensis em quatis, juparás e no olingo Bassaricyon gabii (Grimaldi Jr. \& Tesh, 1993).

\section{- Ordem Primata}

Os primatas não humanos podem ser divididos em dois grupos: os catarrinos (infraordem Catarrhini), provenientes dos continentes africano, europeu e asiático (primatas do Velho Mundo), e os platirrinos (infraordem Platyrrhini), proveniente das Américas (primatas do Novo Mundo). A diferença básica entre os dois grupos é que os catarrinos têm as narinas voltadas para baixo em um focinho longo, enquanto os platirrinos têm as narinas voltadas para os lados, num focinho mais curto (Verona \& Pissinatti, 2007). As diferentes espécies de primatas neotropicais estão incluídas nas famílias Cebidae (micos) e Callitrichidae (saguis), embora classificações mais modernas reconheçam ainda três outras famílias: Aotidae, Pithecidae e Atelidae. Nas Américas, esses primatas ocupam distintos estratos arbóreos e apresentam hábitos alimentares variados, incluindo espécies que se alimentam de frutos, invertebrados e até de pequenos mamíferos (Verona \& Pissinatti, 2007).

Até o momento, poucos trabalhos diagnosticaram a infecção natural de Leishmania sp. em primatas do Novo Mundo. A infecção por L. shawi foi descrita nos cebídeos Cebus apella e Chiropotes satanas (Lainson et al., 1989), 
enquanto a infecção por L. amazonensis foi diagnosticada em Aotus trivirgatus e em Saguinus geoffroyi (Grimaldi Jr. \& Tesh, 1993). Recentemente, um Callicebus nigrifrons, mantido no zoológico de Belo Horizonte/MG, apresentou uma doença fatal compatível com a leishmaniose visceral (LV). Exames histológicos, imuno-histoquímicos, e a positividade na reação de PCR específica para Leishmania do complexo donovani, confirmaram a infecção por L. infantum (Malta et al., 2010). Outras espécies de primatas positivas no mesmo estudo apenas em reação de PCR de sangue e sem sinais clínicos de LV foram Alouatta guariba, Cebus xanthosternos, Leonthopitecus crysomelas, Aotus nigriceps, Pithecia irrorata e Saguinus imperator (Malta et al., 2010).

Outras espécies de Leishmania que circulam nas Américas já demonstraram ser capazes de infectar outros primatas do Novo Mundo, mas apenas em condições experimentais. Na grande maioria de tais estudos, o foco principal era a avaliação da resposta desses primatas a diferentes tratamentos ou a avaliação de sua resposta imunológica visando ao desenvolvimento de vacinas. Uma vez que o foco deste capítulo são os potenciais reservatórios nas Américas, iremos nos ater apenas aos estudos experimentais que utilizaram platirrinos e espécies de Leishmania que circulam nas Américas.

Micos-estrela Callithrix penicillata foram, durante muitos anos, utilizados em estudos experimentais com $L$. braziliensis e L. amazonensis (Cuba et al., 1990; Cuba-Cuba \& Marsden, 1993). Macacos-de-cheiro Saimiri sciureus experimentalmente infectados desenvolveram lesões cutâneas não ulceradas, no qual foi possível o reisolamento de parasitos (L. braziliensis e/ou L. panamensis) (Pung, Hulsebos \& Kuhn, 1988).

Observou-se o mesmo perfil em Cebus apella experimentalmente infectados por L. lainsoni, os quais apresentaram amastigotas na pele e desenvolvimento de lesões cutâneas nos locais de inoculação (Silveira et al., 1990). Essa mesma espécie também desenvolveu lesões cutâneas após a infecção experimental por L. amazonensis, L. braziliensis, L. mexicana e L. guyanensis (Silveira et al., 1990; Garcez et al., 2002; Grimaldi Jr., 2008). Já Cebus nigrivittatus apresentaram um quadro de leishmaniose visceral fatal após inoculação experimental por L. infantum (Vouldoukis et al., 1986).

Também inoculados com Leishmania responsáveis por formas tegumentares da doença no homem, macacos-coruja Aotus trivirgatus desenvolveram lesões cutâneas locais após inoculação experimental de L. braziliensis, L. mexicana e $L$. panamensis (Christensen \& Vasquez, 1981; Lujan et al., 1986).

Vale ressaltar que todas as espécies de platirrinos estão incluídas na lista da Convention on International Trade in Endangered Species of Wild Fauna and Flora (Cites), o que significa que, apesar de nem todas as espécies estarem ameaçadas de extinção, todas têm algum grau de vulnerabilidade (Verona \& Pissinatti, 2007). Por esse motivo, muitas espécies, como o mico-leão-dourado Leonthopitecus rosalia, são submetidos a programas de conservação. Tais programas frequentemente incluem intercâmbio, translocação e reintrodução de animais, sem que se considere a prevalência e perfil de infecção por parasitos, como Leishmania spp. e outros tripanossomatídeos. Dado o caráter focal de transmissão do parasito, programas como esse podem desencadear, na introdução de mamíferos infectados, e promover o estabelecimento de novos ciclos de transmissão (Lisboa et al., 2006).

\section{- Ordem Chiroptera}

Os morcegos são os únicos mamíferos capazes de voar e, à exceção dos pássaros, os únicos animais que realizam migração sazonal, uma característica que se sugere ter evoluído várias vezes e de forma independente nas distintas linhagens de morcegos. Essas espécies de mamíferos noturnos executam um verdadeiro voo alado, característica que provavelmente foi herdada de antepassados que apenas deslizavam no ar, e que aparentemente também evoluiu várias vezes e de forma independente dentro desse táxon. Excetuando-se os morcegos frugívoros do Velho Mundo, os quirópteros apresentam um sofisticado sistema de ecolocalização que lhes permite identificar o meio ambiente. Ambos, o voo e esse sistema de orientação sensível, resultaram em sua elevada capacidade de dispersão por diferentes 
ambientes. Apesar de sua alta diversidade, atualmente os morcegos são considerados como um grupo monofilético (Jones \& Teeling, 2006; Bishop, 2008; Bisson, Safi \& Holland, 2009).

Os morcegos são comumente encontrados infectados por diversos tripanossomatídeos, principalmente do gênero Trypanosoma: T. cruzi, T. verspertilionis, T. (Megatrypanum) sp., entre outros. Em relação à infecção por Leishmania, há apenas um relato de isolamento de parasitos, no caso L. infantum, em sangue de morcegos frugívoros Carollia perspicillata na Venezuela (Lima et al., 2008). Antes disso, Lampo e colaboradores já haviam mostrado que morcegos constituem fonte alimentar de Lutzomyia longipalpis em cavernas da Venezuela (Lampo et al., 2000). Recentemente, um estudo em São Paulo/SP conseguiu diagnosticar, utilizando PCR em macerado de baço e fígado, e posterior sequenciamento dos produtos amplificados, a infecção por L. infantum em Molossus molossus e Glossophaga soricina, e por L. amazonensis nestas mesmas duas espécies e em Molossus rufus, Nyctinomops laticaudatus, Eumops glaucinus, E. auripendulus, Artibeus lituratus, Sturnira lilium e Myotis nigricans (Savani et al., 2010). Antes disso, apenas evidências inconclusivas baseadas em reações sorológicas, e mesmo assim, apenas no Velho Mundo, haviam sido reportadas (Morsy, Salama \& Abdel Hamid, 1987). De fato, mais importante do que considerar morcegos como potenciais reservatórios de Leishmania sp. com base apenas em dois estudos é não excluir tal possibilidade, dada a quase inexistência de estudos que envolvem Leishmania e quirópteros.

Nesse sentido, um aspecto a ser considerado é que esses mamíferos voadores representam 39\% das 560 espécies de mamíferos reportadas nas florestas tropicais sul-americanas, sendo o grupo de mamífero mais comum em termos de diversidade e biomassa (Rotureau, 2006; Emmons \& Feer, 1997). Além disso, são encontrados em ambientes silvestre, doméstico e sinantrópico, sendo capaz de colonizar hábitats variados em diversos ecótopos. Seus refúgios incluem ocos de árvores, folhas de bananeiras, forros de habitações humanas e construções rurais. Sua elevada abundância e adaptabilidade a ambientes peridomiciliares reforçam a necessidade de se investigar o possível papel desses mamíferos, já reconhecidos como potenciais reservatórios de outros tripanossomatídeos, como o T. cruzi (Roque \& Jansen, 2010), também nos ciclos de transmissão de Leishmania spp.

\section{- Outras Ordens de Potenciais Reservatórios}

Além das sete ordens citadas anteriormente, a infecção por Leishmania spp. já foi encontrada em outras duas ordens de mamíferos nas Américas: Perissodactyla e Artiodactyla.

A ordem Perissodactyla é composta de mamíferos ungulados, herbívoros, cuja principal característica é a presença de um número ímpar de dedos não articulados. São três as famílias, sendo duas delas presentes nas Américas: Tapiridae (antas) e Equidae (equinos e asininos). As antas são ainda um grupo muito pouco estudado, visto que dependem de uma grande área de vida e são bastante sensíveis aos processos de devastação, fatores que certamente contribuíram para que as três espécies de antas presentes nas Américas sejam consideradas criticamente em perigo pela Union for Conservation of Nature and Natural Resources (IUCN) (Mangini, 2007). A captura desses animais no campo é extremamente difícil, e até o momento não há registro de infecção por Leishmania sp. nesses mamíferos. Já em relação aos equídeos, aqui incluídos os cavalos, asnos e os híbridos resultantes do cruzamento entre eles, já foram reportadas infecções naturais por L. braziliensis (Aguilar et al., 1989; Vedovello et al., 2008) e reações sorológicas positivas após a infecção experimental por L. infantum (Cerqueira et al., 2003).

A ordem Artiodactyla é caracterizada pelos ungulados que apresentam um número par de dedos articulados. Nas Américas, seus representantes estão incluídos nas famílias Suidae (porcos e javalis), Tayassuidae (catetos e queixadas), Camelidae (lhamas, alpacas e similares), Cervidae (veados e cervos), Antilocapridae (antilocapras) e Bovidae (bovinos, ovinos, cabras e antílopes). Destes, apenas porcos domésticos (Sus scrofa) já foram encontrados infectados por Leishmania sp., mas apenas em reações sorológicas. Nesse mesmo estudo, a infecção experimental por $L$. infantum 
resultou igualmente apenas em reações sorológicas positivas, não sendo possível o reisolamento de parasitos (MoraesSilva et al., 2006).

A importância dos equídeos, suídeos e bovídeos domésticos, bem como seu potencial papel na epidemiologia das leishmanioses serão discutidas no capítulo 15.

\section{CONCLUSÕES E PERSPECTIVAS}

No caso da leishmaniose visceral humana, causada pela $L$. infantum, a ideia de que os cães são os principais responsáveis pela manutenção da parasitose resulta em que a eliminação dos cães soropositivos seja considerada por muitos a única forma de controle. Ignora-se por completo a possibilidade da participação de mamíferos silvestres e sinantrópicos infectados que podem se aproximar de áreas domiciliadas e servir de fonte de infecção ao vetor.

Este capítulo cita inúmeros casos de diferentes espécies de mamíferos que podem manter o ciclo de transmissão e servir de constante fonte de realimentação a um sistema peridomiciliar de transmissão da parasitose. A situação é ainda mais grave para as demais espécies de Leishmania sp., responsáveis por graves doenças humanas e cujo atual conhecimento dos ciclos de transmissão não permitem sequer a determinação dos principais reservatórios envolvidos na manutenção desses parasitos. Na Região Amazônica, o risco de contrair as formas tegumentares da doença ao se expor diretamente aos ciclos silvestres de transmissão, quando da invasão do homem para caça ou coleta extrativista, é outra realidade que deve ser considerada.

De fato, ainda estamos muito longe de entender os fatores que envolvem a manutenção das diferentes espécies de Leishmania na natureza. Nesse sentido, estudos em campo e em cativeiro utilizando potenciais reservatórios devem ser encorajados. Tais estudos não devem se restringir apenas a diagnosticar a infecção, mas devem, principalmente, buscar o entendimento do curso e o perfil de infecção nos hospedeiros silvestres. Quais os fatores responsáveis pela maior transmissibilidade ao vetor e como o manejo ambiental pode resultar em maior ou menor emergência da parasitose em ambientes próximos aos ciclos silvestres de transmissão são as duas primeiras perguntas a serem respondidas. A comunidade científica, ao longo dos anos, já mostrou que diversas espécies silvestres podem se infectar. O foco agora deve ser outro: quais dessas espécies efetivamente transmitem o parasito, são reservatórios e podem amplificar os focos enzoóticos, constituindo risco de transmissão ao homem?

A mudança de paradigmas na pesquisa e a vigilância de reservatórios silvestres dessa parasitose é necessária e urgente. Tal mudança passa, entre outros fatores, pelo entendimento do que significa estar incluído num sistema reservatório e pela necessidade de compreendermos o papel que cada hospedeiro desempenha na manutenção desses parasitos na natureza. Os fatores envolvidos na amplificação dos focos enzoóticos são particulares para cada local e em cada momento, e entender alguns desses fatores pode fornecer subsídios para a proposição de efetivas e sustentáveis estratégias de vigilância das leishmanioses.

\section{REFERÊNCIAS}

AGUILAR, C. M. et al. Zoonotic cutaneous leishmaniasis due to Leishmania (Viannia) braziliensis associated with domestic animals in Venezuela and Brazil. Memórias do Instituto Oswaldo Cruz, 84(1): 19-28, 1989.

AgUiRRE, A. A. \& TABOR, G. M. Global factors driving emerging infectious diseases. Annals of the New York Academy of Sciences, 1.149: 1-3, 2008.

ARIAS, J. R. et al. The opossum, Didelphis marsupialis (Marsupialia: Didelphidae), as a reservoir host of Leishmania braziliensis guyanensis in the Amazon Basin of Brazil. Transactions of the Royal Society of Tropical Medicine and Hygiene, 75(4): 537-541, 1981. 
ASHFORD, R. W. Leishmaniasis reservoir and their significance in control. Clinics in Dermatology, 14: 523-532, 1996.

ASHFORD, R. W. What it takes to be a reservoir host. Belgian Journal of Zoology, 127: 85-90, 1997.

ASHFORD, R. W. The leishmaniases as emerging and reemerging zoonoses. International Journal for Parasitology, 30(12-13): 1.269-1.281, 2000.

AUSTAD, S. N. The adaptable opossum. Scientific American, 258: 54-59, 1988.

BARBOSA, P. B. et al. Experimental infection parameters in Galea spixii (Rodentia: Caviidae) with Leishmania infantum chagasi. Memórias do Instituto Oswaldo Cruz, 103(6): 545-548, 2008.

BISHOP, K. L. The evolution of flight in bats: narrowing the field of plausible hypotheses. The Quarterly Review of Biology, 83(2): 153-169, 2008.

BISSON, I. A.; SAFI, K. \& HOLLAND, R. A. Evidence for repeated independent evolution of migration in the largest family of bats. PLoS One, 4(10): e7.504, 2009.

BONVICINO, C. R.; OTAZU, I. B. \& D'ANDREA, P. S. Karyologic evidence of diversification of the genus Thrichomys (Rodentia, Echimyidae). Cytogenetics and Genome Research, 97(3-4): 200-204, 2002.

BONVICINO, C. R. et al. The chromosomes of Nectomys (Rodentia, Cricetidae) with $2 \mathrm{n}=52,2 \mathrm{n}=56$, and interspecific hybrids $(2 \mathrm{n}=54)$. Cytogenetics and Cell Genetics, 73(3): 190-193, 1996.

BORODIN, P. M. et al. Reproductive isolation due to the genetic incompatibilities between Thrichomys pachyurus and two subspecies of Thrichomys apereoides (Rodentia, Echimyidae). Genome, 49(2): 159-167, 2006.

BRANDÃO-FILHO, S. P. et al. Wild and synanthropic hosts of Leishmania (Viannia) braziliensis in the endemic cutaneous leishmaniasis locality of Amaraji, Pernambuco State, Brazil. Transactions of the Royal Society of Tropical Medicine and Hygiene, 97(3): 291-296, 2003.

BRITTO, C. C. Usefulness of PCR-based assays to assess drug efficacy in Chagas disease chemotherapy: value and limitations. Memórias do Instituto Oswaldo Cruz, 104, supl. 1: 122-135, 2009.

BUGGE, J. Cephalic arterial pattern in New World edentates and old World pangolins with special reference to their phylogenetic relationships and taxonomy. Acta Anatomica (Basel), 105(1): 37-46, 1979.

BUSH, A. O. et al., Parasitism: the diverisity and ecology of animal parasites. Cambridge: Cambridge University Press, 2001.

CERBINO, N. J.; WERNECK, G. L. \& COSTA, C. H. Factors associated with the incidence of urban visceral leishmaniasis: an ecological study in Teresina, Piauí State, Brazil. Cadernos de Saúde Pública, 25(7): 1.543-1.551, 2009.

CERQUEIRA, E. J. et al. Experimental infection of Equus asinus with Leishmania chagasi Cunha \& Chagas, 1937. Revista da Sociedade Brasileira de Medicina Tropical, 36(6): 695-701, 2003.

CHAVES, L. F. et al. Sources and sinks: revisiting the criteria for identifying reservoirs for American cutaneous leishmaniasis. Trends in Parasitology, 23(7): 311-316, 2007.

CHRISTENSEN, H. A. \& DE VASQUEZ, A. M. Susceptibility of Aotus trivirgatus to Leishmania braziliensis and L. mexicana. The American Journal of Tropical Medicine and Hygiene, 30(1): 54-56, 1981.

CORREDOR, A. et al. Epidemiology of visceral leishmaniasis in Colombia. The American Journal of Tropical Medicine and Hygiene, 40(5): 480-486, 1989.

COURTENAY, O. et al. Visceral leishmaniasis in the hoary zorro Dusicyon vetulus: a case of mistaken identity. Transactions of the Royal Society of Tropical Medicine and Hygiene, 90(5): 498-502, 1996.

COURTENAY, O. et al. Infectiousness in a cohort of brazilian dogs: why culling fails to control visceral leishmaniasis in areas of high transmission. The Journal of Infectious Diseases, 186(9): 1.314-1.320, 2002.

CUBA, C. A. C. et al. Experimental infection with Leishmania (Viannia) braziliensis and Leishmania (Leishmania) amazonensis in the marmoset, Callithrix penicillata (Primates: Callithricidae). Memórias do Instituto Oswaldo Cruz, 85(4): 459-467, 1990. 
CUBA-CUBA, C. A. \& MARSDEN, P. D. Marmosets in New World leishmaniasis research. Medicina (B Aires), 53(5): 419$423,1993$.

CURI, N. H.; MIRANDA, I. \& TALAMONI, S. A. Serologic evidence of Leishmania infection in free-ranging wild and domestic canids around a Brazilian National Park. Memórias do Instituto Oswaldo Cruz, 101(1): 99-101, 2006.

DAHROUG, M. A. et al. Leishmania (Leishmania) chagasi in captive wild felids in Brazil. Transactions of the Royal Society of Tropical Medicine and Hygiene, 104(1): 73-74, 2010.

DANTAS-TORRES, F. The role of dogs as reservoirs of Leishmania parasites, with emphasis on Leishmania (Leishmania) infantum and Leishmania (Viannia) braziliensis. Veterinary Parasitology, 149(3-4): 139-146, 2007.

DANTAS-TORRES, F. Canine leishmaniosis in South America. Parasites and Vectors, 2, supl. 1: S1, 2009.

DANTAS-TORRES, F. \& BRANDÃO-FILHO, S. P. Visceral leishmaniasis in Brazil: revisiting paradigms of epidemiology and control. Revista do Instituto de Medicina Tropical de São Paulo, 48(3): 151-156, 2006.

DASZAK, P. et al. Collaborative research approaches to the role of wildlife in zoonotic disease emergence. Current Topics in Microbiology and Immunology, 315: 463-475, 2007.

DE ESTEBAN-TRIVIGNO, S.; MENDOZA, M. \& DE RENZI, M. Body mass estimation in xenarthra: a predictive equation suitable for all quadrupedal terrestrial placentals? Journal of Morphology, 269(10): 1.276-1.293, 2008.

DEANE, L. M. \& DEANE, M. P. Observações preliminares sobre a importância comparativa do homem, do cão e da raposa (Lycalopex vetulus) como reservatórios da Leishmania donovani em áreas endêmicas de Calazar, no Ceará. Hospital, 48: 79-98, 1955.

DEDET, J. P.; GAY, F. \& CHATENAY, G. Isolation of Leishmania species from wild mammals in French Guiana. Transactions of the Royal Society of Tropical Medicine and Hygiene, 83(5): 613-615, 1989.

DESJEUX, P. Leishmaniasis: current situation and new perspectives. Comparative Immunology, Microbiology and Infectious Diseases, 27(5): 305-318, 2004.

EMMONS, L. H. \& FEER, F. Neotropical Rainforest Mammals: a field guide. 2. ed. Chicago: University of Chicago Press, 1997.

FIGUEIREDO, F. B. et al. First report of natural infection of a bush dog (Speothos venaticus) with Leishmania (Leishmania) chagasi in Brazil. Transactions of the Royal Society of Tropical Medicine and Hygiene, 102 (2): 200-201, 2008.

FLYNN, J. J. \& WYSS, A. R. Recent advances in South American mammalian paleontology. Tree, 13(11): 449-455, 1998.

GARCEZ, L. M. et al. Leishmania (Leishmania) amazonensis-induced cutaneous leishmaniasis in the primate Cebus apella: a model for vaccine trials. International Journal for Parasitology, 32(14): 1.755-1.764, 2002.

GAUDIN, T. J. \& BIEWENER, A. A. The functional morphology of xenarthrous vertebrae in the armadillo Dasypus novemcinctus (Mammalia, Xenarthra). Journal of Morphology, 214(1): 63-81, 1992.

GENTILE, B. et al. Dermal leishmaniasis in French Guiana: the sloth (Choloepus didactylus) as a reservoir host. Transactions of the Royal Society of Tropical Medicine and Hygiene, 75(4): 612-613, 1981.

GIORGIO, S. Moderna visão da evolução da virulência. Revista de Saúde Pública, 29(5): 398-402, 1995.

GOMES, R. B. et al. Antibodies against Lutzomyia longipalpis saliva in the fox Cerdocyon thous and the sylvatic cycle of Leishmania chagasi. Transactions of the Royal Society of Tropical Medicine and Hygiene, 101(2): 127-133, 2007.

GRIMALDI JR., G. The utility of rhesus monkey (Macaca mulatta) and other non-human primate models for preclinical testing of Leishmania candidate vaccines. Memórias do Instituto Oswaldo Cruz, 103(7): 629-644, 2008.

GRIMALDI JR., G. \& TESH, R. B. Leishmaniases of the New World: current concepts and implications for future research. Clinical Microbiology Reviews, 6(3): 230-250, 1993.

GRIMALDI JR., G. et al. Characterization and classification of leishmanial parasites from humans, wild mammals, and sand flies in the Amazon region of Brazil. The American Journal of Tropical Medicine and Hygiene, 44(6): 645-661, 1991. 
GRIMALDI JR., G. et al. Description of Leishmania equatorensis sp. n (Kinetoplastida: Trypanosomatidae), a new parasite infecting arboreal mammals in Ecuador. Memórias do Instituto Oswaldo Cruz, 87(2): 221-228, 1992.

GUERIN, P. J. et al. Visceral leishmaniasis: current status of control, diagnosis, and treatment, and a proposed research and development agenda. The Lancet Infectious Diseases, 2(8): 494-501, 2002.

HAYDON, D. T. et al. Identifying reservoirs of infection: a conceptual and practical challenge. Emerging Infectious Diseases, 8(12): 1.468-1.473, 2002.

HERRERA, L. et al. Trypanosoma cruzi infection in wild mammals of the National Park Serra da Capivara and its surroundings (Piauí, Brazil), an area endemic for Chagas disease. Transactions of the Royal Society of Tropical Medicine and Hygiene, 99(5): 379-388, 2005.

HERRERA, H. M. et al. The coati (Nasua nasua, Carnivora, Procyonidae) as a reservoir host for the main lineages of Trypanosoma cruzi in the Pantanal region, Brazil. Transactions of the Royal Society of Tropical Medicine and Hygiene, 102(11): 1.133-1.139, 2008.

JANSEN, A. M. \& CORTEZ, M. G. Los reservatorios silvestres y su relación con la ecología y la complejidad de los ciclos de transmissión de Trypanosoma cruzi. In: CORTEZ, M. G. (Ed.). Triatominos de Bolivia y la Enfermedad de Chagas. 1. ed. La Paz: Ministerio de Salud y Deportes, 2007.

JANSEN, A. M. et al. The sylvatic cycle of Trypanosoma cruzi: a still unsolved puzzle. Memórias do Instituto Oswaldo Cruz, 94, supl. 1: 203-204, 1999.

JONES, G. \& TEELING, E. C. The evolution of echolocation in bats. Tree, 21(3): 149-156, 2006.

JONES, K. E. et al. Global trends in emerging infectious diseases. Nature, 451(7.181): 990-993, 2008.

KERR, S. F.; MCHUGH, C. P. \& DRONEN JR., N. O. Leishmaniasis in Texas: prevalence and seasonal transmission of Leishmania mexicana in Neotoma micropus. The American Journal of Tropical Medicine and Hygiene, 53(1): 73-77, 1995.

KERR, S. F. et al. Leishmania amazonensis infections in Oryzomys acritus and Oryzomys nitidus from Bolivia. The American Journal of Tropical Medicine and Hygiene, 75(6): 1.069-1.073, 2006.

KILLICK-KENDRICK, R. et al. Possible origins of Leishmania chagasi. Annals of Tropical Medicine and Parasitology, 74(5): 563-565, 1980.

KREUTZER, R. D. et al. Characterization of Leishmania colombiensis sp. n (Kinetoplastida: Trypanosomatidae), a new parasite infecting humans, animals, and phlebotomine sand flies in Colombia and Panama. The American Journal of Tropical Medicine and Hygiene, 44(6): 662-675, 1991.

LAINSON, R. \& SHAW, J. J. The role of animals in the epidemiology of South American leishmaniasis. In: LUMSDEN, W. H. R. \& EVANS, D. (Eds.). Biology of the Kinetoplastida. London: Academic Press, 1979.

LAINSON, R. \& SHAW, J. J. Leishmania (Viannia) naiffi sp. n., a parasite of the armadillo, Dasypus novemcinctus in Amazonian Brazil. Annales de Parasitologie Humaine et Comparée, 64(1): 3-9, 1989.

LAINSON, R. \& SHAW, J. The neotropical Leishmania species. In: COLLIER, L.; BALOWS, A. \& SUSSMAN, M. (Eds.). Topley \& Wilson's Microbiology and Microbial Infectious Diseases. 9. ed. London: Arnold, 1998.

LAINSON, R.; ISHIKAWA, E. A. \& SILVEIRA, F. T. American visceral leishmaniasis: wild animal hosts. Transactions of the Royal Society of Tropical Medicine and Hygiene, 96(6): 630-631, 2002.

LAINSON, R.; SHAW, J. J. \& POVOA, M. The importance of edentates (sloths and anteaters) as primary reservoirs of Leishmania braziliensis guyanensis, causative agent of "pianbois" in north Brazil. Transactions of the Royal Society of Tropical Medicine and Hygiene, 75(4): 611-612, 1981.

LAINSON, R. et al. Leishmaniasis in Brazil: XIII. Isolation of Leishmania from armadillos (Dasypus novemcinctus), and observations on the epidemiology of cutaneous leishmaniasis in north Pará State. Transactions of the Royal Society of Tropical Medicine and Hygiene, 73(2): 239-242, 1979. 
LAINSON, R. et al. Leishmania (Viannia) shawi sp. n., a parasite of monkeys, sloths and procyonids in Amazonian Brazil. Annales de Parasitologie Humaine et Comparée, 64(3): 200-207, 1989.

LAINSON, R. et al. Amazonian visceral leishmaniasis--distribution of the vector Lutzomyia longipalpis (Lutz \& Neiva) in relation to the fox Cerdocyon thous (linn.) and the efficiency of this reservoir host as a source of infection. Memórias do Instituto Oswaldo Cruz, 85(1): 135-137, 1990.

LAMPO, M. et al. A possible role of bats as a blood source for the Leishmania vector Lutzomyia longipalpis (Diptera: Psychodidae). The American Journal of Tropical Medicine and Hygiene, 62 (6): 718-719, 2000.

LANGE, R. R. \& SCHMIDT, E. M. S. Rodentia: roedores silvestres (Capivara, Cutia, Paca, Ouriço). In: CUBAS, Z. S.; SILVA, J. C. R. \& CATÃo-DIAS, J. L. (Eds.). Tratado de Animais Selvagens. 1. ed. São Paulo: Roca, 2007.

LE POUNT, F.; MOUCHET, J. \& DESJEUX, P. Leishmaniasis in Bolivia. VII. Infection of sentinel porcupines (Coendou prehensilis, L.) by Leishmania (Le.) chagasi. Memórias do Instituto Oswaldo Cruz, 84(4): 575, 1989.

LIMA, H. et al. Cotton rats (Sigmodon hispidus) and black rats (Rattus rattus) as possible reservoirs of Leishmania spp. in Lara State, Venezuela. Memórias do Instituto Oswaldo Cruz, 97(2): 169-174, 2002.

LIMA, H. et al. Isolation and molecular identification of Leishmania chagasi from a bat (Carollia perspicillata) in northeastern Venezuela. Memórias do Instituto Oswaldo Cruz, 103(4): 412-414, 2008.

LIMA, V. M. et al. Evidence of Leishmania spp. antibodies and DNA in bush dogs (Speothos venaticus) in Brazil. Journal of Zoo and Wildlife Medicine, 40(1): 91-94, 2009.

LISBOA, C. V. et al. Stable infection of primates with Trypanosoma cruzi I and II. Parasitology, 133(5): 603-611, 2006.

LUJAN, R. et al. Leishmania braziliensis: development of primary and satellite lesions in the experimentally infected owl monkey, Aotus trivirgatus. Experimental Parasitology, 61(3): 348-358, 1986.

LUPPI, M. M. et al. Visceral leishmaniasis in captive wild canids in Brazil. Veterinary Parasitology, 155(1-2): 146-151, 2008.

MACHADO, M. I. et al. Naturally acquired infections with Leishmania enriettii Muniz and Medina 1948 in guinea-pigs from Sao Paulo, Brazil. Parasitology, 109(2): 135-138, 1994.

MADEIRA, M. F. et al. Parasitological diagnosis of canine visceral leishmaniasis: is intact skin a good target? Research in Veterinary Science, 87(2): 260-262, 2009.

MALTA, M. C. et al. Naturally acquired visceral leishmaniasis in non-human primates in Brazil. Veterinary Parasitology, 169(1-2): 193-197, 2010.

MANGINI, P. R. Perissodactyla - Tapiridae (Anta). In: CUBAS, Z. S.; SILVA, J. C. R. \& CATÃo-DIAS, J. L. (Eds.). Tratado de Animais Selvagens. 1. ed. São Paulo: Roca, 2007.

MAURICIO, I. L.; STOTHARD, J. R. \& MILES, M. A. The strange case of Leishmania chagasi. Parasitology Today, 16(5): 188$189,2000$.

McHUGH, C. P. et al. Short report: a disseminated infection of Leishmania mexicana in an eastern woodrat, Neotoma floridana, collected in Texas. The American Journal of Tropical Medicine and Hygiene, 69(5): 470-472, 2003.

MENDONÇA, M. G. et al. Persistence of Leishmania parasites in scars after clinical cure of American cutaneous leishmaniasis: is there a sterile cure? The Journal of Infectious Diseases, 189(6): 1.018-1.023, 2004.

MILLS, J. N. \& CHILDS, J. E. Ecologic studies of rodent reservoirs: their relevance for human health. Emerging Infectious Diseases, 4(4): 529-537, 1998.

MIMORI, T. et al. Identification, using isoenzyme electrophoresis and monoclonal antibodies, of Leishmania isolated from humans and wild animals of Ecuador. The American Journal of Tropical Medicine and Hygiene, 40(2): 154-158, 1989.

MIRANDA, F. \& COSTA, A. M. Xenarthra. In: CUBAS, Z. S.; SILVA, J. C. R. \& CATÃo-DIAS, J. L. (Eds.). Tratado de Animais Selvagens. 1 ed. São Paulo: Roca, 2006.

MOLLER-KRULL, M. et al. Retroposed elements and their flanking regions resolve the evolutionary history of xenarthran mammals (armadillos, anteaters, and sloths). Molecular Biology and Evolution, 24(11): 2.573-2.582, 2007. 
MORAES-SILVA, E. et al. Domestic swine in a visceral leishmaniasis endemic area produce antibodies against multiple Leishmania infantum antigens but apparently resist to L. infantum infection. Acta Tropica, 98(2): 176-182, 2006.

MORSY, T. A.; SALAMA, M. M. \& ABDEL HAMID, M. Y. Detection of Leishmania antibodies in bats. Journal of the Egyptian Society of Parasitology, 17(2): 797-798, 1987.

NAIFF, R. D. et al. Epidemiological and nosological aspects of Leishmania naiffi Lainson \& Shaw, 1989. Memórias do Instituto Oswaldo Cruz, 86(3): 317-321, 1991.

NERY GUIMARÃES, F. Comportamento da L. braziliensis em camundongos (Mus musculus, var. albina); Infecções ligeiras em "Cotton-rats" (Sigmodum hispidus hispidus); Animais refratários. Hospital, 40(2): 11-20, 1951a.

NERY GUIMARÃES, F. Comportamento da Leishmania braziliensis Vianna, 1911 em Hamsters (Cricetus [Mesocricetus] auratus). Hospital, 40(1): 25-46, 1951b.

NOIREAU, F.; DIOSQUE, P. \& JANSEN, A. M. Trypanosoma cruzi: adaptation to its vectors and its hosts. Veterinary Research, 40(2): 26, 2009.

OLIFIERS, N.; GENTILE, R. \& FISZON, J. T. Relation between small-mammal species composition and anthropic variables in the Brazilian Atlantic Forest. Brazilian Journal of Biology, 65(3): 495-501, 2005.

OLIVEIRA, F. S. et al. PCR-based diagnosis for detection of Leishmania in skin and blood of rodents from an endemic area of cutaneous and visceral leishmaniasis in Brazil. Veterinary Parasitology, 129(3-4): 219-227, 2005.

PAJOT, F. X. et al. Epidemiology of leishmaniasis in French Guiana. Transactions of the Royal Society of Tropical Medicine and Hygiene, 76(1): 112-113, 1982.

PRATLONG, F. et al. Human cutaneous leishmaniasis caused by Leishmania naiffi is wide-spread in South America. Annals of Tropical Medicine and Parasitology, 96(8): 781-785, 2002.

PUNG, O. J.; HULSEBOS, L. H. \& KUHN, R. E. Experimental American leishmaniasis and Chagas' disease in the Brazilian squirrel monkey: cross immunity and electrocardiographic studies of monkeys infected with Leishmania braziliensis and Trypanosoma cruzi. International Journal for Parasitology, 18(8): 1.053-1.059, 1988.

QUINNELL, R. J. \& COURTENAY, O. Transmission, reservoir hosts and control of zoonotic visceral leishmaniasis. Parasitology, 136(14): 1.915-1.934, 2009.

RAYMOND, R. W. et al. Temporal and spatial distribution of Leishmania mexicana infections in a population of Neotoma micropus. Memórias do Instituto Oswaldo Cruz, 98(2): 171-180, 2003.

RHYAN, J. C. \& SPRAKER, T. R. Emergence of diseases from wildlife reservoirs. Veterinary Pathology, 47(1): 34-39, 2010.

ROQUE, A. L. R. Avaliação do Potencial de Pequenos Mamíferos e Importância de Animais Domésticos na Manutenção dos Ciclos de Transmissão de Tripanosomatídeos: Trypanosoma cruzi, Leishmania infantum e Leishmania braziliensis, 2009. Tese de Doutorado, Rio de Janeiro: Instituto Oswaldo Cruz, Fundação Oswaldo Cruz.

ROQUE, A. L. R. \& JANSEN, A. M. Reservatórios do Trypanosoma cruzi e sua relação com os vetores. In: GALVÃo, C. (Org.). Vetores da Doença de Chagas no Brasil. Rio de Janeiro: Editora Fiocruz, 2010.

ROQUE, A. L. R. et al. Trypanosoma cruzi: distinct patterns of infection in the sibling caviomorph rodent species Thrichomys apereoides laurentius and Thrichomys pachyurus (Rodentia, Echimyidae). Experimental Parasitology, 111(1): 37-46, 2005.

ROQUE, A. L. R. et al. Trypanosoma cruzi transmission cycle among wild and domestic mammals in three areas of orally transmitted Chagas disease outbreaks. The American Journal of Tropical Medicine and Hygiene, 79(5): 742-749, 2008.

ROQUE, A. L. R. et al. Thrichomys laurentius (Rodentia; Echimyidae) as a putative reservoir of Leishmania infantum and $L$. braziliensis: patterns of experimental infection. PLoS Neglected Tropical Diseases, 4(2): e589, 2010.

ROTUREAU, B. Ecology of the Leishmania species in the Guianan ecoregion complex. The American Journal of Tropical Medicine and Hygiene, 74(1): 81-96, 2006.

SÁ, P. G. S. Criação e manejo de cães. In: ANDRADE, A.; PINTO, S. C. \& OLIVEIRA, R. S. (Eds.). Animais de Laboratório: criação e experimentação. 1. ed. Rio de Janeiro: Editora Fiocruz, 2002. 
SAKTHIANANDESWAREN, A.; FOOTE, S. J. \& HANDMAN, E. The role of host genetics in leishmaniasis. Trends in Parasitology, 25(8): 383-391, 2009.

SALAM, M. A. et al. PCR for diagnosis and assessment of cure in kala-azar patients in Bangladesh. Acta Tropica, 113(1): $52-55,2010$.

SANTIAGO, M. E. et al. An investigation of Leishmania spp. in Didelphis spp. from urban and peri-urban areas in Bauru (São Paulo, Brazil). Veterinary Parasitology, 150(4): 283-290, 2007.

SAVANI, E. S. et al. The first record in the Americas of an autochthonous case of Leishmania (Leishmania) infantum chagasi in a domestic cat (Felix catus) from Cotia County, São Paulo State, Brazil. Veterinary Parasitology, 120(3): 229-233, 2004.

SAVANI, E. S. et al. Detection of Leishmania (Leishmania) amazonensis and Leishmania (Leishmania) infantum chagasi in Brazilian bats. Veterinary Parasitology, 168(1-2): 5-10, 2010.

SCHALLIG, H. D. et al. Didelphis marsupialis (common opossum): a potential reservoir host for zoonotic leishmaniasis in the metropolitan region of Belo Horizonte (Minas Gerais, Brazil). Vector Borne and Zoonotic Diseases, 7(3): 387-393, 2007.

SHAW, J. The leishmaniases--survival and expansion in a changing world. A mini-review. Memórias do Instituto Oswaldo Cruz, 102(5): 541-547, 2007.

SHERLOCK, I. A. Ecological interactions of visceral leishmaniasis in the state of Bahia, Brazil. Memórias do Instituto Oswaldo Cruz, 91(6): 671-683, 1996.

SHERLOCK, I. A. et al. Natural infection of the opossum Didelphis albiventris (Marsupialia, Didelphidae) with Leishmania donovani, in Brazil. Memórias do Instituto Oswaldo Cruz, 79(4): 511, 1984.

SILVA, A. V. et al. The first record of American visceral leishmaniasis in domestic cats from Rio de Janeiro, Brazil. Acta Tropica, 105(1): 92-94, 2008.

SILVA, E. S. et al. Visceral leishmaniasis in the crab-eating fox (Cerdocyon thous) in south-east Brazil. The Veterinary Record, 147(15): 421-422, 2000.

SILVA, E. S.; GONTIJO, C. M. \& MELO, M. N. Contribution of molecular techniques to the epidemiology of neotropical Leishmania species. Trends in Parasitology, 21(12): 550-552, 2005.

SILVA, J. C. R. \& ADANIA, C. H. Carnivora - Felidae (Onça, Suçuarana, Jaguatirica, Gato-do-mato). In: CUBAS, Z. S.; SILVA, J. C. R. \& CATÃo-DIAS, J. L. (Eds.). Tratado de Animais Selvagens. 1. ed. São Paulo: Roca, 2007.

SILVEIRA, F. T. et al. [Experimental cutaneous leishmaniasis: I--on the susceptibility of the primate Cebus apella (Cebidae) to the infection caused by Leishmania (Viannia) lainsoni Silveira, Shaw and Ishikawa, 1987]. Revista da Sociedade Brasileira de Medicina Tropical, 22(3): 125-130, 1989.

SILVEIRA, F. T. et al. [Experimental skin leishmaniasis: II--course of the infection in the Cebus apella primate (Cebidae) caused by Leishmania (V.) braziliensis and L. (L.) amazonensis]. Revista da Sociedade Brasileira de Medicina Tropical, 23(1): 5-12, 1990.

SILVEIRA, F. T. et al. Cutaneous leishmaniasis in Amazonia: isolation of Leishmania (Viannia) lainsoni from the rodent Agouti paca (Rodentia: Dasyproctidae), in the state of Para, Brazil. Revista do Instituto de Medicina Tropical de São Paulo, 33(1): 18-22, 1991.

SLENNING, B. D. Global climate change and implications for disease emergence. Veterinary Pathology, 47(1): 28-33, 2010.

SWAN, G. E.; COETZER, J. A. \& TERBLANCHE, H. M. Integrating global animal health, public health and tropical animal health issues into the veterinary curriculum: a South African/African perspective. Revue Scientifique et Technique, 28(2): 727-738, 2009 .

TESH, R. B. Control of zoonotic visceral leishmaniasis: is it time to change strategies? The American Journal of Tropical Medicine and Hygiene, 52(3): 287-292, 1995.

THOMAZ-SOCCOL, V. et al. Monophyletic origin of the genus Leishmania Ross, 1903. Annales de Parasitologie Humaine et Comparée, 68(2): 107-108, 1993. 
TRAVI, B. L. et al. Didelphis marsupialis, an important reservoir of Trypanosoma (Schizotrypanum) cruzi and Leishmania (Leishmania) chagasi in Colombia. The American Journal of Tropical Medicine and Hygiene, 50(5): 557-565, 1994.

TRAVI, B. L. et al. Leishmania (Leishmania) chagasi: clinical and parasitological observations in experimentally infected Didelphis marsupialis, reservoir of New World visceral leishmaniasis. Experimental Parasitology, 88(1): 73-75, 1998a.

TRAVI, B. L. et al. Dynamics of Leishmania chagasi infection in small mammals of the undisturbed and degraded tropical dry forests of northern Colombia. Transactions of the Royal Society of Tropical Medicine and Hygiene, 92(3): 275-278, 1998b.

TRAVI, B. L. et al. Susceptibility of spiny rats (Proechimys semispinosus) to Leishmania (Viannia) panamensis and Leishmania (Leishmania) chagasi. Memórias do Instituto Oswaldo Cruz, 97(6): 887-892, 2002.

VAN DER SNOEK, E. M. et al. Spontaneous cure of American cutaneous leishmaniasis due to Leishmania naiffi in two Dutch infantry soldiers. Clinical and Experimental Dermatology, 34(8): e889-e891, 2009.

VAN WYNSBERGHE, N. R. et al. Retention of Leishmania (Leishmania) mexicana in naturally infected rodents from the State of Campeche, Mexico. Memórias do Instituto Oswaldo Cruz, 95(5): 595-600, 2000.

VAN WYNSBERGHE, N. R. et al. Comparison of small mammal prevalence of Leishmania (Leishmania) mexicana in five foci of cutaneous leishmaniasis in the State of Campeche, Mexico. Revista do Instituto de Medicina Tropical de São Paulo, 51(2): 87-94, 2009 .

VASCONCELOS, I. A. et al. The identity of Leishmania isolated from sand flies and vertebrate hosts in a major focus of cutaneous leishmaniasis in Baturité, northeastern Brazil. The American Journal of Tropical Medicine and Hygiene, 50(2): 158-164, 1994.

VEDOVELLO, F. D. et al. American cutaneous leishmaniasis in horses from endemic areas in the north-central mesoregion of Parana state, Brazil. Zoonoses Public Health, 55(3): 149-155, 2008.

VERONA, C. E. S. \& PISSINATTI, A. Primatas do Novo Mundo (Sagui, Macaco-prego, Macaco-aranha, Bugio). In: CUBAS, Z. S.; SILVA, J. C. R. \& CATÃo-DIAS, J. L. (Eds.). Tratado de Animais Selvagens. 1. ed. São Paulo: Roca, 2007.

VOULDOUKIS, I. et al. Susceptibility of Cebus nigrivittatus to Leishmania infantum. The Journal of Parasitology, 72(3): 472-473, 1986.

WEISS, R. A. \& McMICHAEL, A. J. Social and environmental risk factors in the emergence of infectious diseases. Nature Medicine, 10, supl. 12: S70-S76, 2004.

WILSON, D. E. \& REEDER, D. M. Mammal Species of the World: a taxonomic and geographic reference. 3. ed. Baltimore: Johns Hopkins University Press, 2005.

WOOLHOUSE, M. E.; TAYLOR, L. H. \& HAYDON, D. T. Population biology of multihost pathogens. Science, 292(5.519): 1.109$1.112,2001$.

WORLD HEALTH ORGANIZATION (WHO). Control of the leishmaniasis. Techinical Report Series 793. Geneva, 1990.

WORLD HEALTH ORGANIZATION (WHO). Leishmaniasis: background information. A brief history of the diseases. Disponível em: <www who int/leishmaniasis/en>. Acesso em: 11 jun. 2010. 


\title{
15 \\ Os Parasitos e a Questão da Infecção em Animais Domésticos e Domiciliados
}

Fabiano Borges Figueiredo I Maria de Fátima Madeira

\begin{abstract}
A s leishmanioses são doenças mundialmente negligenciadas, que afetam em sua grande maioria populações mais vulneráveis ou carentes, refletindo um conjunto de circunstâncias epidemiológicas provocadas pela multiplicidade de espécies do parasito, de insetos vetores, de diferentes reservatórios envolvidos no ciclo natural, de fatores ecológicos que interferem nessa cadeia e do envolvimento de políticas públicas de saúde, cujo impacto pode ser sentido no controle dessa endemia em várias regiões do mundo (WHO, 2008; Brasil, 2006, 2010).

Nos últimos anos, as leishmanioses têm sido incriminadas, junto com outras doenças também transmitidas por artrópodes, como uma doença emergente e reemergente, cuja propagação pode estar associada ao comportamento humano, em virtude dos processos migratórios, ações de desmatamentos, projetos de construção de rodovias e, também, de conflitos sociais (Shaw, 2007). Os fatores ambientais, como o aquecimento global por exemplo, interferem nos microambientes atuando sobre os processos naturais e podem ter influência direta na densidade dos agentes vetores, embora não esteja evidenciada a demonstração desse impacto (Kuhn, 1999). Outro fator que pode também incidir na modificação e propagação geográfica das leishmanioses é o aparecimento de novos genótipos/fenótipos de parasitos e vetores, a partir de pressões seletivas naturais (Pacheco et al., 1995), cujo conhecimento e rastreamento de subpopulações de parasitos circulantes nos diferentes hospedeiros pode contribuir para melhor compreensão da epidemiologia em diversas áreas endêmicas.
\end{abstract}

Em inúmeros focos de leishmaniose descritos no mundo, observa-se uma grande variedade de animais mamíferos pertencentes a grupos taxonômicos distintos, incriminados como possíveis reservatórios, ou simplesmente como hospedeiros acidentais, no ciclo de transmissão de diferentes espécies de Leishmania.

Neste capítulo abordaremos os diferentes aspectos que envolvem a infecção de animais domésticos por protozoários do gênero Leishmania, com base em relatos da literatura científica e na experiência dos autores.

\section{DESENVOLVIMENTO}

Entre os animais domésticos envolvidos com parasitos do gênero Leishmania, o cão (Canis familiaris) apresenta papel de destaque, seja pela proximidade que tem com o homem, funcionando como elo no ciclo de transmissão, seja 
pelo papel mantenedor e dispersor de determinadas espécies, principalmente em áreas urbanas (Marzochi \& Marzochi, 1994; Dantas-Torres, 2007; Madeira et al., 2006b; Figueiredo et al., 2009; Marzochi et al., 2009). Esse animal tem sido encontrado naturalmente infectado por diferentes espécies de Leishmania, incluindo espécies dermotrópicas como L. braziliensis, L. amazonensis, L. mexicana, L. colombiensis, L. panamensis, L. peruviana, L. pifanoi, L. tropica, L. major e espécies viscerotrópicas como L. donovani e L. chagasi (sin. L. infantum) (Gallego, 2004; Solano-Gallego et al., 2009; Dantas-Torres, 2009). Entretanto, o leque de espécies que possam estar infectando esse animal pode ser maior, uma vez que a etiologia nem sempre é confirmada. Tais dados demonstram que cães domésticos são suscetíveis a inúmeras espécies do gênero Leishmania, no entanto, sua importância epidemiológica encontra-se principalmente no ciclo de transmissão das espécies causadoras da leishmaniose visceral, no qual são centradas as ações de controle.

No Brasil, das espécies causadoras da doença tegumentar humana, o cão doméstico tem sido incriminado como um eventual hospedeiro somente no ciclo epidemiológico de L. braziliensis. Seu envolvimento foi sinalizado já no início do século XX, após ter sido relatado o encontro de cães portando úlceras semelhantes às encontradas no homem (Pedroso, 1913). Essa hipótese foi mais tarde reforçada por Aragão (1927), que conseguiu reproduzir uma lesão no focinho de um cão ao inocular um macerado de Phlebotomus intermedius, comprovando, assim, a possibilidade da infecção experimental de cães com transmissão por meio de um inseto da família Phlebotominae. Posteriormente, a participação do cão doméstico no ciclo de transmissão da leishmaniose tegumentar passou a ser objeto de estudo durante vários surtos ocorridos na Região Sudeste do Brasil (Araújo \& Coura, 1978; Coutinho et al., 1985; Falqueto et al., 1986; Pirmez et al., 1988). Esses estudos contribuíram, de certa forma, com argumentos favoráveis à implicação desses animais como possíveis reservatórios de L. braziliensis, uma vez que eram frequentemente encontrados naturalmente infectados em áreas de ocorrência dos casos humanos, embora outros estudos tenham apontado o cão doméstico como mero hospedeiro acidental nesse ciclo.

A infecção canina causada por $L$. braziliensis geralmente não compromete o estado geral do animal, e a doença manifesta-se com lesões cutâneas localizadas preferencialmente na bolsa escrotal, pavilhão auricular e focinho, que são os locais de pouco pelo preferidos pelo inseto vetor (Aragão, 1927). As lesões podem permanecer em atividade por longos períodos ou intercaladas com períodos de cicatrização. Frequentemente a resposta imune humoral é baixa ou mesmo negativa (Madeira et al., 2003a; Serra et al., 2003), inviabilizando os métodos sorológicos como ferramenta única no diagnóstico. Por sua vez, o diagnóstico clínico nem sempre é uma tarefa fácil, tendo em vista que podem ser confundidas com doenças clinicamente semelhantes, entre elas a esporotricose canina ocasionada pelo Sporothrix schenckii, que constitui o principal diagnóstico diferencial, especialmente em áreas de sobreposição de ambos os agentes (Santos et al., 2007). Além das características clínicas bem semelhantes, como as lesões cutâneas ulceradas e nodulares nas regiões periféricas como orelhas e focinho, o diagnóstico sorológico e o teste intradérmico (teste de Montenegro) podem apresentar resultados falso-positivos, agregando ainda mais um fator de confusão (Santos et al., 2007).

O teste de Montenegro (1926), que mede a hipersensibilidade do tipo retardado a antígenos de Leishmania, de grande aplicação no diagnóstico da leishmaniose tegumentar humana, foi utilizado pela primeira vez na leishmaniose tegumentar canina (LTC) (Pirmez et al., 1988) como proposta alternativa no diagnóstico desses animais. Entretanto, os resultados obtidos não foram conclusivos para determinação da infecção. Estudos posteriores revelaram que os resultados negativos encontrados (Pirmez et al., 1988) não estavam relacionados a uma imunossupressão específica do cão infectado, mas sim à apresentação do conteúdo proteico do antígeno (Marzochi \& Barbosa-Santos, 1988), mostrando-se útil como instrumento nos inquéritos epidemiológicos (Santos et al., 1998). É importante ressaltar que a positividade desse teste, como ocorre no homem, não descarta outras infecções.

Assim, o diagnóstico confirmatório da LTC deve empregar métodos que possibilitem a demonstração do parasito nas lesões cutâneas, os quais podem ser feitos por meio de exames citológicos e histopatológicos ou através do isolamento em meio de cultura, permitindo posteriormente a identificação da amostra isolada. Métodos moleculares 
também são amplamente empregados com fins diagnósticos. Na LTC, apesar dos relatos da evidência de DNA parasitário pela PCR em sangue de cães infectados (Reithinger et al., 2000; Reithinger \& Davies, 2002; Reithinger et al., 2003), a demonstração da viabilidade e infectividade desses parasitos é primordial para subsidiar as discussões relacionadas ao papel que o cão doméstico possa assumir no ciclo de transmissão (Dantas-Torres, 2007; Reithinger \& Davies, 1999). Métodos tradicionais de diagnóstico como a cultura, em várias ocasiões, não foram capazes de detectar a presença do parasito em locais diferentes da lesão cutânea (Madeira et al., 2006b; Herrer \& Christensen, 1976; Pirmez, Marzochi \& Coutinho, 1988), sugerindo que os flebotomíneos possam ter baixa probabilidade de se infectarem quando alimentados fora do sítio das lesões cutâneas (Silveira et al., 1989). Embora ainda sejam escassos os estudos que investiguem a distribuição de L. braziliensis nos tecidos do cão infectado, Madeira e colaboradores (2005), avaliando um grupo de 19 cães naturalmente infectados por L. braziliensis, demonstrou a presença exclusiva desta espécie somente em lesões cutâneas, corroborando achados anteriores. Os animais desse grupo apresentaram títulos sorológicos, avaliados pela imunofluorescência indireta (IFI), que variaram de resultados negativos a títulos de 1:640, revelando, por um lado, a diversidade sorológica de cães com LTC e por outro, que títulos elevados não são exclusivos da leishmaniose visceral canina (LVC). Tais resultados, também já assinalados por outros autores (Falqueto et al., 1986; Pirmez, Marzochi \& Coutinho, 1988), sugerem a hipótese de que L. braziliensis talvez possua uma tendência de se restringir ao sítio da lesão cutânea de cães infectados (Madeira et al., 2006b; Madeira et al., 2005). Tais observações, associadas a inúmeras outras questões levantadas acerca do papel que o cão doméstico possa desempenhar no ciclo de transmissão da LT, têm sido discutidas (Dantas-Torres, 2007; Reithinger \& Davies, 1999) e, a nosso ver, esse debate deve ser incentivado. Por recomendação do Ministério da Saúde (Brasil, 2010), o sacrifício de cães com LTC não constitui uma das medidas de controle. A eutanásia é indicada somente quando os animais doentes evoluírem para o agravamento das lesões cutâneas ou a partir do surgimento de lesões mucosas e infecções secundárias que possam conduzir o animal ao sofrimento.

Diferentemente do que ocorre no ciclo de transmissão da LT, durante o qual se desconhece o potencial do cão doméstico como reservatório, na LV, tal papel já está bem definido e sedimentado, sendo considerado um importante reservatório doméstico de espécies viscerotrópicas em países do Velho e Novo Mundo. A notificação constante de cães infectados nas áreas endêmicas de LV, associado ao aparecimento dos casos humanos, tem reforçado que esse animal possa ser responsável pela manutenção e amplificação de ciclos instalados no peridomicílio (Marzochi \& Marzochi, 1994; Marzochi et al., 2009; Paranhos-Silva et al., 1996; Palatnik-de-Sousa et al., 2001).

No Brasil, a LV é endêmica, especialmente na Região Nordeste. A transmissão autóctone, associada à Lutzomyia longipalpis, é registrada em praticamente todos os estados brasileiros, inclusive na Região Sul do país (Souza, Santos \& Andrade Filho, 2009). Nos últimos anos, tem-se registrado um marcado aumento na incidência da LV, principalmente nos centros urbanos (Brasil, 2006). A doença, antes restrita às áreas rurais, avançou para regiões indenes instalandose nos grandes centros urbanos, passando a ser considerada como um grave problema da saúde pública. O processo de urbanização das cidades e ocupação do solo urbano, muitas vezes sem planejamento, certamente contribuiu para a mudança no perfil epidemiológico da LV. Em particular, no município do Rio de Janeiro, o processo de ocupação do espaço também foi associado ao processo de instalação e propagação da LT (Kawa \& Sabroza, 2002).

o quadro clínico da LVC é bastante variável, apresentando-se desde aparente estado sadio a quadros severos de caquexia associada a outras complicações (Marzochi et al., 1985b; Alvar et al., 2004). A evolução da doença também é bastante variável, podendo apresentar uma forma aguda e grave, levando o animal a óbito em poucas semanas, evoluir de uma forma lenta que pode durar anos, acompanhada ou não de sintomas, ou evoluir para uma forma grave e até mesmo regredir espontaneamente (Marzochi et al., 1985b). Os sinais clínicos mais comuns relatados na literatura são as alterações cutâneas (alopecia, dermatites, descamações, úlceras cutâneas, onicogrifose); sinais oculares (conjuntivite, ceratoconjuntivite, uveíte); alterações cervicais (linfoadenopatia - local ou generalizada); 
anemia, febre e hepatoesplenomegalia (Marzochi et al., 1985b; Alvar et al., 2004; Silva et al., 2001). Em fases avançadas da doença, pode ocorrer paresia dos membros posteriores, caquexia, inanição e morte. Cães infectados também podem permanecer sem sinais clínicos por um longo período de tempo (Marzochi et al., 1985b; Almeida et al., 2005), sendo a forma assintomática relatada em proporções que podem representar cerca de $40 \%$ a $60 \%$ da população soropositiva (Marzochi \& Marzochi, 1994; Dantas-Torres, Brito \& Brandão-Filho, 2006).

Na LVC, a distribuição do parasito pode ser extensiva, alcançando órgãos como baço, fígado, linfonodos, pele, medula óssea etc. (Alvar et al., 2004), oposto do que ocorre no homem, no qual o parasito é normalmente limitado à medula óssea, baço e fígado. $\mathrm{O}$ acometimento do sistema nervoso central também é descrito na infecção por $L$. infantum (Vinuelas et al., 2001). A presença do parasito nos mais diferentes tecidos e órgãos provoca reações características da LVC, entre as quais a ativação policlonal de células B, produzindo elevados níveis séricos de imunoglobulinas, que, se por um lado não tem significado de proteção, por outro, facilita o diagnóstico laboratorial através de testes sorológicos. A pesquisa parasitológica por meio de métodos clássicos ou moleculares pode ser feita em diversos espécimes clínicos, como sangue, aspirados ou através de biópsias de lesões cutâneas, vísceras, gânglio ou pele (Madeira et al., 2006b; Marzochi et al., 1985b; Ashford et al., 1995; Lachaud et al., 2002; Reithinger \& Dujardin, 2007).

Atualmente é aceito que o background genético dos cães, determinado por diversos fatores, pode influenciar no perfil que determina a resistência ou suscetibilidade da LVC. A resistência é caracterizada por baixa produção de anticorpos e a imunidade celular está presente. Já em animais considerados suscetíveis, ocorre uma multiplicação acelerada do parasito com uma superprodução de anticorpos específicos e não específicos para Leishmania, o que acarreta danos para diversos órgãos (Saridomichelakis, 2009).

A prevalência da LVC é dada normalmente por meio de dados sorológicos obtidos após os inquéritos (Brasil, 2006). Métodos parasitológicos não são aplicados, em razão do grande volume de trabalho gerado, embora o valor de cada método empregado possa variar de acordo com o objeto da investigação.

Apesar do amplo espectro clínico da LVC, que pode variar de acordo com a fase da doença e o status imunológico do cão, são as alterações dermatológicas os sinais mais relevantes citados por diversos autores (Alvar et al., 2004; Silva et al., 2001; Marzochi et al., 1985a; Lima et al., 2004). A ulceração cutânea, que constitui uma dessas alterações, pode estar relacionada a uma ação direta do parasito (Ridley \& Ridley, 1983), ou mesmo ser resultado do depósito de imunocomplexos naquele local. Em um estudo feito com 150 cães infectados por L. infantum, contatou-se que $40 \%$ dos animais apresentavam úlceras cutâneas (Ciaramella et al., 1997). Em outro estudo, conduzido no município do Rio de Janeiro, lesões cutâneas foram encontradas em 47,0\% dos 68 animais avaliados (Madeira et al., 2006b). Nesse estudo, comprovou-se a presença de L. chagasi, no sítio da lesão, em oito animais; L. braziliensis em 16, e em oito casos não se observou a presença de Leishmania.

Esses resultados sugerem que a presença de lesões cutâneas, embora descrita em vários estudos como um dos sinais importantes de LVC, nem sempre podem estar associadas à infecção por L. chagasi, principalmente em áreas onde ocorre a sobreposição com a forma tegumentar. Tanto dados clínicos quanto sorológicos devem ser interpretados com cautela nessa situação. Nesse estudo, comprovou-se a presença L. braziliensis em 50\% das lesões investigadas em cães sororreatores, das quais $25 \%$ foram negativas. Lesões cutâneas também devem ser investigadas para o diagnóstico diferencial por outras doenças, como neoplasias, infecções fúngicas e bacterianas e até mesmo lesões provocadas por traumas.

O parasitismo de pele íntegra, descrito de forma pioneira na década de 1950 por Deane e Deane (1954), é uma das características que fazem do cão um elemento de importância no ciclo de transmissão da LV. Os fatores que determinam a disseminação de $L$. chagasi para os diferentes sítios anatômicos do cão doméstico são desconhecidos (Colmenares, 2002). Entretanto, o parasitismo de pele tem sido apontado como um evento tardio no curso da infecção canina (Tafuri, 
Oliveira \& Melo, 2001), estando fortemente associado às manifestações clínicas comuns da LVC (Solano-Gallego et al., 2004; Giunchetti et al., 2006; Reis et al., 2006). O encontro de L. chagasi, nesse órgão, poderia estar relacionado às áreas de maior irrigação sanguínea, como observado por Travi e colaboradores (2001), que destacaram o maior potencial infectivo da pele da orelha para flebótomos quando comparado à pele do abdômen.

Já outros estudos não conseguiram demonstrar diferenças relacionadas à densidade parasitária quando diferentes locais desse órgão foram investigados (Saridomichelakis et al., 2007). Pesquisando simultaneamente a pele da orelha e da região escapular em um grupo de 394 cães sororreatores, eutanasiados pelo programa de controle da LV, Madeira e colaboradores (2009a), além de comprovar o parasitismo em 78,7\% dos animais, também não observou diferenças estatísticas para a chance de isolamento de L. chagasi em ambos os locais de pele investigados.

Os resultados obtidos nesse estudo sugerem que L. chagasi possa estar distribuída de forma uniforme na pele de cães infectados, e apontam este sítio como um bom alvo na confirmação parasitológica da LVC, independentemente da condição clínica do animal. Por essa razão, a biopsia de pele íntegra de cães suspeitos de LVC, como ferramenta na confirmação parasitológica de cães sororreatores, tem sido utilizada por diversos pesquisadores com grande sucesso (Figueiredo et al., 2010; Madeira et al., 2009a; Paula et al., 2009). Apesar da sorologia ser determinante nos casos de LVC, estudos também têm demonstrado o isolamento parasitário em pele íntegra de animais soronegativos (Figueiredo et al., 2010; Barrouin-Melo et al., 2004), indicando que diferentes parâmetros devem ser avaliados no momento do diagnóstico desses animais.

Pelo fato de a LV assumir formas graves e letais, as ações sanitárias direcionadas para essa forma da doença são mais rigorosas que aquelas direcionadas à forma tegumentar. As ações de controle estão centradas no diagnóstico precoce e no tratamento dos casos humanos, vigilância entomológica, saneamento ambiental e controle químico, vigilância e monitoramento canino com eutanásia de cães sororreatores (Brasil, 2006).

Nas áreas endêmicas de LV, o diagnóstico da LVC é dado principalmente por ferramentas sorológicas que, embora apresentem vantagens sobre os métodos parasitológicos, podem ter o seu resultado limitado, especialmente pela possível reatividade cruzada com outras doenças, sendo importante a consideração de outros aspectos para o diagnóstico final.

No Brasil, tais programas iniciaram-se por volta da década de 1950 durante um surto ocorrido no estado do Ceará, estendendo-se mais tarde para outras regiões do país. A estratégia do sacrifício canino foi por muito tempo priorizada, orientando as áreas para o controle vetorial. No entanto, a partir de observações de que a eliminação de cães sororreatores estivesse exercendo pouca ou até mesmo nenhuma influência no surgimento de novos casos, humanos ou caninos (Evans et al., 1992; Dietze et al., 1997; Ashford et al., 1998, Paranhos-Silva et al., 1998), abriram-se questionamentos quanto à aplicação dessa medida realizada de forma vertical, desconsiderando outras variáveis (Palatnik-de-Sousa et al., 2001).

A partir dessas observações, o Ministério da Saúde lançou estratégias com maior abrangência e integração, considerando as particularidades de cada região, aplicando esforços não só no controle vetorial, mas também no conhecimento da fauna e dos parasitos que possam estar circulando nessas regiões, para que ações de controle individualizadas possam ser desencadeadas (Brasil, 2006).

Uma importante questão é a sobreposição de áreas endêmicas, seja por diferentes espécies de Leishmania ou por diferentes gêneros de tripanossomatídeos. Áreas com tal característica favorecem o aparecimento de infecções mistas, dificultando um correto diagnóstico. No Brasil, a coinfecção natural de cães domésticos, com diferentes espécies de tripanossomatídeos tem sido registrada. No município do Rio de Janeiro, três casos de coinfecção por L. braziliensis e L. chagasi foram descritos (Madeira et al., 2006a, 2006b). Nesse mesmo município foi também descrito um caso de coinfecção canina, desta vez por L. braziliensis e um Trypanosoma sp., cuja identidade até então era desconhecida 
(Madeira et al., 2003b). No estado de Mato Grosso, área endêmica para L. chagasi e T. evansi, um caso de coinfecção por ambas as espécies foi também descrito (Savani et al., 2005). Tais relatos demonstram que cães domésticos são suscetíveis a diferentes membros da família Trypanosomatidae, inclusive em coinfecções, e ressaltam a importância da adoção de ferramentas diagnósticas que possam discriminar com segurança os agentes etiológicos envolvidos, notadamente em área endêmicas de sobreposição. De outro lado, em áreas de sobreposição, onde circulam diferentes tripanossomatídeos, dados sorológicos obtidos após os inquéritos podem não refletir dados reais da prevalência de LVC (Madeira et al., 2006b).

Recentemente, a descrição de um novo parasito, denominado Trypanosoma caninum (Madeira et al., 2009b), pode abrir discussões relacionadas ao controle da LVC. Esse parasito foi isolado no município do Rio de Janeiro e, inicialmente, tal achado parecia ser ocasional, sem importância epidemiológica. No entanto, a partir do encontro de outros isolados similares à espécie original, tanto no município do Rio de Janeiro (Pinto et al., 2010) como em diferentes regiões do Brasil (dados em fase de publicação), levantam a suspeita de um ciclo natural desse protozoário entre cães domésticos. Pouco se sabe sobre a biologia e epidemiologia desse novo parasito, contudo, um dado interessante é o isolamento exclusivo em fragmentos de pele íntegra, característica não muito comum aos parasitos do gênero Trypanosoma. Inúmeros aspectos precisam ainda ser esclarecidos, sobretudo os relacionados ao ciclo natural e ao impacto que esse parasito possa causar em áreas onde L. chagasi e L. braziliensis ocorrem, uma vez que compartilham o mesmo hospedeiro.

A circulação de T. caninum em áreas de ocorrência das leishmanioses abre um alerta, principalmente no que diz respeito aos aspectos relacionados ao diagnóstico e à eutanásia de cães, com base somente em evidências sorológicas, visto que a reatividade sorológica cruzada entre membros da família Trypanosomatidae é um fato que constitui um dos maiores problemas em áreas endêmicas de sobreposição com diferentes agentes etiológicos (Madeira et al., 2009b; Saldana \& Sousa, 1996; Caballero et al., 2007). Segundo Marzochi e colaboradores (2009), apesar de nenhum caso de LV humana ter sido relatado nos últimos anos no município do Rio de Janeiro, a persistência da soroprevalência canina torna-se fato preocupante.

Estratégias alternativas no controle da LVC têm sido propostas, desde diferentes protocolos terapêuticos (Slappendel \& Teske, 1997), uso de coleiras impregnadas com inseticida (Killick-Kendrick et al., 1997), até o desenvolvimento de vacinas (Silva et al., 2000). Entretanto, tais alternativas devem ser tratadas com cautela, pois devem considerar diferentes aspectos, desde custos, praticidade de aplicação em larga escala e eficácia.

Atualmente, no Brasil, duas vacinas comerciais (Leishmune e Leish-Tec) são disponibilizadas. Ambas foram aprovadas e estão registradas no Ministério da Agricultura, Pecuária e Abastecimento, órgão responsável pela aprovação e liberação de produtos terapêuticos e profiláticos de uso animal. Contudo, por meio de nota técnica publicada no Diário Oficial da União em 10 de julho de 2007, o Ministério da Saúde não recomenda o uso desses produtos como uma das medidas de controle da LV, uma vez que ainda estão sendo realizados estudos para avaliar sua eficácia. Adicionalmente, o tratamento desses animais também não constitui uma medida de controle aceita pelo Ministério da Saúde brasileiro, tendo em vista que tal prática poderá levar ao risco da seleção de subpopulações de parasitos resistentes às drogas utilizadas para o tratamento humano.

Os agentes causadores das leishmanioses são transmitidos por insetos flebotomíneos em que, durante o repasto sanguíneo, formas promastigotas são inoculadas na pele dos hospedeiros vertebrados. Em áreas endêmicas com casos caninos comprovados, e na ausência desses insetos, tem sido sugerido que talvez outras formas de transmissão possam estar ocorrendo entre os cães, incluindo a transmissão vertical (Pangrazio et al., 2009), transfusões sanguíneas (Freitas et al., 2006) e transmissão via venérea (Silva et al., 2009). Apesar de tais mecanismos não possuírem significância epidemiológica, devem ser considerados em áreas nas quais a densidade de flebotomíneos é baixa ou inexistente. 
Adicionalmente, outros artrópodes como pulgas e carrapatos também têm sido sugeridos como vetores em potencial de L. chagasi (Coutinho et al., 2005; Coutinho \& Linardi, 2007), embora ainda faltem evidências que comprovem este modo de transmissão (Dantas-Torres et al., 2010).

No Brasil, L. braziliensis e L. chagasi são as espécies comumente encontradas na infecção natural canina e, apesar de L. braziliensis exibir grande polimorfismo genético (Cupolillo, Grimaldi \& Momen, 1997; Ishikawa et al., 2002), o mesmo não pode ser atribuído a $L$. chagasi, que em vários estudos tem apresentado baixo nível de variações genéticas (Momen \& Grimaldi, 1989), o que pode ser reflexo das características epidemiológicas desta espécie (Lainson \& Rangel, 2005).

Considerando-se as diferentes características das leishmanioses caninas e os quadros clínicos apresentados por ambas as doenças, parece razoável acreditar que cães domésticos exerçam papéis diferenciados nos ciclos de transmissão da LT e da LV, fazendo supor que na LTC deva existir maior tendência de elevadas densidades vetoriais para a ocorrência da transmissão de L. braziliensis para o homem e para outros animais domésticos. A propagação de L. braziliensis e L. chagasi para novas áreas onde existam condições propícias para a instalação de novos focos é preocupante, e o controle deve considerar a complexidade epidemiológica de ambas as espécies. Todavia, animais errantes, apesar de presentes em várias regiões endêmicas, não são contemplados nas ações específicas de controle das leishmanioses, constituindo também mais um elemento de preocupação. Esses animais podem albergar e disseminar outros parasitos, carreados ou não por vetores, que podem ameaçar a saúde humana. Seu monitoramento deve fazer parte das estratégias de controle.

o papel de outros animais domésticos como possíveis hospedeiros dos parasitos do gênero Leishmania também tem sido especulado, reservando ao gato (Felis catus) um papel de destaque, em razão sobretudo dos casos de infecção natural relatados em diferentes partes do mundo, tanto por espécies causadoras da forma tegumentar como da visceral. O primeiro caso de leishmaniose felina foi descrito em 1912, na Argélia (Sergent, Lombard \& Quilichini, 1912), e embora tenha sido considerado um evento raro (Bonfante-Garrido et al., 1991), nos últimos anos a frequência desse achado tem sido maior do que o esperado (Simões-Mattos et al., 2005).

Em 1931, Machattie, Mills e Chadwick (1931) descreveram dois casos de leishmaniose tegumentar felina (LTF) naturalmente adquirida, no Iraque. Em ambos os casos, o parasito envolvido foi Leishmania tropica e as alterações clínicas encontradas foram lesões extensas no focinho, pequenas ulcerações em membros e pápulas interdigitais. A LTF provocada por L. tropica também foi relatada nos Estados Unidos por Craig e colaboradores (1986) e por Barnes, Stanley e Craig (1993), cujos autores relataram a presença de lesões localizadas nas orelhas, tronco, focinho e na mucosa nasal. Na Venezuela, Bonfante-Garrido e colaboradores (1991) descreveram a LTF causada por L. venezuelensis em três gatos que apresentavam lesões nodulares e nódulos na face, no focinho e nas orelhas.

No Brasil, Schubach e colaboradores (2004) diagnosticaram, pela primeira vez, dois casos autóctones de LTF causada por $L$. braziliensis. Nesse relato, um dos animais apresentava úlcera cutânea e endurecimento no plano nasal, além de duas úlceras menores na face. O segundo gato possuía uma pápula na ponta do nariz e uma lesão vegetante na mucosa nasal. Quatro anos mais tarde um terceiro gato foi encontrado parasitado também por L. braziliensis, entretanto, além das lesões cutâneas localizadas na face, o animal apresentava-se apático, desidratado, desnutrido, caquético, com plano nasal edemaciado, mucosas nasais congestas e narinas totalmente obstruídas (Figueiredo et al., 2008). Ainda em relação à LTF, De Souza e colaboradores (2005) diagnosticaram um felino doméstico infectado por Leishmania amazonensis. Nesse caso, uma lesão nodular única foi encontrada no focinho e muitos nódulos de diferentes tamanhos nas orelhas e regiões digitais de todas as patas.

As manifestações clínicas da LTF parecem similares àquelas que ocorrem nos caninos, cujas lesões cutâneas localizam-se preferencialmente em áreas de pouco pelo, como orelhas e áreas da face (Simões-Mattos et al., 2005). Contudo, pela escassez de dados na literatura, pouco se sabe sobre o curso natural da infecção nesses animais. Em 
estudos experimentais, demonstrou-se que gatos são suscetíveis a L. braziliensis, apresentando clínica similar aos achados descritos antes, sendo também observado casos de cura clínica (Simões-Mattos et al., 2005).

Os relatos da infecção por espécies causadoras da leishmaniose visceral também são descritas em várias regiões do mundo. Na leishmaniose visceral felina (LVF) as alterações clínicas seguem, como na LTF, um padrão semelhante ao da doença canina, no qual, além das implicações sistêmicas, são encontradas uma gama de alterações dermatológicas (Dantas-Torres et al., 2006).

Ozon e colaboradores, em 1998 (Ozon et al., 1998), na França, descreveram um caso de LVF causada por $L$. infantum. Nesse achado os autores relataram que o animal apresentava alopecia, dermatite seborreica e úlcera crostosa por todo o corpo. Mediante punção de medula óssea pôde-se confirmar a presença de numerosas formas amastigotas parasitando macrófagos. Na Itália, Poli e colaboradores (2002), durante exame físico de um gato com histórico de letargia, observaram lesões nodulares ulceradas nas pálpebras, perda de peso, disorexia severa, estomatite ulcerativa, linfadenopatia generalizada e esplenomegalia. A presença de $L$. infantum, nesse animal, foi confirmada pela PCR. Nesse mesmo estudo, demonstrou-se, experimentalmente, que esses animais, infectados por $L$. infantum podem servir de fonte de infecção para P. perniciosus (Poli et al., 2002).

No Brasil, Savani e colaboradores (2004) identificaram, também através da PCR, a infecção de um gato por Leishmania infantum chagasi. Presença de lesão nodular localizada no focinho, perda excessiva de peso e musculatura, desidratação severa e uma linfadenopatia generalizada foram constatadas nesse caso.

A confirmação dos casos de leishmaniose felina segue o mesmo padrão realizado nos caninos, entretanto não existem kits validados para o diagnóstico sorológico. Em muitos dos relatos encontrados na literatura os resultados são obtidos com base em exames parasitológicos diretos realizados em aspirado de linfonodo, fígado e de lesões cutâneas (Savani et al., 2004; Costa-Durão et al., 1994), por meio de exames histopatológicos (Ozon et al., 1998; Grevot et al., 2005; Hervas et al., 2001), por isolamento em cultura (Schubach et al., 2004; Figueiredo et al., 2008; Kirkpatrick, Farrel \& Goldschmidt, 1984) e por meio de técnicas moleculares em que se empregam fragmentos de pele e órgãos do sistema fagocítico-mononuclear (Poli et al., 2002; Savani et al., 2004; Passos et al., 1996).

A sorologia para o diagnóstico, tanto da LTF como da LVF, são realizados tendo por base técnicas in house desenvolvidas pelos próprios laboratórios, utilizando cepas de parasitos homólogos isoladas nas próprias regiões, o que restringe sua utilização em inquéritos censitários e dificulta a vigilância da leishmaniose felina nas áreas endêmicas (Poli et al., 2002; Figueiredo et al., 2010).

Embora sem importância ainda comprovada no ciclo das leishmanioses, a descrição dos casos felinos dessa zoonose demonstra que esses animais também são suscetíveis a diferentes espécies de Leishmania, sendo importante ressaltar que, como ocorre com os cães, a doença felina pode ser confundida com outras doenças que apresentem clínica semelhante. Os donos e os profissionais envolvidos no cuidado desses animais devem estar atentos para a ocorrência das leishmanioses, devendo procurar a confirmação de casos suspeitos.

Com relação aos equinos, asininos e suínos, apesar dos relatos da infecção natural por Leishmania serem extremamente raros, existem registros em diferentes regiões (Yoshida et al., 1990; Aguilar \& Rangel, 1986; BarbosaSantos et al., 1994; Rolão et al., 2005; Vexenat et al., 1986).

No sul da Alemanha, a infecção por $L$. infantum de um equino foi diagnosticada com base em exame histológico, imuno-histoquímico e PCR. Os exames sorológicos empregados nesse estudo (IFI e Elisa) não identificaram positividade no animal (Koehler et al., 2002). Em uma região endêmica para LTA no Brasil, testes de aglutinação direta identificaram que $76 \%$ dos equinos avaliados apresentaram positividade, sendo que no mesmo grupo estudado a técnica de PCR confirmou a presença de Leishmania (Viannia) em 7\% dos animais. Somente um animal apresentou lesão característica (Vedovello Filho et al., 2008). 
Em 1987, Brazil e colaboradores (1987) identificaram a infecção em um suíno, provavelmente pela forma tegumentar da doença. Dezenove anos mais tarde, realizou-se um estudo conduzido em uma região de grande pressão endêmica na Bahia. Nesse estudo, apesar de os autores demonstrarem uma prevalência sorológica entre $27,02 \%$ e 53,38\% em uma população de suínos, não conseguiram comprovar o parasitismo nesses animais através da cultura parasitológica e da técnica de PCR em amostras de pele e baço (Moraes-Silva et al., 2006).

A raridade dos achados descritos demonstra que a participação desses animais no ciclo de transmissão dessas doenças pode ser irrelevante, o que não justifica o acompanhamento rotineiro para o controle das leishmanioses.

\section{PERSPECTIVAS E CONCLUSÕES}

Desde a descrição do gênero Leishmania em 1903, por Ross, obtiveram-se inúmeros avanços em diferentes aspectos. No entanto, considerando o cenário atual das leishmanioses, constata-se que a doença continua se expandindo para novos focos, cujo controle ainda se constitui um grande desafio para os órgãos responsáveis. Sem dúvida, as modificações ambientais interferiram nos diferentes elos que compõem a cadeia de transmissão. Nesse contexto, os animais domésticos, sobretudo os cães, têm sido um importante elemento de preocupação. Na LV, apesar de bem sedimentada a participação do cão como reservatório, busca-se justificar com segurança a prática da eutanásia como uma das medidas de controle. Já na LT, tenta-se estabelecer qual é a real importância desse animal no ciclo de transmissão. Adicionalmente, as ferramentas aplicadas atualmente nos inquéritos caninos têm valor limitado, uma vez que em áreas de sobreposição de LT e LV não permitem a discriminação dos casos de LVC e LTC, devendo considerar que para a LTC não há indicação de eutanásia. Lacunas no conhecimento, relacionadas ao papel de outros animais domésticos, ainda persistem. Especialmente em relação aos gatos domésticos, apesar de os relatos serem esporádicos, a vigilância e a notificação dos casos torna-se essencial, já que ocorrem por diferentes espécies de Leishmania e em várias regiões do mundo.

Ainda nesse contexto, não podemos deixar de mencionar a descrição de T. caninum, um novo parasito que possivelmente está circulando entre cães domésticos, fato que poderá se tornar fator de confusão no diagnóstico desses animais quando avaliados pela sorologia, visto que ferramentas sorológicas não contam com poder discriminatório entre os diferentes membros da família Trypanosomatidae. Pouco se sabe ainda sobre essa nova espécie e estudos são necessários, sobretudo no tocante aos aspectos biológicos e epidemiológicos que envolvem esse parasito, sendo um dos grandes desafios o conhecimento da prevalência na infecção canina e no impacto que poderá causar em áreas onde as leishmanioses caninas ocorrem.

Ao fim desta exposição, evidencia-se cada vez mais a relevância da utilização de métodos diagnósticos que sejam capazes de confirmar e discriminar com segurança a infecção nos animais suspeitos, sobretudo no que diz respeito à aplicação de métodos que objetivem a correta identificação dos agentes etiológicos que possam estar circulando particularmente nos animais domésticos. O conhecimento das áreas acometidas pelas leishmanioses, assim como o conhecimento da presença de outros tripanossomatídeos nessas áreas, são fundamentais para que específicas ações de controle sejam desencadeadas.

\section{REFERÊNCIAS}

AGUILAR, C. M. \& RANGEL, E. F. Cutaneous leishmaniasis in a mule (Equus caballus x Equus asinus) in an endemic area of the State of Rio de Janeiro. Memórias do Instituto Oswaldo Cruz, 81(2): 239-240, 1986.

ALMEIDA, M. A. et al. Clinical and serological aspects of visceral leishmaniasis in northeast Brazilian dogs naturally infected with Leishmania chagasi. Veterinary Parasitology, 127(3-4): 227-232, 2005. 
ALVAR, J. et al. Canine leishmaniasis. Advances in Parasitology, 57: 1-88, 2004.

ARAGÃO, H. B. Leishmaniose tegumentar e sua transmissão pelos phlebotomos. Memórias do Instituto Oswaldo Cruz, 20: 177-186, 1927.

ARAÚJO FILHO, N. A. \& COURA, J. R. Leishmaniose tegumentar americana na Ilha Grande, Rio de Janeiro. IV. Reservatórios domésticos. Revista da Sociedade Brasileira de Medicina Tropical, 15: 82-103, 1978.

ASHFORD, D. A. et al. Comparison of the polymerase chain reaction and serology for the detection of canine visceral leishmaniasis. The American Journal of Tropical Medicine and Hygiene, 53(3): 251-255, 1995.

ASHFORD, D. A. et al. Studies on control of visceral leishmaniasis: impact of dog control on canine and human visceral leishmaniasis in Jacobina, Bahia, Brazil. The American Journal of Tropical Medicine and Hygiene, 59(1): 53-57, 1998.

BARBOSA-SANTOS, E. G. et al. Leishmaniasis disseminated by Leishmania braziliensis in a mare (Equus cabalus) immunotherapy and chemotherapy assays. Memórias do Instituto Oswaldo Cruz, 89(2): 217-220, 1994.

BARNES, J. C.; STANLEY, O. \& CRAIG, T. M. Diffuse cutaneous leishmaniasis in a cat. Journal of the American Veterinary Medical Association, 202(3): 416-418, 1993.

BARROUIN-MELO, S. M. et al. Comparison between splenic and lymph node aspirations as sampling methods for the parasitological detection of Leishmania chagasi infection in dogs. Memórias do Instituto Oswaldo Cruz, 99(2): 195-197, 2004.

BONFANTE-GARRIDO, R. et al. Natural infection of cats with Leishmania in Barquisimeto, Venezuela. Transactions of the Royal Society of Tropical Medicine and Hygiene, 85(1): 53, 1991.

BRASIL. Ministério da Saúde. Manual de Vigilância e Controle da Leishmaniose Visceral. Brasília: Ministério da Saúde, 2006.

BRASIL. Ministério da Saúde. Manual de Controle da Leishmaniose Tegumentar Americana. Brasília: Ministério da Saúde, Fundação Nacional de Saúde, 2010.

BRAZIL, R. P. et al. Natural infection of a pig (Sus scrofa) by Leishmania in a recent focus of cutaneous leishmaniasis on the Island of Sao Luis, Maranhao. Memórias do Instituto Oswaldo Cruz, 82(1): 145, 1987.

CABALLERO, Z. C. et al. Evaluation of serological tests to identify Trypanosoma cruzi infection in humans and determine crossreactivity with Trypanosoma rangeli and Leishmania spp. Clinical and Vaccine Immunology, 14(8): 1.045-1.049, 2007.

CIARAMELLA, P. et al. A retrospective clinical study of canine leishmaniasis in 150 dogs naturally infected by Leishmania infantum. The Veterinary Record, 141(21): 539-543, 1997.

COLMENARES, M. et al. Mechanisms of pathogenesis: differences amongst Leishmania species. Transactions of the Royal Society of Tropical Medicine and Hygiene, 96, supl. 1: S3-S7, 2002.

COSTA-DURÃo, J. F. et al. Primeiro caso de leishmaniose em gato doméstico (Felis catus domesticus) detectado em Portugual (Conselho de Sesimbra). Revista Portuguesa de Ciências Veterinárias, 89: 140-144, 1994.

COUTINHO, M. T. \& LINARDI, P. M. Can fleas from dogs infected with canine visceral leishmaniasis transfer the infection to other mammals? Veterinary Parasitology, 147(3-4): 320-325, 2007.

CoUTinHo, M. T. et al. Participation of Rhipicephalus sanguineus (Acari: Ixodidae) in the epidemiology of canine visceral leishmaniasis. Veterinary Parasitology, 128(1-2): 149-155, 2005.

COUTINHO, S. G. et al. A survey for American cutaneous and visceral leishmaniasis among 1,342 dogs from areas in Rio de Janeiro (Brazil) where the human diseases occur. Memórias do Instituto Oswaldo Cruz, 80(1): 17-22, 1985.

CRAIG, T. M. et al. Dermal leishmaniasis in a Texas cat. The American Journal of Tropical Medicine and Hygiene, 35(6): 1.100$1.102,1986$.

CUPOLILLO, E.; GRIMALDI JR., G. \& MOMEN, H. Genetic diversity among Leishmania (Viannia) parasites. Annals of Tropical Medicine and Parasitology, 91(6): 617-626, 1997.

DANTAS-TORRES, F. The role of dogs as reservoirs of Leishmania parasites, with emphasis on Leishmania (Leishmania) infantum and Leishmania (Viannia) braziliensis. Veterinary Parasitology, 149(3-4): 139-146, 2007. 
DANTAS-TORRES, F. Canine leishmaniosis in South America. Parasites and Vectors, 2: 1-8, 2009.

DANTAS-TORRES, F.; BRITO, M. E. \& BRANDÃO-FILHO, S. P. Seroepidemiological survey on canine leishmaniasis among dogs from an urban area of Brazil. Veterinary Parasitology, 140(1-2): 54-60, 2006.

DANTAS-TORRES, F. et al. Leishmaniose Felina: revisão de literatura. Clínica Veterinária, 61: 32-40, 2006.

DANTAS-TORRES, F. et al. Cutaneous and visceral leishmaniasis in dogs from a rural community in northeastern Brazil. Veterinary Parasitology, 170(3-4): 313-317, 2010.

DEANE, L. M. \& DEANE, M. P. Encontro de leishmânias nas vísceras e na pele de uma raposa, em zona endêmica de calazar, nos arredores de Sobral, Ceará. O Hospital, 45: 419-421, 1954.

DE SOUZA, A. I. et al. Feline leishmaniasis due to Leishmania (Leishmania) amazonensis in Mato Grosso do Sul State, Brazil. Veterinary Parasitology, 128(1-2): 41-45, 2005.

DIETZE, R. et al. Effect of eliminating seropositive canines on the transmission of visceral leishmaniasis in Brazil. Clinical Infectious Diseases, 25(5): 1.240-1.242, 1997.

EVANS, T. G. et al. Epidemiology of visceral leishmaniasis in northeast Brazil. The Journal of Infectious Diseases, 166(5): 1.124-1.132, 1992.

FALQUETO, A. et al. Participation of the dog in the cycle of transmission of cutaneous leishmaniasis in the municipality of Viana, State of Espírito Santo, Brazil. Memórias do Instituto Oswaldo Cruz, 81(2): 155-163, 1986.

FIGUEIREDO, F. B. et al. Leishmaniose tegumentar americana em felino doméstico no município do Rio de Janeiro, Brasil relato de caso. Clínica Veterinária, 74, ano XIII, 2008.

FIGUEIREDO, F. B. et al. Efficacy of an indirect immunofluorescence test in the diagnosis of canine leishmaniosis. The Veterinary Journal, 186(1): 123-124, 2010.

FIGUEIREDO, F. B. et al. Serological evaluation for detection of anti-Leishmania antibodies in dogs and cats in the district of Santa Rita de Cassia, municipality of Barra Mansa, State of Rio de Janeiro. Revista da Sociedade Brasileira de Medicina Tropical, 42(2): 141-145, 2009.

FREITAS, E. et al. Transmission of Leishmania infantum via blood transfusion in dogs: potential for infection and importance of clinical factors. Veterinary Parasitology, 137(1-2): 159-167, 2006.

GALLEGO, M. Emerging parasitic zoonoses: leishmaniosis. Revue Scientifique et Technique, 23(2): 661-676, 2004.

GIUNCHETTI, R. C. et al. Relationship between canine visceral leishmaniosis and the Leishmania (Leishmania) chagasi burden in dermal inflammatory foci. Journal of Comparative Pathology, 135(2-3): 100-107, 2006.

GREVOT, A. et al. Leishmaniosis due to Leishmania infantum in a FIV and FelV positive cat with a squamous cell carcinoma diagnosed with histological, serological and isoenzymatic methods. Parasite, 12(3): 271-275, 2005.

HERRER, A. \& CHRISTENSEN, H. A. Natural cutaneous leishmaniasis among dogs in Panama. The American Journal of Tropical Medicine and Hygiene, 25(1): 59-63, 1976.

HERVAS, J. et al. Granulomatous (pseudotumoral) iridociclitis associated with leishmaniasis in a cat. The Veterinary Record, 149(20): 624-625, 2001.

ISHIKAWA, E. A. Y. et al. Genetic variation in populations of Leishmania species in Brazil. Transactions of the Royal Society of Tropical Medicine and Hygiene, 96, supl. 1: 111-121, 2002.

KAWA, H. \& SABROZA, P. C. Spatial distribution of tegumentary leishmaniasis in the city of Rio de Janeiro. Cadernos de Saúde Pública, 18(3): 853-865, 2002.

KILLICK-KENDRICK, R. et al. Protection of dogs from bites of phlebotomine sandflies by deltamethrin collars for control of canine leishmaniasis. Medical and Veterinary Entomology, 11(2): 105-111, 1997.

KIRKPATRICK, C. E.; FARRELL, J. P. \& GOLDSCHMIDT, M. H. Leishmania chagasi and L. donovani: experimental infections in domestic cats. Experimental Parasitology, 58(2): 125-131, 1984. 
KOEHLER, K. et al. Cutaneous leishmaniosis in a horse in southern Germany caused by Leishmania infantum. Veterinary Parasitology, 109(1-2): 9-17, 2002.

KUHN, K. G. Global warming and leishmaniasis in Italy. Bulletin of Tropical Medicine and International Health, 7: 1-2, 1999.

LACHAUD, L. et al. Value of two PCR methods for the diagnosis of canine visceral leishmaniasis and the detection of asymptomatic carriers. Parasitology, 125: 197-207, 2002.

LAINSON, R. \& RANGEL, E. F. Lutzomyia longipalpis and the eco-epidemiology of American visceral leishmaniasis, with particular reference to Brazil: a review. Memórias do Instituto Oswaldo Cruz, 100(8): 811-827, 2005.

LIMA, W. G. et al. Canine visceral leishmaniasis: a histopathological study of lymph nodes. Acta Tropica, 92 (1): 43-53, 2004.

MACHATTIE, C.; MILLS, E. A. \& CHADWICK, C. R. Naturally occurring oriental sore of the domestic cat in Iraq. Transactions of the Royal Society of Tropical Medicine and Hygiene, XXV: 103-107, 1931.

MADEIRA, M. F. et al. Leishmania (Viannia) braziliensis in naturally infected dogs. Revista da Sociedade Brasileira de Medicina Tropical, 36(5): 551-555, 2003a.

MADEIRA, M. F. et al. Co-infecção natural por Leishmania (Viannia) braziliensis e Trypanosoma sp. em cão doméstico. Revista da Sociedade Brasileira de Medicina Tropical, 37(1): 217, 2003b.

MADEIRA, M. F. et al. Is Leishmania (Viannia) braziliensis preferentially restricted to the cutaneous lesions of naturally infected dogs? Parasitology Research, 97(1): 73-76, 2005.

MADEIRA, M. F. et al. Mixed infection with Leishmania (Viannia) braziliensis and Leishmania (Leishmania) chagasi in a naturally infected dog from Rio de Janeiro, Brazil. Transactions of the Royal Society of Tropical Medicine and Hygiene, 100(5): 442-445, 2006a.

MADEIRA, M. F. et al. Post mortem parasitological evaluation of dogs seroreactive for Leishmania from Rio de Janeiro, Brazil. Veterinary Parasitology, 138(3-4): 366-370, 2006b.

MADEIRA, M. F. et al. Parasitological diagnosis of canine visceral leishmaniasis: is intact skin a good target? Research in Veterinary Science, 87(2): 260-262, 2009a.

MADEIRA, M. F. et al. Trypanosoma caninum n. sp. (Protozoa: Kinetoplastida) isolated from intact skin of a domestic dog (Canis familiaris) captured in Rio de Janeiro, Brazil. Parasitology, 136(4): 411-423, $2009 \mathrm{~b}$.

MARZOCHI, M. C. \& BARBOSA-SANTOS, E. G. Evaluation of a skin test on the canine mucocutaneous leishmaniasis diagnosis. Memórias do Instituto Oswaldo Cruz, 83(3): 391-392, 1988.

MARZOCHI, M. C. A. \& MARZOCHI, K. B. F. Tegumentary and visceral leishmaniasis in Brazil: emerging anthropozoonosis and possibilities for their control. Cadernos de Saúde Pública, 10(2): 359-375, 1994.

MARZOCHI, M. C. A. et al. Leishmaniose visceral na cidade do Rio de Janeiro - Brasil. Cadernos de Saúde Pública, 1(1): 5-17, $1985 \mathrm{a}$.

MARZOCHI, M. C. et al. Canine visceral leishmaniasis in Rio de Janeiro, Brazil. Clinical, parasitological, therapeutical and epidemiological findings (1977-1983). Memórias do Instituto Oswaldo Cruz, 80(3): 349-357, 1985b.

MARZOCHI, M. C. et al. Visceral leishmaniasis in Rio de Janeiro, Brazil: eco-epidemiological aspects and control. Revista da Sociedade Brasileira de Medicina Tropical, 42(5): 570-580, 2009.

MOMEM, H. \& GRIMALDI, J. G. Enzyme Electrophoretic Evidence for the Importation of L. infantum into the New World. New York: Plenum, 1989.

MONTENEGRo, J. A cutis reacção na leishmaniose. Annais da Faculdade de Medicina da Universidade de São Paulo, 1: 323 330, 1926.

MORAES-SILVA, E. et al. Domestic swine in a visceral leishmaniasis endemic area produce antibodies against multiple Leishmania infantum antigens but apparently resist to L. infantum infection. Acta Tropica, 98(2): 176-182, 2006.

OZON, C. et al. Disseminated feline leishmaniosis due to Leishmania infantum in Southern France. Veterinary Parasitology, 75(2-3): 273-277, 1998. 
PACHECO, R. S. et al. Genotypic polymorphisms in experimental metastatic dermal leishmaniasis. Molecular and Biochemical Parasitology, 69(2): 197-209, 1995.

PALATNIK-DE-SOUSA, C. B. et al. Impact of canine control on the epidemiology of canine and human visceral leishmaniasis in Brazil. The American Journal of Tropical Medicine and Hygiene, 65(5): 510-517, 2001.

PANGRAZIO, K. K. et al. Tissue distribution of Leishmania chagasi and lesions in transplacentally infected fetuses from symptomatic and asymptomatic naturally infected bitches. Veterinary Parasitology, 165(3-4): 327-331, 2009.

PARANHOS-SILVA, M. et al. A cross-sectional serodiagnostic survey of canine leishmaniasis due to Leishmania chagasi. The American Journal of Tropical Medicine and Hygiene, 55(1): 39-44, 1996.

PARANHOS-SILVA, M. et al. Cohort study on canine emigration and Leishmania infection in an endemic area for American visceral leishmaniasis. Implications for the disease control. Acta Tropica, 69(1): 75-83, 1998.

PASSOS, V. M. et al. Natural infection of a domestic cat (Felis domesticus) with Leishmania Viannia) in the metropolitan region of Belo Horizonte, State of Minas Gerais, Brazil. Memórias do Instituto Oswaldo Cruz, 91(1): 19-20, 1996.

PAULA, C. C. et al. Canine visceral leishmaniasis in Marica, State of Rio de Janeiro: first report of an autochthonous case. Revista da Sociedade Brasileira de Medicina Tropical, 42(1): 77-78, 2009.

PEDroso, A. M. Leishmaniose local do cão. Annais Paulistas de Medicina e Cirurgia, 1: 33-34, 1913.

PINTO, A. G. S. et al. Isolation of Trypanosoma caninum in domestic dogs in Rio de Janeiro. Brazil. Parasitology, 26: 1-8, 2010.

PIRMEZ, C.; MARZOCHI, M. C. \& COUTINHO, S. G. Experimental canine mucocutaneous leishmaniasis (Leishmania braziliensis braziliensis). Memórias do Instituto Oswaldo Cruz, 83(2): 145-151, 1988.

PIRMEZ, C. et al. Canine American cutaneous leishmaniasis: a clinical and immunological study in dogs naturally infected with Leishmania braziliensis braziliensis in an endemic area of Rio de Janeiro, Brazil. The American Journal of Tropical Medicine and Hygiene, 38(1): 52-58, 1988.

POLI, A. et al. Feline leishmaniosis due to Leishmania infantum in Italy. Veterinary Parasitology, 106(3): 181-191, 2002.

REIS, A. B. et al. Parasite density and impaired biochemical/hematological status are associated with severe clinical aspects of canine visceral leishmaniasis. Research in Veterinary Science, 81(1): 68-75, 2006.

REITHINGER, R. \& DAVIES, C. R. Is the domestic dog (Canis familiaris) a reservoir host of American cutaneous leishmaniasis? A critical review of the current evidence. The American Journal of Tropical Medicine and Hygiene, 61(4): 530-541, 1999.

REITHINGER, R. \& DAVIES, C. R. American cutaneous leishmaniasis in domestic dogs: an example of the use of the polymerase chain reaction for mass screening in epidemiological studies. Transactions of the Royal Society of Tropical Medicine and Hygiene, 96, supl. 1: S123-S126, 2002.

REITHINGER, R. \& DUJARDIN, J. C. Molecular diagnosis of leishmaniasis: current status and future applications. Journal of Clinical Microbiology, 45(1): 21-25, 2007.

REITHINGER, R. et al. Use of PCR to detect Leishmania (Viannia) spp. in dog blood and bone marrow. Journal of Clinical Microbiology, 38(2): 748-751, 2000.

REITHINGER, R. et al. Evaluation of PCR as a diagnostic mass-screening tool to detect Leishmania (Viannia) spp. in domestic dogs (Canis familiaris). Journal of Clinical Microbiology, 41(4): 1.486-1.493, 2003.

RIDLEY, D. S. \& RIDLEY, M. J. The evolution of the lesion in cutaneous leishmaniasis. The Journal of Pathology, 141(1): 83-96, 1983.

ROLAO, N. et al. Equine infection with Leishmania in Portugal. Parasite, 12(2): 183-186, 2005.

SALDANA, A. \& SOUSA, O. E. Trypanosoma rangeli and Trypanosoma cruzi: cross-reaction among their immunogenic components. Memórias do Instituto Oswaldo Cruz, 91(1): 81-82, 1996.

SANTOS, E. G. et al. Epidemiological survey on canine population with the use of immunoleish skin test in endemic areas of human American cutaneous leishmaniasis in the state of Rio de Janeiro, Brazil. Revista do Instituto de Medicina Tropical de São Paulo, 40(1): 41-47, 1998. 
SANTOS, I. B. et al. Sporotrichosis: the main differential diagnosis with tegumentary leishmaniosis in dogs from Rio de Janeiro, Brazil. Veterinary Parasitology, 143(1): 1-6, 2007.

SARIDOMICHELAKIS, M. N. Advances in the pathogenesis of canine leishmaniosis: epidemiologic and diagnostic implications. Veterinary Dermatology, 20(5-6): 471-489, 2009.

SARIDOMICHELAKIS, M. N. et al. Regional parasite density in the skin of dogs with symptomatic canine leishmaniosis. Veterinary Dermatology, 18(4): 227-233, 2007.

SAVANI, E. S. et al. Occurrence of co-infection by Leishmania (Leishmania) chagasi and Trypanosoma (Trypanozoon) evansi in a dog in the state of Mato Grosso do Sul, Brazil. Memórias do Instituto Oswaldo Cruz, 100(7): 739-741, 2005.

SAVANI, E. S. et al. The first record in the Americas of an autochthonous case of Leishmania (Leishmania) infantum chagasi in a domestic cat (Felix catuS) from Cotia County, Sao Paulo State, Brazil. Veterinary Parasitology, 120(3): 229-233, 2004.

SCHUBACH, T. M. et al. American cutaneous leishmaniasis in two cats from Rio de Janeiro, Brazil: first report of natural infection with Leishmania Viannia) braziliensis. Transactions of the Royal Society of Tropical Medicine and Hygiene, 98(3): 165-167, 2004.

SERGENT, E.; LOMBARD, J. \& QUILICHINI, M. La leishmaniose à Alger: infection simultanée d'un enfant, d'un chien et d'un chat dans la même habitation. Bulletin de la Société de Pathologie Exotique et de ses Filiales, 5: 93-98, 1912.

SERRA, C. M. et al. Canine tegumentary leishmaniasis in Morada das Águias (Serra da Tiririca), Maricá, Rio de Janeiro, Brazil. Cadernos de Saúde Pública, 19(6): 1.877-1.880, 2003.

SHAW, J. The leishmaniases-survival and expansion in a changing world. A mini-review. Memórias do Instituto Oswaldo Cruz, 102(5): 541-547, 2007.

SILVA, E. S. et al. Visceral leishmaniasis in the Metropolitan Region of Belo Horizonte, State of Minas Gerais, Brazil. Memórias do Instituto Oswaldo Cruz, 96(3): 285-291, 2001.

SILVA, F. L. et al. Venereal transmission of canine visceral leishmaniasis. Veterinary Parasitology, 160(1-2): 55-59, 2009.

SILVA, V. O. et al. A phase III trial of efficacy of the FML-vaccine against canine kala-azar in an endemic area of Brazil (Sao Gonçalo do Amaranto, RN). Vaccine, 19(9-10): 1.082-1.092, 2000.

SILVEIRA, F. T. et al. Sensitivity of the culture of circulating leukocytes in the detection of Leishmania in the peripheral blood of patients with tegumentary leishmaniasis. Revista da Sociedade Brasileira de Medicina Tropical, 22(3): 143-146, 1989.

SIMOES-MATTOS, L. et al. The susceptibility of domestic cats (Felis catus) to experimental infection with Leishmania braziliensis. Veterinary Parasitology, 127(3-4): 199-208, 2005.

SLAPPENDEL, R. J. \& TESKE, E. The effect of intravenous or subcutaneous administration of meglumine antimonate (Glucantime) in dogs with leishmaniasis. A randomized clinical trial. The Veterinary Quarterly, 19(1): 10-13, 1997.

SOLANO-GALLEGO, L. et al. Histological and immunohistochemical study of clinically normal skin of Leishmania infantuminfected dogs. Journal of Comparative Pathology, 130(1): 7-12, 2004.

SOLANO-GALLEGO, L. et al. Directions for the diagnosis, clinical staging, treatment and prevention of canine leishmaniosis. Veterinary Parasitology, 165(1-2): 1-18, 2009.

SOUZA, G. D.; SANTOS, E. \& ANDRADE FILHO, J. D. The first report of the main vector of visceral leishmaniasis in America, Lutzomyia longipalpis (Lutz \& Neiva) (Diptera: Psychodidae: Phlebotominae), in the state of Rio Grande do Sul, Brazil. Memórias do Instituto Oswaldo Cruz, 104(8): 1.181-1.182, 2009.

TAFURI, W. L.; OLIVEIRA, M. R. \& MELO, M. N. Canine visceral leishmaniosis: a remarkable histopathological picture of one case reported from Brazil. Veterinary Parasitology, 96(3): 203-212, 2001.

TRAVI, B. L. et al. Canine visceral leishmaniasis in Colombia: relationship between clinical and parasitologic status and infectivity for sand flies. The American Journal of Tropical Medicine and Hygiene, 64(3-4): 119-124, 2001.

VEDOVELLO FILHO, D. et al. American cutaneous leishmaniasis in horses from endemic areas in the north-central mesoregion of Parana state, Brazil. Zoon Public Health, 55(3): 149-155, 2008. 
VEXENAT, J. A. et al. Infecção natural de Equus asinus por Leishmania braziliensis braziliensis - Bahia, Brasil. Memórias do Instituto Oswaldo Cruz, 8(2): 237-238, 1986.

VINUELAS, J. et al. Meningeal leishmaniosis induced by Leishmania infantum in naturally infected dogs. Veterinary Parasitology, 101(1): 23-27, 2001.

WORLD HEALTH ORGANIZATION (WHO). Control of Leishmaniases. Technical Report Series 793. Geneva, 2008.

YOSHIDA, E. L. et al. Human, canine and equine (Equus caballus) leishmaniasis due to Leishmania braziliensis (= L. braziliensis braziliensis) in the south-west region of Sao Paulo State, Brazil. Memórias do Instituto Oswaldo Cruz, 85(1): 133-134, 1990. 
parte V

Modelos Experimentais no

Estudo das Leishmanioses do

Continente Americano 


\title{
Modelos Experimentais na Leishmaniose Visceral
}

\author{
Renato Porrozzi I Amanda dos Santos Cavalcanti I Elisa Cupolillo
}

\begin{abstract}
A leishmaniose visceral (LV) é uma doença que acomete o homem e outros animais e está associada à infecção por - Leishmania (Leishmania) donovani ou Leishmania (Leishmania) infantum (sin. L. chagasi), que é normalmente fatal se não tratada. Embora a sinonímia de L. chagasi em relação a L. infantum já seja bastante aceita, neste capítulo utilizaremos os dois nomes, mantendo a nomenclatura utilizada na fonte bibliográfica. Essas espécies de Leishmania acometem os tecidos componentes do sistema fagocítico mononuclear (SFM), principalmente baço, fígado e medula óssea. Clinicamente a leishmaniose visceral humana (LVH), também chamada de calazar, caracteriza-se por abdômen protuso, principalmente associado à hepatoesplenomegalia, febre prolongada, perda de peso, anemia progressiva, leucopenia e hipergamaglobulinemia. Até o momento não existe vacina disponível contra LV, sendo as drogas mais comumente utilizadas no tratamento os antimoniais pentavalentes (Glucantime ${ }^{\circledR}$, Pentostam ${ }^{\circledR}$ ), a anfotericina B, a pentamidina e a miltefosina. Entretanto, tais drogas estão associadas ao desenvolvimento de resistência e toxicidade (Croft \& Engel, 2006). Mais recentemente, a coinfecção Leishmania-vírus da imunodeficiência adquirida (HIV) tornou-se um importante fator em que pacientes soropositivos são mais suscetíveis ao parasito (Del-Giudice et al., 2002).
\end{abstract}

Infecções experimentais em voluntários humanos, com cepas do parasito que causam leishmaniose visceral utilizando amastigotas obtidas de tecido animal ou promastigotas de cultura, não foram bem-sucedidas. A primeira tentativa eficaz de infecção experimental em seres humanos ocorreu em pacientes com doenças incuráveis inoculados com altas doses infectantes de $L$. donovani via intramuscular, na qual foi possível isolar parasitos do sangue seis meses após a infecção. Entretanto, os pacientes nunca apresentaram nenhum sinal típico de calazar, provavelmente em razão de particularidades na suscetibilidade dos seres humanos envolvidos, como doenças concomitantes, malnutrição etc. (Melby, 1991). A infecção experimental de seres humanos pode contribuir significativamente para o avanço dos conhecimentos sobre a imunopatogênese da infecção por Leishmania, porém, aspectos éticos limitam esse tipo de estudo.

\section{MODELOS DE ANIMAIS EXPERIMENTAIS PARA A LEISHMANIOSE VISCERAL}

Grande parte dos conhecimentos sobre a imunopatologia do hospedeiro durante a LV vem de estudos realizados em modelos experimentais utilizando animais, principalmente pela necessidade de procedimentos invasivos para a 
obtenção de tecidos infectados. A maioria dos conhecimentos foi gerada tendo por base quatro modelos animais. De acordo com dados pesquisados na base de dados PubMed, quando da elaboração deste capítulo, nos últimos dez anos os camundongos foram os animais mais utilizados, tendo sido citados em 60,56\% dos artigos publicados, seguidos por hamsters $(25,23 \%)$, cães $(20,18 \%)$ e primatas não humanos (3,3\%). Outras espécies animais, como asininos (Cerqueira et al., 2003) e suínos (Moraes-Silva et al., 2006), já foram utilizadas em infecções experimentais por Leishmania spp., mas não foram capazes de reproduzir a infecção, sendo descartado seu uso como modelo experimental.

Diversos fatores influenciam na suscetibilidade das diferentes espécies animais às leishmânias viscerotrópicas, entre os quais estão via e quantidade do inóculo, cepas do parasito e fatores genéticos do hospedeiro.

\section{Hamster}

o hamster dourado da Síria (Mesocricetus auratus) é altamente suscetível às leishmânias viscerotrópicas, representando um dos modelos mais antigos de estudo da leishmaniose visceral. A infecção, em geral, leva à doença e morte do animal (Melby et al., 2001), sendo útil para a caracterização de moléculas e de mecanismos envolvidos na patogênese. Esses animais, quando infectados com L. donovani, apresentam patologia semelhante à observada em humanos, quase mimetizando o calazar (Duarte \& Corbett, 1984; Sartori et al., 1992). Além disso, a infecção reproduz dois eventos da LVH: a supressão da resposta Th1 específica na fase ativa da infecção (Bunn-Moreno et al., 1985; Nickol \& Bonventre, 1985a) e a ativação policlonal dos linfócitos B (Bunn-Moreno et al., 1985; Campos-Neto \& BunnMoreno, 1982). No fígado dos hamsters há hiperplasia e parasitismo de células de Kupffer, assim como granulomas com macrófagos parasitados nos espaços portais (Duarte \& Corbett, 1984). No entanto, poucas linhagens isogênicas de hamster podem ser obtidas comercialmente, limitando as manipulações experimentais. Outro fator limitante é a disponibilidade comercial reduzida de reagentes imunológicos, o que restringe os estudos dessa natureza.

Considerando a alta parasitemia apresentada por hamsters experimentalmente infectados, eles podem ser utilizados para o repasto sanguíneo de flebótomos em testes de eficiência vetorial (Montoya-Lerma et al., 2003). Usualmente, esse modelo é também utilizado para a manutenção de cepas de Leishmania spp. ou para passagens seriadas visando à manutenção da virulência dos parasitos (Shukina \& Gorbunova, 1987).

Hamsters infectados com leishmânias viscerotrópicas desenvolvem uma doença progressiva, com hepatoesplenomegalia, hipoalbuminemia, hipergamaglobulinemia, pancitopenia (Goto \& Lindoso, 2004), diminuição da proliferação linfocitária e glomerulonefrite, bem como alterações morfológicas nos hepatócitos (Vianna, Takiya \& Brito-Gitirana, 2002), embora já tenha sido relatado pleomorfismo clínico (Requena et al., 2000).

Infecções experimentais em hamsters demonstram ausência de resposta linfoproliferativa diante da indução com antígenos de Leishmania (Rodrigues, Silva \& Campos-Neto, 1992). De acordo com Goto e Lindoso (2004), o melhor modelo para estudar a supressão da células T aos antígenos de Leishmania é o hamster infectado com L. donovani ou $L$. chagasi que desenvolve a doença progressiva. O estudo dos mecanismos imunossupressores indica causas multifatoriais como, por exemplo, a apoptose seletiva de populações de linfócitos na fase inicial da infecção ou a produção de citocinas supressoras pelas células apresentadoras de antígeno (Goto, 2004).

Os estudos indicam que tanto formas promastigotas como amastigotas causam infeção progressiva, entretanto o desenvolvimento da sintomatologia clínica ocorre mais precocemente com o uso de formas amastigotas (Riça-Capela et al., 2003). As vias de inoculação mais comumente utilizadas são a intraperitoneal (IP) e a intracardíaca (IC), com a infecção ocorrendo mais rapidamente na segunda. Wyllie e Fairlamb (2006) realizaram estudo sobre o refinamento do uso desse modelo para a infecção experimental por L. donovani. Constataram, com isso, que a via IP é tão eficiente em promover a infecção quanto a IC, uma vez que a via IC requer habilidade do pesquisador e é extremamente perigosa para o animal, podendo causar parada cardíaca, tamponamento cardíaco e hemorragia. 
A ascite é um achado comum em ambas as vias de inoculação (Riça-Capela et al., 2003; Wyllie \& Fairlamb, 2006), podendo afetar 50\% dos animais 24 semanas após a infecção. Interessantemente, fêmeas lactantes não devem ser utilizadas, pois embora haja soroconversão, são resistentes à infecção, não apresentando carga parasitária nem sintomatologia clínica (Gomez-Ochoa et al., 2003). Doses maiores ou iguais a $10^{5}$ promastigotas/animal reduzem o tempo de aparecimento dos sintomas, quando comparadas às doses de $10^{4}$ ou $10^{3}$ promastigotas (Requena et al., 2000), indicando que a dose infectante influencia no período pré-patente.

Não há uma maneira clara para monitorar a progressão da LV em hamsters até fases avançadas da infecção, quando o sinal mais notável é a significativa perda de peso. Em geral é utilizada como ponto de corte a perda de peso corporal maior que $25 \%$ (Requena et al., 2000), e a maioria dos trabalhos considera apenas o tempo da infecção. Contudo, já se demonstrou que a carga parasitária tissular de animais com perda de $10 \%$ do peso inicial não difere daquela de animais com $25 \%$ de perda. Dessa forma, recomenda-se que a perda de $10 \%$ do peso inicial do animal seja considerada como ponto final do experimento, o que evita não apenas a morte do animal, permitindo seu uso para futuras pesquisas de desenvolvimento de drogas, como também seu sofrimento exacerbado (Wyllie \& Fairlamb, 2006).

Os hamsters são comumente utilizados na fase primária do desenvolvimento de vacinas e no desenvolvimento de drogas (Garg \& Dube, 2006). Como são altamente suscetíveis, nesse tipo de pesquisa altas doses de drogas podem ser requeridas. Uma vez que as características clínico-patológicas e os mecanismos imunopatológicos da LV no hamster são similares àqueles apresentados na doença humana, esses animais são um bom modelo para se estudar a forma progressiva da doença humana. No entanto, deve ser considerado que ainda não são um modelo ideal, pois muitos animais desenvolvem ascite, falha renal e síndrome nefrótica, o que é raramente observado nas doenças humana e canina (Wilson, Jeronimo \& Pearson, 2005).

\section{Camundongo}

A evolução da infecção experimental com espécies viscetrópicas de Leishmania tem sido estudada em diferentes cepas de camundongos, estando grande parte dos conhecimentos relacionada aos estudos realizados com $L$. donovani. Diferentes cepas de animais, como camundongos isogênicos (geneticamente idênticos), animais com genes nocauteados ou transgênicos e o grande repertório de reagentes imunológicos permitiram um significativo salto no conhecimento da imunopatogênese da LV. Um dos aspectos mais marcantes da infecção experimental em modelos murinos é a distinta capacidade de crescimento do parasito em diferentes órgãos.

Nesses modelos geralmente é feito o uso de altas doses ( $10^{7}$ ou mais) intravenosas (IV) ou intraperitoneais (IP) de amastigotas ou promastigotas (Leclercq et al., 1996; Rolão, Melo \& Campino, 2004; Wilson \& Weinstock, 1996). Um estudo sobre a influência da via de inoculação mostrou que tanto a via IV quanto a IP são capazes de produzir infecções progressivas em camundongos BALB/c infectados com L. infantum. Entretanto, apesar de ocorrer maior dispersão de parasitos nos tecidos pela via IV, a via IP resulta em maior homogeneidade da infecção (Rolão, Melo \& Campino, 2004). Além disso, há dificuldade técnica de inoculação IV em animais de pequeno porte e, assim, parte dos parasitos pode ser perdida. O uso de doses de $10^{7}$ promastigotas pela via intradérmica (ID), a que melhor mimetiza a infecção natural, parece promissor e a resposta observada assemelha-se àquela obtida com baixas doses $\left(10^{4}\right)$ pela via intravenosa. A inoculação ID de promastigotas de L. infantum em camundongos BALB/c estabelece infecção crônica que se assemelha àquela observada nas infecções subclínicas da LV humana e canina. Contudo, utilizando a via ID, a doença e a resposta imune subsequentes aparecem mais tardiamente quando em comparação com a observada na IV com altas doses de parasitos (Ahmed et al., 2003). Fatores como a dose e a via do inóculo podem influenciar a progressão da doença, bem como a intensidade da resposta imunológica, devendo por isso serem levados em consideração no desenho experimental, principalmente em testes de vacinas. 
Fatores genéticos influenciam a resistência ou a suscetibilidade à infecção de camundongos por espécies viscerotrópicas. Dessa forma, o sucesso da infecção experimental depende da linhagem do camundongo (Pereira \& Alves, 2008). Estudos mostraram que algumas linhagens de camundongos são resistentes à infecção por $L$. donovani como o C3H e o C57BL/6, enquanto outras como B10.D2, C57BL/10 e BALB/c são suscetíveis (Wilson \& Streit, 1996; Blackwell \& Plant, 1986; Nickol \& Bonventre, 1985b). Nos camundongos BALB/c, é interessante observar que inicialmente eles se mostram suscetíveis à infecção por $L$. donovani apresentando carga parasitária variável e geralmente elevada no fígado e baço (Wilson \& Streit, 1996; Murray, 1982; Melby et al., 2001). Após algumas semanas, eles podem controlar a carga parasitária nesses órgãos mantendo uma infecção crônica (Blackwell et al., 1985; Murray, Masur \& Keithly, 1982).

O crescimento do parasito no interior de macrófagos tissulares é determinado pela bomba próton-cátion fagolisosssomal codificada pelo gene SLc11a1 (anteriormente denominado Nramp ou Lsh/Bcg/Ity) (Leclercq et al., 1996; Blackwell et al., 2001). Cepas de camundongos resistentes, como CBA, possuem o gene SLc11a1 funcional e são capazes de controlar o crescimento parasitário independentemente de mecanismos imunológicos (Blackwell \& Plant, 1986; Crocker, Blackwell \& Bradley, 1984). Cepas geneticamente suscetíveis, C57BL/6 e BALB/c, contêm uma mutação nesse gene com uma glicina no lugar de uma asparagina na posição 169. Tal mutação resulta na perda da funcionalidade, o que permite o crescimento parasitário e, consequentemente, há um aumento de cinquenta a cem vezes na carga parasitária hepática (Vidal et al., 1995). Todavia, mesmo os camundongos mutantes são capazes de conter a infecção após algumas semanas. Esse mecanismo é mediado por haplótipos do complexo principal de histocompatibilidade (Leclercq et al., 1996; Blackwell, 1983), indicando o papel crucial da resposta imune adquirida na fase tardia da infecção (Lipoldova \& Demant, 2006).

A despeito da espécie de Leishmania utilizada (L. donovani, L. infantum ou L. chagasi), ocorre no fígado uma infecção aguda e autorresolutiva, em que os parasitos se multiplicam rapidamente durante as primeiras quatro semanas e a infecção se resolve ao fim de oito semanas (Wilson \& Weinstock, 1996; Wilson et al., 1996). Embora não ocorra a eliminação total dos parasitos do fígado dos camundongos, este órgão apresenta leve dano tecidual e os animais apresentam resistência a infecções subsequentes. Possivelmente, a persistência parasitária deve mediar a imunidade duradoura observada. A resolução da infecção é mais rápida nos modelos empregando-se amastigotas de L. donovani, mas o mesmo padrão de resposta tecido específica é observado nas infecções por L. infantum (Squires et al., 1989; Squires et al., 1990; Stanley \& Engwerda, 2007). Tanto células CD4+ como CD8+ são ativadas após infecção, gerando uma resposta mista Th1/Th2 (Kaye, Curry \& Blackwell, 1991; Miralles et al., 1994).

A resolução da infecção no fígado requer um controle fino envolvendo o desenvolvimento de um infiltrado de células inflamatórias ao redor de macrófagos infectados conhecidos como granulomas, que têm sido extensivamente estudados (Stanley \& Engwerda, 2007; McElrath, Murray \& Cohn, 1988; Murray, 2001). Após a infecção de camundongos suscetíveis, com amastigotas de $L$. donovani ou L. infantum, o destino dos parasitos no fígado é a fagocitose por células de Kupffer, onde se alojam no interior de vacúolos parasitóforos e se replicam. A infecção das células de Kupffer serve como um nicho de replicação parasitária e ponto inicial para a formação do granuloma, que aos poucos se torna envolto por células imigrantes. Frequentemente é observada a fusão das células de Kupffer infectadas, formando células multinucleadas (Murray, 2001).

Todo o processo de formação do granuloma requer a produção de quimiocinas (Cotterell, Engwerda \& Kaye, 1999) para o recrutamento de monócitos, neutrófilos, linfócitos $\operatorname{CD} 4+$ e $C D 8+$, bem como a produção de citocinas inflamatórias, necessárias para a ativação das células infectadas e consequente controle do crescimento parasitário (Cervia, Rosen \& Murray, 1993; Smelt et al., 2000). Dessa forma, a redução da carga parasitária está diretamente associada à produção de citocinas pró-inflamatórias (Th1), dentre as quais destacam-se IL-2, IL-12, INFr, TNF (Squires et al., 1989; Engwerda et al., 2004; Ghalib et al., 1995; Murray et al., 1993; Murray, 1997). Citocinas Th2 também 
são essenciais na resolução da infecção hepática, atuando na indução de células CD8+, importantes na memória imunológica e proteção duradoura (Stager et al., 2003).

Por sua vez, citocinas com papel regulador como TGF $\beta$, IL-10 e IL-27 também são produzidas nos granulomas em formação e desempenham papel crítico para o balanço da imunidade protetora e para a prevenção da imunopatologia associada (Murphy et al., 2001; Wilson et al., 1998; Rosas et al., 2006). Células T matadoras naturais (NKT Cells Natural Killer T cells), com um receptor de células T invariável e restrito por CD1d (iNKT), são um subgrupo de células T com grande potencial imunorregulador, que por meio da produção de citocinas do tipo Th1 ou Th2, influenciam tanto a resposta imune inata como a adquirida. O número e o tamanho dos granulomas aumentam rapidamente nas primeiras quatro semanas de infecção. Após esse período, o número de células infectadas diminui e apenas poucas células de Kupffer ou monócitos parasitados podem ser observados.

O baço é um local de persistência parasitária onde os parasitos crescem lentamente, gerando alterações importantes tanto na arquitetura quanto na função do órgão. Interessantemente, no baço tanto citocinas do perfil Th1 quanto Th2 são produzidas durante a infecção de camundongos BALB/c com L. donovani (Melby et al., 2001). Grandes

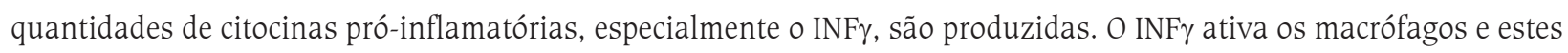
produzem a enzima óxido nítrico sintase induzida (iNOS), que catalisa a produção de óxido nítrico, um dos principais mecanismos microbicidas dos macrófagos. Entretanto, os parasitos ainda conseguem sobreviver nesse local (Mauel, Ransijn \& Buchmuller-Rouiller, 1991). O baço é um importante órgão linfoide que consiste da polpa vermelha e da polpa branca, as quais se encontram separadas por uma zona marginal. Na polpa branca, folículos de células B e áreas de células T estão dispostos ao redor de uma arteríola central. Dessa forma, o tecido esplênico mantém um íntimo contato com a circulação sanguínea, o que é extremamente importante para indução da imunidade. Nos momentos iniciais após a infecção com $L$. donovani, os parasitos infectam os macrófagos da zona marginal, sendo encontrados após uma semana nos macrófagos da polpa vermelha. Mais tardiamente, durante a infecção, a morfologia do órgão é alterada com perda de macrófagos da zona marginal, progressiva destruição das células dendríticas e perda dos centros germinativos (Gorak, Engwerda \& Kaye, 1998), o que pode estar diretamente associado à produção desregulada de anticorpos durante a leishmaniose visceral.

Embora a maioria dos eventos imunopatológicos observados durante a infecção com $L$. donovani seja similar àqueles observados na infecção com $L$. infantum, diferenças devem existir devido principalmente à expressão diferencial de moléculas relacionadas com a virulência dos parasitos. De fato, alguns autores têm relatado diferenças na suscetibilidade de isolados de L. infantum do mesmo zimodema (Baptista-Fernandes et al., 2007) ou mesmo em clones de um mesmo isolado (Garin et al., 2001).

\section{Canino}

O cão é um excelente modelo de estudo para o entendimento da LV, uma vez que reproduz vários aspectos da doença humana. O maior problema na utilização de cães como modelos experimentais é a falta de marcadores imunológicos e de reagentes específicos importantes para determinar a base da resposta imunológica protetora desses animais (Moreno \& Alvar, 2002).

O interesse em estudar o modelo experimental canino também está relacionado ao papel que esses animais desempenham no ciclo zoonótico da LV. O melhor entendimento dos mecanismos imunopatológicos durante a leishmaniose visceral canina (LVC) pode direcionar o desenvolvimento de vacinas e de medidas de controle, com implicações econômicas no sistema de saúde e na indústria farmacêutica (Goto \& Lindoso, 2004). Outro fator que reforça o valor dos estudos com cães como modelo experimental é a apresentação clínica da infecção. A infecção canina pode ser assintomática, na qual há evidências sorológicas, porém nenhuma manifestação clínica; pode evoluir 
para uma doença branda, forma oligossintomática; ou ainda, evoluir para uma doença grave, polissintomática, na qual é observada severidade nos sinais clínicos (Baneth \& Jaffe, 1999).

Os sinais clínicos da LVC como hepatoesplenomegalia, pancitopenia, hipertermia e hipergamaglobulinemia são semelhantes àqueles observados na doença humana, embora na LVH não sejam observadas com frequência lesões de pele como dermatite e úlceras cutâneas. Predominantemente, os cães assintomáticos apresentam baixo parasitismo tissular, enquanto os sintomáticos, alto parasitismo (Alves et al., 2009; Boggiatto et al., 2010; Manna et al., 2009). Os cães infectados apresentam hipergamaglobulinemia moderada a alta que aumenta com a progressão da doença, sendo observados títulos baixos nas formas oligo e assintomática (Baneth \& Jaffe, 1999), embora não seja possível relacionar os isotipos de IgG com o perfil clínico (Boggiatto et al., 2010). É também observada uma forte correlação entre o aparecimento da clínica e a perda da resposta proliferativa antígeno específica (Santos et al., 2008). A apresentação clínica da leishmaniose é consequência da interação entre o parasito e a resposta imunológica do hospedeiro (Chamizo, Moreno \& Alvar, 2005), e o resultado da infecção depende principalmente da imunocompetência do animal que, em última análise, leva o macrófago a destruir o parasito (Chamizo, Moreno \& Alvar, 2005; Ferrer, 1999; Santos-Gomes et al., 2003).

Dessa forma, a sobrevida do parasito e a evolução da infecção sofrem influência de fatores genéticos do hospedeiro. Diversos genes relacionados à suscetibilidade e resistência dos hospedeiros infectados por Leishmania já foram identificados em murinos, humanos e canídeos (Sakthianandeswaren, Foote \& Handman, 2009). Polimorfismos em certas regiões do gene Slc11a1 estão associados ao aumento do risco para LVC (Sanchez-Robert et al., 2008). Cães da raça Ibizan Hound já foram identificados como resistentes à LVC em razão da forte resposta celular (Solano-Gallego et al., 2000). Além disso, no estudo de Sanchez-Robert e colaboradores (2008) foram determinados seis haplótipos do gene Slc11a1 específicos dessa raça.

Uma vez que os animais desenvolvem alterações clínicas, patológicas e imunológicas semelhantes, os cães com LVC podem ser um bom modelo para entender a patogênese da doença humana e canina (Alves et al., 2010), e ainda para estudos que visem ao desenvolvimento de vacinas para LVC.

Infecções experimentais em cães têm sido conduzidas desde o início do século XX, quando o papel dos cães como reservatório foi confirmado. Um dos principais problemas na infecção experimental canina é a natureza imprevisível da resposta, o que limita a obtenção de uma resposta homogênea e reprodutível, necessária para obtermos conclusões definitivas acerca da experimentação. Em vista disso, torna-se relevante estabelecer os parâmetros para induzir um estágio particular da resposta imune ou da doença. Desse modo, podemos obter um longo período pré-patente, uma resposta celular específica, uma resposta humoral exacerbada ou um rápido aparecimento dos sinais clínicos, adequando o modelo à proposta do estudo (Moreno \& Alvar, 2002).

Existem diferentes metodologias para a infecção experimental em relação a vias de inoculação, forma e dose infectantes. Em termos práticos, embora a via IV seja mais artificial, em relação ao que ocorre naturalmente, parece ser a melhor rota para induzir a doença sintomática, pois permite a rápida dispersão sistêmica dos parasitos vivos (Martínez-Moreno et al., 1995; Poot et al., 2005; Rodriguez-Cortes et al., 2007a; Maia et al., 2010; ), sendo que cães infectados por essa via têm maior potencial de transmissão para flebótomos (Travi et al., 2009).

A infecção pela via ID tem evolução mais lenta e período pré-patente longo (Paranhos-Silva et al., 2003; Pinelli et al., 1994), sendo mais próxima da infecção natural. Além disso, é predominantemente assintomática, mesmo com a inoculação de altas doses de parasitos (Santos-Gomes, Campino \& Abranches, 2000; Paranhos-Silva et al., 2003; Chamizo, Moreno \& Alvar, 2005; Silvestre et al., 2008). É importante ressaltar que na inoculação por essa via não há a formação do leishmanioma e não são mais detectados parasitos no local 24 horas após a inoculação (Santos-Gomes, Campino \& Abranches, 2000). 
No que se refere à forma infectante, alguns autores (Campino et al., 2000; Santos-Gomes et al., 2003) consideram que cães experimentalmente infectados com amastigotas desenvolvem infecção sintomática, enquanto os infectados com promastigotas desenvolvem infecção assintomática, embora com alterações hematológicas e proteicas. Entretanto, diversos estudos (Pinelli et al., 1994; Martínez-Moreno et al., 1995; Carrera et al., 1996; Nieto et al., 1999; Rhalem et al., 1999; Leandro et al., 2001; Travi et al., 2009) não corroboram esta ideia. Assim, deve-se considerar que tanto amastigotas como promastigotas produzem resposta clínica pleomórfica.

Outro ponto que pode ser explorado no uso de cães como modelo experimental para LV é a avaliação da resposta funcional. As células T e as citocinas por elas produzidas exercem papel central na resposta imune contra patógenos intracelulares (Pinelli et al., 1999). Uma vez que Leishmania são parasitos intracelulares obrigatórios, a proteção é dependente da atividade das citocinas, que podem modular tanto a destruição dos parasitos dentro das células como a multiplicação destes. Em contrapartida, ocorre proliferação intensa de linfócitos B e também a produção de anticorpos, que é abundante, porém não protetora (Almeida et al., 2005). No cão, é observada correlação inversa entre a resposta imune mediada por células e a carga parasitária. São observados picos de parasitemia na ausência de resposta imune celular específica e vice-versa (Rodríguez-Cortés et al., 2007b). Dessa forma, assim como em humanos, cães assintomáticos podem ser capazes de produzir e manter resposta imune celular efetiva que inibe a replicação do parasito nos órgãos-alvo.

Atualmente não há dados conclusivos sobre os mecanismos imunológicos responsáveis pela resistência ou progressão da LVC. A resposta imune Th2, associada à progressão da doença representada pela baixa síntese de IFN- $\gamma$ e aumento dos níveis de IL-10 (Sharma \& Singh, 2009), tem sido apenas parcialmente demonstrada na LVC (Quinnell et al., 2001; Lage et al., 2007; Alves et al., 2009). Demonstrou-se a associação da carga parasitária com a evolução clínica da LVC e com a expressão de determinadas citocinas, como INF- $\gamma$, IL-2, IL-6, IL-10 e IL-12 (Santos-Gomes et al., 2002; Barbieri, 2006; Lage et al., 2007; Manna et al., 2008), o que ressalta o papel crucial dos linfócitos T e de citocinas na modulação da resposta imunológica protetora. Manna e colaboradores (2006; 2009) e Alves e colaboradores (2009) demonstraram a expressão de IFN- $\gamma$ e TNF- $\alpha$ em cães assintomáticos e IL-10 e TGF- $\beta$ em cães sintomáticos. Culturas de células mononucleares de sangue periférico de cães assintomáticos infectados experimentalmente com L. infantum apresentam resposta predominantemente Th1, mostrando IFN- $\gamma$ e TNF- $\alpha$ como as principais citocinas envolvidas na ativação do mecanismo leishmanicida dos macrófagos (Pinelli et al., 1994; Santos-Gomes et al., 2002; Carrillo \& Moreno, 2009), contudo, tal perfil não foi mostrado por outros autores (Poot et al., 2005). A variabilidade na resposta pode estar relacionada à metodologia utilizada nos diferentes estudos ou possivelmente à cepa do parasito envolvida.

Altos níveis de anticorpos específicos têm sido associados à disseminação do parasito para os diferentes tecidos (Martínez-Moreno et al., 1995; Solano-Gallego et al., 2001). Diversos estudos têm demonstrado resultados contraditórios (Pinelli et al., 1994; Nieto et al., 1999; Rhalem et al., 1999; Rodríguez-Cortés et al., 2007b; Boggiatto et al., 2010; Carson et al., 2010), na análise dos isotipos de IgG no soro de cães sintomáticos e assintomáticos, evidenciando a falta de especificidade dos reagentes comerciais em detectar essas subclasses (Day, 2007). Além disso, a resposta depende do tipo do antígeno utilizado no ensaio sorológico (Silvestre et al., 2008; Maia et al., 2010). No modelo canino a razão IgG2:IgG1 não é preditiva da evolução clínica ou parasitológica da infecção (Carson et al., 2010). Animais sintomáticos produzem IgM mais tardiamente do que a IgG, sugerindo que aquela imunoglobulina não pode ser considerada um marcador de fase aguda na LVC (Rodríguez-Cortés et al., 2007b).

O estudo da patogênese ou da resposta imune durante a infecção com leishmânias viscerotrópicas em cães experimentalmente infectados se mostra vantajosa em relação à avaliação em animais naturalmente infectados, pois permite o controle de todos os aspectos da infecção além do acompanhamento da evolução clínica. Entretanto, quando tal modelo for extrapolado para se obter informações sobre a doença humana, devem-se levar em consideração as diferenças metabólicas e fisiológicas entre essas espécies. 


\section{Primatas não humanos}

Em geral, primatas não humanos são utilizados como o último modelo experimental para estudos de segurança e eficácia de vacinas e drogas, já avaliadas em outros modelos animais. A relação filogenética, a similaridade anatômica, fisiológica e da resposta imunológica com os seres humanos fazem desses animais excelentes modelos para a pesquisa biomédica (Kennedy et al., 1997). Em virtude disso, é esperado que eles mimetizem vários aspectos da interação de humanos com parasitos do complexo L. donovani. Uma grande variedade de macacos do Novo Mundo e do Velho Mundo é utilizada como modelo experimental para leishmânias viscerotrópicas, sendo especialmente útil no estudo da biologia, patogênese e da resposta imune contra esses parasitos. Primatas do Novo Mundo, como o macaco-coruja - Aotus trivirgatus (Chapman, Hanson \& Hendricks, 1981; Broderson, Chapman \& Hanson, 1986), o macaco-de-cheiro - Saimiri sciureus (Chapman, Júnior \& Hanson, 1981; Dennis et al., 1985; Dennis et al., 1986) e o sagui - Callithrix jacchus (Marsden et al., 1981), parecem ter diferentes níveis de suscetibilidade. Os sintomas e sinais clínicos apresentados nesses modelos são análogos àqueles observados em pacientes com LV. Primatas do Velho Mundo, como macacos 'sykes' - Cercophitecus mitis - e babuínos - Papio cynocephalus - mostram suscetibilidade moderada a baixa a infecções induzidas por $L$. donovani, tendendo para cura espontânea (Githure et al., 1986). O langur indiano - Presbytis entellus (Dube et al., 1999; Misra, Dube \& Naik, 2004), o macaco verde africano Cercophitecus aethiops (Binhazim et al., 1993; Gicheru et al., 1995; Olobo, Gicheru \& Anjili, 2001) e o macaco rhesus - Macaca mulatta (Porrozzi et al., 2006) - também são capazes de mimetizar a doença observada em humanos com uma grande variedade individual na intensidade dos sinais clínicos e na resposta imunológica.

Considerando o ponto de vista da imunologia, a possibilidade do uso de primatas não humanos como modelo experimental da leishmaniose visceral torna-se uma importante ferramenta para entender os mecanismos envolvidos na aquisição de imunidade. Neste sentido, é importante salientar que reagentes que detectam imunoglobulinas humanas, antígenos de superfície de linfócitos e citocinas fazem reação cruzada com aqueles de primatas não humanos (Porrozzi et al., 2006; Souza-Lemos et al., 2008; Campos et al., 2010). Níveis variáveis, porém significantes de IFN $\gamma$, foram observados em sobrenadantes de culturas de células mononucleares de sangue periférico de macacos rhesus infectados com L. infantum e estimulados com antígeno solúvel de Leishmania (Porrozzi et al., 2006). Nesse modelo, observou-se a formação de granulomas hepáticos, principalmente no período de até nove semanas pós-infecção que se encontram associados à eliminação dos parasitos e à resolução da infecção. Esse tipo de formação de granulomas imunes está intimamente relacionado com a produção de IFN $\gamma$.

Primatas não humanos para o uso como modelo experimental podem ser diretamente provenientes da natureza, uma vez que em certas regiões da África são considerados praga pela população local (Olobo, Gicheru \& Anjili et al., 2001), ou de colônias de reprodução. No entanto, é importante destacar que esses animais podem albergar agentes infecciosos que representam risco para a saúde dos profissionais que os manipulam, tais como vírus do Herpes B (Herpesvirus simiae) e o vírus STLV-1, próprios de macacos. Além disso, os animais capturados na natureza podem estar infectados como uma série de patógenos humanos como Plasmodium vivax e Plasmodium falciparum, vírus da Hepatite A, Bacillus anthracis (Antrax) e vírus Ebola, entre outros (Kennedy et al., 1997). Isso gera um custo extra para a viabilização dos experimentos, tendo em vista que procedimentos de biossegurança e quarentena devem ser implementados. A despeito dessas considerações, a demanda para o uso de primatas não humanos na pesquisa biomédica está aumentando. Estudos visando aos testes de novas vacinas e drogas para leishmaniose visceral necessitam de um modelo que seja não somente capaz de reproduzir os eventos básicos da imunopatogênese, mas também uma resposta fisiológica e imunológica que se assemelhem mais com a esperada em humanos do que as obtidas em modelos animais de pequeno porte. 


\section{CONSIDERAÇÕES FINAIS}

Como exposto, vários modelos animais para LV estão disponíveis e cada um é dotado de características específicas que devem ser consideradas, pois nenhum dos modelos reproduz fielmente a doença humana. Isto, logicamente, reflete as diferenças fisiológicas das espécies e as diferenças entre a infecção natural e a artificial. Na infecção natural os flebotomíneos inoculam algumas centenas de promastigotas metacíclicos, enquanto nas infecções experimentais utilizam-se doses muito altas de promastigotas de cultura ou mesmo de amastigotas. As vias de inoculação experimental também são diferentes da infecção natural, o que pode e deve induzir resposta imunológica e evolução clínica distintas. Em termos gerais, podemos considerar como modelo animal o conjunto de metodologias empregadas, incluindo a espécie animal, para que possamos induzir mecanismos patológicos similares àqueles da doença humana.

É importante ressaltar que a escolha do modelo também deve levar em consideração que este deve permitir a avaliação acurada dos fenômenos biológicos que se pretende abordar. Nesse sentido, a disponibilidade de reagentes imunológicos para abordar questões relacionadas com os mecanismos imunopatológicos associados à doença em questão é de fundamental importância. Outro fator relevante, porém pouco explorado, é a escolha do gênero dos animais utilizados na infecção por Leishmania spp. Tanto em camundongos quanto em hamsters, aparentemente machos são mais suscetíveis que fêmeas, provavelmente em virtude da influência hormonal sobre a síntese e a secreção de citocinas que interferem no curso da infecção (Travi et al., 2002). Em outros modelos animais, tal aspecto tem sido negligenciado e não há informação disponível. Animais de pequeno porte, principalmente os camundongos, são os mais utilizados na pesquisa biomédica, o mesmo se refletindo no caso da pesquisa em LV. Tais animais podem ser 'convencionais', cuja biota é indefinida, ou 'gnotobióticos', que podem ser com flora definida ou totalmente livres de vida associada. A condição sanitária é relevante quando se deseja isolar um fenômeno biológico e detalhálo, pois infecções associadas podem interferir nos resultados. É claro que essas condições podem ser conseguidas para outros modelos animais, entretanto é muito mais difícil e de custo mais alto. Outra ferramenta que contribui significativamente para o entendimento da patogênese da LV e de outras doenças é o uso de camundongos nocauteados para determinados genes (Murray \& Nathan, 1999; Murray et al., 2000; Engwerda et al., 2004), o que permite estudar de forma pontual a participação das moléculas expressas durante a infecção por leishmânias viscerotrópicas. Juntamente com os hamsters, os camundongos são a primeira escolha para estudos de mecanismos básicos da imunopatogênese da LV, de desenvolvimento de vacinas e de novos fármacos. Todavia, importantes diferenças na fisiologia, metabolismo e resposta imune podem exigir o uso de outros modelos animais.

Os cães representam um excelente modelo para o estudo da LVH, pois, como já visto, apresentam vários aspectos similares àqueles observados em humanos. Além disso, como hospedeiros acidentais, adquirem a infecção, tornando possível a comparação entre as infecções natural e experimental. Embora avanços no conhecimento dessa enfermidade tenham sido alcançados nos últimos anos, os conhecimentos sobre os mecanismos imunológicos responsáveis pela proteção ou progressão da infecção ainda são fragmentados. Os cães são os modelos usados na segunda fase em testes de vacinas e drogas, mas em razão das diferenças no metabolismo de drogas e da escassez de dados acurados sobre a resposta imune, deve-se ter cuidado nas extrapolações para a doença humana.

A proximidade filogenética de uma determinada espécie não garante que seja o melhor modelo experimental. Primatas do Novo Mundo aparentam ser melhores modelos para a malária induzida por Plasmodium falciparum (Carvalho et al., 2005) do que os do Velho Mundo, que são resistentes a essa espécie de Plasmodium. Para estudos de LV, os macacos encontrados nas Américas, distantes cerca de 30 milhões de anos (MA) da espécie humana, são mais suscetíveis a infecção por leishmânias viscerotrópicas do que o macaco verde africano, distante cerca de 15-20 MA, e do que o macaco rhesus, distante cerca de 8-9 MA, por exemplo (Kennedy et al., 1997). 
Embora menos suscetíveis, as espécies do Velho Mundo desenvolvem uma doença muito próxima à observada em humanos (Olobo, Gicheru \& Anjili, 2001; Porrozzi et al., 2006), com sintomatologia transiente e eventual controle da infecção. De certa forma isso limita os testes de vacinas, pois a infecção subclínica nos grupos-controle dificulta a interpretação dos resultados, mascarando uma possível proteção da vacina. Os primatas não humanos são os animais de escolha para estudos de segurança, imunogenicidade e proteção no teste de vacinas e drogas candidatas para a LV (terceira fase da experimentação animal). Em contrapartida, são mais difíceis de ser utilizados, em razão do alto custo de manutenção e experimentação, do forte apelo ético e do fato de algumas espécies estarem em risco de extinção.

A escolha do melhor modelo de experimentação animal não obedece a regras claras, já que diversos fatores limitam a reprodução acurada da doença humana. O objetivo da pesquisa deve ser claro, devendo-se procurar o modelo que mais se aproxime da questão abordada. A padronização dos procedimentos é essencial e deve-se ter em mente que nenhum modelo traz garantia absoluta de reprodutibilidade do fenômeno estudado para a espécie humana.

\section{REFERÊNCIAS}

AHMED, S. et al. Intradermal infection model for pathogenesis and vaccine studies of murine visceral leishmaniasis. Infection and Immunity, 71(1): 401-410, 2003.

ALMEIDA, M. A. et al. Antileishmanial antibody profile in dogs naturally infected with Leishmania chagasi. Veterinary Immunology and Immunopathology, 106(1-2): 151-158, 2005.

ALVES, C. F. et al. Expression of IFN-[gamma], TNF-[alpha], IL-10 and TGF-[beta] in lymph nodes associates with parasite load and clinical form of disease in dogs naturally infected with Leishmania (Leishmania) chagasi. Veterinary Immunology and Immunopathology, 128(4): 349-358, 2009.

ALVES, G. B. B. et al. Cardiac and pulmonary alterations in symptomatic and asymptomatic dogs infected naturally with Leishmania (Leishmania) Chagasi. Brazilian Journal of Medical and Biological Research, 43: 310-315, 2010.

BANETH, G. \& JAFFE, C. L. Canine visceral leishmaniasis in Israel: an overview of an emerging disease with reference to wild canids and human infection. In: CANINE LEISHMANIASIS: AN UPDATE. PROCEEDINGS OF THE INTERNATIONAL CANINE LEISHMANIASIS FORUM BARCELONA, Spain, 1999.

BAPTISTA-FERNANDES, T. et al. Intra-specific variability of virulence in Leishmania infantum zymodeme MON-1 strains. Comparative Immunology, Microbiology and Infectious Diseases, 30(1): 41-53, 2007.

BARBIERI, C. L. Immunology of canine leishmaniasis. Parasite Immunology, 28(7): 329-337, 2006.

BINHAZIM, A. A. et al. Comparative susceptibility of African green monkeys (Cercopithecus aethiops) to experimental infection with Leishmania leishmania donovani and Leishmania leishmania infantum. Laboratory Animal Science, 43(1): 37-47, 1993.

BLACKWELL, J. M. \& PLANT, J. E. Expression of the natural resistance gene (Lsh) in wild mice infected experimentally with Leishmania donovani or Salmonella typhimurium. Current Topics in Microbiology and Immunology, 127: 323-330, 1986.

BLACKWELL, J. M. et al. An H-11-linked gene has a parallel effect on Leishmania major and L. donovani infections in mice. Immunogenetics, 21(4): 385-395, 1985.

BLACKWELL, J. M. et al. SLC11A1 (formely NRAMP1) and disease resistence. Cell Microbiology, 3: 773-784, 2001.

BLACKWELL, J. M. Leishmania donovani infection in heterozygous and recombinant H-2 haplotype mice. Immunogenetics, 18(2): 101-109, 1983.

BOGGIATTO, P. M. et al. Immunologic indicators of clinical progression during canine Leishmania infantum infection. Clinical and Vaccine Immunology, 17(2): 267-273, 2010.

BRODERSON, J. R. CHAPMAN JR., W. L. \& HANSON, W. L. Experimental visceral leishmaniasis in the owl monkey. Veterinary Pathology, 23(3): 293-302, 1986. 
BUNN-MORENO, M. M. et al. Hypergammaglobulinaemia in Leishmania donovani infected hamsters: possible association with a polyclonal activator of B cells and with suppression of T cell function. Clinical \& Experimental Immunology, 59(2): 427-434, 1985.

CAMPINO, L. et al. Infectivity of promastigotes and amastigotes of Leishmania infantum in a canine model for leishmaniosis. Veterinary Parasitology, 92(4): 269-275, 2000.

CAMPOS, S. N. et al. Systemic and compartmentalised immune responses in a Leishmania braziliensis-macaque model of self-healing cutaneous leishmaniasis. Veterinary Immunology and Immunopathology, 137(1-2): 149-154, 2010.

CAMPOS-NETO, A. \& BUNN-MORENO, M. M. Polyclonal B cell activation in hamsters infected with parasites of the genus Leishmania. Infection and Immunity, 38(3): 871-876, 1982.

CARRERA, L. et al. Antibody response in dogs experimentally infected with Leishmania infantum: infection course antigen markers. Experimental Parasitology, 82(2): 139-146, 1996.

CARRILLO, E. \& MORENO, J. Cytokine profiles in canine visceral leishmaniasis. Veterinary Immunology and Immunopathology, $128(1-3): 67-70,2009$

CARSON, C. et al. Comparison of monoclonal and polyclonal antibodies for the detection of canine IgG1 and IgG2, and associations with infection outcome in Leishmania infantum naturally infected dogs. Veterinary Immunology and Immunopathology, 133(2-4): 264-268, 2010.

CARVALHO, L. J. M. et al. Immunization of Saimiri sciureus monkeys with a recombinant hybrid protein derived from the Plasmodium falciparum antigen glutamate rich protein and merozoite surface protein 3 can induce partial protection with Freund and Montanide ISA720 adjuvants. Clinical and Diagnostic Laboratory Immunology, 12(2): 242-248, 2005.

CERQUEIRA, E. J. et al. Experimental infection of Equus asinus with Leishmania chagasi (Cunha \& Chagas, 1937). Revista da Sociedade Brasileira de Medicina Tropical, 36(6): 695-701, 2003.

CERVIA, J. S.; ROSEN, H. \& MURRAY, H. W. Effector role of blood monocytes in experimental visceral leishmaniasis. Infection and Immunity, 61(4): 1.330-1.333, 1993.

CHAMIZO, C.; MORENO, J. \& ALVAR, J. Semi-quantitative analysis of cytokine expression in asymptomatic canine leishmaniasis. Veterinary Immunology and Immunopathology, 103: 67-75, 2005.

CHAPMAN JR., W. L. \& HANSON, W. L. Visceral leishmaniasis in the squirrel monkey (Saimiri sciurea). The Journal of Parasitology, 67(5): 740-741, 1981.

CHAPMAN JR., W. L.; HANSON, W. L. \& HENDRICKS, L. D. Leishmania donovani in the owl monkey (aotus trivirgatus). Transactions of the Royal Society of Tropical Medicine and Hygiene, 75(1): 124-125, 1981.

COTTERELL, S. E.; ENGWERDA, C. R. \& KAYE, P. M. Leishmania donovani infection initiates T cell-independent chemokine responses, which are subsequently amplified in a T cell-dependent manner. European Journal of Immunology, 29(1): 203-214, 1999.

CROCKER, P. R.; BLACKWELL, J. M. \& BRADLEY, D. J. Expression of the natural resistance gene Lsh in resident liver macrophages. Infection and Immunity, 43(3): 1.033-1.040, 1984.

CROFT, S. L. \& ENGEL, J. Miltefosine: discovery of the antileishmanial activity of phospholipid derivatives. Transactions of the Royal Society of Tropical Medicine and Hygiene, 100, supl. 1: S4-S8, 2006.

DAY, M. J. Immunoglobulin G subclass distribution in canine leishmaniosis: a review and analysis of pitfalls in interpretation. Veterinary Parasitology, 147(1-2): 2-8, 2007.

DEL-GIUDICE, P. et al. Impact of highly active antiretroviral therapy on the incidence of visceral Leishmaniasis in a French cohort of patients infected with human immunodeficiency virus. The Journal of Infectious Diseases, 186(9): 1.366$1.370,2002$.

DENNIS, V. A. et al. Leishmania donovani: clinical, hematologic and hepatic changes in squirrel monkeys (Saimiri sciureus). The Journal of Parasitology, 71(5): 576-582, 1985. 
DENNIS, V. A. et al. Leishmania donovani: cellular and humoral immune responses after primary and challenge infections in squirrel monkeys, Saimiri sciureus. Experimental Parasitology, 61(3): 319-334, 1986.

DUARTE, M. I. S. \& CORBETT, C. E. P. Histopathological and ultrastructural aspects of interstitial pneumonitis of experimental visceral leishmaniasis. Transactions of the Royal Society of Tropical Medicine and Hygiene, 78(5): 683-688, 1984.

DUBE, A. et al. Leishmania donovani: cellular and humoral immune responses in Indian langur monkeys, Presbytis entellus. Acta Tropica, 73(1): 37-48, 1999.

ENGWERDA, C. R. et al. Distinct roles for lymphotoxin-alpha and tumor necrosis factor in the control of Leishmania donovani infection. American Association of Pathologists, 165(6): 2.123-2.133, 2004.

FERRER, L. Clinical aspects of Canine Leishmaniasis. In: CANINE LEISHMANIASIS: AN UPDATE. PROCEEDINGS OF THE INTERNATIONAL CANINE LEISHMANIASIS FORUM BARCELONA, Spain, 1999.

GARG, R. \& DUBE, A. Animal models for vaccine studies for visceral leishmaniasis. The Indian Journal of Medical Research, 123(3): 439-454, 2006.

GARIN, Y. J.-F. et al. Virulence of Leishmania infantum is expressed as a clonal and dominant phenotype in experimental infections. Infection and Immunity, 69(12): 7.365-7.373, 2001.

GHALIB, H. W. et al. IL-12 enhances Th1-type responses in human Leishmania donovani infections. The Journal of Immunology, 154(9): 4.623-4.629, 1995.

GICHERU, M. M. et al. Visceral leishmaniasis in vervet monkeys: immunological responses during asymptomatic infections. Scandinavian Journal of Immunology, 41(2): 202-208, 1995.

GITHURE, J. I. et al. The suitability of East African primates as animal models of visceral leishmaniasis. Transactions of the Royal Society of Tropical Medicine and Hygiene, 80(4): 575-576, 1986.

GOMEZ-OCHOA, P. et al. Lactating females Syrian hamster (Mesocricetus auratus) show protection against experimental Leishmania infantum infection. Veterinary Parasitology, 116(1): 61-64, 2003.

GORAK, P. M.; ENGWERDA, C. R. \& KAYE, P. M. Dendritic cells, but not macrophages, produce IL-12 immediately following Leishmania donovani infection. European Journal of Immunology, 28(2): 687-695, 1998.

GOTO, H. \& LINDOSO, J. A. Immunity and immunosuppression in experimental visceral leishmaniasis. Brazilian Journal of Medical and Biological Research, 37: 615-623, 2004.

GOTO, H. Imunidade Inata e Imunopatogenia nas Leishmanioses Experimentais, 2004. Tese de Doutorado, São Paulo: Universidade de São Paulo.

KAYE, P. M.; CURRY, A. J. \& BLACKWELL, J. M. Differential production of Th1- and Th2-derived cytokines does not determine the genetically controlled or vaccine-induced rate of cure in murine visceral leishmaniasis. The Journal of Immunology, 146(8): 2.763-2.770, 1991.

KENNEDY, R. C. et al. Nonhuman primates and their potential use in immunologically based investigations. The Immunologist, 5(5): 150-156, 1997.

LAGE, R. S. et al. Analysis of the cytokine profile in spleen cells from dogs naturally infected by Leishmania chagasi. Veterinary Immunology and Immunopathology, 115(1-2): 135-145, 2007.

LEANDRO, C. et al. Cell mediated immunity and specific IgG1 and IgG2 antibody response in natural and experimental canine leishmaniosis. Veterinary Immunology and Immunopathology, 79(3-4): 273-284, 2001.

LECLERCQ, V. et al. The outcome of the parasitic process initiated by Leishmania infantum in laboratory mice: a tissuedependent pattern controlled by the Lsh and MHC loci. The Journal of Immunology, 157(10): 4.537-4.545, 1996.

LIPOLDOVA, M. \& DEMANT, P. Genetic susceptibility to infectious disease: lessons from mouse models of leishmaniasis. Nature Reviews. Genetics, 7(4): 294-305, 2006.

MAIA, C. et al. Experimental canine leishmaniasis: clinical, parasitological and serological follow-up. Acta Tropica, 116(3):193-199, 2010. 
MANNA, L. et al. Leishmania DNA load and cytokine expression levels in asymptomatic naturally infected dogs. Veterinary Parasitology, 142(3-4): 271-280, 2006.

MANNA, L. et al. Leishmania DNA quantification by real-time PCR in naturally infected dogs treated with miltefosine. Annals of the New York Academy of Sciences, 1.149: 358-360, 2008.

MANNA, L. et al. Evidence for a relationship between Leishmania load and clinical manifestations. Research in Veterinary Science, 87(1): 76-78, 2009.

MARSDEN, P. D. et al. Experimental Leishmania chagasi infections in the marmoset Callithrix jacchus jacchus. Transactions of the Royal Society of Tropical Medicine and Hygiene, 75(2): 314-315, 1981.

MARTínEZ-MORENO, A. et al. Humoral and cell-mediated immunity in natural and experimental canine leishmaniasis. Veterinary Immunology and Immunopathology, 48(3-4): 209-220, 1995.

MAUEL, J.; RANSIJN, A. \& BUCHMULLER-ROUILLER, Y. Killing of Leishmania parasites in activated murine macrophages is based on an L-arginine-dependent process that produces nitrogen derivatives. Journal of Leukocyte Biology, 49(1): 73-82, 1991.

McELRATH, M. J.; MURRAY, H. W. \& COHN, Z. A. The dynamics of granuloma formation in experimental visceral leishmaniasis. The Journal of Experimental Medicine, 167(6): 1.927-1.937, 1988.

MELBY, P. C. et al. Leishmania donovani: evolution and architecture of the splenic cellular immune response related to control of infection. Experimental Parasitology, 99(1): 17-25, 2001.

MELBY, P. C. et al. The hamster as a model of human visceral Leishmaniasis: progressive disease and impaired generation of nitric oxide in the face of a prominent Th1-like cytokine response. The Journal of Immunology, 166(3): 1.912-1.920, 2001.

MELBY, P. C. Experimental leishmaniasis in humans: review. Reviews of Infectious Diseases, 13(5): 1.009-1.017, 1991.

MIRALLES, G. D. et al. Th1 and Th2 cell-associated cytokines in experimental visceral leishmaniasis. Infection and Immunity, 62(3): 1.058-1.063, 1994.

MISRA, A.; DUBE, A. \& NAIK, S. Immune responses in normal Indian langur monkeys (Presbytis entellus)--a primate model for visceral leishmaniasis. Journal of Medical Primatology, 33(2): 65-69, 2004.

MONTOYA-LERMA, J. et al. Comparative vectorial efficiency of Lutzomyia evansi and Lu. longipalpis for transmitting Leishmania chagasi. Acta Tropica, 85(1): 19-29, 2003.

MORAES-SILVA, E. et al. Domestic swine in a visceral leishmaniasis endemic area produce antibodies against multiple Leishmania infantum antigens but apparently resist to L. infantum infection. Acta Tropica, 98(2): 176-182, 2006.

MORENO, J. \& ALVAR, J. Canine leishmaniasis: epidemiological risk and the experimental model. Trends in Parasitology, 18(9): 399-405, 2002.

MURPHY, M. L. et al. IL-10 mediates susceptibility to Leishmania donovani infection. European Journal of Immunology, 31(10): 2.848-2.856, 2001.

MURRAY, H. W. \& NATHAN, C. F. Macrophage microbicidal mechanisms in vivo: reactive nitrogen versus oxygen intermediates in the killing of intracellular visceral Leishmania donovani. The Journal of Experimental Medicine, 189(4): 741-746, 1999.

MURRAY, H. W. Cell-mediated immune response in experimental visceral leishmaniasis. II. Oxygen-dependent killing of intracellular Leishmania donovani amastigotes. The Journal of Immunology, 129(1): 351-357, 1982.

MURRAY, H. W. Endogenous interleukin-12 regulates acquired resistance in experimental visceral leishmaniasis. The Journal of Infectious Diseases, 175(6): 1.477-1.479, 1997.

MURRAY, H. W. et al. Role and effect of IL-2 in experimental visceral leishmaniasis. The Journal of Immunology, 151(2): 929-938, 1993.

MURRAY, H. W. et al. Visceral leishmaniasis in mice devoid of tumor necrosis factor and response to treatment. Infection and Immunity, 68(11): 6.289-6.293, 2000. 
MURRAY, H. W. Tissue granuloma structure-function in experimental visceral leishmaniasis. International Journal of Experimental Pathology, 82(5): 249-267, 2001.

MURRAY, H. W.; MASUR, H. \& KEITHLY, J. S. Cell-mediated immune response in experimental visceral leishmaniasis. I. Correlation between resistance to Leishmania donovani and lymphokine-generating capacity. The Journal of Immunology, 129(1): 344-350, 1982.

NICKOL, A. D. \& BONVENTRE, P. F. Immunosuppression associated with visceral leishmaniasis of hamsters. Parasite Immunologyogy, 7(4): 439-449, 1985a.

NICKOL, A. D. \& BONVENTRE, P. F. Visceral leishmaniasis in congenic mice of susceptible and resistant phenotypes: T-lymphocyte-mediated immunosuppression. Infection and Immunity, 50(1): 169-174, 1985b.

NIETO, C. G. et al. Analysis of the humoral immune response against total and recombinant antigens of Leishmania infantum: correlation with disease progression in canine experimental leishmaniasis. Veterinary Immunology and Immunopathology, 67(2): 117-130, 1999.

OLOBO, J. O.; GICHERU, M. M. \& ANJILI, C. O. The African Green Monkey model for cutaneous and visceral leishmaniasis. Trends in Parasitology, 17(12): 588-592, 2001.

PARANHOS-SILVA, M. et al. A follow-up of Beagle dogs intradermally infected with Leishmania chagasi in the presence or absence of sand fly saliva. Veterinary Parasitology, 114(2): 97-111, 2003.

PEREIRA, B. A. S. \& ALVES, C. R. Immunological characteristics of experimental murine infection with Leishmania (Leishmania) amazonensis. Veterinary Parasitology, 158(4): 239-255, 2008.

PINELLI, E. et al. Cellular and humoral immune responses in dogs experimentally and naturally infected with Leishmania infantum. Infection and Immunity, 62 (1): 229-235, 1994.

PINELLI, E. et al. Detection of canine cytokine gene expression by reverse transcription-polymerase chain reaction. Veterinary Immunology and Immunopathology, 69(2-4): 121-126, 1999.

POOT, J. et al. Detailed analysis of an experimental challenge model for Leishmania infantum (JPC strain) in dogs. Veterinary Parasitology, 130(1-2): 41-53, 2005.

PORROZZI, R. et al. Leishmania infantum induced primary and challenge infections in rhesus monkeys (Macaca mulatta): a primate model for visceral leishmaniasis. Transactions of the Royal Society of Tropical Medicine and Hygiene, 100(10): 926-937, 2006

QUINNELL, R. J. et al. Tissue cytokine responses in canine visceral leishmaniasis. The Journal of Infectious Diseases, 183(9): 1.421-1.424, 2001.

REQUENA, J. M. et al. Immune and clinical parameters associated with Leishmania infantum infection in the golden hamster model. Veterinary Immunology and Immunopathology, 76(3-4): 269-281, 2000.

RHALEM, A. et al. Immune response against Leishmania antigens in dogs naturally and experimentally infected with Leishmania infantum. Veterinary Parasitology, 81(3): 173-184, 1999.

RIÇA-CAPELA, M. J. et al. Immunological and histopathological studies in a rodent model infected with Leishmania infantum promastigotes or amastigotes. Parasitology Research, 89(3): 163-169, 2003.

RODRIGUES, J. V.; SILVA, J. S. \& CAMPOS-NETO, A. Selective inability of spleen antigen presenting cells from Leishmania donovani infected hamsters to mediate specific T cell proliferation to parasite antigens. Parasite Immunologyogy, 14(1): 49-58, 1992.

RODRÍGUEZ-CORTÉS, A. et al. A long term experimental study of canine visceral leishmaniasis. International journal for Parasitology, 37(6): 683-693, 2007a.

RODRÍGUEZ-CORTÉS, A. et al. Leishmania-specific isotype levels and their relationship with specific cell-mediated immunity parameters in canine leishmaniasis. Veterinary Immunology and Immunopathology, 116(3-4): 190-198, 2007b. 
ROLÃO, N.; MELO, C. \& CAMPINO, L. Influence of the inoculation route in BALB/c mice infected by Leishmania infantum. Acta Tropica, 90(1): 123-126, 2004.

ROSAS, L. E. et al. Interleukin-27R (WSX-1/T-cell cytokine receptor) gene-deficient mice display enhanced resistance to Leishmania donovani infection but develop severe liver immunopathology. American Association of Pathologists, 168(1): 158-169, 2006.

SAKTHIANANDESWAREN, A.; FOOTE, S. J. \& HANDMAN, E. The role of host genetics in leishmaniasis. Trends in Parasitology, 25(8): 383-391, 2009.

SANCHEZ-ROBERT, E. et al. Slc11a1 (formerly Nramp1) and susceptibility to canine visceral leishmaniasis. Veterinary Research, 39: 36-47, 2008.

SANTOS, W. L. et al. Associations among immunological, parasitological and clinical parameters in canine visceral leishmaniasis: Emaciation, spleen parasitism, specific antibodies and leishmanin skin test reaction. Veterinary Immunology and Immunopathology, 123(3-4): 251-259, 2008.

SANTOS-GOMES, G. M. et al. Cytokine expression during the outcome of canine experimental infection by Leishmania infantum. Veterinary Immunology and Immunopathology, 88: 21-30, 2002.

SANTOS-GOMES, G. M. et al. Experimental canine leishmaniasis: evolution of infection following re-challenge with Leishmania infantum. Acta Tropica, 87(2): 235-244, 2003.

SANTOS-GOMES, G.; CAMPINO, L. \& ABRANCHES, P. Canine experimental infection: intradermal inoculation of Leishmania infantum promastigotes. Memórias do Instituto Oswaldo Cruz, 95(2):193-198, 2000.

SARTORI, A. et al. Immune complex glomerulonephritis in experimental kala-azar. II: Detection and characterization of parasite antigens and antibodies eluted from kidneys of Leishmania donovani infected hamsters. Clinical \& Experimental Immunology, 87(3): 386-392, 1992.

SHARMA, U. \& SINGH, S. Immunobiology of leishmaniasis. Indian Journal of Experimental Biology, 47(6): 412-423, 2009.

SHUKINA, E. E. \& GORBUNOVA, L. A. Experimental visceral leishmaniasis in golden hamsters. Parazitologiia, 21(5): 637$642,1987$.

SILVESTRE, R. et al. Serological evaluation of experimentally infected dogs by LicTXNPX-ELISA and amastigote-flow cytometry. Veterinary Parasitology, 158(1-2): 23-30, 2008.

SMELT, S. C. et al. B cell-deficient mice are highly resistant to Leishmania donovani infection, but develop neutrophilmediated tissue pathology. The Journal of Immunology, 164(7): 3.681-3.688, 2000.

SOLANO-GALLEGO, L. et al. The Ibizian hound presents a predominantly cellular immune response against natural Leishmania infection. Veterinary Parasitology, 90: 37-45, 2000.

SOLANO-GALLEGO, L. et al. Prevalence of Leishmania infantum infection in dogs living in an area of canine leishmaniasis endemicity using PCR on several tissues and serology. J Clin Microbiol, 39(2): 560-563, 2001.

SOUZA-LEMOS, C. et al. Dynamics of immune granuloma formation in a Leishmania braziliensis induced self-limiting cutaneous infection in the primate Macaca mulatta.J Pathol, 216(3): 375-386, 2008.

SQUIRES, K. E. et al. Experimental visceral leishmaniasis: role of endogenous IFN-gamma in host defense and tissue granulomatous response. The Journal of Immunology, 143(12): 4.244-4.249, 1989.

SQUIRES, K. E. et al. Defect in the tissue cellular immune response: experimental visceral leishmaniasis in euthymic C57BL/6 ep/ep mice. Infection and Immunity, 58(12): 3.893-3.898, 1990.

STAGER, S. et al. Natural antibodies and complement are endogenous adjuvants for vaccine-induced CD8 + T-cell responses. Nat Med, 9(10): 1.287-1.292, 2003.

STANLEY, A. C. \& ENGWERDA, C. R. Balancing immunity and pathology in visceral leishmaniasis. Immunol Cell Biol, 85(2): 138-147, 2007. 
TRAVI, B. L. et al. Gender is a major determinant of the clinical evolution and immune response in hamsters infected with Leishmania spp.. Infection and Immunity, 70(5): 2.288-2.296, 2002.

TRAVI, B. L. et al. Clinical, parasitologic, and immunologic evolution in dogs experimentally infected with sand fly-derived Leishmania chagasi promastigotes. The American Journal of Tropical Medicine and Hygiene, 81(6): 994-1.003, 2009.

VIANNA, V. L.; TAKIYA, C. M. \& BRITO-GITIRANA, L. Histopathologic analysis of hamster hepatocytes submitted to experimental infection with Leishmania donovani. Parasitology Research, 88(9): 829-836, 2002.

VIDAL, S. et al. The Ity/Lsh/Bcg locus: natural resistance to infection with intracellular parasites is abrogated by disruption of the Nramp1 gene. The Journal of Experimental Medicine, 182 (3): 655-666, 1995.

WILSON, M. E. \& STREIT, J. A. Visceral leishmaniasis. Gastroenterol Clinics of North America, 25(3): 535-551, 1996.

WILSON, M. E. \& WEINSTOCK, J. V. Hepatic granulomas in murine visceral Leishmaniasis caused by Leishmania chagasi. Methods, 9(2): 248-254, 1996.

WILSON, M. E.; JERONIMO, S. M. \& PEARSON, R. D. Immunopathogenesis of infection with the visceralizing Leishmania species. Microbial Pathogenesis, 38(4): 147-160, 2005.

WILSON, M. E. et al. Local suppression of IFN-gamma in hepatic granulomas correlates with tissue-specific replication of Leishmania chagasi. Journal of Immunology, 156(6): 2.231-2.239, 1996.

WILSON, M. E. et al. The importance of TGF-beta in murine visceral leishmaniasis. The Journal of Immunology, 161(11): 6.148-6.155, 1998.

WYLLIE, S. \& FAIRLAMB, A. H. Refinement of techniques for the propagation of Leishmania donovani in hamsters. Acta Tropica, 97(3): 364-369, 2006. 


\title{
17 \\ Modelos Experimentais na Leishmaniose Tegumentar Americana
}

\author{
Sylvio Celso Gonçalves da Costa I Tânia Zaverucha do Valle
}

\begin{abstract}
A s leishmanioses são doenças que atingem o homem e animais domésticos, constituindo doenças espectrais com uma ampla variação de manifestações clínicas. Essas variações são consequência de vários fatores que dependem tanto do parasito quanto do hospedeiro. Primeiramente, devemos considerar as várias espécies de protozoários que causam a doença no homem e nos reservatórios domésticos e silvestres. No Novo Mundo, por exemplo, as leishmanioses ocorrem do sul dos Estados Unidos à região norte da Argentina e são causadas por diferentes espécies, tais como L (V.) braziliensis, L. (L.) amazonensis, L. (V.) guyanensis e L (L.) infantum.
\end{abstract}

Em seguida, precisamos levar em conta a diversidade de cepas, a carga parasitária no momento da infecção, o estado imunológico do hospedeiro, as infecções concomitantes etc. Infecções concomitantes, por exemplo, podem mudar o curso de uma infecção de maneira surpreendente, tanto diretamente quanto por consequência do tratamento com algumas drogas. Da mesma forma, drogas utilizadas no tratamento de outras doenças como o câncer, também podem alterar o curso de uma infecção por Leishmania (Gurubacharya et al., 2006; Desjeux \& Alvar, 2003).

Essa variedade de lesões tem sido estudada nos modelos experimentais, o que tem permitido um melhor entendimento do que se passa no homem e nos reservatórios domésticos e silvestres (Lainson \& Rangel, 2005; Schubach et al., 2001). A escolha do modelo a ser utilizado, no entanto, é um ponto crucial em tais estudos, uma vez que ele deve representar da melhor maneira possível as condições que queremos analisar.

Neste capítulo temos por objetivo expor a variedade de modelos disponíveis para o estudo da leishmaniose tegumentar, comentando sobre alguns dos avanços científicos que foram possíveis graças a sua utilização.

\section{LEISHMANIA (L.) MAJOR: A CONSTRUÇÃO DA IMUNOPATOLOGIA DAS LEISHMANIOSES}

Os camundongos são os mais bem conhecidos e mais utilizados modelos mamíferos para o estudo de doenças infecciosas, genética, imunologia, toxicologia etc. Seu porte pequeno, facilidade de se reproduzir em cativeiro, amabilidade, rápido tempo de geração e tamanho da prole são algumas das características que o tornam modelos bastante práticos. Muito mais do que isso, o Projeto Genoma Camundongo apontou a grande semelhança entre o genoma deste animal e o do homem. Em uma comparação feita utilizando-se resultados preliminares com $96 \%$ do 
genoma do camundongo completo, e outros tanto do genoma humano, admitiu-se que mais de $90 \%$ dos dois genomas poderiam ser particionados em regiões correspondentes, revelando que a ordem dos genes no ancestral comum mais recente foi mantida em ambas as espécies. Além disso, mais de 40\% do genoma do humano poderia ter seus nucleotídeos alinhados com o genoma do camundongo. Na realidade, a proporção de genes de camundongo sem nenhum homólogo detectável no homem parece ser de menos de 1\% do total (Waterston et al., 2002). Sua semelhança com o genoma humano, associada ao fato de suportar bem a consanguinidade, além de todas as vantagens citadas antes, e ainda o baixo custo de sua manutenção, tornaram o camundongo o modelo de escolha para o estudo de fisiologia, biologia do desenvolvimento, imunologia, patologias humanas, entre outros.

Dessa forma, grande parte dos estudos em leishmaniose tegumentar foram então realizados nesse organismo. Investigações experimentais no modelo murino empregando a L. (L.) major, isoladas no Mediterrâneo, foram extremamente importantes, pois estabeleceram o paradigma Th1/Th2. Isto é, foi visto que a resistência a essa infecção é em grande parte controlada pela genética do hospedeiro. Assim, os camundongos da linhagem C57BL/6 cicatrizam espontaneamente após o desenvolvimento de uma lesão cutânea e os animais se tornam resistentes a um novo desafio, constituindo-se então num bom modelo para a forma humana da leishmaniose tegumentar causada por $L$. (L.) major. Por sua vez, a linhagem BALB/c, quando infectada com essa mesma amostra de Leishmania, desenvolve uma infecção que se torna sistêmica e mata o camundongo em algumas semanas (Kellina, 1973; Nasseri \& Modabber, 1979). Evidenciou-se que a linhagem resistente C57BL/6 desenvolve uma resposta Th1 que se baseia na produção de IL-12 e $\gamma$-interferon ( $\gamma$-IFN) e a consequente ativação dos macrófagos, que têm a capacidade de controlar a proliferação dos parasitos e o desenvolvimento da lesão pela $L$. (L.) major. De modo contrário, a linhagem BALB/c, que é sensível, desenvolve uma resposta do tipo Th2, exprimindo citocinas como IL-4 e IL-5 (Scott et al., 1988).

Camundongos BALB/C tratados por anticorpos anti-IL-4 no momento da infecção ou animais deficientes para o gene IL-4 conseguem resolver a infecção (Sadick et al., 1990; Kopf et al., 1996), o que demonstra o papel fundamental dessa citocina no desenvolvimento da imunidade contra o parasito. Três dias após a injeção de promastigotas mortos ou extratos parasitários, os gânglios provenientes de BALB/c passam a produzir $\gamma$-IFN, IL-4 e IL-5, enquanto os gânglios de linhagens C57BL/6 imunizados com os mesmos antígenos produzem apenas $\gamma$-IFN. Apesar do importante papel da IL-4, quando camundongos $\mathrm{C} 3 \mathrm{H}$, também resistentes, são tratados por injeções dessa citocina no momento da infecção, eles desenvolvem uma forte resposta Th2 que, por ser transitória, não reverte seu fenótipo resistente (Chatelain, Varkila \& Coffman, 1992). De forma semelhante, muito embora tenhamos evidências do papel central do $\gamma$-IFN na resistência à infecção por Leishmania, a administração dessa citocina aos camundongos sensíveis não é suficiente para protegê-los contra a infecção por Leishmania (Sacks \& Noben-Trauth, 2002).

Devemos chamar atenção também para o fato de que a administração de IL-12 a camundongos BALB/c induz uma proteção extremamente eficaz e que este efeito protetor contra $L$. (L.) major está associado à menor produção de IL-4 e ao aumento da síntese de $\gamma$-IFN (Heinzel et al., 1993). Tanto na leishmaniose humana quanto na experimental, o desenvolvimento de uma imunidade depende da produção de $\gamma$-IFN induzido pela IL-12. Vemos que o $\gamma$-IFN é capaz de ativar os macrófagos infectados que eliminarão os parasitos via produção de óxido nítrico (NO) (Sacks \& NobenTrauth, 2002; Reiner \& Locksley, 1995). Alguns autores empregando extratos de Leishmania conseguem induzir uma proteção contra Leishmania desde que os antígenos sejam injetados juntamente com a IL-12 (Mougneau et al., 1995).

Desde quando foram descritas as diferenças de suscetibilidade de cada linhagem de camundongo à infecção por L. (L.) major até hoje, muitos estudos foram realizados utilizando-se o modelo murino, explorando especialmente a dicotomia entre as linhagens C57BL/6 e BALB/c e o paradigma Th1/Th2. Embora alguns autores defendam que esse paradigma simplifica mecanismos imunológicos mais complexos (discutido por Sacks e Noben-Trauth, 2002), o estudo das linhagens C57BL/6 e BALB/c foi fundamental para a melhor compreensão da imunopatologia das leishmanioses. 


\section{AS PRINCIPAIS LEISHMÂNIAS DO NOVO MUNDO: L. (L.) AMAZONENSIS E L. (V.) BRAZILIENSIS}

L. (V.) braziliensis é a espécie mais importante como agente da leishmaniose tegumentar americana, sendo a espécie de mais ampla distribuição no Novo Mundo e responsável por um grande problema de saúde pública. Suas manifestações clínicas variam de úlceras cutâneas a formas mucocutâneas erosivas com destruição do trato nasofaringeal.

O ensaio dessa Leishmania em modelo murino, entretanto, apresenta dificuldades. Em modelos experimentais, a $L$. (V.) braziliensis se desenvolve melhor no hamster (Mesocricetus auratus) ou em primatas. Embora o modelo murino infectado por L. (V.) braziliensis tenha sido retomado por alguns grupos (Pereira et al., 2009), a facilidade de infecção experimental empregando L. (L.) amazonensis determinou um amplo predomínio dessa espécie sobre as investigações experimentais com $L$. (V.) braziliensis. É interessante salientar que as investigações com $L$. (L.) amazonensis no modelo murino permitem o estudo de diferentes aspectos da leishmaniose tegumentar, uma vez que é possível se obter uma lesão localizada com cura espontânea, assim como uma doença que evolua para uma lesão de mucosa. Finalmente, tal modelo também proporcionou resultados extraordinários nos estudos da forma difusa (Cupolilo et al., 2003).

Um dos grandes problemas que devem ser discutidos envolve conhecimentos estabelecidos sobre a imunologia das leishmanioses de maneira geral, quando diferentes grupos de pesquisadores tentam estabelecer uma correlação entre a imunopatologia da leishmaniose cutânea humana e os resultados obtidos nos modelos experimentais. Esses resultados são geralmente obtidos com uma espécie de Leishmania, predominando os resultados obtidos com $L$. (L.) major, e a seguir generalizados para outras. Algumas coisas básicas podem ser generalizadas, como, por exemplo, o papel do $\gamma$-IFN, que é importante no controle não apenas de aspectos clínicos causados por uma espécie de Leishmania, mas de muitas infecções, principalmente em casos de parasitos de macrófagos. Um dos pontos cuja generalização leva a conclusões equivocadas é o fato de que os resultados obtidos em modelos experimentais partem do princípio de que a linhagem C57BL/6 é resistente às infecções por Leishmania; esses camundongos são considerados como uma linhagem que recapitula os pontos mais importantes da infecção humana por esse parasito. Os resultados que temos obtido utilizando a linhagem C57BL/6 infectada por L. (L.) amazonensis são, em muitos aspectos, completamente diferentes dos resultados obtidos com L. (L.) major. Conforme já discutido, os camundongos C57BL/6 infectados com L. (L.) major desenvolvem uma lesão cutânea capaz de evoluir para a cura espontânea semelhante ao que pode ocorrer na infecção no homem (Stebut, 2007). Quando se analisa o comportamento de uma cepa de L. (L.) amazonensis isolada de um paciente com forma difusa, em três linhagens diferentes de camundongos, observamos o desenvolvimento de uma lesão nodular progressiva que evolui para uma lesão ulcerada. As linhagens BALB/c, C57BL/6 e C57BL/10 são consideradas suscetíveis nos ensaios que realizamos empregando um desafio de $10^{4}$ amastigotas purificadas. Observamos nesses modelos o desenvolvimento de metástases nas diferentes patas, cauda, focinho e mucosa oral. A ocorrência de amputação espontânea da pata infectada inicialmente foi frequente nos experimentos. Podemos considerar também esses camundongos como excelentes modelos para estudos de forma mucocutânea, uma vez que pode ocorrer comprometimento de boca e focinho (Cupolilo et al., 2003). Dessa forma, vemos que a linhagem C57BL/6 é sensível para L. (L.) amazonensis (Figura 1).

A resistência de C57BL/6 às infecções por L. (L.) major está correlacionada à produção de $\gamma$-IFN, que ativa os macrófagos infectados pelo parasito que serão eliminados pelo NO produzido. A cura da leishmaniose cutânea é dependente de células Th1. O $\gamma$-IFN é igualmente essencial ao controle da L. (L.) amazonensis. Estudos com camundongos C57BL/6 deficientes para $\gamma$-IFN ( $\gamma$-IFN knockout) mostraram que esses animais desenvolvem uma patologia mais grave que os animais não deficientes da mesma linhagem. Essa diferença entretanto não é observada nos primeiros dois meses após a infecção, sugerindo que o $\gamma$-IFN não seja necessário no início da infecção (Pinheiro \& Rossi-Bergmann, 2007). 
Figura 1 - 0 camundongo C57BL/6 e sua sensibilidade à L. (L.) amazonensis

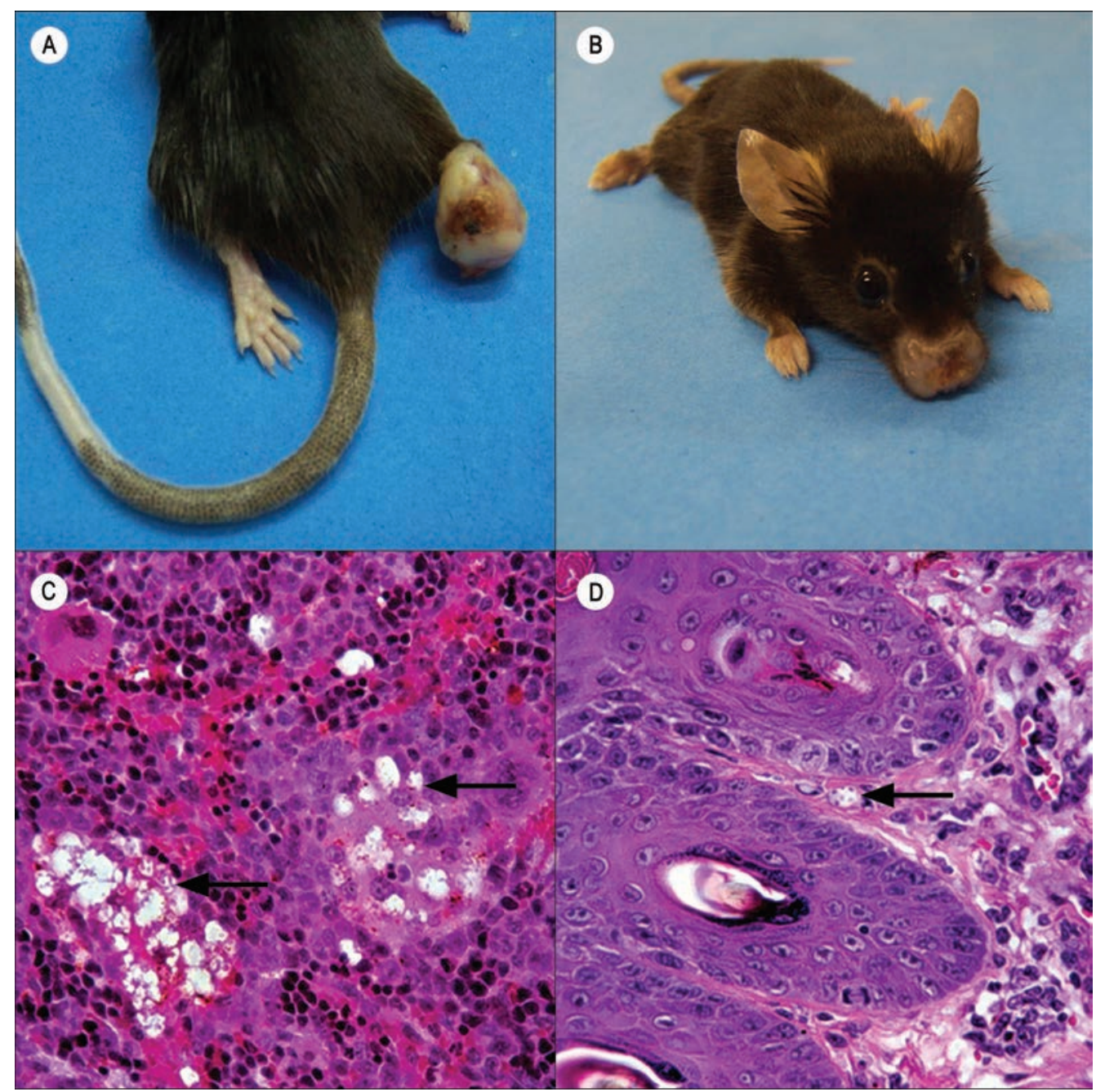

A - Lesão no coxim plantar 90 dias após a infecção com $10^{4}$ promastigotas; B - Lesão metastática, ulcerada no focinho 90 dias após a infecção por $10^{6}$ promastigotas de L. (L.) amazonensis no coxim plantar; C - Histopatologia do baço 90 dias após a infecção por $10^{6}$ promastigotas de L. (L.) amazonensis no coxim plantar. Presença de amastigotas (setas) 400x; D - Histopatologia da pele do focinho 90 dias após a infecção por $10^{6}$ promastigotas de L. (L.) amazonensis no coxim plantar. Presença de amastigotas (seta) 400x. Coloração por eosina e hematoxilina.

Utilizando a L. (L.) amazonensis também tivemos a oportunidade de estudar a importância da resposta Th1 em ensaios vacinais empregando camundongos albinos (Swiss Webster). Animais vacinados com fração microssomal de L. (L.) amazonensis sob a imunomodulação do Mycobacterium bovis BCG e da ciclofosfamida foram protegidos contra a infecção experimental, e mostraram uma indução bastante forte de resposta Th1 (Zaverucha do Valle, 2005) (Figura 2). Neste modelo, o BCG atua imunomodulando a resposta imunológica do camundongo, uma vez que induz o desenvolvimento de uma resposta Th1 e atrai células inflamatórias, em especial macrófagos, para o local de inoculação. Dessa forma, quando injetamos o antígeno vacinal dentro do granuloma do BCG, encontramos ali um ambiente favorável para o desenvolvimento de uma resposta protetora efetiva. A ciclofosfamida é um imunossupressor que provoca forte leucopenia. Entretanto, quando cessa esse efeito citotóxico ela causa um efeito rebote, que se traduz em leucocitose. Assim, quando utilizada no momento certo, a ciclofosfamida também pode atuar como um imunomodulador que auxilia no desenvolvimento da resposta protetora. 
Figura 2 - Camundongos albinos heterozigotos (Swiss Webster), vacinados com fração microssomal de L. (L.) amazonensis sob imunomodulação de BCG e ciclofosfamida, mostram proteção contra a infecção por $10^{4}$ de amastigotas do parasito no coxim plantar traseiro

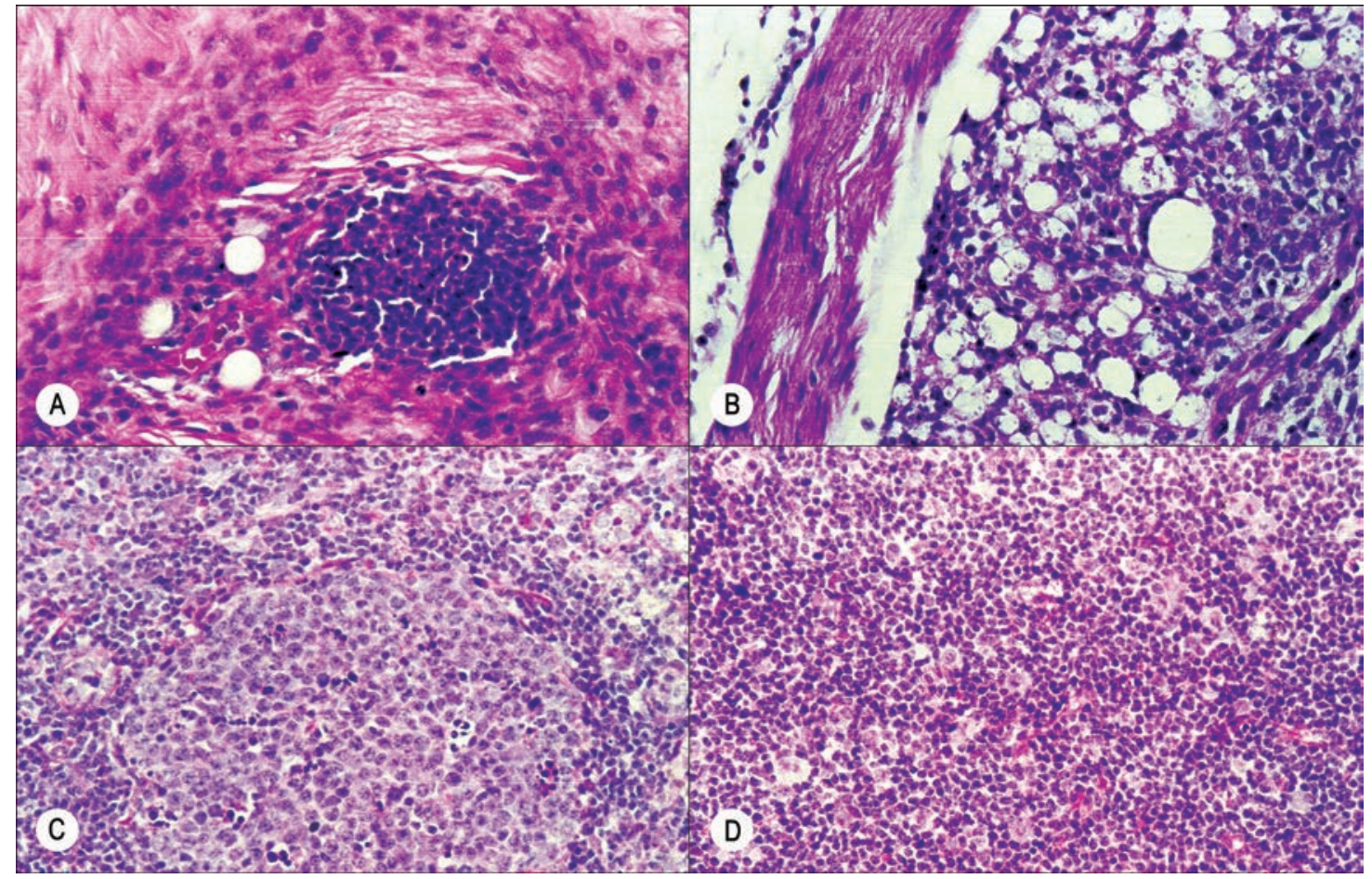

A - Histopatologia do coxim plantar de um animal vacinado 21 dias após a infecção. Presença de forte infiltrado inflamatório no local da infecção; B - Histopatologia do coxim plantar de um animal-controle (somete infectado) 21 dias após a infecção. Presença maciça de amastigotas no local da infecção; C - Histopatologia do linfonodo drenante ao local da infecção, após 21 dias, em animal vacinado. Observa-se zona de intensa linfoproliferação; D - Histopatologia do linfonodo drenante ao local da infecção, após 21 dias, em animal-controle. Sem alterações. 400x. Coloração por eosina e hematoxilina.

Dentro desse quadro, precisamos investigar vários aspectos do estado de resistência que podemos induzir com frações subcelulares de membrana, flagelo e microssomal, em camundongos previamente imunizados com o BCG, podendo-se incluir um imunomodulador como a CY, antes do desafio com a forma infectante.

Assim, esse esquema de vacinação nas infecções por Leishmania torna-se uma poderosa arma e podemos considerar que a produção de citocinas pró-inflamatórias como TNF, IL-12 e IL-6 são essenciais na ativação de uma resposta imunológica protetora contra patógenos intracelulares. TNF e IL-12 são fatores importantes em induzir a imunidade protetora e induzir a produção de $\gamma$-IFN pelas células T. Ficou demonstrado que a produção de IL-12 no camundongo é fundamental para o desenvolvimento de uma imunidade protetora contra um desafio intravenoso por $M$. tuberculosis (Cooper et al., 1997). Os estudos no modelo murino têm evidenciado que o TNF e o $\gamma$-IFN são fundamentais para a expressão de óxido nítrico induzível (iNOS), que tem papel-chave na morte dos amastigotas e outros microrganismos parasitas de macrófagos. Todavia, podemos afirmar que a produção em excesso de TNF contribui para a exacerbação dos processos inflamatórios das lesões causadas por Leishmania. Outro aspecto a ser considerado é o fato de que a citocina anti-inflamatória IL-10 controla de maneira efetiva o TNF, IL-12 e $\gamma$-IFN, diminuindo drasticamente os níveis dessas citocinas. Foi evidenciado que penetrando no macrófago a Leishmania pode, pelo menos parcialmente, inibir a ativação da célula do hospedeiro pelo $\gamma$-IFN, o que conduz a uma baixa produção de $\mathrm{O}_{2}, \mathrm{H}_{2} \mathrm{O}_{2}$ e NO (Mauel, 1996).

É preciso enfatizar que o fosfoglucano, uma importante molécula da superfície da Leishmania, inibe seletivamente a síntese de IL-12 pelo macrófago. Essa inibição da produção de IL-12 pelo macrófago constitui uma estratégia para a 
sobrevivência do parasito, retardando a produção de $\gamma$-IFN e inibindo a produção de NO pelo macrófago. O fosfoglucano, na realidade, engloba três moléculas diferentes: o lipofosfoglucano (LPG), a fosfatase ácida que é secretada e o proteofosfoglucano (Mengeling, Beverley \& Turco, 1997). Assim, no modelo de vacinação em que empregamos a fração microssomal modulada pelo BCG e pela CY podemos observar, no primeiro dia após a infecção por L. (L.) amazonensis, níveis séricos bastante elevados de $\gamma$-IFN e baixos níveis de IL-10. Quando comparamos com o grupo controle que só recebeu a dose de infecção, os níveis de $\gamma$-IFN são baixos (Zaverucha do Valle, 2005; Zaverucha do Valle et al., 2007). Nesse contexto, devemos considerar que os ensaios de vacinação que dão um estado de proteção indiscutível permitem avaliar os fatores que garantem o conhecimento das condições imunológicas que induzem resistência em diferentes hospedeiros experimentais.

As infecções pelas diferentes espécies de Leishmania vêm se expandindo pelo mundo. No caso da L. (L.) amazonensis podemos constatar que hoje em dia, na Região Centro-Oeste do Brasil, ela ocorre na cidade de Campo Grande, a capital do estado, e no município de Dourados, em Mato Grosso do Sul (Dorval et al., 2006). Ela está determinando infecções no homem com uma característica espectral que vai de casos cutâneos a formas viscerais (Barral et al., 1991). Como tem sido discutido por alguns autores, a leishmaniose tende a ser mais grave em áreas onde ela acaba de ser introduzida (Vieira \& Coelho, 1998). Tal fato requer uma investigação em modelos experimentais visando a avaliar a virulência das amostras que têm sido isoladas do homem e de reservatórios domésticos e silvestres.

No Rio de Janeiro, durante anos ocorria apenas L. (V.) braziliensis causando formas cutâneas e mucocutâneas (Oliveira-Neto et al., 2000, Grimaldi et al., 1989). Recentemente foi diagnosticado o primeiro caso de forma cutâneodifusa autóctone, causada por L. (L.) amazonensis no Rio de Janeiro. Esse caso, caracterizado por lesões cutâneas múltiplas e progressivas, apresentando resistência à quimioterapia, foi encontrado em uma criança na cidade de Paraty (Azeredo-Coutinho et al., 2007). O teste cutâneo conhecido como reação de Montenegro foi negativo e a análise histopatológica mostrou um infiltrado mononuclear na derme com macrófagos altamente parasitados, $L$. (L.) amazonensis foi identificada por eletroforese de isoenzima e PCR-RFLP (Azeredo-Coutinho et al., 2007). Nosso grupo de pesquisa tem estudado no modelo murino algumas espécies de Leishmania causadoras da infecção no homem e em reservatórios domésticos e silvestres. Assim, utilizando diferentes técnicas de diagnóstico e avaliando o comportamento das cepas isoladas nos modelos experimentais, podemos ter uma ideia melhor das características biológicas da espécie de Leishmania isolada e as variações de cepas de uma determinada espécie. A preocupação com a expansão das leishmanioses na Região Centro-Oeste determinou o emprego de várias técnicas de biologia molecular para a detecção e identificação, de forma mais precisa, das espécies de Leishmania que estão ocorrendo antes do início dos experimentos no modelo murino, que é o foco principal da linha de pesquisa de nosso grupo de trabalho. Nesse último caso, o emprego de diferentes linhagens de camundongos inbred abriu caminho para as pesquisas com $L$. (L.) amazonensis (Cupolilo et al., 2003; Cupolilo, 2002).

Como discutimos anteriormente, o estudo de L. (V.) braziliensis em modelo animal é geralmente realizado em hamsters ou primatas, uma vez que o camundongo é resistente à infecção por essa espécie de Leishmania. O hamster é comumente utilizado para o isolamento do parasito obtido de lesões de pacientes, podendo também ser utilizado em estudos de quimioterapia (Sinagra et al., 2007). O macaco rhesus também se mostrou suscetível à infecção por L. (V.) braziliensis, desenvolvendo uma doença semelhante à de humanos (Teva et al., 2003) e tem sido utilizado em estudos de imunologia e imunoproteção (Grimaldi Jr., 2008). Um trabalho utilizando esses animais infectados por L. (V.) braziiensis permitiu o estudo de diferentes momentos na infecção. Os autores observaram desde a formação da lesão até a cura espontânea, que ocorreu em seis meses. O estudo mostrou que neutrófilos estão envolvidos de forma decisiva no controle do parasito e na inflamação nos primeiros momentos da infecção. Além disso, granulócitos infectados fagocitados por células monocíticas parecem participar do estabelecimento da lesão. De forma semelhante, o modelo também mostra que células $\mathrm{CD}^{+}$e $\mathrm{CD} 8^{+}$produtoras de $\gamma$-IFN e $\alpha$-TNF são importantes na cura da lesão 
(Souza-Lemos et al., 2008). Esse primata pode ser muito interessante para compreender os diferentes aspectos da doença em um modelo muito semelhante ao homem, podendo assim ser utilizado em estudos de vacinação.

\section{LEISHMANIA (L.) MEXICANA: SUA IMPORTÂNCIA EM PAÍSES DO NOVO MUNDO}

Leishmania (L.) mexicana está envolvida principalmente com formas cutâneas, infectando o homem e vários hospedeiros vertebrados. Podemos encontrá-la na América do Norte, Central e do Sul, tendo vários vetores assinalados na literatura, dos quais destacamos Lu olmeca e Lu anthophora. No México causa no homem a úlcera de chiclero - lesões, em geral nas orelhas, que aparecem em trabalhadores que fazem a extração da borracha das árvores (seringueiras). Nos Estados Unidos, as investigações realizadas no Sul e região central do Texas têm mostrado casos autóctones de homens com leishmaniose cutânea. Esses autores observaram que roedores silvestres como Neotoma micropus apresentam lesões na base da orelha (McHugh, Grogl \& Kerr, 1990; McHugh, Melby \& LaFon, 1996). Ensaios experimentais realizados em camundongos da linhagem C57BL/10 apresentaram um comportamento semelhante com inoculações subcutâneas quando variações genéticas nessa cepa foram testadas. Tais variações genéticas (alelos alternativos a níveis Lsh, H-2 ou H-11) indicaram, entretanto, alguma influência na visceralização e expansão de metástases (Roberts, Alexander \& Blackwell, 1989).

Quando realizamos experimentos em hamster, com a dose de infecção numa das patas do animal, vamos observar que esta espécie invade rapidamente o linfonodo drenante, lá se multiplicando intensamente. Temos com frequência a formação de metástases nas outras patas, nas orelhas e no focinho.

Já no modelo murino, ficou evidenciado que quatro linhagens de camundongos singênicos, como AKR, C57BL/6, DBA/2 e NMRI são relativamente resistentes à leishmaniose cutânea causada por L. (L.) mexicana. BALB/c foi considerado o mais sensível, tendo sido demonstrado, além disso, que os camundongos híbridos oriundos do cruzamento de machos da linhagem C57BL/6 com fêmeas BALB/c não eram mais sensíveis que o C57BL/6, ficando assim evidenciado que a resistência é consequência de um caráter hereditário dominante (Perez, Malave \& Arredondo, 1979). Tem sido observado que as fêmeas da linhagem DBA/2 são relativamente mais resistentes à infecção por L. (L.) mexicana quando comparamos com os machos. Viu-se que a produção de $\gamma$-IFN é um fator importante, por si só suficiente para bloquear o crescimento de L. (L.) mexicana em fêmeas DBA/2. Quando as observações chegam a um tempo maior, como 12 semanas, observou-se que os machos apresentam amplas lesões que não cicatrizam, que as fêmeas apresentam lesões muito pequenas e que o $\gamma$-IFN é detectado apenas nas fêmeas (Satoskar \& Alexander, 1995).

\section{INFECÇÕES NA COBAIA POR LEISHMANIA (L.) ENRIETTII}

A Leishmania (L.) enriettii é uma espécie que foi descoberta parasitando espontaneamente cobaias domésticas (Cavia porcellus) no estado do Paraná, Brasil, provocando lesões cutâneas exuberantes, principalmente aquelas que se localizam no pavilhão auricular (Medina, 1946). As infecções por L. (L.) enriettii produzem uma lesão local que se assemelha em muitos aspectos ao botão do oriente, lesão muito característica causada por $L$. (L.) major. São lesões que cicatrizam com o desenvolvimento de hipersensibilidade retardada que surge após certo período da infecção e é revelada pelo teste de Montenegro. Metástases ocorrem com frequência em áreas do corpo desprovidas de pelos, como o nariz, orelhas, lábios, patas e genitália (Bryceson et al., 1970).

A interação de $L$. (L.) enriettii com macrófagos ativados de cobaia tem sido bastante estudada há vários anos. É importante salientar que após inoculações subcutâneas na cobaia, essa espécie de Leishmania induz tanto uma resposta mediada por células quanto a produção de anticorpos. A cicatrização, que ocorre em geral após três meses, deixa o animal com uma imunidade consistente e favorece as investigações in vitro. Os estudos histopatológicos foram 
realizados há muitos anos no Instituto Oswaldo Cruz, cujos resultados revelaram o crescimento da lesão com intensa proliferação de formas amastigotas na pele de cobaias (Magarinos-Torres, Muniz \& Cardoso, 1948). O esfregaço das lesões em uma lâmina corada pelo May-Grünwald-Giemsa permitiu a observação das formas amastigotas e seus aspectos morfológicos. Esses estudos morfológicos foram facilitados pelo grande tamanho dos amastigotas.

Além disso, o crescimento extraordinário das lesões nodulares cutâneas nas orelhas é frequente. Os cortes histológicos apresentam um infiltrado dérmico abundante e difuso de macrófagos, plasmócitos, linfócitos. Os macrófagos apresentam sempre vacúolos parasitóforos que permitem o estudo morfológico. A observação em meios de cultura no laboratório colocou essa espécie de Leishmania em um modelo exemplar também para estudos bioquímicos e de biologia molecular, servindo de base para investigações na área da quimioterapia.

Por sua vez, o estudo das infecções experimentais com L. (L.) enriettii nas cobaias constitui um modelo que contribui bastante para os conhecimentos que temos sobre a imunologia das leishmanioses. Esta infecção induz imunidade celular e imunidade humoral contra os antígenos do parasito, sendo que a hipersensibilidade retardada torna-se detectável sete dias após a dose de desafio $\left(10^{6}\right)$, aumentando nas quatro semanas iniciais. Células recolhidas dos linfonodos respondem in vitro, ocorrendo transformação blástica e liberação de linfocinas. Estudos realizados com esse modelo experimental demonstraram, com clareza, a transferência de hipersensibilidade retardada para animais não imunizados (Doyle et al., 1974; Mauel, Behin \& Noerjasi, 1973). A proteção pode ser detectada pela associação de infecção e quimioterapia (El-on, Witztum \& Schnur, 1986) e estudos histopatológicos envolvendo a eliminação de L. (L.) enriettii têm sido realizados (Monroy et al., 1980).

A ocorrência de infecções naturais por $L$. (L.) enriettii foram raramente descritas, porém mais recentemente tem sido observada nos arredores de Curitiba, no município de Itaara no Rio Grande do Sul e no estado de São Paulo (Machado et al., 1994; Ecco et al., 2000; Luz, Giovannoni \& Borba, 1967).

\section{LESÕES CUTÂNEAS POR L. (L.) INFANTUM}

A espécie L. (L.) infantum Nicolle 1908, provoca no homem e no cão uma doença espectral, que varia de formas cutâneas localizadas, formas viscerais assintomáticas e formas viscerais extremamente graves (Bensaid et al., 2006; Carnauba et al., 2009; Gradoni \& Gramiccia, 1994; Hatam, Hosseini \& Ardehali, 1997). O cão é considerado um reservatório doméstico extremamente importante da $L$. (L.) infantum na China, nos países da bacia do Mediterrâneo e nas Américas, aparecendo em novas áreas endêmicas, altamente infectado com essa espécie de Leishmania, encontrada em diversos órgãos, em lesões cutâneas, bem como na pele íntegra (Cortada et al., 2004; Gradoni, 2001; Madeira et al., 2004). Uma das situações comuns é a que ocorre no campo, tanto aqui como em muitos outros países, onde o cão fica solto, muitas vezes no meio do gado, e é conhecido como "um cão perdido", o que agrava os problemas de controle da epidemiologia das leishmanioses (Guerin et al., 2002). Podemos citar como exemplo os resultados obtidos com alta incidência de positividade como 80\% em Marselha, na França, 67\% em Majorca, na Espanha e 70\% em Anastácio, Mato Grosso do Sul, Brasil, o que evidencia a importância epidemiológica do cão como reservatório dessa infecção (Cortada et al., 2004; Berrahal et al., 1996; Solano-Gallego et al., 2001).

A importância das investigações com L. (L.) infantum em modelos experimentais, tanto no cão quanto no hamster, é a de entender problemas que ocorrem nas infecções humanas e nos reservatórios domésticos. O cão constitui um excelente modelo para o estudo tanto da leishmaniose visceral quanto da leishmaniose tegumentar. Muitos aspectos dos sintomas que ocorrem nos cães são semelhantes àqueles que ocorrem em humanos e, assim, constituem um bom modelo para as leishmanioses. Devemos considerar como exceções a perda de pelos, o crescimento exagerado das unhas etc. (Peters \& Killick-Kendrick, 1987). O progresso que tem sido obtido na leishmaniose canina poderá trazer 
uma grande ajuda nos avanços que tentamos obter nas investigações da leishmaniose humana. o grande problema que dificultou tal avanço foi a falta de marcadores imunológicos e reagentes para os cães, o que favoreceu uma extraordinária evolução na leishmaniose experimental no modelo murino (Solbach \& Laskay, 2000). Recentemente, alguns progressos foram alcançados pela biologia molecular por meio da clonagem e do sequenciamento de muitas citocinas de cão, o que refletiu em importantes estudos sobre a imunologia, o desenvolvimento de vacinas e de várias técnicas de diagnóstico para a leishmaniose canina (Argyle et al., 1999; Devos et al., 1992; Pinelli et al., 1999; Quinnell et al., 2001; Reis et al., 2010).

A caracterização de linhagens de L. (L.) infantum com tropismo cutâneo tem sido feita utilizando-se um painel enzimático, apresentando 15 loci, que permite diferenciar dois grupos com zimodema Montpellier (MON I), característico de cepas tipicamente causadoras de leishmaniose visceral. Vários estudos mostraram que as cepas com características de um zimodema relacionado a formas cutâneas podem estar envolvidas com lesões nodulares, lesões ulceradas e lesões de mucosa. Os estudos baseados no polimorfismo genético de L. (L.) infantum têm sido obtidos com experimentos empregando a digestão do kDNA com endonucleases, e apontaram diferenças inquestionáveis entre cepas viscerotrópicas e cepas com tropismo cutâneo (Angelici, Gramiccia \& Gradoni, 1989). A grande dificuldade de investigações comparando cepas viscerotrópicas com aquelas que apresentam tropismo cutâneo (Gradoni \& Gramiccia, 1994; Hatam, Hosseini \& Ardehali, 1997), é que estas cepas não infectam camundongos isogênicos (Pozio et al., 1985). Dessa forma, os estudos experimentais com L. (L.) infantum têm sido realizados sobretudo em cães (Travi et al., 2009). Uma das questões levantadas é se estamos tratando de tropismo de cepas de L. (L.) infantum ou de estados imunológicos dos hospedeiros.

\section{DROGAS IMUNOSSUPRESSORAS E SEUS EFEITOS NO CURSO DAS LEISHMANIOSES}

Um outro modelo experimental muito importante no estudo das leishmanioses é o do animal imunossuprimido. Nas últimas décadas, com o aumento dos casos de HIV, das cirurgias de transplante e dos tratamentos quimioterápicos contra o câncer, a importância desse modelo tem crescido muito. As leishmanioses são doenças oportunistas e a imunossupresão do hospedeiro pode levar a casos graves, com evolução bastante diferente daquela observada em hospedeiro imunocomptentes. Assim, formas viscerais assintomáticas no homem podem evoluir para formas sintomáticas de diferentes padrões de gravidade após algum efeito imunossupressor, dos quais o mais impactante tem sido as infecções concomitantes com o vírus HIV. Além disso, amplos estudos têm indicado que muitos casos com lesões cutâneas após uma infecção pelo vírus HIV evoluem para uma forma visceral. Finalmente, o tratamento de doenças com drogas imunossupressoras também determina modificações no curso dessas infecções espectrais como as leishmanioses (Motta et al., 2003).

Desse modo, diferentes autores têm investigado a ação de drogas imunossupressoras no curso de infecções por diferentes espécies de Leishmania. Nesse particular, temos amplas investigações sobre os efeitos da ciclosporina A (CsA), da ciclofosfamida e dos corticosteroides. A CsA é um metabolito extraído de fungos (Tolypocladium inflatum). Sendo um polipeptídeo de 11-aminoácidos, cíclico, lipofílico, altamente estável e insolúvel em água, vem sendo amplamente empregada em transplante de órgãos no homem desde o início dos anos 1980 pelas suas propriedades imunossupressoras. A CsA é capaz de inibir a formação de lesões causadas por $L$. (L.) tropica no modelo murino quando a linhagem BALB/c é empregada (Behforouz, Wenger \& Mathison, 1986; Solbach, Forberg \& Rollinghoff, 1986). Quanto a isso, devemos ressaltar que a CsA não tem nenhuma ação tóxica sobre as formas amastigotas. Trata-se de uma droga citotóxica, inibidora do primeiro sinal para ativação do linfócito T (Alvarez et al., 2004; Garcia et al., 2004). A CsA aumenta a expressão de TGF- $\beta$ e inibe a produção de IL-2 por população e de células T, contribuindo assim para a inibição de diferentes fatores, incluindo $\gamma$-IFN, GM-CSF e CM-CSF. A CSA não é mielossupressora nas doses consideradas 
supressoras nos experimentos imunológicos desenvolvidos normalmente em vários laboratórios, sendo seus efeitos reversíveis após um período de terapia descontínua (Wong, Winslow \& Cooper, 1993). É interessante salientar que outras investigações revelaram que doses diárias de CsA exacerbam a infecção por $L$. (L.) donovani em linhagens C57BL/10. Tal linhagem, quando recebe um desafio de $10^{6}$ amastigotas por via intravenosa, controla a infecção após alguns meses (Adinolfi \& Bonventre, 1990). Uma área cujas pesquisas ainda precisam de aprofundamento é a que se relaciona às investigações empregando CsA em diferentes linhagens de camundongos infectados com diferentes espécies de Leishmania.

Outra droga imunossupressora a ser enfatizada é a ciclofosfamida (CY), um agente alquilante derivado do gás mostarda (Turk, 1978) que foi introduzida na quimioterapia do câncer. Nos modelos experimentais de infecções, tem a propriedade de bloquear a ação de células T supressoras. Sua ação em diferentes infecções varia em função do tempo de sua aplicação, que tem sido feita inclusive antes ou depois do desafio com o agente infeccioso (Zaverucha do Valle et al., 2007; Gonçalves da Costa, Santos \& Lagrange, 1988). Tal ação é semelhante à que se obtêm com uma dose de irradiação subletal de Raios X (550 rad) poucas horas antes da infecção (Ulczak \& Blackwell, 1983). Em infecções por L. (L.) enriettii em cobaias, o tratamento com elevada dose $(300 \mathrm{mg} / \mathrm{kg})$ de ciclofosfamida três dias antes da infecção gera lesões muito maiores e um prolongamento do processo inflamatório, o que determina a cicatrização muito mais tardiamente se comparada à lesão do grupo-controle (Turk \& Belehu, 1974).

A cortisona tem contribuído para o agravamento das infecções por Leishmania, pois está envolvida em tratamento de diferentes doenças e vem sendo administrada como rotina na clínica médica. Nos últimos 25 anos essa droga tem aumentado de forma extraordinária os casos assintomáticos de leishmaniose visceral, tanto no Mediterrâneo quanto na América do Sul (Pittalis et al., 2006). Outro fato que precisa ser enfatizado é o que diz respeito à ocorrência de reativação da infecção por tratamento sistêmico com corticosteroide, após um longo período de tratamento encerrado com 'cura clínica' (Tuon et al., 2007). Além disso, formas mucocutâneas disseminadas pelo uso crônico de corticosteroide vêm sendo registradas na literatura (Motta et al., 2003). Ensaios experimentais no modelo murino determinam uma depressão dos linfócitos circulantes, bem como o sequestro de linfócitos periféricos na medula óssea (Cohen, 1972). O emprego da cortisona antes da imunização com um antígeno mostra um efeito depressivo na hipersensibilidade retardada e suprime a síntese de imunoglobulinas, especialmente o tipo 7S (Elliott \& Sinclair, 1968). Observou-se que a cortisona é capaz de influenciar os linfócitos de vida curta e nos casos em que a expressão da imunidade celular estava estimulada pelo BCG, o tratamento pela cortisona bloqueou os efeitos de proteção induzidos pelo próprio BCG (Smrkovski, Reed \& Larson, 1980). Em resumo, podemos dizer que a cortisona no modelo murino induz a uma diminuição de linfócitos circulantes, o que determina a liberação de novos linfócitos da medula óssea. O efeito da cortisona na resposta mediada por células atua, em parte, pelos efeitos que atingem o sistema fagocítico mononuclear (Rinehart et al., 1975). O macrófago, principal célula onde reside a Leishmania, constitui-se no maior produtor de IL-12. Assim, após a infecção por Leishmania, ela começa a sobreviver em virtude do baixo nível de produção de $\gamma$-IFN. Complementando esses fatores que favorecem a proliferação dos amastigotas, teremos em consequência a falta de ativação do macrófago e a produção insuficiente de No, cuja molécula é considerada fundamental para matar os amastigotas de Leishmania.

\section{COMENTÁRIOS FINAIS E PERSPECTIVAS}

O conhecimento que se tem atualmente sobre os modelos experimentais nas leishmanioses, tem sido enriquecido com o emprego de imunomoduladores, objetivando-se sobretudo estabelecer mecanismos de resistência. Temse evidenciado que a estimulação de uma resposta Th1 e o envolvimento do $\gamma$-IFN é um caminho-chave para a resolução das lesões por Leishmania. Assim, as investigações com o modelo murino desenvolvido com L. (L.) major 
estabeleceram o conceito de que a linhagem BALB/c é sensível e que os camundongos C57BL/6 são resistentes às infecções experimentais com Leishmania.

Os resultados obtidos com L. (L.) amazonensis têm demonstrado que o C57BL/6 é sensível às infecções, com uma característica bastante interessante: após seis meses de infecção ocorre uma retração da primoinfecção, dando a impressão de que, passado certo tempo, haveria indícios de cura. Entretanto, a infecção segue com uma expansão extraordinária e metástases generalizadas, podendo advir a amputação da pata da primoinfecção. Lesões metastáticas na região nasal, com a ocorrência de muitos macrófagos parasitados, indicam que esse caso pode ser considerado um excelente modelo para estudos de lesões mucocutâneas. Além disso, tem-se observado a invasão da medula óssea, com a ocorrência de macrófagos altamente infectados (Cupolilo et al., 2003). Percebemos, assim, que a ideia de que a linhagem C57BL/6 é resistente tem de ficar restrita aos experimentos com L. (L.) major. O conceito de que a maioria dos camundongos singênicos, como C3H/HeN, CBA, C57BL/6, entre outros, resolvem espontaneamente as lesões (resistentes), é um problema limitado à leishmaniose cutânea do Velho Mundo (Milon, Del Giudice \& Louis, 1995).

Como perspectiva para as investigações, faz-se necessário conduzir experiências a médio e longo prazos, investigando sob o ponto de vista tanto imunológico quanto imunopatológico os modelos experimentais com $L$. (L.) amazonensis. Isso, para que possamos ter ideia dos graves problemas que ela vem trazendo há anos no Novo Mundo, e que agora traz um novo nível de preocupação em razão da expansão de novas áreas epidemiológicas e dos casos de associação das leishmanioses com infecções concomitantes. Nesse último caso, a associação com o vírus HIV tem se expandido, necessitando de estudos imediatos.

\section{REFERÊNCIAS}

ADINOLFI, L. E. \& BONVENTRE, P. F. Cyclosporin A treatment converts Leishmania donovani infected C57BL/10 (curing) mice to a noncuring phenotype. Infection and Immunity, 58(9): 3.151-3.153, 1990.

ALVAREZ, C. M. et al. Kidney transplant patients with long term graft survival have altered expression of molecules associated with T cell activation. Transplantation, 78(10): 1.541-1.547, 2004.

ANGELICI, M. C.; GRAMICCIA, M. \& GRADONI, L. Study on genetic polymorphism of Leishmania infantum through the analysis of restriction enzyme digestion patterns of kinetoplast DNA. Parasitology, 99(3): 301-309, 1989.

ARGYLE, D. J. et al. Cloning, sequencing, and characterization of dog interleukin-18. Immunogenetics, 49(6): 541-543, 1999.

AZEREDO-COUTINHO, R. B. et al. First report of diffuse cutaneous leishmaniasis and Leishmania amazonensis infection in Rio de Janeiro State, Brazil. Transactions of the Royal Society of Tropical Medicine and Hygiene, 101(7): 735-737, 2007.

BARRAL, A. et al. Leishmaniasis in Bahia, Brazil: evidence that Leishmania amazonensis produces a wide spectrum of clinical disease. The American Journal of Tropical Medicine and Hygiene, 44(5): 536-546, 1991.

BEHFOROUZ, N. C.; WENGER, C. D. \& MATHISON, B. A. Prophylactic treatment of BALB/c mice with cyclosporine A and its analog B-5-49 enhances resistance to Leishmania major. The Journal of Immunology, 136(8): 3.067-3.075, 1986.

BENSAID, M. et al. Occurrence of Leishmania infantum cutaneous leishmaniasis in Central Tunisia. Transactions of the Royal Society of Tropical Medicine and Hygiene, 100(6): 521-526, 2006.

BERRAHAL, F. et al. Canine leishmaniasis: identification of asymptomatic carriers by polymerase chain reaction and immunoblotting. The American Journal of Tropical Medicine and Hygiene, 55(3): 273-277, 1996.

BRYCESON, A. D. et al. Cell Mediated Immunity in cutaneous Leishmaniasis of guinea pig. Transactions of the Royal Society of Tropical Medicine and Hygiene, 64(4): 472, 1970.

CARNAUBA JR., D. et al. Atypical disseminated leishmaniasis similar to post-kala-azar dermal leishmaniasis in a Brazilian AIDS patient infected with Leishmania (Leishmania) infantum chagasi: a case report. International Journal of Infectious Diseases, 13(6): E504-E507, 2009. 
COHEN, J. J. Thymus derived lymphocytes sequestered in the bone marrow of hydrocortisone treated mice. The Journal of Immunology, 108(3): 841-844, 1972.

COOPER, A. M. et al. Interleukin 12 (IL-12) is crucial to the development of protective immunity in mice intravenously infected with mycobacterium tuberculosis. The Journal of Experimental Medicine, 186(1): 39-45, 1997.

CORTADA, V. et al. Canine visceral leishmaniosis in Anasticio, Mato Grosso do Sul State, Brazil. Veterinary Research Communications, 28(5): 365-374, 2004.

CUPOLILO, S. M. Reinfecção por Leishmania (L.) amazonensis no Modelo Murino: um estudo histopatológico e imunohistoquímico, 2002. Tese de Doutorado, Rio de Janeiro: Instituto Oswaldo Cruz, Fundação Oswaldo Cruz.

CUPOLILO, S. M. et al. Biological behavior of Leishmania (L.) amazonensis isolated from a human diffuse cutaneous leishmaniasis in inbred strains of mice. Histology and Histopathology, 18(4): 1.059-1.065, 2003.

CHATELAIN, R.; VARKILA, K. \& COFFMAN, R. L. Il-4 Induces a Th2 response in Leishmania major infected mice. Journal of Immunology, 148(4): 1.182-1.187, 1992.

DESJEUX, P. \& ALVAR, J. Leishmania/HIV co-infections: epidemiology in Europe. Annals of Tropical Medicine and Parasitology, 97: 3-15, 2003.

DEVOS, K. et al. Cloning and expression of the canine interferon-gamma gene. Journal of Interferon Research, 12(2): 95$102,1992$.

DORVAL, M. E. et al. [Occurrence of American tegumentary leishmaniasis in the Mato Grosso do Sul State associated to the infection for Leishmania (Leishmania) amazonensis]. Revista da Sociedade Brasileira de Medicina Tropical, 39(1): 43-46, 2006.

DOYLE, J. J. et al. Antibody induced movement of membrane components of Leishmania enriettii. Journal of Experimental Medicine, 139(5): 1.061-1.069, 1974.

ECCO, R. et al. Leishmaniose citânea em cobaias (Cavia porcellus). Ciência Rural, 30(3): 525-528, 2000.

EL-ON, J.; WITZTUM, A. \& SCHNUR, L. F. Protection of guinea pigs against cutaneous leishmaniasis by combined infection and chemotherapy. Infection and Immunity, 51(2): 704-706, 1986.

ELLIOTT, E. V. \& SINCLAIR, N. R. Effect of cortisone acetate on $19 \mathrm{~S}$ and 7S haemolysin antibody. A time course study. Immunology, 15(5): 643-652, 1968.

GARCIA, L. et al. Culture-independent species typing of neotropical Leishmania for clinical validation of a PCR-based assay targeting heat shock protein 70 genes. Journal of Clinical Microbiology, 42(5): 2.294-2.297, 2004.

GONCALVES DA COSTA, S.; SANTOS, E. B. \& LAGRANGE, P. H. Vaccination of mice against Leishmania mexicana amazonensis with microsomal fraction associated with BCG. Annales de l'Institut Pasteur. Immunologie, 139(2): 143-156, 1988.

GRADONI, L. An update on antileishmanial vaccine candidates and prospects for a canine Leishmania vaccine. Veterinary Parasitology, 100(1-2): 87-103, 2001.

GRADONI, L. \& GRAMICCIA, M. Leishmania infantum tropism: strain genotype or host immune status? Parasitology Today, $10(7): 264-267,1994$.

GRIMALDI JR., G. The utility of rhesus monkey (Macaca mulatta) and other non-human primate models for preclinical testing of Leishmania candidate vaccines - a review. Memórias do Instituto Oswaldo Cruz, 103(7): 629-644, 2008.

GRIMALDI JR., G.; TESH, R. B. \& McMAHON-PRATT, D. A review of the geographic distribution and epidemiology of leishmaniasis in the New World. The American Journal of Tropical Medicine and Hygiene, 41(6): 687-725, 1989.

GUERIN, P. J. et al. Visceral leishmaniasis: current status of control, diagnosis, and treatment, and a proposed research and development agenda. The Lancet Infectious Diseases, 2(8): 494-501, 2002.

GURUBACHARYA, R. L. et al. Prevalence of visceral Leishmania \& HIV co-infection in Nepal. Indian Journal of Medical Research, 123(3): 473-474, 2006. 
HATAM, G. R.; HOSSEINI, S. M. H. \& ARDEHALI, S. Dermotropic isolates of Leishmania infantum in Iran. Transactions of the Royal Society of Tropical Medicine and Hygiene, 91(4): 440, 1997.

HEINZEL, F. P. et al. Recombinant Interleukin-12 cures mice infected with Leishmania major. Journal of Experimental Medicine, 177(5): 1.505-1.509, 1993.

KELLINA, O. [Differences in the sensitivity of inbred mice of different lines to Leishmania tropica major]. O razlichiiakh $\mathrm{v}$ chuvstvitel'nosti inbrednykh myshei raznykh linii k Leishmania tropica major. Meditsinskaia Parazitologiia i Parazitarnye Bolezni, 42(3): 279-285, 1973.

KOPF, M. et al. IL-4-deficient BALB/c mice resist infection with Leishmania major. Journal of Experimental Medicine, 184(3): 1.127-1.136, 1996.

LAINSON, R. \& RANGEL, E. F. Lutzomyia longipalpis and the eco-epidemiology of American visceral leishmaniasis, with particular reference to Brazil - A Review. Memorias do Instituto Oswaldo Cruz, 100(8): 811-827, 2005.

LUZ, E.; GIOVANNONI, M. \& BORBA, A. M. Infecção de Lutzomyia monticola por Leishmania enrietti. Anais da Faculdade de Medicina da Universidade Federal do Paraná, 9-10: 121-128, 1967.

MACHADO, M. I. et al. Naturally acquired infections with Leishmania enriettii (Muniz and Medina, 1948) in guinea pigs from São Paulo, Brazil. Parasitology, 109: 135-138, 1994.

MADEIRA, M. F. et al. Identification of Leishmania (Leishmania) chagasi isolated from healthy skin of symptomatic and asymptomatic dogs seropositive for leishmaniasis in the Municipality of Rio de Janeiro, Brazil. Brazilian Journal of Infectious Diseases, 8: 440-444, 2004.

MAGARINOS-TORRES, C.; MUNIZ, J. \& CARDOSO, R. A. Caracteres do granuloma histiocitário na leishmaniose espontânea da cobaia. O Hospital, XXXII(3): 405-408, 1948.

MAUEL, J. Intracellular survival of protozoan parasites with special reference to Leishmania spp., Toxoplasma gondii and Trypanosoma cruzi. Advances in Parasitology, 38: 1-51, 1996.

MAUEL, J.; BEHIN, R. \& NOERJASI, B. Quantitative release of live microorganisms from infected macrophages by sodium dodecyl sulfate. Nature New Biology, 244(133): 93-94, 1973.

McHUGH, C. P.; GROGL, M. \& KERR, S. F. Isolation of Leishmania mexicana from Neotoma micropus collected in Texas. The Journal of Parasitology, 76(5): 741-742, 1990.

McHUGH, C. P.; MELBY, P. C. \& LaFON, S. G. Leishmaniasis in Texas: epidemiology and clinical aspects of human cases. The American Journal of Tropical Medicine and Hygiene, 55(5): 547-555, 1996.

MEDINA, H. Estudos sobre leishmaniose. Primeiros casos de leishmaniose espontânea observada em cobaios. Arquivos de Biologia e Tecnologia, 1: 39-74, 1946.

MENGELING, B. J.; BEVERLEY, S. M. \& TURCO, S. J. Designing glycoconjugate biosynthesis for an insidious intent: phosphoglycan assembly in Leishmania parasites. Glycobiology, 7(7): 873-880, 1997.

MILON, G.; DEL GIUDICE, G. \& LOUIS, J. A. Immunobiology of experimental cutaneous leishmaniasis. Parasitology Today, 11(7): 244-247, 1995.

MONROY, A. et al. Histological studies of the elimination of Leishmania enriettii from skin lesions in the guinea pig. British Journal of Experimental Pathology, 61(6): 601-610, 1980.

MOTTA, A. C. et al. Disseminated mucocutaneous leishmaniasis resulting from chronic use of corticosteroid. International Journal of Dermatology, 42(9): 703-706, 2003.

MOUGNEAU, E. et al. Expression cloning of a protective Leishmania antigen. Science, 268(5.210): 563-566, 1995.

NASSERI, M. \& MODABBER, F. Z. Generalized infection and lack of delayed hypersensitivity in balb-C mice infected with Leishmania tropica major. Infection and Immunity, 26(2): 611-614, 1979.

OLIVEIRA-NETO, M. P. et al. American tegumentary leishmaniasis (ATL) in Rio de Janeiro State, Brazil: main clinical and epidemiologic characteristics. International Journal of Dermatology, 39(7): 506-514, 2000. 
PEREIRA, C. G. et al. Different isolates from Leishmania braziliensis complex induce distinct histopathological features in a murine model of infection. Veterinary Parasitology, 165(3-4): 231-240, 2009.

PEREZ, H.; MALAVE, I. \& ARREDONDO, B. The effects of protein malnutrition on the course of Leishmania mexicana infection in C57Bl/6 mice: nutrition and susceptibility to leishmaniasis. Clinical and Experimental Immunology, 38(3): 453-460, 1979

PETERS, W. \& KILLICK-KENDRICK, R. The Leishmaniasis in Biology and Medicine. London: Academic Press, 1987.

PINELLI, E. et al. Detection of canine cytokine gene expression by reverse transcription-polymerase chain reaction. Vet Immunol Immunopathol, 69(2-4): 121-126, 1999.

PINHEIRO, R. O. \& ROSSI-BERGMANN, B. Interferon-gamma is required for the late but not early control of Leishmania amazonensis infection in C57Bl/6 mice. Memórias do Instituto Oswaldo Cruz, 102(1): 79-82, 2007.

PITTALIS, S. et al. Leishmania infantum leishmaniasis in corticosteroid treated patients. BMC Infect Dis, 6: 177, 2006.

POZIO, E. et al. Isolation of the agent causing cutaneous leishmaniasis in Italy and its visceralization in inbred hamsters. Transactions of the Royal Society of Tropical Medicine and Hygiene, 79(2): 260-261, 1985.

QUINNELL, R. J. et al. Tissue cytokine responses in canine visceral leishmaniasis. The Journal of Infectious Diseases, 183(9): 1.421-1.424, 2001.

REINER, S. L. \& LOCKSLEY, R. M. The regulation of immunity to Leishmania major. Annual Review of Immunology, 13: 151-177, 1995.

REIS, A. B. et al. Immunity to Leishmania and the rational search for vaccines against canine leishmaniasis. Trends in Parasitology, 26(7): 341-349, 2010.

RINEHART, J. J. et al. Effects of corticosteroid therapy on human monocyte function. The New England Journal of Medicine, 292(5): 236-241, 1975.

ROBERTS, M.; ALEXANDER, J. \& BLACKWELL, J. M. Influence of Lsh, H-2, and an H-11-linked gene on visceralization and metastasis associated with Leishmania mexicana infection in mice. Infection and Immunity, 57(3): 875-881, 1989.

SACKS, D. \& NOBEN-TRAUTH, N. The immunology of susceptibility and resistance to Leishmania major in mice. Nature Reviews Immunology, 2(11): 845-858, 2002.

SADICK, M. D. et al. Cure of murine leishmaniasis with anti-interleukin 4 monoclonal antibody. Evidence for a $\mathrm{T}$ celldependent, interferon gamma-independent mechanism. Journal of Experimental Medicine, 171(1): 115-127, 1990.

SATOSKAR, A. \& ALEXANDER, J. Sex-determined susceptibility and differential IFN-gamma and TNF-alpha mRNA expression in DBA/2 mice infected with Leishmania mexicana. Immunology, 84(1): 1-4, 1995.

SCOTT, P. et al. Immunoregulation of cutaneous leishmaniasis. T cell Lines that transfer protective immunity or exacerbation belong to different $\mathrm{T}$ helper subsets and respond to distinct parasite antigens. Journal of Experimental Medicine, 168(5): $1.675-1.684,1988$.

SCHUBACH, A. et al. Leishmanial antigens in the diagnosis of active lesions and ancient scars of American tegumentary leishmaniasis patients. Memórias do Instituto Oswaldo Cruz, 96(7): 987-996, 2001.

SINAGRA, A. et al. The activity of azithromycin against Leishmania (Viannia) braziliensis and Leishmania (Leishmania) amazonensis in the golden hamster model. Revista da Sociedade Brasileira de Medicina Tropical, 40(6): 627-630, 2007.

SMRKOVSKI, L. L.; REED, S. G. \& LARSON, C. L. Effect of cortisone and cyclophosphamide on the immunological role of BCG in BALB/c mice challenged with Leishmania donovani. The American Journal of Tropical Medicine and Hygiene, 29(1): 16-20, 1980.

SOLANO-GALLEGO, L. et al. Prevalence of Leishmania infantum infection in dogs living in an area of canine leishmaniasis endemicity using PCR on several tissues and serology. Journal of Clinical Microbiology, 39(2): 560-563, 2001.

SOLBACH, W. \& LASKAY, T. The host response to Leishmania infection. Advances in Immunology, 74: 275-317, 2000. 
SOLBACH, W.; FORBERG, K. \& ROLLINGHOFF, M. Experimental Leishmaniasis in BALB/c mice - cyclosporin A prevents the development of cutaneous lesions. Immunobiology, 170(1-2): 90, 1986.

SOUZA-LEMOS, C. et al. Dynamics of immune granuloma formation in a Leishmania braziliensis induced self limiting cutaneous infection in the primate Macaca mulatta. The Journal of Pathology, 216(3): 375-386, 2008.

STEBUT, E. Cutaneous Leishmania infection: progress in pathogenesis research and experimental therapy. Experimental Dermatology, 16(4): 340-346, 2007.

TEVA, A. et al. Leishmania (Viannia) braziliensis induced chronic granulomatous cutaneous lesions affecting the nasal mucosa in the rhesus monkey (Macaca mulatta) model. Parasitology, 127(5): 437-447, 2003.

TRAVI, B. L. et al. Clinical, parasitologic, and immunologic evolution in dogs experimentally infected with sand fly derived Leishmania chagasi promastigotes. The American Journal of Tropical Medicine and Hygiene, 81(6): 994-1.003, 2009.

TUON, F. F. et al. Cutaneous leishmaniasis reactivation 2 years after treatment caused by systemic corticosteroids - first report. International Journal of Dermatology, 46(6): 628-630, 2007.

TURK, J. Immunology in Clinical Medicine. London: William Heinemann Medical Books, 1978.

TURK, J. L. \& BELEHU, A. Immunological spectra in infectious diseases. In: Parasites in the Immunized Host: mechanisms of survival. London, New York: John Wiley \& Sons, 1974. (Ciba Foundation Symposium, 25)

ULCZAK, O. M. \& BLACKWELL, J. M. Immunoregulation of genetically controlled acquired responses to Leishmania donovani infection in mice: the effects of parasite dose, cyclophosphamide and sublethal irradiation. Parasite Immunology, 5(5): 449-463, 1983.

VIEIRA, J. B. \& COELHO, G. E. [Visceral leishmaniasis or kala-azar: the epidemiological and control aspects]. Revista da Sociedade Brasileira de Medicina Tropical, 31, supl. 2: 85-92, 1998.

WATERSTON, R. H. et al. Initial sequencing and comparative analysis of the mouse genome. Nature, 420(6.915): 520562, 2002.

WONG, R. L.; WINSLOW, C. M. \& COOPER, K. D. The mechanisms of action of cyclosporin A in the treatment of psoriasis. Immunology Today, 14(2): 69-74, 1993.

ZAVERUCHA DO VALLE, T. et al. Experimental Leishmania (L.) amazonensis leishmaniasis: characterization and immunogenicity of subcellular fractions. Immunological Investigations, 36(4): 473-492, 2007.

ZAVERUCHA DO VALLE, T. Vacinação Murina com Frações Subcelulares de Leishmania (Leishmania) amazonensis sob Modulação de Mycobacterium bovis BCG e Ciclofosfamida, 2005. Tese de Doutorado, Rio de Janeiro: Instituto Oswaldo Cruz, Fundação Oswaldo Cruz. 
parte VI

Espectro Clínico das Leishmanioses 


\title{
Formas Clínicas das Leishmanioses Tegumentares nas Américas
}

\author{
Rilza Beatriz de Azeredo-Coutinho I Sergio C. F. Mendonça
}

A s leishmanioses têm distribuição mundial, com ocorrência em 98 países e três territórios distribuídos por cinco continentes, totalizando uma incidência anual estimada entre 0,7 e 1 milhão de casos de leishmaniose cutânea e entre 200 e 400 mil casos de leishmaniose visceral. Os dez países com maior incidência de leishmaniose cutânea são Afeganistão, Argélia, Colômbia, Brasil, Irã, Síria, Etiópia, Sudão, Costa Rica e Peru, onde ocorrem 70\% a 75\% dos casos da infecção (Alvar et al., 2012). O termo leishmaniose tegumentar designa a infecção por Leishmania que afeta a pele, mucosas ou semimucosas. A leishmaniose tegumentar do Novo Mundo ou leishmaniose tegumentar americana (LTA) é uma doença com múltiplas formas de apresentação clínica, cuja expressão depende de fatores inerentes à resposta imune do hospedeiro humano, ao agente etiológico e ao vetor envolvido na transmissão.

Os agentes etiológicos da LTA pertencem a dois subgêneros, Viannia e Leishmania, em contraste com a leishmaniose cutânea do Velho Mundo, onde apenas o subgênero Leishmania está representado. Encontram-se no subgênero Viannia espécies compreendidas no complexo L. braziliensis, como Leishmania (V.) braziliensis, L. (V.) peruviana, L. (V.) colombiensis, L. (V.) lainsoni, L. (V.) shawii, L. (V.) naiffi e no complexo L. guyanensis, como L. (V.) guyanensis e L. (V.) panamensis. Quanto ao subgênero Leishmania, a LTA pode ser causada por algumas espécies do complexo $L$. mexicana: L. (L.) amazonensis, L. (L.) mexicana, L. (L.) garnhami, L. (L.) venezuelensis e L. (L.) pifanoi (Grimaldi, Tesh \& McMahon-Pratt, 1989; Cupolillo, Grimaldi Jr. \& Momen, 1994).

A leishmaniose tegumentar, à semelhança da hanseníase, apresenta um espectro de formas clínicas (Destombes, 1960) cuja expressão sofre influência da resposta imune específica contra Leishmania mediada por células do hospedeiro humano. Nesse espectro, o polo hiperérgico está representado pela leishmaniose mucosa, caracterizada por pobreza parasitária tecidual e uma potente resposta pró-inflamatória específica contra Leishmania, demonstrada por forte reação ao teste cutâneo com leishmanina (teste de Montenegro) ou intensa proliferação in vitro de células mononucleares sob estímulo de antígenos de Leishmania. Em contraste, o polo anérgico do espectro está representado pela leishmaniose difusa, caracterizada por ausência dessa resposta imune específica mediada por células e lesões ricas em parasitos (Convit et al., 1993).

Várias classificações da LTA têm sido propostas com base em características clínicas e/ou imunopatológicas (Azulay, 1977; Marzochi \& Marzochi, 1994). Classificações baseadas no quadro clínico e aspecto morfológico das lesões 
cutâneas foram elaboradas por vários autores, como Rabello em 1925; da Matta, que adotou o termo tegumentar (1915); Aguiar Pupo (1946) ou Jorge Lobo (1947), revisadas por Azulay (1977). Pode-se concluir que não existe uma classificação ideal. Modificações têm sido introduzidas com o passar dos anos, acompanhando a aquisição de novos conceitos e conhecimentos técnicos-científicos.

M. Marzochi e K. Marzochi (Marzochi \& Marzochi, 1994) propuseram a classificação descrita a seguir, fundamentada nos aspectos clínicos e evolutivos da doença.

1 - Grupo subclínico:

1.1 - Leishmaniose cutânea inaparente ou subclínica: nesta forma, há ausência de lesão cutânea, ativa ou cicatrizada; a intradermorreação de Montenegro é positiva. Os testes sorológicos podem mostrar-se positivos.

2 - Grupo cutâneo:

2.1 - Leishmaniose cutânea localizada: são lesões únicas ou múltiplas, em geral próximas ao sítio de inoculação; a intradermorreação de Montenegro é positiva e a sorologia em geral positiva.

2.2 - Leishmaniose cutânea disseminada: lesões cutâneas múltiplas, podendo chegar a centenas; são ulceradas ou acneiformes, distantes do sítio de inoculação; intradermorreação de Montenegro positiva ou negativa, de acordo com a espécie envolvida; a sorologia em geral é positiva.

2.3 - Leishmaniose cutânea difusa: as lesões são múltiplas, sem tendência à ulceração, papulosas ou nodulares, distantes do sítio de inoculação primário. A intradermorreação de Montenegro é negativa e a sorologia positiva.

3 - Grupo mucoso ou leishmaniose mucosa:

3.1 - Leishmaniose mucosa tardia: lesões nas mucosas da face, mais frequentemente na mucosa nasal. Verifica-se presença de cicatriz ou história de lesão cutânea prévia. A intradermorreação de Montenegro é fortemente positiva.

3.2 - Leishmaniose mucosa indeterminada ou isolada: presença de lesão mucosa e ausência de lesão ativa ou cicatriz de lesão cutânea anterior. A intradermorreação de Montenegro é fortemente positiva.

3.3 - Leishmaniose mucosa primária: lesão em mucosa ou semimucosa externa, exposta à picada do inseto vetor; lesão por inoculação direta por aposição, como nos lábios ou glande; intradermorreação de Montenegro e sorologia positivas.

4 - Grupo misto ou leishmaniose mucocutânea:

4.1 - Forma mucocutânea concomitante: quando há presença de lesão cutânea e mucosa ativas simultaneamente. A intradermorreação de Montenegro e a sorologia são ambas fortemente positivas.

4.2 - Forma mucocutânea contígua: a lesão mucosa se dá por contiguidade a uma lesão cutânea adjacente ativa ou cicatrizada. A intradermorreação de Montenegro é positiva e a sorologia pode mostrar reatividade.

5-Grupo linfático ou leishmaniose linfática: observa-se linfadenopatia regional ou linfangite nodular, isoladamente ou associadas a lesões cutâneas. A intradermorreação de Montenegro em geral é negativa, dependendo do tempo de evolução da doença; a sorologia pode ser positiva.

\section{LEISHMANIOSE SUBCLÍNICA}

A infecção subclínica pode ser evidenciada de maneira indireta, por detecção de anticorpos específicos contra Leishmania, reatividade ao teste cutâneo de Montenegro, ou presença de DNA parasitário, evidenciado por métodos 
moleculares. Estudos realizados em áreas endêmicas referiram taxas variáveis de infecção subclínica, dependendo da região estudada e metodologia empregada, como 5\% a 39,4\% (Oliveira-Neto et al., 1988; Marzochi et al., 1980).

\section{LEISHMANIOSE CUTÂNEA LOCALIZADA}

Na leishmaniose cutânea (LC) do Novo Mundo, a lesão típica e classicamente descrita é a úlcera com bordas em moldura (Figura 1). Após a picada do flebotomíneo infectado e um período de incubação que pode durar de 15 dias a três meses (Marzochi, 1992), surge no local uma pápula eritematosa atingindo poucos milímetros de diâmetro. A lesão assume coloração rubra, devido ao extravasamento local de hemácias provocada por ação de substâncias anticoagulantes existentes na saliva do inseto vetor (Almeida et al., 2003). Em poucos dias forma-se pápula mais consistente, que aumenta de tamanho, com crescimento progressivo, infiltração e finalmente necrose central, que então se recobre por crosta, assumindo aspecto semelhante a um 'vulcão' (Figura 2). Com o aumento de volume, formase úlcera com bordas elevadas, roliças, emoldurando a ulceração propriamente dita, a qual é recoberta por tecido de granulação grosseiro, com pouca secreção. A forma ulcerosa típica com borda saliente em moldura foi caracterizada por Lindenberg (1901) em sua primeira comunicação sobre a "úlcera de Bauru", uma de suas denominações no Brasil. A base é firme, endurada e pouco dolorosa. O fato de úlceras leishmanióticas, por vezes grandes, não despertarem dor no indivíduo poderia estar relacionado com a evidência de infiltrado inflamatório perineural periférico na infecção por Leishmania (Kubba, 1987).

Figura 1 - Leishmaniose cutânea localizada: úlcera com bordas em moldura e lesão satélite

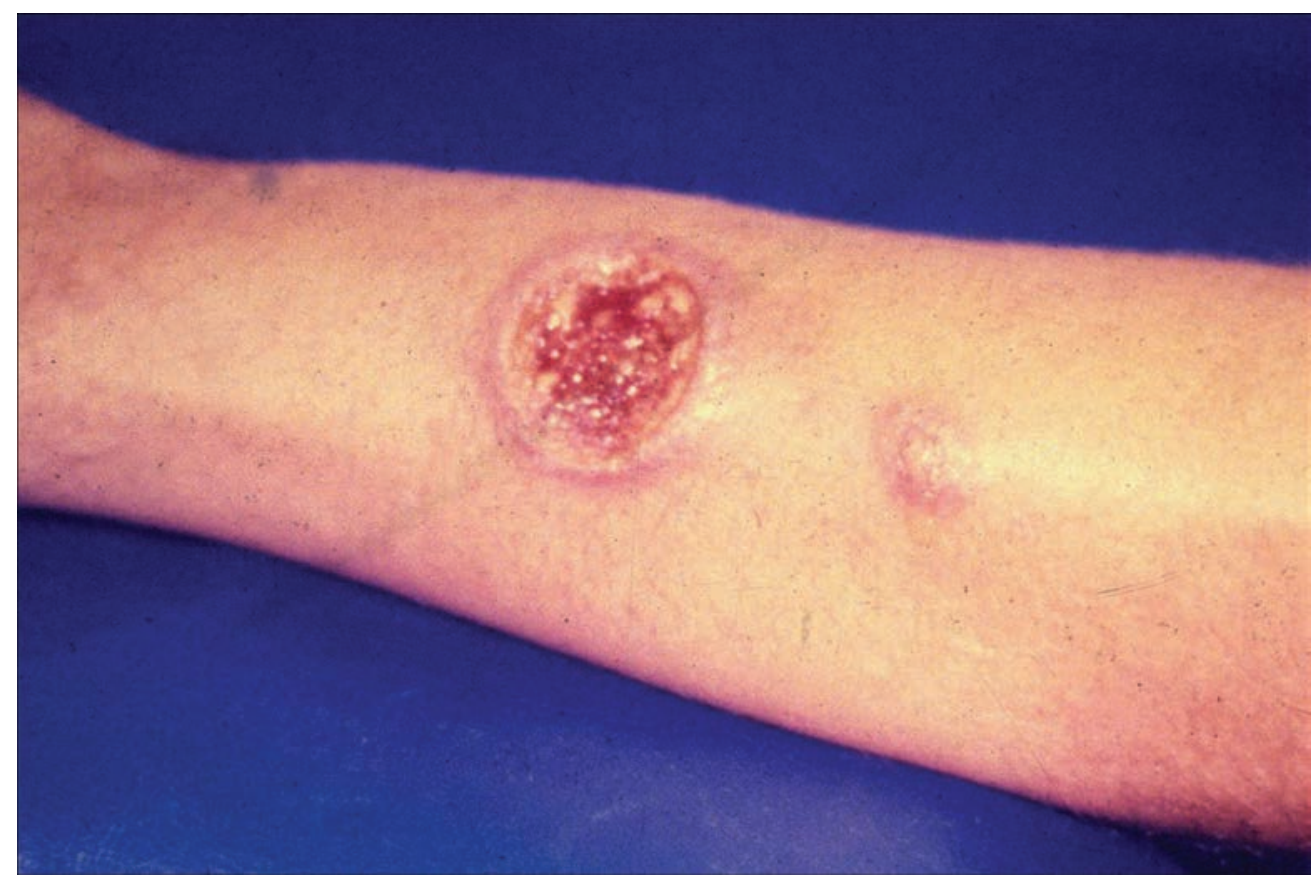


Figura 2 - Leishmaniose cutânea localizada: lesão em fase inicial, pápula recoberta por crosta

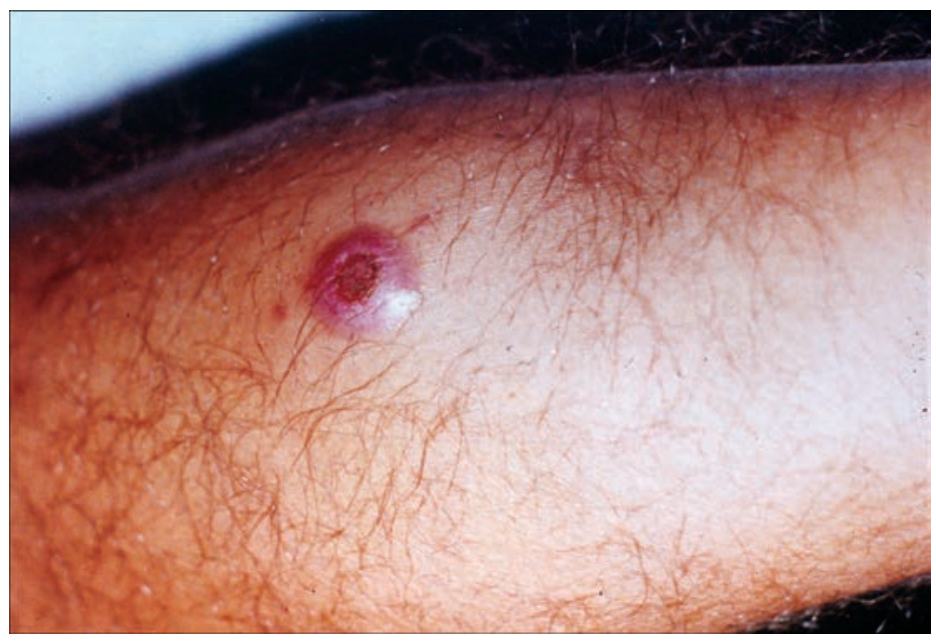

A úlcera é o tipo de lesão mais comum, sendo única em até 90\% dos casos, em áreas expostas, medindo de poucos centímetros até $20 \mathrm{~cm}$ ou mais (Llanos-Cuentas et al., 1984; Azeredo-Coutinho \& Mendonça, 2002). Na leishmaniose cutânea localizada (LCL) verificam-se poucas lesões, em contraste com a leishmaniose disseminada, que pode apresentar centenas delas. Nas regiões do Brasil onde ocorre a transmissão domiciliar ou peridomiciliar, os vetores flebotomíneos invadem o domicílio em sua atividade noturna, picando o indivíduo durante o sono, produzindo lesões em locais habitualmente cobertos. Podem ser observadas lesões localizadas nas axilas (Figura 3), pálpebra superior, nádegas, períneo ou genitália (Schubach et al., 1998a). Esta última localização também tem sido atribuída à inoculação direta do parasito ou à disseminação hematogênica.

A doença causada por L. guyanensis em geral apresenta múltiplas lesões, pois flebotomíneos vetores infectados, quando perturbados pelo homem em seu hábitat natural, produzem várias picadas simultâneas (Marzochi, 1992).

Figura 3 - Leishmaniose cutânea localizada: lesão axilar

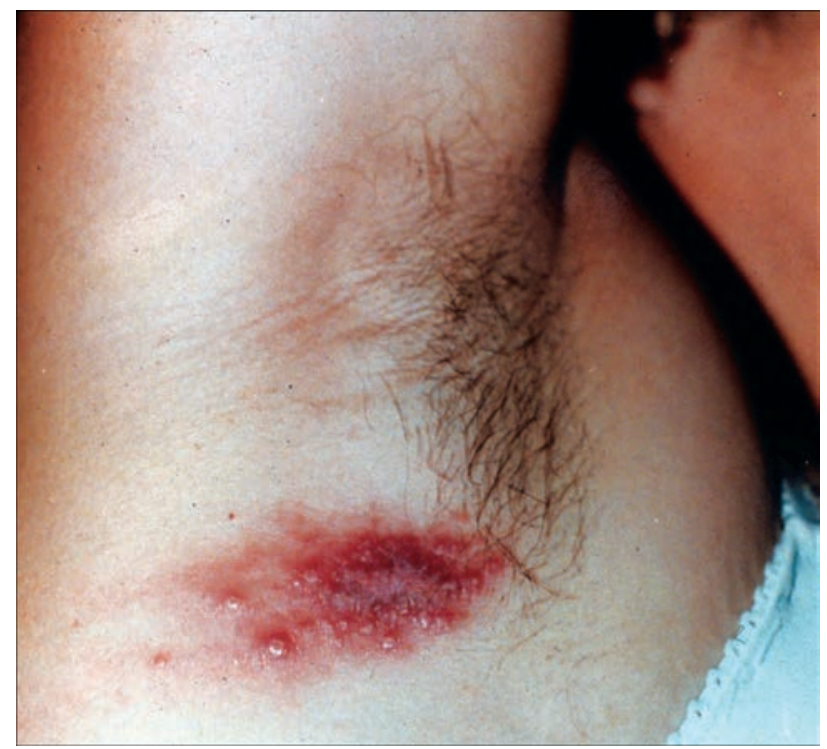


A L. amazonensis também é responsável por casos de LCL. Na maioria das vezes, são lesões únicas, ulceradas, que podem exibir borda mais infiltrada que as demais úlceras causadas por outras espécies (Silveira, Lainson \& Corbett, 2004).

Na LCL, existe o desenvolvimento de uma resposta imune específica intensa contra Leishmania definida por linfoproliferação e produção de citocinas do tipo 1, com atividade pró-inflamatória, como interferon-gama (IFN- $\gamma$ ), interleucina (IL)-2 e fator de necrose tumoral-alfa (TNF- $\alpha$ ) (Mendonça et al., 1986; Castés et al., 1988; Pirmez et al., 1993; Da-Cruz et al., 1996). No entanto, a resposta reguladora de citocinas do tipo 2 também está representada neste contexto, pela produção de IL-4, IL-5, IL-10, IL-13 e fator transformador de crescimento-beta (TGF- $\beta$ ) (Salhi, 2008; Barral-Netto \& Barral, 1994), que inibem diversas funções dos macrófagos e a ativação de células efetoras. Portanto, a LCL mostra uma tendência ao equilíbrio desses dois tipos de resposta, situando-se centralmente no espectro da LTA (Silveira, Lainson \& Corbett, 2004).

A intradermorreação de Montenegro em pacientes com LCL em atividade é positiva (Furtado, 1980), embora nas fases iniciais da doença possa ainda não mostrar reatividade. Na infecção por L. amazonensis, porém, a observação de 50\% dos indivíduos com o teste cutâneo negativo, durante a atividade da doença, indicaria uma habilidade dessa espécie de inibir a resposta imune celular específica (Silveira et al., 1991).

A LC é considerada uma grande simuladora de outras afecções dermatológicas, devido à variedade morfológica das lesões que pode produzir. Além da úlcera clássica, outros aspectos morfológicos de lesões que podem ser observados, em menor frequência, são lesões vegetantes, de caráter seco (verrucosa) ou úmido (framboesoide); placas, lesões pápulotuberosas, tuberosas, hiperceratóticas, liquenoides, nodulares, lupoides ou sarcoides (Azulay, 1977). Lesões verrucosas, de curso crônico, foram consideradas uma forma clínica à parte por Diaz e colaboradores (2002). A maior expressão das citocinas IL-10 e TGF- $\beta$, com atividade inibitória de macrófagos e da ação de IFN- $\gamma$, foi relatada em lesões de leishmaniose de curso crônico quando comparadas àquelas com até dois meses de evolução (Barral-Netto et al., 1992; Melby et al., 1994), indicando um papel dessas citocinas na manutenção da patologia. Lesões de apresentação atípica podem evoluir com alta taxa de recorrência e resposta inadequada à terapia antimonial (Guimarães et al., 2009), e podem estar associadas com a infecção pelo vírus HIV ou outra causa de imunodeficiência. Tais lesões podem ser confundidas com outras dermatoses, infecciosas ou não, exigindo investigação diagnóstica apurada. No entanto, em áreas endêmicas de transmissão ativa, qualquer tipo de lesão cutânea que não evolua para cura com tratamentos habituais, em período de tempo equivalente a duas ou três semanas, deve suscitar a suspeita diagnóstica de leishmaniose.

A resposta à terapia antimonial na LCL é, em geral, boa. Na grande maioria dos casos, as lesões evoluem para a cura clínica com formação de cicatriz atrófica, sob terapia específica, havendo relato de taxas de cura de $75 \%$ até $95 \%$ (Azeredo-Coutinho \& Mendonça, 2002). O tempo decorrido entre o início da terapia antimonial e a cura clínica pode levar em torno de cem dias em média, verificado em estudo realizado no município do Rio de Janeiro, onde o agente etiológico é L. braziliensis (Azeredo-Coutinho \& Mendonça, 2002).

Lesões localizadas no tronco, cabeça e membros superiores tendem a evoluir para cicatrização mais rapidamente do que aquelas localizadas nos membros inferiores (Llanos-Cuentas et al., 1984). A cura espontânea das lesões é observada em áreas endêmicas, seja em pacientes que não tiveram acesso aos serviços de saúde e à terapia específica, em pacientes que recusaram tratamento, no caso de gestantes, nas quais está contraindicada a terapia antimonial (Marsden et al., 1984). Nestas, a doença costuma progredir de forma acelerada durante a gestação e apresentar forte tendência à cura espontânea após o parto. Em área endêmica do estado da Bahia, a cura espontânea da LTA pôde ser observada em período de seis meses a um ano em $86 \%$ de indivíduos não tratados, os quais permaneceram livres de doença após um período de observação de 11 anos (Costa et al., 1987). Em casuística do Rio de Janeiro, durante período de um ano, dentre 168 pacientes, 13 evoluíram para cura espontânea no decorrer da investigação diagnóstica, comprovada por pesquisa de DNA de Leishmania (Fagundes et al., 2010). 


\section{LEISHMANIOSE LINFÁTICA}

Linfonodos e demais estruturas do sistema linfático são, com frequência, afetados na LTA. A linfangite nodular ascendente (Floch, 1954) refere-se ao cordão linfático espessado e com sinais inflamatórios, acompanhado de linfonodos enfartados ao longo do seu trajeto, desde a lesão cutânea até os linfonodos de drenagem regionais. Daí a denominação, por vezes empregada, de forma esporotricoide (Cozzani et al., 2010). Porém, em contraste com a esporotricose, esses linfonodos ao longo do cordão linfático não mostram tendência à fistulização. Na LTA, em pacientes de áreas endêmicas do Rio de Janeiro, 52 indivíduos (25\%) apresentavam acometimento linfático, compreendendo linfadenopatia regional ou satélite (65\%) e linfangite nodular em 35\% (Azeredo-Coutinho \& Mendonça, dados não publicados). A adenopatia regional foi observada em 127 de 181 indivíduos, no Nordeste (Harms et al., 2005). A invasão precoce de cadeias linfáticas foi comprovada na infecção por Leishmania por meio de isolamento de parasitos de gânglios linfáticos de drenagem antes mesmo de surgimento de úlcera cutânea (Barral et al., 1995). É também referida a leishmaniose bubônica, observada na Região Nordeste do Brasil, na qual o processo inflamatório é intenso nos linfonodos e vasos linfáticos de drenagem. Nesses casos, o enfartamento ganglionar pode preceder o aparecimento da lesão cutânea (Sousa et al., 1995).

\section{LEISHMANIOSE RECIDIVA CÚTIS}

Trata-se de quadro de recidiva de LCL. Outras denominações encontradas na literatura especializada são metaleishmaniose e leishmaniose cutânea recidivante, entre outras. Essa forma clínica foi caracterizada por Berlin em 1940 (Berlin et al., 1940), com relação à LCL do Velho Mundo, e denominada leishmaniose 'recidiva cútis' (LRC), sendo posteriormente também descrita na LTA (Oliveira-Neto et al., 1998). Meses ou anos após a resolução da LCL, espontaneamente ou sob tratamento específico, surgem pápulas, eritema, descamação, tubérculos ou nódulos, geralmente na periferia da cicatriz da lesão anterior, indicando atividade da doença (Figura 4). Nesses casos, verifica-se resposta exacerbada aos antígenos de Leishmania ao teste de Montenegro nos pacientes (Sagher, 1947), além de formação de reação granulomatosa tuberculoide tecidual com escassez de parasitos ao exame histopatológico da lesão. A recaída da lesão de LCL, após terapia adequada, é evento infrequente, situando-se em torno de 10\% (Netto et al., 1990).

Figura 4 - Leishmaniose tegumentar americana: leishmaniose recidiva cútis

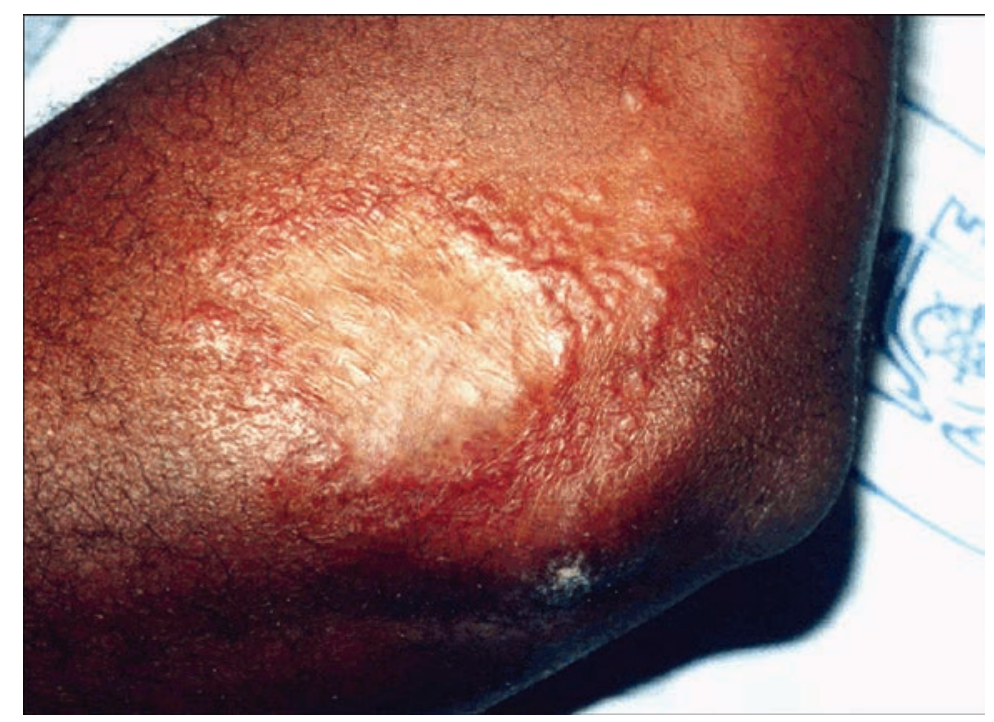


A persistência de parasitos viáveis no local da lesão após a cicatrização com terapia específica ou não, é relatada na leishmaniose humana (Saravia et al., 1990; Schubach et al., 1998b). Trata-se de um dos fatores implicados na reativação de lesões da LCR, no desenvolvimento de lesões cutâneas da leishmaniose dérmica pós-calazar e das lesões mucosas na LTA (Aebischer, 1994). Exame de PCR com isolamento de parasitos de lesões cutâneas antes da terapia e na reativação forneceu evidência de que, quando a reativação ocorria no mesmo local da lesão primária, a mesma cepa estaria envolvida, sugerindo uma recaída da infecção original, que em geral se manifestaria dentro de um ano após a infecção inicial (Saravia et al., 1990). O período de tempo entre a infecção inicial e a recidiva pode ser variável, segundo os relatos clínicos, tendo sido descrito de até trinta anos de intervalo. O mecanismo envolvido na reativação das lesões já cicatrizadas não está ainda totalmente esclarecido.

\section{LEISHMANIOSE DISSEMINADA}

A leishmaniose disseminada (LD), por vezes denominada leishmaniose cutânea disseminada, ao contrário da LCL, caracteriza-se pela presença de lesões múltiplas, em geral mais de dez, distribuídas em regiões não contíguas do corpo (Figura 5), podendo chegar a centenas (Carvalho et al., 1994; Machado et al., 2011). Alguns autores consideram que para caracterizar esse quadro, devem ser observadas mais de vinte lesões (Vieira et al., 2002). Na LTA, esta forma de apresentação clínica está associada à infecção por L. braziliensis, L. amazonensis, L. guyanensis e L. panamensis (Vieira-Gonçalves et al., 2008; Carvalho et al., 1994; Costa et al., 1986; Couppié et al., 2004; Rincón et al., 2009). Afeta predominantemente o adulto do sexo masculino, porém há casos descritos em mulheres e crianças (Costa et al., 1986; Rincón et al., 2009). A apresentação inicial é uma úlcera, como na LCL. A seguir, em período variável de dias ou duas a três semanas, desenvolvem-se numerosas pápulas foliculares ou acneiformes, pústulas, placas, lesões verrucosas, que podem ou não sofrer necrose central e formar crosta (Carvalho et al., 1994; Couppié et al., 2004). As lesões podem confluir e localizar-se na genitália, no couro cabeludo ou na região periungueal. Sintomas constitucionais como febre, astenia e mal-estar estão presentes em alguns pacientes (Carvalho et al., 1994) no início da disseminação das lesões. A mucosa das vias aéreas superiores pode estar acometida em qualquer fase da doença, precedendo o quadro cutâneo ou mesmo após terapia, em frequência variável, na LD causada por L. braziliensis ou L. amazonensis (Carvalho et al., 1994; Machado et al., 2011; Costa et al., 1986). Por essa razão, a denominação leishmaniose disseminada é mais apropriada do que leishmaniose cutânea disseminada. Sob terapia com antimoniais pentavalentes, em geral observa-se evolução para a cura clínica na maioria dos pacientes, porém em série descrita por Machado e colaboradores (2011) houve falha terapêutica em 76\% dos casos. Nos tecidos, o número de formas amastigotas depende da espécie de Leishmania envolvida: alto para L. amazonensis e baixo para as espécies do subgênero Viannia (Silveira, Lainson \& Corbett, 2005). Quanto aos testes sorológicos para Leishmania, são positivos, frequentemente em títulos altos.

$\mathrm{Na}$ avaliação da resposta imune mediada por células específicas contra Leishmania, a intradermorreação de Montenegro é em geral positiva. Quanto aos testes in vitro, na maioria dos pacientes há presença de linfoproliferação e produção de IFN- $\gamma$ em resposta ao estímulo com antígenos de Leishmania. Em pacientes com LD causada por L. amazonensis, nos quais o teste de Montenegro foi negativo, a resposta linfoproliferativa a antígenos de Leishmania foi ausente e também se verificou baixa contagem de células T CD4+ (Carvalho et al., 1994). Em outro estudo, pacientes com LD apresentaram capacidade de produção de IFN- $\gamma$, porém os níveis dessa citocina e TNF- $\alpha$ foram significativamente mais baixos quando comparados aos pacientes com LCL (Turetz et al., 2002). A avaliação da frequência de células produtoras de IFN- $\gamma$, por imuno-histoquímica, também mostrou menor frequência destas na LD em comparação à LCL, porém a expressão de iNOS (óxido nítrico sintase induzível) foi semelhante em ambas formas clínicas (Vieira et al., 2002). 
Figura 5 - Leishmaniose disseminada

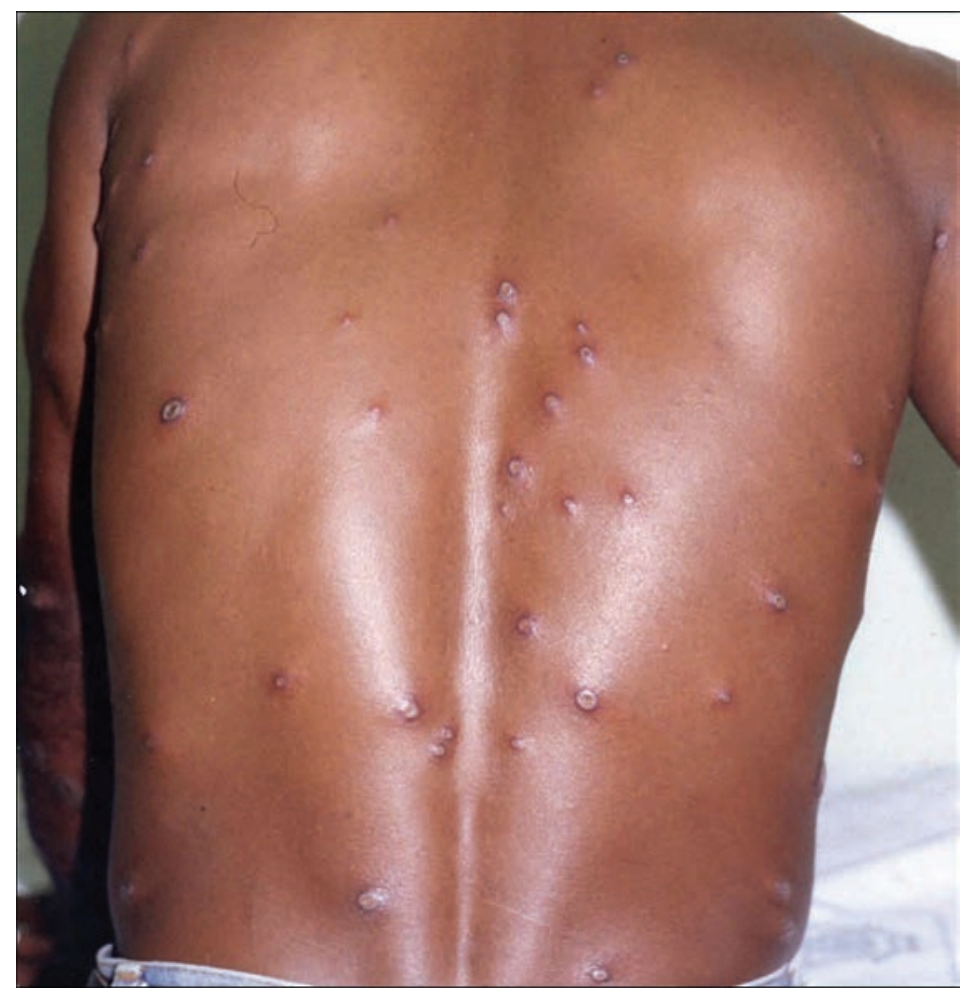

Vários fatores sugerem que a disseminação hematogênica dos parasitos seria o mecanismo envolvido na patogênese da LD. A presença de sinais e sintomas sistêmicos tais como febre, mal-estar, além da rápida evolução para disseminação das lesões apoiaria tal hipótese. A presença de DNA de Leishmania foi observada em células mononucleares do sangue periférico em 19\% pacientes com leishmaniose causada por espécies do subgênero Viannia (Vergel et al., 2006), e em $24,8 \%$ de indivíduos com infecção por causada por L. braziliensis, sugerindo que a circulação de amastigotas pode ocorrer na leishmaniose (De Oliveira Câmera et al., 2006).

Na maioria das vezes a sorologia para HIV é negativa nesses pacientes (Carvalho et al., 1994), embora haja relatos de associação à síndrome de reconstituição imune (Posada-Vergara et al., 2005). A LD é considerada uma forma borderline no espectro imunopatológico das leishmanioses, situada entre a LC e o polo hiperérgico (LM), quando causada por L. braziliensis ou entre a LC e o polo anérgico (leishmaniose cutânea difusa), quando o agente etiológico é a L. amazonensis (Silveira, Lainson \& Corbett, 2004).

\section{LEISHMANIOSE CUTÂNEA DIFUSA}

A leishmaniose cutânea difusa (LCD), também chamada LCD anérgica, foi descrita por Convit e Lapenta (1948), na Venezuela, observando casos que apresentavam lesões nodulares disseminadas, sem ulceração, ricas em formas amastigotas e teste de intradérmico de Montenegro negativo. Com sinonímia variada, foi inicialmente confundida com a hanseníase virchowiana, daí a denominação anterior de leishmaniose anérgica hansenoide (Silva, 1978). Posteriormente, esse conjunto de manifestações clínicas foi associado a uma resposta imune celular específica deficiente do hospedeiro contra Leishmania (Convit, Pinardi \& Rondon, 1972). Nas Américas, seus agentes causadores são espécies pertencentes ao subgênero Leishmania e ao complexo mexicana: L. venezuelensis, L. pifanoi, L. mexicana 
e L. amazonensis. Esta última é a única espécie responsável pelos casos de LCD no Brasil. A ausência de uma resposta imune efetiva, mediada por células específicas contra Leishmania, é indicada in vivo pela ausência de reatividade ao teste de Montenegro. Na avaliação da imunidade in vitro, verifica-se ausência de produção de IFN- $\gamma$ por células mononucleares do sangue periférico, ausência de expressão de mRNA de IFN- $\gamma$, presença de expressão de mRNA de IL-10, além de alta expressão de mRNA de IL-4 (Pirmez et al., 1993; Bomfim et al., 1996).

O exame histopatológico das lesões de LCD revela epiderme preservada ou com ligeira atrofia e presença da faixa de Unna (uma fina camada de colágeno subepidérmica sem macrófagos parasitados), à semelhança da hanseníase virchowiana. o infiltrado inflamatório situado na derme é constituído de histiócitos vacuolados nos quais há abundância de formas amastigotas, além de linfócitos e plasmócitos.

A LCD inicia-se, com frequência, na infância (Diaz et al., 1985; Azeredo-Coutinho et al., 2007), com lesão ulcerada inicial que evolui algumas vezes para a cicatrização ou não, seguindo-se o aparecimento de nódulos ou placas de superfície lisa, da cor da pele ou acastanhadas, localizadas em áreas expostas como face, membros superiores e inferiores (Figura 6). Essas lesões, em geral, não apresentam ulceração e a doença tende a evitar as mucosas (Silva, 1978). Quando a invasão da semimucosa ou mucosa é verificada, se dá por contiguidade com as lesões cutâneas. Lesões ósseas como osteopenia, lesões osteolíticas ou osteomielite podem ocorrer (Costa et al., 2005). Sem tratamento, a doença progride inexoravelmente, levando à infiltração difusa da face, aumento do número e tamanho dos nódulos, produzindo desfiguração e afastando o paciente do convívio social.

Figura 6 - Leishmaniose cutânea difusa

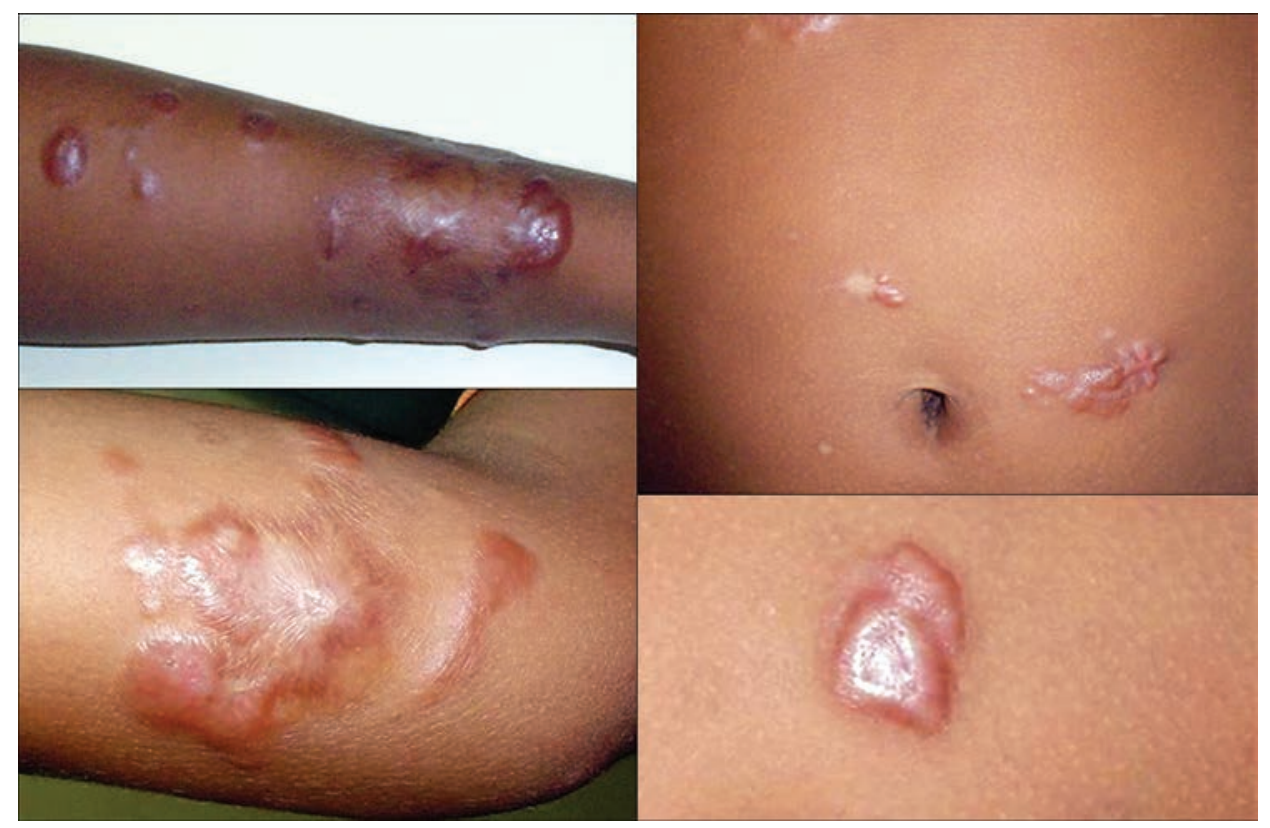

Embora haja relatos de regressão espontânea de grupos de lesões na leishmaniose difusa (Costa et al., 1995), a terapia específica com antimonial pentavalente, anfotericina B ou isetionato de pentamidina, em geral proporciona melhora clínica apenas transitória. Nestas fases de involução clínica, foi observada produção de IFN- $\gamma$, aumento da expressão de mRNA de IFN- $\gamma$ e redução da expressão de mRNA de IL-10. Porém, essa alteração no perfil de produção de citocinas foi fugaz e insuficiente para evitar as recaídas subsequentes. Propostas terapêuticas envolvendo imunoterapia 
com vacina composta de BCG e extrato de promastigotas de Leishmania (Convit et al., 2004) ou associação de pentamidina, alopurinol e IFN- $\gamma$ recombinante (Salaiza-Suazo et al., 1999) não apresentaram resultados promissores.

\section{LEISHMANIOSE DÉRMICA PÓS-CALAZAR}

A leishmaniose dérmica pós-calazar manifesta-se em indivíduos portadores de leishmaniose visceral, após tratamento com antimoniais pentavalentes. Essa forma clínica é associada tipicamente a $L$. donovani, porém nas Américas, a leishmaniose dérmica pós-calazar, embora excepcional, foi reportada em associação à infecção pelo vírus HIV (Bittencourt et al., 2003). Observa-se um período variável de tempo entre o tratamento da leishmaniose visceral e o aparecimento das lesões cutâneas: máculas hipocrômicas, lesões maculopapulosas ou nodulares. Eventualmente atingem as mucosas. As lesões albergam amastigotas, visualizados em esfregaços ou biópsias de lesões, demonstrando a importância epidemiológica desses pacientes em áreas endêmicas do Velho Mundo, aos quais seria atribuído o papel de reservatórios dos parasitos (Das et al., 2009).

\section{LEISHMANIOSE MUCOSA}

Na leishmaniose tegumentar americana, a leishmaniose mucosa (LM) é considerada uma das formas graves. Afeta as mucosas das vias aéreas superiores, levando, sem terapia e acompanhamento adequados, à destruição da pirâmide nasal (Figura 7). No Brasil, a LM representava 3\% dos casos de leishmaniose tegumentar nos anos 80 (Jones et al., 1987). Na Bolívia, onde a proporção de casos de LM com relação aos casos de LC é 1:6, um dos mais altos da América Latina, estima-se que em média 20\% dos indivíduos com LC desenvolvam LM (García et al., 2009). 0 termo leishmaniose mucocutânea deve ser aplicado aos casos com presença simultânea de lesões mucosas e cutâneas, representando 14\% a 28\% de casos de acometimento mucoso entre pacientes com LC (Marsden et al., 1986). A lesão mucosa tardia, ou forma mucosa metastática, característica da infecção por espécies do subgênero Viannia, particularmente L. braziliensis (Amato et al., 2008), surge após período variável de intervalo da doença cutânea. Os pacientes referem história de lesão cutânea anterior, que evoluiu para cicatriz atrófica, na vigência ou não de tratamento específico. Para aqueles sem história de lesão cutânea prévia, admite-se que esta poderia ter sido efêmera ou diminuta, não tendo sido notada pelo paciente. A lesão mucosa surge em geral alguns anos após o surgimento da lesão cutânea, ou mesmo décadas depois: 46\% dos casos em até dois anos (Marsden, 1986) ou 50\% dos casos em até cinco anos (Amato et al., 2008) ou seis anos (Jones et al., 1987). No entanto, a infiltração precoce de mucosas pôde ser detectada em seis entre 220 indivíduos com LC, por exame otorrinolaringológico com fibromicroscopia (Boaventura et al., 2006).

A LM tem curso crônico, com sintomas de obstrução nasal, epistaxe, secreção nasal, eliminação de crostas, dor, deformidade e edema. A lesão inicial ocorre no nariz, no septo cartilaginoso, havendo disseminação retrógrada para a cavidade nasal, palato, tonsilas, chegando à laringe, quando há tosse, rouquidão, cornagem e obstrução ao fluxo aéreo. A progressão da doença leva à perfuração do septo nasal, colapso da pirâmide nasal, infiltração e edema do lábio superior, produzindo o 'nariz de tapir'. Quadros avançados podem evoluir para a morte por desnutrição e complicações, como pneumonia aspirativa, obstrução das vias aéreas e insuficiência respiratória aguda (Marsden, 1986).

Os pacientes com LM exibem uma intensa resposta ao teste de Montenegro (Figura 8), denotando uma hipersensibilidade aos antígenos de Leishmania, que pode ser verificada também em ensaios de linfoproliferação in vitro (Castés, Agnelli \& Rondón, 1984). A LM situa-se no polo hiperérgico do espectro da leishmaniose, com pobreza parasitária e intensa resposta inflamatória acompanhada de lesão tecidual. A resposta imune celular se caracteriza por produção aumentada de IFN- $\gamma$ e TNF- $\alpha$ associada a baixos níveis de IL-10 (Da-Cruz et al., 1996; Bacellar et al., 2002) e baixa expressão do receptor de IL-10 nas lesões (Faria et al., 2005). Tais dados indicam a existência de uma resposta pró-inflamatória de citocinas potencialmente lesivas para os tecidos do hospedeiro, com insuficiência de uma contrapar- 
tida regulatória para o controle dessa resposta. Porém, foi referido por Marsden (1986) o achado de cinco pacientes com leishmaniose mucosa e intradermorreação negativa, três dois quais apresentaram lesões múltiplas e extensas, de longo tempo de evolução e associada à desnutrição, concluindo o referido autor que o teste cutâneo negativo na LM seria indicador de mau prognóstico.

Figura 7 - Leishmaniose mucosa

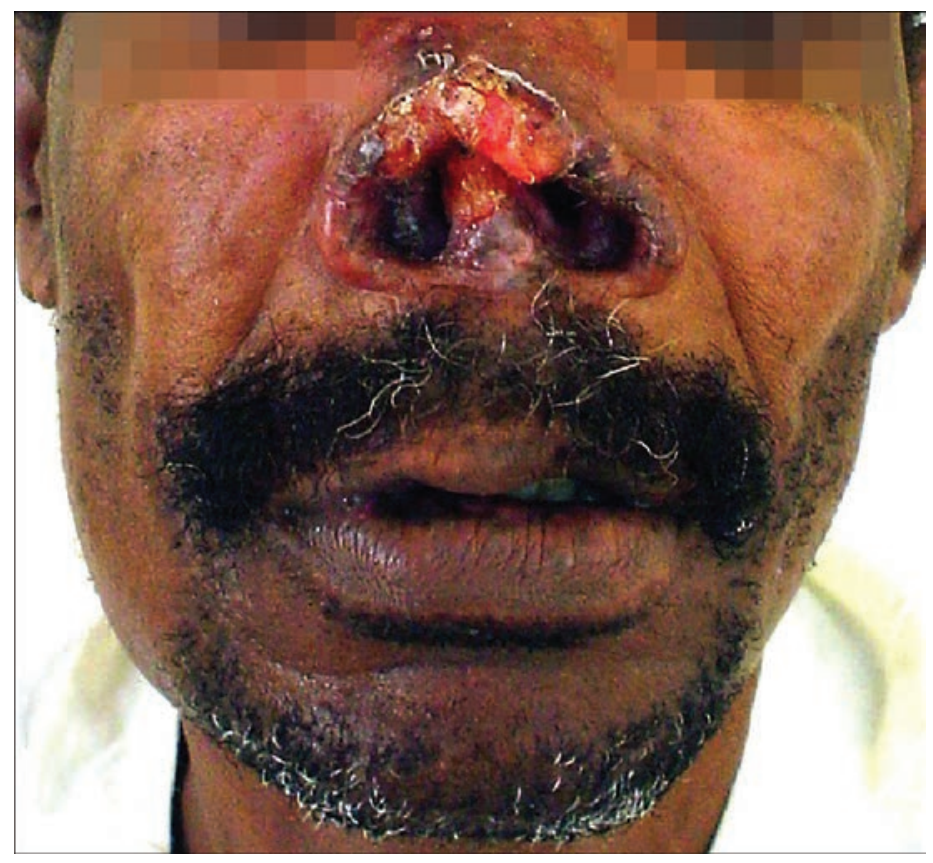

Figura 8 - Reação flictenular ao teste de Montenegro em paciente com leishmaniose mucosa

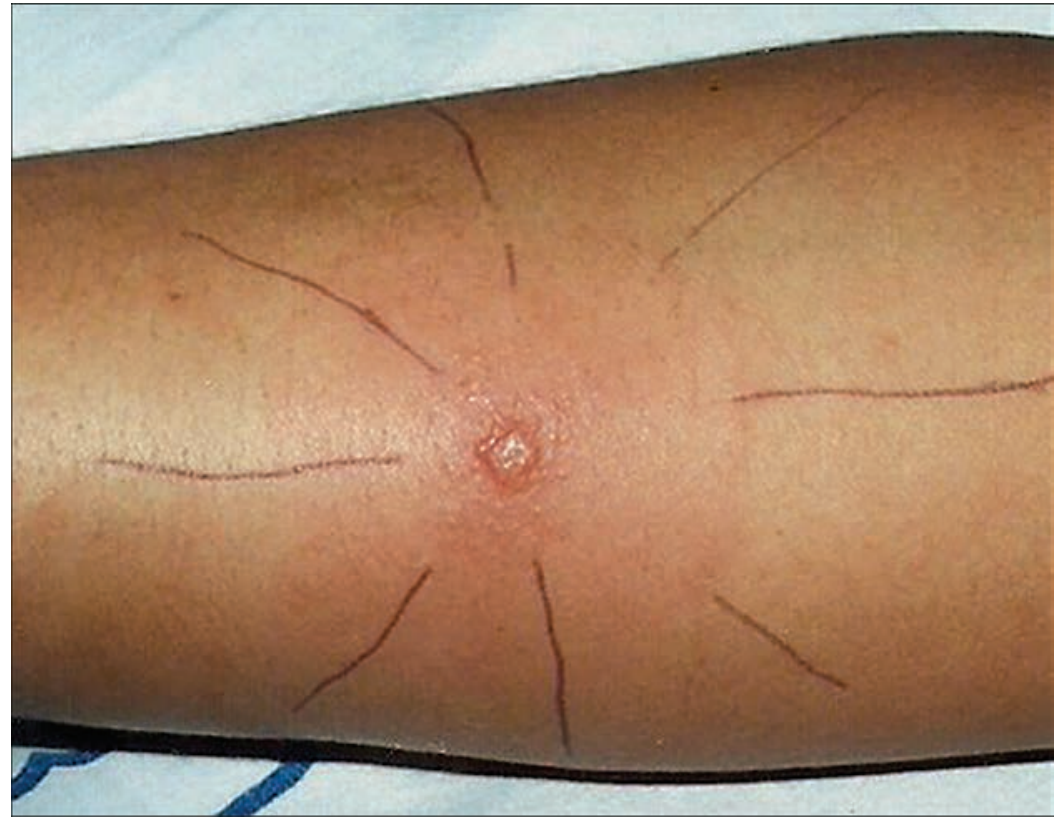


O tratamento da LM com antimonial pentavalente, mesmo em esquemas e doses adequados, pode apresentar resposta insatisfatória, com recidivas frequentes. O tratamento da LM deve ser iniciado preferencialmente em regime de internação hospitalar, pois o processo inflamatório das lesões infiltrativas, edematosas ou ulceradas na mucosa das vias aéreas superiores pode se exacerbar, levando à obstrução e necessidade de traqueostomia de urgência. Tal fenômeno foi interpretado como uma reação semelhante à de Jarisch-Herxheimer (Costa, Netto \& Marsden, 1986). Coadjuvantes à terapia com antimoniais, como o emprego concomitante de pentoxifilina, um inibidor de TNF- $\alpha$ (Lessa et al., 2001), foram empregados com o objetivo de modular negativamente a reação inflamatória provocada pela resposta celular do tipo 1 que é exacerbada nessa forma clínica.

Além de L. braziliensis, outras espécies do subgênero Viannia, tais como L. guyanensis e L. panamensis, podem causar lesões mucosas (Santrich et al., 1990; Osório, Castillo \& Ochoa, 1998). Embora essa forma clínica seja comumente associada a espécies do subgênero Viannia (Disch et al., 2005), casos de LM causados por L. amazonensis, espécie pertencente ao subgênero Leishmania, foram relatados no Brasil (Barral et al., 1991).

Como conclusão, percebe-se que nas Américas, a LTA tem como agentes etiológicos uma variedade substancial de espécies pertencentes a dois subgêneros (Viannia e Leishmania). Consequentemente, a LTA se expressa por meio de ampla diversidade de apresentações clínicas, que reflete uma superposição de espectros imunopatológicos de infecções causadas por leishmânias dermotrópicas filogeneticamente distantes, que provavelmente desenvolveram diferentes estratégias de sobrevivência no hospedeiro mamífero. Tais diferenças podem representar um desafio formidável para a descoberta de novos alvos e estratégias para tratamento e vacinas. Esse grande número de diferentes espécies de leishmânias causadoras de LTA está adaptado ao parasitismo de várias espécies de flebotomíneos vetores, que apresentam, por sua vez, significativa heterogeneidade ecológica. Por conseguinte, as características epidemiológicas envolvidas na transmissão da LTA divergem muito, de acordo com a região e a espécie envolvida, o que dificulta sobremaneira o controle dessa endemia.

\section{REFERÊNCIAS}

AEBISCHER, T. Recurrent cutaneous leishmaniasis: a role for persistent parasites? Parasitology Today, 10(1): 25-28, 1994.

ALMEIDA, M. C. et al. Leishmanial infection: analysis of its first steps. A Review. Memórias do Instituto Oswaldo Cruz, 98(7): 861-870, 2003.

ALVAR, J. et al., Leishmaniasis worldwide and global estimates of its incidence. PLoS One, 7(5): 1-12, 2012.

AMATO, V. S. et al. Mucosal leishmaniasis. Current scenario and prospects for treatment. Acta Tropica, 105(1): 1-9, 2008.

AZEREDO-COUTINHO, R. B. \& MENDONÇA, S. C. An intermittent schedule is better than continuous regimen of antimonial therapy for cutaneous leishmaniasis in the municipality of Rio de Janeiro, Brazil. Revista da Sociedade Brasileira de Medicina Tropical, 35(5): 477-481, 2002.

AZEREDO-COUTINHO, R. B. et al. First report of diffuse cutaneous leishmaniasis and Leishmania amazonensis infection in Rio de Janeiro State, Brazil. Transactions of the Royal Society of Tropical Medicine and Hygiene, 101(7): 735-737, 2007.

AZULAY, R. D. Classificação clínico-imunopatológica da Leishmaniose. Anais Brasileiros de Dermatologia, 52: 345-351, 1977.

BACELLAR, O. et al. Up-regulation of Th1-type responses in mucosal leishmaniasis patients. Infection and Immunity, 70(12): 6.734-6.740, 2002.

BARRAL, A. et al. Leishmaniasis in Bahia, Brazil: evidence that Leishmania amazonensis produces a wide spectrum of clinical disease. The American Journal of Tropical Medicine and Hygiene, 44(5): 536-546, 1991.

BARRAL, A. et al. Lymphadenopathy as the first sign of human cutaneous infection by Leishmania braziliensis. The American Journal of Tropical Medicine and Hygiene, 53(3): 256-259, 1995. 
BARRAL-NETTO, M. \& BARRAL, A. Transforming growth factor-beta in tegumentary leishmaniasis. Brazilian Journal of Medical and Biological Research, 27(1): 1-9, 1994.

BARRAL-NETTO, M. et al. Transforming growth factor-beta in leishmanial infection: a parasite escape mechanism. Science, 257(5.069): 545-548, 1992.

BERLIN, C. Leishmaniasis recidiva cutis. Archiv für Dermatologie und Syphilis, 41: 874, 1940.

BITTENCOURT, A. et al. Post-kala-azar dermal leishmaniasis associated with AIDS. The Brazilian Journal of Infectious Diseases, 7(3): 229-233, 2003.

BOAVENTURA, V. S. et al. Concomitant early mucosal and cutaneous leishmaniasis in Brazil. The American Journal of Tropical Medicine and Hygiene, 75(2): 267-269, 2006.

BOMFIM, G. et al. Variation of cytokine patterns related to therapeutic response in diffuse cutaneous leishmaniasis. Experimental Parasitology, 84(2): 188-194, 1996.

CARVALHO, E. M. et al. Clinical and immunological aspects of disseminated cutaneous leishmanisis. Acta Tropica, 56(4): 315-325, 1994.

CASTÉS, M.; AGNELLI, A. \& RONDóN, A. J. Mechanisms associated with immunoregulation in human American cutaneous leishmaniasis. Clinical and Experimental Immunology, 57(2): 279-286, 1984.

CASTÉS, M. et al. T-Cell Subpopulations, expression of interleukin-2 receptor, and production of interleukin-2 and gamma interferon in human American cutaneous leishmaniasis. Journal of Clinical Microbiology, 26(6): 1.207-1.213, 1988.

CONVIT, J. \& LAPENTA, L. Sobre un caso de Leishmaniasis Tegumentaria de forma diseminada. Revista de la Policlínica Caracas, 10(100): 153-158, 1948.

CONVIT, J.; PINARDI, M. E. \& RONDÓN, A. J. Diffuse cutaneous leishmaniasis: a disease due to an immunological defect of the host. Transactions of the Royal Society of Tropical Medicine and Hygiene, 66(4): 603-610, 1972.

CONVIT, J. et al. The clinical and immunological spectrum of American cutaneous leishmaniasis. Transactions of the Royal Society of Tropical Medicine and Hygiene, 87(4): 444-448, 1993.

CONVIT, J. et al. Therapy of Venezuelan patients with severe mucocutaneous or early lesions of diffuse cutaneous leishmaniasis with a vaccine containing pasteurized Leishmania promastigotes and bacillus Calmette-Guerin: preliminary report. Memórias do Instituto Oswaldo Cruz, 99(1): 57-62, 2004.

COSTA, A. A. et al. Imaging exams of bone lesions in patients with diffuse cutaneous leishmaniasis (DCL). Acta Tropica, 96(1): 9-15, 2005.

COSTA, J. M. L.; NETTO, E. M. \& MARSDEN, P. D. Acute airway obstruction due to oedema of the larynx following antimony therapy in mucosal leishmaniasis. Revista da Sociedade Brasileira de Medicina Tropical, 19(2): 109, 1986.

COSTA, J. M. et al. Disseminated cutaneous leishmaniasis in a field clinic in Bahia, Brazil: a report of eight cases. The Journal of Tropical Medicine and Hygiene, 89(6): 319-323, 1986.

COSTA, J. M. et al. Spontaneous healing of cutaneous Leishmania braziliensis braziliensis ulcers. Transactions of the Royal Society of Tropical Medicine and Hygiene, 81(4): 606, 1987.

COSTA, J. M. et al. Spontaneous regional healing of extensive skin lesions in diffuse cutaneous leishmaniasis (DCL). Revista da Sociedade Brasileira de Medicina Tropical, 28(1): 45-47, 1995.

COUPPIÉ, P. et al. Disseminated cutaneous leishmaniasis due to Leishmania guyanensis: case of a patient with 425 lesions. The American Journal of Tropical Medicine and Hygiene, 71(5): 558-560, 2004.

COZZANI, E. et al. Cutaneous sporotrichoid leishmaniasis resistant to pentavalent antimonial therapy: complete resolution with itraconazole. Clinical and Experimental Dermatology, 36(1): 49-51, 2010.

CUPOLILlO, E.; GRIMALDI JR., G. \& MOMEN, H. A general classification of New World Leishmania using numerical zymotaxonomy. The American Journal of Tropical Medicine and Hygiene, 50(3): 296-311, 1994. 
DA-CRUZ, A. M. et al. Tumor necrosis factor alpha in human American tegumentary leishmaniasis. Memórias do Instituto Oswaldo Cruz, 91(2): 225-229, 1996.

DAS, V. N. et al. Short report: development of post-kala-azar dermal leishmaniasis (PKDL) in miltefosine-treated visceral leishmaniasis. The American Journal of Tropical Medicine and Hygiene, 80(3): 336-338, 2009.

DE OLIVEIRA CÂMERA, P. et al. Haematogenous dissemination of Leishmania (Viannia) braziliensis in human American tegumentary leishmaniasis. Transactions of the Royal Society of Tropical Medicine and Hygiene, 100(12): 1.1121.117, 2006.

DESTOMBES, P. Application du concept de 'sistématisation polaire' aux leishmanioses cutanées. Bulletin de la Société de Pathologie Exotique et de ses Filiales, 53: 299-301, 1960.

DIAZ, H. B. et al. Leishmaniose difusa anérgica na República Dominicana. Estudo de 20 casos. Anais Brasileiros de Dermatologia, 60, supl. 1: 229-236, 1985.

DIAZ, N. L.et al. Intermediate or chronic cutaneous leishmaniasis: leukocyte immunophenotypes and cytokine characterisation of the lesion. Experimental Dermatology, 11(1): 34-41, 2002.

DISCH, J. et al. Leishmania (Viannia) subgenus kDNA amplification for the diagnosis of mucosal leishmaniasis. Diagnostic Microbiology and Infectious Disease, 51(3): 185-190, 2005.

FAGUNDES, A. et al. Evaluation of polymerase chain reaction in the routine diagnosis for tegumentary leishmaniasis in a referral centre. Memórias do Instituto Oswaldo Cruz, 105(1): 109-112, 2010.

FARIA, D. R. et al. Decreased in situ expression of interleukin-10 receptor is correlated with the exacerbated inflammatory and cytotoxic responses observed in mucosal leishmaniasis. Infection and Immunity, 73(12): 7.853-7.859, 2005.

FLOCH, H. Endemic lymphangitis in warm countries, elephantiasis, filariasis and American forest leishmaniasis. Bulletin de la Société de Pathologie Exotique et de ses Filiales, 47(4): 539-544, 1954.

FURTADO, T. Critérios para o diagnóstico da leishmaniose tegumentar americana. Anais Brasileiros de Dermatologia, $55(2): 81-86,1980$.

GARCÍA, A. L. et al. Leishmaniases in Bolivia: comprehensive review and current status. The American Journal of Tropical Medicine and Hygiene, 80(5): 704-711, 2009.

GRIMALDI JR., G.; TESH, R. B. \& McMAHON-PRATT, D. A review of the geographic distribution and epidemiology of leishmaniasis in the New World. The American Journal of Tropical Medicine and Hygiene, 41(6): 687-725, 1989.

GUIMARÃES, L. H. et al. Atypical manifestations of tegumentary leishmaniasis in a transmission area of Leishmania braziliensis in the state of Bahia, Brazil. Transactions of the Royal Society of Tropical Medicine and Hygiene, 103(7): $712-715,2009$

HARMS, G. et al. Cutaneous leishmaniasis associated with extensive lymphadenopathy during an epidemic in Ceará State, northeast Brazil. Acta Tropica, 93(3): 303-310, 2005.

JONES, T. C. et al. Epidemiology of American cutaneous leishmaniasis due to Leishmania braziliensis braziliensis. The Journal of Infectious Diseases, 156(1): 73-83, 1987.

KUBBA, R. et al. Peripheral nerve involvement in cutaneous leishmaniasis (Old World). International Journal of Dermatology, 26(8): 527-531, 1987.

LESSA, H. A. et al. Successful treatment of refractory mucosal leishmaniasis with pentoxifylline plus antimony. The American Journal of Tropical Medicine and Hygiene, 65(2): 87-89, 2001.

LinDEnBERG, A. L'ulcère de Bauru ou le bouton d'Orient au Brésil. Bulletin de la Société de Pathologie Exotique et de ses Filiales, 2: 252-254, 1901.

LLANOS-CUENTAS, E. A. et al. Human mucocutaneous leishmaniasis in Três Braços, Bahia, Brazil, an area of Leishmania braziliensis braziliensis transmission. II. Cutaneous disease. Presentation and evolution. Revista da Sociedade Brasileira de Medicina Tropical, 17: 169-177, 1984. 
MACHADO, P. R. et al. Reappraisal of the immunopathogenesis of disseminated leishmaniasis: in situ and systemic immune response. Transactions of the Royal Society of Tropical Medicine and Hygiene, 105(8): 438-444, 2011.

MARSDEN, P. D. Mucosal leishmaniasis ('espundia' Escomel, 1911). Transactions of the Royal Society of Tropical Medicine and Hygiene, 80: 859-876, 1986.

MARSDEN, P. D. et al. Spontaneous healing of Leishmania braziliensis braziliensis skin ulcers. Transactions of the Royal Society of Tropical Medicine and Hygiene, 78(4): 561-562, 1984.

MARZOCHI, M. C. A. Leishmanioses no Brasil: as leishmanioses tegumentares. JBM, 63(5/6): 82-104, 1992.

MARZOCHI, M. C. A. \& MARZOCHI, K. B. Tegumentary and visceral leishmaniasis in Brazil - emerging anthropozoonosis and possibilities for their control. Cadernos de Saúde Pública, 10, supl. 2: 359-375, 1994.

MARZOCHI, M. C. A. et al. Reação de imunofluorescência indireta e intradermorreação para leishmaniose tegumentar americana em moradores na área de Jacarepaguá (Rio de Janeiro): estudo comparativo dos resultados observados em 1974 e 1978. Revista do Instituto de Medicina Tropical de São Paulo, 22(3): 149-155, 1980.

MELBY, P. C. et al. Increased expression of proinflammatory cytokines in chronic lesions of human cutaneous leishmaniasis. Infection and Immunity, 62(3): 837-842, 1994.

MENDONÇA, S. C. et al. Human American cutaneous leishmaniasis (Leishmania b. braziliensis) in Brazil: lymphoproliferative responses and influence of therapy. Clinical and Experimental Immunology, 64: 269-276, 1986.

NETTO, E. M. et al. Long-term follow-up of patients with Leishmania Viannia) braziliensis infection and treated with Glucantime. Transactions of the Royal Society of Tropical Medicine and Hygiene, 84: 367-370, 1990.

OLIVEIRA-NETO, M. P. et al. An outbreak of American cutaneous leishmaniasis (Leishmania braziliensis braziliensis) in a periurban area of Rio de Janeiro city, Brazil: clinical and epidemiological studies. Memórias do Instituto Oswaldo Cruz, 83(4): 427-435, 1988.

OLIVEIRA-NETO, M. P. et al. Leishmaniasis recidiva cutis in New World cutaneous leishmaniasis. International Journal of Dermatology, 37(11): 846-849, 1998.

OSORIO, L. E.; CASTILLO, C. M. \& OCHOA, M. T. Mucosal leishmaniasis due to Leishmania Viannia) panamensis in Colombia: clinical characteristics. The American Journal of Tropical Medicine and Hygiene, 59(1): 49-52, 1998.

PIRMEZ, C. et al. Cytokine patterns in the pathogenesis of human leishmaniasis. The Journal of Clinical Investigation, 91(4): 1.390-1.395, 1993.

POSADA-VERGARA, M. P. et al. Tegumentary leishmaniasis as a manifestation of immune reconstitution inflammatory syndrome in 2 patients with AIDS. The Journal of Infectious Diseases, 192(10): 1.819-1.822, 2005.

RINCón, M. Y. et al. Leishmaniasis Cutánea Diseminada: reporte de dos casos en Santander, Colômbia. Revista de Salud Publica (Bogota), 11(1): 145-150, 2009.

SAGHER, F. Leishmania vaccine test in leishmaniasis of the skin (Oriental sore); quantitative experiments. Archiv für Dermatologie und Syphilis, 55(5): 658-663, 1947.

SALAIZA-SUAZO, N. et al. Treatment of two patients with diffuse cutaneous leishmaniasis caused by Leishmania mexicana modifies the immunohistological profile but not the disease outcome. Tropical Medicine \& International Health, 4(12): 801-811, 1999.

SALHI, A. et al. Immunological and genetic evidence for a crucial role of IL-10 in cutaneous lesions in humans infected with Leishmania braziliensis. The Journal of Immunology, 180(9): 6.139-6.148, 2008.

SANTRICH, C. et al. Mucosal disease caused by Leishmania braziliensis guyanensis. The American Journal of Tropical Medicine and Hygiene, 42(1): 51-55, 1990.

SARAVIA, N. G. et al. Recurrent lesions in human Leishmania braziliensis infection-reactivation or reinfection? The Lancet, 336(8.712): 398-402, 1990. 
SCHUBACH, A. et al. Leishmaniasis of glans penis. Journal of the European Academy of Dermatology and Venereology, 10(3): 226-228, 1998a.

SCHUBACH, A. et al. Cutaneous scars in American tegumentary leishmaniasis patients: a site of Leishmania (Viannia) braziliensis persistence and viability eleven years after antimonial therapy and clinical cure. The American Journal of Tropical Medicine and Hygiene, 58(6): 824-827, 1998b.

SILVA, D. Leishmaniose anérgica hansenóide. Anais Brasileiros de Dermatologia, 53: 161-168, 1978.

SILVEIRA, F. T.; LAINSON, R. \& CORBETT, C. E. P. Clinical and Immunopathological spectrum of American cutaneous leishmaniasis with special reference to the disease in Amazonian Brazil - a review. Memórias do Instituto Oswaldo Cruz, 99(3): 239-251, 2004.

SILVEIRA, F. T. ; LAINSON, R. \& CORBETT, C. E. Further observations on clinical, histopathological, and immunological features of borderline disseminated cutaneous leishmaniasis caused by Leishmania (Leishmania) amazonensis. Memórias do Instituto Oswaldo Cruz, 100(5): 525-534, 2005.

SILVEIRA, F. T. et al. Cutaneous leishmaniasis due to Leishmania (Leishmania) amazonensis in Amazonian Brazil, and the significance of a negative Montenegro skin-test in human infections. Transactions of the Royal Society of Tropical Medicine and Hygiene, 85(6): 735-738, 1991.

SOUSA, A. Q. et al. Bubonic leishmaniasis: a common manifestation of Leishmania (Viannia) braziliensis infection in Ceara, Brazil. The American Journal of Tropical Medicine and Hygiene, 53(4): 380-385, 1995.

TURETZ, M. L. et al. Disseminated leishmaniasis: a new and emerging form of leishmaniasis observed in northeastern Brazil. The Journal of Infectious Diseases, 186(12): 1.829-1.834, 2002.

VERGEL, C. et al. Evidence for Leishmania (Viannia) parasites in the skin and blood of patients before and after treatment. The Journal of Infectious Diseases, 194(4): 503-511, 2006.

VIEIRA, M. G. et al. B-cell infiltration and frequency of cytokine producing cells differ between localized and disseminated human cutaneous leishmaniases. Memórias do Instituto Oswaldo Cruz, 97(7): 979-983, 2002.

VIEIRA-GONÇALVES, R. et al. Clinical features of cutaneous and disseminated cutaneous leishmaniasis caused by Leishmania (Viannia) braziliensis in Paraty, Rio de Janeiro. International Journal of Dermatology, 47: 926-932, 2008. 


\title{
Leishmaniose Visceral
}

\author{
Dorcas Lamounier Costa I Carlos Henrique Nery Costa
}

\begin{abstract}
$\mathrm{A}_{\mathrm{d}}^{\mathrm{s}}$ s leishmanioses são doenças causadas por protozoários intracelulares obrigatórios da família Trypanosomatidae, da ordem Kinetoplastidae, do gênero Leishmania. As espécies que causam leishmaniose visceral (LV) pertencem ao complexo L. donovani: L. donovani (sin. Leishmania archibaldi) na Índia e na África Oriental e L. infantum (sin. L. chagasi) nas demais regiões do mundo (Lukes et al., 2007; Ibrahim \& Barker, 2001; Mauricio et al., 2000; Costa et al., 2000). O parasito é geralmente transmitido por flebotomíneos conhecidos popularmente como mosquito-palha, asa dura, tatuquiras, birigui, que pertencem ao gênero Lutzomyia na América do Sul e ao gênero Phlebotomus nas demais áreas do mundo. O principal reservatório doméstico de Leishmania nas Américas é o cão (Canis familiaris), e no ambiente silvestre são sobretudo as raposas (Lycalopex vetulus e Cerdocyon thous) e os marsupiais (Didelphis albiventris, D. marsupialis). O homem parece desempenhar papel secundário como reservatório de Leishmania nas Américas (Costa et al., 2000). Na Índia, a doença é tipicamente antroponótica. A doença também é considerada antroponótica na região Leste da África, mas existe evidência da participação de reservatórios animais como roedores e canídeos nessa área (Dereure et al., 2000; Dereure et al., 2003). Nas demais regiões do Velho Mundo, os canídeos, os roedores e as pessoas participam da cadeia de transmissão com importância variável dentro dos ciclos epidêmicos. Outras formas de transmissão, apesar de raras, incluem a transmissão congênita (Meinecke et al., 1999), a transmissão por transfusão de hemoderivados (Dey \& Singh, 2006) ou por agulhas (Desjeux \& Alvar, 2003) e outros materiais perfuro-cortantes contaminados (Evans \& Pearson, 1988).
\end{abstract}

A leishmaniose visceral é a apresentação mais grave da infecção e tem sido alvo de especial atenção nas duas últimas décadas, quando grandes epidemias foram descritas no Sudão, na Índia, em Bangladesh e no Brasil (Collin et al., 2004; Costa, Pereira \& Araújo, 1990; Thakur, 1984; Rahman \& Islam, 1983). Estima-se que entre 200 mil e 400 mil casos da doença ocorram a cada ano em 88 países onde a LV é endêmica (Alvar et al., 2012).

A leishmaniose visceral foi notificada pela primeira vez na América do Sul em 1913 (Migone, 1913 apud Alencar, 1959). A primeira identificação de Leishmania no Brasil deu-se em 1934, em material de biópsia hepática post mortem (Penna, 1934), ao passo que o primeiro caso da doença em indivíduo vivo foi relatado em 1936 (Chagas, 1936). A LV foi descrita como endemia predominantemente rural em diversas regiões do país desde então (Alencar, 1977), embora a ocorrência da doença de forma endêmica em meio urbano tenha sido relatada desde 1955 (Deane \& Deane, 1955). 
Contudo, a partir de 1980 epidemias foram notificadas em diversas cidades do Nordeste, tendo avançado para as Regiões Centro-Oeste, Sul e Sudeste (Costa, Pereira \& Araújo, 1990; Oliveira et al., 2001, 2006; Jeronimo et al., 1994; Costa, 2008). As condições que favoreceram a instalação da leishmaniose em regiões urbanas do Brasil são desconhecidas, mas talvez estejam relacionadas ao desmatamento, às condições precárias de saneamento decorrentes do crescimento desordenado das cidades, o que terminou por favorecer a adaptação do vetor Lu. longipalpis e propiciou o contato direto entre os ciclos silvestre e urbano da LV (Harhay et al., 2011). Por sua vez, o êxodo rural intenso nas últimas décadas, as moradias superpovoadas e a abundância de reservatórios caninos no peridomicílio facilitaram o contato de pessoas suscetíveis com o parasito (Costa, Pereira \& Araújo, 1990; Lainson \& Rangel, 2005; Costa et al., 2005; Killick-Kendrick, 1990) e contribuíram para a emergência das epidemias urbanas notificadas no país a partir de 1981.

A leishmaniose urbana trouxe novas características à doença. Um terço dos indivíduos acometidos são crianças com menos de dois anos de idade, que apresentam doença rapidamente progressiva e elevado índice de complicações, especialmente infecções bacterianas e sangramentos. A letalidade da LV no Brasil apresenta tendência crescente, com oscilação entre 7\% e 13,3\% (Oliveira et al., 2006; Rey et al., 2005; Cavalcante, 2007), níveis comparáveis aos encontrados em campos de refugiados no Sudão (Collin et al., 2004; Seaman et al., 1996). Além do rápido processo de urbanização da doença, outras condições possivelmente relacionadas a esse desfecho desfavorável são a expansão da epidemia da síndrome de imunodeficiência adquirida (Aids), o acometimento de grupos vulneráveis em consequência da grande força de transmissão da infecção e o diagnóstico tardio.

\section{MANIFESTAÇÕES CLÍNICAS NA LEISHMANIOSE VISCERAL}

As manifestações clínicas da infecção pela L. chagasi variam desde a infecção assintomática ou oligossintomática até a doença progressiva e potencialmente fatal (Pearson \& Sousa, 1996; Jerônimo et al., 2000). A variedade de manifestações clínicas decorrentes da infecção depende da habilidade que o parasito tem em evadir-se dos mecanismos de defesa mediante complexa interação com o hospedeiro (Saha et al., 2006; Teixeira et al., 2006). A maioria dos indivíduos infectados por Leishmania não apresenta doença clinicamente manifesta (Jerônimo et al., 2000; Nandy, Neogy \& Chowdhury, 1987; Badaró et al., 1986a, 1986b; Caldas et al., 2002) e, em regióes endêmicas, estima-se que apenas $20 \%$ dos indivíduos infectados desenvolvam a forma clássica da doença (Badaró et al., 1986a; Silveira et al., 2010a, 2010b; Evans et al., 1992). Os fatores que determinam a gravidade das manifestações clínicas podem estar relacionados às condições ambientais (Moreno et al., 2005), à idade (Caldas et al., 2002), ao estado nutricional (Badaró et al., 1986a; Bern et al., 2007) e à resposta imune inicial do indivíduo acometido (Gama et al., 2004). Nas infecções inaparentes ou assintomáticas não há manifestações clínicas e a evidência da infecção é usualmente verificada em estudos epidemiológicos, por meio de sorologia ou de reação intradérmica de Montenegro. Os títulos de anticorpos em geral são baixos e podem permanecer positivos por um longo período. Na forma oligossintomática o quadro clínico é discreto, tem curta duração e frequentemente evolui para cura espontânea. A forma clássica da doença caracteriza-se por febre recorrente, palidez, emagrecimento, hepatoesplenomegalia, anemia, leucopenia, plaquetopenia e hipergamaglobulinemia (Berman, 1997; Herwaldt, 1999; Zijlstra et al., 1991) (Figura 1).

O período de incubação da LV varia de três a oito meses (Piscopo \& Mallia, 2007), pode ser tão breve quanto dez dias (Manson-Bahr \& Apted, 1982 apud Pearson \& Sousa, 1995), tão longo quanto 34 meses (Stone, Tool \& Pugsley, 1952) ou até maior que quatro anos (Neto, 1978). A doença predomina em crianças nos primeiros anos de vida e associa-se à grande morbidade e ao elevado número de óbitos (Silva, Stewart \& Costa, 2005; Al-Jurayyan et al., 1995; Grech et al., 2000; Abdelmoula et al., 2003; Pedrosa \& Rocha, 2004; Minodier et al., 2005). A doença apresenta-se de forma especialmente grave em crianças (Pedrosa \& Rocha, 2004; Daher et al., 2008; Pastorino et 
al., 2002), em idosos e em pessoas portadoras de imunodeficiências, originando quadros de difícil diagnóstico e tratamento (Cruz et al., 2006; Sinha, Pandey \& Bhattacharya, 2005). A letalidade é maior entre crianças com menos de dois anos de idade e entre os adultos (Oliveira et al., 2006; Caldas et al., 2002; Costa, 2009), em comparação às crianças em idade escolar e aos adolescentes. A distribuição da doença entre os sexos é semelhante durante a infância, mas predomina em homens a partir da adolescência (Oliveira et al., 2006; Evans et al., 1992; Pedrosa \& Rocha, 2004; Deane \& Deane, 1962).

Figura 1 - Irmãs com LV. Notar o bom estado geral, apesar da grande hepatoesplenomegalia

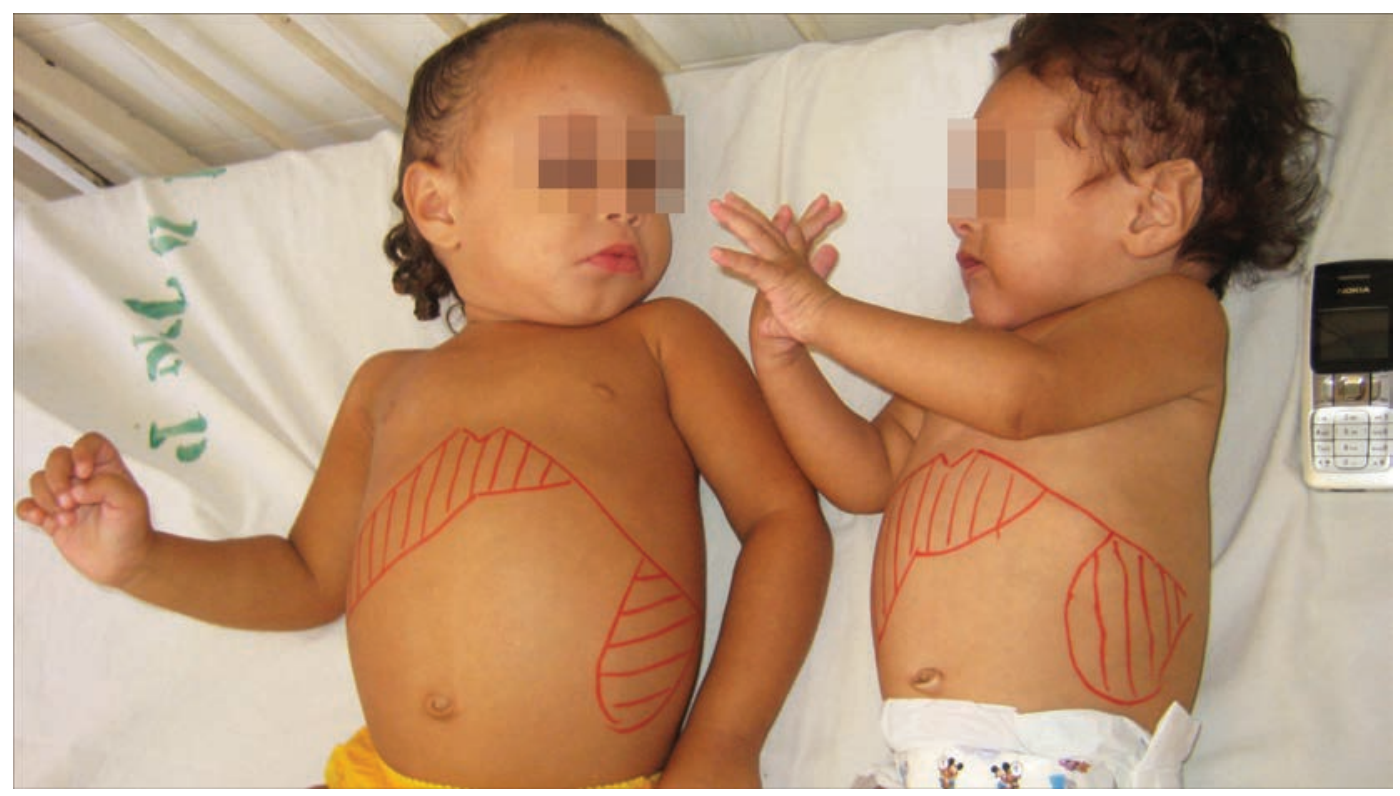

Na doença subaguda ou crônica, observa-se febre, adinamia, inapetência, perda de peso, palidez e aumento do volume abdominal decorrente da hepatoesplenomegalia e da fraqueza da parede abdominal (Figura 2). Os sintomas podem persistir por semanas ou meses (Herwaldt, 1999) e o paciente pode apresentar-se debilitado e incapacitado de exercer suas atividades usuais à época do diagnóstico (Desjeux, 1996). A febre pode ser intermitente ou remitente, mas costuma ser bem tolerada. A presença de calafrios pode causar confusão com o diagnóstico de malária ou de bacteriemia (Jerônimo, Sousa \& Pearson, 2005). A hepatoesplenomegalia está presente na maioria dos pacientes e o aumento do baço quase sempre é mais evidente que o aumento do fígado (Oliveira et al., 2006; Jerônimo et al., 1994; Cavalcante, 2007; Silva et al., 1997). O aumento dos linfonodos é muito frequente em pacientes do Sudão e da Índia (Zijlstra et al., 1991; Babiker et al., 2007; Sen Gupta \& Mukherjee, 1968), mas é menos evidente na leishmaniose americana.

A desnutrição tem sido descrita como fator de risco para a aquisição da LV, especialmente em crianças vivendo em áreas endêmicas (Badaró et al., 1986a; Caldas et al., 2002; Maciel et al., 2008; Harrison et al., 1986; Dye \& Williams, 1993; Anstead et al., 2001; Cerf et al., 1987), mas não se conhece exatamente o efeito do estado nutricional do paciente sobre o prognóstico das pessoas que evoluíram para as formas sintomáticas. Alguns estudos relataram que os pacientes desnutridos têm pior prognóstico, maior letalidade e maior índice de complicações, como infecções bacterianas (Collin et al., 2004; Rey et al., 2005; Cavalcante, 2007; Seaman et al., 1996; Pastorino et al., 2002; Cunha et al., 1995), enquanto outros não identificaram a desnutrição como fator de risco para o desfecho desfavorável (Pastorino et al., 2002; Costa, 2009; Cunha et al., 1995) ou não apresentavam clara sequência temporal (Collin et al., 2004; Cavalcante, 2007; Seaman et al., 1996; Queiroz, Alves \& Correia, 2004). 
Figura 2 - Criança com LV e desnutrição grave

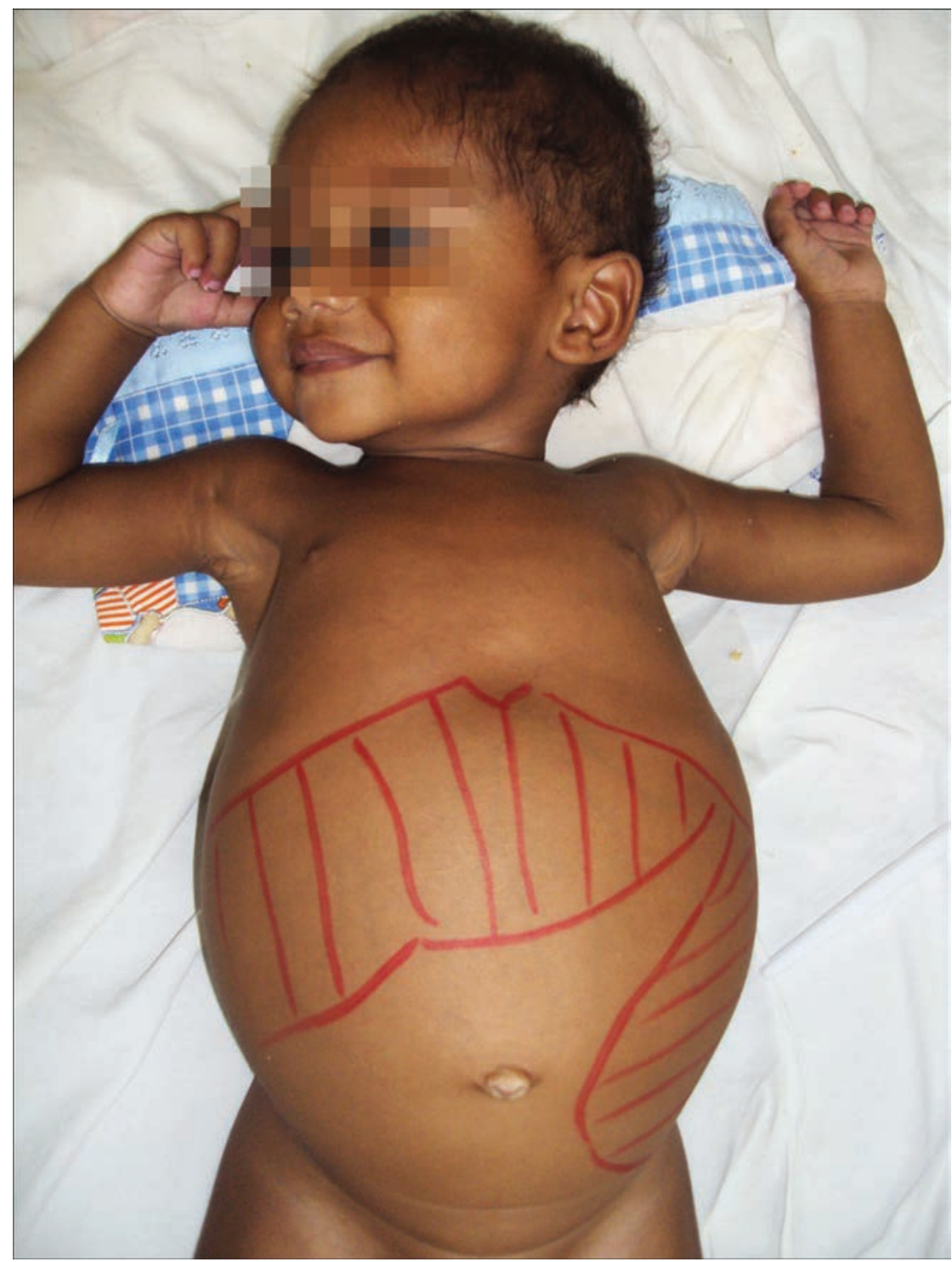

As complicações mais associadas ao óbito são as infecções bacterianas e os distúrbios da coagulação sanguínea. A frequência de infecções bacterianas na LV varia de 11\% a 60\% (Costa, 2009; Queiroz, Alves \& Correia, 2004) nos relatos brasileiros publicados, podendo representar a primeira manifestação da LV (Garcés et al., 1990). Diversos patógenos e variadas formas de apresentação dessas infecções foram descritas, mas as infecções respiratórias e urinárias parecem ser as mais comuns (Andrade, Carvalho \& Rocha, 1990; Barati et al., 2008; Kadivar et al., 2000). As alterações da coagulação sanguínea foram descritas desde os primeiros relatos da doença no Brasil (Alencar, 1977; Prata, 1957), sendo fortemente associadas ao risco de morte (Costa, 2009). Equimoses, epistaxes, petéquias, sangramentos digestivos e de mucosas gengivais podem ocorrer isoladamente ou em associação, podendo ocasionar graves complicações, com choque seguido de morte (Kotwal et al., 2000). Há evidência de que tais sangramentos sejam consequência de coagulação intravascular disseminada (Costa, 2009; Lomtadze et al., 2005) e é comum que sejam refratários às diversas abordagens terapêuticas como transfusão de plasma fresco, de concentrado de plaquetas e de 
vitamina K. O envolvimento do fígado ocorre em grande parte dos pacientes (Ashkan \& Rahim, 2008) com LV; é bem reconhecido e formas graves de dano hepático têm sido descritas (Ashkan \& Rahim, 2008; Baranwal, Mandal \& Singh, 2007; Khaldi et al., 1990). Alterações renais ocorrem em grande proporção dos pacientes, mas tendem a ser leves e reversíveis após o tratamento (Dutra et al., 1985). Contudo, síndrome nefrítica aguda (Salgado-Filho, Ferreira \& Costa, 2003), glomerulonefrite necrotizante (Chaigne et al., 2004), nefrite intersticial (Daher et al., 2008) e insuficiência renal (Caravaca et al., 1991) foram descritas.

Sintomas pulmonares são comuns em pacientes com LV, frequentemente atribuídos a complicações bacterianas (Alencar, 1959; Andrade, Carvalho \& Rocha, 1990; Kadivar et al., 2000; Prata, 1957). Pneumonite intersticial foi descrita em autópsia de paciente com LV (Andrade, 1959) possivelmente relacionada a processo inflamatório com padrão Th2 (Tuon et al., 2009), o que aumentaria a chance de infecção bacteriana secundária.

Outras apresentações atípicas da LV podem ser vistas de forma menos consistente ou com apresentação mais inespecífica em pacientes com LV, como vômitos, cefaleia, diarreia, artralgia, dor abdominal (Queiroz, Alves \& Correia, 2004; Singh et al., 1999), púrpura (Rizos et al., 2005), síndrome hemofagocítica (Agarwal et al., 2006; Gagnaire, Galambrun \& Stephan, 2000; Sotoca Fernandez et al., 2008) e síndrome de Guillain-Barré (Attarian, 2003).

A transmissão materno-fetal da LV é raramente relatada e pode resultar em infecção placentária, óbito fetal ou recém-nascido de baixo peso para a idade gestacional (Eltoum et al., 1992). A doença pode ainda se manifestar com sintomas precoces como febre, hemorragias, icterícia e morte no período neonatal (Mescouto-Borges et al., 2013) ou a criança pode apresentar sinais e sintomas de LV clássica muitos meses após o nascimento (Meinecke et al., 1999; Eltoum et al., 1992; Boehme et al., 2006; Nyakundi et al., 1988).

\section{MANIFESTAÇÕES HEMATOLÓGICAS E COAGULAÇÃO NA LEISHMANIOSE VISCERAL}

As manifestações hematológicas são comuns na LV e, juntamente com as infecções bacterianas, constituem os mais importantes fatores de risco para a morte (Oliveira et al., 2006; Abdelmoula et al., 2003; Pastorino et al., 2002; Martins, Alencar \& Magalhães, 1965; Werneck et al., 2003). As anormalidades mais frequentemente relatadas incluem anemia, leucopenia, plaquetopenia e alterações do sistema de coagulação sanguínea (Al-Jurayyan et al., 1995; Kotwal et al., 2000; Singh et al., 1999; Mishra et al., 2004). É provável que tenham etiologia multifatorial, mas como as causas não são claramente entendidas, a abordagem terapêutica preconizada para os pacientes que apresentam sangramentos em decorrência da LV é empírica, inespecífica e parece pouco eficaz em grande proporção de casos (Figuras 3 e 4).

A incidência das manifestações hemorrágicas varia em estudos realizados em diversas regiões: 7,1\% na Índia (Thakur, 1984), 8\% na Albânia (Lita et al., 2002) e 15\% no Nepal (Singh et al., 1999); 36\% em crianças no Paquistão (Rathore, Buksh \& Hassan, 1996) e 51\% no Sudão, em uma população de refugiados, tendo a epistaxe como única descrição nesse país (Zijlstra et al., 1991). As descrições de pacientes com LV, no Brasil, também indicam grande variabilidade na incidência de hemorragias: 11,4\% no Mato Grosso do Sul (Oliveira et al., 2006), 28,2\% em crianças procedentes de vários estados do Brasil e tratadas em São Paulo (Pastorino et al., 2002), 11,4\% em Pernambuco (Queiroz, Alves \& Correia, 2004), 9\% e 16\% no Ceará (Rey et al., 2005; Cavalcante, 2007), 10,2\% em Minas Gerais (Silva et al., 2001) e 20,7\% em uma população indígena no estado de Roraima (Guerra et al., 2004). Em Alagoas, em uma descrição de 530 pacientes, não há referência a sangramentos (Pedrosa \& Rocha, 2004); já em outros estudos internacionais, apesar de relatarem trombocitopenia na maior parte dos pacientes, não fazem referência a sangramentos (Abdelmoula et al., 2003; Campos Jr., 1995; Tanir, Taylan Ozkan \& Daglar, 2006; Harms, Schonian \& Feldmeier, 2003). No Piauí, em um estudo envolvendo 883 pacientes, observou-se que $25 \%$ deles apresentaram sangramentos, com forte associação com a morte (Costa, 2009). 
Figura 3 - Criança com LV apresentando petéquias e equimoses

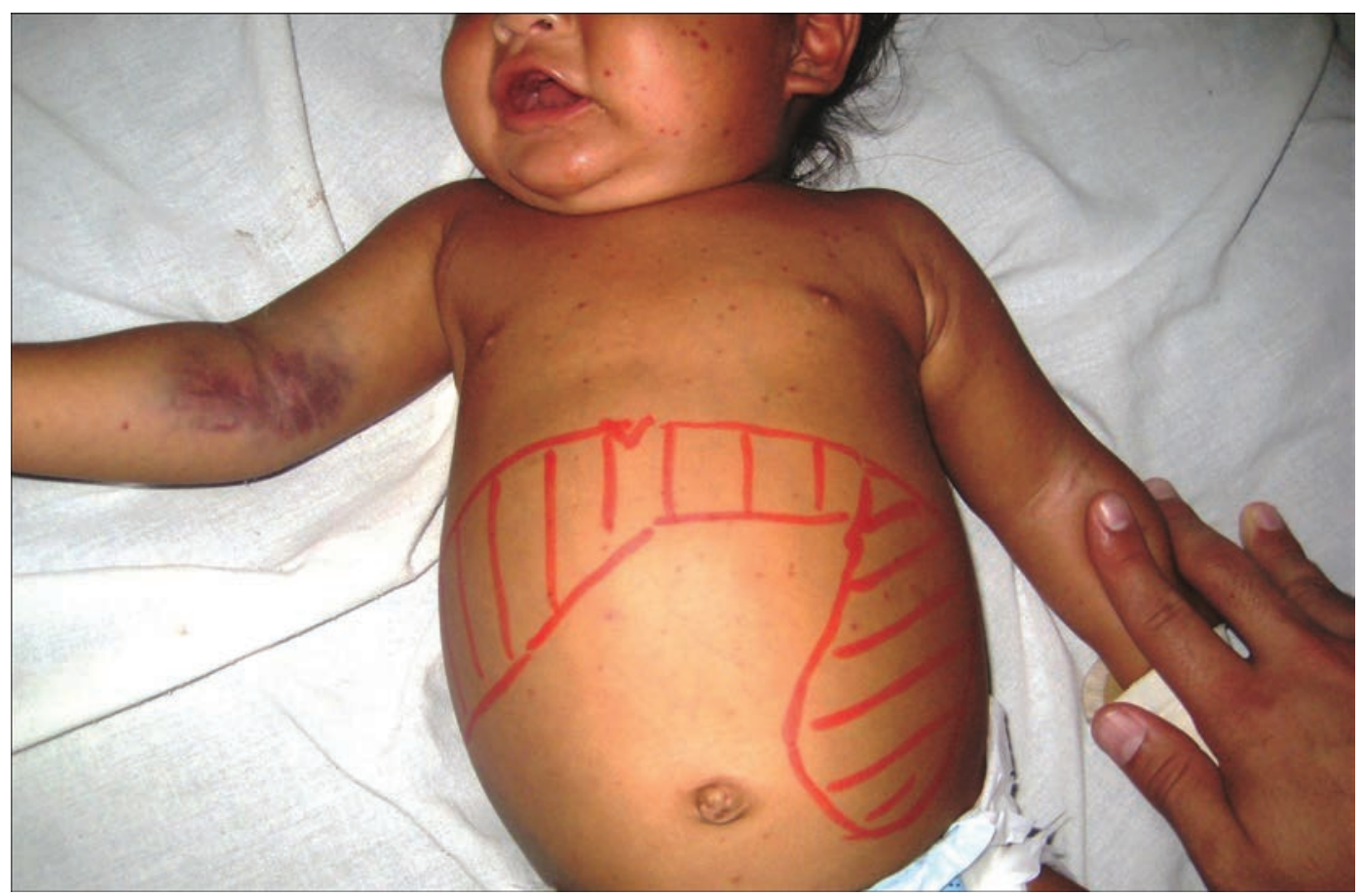

Figura 4 - Lactente com LV apresentando icterícia, anasarca e sangramentos

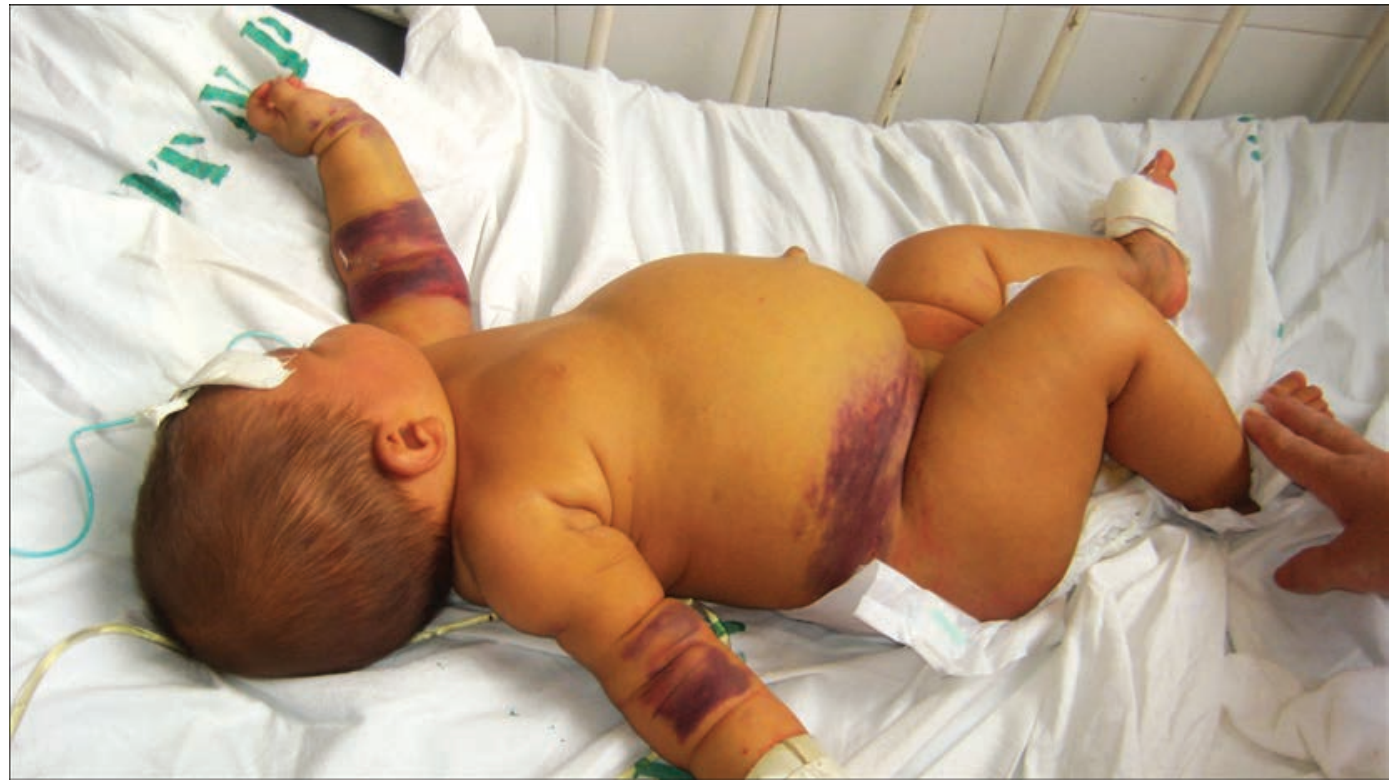

Diversos mecanismos patogenéticos têm sido sugeridos para explicar os sangramentos em pacientes com LV, mas restam inúmeras indagações e incertezas sobre os reais condicionantes dos distúrbios da coagulação sanguínea que se apresentam na LV. A plaquetopenia observada na maior parte dessas pessoas pode ser decorrente de hiperesplenismo 
ou disfunção da medula óssea (Kotwal et al., 2000), mas não existe evidência de que tais distúrbios da homeostasia possam resultar de transtornos da mielopoiese (Pollacket al., 1988; Pippard et al., 1986). De todo modo, a plaquetopenia explica apenas uma fração dos distúrbios da homeostasia e há grande controvérsia com respeito ao limite mínimo do número de plaquetas necessário à hemostase. Observou-se que pacientes no que diz menos de 10 mil plaquetas $/ \mathrm{mm}^{3}$ podem ter hemostase perfeita e que o maior risco para sangramento nesses pacientes ocorre quando outros fatores, como anormalidades do sistema fibrinolítico, associam-se à trombocitopenia (George, 2004). Ademais, a contagem das plaquetas no sangue periférico é um índice imperfeito do número total de plaquetas que o indivíduo possui, pois pode estar subestimada por não avaliar o número de plaquetas sequestradas em sítios de sangramento e no baço, ou superestimada na presença de fragmentação de hemácias decorrente de doenças sistêmicas, como descrito na leucemia (van der Meer et al., 2003).

As alterações da coagulação podem ainda estar relacionadas à deficiente produção hepática de fatores de coagulação, mas insuficiência hepática ou hepatite fulminante são eventos raros em pacientes com LV que apresentam sangramento (Baranwal, Mandal \& Singh, 2007; Singh, Sinha \& Sharma, 1995). As alterações histopatológicas do fígado na LV não têm padrão uniforme, e geralmente a repercussão clínica é discreta. Os padrões mais frequentemente descritos são a hipertrofia e hiperplasia do sistema retículo-endotelial, às vezes com intenso parasitismo das células de Kupffer, infiltrado portal por macrófagos, linfócitos e células plasmáticas e discretas alterações dos hepatócitos, sem parasitismo (Khaldi et al., 1990; El Hag et al., 1994; Duarte \& Corbett, 1987). Estudos da função hepática envolvendo amostras suficientes de pacientes são necessários, para que se conheça melhor a importância dessas alterações na gênese dos sangramentos.

Hemofagocitose (Gagnaire, Galambrun \& Stephan, 2000) e diseritropoiese (Wickramasinghe, Abdalla \& Kasili, 1987) têm sido descritas com mais raridade, uma vez que o exame histológico da medula óssea não faz parte da rotina diagnóstica de muitos centros nas áreas de maior endemicidade. Como essas manifestações, apesar de sinalizar maior gravidade da doença, podem ser revertidas após o tratamento específico da leishmaniose, sua incidência pode ser subestimada.

É possível, enfim, que a coagulopatia na LV tenha mecanismos patogenéticos semelhantes aos mecanismos envolvidos na coagulação intravascular disseminada (CID), observada em pacientes com sepse bacteriana. A CID tem sido descrita em casos isolados ou em pequenas séries de casos, associada à LV, e tem sido geralmente percebida como uma rara complicação da LV (Mishra et al., 2004; Chaliasos et al., 1996; Blount, Hartmann \& Nernoff, 1980). Contudo, um estudo dos marcadores da CID envolvendo 45 crianças com LV, na Geórgia, concluiu que 43 (95,6\%) delas apresentavam níveis elevados de dímero D no sangue e que 36 (80\%) apresentavam complexos solúveis de monômeros de fibrina detectáveis, indicando que a ativação da coagulação sanguínea estava presente na maioria desses pacientes. Tais produtos associaram-se significantemente com a gravidade da doença, com a ocorrência de sangramentos e com o número de plaquetas no sangue periférico (Lomtadze et al., 2005). No Piauí, também se observou que os níveis de dímero $\mathrm{D}$ e dos produtos de degradação da fibrina estavam elevados na maior parte dos pacientes com LV, e que esses níveis eram mais elevados entre os pacientes que apresentavam sangramentos. Tais alterações foram fortemente correlacionadas à atividade inflamatória mediada por citocinas (Costa et al., 2013).

Outra variante da LV é a síndrome viscerotrópica oligoparasitária, com manifestações pouco específicas e causada pela L. tropica, espécie historicamente associada à leishmaniose cutânea. Essa forma de apresentação foi notificada em soldados norte-americanos que estiveram em serviço na Guerra do Golfo Pérsico (Magill et al., 1993). 


\section{DIFERENÇAS DA APRESENTAÇÃO DA LV NAS AMÉRICAS, NA ÁSIA E NA ÁFRICA}

A síndrome clássica da leishmaniose visceral é muito semelhante nas distintas regiões do globo, apesar das diferenças regionais dos flebotomíneos e dos parasitos e das variações genéticas das diversas populações afetadas.

Atualmente, a LV incide em cidades de médio e grande portes no Brasil, enquanto predomina em pequenas vilas e áreas rurais no Velho Mundo.

A LV que ocorre no subcontinente indiano e na África Oriental não tem reservatório animal reconhecido. Ela é transmitida por vetores predominantemente antropofílicos do gênero Phlebotomus, destacando-se $P$. papatasi, $P$. argentipes, $P$. orientalis e $P$. sergenti. A doença zoonótica causada por $L$. donovani acontece na bacia do Mediterrâneo, na África Ocidental, no norte da China, no Irã e no Paquistão. Na América do Sul, a doença zoonótica causada por L. chagasi é transmitida por flebotomíneos pertencentes ao gênero Lutzomyia, como Lu. longipalpis, Lu. cruzi e Lu. evansi (Killick-Kendric, 1990; Walsh, Molyneux \& Birley, 1993).

A doença acomete pessoas mais jovens na América, em comparação com a África e a Ásia (Olliaro et al., 2011), e mais de 40\% das pessoas acometidas no Brasil têm menos de quatro anos de idade (Oliveira et al., 2006; Pastorino et al., 2002). Essa maior proporção de crianças muito jovens com LV, na América, pode estar relacionada à maior força de transmissão na doença zoonótica, na qual existe um reservatório doméstico proximamente em contato com as pessoas, em comparação à doença antroponótica da Ásia e da África.

A grave desnutrição é frequente em pacientes com LV nos países do sudeste asiático e do leste da África, mas é pouco frequente em pacientes no Brasil (Olliaro et al., 2011). Observou-se que o grau de desnutrição de pessoas com LV no Piauí tem relação inversa ao tempo decorrido entre os primeiros sinais da doença e o diagnóstico, o que pode significar que a menor prevalência de desnutrição associada à LV possa estar relacionada à doença mais aguda na Américas em relação às outras áreas do mundo.

As diferenças mais marcantes na apresentação da enfermidade no Velho e no Novo Mundo dizem respeito principalmente à presença de linfonodomegalias e à síndrome cutânea conhecida como leishmaniose dérmica pós-calazar.

A leishmaniose dérmica pós-calazar acontece em cerca de 50\% dos pacientes no Sudão (Collin et al., 2004) e em 5\% a 10\% dos pacientes na Índia (Zijlstra et al., 2003; Zijlstra \& El-Hassan, 2001). No Brasil, os raros casos diagnosticados referem-se a pacientes coinfectados pelo HIV (Carnaúba et al., 2009; Bittencourt et al., 2003). Em pacientes sudaneses as lesões cutâneas aparecem, em média, após 56 dias do final do tratamento, enquanto em pacientes indianos esse intervalo pode ser de vários anos. As máculas e pápulas surgem inicialmente na região perioral, disseminando-se para toda a face, tronco e extremidades. Eventualmente as lesões podem se estender para todo o corpo, formando nódulos ulcerados. Embora sintomas da leishmaniose dérmica pós-calazar sejam sutis na maioria dos pacientes, essa condição pode durar anos ou décadas, permanecendo o paciente infectante para os flebotomíneos durante esse período, o que torna a condição de grande interesse para o controle da infecção (Bern, Courtenay \& Alvar, 2010; Collin et al., 2004). Nas Américas, mantém-se controversa a importância do homem na cadeia de transmissão da infecção (Costa et al., 2000, 2002).

A linfonodomegalia generalizada é frequente em pacientes com LV no Sudão (Zijlstra et al., 1991) e na Índia (Sen Gupta \& Mukherjee, 1968), mas é incomum nas Américas. No Brasil, alguns autores relataram altas prevalências de linfonodomegalia (Alencar, 1959; Daher et al., 2008; Pastorino et al., 2002; Prata, 1957), enquanto outros não fizeram referência a aumento dos linfonodos (Cavalcante, 2007; Pastorino et al., 2002; Silva et al., 1997; Queiroz, Alves \& Correia, 2004; Silva et al., 2001; Guerra et al., 2004), possivelmente porque tal sinal inexistia ou não era evidente (Tabela 1). 
Tabela 1 - Principais diferenças da leishmaniose visceral no Velho e no Novo Mundo

\begin{tabular}{|c|c|c|}
\hline & Velho Mundo & Novo Mundo \\
\hline Agente etiológico & $\begin{array}{l}\text { Leishmania donovani: } \\
\text { Subcontinente Indiano, Paquistão, Nepal, } \\
\text { África Oriental } \\
\text { L. infantum: } \\
\text { Oriente Médio, bacia do Mediterrâneo, } \\
\text { Ásia Central e África Ocidental }\end{array}$ & L. infantum \\
\hline Vetor & $\begin{array}{l}\text { Phlebotomus spp., principalmente P. papatasi, } \\
\text { P. argentipes, } \text { P. chinensis, } \text { P. smirnovi, } \\
\text { P. longiductus, } \text { P. orientalis, P. ariasi, } \\
\text { P. perniciosus, P. neglectus }\end{array}$ & Lutzomyia longipalpis; Lu. cruzi \\
\hline Reservatórios & $\begin{array}{l}\text { Índia: pessoas } \\
\text { China: cães, outros reservatórios silvestres } \\
\text { África Oriental: pessoas, cães, canídeos, roedores } \\
\text { Mediterrâneo: roedores, cães }\end{array}$ & Cães, pessoas, canídeos silvestres, marsupiais \\
\hline \multicolumn{3}{|l|}{ Apresentação clínica } \\
\hline Idade & Principalmente adolescentes e adultos & Principalmente crianças \\
\hline Linfonodomegalia & Frequente & Pouco frequente \\
\hline Leishmaniose dérmica pós-calazar & Frequente & Rara \\
\hline Hiperpigmentação cutânea & Frequente & Rara \\
\hline
\end{tabular}

\section{LEISHMANIOSE VISCERAL ASSOCIADA À AIDS}

A história natural da LV tem apresentado grandes mudanças nas duas últimas décadas, quando foi reconhecida como importante doença oportunista em pacientes com HIV. A coinfecção LV/HIV já foi notificada em pelo menos 35 países em uma proporção que varia de $2 \%$ a $12 \%$ de todos os indivíduos com LV, com tendências a aumentar dramaticamente (Alvar et al., 2008; WHO, 2007). Em regiões onde ambas as infecções são endêmicas, a incidência de LV em indivíduos infectados pelo HIV pode ultrapassar 30\% (Lyons, Veeken \& Long, 2003). A maior incidência da coinfecção Leishmania/HIV tem sido observada na bacia do Mediterrâneo, com mais de dois mil casos notificados à Organização Mundial da Saúde (OMS). No Brasil a coinfecção LV/HIV tem sido descrita em pequenas séries de casos, mas a real incidência pode estar subestimada em razão de falhas do sistema de vigilância epidemiológica (Cruz et al., 2006; Rabello, Orsini \& Disch, 2003). Em estudo realizado em Teresina, um terço dos pacientes adultos que receberam diagnóstico de LV também estava infectado pelo HIV. A LV foi a primeira manifestação clínica da imunodeficiência em metade desses pacientes, sendo a letalidade maior que em qualquer outro subgrupo analisado (Costa, 2009).

A infecção pelo HIV eleva a chance de um indivíduo desenvolver LV de cem para mil vezes, reduzindo as possibilidades terapêuticas e aumentando consideravelmente a possibilidade de reativações (Desjeux, 2004; Guerin et al., 2002; WHO, 2004; Lopez-Velez et al., 2004). Discute-se se a coinfecção LV/HIV resultaria de infecção primária ou de reativação de infecção latente, uma vez que a infecção primária por Leishmania poderia favorecer a imunossupressão em paciente previamente infectado pelo HIV ou, de igual modo, a infecção latente por Leishmania poderia ser reativada pela depleção imunológica da Aids (Marques et al., 2007; Paredes et al., 2003). A apresentação clínica da LV causada pela $L$. infantum e $L$. donovani em pessoas infectadas pelo HIV costuma ser semelhante à 
apresentação em pessoas não infectadas (Cruz et al., 2006; Alvar et al., 1997, 2008) - com febre, perda de peso, hepatoesplenomegalia e pancitopenia -, mas manifestações atípicas, sem febre ou esplenomegalia, ocorrem em aproximadamente 15\% dos casos (Cruz et al., 2006). O envolvimento do trato gastrointestinal, trato respiratório, linfonodos, pele ou sistema nervoso é mais frequentemente observado em pacientes imunodeprimidos (Sinha, Pandey \& Bhattacharya, 2005; Peters et al., 1990).

A infecção pelo HIV e pela Leishmania provoca distúrbios imunes recíprocos e progressivos. Ambos os patógenos podem infectar células como macrófagos e células dendríticas, onde se multiplicam, estabelecem infecção latente e causam alterações semelhantes do sistema imune, modificando a resposta Th1 ou Tho para a resposta Th2 (Cruz et al., 2006; Wolday et al., 1999). A ativação imune crônica mediada por citocinas induzidas por um dos patógenos pode alterar o curso da doença causada pelo outro patógeno, levando a um ciclo vicioso de multiplicação incontrolada tanto do HIV quanto da Leishmania (Wolday et al., 1999; Bentwich et al., 1998; Garg, Trudel \& Tremblay, 2007). Por isso, em regiões onde as duas infecções coexistem, sugere-se que a triagem sorológica para o HIV deva ser oferecida a todo paciente com LV, assim como o diagnóstico de LV deve ser considerado em pacientes com HIV que apresentem o quadro clássico de LV ou sinais e sintomas mal definidos como febre, anemia, astenia, emagrecimento ou esplenomegalia.

\section{DIAGNÓSTICO LABORATORIAL DA LEISHMANIOSE VISCERAL}

O diagnóstico da LV é complexo, pela diversidade das manifestações clínicas comuns a outras condições como malária, anemia falciforme, doença de Chagas aguda, hepatite, cirrose com hipertensão portal, esquistossomose, tripanossomíase africana, tuberculose miliar, brucelose, Aids, febre tifoide, endocardite bacteriana, histoplasmose, leucemias, aplasia de medula (Herwaldt, 1999; Al-Ghazaly et al., 2006; Gupta et al., 2008). Assim, a confirmação laboratorial antes do início do tratamento é vital e requer um sensível balanço entre a sensibilidade e a especificidade e, ainda, entre o custo e os riscos.

As alterações laboratoriais inespecíficas incluem anemia, leucopenia (com neutropenia, acentuada eosinopenia e relativas linfocitose e monocitose), plaquetopenia, hipoalbuminemia e hipergamaglobulinemia. Múltiplos fatores provavelmente estão envolvidos na sua gênese, como hiperesplenismo, resposta imune e deficiências nutricionais (Kotwal et al., 2000). A anemia pode ser normocítica e normocrômica (Prata, 1957), microcítica e hipocrômica (Alencar, 1959; Al-Jurayyan et al., 1995; Grech et al., 2000; Singh et al., 1999) ou megaloblástica (Sinha et al., 2006), e pode ser muito intensa e levar à descompensação hemodinâmica (Queiroz, Alves \& Correia, 2004). Acreditava-se inicialmente que tais alterações fossem decorrentes da insuficiência medular secundária ao parasitismo, contudo, estudos posteriores revelaram que a medula óssea é quase sempre hipercelular ou normocelular (Al-Jurayyan et al., 1995; Mourão, 1960), não havendo evidências de que essa anemia seja em razão da eritropoiese deficiente. Estudo realizado em Israel sugeriu que a pancitopenia seja facilitada pela resposta imune através da opsonização de hemácias, leucócitos e plaquetas por autoanticorpos (Pollack et al., 1988). Mais recentemente, tem-se sugerido que essas alterações sejam relacionadas à destruição periférica aumentada de células no baço coordenada pela resposta inflamatória (Woodruff et al., 1972). A descrição de anemia associada à hipoferrinemia e ao aumento das reservas de ferro no organismo durante a LV (Pippard et al., 1986), sugere que a hiperplasia reticuloendotelial seja acompanhada da retenção anormal de ferro nos macrófagos, típica das anemia das doenças crônicas.

O diagnóstico da LV pode ser confirmado por diversas formas: visualização direta de parasitos, cultura ou inoculação em animais; deteç̧ão de ácido desoxirribonucleico (DNA) em amostras de tecido; ou imunodiagnóstico por meio da deteç̧ão de antígenos do parasito ou de anticorpos anti-Leishmania em amostras de tecido, sangue, urina (Sundar \& Raí, 2002). Os exames parasitológicos são a referência do diagnóstico, mas exigem procedimentos invasivos e têm sensibilidade dependente do treinamento dos laboratoristas e do tempo dedicado à busca (Silva, 
Stewart \& Costa, 2005). A sensibilidade do exame microscópico de aspirado esplênico varia entre 95\% e 98\% (Kager et al., 1983; Zijlstra et al., 1992), mas o procedimento é invasivo e as complicações podem ser graves, mesmo com as técnicas consideradas mais seguras (Chulay \& Bryceson, 1983). A sensibilidade na detecção de formas amastigotas em esfregaços de medula óssea tem sensibilidade de 70\% (Zijlstra et al., 1992; Chouihi et al., 2009), mas pode ultrapassar 95\% quando o material é examinado por técnico experiente durante longo período (Jurayyan et al., 1995). Os parasitos também podem ser detectados, com menor sensibilidade, no material de biópsia hepática ou de linfonodos (Zijlstra et al., 1992). O cultivo de parasitos em diversos meios de cultura como meio monofásico de Schneider ou meio difásico de Novy-McNeal Nicolle (NNN) paralelo à pesquisa direta aumenta a sensibilidade da deteçã̃o. A cultura do creme leucocitário do sangue periférico alcança sensibilidade de 60\% (Chouihi et al., 2009), aproxima-se de 70\% em pacientes coinfectados pelo HIV (Lopez-Velez et al., 1995) e pode ser útil em situações em que o aspirado de medula óssea não possa ser viabilizado. As técnicas tradicionais de cultura exigem período de incubação de até quatro semanas (Sundar \& Rai, 2002), mas novas técnicas de microcultura utilizando tubos capilares ou técnicas de minicultura usando placas de 96 poços ou microtubos (Eppendorf) demonstraram vantagens relacionadas ao menor custo, simplicidade no preparo e manuseio, maior sensibilidade e menor tempo de incubação mesmo com baixas parasitemias (Ihalamulla, Rajapaksa \& Karunaweera, 2005; Allahverdiyev et al., 2005; Boggild et al., 2008; Hide et al., 2007).

A detecção de DNA do parasito em amostras de sangue, medula óssea ou produtos de biópsias mediante a reação de polimerização em cadeia (polimerase chain reaction - PCR) é promissora, mas ainda não está padronizada (Rabello, Orsini \& Disch, 2003). A técnica apresenta sensibilidade superior à pesquisa de amastigotas em esfregaços de medula óssea (Alam et al., 2009), mas a sensibilidade de deteção de DNA Leishmania no sangue periférico foi de apenas 70\% (Osman et al., 1997). O método de PCR em tempo real apresenta as mesmas dificuldades da técnica convencional, tem sensibilidade comparável, mas pode ser útil no acompanhamento da carga parasitária durante o tratamento (Lachaud et al., 2000), na definição da cura da infecção (Bastien, Procop \& Reischl, 2008) e na identificação de recidivas (Bourgeois et al., 2008).

Os métodos imunodiagnósticos que detectam anticorpos ou antígenos são úteis em situações em que os exames de deteç̧ão direta do parasito não estejam disponíveis. Métodos imunodiagnósticos baseados na detecção de anticorpos como difusão em gel, reação de fixação de complemento, teste de hemaglutinação indireta, teste indireto de anticorpos fluorescentes e contraimunoeletroforese apresentam limitações relacionadas à sensibilidade e à especificidade (Sundar \& Raí, 2002). O teste de aglutinação direta (DAT) é simples e de baixo custo, apresenta sensibilidade e especificidade entre $70 \%$ e 100\% (Pedras et al., 2008) e tem se mostrado útil como primeiro instrumento diagnóstico em área endêmica (Boelaert et al., 2004). Os testes imunocromatográficos são de fácil execução e interpretação, não necessitam de infraestrutura laboratorial, não exigem laboratoristas especializados e são hoje promissores para o diagnóstico rápido em áreas endêmicas, onde o acesso às técnicas laboratoriais é dificultado. A sensibilidade e a especificidade desses testes rápidos em diversos estudos têm sido superiores a 95\% (Sundar et al., 1998; Berne et al., 2000). Uma meta-análise recentemente publicada analisou o desempenho do DAT e dos testes imunocromatográficos que utilizam o antígeno rK39, os tendo classificado como bons a excelentes, além de comparáveis entre si (Chappuis et al., 2006). Um estudo multicêntrico com um teste comercial para deteç̧ão de anticorpo contra o antígeno rK39 de L. infantum, realizado no Brasil, mostrou sensibilidade de 93\% e especificidade de 97\% (Assis et al., 2008), o que abre a perspectiva para o diagnóstico rápido, de fácil realização e interpretação.

Os testes baseados em antígenos são mais específicos que os testes baseados em anticorpos, sendo promissores para situações em que a produção de anticorpos é insuficiente, como em pacientes imunodeprimidos (Sundar \& Raí, 2002), além de apresentar bom valor prognóstico, com utilidade no acompanhamento do tratamento e na detecção de recidivas (Colmenares et al., 1995). 


\section{INTERAÇÃO LEISHMANIA-HOSPEDEIRO NA LEISHMANIOSE VISCERAL}

Os mecanismos de controle do organismo sobre a Leishmania ou a predisposição à infecção não são bem compreendidos. A participação da resposta imune adaptativa nas alterações observadas em pacientes com LV é reforçada por diversas evidências: a hipergamaglobulinemia é constante nesses pacientes; o teste de Coombs pode ser positivo em pacientes com LV clássica ou associada à anemia hemolítica (Pollack et al., 1988; Mahajan \& Marwaha, 2007); pacientes com LV apresentam maior predisposição a infecções bacterianas (Andrade, Carvalho \& Rocha, 1990); a melhora clínica, parasitológica e hematológica é precedida da liberação de imunocomplexos circulantes (Pearson et al., 1983). A resposta humoral que se segue à infecção é caracterizada por estimulação policlonal das células B e produção de anticorpos anti-Leishmania (El Amin, Wright \& Veug, 1986), responsável pela hipergamaglobulinemia quase sempre presente em pessoas com LV (Pearson \& Sousa, 1995). É possível que os anticorpos desempenhem função importante nas interações precoces entre promastigotas e macrófagos, que são críticas para o desfecho da infecção (Pearson et al., 1983). O teste cutâneo de Montenegro é negativo na fase de atividade da doença - quando altos níveis de anticorpos contra os antígenos de Leishmania são detectáveis -, torna-se positivo após o tratamento, mas não está associado ao prognóstico da doença (Almeida Silva et al., 2006; Wilson, Jerônimo \& Pearson, 2005). A ocorrência de infecções subclínicas ou assintomáticas em uma grande proporção de indivíduos que residem nas áreas endêmicas, associada à detecção de anticorpos anti-Leishmania (Badaró et al., 1986b), constitui evidência da participação de imunidade naturalmente adquirida no curso da infecção.

É bem aceito que a resposta imune mediada por células desempenha relevante função na suscetibilidade e na resistência à infecção e também na resposta à terapia (Awasthi, Mathur \& Saha, 2004). Duas populações de linfócitos $\mathrm{T}$ auxiliadores (T helper-Th), com diferentes papéis de proteção e diferentes tipos de reações imunopatológicas, participam da produção de citocinas. Células T-helper tipo-1 (Th1) produzem IFN- $\gamma$ e IL-2 e sua ativação promove a opsonização dos antígenos fixadores de complemento, a ativação de macrófagos e respostas citotóxicas dependentes de anticorpos e hipersensibilidade tardia. Por essas razões, as células Th1 são consideradas responsáveis pela resposta imune dependente de macrófagos e igualmente responsável pela eliminação da Leishmania com consequente resistência à doença (Awasthi, Mathur \& Saha, 2004). A população de linfócitos CD4 denominada T-helper tipo-2 (Th2), por sua vez, é produtora de fatores de estimulação de linfócitos B como as IL-4, IL-5, IL-6, IL-9, IL-10 e IL13, sendo essencial na resposta humoral (Romagnani, 1996), associando-se a maior sobrevida do parasito no meio intracelular (Gama et al., 2004). Fatores ambientais e genéticos agem em concerto para determinar a polarização Th1 ou Th2 (Romagnani, 2000). Essa imunidade mediada por células é nitidamente polarizada em camundongos infectados por Leishmania. Animais resistentes à infecção produzem grande quantidade de IFN- $\gamma$ em resposta aos antígenos da Leishmania, enquanto animais suscetíveis produzem mais IL-4 (Heinzel et al., 1989). Contudo, não é nítida a polaridade na infecção humana e a resposta imune Th1/Th2 mista tem sido observada em diversos estudos (Berman, 1997; Wilson, Jerônimo \& Pearson, 2005; Peruhype-Magalhães et al., 2006; Nylen \& Sacks, 2007; Karp et al., 1993).

Os neutrófilos são as primeiras células a migrar para o local da infecção após a inoculação de promastigotas de Leishmania pelos flebotomíneos, e desempenham papel crítico na resposta protetora precoce tanto por suas funções como células efetoras envolvidas na morte dos parasitos como por sua ação no desenvolvimento da resposta imune Th1 protetora (McFarlane et al., 2008; Peters et al., 2008). As formas promastigotas de L. infantum fagocitadas convertemse em amastigotas nos macrófagos da pele, eventualmente disseminando-se para os fagócitos mononucleares por meio do sistema retículoendotelial (Awasthi, Mathur \& Saha, 2004). A opsonização de promastigotas pelos fagócitos mononucleares é inicialmente mediada pela via receptores de complemento tipo 3 (CR3), receptores para glicosilação de produtos finais, receptores para fibronectina e receptores da manose/frutose (Awasthi, Mathur \& Saha, 2004). Uma vez desencadeada a resposta imune do hospedeiro, complemento e anticorpos anti-Leishmania são depositados na superfície do parasito, contribuindo para a adesão via receptores de complemento 1 e 3 (CR1 e CR3) assim como pelos receptores 
de fixação de complemento (FC) (Pearson \& Sousa, 1995). A ativação do complemento na superfície dos promastigotas de Leishmania aparenta ser um importante fator na infectividade do parasito em mamíferos, favorecendo a sua adesão e a invasão de macrófagos via receptores de complemento (Minodier et al., 1999; Engwerda, Ato \& Kaye, 2004). As formas promastigotas fagocitadas pelos macrófagos são internalizadas nos fagolisossomos (Awasthi, Mathur \& Saha, 2004), e a destruição dos micro-organismos fagocitados é mediada por metabólitos tóxicos do oxigênio, principalmente óxido nítrico, peróxido de hidrogênio e superóxido aniônico (Awasthi, Mathur \& Saha, 2004). Os promastigotas necessitam superar os dois primeiros mecanismos de defesa do hospedeiro: a lise pelo complemento e a destruição pelos fagócitos, de forma a sobreviver e garantir a conversão em formas amastigotas e sua posterior replicação (Weigand et al., 2004). Os mecanismos da modulação das funções dos macrófagos incluem a inibição da resposta oxidativa inicial, a neutralização dos metabólitos oxidativos, a inativação das enzimas lisossomais, a manutenção de um pH constante no interior do fagolisossomo, a repressão de produção de citocinas envolvidas na resposta inflamatória, a inibição da capacidade do hospedeiro em apresentar os antígenos do parasito aos outros componentes do sistema imune e, ainda, a infestação dos macrófagos que têm atividade anti-Leishmania reduzida (Wilson, Jerônimo \& Pearson, 2005; Olivier, Gregory \& Forget, 2005; Bertholet, 2003). Em adição a essas funções inibitórias, a Leishmania promove a produção de várias moléculas imunossupressoras como metabólitos do ácido aracdônico - e as citocinas fator transformador de crescimento-beta (TGF- $\beta$ e IL-10) - e age sobre mecanismos que alteram diversas vias de sinalização celular do hospedeiro (Olivier, Gregory \& Forget, 2005). Na fase inicial da infecção por Leishmania a enzima óxido nítrico sintase tipo 2 (NOS2) exerce atividade antimicrobiana, controla a função de células natural killer e a expressão de citocinas como IFN- $\gamma$ ou TGF- $\gamma$ (Bogdan, Rollinghoff \& Diefenbach, 2000).

A imunidade contra Leishmania spp. requer a contínua presença do parasito e a virulência deste parece estar intimamente relacionada aos constituintes da membrana externa dos promastigotas, densa camada composta por moléculas ancoradas por glicosilfosfatidilinositol (GPI). Essas moléculas incluem proteínas como a protease de superfície gp63 e os proteofosfoglicanos, dos quais o mais abundante é o lipofosfoglicano (LPG), implicado em vários estágios necessários ao estabelecimento da infecção em macrófagos e à sobrevivência do parasito no inseto vetor. Cepas mutantes de $L$. major que não possuem LPG e outros fosfoglicanos têm a capacidade de persistir indefinidamente em animais infectados sem causar doença (Uzonna et al., 2004). Por sua vez, a gp63 auxilia a entrada e a sobrevivência do parasito na célula hospedeira (Awasthi, Mathur \& Saha, 2004).

A resolução da infecção por Leishmania depende da produção de IFN- $\gamma$ IL-2 e IL-12 pelos linfócitos T CD4 do tipo Th1 (Carvalho et al., 1992). Supõe-se, no entanto, que a resposta Th2, que envolve a produção de citocinas de suscetibilidade como IL-4, IL-10 e TNF- $\alpha$, na ausência de IL-12, esteja exacerbada em pessoas que apresentam doença progressiva (Gama et al., 2004; Heinzel et al., 1989). A resposta significativa de IFN- $\gamma$ após a soroconversão está associada à maior chance de que os indivíduos permaneçam assintomáticos ou evoluam com autorresolução da infecção subclínica (Carvalho et al., 1992). Níveis mais elevados de IL-10 e de TNF- $\alpha$ foram observados em pacientes com doença aguda, em comparação com pacientes oligossintomáticos (Gama et al., 2004).

A resposta Th1 deve estar compensada pela ausência de resposta aos estímulos Th1 ou pelo incremento de citocinas antagonistas (Ansari, Saluja \& Salotra, 2006). Quando a resposta imune mediada por células Th1 está reprimida, observa-se produção diminuída de IFN- $\gamma$ e IL-2 e níveis elevados de IL-4 podem ser detectados. A adição de anticorpos anti-IL-10 restaura a produção de IFN- $\gamma$ e IL-2, indicando o efeito supressor da IL-10 sobre a resposta de células T em pessoas com doença ativa. Da mesma forma, a adição de anti-IL-2 também tem efeito benéfico em infecções por L. major, sugerindo que IL-2 seja outro fator de suscetibilidade a Leishmania. Pessoas com infecção assintomática ou que foram submetidas a quimioterapia específica eficaz desenvolvem respostas protetoras do tipo Th-1 baseada na produção de IFN- $\gamma$, IL-2 e IL-12 (Roberts, 2005), e na maior parte das pessoas o teste cutâneo de hipersensibilidade retardada se torna positivo; contudo, a doença pode acontecer tempos mais tarde em situações 
de imunodeficiência (Pearson \& Sousa, 1995). Adicionalmente, a IL-10 e TGF- $\beta$ previnem a expansão de células Th1 e inibem a consequente ativação de macrófagos pelo IFN- $\gamma$ (Ribeiro-de-Jesus et al., 1998). Foi documentado que TGF- $\beta$ é produzido in vivo e in vitro durante a infecção por Leishmania, e que tem importância na progressão da doença em roedores (Barral-Netto et al., 1992). Essa citocina também está elevada na medula óssea de pacientes com LV (Gantt et al., 2003) e nos granulomas hepáticos de camundongos suscetíveis. Foi sugerido que TGF- $\beta$ secretado localmente inibe a resposta Th1 na LV murina (Wilson et al., 1998).

As citocinas IL-10 e IFN- $\gamma$ são fundamentais no desfecho da doença e os altos níveis de IFN- $\gamma$ e de IL-10 durante o período de atividade da LV continuam sendo um desafio para a compreensão da patogênese da doença. Tem sido sugerido que a proliferação de linfócitos e a ativação de macrófagos mediada por IFN- $\gamma$ podem ser reguladas pela IL-10 durante a doença ativa. É possível que IL-10, com sua ação supressora sobre a função microbicida dos macrófagos, contribua para a patogênese da LV através da inibição da ativação e do bloqueio da atividade leishmanicida dos macrófagos do hospedeiro, o que favorece a instalação e progressão da doença (PeruhypeMagalhães et al., 2006; Karp et al., 1993; Ribeiro-de-Jesus et al., 1998; Ghalib et al., 1993; Caldas et al., 2005; Carvalho et al., 1994; Bhattacharyya et al., 2001). Indivíduos com LV apresentam níveis mais elevados de IFN- $\gamma$, IL10 e IL-6 que os controles, porém, estes níveis declinam após o tratamento e associam-se à má resposta terapêutica. Admite-se que tanto a citocina TNF- $\alpha$ como IL-6 aumentam a expressão do IFN- $\gamma$ R1, favorecendo a resolução da LV (Sanceau, Merlin \& Wietzerbin, 1992). Linfócitos CD4 do tipo Th2 que produzem IL-4 e IL-5, mas não produzem IFN- $\gamma$ ou IL-2, foram apontados como responsáveis pela progressão da doença. Os níveis de IL-10 e IFN- $\gamma$ são restaurados após o tratamento, mas os níveis de IL-6 tendem a permanecer elevados por longos períodos (Ansari, Saluja \& Salotra, 2006).

As células dendríticas são consideradas sentinelas do sistema imune; agem como potentes células apresentadoras de antígenos, podem induzir a ativação de células T CD4 + e são fonte de diferentes citocinas como IL-10, IL-12 e IFN- $\gamma$ (Awasthi, Mathur \& Saha, 2004). As células dendríticas ativam células T por reconhecimento direto da Leishmania e são consideradas um importante elo entre a imunidade inata e a imunidade adaptativa, capazes de regular a imunidade nos estágios finais da doença.

\section{IMUNOPATOGENIA DA LEISHMANIOSE VISCERAL}

Existe um ritmo diferenciado de parasitismo nos órgãos infectados em um mesmo indivíduo infectado por Leishmania (Squires et al., 1990). Os parasitos se multiplicam rapidamente no fígado nas primeiras semanas, enquanto o crescimento no baço é lento nesse período. No entanto, a multiplicação dos parasitos no interior dos granulomas hepáticos é autolimitada, enquanto a resposta esplênica após a resolução hepática é mantida e progressiva, sem formação de granulomas, com destruição de folículos de células dendríticas e eventual perda dos centros germinativos (Engwerda, Ato \& Kaye, 2004; Stanley \& Engwerda, 2007). O progressivo acometimento do baço é associado a altos níveis de TNF- $\alpha$ que promove a destruição da zona marginal de macrófagos e das células do estroma esplênico, enquanto IL-10 associa-se à deficiente migração de células dendríticas (Karp et al., 1993; Stanley \& Engwerda, 2007; Malla \& Mahajan, 2006; Veres et al., 1977).

O baço aumenta em volume à medida que os folículos linfoides esplênicos são substituídos por células mononucleares parasitadas. No fígado, há marcada hiperplasia das células de Kupffer. Fagócitos mononucleares infectados são ainda encontrados na medula óssea, linfonodos, pele, intestino delgado e outros órgãos (Wilson, Jerônimo \& Pearson, 2005). No interior das células os amastigotas se replicam por divisão binária, eventualmente rompendo a célula hospedeira e disseminando-se para outras células. 


\section{TRATAMENTO DA LEISHMANIOSE VISCERAL}

O arsenal de medicações autorizadas para o tratamento da LV é muito limitado. As drogas leishmanicidas mais potentes disponíveis no Brasil são os antimoniais pentavalentes e a anfotericina B, mas, a despeito da sua ampla disponibilidade para uso clínico, a letalidade no país tem se mantido elevada.

Os compostos antimoniais, sob a forma de sais trivalentes, foram usados pela primeira vez no tratamento da leishmaniose em 1912, por Gaspar Vianna (Vianna, 1913). Os antimoniais pentavalentes foram introduzidos na década de 1940 e incluem o antimoniato de metilglucamina e o estibogluconato de sódio, sendo apenas o primeiro comercializado no Brasil. Esses fármacos têm a vantagem de poderem ser administrados em nível ambulatorial, o que diminui os riscos relacionados à hospitalização (Costa et al., 2007). A dose recomendada no Brasil é de $20 \mathrm{mg}$ de sal pentavalente por kg/dia, com aplicação intravenosa ou intramuscular por trinta dias, com limite de três ampolas/ dia. Os antimoniais podem ocasionar cardiotoxicidade dose e tempo dependentes; por isso, os pacientes devem ser avaliados semanalmente e em caso de arritmias o medicamento deve ser imediatamente suspenso. Outros eventos adversos incluem pancreatite grave, artralgias, adinamia, anorexia, dor no local da aplicação e aumento da diurese por perda transitória da capacidade de concentração urinária.

A anfotericina B foi usada pela primeira vez, obtendo sucesso, na terapêutica da leishmaniose visceral por Prata, em 1960, que tratou e curou três pacientes em Salvador/BA (Prata, 1963). Porém, sua utilidade no tratamento da LV somente foi reconhecida a partir da década de 1990, em razão da diminuição da eficácia dos antimoniais pentavalentes na Índia. É a droga com ação leishmanicida mais potente, tanto in vitro (Berman \& Wyler, 1980) quanto in vivo (Mishra et al., 1994; Thakur et al., 1997), sendo recomendada para o tratamento de gestantes e de pacientes que tenham contraindicações ao uso dos antimoniais pentavalentes ou que tenham apresentado toxicidade ou refratariedade relacionada a estes.

O desoxicolato de anfotericina é a formulação mais acessível, sendo a dose recomendada no Brasil de $1 \mathrm{mg} / \mathrm{kg} /$ dia durante 14 a 20 dias. Reações adversas são frequentes, principalmente aquelas associadas à infusão, como febre, calafrios, náuseas, vômitos, tromboflebite. Os sintomas podem ser aliviados com antipiréticos, anti-inflamatórios não hormonais, antieméticos e anti-histamínicos. A nefrotoxicidade é o principal fator limitante ao seu uso, mas outros eventos adversos incluem dispneia transitória, hipotensão ou hipertensão arterial, miocardite, hipocalemia, disfunção renal, anemia e trombocitopenia.

As formulações lipídicas de anfotericina B, em que o desoxicolato é substituído por outros lipídeos, apresentam menos efeitos tóxicos e podem ser administradas em intervalo mais curto que o desoxicolato de anfotericina B (Meyyerhoff, 1999; Thakur et al., 1996). Três formulações estão comercialmente disponíveis: a anfotericina B lipossomal, a anfotericina B em complexo lipídico e a anfotericina B em dispersão coloidal. Tais formulações apresentam elevada eficácia, poucos efeitos colaterais e necessitam de curto tempo de tratamento, que pode variar de um dia (Sundar, 2001; Thakur, 2001; Sundar et al., 2010), dois dias (Syriopoulou et al., 2003), cinco dias (Dietze et al., 1995), sete e dez dias (Dietze et al., 1993). Embora essas formulações fossem inicalmente muito caras, os preços preferenciais que agora são oferecidos aos países endêmicos pela Organização Mundial da Saúde e pelas organizações não governamentais faz com elas sejam uma opção mesmo em países muito pobres. A anfotericina B lipossomal é recomendada no Brasil na dose de 3 $\mathrm{mg} / \mathrm{kg} / \mathrm{dia}$, durante sete dias ou $4 \mathrm{mg} / \mathrm{kg} / \mathrm{dia}$, durante cinco dias (Brasil, 2006).

Algumas drogas de uso oral foram testadas: a sitamaquina (Sherwood et al., 1994; Dietze et al., 2001), os azóis (Wali et al., 1990) e o alopurinol, que apresentaram alguma eficácia, mas não foram suficientes para induzir a cura clínica. A miltefosina apresentou bons resultados na Índia (Sundar et al., 2006; Jha et al., 1999), mas o único ensaio clínico conduzido no Brasil, ainda não publicado, foi interrompido precocemente em decorrência da baixa efetividade. 
A terapia combinada para o tratamento da LV tem sido defendida como uma alternativa para aumentar a eficácia e a tolerância às drogas, para reduzir o tempo de tratamento e para limitar a emergência de resistência. Nesse sentido, diversas associações já foram testadas: alopurinol e estibogluconato de sódio (Ragusa et al., 1993); pentamidina e estibogluconato (Bryceson et al., 1985); alopurinol e pentamidina (Das et al., 2001); aminosidina e estibogluconato (Seaman et al., 1993; Thakur et al., 1995); antimoniato de meglumina e interferon gama (Badaró et al., 1990), com resultados insatisfatórios. A associação de desoxicolato de anfotericina B e antimoniato de N-metil glucamina durante sete ou dez dias, para o tratamento da LV em Minas Gerais, resultou em índice de cura de 98\% (Carvalho, 2005). Um esquema de uma dose de anfotericina B lipossomal, seguida por 14 dias de miltefosina, apresentou elevado índice de cura em pacientes com LV tratados na Índia (Sundar et al., 2008).

A busca por terapias isoladas ou combinadas que sejam seguras, eficazes, acessíveis e de fácil administração para o tratamento da LV continua sendo o foco das pesquisas futuras. Para mais detalhes sobre o tratamento das formas graves de leishmaniose, o leitor deve consultar bibliografia específica adicional (Brasil, 2006).

\section{CONCLUSÃO}

Mais de um século após as primeiras descrições da LV, a doença continua se diversificando e emergindo para áreas historicamente livres da transmissão. Os planos de combate à doença exigem melhor compreensão do sistema de reservatórios e da importância das condições sanitárias das cidades na perpetuação e na expansão da epidemia. O efeito dos novos inseticidas no controle de vetores necessita ser testado. No Brasil, a doença zoonótica de áreas rurais tem cedido espaço para a doença periurbana, presumidamente antroponótica, com grande predominância de indivíduos assintomáticos ou oligossintomáticos em comparação com aqueles que desenvolvem a forma clássica. 0 diagnóstico da infecção está ancorado em métodos microbiológicos e sorológicos, mas as técnicas moleculares e os testes imunocromatográficos rápidos estão sendo aperfeiçoados. A LV, no Brasil e na África, continua sensível aos antimoniais pentavalentes, exceto em pacientes coinfectados pelo HIV, mas a resistência às drogas constitui grave problema no subcontinente indiano. As formulações lipídicas de anfotericina B representam o grande avanço para o tratamento da LV. Investimentos tecnológicos para a compreensão da resposta imune e da patogênese da leishmaniose para o desenvolvimento de vacinas devem ser incentivados, tendo em vista que a proteção conferida pela imunidade de grupo, mesmo que discreta, pode ter grande impacto sobre a transmissão.

\section{REFERÊNCIAS}

ABDELMOULA, M. S. et al. La leishmaniose viscerale chez l'enfant: facteurs pronostiques. La Tunisie Médicale, 81(8): 535$539,2003$.

AGARWAL, S. et al. Hemophagocytic syndrome associated with visceral leishmaniasis. Indian Journal of Pediatrics, 73(5): 445-446, 2006.

ALAM, M. Z. et al. PCR diagnosis of visceral leishmaniasis in an endemic region, Mymensingh district, Bangladesh. Tropical Medicine \& International Health, 14(5): 499-503, 2009.

ALENCAR, J. E. Aspectos clínicos do calazar americano. Separata da Revista Brasileira de Malariologia e Doenças Tropicais, 1(11): 19-44, 1959.

ALENCAR, J. E. Leishmaniose visceral no Brasil. Revista Médica da Universidade Federal do Ceará, 17/18: 129-148, 1977.

AL-GHAZALY, J. et al. Pattern of haematological diseases diagnosed by bone marrow examination in Yemen: a developing country experience. Clinical and Laboratory Haematology, 28(6): 376-381, 2006.

AL-JURAYYAN, N. A. et al. The haematological manifestations of visceral leishmaniasis in infancy and childhood. Journal of Tropical Pediatrics, 41(3): 143-148, 1995. 
ALLAHVERDIYEV, A. M. et al. The value of a new microculture method for diagnosis of visceral leishmaniasis by using bone marrow and peripheral blood. The American Journal of Tropical Medicine and Hygiene, 73(2): 276-280, 2005.

ALMEIDA SILVA, L. et al. Immunologic tests in patients after clinical cure of visceral leishmaniasis. The American Journal of Tropical Medicine and Hygiene, 75(4): 739-743, 2006.

ALVAR, J. et al. Leishmania and human immunodeficiency virus coinfection: the first 10 years. Clinical Microbiology Reviews, 10(2): 298-319, 1997.

ALVAR, J. et al. The relationship between leishmaniasis and Aids: the second 10 years. Clinical Microbiology Reviews, 21(2): 334-359, 2008.

ALVAR, J. et al. Leishmaniasis worldwide and global estimates of its incidence. Plos One, 7(5): e35671, 2012.

ANDRADE, T. M.; CARVALHO, E. M. \& ROCHA, H. Bacterial infections in patients with visceral leishmaniasis. The Journal of Infectious Diseases, $162(6):$ 1.354-1.359, 1990.

ANDRADE, Z. Pneumonite intersticial no calazar. O Hospital, 55: 71-83, 1959.

ANSARI, N. A.; SALUJA, S. \& SALOTRA, P. Elevated levels of interferon-gamma, interleukin-10, and interleukin-6 during active disease in Indian kala azar. Clinical Immunology, 119(3): 339-345, 2006.

ANSTEAD, G. M. et al. Malnutrition alters the innate immune response and increases early visceralization following Leishmania donovani infection. Infection and Immunity, 69(8): 4.709-4.718, 2001.

ASHKAN, M. M. \& RAHIM, K. M. Visceral leishmanisis in paediatrics: a study of 367 cases in southwest Iran. Tropical Doctor, 38(3): 186-188, 2008.

ASSIS, T. S. M. et al. Validação do teste imunocromatográfico rápido IT-LEISH para o diagnóstico da leishmaniose visceral humana. Epidemiologia e Serviços de Saúde, 17(2): 107-116, 2008.

ATTARIAN, S. et al. Guillain-Barre syndrome revealing visceral leishmaniasis in an immunocompetent woman. Revue Neurologique (Paris), 159(11): 1.046-1.048, 2003.

AWASTHI, A.; MATHUR, R. K. \& SAHA, B. Immune response to Leishmania infection. The Indian Journal of Medical Research, $119(6): 238-258,2004$.

BABIKER, Z. O. et al. Utility of lymph node aspiration in the diagnosis of visceral leishmaniasis in Sudan. The American Journal of Tropical Medicine and Hygiene, 76(4): 689-693, 2007.

BADARÓ, R. et al. A prospective study of visceral leishmaniasis in an endemic area of Brazil. The Journal of Infectious Diseases, 154(4): 639-649, 1986a.

BADARÓ, R. et al. New perspectives on a subclinical form of visceral leishmaniasis. The Journal of Infectious Diseases, 154(6): 1.003-1.011, $1986 \mathrm{~b}$.

BADARÓ, R. et al. Treatment of visceral leishmaniasis with pentavalent antimony and interferon gamma. The New England Journal of Medicine, 322(1): 16-21, 1990.

BARANWAL, A. K.; MANDAL, R. N. \& SINGH, R. Fulminant hepatic failure complicating visceral leishmaniasis in an apparently immunocompetent child. Indian Journal of Pediatrics, 74(5): 489-491, 2007.

BARATI, M. et al. Bacterial infections in children with visceral leishmaniasis: observations made in Kerman province, southern Iran, between 1997 and 2007. Annals of Tropical Medicine and Parasitology, 102(7): 635-641, 2008.

BARRAL-NETTO, M. et al. Transforming growth factor-beta in leishmanial infection: a parasite escape mechanism. Science, 257(5.069): 545-548, 1992.

BASTIEN, P.; PROCOP, G. W. \& REISCHL, U. Quantitative real-time PCR is not more sensitive than 'conventional' PCR. Journal of Clinical Microbiology, 46(6): 1.897-1.900, 2008.

BENTWICH, Z. et al. Immune activation in the context of HIV infection. Clinical and Experimental Immunology, 111(1): 1-2, 1998. 
BERMAN, J. D. Human leishmaniasis: clinical, diagnostic, and chemotherapeutic developments in the last 10 years. Clinical Infectious Diseases, 24(4): 684-703, 1997.

BERMAN, J. D. \& WYLER, D. J. An in vitro model for investigation of chemotherapeutic agents in leishmaniasis. The Journal of Infectious Diseases, 142(1): 83-86, 1980.

BERN, C.; COURTENAY, O. \& ALVAR, J. Of cattle, sand flies and men: a systematic review of risk factor analyses for South Asian visceral leishmaniasis and implications for elimination. PLoS Neglected Tropical Diseases, 4(2): e599, 2010.

BERN, C. et al. Use of the recombinant K39 dipstick test and the direct agglutination test in a setting endemic for visceral leishmaniasis in Nepal. The American Journal of Tropical Medicine and Hygiene, 63(3-4): 153-157, 2000.

BERN, C. et al. The epidemiology of visceral leishmaniasis and asymptomatic leishmanial infection in a highly endemic Bangladeshi village. The American Journal of Tropical Medicine and Hygiene, 76(5): 909-914, 2007.

BERTHOLET, S. et al. Leishmania donovani-induced expression of suppressor of cytokine signaling 3 in human macrophages: a novel mechanism for intracellular parasite suppression of activation. Infection and Immunity, 71(4): 2.095-2.101, 2003.

BHATTACHARYYA, S. et al. Immunomodulatory role of interleukin-10 in visceral leishmaniasis: defective activation of protein kinase C-mediated signal transduction events. Infection and Immunity, 69(3): 1.499-1.507, 2001.

BITTENCOURT, A. et al. Post-kala-azar dermal leishmaniasis associated with Aids. The Brazilian Journal of Infectious Disease, $7(3):$ 229-233, 2003.

BLOUNT, E. R.; HARTMANN, R. \& NERNOFF, J. Kala-azar as a cause of disseminated intravascular coagulation. Clinical Pediatrics (Phila), 19(2): 139-140, 1980.

BOEHME, C. C. et al. Congenital visceral leishmaniasis. Emerging Infectious Diseases, 12(2): 359-360, 2006.

BOELAERT, M. et al. A comparative study of the effectiveness of diagnostic tests for visceral leishmaniasis. The American Journal of Tropical Medicine and Hygiene, 70(1): 72-77, 2004.

BOGDAN, C.; ROLLINGHOFF, M. \& DIEFENBACH, A. The role of nitric oxide in innate immunity. Immunological Reviews, 173 : $17-26,2000$.

BOGGILD, A. K. et al. Optimization of microculture and evaluation of miniculture for the isolation of Leishmania parasites from cutaneous lesions in Peru. The American Journal of Tropical Medicine and Hygiene, 79(6): 847-852, 2008.

BOURGEOIS, N. et al. Long-term monitoring of visceral leishmaniasis in patients with Aids: relapse risk factors, value of polymerase chain reaction, and potential impact on secondary prophylaxis. Journal of Acquired Immune Deficiency Syndromes, 48(1): 13-19, 2008.

BRASIL. Ministério da Saúde. Leishmaniose Visceral Grave: normas e condutas. 1. ed. Brasília: Coordenação Geral de Vigilância Epidemiológica, Departamento de Vigilância Epidemiológica, Secretaria de Vigilância em Saúde, Ministério da Saúde, 2006.

BRYCESON, A. D. et al. Visceral leishmaniasis unresponsive to antimonial drugs. II. Response to high dosage sodium stibogluconate or prolonged treatment with pentamidine. Transactions of the Royal Society of Tropical Medicine and Hygiene, 79(5): 705-714, 1985.

CALDAS, A. J. et al. Risk factors associated with asymptomatic infection by Leishmania chagasi in north-east Brazil. Transactions of the Royal Society of Tropical Medicine and Hygiene, 96(1): 21-28, 2002.

CALDAS, A. et al. Balance of IL-10 and interferon-gamma plasma levels in human visceral leishmaniasis: implications in the pathogenesis. BMC Infectious Diseases, 5: 113, 2005.

CAMPOS JR., D. Características clínico-epidemiológicas do calazar na criança: estudo de 75 casos. Jornal de Pediatria, 71(5): 261-265, 1995.

CARAVACA, F. et al. Acute renal failure in visceral leishmaniasis. American Journal of Nephrology, 11(4): 350-352, 1991. 
CARNAUBA JR., D. et al. Atypical disseminated leishmaniasis similar to post-kala-azar dermal leishmaniasis in a Brazilian Aids patient infected with Leishmania (Leishmania) infantum chagasi: a case report. International Journal of Infectious Diseases, 13(6): e504-e507, 2009

CARVALHO, E. M. et al. Immunologic markers of clinical evolution in children recently infected with Leishmania donovani chagasi. The Journal of Infectious Diseases, 165(3): 535-540, 1992.

CARVALHO, E. M. et al. Restoration of IFN-gamma production and lymphocyte proliferation in visceral leishmaniasis. The Journal of Immunology, 152(12): 5.949-5.956, 1994.

CARVAlHo, S. F. G. Associação de Antimonial Pentavalente e Desoxicolato de Anfotericina B no Tratamento da Leishmaniose Visceral em Crianças e Adolescentes, 2005. Tese de Doutorado, Belo Horizonte: Universidade Federal de Minas Gerais.

CAVAlCANTE, M. H. L. Leishmaniose Visceral Americana: aspectos clínicos e laboratoriais preditivos de prognóstico, 2007. Dissertação de Mestrado, Fortaleza: Universidade Estadual do Ceará.

CERF, B. J. et al. Malnutrition as a risk factor for severe visceral leishmaniasis. The Journal of Infectious Diseases, 156(6): 1.030-1.033, 1987.

CHAGAS, E. Primeira verificação em indivíduo vivo da leishmaniose visceral no Brasil. Brasil-Médico, 50(11): 221-223, 1936.

CHAIGNE, V. et al. A patient with visceral leishmaniasis and acute renal failure in necrotizing glomerulonephritis. Nephrologie, 25(5): 179-183, 2004.

CHALIASOS, N. et al. A 7-month-old girl with fever and bleeding. The Lancet, 347(9.008): 1.086, 1996.

CHAPPUIS, F. et al. A meta-analysis of the diagnostic performance of the direct agglutination test and rK39 dipstick for visceral leishmaniasis. BMJ, 333(7.571): 723, 2006

CHOUIHI, E. et al. Cultures on NNN medium for the diagnosis of leishmaniasis. Pathologie Biologie (Paris), 57(3): 219-224, 2009.

CHULAY, J. D. \& BRYCESON, A. D. Quantitation of amastigotes of Leishmania donovani in smears of splenic aspirates from patients with visceral leishmaniasis. The American Journal of Tropical Medicine and Hygiene, 32(3): 475-479, 1983.

COLLIN, S. et al. Conflict and kala-azar: determinants of adverse outcomes of kala-azar among patients in southern Sudan. Clinical Infectious Diseases, 38(5): 612-619, 2004.

COLMENARES, M. et al. Short report: detection of 72-75-kD and 123-kD fractions of Leishmania antigen in urine of patients with visceral leishmaniasis. The American Journal of Tropical Medicine and Hygiene, 52(5): 427-428, 1995.

COSTA, C. H. Characterization and speculations on the urbanization of visceral leishmaniasis in Brazil. Cadernos de Saúde Pública, 24(12): 2.959-2.963, 2008.

COSTA, C. H.; PEREIRA, H. F. \& ARAUJO, M. V. Epidemia de leishmaniose visceral no Estado do Piauí, Brasil (1980-1986). Revista de Saúde Pública, 24: 361-372, 1990.

COSTA, C. H. et al. Competence of the human host as a reservoir for Leishmania chagasi. The Journal of Infectious Diseases, 182(3): 997-1000, 2000.

COSTA, C. H. et al. Asymptomatic human carriers of Leishmania chagasi. The American Journal of Tropical Medicine and Hygiene, 66(4): 334-337, 2002.

COSTA, C. H. et al. Household structure and urban services: neglected targets in the control of visceral leishmaniasis. Annals of Tropical Medicine and Parasitology, 99(3): 229-236, 2005.

CosTA, C. H. et al. Kala-azar is a slow-motion systemic inflamatory response syndrome: lessons from death. In: INTERNATIONAL CONGRESS OF IMMUNOLOGY, 13, 21-25 ago. 2007, Rio de Janeiro.

COSTA, D. L. Fatores de Prognóstico na Leishmaniose Visceral: alterações clínicas e laboratoriais associadas à resposta imune, aos distúrbios da coagulação e à morte, 2009. Tese de Doutorado, Belo Horizonte: Universidade Federal de Minas Gerais.

COSTA, D. L. et al. Serum cytokines associated with severity and complication of kala-azar. Pathogens and Global Health, 107(2): $78-87,2013$. 
CRUZ, I. et al. Leishmania/HIV co-infections in the second decade. The Indian Journal of Medical Research, 123(3): 357-388, 2006.

CUNHA, S. et al. Visceral leishmaniasis in a new ecological niche near a major metropolitan area of Brazil. Transactions of the Royal Society of Tropical Medicine and Hygiene, 89(2): 155-158, 1995.

DAHER, E. F. et al. Clinical presentation and renal evaluation of human visceral leishmaniasis (kala-azar): a retrospective study of 57 patients in Brazil. The Brazilian Journal of Infectious Diseases, 12(4): 329-332, 2008.

DAS, V. N. et al. A randomized clinical trial of low dosage combination of pentamidine and allopurinol in the treatment of antimony unresponsive cases of visceral leishmaniasis. The Journal of the Association of Physicians of India, 49: 609-613, 2001.

DEANE, L. M. \& DEANE, M. P. Leishmaniose visceral urbana (no cão e no homem) em Sobral. O Hospital, 67: 75-87, 1955.

DEANE, L. M. \& DEANE, M. P. Visceral leishmaniasis in Brazil: geographical distribution and transmission. Revista do Instituto de Medicina Tropical de São Paulo, 4: 198-212, 1962.

DEREURE, J. et al. Visceral leishmaniasis in Sudan: first identifications of Leishmania from dogs. Transactions of the Royal Society of Tropical Medicine and Hygiene, 94(2): 154-155, 2000.

DEREURE, J. et al. Visceral leishmaniasis in eastern Sudan: parasite identification in humans and dogs; host-parasite relationships. Microbes and Infection, 5(12): 1.103-1.108, 2003.

DESJEUX, P. Leishmaniasis: public health aspects and control. Clinics in Dermatology, 14: 417-423, 1996.

DESJEUX, P. Leishmaniasis: current situation and new perspectives. Comparative Immunology, Microbiology and Infectious Diseases, 27(5): 305-318, 2004.

DESJEUX, P. \& ALVAR, J. Leishmania/HIV co-infections: epidemiology in Europe. Annals of Tropical Medicine and Parasitology, 97, supl. 1: 3-15, 2003.

DEY, A. \& SINGH, S. Transfusion transmitted leishmaniasis: a case report and review of literature. Indian Journal of Medical Microbiology, 24(3): 165-170, 2006.

DIETZE, R. et al. Treatment of Brazilian kala-azar with a short course of amphocil (amphotericin B cholesterol dispersion). Clinical Infectious Diseases, 17(6): 981-986, 1993

DIETZE, R. et al. Treatment of kala-azar in Brazil with Amphocil (amphotericin B cholesterol dispersion) for 5 days. Transactions of the Royal Society of Tropical Medicine and Hygiene, 89(3): 309-311, 1995.

DIETZE, R. et al. Phase 2 trial of WR6026, an orally administered 8-aminoquinoline, in the treatment of visceral leishmaniasis caused by Leishmania chagasi. The American Journal of Tropical Medicine and Hygiene, 65(6): 685-689, 2001.

DUARTE, M. I. \& CORBETT, C. E. Histopathological patterns of the liver involvement in visceral leishmaniasis. Revista do Instituto de Medicina Tropical de São Paulo, 29(3): 131-136, 1987.

DUTRA, M. et al. Renal involvement in visceral leishmaniasis. American Journal of Kidney Diseases, 6(1): 22-27, 1985.

DYE, C. \& WILLIAMS, B. Malnutrition, age and the risk of parasitic disease: visceral leishmaniasis revisited. Proceedings of Royal Society of London B, 254: 33-39, 1993.

EL AMIN, E. M.; WRIGHT, E. P. \& VLUG, A. Characterization of the humoral immune response in Sudanese leishmaniasis: specific antibody detected by class- and subclass-specific reagents. Clinical and Experimental Immunology, 64(1): 14-19, 1986.

EL HAG, I. A. et al. Liver morphology and function in visceral leishmaniasis (Kala-azar). Journal of Clinical Pathology, 47(6): 547-551, 1994.

ELTOUM, I. A. et al. Congenital kala-azar and leishmaniasis in the placenta. The American Journal of Tropical Medicine and Hygiene, 46(1): 57-62, 1992.

ENGWERDA, C. R.; ATO, M. \& KAYE, P. M. Macrophages, pathology and parasite persistence in experimental visceral leishmaniasis. Trends in Parasitology, 20(11): 524-530, 2004. 
EVANS, T. G. \& PEARSON, R. D. Clinical and immunological responses following accidental inoculation of Leishmania donovani. Transactions of the Royal Society of Tropical Medicine and Hygiene, 82(6): 854-856, 1988.

EVANS, T. G. et al. Epidemiology of visceral leishmaniasis in northeast Brazil. The Journal of Infectious Diseases, 166(5): 1.124-1.132, 1992.

GAGNAIRE, M. H.; GALAMBRUN, C. \& STEPHAN, J. L. Hemophagocytic syndrome: a misleading complication of visceral leishmaniasis in children - a series of 12 cases. Pediatrics, 106(4): E58, 2000.

GAMA, M. E. et al. Serum cytokine profile in the subclinical form of visceral leishmaniasis. Brazilian Journal of Medical and Biological Research, 37(1): 129-136, 2004.

GANTT, K. R. et al. Activation of TGF-beta by Leishmania chagasi: importance for parasite survival in macrophages. The Journal of Immunology, 170(5): 2.613-2.620, 2003.

GARCÉS, J. M. et al. Bacterial infection as a presenting manifestation of visceral leishmaniasis. Reviews of Infectious Diseases, 12(3): 518-519, 1990.

GARG, R.; TRUDEL, N. \& TREMBLAY, M. J. Consequences of the natural propensity of Leishmania and HIV-1 to target dendritic cells. Trends in Parasitology, 23(7): 317-324, 2007.

GEORGE, J. N. For low platelets, how low is dangerous? Cleveland Clinic Journal of Medicine, 71(4): 277-278, 2004.

GHALIB, H. W. et al. Interleukin 10 production correlates with pathology in human Leishmania donovani infections. The Journal of Clinical Investigation, 92(1): 324-329, 1993.

GRECH, V. et al. Visceral leishmaniasis in Malta--an 18 year paediatric, population based study. Archives of Disease in Childhood, 82(5): 381-385, 2000.

GUERIN, P. J. et al. Visceral leishmaniasis: current status of control, diagnosis, and treatment, and a proposed research and development agenda. The Lancet Infectious Diseases, 2(8): 494-501, 2002.

GUERRA, J. A. et al. Visceral leishmaniasis among Indians of the State of Roraima, Brazil: clinical and epidemiologic aspects of the cases observed from 1989 to 1993. Revista da Sociedade Brasileira de Medicina Tropical, 37(4): 305-311, 2004.

GUPTA, V. et al. A study of clinico-haematological profiles of pancytopenia in children. Tropical Doctor, 38(4): 241-243, 2008.

HARHAY, M. et al. Urban Parasitology: visceral leishmaniasis in Brazil. Trends in Parasitology, 27(9): 403-409, 2011.

HARMS, G.; SCHONIAN, G. \& FELDMEIER, H. Leishmaniasis in Germany. Emerging Infectious Diseases, 9(7): 872-875, 2003.

HARRISON, L. H. et al. Reciprocal relationships between undernutrition and the parasitic disease visceral leishmaniasis. Reviews of Infectious Diseases, 8(3): 447-453, 1986.

HEINZEL, F. P. et al. Reciprocal expression of interferon gamma or interleukin 4 during the resolution or progression of murine leishmaniasis. Evidence for expansion of distinct helper T cell subsets. The Journal of Experimental Medicine, 169(1): 59-72, 1989.

HERWALDT, B. L. Leishmaniasis. The Lancet, 354(9.185): 1.191-1.199, 1999.

HIDE, M. et al. A microculture technique for isolating live Leishmania parasites from peripheral blood of visceral leishmaniasis patients. Acta Tropica, 102(3): 197-200, 2007.

IBRAHIM, M. E. \& BARKER, D. C. The origin and evolution of the Leishmania donovani complex as inferred from a mitochondrial cytochrome oxidase II gene sequence. Infection, Genetics and Evolution, 1(1): 61-68, 2001.

IHALAMULLA, R. L.; RAJAPAKSA, U. S. \& KARUNAWEERA, N. D. Microculture for the isolation of Leishmania parasites from cutaneous lesions - Sri Lankan experience. Annals of Tropical Medicine and Parasitology, 99(6): 571-575, 2005.

JERÔNIMO, S. M. B.; SOUSA, A. Q. \& PEARSON, R. D. Leishmania species: visceral (Kala-Azar), cutaneous, and mucocutaneous leishmaniasis. In: MANDELL, G. L.; BENNETT, J. E. \& DOLIN, R. (Eds.). Principles and Practice of Infectious Diseases. 6. ed. New York, Edimburgh, London, Melbourne, Tokyo: Churchill Levingstone Inc., 2005. 
JERÔNIMO, S. M. et al. An urban outbreak of visceral leishmaniasis in Natal, Brazil. Transactions of the Royal Society of Tropical Medicine and Hygiene, 88(4): 386-388, 1994.

JERÔNIMO, S. M. et al. Natural history of Leishmania (Leishmania) chagasi infection in Northeastern Brazil: long-term follow-up. Clinical Infectious Diseases, 30(3): 608-609, 2000.

JHA, T. K. et al. Miltefosine, an oral agent, for the treatment of Indian visceral leishmaniasis. The New England Journal of Medicine, 341(24): 1.795-1.800, 1999.

KADIVAR, M. R. et al. Childhood visceral leishmaniasis complicated by bacterial infections. Eastern Mediterranean Health Journal, 6(5-6): 879-883, 2000 .

KAGER, P. A. et al. Splenic aspiration; experience in Kenya. Tropical and Geographical Medicine, 35(2): 125-131, 1983.

KARP, C. L. et al. In vivo cytokine profiles in patients with kala-azar. Marked elevation of both interleukin-10 and interferongamma. The Journal of Clinical Investigation, 91(4): 1.644-1.648, 1993.

KHALDI, F. et al. Severe forms of liver involvement in visceral leishmaniasis. Apropos of 7 cases. Archives Françaises de Pédiatrie, 47(4): 257-260, 1990.

KILLICK-KENDRICK, R. Phlebotomine vectors of the leishmaniases: a review. Medical and Veterinary Entomology, 4(1): 1-24, 1990.

KOTWAL, J. et al. Hematological changes in visceral leishmaniasis. The Journal of the Association of Physicians of India, 48(3): 363-364, 2000.

LACHAUD, L. et al. Optimized PCR using patient blood samples for diagnosis and follow-up of visceral Leishmaniasis, with special reference to Aids patients. Journal of Clinical Microbiology, 38(1): 236-240, 2000.

LAINSON, R. \& RANGEL, E. F. Lutzomyia longipalpis and the eco-epidemiology of American visceral leishmaniasis, with particular reference to Brazil: a review. Memórias do Instituto Oswaldo Cruz, 100(8): 811-827, 2005.

LITA, G. et al. Pediatric visceral leishmaniasis in Albania. International Journal of Infectious Diseases, 6(1): 66-68, 2002.

LOMTADZE, M. L. et al. Study of intravascular coagulation activation markers in patients with visceral leishmaniasis. Georgian Medical News, 124-125: 47-50, 2005.

LOPEZ-VELEZ, R. et al. Parasitic culture of buffy coat for diagnosis of visceral leishmaniasis in human immunodeficiency virus-infected patients. Journal of Clinical Microbiology, 33(4): 937-939, 1995.

LOPEZ-VELEZ, R. et al. Amphotericin B lipid complex versus no treatment in the secondary prophylaxis of visceral leishmaniasis in HIV-infected patients. The Journal of Antimicrobial Chemotherapy, 53(3): 540-543, 2004.

LUKES, J. et al. Evolutionary and geographical history of the Leishmania donovani complex with a revision of current taxonomy. Proceedings of the National Academy of Sciences of the USA, 104(22): 9.375-9.380, 2007.

LYONS, S.; VEEKEN, H. \& LONG, J. Visceral leishmaniasis and HIV in Tigray, Ethiopia. Tropical Medicine \& International Health, 8(8): 733-739, 2003.

MACIEL, B. L. et al. Association of nutritional status with the response to infection with Leishmania chagasi. The American Journal of Tropical Medicine and Hygiene, 79(4): 591-598, 2008.

MAGILL, A. J. et al. Visceral infection caused by Leishmania tropica in veterans of Operation Desert Storm. The New England Journal of Medicine, 328(19): 1.383-1.387, 1993.

MAHAJAN, V. \& MARWAHA, R. K. Immune mediated hemolysis in visceral leishmaniasis. Journal of Tropical Pediatrics, 53(4): 284-286, 2007.

MALLA, N. \& MAHAJAN, R. C. Pathophysiology of visceral leishmaniasis - some recent concepts. The Indian Journal of Medical Research, 123(3): 267-274, 2006.

MANSON-BAHR, P. E. C. \& APTED, F. I. C. Leishmaniasis. In: MANSON-BAHR, P. \& APTED, F. (Eds.). Manson's Tropical Diseases. 18. ed. London: Bailliere Tindall, 1982. 
MARQUES, N. et al. Leishmaniose visceral e infecção por vírus da imunodeficiência humana na era da terapêutica antiretrovírica de alta eficácia. Acta Médica Portuguesa, 20(4): 291-298, 2007.

MARTINS, J. M.; ALENCAR, J. E. \& MAGALHÃES, V. B. The anemia of kala-azar. Revista do Instituto de Medicina Tropical de São Paulo, 7(1): 47-64, 1965.

MAURICIO, I. L.; STOTHARD, J. R. \& MILES, M. A. The strange case of Leishmania chagasi. Parasitology Today, 16(5): 188$189,2000$.

MAURICIO, I. L. et al. Genetic typing and phylogeny of the Leishmania donovani complex by restriction analysis of PCR amplified gp63 intergenic regions. Parasitology, 122(4): 393-403, 2001.

McFARLANE, E. et al. Neutrophils contribute to development of a protective immune response during onset of infection with Leishmania donovani. Infection and Immunity, 76(2): 532-541, 2008.

MEINECKE, C. K. et al. Congenital transmission of visceral leishmaniasis (Kala Azar) from an asymptomatic mother to her child. Pediatrics, 104(5): e65, 1999.

MESCOUTO-BORGES, M. R. et al. Congenitally transmitted visceral leishmaniasis: report of two Brazilian human cases. Brazilian Society of Infectious Diseases, 17(2): 263-266, 2013.

MEYERHOFF, A. U.S. food and drug administration approval of AmBisome (liposomal amphotericin B) for treatment of visceral leishmaniasis. Clinical Infectious Diseases, 28(1): 42-48, 1999.

MIGONE, L. Un cas de Kala-Azar à Assunción (Paraguay). Bulletin de la Société de Pathologie Exotique, 6: 118, 1913.

MINODIER, P. et al. Mediterranean visceral leishmaniasis: physiopathology. Presse Med, 28(1): 33-39, 1999.

MINODIER, P. et al. First-line liposomal amphotericin B for pediatric visceral leishmaniasis in southern France. Archives de Pédiatrie, 12(7): 1.102-1.108, 2005.

MISHRA, M. et al. Amphotericin versus sodium stibogluconate in first-line treatment of Indian kala-azar. The Lancet, 344(8.937): 1.599-1.600, 1994.

MISHRA, P. et al. Disseminated intravascular coagulation as an unusual presentation of Kala-azar: report of two cases. Scandinavian Journal of Infectious Diseases, 36(6-7): 519-521, 2004.

MORENO, E. C. et al. Risk factors for Leishmania chagasi infection in an urban area of Minas Gerais State. Revista da Sociedade Brasileira de Medicina Tropical, 38(6): 456-463, 2005.

MOURÃo, O. G. A Medula Óssea no Calazar: importância diagnóstica e interpretação da síndrome pancitopênica, 1960. Cadeira Terapêutica Clínica, Belos Horizonte: Universidade de Minas Gerais.

NANDY, A.; NEOGY, A. B. \& CHOWDHURY, A. B. Leishmanin test survey in an endemic village of Indian kala-azar near Calcutta. Annals of Tropical Medicine and Parasitology, 81(6): 693-699, 1987.

NETO, V. A. Visceral leishmaniasis with an incubation period of at least 4 years. Revista do Instituto de Medicina Tropical de São Paulo, 20(5): 312-314, 1978.

NYAKUNDI, P. M. et al. Congenital visceral leishmaniasis: case report. Transactions of the Royal Society of Tropical Medicine and Hygiene, 82(4): 564, 1988.

NYLEN, S. \& SACKS, D. Interleukin-10 and the pathogenesis of human visceral leishmaniasis. Trends in Immunology, 28(9): 378-384, 2007.

OLIVEIRA, A. L. et al. Emergent outbreak of visceral leishmaniasis in Mato Grosso do Sul State. Revista da Sociedade Brasileira de Medicina Tropical, 39(5): 446-450, 2006.

OLIVEIRA, C. D. et al. Spatial distribution of human and canine visceral leishmaniasis in Belo Horizonte, Minas Gerais State, Brasil, 1994-1997. Cadernos de Saúde Pública, 17(5): 1.231-1.239, 2001.

OLIVIER, M.; GREGORY, D. J. \& FORGET, G. Subversion mechanisms by which Leishmania parasites can escape the host immune response: a signaling point of view. Clinical Microbiology Reviews, 18(2): 293-305, 2005. 
OLLIARO, P. et al. What is a typical patient with visceral leishmaniasis? Characterizing the demographic and nutritional profile of patients in Brazil, East Africa and South Asia. The American Journal of Tropical Medicine and Hygiene, $84(4): 543-550,2011$

OSMAN, O. F. et al. Evaluation of PCR for diagnosis of visceral leishmaniasis. Journal of Clinical Microbiology, 35(10): 2.4542.457, 1997.

PAREDES, R. et al. Leishmaniasis in HIV infection. Journal of Postgraduate Medicine, 49(1): 39-49, 2003.

PASTORINO, A. C. et al. Visceral leishmaniasis: clinical and laboratorial aspects. Jornal de Pediatria (Rio de Janeiro), 78(2): 120-127, 2002.

PEARSON, R. D. \& SOUSA, A. Q. Leishmania species: visceral (Kala-Azar), cutaneous, and mucocutaneous leishmaniasis. In: MANDELL, G. L.; BENNETT, J. E. \& DOLIN, R. (Eds.). Principles and Practice of Infectious Diseases. 4. ed. New York, Edimburgh, London, Melbourne, Tokyo: Churchill Levingstone Inc., 1995.

PEARSON, R. D. \& SOUSA, A. Q. Clinical spectrum of Leishmaniasis. Clinical Infectious Diseases, 22(1): 1-13, 1996.

PEARSON, R. D. et al. Circulating immune complexes and rheumatoid factors in visceral leishmaniasis. The Journal of Infectious Diseases, 147(6): 1.102, 1983.

PEDRAS, M. J. et al. Comparative evaluation of direct agglutination test, rK39 and soluble antigen ELISA and IFAT for the diagnosis of visceral leishmaniasis. Transactions of the Royal Society of Tropical Medicine and Hygiene, 102(2): $172-178,2008$.

PEDROSA, C. M. \& DA ROCHA, E. M. Clinical and epidemiological aspects of visceral leishmaniasis in children up to 15 years of age in Alagoas, Brasil. Revista da Sociedade Brasileira de Medicina Tropical, 37(4): 300-304, 2004.

PENNA, H. A. Leishmaniose visceral no Brasil. Brasil-Médico, 48(46): 929-930, 1934.

PERUHYPE-MAGALHAES, V. et al. Mixed inflammatory/regulatory cytokine profile marked by simultaneous raise of interferon-gamma and interleukin-10 and low frequency of tumour necrosis factor-alpha+ monocytes are hallmarks of active human visceral Leishmaniasis due to Leishmania chagasi infection. Clinical and Experimental Immunology, 146(1): 124-132, 2006

PETERS, B. S. et al. Visceral leishmaniasis in HIV infection and Aids: clinical features and response to therapy. The Quarterly Journal of Medicine, 77(283): 1.101-1.111, 1990.

PETERS, N. C. et al. In vivo imaging reveals an essential role for neutrophils in leishmaniasis transmitted by sand flies. Science, 321(5.891): 970-974, 2008.

PIPPARD, M. J. et al. Mechanism of anaemia in resistant visceral leishmaniasis. Annals of Tropical Medicine and Parasitology, 80(3): 317-323, 1986.

PISCOPO, T. V. \& MALLIA AZZOPARDI, C. Leishmaniasis. Postgraduate Medical Journal, 83(976): 649-657, 2007.

POLLACK, S. et al. Immunological studies of pancytopenia in visceral leishmaniasis. Israel Journal of Medical Sciences, 24(2): 70-74, 1988.

PRATA, A. R. Quadro Clínico e Laboratorial do Calazar, 1957. Tese de Livre-Docência, Salvador: Universidade da Bahia.

PRATA, A. R. Treatment of kala-azar with amphotericin B. Transactions of the Royal Society of Tropical Medicine and Hygiene, 57: 266-268, 1963.

QUEIROZ, M. J.; ALVES, J. G. \& CORREIA, J. B. Visceral leishmaniasis: clinical and epidemiological features of children in an endemic area. Jornal de Pediatria (Rio de Janeiro), 80(2): 141-146, 2004.

RABELLO, A.; ORSINI, M. \& DISCH, J. Leishmania/HIV co-infection in Brazil: an appraisal. Annals of Tropical Medicine and Parasitology, 97, supl. 1: 17-28, 2003.

RAGUSA, R. et al. Treatment of visceral leishmaniasis with meglumine and allopurinol. American Journal of Diseases of Children, 147(6): 611-612, 1993. 
RAHMAN, K. M. \& ISLAM, N. Resurgence of visceral leishmaniasis in Bangladesh. Bulletin of the World Health Organization, 61(1): 113-116, 1983.

RATHORE, M. H.; BUKSH, D. \& HASSAN, M. Visceral leishmaniasis in Pakistani children. Southern Medical Journal, 89(5): 491-493, 1996.

REY, L. C. et al. American visceral leishmaniasis (kala-azar) in hospitalized children from an endemic area. Jornal de Pediatria (Rio de Janeiro), 81(1): 73-78, 2005.

RIBEIRO-DE-JESUS, A. et al. Cytokine profile and pathology in human leishmaniasis. Brazilian Journal of Medical and Biological Research, 31(1): 143-148, 1998.

RIZOS, E. et al. Cryoglobulinemic purpura in visceral leishmaniasis. Rheumatology International, 25(6): 469-471, 2005.

ROBERTS, M. T. Current understandings on the immunology of leishmaniasis and recent developments in prevention and treatment. British Medical Bulletin, 75-76: 115-130, 2005.

ROMAGNANI, S. Understanding the role of Th1/Th2 cells in infection. Trends in Microbiology, 4(12): 470-473, 1996.

ROMAGnANI, S. T-cell subsets (Th1 versus Th2). Annals of Allergy, Asthma \& Immunology, 85(1): 9-18, 2000.

SAHA, S. et al. Immune responses in kala-azar. The Indian Journal of Medical Research, 123(3): 245-266, 2006.

SALGADO-FILHO, N.; FERREIRA, T. M. A. F. \& COSTA, J. M. L. Envolvimento da função renal em pacientes com leishmaniose visceral (calazar). Revista da Sociedade Brasileira de Medicina Tropical, 36(2): :217-221, 2003.

SANCEAU, J.; MERLIN, G. \& WIETZERBIN, J. Tumor necrosis factor-alpha and IL-6 up-regulate IFN-gamma receptor gene expression in human monocytic THP-1 cells by transcriptional and post-transcriptional mechanisms. The Journal of Immunology, 149(5): 1.671-1.675, 1992.

SEAMAN, J. et al. Epidemic visceral leishmaniasis in Sudan: a randomized trial of aminosidine plus sodium stibogluconate versus sodium stibogluconate alone. The Journal of Infectious Diseases, 168(3): 715-720, 1993.

SEAMAN, J. et al. Epidemic visceral leishmaniasis in southern Sudan: treatment of severely debilitated patients under wartime conditions and with limited resources. Annals of Internal Medicine, 124(7): 664-672, 1996.

SEN GUPTA, P. C. \& MUKHERJEE, A. M. Lymphadenopathy in Indian Kala-azar and Dermal leishmanoid. Indian J Pathol Bacteriol, 11(3): 172-178, 1968.

SHERWOOD, J. A. et al. Phase 2 efficacy trial of an oral 8-aminoquinoline (WR6026) for treatment of visceral leishmaniasis. Clinical Infectious Diseases, 19(6): 1.034-1.039, 1994.

SILVA, A. R. et al. Visceral leishmaniasis (kala-azar) on Ilha de Sao Luis, Maranhao. Brazil: its evolution and outlook. Revista da Sociedade Brasileira de Medicina Tropical, 30(5): 359-368, 1997.

SILVA, E. S. et al. Visceral leishmaniasis in the Metropolitan Region of Belo Horizonte, State of Minas Gerais, Brazil. Memórias do Instituto Oswaldo Cruz, 96(3): 285-291, 2001.

SILVA, M. R.; STEWART, J. M. \& COSTA, C. H. Sensitivity of bone marrow aspirates in the diagnosis of visceral leishmaniasis. The American Journal of Tropical Medicine and Hygiene, 72(6): 811-814, 2005.

SILVEIRA, F. T. et al. Further evidences on a new diagnostic approach for monitoring human Leishmania (L.) infantum chagasi infection in Amazonian Brazil. Parasitology Research, 106(2): 377-386, 2010a.

SILVEIRA, F. T. et al. A prospective study on the dynamics of the clinical and immunological evolution of human Leishmania (L.) infantum chagasi infection in the Brazilian Amazon region. Transactions of the Royal Society of Tropical Medicine and Hygiene, 104(8):529-35, $2010 \mathrm{~b}$.

SINGH, K. et al. Clinical and laboratory study of kala-azar in children in Nepal. Journal of Tropical Pediatrics, 45(2): 95-97, 1999.

SINGH, U. K.; SINHA, R. K. \& SHARMA, V. K. Fulminant hepatitis in Kala-azar. Indian Journal of Pediatrics, 62 (5): $571-574,1995$.

SINHA, A. K. et al. Incidence of megaloblastic anaemia and its correction in leishmaniasis - a prospective study at BPKIHS hospital, Nepal. Indian Journal of Pathology \& Microbiology, 49(4): 528-531, 2006. 
SINHA, P. K.; PANDEY, K. \& BHATTACHARYA, S. K. Diagnosis \& management of Leishmania/HIV co-infection. The Indian Journal of Medical Research, 121(4): 407-414, 2005.

SOTOCA FERNANDEZ, J. V. et al. Hemophagocytic syndrome secondary to visceral leishmaniasis. Anales de Pediatría: Publicación Oficial de la Asociación Española de Pediatría (Barcelona), 69(1): 46-48, 2008.

SQUIRES, K. E. et al. Defect in the tissue cellular immune response: experimental visceral leishmaniasis in euthymic C57BL/6 ep/ep mice. Infection and Immunity, 58(12): 3.893-3.898, 1990.

STANLEY, A. C. \& ENGWERDA, C. R. Balancing immunity and pathology in visceral leishmaniasis. Immunology and Cell Biology, 85(2): 138-147, 2007.

STONE, H. H.; TOOL, C. D. \& PUGSLEY, W. S. Kala-azar (visceral leishmaniasis): report of a case with 34 month incubation period and positive Doan-Wright test. Annals of Internal Medicine, 36(2:2): 686-693, 1952.

SUNDAR, S. Treatment of visceral leishmaniasis. Medical Microbiology and Immunology, 190(1-2): 89-92, 2001.

SUNDAR, S. \& RAI, M. Laboratory diagnosis of visceral leishmaniasis. Clinical and Diagnostic Laboratory Immunology, 9(5): 951-958, 2002.

SUNDAR, S. et al. Rapid accurate field diagnosis of Indian visceral leishmaniasis. The Lancet, 351(9.102): 563-565, 1998.

SUNDAR, S. et al. Oral miltefosine for the treatment of Indian visceral leishmaniasis. Transactions of the Royal Society of Tropical Medicine and Hygiene, 100, supl. 1: S26-S33, 2006.

SUNDAR, S. et al. New treatment approach in Indian visceral leishmaniasis: single-dose liposomal amphotericin B followed by short-course oral miltefosine. Clinical Infectious Diseases, 47(8): 1.000-1.006, 2008.

SUNDAR, S. et al. Single-dose liposomal amphotericin B for visceral leishmaniasis in India. The New England Journal of Medicine, 362(6): 504-512, 2010.

SYRIOPOULOU, V. et al. Two doses of a lipid formulation of amphotericin B for the treatment of Mediterranean visceral leishmaniasis. Clinical Infectious Diseases, 36(5): 560-566, 2003.

TANIR, G.; TAYLAN OZKAN, A. \& DAGLAR, E. Pediatric visceral Leishmaniasis in Turkey. Pediatrics International, 48(1): 66-69, 2006.

TEIXEIRA, M. J. et al. Chemokines in host-parasite interactions in leishmaniasis. Trends in Parasitology, 22(1): 32-40, 2006.

THAKUR, C. P. Epidemiological, clinical and therapeutic features of Bihar kala-azar (including post kala-azar dermal leishmaniasis). Transactions of the Royal Society of Tropical Medicine and Hygiene, 78(3): 391-398, 1984.

THAKUR, C. P. A single high dose treatment of kala-azar with Ambisome (amphotericin B lipid complex): a pilot study. International Journal of Antimicrobial Agents, 17(1): 67-70, 2001.

THAKUR, C. P. et al. Aminosidine plus sodium stibogluconate for the treatment of Indian kala-azar: a randomized dosefinding clinical trial. Transactions of the Royal Society of Tropical Medicine and Hygiene, 89(2): 219-223, 1995.

THAKUR, C. P. et al. Comparison of three treatment regimens with liposomal amphotericin B (AmBisome) for visceral leishmaniasis in India: a randomized dose-finding study. Transactions of the Royal Society of Tropical Medicine and Hygiene, 90(3): 319-322, 1996.

THAKUR, C. P. et al. Amphotericin B is superior to sodium antimony gluconate in the treatment of Indian post-kala-azar dermal leishmaniasis. Annals of Tropical Medicine and Parasitology, 91(6): 611-666, 1997.

TUON, F. F. et al. In situ immune responses to interstitial pneumonitis in human visceral leishmaniasis. Parasite Immunology, 31(2): 98-103, 2009.

UZONNA, J. E. et al. Vaccination with phosphoglycan-deficient Leishmania major protects highly susceptible mice from virulent challenge without inducing a strong Th1 response. The Journal of Immunology, 172(6): 3.793-3.797, 2004.

VAN DER MEER, W. et al. Pseudoplatelets: a retrospective study of their incidence and interference with platelet counting. Journal of Clinical Pathology, 56(10): 772-774, 2003. 
VERESS, B. et al. Morphology of the spleen and lymph nodes in fatal visceral leishmaniasis. Immunology, 33(5): 605-610, 1977.

VIANNA, G. O. Tratamento da Leishmaniose tegumentar por injeções intravenosas de Tártaro Emético. Archivos Brasileiros de Medicina, 2: 426-428, 1913.

WALI, J. P. et al. Ketoconazole in treatment of visceral leishmaniasis. The Lancet, 336(8.718): 810-811, 1990.

WALSH, J. F.; MOLYNEUX, D. H. \& BIRLEY, M. H. Deforestation: effects on vector-borne disease. Parasitology, 106, supl.: S55-S75, 1993.

WEIGAND, M. A. et al. The systemic inflammatory response syndrome. Best Practice \& Research. Clinical Anaesthesiology, 18(3): 455-475, 2004.

WERNECK, G. L. et al. Prognostic factors for death from visceral leishmaniasis in Teresina, Brazil. Infection, 31(3): 174-177, 2003.

WICKRAMASINGHE, S. N.; ABDALLA, S. H. \& KASILI, E. G. Ultrastructure of bone marrow in patients with visceral leishmaniasis. Journal of Clinical Pathology, 40(3): 267-275, 1987.

WILSON, M. E.; JERONIMO, S. M. \& PEARSON, R. D. Immunopathogenesis of infection with the visceralizing Leishmania species. Microbial Pathogenesis, 38(4): 147-160, 2005.

WILSON, M. E. et al. The importance of TGF-beta in murine visceral leishmaniasis. The Journal of Immunology, 161(11): 6.148-6.155, 1998.

WOLDAY, D. et al. Leishmania-HIV interaction: immunopathogenic mechanisms. Parasitology Today, 15(5): 182-187, 1999.

WOODRUFF, A. W. et al. The anaemia of kala-azar. British Journal of Haematology, 22(3): 319-329, 1972.

WORLD HEALTH ORGANIZATION (WHO). Special Programme for Research and Training in Tropical Diseases (TDR). Scientific working group (SWG). Report of the scientific working group meeting on Leishmaniasis. Geneva: WHO, 2004.

WORLD HEALTH ORGANIZATION (WHO). Report of the Fifth Consultative Meeting on Leishmania/HIV Coinfection. Addis Ababa: WHO, 2007.

ZIJLSTRA, E. E. \& EL-HASSAN, A. M. Leishmaniasis in Sudan. Post kala-azar dermal leishmaniasis. Transactions of the Royal Society of Tropical Medicine and Hygiene, 95, supl. 1: S59-S76, 2001.

ZIJLSTRA, E. E. et al. Kala-azar in displaced people from southern Sudan: epidemiological, clinical and therapeutic findings. Transactions of the Royal Society of Tropical Medicine and Hygiene, 85(3): 365-369, 1991.

ZIJLSTRA, E. E. et al. Kala-azar: a comparative study of parasitological methods and the direct agglutination test in diagnosis. Transactions of the Royal Society of Tropical Medicine and Hygiene, 86(5): 505-507, 1992.

ZIJLSTRA, E. E. et al. Post-kala-azar dermal leishmaniasis. The Lancet Infectious Diseases, 3(2): 87-98, 2003. 
parte VII

Resposta Imune na Leishmaniose

Tegumentar Americana 


\title{
A Resposta Imune na Leishmaniose Tegumentar Americana Ativa
}

\author{
Fátima Conceição-Silva I Fernanda Nazaré Morgado I Sergio G. Coutinho
}

\begin{abstract}
A s leishmanioses tegumentares são infecções produzidas por várias espécies do gênero Leishmania, com distribuição geográfica mundial e várias formas de apresentação clínica. Nas Américas, as apresentações clínicas de acometimento cutâneo e/ou mucoso são genericamente denominadas leishmaniose tegumentar americana (LTA). Dados da literatura indicam que condições socioeconômicas como grau de nutrição, presença de comorbidades e diferenças regionais como a espécie do parasito circulante e o grupo populacional acometido, podem produzir não apenas diferentes formas clínicas, mas também diferentes graus de gravidade e de resposta terapêutica. Assim, os fatores intervenientes no estabelecimento e evolução da infecção podem ser tão variados e importantes que todo o conhecimento produzido, e não foi pouco, ainda não foi capaz de traçar um painel completo de relação de causa e efeito entre o tipo de parasito, a resposta do hospedeiro e a apresentação clínica/evolução da LTA no ser humano. Dessa forma, neste capítulo sobre resposta imune nas lesões ativas de LTA, procuraremos apresentar os conceitos já bem estabelecidos, assim como algumas questões ainda não totalmente esclarecidas.
\end{abstract}

\section{RELAÇÃO PARASITO-HOSPEDEIRO NA RESPOSTA IMUNE À LTA}

O sucesso do hospedeiro em controlar a infecção por Leishmania depende em grande parte da capacidade do sistema imune, principalmente a chamada imunidade celular, dirigir a resposta aos sítios de infecção. Por isso, citocinas e quimiocinas tornam-se importantes no processo, funcionando como direcionadoras, facilitadoras, estimuladoras ou moduladoras da resposta imune. No entanto, nos últimos anos tem sido demonstrada a importância da resposta imune inata, sendo sugerido por alguns autores que eventos ocorridos nos primeiros momentos da infecção são determinantes ou pelo menos têm grande influência no estabelecimento e desenvolvimento da infecção. Os artigos referentes a esses dados serão apresentados adiante, neste capítulo.

o balanço entre a capacidade de resposta do sistema imune do organismo hospedeiro e a capacidade de evasão do parasito, sua virulência/adaptação ao meio, determina o tipo de evolução e a gravidade da infecção. Pelos estudos epidemiológicos realizados em áreas endêmicas é possível inferir que a maioria dos indivíduos infectados é capaz de controlar a infecção, de modo a permitir a coabitação com o parasito sem desenvolvimento de doença. Apesar de 
não haver números precisos, estima-se que cerca de 70\% das pessoas infectadas permanecem em equilíbrio com 0 patógeno, não desenvolvendo qualquer sinal ou sintoma de doença (Fagundes et al., 2007; Silveira et al., 2010).

Com tais dados em mente, podemos indicar o primeiro ponto de questionamento para a compreensão da dinâmica dessa infecção: que fatores estariam atuando na relação entre parasito e hospedeiro para determinar infecção ou doença? A primeira resposta a isto é: até o momento não sabemos de forma completa. Mas existem algumas indicações de fatores que influenciam a dicotomia entre infecção e doença.

Já está bem estabelecido no modelo murino de leishmaniose cutânea produzida por Leishmania major que a resposta imune do tipo 1, com predominância de IFN- $\gamma$ e IL-12, leva à cura das lesões e proteção contra reinfecções. Já a resposta do tipo 2, com predominância de IL-4, IL-5 e IL-10, entre outras, produz doença grave, visceralizante e geralmente fatal (Locksley et al., 1991; Scott, 1991). No entanto, essa dicotomia não é evidente em casos humanos e em alguns modelos de leishmaniose visceral (Melby et al., 2001). Fica então a dúvida: o modelo Th1 x Th2 é regra ou exceção? Vamos tentar demonstrar aqui que nos pacientes temos os dois tipos de resposta presente, com predominância de resposta do tipo 1 naqueles com evolução benigna e do tipo 2 naqueles com dificuldade de resposta ao tratamento, como no caso da forma cutânea difusa. Uma terceira opção acontece nos pacientes da forma mucosa, em que as duas respostas acentuadamente exacerbadas parecem ser responsáveis pela gravidade da lesão (Cruz et al., 2002).

Mas seria apenas a resposta do hospedeiro a responsável pelo direcionamento da infecção para cura ou agravamento? Até meados da década de 1990 era possível imaginar a resposta imune do hospedeiro como determinante do quadro clínico da LTA. Naquela época, vários autores procuravam marcadores genéticos que pudessem ser correlacionados às diversas apresentações clínicas ou pelo menos à gravidade da infecção tanto no ser humano (Blackwell, 1996; Blackwell et al., 1997) como no modelo murino (Blackwell, 1998). Após algumas frustrações, os estudos se dirigiram para as variedades dos parasitos, relacionando diferenças regionais entre os parasitos circulantes e a apresentação clínica (Tojal et al., 2006; Medeiros, Silva \& Roselino, 2008). Essa mesma abordagem tem sido usada para a verificação da relação de clones de Leishmania spp. e resistência ao tratamento, fato que tem se tornado bastante preocupante e que será abordado em capítulo específico (Baptista et al., 2009; Calvopina et al., 2006).

Um dos trabalhos que mais suscitou discussão à época em que foi publicado demonstrava que, dependendo da carga parasitária inicial, lesões murinas produzidas por L. major em camundongos BALB/c poderiam se apresentar mais benignas do que o classicamente descrito (Bretscher, Ogunremi \& Menon, 1997). Após essa publicação, realizaram-se muitos estudos com inoculação de pequeno número de parasitos em modelo animal. Porém, mais uma vez, dependendo da espécie do protozoário e dentro da mesma espécie do isolado utilizado, tais resultados podiam variar. Nesse mesmo contexto, classicamente era sabido que a via de inoculação do parasito no modelo murino poderia modificar a evolução da doença (Liew, Hale \& Howard, 1985; Rolão, Melo \& Campino, 2004). Apesar da via subcutânea em coxim plantar ser a mais utilizada, as vias intraperitoneal e endovenosa também eram possíveis.

A partir do trabalho de Bretscher, Ogunremi e Menon (1997), alguns autores começaram a procurar meios de produzir infecção experimental que fosse a mais próxima possível da infecção natural no homem e em animais de área endêmica. Assim, surgiram os primeiros trabalhos usando a área intermediária entre as duas camadas do tecido auricular como via de infecção para pequenas quantidades de parasitos (entre dez e cem por orelha) (Méndez et al., 2001; Belkaid et al., 2002), calculado como a média de parasitos naturalmente inoculados por flebótomos infectados na natureza (Belkaid et al., 1998). Outros modelos animais, como cães e símios, também são usados no estudo da leishmaniose experimental, sendo seu emprego discutido em capítulo específico.

Por que tanta atenção com os modelos animais, notadamente os murinos, se sabemos que a infecção e a evolução clínico/laboratorial não reproduzem a infecção humana e que as leishmânias do Novo Mundo não têm modelos animais totalmente apropriados? Mesmo não se podendo usar de forma absoluta os resultados obtidos nos modelos experimen- 
tais, duas situações são evidentes: as linhas gerais de resposta imune ante a infecção são as mesmas não importando a espécie infectada, incluindo o ser humano; os estudos dos primeiros momentos da infecção são muito difíceis de serem obtidos no homem, pois na maioria dos casos o paciente procura o serviço médico com a doença já estabelecida. Dessa forma, apesar de priorizarmos os dados obtidos no estudo de pacientes, muitos dos resultados aqui discutidos foram descritos principalmente no modelo murino de infecção por L. major. Com tais pontos em mente, abordaremos inicialmente a resposta imune nas LTA durante a fase ativa da doença, detalhando, a seguir, alguns pontos que possam ter maior relevância ou que ainda não estejam totalmente esclarecidos.

\section{CÉLULAS T, CITOCINAS E OUTROS PRODUTOS/MEDIADORES NA LTA}

Os protozoários do gênero Leishmania causadores da LTA utilizam a pele como porta de entrada no organismo hospedeiro, através da picada do flebotomíneo vetor. Em geral, a pele nos protege contra a infecção por patógenos de duas maneiras: prevenindo a entrada (função de barreira); iniciando resposta inflamatória (função imune). A resposta imune na LTA tem sido amplamente estudada por diversos autores, e vários modelos de infecção experimental têm sido utilizados. Dependendo da cepa de camundongo e da espécie de Leishmania, é possível desenvolver modelos de resistência ou suscetibilidade (Moura et al., 2005). Como resultado obtido com base em tais estudos, tem-se que as células $\mathrm{CD}^{+}$constituem as células efetoras mais importantes durante a resposta contra esse protozoário (Sacks \& Noben-Trauth, 2002). Essas células se dividem em pelo menos duas subpopulações de linfócitos T auxiliares, de acordo com o padrão de citocinas secretadas: Th1 e Th2 (Romagnani, 1991). No caso da leishmaniose, as evidências demonstram que um infiltrado inflamatório dominado por IFN- $\gamma$, produzido principalmente por células Th1, se correlaciona com resistência à infecção (Rogers et al., 2002). Ao contrário, a prevalência de células Th2 com produção de IL-4 e IL-10 está relacionada à suscetibilidade e incapacidade de controle parasitário (Reed \& Scott, 1993).

De modo geral, considera-se atualmente que a forma com que as células do sistema imune interagem entre si esteja diretamente relacionada com a capacidade de controlar o crescimento parasitário e o desenvolvimento de formas clínicas mais ou menos graves. Assim, a resposta imune adequada para o controle da carga parasitária dependeria da ativação de linfócitos $\mathrm{CD}^{+}$do tipo 1 que produzem citocinas, como por exemplo o IFN- $\gamma$. Esta, por sua vez, leva à ativação dos macrófagos através da expressão da enzima NOS2 e a consequente produção de NO e radicais superóxidos.

A óxido nítrico sintase do tipo 2 (NOS2), ou óxido nítrico sintase induzida (iNOS), é uma enzima celular que catalisa a síntese de óxido nítrico (NO) a partir do aminoácido L-arginina (Michel \& Feron, 1997; Qadoumi et al., 2002). Citocinas anti-inflamatórias diminuem a sua expressão (IL-10 e IL-4) e consequentemente a produção de NO, inibindo a eliminação de parasitos intracelulares em macrófagos humanos infectados, gerando as formas graves da infecção, como demonstrado para L. major e L. infantum (Brandonisio et al., 2001). No entanto, Liese, Schleicher e Bogdan (2008) publicaram resultados sugerindo que as ações de NO e phox seriam dependentes do tecido, pois eram pouco presentes em fígado e baço de camundongos cronicamente infectados com L. donovani.

Com base nesses resultados, os autores sugeriram que outras vias poderiam ser responsáveis pelo controle da infecção em órgãos viscerais nas fases de infecção estabelecida. Contudo, outros estudos são necessários para melhor compreender as variações entre as fases de estabelecimento e manutenção da infecção. Nesse ponto, em particular, temos um problema para comparar os resultados obtidos ao realizar estudos em pacientes de LTA. Além de não ser possível o estudo de lesões humanas nas primeiras horas/dias de infecção (fase de estabelecimento), a maior parte dos trabalhos faz correlação entre parâmetros imunológicos e tempo de evolução, dividindo as lesões em recentes e tardias. O problema consiste no seguinte: quando considerar uma lesão de LTA como tardia? Essas definições têm trazido confusão, pois o tempo de corte varia entre as publicações, e uma lesão considerada recente num grupo já pode estar sendo considerada tardia por outro grupo de pesquisadores. Assim, é possível que 
a melhor maneira de se comparar os resultados seja a divisão por tempo de evolução das lesões, excluindo-se a classificação de recente e tardia.

A divisão em Th1 e Th2 seria uma forma simplificada de explicar como ocorre a resposta imune na leishmaniose. Entretanto, sabe-se que a LTA se caracteriza por um amplo espectro de manifestações clínicas relacionadas ao tipo de resposta imunológica produzida pelo hospedeiro e a espécie de Leishmania envolvida. Nesse sentido, Antonelli e colaboradores (2005) sugerem uma correlação entre parâmetros clínicos e imunológicos. Os autores indicaram que a presença de células $\mathrm{CD}^{+}$estava correlacionada aos maiores diâmetros de resposta ao teste de Montenegro, enquanto o tamanho da lesão era associado à produção de IFN- $\gamma$ e TNF- $\alpha$. Pelo menos três formas clínicas de LTA são bem caracterizadas: a leishmaniose cutânea localizada (LCL), a leishmaniose mucosa (LM) e a leishmaniose cutânea difusa (LCD). Existem, ainda, a forma cutânea disseminada e as formas atípicas (Cruz et al., 1999; López-Escobar et al., 2007; Ejaz, Raza \& Iftikhar, 2007; Masmoudi et al., 2008).

Pirmez e colaboradores (1993) sugeriram que o curso clínico da infecção por L. braziliensis no homem estaria associado ao padrão local específico de produção de citocinas, pois observaram predominância relativa de RNAms de citocinas do tipo 1, como a IL-2, IFN- $\gamma$, e linfotoxinas em lesões cutâneas localizadas e em reações de hipersensibilidade tardia provocadas pelo teste de Montenegro. Nas lesões provenientes de formas crônicas e destrutivas da leishmaniose mucocutânea havia a presença simultânea de RNAms de citocinas dos tipos 1 e 2, porém com marcante abundância de IL-4. Já Faria e colaboradores (2009) demonstraram que em lesões cutâneas consideradas estabelecidas havia maior quantidade de células CD8 $8^{+}$expressando granzima A, assim como maior positividade para IFN- $\gamma$ e IL-10. Já nas lesões consideradas recentes, havia apreciável quantidade de neutrófilos e eosinófilos, se comparadas a lesões mais antigas. Castellano e colaboradores (2009) observaram que durante a leishmaniose cutânea ativa havia um padrão de citocinas que incluía tanto do tipo 1 quanto do tipo 2, com produção de TNF- $\alpha$, IFN- $\gamma$, IL-12, IL-4 e IL-10. Já os indivíduos curados apresentavam somente produção de IFN- $\gamma$ em altos níveis. No entanto, o processo de cura na leishmaniose cutânea é complexo e tem sobreposição de fases, como descrito por Greenhalgh (1998). Nesse sentido, recentemente Morgado e colaboradores (2010) demonstraram que cicatrizes de pacientes com um ano de cura clínica ainda apresentavam, microscopicamente, sinais evidentes de atividade inflamatória. Os autores sugeriram que o processo local de cicatrização era lento, permitindo as recidivas precoces da infecção, uma vez que sinais de diminuição do processo inflamatório local só foram evidenciados após três anos de cura clínica das lesões de LTA.

Esterrre e colaboradores (1992) caracterizaram a resposta imune celular em pacientes com leishmaniose cutânea localizada e observaram que o infiltrado inflamatório era composto em sua maior parte por linfócitos T, macrófagos e uma pequena porção de células B, natural killer e granulócitos. Além disso, as células $\mathrm{CD} 4^{+}$e $\mathrm{CD} 8^{+}$apresentavam-se em quantidades iguais. Lima e colaboradores (1994) encontraram resultados semelhantes quanto à proporção de linfócitos $\mathrm{T} \mathrm{CD}^{+}$e $\mathrm{CD} 8^{+}$e células $\mathrm{B}$, e quando relacionaram o tempo de lesão e o fenótipo celular notaram que a porcentagem das células positivas se mantinha fixa para todos os tipos celulares, com exceção das células T $\gamma \delta$, que reduziram com 0 tempo. Com base em tais resultados, esses pesquisadores concluíram que provavelmente essas células seriam importantes na fase inicial da resposta imune na doença granulomatosa. No entanto, Cruz e colaboradores (2005), examinando células isoladas de lesão e sangue periférico por citometria de fluxo, evidenciaram grande variabilidade na razão CD4/ CD8. Morgado e colaboradores (2008), estudando lesões cutâneas de LTA ativas recentes e tardias, demonstraram que, apesar de as lesões com mais de seis meses de evolução apresentarem áreas de fibrose em meio ao processo inflamatório, a composição celular era semelhante às lesões recentes. Contudo, diferenças puderam ser observadas, como o maior acúmulo de células $\mathrm{CD}^{+}$nas lesões tardias, assim como uma diminuição gradual das células $\mathrm{CD} 8^{+}$, provavelmente relacionada ao menor número de parasitos, indicando que a dinâmica do processo mudava de forma gradual.

Em outro estudo, Díaz e colaboradores (2002) realizaram a caracterização fenotípica de leucócitos e de moléculas associadas à ativação nos sítios de lesões de pacientes com diferentes formas clínicas (leishmaniose cutânea difusa 
- LCD, leishmaniose cutânea localizada - LCL e leishmaniose cutânea crônica - LCC). Observou-se que o número de células $\mathrm{T} \mathrm{CD}^{+}$e $\mathrm{CD} 8^{+}$foi semelhante nas lesões dos pacientes de LCL e LCC, e significativamente diferente nas lesões dos pacientes de LCD. Além disso, as lesões de LCL apresentaram cerca da metade do número de células $\mathrm{CD} 9^{+}$recentemente ativadas quando comparadas às lesões de LCC, porém a maioria era $\mathrm{CLA}^{+}$, enquanto as lesões LCC apresentaram os números mais altos de células $\mathrm{CD} 69^{+}$, estando somente um terço expressando CLA. Segundo os autores, isso sugere que o granuloma de pacientes LCC contém muitas células T ativadas que não são 'marcadas/ primadas' com o antígeno cutâneo, contribuindo assim para uma resposta imune aberrante. Por sua vez, o granuloma dos pacientes LCD apresentava as menores quantidades de células CLA e CD69+. Castés e Tapia (1998) observaram ausência de produção de IL-2 e IFN- $\gamma$ por linfócitos de pacientes LCD estimulados com antígeno de Leishmania sp. Em trabalho posterior (Díaz et al., 2002), pacientes com LCD apresentaram menor expressão de NOS2 associada à resposta do tipo 2, com níveis aumentados de células IL-4+ e IL-10+, que manteriam um estado tolerogênico incapaz de controlar a infecção, levando à disseminação do parasito pela pele. Corroborando tais dados, Carneiro e colaboradores (2009) evidenciaram maior quantidade de células regulatórias, a partir da expressão de Foxp3, em pacientes com a forma cutânea difusa, quando comparados às formas mucosa e cutânea localizada. Em conjunto, os dados se relacionam à hiporresponsividade observada nesses pacientes e ao quadro clínico da leishmaniose difusa que se caracteriza por lesões nodulares na pele, disseminadas por todo o corpo e rica em elementos parasitários, com elevada taxa de falha terapêutica (Barral et al., 1995).

Todo o acúmulo de células no sítio das lesões pode ocorrer por duas vias principais: a proliferação in situ ou a migração através do endotélio. Morgado e colaboradores (2008) demonstraram a presença de células positivas para o marcador de proliferação Ki67 nas lesões ativas de LTA, indicando que, pelo menos em parte, havia proliferação celular local. Por sua vez, Mendes-Aguiar e colaboradores (2009) constataram que antígenos de Leishmania eram capazes de aumentar a expressão in vitro de CLA em PBMC e que células positivas se acumulavam no sítio das lesões. Com base nos resultados obtidos os autores sugeriram que o parasito poderia modular as moléculas responsáveis pela migração celular no sítio das lesões, influenciando a composição celular do processo inflamatório. Estudando a composição do infiltrado inflamatório por imuno-histoquímica, Morgado e colaboradores (2008) verificaram que células CLA ${ }^{+}$ acumulavam-se nas lesões, principalmente ao redor de vasos, e que seu número era diretamente proporcional às células positivas para $\mathrm{CD} 3, \mathrm{CD} 4$ e CD8. Além do repertório descrito, alguns trabalhos têm apontado a presença e possível função de células do tipo gama-delta em relação à proteção e patogenia na LTA (Gollob et al., 2008).

Apesar das diferenças indicadas na organização do processo inflamatório em relação a algumas apresentações clínicas, e ou diferentes tempos de evolução das lesões, de modo geral as semelhanças são bastante importantes. Se o processo inflamatório apresenta pequenas diferenças entre as formas clínicas, estas seriam o resultado de associações de condições? Apesar de muitos fatores terem sido apontados como envolvidos no processo de cura ou agravamento das lesões, os mecanismos precisos que dirigem uma lesão para a cura ou para o agravamento/ manutenção do processo inflamatório ainda não são totalmente compreendidos. O parasito pode, por exemplo, exercer influência importante em todo o processo. Vários artigos foram publicados revelando diferenças de resposta e apresentação clínica entre espécies de Leishmania e dentro da mesma espécie. Como exemplo, temos o estudo de Matta e colaboradores (2009), que verificaram diferentes perfis de produção de citocinas e resposta imune celular em pacientes infectados com L. guyanensis em relação aos casos típicos de infecção por L. braziliensis. Em outro estudo, Schriefer e colaboradores (2009) detectaram a presença de populações diferentes de L. braziliensis, relacionados a diferentes apresentações clínicas, que apresentavam circulação em pontos distintos de uma mesma área endêmica.

Mais recentemente publicou-se um estudo sugerindo a complexidade de resposta imune durante a infecção por parasitos do gênero Leishmania. Cruz e colaboradores (2010) demonstraram que pacientes de LTA com sorologia positiva para Toxoplasma gondii apresentavam linfócitos isolados de lesão capazes de proliferar em resposta ao T. gondii, 
fato que não ocorria em pacientes soronegativos para toxoplasmose. Esse resultado sugere que células ativadas com diferentes especificidades podem contribuir para o estabelecimento e/ou manutenção do processo inflamatório in situ. Assim, o microambiente da lesão poderia ser formado não apenas pelas células primariamente específicas, mas também por células ativadas por outros antígenos e que seriam capazes de responder aos produtos secretórios locais, produzindo mais citocinas e outras substâncias capazes de manter ou amplificar o processo inflamatório per se.

Ainda com esse fim, foi relatado que a coinfecção por helmintos intestinais, cujos antígenos estimulam resposta do tipo 2, levava à necessidade de maior tempo de tratamento para a cura das lesões de LTA (O'Neal et al., 2007). No entanto, estudo recente não confirmou tal achado (Newlove et al., 2011). Da mesma forma, a coinfecção LeishmaniaHIV pode se apresentar como menor ou maior gravidade na dependência do grau de supressão do sistema imunológico, sendo frequente a presença de lesões disseminadas e recidivas na forma tegumentar (Cruz et al., 1992, 2006; Alvar et al., 2008; Lindoso et al., 2009). Recentemente demonstrou-se que a infecção pelo HIV-1 aumenta a expressão de superfície do receptor de fosfatidilserina CD91/LRP-1 em macrófagos humanos, facilitando assim a fagocitose de Leishmania sp. por macrófagos vizinhos ainda não infectadas pelo protozoário (Lodge et al., 2012). Todavia, a exemplo de outras infecções, tem sido cada vez mais frequente a descrição de quadros de síndrome de reconstituição imune após o início de terapia antirretroviral, levando ao surgimento ou exacerbação de leishmaniose tanto tegumentar quanto visceral (Auyeung, French \& Hollingsworth, 2010).

Com relação à forma mucosa da LTA, verificou-se que a intensa destruição tecidual, comum nesta forma clínica, seria consequência de uma resposta inflamatória exacerbada e não controlada (Pirmez et al., 1993; Faria et al., 2005; Carvalho et al., 2007). Esse descontrole seria causado pelo excesso de IFN- $\gamma$ e granzima A, associados à baixa expressão do receptor de IL-10. Faria e colaboradores (2005) e Carvalho e colaboradores (2007) demonstraram que em comparação com as lesões cutâneas, as formas mucosas apresentavam, in situ, maior concentração de células expressando CD28 $\mathrm{CD} 9^{+} \mathrm{CD} 62 \mathrm{~L}^{\text {low }}$ e menor capacidade de modular a produção de IFN- $\gamma$. Com vistas a isso, Gaze e colaboradores (2006) evidenciaram que o sangue periférico de pacientes da forma mucosa apresentava maior frequência de células ativadas, como $\mathrm{CD} 4{ }^{+} \mathrm{CD} 69^{+}$e $\mathrm{CD} 8{ }^{+} \mathrm{CD} 69^{+}$, e maior produção de TNF- $\alpha$. Além disso, os pacientes de forma mucosa apresentavam um desequilíbrio entre TNF- $\alpha$ e IL-10 que não era verificado no estudo de pacientes com forma cutânea de LTA. Com base em tal dado, os autores reafirmavam a sugestão de que a resposta inflamatória era menos controlada nas lesões mucosas de LTA em relação às lesões cutâneas. Resultados semelhantes já haviam sido publicados por Bacellar e colaboradores (2002).

Castellucci e colaboradores $(2005,2006)$ associaram predisposição ao desenvolvimento de forma mucosa com características genéticas (polimorfismo do promotor IL6-174 G/C), que levavam à baixa produção de IL-6 e tendência a reações pró-inflamatórias. Outros polimorfismos já foram evidenciados, como o polimorfismo do promotor CCL2/MCP-1 da proteína quimiotática de monócitos (MCP-1) (Ramasawmy et al., 2010). A alta expressão de MCP1 aumentaria o risco de desenvolvimento de leishmaniose mucosa. Assim, a forma mucosa constituiria o polo hiperresponsivo da LTA, com necrose nasofaríngea associada à alta produção de TNF- $\alpha$ e IFN- $\gamma$ no soro dos pacientes e baixa atividade de citocinas anti-inflamatórias (Castés \& Tapia, 1998; Blackwell, 1999; Ribeiro-de-Jesus et al., 1998). Além disso, mesmo na forma mucosa, diferentes sítios de lesão podem apresentar perfis inflamatórios distintos. Assim, Palmeiro e colaboradores (2012) demonstraram que as lesões orais de LTA diferem das lesões nasais, já que apresentaram maior número de neutrófilos, parasitos, células em proliferação e NOS2 que as lesões nasais. Essas diferenças, juntamente com o tempo menor de evolução e sintomas mais intensos, sugerem um processo inflamatório mais recente. Isso poderia ser explicado por alterações da cavidade oral produzidas pelas lesões, o que levaria a dificuldades na alimentação e ao surgimento de estigma social. Além disso, a frequente má conservação dos dentes e a inflamação gengival tendem a amplificar a destruição dos tecidos e dos sintomas, o que pode prejudicar e confundir o diagnóstico correto, retardando o início do tratamento específico. 
Em conjunto, os dados da literatura que relacionam formas clínicas com padrão inflamatório e carga parasitária indicam que o controle da carga parasitária dependeria dos tipos de citocinas produzidas localmente. Em adição, a participação do óxido nítrico já foi relatada. Stenger e colaboradores (1996) verificaram a expressão de NOS2 (óxido nítrico sintase tipo 2) a longo prazo no sítio da lesão de pele original e no linfonodo drenante em camundongos infectados com L. major, constatando que a atividade de NOS2 foi dependente de células T CD4 ${ }^{+}$, mas não de CD8 ${ }^{+}$. A inibição da NOS2 por L-NIL (L-N-iminoethyl-lysine) determinou um aumento da carga parasitária no tecido cutâneo e linfonodo drenante, levando à reativação da doença. Concluíram, então, que a atividade de Nos2 seria crucial para o controle de parasitos persistentes nos hospedeiros imunocompetentes após a resolução da infecção primária.

Nas fases de imunossupressão, a inibição da atividade de NOS2 seria um dos mecanismos responsáveis pela reativação endógena de infecções latentes por microrganismos sensíveis ao NO. Também verificou-se a importância da NO para o controle da carga parasitária em lesões ativas de LCL. Morgado e colaboradores (2008), ao avaliarem lesões cutâneas ativas, observaram uma associação entre a maior intensidade da enzima Nos2 e a menor quantidade de parasitos por área de tecido (Figura 1). Por sua vez, esse protozoário pode desenvolver mecanismos de escape que possibilitem a sobrevivência dentro dos macrófagos (célula hospedeira clássica de amastigotas) e o desenvolvimento de lesões crônicas.

A infecção por Leishmania spp. induz a liberação de citocinas que inibem a morte parasitária mediada por No, como TGF- $\beta$ e IL-10 (Barral-Netto \& Barral, 1994). O fosfoglicano do parasito regula negativamente a produção de IL-12, consequentemente inibindo a expansão de Th1 e a liberação de NO estimulada por INF- $\gamma$. O TGF- $\beta$ é o supressor mais potente da expressão de NOS2 em macrófagos murinos e atua ao nível pós-transcripcional, desestabilizando o RNAm de NOS2, retardando a síntese da enzima e acelerando a sua degradação (Brandonisio et al., 2001). Além disso, o próprio parasito é capaz de produzir radicais livres e outras substâncias como a enzima arginase, que poderiam modular a resposta imune local de forma precoce (Soares-Bezerra et al., 2008; Vendrame et al., 2007, 2010).

Ainda em relação à ação de citocinas no desenvolvimento e manutenção da atividade inflamatória nas lesões de LTA, o TNF- $\alpha$ merece destaque, não só por seus efeitos potenciais, mas também pela controvérsia gerada por resultados conflitantes. Já foi verificada a relação entre TNF- $\alpha$ com doença, já que no soro seus níveis de detecção foram mais altos antes do tratamento que após, enquanto na doença em atividade as concentrações mais elevadas foram encontradas em pacientes de forma mucosa (Cruz et al., 1996). Blackwell (1999) discutiu a associação alélica no polimorfismo de TNF- $\alpha$ e o aumento da suscetibilidade ao surgimento de formas mucosas de LTA. Como o TNF- $\alpha$ é produzido principalmente por macrófagos logo nos primeiros momentos da infecção, seu papel na resposta inata tem sido colocado em evidência. No entanto, outras funções também podem ser detectadas.

A exemplo de outros sistemas, boa parte dos resultados foram obtidos no modelo murino de infecção por L. major. A maior parte desses resultados apontam para a melhora parcial da infecção em camundongos tratados com a citocina (Titus, Sherry \& Cerami, 1989), sugerindo que TNF- $\alpha$ funcione como cofator associado a outras citocinas. No entanto, estudos relacionados ao uso de antagonistas do TNF- $\alpha$ que levam ao agravamento da leishmaniose foram recentemente publicados, sugerindo que essa citocina funcione como molécula-chave na determinação da gravidade da apresentação clínica (De Leonardis et al., 2009; Franklin, Greenspan \& Chen, 2009). Além disso, diferenças de resposta entre TNF- $\alpha$, ligado à membrana ou solúvel, e entre diferentes camundongos KO infectados com diferentes cepas de Leishmania, tem dificultado o esclarecimento da real função e importância dessa citocina na evolução da LTA (Körner et al., 2010).

Recentemente, o paradigma Th1/Th2 foi reavaliado e uma nova subpopulação de linfócitos foi descrita: células Th17 (Korn et al., 2007). Tais células foram assim denominadas, uma vez que a IL-17 é sua citocina de assinatura. Sua diferenciação depende do estímulo produzido pela citocina pró-inflamatória IL-6 associado à citocina imunossupressora TGF- $\beta$, e sua sobrevivência depende da IL-23 (Stockinger \& Veldhoen, 2007). Sua função efetora 
está ligada a ação pró-inflamatória. Por meio da produção de IL-22 e IL-17 e da indução de quimiocinas e quimiotaxia de células efetoras, como neutrófilos e macrófagos, Th17 parece ser eficiente em orquestrar a resposta imune contra patógenos extracelulares e infiltrantes nos tecidos (Korn et al., 2007). Existem atualmente alguns trabalhos em leishmaniose que se concentram em entender a participação dessas células durante o processo inflamatório. Anderson e colaboradores (2009), estudando camundongos C57BL/6 knockout para IL-27R infectados com L. major, observaram que esses animais desenvolviam lesões mais graves associadas ao aparecimento de células CD $4^{+} \mathrm{IL}-17^{+}$.

Figura 1 - Estudo imuno-histoquímico de lesões ativas de LTA

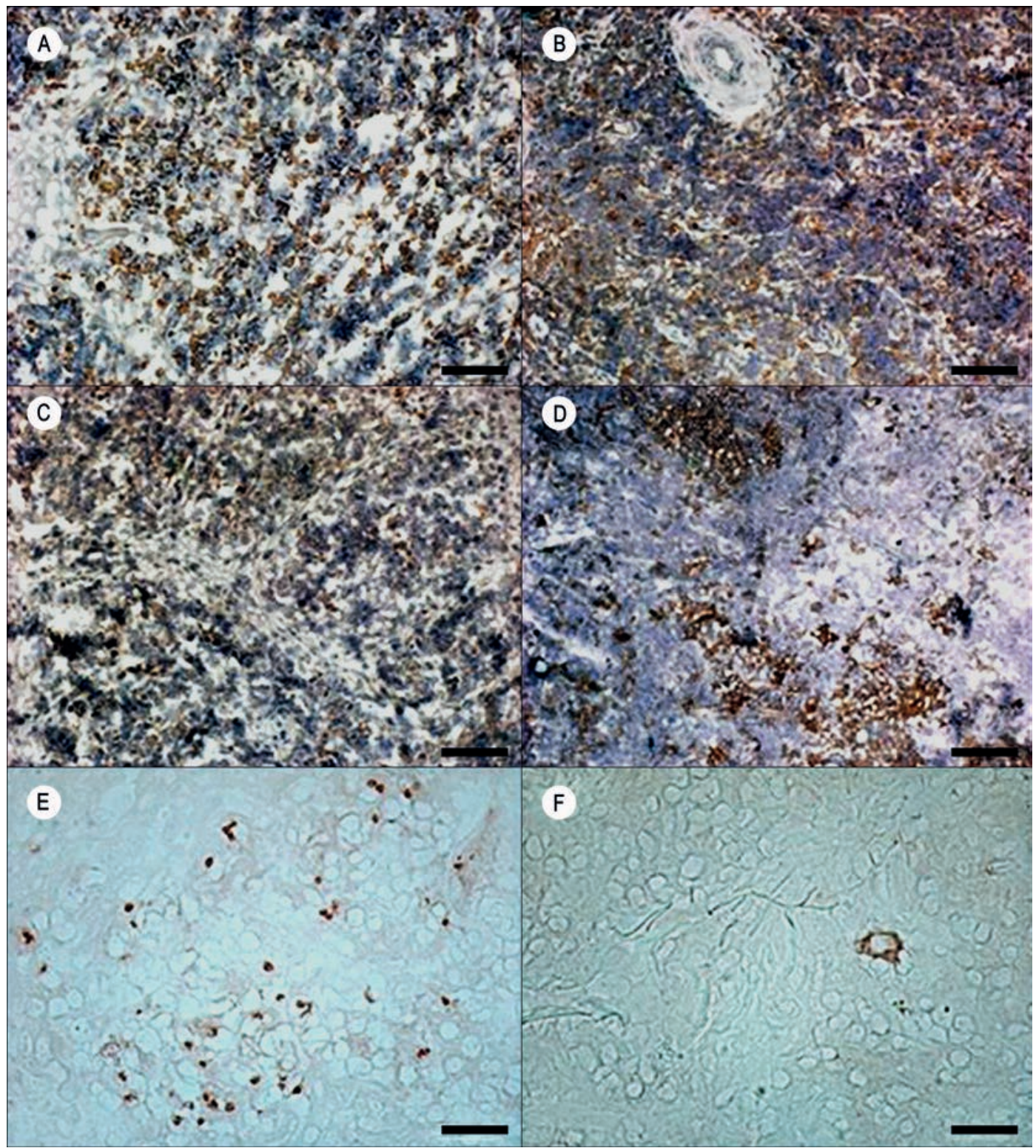

A-B - detecção de macrófagos; C-D - intensidade de expressão de NOS2; E-F - amastigotas de Leishmania braziliensis em uma lesão recente (A, C, E) e uma lesão tardia $(B, D, F)$. Aumento 200x $(A-D$, barra $=50 \mu \mathrm{m})$ e 400x $(E-F$, barra $=25 \mu \mathrm{m})$

Fonte: adaptado de Morgado et al., 2008. 
Em trabalho posterior, observou-se a relação entre a produção das citocinas IL-17 e IL-23 e a proteção ao desenvolvimento de calazar humano causado por L. donovani (Pitta et al., 2009). Os autores concluíram que um defeito na produção de Th17 poderia aumentar o risco de desenvolvimento de calazar. A possível associação entre a presença dessas células e o desenvolvimento de determinadas formas clínicas de LTA ainda precisa ser esclarecida. Neste contexto, recentemente verificou-se o aumento de receptores Notch e ligantes Delta-like em pacientes com má resposta ao tratamento, sugerindo que eles necessitam de uma abordagem terapêtica mais agressiva ou, pelo menos, de uma abordagem terapêutica mais completa e de um rigoroso acompanhamento (Rodrigues et al., 2011).

Outros fatores, como estímulos enzimáticos a vias não protetoras de resposta imune, ação de células e citocinas ligadas a resposta imune inata etc. também tem sido implicados na modulação da resposta imune ao parasito e, consequentemente, ao controle ou exacerbação da doença (Rodrigues et al., 2011; Guimarães-Costa et al., 2009; Maretti-Mira et al., 2011a, 2011b; Mottet \& Golshayan, 2007).

Além de citocinas, radicais livres e enzimas, outras substâncias têm sido relacionadas à modulação da resposta imune durante as infecções. Dentre elas, o zinco tem merecido destaque, tendo sido acumulada uma boa quantidade de informação nos últimos anos. Em recente revisão, Prasad (2009) indica a função desse metal na modulação da resposta imune mediada por células em várias doenças infecciosas, inclusive a leishmaniose. A função moduladora ocorreria pelas ações antioxidantes e anti-inflamatórias, pois funciona como sinal intracelular para células do sistema imune. Na leishmaniose visceral já foi verificado o baixo nível de zinco no plasma de pacientes com doença clínica (Overbeck, Rink \& Haase, 2008). No entanto, não está claro se essa observação é causa ou efeito do agravamento da infecção. Em modelos experimentais, nos quais se pode variar o aporte nutricional, já foi verificado na infecção por L. major que camundongos suscetíveis apresentam baixa concentração plasmática de zinco e que camundongos resistentes apresentam altas concentrações de cobre (Amini et al., 2009).

Resultados semelhantes já haviam sido obtidos em pacientes de leishmaniose. Van Weyenbergh e colaboradores (2004) verificaram que pacientes com diferentes formas da doença (cutânea, mucosa e visceral) apresentavam baixa concentração plasmática de zinco durante a fase ativa da doença, mas apenas na lesão mucosa ou visceral foi possível detectar pacientes com franca deficiência de zinco. Níveis elevados de cobre foram obtidos nos pacientes com forma cutânea e visceral. Mais importante que isso, a relação cobre/zinco estava elevada em todos os casos de deficiência da resposta imune celular com aumento da resposta imune humoral, principalmente naqueles com IgG alta. Como os próprios autores afirmam que deficiências desses dois metais podem ter várias causas e que a literatura é pobre nesse campo de estudo, ainda não se pode afirmar se tais parâmetros são causa ou efeito da gravidade de casos de infecção por Leishmania sp.

As deficiências nutricionais são indicadas como responsáveis, pelo menos em parte, por deficiências no funcionamento do sistema imune, contribuindo para o agravamento de várias doenças infecciosas. Nesse sentido, recentemente Malafaia (2009) demonstraram que a eficácia da vacinação experimental com L. infantum em camundongos BALB/C era diminuída pela presença de subnutrição proteico-calórica. Em relação aos seres humanos, Machado-Coelho e colaboradores (2005) verificaram que a subnutrição grave estava relacionada ao risco de pelo menos quatro vezes para o surgimento de lesões de difícil manejo na forma mucosa da LTA. Na leishmaniose visceral essa relação de nutrição e doença tem sido melhor estudada, e recentemente Malafaia publicou artigo de revisão (Malafaia, 2009) abrangendo o conhecimento atual sobre o assunto.

Em resumo, uma intrincada rede de linfócitos e produtos secretórios atua, mediante ações estimuladoras ou moduladoras, levando ao surgimento de diferentes formas clínicas ou diferentes níveis de gravidade. No entanto, nos últimos anos, estudos de outras células entraram em evidência, entre elas células importantes na imunidade inata em leishmaniose, como as células dendríticas, os neutrófilos e os mastócitos. 


\section{A IMUNIDADE INATA E A LEISHMANIOSE}

Os parasitos do gênero Leishmania são transmitidos através da picada do flebotomíneo, que injeta as formas promastigotas na derme do hospedeiro. Após a invasão parasitária, o sistema imune inato da pele induz duas vias de respostas: o recrutamento de células inflamatórias para o sítio de lesão e a ativação da resposta imune adaptativa (Maurer, Dondji \& Stebut, 2009). A infiltração de neutrófilos, macrófagos e células dendríticas se faz necessária à contenção do parasito e ao controle de sua disseminação.

Nos últimos anos, estudos focados na função de neutrófilos na leishmaniose começaram a surgir. Mas, em particular na leishmaniose murina, os resultados têm sido contraditórios. Lima e colaboradores (1998) sugeriram a participação dessas células no controle da carga parasitária em camundongos C57BL/6 infectados com L. major, pois a ausência de neutrófilos levava ao desenvolvimento de doença grave e disseminada. Resultados semelhantes foram observados por Ribeiro-Gomes e colaboradores (2004). Nesse estudo os autores compararam a infecção por L. major em BALB/c e C57Bl/6 e demonstraram que, tanto in vitro quanto in vivo, a presença de neutrófilos aumentava o número de parasitos e exacerbava a doença no BALB/c, além de ter efeito contrário no C57Bl/6. Assim, Tacchini-Cottier e colaboradores (2000) sugeriram que a ausência de neutrófilos gerava um efeito protetor associado à redução da resposta Th2 e à resolução parcial da lesões em camundongos suscetíveis (BALB/c) infectados com L. major. Essa aparente contradição se dá em razão da variação no modelo de camundongos e parasitos, já que Novais e colaboradores (2009), estudando camundongos BALB/c infectados com L. braziliensis, demonstraram que a depleção de neutrófilos levava a um aumento da carga parasitária, tanto in vitro quanto in vivo, e que a presença de neutrófilos estimulava macrófagos a produzir TNF- $\alpha$ e radicais de superóxido. A comparação desses resultados sugere que a espécie do parasito estimula diferentes vias metabólicas ou diferentes subpopulações de células, o que leva a resultados conflitantes.

Ainda com relação ao modelo de infecção por L. major, Van Zandbergen e colaboradores (2004) constataram que os neutrófilos poderiam funcionar como vetores para a entrada de Leishmania spp. em macrófagos, num modelo denominado 'cavalo de troia'. Nesse modelo, o parasito seria inicialmente fagocitado por neutrófilos e estes seriam incapazes de eliminá-los através de seus mecanismos microbicidas. O neutrófilo entraria em processo de apoptose e o conjunto seria fagocitado pelos macrófagos, o que levaria a sua inativação. O resultado seria a entrada silenciosa de parasitos nos macrófagos e sua persistência nesta célula. Em 2008, tais dados foram confirmados pelo trabalho desenvolvido por Peters e colaboradores (2008), que demonstraram a participação dos neutrófilos nas etapas iniciais de infecção. Todos esses resultados conflitantes levaram à publicação de um artigo intitulado "Neutrophils soldiers or Trojan Horses?" (John \& Hunter, 2008), em que são discutidas as diferentes possibilidades de função dessa célula.

A fagocitose de patógenos não constitui a única função efetora de neutrófilos. Essas células secretam citocinas (ex.: TNF- $\alpha$, IFN- $\gamma$ ) e quimiocinas responsáveis pelo recrutamento e ativação de células dendríticas, macrófagos e linfócitos B (Nathan, 2006). Nos grânulos de neutrófilos são encontradas diversas moléculas com ação antimicrobiana, principalmente enzimas (elastase, protease, mieloperoxidase), lactoferrina, lisozima e defensinas. A liberação desse conteúdo também constitui uma função efetora dessas células. Sob ativação, os neutrófilos podem liberar as enzimas de seus grânulos assim como sua cromatina, que formam fibras extracelulares responsáveis pela contenção e eliminação de bactérias gram-positivas e gram-negativas (Brinkmann et al., 2004). As proteases (como exemplo, a elastase neutrofílica) exercem efeito tóxico, assim como as histonas presentes nas fibras. O DNA é o maior componente desse conjunto, que foi denominado 'trap', ou 'neutrophil extracellular traps (NET)', e passou a ser considerado mais uma função efetora de neutrófilos (Wartha \& Henriques-Normark, 2008).

Desde sua descrição inicial, a presença de NETs passou a ser investigada em diversos processos inflamatórios infecciosos ou não, inclusive na leishmaniose. Em estudo in vitro de interação entre neutrófilos murinos e promastigotas evidenciou-se o aprisionamento dessas formas nas redes de fibras e, consequentemente, sua imobilização e morte 
(Guimarães-Costa et al., 2009). Em estudo recente, foi possível a observação de amastigotas íntegras envolvidas por NETs compostas por histonas e elastase em lesões ativas de LTA humana, assim como áreas contendo antígenos amorfos de amastigotas já não mais envolvidos por tais redes. Mas a possibilidade de ação efetiva no controle da carga parasitária na leishmaniose in vivo ainda não foi comprovada.

Atualmente, o que se sabe é que a elastase neutrofílica é capaz de ativar macrófagos humanos e induzir a secreção de TNF- $\alpha$ (Fadok et al., 2001). Em adição, a inibição da elastase neutrofílica, em modelo murino, impediu a atividade leishmanicida de macrófagos mesmo na presença dos neutrófilos, mostrando a participação desta enzima na atividade microbicida (Ribeiro-Gomes et al., 2004, 2007; Ribeiro-Gomes, Silva \& Dosreis, 2006). Como já mencionado, em recente publicação (Novais et al., 2009) evidenciou-se que neutrófilos podem auxiliar o controle da carga parasitária por meio da cooperação com macrófagos e associado à produção de produtos secretórios próinflamatórios. Dessa forma, os dados publicados parecem demonstrar que o balanço entre a capacidade de penetração parasitária e a formação de redes, juntamente com o tipo de interação entre linfócitos, neutrófilos e macrófagos, poderiam determinar a evolução das lesões de LTA.

As células de Langerhans/células dendríticas epidérmicas também são componentes importantes da resposta imune inata da pele, pois iniciam a resposta imune adaptativa local de células T (Brewig et al., 2009). Elas migram para a derme, onde captam antígenos e se dirigem para o linfonodo regional, onde apresentam antígenos para as células T, iniciando assim a resposta imune celular (Moll, Flohé \& Röllinghoff, 1995). Durante a migração, essas células tornam-se capazes de sensibilizar linfócitos T naive. Elas são capazes de fagocitar L. major, porém, isso parece não ser importante para eliminação de parasitos, mas sim para a aquisição de antígenos para apresentação à célula T. Ao longo do processo de maturação tais células aumentam a expressão de moléculas do MHC-II e de moléculas coestimulatórias B7-1 (CD80) e B7-2 (CD86), CD40 e CD83 (Katou et al., 2000), tornando-se assim potentes estimuladoras da proliferação de células T específicas para L. major e produção de linfocinas, sendo para tal mais eficientes do que os macrófagos (Moll et al., 1993). Silveira e colaboradores (2008) mostram uma relação espécie-específica entre a densidade de células de Langerhans e o perfil de células $\mathrm{CD} 4^{+}$e $\mathrm{CD}^{+}$no infiltrado celular de lesões de pele em pacientes com LTA. Os autores concluem que células de Langerhans podem influenciar a dicotomia existente entre L. braziliensis e L. amazonensis. Enquanto L. braziliensis direciona a resposta para o polo de hiperresponsividade com forte produção de citocinas do tipo 1, a L. amazonensis apresenta efeito contrário, direcionando a resposta para o polo hiporresponsivo com forte produção de citocinas do tipo 2 e redução da infiltração de células $\mathrm{CD} 4^{+}$e $\mathrm{CD} 8^{+}$.

Ritter e Osterloch (2007), em trabalho de revisão, discutem a existência de subpopulações de células dendríticas na leishmaniose experimental de L. major. Os autores sugerem que essas subpopulações de células dendríticas e a compartimentalização da apresentação antigênica seriam críticas para a qualidade de resposta de células T. As células dendríticas dérmicas carreariam antígenos para o linfonodo após alguns dias de infecção e seriam responsáveis pela ativação de células $\mathrm{T}$ efetoras antígeno-específicas, na porção externa da região paracortical. Já a região interna do paracórtex do linfonodo constituiria uma área especializada, onde a resposta de células T seria controlada por células dendríticas capazes de carrear antígenos próprios e induzir tolerância.

Na leishmaniose, sua participação principal seria pela ativação de células regulatórias e redução do processo inflamatório após semanas de infecção. Assim, o equilíbrio das interações entre os diferentes subtipos de células dendríticas e células T seria necessário para o desenvolvimento de uma resposta imune eficiente na leishmaniose. Subpopulações de células dendríticas já foram identificadas na infecção por L. braziliensis (Carvalho, Pearce \& Scott, 2008). Os autores verificaram a presença de duas supopulações: suscetível à infecção, incapazes de produzir moléculas coestimulatórias ou IL-12, porém boas produtoras de TNF- $\alpha$, promovendo por isso o acúmulo de macrófagos em sítio de sobrevivência do parasito; resistentes à infecção, porém produzem MHC-II, moléculas coestimulatórias e IL-12, e promovem a geração de células Th1. 
A IL-12 é citocina fortemente produzida pelas células dendríticas maduras (Liese, Schleicher \& Bogdan, 2008). Estudos de infecção com L. major revelaram que IL-12 tem papel fundamental na geração de imunidade protetora através da ativação de células NK, células $\mathrm{CD} 8^{+}$e diferenciação da resposta em Th1 com produção de IFN- $\gamma$ (Sacks \& Noben-Trauth, 2002; Scharton-Kersten et al., 1995; Trinchieri, Pflanz \& Kastelein, 2003; Schleicher et al., 2004). Díaz e colaboradores (2006), estudando lesões de LTA, constataram que lesões da forma cutânea localizada, quando comparadas às lesões disseminadas, apresentavam maior quantidade de IL-12, o que poderia ser relacionado ao prognóstico favorável e cura dessas lesões.

A produção de IL-12 pelas células dendríticas pode ser estimulada por receptores semelhantes ao Toll (TLR). TLR são glicoproteínas transmembranares expressas por diferentes tipos celulares na pele humana. Constituem importantes receptores de reconhecimento de padrões (componentes de patógenos microbianos) e iniciam as respostas imunológicas cutâneas. Existem pelo menos dez tipos de TLR já descritos (Miller, 2008), e o reconhecimento antigênico gera uma cascata de sinalização intracelular que inclui a ativação do adaptador MyD88 (fator de diferenciação

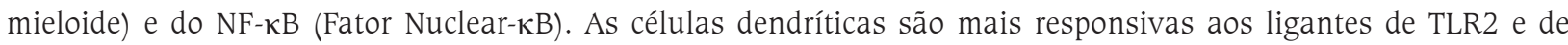
TLR7/8 (Renn et al., 2006).

Em outro estudo (Vargas-Inchaustegui et al., 2009), utilizando-se L. braziliensis e células dendríticas TLR/ e outras MyD88\%, observou-se que MyD88 era indispensável à produção de resposta protetora, que incluía a ativação de células $\mathrm{CD}^{+}$e produção de IL-12 e IFN- $\gamma$. Já TLR2 parece ter função reguladora durante a resposta, já que sua ausência gerou resposta protetora e resistência à infecção. As proteínas adaptadoras MyD88 podem ser utilizadas por outros tipos de TLR (Modlin \& Cheng, 2004). TLR4 já foi associado ao controle eficiente da infecção por L. major via ativação recente de NOS2 (Kropf et al., 2004). A ausência de TLR4 levou à alta atividade de arginase e crescimento parasitário. Em estudo sobre leishmaniose visceral por L. infantum, observou-se que TLR9 de células dendríticas eram importantes para ativação de células NK através de IL-12 (Schleicher et al., 2007).

Em recente estudo (Pereira et al., 2009), um paciente apresentando a forma cutânea difusa da LTA alcançou cura após imunoterapia com vacina de L. braziliensis e L. amazonensis associados ao BCG. O paciente desenvolveu a cura de todas as lesões com redução da carga parasitária. A análise do sangue periférico mostrou aumento de células $\mathrm{NK}\left(\mathrm{CD} 16^{+} \mathrm{CD} 56^{+}\right)$e monócitos $\left(\mathrm{CD} 14^{+} \mathrm{CD} 16^{+}\right)$, apesar da manutenção da negatividade da IDRM e da ausência de produção de IFN- $\gamma$. A análise do infiltrado celular das lesões evidenciou aumento de linfócitos CD56 associado ao controle da carga parasitária. Tal trabalho sugere a importante participação das células do sistema imune inato no controle da carga parasitária. Porém, Tuon e colaboradores (2008), estudando lesões mucosas recidivantes de LTA, observaram maior número de células NK e $\mathrm{CD} 8^{+}$quando comparadas às lesões que atingiam a cura propriamente dita. Associaram o risco de desenvolvimento de reativação com a alta atividade dessas células e à baixa regulação do processo inflamatório. Tais diferenças podem ter se dado em razão do tecido estudado ou mesmo a diferenças não detectadas entre os parasitos implicados na infecção, já que alguns trabalhos relatam a presença de clones mais resistentes ao tratamento (Baptista et al., 2009; Azeredo-Coutinho et al., 2007).

Em trabalho experimental (Oliveira et al., 2005), observou-se que promastigotas de L. braziliensis vivas induziam a ativação de mastócitos em cultura e produção de altos níveis de IL-4 intracelular e IL-12. Os dados sugerem a participação de mastócitos no estabelecimento inicial das lesões ativas. Tuon e colaboradores (2008) sugerem a importância dos mastócitos na fase de cura das lesões. Em conjunto com dados anteriores (Amato et al., 2008), os autores evidenciaram a redução da população de mastócitos locais após o tratamento tanto da leishmaniose cutânea quanto da leishmaniose mucosa, e a relação com os processos recentes de cura. Além disso, observaram que as lesões causadas por L. braziliensis apresentavam número significativamente maior de mastócitos que as lesões causadas por L. amazonensis. 
Indiretamente, a função de mastócitos na fase inicial de estabelecimento das lesões também foi verificada em modelo experimental de L. amazonensis (Oliveira Cardoso et al., 2010). Os autores verificaram a predominância de eosinófilos e mastócitos na fase inicial da infecção em todas as cepas de camundongos estudados, independentemente de suscetibilidade ou resistência. No entanto, mais uma vez, como o estudo de lesões precoces em pacientes é difícil, obteve-se a maior parte dos resultados em modelo murino ou in vitro. E mais: alguns resultados são conflitantes, alguns demonstrando a importância (Maurer et al., 2006), outros indicando um papel secundário dessas células no controle da infecção (Wershil et al., 1996).

Em outro trabalho, Oliveira Cardoso e colaboradores (2010) sugerem que mastócitos poderiam não ser importantes na destruição direta de parasitos, mas poderiam agir auxiliando o influxo de polimorfonucleares para o sítio das lesões. Essa seria uma importante função, já que as células polimorfonucleares são capazes de secretar citocinas e enzimas responsáveis pela ação da resposta imune inata e pela migração de macrófagos no início da infecção. Todavia, este é um campo ainda em aberto, com muitas questões ainda precisando ser estudadas/identificadas em relação ao real papel de mastócitos na resposta imune aos patógenos teciduais como as leishmânias. Um exemplo disso é a descrição de que sob determinadas circunstâncias mastócitos também podem produzir traps, secretar grandes quantidades de TNF- $\alpha$ e destruir bactérias intracelulares por mecanismos de estresse oxidativo (Von Köckritz-Blickwede \& Nizet, 2009).

Se apenas a interação parasito-hospedeiro tivesse importância no estabelecimento da infecção por espécies de Leishmania, ainda assim teríamos uma grande quantidade de perguntas não respondidas. Mas, nos últimos anos, uma linha de pesquisa indicando a ação de substâncias dos flebotomíneos coinoculadas com os parasitos tem mostrado a possível relação entre essas substâncias e a capacidade de o parasito sobreviver e penetrar nas células hospedeiras nas primeiras horas de infecção, o que sugere um terceiro componente nesta interação.

\section{INFLUÊNCIA DO FLEBOTOMÍNEO (SALIVA) NA RESPOSTA IMUNE LOCAL}

A entrada de formas promastigotas de Leishmania sp. no hospedeiro vertebrado depende do rompimento da integridade da pele através da picada dos insetos vetores. Os primeiros resultados que discutiram a função da saliva de flebotomíneos na infecção por parasitos do gênero Leishmania surgiram no fim da década de 1980, com os trabalhos de Richard Titus e seu grupo (Titus \& Ribeiro, 1988). Demonstrou-se nessa mesma época que a composição poderia variar dentro das espécies de flebotomíneos (Warburg et al., 1994). Nos últimos anos, alguns trabalhos publicados apresentaram como tema a influência da saliva de flebotomíneo na evolução da leishmaniose, principalmente no tipo de resposta produzida logo nos primeiros momentos de infecção. Durante a ingestão de sangue, a saliva do flebotomíneo, que contém uma grande variedade de moléculas hemostáticas, inflamatórias e imunomodulatórias, é injetada na derme do hospedeiro definitivo (Ribeiro, 1995).

Dentro desse contexto, é fácil imaginar que tais proteínas podem interagir com o organismo do hospedeiro, produzindo ações que podem modular a resposta inflamatória local. Por exemplo, foi demonstrado que as proteínas da saliva estimulam a produção de diferentes isotipos de anticorpos. Curiosamente, a fração PpSP30 foi considerada imunodominante, sendo reconhecida por todas as subclasses de IgG, enquanto PpSP12 não foi reconhecida por IgG4 (Marzouki et al., 2011). Os resultados obtidos nesse tópico são controversos e podem ser diferentes de acordo com a espécie de flebotomíneo, fonte de saliva e modelo de infecção estudado. Análises immunoproteômicas podem ajudar a identificar o impacto de cada proteína salivar sobre a infecção por Leishmania e também para selecionar potenciais candidatos a vacinas (Marzouki et al., 2011).

Uma rápida revisão do assunto demonstra que a maioria dos trabalhos publicados indicam uma facilitação da infecção na presença de componentes da saliva. Por exemplo, evidenciou-se que a saliva de flebotomíneo aumentava a 
infecção por L. braziliensis (Moura et al., 2007). Os autores demonstraram que a saliva de flebótomos modula a resposta inicial do hospedeiro. Mais importante ainda, a pré-exposição à saliva de L. intermedia modifica significativamente a resposta do hospedeiro a L. braziliensis, em termos de recrutamento celular e expressão de citocinas e quimiocinas, 0 que pode por sua vez favorecer a multiplicação do parasito.

Outro estudo demonstrou que a taxa de incidência de hipersensibilidade retardada ao antígeno Leishmania foi maior entre os pacientes que previamente apresentavam anticorpos para saliva de Lu. longipalpis do que entre aqueles previamente negativos. Os resultados sugeriram que montar uma resposta imune antissaliva ajuda o desenvolvimento de uma resposta mediada por células anti-Leishmania (Aquino et al., 2010). Nesse sentido, vários grupos têm tentado isolar componentes da saliva para estudar seu papel isolado ou em associação de mais de um componente, como forma de entender o processo inicial de sobrevivência do parasito no ambiente hostil da pele. Exemplo dessa possibilidade é o uso de frações de saliva enriquecidas com substâncias como a maxidilan, que funciona como um vasodilatador aumentando o aporte de sangue e células para o local, além de modular algumas citocinas in vitro (Soares et al., 1998; Brodie et al., 2007; Svensjö et al., 2009) ou proteofosfoglicanos que alteram a função de macrófago, aumentando a possibilidade de infecção dessas células em modelo in vitro (Rogers et al., 2009). Outra função intrigante e que ainda não foi totalmente esclarecida é a que diz respeito ao recrutamento precoce e mantido de neutrófilos para a região da picada do flebotomíneo, ao contrário de outros tipos de injúria que apenas produzem um fluxo rápido e transitório nos primeiros minutos após a solução de continuidade do tecido (Peters \& Sacks, 2009).

Dados já publicados reforçam a hipótese de que proteínas salivares do vetor podem desencadear a apoptose caspase-dependente e mediada por FasL, favorecendo a sobrevivência de Leishmania sp. dentro de neutrófilos. Essa ação pode representar um importante mecanismo para o estabelecimento de infecção no hospedeiro vertebrado (Prates et al., 2011). Contudo, também verificou-se que o efeito predominante do extrato total da saliva de Phlebotomus papatasi foi a indução de células CD8 $8^{+}$produtoras de IL-10, sugerindo um possível efeito negativo da pré-exposição à saliva sobre o resultado da leishmaniose humana. Nesse mesmo trabalho foi no entanto demonstrado que, quando as subpopulações de linfócitos eram isoladamente estimuladas, linfócitos $\mathrm{CD} 4^{+}$ativados produziram quantidades elevadas de IFN- $\gamma$, sugerindo que as diferentes proteínas que compõem a saliva podem estimular diferentes subpopulações com diferentes funções predominantes. Assim, a possiblidade de ativação de linfócitos produtores de diferentes padrões de citocinas proporciona a lógica para definir melhor a natureza dos antígenos salivares que poderiam ser utilizados para o desenvolvimento de vacinas (Abdeladhim et al., 2011).

Esse é um assunto ainda em aberto e muitos resultados ainda deverão ser produzidos antes de se ter maior clareza da real função/importância desses componentes na infecção por Leishmania sp. No entanto, muitos estudos têm sido realizados no sentido de se verificar a possibilidade de imunização com frações de saliva de flebótomos, isoladamente ou em associação com outros compostos (Tavares et al., 2011). Já foi demonstrado que a imunização com saliva de $L u$. Longipalpis, ou com um plasmídeo de DNA que codifica a proteína de saliva denominada LJM19, induz proteção em hamsters inoculados com uma mistura de L. braziliensis e Lu. intermedia. Tais achados apontam para um importante papel da resposta imune contra os componentes da saliva, sugerindo a possibilidade de desenvolver uma vacina usando um único componente da saliva de Lu. longipalpis na indução de proteção contra diferentes espécies de Leishmania, mesmo quando transmitidas por um vetor diferente.

O processo inflamatório é dinâmico, e nos últimos anos vários estudos revelaram a importância do estímulo e controle da migração celular como forma de equilibrar, exacerbar ou suprimir a resposta imune localizada em tecidos. Assim, vários artigos foram publicados indicando a ação de moléculas de adesão e coestimulatórias, assim como de quimiocinas no processo inflamatório produzido pela infecção por leishmânias. 


\section{QUIMIOCINAS E A DINÂMICA DE MIGRAÇÃO DE CÉLULAS INFLAMATÓRIAS}

Quimiocinas pertencem a uma grande família de pequenas proteínas, cujas principais funções são o recrutamento e a ativação de células específicas durante a organização e manutenção da resposta imune. Essas funções determinariam um papel-chave no processo inflamatório, pois poderia regular e direcionar o tipo celular predominante ou mais ativo numa determinada situação inflamatória. As primeiras quimiocinas descritas foram as responsáveis pelo recrutamento de neutrófilos (IL-8/CXCL8) e macrófagos (MIP-1). Daí em diante uma grande variedade de proteínas e seus receptores foi sendo identificada, e o mecanismo de ação em algumas infecções descrito. Para diminuir a confusão, anos mais tarde foi instituída uma nomenclatura com base nos resíduos de cisteína presente nessas moléculas. Não pretendemos aqui fazer uma extensa revisão sobre quimiocinas e leishmaniose, pois a quantidade de informação disponível é bastante grande. Com relação a isso, Oghumu e colaboradores (2010) publicaram uma revisão na qual vários resultados foram organizados.

Em relação a quimiocinas e leishmaniose, os dados até o momento publicados apontam para um importante papel dessas proteínas e seus receptores na orquestração da resposta imune no sítio das lesões, já que estão envolvidas desde as primeiras horas de infecção na migração celular para o local da picada do flebotomíneo. Têm também papel significativo no estabelecimento da resposta imune celular específica localizada na região de injúria, pois também atuam no processo de diferenciação e maturação celular.

No modelo murino (Teixeira et al., 2006), alguns resultados interessantes puderam ser obtidos. Charmoy e colaboradores (2010), usando o modelo de infecção murina pela L. major, evidenciaram que CCL3, CCL4, CCL5 e CCL20 produzidas por neutrófilos eram capazes de atrair células dendríticas para o sítio da infecção. Ainda nesse artigo, os autores puderam verificar algumas diferenças entre camundongos suscetíveis e resistentes. C57Bl/6, considerado resistente, produzia maior quantidade de CCL3 em comparação ao BALB/c (suscetível). Quando CCL3 foi neutralizada ou quando foi usado camundongo $\mathrm{CCL}^{-}$, ocorria uma fase transitória de suscetibilidade, com maior número de parasitos e retardo no estabelecimento da resposta tipo 1. Os autores verificaram que essa maior suscetibilidade ocorria em virtude da deficiência no estabelecimento de células dendríticas e macrófagos, pois a neutralização in vivo de CCL3 levava à diminuição da migração dessas células e a uma queda na produção de IFN- $\gamma$. Além disso, a transferência de células $\mathrm{CCL}^{+}$em camundongos deficientes restaurava a resistência à infecção. Uma possível razão para a recuperação é a ação de CCL3 no estímulo à produção de IL-12 por macrófagos. No entanto, é preciso notar que a suscetibilidade descrita foi apenas transitória. Por isso, outros mecanismos devem estar envolvidos no controle da infecção.

Em pacientes, a relação entre quimiocinas e doença na leishmaniose foi bem caracterizada em algumas formas da doença. Por exemplo, na infecção por L. mexicana (Ritter \& Körner, 2002) demonstrou-se que a forma localizada apresentava maior expressão de CCL2, CXCL9 e CXCL10. Já na forma difusa da doença era verificada a predominância de CCL3 durante a resposta do tipo 2, com infiltrado mais difuso constituído por poucas células CD4 ${ }^{+}$. Em artigo de revisão em 2006, Teixeira e colaboradores (2006) discutiram que o tipo e a quantidade de quimiocinas produzidas no sítio das lesões poderia determinar a composição do infiltrado inflamatório, influenciando assim a forma clínica e a evolução da doença. E também pontuaram algumas particularidades entre as infecções produzidas por diferentes espécies do parasito. Geiger e colaboradores (2010) avaliaram a presença de células CCR4 (Th2) e CXCR3 (Th1/TC1) nas lesões ativas de LTA. Não se observaram células CCR4 ${ }^{+}$em todas as lesões estudadas. A intensidade de células $\mathrm{CXCR}^{+}$foi menor nas lesões com mais de seis meses de evolução, quando comparadas às lesões com menos de seis meses. A dupla marcação evidenciou que as células CXCR3 eram células CD4 ${ }^{+}$(Th1) e CD8 ${ }^{+}$(TC1), e sugeriram que esses tipos celulares estariam associados à resolução das lesões.

Assim, seja direcionando a iniciação da resposta, seja fazendo a atração e facilitação de migração celular para os linfonodos de drenagem e/ou para os sítios de lesão, as quimiocinas parecem exercer papel importante na 
determinação da evolução dos casos de leishmaniose. No entanto, vários pontos ainda não foram esclarecidos e outros estudos no assunto se fazem necessários.

\section{PERSPECTIVAS PARA A PESQUISA EM IMUNOLOGIA DAS LEISHMANIOSES}

Tendo em vista a extensão do assunto e sua multiplicidade de abordagem, certamente valorosos pontos não foram abordados com a devida abrangência ou não foram sequer mencionados. Ainda assim, os dados apresentados foram organizados de modo a proporcionar uma visão panorâmica do assunto, na tentativa de levantar questionamentos sobre alguns caminhos traçados.

Como já foi bem estabelecido no modelo experimental de infecção por L. major, o controle da infecção depende do desenvolvimento de linfócitos TCD4 ${ }^{+}$IFN $-\gamma^{+}$para indução da atividade microbicida de macrófagos hospedeiros (Anderson et al., 2009). Assim, o desenvolvimento de subpopulações de células Th1 estaria relacionado às formas benignas e ao processo de cura clínica na leishmaniose, enquanto a predominância de linfócitos Th2 geraria uma resposta desfavorável ao hospedeiro, com deficiência em controle da carga parasitária. Entretanto, os mecanismos regulatórios envolvidos são complexos e em algum momento se sobrepõem, tornando às vezes difícil a compreensão do todo. Assim, desenhar abordagens experimentais que possam dissecar todas as variáveis possíveis é uma meta. As leishmanioses, em geral, são infecções com carência de boas abordagens terapêuticas e que não têm até hoje ações imunoprofiláticas para a proteção da população sob risco. Compreender melhor os mecanismos envolvidos na regulação do binômio infecção/doença pode trazer subsídios que auxiliem ou facilitem a tarefa de desenvolvimentos de novas drogas e profiláticos.

\section{REFERÊNCIAS}

ABDELADHIM, M. et al. Human cellular immune response to the saliva of Phlebotomus papatasi is mediated by IL-10producing CD8 + T cells and Th1-polarized CD4+ lymphocytes. PLoS Neglected Tropical Diseases, 5(10): e1.345, 2011.

ALVAR, J. et al. The relationship between leishmaniasis and Aids: the second 10 years. Clinical Microbiology Reviews, 21(2): 334-359, 2008.

AMATO, V. S. et al. Histopathology of mast cells and cytokines during healing of human mucosal leishmaniasis. Parasite Immunology, 30(11-12): 637-640, 2008.

AMINI, M. et al. Biochemical association between essential trace elements and susceptibility to Leishmania major in BALB/C and C57BL/6 mice. Brazilian Journal of Infectious Disease, 13(2): 83-85, 2009.

ANDERSON, C. F. et al. IL-27 regulates IL-10 and IL-17 from CD4+ cells in nonhealing Leishmania major infection. The Journal of Immunology, 183(7): 4.619-4.627, 2009.

ANTONELLI, L. R. V. et al. Activated inflammatory T cells correlate with lesion size in human cutaneous leishmaniasis. Immunology Letters, 101(2): 226-230, 2005.

AQUINO, D. M. C. et al. Epidemiological study of the association between anti-Lutzomyia longipalpis saliva antibodies and development of delayed-type hypersensitivity to Leishmania antigen. The American Journal of Tropical Medicine Hygiene, 83(4): 825-827, 2010.

AUYEUNG, P.; FRENCH, M. A. \& HOLLINGSWORTH, P. N. Immune restoration disease associated with Leishmania donovani infection following antiretroviral therapy for HIV infection. Journal of Microbiology, Immunology, and Infection, 43(1): 74-76, 2010.

AZEREDO-COUTINHO, R. B. G. et al. Sensitivity of Leishmania braziliensis promastigotes to meglumine antimoniate (glucantime) is higher than that of other Leishmania species and correlates with response to therapy in American tegumentary leishmaniasis. The Journal of Parasitology, 93(3): 688-693, 2007. 
BACELLAR, O. et al. Up-regulation of Th1-type responses in mucosal leishmaniasis patients. Infection \& Immunity, 70(12): 6.734-6.740, 2002.

BAPTISTA, C. et al. Leishmania (Viannia) braziliensis genotypes identified in lesions of patients with atypical or typical manifestations of tegumentary leishmaniasis: evaluation by two molecular markers. Experimental Parasitology, 121(4): 317-322, 2009.

BARRAL, A. et al. Polar and subpolar diffuse cutaneous leishmaniasis in Brazil: clinical and immunopathologic aspects. International Journal of Dermatology, 34(7): 474-479, 1995.

BARRAL-NETTO, M. \& BARRAL, A. Transforming growth factor-beta in tegumentary leishmaniasis. Brazilian Journal of Medical and Biological Research, 27(1): 1-9, 1994.

BELKAID, Y. et al. Development of a natural model of cutaneous leishmaniasis: powerful effects of vector saliva and saliva preexposure on the long-term outcome of Leishmania major infection in the mouse ear dermis. The Journal of Experimental Medicine, 188(10): 1.941-1.953, 1998.

BELKAID, Y. et al. CD8 + T cells are required for primary immunity in C57BL/6 mice following low-dose, intradermal challenge with Leishmania major. The Journal of Immunology, 168(8): 3.992-4.000, 2002.

BLACKWELL, J. M. Genetic susceptibility to leishmanial infections: studies in mice and man. Parasitology, 112, supl.: S67-S74, 1996.

BLACKWELL, J. M. Genetics of host resistance and susceptibility to intramacrophage pathogens: a study of multicase families of tuberculosis, leprosy and leishmaniasis in north-eastern Brazil. International Journal for Parasitology, 28(1): 21-28, 1998.

BLACKWELL, J. M. Tumour necrosis factor alpha and mucocutaneous leishmaniasis. Parasitology Today, 15(2): 73-75, 1999.

BLACKWELL, J. M. et al. Immunogenetics of leishmanial and mycobacterial infections: the Belem Family Study. Philosophical Transactions of the Royal Society of London. Series B, Biological Sciences, 352(1.359): 1.331-1.345, 1997.

BRANDONISIO, O. et al. Nitric oxide production by Leishmania-infected macrophages and modulation by cytokines and prostaglandins. Parassitologia, 43, supl. 1: 1-6, 2001.

BRETSCHER, P. A.; OGUNREMI, O. \& MENON, J. N. Distinct immunological states in murine cutaneous leishmaniasis by immunising with different amounts of antigen: the generation of beneficial, potentially harmful, harmful and potentially extremely harmful states. Behring Institute Mitteilungen, 98: 153-159, 1997.

BREWIG, N. et al. Priming of $\mathrm{CD} 8+$ and $\mathrm{CD} 4+\mathrm{T}$ cells in experimental leishmaniasis is initiated by different dendritic cell subtypes. The Journal of Immunology, 182(2): 774-783, 2009.

BRINKMANN, V. et al. Neutrophil extracellular traps kill bacteria. Science, 303(5.663): 1.532-1.535, 2004.

BRODIE, T. M. et al. Immunomodulatory effects of the Lutzomyia longipalpis salivary gland protein maxadilan on mouse macrophages. Infection \& Immunity, 75(5): 2.359-2.365, 2007.

CALVOPINA, M. et al. Leishmania isoenzyme polymorphisms in Ecuador: relationships with geographic distribution and clinical presentation. BMC Infectious Diseases, 6: 139, 2006.

CARNEIRO, F. P. et al. Foxp3 expression in lesions of the different clinical forms of American tegumentary leishmaniasis. Parasite Immunology, 31(10): 646-651, 2009.

CARVALHO, L. P.; PEARCE, E. J. \& SCOTT, P. Functional dichotomy of dendritic cells following interaction with Leishmania braziliensis: infected cells produce high levels of TNF-alpha, whereas bystander dendritic cells are activated to promote T cell responses. The Journal of Immunology, 181(9): 6.473-6.480, 2008.

CARVALHO, L. P. et al. Differential immune regulation of activated T cells between cutaneous and mucosal leishmaniasis as a model for pathogenesis. Parasite Immunology, 29(5): 251-258, 2007.

CASTELLANO, L. R. et al. Th1/Th2 immune responses are associated with active cutaneous leishmaniasis and clinical cure is associated with strong interferon-gamma production. Human Immunology, 70(6): 383-390, 2009. 
CASTELLUCCI, L. et al. Familial aggregation of mucosal leishmaniasis in northeast Brazil. The American Journal of Tropical Medicine Hygiene, 73(1): 69-73, 2005.

CASTELLUCCI, L. et al. IL6 -174 G/C promoter polymorphism influences susceptibility to mucosal but not localized cutaneous leishmaniasis in Brazil. The Journal of Infectious Diseases, 194(4): 519-527, 2006.

CASTÉS, M. \& TAPIA, F. J. Immunopathology of American tegumentary leishmaniasis. Acta Científica Venezolana, 49(1): 42-56, 1998.

CHARMOY, M. et al. Neutrophil-derived CCL3 is essential for the rapid recruitment of dendritic cells to the site of Leishmania major inoculation in resistant mice. PLoS Pathogens, 6(2): e1000755, 2010.

CRUZ, A. M. et al. Cellular and humoral immune responses of a patient with American cutaneous leishmaniasis and Aids. Transactions of the Royal Society of Tropical Medicine and Hygiene, 86(5): 511-512, 1992.

CRUZ, A. M. et al. Tumor necrosis factor-alpha in human american tegumentary leishmaniasis. Memórias do Instituto Oswaldo Cruz, 91(2): 225-229, 1996.

CRUZ, A. M. et al. Atypical mucocutaneous leishmaniasis caused by Leishmania braziliensis in an acquired immunodeficiency syndrome patient: T-cell responses and remission of lesions associated with antigen immunotherapy. Memórias do Instituto Oswaldo Cruz, 94(4): 537-542, 1999.

CRUZ, A. M. et al. T-cell-mediated immune responses in patients with cutaneous or mucosal leishmaniasis: long-term evaluation after therapy. Clinical and Diagnostic Laboratory Immunology, 9(2): 251-256, 2002.

CRUZ, A. M. et al. Flow cytometric analysis of cellular infiltrate from American tegumentary leishmaniasis lesions. The British Journal of Dermatology, 153(3): 537-543, 2005.

CRUZ, A. M. et al. Immunopathologic changes in HIV-Leishmania co-infection. Revista da Sociedade Brasileira de Medicina Tropical, 39, supl. 3: 75-79, 2006.

CRUZ, A. M. et al. T cells specific to leishmania and other nonrelated microbial antigens can migrate to human leishmaniasis skin lesions. The Journal of Investigative Dermatology, 130(5): 1.329-1.336, 2010.

DE LEONARDIS, F. et al. Visceral leishmaniasis and anti-TNF-alpha therapy: case report and review of the literature. Clinical and Experimental Rheumatology, 27(3): 503-506, 2009.

DÍAZ, N. L.et al. Intermediate or chronic cutaneous leishmaniasis: leukocyte immunophenotypes and cytokine characterisation of the lesion. Experimental Dermatology, 11(1): 34-41, 2002.

DÍAZ, N. L. et al. Inducible nitric oxide synthase and cytokine pattern in lesions of patients with American cutaneous leishmaniasis. Clinical and Experimental Dermatology, 31(1): 114-117, 2006.

EJAZ, A.; RAZA, N. \& IFTIKHAR, N. Recurrent cutaneous leishmaniasis presenting as sporotrichoid abscesses: a rare presentation near Afghanistan border. Dermatology Online Journal, 13(2): 15, 2007.

ESTERRE, P. et al. Cell populations in the lesion of human cutaneous leishmaniasis: a light microscopical, immunohistochemical and ultrastructural study. Virchows Archiv. A, Pathological Anatomy and Histopathology, 421(3): 239-247, 1992.

FADOK, V. A. et al. Differential effects of apoptotic versus lysed cells on macrophage production of cytokines: role of proteases. The Journal of Immunology, 166(11): 6.847-6.854, 2001.

FAGUNDES, A. et al. First encounter of subclinical human Leishmania (Viannia) infection in State of Rio Grande do Sul, Brazil. Memórias do Instituto Oswaldo Cruz, 102(8): 1.003-1.005, 2007.

FARIA, D. R. et al. Decreased in situ expression of interleukin-10 receptor is correlated with the exacerbated inflammatory and cytotoxic responses observed in mucosal leishmaniasis. Infection \& Immunity, 73(12): 7.853-7.859, 2005.

FARIA, D. R. et al. Recruitment of CD8(+) T cells expressing granzyme A is associated with lesion progression in human cutaneous leishmaniasis. Parasite Immunology, 31(8): 432-439, 2009.

FRANKLIN, G.; GREENSPAN, J. \& CHEN, S. Anti-tumor necrosis factor-alpha therapy provokes latent leishmaniasis in a patient with rheumatoid arthritis. Annals of Clinical Laboratory Science, 39(2): 192-195, 2009. 
GAZE, S. T. et al. Mucosal leishmaniasis patients display an activated inflammatory T-cell phenotype associated with a nonbalanced monocyte population. Scandinavian Journal of Immunology, 63(1): 70-78, 2006.

GEIGER, B. et al. Resolving lesions in human cutaneous leishmaniasis predominantly harbour chemokine receptor CXCR3positive T helper 1/T cytotoxic type 1 cells. The British Journal of Dermatology, 162(4): 870-874, 2010.

GOLLOB, K. J. et al. Immunoregulatory mechanisms and CD4-CD8- (double negative) T cell subpopulations in human cutaneous leishmaniasis: a balancing act between protection and pathology. International Immunopharmacology, 8(10): 1.338-1.343, 2008.

GREENHALGH, D. G. The role of apoptosis in wound healing. The International Journal of Biochemistry \& Cell Biology, 30(9): 1.019-1.030, 1998.

GUIMARÃES-COSTA, A. B. et al. Leishmania amazonensis promastigotes induce and are killed by neutrophil extracellular traps. Proceedings of the National Academy of Sciences of the USA, 106(16): 6.748-6.753, 2009.

JOHN, B. \& HUNTER, C. A. Immunology. Neutrophil soldiers or Trojan Horses? Science, 321(5.891): 917-918, 2008.

KATOU, F. et al. Immunological activation of dermal Langerhans cells in contact with lymphocytes in a model of human inflamed skin. The American Journal of Pathology, 156(2): 519-527, 2000.

KORN, T. et al. Th17 cells: effector T cells with inflammatory properties. Seminars in Immunology, 19(6): 362-371, 2007.

KÖRNER, H. et al. The role of TNF in parasitic diseases: still more questions than answers. International Journal for Parasitology, 40(8): 879-888, 2010.

KROPF, P. et al. Toll-like receptor 4 contributes to efficient control of infection with the protozoan parasite Leishmania major. Infection \& Immunity, $72(4):$ 1.920-1.928, 2004.

LIESE, J.; SCHLEICHER, U. \& BOGDAN, C. The innate immune response against Leishmania parasites. Immunobiology, 213(3-4): 377-387, 2008.

LIEW, F. Y.; HALE, C. \& HOWARD, J. G. Prophylactic immunization against experimental leishmaniasis. IV. Subcutaneous immunization prevents the induction of protective immunity against fatal Leishmania major infection. The Journal of Immunology, 135(3): 2.095-2.101, 1985.

LIMA, G. M. et al. The role of polymorphonuclear leukocytes in the resistance to cutaneous Leishmaniasis. Immunology Letters, 64(2-3): 145-151, 1998.

LIMA, H. C. et al. American cutaneous leishmaniasis: in situ characterization of the cellular immune response with time. The American Journal of Tropical Medicine Hygiene, 50(6): 743-747, 1994.

LINDOSO, J. A. L. et al. Unusual manifestations of tegumentary leishmaniasis in Aids patients from the New World. The British Journal of Dermatology, 160(2): 311-318, 2009.

LOCKSLEY, R. M. et al. Induction of Th1 and Th2 CD4+ subsets during murine Leishmania major infection. Research in Immunology, 142(1): 28-32, 1991.

LODGE, R. et al. HIV-1 Promotes intake of Leishmania parasites by enhancing phosphatidylserine-mediated, CD91/LRP-1dependent phagocytosis in human macrophages. PLoS One, 7(3): e32.761, 2012.

LÓPEZ-ESCOBAR, M. et al. Sporotrichoid cutaneous leishmaniasis. Actas Dermo-Sifiliográficas, 98(6): 444-445, 2007.

MACHADO-COELHO, G. L. L. et al. Risk factors for mucosal manifestation of American cutaneous leishmaniasis. Transactions of the Royal Society of Tropical Medicine and Hygiene, 99(1): 55-61, 2005.

MALAFAIA, G. Protein-energy malnutrition as a risk factor for visceral leishmaniasis: a review. Parasite Immunology, 31(10): 587-596, 2009.

MARETTI-MIRA, A. C. et al. Therapeutic failure in American cutaneous leishmaniasis is associated with gelatinase activity and cytokine expression. Clinical and Experimental Immunology, 163(2): 207-214, 2011a.

MARETTI-MIRA, A. C. et al. MMP-9 activity is induced by Leishmania braziliensis infection and correlates with mucosal leishmaniasis. Acta Tropica, 119(2-3): 160-164, $2011 \mathrm{~b}$. 
MARZOUKI, S. et al. Characterization of the antibody response to the saliva of Phlebotomus papatasi in people living in endemic areas of cutaneous leishmaniasis. The American Journal of Tropical Medicine Hygiene, 84(5): 653-661, 2011.

MASMOUDI, A. et al. Sporotrichoid cutaneous leishmaniasis in Tunisia: a clinical and histological study. Annales de Dermatologie et de Vénéréologie, 135(1): 63-67, 2008.

MATTA, N. E. et al. Leishmania (Viannia) guyanensis induces low immunologic responsiveness in leishmaniasis patients from an endemic area of the Brazilian Amazon Highland. The American Journal of Tropical Medicine Hygiene, 80(3): 339-344, 2009.

MAURER, M. et al. Skin mast cells control T cell-dependent host defense in Leishmania major infections. Faseb Journal, 20(14): 2.460-2.467, 2006.

MAURER, M.; DONDJI, B. \& VON STEBUT, E. What determines the success or failure of intracellular cutaneous parasites? Lessons learned from leishmaniasis. Medical Microbiology and Immunology, 198(3): 137-146, 2009.

MEDEIROS, A. R.; SILVA, W. A. \& ROSELINO, A. M. DNA sequencing confirms the involvement of Leishmania (L.) amazonensis in American tegumentary leishmaniasis in the state of São Paulo, Brazil. Clinics (São Paulo), 63(4): 451-456, 2008.

MELBY, P. C. et al. The hamster as a model of human visceral leishmaniasis: progressive disease and impaired generation of nitric oxide in the face of a prominent Th1-like cytokine response. The Journal of Immunology, 166(3): 1.912-1.920, 2001.

MENDES-AGUIAR, C. D. O. et al. The skin homing receptor cutaneous leucocyte-associated antigen (CLA) is up-regulated by Leishmania antigens in T lymphocytes during active cutaneous leishmaniasis. Clinical and Experimental Immunology, 157(3): 377-384, 2009.

MÉNDEZ, S. et al. The potency and durability of DNA- and protein-based vaccines against Leishmania major evaluated using low-dose, intradermal challenge. The Journal of Immunology, 166(8): 5.122-5.128, 2001.

MICHEL, T. \& FERON, O. Nitric oxide synthases: which, where, how, and why? The Journal of Clinical Investigation, 100(9): 2.146-2.152, 1997.

MILLER, L. S. Toll-like receptors in skin. Advances in Dermatology, 24: 71-87, 2008.

MODLIN, R. L. \& CHENG, G. From plankton to pathogen recognition. Nature Medicine, 10(11): 1.173-1.174, 2004.

MOLL, H.; FLOHÉ, S. \& RÖLLINGHOFF, M. Dendritic cells in Leishmania major-immune mice harbor persistent parasites and mediate an antigen-specific T cell immune response. European Journal of Immunology, 25(3): 693-699, 1995.

MOLL, H. et al. Langerhans cells transport Leishmania major from the infected skin to the draining lymph node for presentation to antigen-specific T cells. European Journal of Immunology, 23(7): 1.595-1.601, 1993.

MORGADO, F. N. et al. Is the in situ inflammatory reaction an important tool to understand the cellular immune response in American tegumentary leishmaniasis? The British Journal of Dermatology, 158(1): 50-58, 2008.

MORGADO, F. N. et al. Signs of an in situ inflammatory reaction in scars of human American tegumentary leishmaniasis. Parasite Immunology, 32(4): 285-295, 2010.

MOTTET, C. \& GOLSHAYAN, D. CD4+CD25+Foxp3+ regulatory T cells: from basic research to potential therapeutic use. Swiss Medical Weekly, 137(45-46): 625-634, 2007.

MOURA, T. R. et al. Toward a novel experimental model of infection to study American cutaneous leishmaniasis caused by Leishmania braziliensis. Infection \& Immunity, 73(9): 5.827-5.834, 2005.

MOURA, T. R. et al. Enhanced Leishmania braziliensis infection following pre-exposure to sandfly saliva. PLoS Neglected Tropical Diseases, 1(2): e84, 2007.

NATHAN, C. Neutrophils and immunity: challenges and opportunities. Nature Reviews. Immunology, 6(3): 173-182, 2006.

NEWLOVE, T. et al. Antihelminthic therapy and antimony in cutaneous leishmaniasis: a randomized, double-blind, placebocontrolled trial in patients co-infected with helminths and Leishmania braziliensis. The American Journal of Tropical Medicine Hygiene, 84(4): 551-555, 2011. 
NOVAIS, F. O. et al. Neutrophils and macrophages cooperate in host resistance against Leishmania braziliensis infection. The Journal of Immunology, 183(12): 8.088-8.098, 2009.

OGHUMU, S. et al. Role of chemokines in regulation of immunity against leishmaniasis. Experimental Parasitology, 126(3): 389-396, 2010.

OLIVEIRA, M. P. et al. Leishmania (Viannia) braziliensis: human mast cell line activation induced by logarithmic and stationary promastigote derived-lysates. Experimental Parasitology, 109(2): 72-79, 2005.

OLIVEIRA CARDOSO, F. et al. Immunopathological studies of Leishmania amazonensis infection in resistant and in susceptible mice. The Journal of Infectious Diseases, 201(12): 1.933-1.940, 2010.

O'NEAL, S. E. et al. Influence of helminth infections on the clinical course of and immune response to Leishmania braziliensis cutaneous leishmaniasis. The Journal of Infectious Diseases, 195(1): 142-148, 2007.

OVERBECK, S.; RINK, L. \& HAASE, H. Modulating the immune response by oral zinc supplementation: a single approach for multiple diseases. Archivum Immunologiae et Therapiae Experimentalis (Warsz), 56(1): 15-30, 2008.

PALMEIRO, M. R. et al. Comparative study of the in situ immune response in oral and nasal mucosal leishmaniasis. Parasite Immunology, 34(1): 23-31, 2012.

PEREIRA, L. I. A. et al. Increase of NK cells and proinflammatory monocytes are associated with the clinical improvement of diffuse cutaneous leishmaniasis after immunochemotherapy with BCG/Leishmania antigens. The American Journal of Tropical Medicine Hygiene, 81(3): 378-383, 2009.

PETERS, N. C. \& SACKS, D. L. The impact of vector-mediated neutrophil recruitment on cutaneous leishmaniasis. Cellular Microbiology, 11(9): 1.290-1.296, 2009.

PETERS, N. C. et al. In vivo imaging reveals an essential role for neutrophils in leishmaniasis transmitted by sand flies. Science, 321(5.891): 970-974, 2008.

PIRMEZ, C. et al. Cytokine patterns in the pathogenesis of human leishmaniasis. The Journal of Clinical Investigation, 91(4): 1.390-1.395, 1993.

PITTA, M. G. R. et al. IL-17 and IL-22 are associated with protection against human kala azar caused by Leishmania donovani. The Journal of Clinical Investigation, 119(8): 2.379-2.387, 2009.

PRASAD, A. S. Zinc: role in immunity, oxidative stress and chronic inflammation. Current Opinion in Clinical Nutrition and Metabolic Care, 12 (6): 646-652, 2009.

PRATES, D. B. et al. Lutzomyia longipalpis saliva drives apoptosis and enhances parasite burden in neutrophils. Journal of Leukocyte Biology, 90(3): 575-582, 2011.

QADOUMI, M. et al. Expression of inducible nitric oxide synthase in skin lesions of patients with American cutaneous leishmaniasis. Infection \& Immunity, 70(8): 4.638-4.642, 2002.

RAMASAWMY, R. et al. The -2518bp promoter polymorphism at CCL2/MCP1 influences susceptibility to mucosal but not localized cutaneous leishmaniasis in Brazil. Infection, Genetics and Evolution, 10(5): 607-613, 2010.

REED, S. G. \& SCOTT, P. T-cell and cytokine responses in leishmaniasis. Current Opinion in Immunology, 5(4): 524-531, 1993.

RENN, C. N. et al. TLR activation of Langerhans cell-like dendritic cells triggers an antiviral immune response. The Journal of Immunology, 177(1): 298-305, 2006.

RIBEIRO, J. M. Blood-feeding arthropods: live syringes or invertebrate pharmacologists? Infectious Agents and Disease, 4(3): 143-152, 1995.

RIBEIRO-DE-JESUS, A. et al. Cytokine profile and pathology in human leishmaniasis. Brazilian Journal of Medical and Biological Research, 31(1): 143-148, 1998.

RIBEIRO-GOMES, F. L.; SILVA, M. T. \& DOSREIS, G. A. Neutrophils, apoptosis and phagocytic clearance: an innate sequence of cellular responses regulating intramacrophagic parasite infections. Parasitology, 132, supl: S61-S68, 2006. 
RIBEIRO-GOMES, F. L. et al. Macrophage interactions with neutrophils regulate Leishmania major infection. The Journal of Immunology, 172(7): 4.454-4.462, 2004.

RIBEIRO-GOMES, F. L. et al. Neutrophils activate macrophages for intracellular killing of Leishmania major through recruitment of TLR4 by neutrophil elastase. The Journal of Immunology, 179(6): 3.988-3.994, 2007.

RITTER, U. \& KÖRNER, H. Divergent expression of inflammatory dermal chemokines in cutaneous leishmaniasis. Parasite Immunology, 24(6): 295-301, 2002.

RITTER, U. \& OSTERLOH, A. A new view on cutaneous dendritic cell subsets in experimental leishmaniasis. Medical Microbiology and Immunology, 196(1): 51-59, 2007.

RODRIGUES, K. M. P. et al. Influence of the Notch system in the therapeutic response of American tegumentary leishmaniasis. The British Journal of Dermatology, 164(6): 1.228-1.234, 2011.

ROGERS, K. A. et al. Type 1 and type 2 responses to Leishmania major. Fems Microbiology Letters, 209(1): 1-7, 2002.

ROGERS, M. et al. Proteophosophoglycans regurgitated by Leishmania-infected sand flies target the L-arginine metabolism of host macrophages to promote parasite survival. PLoS Pathogens, 5(8): e1000555, 2009.

ROLÃO, N.; MELO, C. \& CAMPINO, L. Influence of the inoculation route in BALB/c mice infected by Leishmania infantum. Acta Tropica, 90(1): 123-126, 2004.

ROMAGNANI, S. Human TH1 and TH2 subsets: doubt no more. Immunology Today, 12(8): 256-257, 1991.

SACKS, D. \& NOBEN-TRAUTH, N. The immunology of susceptibility and resistance to Leishmania major in mice. Nature Reviews. Immunology, 2(11): 845-858, 2002.

SCHARTON-KERSTEN, T. et al. IL-12 is required for natural killer cell activation and subsequent T helper 1 cell development in experimental leishmaniasis. The Journal of Immunology, 154(10): 5.320-5.330, 1995.

SCHLEICHER, U. et al. Control of Leishmania major in the absence of Tyk2 kinase. European Journal of Immunology, 34(2): 519-529, 2004.

SCHLEICHER, U. et al. NK cell activation in visceral leishmaniasis requires TLR9, myeloid DCs, and IL-12, but is independent of plasmacytoid DCs. The Journal of Experimental Medicine, 204(4): 893-906, 2007.

SCHRIEFER, A. et al. Geographic clustering of leishmaniasis in northeastern Brazil. Emerging Infectious Disease, 15(6): 871-876, 2009.

SCOTT, P. IFN-gamma modulates the early development of Th1 and Th2 responses in a murine model of cutaneous leishmaniasis. The Journal of Immunology, 147(9): 3.149-3.155, 1991.

SILVEIRA, F. T. et al. Reviewing the role of the dendritic Langerhans cells in the immunopathogenesis of American cutaneous leishmaniasis. Transactions of the Royal Society of Tropical Medicine and Hygiene, 102(11): 1.075-1.080, 2008.

SILVEIRA, F. T. et al. A prospective study on the dynamics of the clinical and immunological evolution of human Leishmania (L.) infantum chagasi infection in the Brazilian Amazon region. Transactions of the Royal Society of Tropical Medicine and Hygiene, 104(8): 529-535, 2010.

SOARES, M. B. et al. The vasoactive peptide maxadilan from sand fly saliva inhibits TNF-alpha and induces IL-6 by mouse macrophages through interaction with the pituitary adenylate cyclase-activating polypeptide (PACAP) receptor. The Journal of Immunology, 160(4): 1.811-1.816, 1998.

SOARES-BEZERRA, R. J. et al. Effect of mesoionic 4-phenyl-5-(cinnamoyl)-1, 3, 4-thiadiazolium-2-phenylamine chloride derivative salts on the activities of the nitric oxide synthase and arginase of Leishmania amazonensis. Journal of Enzyme Inhibition and Medicinal Chemistry, 23(3): 328-333, 2008.

STENGER, S. et al. Reactivation of latent leishmaniasis by inhibition of inducible nitric oxide synthase. The Journal of Experimental Medicine, 183(4): 1.501-1.514, 1996.

STOCKINGER, B. \& VELDHOEN, M. Differentiation and function of Th17 T cells. Current Opinion in Immunology, 19(3): 281-286, 2007. 
SVENSJÖ, E. et al. Salivary gland homogenates of Lutzomyia longipalpis and its vasodilatory peptide maxadilan cause plasma leakage via PAC1 receptor activation. Journal of Vascular Research, 46(5): 435-446, 2009.

TACCHINI-COTTIER, F. et al. An immunomodulatory function for neutrophils during the induction of a CD4+ Th2 response in BALB/c mice infected with Leishmania major. The Journal of Immunology, 165(5): 2.628-2.636, 2000.

TAVARES, N. M. et al. Lutzomyia longipalpis saliva or salivary protein LJM19 protects against Leishmania braziliensis and the saliva of its vector, Lutzomyia intermedia. PLoS Neglected Tropical Diseases, 5(5): e1169, 2011.

TEIXEIRA, M. J. et al. Chemokines in host-parasite interactions in leishmaniasis. Trends in Parasitology, 22 (1): 32-40, 2006.

TITUS, R. G. \& RIBEIRO, J. M. Salivary gland lysates from the sand fly Lutzomyia longipalpis enhance Leishmania infectivity. Science, 239(4.845): 1.306-1.308, 1988

TITUS, R. G.; SHERRY, B. \& CERAMI, A. Tumor necrosis factor plays a protective role in experimental murine cutaneous leishmaniasis. The Journal of Experimental Medicine, 170(6): 2.097-2.104, 1989.

TOJAL DA SILVA, A. C. et al. Species diversity causing human cutaneous leishmaniasis in Rio Branco, state of Acre, Brazil. Tropical Medicine \& International Health: TM \& IH, 11(9): 1.388-1.398, 2006.

TRINCHIERI, G.; PFLANZ, S. \& KASTELEIN, R. A. The IL-12 family of heterodimeric cytokines: new players in the regulation of T cell responses. Immunity, 19(5): 641-644, 2003.

TUON, F. F. et al. Local immunological factors associated with recurrence of mucosal leishmaniasis. Clinical Immunology, 128(3): 442-446, 2008.

VAN WEYENBERGH, J. et al. Zinc/copper imbalance reflects immune dysfunction in human leishmaniasis: an ex vivo and in vitro study. BMC Infectious Diseases, 4: 50, 2004.

VAN ZANDBERGEN, G. et al. Cutting edge: neutrophil granulocyte serves as a vector for Leishmania entry into macrophages. The Journal of Immunology, 173(11): 6.521-6.525, 2004.

VARGAS-INCHAUSTEGUI, D. A. et al. Distinct roles for MyD88 and Toll-like receptor 2 during Leishmania braziliensis infection in mice. Infection \& Immunity, 77(7): 2.948-2.956, 2009.

VENDRAME, C. M. V. et al. Effect of insulin-like growth factor-I on Leishmania amazonensis promastigote arginase activation and reciprocal inhibition of NOS2 pathway in macrophage in vitro. Scandinavian Journal of Immunology, 66(2-3): 287296, 2007.

VENDRAME, C. M. V. et al. Insulin-like growth factor-I induced and constitutive arginase activity differs among isolates of Leishmania derived from patients with diverse clinical forms of Leishmania braziliensis infection. Transactions of the Royal Society of Tropical Medicine and Hygiene, 104(8): 566-568, 2010.

VON KÖCKRITZ-BLICKWEDE, M. \& NIZET, V. Innate immunity turned inside-out: antimicrobial defense by phagocyte extracellular traps. Journal of Molecular Medicine, 87(8): 775-783, 2009.

WARBURG, A. et al. Saliva of Lutzomyia longipalpis sibling species differs in its composition and capacity to enhance leishmaniasis. Philosophical Transactions of the Royal Society of London. Series B, Biological Sciences, 345(1.312): 223-230, 1994.

WARTHA, F. \& HENRIQUES-NORMARK, B. ETosis: a novel cell death pathway. Science Signaling, 1(21): pe25, 2008.

WERSHIL, B. K. et al. Mast cell-dependent neutrophil and mononuclear cell recruitment in immunoglobulin E-induced gastric reactions in mice. Gastroenterology, 110(5): 1.482-1.490, 1996. 


\title{
Resposta Imune Celular no Processo de Cura da Leishmaniose Tegumentar Americana
}

\author{
Adriano Gomes-Silva I Alda Maria Da-Cruz I Claude Pirmez \\ Eduardo Fonseca Pinto I Márcia Pereira-Oliveira
}

\begin{abstract}
A infecção por protozoários dermotrópicos do gênero Leishmania leva a diferentes desfechos clínicos, sendo o grau de acometimento tecidual diretamente relacionado aos mecanismos patogênicos que se estabelecem em decorrência da interação entre o parasito, o vetor e o hospedeiro. Existem evidências de que a infecção por Leishmania, à semelhança do que ocorre em determinadas doenças parasitárias, como a toxoplasmose, induz a uma imunidade duradoura, capaz de controlar o patógeno. O fato de haver persistência parasitária possibilita que o sistema imune seja constantemente estimulado, mantendo assim o pool de células efetoras específicas aos antígenos de Leishmania, configurando uma imunidade concomitante, a qual seria perdida caso o hospedeiro eliminasse por completo a presença do parasito. Entretanto, tem-se observado que hospedeiros infectados por Leishmania são capazes de produzir uma verdadeira memória imunológica baseada, sobretudo, em células de memória central (Coutinho et al., 2002; Scott et al., 2004; Zaph et al., 2004; Scott, 2005; Gollob, Antonelli \& Dutra, 2005; Bogdan, 2008; Okwor \& Uzonna, 2008). As características funcionais e quantitativas das células efetoras que se perpetuam na circulação após a remissão clínica devem exercer relevante papel no estabelecimento da homeostasia do organismo na fase de cura da leishmaniose. Assim, a definição do perfil de resposta imune relacionada à cura clínica pode auxiliar a estabelecer parâmetros laboratoriais associados a diferentes desfechos clínicos (cura clínica, reativação, evolução com disseminação cutânea ou forma mucosa), tendo o potencial de auxiliar na avaliação do prognóstico da leishmaniose tegumentar americana (LTA).

A maioria dos estudos imunológicos sobre a leishmaniose que ocorre nas Américas busca entender os mecanismos associados ao desenvolvimento da lesão, sendo menos frequentes aqueles que analisam os fenômenos subjacentes ao controle da infecção e à remissão da reação inflamatória tecidual (Ribeiro-de-Jesus et al., 1998; Amato, Andrade \& Duarte, 2003). Além disso, a infecção por L. (Viannia) braziliensis é a mais estudada, com poucas contribuições relativas a infecções por outras espécies dermotrópicas de importância epidemiológica como a L. (V.) guyanensis (Romero et al., 2005; Matta et al., 2009) e a L. (Leishmania) amazonensis (Silveira et al., 2009). Neste capítulo, abordaremos as características imunológicas associadas à cura da leishmaniose e a resposta imune duradoura que se estabelece após a remissão do processo imunopatogênico.
\end{abstract}




\section{DESFECHOS CLÍNICOS NA LEISHMANIOSE TEGUMENTAR AMERICANA}

Estima-se que cerca de $40 \%$ dos indivíduos infectados por Leishmania não desenvolvam a doença, os quais caracterizam a forma assintomática ou subclínica. Dentre os que apresentam doença na infecção por L. braziliensis, a leishmaniose cutânea (LC) é a forma clínica mais comum, sendo que as lesões tendem a ser únicas, havendo ainda casos em que estas são numerosas ou mesmo disseminadas pelo tegumento.

A leishmaniose cutânea é em geral benigna, sendo curada com o uso de drogas leishmanicidas ou mesmo espontaneamente. O processo de cicatrização é lento, com persistência do infiltrado inflamatório e parasitos nos tecidos por longo período pós-cura (Schubach et al., 1998; Morgado et al., 2010). A reconstituição do tecido cutâneo por fibrose produz cicatrizes bastante características, que podem permanecer nesse estágio durante toda a vida. A infecção primária, aparente ou não, induz a uma imunidade que tende a ser duradoura (Da-Cruz et al., 2002), sendo creditada a ela a propriedade de controlar o patógeno, protegendo os indivíduos de reativação ou reinfecções. Entretanto, há casos que evoluem com reativação da infecção, havendo o surgimento de novas lesões, geralmente em bordos da cicatriz, conhecido como leishmaniose recidiva cútis (Oliveira-Neto et al., 1998).

As lesões cutâneas também podem surgir em diferentes locais da úlcera inicial, sugerindo uma disseminação hematogênica a partir de um sítio primário, que poderia ser a própria cicatriz ou mesmo o linfonodo drenante, já que este último é precocemente acometido pela infecção (Coutinho, Pirmez \& Da-Cruz, 2002; Barral et al., 1995; Schubach et al., 1998; Oliveira-Camera et al., 2006). O acometimento da mucosa de vias aéreas superiores ocorre, sobretudo, na infecção por L. braziliensis, seja ela assintomática ou não, havendo evidências de que a metástase do parasito para esse sítio possa ocorrer precocemente, ainda durante o evento primário (Pessôa \& Barreto, 1948). Por sua vez, o tratamento inadequado é considerado um fator predisponente para o desenvolvimento de leishmaniose mucosa (LM). A evolução para a LM ocorre em média após 4,5 anos (Zajtchuk et al., 1989). A resposta ao tratamento na LM é boa, mas as recidivas são frequentes, havendo variações regionais.

Há evidências de que os mecanismos patogênicos que são induzidos durante a doença ativa imprimem no organismo um grau de responsividade das células aos antígenos parasitários que é mantido mesmo após a cura clínica, provavelmente de forma equilibrada por mecanismos reguladores (Matos et al., 2007; Tuon et al., 2008). Fatores que levem à ruptura dessa relação podem favorecer a replicação parasitária ou propiciar a expansão de células efetoras capazes de induzir lesão tecidual, causando como consequência a reativação da infecção ou a suscetibilidade a reinfecções.

\section{SUBCLASSES DE IMUNOGLOBULINAS ANTI-LEISHMANIA}

O perfil de produção de classes e subclasses de imunoglobulinas anti-Leishmania durante as fases de doença ativa e após a cura da LTA tem sido descrito por vários autores (Souza et al., 2005; Gomes-Silva et al., 2008; Pissinate et al., 2008; Barroso-Freitas et al., 2009; Castellano et al., 2009). Acredita-se que a concentração de anticorpos específicos ao patógeno seja diretamente proporcional à carga parasitária e ao tempo de exposição aos antígenos de Leishmania (Gutierrez et al., 1991). Isso pode explicar por que pacientes com a forma mucosa da doença apresentam níveis mais elevados de imunoglobulinas específicas quando comparada com a LC (Junqueira et al., 2003). Embora o verdadeiro papel das imunoglobulinas na LTA não seja bem compreendido, há evidências que demonstram uma diminuição dos níveis séricos das imunoglobulinas IgG total, específica aos antígenos de Leishmania, após o controle da infecção parasitária (Mendonça et al., 1988; Brito et al., 2001; Castellano et al., 2009).

A análise prospectiva dos níveis das subclasses de IgG reativas a antígenos de Leishmania produzidas por pacientes com LC, acompanhada ao longo de diferentes períodos de tempo pós-tratamento, mostra que há uma importante 
diminuição dos índices de deteç̧ão de IgG1 e IgG3 anti-Leishmania após a cura clínica (Fagundes-Silva et al., 2012). Além disso, estas subclasses, quando comparadas à IgG total, apresentam uma curva de decaimento de positividade ante o antígeno de Leishmania bem mais expressiva ao longo do tempo de cura, tendendo a se tornar negativa na grande maioria dos indivíduos com mais de dois anos de cura clínica estável, ou seja, naqueles que não apresentaram episódios de reativação da doença.

Tais resultados são consoantes com a demonstração de redução dos antígenos de Leishmania por provável controle da carga parasitária, possivelmente seguida de redução da celularidade em cicatrizes de LC (Morgado et al., 2010). Todavia, resultados preliminares mostram pacientes que sofreram episódios de reativação da doença ao longo do período de acompanhamento clínico, que exibiram um aumento significativo dos níveis séricos ('índice Elisa') de IgG1, os quais regrediram novamente após intervenção terapêutica e cicatrização da lesão (Fagundes-Silva et al., dados não publicados). Também já foi observado que a IgG3 é a primeira imunoglobulina a apresentar diminuição antígenoespecífica dos títulos séricos em indivíduos LM após o tratamento (Junqueira et al., 2003).

Dessa forma, a mensuração dos níveis de IgG1 e IgG3 demonstra ter uma importante associação com o prognóstico desses indivíduos. Nos casos de manifestações clínicas mais graves, como a leishmaniose mucosa, são verificados níveis significativamente mais elevados de imunoglobulinas específicas (Valli et al., 1999; Junqueira et al., 2003), portanto, pacientes que mantêm níveis elevados de anticorpos anti-Leishmania ao longo do tempo pós-cura clínica devem ser considerados casos com risco provável de evoluir para formas mais graves da doença. Assim, os níveis séricos elevados das subclasses de Igs devem ser associados à indução principalmente de células $\mathrm{T} \mathrm{CD}^{+}$de perfil 1 , as quais auxiliam no processo de indução de linfócitos B para produzirem as subclasses de imunoglobulinas, como a IgG1.

\section{RESPOSTA IMUNE CELULAR DURADOURA}

Os linfócitos T efetores específicos aos antígenos de Leishmania estão presentes nos sítios inflamatórios e devem participar dos mecanismos imunológicos necessários para conter a replicação do parasito (Pirmez et al., 1990; Conceição-Silva et al., 1990; Da-Cruz et al., 2010). No entanto, sabe-se que a atividade funcional dessas células também pode resultar na geração de eventos patogênicos que resultam em dano ao tecido hospedeiro. Apesar de a lesão estar primordialmente confinada à pele, observa-se que há uma repercussão sistêmica, posto que há um aumento do percentual de células sanguíneas $\mathrm{T} \mathrm{CD}^{+}{ }^{+} \mathrm{CD} 69^{+}$, portanto recentemente ativadas. Tais células estão percentualmente mais elevadas nos casos de lesões cutâneas de maior diâmetro como também nos pacientes de LM, corroborando a associação dessas células com a gravidade da doença (Antonelli et al., 2005; Carvalho et al., 2007).

Durante a fase ativa da LC há um maior percentual de linfócitos T CD4+ reativos aos antígenos de Leishmania no sangue periférico, quando comparado aos linfócitos T $\mathrm{CD} 8^{+}$. O processo de cura clínica resulta em aumento de TCD $8^{+}$, sugerindo a participação dessas células durante o evento de cicatrização da LC (Coutinho, Pirmez \& Da-Cruz, 2002; Da-Cruz et al., 1994; Toledo et al., 2001). Além disso, logo após o processo de cicatrização também se observou no sangue periférico um aumento significante do percentual de células T $\mathrm{CD} 8^{+}$produtoras de IFN- $\gamma$, quando comparado ao período pré-tratamento (Toledo et al., 2001).

Outra evidência da participação dessas células na cura clínica é o fato de as lesões que evoluíram para cura espontânea terem exibido um percentual de linfócitos $\mathrm{T} \mathrm{CD} 8^{+}$em apoptose mais baixo, portanto com maior sobrevida do que as tratadas com antimonial (Bertho et al., 2000). Tais resultados sugerem que essa subpopulação de linfócito T deve participar do processo de cura, com provável ação citotóxica ante as células infectadas. Por sua vez, observouse que pacientes com LM apresentam atividade citotóxica mais elevada de T CD8 ${ }^{+}$específico à Leishmania ante macrófagos infectados, quando comparados com casos de LC (Brodskyn et al., 1997). 
Após um ano do término do tratamento há uma redução das subpopulações de linfócitos T reativos aos antígenos de Leishmania (Cruz et al., 2002). O percentual de células T recém-ativadas ante os antígenos de Leishmania está correlacionado negativamente com o tempo de cura, tanto para T CD4+ quanto para T CD8 (Pereira-Carvalho et al., 2013). Em paralelo, a ativação dos linfócitos com antígenos de Leishmania aumenta a expressão de moléculas que os direcionam para o sítio inflamatório, como o antígeno leucocitário associado à pele (CLA, do inglês cutaneous lymphocyte-associated antigen), possibilitando-as transmigrar e contribuir para a formação do infiltrado inflamatório. No entanto, o percentual de linfócitos T expressando o CLA na membrana se reduz após a cura clínica, sugerindo que a diminuição da capacidade de migração para a pele deve favorecer a resolução da lesão, sendo relacionada a um bom prognóstico da doença (Mendes-Aguiar et al., 2009).

Considerando as características de diferenciação linfocitária, as células que são expandidas após estímulo antigênico podem ser de dois tipos - memória efetora $\left(\mathrm{T}_{\mathrm{ME}}\right)$ e memória central $\left(\mathrm{T}_{\mathrm{MC}}\right)$-, sendo a primeira capaz de migrar para os tecidos e responder mais imediatamente ante o antígeno específico (Esser et al., 2003). Desse modo, a população $\mathrm{T}_{\mathrm{ME}}$ é capaz de controlar prováveis replicações parasitárias e a disseminação da infecção mediante um ambiente de citocinas inflamatórias como IFN- $\gamma$ e TNF. A segunda população de células de memória apresenta uma longevidade maior e não necessita de estimulação antigênica continuada. Essas $\mathrm{T}_{\mathrm{Mc}}$ apresentam moléculas que as direcionam para os órgãos linfoides secundários, onde respondem em grande magnitude, com expansão clonal e geração de células filhas capazes de exercer funções efetoras quando entrarem novamente em contato com o antígeno específico (Esser et al., 2003).

A manutenção de células de memória específicas aos antígenos de Leishmania tem sido descrita principalmente em modelos experimentais, nos quais se tem observado uma resposta imune protetora por longo tempo de forma independente da estimulação antigênica (Zaph et al., 2004). Porém, ainda são desconhecidos os mecanismos envolvidos na geração e manutenção dessas células de memória. Dentre as várias hipóteses, acredita-se que para a formação de células $\mathrm{T}_{\mathrm{M}}$, após o estímulo com os antígenos de Leishmania, faz-se necessária a atuação de mecanismos regulatórios, como por exemplo, a participação de moléculas como CTLA-4, que resulta na diminuição dos níveis de ativação da resposta celular específica (Zaph et al., 2004; Gollob, Antonelli \& Dutra, 2005; Gollob et al., 2008). Nesse contexto, uma provável redução gradativa da intensidade de resposta imune Leishmania-específica de forma dependente do tempo de cura parece contribuir para que esses indivíduos desenvolvam células de memória com características de $\mathrm{T}_{\mathrm{MC}}$, embora a persistência parasitária seja fato comprovado.

Em conjunto, tais resultados sugerem que há uma diminuição da intensidade de resposta imune, tanto celular quanto humoral, associada com a estabilidade da cura clínica. Essa diminuição gradativa da reatividade de linfócitos específicos ainda não é bem entendida, mas parece ser resultado de um processo de reorganização da resposta imune específica, podendo ocorrer tanto em função de uma redução gradativa da carga parasitária e consequente diminuição da estimulação antigênica quanto a esgotamento de clones específicos. Após a cura clínica estável da LTA é possível que a maioria das células T efetoras morra por apoptose, enquanto um pequeno número de linfócitos remanescentes, resistentes à morte programada, permaneça como células de memória.

As diferentes formas clínicas da LTA têm sido associadas ao perfil de produção de citocinas. Na LC, forma clínica considerada benigna, a infecção induz uma resposta imune adaptativa caracterizada por um perfil misto de produção de

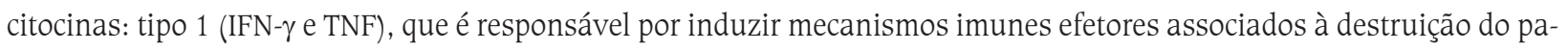
rasito, mas que também pode levar ao dano tecidual; tipo 2, em que há produção de citocinas (IL-5, IL-4 e IL-10) que podem favorecer a replicação do parasito no macrófago, mas que também são importantes para contrabalancear os efeitos inflamatórios (Coutinho, Pirmez \& Da-Cruz, 2002; Pirmez et al., 1993; Coutinho et al., 1996; Da-Cruz \& Pirmez, 2013).

Evidências sugerem que indivíduos portadores de um prognóstico favorável ante a infecção por Leishmania devem apresentar um balanço harmônico entre a resposta inflamatória e a regulatória, o que foi demonstrado pela produção 
equilibrada de IFN- $\gamma$ e IL-10 vista em pacientes com desfecho clínico favorável (Bittar et al., 2007; Gomes-Silva et al., 2007; Tuon et al., 2008). É importante chamar a atenção para o papel dicotômico da IL-10, que embora apresente funções significativas no favorecimento da replicação parasitária, também atua na imunorregulação, imprescindível para evitar uma exacerbação da resposta inflamatória, como a que ocorre nos indivíduos com a forma mucosa.

Nesse sentido, a cura espontânea da LC em primatas não humanos infectados com L. braziliensis coincide com o aumento de células $\mathrm{T} \mathrm{CD} 4{ }^{+} \mathrm{CD} 25^{+}$produtoras de IL-10 na lesão (Souza-Lemos et al., 2008). o percentual de células $\mathrm{T}$ do sangue, com fenótipo $\mathrm{CD} 4{ }^{+} \mathrm{CD} 25^{+} \mathrm{FOXP3}^{+}$produtoras de IL-10, não difere entre indivíduos assintomáticos, curados após tratamento ou durante a doença ativa (Salhi et al., 2008). Possivelmente para células T reguladoras a avaliação do percentual no sangue periférico não reflita de forma fidedigna o efeito que elas podem apresentar no sítio inflamatório. Já em humanos não se constatou diferenças entre o percentual de linfócitos Treg $\mathrm{CD}^{+} \mathrm{CD}_{2} 5^{+}$no sangue de indivíduos LC e de indivíduos-controle não infectados. No entanto, a capacidade imunorreguladora das células provenientes de indivíduos LC pode ser mais robusta em razão de maior expressão de CTLA-4, molécula importante no contato célula-célula (Campanelli et al., 2006). É provável que nos indivíduos com desfecho clínico favorável uma atuação de células Treg em número ou intensidade de ação moderados possa conferir uma resposta imune adaptativa capaz de conter a ação do parasito e em adição impedir que mecanismos de natureza inflamatória atinjam proporções excessivas a ponto de levarem a uma lesão tecidual.

O controle da carga parasitária e a redução da ação de células inflamatórias são eventos que antecedem o processo de remodelamento do tecido e formação da cicatriz. Assim, teoricamente os indivíduos com deficiência em regular a resposta inflamatória desencadeada pelo parasito estarão mais predispostos a evoluir para quadros clínicos crônicos, ou seja, com maior tempo de evolução da lesão. Nesse contexto, os indivíduos com LM que mantêm altos níveis de produção de IFN- $\gamma$ em resposta a antígenos de Leishmania, mesmo anos após a cura clínica, foram os que apresentaram os mais longos tempos de duração entre o surgimento da lesão mucosa e a confirmação diagnóstica. A capacidade de produzir IFN- $\gamma$ em indivíduos LC parece estar relacionada ao polimorfismo genético, ao menos com relação à região +874 , já que houve associação entre a secreção dessa citocina e os genótipos associados à alta e à baixa produção de

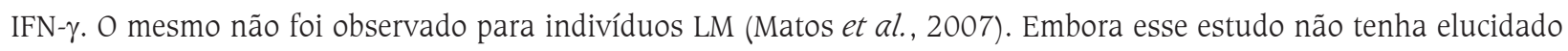
com bases genéticas a causa pela qual indivíduos curados de LM permanecem altos produtores de IFN- $\gamma$, é possível que essa, ou o conjunto dessas mutações pontuais, em associação com outros fatores, possa contribuir para a excessiva programação dos clones de linfócitos específicos em permanecerem secretores de elevados níveis de citocinas do tipo 1, mesmo após o estabelecimento da cura clínica.

A lesão mucosa parece ocorrer em função da exacerbação da resposta inflamatória caracterizada por uma alta produção de IFN- $\gamma$ e baixa produção de IL-10, ou mesmo deficiência em receptor para IL-10 (Bacellar et al., 2002; Faria et al., 2005). Além disso, pacientes de LM que apresentam resposta inflamatória tecidual mais intensa, como elevada relação IFN- $\gamma / \mathrm{IL}-10$ e altos percentuais de células $\mathrm{T} \mathrm{CD}^{+}$e NK na mucosa, estão mais propensos a evoluírem com episódios de recidivas (Tuon et al., 2008). Tais resultados corroboram com a assertiva de que a permanência por longo tempo sob estímulo inflamatório imprime uma capacidade sustentada de secreção de IFN- $\gamma$, caracterizando o grupo de indivíduos com alta produção dessa citocina (Carvalho et al., 1985). Assim, o fato de os pacientes de LM manterem a capacidade de produzir níveis elevados de IFN- $\gamma$ e baixos de IL-10, indica que a manutenção da cura clínica na forma mucosa pode ser mais tênue que na LC, o que pode justificar as reativações mais frequentes (Junqueira et al., 2003; Tuon et al., 2008).

\section{CONCLUSÕES E PERSPECTIVAS}

O tempo após a cicatrização da lesão parece ser fundamental para a ocorrência de um abrandamento das atividades imunes efetoras específicas ao parasito, refletindo uma condição de equilíbrio parasito/hospedeiro. Essa linha de 
raciocínio está de acordo com o fato de os indivíduos curados de LC apresentarem uma cura clínica estável, visto que mesmo longo tempo após a cicatrização, a resposta imunológica dos mesmos continua eficiente em controlar a replicação parasitária, sem, no entanto, apresentar níveis de ativação desregulados a ponto de cursar com destruição tecidual e consequente recorrência das lesões ou evolução para forma mucosa da doença. Assim, é possível que após a cura clínica a persistência prolongada de níveis elevados de ativação de linfócitos T e B denotem sinais de desequilíbrio entre o parasito e o hospedeiro, indicando mais chances de tais indivíduos apresentarem um prognóstico desfavorável.

\section{REFERÊNCIAS}

AMATO, V. S.; ANDRADE, H. F. \& DUARTE, M. I. Mucosal leishmaniasis: in situ characterization of the host inflammatory response, before and after treatment. Acta Tropica, 85(1): 39-49, 2003.

ANTONELLI, L. R. et al. Activated inflammatory T cells correlate with lesion size in human cutaneous leishmaniasis. Immunology Letters, 101(2): 226-230, 2005.

BACELLAR, O. et al. Up-regulation of Th1-type responses in mucosal leishmaniasis patients. Infection and Immunity, 70(12): 6.734-6.740, 2002.

BARRAL, A. et al. Lymphadenopathy as the first sign of human cutaneous infection by Leishmania braziliensis. The American Journal of Tropical Medicine and Hygiene, 53(3): 256-259, 1995.

BARROSO-FREITAS, A. P. et al. Accuracy of an ELISA and indirect immunofluorescence for the laboratory diagnosis of American tegumentary leishmaniasis. Transactions of the Royal Society of Tropical Medicine and Hygiene, 103(4): 383-389, 2009.

BERTHO, A. L. et al. Detection of early apoptosis and cell death in T CD4+ and CD8 + cells from lesions of patients with localized cutaneous leishmaniasis. Brazilian Journal of Medical and Biological Research, 33(3): 317-325, 2000.

BITTAR, R. C. et al. T-cell responses associated with resistance to Leishmania infection in individuals from endemic areas for Leishmania (Viannia) braziliensis. Memórias do Instituto Oswaldo Cruz, 102(5): 625-630, 2007.

BOGDAN, C. Mechanisms and consequences of persistence of intracellular pathogens: leishmaniasis as an example. Cellular Microbiology, 10(6): 1.221-1.234, 2008.

BRITO, M. E. F. et al. Dynamics of the antibody response in patients with therapeutic or spontaneous cure of American cutaneous leishmaniasis. Transactions of the Royal Society of Tropical Medicine and Hygiene, 95(2): 203-206, 2001.

BRODSKYN, C. I. et al. Parasite-driven in vitro human lymphocyte cytotoxicity against autologous infected macrophages from mucosal leishmaniasis. The Journal of Immunology , 159(9): 4.467-4.473, 1997.

CAMPANELLI, A. P. et al. CD4+CD25 + T cells in skin lesions of patients with cutaneous leishmaniasis exhibit phenotypic and functional characteristics of natural regulatory T cells. The Journal of Infectious Diseases, 193(9): 1.313-1.322, 2006.

CARVAlHO, E. M. et al. Cell mediated immunity in American cutaneous and mucosal leishmaniasis. The Journal of Immunology, 135(6): 4.144-4.148, 1985.

CARVALHO, L. P. et al. Differential immune regulation of activated T cells between cutaneous and mucosal leishmaniasis as a model for pathogenesis. Parasite Immunology, 29(5): 251-258, 2007.

CASTELLANO, L. R. et al. Th1/Th2 immune responses are associated with active cutaneous leishmaniasis and clinical cure is associated with strong interferon-gamma production. Human Immunology, 70(6): 383-390, 2009.

CONCEIÇÃO-SILVA, F. et al. Quantitative study of Leishmania braziliensis braziliensis reactive T cells in peripheral blood and in the lesions of patients with American mucocutaneous leishmaniasis. Clinical and Experimental Immunology, 79(2): 221-226, 1990.

COUTINHO, S. G. PIRMEZ, C. \& DA-CRUZ, A. M. Parasitological and immunological follow-up of American tegumentary leishmaniasis patients. Transactions of the Royal Society of Tropical Medicine and Hygiene, 96, supl. 1: S173-S178, 2002. 
COUTINHO, S. G. et al. T-cell responsiveness of American cutaneous leishmaniasis patients to purified Leishmania pifanoi amastigote antigens and Leishmania braziliensis promastigote antigens: immunologic patterns associated with cure. Experimental Parasitology, 84(2): 144-155, 1996.

DA-CRUZ, A. M. \& PIRMEZ, C. Leishmaniose tegumentar americana. In: CoURA, J. R. (Org.). Dinâmica das Doenças Infecciosas. Rio de Janeiro: Guanabara Koogan, 2013.

DA-CRUZ, A. M. et al. Leishmania-reactive CD4+ and CD8 + T cells associated with cure of human cutaneous leishmaniasis. Infection and Immunity, 62(6): 2.614-2.618, 1994.

DA-CRUZ, A. M. et al. T-cell-mediated immune responses in patients with cutaneous or mucosal leishmaniasis: long-term evaluation after therapy. Clinical and Diagnostic Laboratory Immunology, 9(2): 251-256, 2002.

DA-CRUZ, A. M. et al. T cells specific to Leishmania and other nonrelated microbial antigens can migrate to human leishmaniasis skin lesions. The Journal of Investigative Dermatology, 130(5): 1.329-1.336, 2010.

ESSER, M. T. et al. Memory T cells and vaccines. Vaccine, 21(5-6): 419-430, 2003.

FAGUNDES-SILVA, G. A. et al. Decrease in anti-Leishmania IgG3 and IgG1 after cutaneous leishmaniasis lesion healing is correlated with the time of clinical cure. Parasite immunology, 34(10): 486-491, 2012.

FARIA, D. R. et al. Decreased in situ expression of interleuykin-10 receptor is correlated with the exacerbated inflammatory and cytotoxic responses observed in mucosal leishmaniasis. Infection and Immunity, 73(12): 7.853-7.859, 2005.

GOLLOB, K. J.; ANTONELLI, L. R. \& DUTRA, W. O. Insights into CD4+ memory T cells following Leishmania infection. Trends in Parasitology, 21(8): 347-350, 2005.

GOLLOB, K. J. et al. Immunoregulatory mechanisms and CD4-CD8- (double negative) T cell subpopulations in human cutaneous leishmaniasis: a balancing act between protection and pathology. International Immunopharmacology, 8(10): 1.338-1.343, 2008.

GOMES-SILVA, A. et al. Can interferon-gamma and interleukin-10 balance be associated with severity of human Leishmania Viannia) braziliensis infection? Clinical and Experimental Immunology, 149(3): 440-444, 2007.

GOMES-SILVA, A. et al. Serological reactivity of different antigenic preparations of Leishmania (Leishmania) amazonensis and the Leishmania braziliensis complex. Revista da Sociedade Brasileira de Medicina Tropical, 41(2): 135-141, 2008.

GUTIERREZ, Y. et al. Correlation between histopathology, immune response, clinical presentation, and evolution in Leishmania braziliensis infection. The American Journal of Tropical Medicine and Hygiene, 45(3): 281-289, 1991.

JUNQUEIRA PEDRAS, M. et al. Antibody subclass profile against Leishmania braziliensis and Leishmania amazonensis in the diagnosis and follow-up of mucosal leishmaniasis. Diagnostic Microbiology and Infectious Diseases, 47(3): 477-485, 2003.

MATOS, G. I. et al. IFNG +874T/A polymorphism is not associated with American tegumentary leishmaniasis susceptibility but can influence Leishmania induced IFN-gamma production. BMC Infectious Disease, 24(7): 33, 2007.

MATTA, N. E. et al. Leishmania (Viannia) guyanensis induces low immunologic responsiveness in leishmaniasis patients from an endemic area of the Brazilian Amazon Highland. The American Journal of Tropical Medicine and Hygiene, 80(3): 339-344, 2009.

MENDES-AGUIAR, C. O. et al. The skin homing receptor cutaneous leucocyte-associated antigen (CLA) is up-regulated by Leishmania antigens in T lymphocytes during active cutaneous leishmaniasis. Clinical and Experimental Immunology, 157(3): 377-384, 2009.

MENDONÇA, S. C. F. et al. Indirect immunofluorescence test in new world leishmaniasis: sorological and clinical relationship. Memórias do Instituto Oswaldo Cruz, 83(3): 347-355, 1988.

MORGADO, F. N. et al. Signs of an in situ inflammatory reaction in scars of human American tegumentary leishmaniasis. Parasite Immunology, 32(4): 285-295, 2010.

OKWOR, I. \& UZONNA, J. Persistent parasites and immunologic memory in cutaneous leishmaniasis: implications for vaccine designs and vaccination strategies. Immunologic Research, 41(2): 123-136, 2008. 
OLIVEIRA-CAMERA, P. et al. Haematogenous dissemination of Leishmania (Viannia) braziliensis in human American tegumentary leishmaniasis. Transactions of the Royal Society of Tropical Medicine and Hygiene, 100(12): 1.112-1.117, 2006.

OLIVEIRA-NETO, M. P. et al. Leishmaniasis recidiva cutis in New World cutaneous leishmaniasis. International Journal of Dermatology, 37(11): 846-849, 1998.

PEREIRA-CARVALHO, R. et al. Leishmania braziliensis-reactive T cells are down-regulated in long-term cured cutaneous leishmaniasis, but the renewal capacity of T effector memory compartments is preserved. PLoS One, 8(11): e81529, 2013.

PESSÔA, S. B. \& BARRETO, M. P. Leishmaniose Tegumentar Americana. Rio de Janeiro: Serviço de documentação, Imprensa Nacional, Ministério da Educação e Saúde, 1948.

PIRMEZ, C. et al. Immunologic responsiveness in American cutaneous leishmaniasis lesions. The Journal of Immunology , 145(9): 3.100-3.104, 1990.

PIRMEZ, C. et al. Cytokine patterns in the pathogenesis of human leishmaniasis. The Journal of Clinical Investigation, 91(4): 1.390-1.395, 1993.

PISSINATE, J. F. et al. Upgrading the flow-cytometric analysis of anti-Leishmania immunoglobulins for the diagnosis of American tegumentary leishmaniasis. Journal of Immunological Methods, 336(2): 193-202, 2008.

RIBEIRO-DE-JESUS, A. et al. Cytokine profile and pathology in human leishmaniasis. Brazilian Journal of Medical and Biological Research, 31(1): 143-148, 1998.

ROMERo, G. A. et al. Antibody response in patients with cutaneous leishmaniasis infected by Leishmania (Viannia) braziliensis or Leishmania (Viannia) guyanensis in Brazil. Acta Tropica, 93(1): 49-56, 2005.

SALHI, A. et al. Immunological and genetic evidence for a crucial role of IL-10 in cutaneous lesions in humans infected with Leishmania braziliensis. The Journal of Immunology, 180(9): 6.139-6.148, 2008.

SCHUBACH, A. et al. Detection of Leishmania DNA by the polymerase chain reaction in scars of treated human patients. Journal of Infectious Diseases, 178(3): 911-914, 1998.

SCOTT, P. Immunologic memory in cutaneous leishmaniasis. Cellular Microbiology, 7(12): 1.707-1.713, 2005.

SCOTT, P. et al. The development of effector and memory T cells in cutaneous leishmaniasis: the implications for vaccine development. Immunological Reviews, 201: 318-338, 2004.

SILVEIRA, F. T. et al. Immunopathogenic competences of Leishmania (V.) braziliensis and L. (L.) amazonensis in American cutaneous leishmaniasis. Parasite Immunology, 31(8): 423-431, 2009.

SOUZA, M. A. et al. Immunoglobulin isotype and IgG subclass profiles in American tegumentary leishmaniasis. Revista da Sociedade Brasileira de Medicina Tropical, 38(2): 137-141, 2005.

SOUZA-LEMOS, C. et al. Dynamics of immune granuloma formation in a Leishmania braziliensis-induced self-limiting cutaneous infection in the primate Macaca mulatta. The Journal of Pathology, 216(3): 375-386, 2008.

TOLEDO, V. P. et al. Immunochemotherapy in American cutaneous leishmaniasis: immunological aspects before and after treatment. Memórias do Instituto Oswaldo Cruz, 96(1): 89-98, 2001.

TUON, F. F. et al. Local immunological factors associated with recurrence of mucosal leishmaniasis. Clinical Immunology, 128(3): 442-446, 2008.

VALLI, L. C. et al. Humoral immune responses among mucosal and cutaneous leishmaniasis patients caused by Leishmania braziliensis. The Journal of Parasitology, 85(6): 1.076-1.083, 1999.

ZAJTCHUK, J. T. et al. Mucosal leishmaniasis in Brazil. Laryngoscope, 99(9): 925-939, 1989.

ZAPH, C. et al. Central memory T cells mediate long-term immunity to Leishmania major in the absence of persistent parasites. Nature Medicine, 10(10): 1.104-1.110, 2004. 
parte VIII

\section{Tratamento e Diagnóstico das Leishmanioses}




\title{
Estado da Arte no Tratamento da Leishmaniose Tegumentar Americana no Brasil
}

\author{
Armando 0. Schubach I Fátima Conceição-Silva
}

$\mathrm{I}^{\mathrm{n}}$

niciamos este capítulo com uma indagação: como se trata essa doença infecciosa, que acomete diferentes populações (diversidade genética populacional), em diferentes regiões do planeta (diferenças no acesso ao sistema de saúde e questões intrínsecas de saúde, como desnutrição e comorbidades) e é produzida por mais de vinte diferentes espécies (variabilidade genética do parasito)? Ah, e não nos esqueçamos das diferenças entre os insetos vetores! Se a primeira resposta que lhe veio à mente foi 'com sais de antimônio', você estaria certo até alguns anos atrás. Surpreendentemente esse metal pesado, nas duas formulações principais (trivalente e pentavalente), foi altamente eficaz por quase um século. Mas, nos últimos anos, notícias de falha terapêutica têm colocado em dúvida sua resposta. Adicionalmente, é preocupante a limitação de medicamentos de segunda escolha disponíveis. Então, voltemos à pergunta: de que forma são tratadas as leishmanioses?

Em recente revisão (Shukla et al., 2010), é afirmada uma verdade que nos é bem próxima: a de que as leishmanioses não têm sido mantidas na lista de doenças negligenciadas à toa. Essa infecção tem recebido poucos recursos para pesquisa clínica e de desenvolvimento terapêutico, uma vez que a maioria dos casos ocorre em locais onde impera a pobreza e/ou que são remotos. No entanto, o aumento dos casos de falha terapêutica e a melhor detecção de efeitos adversos têm apontado para uma necessidade urgente de pesquisa e desenvolvimento de novas drogas com boa eficácia e baixa incidência de efeitos adversos (para detalhes, ver o capítulo 23 - "Modelos de estudo para 0 desenvolvimento de drogas anti-Leishmania"). Entretanto, esse não é um trabalho fácil. Ainda existem importantes lacunas para o esclarecimento do mecanismo de ação dos sais de antimônio no tratamento das leishmanioses. Para abordar esse assunto primeiramente precisamos rever como esse metal pesado começou a ser usado no tratamento da infecção por parasitos do gênero Leishmania.

Poucos anos após considerar que havia diferenças morfológicas entre L. tropica e o agente etiológico da leishmaniose tegumentar do Novo Mundo, ao qual denominou L. braziliensis (Vianna, 1911), o médico brasileiro Gaspar Vianna introduziu, com sucesso, o composto antimonial tartarato de potássio e antimônio (tártaro emético) no tratamento das leishmanioses (Vianna, 1914). No ano seguinte, tal sucesso foi confirmado por D’Utra e Silva (1915).

Nas sínteses posteriores, o antimônio trivalente $\left(\mathrm{Sb}^{3+}\right)$ foi substituído pela espécie pentavalente $\left(\mathrm{Sb}^{5+}\right)$, menos tóxica. Bramachani utilizou o primeiro antimonial pentavalente (ureia estibilamina) (Marsden, 1985), a partir do qual 
se deu início ao desenvolvimento de an timoniais pentavalentes, mais estáveis, que até os dias atuais são utilizados no tratamento das leishmanioses: Pentostan ${ }^{\circledR}$ (estibogluconato de sódio), da Wellcome e Glucantime ${ }^{\circledR}$ (antimoniato de N-metil glucamina), produzido pela Rhodia durante a Segunda Guerra Mundial. Desde 2007, o Glucantime®é fabricado no Brasil, pela Sanofi-Aventis, e distribuído para a rede de saúde pela Secretaria de Vigilância em Saúde do Ministério da Saúde (SVS/MS). A caracterização da estrutura do antimoniato de N-metil glucamina foi estudada por Roberts, McMurray e Rainey (1998). A droga é obtida pela reação de antimônio pentavalente com NMG (N-metil-D-glucamina). Os autores observaram duas principais faixas de massa na droga, de MM 507 NMG-Sb-NMG e MM $820(\mathrm{Sb})_{2}$ - $(\mathrm{NMG})_{3}$, o que sugere a existência de uma mistura de complexos em equilíbrio quando em solução aquosa. No entanto, o completo entendimento de seu metabolismo e mecanismo de ação ainda precisam ser mais bem estudados.

\section{ESTADO DA ARTE}

Não seria melhor começar a entender como as velhas coisas funcionam para poder planejar as novas, tão necessárias? Uma das possibilidades é a realização de revisões sistemáticas, componentes importantes da 'medicina baseada em evidências', tentando achar os pontos comuns que possam ser usados como critério para o estabelecimento do que seria uma droga padrão para o tratamento da leishmaniose. Entretanto, tais revisões costumam priorizar a efetividade em detrimento da segurança (Loke, Price \& Herxheimer, 2007).

Encontramos poucas revisões sistemáticas sobre o tratamento da leishmaniose tegumentar americana (LTA). Em uma delas, sobre o tratamento da forma cutânea (Tuon et al., 2008a), verificou-se que os antimoniais pentavalentes foram as drogas mais avaliadas, com um total de 1.150 pacientes e um índice de cura de $76,5 \%$. Quando utilizada, a pentamidina alcançou índices de cura similares, enquanto outras drogas obtiveram resultados inferiores.

Em outra revisão, sobre o tratamento da forma mucosa nos últimos quarenta anos (Amato et al., 2007), é referido que, além de terem surgido poucos medicamentos nesse período, a resistência aos medicamentos disponíveis aumentou, sendo que o índice de cura atualmente observado em grandes estudos não chega a ser superior a 70\%. Nos casos de leishmaniose mucosa analisados, a pentamidina e a anfotericina foram tão efetivos quanto os antimoniais, enquanto outras terapias mostraram-se controversas. Os autores dessas duas revisões concordam que aspectos como custo, efeitos adversos, experiência local e a disponibilidade de medicamentos devem ser considerados ao se elaborar recomendações para o tratamento das leishmanioses, particularmente nos países em desenvolvimento, onde há escassez de recursos.

Após revisar 38 ensaios clínicos envolvendo diferentes intervenções para o tratamento de LTA causada por $L$. braziliensis ou por L. panamensis (Gonzalez et al., 2009), outros autores concluíram que não há consenso sobre o melhor esquema terapêutico e que a base de evidências para o tratamento da LTA apresenta muitas limitações em razão de falhas nos estudos realizados. Tais autores sugerem ainda a criação de uma estratégia internacional para melhorar a qualidade e padronizar futuros ensaios clínicos.

Após rever a segurança do tratamento da forma cutânea da LTA (Oliveira et al., 2010), concluiu-se pela necessidade da realização de ensaios clínicos com medicamentos já utilizados para o tratamento da LTA. Tais ensaios devem incluir avaliação de efeitos adversos, com critérios de classificação de gravidade bem definidos. Os autores também recomendam que o monitoramento dos efeitos adversos clínicos, laboratoriais e eletrocardiográficos seja realizado, ao menos, a cada dez dias durante o tratamento e no trigésimo dia após seu término, independentemente do esquema terapêutico adotado. E que a avaliação inclua hemograma completo, dosagem de ureia, creatinina, glicose, eletrólitos, enzimas hepáticas e pancreáticas, além de eletrocardiograma. Dessa forma, as informações obtidas poderiam ser mais conclusivas sobre os reais efeitos terapêuticos e/ou adversos dos diferentes esquemas de administração das drogas atualmente em uso. 
Distintos esquemas terapêuticos, instituídos em bases empíricas, têm sido preconizados e publicados sob a forma de relatos de casos e de séries de casos. Entretanto, não há consenso sobre qual o melhor deles, nem sobre a sua segurança, uma vez que é limitado o conhecimento proveniente de ensaios clínicos. Todas as revisões sistemáticas encontradas apontavam para a deficiência dos estudos sobre as drogas amplamente utilizadas para o tratamento da LTA (antimoniais, pentamidina e anfotericina B) (Tuon et al., 2008a; Amato et al., 2007; Gonzalez et al., 2009; Oliveira, 2010; Gonzalez et al., 2010).

\section{O TRATAMENTO DA LTA NO BRASIL}

No Brasil, a droga de primeira escolha para o tratamento da forma cutânea da LTA é o antimoniato de N-metilglucamina (Glucantime ${ }^{\circledR}$ ), recomendado pelo Ministério da Saúde, em 2010, na dose de 10-20 mg Sb ${ }^{5+} / \mathrm{kg} / \mathrm{dia}$ durante vinte dias consecutivos (Brasil, 2010). A droga é considerada eficaz, apesar da toxicidade e queixas de desconforto na administração. No entanto, a experiência do ambulatório de leishmaniose, vinculado ao Laboratório de Vigilância em Leishmanioses (VigiLeish), do Instituto de Pesquisa Clínica Evandro Chagas (Ipec/Fiocruz), tem demonstrado eficácia satisfatória na utilização de esquema de tratamento com baixa dose de antimônio pentavalente ( $5 \mathrm{mg} \mathrm{Sb}{ }^{5+} / \mathrm{kg} / \mathrm{dia}$ ) por um período de tempo maior (trinta dias) (Oliveira-Neto et al., 1996; Oliveira-Neto et al., 1997a, 1997b; Schubach et al., 2005). Contudo, não existe consenso sobre a eficácia e aplicabilidade desse esquema em outras áreas do país.

Para exercer ação anti-Leihsmania, o antimoniato de N-metil-glucamina deve alcançar os amastigotas intracelulares. Para que isso ocorra, é necessário atravessar tanto a membrana celular da célula do hospedeiro, como também a membrana do fagolisossoma, onde estão os amastigotas. Dessa forma, a conversão da forma pentavalente para a trivalente parece ser importante para que seu efeito aconteça, sendo a forma pentavalente considerada proativa (Ouellette, Drummelsmith \& Papadopoulou, 2004).

Ainda hoje, os mecanismos de ação do antimônio pentavalente não foram completamente elucidados. São descritos diversos mecanismos envolvidos na destruição da Leishmania, incluindo a inibição no processo de glicogenólise e na oxidação de ácidos graxos pelo parasito, que reduz a produção de adenosina-trifosfato (ATP), mas nenhum dos mecanismos é perfeitamente conhecido. Contudo, estudos recentes demonstram que o antimônio pentavalente exerce efeitos sobre a resposta imunológica, aumentando a fagocitose por monócitos e neutrófilos, além da produção de ânion superóxido e TNF- $\alpha$, que por sua vez também faz com que a produção de óxido nítrico (NO) seja aumentada (MunizJunqueira \& Paula-Coelho, 2008). Tais dados sugerem que não só os mecanismos 'leishmanicidas' do antimônio pentavalente estão relacionados à resposta terapêutica, mas também a efeitos imunomoduladores, promovendo ainda uma resposta imune mais eficaz contra o parasito. Lamentavelmente, casos de resistência ao antimoniato de N-metilglucamina têm sido crescentes, o que é preocupante e torna urgente a descoberta de novas drogas para o tratamento das leishmanioses (Ouellette, Drummelsmith \& Papadopoulou, 2004; Sampaio \& Marsden, 1997; Machado et al., 2002; Jha, 2006; Rodrigues et al., 2006; Rojas et al., 2006; Santos et al., 2008).

Outras drogas têm sido usadas para o tratamento da LTA, mas na maioria dos casos são consideradas de segunda escolha (Croft \& Yardley, 2002; Croft, Seifert \& Yardley, 2006). Contudo, na dependência da região geográfica e da espécie de Leishmania envolvida, tais drogas têm sido apontadas como mais eficazes, sendo atualmente preconizadas como tratamento de primeira escolha (Reviez et al., 2013). A anfotericina B nas três apresentações (desoxicolato, de dispersão coloidal e lipossomal) apresenta excelentes resultados terapêuticos, incluindo os casos resistentes aos antimoniais (Gontijo \& Carvalho, 2003; Basano \& Camargo, 2004; Singh \& Sivakumar, 2004). Entre os inconvenientes, podemos citar a necessidade de internação hospitalar ou em regime de hospital-dia, os efeitos adversos consideráveis da anfotericina desoxicolato, além do elevado custo das apresentações lipídicas. 
A pentamidina é outra droga de segunda linha que, em estudos iniciais, mostrou eficácia comparável aos antimoniais e custo inferior, apesar de efeitos adversos importantes como hipoglicemia e hipotensão. Entretanto, o uso mais frequente dessa droga levou à rápida queda em sua eficácia na Índia, sugerindo o desenvolvimento de resistência parasitária (Ouellette, Drummelsmith \& Papadopoulou, 2004; Bray et al., 2003).

A miltefosina é o primeiro medicamento oral reconhecido para o tratamento das leishmanioses. A droga foi registrada em 2002, para o tratamento da leishmaniose visceral na Índia, e tem sido considerado um medicamento promissor (Berman, 2008). Diferentemente do que vem ocorrendo com antimoniais pentavalentes, anfotericina e pentamidina, os estudos com miltefosina têm seguido as normas de boas práticas clínicas. Tal fato tem permitido acumular evidências sobre eficácia e segurança num curto espaço de tempo. Outros autores sugerem a necessidade de mais estudos controlados sobre o assunto (Blum \& Hatz, 2009). Experiências no Velho Mundo indicam índices de cura superiores aos antimoniais, porém, tais estudos foram realizados com um pequeno número de participantes (Blum \& Hatz, 2009; Rahman, Bari \& Mumtaz, 2007). Nas leishmanioses tegumentares do continente americano, os resultados com a miltefosina são contraditórios. Os primeiros resultados demonstraram efeitos promissores para L. panamensis e ruins para L. mexicana, enquanto a L. braziliensis apresentou bons resultados em estudos na Bolívia e na Colômbia, e um fracasso em estudos na Guatemala (Berman, 2008; Blum \& Hatz, 2009; Soto et al., 2008). Mais recentemente, a miltefosina foi apontada como droga mais eficaz que o antimoniato de meglumina para casos de LTA produzidos por L. panamensis e L. guyanensis (Reviez et al., 2013). A ação da miltefosine sobre o conteúdo lipídico de membrana, indução de apoptose e ação sobre a reposta de macrófagos já foi indicado, o que pode levar à obtenção de dados mais precisos sobre seu uso (Vincent et al., 2014). Assim, os resultados obtidos até o momento sugerem que o emprego dessa droga deve levar em consideração o contexto da região, parasito envolvido e condições do paciente.

O tratamento local também tem sido considerado como opção alternativa. Muitos autores têm restrições ao seu uso em razão do potencial risco de desenvolvimento de lesões mucosas (LM). No entanto, esse tipo de tratamento pode ser considerado em casos em que os fatores de risco para LM estejam ausentes ou minimizados (Blum et al., 2012). Este pode ser realizado com aplicações intralesionais de drogas antimoniais, com outras drogas ou com crioterapia local. Esta última mostrou $84 \%$ de remissão das lesões em pacientes com leishmaniose cutânea por L. major, em estudo realizado na Jordânia (Mosleh et al., 2008). Resultados de tratamento intralesional em ulcerações produzidas por $L$. braziliensis também são promissores (Oliveira-Neto et al., 1997c; Vasconcellos, 2009). Após revisão sistemática de 14 ensaios clínicos com 1.221 pacientes, concluiu-se que a paromomicina tópica foi inferior ao antimonial no tratamento da forma cutânea da LTA (Kim et al., 2009).

Além dessas, outras drogas também podem ser utilizadas como alternativa aos antimoniais. Todavia, a eficácia de tais drogas não se mostra superior ao antimoniato de N-metil-glucamina ou apresentam efeitos adversos consideráveis (Tuon et al., 2008a). Estudos recentes encontraram potencial para desenvolver novas drogas, tendo como base alcaloides (Mishra et al., 2009). Esse achado e a descoberta de um potente inibidor de pteridina reductase 1 (PTR1) em L. major (Cavazzuti et al., 2008) podem orientar o desenvolvimento de novas drogas para tratamento da leishmaniose tegumentar nas próximas décadas.

Algumas outras preparações, incluindo substâncias naturais da flora, têm sido testadas, a maior parte ainda em fase experimental (Costa et al., 2009; Silva et al., 2009; Tempone et al., 2008; Machado, Leon \& Castro, 2007; Ferreira et al., 2004; Leon et al., 2001). Para detalhes sobre o desenvolvimento de novas drogas, também sugerimos a leitura do capítulo 23 - "Modelos de estudo para o desenvolvimento de drogas anti-Leishmania".

Outro tipo de intervenção ainda pouco explorada é a imunoterapia isolada, ou mais comumente associada ao tratamento antimonial. Tal método é baseado na participação da resposta imune do paciente na evolução da infecção para cura, ou para a manutenção de atividade inflamatória (para mais detalhes, consultar capítulos pertinentes 
ao assunto neste livro). Em recente revisão, Musa e colaboradores (2010) discutem o estado da arte nesse tipo de tratamento. E colocam um ponto que deve ser discutido: a terapia combinada entre quimioterápico e imunoterapia poderia ser eficaz em menor tempo e necessitar de menor quantidade de sal de antimônio. Isso poderia diminuir dois grandes problemas quando se pensa em tratamento de leishmaniose: os efeitos adversos e a resistência às drogas (Musa et al., 2010; Machado-Pinto et al., 2002). No Brasil, tal abordagem tem sido utilizada por Mayrink e colaboradores $(1992,1996)$.

De forma semelhante, Convit e colaboradores (2003) revisaram os tratamentos realizados na Venezuela, com a associação entre drogas e a estimulação do sistema imune. Em ambos os casos, antígenos mais ou menos puros de várias espécies de Leishmania eram injetados como forma de estimular a resposta imune específica de forma direta. Alguns estudos empregaram a injeção desses antígenos na presença de adjuvantes como o BCG (Convit et al., 2003; Musa et al., 2008) ou o GM-CSF (Badaró et al., 1994, 2006). Apesar dos resultados promissores, a dificuldade de padronização dos preparados, com consequente produção de resultados conflitantes, levou a imunoterapia ao desuso, embora, ainda hoje, esse tipo de abordagem seja utilizada principalmente no tratamento da leishmaniose cutânea difusa (Convit et al., 2003, 2004; Musa et al., 2008; Badaró et al., 1994, 2006; Convit et al., 2004).

\section{Cura clínica e falha terapêutica na LTA}

Há outra pergunta que durante muito tempo perseguiu o estudo da leishmaniose: a cura nos casos de leishmaniose é parasitológica ou apenas clínica? Hoje é consenso pensar que a persistência parasitária é um fato. Mas nem sempre foi assim. Os primeiros resultados indicando a presença de parasitos viáveis em lesões cicatrizadas foram bastante combatidos, sendo necessários vários anos até o conhecimento se firmar (Schubach et al., 1987, 1988, 1989; 1998a, 1998b, 2001; Mendonça et al., 2004; Amato et al., 2003). Apesar dos estudos já realizados, pouco se sabe sobre os possíveis fatores envolvidos na evolução das lesões tegumentares para a cura clínica e na proteção contra recidivas e reinfecções. Estudos sistemáticos avaliando vários aspectos (clínicos e laboratoriais) poderiam trazer subsídios para o conhecimento da dinâmica desse processo infeccioso.

De maneira geral, todos os resultados sugerem um equilíbrio dinâmico entre o parasito e o sistema imune, principalmente no local da lesão. Alguns estudos indicam que a cicatrização de lesões de pele envolve um complexo processo que na LTA poderia estar alterado, já que a cura clínica não é estéril. Há a possibilidade de que poucos parasitos sobreviventes possam facilitar a manutenção da imunidade protetora. Já foi sugerido que células $\mathrm{T}$ de memória necessitem da reestimulação causada tanto por reações cruzadas, a partir de patógenos relacionados ou do ambiente, quanto pela presença de antígenos do inóculo primário (Moll, Flohe \& Rollinghoff, 1995).

Alguns dos mecanismos que controlam o processo inflamatório e a cicatrização já foram descritos (Choi \& Kropf, 2009; Guan, Ohshima \& Kondo, 2000). Como exemplo, podemos citar: a redução da celularidade via apoptose (Guan, Ohshima \& Kondo, 2000; Greenhalgh, 1998); a transição da fase inflamatória para a fase de cicatrização via TGF- $\beta$ (fator de crescimento tumoral - $\beta$ ) (Greenhalgh, 1998); e a função de NO (Stenger et al., Stenger et al., 1996). Em particular, NO parece ser crucial para o controle de parasitos persistentes nos hospedeiros imunocompetentes após a resolução da infecção primária. No ser humano, esse mesmo fenômeno pôde ser observado com a descrição de parasitos viáveis nas cicatrizes de LTA (Schubach et al., 1998a; Mendonça et al., 2004; Morgado et al., 2010) e na reativação da doença em pacientes coinfectados pelo HIV (Kubar et al., 1998; Czechowicz et al., 1999).

Outros fatores, como doenças concomitantes, o uso de determinadas drogas, idade, localização, número e tempo de evolução das lesões, também poderiam influenciar a evolução da LTA para cicatrização ou manutenção de atividade. Um fato conhecido é a demora na cicatrização de lesões localizadas na região das pernas, em razão das dificuldades de drenagem local. Por fim, fatores pertencentes a variações genéticas do parasito (Colmenares et al., 2002; Baptista 
et al., 2009), assim como a carga parasitária, poderiam estar envolvidos na manutenção da atividade inflamatória e, consequentemente, na ocorrência de falha terapêutica precoce ou tardia. Nos países do Novo Mundo, por exemplo, as leishmanioses tendem a ser mais graves, e a remissão espontânea é muito mais rara que nos países do Velho Mundo (Neuber, 2008).

No manejo do paciente com LTA é importante reconhecer quando o tratamento antimonial está sendo ineficaz, para então decidir que outras medidas devem ser tomadas. Segundo o manual do Ministério da Saúde (Brasil, 2010), são estabelecidas definições diferentes para falha terapêutica e recidiva. A falha terapêutica seria caracterizada pela ausência de remissão clínica três meses após dois tratamentos completos, enquanto a recidiva caracterizar-se-ia pelo reaparecimento de lesão, em qualquer parte do corpo, no período de até um ano após a cura clínica, desde que seja descartada a hipótese de reinfecção. O manual recomenda ainda que os pacientes sejam acompanhados por três meses consecutivos, devendo observar-se, ao final desse período, a reepitelização das lesões com regressão total da infiltração e do edema. Entretanto, nos casos com evidência de cicatrização progressiva das lesões sem cumprir totalmente tais critérios, sugere-se o prolongamento da observação, sem tratamento, até completar seis meses (Brasil, 2010).

No Rio de Janeiro, é reduzido o número de indivíduos que não respondem ao tratamento. No Ipec/Fiocruz, num período de dez anos (1999 a 2009), a taxa de insucesso ao primeiro esquema terapêutico foi de $11 \%$, e menos de $2 \%$ do total de casos preencheram os critérios de falha terapêutica do Ministério da Saúde (Nascimento, 2009). No entanto, outros autores referem um aumento de possíveis casos de resistência aos antimoniais (Rodrigues et al., 2006; Rojas et al., 2006; Santos et al., 2002). Em outras regiões do Brasil, as percentagens de falha terapêutica relatadas podem chegar a 47\% (Rodrigues et al., 2006; Rojas et al., 2006; Machado-Pinto et al., 2002). O insucesso terapêutico é preocupante, tendo em vista a escassez de alternativas para o controle da infecção.

Os fatores que influenciam ou determinam o insucesso terapêutico ainda não são claros. Alguns autores o relacionam a fatores tão diferentes quanto peso, número de lesões, coinfecções e comorbidades (sobretudo aquelas responsáveis por variados graus de imunossupressão), virulência do parasito e cepas de Leishmania spp. que desenvolveram resistência ao antimoniato de N-metil-glucamina (Machado et al., 2002; Rodrigues et al., 2006; Rojas et al., 2006; Santos et al., 2008; Thakur, Kumar \& Pandey, 1991; Cruz et al., 1992; Barral-Netto et al., 1998; Sampaio et al., 2002; Azeredo-Coutinho et al., 2007; Unger et al., 2009).

Muitos desses fatores são difíceis de comprovar e nem sempre é possível a correlação entre os achados experimentais e a evolução dos pacientes com LTA. Além disso, outros fatores intervenientes podem agir de maneira sinérgica na determinação da resposta ao tratamento. Uma das possibilidades mais estudadas é a existência de parasitos resistentes ao antimônio (Azeredo-Coutinho et al., 2007). Outra possibilidade seria a existência de parasitos com grande capacidade de replicação, aumentando assim o processo inflamatório e a carga parasitária, consequentemente dificultando sua eliminação. Recentemente, descreveu-se a existência de diferentes clones isolados do mesmo paciente durante a fase inicial e durante o diagnóstico de recidiva das lesões. No entanto, nesse mesmo estudo, outros casos não apresentavam diferença (Baptista et al., 2009).

Um aspecto pouco explorado é a relação entre a resposta imune in situ e a resposta terapêutica. A experiência acumulada no acompanhamento de casos de leishmaniose cutânea difusa (LCD) causada por L. amazonensis, assim como a dificuldade de controle terapêutico associado à presença de resposta imune do tipo 2 (considerada não protetora), e a reversão de resposta de tipo 2 para tipo 1 no tratamento bem-sucedido da leishmaniose visceral corroboram tais achados (Santos et al., 2008; Thakur, Kumar \& Pandey, 1991; Barral-Netto et al., 1998). Contudo, ainda são obscuras as condições imunológicas que influenciam ou determinam a reativação/recidiva da doença. Belkaid e colaboradores (2002), estudando camundongos C57Bl/6 infectados por L. major, observaram acúmulo de linfócitos T efetores ( $\mathrm{CD} 4{ }^{+} \mathrm{CD} 25$ produtores de IFN- $\gamma$ ) e células T regulatórias ( $\mathrm{CD} 4^{+} \mathrm{CD} 25^{+}$e produtoras de IL-10) na fase crônica da infecção. Em 2004, o mesmo grupo (Mendez et al., 2004) sugeriu que o equilíbrio entre esses dois tipos 
celulares seria responsável pelo controle da resposta imune e carga parasitária, e que a alteração nessa população poderia levar à reativação da doença. Em adição, Stenger e colaboradores (1996) demonstraram a produção mantida de NO nas lesões cicatrizadas de camundongos infectados com L. major. Seus estudos indicaram que a atividade de NOS2 seria crucial para o controle de parasitos persistentes e que durante quadros de imunossupressão, sua ausência poderia facilitar o escape parasitário e a consequente reativação da LTA.

Outras causas de reativação poderiam ser a depleção de células TCD4 ${ }^{+}$e o tratamento tópico com TGF- $\beta$ (Aebischer, 1994). Recentemente, sugeriu-se que a função exacerbada de $\mathrm{CD}^{+}$, associada a uma função regulatória ineficaz, poderia estar ligada aos quadros de recidiva de lesão mucosa da LTA (Tuon et al., 2008b). Outros artigos têm apontado a função da resposta imune celular específica, inclusive na associação com proteção (Barral-Netto et al., 1998; Sampaio et al., 2002; Cruz et al., 1994).

Até então, a maioria dos estudos têm enfocado a resposta imune estabelecida após a infecção. Todavia, nos últimos anos várias evidências têm indicado que a organização do processo inflamatório já nos primeiros momentos da infecção, e a indução da resposta imune específica, associada aos mecanismos de escape próprios do parasito, poderiam ser determinantes para o desenvolvimento de doença ou proteção. Esse determinado ponto é discutido em detalhes em recente revisão de Maurer, Dondji e Stebut (2009).

Sumarizando, apesar de todo o conhecimento acumulado, ainda são escassas e geralmente descritivas e inconclusivas as causas de insucesso terapêutico e dos mecanismos de ação das drogas (Tuon et al., 2008a; Machado et al., 2002; Rodrigues et al., 2006; Rojas et al., 2006; Santos et al., 2008; Unger et al., 2009; Ramírez \& Guevara, 1997; Mavilia et al., 2002; Calvopina et al., 2006). Entretanto, entender as causas desse insucesso poderia auxiliar na compreensão da dinâmica das lesões na LTA, na correta utilização das drogas, no estabelecimento de critérios de cura reprodutíveis e na intervenção rápida nos casos de insucesso terapêutico, melhorando assim o manejo clínico dos pacientes com LTA.

\section{CONCLUSÕES E PERSPECTIVAS}

Pelo que foi aqui exposto e pelo estado atual do conhecimento sobre as drogas usadas no tratamento das leishmanioses, não existe um único esquema terapêutico aplicável a todas as formas de leishmaniose existentes ao redor do mundo. Esquemas terapêuticos estudados em determinadas regiões costumam ser aplicados para tratar populações residentes em outras áreas geográficas, obtendo-se resultados variáveis. O ideal seria que os regimes terapêuticos mais adequados fossem estabelecidos para cada área endêmica, com base em sua efetividade e toxicidade, sem se descuidar das dificuldades de administração e de custo (Hepburn, 2000, 2001).

o cenário atual do tratamento das leishmanioses humanas no Brasil apresenta características peculiares, pela variedade dos contextos onde acontece a transmissão. Essa diversidade estaria relacionada com as espécies de Leishmania, dos vetores, dos reservatórios e dos ecossistemas. A apresentação clínica exibe polimorfismo com espectro de gravidade variável. A variação na resposta observada ao tratamento antimonial pode ser explicada, em parte, por problemas metodológicos que impedem a comparação sistemática das diferentes experiências terapêuticas e, em parte, pela resposta imunológica do indivíduo (Romero et al., 2001a; Mendonça et al., 1986, 1988; ConceiçãoSilva et al., 1990). Torna-se desejável a realização de estudos capazes de identificar peculiaridades regionais, assim como comparar os resultados obtidos em diferentes regiões. Estudos acoplados aos ensaios clínico-terapêuticos, para avaliar a resposta imunológica dos indivíduos antes e após o tratamento, e a farmacocinética do antimoniato de N-metil glucamina, poderiam auxiliar na compreensão da resposta terapêutica.

É possível que as diferenças na resposta terapêutica ao antimoniato de N-metil glucamina, apresentada por indivíduos infectados em áreas de transmissão de L. (V.) braziliensis, pudessem ser explicadas por variações ainda 
não bem estudadas dentro da mesma espécie (Romero et al., 2001a). O fenômeno da persistência parasitária na LTA nos faz refletir sobre os objetivos do tratamento e sobre a necessidade ou não de eliminar definitivamente o parasito, com o intuito de atingir a cura clínica (Schubach et al., 1998a, 1998b, 2001; Mendonça et al., 2004). Tais observações tornam fundamentais tanto o estudo sistemático de sensibilidade in vitro ao antimonial, quanto a caracterização fenotípica e genotípica dos isolados.

A população brasileira tem apresentado um acelerado processo de envelhecimento. Entre 1980 e 2000, o número de pessoas acima de 60 anos aumentou de sete milhões (6,1\%) para 14,5 milhões (8,6\%) (Carvalho \& Garcia, 2003; IBGE, 1981, 2001). De 107.331 casos de LTA notificados no Brasil entre janeiro de 2000 e novembro de 2003, 12.265 $(11,42 \%)$ ocorreram em pessoas entre 50 e 64 anos e 6.621 (6,16\%) casos em pessoas acima de 65 anos (Sinan, 2003). A preservação da mobilidade física é um fator essencial à manutenção da vida ativa em idosos (Giatti \& Barreto, 2003), o que torna os efeitos adversos do aparelho locomotor - como as artralgias - particularmente indesejados nesse grupo de pacientes. Diante dos problemas e limitações do uso dos antimoniais pentavalentes na dose de $20 \mathrm{mg} \mathrm{Sb} / \mathrm{kg} /$ dia (Brasil, 2010), esquemas terapêuticos alternativos menos tóxicos, contínuos ou de forma intermitente, com dose de $5 \mathrm{mg} / \mathrm{kg} /$ dia de antimônio, além do tratamento via intralesional merecem ser mais bem avaliados. Adicionalmente, a duração do tratamento da forma mucosa (LM), assim como os critérios atualmente recomendados para avaliar a resposta terapêutica, deveriam ser revistos.

O tratamento da LTA deve alcançar dois objetivos: a cicatrização das lesões cutâneas e a prevenção do envolvimento tardio das mucosas. A indicação de altas doses de $\mathrm{Sb}^{5+}$ (Herwaldt \& Berman, 1992) baseia-se em evidências de que poderia haver indução de resistência com o uso de subdoses (Grogl, Thomason \& Franke, 1992). Entretanto, estudos clínicos no Rio de Janeiro, com seguimento prolongado de pacientes, têm sugerido que tanto o uso de esquemas regulares com doses baixas (5mg Sb ${ }^{5+} / \mathrm{kg} /$ dia) por via sistêmica (Oliveira-Neto et al., 1996, 1997a, 1997b, 1997c; Schubach et al., 2005), quanto a terapia intralesional com antimoniato de N-metil glucamina (Oliveira-Neto et al., 1997c; Vasconcellos, 2009), podem constituir esquemas eficazes, alcançando percentuais de cura semelhantes àqueles obtidos com doses mais elevadas, além de menor toxicidade, mais facilidade de execução e custo menor (Harms et al., 1991; Sharquie, 1995; Claros et al., 1996; Tallab et al., 1996).

O reconhecimento, recomendação e aceitação de novos esquemas terapêuticos devem ser precedidos pela demonstração de sua superioridade ou não inferioridade em relação aos tratamentos atualmente preconizados. Os estudos publicados sobre efetividade e segurança de esquemas alternativos com antimoniato de N-metil glucamina (Oliveira-Neto et al., 1996, 1997a, 1997b, 1997c, 2000; Schubach et al., 2005; Azeredo-Coutinho \& Mendonça, 2002) não permitiram a obtenção de resultados conclusivos, por conta de diferentes falhas metodológicas: desenho do estudo inadequado (descritivo, tipo série de casos ou comparação de séries históricas); utilização de amostras de conveniência ou insuficientes; não inclusão de idosos; desfechos de eficácia/efetividade não definidos ou com erro de classificação; ausência de variáveis laboratoriais e/ou eletrocardiográficas e/ou de medida de intensidade para avaliar segurança; publicação em revistas de baixo impacto ou pouco difundidas entre os profissionais da área de doenças infecciosas.

Conclui-se pela necessidade de se comparar efetividade e segurança entre os esquemas de tratamento para LTA atualmente recomendados no Brasil e os esquemas alternativos, levando-se em consideração aspectos referentes à resposta imunológica do indivíduo e aspectos referentes ao parasito (Romero et al., 2001a, 2001b).

Como forma de contribuir para o manejo dos pacientes, incluímos, a seguir, uma adaptação do protocolo do VigiLeish/Ipec/Fiocruz para tratamento e acompanhamento de pacientes com LTA. Esperamos que as informações possam ser úteis aos interessados. 


\author{
Instituto de Pesquisa Clínica Evandro Chagas (Ipec/Fiocruz) \\ Laboratório de Vigilância em Leishmanioses (VigiLeish) \\ Roteiro Prático para o Tratamento da LTA
}

\title{
1. MEDIDAS GERAIS
}

\section{COMORBIDADES}

Tratamentos para outras doenças concomitantes como hipertensão arterial, diabetes etc. deverão ser iniciados, preferencialmente, durante a investigação diagnóstica, a fim de estabilizar o paciente antes de começar o tratamento específico.

Nos casos de lesões abaixo dos joelhos, sem insuficiência arterial associada, o repouso com os membros inferiores elevados é um método terapêutico auxiliar.

A infecção bacteriana secundária e o eczema são frequentes complicações que podem modificar o aspecto das lesões. Ambas as complicações devem ser diagnosticadas e tratadas, criteriosamente, durante a fase de investigação diagnóstica.

\section{InFECÇ̃̃o BACTERIANA SECUndáRIA}

A infecção bacteriana secundária, consequência da má higiene local, é um achado comum. A frequente lavagem das lesões cutâneas, com água e sabão, removendo as crostas e secreções, deve ser realizada.

O uso de antibióticos pode estar indicado para alívio dos sintomas inflamatórios associados. Entretanto, uma vez estabelecido o diagnóstico de leishmaniose e iniciado o tratamento específico, o processo de cicatrização deve ocorrer independentemente da utilização ou não de antibioticoterapia.

O controle da infecção secundária também pode interferir positivamente no resultado da cultura para Leishmania, durante a fase de investigação diagnóstica.

Nos casos de LM com crostas e obstrução nasal, as cavidades nasais deverão ser instiladas com solução fisiológica de cloreto de sódio $(0,9 \%)$ ou hipertônica (3\%), por várias vezes ao dia durante todo o período do acompanhamento, a fim de possibilitar uma boa visualização das mucosas das cavidades nasais, assim como o alívio sintomático do paciente.

\section{ECZEMA}

Com frequência, observa-se eczema associado à infecção secundária, ao uso indiscriminado de tópicos, estase venosa etc. Nesses casos, além da suspensão dos fatores associados, indica-se o uso de corticosteroides tópicos.

\section{SituaÇões ESPECIAIS NA LeISHMANIOSE Mucosa}

Pacientes com lesões na laringe ou com extensas lesões nas vias aéreas e digestivas superiores deverão ser internados a fim de prevenir a instalação de um quadro de insuficiência respiratória por edema local, mais provável de ocorrer nas primeiras 72 horas após início do tratamento. A profilaxia com corticosteroides deverá ser iniciada antes da primeira dose do tratamento específico. Utiliza-se hidrocortisona $100 \mathrm{mg} \mathrm{EV}$, de 6/6h durante um mínimo de 24 horas, e descontinuada durante os próximos dois dias (Brasil, 2010). 


\section{TRATAMENTO ESPECÍFICO DE PRIMEIRA LINHA: ANTIMONIATO DE N-METIL GLUCAMINA}

\section{ESQUEMA PadRÃO}

$\mathrm{O}$ antimoniato de $\mathrm{N}$-metil-glucamina (antimoniato de meglumina) é apresentado em ampolas de $5 \mathrm{~mL}$ contendo $1,5 \mathrm{~g}$ de antimoniato de $\mathrm{N}$-metil-glucamina, equivalente a $405 \mathrm{mg}$ de antimônio pentavalente $\left(\mathrm{Sb}^{5+}\right)$. Portanto, $5 \mathrm{~mL}$ correspondem a $405 \mathrm{mg}$ de $\mathrm{Sb}^{5+}$ e cada $1 \mathrm{~mL}$ a $81 \mathrm{mg}$ de $\mathrm{Sb}^{5+}$.

A Organização Mundial da Saúde (OMS) recomenda tratar os pacientes com LC com doses de $10-20 \mathrm{mg} \mathrm{Sb}^{5+} / \mathrm{kg}$ / dia e os pacientes com LM com doses de $20 \mathrm{mg} \mathrm{Sb}^{5+} / \mathrm{kg} /$ dia, via intramuscular ou endovenosa, por um período mínimo de quatro semanas. Nos casos de LC, o tratamento deverá ser continuado sem intervalos até a cura, sempre que esta não seja observada ao final do período mínimo. Nos casos de LM, o tratamento deverá ser prolongado por alguns dias após a cura clínica e parasitológica. Em casos de toxicidade ou de má resposta à terapêutica, pode-se utilizar doses de $10-15 \mathrm{mg} \mathrm{Sb}{ }^{5+} / \mathrm{kg}$ a cada 12 horas. Recaídas devem ser tratadas com o mesmo esquema terapêutico durante, pelo menos, o dobro do tempo do tratamento original (WHO, 1984, 1990).

No Brasil, o Ministério da Saúde recomenda tratar os pacientes com LC com 10-20 $\mathrm{mg} \mathrm{Sb}^{5+} / \mathrm{kg} /$ dia durante vinte dias. Os pacientes com LM devem utilizar $20 \mathrm{mg} \mathrm{Sb}^{5+} / \mathrm{kg} /$ dia durante trinta dias. Em ambos os casos, pode-se utilizar a via intramuscular ou endovenosa, devendo-se respeitar o limite máximo de três ampolas diárias (1.215 mg Sb $\left.{ }^{5+}\right)$. Caso seja utilizada a via EV, não há necessidade de diluição, embora o produto possa ser diluído em solução glicosada por comodidade de administração. Se não houver cicatrização completa após 12 semanas do término do tratamento, o esquema terapêutico deverá ser repetido durante trinta dias apenas uma vez. Em caso de não resposta, utilizar uma das drogas de segunda escolha. Na forma cutânea difusa, pode haver uma boa resposta inicial, porém são frequentes as múltiplas recidivas (Brasil, 2010).

Outros autores têm sugerido que $20 \mathrm{mg} \mathrm{Sb} / \mathrm{kg} /$ dia, sem limite máximo de dose diária, é mais eficaz sem diferir em toxicidade dos esquemas com doses menores (Herwaldt, 1992).

\section{Esquemas Alternativos para Pacientes Idosos ou com Comorbidades que Contraindiquem o Tratamento Antimonial Padrão}

No Laboratório de Vigilância em Leishmanioses (VigiLeish) do Instituto de Pesquisa Clínica Evandro Chagas (Ipec/ Fiocruz), no Rio de Janeiro, a dose de $5 \mathrm{mgSb}{ }^{5+} / \mathrm{kg} \mathrm{dia}^{1}$ por via intramuscular (IM) é utilizada na rotina de tratamento de pacientes com LTA. Entretanto, em outro contexto que não ensaios clínicos controlados, tais esquemas devem ser reservados para pacientes idosos ou com comorbidades que contraindiquem o tratamento antimonial padrão (Brasil, 2010).

Mesmo quando utilizarmos algum dos esquemas alternativos com antimoniato de N-metil glucamina, pacientes idosos ou apresentando outras complicações clínicas podem necessitar de internação hospitalar ou tratamento em regime de hospital-dia, para monitoração de efeitos adversos.

\section{Dose baixa contínua}

Os pacientes com a forma cutânea recebem tratamento com $5 \mathrm{mgSb}{ }^{5+} / \mathrm{kg} /$ dia durante trinta dias contínuos. Mesmo que não ocorra epitelização das lesões ao final do tratamento, o mesmo é interrompido e o paciente é reavaliado a cada 15 dias. Caso não ocorra progressão para a cura o tratamento poderá ser reiniciado, com a mesma dosagem e tempo de administração.

\footnotetext{
${ }^{1}$ Exemplo de cálculo de dose para um paciente de $60 \mathrm{~kg}$ :

$5 \mathrm{mg} \mathrm{Sb}{ }^{5+} / \mathrm{kg} / \mathrm{dia}=300 \mathrm{mg} \mathrm{Sb}{ }^{5+} / \mathrm{dia}=3,7 \mathrm{ml} / \mathrm{dia}$, arredondando, $=3,5 \mathrm{ml} / \mathrm{dia} \mathrm{EV} \mathrm{ou} \mathrm{IM}$

$20 \mathrm{mg} \mathrm{Sb}{ }^{5+} / \mathrm{kg} / \mathrm{dia}=1.200 \mathrm{mg} \mathrm{Sb}{ }^{5+} / \mathrm{dia}=14,8 \mathrm{ml} / \mathrm{dia}$, arredondando, $=15 \mathrm{ml} / \mathrm{dia} \mathrm{EV}$ ou $\mathrm{IM}$.
} 
Os pacientes com a forma mucosa serão tratados por um mínimo de trinta dias. Porém, o tratamento é continuado, preferencialmente sem interrupção, até a epitelização completa e desinfiltração das mucosas, o que costuma ocorrer entre trinta e noventa dias de tratamento.

\section{Dose baixa em séries}

$\mathrm{Na}$ experiência de alguns autores, esquemas em séries de dez dias intercaladas por períodos de dez dias sem medicação, até a cicatrização das lesões, acarretaram menor incidência de efeitos adversos e menor índice de abandono (Azeredo-Coutinho \& Mendonça, 2002). As frequentes interrupções e dificuldade de concluir o esquema antimonial em idosos e pacientes com comorbidades (cardiopatias, nefropatias e hepatopatias), mesmo quando tratados com doses baixas em regime de internação ou de hospital-dia, induziu o uso de $5 \mathrm{mg} \mathrm{Sb}{ }^{5+} / \mathrm{kg} /$ dia em séries de dez dias, atualmente adotada para esses casos no VigiLeish. No tratamento da forma cutânea, caso não ocorra epitelização das lesões até o final da 3 a série, parar o tratamento e fazer avaliações quinzenais. Caso não ocorra progressão para a cura, o retratamento com o mesmo esquema terapêutico poderá ser considerado.

No tratamento da forma mucosa, administrar a quantidade de séries necessárias até a epitelização e desinfiltração das mucosas.

\section{Via intralesional}

Pacientes, preferencialmente com uma ou duas lesões cutâneas, que, por qualquer motivo, apresentem impossibilidade de receber medicação parenteral regular ou que apresentem sinais de toxicidade importante ao antimonial por via sistêmica, poderão ser submetidos a tratamento intralesional com antimoniato de N-metil glucamina. Essa via não deve ser utilizada no caso de contraindicação do tratamento sistêmico por reação local ao antimoniato de N-metil glucamina. Injeta-se o volume necessário para infiltrar a lesão (geralmente entre 5-20 mL). A evolução das lesões costuma ser semelhante àquela observada com tratamento contínuo ou em séries. A critério médico, poderá ser indicada uma segunda aplicação no 15 dia. Caso não ocorra epitelização das lesões no 30 dia, poderá ser indicada uma terceira aplicação. Avaliar a evolução quinzenalmente. Caso não ocorra progressão para a cura, o retratamento com o mesmo esquema terapêutico poderá ser considerado.

\section{Efeitos adversos}

Alguns efeitos adversos podem ser observados, embora não constituam necessariamente motivo de suspensão do tratamento: artralgia, mialgia, anorexia, dor abdominal, prurido, febre, cefaleia, edema, herpes zoster e erupções cutâneas (Brasil, 2010). Alterações renais, cardíacas, hepáticas, pancreáticas e hematológicas, além de fatalidades, têm sido relatadas (Oliveira, 2010; Aronson et al., 1998; Saenz et al., 1991; Deps et al., 2000; Franke et al., 1990; Hepburn et al., 1994a, 1994b; Saldanha et al., 2000; Seaton et al., 1999; Ribeiro et al., 1999; Rodrigues et al., 1999; Sampaio et al., 1997). Artralgias, dor e desconforto no local de aplicação das injeções são frequentes, especialmente quando grandes volumes do medicamento são injetados por via IM (Thakur \& Kumar, 1990). Alterações eletrocardiográficas frequentes são as alterações do ritmo cardíaco ou da repolarização ventricular: com achatamento ou inversão de onda T e alargamento do espaço QT corrigido (suspender temporariamente o tratamento caso QTC $>0,46$ segundo). $\mathrm{O}$ tratamento é contraindicado em gestantes. Durante o uso do antimoniato de N-metil glucamina, orientar as mulheres em idade fértil para que façam uso de método contraceptivo de barreira. 


\section{MEDICAMENTOS DE SEGUNDA LINHA}

\section{ANFOTERICINA B}

No Brasil, a anfotericina B desoxicolato é considerada droga de primeira escolha no tratamento de gestantes e de segunda escolha quando não se obtém resposta ao tratamento com antimonial pentavalente ou na impossibilidade de seu uso (Brasil, 2010).

A anfotericina B desoxicolato deverá ser diluída em solução de glicose $5 \%$ a uma concentração de $0,1 \mathrm{mg} / \mathrm{mL}$ (não utilizar soluções contendo eletrólitos). A administração deve ser diária ou em dias alternados, por um período de uma a quatro horas de infusão endovenosa. A dose inicial é de 0,3-0,5 mg/Kg/dia, aumentando-se progressivamente até 1 $\mathrm{mg} / \mathrm{Kg} /$ dia até alcançar a dose máxima diária de $50 \mathrm{mg}$. As doses totais recomendadas são de 1 a $1,5 \mathrm{~g}$ para LC, e de 2,5 a 3 g para LM (Brasil, 2010).

Embora em países como o Brasil, a anfotericina B lipossomal ainda não esteja aprovada para o tratamento da leishmaniose cutânea, a experiência acumulada permite indicar seu uso nos casos em que as demais opções terapêuticas tenham sido utilizadas sem sucesso ou contraindicadas, particularmente, no caso de insuficiência renal. A administração deve ser diária, por um período de trinta a sessenta minutos de infusão endovenosa, na dose de 1 a 4 $\mathrm{mg} / \mathrm{Kg} / \mathrm{dia}$, sem limite de dose máxima diária. A dose total utilizada costuma ser a mesma da anfotericina desoxicolato (Brasil, 2010).

Os efeitos adversos mais comuns são: febre, cefaleia, náuseas, vômitos, anorexia, tremores, calafrios, flebite no local da infusão, hipotensão, hipopotassemia, hipomagnesemia, dor lombar, insuficiência renal aguda e distúrbios do comportamento (Brasil, 2010).

\section{Pentamidina}

A pentamidina pode ser encontrada sob a formulação de mesilato e de isotionato, em frascos/ampolas contendo $300 \mathrm{mg}$. A formulação de isotionato costuma ser melhor tolerada. Em consequência de sua ação hipoglicemiante, a droga deve ser administrada após a alimentação e o paciente deve permanecer em repouso por 15 minutos antes e após as injeções. A dose habitual é de $2-4 \mathrm{mg} / \mathrm{Kg}$, IM, em dias alternados, recomendando-se não ultrapassar a dose total de $2 \mathrm{~g}$ (Brasil, 2010).

Os efeitos adversos mais frequentes são: dor, induração e abscessos estéreis no local da aplicação, além de náuseas, vômitos, tonteira, adinamia, mialgias, cefaleia, hipotensão, lipotímias, síncope, hipoglicemia e hiperglicemia. o diabetes mellitus pode se manifestar com dose total acima de $1 \mathrm{~g}$. O tratamento é contraindicado na gestação, diabetes mellitus, insuficiência renal, insuficiência hepática, cardiopatias e em crianças com peso inferior a $8 \mathrm{~kg}$ (Brasil, 2010).

\section{MILTEFOSINA}

A utilização deste medicamento no tratamento da LTA tem sido investigada. Seus principais efeitos adversos estão relacionados à via oral, afetando o trato gastrointestinal, além da elevação das aminotransferases e da creatina fosfoquinase (Berman, 2008; Soto et al., 2004, 2008, 2009; Soto \& Soto, 2006).

\section{AVALIAÇÃO DA EFETIVIDADE DO TRATAMENTO}

A resposta ao tratamento, com evolução para a cura clínica, deverá ser acompanhada por exame físico seriado (Romero et al., 2005, 2006). 


\section{Acompanhamento Dermatológico}

A avaliação dermatológica, para verificar a resposta terapêutica, deve ser repetida durante e imediatamente após o tratamento de pacientes com a forma cutânea.

Ao término do tratamento espera-se que as lesões estejam epitelizadas (recobertas por uma 'pele fina'), embora possam apresentar crostas e descamação em sua superfície, infiltração (bordas salientes, perceptíveis à palpação) e mantenham algum grau de eritema (cicatriz rósea).

Nos casos em que não ocorra epitelização das lesões (geralmente úlceras localizadas abaixo dos joelhos), manter sem tratamento específico (apenas cuidados locais) e reavaliar quinzenalmente, devendo ser observada a contínua melhora da lesão, com superficialização do fundo e diminuição da área ulcerada em consequência da epitelização progressiva das bordas. Lesões localizadas acima dos joelhos costumam epitelizar totalmente em até trinta dias após o término do tratamento, enquanto lesões localizadas nas pernas e pés poderão demorar noventa dias ou mais, especialmente no caso de insuficiência vascular associada.

A partir da constatação da epitelização das lesões, os pacientes deverão ser reavaliados após 1, 3, 6, 9, 12, 18 e 24 meses e, se possível, anualmente até o 5 o ano. Nesse período deverá ser observada a cicatrização progressiva das lesões: ausência de crostas na avaliação do primeiro mês; ausência de descamação até o terceiro mês; ausência de infiltração até o sexto (eventualmente nono) mês; e ausência de eritema até o nono mês (eventualmente um ano).

A qualquer momento após o tratamento pode ocorrer a inversão desse processo de cura, com o reaparecimento de ulceração, crostas, descamação, infiltração ou eritema já resolvidos, com ou sem história de trauma local. Sugere-se tratar a lesão com cuidados locais e reavaliar em duas semanas. Caso o quadro se mantenha ou piore nesse período, idealmente, deve-se reavaliar o diagnóstico (principalmente nos casos tratados sem comprovação parasitológica). Nos casos com diagnóstico confirmado, considerar a necessidade de reiniciar o tratamento.

A conduta deverá ser semelhante quando não se observar boa resposta terapêutica inicial (ausência de tendência progressiva para a epitelização) (Romero et al., 2005; Romero et al., 2006).

\section{ACOMPANHAMENTO OTORRINOLARINGOLÓGICO}

Nos pacientes com a forma cutânea (sem lesão mucosa anterior ao tratamento), o ideal é que a avaliação otorrinolaringológica deva ser realizada ao término do tratamento, após 1, 3, 6, 9, 12, 18 e 24 meses e, se possível, anualmente até $05 .^{\circ}$ ano.

Nos pacientes com a forma mucosa, o ideal é que a avaliação otorrinolaringológica deva ser repetida a cada sete a dez dias de tratamento e ao seu término. A partir da constatação da epitelização completa e desinfiltração das lesões, os pacientes deverão ser reavaliados após 1, 3, 6, 9, 12, 18 e 24 meses e, se possível, anualmente até o 5o ano.

Nesse período deverá ser monitorada a eventual reativação das lesões mucosas.

\section{Recidivas de Lesões e Evolução da Forma Cutânea para a Forma Mucosa}

Pacientes que apresentem recidiva das lesões ou evolução de LC para LM deverão, como procedimento ideal, reiniciar a investigação diagnóstica (sobretudo aqueles sem comprovação parasitológica). Confirmado o diagnóstico de LTA, o tratamento deverá ser reiniciado com a mesma dosagem e pelo mesmo período, de preferência sob supervisão direta, em regime de internação hospitalar ou de hospital-dia.

Em caso de insucesso no segundo tratamento, avaliar a possibilidade de utilização de antimoniato de N-metil

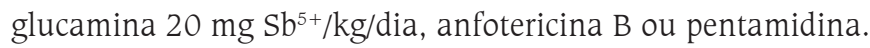


Sempre que houver evolução aberrante ou má resposta à terapêutica, deverá ser investigada a coinfecção pelo HIV ou outras doenças associadas de natureza infecciosa ou degenerativa (Romero et al., 2005, 2006).

\section{AVALIAÇÃO DA SEGURANÇA DO TRATAMENTO}

A monitorização de efeitos adversos ao tratamento, independentemente da droga e do esquema terapêutico utilizado, deverá constar minimamente de exame clínico, eletrocardiograma, hemograma, provas de função hepática, renal e pancreática.

A classificação de gravidade dos efeitos adversos clínicos, laboratoriais e eletrocardiográficos encontra-se nos Quadros 1 e 2.

Quadro 1 - Classificação de gravidade de efeitos adversos clínicos

\begin{tabular}{|c|c|c|c|c|}
\hline TOXICIDADE CLÍNICA & GRAU 1 & GRAU 2 & GRAU 3 & GRAU 4 \\
\hline Regra geral & $\begin{array}{l}\text { Leve } \\
\text { sinal ou sintoma passageiro } \\
\text { ou leve; sem limitação de } \\
\text { atividade; sem necessitar } \\
\text { cuidado médico ou tto. }\end{array}$ & $\begin{array}{l}\text { MODERADO } \\
\text { limitação de atividade leve a } \\
\text { moderada; podendo necessitar } \\
\text { cuidado médico ou tratamento }\end{array}$ & $\begin{array}{l}\text { Grave } \\
\text { limitação de atividade importante; } \\
\text { necessidade de cuidado médico ou } \\
\text { tratamento; possível hospitalização }\end{array}$ & $\begin{array}{l}\text { RISCO DE VIDA POTENCIAL } \\
\text { limitação extrema de atividade; } \\
\text { grande necessidade de cuidado } \\
\text { médico e tratamento; provável/ } \\
\text { hospitalização }\end{array}$ \\
\hline Alergia & prurido sem exantema & urticária /angioedema localizado & urticária /angioedema generalizado & anafilaxia \\
\hline Reação local & sensibilidade ou eritema & $\begin{array}{l}\text { enduração }<10 \mathrm{~cm} \text { ou flebite } \\
\text { ou inflamação }\end{array}$ & enduração > 10 cm ou ulceração & necrose \\
\hline Farmacodermia & eritema, prurido & $\begin{array}{l}\text { exantema maculopapular difuso } \\
\text { ou descamação seca }\end{array}$ & $\begin{array}{l}\text { vesiculação, descamação úmida, } \\
\text { ulceração }\end{array}$ & $\begin{array}{l}\text { dermatite exfoliativa, lesões } \\
\text { mucosas, Stevens Johnson, eritema } \\
\text { multiforme, necrose necessitando } \\
\text { desbridamento }\end{array}$ \\
\hline
\end{tabular}

Fonte: adaptado de Adult Aids Clinical Trials Group, August, 1992 (Adult Aids Clinical Trials Group).

Quadro 2 - Classificação de gravidade de efeitos adversos laboratoriais e eletrocardiográficos

\begin{tabular}{|c|c|c|c|c|}
\hline TOXICIDADE LABORATORIAL & GRAU 1 & GRAU 2 & GRAU 3 & GRAU 4 \\
\hline \multicolumn{5}{|l|}{ HeMATOLOGIA } \\
\hline Hemoglobina & $10,5-9,6 \mathrm{~g} / \mathrm{dL}$ & $9,5-8,0 \mathrm{~g} / \mathrm{dL}$ & $7,9-6,5 \mathrm{~g} / \mathrm{dL}$ & $<6,5 \mathrm{~g} / \mathrm{dL}$ \\
\hline Plaquetopenia & $99.000-5.000 / \mathrm{mm}^{3}$ & $74.999-50.000 / \mathrm{mm}^{3}$ & $49.999-20.000 / \mathrm{mm}^{3}$ & $<20.000 / \mathrm{mm}^{3}$ ou petéquias difusas \\
\hline Neutropenia & $1.500-1.000 / \mathrm{mm}^{3}$ & $999-750 / \mathrm{mm}^{3}$ & $749-500 / \mathrm{mm}^{3}$ & $<500 / \mathrm{mm}^{3}$ \\
\hline \multicolumn{5}{|l|}{ BioquímicA } \\
\hline Ureia & $100-50 \mathrm{mg} / \mathrm{dL}$ & $101-200 \mathrm{mg} / \mathrm{dL}$ & $201-400 \mathrm{mg} / \mathrm{dL}$ & $>400 \mathrm{mg} / \mathrm{dL}$ \\
\hline Creatinina & $>1,0-1,5 \times$ ULN & $>1,5-3,0 \times$ ULN & $>3,0-6,0 \times$ ULN & $>6,0 \times$ ULN ou necessidade de diálise \\
\hline Hipoglicemia & $66-55 \mathrm{mg} / \mathrm{dL}$ & $54-40 \mathrm{mg} / \mathrm{dL}$ & $39-30 \mathrm{mg} / \mathrm{dL}$ & $<30 \mathrm{mg} / \mathrm{dL}$ ou alts. mentais / coma \\
\hline Hiperglicemia & $116-160 \mathrm{mg} / \mathrm{dL}$ & $161-250 \mathrm{mg} / \mathrm{dL}$ & $251-500 \mathrm{mg} / \mathrm{dL}$ & $<500 \mathrm{mg} / \mathrm{dL}$ ou cetoacidose / convulsões \\
\hline TGO/AST & $1,25-2,5 \times$ ULN & $>2,5-5,0 \times$ ULN & $>5,0-10,0 \times$ ULN & $>10,0 \times$ ULN \\
\hline
\end{tabular}


Quadro 2 - Classificação de gravidade de efeitos adversos laboratoriais e eletrocardiográficos (continuação)

\begin{tabular}{|c|c|c|c|c|}
\hline TOXICIDADE LABORATORIAL & GRAU 1 & GRAU 2 & GRAU 3 & GRAU 4 \\
\hline \multicolumn{5}{|l|}{ Bloquímica } \\
\hline TGP/ALT & $1,25-2,5 \times$ ULN & $>2,5-5,0 \times$ ULN & $>5,0-10,0 \times$ ULN & $>10,0 \times$ ULN \\
\hline Fosfatase Alc. & $1,25-2,5 \times$ ULN & $>2,5-5,0 \times$ ULN & $>5,0-10,0 \times$ ULN & $>10,0 \times$ ULN \\
\hline Amilase & $1,1-1,5 \times$ ULN & $>1,5-2,0 \times$ ULN & $>2,0-5,0 \times$ ULN & $>5,0 \times$ ULN \\
\hline Lipase & $1,1-1,5 \times$ ULN & $>1,5-2,0 \times$ ULN & $>2,0-5,0 \times$ ULN & $>5,0 \times$ ULN \\
\hline Triglicerídeos & - & $400-750 \mathrm{mg} / \mathrm{dL}$ & $751-1.200 \mathrm{mg} / \mathrm{dL}$ & $<1.200 \mathrm{mg} / \mathrm{dL}$ \\
\hline Colesterol & $200-239 \mathrm{mg} / \mathrm{dL}$ & $240-300 \mathrm{mg} / \mathrm{dL}$ & $301-400 \mathrm{mg} / \mathrm{dL}$ & $<400 \mathrm{mg} / \mathrm{dL}$ \\
\hline Hipopotassemia & $3,4-3,0 \mathrm{mEq} / \mathrm{L}$ & $2,9-2,5 \mathrm{mEq} / \mathrm{L}$ & $2,4-2,0 \mathrm{mEq} / \mathrm{L}$ & $<2,0 \mathrm{mEq} / \mathrm{L}$ \\
\hline \multicolumn{5}{|l|}{ ECG } \\
\hline & $0,44 \mathrm{~s}<\mathrm{QTC}<0,46 \mathrm{~s}$ & $\begin{array}{l}\text { alts. transitórias, } \\
\text { assintomáticas, } \\
\text { não tto. }\end{array}$ & $\begin{array}{l}\text { alts. recorrentes / } \\
\text { persistentes, sintomáticas } \\
\text { podendo necessitar cuidado } \\
\text { médico ou tto. ou } 0,46 \mathrm{~s} \leq \\
\text { QTc }<0,50 \text { s }\end{array}$ & $\begin{array}{l}\text { arritmia instável, necessidade tto./ hospitalização ou } \\
\text { QTc } \geq 0,50 \text { s }\end{array}$ \\
\hline
\end{tabular}

Fonte: adaptado de Adult Aids Clinical Trials Group, August, 1992 (Adult Aids Clinical Trials Group).

\section{EXAMES LABORATORIAIS E ELETROCARDIOGRÁFICO PARA MONITORAR EFEITOS ADVERSOS}

Hemograma, glicose, ureia, creatinina, AST, ALT, fosfatase alcalina, gama GT, amilase, lipase e eletrocardiograma (ECG) deverão ser realizados antes do tratamento, a cada sete a dez dias durante o tratamento, ao término deste e trinta dias após.

Para anfotericina B acrescentar dosagens de $\mathrm{Na}$ e K, e utilizar intervalos de avaliação mais curtos.

Ao se utilizar a pentamidina, a glicemia deve ser acompanhada mensalmente durante seis meses sempre que a dose total ultrapassar $1 \mathrm{~g}$.

\section{ACOMPANHAMENTO CLÍNICO}

A avaliação clínica deve ser realizada antes do tratamento, para detectar e controlar possíveis comorbidades que possam interferir na boa resposta ou na tolerância ao tratamento específico da LTA.

Para o monitoramento de efeitos adversos, o ideal é que a avaliação deva ser repetida a cada sete a dez dias durante o tratamento, de acordo com as condições clínicas do paciente, ao término do tratamento e trinta dias após. Entretanto, alterações surgidas durante o tratamento e presentes ao seu término devem ser monitoradas até a sua normalização.

Vale destacar que a realização de duas ou mais avaliações, durante o tratamento, permite detectar precocemente progressões na gravidade dos efeitos adversos, para que se possa intervir a tempo. É importante sempre lembrar que, se algum efeito adverso grave for detectado na avaliação pós-tratamento, pouco poderá ser feito além de se aguardar a eliminação da droga pelo organismo. Por exemplo, um prolongamento no intervalo QTc acima de 0,50 ms no eletrocardiograma não costuma causar sintomas, mas é um fator de risco para arritmia súbita e fatal.

Em casos de alterações persistentes ou rapidamente progressivas, recomenda-se a suspensão temporária do tratamento até a normalização dos exames. Os exames alterados ao término do tratamento deverão ser monitorados até a sua normalização. 
Pacientes que necessitem interromper temporariamente o tratamento por toxicidade, ao recomeçar, deverão dar sequência ao tratamento a partir da última dose administrada, como se não tivesse havido qualquer interrupção. A orientação de condutas em caso de efeito adverso encontra-se no Quadro 3.

Quadro 3 - Orientação de condutas em caso de efeito adverso

\begin{tabular}{|c|c|c|c|}
\hline & \multicolumn{3}{|c|}{ TIPO DE EFEITO ADVERSO } \\
\hline & cLínico & LABORATORIAL & ELETROCARDIOGRÁFICO \\
\hline Grau 1 & manter tto. & manter tto. & manter tto. \\
\hline Grau 2 & $\begin{array}{l}\text { considerar interrupção temporária do tto., } \\
\text { usar sintomáticos }\end{array}$ & interromper tto., aguardar $\leq \mathrm{Gl}$ para reintroduzir & Considerar interrupção temporária do tto. \\
\hline Grau 3 & $\begin{array}{l}\text { interromper tto., usar sintomáticos, } \\
\text { aguardar } \leq \text { G2 para reintroduzir }\end{array}$ & interromper tto., aguardar $\leq \mathrm{G} 1$ para reintroduzir & $\begin{array}{l}\text { interromper tto., aguardar } Q T \mathrm{Tc} \leq 0,46 \mathrm{~s} \text { ou } \\
\text { regressão das alterações para reintroduzir }\end{array}$ \\
\hline Grau 4 & interromper definitivamente tto. & interromper definitivamente tto. & interromper definitivamente tto. \\
\hline
\end{tabular}

Fonte: adaptado de Adult Aids Clinical Trials Group, August, 1992 (Adult Aids Clinical Trials Group).

\section{REFERÊNCIAS}

ADULT AIDS CLINICAL TRIALS GROUP. Aids table for grading severity of adult adverse experiences, 1992 [cited 2008 Mars 24]. Disponível em: <http://rsc.tech-res.com/Document/safetyandpharmacovigilance/Table_for_Grading_Severity_of_ Adult_AEs_v01a.pdf > . Acesso em: 6 jul. 2004.

AEBISCHER, T. Recurrent cutaneous leishmaniasis: a role for persistent parasites? Parasitology Today, 10: 25-28, 1994.

AMATO, V. S. et al. Persistence of tumor necrosis factor-alpha in situ after lesion healing in mucosal leishmaniasis. The American Journal of Tropical Medicine and Hygiene, 68(5): 527-528, 2003.

AMATO, V. S. et al. Treatment of mucosal Leishmaniasis in Latin America: systematic review. The American Journal of Tropical Medicine and Hygiene, 77(2): 266-274, 2007.

ARONSON, N. E. et al. Safety and efficacy of intravenous sodium stibogluconate in the treatment of leishmaniasis: recent U.S. military experience. Clinical Infectious Diseases, 27(6): 1.457-1.464, 1998.

AZEREDO-COUTINHO, R. B. \& MENDONCA, S. C. An intermittent schedule is better than continuous regimen of antimonial therapy for cutaneous leishmaniasis in the municipality of Rio de Janeiro, Brazil. Revista da Sociedade Brasileira de Medicina Tropical, 3(5): 477-481, 2002.

AZEREDO-COUTINHO, R. B. et al. Sensitivity of Leishmania braziliensis promastigotes to meglumine antimoniate (glucantime) is higher than that of other Leishmania species and correlates with response to therapy in American tegumentary leishmaniasis. The Journal of Parasitology, 93(3): 688-693, 2007.

BADARÓ, R. et al. Granulocyte-macrophage colony-stimulating factor in combination with pentavalent antimony for the treatment of visceral Leishmaniasis. European Journal of Clinical Microbiology \& Infectious Diseases, 13, supl. 2: S23-S28, 1994.

BADARó, R. et al. Immunotherapy for drug-refractory mucosal leishmaniasis. The Journal of Infectious Diseases, 194(8): 1.151-1.159, 2006.

BAPTISTA, C. et al. Leishmania (Viannia) braziliensis genotypes identified in lesions of patients with atypical or typical manifestations of tegumentary leishmaniasis: evaluation by two molecular markers. Experimental Parasitology, 121(4): 317-322, 2009.

BARRAL-NETTO, M. et al. Human leishmaniasis cytokines, Bahia, Brazil. Brazilian Journal of Medical and Biological Research, 31(1): 149-155, 1998. 
BASANO, S. A. \& CAMARGO, L. M. A. Leishmaniose tegumentar americana: histórico, epidemiologia e perspectivas de controle. Revista Brasileira de Epidemiologia, 7(3): 328-337, 2004.

BELKAID, Y. et al. CD8(+) T cells are required for primary immunity in C57BL/6 mice following low-dose, intradermal challenge with Leishmania major. The Journal of Immunology, 168(8): 3.992-4.000, 2002.

BERMAN, J. J. Treatment of leishmaniasis with miltefosine: 2008 status. Expert Opinion on Drug Metabolism and Toxicology, 4(9): 1.209-1.216, 2008.

BLUM, J. A. \& HATZ, C. F. Treatment of cutaneous leishmaniasis in travelers 2009. Journal of Travel Medicine, 16(2): 123131, 2009.

BLUM J. et al. Local or systemic treatment for New World cutaneous leishmaniasis? Re-evaluating the evidence for the risk of mucosal leishmaniasis. International Health, 4(3): 153-63, 2012.

BRASIL. Ministério da Saúde. Secretaria de Vigilância em Saúde. Manual de Vigilância da Leishmaniose Tegumentar Americana. 2. ed. Brasília: Ministério da Saúde, 2010.

BRAY, P. G. et al. Pentamidine uptake and resistance in pathogenic protozoa: past, present and future. Trends in Parasitology, 19(5): 232-239, 2003.

CALVOPINA, M. et al. Leishmaniasis recidiva cutis due to Leishmania Viannia) panamensis in subtropical Ecuador: isoenzymatic characterization. International Journal of Dermatology, 45(2): 116-120, 2006.

CARVALHO, J. A. M. \& GARCIA, R. A. The aging process in the Brazilian population: a demographic approach. Cadernos de saúde Pública, 19(3): 725-733, 2003.

CAVAZZUTI, A. et al. Discovery of potent pteridine reductase inhibitors to guide antiparasite drug development. Proceedings of the National Academy of Sciences of the USA, 105(5): 1.448-1.453, 2008.

CLAROS, P. et al. Intralesional treatment of cutaneous leishmaniasis: a report of two cases. Acta Otorrinolaringológica Española, 47(1): 67-70, 1996.

COLMENARES, M. et al. Mechanisms of pathogenesis: differences amongst Leishmania species. Transactions of the Royal Society of Tropical Medicine and Hygiene, 96, supl. 1: S3-S7, 2002.

CONCEIÇÃO-SILVA, F. et al. Quantitative study of Leishmania braziliensis braziliensis reactive T cells in peripheral blood and in the lesions of patients with American mucocutaneous leishmaniasis. Clinical and Experimental Immunology, 79(2): 221-226, 1990.

CONVIT, J. et al. Immunotherapy of American cutaneous leishmaniasis in Venezuela during the period 1990-99. Transactions of the Royal Society of Tropical Medicine and Hygiene, 97(4): 469-472, 2003.

CONVIT, J. et al. Therapy of Venezuelan patients with severe mucocutaneous or early lesions of diffuse cutaneous leishmaniasis with a vaccine containing pasteurized Leishmania promastigotes and bacillus Calmette-Guerin: preliminary report. Memórias do Instituto Oswaldo Cruz, 99(1): 57-62, 2004.

COSTA, E. V. et al. Antimicrobial and antileishmanial activities of essential oil from the leaves of Annona foetida (Annonaceae). Química Nova, 32: 78-81, 2009.

CROFT, S. L. \& YARDLEY, V. Chemotherapy of leishmaniasis. Current Pharmaceutical Design, 8(4): 319-342, 2002.

CROFT, S. L.; SEIFERT, K. \& YARDLEY, V. Current scenario of drug development for leishmaniasis. The Indian Journal of Medical Research, 123(3): 399-410, 2006.

CRUZ, A. M. et al. Cellular and humoral immune responses of a patient with American cutaneous leishmaniasis and Aids. Transactions of the Royal Society of Tropical Medicine and Hygiene, 86(5): 511-512, 1992.

CRUZ, A. M. et al. Leishmania-reactive $\mathrm{CD}^{+}$and $\mathrm{CD}^{+} \mathrm{T}$ cells associated with cure of human cutaneous leishmaniasis. Infection and Immunity, 62(6): 2.614-2.618, 1994.

CZECHOWICZ, R. T. et al. Reactivation of cutaneous leishmaniasis after surgery. British Journal of Dermatology, 141(6): 1.113-1.116, 1999. 
CHOI, B. S. \& KROPF, P. Evaluation of T cell responses in healing and nonhealing leishmaniasis reveals differences in T helper cell polarization ex vivo and in vitro. Parasite Immunology, 31(4): 199-209, 2009.

DEPS, P. D.et al. Comparative assessment of the efficacy and toxicity of N-methyl-glucamine and BP88 sodium stibogluconate in the treatment of localized cutaneous leishmaniasis. Revista da Sociedade Brasileira de Medicina Tropical, 33(6): 535543, 2000.

D’UTRA E SILVA, O. Sobre a leishmaniose tegumentar e seu tratamento. Memórias do Instituto Oswaldo Cruz, 7: 213-248, 1915.

FERREIRA, I. C. et al. Anti-leishmanial activity of alkaloidal extract from Aspidosperma ramiflorum. Memórias do Instituto Oswaldo Cruz, 99(3): 325-327, 2004.

FRANKE, E. D. et al. Efficacy and toxicity of sodium stibogluconate for mucosal leishmaniasis. Annals of Internal Medicine, 113(12): 934-940, 1990.

GIATTI, L. \& BARRETO, S. M. Health, work, and aging in Brazil. Cadernos de Saúde Pública, 19(3): 759-771, 2003.

GONTIJO, B. \& CARVALHO, M. L. R. American cutaneous leishmaniasis. Revista da Sociedade Brasileira de Medicina Tropical, 36(1): 71-80, 2003.

GONZALEZ, U. et al. Designing and reporting clinical trials on treatments for cutaneous leishmaniasis. Clinical Infectious Diseases, 51(4): 409-419, 2010.

GONZALEZ, U. et al. Interventions for American cutaneous and mucocutaneous leishmaniasis. Cochrane Database Systematic Reviews (Online), 2, 2009.

GREENHALGH, D. G. The role of apoptosis in wound healing. The International Journal of Biochemistry \& Cell Biology, 30(9): 1.019-1.030, 1998.

GROGL, M.; THOMASON, T. N. \& FRANKE, E. D. Drug resistance in leishmaniasis: its implication in systemic chemotherapy of cutaneous and mucocutaneous disease. The American Journal of Tropical Medicine and Hygiene, 47(1): 117-126, 1992.

GUAN, D.; OHSHIMA, T. \& KONDO, T. Immunohistochemical study on Fas and Fas ligand in skin wound healing. The Histochemical Journal, 32(2): 85-91, 2000.

HARMS, G. et al. A randomized trial comparing a pentavalent antimonial drug and recombinant interferon-gamma in the local treatment of cutaneous leishmaniasis. Transactions of the Royal Society of Tropical Medicine and Hygiene, 85(2): 214-216, 1991.

HEPBURN, N. C. Cutaneous leishmaniasis. Clinical and Experimental Dermatology, 25(5): 363-370, 2000.

HEPBURN, N. C. et al. Cardiac effects of sodium stibogluconate: myocardial, electrophysiological and biochemical studies. QJM, 87(8): 465-472, 1994a.

HEPBURN, N. C. et al. Hepatotoxicity of sodium stibogluconate therapy for American cutaneous leishmaniasis. Transactions of the Royal Society of Tropical Medicine and Hygiene, 88(4): 453-455, $1994 \mathrm{~b}$.

HEPBURN, N. C. Management of cutaneous leishmaniasis. Current Opinion in Infectious Diseases, 14(2): 151-154, 2001.

HERWALDT, B. L. \& BERMAN, J. D. Recommendations for treating leishmaniasis with sodium stibogluconate (Pentostam) and review of pertinent clinical studies. The American Journal of Tropical Medicine and Hygiene, 46(3): 296-306, 1992.

INSTITUTO BRASILEIRO DE GEOGRAFIA E ESTATÍSTICA (IBGE). Censo Demográfico 1980. Rio de Janeiro: Fundação Instituto Brasileiro de Geografia e Estatística (IBGE), 1981.

INSTITUTO BRASILEIRO DE GEOGRAFIA E ESTATÍSTICA (IBGE). Censo Demográfico 2000. Rio de Janeiro: Fundação Instituto Brasileiro de Geografia e Estatística (IBGE), 2001.

JHA, T. K. Drug unresponsiveness \& combination therapy for kala-azar. The Indian Journal of Medical Research, 123(3): 389398, 2006

KIM, D. H. et al. Is paromomycin an effective and safe treatment against cutaneous leishmaniasis? A meta-analysis of 14 randomized controlled trials. PLoS Neglected Tropical Diseases, 3(2): e381, 2009. 
KUBAR, J. et al. Visceral leishmaniosis in HIV-positive patients: primary infection, reactivation and latent infection. Impact of the CD4+ T-lymphocyte counts. Aids, 12(16): 2.147-2.153, 1998.

LEON, L. L. et al. Antileishmanial activity of the violacein extracted from Chromobacterium violaceum. The Journal of Antimicrobial Chemotherapy, 48(3): 449-450, 2001.

LOKE, Y. K.; PRICE, D. \& HERXHEIMER, A. Systematic reviews of adverse effects: framework for a structural approach. BMC Medical Research Methodology, 7: 32, 2007.

MACHADO, G. M.; LEON, L. L. \& CASTRO, S. L. Activity of Brazilian and Bulgarian propolis against different species of Leishmania. Memórias do Instituto Oswaldo Cruz, 102(1): 73-77, 2007.

MACHADO, P. et al. Failure of early treatment of cutaneous leishmaniasis in preventing the development of an ulcer. Clinical Infectious Diseases, 34(12): E69-E73, 2002.

MACHADO-PINTO, J. et al. Immunochemotherapy for cutaneous leishmaniasis: a controlled trial using killed Leishmania (Leishmania) amazonensis vaccine plus antimonial. International Journal of Dermatology, 41(2): 73-78, 2002.

MARSDEN, P. D. Pentavalent antimonials: old drugs for new diseases. Revista da Sociedade Brasileira de Medicina Tropical, 18(3): 187-198, 1985.

MAURER, M.; DONDJI, B. \& VON STEBUT, E. What determines the success or failure of intracellular cutaneous parasites? Lessons learned from leishmaniasis. Medical Microbiology and Immunology, 198(3): 137-146, 2009.

MAVILIA, L. et al. Leishmaniasis recidiva cutis: an unusual two steps recurrence. International Journal of Dermatology, 41(8): 506-507, 2002.

MAYRINK, W. et al. Immunotherapy as a treatment of American cutaneous leishmaniasis: preliminary studies in Brazil. Parassitologia, 34(1-3): 159-165, 1992.

MAYRINK, W. et al. Phase I and II open clinical trials of a vaccine against Leishmania chagasi infections in dogs. Memórias do Instituto Oswaldo Cruz, 91(6): 695-697, 1996.

MENDEZ, S. et al. Role for $\mathrm{CD} 4(+) \mathrm{CD} 25(+)$ regulatory $\mathrm{T}$ cells in reactivation of persistent leishmaniasis and control of concomitant immunity. The Journal of Experimental Medicine, 200(2): 201-210, 2004.

MENDONÇA, M. G. et al. Persistence of Leishmania parasites in scars after clinical cure of american cutaneous leishmaniasis: is there a sterile cure? The Journal of Infectious Diseases, 189(6): 1.018-1.023, 2004.

MENDONÇA, S. C. et al. Human American cutaneous leishmaniasis (Leishmania b. braziliensis) in Brazil: lymphoproliferative responses and influence of therapy. Clinical and Experimental Immunology, 64(2): 269-276, 1986.

MENDONÇA, S. C. et al. Indirect immunofluorescence test in New World leishmaniasis: serological and clinical relationship. Memórias do Instituto Oswaldo Cruz, 83(3): 347-355, 1988.

MISHRA, B. B. et al. Alkaloids: future prospective to combat leishmaniasis. Fitoterapia, 80(2): 81-90, 2009.

MOLL, H.; FLOHE, S. \& ROLLINGHOFF, M. Dendritic cells in Leishmania major-immune mice harbor persistent parasites and mediate an antigen-specific T cell immune response. European Journal of Immunology, 25(3): 693-699, 1995.

MORGADO, F. N. et al. Signs of an in situ inflammatory reaction in scars of human American tegumentary leishmaniasis. Parasite Immunology, 32(4): 285-295, 2010.

MOSLEH, I. M. et al. Efficacy of a weekly cryotherapy regimen to treat Leishmania major cutaneous leishmaniasis. Journal of the American Academy of Dermatology, 58(4): 617-624, 2008.

MUNIZ-JUNQUEIRA, M. I. \& PAULA-COELHO, V. N. Meglumine antimonate directly increases phagocytosis, superoxide anion and TNF-alpha production, but only via TNF-alpha it indirectly increases nitric oxide production by phagocytes of healthy individuals, in vitro. International Immunopharmacology, 8(12): 1.633-1.638, 2008.

MUSA, A. M. et al. Immunochemotherapy of persistent post-kala-azar dermal leishmaniasis: a novel approach to treatment. Transactions of the Royal Society of Tropical Medicine and Hygiene, 102(1): 58-63, 2008. 
MUSA, A. M. et al. Immunological stimulation for the treatment of leishmaniasis: a modality worthy of serious consideration. Transactions of the Royal Society of Tropical Medicine and Hygiene, 104(1): 1-2, 2010.

NASCimento, T. L. M. Estudo Clínico-Laboratorial de Casos de Insucesso Terapêtico Durante o Uso de Antimonial Pentavalente no Tratamento de Portadores de Leishmaniose Tegumentar Americana, 2009. Dissertação de Mestrado, Rio de Janeiro: Universidade Federal do Rio de Janeiro.

NEUBER, H. Leishmaniasis. Journal der Deutschen Dermatologischen Gesellschaft, 6(9): 754-765, 2008.

OLIVEIRA, L. F. G. Revisão Sistemática da Segurança do Tratamento da Leishmaniose Cutânea no Novo Mundo, 2010. Dissertação de Mestrado, Rio de Janeiro: Instituto de Pesquisa Clínica Evandro Chagas, Fundação Oswaldo Cruz.

OLIVEIRA L. F. et al. Systematic review of the adverse effect of cutaneous leishmaniasis treatment in the New World. Acta Tropica, 118 (2): 87-96, 2011.

OLIVEIRA-NETO, M. P. et al. High and low doses of antimony $\left(\mathrm{Sb}^{\mathrm{v}}\right)$ in American cutaneous leishmaniasis. A five years followup study of 15 patients. Memórias do Instituto Oswaldo Cruz, 91(2): 207-209, 1996.

OLIVEIRA-NETO, M. P. et al. Treatment of American cutaneous leishmaniasis: a comparison between low dosage (5mg/kg/ day) and high dosage (20mg/kg/day) antimony regimens. Pathologie et Biologie, 45(6): 496-469, $1997 \mathrm{a}$.

OLIVEIRA-NETO, M. P. et al. A low-dose antimony treatment in 159 patients with American cutaneous leishmaniasis. Extensive follow-up studies (up to 10 years). The American Journal of Tropical Medicine and Hygiene, 57(6): 651-655, 1997b.

OLIVEIRA-NETO, M. P. et al. Intralesional therapy of American cutaneous leishmaniasis with pentavalent antimony in Rio de Janeiro, Brazil - an area of Leishmania (V.) braziliensis transmission. International Journal of Dermatology, 36(6): 463-468, 1997c.

OLIVEIRA-NETO, M. P. et al. Mucosal leishmaniasis ('espundia') responsive to low dose of N-methyl glucamine (Glucantime) in Rio de Janeiro, Brazil. Revista do Instituto de Medicina Tropical de São Paulo, 42 (6): 321-325, 2000.

OUELlETte, M.; DRUMmelsmith, J. \& PAPAdOPOUlOU, B. Leishmaniasis: drugs in the clinic, resistance and new developments. Drug Resistance Updates, 7(4-5): 257-266, 2004.

RAHMAN, S. B.; UL BARI, A. \& MUMTAZ, N. Miltefosine in cutaneous leishmaniasis. Journal of the College of Physicians and Surgeons-Pakistan, 17(3): 132-135, 2007.

RAMíREZ, J. L. \& GUEVARA, P. Persistent infections by Leishmania (Viannia) braziliensis. Memórias do Instituto Oswaldo Cruz, $92(3): 333-338,1997$.

REVEIZ, L. et al. Interventions for American cutaneous and mucocutaneous leishmaniasis: a systematic review update. PLoS One, 8(4):e61843, 2013.

RIBEIRO, A. L. et al. Electrocardiographic changes during low-dose, short-term therapy of cutaneous leishmaniasis with the pentavalent antimonial meglumine. Brazilian Journal of Medical and Biological Research, 32 (3): 297-301, 1999.

ROBERTS, W. L.; MCMURRAY, W. J. \& RAINEY, P. M. Characterization of the antimonial antileishmanial agent meglumine antimonate (glucantime). Antimicrob Agents and Chemotherapy, 42(5): 1.076-1.082, 1998.

RODRIGUES, A. M. et al. Factors associated with treatment failure of cutaneous leishmaniasis with meglumine antimoniate. Revista da Sociedade Brasileira de Medicina Tropical, 39(2): 139-145, 2006.

RODRIGUES, M. L. et al. Nephrotoxicity attributed to meglumine antimoniate (Glucantime) in the treatment of generalized cutaneous leishmaniasis. Revista do Instituto de Medicina Tropical de São Paulo, 41(1): 33-37, 1999.

ROJAS, R. et al. Resistance to antimony and treatment failure in human Leishmania (Viannia) infection. The Journal of Infectious Diseases, 193(10): 1.375-1.383, 2006.

ROMERO, G. A. S. et al. Simpósio sobre Tratamento das Leishmanioses. Revista da Sociedade Brasileira de Medicina Tropical, 34, supl. III: 58-68, 2001a.

ROMERO, G. A. et al. Comparison of cutaneous leishmaniasis due to Leishmania (Viannia) braziliensis and L. (V.) guyanensis in Brazil: therapeutic response to meglumine antimoniate. The American Journal of Tropical Medicine and Hygiene, 65(5): 456-465, 2001b. 
ROMERO, G. et al. Critérios para a avaliação da eficácia terapêutica na leishmaniose cutânea. Revista da Sociedade Brasileira de Medicina Tropical, 38, supl. IV: 38-42, 2005.

ROMERo, G. A. et al. O desafio para a realização de ensaios clínicos em leishmaniose tegumentar. Revista da Sociedade Brasileira de Medicina Tropical, 39, supl. III: 100-103, 2006.

SAENZ, R. E. et al. Efficacy and toxicity of pentostam against Panamanian mucosal leishmaniasis. The American Journal of Tropical Medicine and Hygiene, 44(4): 394-398, 1991.

SALDANHA, A. C. et al. Comparative study between sodium stibogluconate BP 88 and meglumine antimoniate in cutaneous leishmaniasis treatment. II. Biochemical and cardiac toxicity. Revista da Sociedade Brasileira de Medicina Tropical, 33(4): 383-388, 2000.

SAMPAIO, R. N. \& MARSDEN, P. D. Treatment of the mucosal form of leishmaniasis without response to glucantime, with liposomal amphotericin B. Revista da Sociedade Brasileira de Medicina Tropical, 30(2): 125-128, 1997.

SAMPAIO, R. N. et al. The evaluation of the tolerance and nephrotoxicity of pentavalent antimony administered in a dose of $40 \mathrm{mg} \mathrm{Sb} / \mathrm{kg} /$ day, $12 / 12 \mathrm{hr}$, for 30 days in the mucocutaneous form of leishmaniasis. Revista da Sociedade Brasileira de Medicina Tropical, 30(6): 457-463, 1997.

SAMPAIO, R. N. et al. American cutaneous leishmaniasis associated with HIV/AIDS: report of four clinical cases. Revista da Sociedade Brasileira de Medicina Tropical, 35(6): 651-654, 2002.

SANTOS, D. O. et al. Leishmaniasis treatment--a challenge that remains: a review. Parasitology Research, 103(1): 1-10, 2008.

SANTOS, M. A. et al. Predictors of an unsatisfactory response to pentavalent antimony in the treatment of American visceral leishmaniasis. Revista da Sociedade Brasileira de Medicina Tropical, 35(6): 629-633, 2002.

SCHUBACH, A. et al. Healed lesion of cutaneous leishmaniasis - a positive culture for Leishmania sp. in the scar tissue eight years after cure. In: REUNIÃO ANUAL SOBRE PESQUISA BÁSICA EM DOENÇA DE CHAGAS, XIV, nov. 1987, Caxambu.

SCHUBACH, A. et al. Cicatricial lesions of cutaneous leishmaniasis (CL). Detection of Leishmania brazilienis braziliensis (Lbb) antigens by the immunoperoxidase avidin \& biotin technique (IP-AB). XV Reunião Anual Sobre Pesquisa Básica em Doença de Chagas; 1988 novembro 1988; Caxambu: Memórias do Instituto Oswaldo Cruz, 83: 129, 1988.

SCHUBACH, A. et al. Cicatricial lesions of cutaneous leishmaniasis (CL): Detection of Leishmania braziliensis braziliensis (Lbb) antigens by the immunoperoxidase avidin-biotin technique (IP) and immunofluorescence (IF). XVI Reunião Anual Sobre Pesquisa Básica em Doença de Chagas; 1989 novembro 1989; Caxambu: Memórias do Instituto Oswaldo Cruz; 1989. p. 92.

SCHUBACH, A. et al. Cutaneous scars in American tegumentary leishmaniasis patients: a site of Leishmania (Viannia) braziliensis persistence and viability eleven years after antimonial therapy and clinical cure. The American Journal of Tropical Medicine and Hygiene, 58(6): 824-827, 1998a.

$\mathrm{SCHUBACH}$, A. et al. Detection of Leishmania DNA by the polymerase chain reaction in scars of treated human patients. The Journal of Infectious Diseases, 178(3): 911-914, 1998b.

$\mathrm{SCHUBACH}$, A. et al. Leishmanial antigens in the diagnosis of active lesions and ancient scars of American tegumentary leishmaniasis patients. Memórias do Instituto Oswaldo Cruz, 96(7): 987-996, 2001.

SCHUBACH, A. O. et al. Retrospective study of 151 patients with cutaneous leishmaniasis treated with meglumine antimoniate. Revista da Sociedade Brasileira de Medicina Tropical, 38(3): 213-217, 2005.

SEATON, R. A. et al. Out-patient parenteral antimicrobial therapy - a viable option for the management of cutaneous leishmaniasis. QJM, 92(11): 659-667, 1999.

SHARQUIE, K. E. A new intralesional therapy of cutaneous leishmaniasis with hypertonic sodium chloride solution. The Journal of Dermatology, 22(10): 732-737, 1995.

SHUKLA, A. K. et al. Rational approaches for drug designing against leishmaniasis. Applied Biochemistry and Biotechnology, $160(8): 2.208-2.218,2010$. 
SILVA, J. R. et al. Chemical and biochemical evaluation of essential oil with economic value from Lauraceae species. Journal of the Brazilian Chemical Society, 20: 1.071-1.076, 2009.

SINGH, S. \& SIVAKUMAR, R. Challenges and new discoveries in the treatment of leishmaniasis. Journal of Infection and Chemotherapy, 10(6): 307-315, 2004.

SISTEMA DE INFORMAÇÃO DE AGRAVOS DE NOTIFICAÇÃO (SINAN). Leishmaniose Tegumentar - Brasil: frequência por UF de residência e faixa etária. Brasília: Sistema de Informação e Agravos de Notificação Compulsória, Ministério da Saúde, 2003.

SOTO, J. \& SOTO, P. Miltefosine: oral treatment of leishmaniasis. Expert Review of Anti-Infective Therapy, 4(2): 177-185, 2006.

SOTO, J. et al. Miltefosine for new world cutaneous leishmaniasis. Clinical Infectious Diseases, 38(9): 1.266-1.272, 2004.

SOTO, J. et al. Efficacy of miltefosine for Bolivian cutaneous leishmaniasis. The American Journal of Tropical Medicine and Hygiene, 78(2): 210-211, 2008.

SOTO, J. et al. Efficacy of extended (six weeks) treatment with miltefosine for mucosal leishmaniasis in Bolivia. The American Journal of Tropical Medicine and Hygiene, 81(3): 387-389, 2009.

STENGER, S. et al. Reactivation of latent leishmaniasis by inhibition of inducible nitric oxide synthase. The Journal of Experimental Medicine, 183(4): 1.501-1.514, 1996.

TALLAB, T. M. et al. Cutaneous leishmaniasis: schedules for intralesional treatment with sodium stibogluconate. International Journal of Dermatology, 35(8): 594-597, 1996.

TEMPONE, A. G. et al. Brazilian flora extracts as source of novel antileishmanial and antifungal compounds. Memórias do Instituto Oswaldo Cruz, 103(5): 443-449, 2008.

THAKUR, C. P. \& KUMAR, K. Efficacy of prolonged therapy with stibogluconate in post kala-azar dermal leishmaniasis. The Indian Journal of Medical Research, 91: 144-148, 1990.

THAKUR, C. P.; KUMAR, M. \& PANDEY, A. K. Comparison of regimes of treatment of antimony-resistant kala-azar patients: a randomized study. The American Journal of Tropical Medicine and Hygiene, 45(4): 435-441, 1991.

TUON, F. F. et al. Local immunological factors associated with recurrence of mucosal leishmaniasis. Clinical Immunology: the Official Journal of the Clinical Immunology Society (Orlando), 128(3): 442-446, $2008 \mathrm{a}$.

TUON, F. F. et al. Treatment of New World cutaneous leishmaniasis--a systematic review with a meta-analysis. International Journal of Dermatology, 47(2): 109-124, 2008b.

UNGER, A. et al. Association of treatment of American cutaneous leishmaniasis prior to ulcer development with high rate of failure in northeastern Brazil. The American Journal of Tropical Medicine and Hygiene, 80(4): 574-579, 2009.

VASCONCELLOS, E. C. F. Avaliação da Eficácia e Segurança do Antimoniato de Meglumina Intralesional, em uma Série de Pacientes com Leishmaniose Cutânea e Contra-Indicação de Terapia Sistêmica, Atendidos no Instituto de Pesquisa Clínica Evandro Chagas (2000-2006), 2009. Dissertação de Mestrado, Rio de Janeiro: Instituto de Pesquisa Clínica Evandro Chagas, Fundação Oswaldo Cruz.

VIANNA, G. Sobre uma nova espécie de Leishmania (Nota preliminar). Brazil Médico, 25: 411, 1911.

VIANNA, G. Sobre o tratamento da leishmaniose tegumentar. Annais Paulistas de Medicina e Cirurgia, II: 167-169, 1914.

VINCENT I. M. et al. Untargeted metabolomic analysis of miltefosine action in Leishmania infantum reveals changes to the internal lipid metabolism. International Journal for Parasitology. Drugs and Drug Resistance, 4(1): 20-27, 2014.

WORLD HEALTH ORGANIZATION (WHO). The Leishmaniases. Geneva: World Health Organization, 1984. (WHO Technical Report Series, 701).

WORLD HEALTH ORGANIZATION (WHO). Control of Leishmaniases: report of a WHO Expert Committee. Geneva: World Health Organization, 1990. 


\section{Modelos de Estudo para o Desenvolvimento de Drogas Anti-Leishmania}

Renata 0. de A. Soares I Leonor Leon

$\mathrm{A}_{\text {mundo, com uma prevalência mundial de } 12 \text { milhões de casos. A doença é endêmica em determinadas áreas }}$ geográficas, representando um sério problema de saúde pública, econômico e político, uma vez que apresenta um aumento anual de casos bastante significativo, o que afeta preferencialmente populações demasiadamente pobres. Além disso, a grande incidência da coinfecção Leishmania/HIV faz com que ela seja considerada um problema emergencial com dificuldade de tratamento (Desjeux, 2004).

O controle das leishmanioses é dificultado pela variedade de espécies de Leishmania e suas manifestações clínicas. O desenvolvimento da infecção leishmanial depende das propriedades do parasito, como a infectividade, a patogenicidade e a virulência, além da heterogenicidade de resposta regulatória à infecção pelo hospedeiro, que resultam em diferentes manifestações clínicas (Murray, 2005). O tratamento das leishmanioses é principalmente baseado no uso de antimoniais pentavalentes, complexados a carboidratos, na forma de estibogliconato de sódio $\left(\right.$ Pentostan $\left.^{\circledR}\right)$ e antimoniato de meglumina $\left(\right.$ Glucantime $\left.^{\circledR}\right)$.

Entre outras drogas utilizadas na terapêutica das leishmanioses estão a anfotericina B, a pentamidina e a miltefosina, sendo esta a primeira droga oral efetiva contra a leishmaniose cutânea, na Colômbia, e contra a visceral, na Índia (Soto et al., 2004; Sundar \& Murray, 2005). No decorrer das últimas décadas, drogas alternativas ou novas formulações de outras drogas padrão têm sido avaliadas e registradas para uso em alguns países. Variações na resposta clínica ao tratamento com esses antimoniais têm sido um persistente problema no tratamento da doença. O longo curso de tratamento provoca um acúmulo de droga em tecidos como baço e fígado, além de causar mialgia, pancreatite, arritmia cardíaca e hepatite, que levam à redução ou mesmo ao abandono do tratamento. Finalmente, dados da literatura têm demonstrado casos de resistência adquirida aos antimoniais (Carvalho et al., 2000; Croft, Seifert \& Yardley, 2006).

Considerando-se a problemática do tratamento das leishmanioses, é essencial a busca experimental de compostos que possibilitem o desenvolvimento de novos fármacos altamente efetivos, sem efeitos colaterais e que não induzam facilmente a resistência. Pretende-se, aqui, esclarecer questões importantes dessa pesquisa, tanto do ponto de vista químico quanto do biológico. 


\section{ESTRATÉGIAS PARA O DESENVOLVIMENTO DE UM NOVO COMPOSTO COM ATIVIDADE LEISHMANICIDA}

Apesar de muitas das drogas testadas contra Leishmania sp. terem sido desenvolvidas para outras patologias, diferentes enfoques foram avaliados para seu uso contra esse parasito. Pode-se citar o estudo de parâmetros estereoquímicos e fisicoquímicos, os quais, juntamente com análise (qualitativa/quantitativa) da relação estrutura versus atividade biológica, podem direcionar a síntese de novos compostos. A identificação de novos alvos biológicos pode levar à posterior modelagem de um inibidor específico.

A descoberta de novos fármacos é um empreendimento de alto custo e longa duração. Assim, é muito mais racional certificar-se que o alvo a ser escolhido de fato tem relação com a doença em foco. Esse fato vai acelerar os estágios iniciais de identificação e validação de alvos, permitindo a definição de resultados biológicos ou terapêuticos esperados.

Tais estratégias são necessárias, mas não suficientes, em razão da complexidade de fatores que influenciam na atividade de uma determinada droga in vivo, incluindo a falta de conhecimento relativo à interação parasito-hospedeiro. Embora a busca de um simples composto, efetivo contra todas as espécies de Leishmania e as formas clínicas da doença, seja considerada por alguns autores uma utopia, o desenvolvimento de uma nova formulação totalmente efetiva, ou ainda sua associação com fármacos já existentes, é altamente relevante. Sendo assim, é da maior importância a definição de um composto líder/protótipo (lead compound) que apresente características específicas para o desenvolvimento de uma nova classe de medicamentos: seletividade, mecanismo de ação definido e disponibilidade em quantidades suficientes para permitir estudos farmacológicos, bioquímicos/moleculares e toxicológicos.

As formas amastigotas se multiplicam dentro de macrófagos, o que dificulta enormemente o acesso de fármacos. Assim, têm sido usados sistemas de liberação de drogas, o que melhora a atividade leishmanicida e diminui os efeitos tóxicos (Romero \& Morilla, 2008). Novas formulações têm sido desenvolvidas para a utilização desses sistemas. Essa metodologia inclui uma redução da dose total da droga e da frequência da administração, levando a uma diminuição de efeitos colaterais e a um aumento da eficácia.

A incorporação de drogas em polímeros biodegradáveis tem inúmeras vantagens, como fácil preparação, longa vida e alta estabilidade em fluidos biológicos (Langer, 1998). Formulações preparadas com nanopartículas biodegradáveis de Poly (D, L-lactídeo) têm sido propostas como um sistema de liberação de drogas (drug delivery) dentro de macrófagos e com aumento do índice terapêutico de compostos leishmanicidas (Rodrigues et al., 1994; Torres-Santos et al., 1999; Pinero et al., 2006). Além dessas nanopartículas, microesferas de fosfolipídeos têm sido testadas em modelos experimentais e in vitro (Venier-Juliene et al., 1995; Medda et al., 2003).

Nos fluxogramas a seguir (Figuras 1 e 2), estão representados alguns parâmetros importantes para o estudo direcionado do desenvolvimento de novos compostos com as características anteriormente citadas.

Figura 1 - Preparo e caracterização de um composto (sintético, semissintético e natural)

Compostos

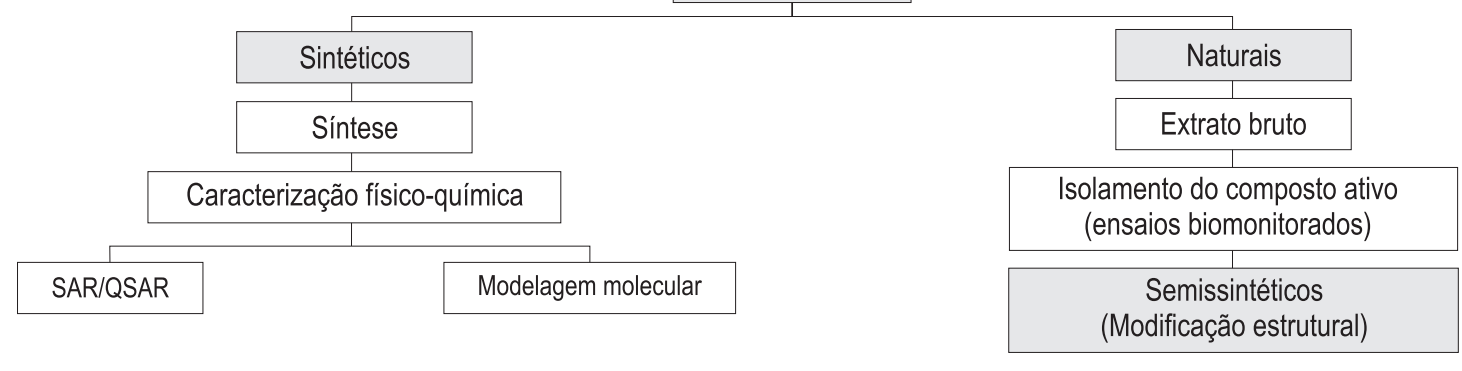


Figura 2 - Modelo integrado para a avaliação de novos compostos potencialmente ativos contra Leishmania sp.

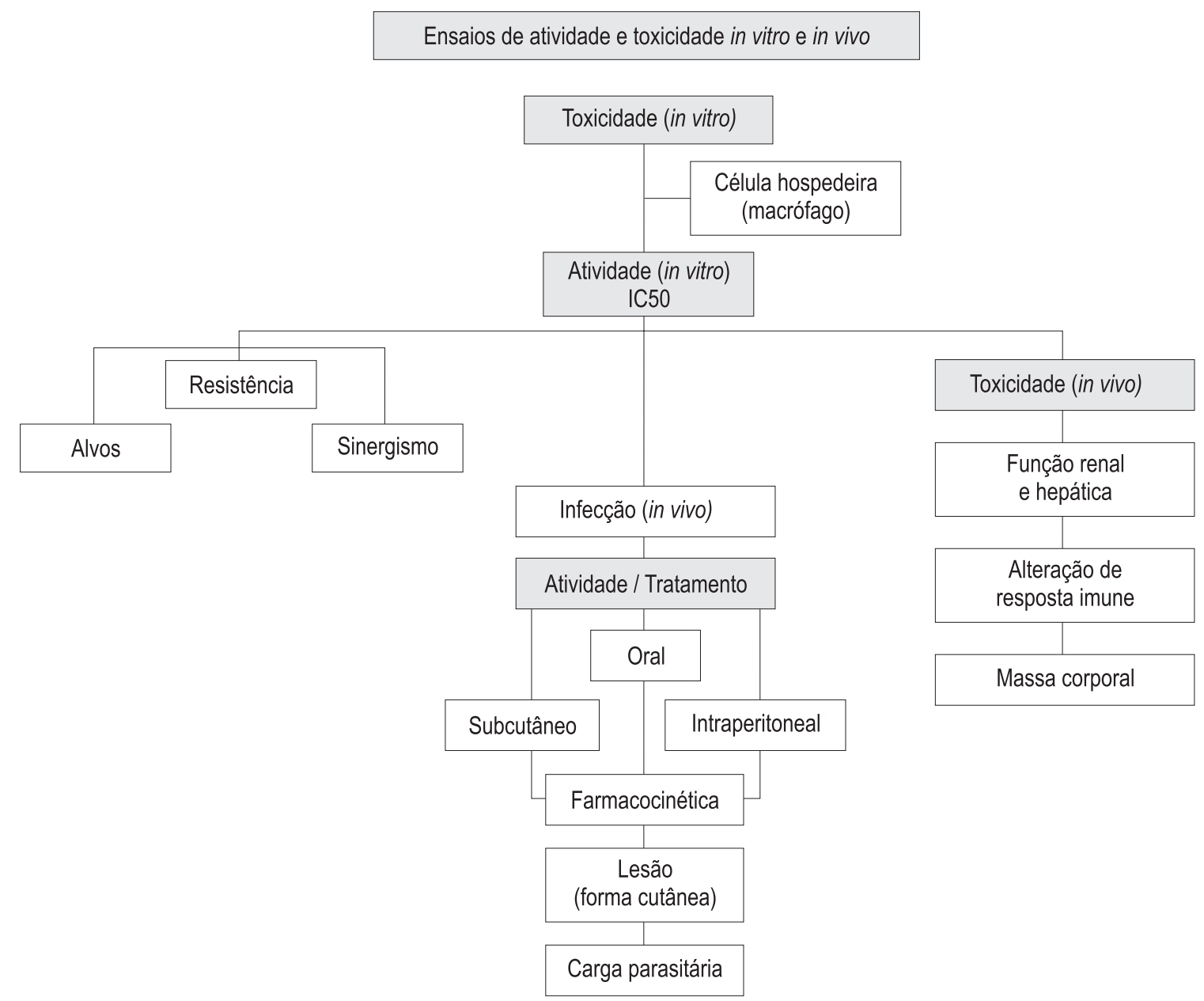

\section{COMPOSTOS SINTÉTICOS E DE ORIGEM NATURAL}

\section{Sintéticos}

A síntese de um novo fármaco tem como objetivo o desenvolvimento de compostos com estrutura química definida (caracterizada por infravermelho - IV, ressonância magnética nuclear - RMN, espectrometria de massas - EM, ponto de fusão etc.), com atividade desejada e um mínimo de toxicidade. Para isso, diferentes métodos são utilizados, entre eles a modelagem molecular e os estudos da relação estrutura/atividade (Korolkovas, 1998).

o planejamento racional baseado na estrutura e no mecanismo de ação de um composto é a estratégia mais eficiente e menos dispendiosa para o desenvolvimento de novos fármacos, capaz de contribuir em todos os estágios do processo, desde a descoberta de protótipos, passando pela sua otimização (com respeito à afinidade ao receptor, à especificidade, à toxicidade e à biodisponibilidade), até a elaboração de compostos candidatos a testes clínicos. Essa metodologia, conhecida como 'modelagem molecular' (termo coletivo que se refere aos métodos teóricos e às técnicas computacionais para modelar ou mimetizar o comportamento das moléculas), é baseada no bloqueio ou estimulação da atividade biológica de biomacromoléculas, tais como proteínas ou ácidos nucleicos (DNA ou RNA), associado a 
diferentes processos patológicos. A informação estrutural do biorreceptor permite a descoberta e síntese de compostos com complementaridade estérica, hidrofóbica e eletrostática ao seu sítio de ligação, os quais podem vir a se tornar fármacos e serem introduzidos na terapêutica medicamentosa (Barreiro et al., 1997).

A utilização de métodos racionais no planejamento da obtenção de substâncias potencialmente ativas tem se mostrado extremamente útil. Nesse sentido, uma das metodologias mais eficientes no estudo da síntese de novas drogas está baseada nos estudos da relação entre estrutura e atividade biológica, que pode ser qualitativa - Structure Activity Relationship (SAR) - e quantitativa (QSAR). Quando a estrutura química de uma substância com atividade biológica é conhecida, pode ser feito um estudo de SAR na tentativa de definir qual parte da molécula é importante na sua atividade. Num estudo de QSAR pode-se identificar e quantificar as propriedades físico-químicas de um grupo de substâncias homólogas, bem como avaliar sua atividade biológica.

A correlação entre essas propriedades é obtida empregando-se procedimentos matemáticos e estatísticos que irão permitir o estabelecimento de equações ou de modelos, os quais poderão ser utilizados no planejamento de novas sínteses de substâncias mais promissoras com relação à sua atividade biológica e apresentando um mínimo de toxicidade (Mello et al., 2004). Sabe-se, por exemplo, que a substituição de um átomo de H por um determinado substituinte (grupos alquila, nitro, ciano, carboxila, halogênio etc.) pode modificar profundamente a potência, a duração e, ainda, a natureza do efeito farmacológico de uma molécula. Os estudos de correlação estrutura-atividade, fundamentados no efeito do substituinte em um determinado anel aromático, são muito comuns na química medicinal, uma vez que mais de $50 \%$ dos fármacos ou compostos bioativos possuem esse tipo de anel. As modificações produzidas pela introdução de um substituinte podem atingir várias propriedades físico-químicas da molécula, tais como hidrofobicidade, densidade eletrônica, conformação estrutural e propriedades farmacocinéticas, entre outras, cuja análise poderá orientar as sínteses a serem seguidas.

A combinação dos dados obtidos pelas técnicas de QSAR com os modelos sugeridos pela química teórica (via modelagem molecular), resultando numa proposta para a síntese de substâncias que sejam potencialmente ativas, com baixa toxicidade e com um alvo molecular definido no parasito, é o que se conhece modernamente como 'síntese racional de fármacos'.

\section{Produtos naturais}

A falta de uma droga efetiva para o tratamento das leishmanioses tem levado a um renovado interesse na reavaliação de remédios tradicionais da medicina popular como fonte de agentes leishmanicidas, principalmente contra a leishmaniose cutânea. Basicamente, dois enfoques são usados na busca de novos compostos de origem vegetal: a avaliação da informação etnomédica e o 'screening' de diversas espécies de plantas contra um parasitoalvo. O primeiro enfoque é considerado mais produtivo, tendo em vista que se baseia na medicina popular, a qual vem acumulando informações ao longo de anos por muitas gerações, e por não terem sido descritos altos níveis de toxicidade durante o longo período de uso em humanos.

Numerosos compostos de origem vegetal têm mostrado atividade antiparasitária em modelos experimentais tanto in vitro como in vivo (Araújo, Alegrio \& Leon, 1997; Monzote et al., 2007; Machado, Leon \& Castro, 2007). O uso empírico de plantas medicinais pela população tem demonstrado que caule, raízes, folhas, sementes e frutos têm eficiência na cura de diversos males, suscitando assim grande interesse no estudo científico delas (Rocha et al., 2005). Atualmente, um dos significativos métodos de pesquisa para o desenvolvimento de novos medicamentos se fundamenta na busca de novos protótipos farmacêuticos encontrados particularmente em produtos de origem natural (Ganesan, 2002).

o estudo biomonitorado permite um isolamento mais rápido e eficaz do composto ativo, podendo-se, ainda, introduzir modificações químicas nesses protótipos naturais (compostos semissintéticos) com o objetivo de amplificar 
sua atividade específica ou mesmo reduzir seu efeito tóxico (Peck et al., 1992). Compostos ativos isolados de produtos naturais, através do uso de diferentes solventes orgânicos (etanol, metanol, clorofórmio, éter de petróleo, hexano), têm sido usados como modelos para a síntese de análogos mais potentes e seletivos. Inúmeros fármacos disponíveis atualmente no mercado farmacêutico foram obtidos sinteticamente, baseados em estruturas naturais ativas.

Um fato que deve ser considerado são as quantidades obtidas de compostos isolados de plantas, já que muitos extratos apresentam misturas complexas de compostos que se encontram em baixíssimas proporções. Além disso, alguns extratos são bastante ativos, mas essa atividade diminui à medida que são fracionados, sugerindo um sinergismo entre compostos presentes em determinados extratos. Uma explicação também aceitável diz respeito à biodisponibilidade de um determinado composto que, uma vez purificado, seria absorvido de forma diferente do extrato. Deve ainda ser considerada a instabilidade dos compostos ativos, que podem se degradar e se tornar inativos durante o processo de extração.

Os constituintes ativos de algumas plantas têm sido isolados e seus efeitos confirmados em ensaios in vitro e in vivo, além de avaliação clínica. A atividade leishmanicida de extratos de plantas tem sido associada a compostos que pertencem a diversos grupos químicos. Metabólitos secundários, tais como alcaloides, terpenoides, flavonoides, considerados no passado como inativos são hoje importantes ferramentas no tratamento e na investigação clínica. Diferentes derivados de alcaloides como os quinolínicos, os isoquinolínicos e os indólicos têm apresentado atividade leishmanicida.

Extratos das folhas de Galipea longiflora (2-propil quinolina e 2-trans-epoxipropil quinolina) se mostraram bastante ativos in vitro e in vivo contra espécies de Leishmania (Akendengue et al., 1999). Alcaloides isoquinolínicos (berberinas) isolados da casca do tronco de Annona spinescens revelaram atividade contra Leishmania sp., enquanto os isolados da casca do caule de Guatteria foliosa foram ativos contra L. donovani e L. amazonensis (Mahiou et al., 1994). Alcaloides indólicos, isolados de diversas plantas usadas na medicina popular na África para o tratamento de leishmanioses, têm apresentado resultados promissores: conodurina e N-desmetil-conodurina, isolados da casca de Peschiera van heurkii, foram ativos contra promastigotas de L. braziliensis e amastigotas de L. amazonensis (Muñoz et al., 1994). Além disso, quinonas (lapachol e $\beta$-lapachona) foram efetivas em experimentos in vitro contra promastigotas e amastigotas de $L$. amazonensis (Lima et al., 2004). Chalconas (licochalcona A), isoladas das raízes de Glycyrrhiza glabra, G. uralensis e G. inflata, levaram a uma diminuição da infecção de macrófagos por L. major e L. donovani, sem apresentar toxicidade para a célula hospedeira (Chen et al., 1993, 1994). Terpenos isolados de diferentes espécies de plantas são altamente efetivos e, dentre esses, dois diterpenos: jatrogrossidione, obtido de Jatropha grossidentata, e jatrophone, de J. isabelii, são ativos contra promastigotas e em infecções in vitro e in vivo; entretanto, apresentam toxicidade incompatível com uma potencial utilização clínica (Schmeda-Hirschman et al., 1996).

\section{MÉTODOS PARA AVALIAÇÃO DA ATIVIDADE/TOXICIDADE DE NOVOS COMPOSTOS}

Um dos grandes problemas no estudo de novos compostos contra as leishmanioses é a falta de padronização de protocolos experimentais para avaliação de substâncias com atividade leishmanicida. Existem na literatura inúmeros protocolos apresentando relevantes variações, tornando muito difícil a análise de diferentes resultados e experimentos, o que, geralmente, leva a informações de pouca importância prática para o desenvolvimento de um novo candidato a fármaco. Os protocolos de ensaios in vitro e in vivo executados nas diferentes etapas devem seguir padrões rigorosos de qualidade de experimentação, coleta, tratamento e análise de dados.

Para a avaliação de um composto (sintético, semissintético ou natural), vários parâmetros devem ser considerados. De maneira geral, esses estudos são feitos in vitro e in vivo. E em qualquer situação devem ser considerados os aspectos biológicos e bioquímicos dos parasitos em estudo. 


\section{Aspectos biológicos}

\section{AvallaÇÃO DA ATIVIDADE/TOXIIIDADE}

- In vitro - é essencial que todos os ensaios sejam realizados com amostras infectivas, isto é, promastigotas contendo altos teores de formas metacíclicas e amastigotas, tanto axênicas como intracelulares.

- Espécie estudada - sabe-se que espécies diferentes apresentam sensibilidades distintas a um mesmo composto, o que também é observado nos estágios evolutivos do parasito e até mesmo em cepas/isolados de uma mesma espécie (Vermeersch et al., 2009). As diferenças bioquímicas entre os estágios evolutivos do parasito estão associadas a essas respostas específicas. Além disso, o parasito deve estar perfeitamente caracterizado através de métodos moleculares (Cupolillo, Grimadi \& Momen, 1994; Cupolillo et al., 2001). A temperatura e o pH devem ser padronizados, assim como o meio de cultura, que poderá variar em função das necessidades nutricionais de cada espécie/isolado.

- Promastigotas/formas metacíclicas - dados da literatura (Cysne-Finkelstein et al., 1998; Croft \& Yardley, 2002) indicam que promastigotas infectivos/não infectivos evidenciam resultados significativamente diferentes com relação à sensibilidade a um determinado composto. Promastigotas na fase logarítmica inicial de crescimento (24 h) apresentam alta sensibilidade, enquanto na fase logarítmica tardia a sensibilidade diminui consideravelmente devido à presença de formas metacíclicas, estas associadas à capacidade infectante do parasito, que aumenta à medida que o parasito alcança esse estágio. É importante ressaltar que ensaios com formas logarítmicas não representam a realidade, uma vez que as populações que infectam (e que são liberadas pelo flebótomo) contêm alto teor de metacíclicos. Deve-se realizar uma curva de crescimento para cada espécie, acompanhada de testes de lise pelo complemento para avaliação do teor de formas metacíclicas.

Os modelos mais usados para avaliação de drogas em amastigotas intracelulares são de macrófagos murinos peritoneais e macrófagos humanos derivados de monócitos. Nesses macrófagos que não se dividem, a relação de amastigotas em divisão dentro das células e a atividade de drogas é facilmente determinada microscopicamente, contando-se a porcentagem de células infectadas ou o número de amastigotas/macrófago ou, ainda, através de métodos colorimétricos ou fluorimétricos. Esses modelos têm suas limitações, como, por exemplo, o lento processo de divisão de L. donovani e L. infantum.

Também têm sido usadas em ensaios de drogas linhagens celulares de camundongo - J774 (Ordóñez-Gutiérrez et al., 2007) - e humanas - THP-1, U937 (Gebre-Hiwot, et al., 1992; Maia et al., 2007). Entretanto, nesses ensaios, em que se usam células em divisão, é necessário um controle muito específico para evitar confundir os efeitos sobre a célula hospedeira com aqueles referentes ao parasito. Além disso, têm sido observadas variações na atividade de compostos em função do sistema utilizado. Por exemplo, antimoniais pentavalentes são fracamente ativos contra amastigotas em cultivos celulares, enquanto se mostram altamente tóxicos quando são usados macrófagos humanos e de camundongos.

- Amastigotas axênicas - essas culturas permitem uma segura avaliação de novos compostos, tanto naturais como sintéticos. Têm sido descritos protocolos para L. amazonensis (Cysne-Finkelstein et al., 1998; Genestra et al., 2003a), L. mexicana (Bates, 1994; Callahan et al., 1997), L. braziliensis (Balanço et al., 1998), L. donovani (Sereno \& Lemesre, 1997; Ephros et al., 1999) e L. infantum (Sereno, Holzmuller \& Lemesre, 2000). Contudo, os amastigotas usados devem ser antecipadamente caracterizados por meio de marcadores bioquímicos, imunológicos e ultraestruturais. Deve-se ainda considerar a alta concentração de soro nessas culturas, o que poderá diminuir a biodisponibilidade do composto em teste. Diferenças quanto à sensibilidade de drogas entre amastigotas axênicas e intracelulares tem sido relatadas para L. donovani (Ephros et al., 1999).

Os métodos de avaliação da atividade de um composto, tanto sintético com natural (definição do IC50 = concentração que inibe $50 \%$ do crescimento parasitário) são, entre outros: contagem dos parasitos remanescentes em microscópio 
óptico; métodos enzimáticos/colorimétricos, como a transformação do brometo de 3-[4,5-dimetiltiazol-2-il]-2,5difeniltetrazólio (MTT) por desidrogenases mitocondriais do parasito, em sal de formazana, ou o Alamar Blue ${ }^{\circledast}$, nome comercial do resazurin (7-hidroxi-3H-fenoxazina-3-1, 10-óxido), um corante azul usado principalmente como indicador de óxido-redução. O resazurin é reduzido a um composto vermelho-claro fluorescente, na presença de células vivas. Alguns trabalhos sugerem maior sensibilidade no uso do resazurin. Além disso, alterações morfológicas são avaliadas por microscopia óptica (coloração de Giemsa) e eletrônica. Tais protocolos são também usados para determinação da toxicidade (viabilidade da célula hospedeira).

- In vivo - a determinação de protocolos que utilizem modelos animais para os estudos das leishmanioses deve levar em conta os Princípios Éticos Básicos para Pesquisa e Experimentação com Animais, os quais são usados pelas comissões de ética como base para a qualificação de projetos de pesquisa que necessitem de experimentações animais. Sendo assim, todo o possível deve ser feito no sentido de utilizar métodos alternativos de estudo (Croft \& Yardley, 1999; Araújo-Jorge, 2000).

Muitos modelos experimentais, como roedores, cães e macacos, têm sido descritos, cada um com suas especificidades. Entretanto, nenhum reproduz o que acontece em seres humanos. Dentre eles, os mais usados para ensaios de drogas são camundongos de diferentes linhagens e hamsters.

A maioria dos modelos experimentais utiliza camundongos pela facilidade de manuseio, pela necessidade de baixas concentrações dos compostos em teste e pela ausência de patógenos. A viabilidade de cepas isogênicas com padrões definidos de fisiologia, imunologia e mapeamento genético fazem desses animais modelos para estudo de novas drogas. Por vezes, são observadas em camundongos e humanos similaridades entre os perfis de infecção causados por algumas espécies de Leishmania, como os fenótipos de suscetibilidade e resistência. Além disso, animais com o mesmo padrão genético possibilitam experimentos com grupos pequenos de animais. Contudo, camundongos selvagens podem refletir melhor a diversidade genética vista no hospedeiro humano (Sakthianandeswaren, Foote \& Handman, 2009).

$\mathrm{Na}$ leishmaniose cutânea, camundongos BALB/c têm um perfil de suscetibilidade à infecção, enquanto camundongos das linhagens C57/Bl e CBA/J apresentam um padrão de resistência, podendo se recuperar da infecção por esse parasito intracelular. Por conta disso, têm sido muito usados para estudos relacionados a drogas (Heinzel et al., 1989; Cangussú et al., 2009; Charret et al., 2009; Rodrigues et al., 2009). Na leishmaniose visceral, camundongos BALB/c representam um bom modelo de estudo, uma vez que, como os seres humanos, têm o fígado e o baço como principais órgãos afetados pela infecção, evoluindo para a autorresolução no fígado e a cronificação da infecção no baço. No mais, o modelo permite o uso de machos e fêmeas sem que ocorra alteração do curso da infecção (Croft \& Yardley, 1999; Sakthianandeswaren, Foote \& Handman, 2009).

Hamsters Syrian Golden (Mesocricetus auratus) podem ser usados para estudos com leishmanioses cutânea e visceral. Esse modelo pode reproduzir, como em camundongos BALB/c, infecções de fígado e baço que podem evoluir para uma doença crônica semelhante à leishmaniose visceral humana. Tais animais são indicados também para experimentos em que ocorra baixa infectividade de camundongos, como, por exemplo, L. braziliensis e L. panamensis. Entretanto, os estudos são limitados, em consequência da pouca oferta de reagentes imunológicos, da falta de uma boa via de infecção e da baixa oferta de animais isogênicos (Croft, Seifert \& Yardley, 2006; Croft \& Yardley, 1999; Melby et al., 1998; Joshi et al., 2009).

A via de inoculação é importante para o estabelecimento da infecção, sendo as mais usadas a intradérmica - id, a subcutânea - sc, a intravenosa - iv e a intraperitoneal - ip (Garg \& Dube, 2006). Para o tratamento são usadas as vias subcutânea, intraperitoneal e oral (Charret et al., 2009; Rodrigues et al., 2009). 
Diferentes protocolos são utilizados para a avaliação da toxicidade in vivo. Dentre eles, destacam-se:

- ensaios de alterações das enzimas hepáticas, indicadoras de dano à célula hepática - transaminase glutâmica pirúvica (TGP) ou alanina aminotransferase (ALT) e transaminase glutâmica oxaloacética (TGO) ou aspartato aminotransferase (AST), e da creatinina, indicadora de toxicidade renal;

- determinação da massa corporal dos animais;

- acompanhamento de possíveis alterações na resposta imunológica por meio da avaliação da população celular do sangue (células T CD4+/CD8 +; T CD4 +CD25+ e células B), produção de citocinas (INF- $\gamma$, IL-2, IL-4, e IL-10) de células obtidas de linfonodos de drenagem da lesão cutânea e baço, assim como a resposta imune humoral (subclasses de IgG);

- deteçãa de parasitos remanescentes em diferentes órgãos, após tratamento, por meio do método de diluição limitante e PCR (Charret et al., 2009; Rodrigues et al., 2009; Berzunza-Cruz et al., 2009).

\section{ASPECTOS BIOQUÍIICOS}

Considerando que tanto o parasito quanto a célula hospedeira são organismos eucariotas e, por isso, têm metabolismo extremamente semelhante, é uma árdua tarefa a definição de alvos metabólicos no parasito, para diferentes compostos. Muitos dos medicamentos usados na clínica das leishmanioses ainda não têm seu mecanismo de ação totalmente esclarecido. Uma importante ferramenta para o desenvolvimento de novos fármacos é o conhecimento de enzimas pertencentes a vias metabólicas ocorrendo diferencialmente no parasito ou mesmo ausentes no hospedeiro (Liñares, Ravaschino \& Rodriguez, 2006). Tais enzimas são consideradas vitais para o crescimento e a sobrevivência do parasito dentro da célula hospedeira.

Dentre as mais estudadas como possíveis alvos para drogas leishmanicidas, destacam-se:

- ornitina descarboxilase (ODC), S-adenosil-L-metionina descarboxilase (AdoMetDC) e espermidina sintetase da biossíntese de poliaminas (Person, 2007; Heby, Roberts \& Ullman, 2003; Heby, Person \& Rentala, 2007);

- tripanotiona redutase (TR) do sistema de óxido-redução (Fairlamb \& Cerami, 1992; Castro-Pinto et al., 2004, 2007);

- óxido nítrico sintase (NOS) e arginase do metabolismo da L-arginina (Genestra et al., 2003a, 2003b; SoaresBezerra et al., 2008; Reguera et al., 2009);

- C14-desmetilase e esqualeno sintase da biossíntese do ergosterol (Torres-Santos et al., 2009);

- cisteína-proteinase (Leon et al., 1994; Ponte-Sucre et al., 2006; Rebello et al., 2009);

- dihidrofolato redutase (DHFR) e pteridina redutase (PTR1) do metabolismo dos folatos (Beck \& Ullman, 1991; Nare et al., 1997; Cunningham \& Beverly, 2001);

- DNA topoisomerases (Das, Ganguly \& Majumder, 2008; Díaz-González et al., 2009).

Essas enzimas têm características que diferem de forma significativa nos parasitos e na célula hospedeira. Explorar tais diferenças pode levar ao desenvolvimento de novos inibidores que irão seletivamente eliminar os parasitos sem causar maiores danos para o hospedeiro.

\section{ESTUDOS DE RESISTÊNCIA}

Resistência às drogas tem se constituído um sério problema para a quimioterapia de diversas doenças, entre elas as leishmanioses (Papadopoulou et al., 1998; Hadighi et al., 2006). Relevantes considerações na análise da importância da resistência às drogas demonstram a facilidade com que um parasito resistente pode ser selecionado 
por uma droga particular, elevando assim o potencial de resistência em uma população. Alguns fatores podem levar o parasito a desenvolver resistência, como, por exemplo, a dose e a frequência de administração da droga, e a duração da infecção no indivíduo (Croft, Seifert \& Yardley, 2006).

Importantes estudos em parasitos tornados resistentes em laboratório têm sido desenvolvidos. A obtenção in vitro de parasitos resistentes à droga pelo aumento crescente de concentrações de drogas, embora possa por vezes diferir dos mecanismos naturais de resistência, ainda é um excelente instrumento para definir os processos bioquímicos e moleculares da resistência às drogas utilizadas na terapêutica das leishmanioses. Entretanto, seus mecanismos ainda não estão bem elucidados (Orlowski \& Garrigos, 1999; Pérez-Victoria et al., 2002; Decuypere et al., 2005; Maltezou, 2008).

A resistência às drogas tem sido associada a diversos fatores, como o aumento dos transportadores $\mathrm{ABC}$, como a glicoproteína P específica (Pgp), envolvida na eliminação de compostos através da membrana celular, na secreção do hormônio esteroide, na distribuição de fosfolipídeos e no transporte de ATP (Pérez-Victoria et al., 2002). Uma grande expressão da Pgp ocorre como resultado da quimioterapia, mas uma vez que ela é encontrada em células normais, sua significância torna-se interessante como alvo terapêutico (Maltezou, 2008; Bradshaw, 1998; Reis, 2000; Leprohon, 2009). Diversos estudos mostram que genes da família Pgp conferem resistência pela Leishmania à Vimblastina ${ }^{\circledR}$, arsenita, antimoniais pentavalentes, miltefosina e Metotrexato ${ }^{\circledast}$ (Papadopoulou et al., 1998; Pérez-Victoria et al., 2002; Légaré, Hettema \& Ouellete, 1994; Richard, Kundig \& Ouellette, 2002; Fischer, Einolf \& Coehn, 2005).

Outros mecanismos pelos quais a Leishmania sp. adquire resistência às drogas adotadas na quimioterapia da doença são o aumento intracelular excessivo dos níveis da tripanotiona, fundamental no processo de apoptose do parasito pelos antimoniais, e a superexpressão da triparedoxina peroxidase, fortemente associadas à resistência a antimoniais trivalentes in vitro (Oullette, 2001; Mandal et al., 2007; Wyllie, Vickers \& Fairlamb, 2008). A diminuição do potencial de membrana mitocondrial com redução do acúmulo do fármaco é também um fator envolvido no mecanismo de resistência in vivo e in vitro (Basselin \& Robert-Gero, 1998; Basselin et al., 2002; Mukherjee, Sen \& Ghose, 2006). Clones de leishmânias resistentes à miltefosina, aos derivados azólicos e à anfotericina $\mathrm{B}$ podem estar relacionados a modificações na composição lipídica de membrana e na biossíntese do ergosterol. Estudos in vitro mostram que a diminuição da concentração ou da modificação estrutural do ergosterol na membrana reduz a afinidade pelo quimioterápico (Croft, Seifert \& Yardley, 2006; Maltezou, 2008; Oullette, 2001).

Finalmente, o conhecimento dos mecanismos de resistência às drogas leishmanicidas pode auxiliar no desenvolvimento de ferramentas para o seu reconhecimento precoce, permitindo a redução da utilização de quimioterapia desnecessária e, por muitas vezes, tóxica. Tais estudos podem proporcionar um tratamento mais eficaz, com a administração de drogas individuais ou mesmo pela combinação de duas ou mais drogas que minimizem o desenvolvimento da resistência pelo parasito (Oullette, 2001; Sereno, Holzmuller \& Lemesre, 2000).

\section{ESTUDOS DE SINERGISMO}

A combinação de drogas tem se revelado essencial no tratamento de parasitoses. Alguns autores sugerem que o sinergismo entre drogas pode ser um artifício viável e urgente no tratamento de severas infecções causadas por fungos, vírus, bactérias e parasitos (Araújo et al., 2000; Johnson et al., 2004; Seifert \& Croft, 2006; Croft, Sundar \& Fairlamb, 2006; Alvar, Croft \& Olliaro, 2006).

Estratégias variadas que envolvem a combinação de drogas já usadas na terapêutica das leishmanioses, ou delas com novos compostos, estão sendo elaboradas. A utilização de compostos combinados, visando, preferencialmente, diferentes alvos de atuação e mecanismos de defesa, tem sido incentivada de modo a aperfeiçoar a capacidade dos 
compostos por meio de efeito sinérgico ou aditivo, prevenindo o aparecimento de resistência à droga, diminuindo as doses requeridas, reduzindo os efeitos colaterais, a alta toxicidade e o custo do tratamento ou, ainda, aumentando o espectro de atividade (Croft, Seifert \& Yardley, 2006; Oullette, 2001; Alvar, Croft \& Olliaro, 2006; Trouiller et al., 2002).

Estudos promissores envolvendo a combinação de várias drogas, para o tratamento das leishmanioses, têm sido desenvolvidos. Na leishmaniose visceral, as combinações de paramomicina com estibogliconato de sódio e de estibogliconato de sódio com alopurinol são investigadas experimentalmente e clinicamente, e seus efeitos sinergísticos são verificados em pacientes não responsivos ao tratamento com estibogliconato de sódio sozinho (Maltezou, 2008; Seifert \& Croft, 2006; Alvar, Croft \& Olliaro, 2006; Trouiller et al., 2002; Chunge et al., 1985; Sundar, 2001). O estibogliconato de sódio combinado ao diperoxovanato parece ser eficaz em reduzir a carga parasitária em camundongos BALB/c infectados com L. donovani resistente a antimônio (Haldar et al., 2009), e a Talidomida ${ }^{\circledR}$ aplicada juntamente com o Glucantime ${ }^{\circledR}$ reduz o curso da infecção experimental com L. major (Solgi et al., 2006).

O sinergismo entre drogas é também obtido quando se combina in vitro e em modelo experimental de leishmaniose cutânea, causada por infecção com L. mexicana, a Amiodarona ${ }^{\circledR}$ e a miltefosina. L. infantum pode ser abolida dos órgãos de camundongos BALB/C depois do tratamento com antimoniato de meglumina com cetoconazol ou metronidazol. Lovastatina e miconazol apresentam efeito sinergístico in vitro contra formas promastigotas de L. donovani e formas amastigotas de L. amazonensis (Haughan, Chance \& Goad, 1992).

Formulações importantes e amplamente conhecidas por sua atividade antiparasitária, como tiossemicarbazonas e semicarbazonas, ao serem combinadas com a pentamidina em diferentes protocolos, causam a morte de promastigotas metacíclicas de L. amazonensis in vitro (Gangneux et al., 1999; Beraldo, 2004; Beraldo \& Gambino, 2004; Soares et al., 2005, 2006; Serrano-Martín et al., 2009).

Diversas substâncias extraídas de produtos naturais têm sido objetos de importantes estudos de combinação de drogas na atividade leishmanicida. Picroliv ${ }^{\circledR}$, um imunoestimulante derivado da Picrorhiza kurroa, sem atividade leishmanicida, ao ser combinada a concentrações subótimas de miltefosina, leva a uma significativa melhora de sua atividade em hamsters infectados com $L$. donovani. Um óleo essencial extraído de Chenopodium ambrosioides, ao ser combinado com a pentamidina in vitro, age contra formas promastigotas de L. amazonensis (WHO, 2006).

A combinação entre drogas com atividade antiparasitária conhecida, que tenham sido descartadas por terem perdido sua efetividade pela resistência parasitária, com novas formulações pode ser uma estratégia exequível para a terapêutica das leishmanioses, que requer estudos criteriosos sobre alvos terapêuticos e resposta imunológica.

\section{CONCLUSÃO}

Consideráveis avanços nas áreas da saúde, e em especial da medicina, têm sido observados (MSF, 2006). Entretanto, grande parte da população mundial encontra-se à margem de seus benefícios e, a cada ano, milhões de pessoas continuam morrendo de doenças que poderiam ser prevenidas e/ou tratadas. De fato, a falta de incentivos para pesquisa $e$ desenvolvimento de novas drogas para o tratamento das doenças infecciosas e parasitárias, classificadas como 'doenças negligenciadas', é uma constatação dessa realidade (Trouiller et al., 2002; Liese, Rosenberg \& Schratz, 2010).

A organização internacional Médicos Sem Fronteiras (MSF) define doenças negligenciadas da seguinte forma:

[...] uma doença mortal, ou muito grave, pode ser considerada negligenciada quando as opções de tratamento são inadequadas ou não existem; quando seu mercado potencial de drogas é insuficiente para provocar uma pronta resposta do setor privado e, por fim, quando o interesse do governo em lutar contra esse tipo de doença é insuficiente. (Liese, Rosenberg \& Schratz, 2010: 67-76) 
Países do Primeiro Mundo não consideram essas doenças prioritárias, nem como ameaça às suas próprias populações, além do que o retorno lucrativo é insuficiente para que a indústria farmacêutica invista em pesquisa e desenvolvimento de novos medicamentos voltados para elas (Liese, Rosenberg \& Schratz, 2010). Entre as doenças classificadas como extremamente negligenciadas, as leishmanioses são de grande interesse médico e econômico no Brasil, estando inclusive inserida nos programas desenvolvidos pelo Drugs for Neglected Diseases initiative - DNDi (DNDI, 2009).

Decorridas várias décadas de estudos relativos às leishmanioses, ainda não existe tratamento realmente eficaz e atóxico para as diferentes formas clínicas dessa parasitose que seja acessível a todos os grupos populacionais. Portanto, é fundamental que haja incentivos para a busca de novos fármacos. o planejamento, a síntese e o desenvolvimento de novos medicamentos são, na maioria das vezes, processos demorados e muito dispendiosos. O trabalho de colaboração multidisciplinar, envolvendo especialistas das áreas de química e biologia, pode levar à descoberta de novos compostos líderes com a atividade leishmanicida esperada e com um mínimo de efeitos secundários tóxicos.

\section{REFERÊNCIAS}

AKENDENGUE, B. et al. Recent advances in the fight against leishmaniasis with natural products. Parasite, 6: 3-8, 1999.

ALVAR, J.; CROFT, S. \& OLLIARO, P. Chemotherapy in the treatment and control of leishmaniasis. Advances in Parasitology, 61: 223-274, 2006.

ARAÚJO, C. A.; ALEGRIO, L. V. \& LEON, L. L. Antileishmanial activity of compounds extracted and characterized from Centrolobium sclerophyllum. Phytochemistry, 49: 751-754, 1997.

ARAUJO, M. S. et al. A combination of benznidazole and ketoconazole enhances efficacy of chemotherapy of experimental Chagas' disease. The Journal of Antimicrobial Chemotherapy, 45(6): 819-824, 2000.

ARAÚJO-JORGE, T. (Org.). Doença de Chagas: manual para experimentação animal. Rio de janeiro: Editora Fiocruz, Instituto Oswaldo Cruz, 2000.

BALANCO, J. M. et al. Axenic cultivation and partial characterization of Leishmania braziliensis amastigote-like stages. Parasitology, 116: 103-113, 1998.

BARREIRO, E. J. et al. Modelagem molecular: uma ferramenta para o planejamento racional de fármacos em química medicinal. Química Nova, 20: 300-310, 1997.

BASSELIN, M. \& ROBERT-GERO, M. Alterations in membrane fluidity, lipid metabolism, mitochondrial activity, and lipophosphoglycan expression in pentamidine-resistant Leishmania. Parasitology Research, 84(1): 78-83, 1998.

BASSELIN, M. et al. Resistance to pentamidine in Leishmania mexicana involves exclusion of the drug from the mitochondrion. Antimicrobial Agents and Chemotherapy, 46(12): 3.731-3.738, 2002.

BATES, P. A. Complete developmental cycle of Leishmania mexicana in axenic culture. Parasitology, 108: 1-9, 1994.

BECK, J. T. \& ULLMAN, B. Biopterin conversion to reduced folates by Leishmania donovani promastigotes. Molecular and Biochemical Parasitology, 49(1): 21-28, 1991.

BERALDO, H. Semicarbazonas e tiossemicarbazonas: o amplo perfil farmacológico e usos clínicos. Química Nova, 27 (3): 461-469, 2004.

BERALDO, H. \& GAMBINO, D. The wide pharmacological versatility of semicarbazones, thiosemicarba-zones and their metal complexes. Mini-reviews in Medicinal Chemistry, 4: 31-39, 2004.

BERZUNZA-CRUZ, M. et al. PCR for identification of species causing American cutaneous leishmaniasis. Parasitology Research, 104(3): 691-699, 2009.

BRADSHAW, D. M. \& ARCECI, R. J. Clinical relevance of trans-membrane drug efflux as a mechanism of multdrug resistance. Journal of Clinical Oncology, 16: 3.674-3.690, 1998. 
CALLAHAN, H. L. et al. An axenic amastigote system for drug screening. Antimicrobial Agents and Chemotherapy, 41: 818822, 1997.

CANGUSSÚ, S. D. et al. Histopathology of Leishmania major infection: revisiting L. major histopathology in the ear dermis infection model. Memórias do Instituto Oswaldo Cruz, 104(6): 918-922, 2009.

CARVAlHO, P. B.; ARRIBAS, M. A. G. \& FERREIRA, E. I. Leishmaniasis. What do we know about chemotherapy. Brazilian Journal of Pharmaceutical Science, 36: 69-96, 2000.

CASTRO-PINTO, D. B. et al. Trypanothione reductase activity is prominent in metacyclic promastigotes and axenic amastigotes of Leishmania amazonensis. Evaluation of its potential as a therapeutic target. Journal of Enzyme Inhibition and Medicinal Chemistry, 19(1): 57-63, 2004.

CASTRO-PINTO, D. B. et al. Leishmania amazonensis trypanothione reductase: evaluation of the effect of glutathione analogs on parasite growth, infectivity and enzyme activity. Journal of Enzyme Inhibition and Medicinal Chemistry, 22(1): 71-75, 2007.

CHARRET, K. et al. Effect of oral treatment with pyrazole carbohydrazide derivatives against murine infection by Leishmania amazonensis. The American Journal of Tropical Medicine and Hygiene, 80: 568-573, 2009.

CHEN, M. et al. Licochalcone A, a novel antiparasitic agent with potent activity against human pathogenic protozoan species of Leishmania. Antimicrobial Agents and Chemotherapy, 37: 2.550-2.556, 1993.

CHEN, M. et al. Antileishmanial activity of licochalcone A, in mice infected with L. major and in hamsters infected with $L$. donovani. Antimicrobial Agents and Chemotherapy, 38: 1.339-1.344, 1994.

CHUNGE, C. N. et al. Visceral leishmaniasis unresponsive to antimonial drugs. III. Successful treatment using a combination of sodium stibogluconate plus allopurinol. Transactions of the Royal Society of Tropical Medicine and Hygiene, 79(5): 715-718, 1985.

CROFT, S. L. \& YARDLEY, V. Animal models of visceral leishmaniasis. In: ZAK, O. \& SANDE, M. (Orgs.). Handbooks of Animals Models of Infection. Academic Press: London, 1999.

CROFT, S. L. \& YARDLEY, V. Chemotherapy of leishmaniasis. Current Pharmaceutical Design, 8(4): 319-342, 2002.

CROFT, S. L.; SEIFERT, K. \& YARDLEY, V. Current scenario of drug development for leishmaniasis. The Indian Journal of Medical Research, 123(3): 399-410, 2006.

CROFT, S. L.; SUNDAR, S. \& FAIRLAMB, A. H. Drug resistance in leishmaniasis. Clinical Microbiology Reviews, 19(1): 111126, 2006.

CUNnINGHAM, A. C. \& BEVERLY, S. M. Pteridine salvage throughout the Leishmania infectious cycle implications for antifolate chemotherapy. Molecular and Biochemical Parasitology, 13: 199-213, 2001.

CUPOLILlO, E.; GRIMADI JR., G. \& MOMEN, H. A general classification of New World Leishmania using numerical zymotaxonomy. The American Journal of Tropical Medicine and Hygiene, 50(3): 296-311, 1994.

CUPOLILlo, E. et al. Recent advances in the taxonomy of the New World leishmanial parasites. Medical Microbiology and Immunology, 190(1-2): 57-60, 2001.

CYSNE-FINKELSTEIN, L. et al. Leishmania amazonensis: long-term cultivation of axenic amastigotes is associated to metacyclogenesis of promastigotes. Experimental Parasitology, 89: 58-62, 1998.

DAS, B. B.; GANGULY, A. \& MAJUMDER, H. K. DNA topoisomerases of Leishmania: the potential targets for anti-leishmanial therapy. Advances in Experimental Medicine and Biology, 625: 103-115, 2008.

DECUYPERE, S. et al. Gene expression analysis of the mechanism of natural $\mathrm{Sb}(\mathrm{V})$ resistance in Leishmania donovani isolates from Nepal. Antimicrobial Agents and Chemotherapy, 49(11): 4.616-4.621, 2005.

DESJEUX, P. Leishmaniasis: current situation and new perspectives. Comparative Immunology, Microbiology and Infectious Diseases, 95: 305-318, 2004. 
DÍAZ-GONZÁLEZ, R. et al. Novel findings on trypanosomatid chemotherapy using DNA topoisomerase inhibitors. Minireviews in Medicinal Chemistry, 9(6): 674-686, 2009.

EPHROS, M. et al. Stage-specific activity of pentavalent antimony against Leishmania donovani axenic amastigotes. Antimicrobial Agents and Chemotherapy, 43(2): 278-282, 1999.

FAIRLAMB, A. H. \& CERAMI, A. Metabolism and functions of trypanothione in the kinetoplastida. Molecular and Biochemical Parasitology, 14: 187-198, 1992.

FISCHER, V.; EINOLF, H. J. \& COEHN, D. Efflux transporters and their clinical relevance. Mini-reviews in Medicinal Chemistry, 5: 183-195, 2005.

GANESAN, A. Recent developments in combinatorial organic synthesis. Drug Discovery Today, 7(1): 47-55, 2002.

GANGNEUX, J. P. et al. Experimental evaluation of second-line oral treatments of visceral leishmaniasis caused by Leishmania infantum. Antimicrobial Agents and Chemotherapy, 43(1): 172-174, 1999.

GARG, R. \& DUBE, A. Animal models for vaccine studies for visceral leishmaniasis. The Indian Journal of Medical Research, 123: 439-454, 2006.

GEBRE-HIWOT, A. et al. An in vitro model for screening antileishmanial drugs: the human leukaemia monocyte cell line, THP-1. Acta Tropica, 51(3-4): 237-245, 1992.

GENESTRA, M. et al. Effect of amidine derivatives on nitric oxide production by Leishmania amazonensis promastigotes and axenic amastigotes. Nitric Oxide, 8(1): 1-6, 2003a.

GENESTRA, M. et al. Comparative analysis of the nitric oxide production by Leishmania sp. Medical Microbiology and Immunology, 192(4): 217-223, 2003b.

HADIGHI, R. et al. Unresponsiveness to Glucantime treatment in Iranian cutaneous leishmaniasis due to drug-resistant Leishmania tropica parasites. PLoS Medicine, 3(5): 162, 2006.

HALDAR, A. K. et al. Sub-optimal dose of sodium antimony gluconate (SAG)-diperoxovanadate combination clears organ parasites from BALB/c mice infected with antimony resistant Leishmania donovani by expanding antileishmanial T-cell repertoire and increasing IFN-gamma to IL-10 ratio. Experimental Parasitology, 122 (2): 145-154, 2009.

HAUGHAN, P. A.; CHANCE, M. L. \& GOAD, L. J. Synergism in vitro of lovastatin and miconazole as anti-leishmanial agents. Biochemistry \& Pharmacology, 44(11): 2.199-2.206, 1992.

HEBY, O.; PERSSON, L. \& RENTALA, M. Targeting the polyamine biosynthetic enzymes: a promising approach to therapy of African sleeping sickness, Chagas' disease, and leishmaniasis. Amino Acids, 33(2): 359-366, 2007.

HEBY, O.; ROBERTS, S. C. \& ULLMAN, B. Polyamine biosynthetic enzymes as drug targets in parasitic protozoa. Biochemical Society Transactions, 31(2): 415-419, 2003.

HEINZEL, F. P. et al. Reciprocal expression of interferon gamma or interleukin 4 during the resolution or progression of murine leishmaniasis. Evidence for expansion of distinct helper $\mathrm{T}$ cell subsets. The Journal of Experimental Medicine, 169: 59-72, 1989 .

INICIATIVA DE DROGAS PARA DOENÇAS NEGLIGENCIADAS (DNDI). Site. Disponível em: <www.dndi.org/index.php/diseases. htm >. Acesso em: 2009.

JOHNSON, M. D. et al. Combination antifungal therapy. Antimicrobial Agents and Chemotherapy, 48(3): 693-715, 2004.

JOSHI, T. et al. B7-H1 Blockade increases survival of dysfunctional CD8 + T cells and confers protection against Leishmania donovani Infections. PLoS Pathogens, 5(5): 10.1371, 2009.

KOROLKOVAS, A. Essentials of Medicinal Chemistry. 2. ed. New York: Wiley-Interscience, 1998.

LANGER, R. Drug delivery and targeting. Nature, 392: 5-10, 1998.

LÉGARÉ, D.; HETTEMA, E. \& OUELLETE, M. The P-glycoprotein gene family in Leishmania. Molecular and Biochemical Parasitology, 68: 81-91, 1994. 
LEON, L. L. et al. Proteinase activities during temperature-induced stage differentiation of species complexes of Leishmania. Acta Tropica, 56(4): 289-298, 1994.

LEPROHON, P. ; LEGARE, D. \& OUELLETTE, M. Intracellular localization of the ABCC proteins of Leishmania and their role in resistance to antimonials. Antimicrobial Agents and Chemotherapy, 53(6): 2.646-2.649, 2009.

LIESE, B.; ROSENBERG, M. \& SCHRATZ, A. Programmes, partnerships, and governance for elimination and control of neglected tropical diseases. The Lancet, 375(9.708): 67-76, 2010.

LIMA, N. et al. Antileishmanial activity of Lapachol analogs. Memórias do Instituto Oswaldo Cruz, 99: 757-761, 2004.

LIÑARES, G. E.; RAVASCHINO, E. L. \& RODRIGUEZ, J. B. Progresses in the field of drug design to combat tropical protozoan parasitic diseases. Current Medicinal Chemistry, 13(3): 335-360, 2006.

MACHADO, G. M. C.; LEON, L. L. \& CASTRO, S. L. Activity of Brazilian and Bulgarian propolis against different species of Leishmania. Memórias do Instituto Oswaldo Cruz, 102: 73-74, 2007.

MAHIOU, V. et al. New aporphine alkaloids from Guatteria foliosa. Journal of Natural Products, 57: 890-895, 1994.

MAIA, C. et al. Infectivity of five different types of macrophages by Leishmania infantum. Acta Tropica, 103(2): 150-155, 2007.

MALTEZOU, H. C. Visceral leishmaniasis: advances in treatment. Recent Patents on Anti-Infective Drug Discovery, 3(3): 192$198,2008$.

MANDAL, G. et al. Increased levels of thiols protect antimony unresponsive Leishmania donovani field isolates against reactive oxygen species generated by trivalent antimony. Parasitology, 134: 1.679-1.687, 2007.

MEDDA, S. et al. Phospholipid microspheres: a novel delivery mode for targeting antileishmanial agent in experimental leishmaniasis. Journal of Drug Targeting, 11(2): 123-128, 2003.

MÉDICOS SEM FRONTEIRAS (MSF). Doenças negligenciadas no Brasil, 2002. Disponível em: <www.msf.org.br/informativos/ info12/info12doenças.htm>. Acesso em: out. 2006.

MELBY, P. C. et al. Cloning of Syrian hamster (Mesocricetus auratus) cytokine cDNAs and analysis of cytokine mRNA expression in experimental visceral leishmaniasis. Infectious and Immunity, 66(5): 2.135-2.142, 1998.

MELLO, H. et al. Antileishmanial pyrazolopyridine derivatives: synthesis and structure-activity relationship analysis. Journal of Medicinal Chemistry, 47(22): 5.427-5.432, 2004.

MONZOTE, L. et al. Combined effect of the essential oil from Chenopodium ambrosioides and antileishmanial drugs on promastigotes of Leishmania amazonensis. Revista do Instituto de Medicina Tropical de São Paulo, 49(4): 257-260, 2007.

MUKHERJEE, P.; SEN, P. C. \& GHOSE, A. C. Lymph node cells from BALB/c mice with chronic visceral leishmaniasis exhibiting cellular anergy and apoptosis: involvement of Ser/Thr phosphatase. Apoptosis, 11(11): 2.013-2.029, 2006.

MUÑOZ, V. et al. Isolation of bis-indole alkaloids with antileishmanial and antibacterial activities from Peschiera van heurkii, (Syn. Tabernaemontana van beurkii). Planta Medica, 60: 455-459, 1994.

MURRAY, H. W. et al. Advances in leishmaniasis. The Lancet, 366(9.496): 1.561-1.577, 2005.

NARE, B. et al. New approaches to Leishmania chemotherapy: pteridine reductase 1 (PTR1) as a target and modulator of antifolate sensitivity. Parasitology, 114: 101-110, 1997.

ORDÓÑEZ-GUTIÉRREZ, L. et al. In vitro effect of new formulations of amphotericin B on amastigote and promastigote forms of Leishmania infantum. International Journal of Antimicrobial Agents, 30(4): 325-329, 2007.

ORLOWSKI, S. \& GARRIGOS, M. Multiple recognition of various amphiphilic molecules by the multidrug resistance P-glycoprotein: molecular mechanisms and pharmacological consequences coming from functional interactions between various drugs. Anticancer Research, 19(4B): 3.109-3.123, 1999.

OULLETTE, M. Biochemical and molecular mechanisms of drug resistance in parasites. Tropical Medicine and International Health, 6(II): 874-882, 2001. 
PAPADOPOUlOU, B. et al. Drug resistance in Leishmania: similarities and differences to other organisms. Drug Resistance Updates, 1(4): 266-278, 1998.

PECK, C. C. et al. Opportunities for integration of pharmacokinetics, pharmacodynamics, and toxicokinetics in rational drug development. Pharmaceutical Research, 9(6): 826-833, 1992.

PÉREZ-VICTORIA, J. M. et al. Multidrug resistance phenotype mediated by the P-glycoprotein-like transporter in Leishmania: a search for reversal agents. Current Drug Targets, 3(4): 311-333, 2002.

PERSSON, L. Ornithine decarboxylase and S-adenosylmethionine decarboxylase in trypanosomatids. Biochemical Society Transactions, 35(2): 314-317, 2007.

PINERO, J. et al. New administration model of trans-chalcone biodegradable polymers for the treatment of experimental leishmaniasis. Acta Tropica, 98: 59-65, 2006.

PONTE-SUCRE, A. et al. Aziridine-2,3-dicarboxylates, peptidomimetic cysteine protease inhibitors with antileishmanial activity. Antimicrobial Agents and Chemotherapy, 50(7): 2.439-2.447, 2006.

REBELLO, K. M. et al. Cysteine proteinases from promastigotes of Leishmania (Viannia) braziliensis. Parasitology Research, 106(1): 95-104, 2009.

REGUERA, R. M. et al. Leishmania major lacking arginase $(A R G)$ are auxotrophic for polyamines but retain infectivity to susceptible BALB/c mice. Molecular and Biochemical Parasitologyl, 165: 48-56, 2009.

REIS, G. Susceptible Host: a resort for parasiteright in the eye of the immune response. Anais da Academia Brasileira de Ciências, 48: 79-82, 2000.

RICHARD, D.; KUNDIG, C. \& OUELLETTE, M. A new type of high affinity folic acid transporter in the protozoa parasite Leishmania and deletion of its gene in methotrexato-resistance cells. Journal of Chemical Biology, 277: 29.460-29.467, 2002.

ROCHA, L. G. et al. A review of natural products with antileishmanial activity. Phytomedicine, 12(6-7): 514-535, 2005.

RODRIGUES JR., J. M. et al. The activity and ultrastructural localization of primaquine loaded poly(d,1-lactide) nanoparticles in Leishmania donovani infected mice. Tropical Medicine and Parasitology, 45: 223-228, 1994.

RODRIGUES, R. et al. Antileishmanial activity of 1,3,4-thiadiazolium-2-aminide in mice infected with Leishmania amazonensis. Antimicrobial Agents and Chemotherapy, 17: 839-842, 2009.

ROMERO, E. L. \& MORILLA, M. J. Drug delivery systems against leishmaniasis? Still an Open Question, 5(7): 805-823, 2008.

SAKTHIANANDESWAREN, A.; FOOTE, S. J. \& HANDMAN, E. The role of host genetics in leishmaniasis. Trends in Parasitology, 25(8): 383-391, 2009.

SCHMEDA-HIRSCHMAN, G. et al. Antiprotozoal activity of jatrogrossidione from Jatropha grossidentata and jatrophone from J. isabelii. Phytotherapy Research, 10: 375-378, 1996.

SEIFERT, K. \& CROFT, S. L. In vitro and in vivo interactions between miltefosine and other antileishmanial drugs. Antimicrobial Agents and Chemotherapy, 50(1): 73-79, 2004.

SERENO, D. \& LEMESRE, J. L. Axenically cultured forms as an in vitro model for investigation of antileishmanial agents. Antimicrobial Agents and Chemotherapy, 41: 972-976, 1997.

SERENo, D.; HOLZMUlleR, P. \& LEMESRE, J. L. Efficacy of second line drugs on antimonyl-resistant amastigotes of Leishmania infantum. Acta Tropica, 74(1): 25-31, 2000.

SERRANO-MARTíN, X. et al. Amiodarone and miltefosine act synergistically against Leishmania mexicana and can induce parasitological cure in a murine model of cutaneous leishmaniasis. Antimicrobial Agents and Chemotherapy, 53(12): 5.108-5.113, 2009.

SOARES, R. O. A. et al. The effectiveness of thiosemicarbazones derivates against Trypanosoma cruzi and Leishmania (L.) amazonensis. In: CONGRESS ON DRUG DISCOVERY \& DEVELOPMENT FOR PARASITIC DISEASES, 2005, Siena. 
SOARES, R. O. A. et al. Synergistic effect of semicarbazones/thiosemicarbazones and pentamidine on Leishmania (L.) amazonensis. In: CONGRESS ON DRUG DISCOVERY \& DEVELOPMENT FOR PARASITIC DISEASES, 2006, Athens.

SOARES-BEZERRA, R. J. et al. Effect of mesoionic 4-phenyl-5-(cinnamoyl)-1,3,4-thiadiazolium-2-phenylamine chloride derivative salts on the activitiesof the nitric oxide synthase and arginase of Leishmania amazonensis. Journal of Enzyme Inhibition and Medicinal Chemistry, 23: 328-333, 2008.

SOLGI, G. et al. Effects of combined therapy with thalidomide and glucantime on leishmaniasis induced by Leishmania major in BALB/c mice. The Korean Journal of Parasitology, 44(1): 55-61, 2006.

SOTO, J. et al. Miltefosine for New World cutaneous leishmaniasis. Clin Infect Dis, 38(9): 1.266-1.267, 2004.

SUNDAR, S. Drug resistance in Indian visceral leishmaniasis. Tropical Medicine \& International Health, 6(11): 849-854, 2001.

SUNDAR, S. \& MURRAY, H. W. Availability of Miltefosine for the treatment of kala-azar in India. Bulletin of the World Health Organization, 83: 394-395, 2005.

TORRES-SANTOS, E. C. et al. Improvement of in vitro and in vivo antileishmanial activities of 2', 6'-dihydroxy-4'methoxychalcone by entrapment in poly (D,L-lactide) nanoparticles. Antimicrobial Agents and Chemotherapy, 43(7): 1.776-1.778, 1999.

TORRES-SANTOS, E. C. et al. Altered sterol profile induced in Leishmania amazonensis by a natural dihydroxymethoxylated chalcone. The Journal of Antimicrobial Chemotherapy, 63(3): 469-472, 2009.

TROUILLER, P. et al. Drug development for neglected diseases: a deficient market and a public-health policy failure. The Lancet, 359: 2.188-2.194, 2002.

VENIER-JULIENNE, M. C. et al. In vitro study of the anti-leishmanial activity of biodegradable nanoparticles. Journal of Drug Targeting, 3(1): 23-29, 1995.

VERMEERSCH, M. et al. In vitro susceptibilities of Leishmania donovani promastigote and amastigote stages to antileishmanial reference drugs: practical relevance of stage-specific differences. Antimicrobial Agents and Chemotherapy, 53(9): 3.8553.859, 2009.

WORLD HEALTH ORGANIZATION (WHO). Engagin General Programme of Work 2006-2015. A global health agenda, 2006. Disponível em: <http://whqlibdoc.who.int/publications/2006/GPW_eng.pdf>.

WYLLIE, S.; VICKERS, T. J. \& FAIRLAMB, A. H. Roles of trypanothione S-transferase and tryparedoxin peroxidase in resistance to antimonials. Antimicrobial Agents and Chemotherapy, 52(4): 1.359-1.365, 2008. 
parte IX

\section{Desafios para o Controle das Leishmanioses}




\title{
A Questão do Controle das Leishmanioses no Brasil
}

\author{
Mauro C. A. Marzochi I Keyla B. Feldman Marzochi \\ Aline Fagundes I Fátima Conceição-Silva
}

$\mathrm{O}$

controle de endemia de ocorrência nacional, atingindo regiões de características diferentes, embora implique principalmente o conhecimento de suas formas de transmissão nos diferentes contextos, além de frequência, distribuição e outros aspectos ecoepidemiológicos pertinentes, requer também informações que vão desde as manifestações clínicas e os diagnósticos de suspeição e confirmatórios, ao acesso à atenção e resposta à terapêutica. Apesar da abordagem delicada ou difícil das leishmanioses, sob qualquer desses aspectos, a complexidade do controle destaca-se pela grande multiplicidade de elementos envolvidos na transmissão e a consequente produção de infecção e doença.

A Organização Mundial da Saúde (OMS) inclui as leishmanioses entre as seis enfermidades consideradas prioritárias ao controle, em escala mundial, sendo que o Brasil contribui com 90\% dos casos que ocorrem nas Américas (WHO, 1990, 2010).

Representadas pela leishmaniose tegumentar americana (LT) e leishmaniose visceral (LV), ocorrem em todas as regiões geográficas do Brasil, tendo sido registrados 320.885 casos entre 2000 e 2010, com média anual de 29.171 casos. No período, somaram-se 2.422 óbitos, todos por LV, mas $88 \%$ dos casos corresponderam à LT (Brasil, 2010b, 2010c).

As leishmanioses, tegumentar e visceral, são duas entidades nosológicas inteiramente distintas clinicamente, exceto quanto às drogas terapêuticas indicadas. Também no aspecto etiológico, embora os agentes biológicos sejam do mesmo gênero Leishmania, as espécies causais se diferenciam. Na LT, conquanto estejam ligadas a grande número de espécies dermotrópicas, explicando a denominação plural de leishmanioses tegumentares pela tendência a padrões clínicos variados a que são associadas, na LV apenas uma espécie viscerotrópica está, de regra, envolvida. Contudo, em relação ao diagnóstico laboratorial, as metodologias são similares. Quanto à distribuição geográfica no país, embora tendam a se superpor na Região Sudeste, o mesmo não ocorre nas demais regiões. Porém, no processo de transmissão, podem envolver elementos epidemiológicos comuns: reservatórios silvestres, sinantrópicos e domésticos - com ênfase ao cão -, a mesma família de insetos vetores e o hospedeiro humano, adulto ou criança de ambos os sexos. Mas, ainda que elementos essenciais sejam comuns na transmissão da LT e LV, eles não participam, igualmente, no contexto de produção de infecção e doença, em forma ou intensidade, implicando diferentes abordagens de combate e perspectivas 
de controle das duas entidades. Ambas definem-se genericamente como zoonoses, doenças primariamente de animais que afetam o homem, mas que também podem se comportar como antropozoonoses - quando é transmitida do animal para o homem; zooantroponose - transmitida do homem para o animal; e anfixenose - quando se transmite indiferenciadamente entre animais e homens; daí que o termo zoonose comporta os demais, em oposição ao termo antroponose, como doença transmitida entre humanos.

A LT compreende um conjunto de enfermidades zoonóticas causadas por várias espécies de protozoários digenéticos da ordem Kinetoplastida, família Trypanosomatidae, do gênero Leishmania, que acometem a pele e/ou mucosas do homem e diferentes espécies de animais silvestres, sinantrópicos e domésticos das regiões quentes e menos desenvolvidas do Velho e do Novo Mundo. A infecção, que se dá a partir da picada no hospedeiro vertebrado suscetível por insetos vetores da família Psychodidae, subfamília Phlebotominae, com a inoculação da Leishmania, caracteriza-se pelo parasitismo das células do sistema fagocítico mononuclear (SFM) da derme - monócitos, histiócitos e macrófagos - do sistema celular de defesa, de cuja interação parasito-hospedeiro decorrerão padrões clínicos variáveis, de ulcerações de pele, únicas ou múltiplas, leves ou graves e, eventualmente, de mucosas com lesões destrutivas, principalmente de vias aéreas superiores, ou nenhuma manifestação clínica aparente, infecção subclínica (Marzochi, Marzochi \& Schubach, 1999). Clinicamente, predomina a forma cutânea ulcerada da LT (97\%) e a doença, em geral, é mais frequente em adultos do sexo masculino (Brasil, 2010b). A LT está distribuída em todas as unidades federadas, mas com magnitudes distintas e diversidades locais relacionadas às variadas espécies do agente etiológico, de vetores e reservatórios, além de diversos determinantes ambientais e socioeconômicos.

A LV, também chamada ainda de calazar, decorre de uma infeção generalizada do SFM de linfonodos, fígado, baço, medula óssea e intestino delgado, causada pela $L$. (L.) chagasi, um protozoário pertencente ao complexo $L$. infantum, subgênero e gênero Leishmania, da família Trypanosomatidae (WHO, 1990). Esse parasito apresenta elevado viscerotropismo e a transmissão ocorre pela picada de restritas espécies de flebotomíneos, infectados após repasto sanguíneo em hospedeiro animal, notadamente o cão, ou humano, portadores de Leishmania na pele. Sua maior importância reside na gravidade clínica como doença sistêmica de evolução crônica e altíssima letalidade em casos não tratados. A doença ocorre em regiões subdesenvolvidas intertropicais, subtropicais e temperadas tanto no Velho como no Novo Mundo (Marzochi, Marzochi \& Schubach, 1999). No Brasil, já foi identificada em todas as regiões geográficas.

O diagnóstico das leishmanioses, tegumentar e visceral, baseia-se nas avaliações clínica e epidemiológica associadas a provas imunológicas como: reação de imunofluorescência indireta (Rifi) e ensaio imunoenzimático (Elisa), disponíveis para o diagnóstico humano e canino; teste rápido imunocromatográfico-Dual-Path Platform (DPP) para diagnóstico canino (Grimaldi et al., 2012; Alves et al., 2012), além do Kalazar Detect (humano e canino) e o Optleish (humano), em validação; e o teste intradérmico de hipersensibilidade cutânea tardia intradermorreação de Montenegro (IDRM), este utilizado somente para pacientes de LT, ou para estudos epidemiológicos em áreas endêmicas de LT e LV (Marzochi, Schubach \& Marzochi, 1999). Porém, exames de confirmação etiológica de ambas as endemias são feitos pela demonstração do parasito por exame direto e indireto - por isolamento em meio de cultura e inoculação em animais (Brasil, 2006, 2010a).

A confirmação etiológica deve ser buscada sempre que possível. O exame direto permite a visualização da Leishmania sp. Na LT, pode ser feito em material obtido por punção, escarificação e/ou biopsia com impressão em lâmina da lesão de pele ou mucosa, aposto em lâmina, corado pelo Giemsa e observado em microscópio, bem como pelo exame histopatológico por hematoxilina-eosina ou métodos imuno-histoquímicos. Na LV, o material para tais testes pode ser obtido a partir de punção de medula óssea, sangue, ou eventualmente, de linfonodos ou baço. O isolamento por cultivo, em meio NNN (ágar-sangue enriquecido) e LIT (infusão de fígado e triptose), além da observação da Leishmania, permite a identificação da espécie quando submetida aos métodos isoenzimáticos, por anticorpos monoclonais ou PCR (Brasil, 2010a), nos mesmos materiais referidos, respectivamente para os pacientes 
suspeitos de LT e LV. A inoculação em animais pode ser feita em hamster, principalmente, mas demanda tempo e complexidade, embora seja técnica muito sensível, indicada em situações particulares. A utilização da PCR, além do material de cultura, pode ser feita em biopsia, sangue e outros espécimes clínicos. Tais exames podem ser utilizados no diagnóstico da LT e LV humana e canina, além de em outros reservatórios. Em vetores, a partir de material do tubo digestivo dos insetos, os mesmos exames podem ser realizados para observação, isolamento e identificação da Leishmania utilizados em pesquisa.

O tratamento humano de ambas as endemias é feito com o antimonial pentavalente, como a droga de escolha, estando indicadas como drogas alternativas a pentamidina na LT e a anfotericina B lipossomal na LV mais grave ou diante de falha terapêutica. Os efeitos adversos frequentes de todos esses medicamentos implicam cuidados clínicos no acompanhamento dos pacientes desde a indicação até a aplicação terapêutica, principalmente com LV.

Tradicionalmente, a abordagem dessas endemias no país se realiza sob a coordenação ativa do Ministério da Saúde e grande envolvimento dos profissionais da saúde, frequentemente associando serviço e pesquisa multidisciplinares em setores de referência nas diferentes regiões. Continua sendo um desafio o diagnóstico clínico precoce, a facilidade de acesso à confirmação laboratorial e a redução continuada do número de casos e de óbitos na LV.

\section{ASSOCIAÇÕES CLÍNICO-PARASITÁRIAS E ECOEPIDEMIOLÓGICAS DAS LEISHMANIOSES}

Nas leishmanioses, características clínicas costumam se associar às diferentes espécies de agentes etiológicos e vetores; e ambos, às características ambientais, incluindo os reservatórios. Animais silvestres e domésticos atuam como reservatórios de leishmânias, admitindo-se que, potencialmente, o homem possa ser também fonte de infecção para esses vetores hematófagos.

O homem, como também o cão, é capaz de albergar a leishmânia durante longo tempo após a infecção inicial, sem apresentar doença - a LT ou a LV. Considera-se que somente uma pequena parcela dos infectados desenvolva sinais e sintomas, que podem ocorrer após variável período de incubação e em quaisquer condições de imunossupressão. É indeterminado, na LT, o papel do homem doente ou infectado como fonte de infecção, assim como, na LV, do indivíduo assintomático. Porém, em menor proporção que o animal, o homem doente de LV pode ser fonte de infecção (Deane, 1956); já a condição do cão como reservatório de leishmânia se deve ao intenso parasitismo cutâneo animal, com isolamento do parasito desde a fase inicial, subclínica (Madeira et al., 2004; Marzochi et al., 1985). E esse mesmo fato, na LV, deve facilitar a infecção intercanina através de mordedura durante as brigas, do coito, por via transplacentária, e provavelmente também por ingestão de carrapatos que sugaram cães doentes (Sherlock, 1964).

Em ambiente rural, as raposas Lycalopex vetulus e Dusicyon thous são incriminadas como reservatórios 'silvestres' da LV - infectadas na mata pelo vetor eventualmente ali circulante - sendo, porém, mais provável que sejam infectadas por sinantropia, ou seja, circulando à cata de alimentos em ambientes próximos a moradias, onde a endemia já esteja instalada - com presença de criadouros de vetores infectados em outros canídeos ou outros animais sinantrópicos - e então se infectando nesse ciclo peridoméstico (Courtenay et al., 2002a). Da mesma forma, poderia ser considerado o marsupial Didelphis albiventris e mesmo roedores encontrados infectados em algumas áreas endêmicas. As raposas, por seus hábitos migratórios, percorrendo grandes distâncias, também poderiam introduzir a L. (L.) chagasi em áreas distantes, com um significado epidemiológico maior que os marsupiais e roedores (Deane, 1956).

Existem no Brasil pelo menos oito espécies de Leishmania que causam doença humana pertencentes aos subgêneros L. (Viannia), relacionadas às leishmanioses tegumentares, e subgênero L. (Leishmania), associada principalmente à leishmaniose cutâneo-difusa e à visceral (Lainson \& Shaw, 1993). A infecção canina está associada mais frequentemente à $L$. (V.) braziliensis (dermotrópica) e à $L$. (L.) chagasi (viscerotrópica). Coincidentemente, essas são as que têm maior potencial de urbanização, enquanto L. (V.) guyanensis e L. (L.) amazonensis (dermotrópicas) 
tendem a atingir, respectivamente, populações humanas assentadas muito perto de matas primárias e populações rurais próximas a ambientes pouco modificados.

Enquanto as leishmânias dermotrópicas do Brasil são consideradas autóctones do continente americano (desde o Texas ao norte da Argentina, excluídos Chile e Uruguai), a leishmânia viscerotrópica que ocorre no Brasil, L. (L.) chagasi, atualmente denominada Leishmania infantum chagasi - com a mesma identidade genética da Leishmania infantum do Mediterrâneo -, admite-se que tenha sido trazida durante o processo de colonização das Américas. No Velho Mundo, as diferentes variedades genéticas do agente da leishmaniose visceral pertencentes ao "complexo infantum' distribuem-se predominantemente na região do Mediterâneo; e ao 'complexo donovani' nas regiões indiana, asiática e leste da África; este não inclui o reservatório canino em sua transmissão, constituindo uma antroponose. Até hoje não se encontrou Leishmania do 'complexo donovani' no Novo Mundo.

Os vetores das leishmânias no Brasil, flebotomíneos pertencentes à ordem Diptera, família Psychodidae, subfamília Phlebotominae, gênero Lutzomyia, são pequenos insetos alados (dípteros) conhecidos popularmente pelos nomes de mosquito-palha, tatuquira, birigui e outros.

$\mathrm{Na}$ grande maioria os flebotomíneos são de hábitos essencialmente florestais, que, nas Américas, incluem mais de quinhentas espécies distribuídas dos Estados Unidos ao norte da Argentina. A maior parte é encontrada na bacia amazônica. Dessas espécies, quatrocentas pertencem ao gênero Lutzomyia. Porém, apenas vinte estão associadas à transmissão das leishmanioses no país (Rangel \& Lainson, 2003).

No Brasil, os principais vetores da LT tendem a se distribuir conforme os diferentes ambientes silvestre, rural, periurbano e urbano (Quadro 1). Na Região Norte, são incriminadas notadamente Lu. umbratilis, Lu. flaviscutellata, Lu. welcomei, Lu. whitmani. Nas demais regiões predominam Lu. whitmani, Lu. migonei, Lu flaviscutellata, Lu. intermedia, Lu.nevai, Lu. pessoai, Lu. fisheri (Brasil, 2010a).

Quadro 1 - A transmissão das leishmanioses no Brasil em diferentes ambientes e perspectivas de controle

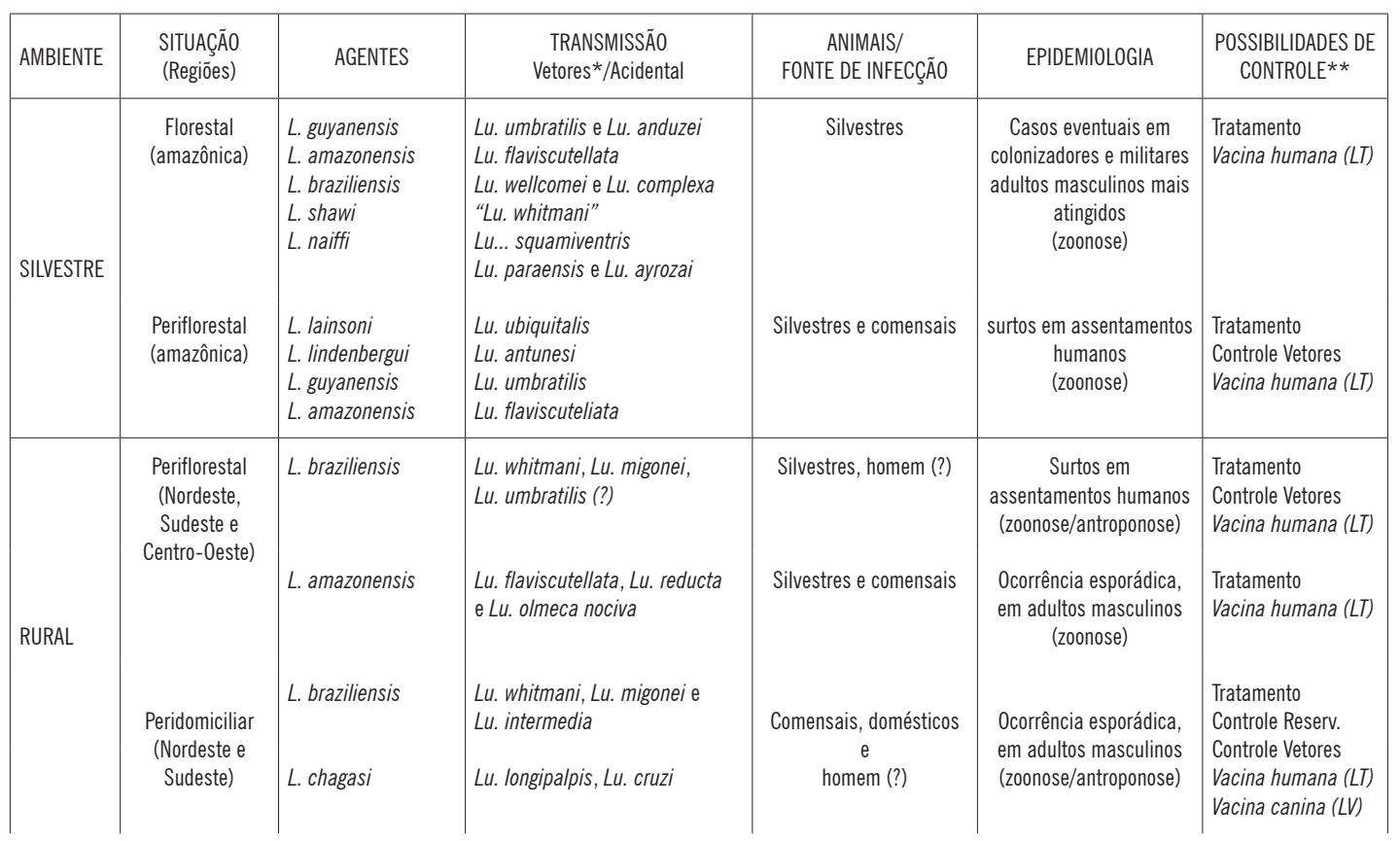


Quadro 1 - A transmissão das leishmanioses no Brasil em diferentes ambientes e perspectivas de controle (continuação)

\begin{tabular}{|c|c|c|c|c|c|c|}
\hline AMBIENTE & $\begin{array}{l}\text { SITUAÇÃ0 } \\
\text { (Regiões) }\end{array}$ & AGENTES & $\begin{array}{c}\text { TRANSMISSÃ0 } \\
\text { Vetores*/Acidental }\end{array}$ & $\begin{array}{c}\text { ANIMAIS/ } \\
\text { FONTE DE INFECÇÃO }\end{array}$ & EPIDEMIOLOGIA & $\begin{array}{l}\text { POSSIBILIDADES DE } \\
\text { CONTROLE** }\end{array}$ \\
\hline PERIURBANA & $\begin{array}{l}\text { Peridomiciliar } \\
\text { (Nordeste, } \\
\text { Sudeste e } \\
\text { Centro-Oeste) }\end{array}$ & $\begin{array}{l}\text { L. braziliensis } \\
\text { L. chagasi }\end{array}$ & $\begin{array}{l}\text { Lu. whitmani, Lu. intermedia, } \\
\text { Lu. migonei, Lu. neivai, } \\
\text { Lu pessoal } \\
\text { Lu. Iongipalpis } \\
\text { Acidental }\end{array}$ & $\begin{array}{c}\text { Comensais, domésticos } \\
\mathrm{e} \\
\text { homem }\end{array}$ & $\begin{array}{l}\text { Surtos em todas as } \\
\text { idades e gêneros } \\
\text { (zoonose/antroponose) }\end{array}$ & $\begin{array}{l}\text { Tratamento } \\
\text { Saneamento } \\
\text { Controle vetores } \\
\text { Controle Reserv. } \\
\text { Controle sangue e } \\
\text { órgãos } \\
\text { Vacina canina (LV) }\end{array}$ \\
\hline URBANA & $\begin{array}{l}\text { Domiciliar } \\
\text { (Nordeste e } \\
\text { Sudeste) }\end{array}$ & $\begin{array}{l}\text { L. braziliensis } \\
\text { L. chagasi }\end{array}$ & $\begin{array}{l}\text { Lu. intermedia } \\
\text { Lu. Iongipalpis } \\
\text { Acidental }\end{array}$ & $\begin{array}{l}\text { Domésticos } \\
\text { e homem }\end{array}$ & $\begin{array}{l}\text { Ocorrência em todas as } \\
\text { idades e gêneros } \\
\text { (antroponose/zoonose) }\end{array}$ & $\begin{array}{l}\text { Tratamento } \\
\text { Saneamento } \\
\text { Controle sangue e } \\
\text { órgãos } \\
\text { Vacina humana (LV) }\end{array}$ \\
\hline
\end{tabular}

Fonte: adaptado de Marzochi \& Marzochi (1997).

(*) Os vetores apresentam grande plasticidade genética (Rangel \& Lainson, 2003).

${ }^{* *}$ Vigilância epidemiológica, Tratamento e Notificação são recomendadas pela OMS como as mínimas medidas de controle a serem adotadas.

A transmissão da LV (do México ao norte da Argentina) está associada, quase que integralmente, a apenas uma espécie do gênero Lutzomyia, à Lu. longipalpis. Outras duas espécies, Lu. evanzi na Colômbia e, mais recentemente, Lu. cruzi no Brasil, estado do Mato Grosso do Sul, foram incriminadas na transmissão (Brasil, 2010b). Em áreas onde Lu. longipalpis é pouco representativa ou ausente no Sudeste, além de Lu. cruzi, cujo papel na transmissão de LV já foi demonstrado no Centro-Oeste, outros flebotomíneos, como Lu. intermedia (mais antropofílica) e Lu. migonei (mais cinofílica), são encontrados (Marzochi et al., 2009; Lainson \& Rangel, 2005; Souza et al., 2003).

Há enorme dificuldade de se identificar criadouros de flebotomíneos. São considerados como potenciais criadouros, em áreas endêmicas, matéria orgânica com certo grau de umidade - do solo e de fendas e reentrâncias de troncos de árvores e das superfícies de paredes (nesse local, mais associado à Lu. longipalpis).

As fêmeas dos flebotomíneos, a cada oviposição, depositam entre quarenta e setenta ovos em solo (Lewis, 1974). A eclosão ocorre após 6 a 17 dias, dando origem às larvas. Estas, por sua vez, evoluem no solo para o estado de pupa em 15 a 70 dias. Após uma a duas semanas dão origem aos adultos, que vivem de 15 a 30 dias. Apenas as fêmeas são hematófagas, com hábitos crepusculares ou noturnos, durante o dia repousando em locais sombreados e úmidos. O repasto sanguíneo é feito em mamíferos e aves. O ciclo completo, de ovo a adulto, dura em média 30 a 90 dias dependendo da temperatura, requerendo mais três dias para se tornar infectante na dependência de fonte de alimentação infectada (Pessoa \& Barretto, 1948).

A infecção do flebotomíneo dá-se durante o repasto sanguíneo em mamíferos infectados (que podem ser referidos como reservatórios, hospedeiros ou fontes de infecção), por ingestão de macrófagos parasitados por Leishmania. $\mathrm{O}$ ciclo do parasito no tubo digestivo do inseto dura em torno de 72 horas. As fêmeas inoculam, durante um novo repasto, saliva contendo o parasito e substâncias com atividade anticoagulante e vasoativa, com papel relevante na infectividade e imunossensibilização do hospedeiro (Titus \& Ribeiro, 1988). Nessa ocasião as formas promastigotas metacíclicas de Leishmania são inoculadas na derme do suscetível, e a partir daí ocorre o parasitismo dos macrófagos locais e/ou a disseminação linfática e sanguínea para outros tecidos ricos em células do SFM, no novo hospedeiro.

Considerando as leishmanioses tegumentares, entre seus agentes etiológicos, a Leishmania (V.) guyanensis causa predominantemente lesões ulceradas cutâneas localizadas e, excepcionalmente, mucosas secundárias em oronasofaringe. A leishmaniose por L. (V.) guyanensis é a mais frequente na Região Norte. De transmissão silvestre, 
verifica-se principalmente ao norte do rio Amazonas (Amapá, Roraima, Amazonas e Pará), em áreas de colonização recente de florestas primárias e secundárias relacionadas aos hábitats de animais silvestres como a preguiça de dois dedos (Choleopus didactilus), tamanduá (Tamandua tetradacyila), marsupiais (Didelphis marsupialis) e roedores. Os flebotomíneos envolvidos nessa transmissão são Lu. umbratilis, Lu. anduzei e Lu. whitmani. Lu. umbratilis costuma pousar em troncos de árvores, atacar o homem em grande intensidade quando perturbada, provocando múltiplas lesões, e é capaz de invadir habitações próximas às matas a mais de cem metros de distância. Existe possibilidade de eventualmente ser encontrada no estado do Maranhão, norte do Mato Grosso, Acre e Rondônia.

A L. (L.) amazonensis, relativamente infrequente, e também de transmissão silvestre, produz úlceras cutâneas localizadas, mas com potencial de produzir em indivíduos com deficiência imunológica inata quadro muito grave de lesões difusas e deformantes, anérgicas e, até o momento, incuráveis, felizmente raras. A transmissão está associada, em geral, à presença de roedores silvestres (Proechimys sp., Orizomys sp.) e marsupiais (Didelphis sp.), sendo a infecção humana incomum porque o vetor, Lu. flaviscutelata, de hábitos noturnos e voo baixo, é pouco antropofílico. Entretanto, a infecção pode ocorrer em diferentes ambientes de todas as regiões do Brasil, provavelmente associada a ciclos enzoóticos de matas residuais.

Outras leishmânias dermotrópicas descritas de ocorrência silvestre, como a L. (V.) lainsoni, L. (V.) naiffi, L. (V.) shawi $e L$. (V.) lindenbergui, acometem o homem na região amazônica, estando também associadas a vetores e reservatórios silvestres (Silveira, Lainson \& Corbett, 2004).

Já a Leishmania (V.) braziliensis destaca-se como o agente mais relevante de leishmaniose tegumentar considerando sua ampla distribuição - da Amazônia ao Sul do país -, frequência e potencial de morbidade humana e animal. Causa lesões cutâneas - localizadas, múltiplas ou disseminadas. Acomete mais frequentemente mucosas - metastáticas (secundárias) após períodos variáveis da lesão cutânea. Essa espécie, como outras dermotrópicas, pode também acometer mucosas por contiguidade de área cutânea e por inoculação direta em mucosas expostas a picadas (primárias); as lesões mucosas secundárias, mais graves e mais raras (cerca de 3\% a 7\% dos casos), acometem o trato respiratório superior (oronasofaringolaríngeo) com lesões destrutivas cuja intensidade depende do tempo de evolução. Contudo, as lesões cutâneas e até mesmo as mucosas secundárias podem evoluir para a cura espontânea, após vários meses, ou recidivar, mesmo as tratadas. L. (V.) braziliensis abrange tanto áreas de colonização recente da Amazônia (Pará, Amazonas, Acre, Rondônia), quanto antiga do Nordeste (Bahia, Pernambuco, Ceará), Centro-Oeste (Mato Grosso, Goiás), Sudeste (Espírito Santo, Rio de Janeiro e São Paulo) e Sul (Paraná, Santa Catarina e, mais recentemente, Rio Grande do Sul) (Fagundes et al., 2007).

A transmissão de L. (V.) braziliensis pode ser silvestre, rural, periurbana e eventualmente urbana, veiculada por diversas espécies do gênero Lutzomyia. Na Região Norte, a transmissão silvestre pode se dar por intermédio de Lu. welcomei - altamente antropofílica, picando o homem mesmo durante o dia e com grande atividade na estação chuvosa -, Lu. davizi, Lu. complexa e outras. No Nordeste, estado da Bahia, o flebotomíneo envolvido é Lu. withmani, encontrado nas proximidades ou invadindo as casas nas imediações de plantações de bananeiras e cacau, admitindo-se a transmissão nos ambientes peridomiciliares e também florestais. No estado do Ceará (serra do Baturité), onde é mais frequente a transmissão periurbana e peridomiciliar, associada à $L u$. withmani e Lu. migonei, também ocorre a florestal, associada a $L u$. wellcomei. Nos estados do Centro-Oeste, Sudeste e Sul, a transmissão pode ser rural e periurbana, em ambiente peridomiciliar, associadas à Lu. intermedia, Lu. withmani e Lu. neivai. Em geral, nas áreas rurais modificadas da caatinga, cerrado e mata atlântica, de Minas Gerais para o norte, a transmissão está associada principalmente à Lu. withmani. E nas áreas litorâneas e vales de grandes rios dos estados do Espírito Santo, Rio de Janeiro, São Paulo, Paraná e Santa Catarina, a transmissão é peridomiciliar e está associada à Lu. intermedia e Lu. neivai, de hábitos predominantemente peridomésticos, e provavelmente também à Lu. whitmani, Lu. migonei, Lu. fischeri e Lu. pessoai (Rangel \& Lainson, 2003; Marcondes, 1996; Marzochi \& Marzochi, 1994). 
Ciclos enzoóticos naturais da L. (V.) braziliensis ainda não estão bem definidos, tanto silvestres como em ambientes alterados extra-amazônicos (Marzochi \& Marzochi, 1994). Contudo, no sul do Pará, em área de transmissão silvestre, foram encontrados como reservatórios suspeitos roedores, dos gêneros Orizomys, Akodon, Proechymis, Rhipidomys e Rattus rattus, e marsupial, Didelphis (Lainson et al., 1994). E na zona da mata de Pernambuco, em ambiente rural, foi isolada L. (V.) braziliensis em animais sinantrópicos, marsupial - Didelphis albiventris - e roedor - Rattus rattus -, bem como em roedores silvestres - Necromys, Nectomys e Akodon (Brandão-Filho et al., 2003). Ao contrário das áreas amazônicas, em outros biomas os achados de reservatórios silvestres e vetores infectados têm sido excepcionais. Por sua vez, ainda se discute a participação do cão doméstico no aumento do risco da infecção humana, não só no Brasil, como na Argentina, no Peru, Equador, na Colômbia e Venezuela (Reithinger et al., 2003; Santos et al., 1998; Travi, Tabares \& Cadena, 2006; Pirmez, Marzochi \& Coutinho, 1988; Falqueto et al., 1986; Cunha, Lima \& Pompeu, 2006).

Nos animais domésticos - cães, assim como equinos e eventualmente gatos -, as manifestações clínicas da LT são semelhantes à doença humana, com evolução crônica e lesões ulceradas únicas ou múltiplas, podendo acometer mucosas (Marzochi \& Marzochi, 1994), com baixa letalidade, mas relevante por sua frequência, morbidade, além de possível papel na transmissão.

Quanto à leishmaniose visceral, zoonose doméstica, é, em geral, associada a um único agente biológico, a Leishmania (L.) chagasi, e a uma espécie principal de flebotomíneo, Lutzomyia longipalpis.

Diferentes quadros clínicos de LV podem ser observados na criança e no adulto associados principalmente ao tempo de doença e às condições prévias de nutrição e outras que afetem a imunidade, embora seja classicamente considerada como doença consuntiva crônica, que leva à morte se não tratada. O calazar no homem é expresso por febre irregular, anemia, hepatoesplenomegalia, micropoliadenia, manifestações intestinais, evoluindo com fenômenos hemorrágicos e caráter consuntivo caracterizado por progressivo e acentuado emagrecimento, com aumento crescente de volume abdominal, edema e outras manifestações, sendo a anemia, a febre e a hepatoesplenomegalia o pano de fundo dessa afecção (Marzochi, Marzochi \& Schubach, 1999).

A LV no cão, à semelhança do que ocorre nas áreas endêmicas do Mediterrâneo, quanto à patogenicidade pode variar de aparente estado sadio ao grave estágio final de doença sistêmica e crônica. Apenas 40\% a 60\% dos cães infectados apresentam sinais clínicos da doença (Marzochi et al., 1985), o que parece estar associado a determinadas raças; assemelha-se também à doença humana, com febre irregular, palidez de mucosas (anemia) e emagrecimento progressivo até à caquexia intensa na fase terminal, acompanhada de apatia, diarreia, hemorragia intestinal, paresia do trem posterior, edema e vômitos. Destacam-se as alterações cutâneas e de fâneros, como perda de pelos, descamação fina, ulcerações com crostas e localizadas nas extremidades. O longo período de evolução da doença, até mais de um ano, e a pouca mobilidade do cão devido à apatia, levam ao alongamento exagerado das unhas. Não responde a tratamento com o antimonial e constitui uma doença de depressão imunológica de origem parasitária (Marzochi et al., 1985).

A transmissão da LV por intermédio de Lu. longipalpis é a mais estudada. No Brasil, Lu. longipalpis, de grande distribuição geográfica, e ainda em expansão, desde Roraima, tem sido progressivamente encontrada em novos locais, e mais recentemente ao sudoeste do Rio Grande do Sul, fronteira com a Argentina (Brasil, 2010c). Lu. longipalpis coloniza facilmente os boqueirões, pés de serra e encostas, mas também vales dos rios no Nordeste, adaptando-se a variadas temperaturas, sendo o período de maior transmissibilidade durante e após a estação chuvosa - quando alcança maior densidade populacional. Muito adaptada ao hábitat humano de áreas rurais, periurbanas ou urbanas, pode picar o homem tanto no interior do domicílio como fora dele. É encontrada também no ambiente silvestre (Lainson \& Rangel, 2005). De preferência alimentar eclética entre homens e animais, o período de atividade máxima inicia-se cerca de uma hora após o crepúsculo, terminando ao redor das 23 horas (Deane, 1956; Quinnell, Dye \& Shaw, 1992; De Souza et al., 1981). No intradomicílio, as fêmeas permanecem em repouso durante o dia, principalmente nas paredes 
dos dormitórios, e se evadem no horário matinal. No peridomićlio, encontram-se nos abrigos dos animais domésticos como galinheiros, chiqueiros, canis, estábulos, também em paióis, de onde invadem o interior das residências. Os machos são os primeiros a serem notados quando os criadouros estão próximos, porque passam, antes das fêmeas, de pupa a alado. $\mathrm{O}$ encontro predominante das fêmeas, que partem em busca de alimento, sugere que os criadouros devam estar mais distantes.

Maior ou menor antropofilia estaria relacionada aos feromônios da Lu. longipalpis, associados a variações morfológicas (manchas no tegumento) do inseto (Ward et al., 1983).

O deslocamento da Lu. longipalpis para a área urbana e periurbana ou rural, onde antes não havia sido observada, seguido ou precedido da introdução da fonte de infecção, pode explicar o aparecimento de novos focos de LV. Contudo, a taxa de infecção natural no flebotomíneo é sempre baixa, mesmo nas áreas endêmicas, e a transmissão dependerá da sua elevada densidade, como se pode observar durante surtos da doença (Deane, 1956).

O período de incubação da LT no homem é de uma semana a dois anos, com média variável entre dois e três meses, sendo desconhecido no cão. Na LV, esse período é também muito variável, de 10 dias a 24 meses, mas em média de duas a seis semanas; no cão, mais variável ainda, pode ir de três meses a vários anos, com média de três a sete meses.

\section{EXPANSÃO GEOGRÁFICA E PERFIS DE DISTRIBUIÇÃO DAS LEISHMANIOSES}

No Brasil, entre 1940 e 2010, a população urbana cresceu de 31,2\% a aproximadamente 85\% (IBGE). Em decorrência da falta de políticas sociais e econômicas, que gerou nas áreas rurais imensas desigualdades sociais, elevado grau de desemprego, pobreza e desnutrição consequente, cresceram os movimentos migratórios nas classes menos favorecidas, com grande afluxo de pessoas às periferias urbanas, em geral do Nordeste para o Sudeste. E assim, surgia uma ruralização de periferias das grandes metrópoles resultante de uma ocupação desordenada de área urbana. Por sua vez, outros fluxos migratórios se davam do Sul e Sudeste para a Amazônia e o Centro-Oeste, com a perspectiva de novas atividades (extrativistas, agropastoris e outras ligadas ao desenvolvimento do interior do país), vindo a ocorrer, em paralelo, a semiurbanização de áreas rurais ou silvestres e se criando ali novos modos de vida. Em comum nessas diferentes regiões, eram e continuam sendo as graves carências de investimentos estruturais em saneamento, atenção à saúde e educação básica. Esses contextos sociodemográficos propiciaram, entre muitos outros males, nas regiões de semiurbanização, o aumento de casos de LT, e nas áreas periurbanas ruralizadas, e mais tarde também em urbanas, a introdução da LV.

\section{Leishmaniose tegumentar}

Ao analisar a evolução da LT no Brasil, caracteriza-se uma expansão geográfica da autoctonia, que, no início da década de 1980, verificada em 19 estados brasileiros, passa a se confirmar, no ano de 2003, em todas as unidades federadas. No período de 2000 a 2010 registraram-se 282.554 casos de LT no país, com média anual de 25.687 casos. Porém, em números absolutos, observam-se nesses anos decréscimo dos registros (33.720 para 21.981casos). No ano de 2010 a Região Norte respondeu pela maioria dos casos de LT $(38,8 \%)$, seguida pelas Regióes Nordeste $(32,4 \%)$, Centro-Oeste $(16,1 \%)$, Sudeste $(9,5 \%)$ e Sul $(2,4 \%)$, mas o Centro-Oeste (estados de Mato Grosso e Goiás) tem apresentado maior expansão, seguido pela Região Nordeste. A doença foi detectada no estado do Rio Grande do Sul a partir de 2000 (Brasil, 2010b).

Por meio de análise da distribuição espacial dos casos de LT no Brasil, no período de 2001 a 2003, foram definidos 24 'circuitos de produção' da doença (delimitação geográfica de áreas de municípios contínuos com maior 
densidade de casos por $\mathrm{km}^{2}$ num período de três anos) (Sabroza, 2002), de importância epidemiológica. Nessas áreas, foram notificados $75 \%$ (21.537 casos) do total registrado em 2004, e os circuitos abrangeram 35\% (1926) dos municípios brasileiros (Brasil, 2010b). Tais circuitos são decorrentes de processos socioambientais particulares e dinâmicos, que em razão desses determinantes, podem apresentar tendência à expansão ou retração geográfica (Sabroza, 2002).

\section{EvoLUÇÃO HISTÓRICA E EPIDEMIOLÓGICA DA LEISHMANIOSE TEGUMENTAR}

Representações em vasos de cerâmica de mutilações semelhantes às provocadas pela leishmaniose mucosa, por povos pré-colombianos, denunciam a antiguidade dessa afecção nas Américas (Vale \& Furtado, 2005; AltamiranoEnciso et al., 2003).

No Brasil, a LT é referida desde 1884 (Rabello, 1925). Epidemias e casos de LT foram registrados no noroeste de São Paulo desde fins do século XIX até a década de 1930; na cidade do Rio de Janeiro, nas décadas de 1910 e 1920; em áreas agrícolas do Vale do Rio Doce - Minas Gerais -, entre os anos de 1920 e 1940, e em zona urbana de Magé (município do Rio de Janeiro) em 1947 (Rabello, 1925; Nery-Guimarães \& Bustamante, 1954; Pessoa, 1949; Orsini, 1940; Aragão, 1927).

Essa expansão da endemia no Sudeste coincidiu com o grande movimento de imigração humana do Nordeste (sobretudo do estado do Ceará) para a Amazônia, atraídos pelo ciclo amazônico de exploração da borracha durante os períodos das grandes secas nordestinas (1877-1880, 1888 e 1889), ao que, porém, seguiu-se, pelo declínio do ciclo da borracha (1912-1932), um retorno em parte para o Nordeste e um refluxo migratório para estados em desenvolvimento do Sudeste pela expansão da cultura cafeeira em São Paulo (1850-1930). Paralelamente, na Amazônia, desde a década de 1870, a extração do látex se mantém nos afluentes da margem direita do rio Amazonas (rios Juruá, Purus, Madeira, Tapajós), onde se estabeleceram os principais seringais e onde já existia ali a L. (V.) braziliensis, certamente em focos naturais enzoóticos (ainda não definidos), e onde também continua predominando a LT por esse parasito, diferentemente da margem esquerda do Amazonas, em que prevalece a doença por L. (V.) guyanensis (Pessoa, 1949; Marzochi \& Marzochi, 1994).

Aragão, em 1921, descreveu um surto de LT de cerca de cinquenta casos em "gente rica e pobre", de ambos os sexos, "em plena cidade do Rio de Janeiro", bairro de Águas Férreas (atual Laranjeiras), referindo casos anteriores em outros bairros (ruas); então considerou que apenas um homem doente em área com grande quantidade de flebotomíneos geraria um foco de LT (cinco dezenas de casos secundários em três a quatro meses), razão pela qual os pacientes foram isolados e tratados debelando-se o surto, embora tenha admitido que cães, nos quais reproduziu a doença, poderiam ser também "depositários" do agente (Aragão, 1927). Takaoka (1928) também defendia a transmissão domiciliar e urbana dessa doença, estudando a topografia da LT em São Paulo. Devem-se destacar outros registros da ocorrência da LT em bairros, nas cidades do Rio de Janeiro - como Realengo e Bangu (D'Utra \& Silva, 1915; Cerqueira \& Vasconcelos, 1922), Laranjeiras e Cosme Velho (Aragão, 1927) -, de Salvador (Rabello, 1925) e de São Paulo (Pessôa \& Barreto, 1948).

Na década de 1950, a LT foi considerada um agravo em extinção, associado à diminuição dos desmatamentos no Sudeste e Sul. No entanto, em anos precedentes e concomitantes, o DDT e o BHC (inseticidas organoclorados) eram utilizados, respectivamente, no controle da malária e doença de Chagas, e ambos em extensas áreas agrícolas.

A partir de 1974 reiniciam-se os registros de casos na cidade do Rio de Janeiro em áreas periurbanas - de Jacarepaguá e bairros vizinhos, até a atualidade -, e de alguns municípios do estado - Nova Iguaçu (Oliveira-Neto et al., 1988), Paracambi (Santos et al., 2005), Paraty (Barbosa et al., 1999), São José do Vale do Rio Preto (Marzochi et al., 1991), entre outros, assim como em área periurbana de Belo Horizonte (Passos et al., 1993). 
Nas décadas de 1970 e 1980, intensificam-se também relatos de transmissão da LT em áreas rurais e periurbanas de estados do Sudeste, Nordeste e Sul - surtos no fim da década de 1980 no norte e oeste do Paraná e, com menor expressão, em Santa Catarina (Marzochi \& Marzochi, 1994).

Coincidentemente, em região de influência da hidrelétrica de Itaipu que recebera grande número de imigrantes da Amazônia em 1970-80, foi referido aumento de casos no sul do Brasil - Paraná (Monteiro et al., 2009) -, no Paraguai (Villar, 1993; Pacheco et al., 1999) e na Argentina (Salomon et al., 2009).

Em paralelo, surtos continuam ocorrendo, sobretudo na Amazônia, associados à derrubada de matas e ainda de transmissão sazonal em áreas próximas a matas residuais no ambiente rural, acometendo trabalhadores das atividades extrativistas, agrícolas, de mineração, ecoturismo e militares em treinamento (Brasil, 2010a).

O ressurgimento da LT a partir de 1970 (e a intensificação da LV na década de 1980 no Nordeste, Centro-Oeste e Sudeste) coincide com ou sucede a suspensão da utilização intradomiciliar dos inseticidas organoclorados no controle da malária e doença de Chagas e com a proibição de uso desses mesmos inseticidas de ação residual nas lavouras quando se utilizava aviões com dispersores em ultrabaixo volume, contaminando o ar, o solo e as águas (Marzochi et al., 1976) -, bem como com os intensos movimentos migratórios associados ao ciclo de mineração do ouro e extração de madeiras na região amazônica, construção de estradas e de barragens (Marzochi \& Marzochi, 1994).

Nesse amplo contexto, os surtos focais de LT humana são acompanhados da LT canina, equina e em roedores sinantrópicos, em grande número de estados, do Nordeste ao Sudeste (Marzochi \& Marzochi, 1994; Cunha, Lima \& Pompeu, 2006).

\section{IMPLICAÇÕES EPIDEMIOLÓGICAS ASSOCIADAS À DISPERSÃO DA LEISHMANIA (VIANNIA) BRAZILIENSIS}

Acreditamos como provável que, fora da Amazônia, local de origem da Leishmania (V.) braziliensis - espécie de maior distribuição geográfica no país e de transmissão predominantemente rural (Brandão-Filho et al., 1999, 2003; Vasconcelos et al., 1987) e peridomiciliar (Aragão, 1927; Cunha, Lima \& Pompeu, 2006; Sabroza, 1981) -, esta não participe originalmente de focos naturais (envolvendo vetores e reservatórios silvestres); mas que tenha sido introduzida pelo homem ou por animais domésticos e sinantrópicos infectados (cães, equídeos, roedores) nos ambientes alterados, antigos ou recentes, cuja transmissão seria facilitada por uma população maior de flebotomíneos, pré-adaptados a novas situações por provável ausência de predadores naturais e maior oferta de alimentos e abrigos (Marzochi \& Marzochi, 1994).

A L. (V.) braziliensis, na Amazônia, apresenta uma infinidade de variantes genéticas (zimodemos), porém uma variabilidade menor em outras regiões (Cupolillo et al., 2003; Gomes et al., 1995; Lopes et al., 1984), com predomínio do zimodemo 27 nos ambientes modificados ou extra-amazônicos (Cupolillo et al., 2003). Contudo, Ishikawa e colaboradores (2002) verificaram entre alguns isolados da Amazônia (Pará) e da Região Sul do Brasil (Paraná) e de país andino (Peru), idêntico perfil genético de L. (V.) braziliensis (Ishikawa et al., 2002).

Tais achados nos fazem acreditar que diferentes padrões de deslocamento (vetores e/ou hospedeiros animais e humanos) implicariam variações nas distribuições clonais dessa leishmânias. E que a dispersão clonal de uma mesma linhagem (geneticamente correlata) por distâncias continentais, como observada, estaria mais dependente do deslocamento do hospedeiro humano que de possíveis outros animais reservatórios ou insetos vetores.

Recolocando assim antigas questões já referidas (Rabello, 1925; Aragão, 1927; Takaoka, 1928, Pessoa, 1949), admitimos que novos dados possam corroborar a possibilidade de o homem e animais domésticos servirem de fonte de infecção da L. (V) braziliensis, tais como: 
- grande homogeneidade genética dessa leishmânia em focos distantes da Amazônia, onde, no entanto, ela tem grande heterogeneidade, como demais leishmânias dermotrópicas estudadas;

- dificuldade de demonstração de reservatórios silvestres da L. (V.) braziliensis;

- ocorrência de transmissão em distintos biomas, portanto em diferentes situações ecológicas (Amazônia, cerrado, mata atlântica, caatinga) pela provável facilidade de adaptação a diferentes espécies de vetores;

- ausência de LT na Região Sudeste, durante o desmatamento da mata atlântica primária na construção da rodovia Rio-Santos, nos anos 70 - vindo os surtos a ocorrer mais de uma década após, em áreas periurbanas de Paraty e municípios do litoral norte de São Paulo;

- imensa diversidade de vetores e hospedeiros para a mesma espécie de Leishmania, diferentemente das demais espécies dermotrópicas; e, a par disso, no homem;

- positividade ao xenodiagnóstico com flebotomíneos sobre a borda da lesão e na pele sã em pacientes de $L$. (V.) braziliensis (Rojas \& Scorza, 1989; Montoya-Lerma et al., 1998);

- isolamento de L. (V.) em pele íntegra e sangue de ex-pacientes (Coutinho, Pirmez \& Cruz, 2002; Oliveira Camera et al., 2006; Guevara et al., 1994; Vergel et al., 2006);

- reisolamento de L. (V.) braziliensis, de cicatrizes de lesões, após vários anos do tratamento (Vergel et al., 2006; Mendonça et al., 2004; Schubach et al., 1998a, 1998b).

Assim, tais dados sugerem a possibilidade de L. (V.) braziliensis continuar introduzindo-se pela presença humana em novas áreas onde existam flebotomíneos em densidade adequada, dando origem a novos focos da endemia (Marzochi \& Marzochi, 1994), cujo longo período de incubação, que torna imperceptíveis os casos secundários, pode, a nosso ver, mascarar a evidência de introdução da L. (V.) braziliensis pelo homem.

o papel do homem, certamente, inclui não só o doente, mas também o portador (caso subclínico), o qual pode apresentar o parasito tanto em cicatrizes, como na pele sã, ou no sangue periférico, por período indeterminado enquanto tentativas de isolamento de outras espécies de leishmânias dermotrópicas no sangue (hemocultura) e na pele (xenodiagnóstico) não obtiveram êxito (Montoya-Lerma et al., 1998; Silveira et al., 1989) -, além da positividade à PCR associada à IDRM positiva sem presença de lesão (Fagundes et al., 2007; Coutinho, Pirmez \& Cruz, 2002; Oliveira Camera et al., 2006; Follador et al., 2002). Em vizinhos de domicílios com caso humano, a resposta daqueles à IDRM é mais exacerbada e o risco de adoecimento é 7,5 vezes maior (Oliveira et al., 2004); também uma positividade maior da IDRM ocorre nos conjuntos familiares em que há casos de lesão em mucosas (Castellucci et al., 2005).

A persistência, no homem, da L. (V.) braziliensis (como infecção subclínica ou após cura espontânea ou terapêutica), poderia torná-lo potencial fonte de infecção natural para os vetores, ou iatrogênica por doação de sangue, órgãos e tecidos, ou acidental por compartilhamento de agulhas e seringas contaminadas (Marzochi \& Marzochi, 1994, 1997), principalmente com a dispersão para áreas periurbanas e urbanas. A eventual aquisição de HIV/Aids poderia levar da situação subclínica ao aparecimento da LT com maior gravidade clínica.

Estudo com xenodiagnóstico, no cão, mostra a potencialidade do mesmo em infectar flebotomíneos (Bezerra et al., 1997).

É plausível admitir que, fora da Amazônia, a expansão da transmissão de L. (V.) braziliensis deva depender não só do crescimento populacional de flebotomíneos em áreas periflorestais logo após o desmatamento (efeito borda), como, sobretudo, da pré-adaptação de certas espécies aos ambientes há muito alterados em áreas rurais, periurbanas e urbanas ainda pouco estudadas (Marzochi \& Marzochi, 1994), associadamente a fontes de infecção ali introduzidas. 


\section{Leishmaniose visceral}

No período de 2000 a 2010 registraram-se 38.331 casos, e um crescimento de notificações em todas as regiões. A média de casos foi de 3.484/ano, e de 220 óbitos/ano. Comparando quinquênios, houve um aumento de 15.120 casos (2001-2005) para 19.434 (2006-2010). Atualmente está distribuída em 21 unidades federadas, atingindo as cinco regiôes brasileiras. Observa-se tendência a variações de ocorrência, com picos quinquenais e decenais.

Até a década de 1990 a Região Nordeste representava 90\% dos casos. Proporcionalmente, porém, essa concentração reduziu-se com a expansão da doença às demais regiões. Assim, entre 2006 e 2010, o Nordeste contribuiu com metade dos casos (48,4\%), seguido pelas Regióes Norte (20,01\%), Sudeste (18,4\%), Centro-Oeste $(8,2 \%)$ e Sul (0,1\%) (Brasil, 2010a). Porém, a mais alta taxa de incidência média foi registrada na Região Norte (4,8/100.000), seguindo-se a Nordeste (3,4/100.000), Centro-Oeste (2,2/100.000), Sudeste (0,8/100.000) e Sul (Brasil, 2010c).

É mais frequente no sexo masculino (64\%) e em crianças menores de 10 anos (49\%), sendo que, em áreas de implantação recente, pode predominar em adultos (Brasil, 2010c; Marzochi et al., 2009). Levando em conta a considerável letalidade geral (5-10\%), têm maior risco os pacientes com diagnóstico tardio, tratados inadequadamente, imunossuprimidos como na coinfecção com HIV, e/ou que apresentam resistência medicamentosa. Essa taxa se eleva a $70-90 \%$ para os doentes não tratados.

\section{EVOLUÇÃO HISTÓRICA E EPIDEMIOLÓGICA DA LEISHMANIOSE VISCERAL}

A LV vem se modificando de zoonose rural para zoonose ou mesmo antroponose periurbana e urbana (Marzochi \& Marzochi, 1997).

O primeiro relato de caso humano no Brasil ocorreu em 1913, seguindo-se a confirmação sucessiva de centenas de casos por meio de exames histopatológicos em amostras de fígado de pacientes, supostamente falecidos de febre amarela, que procediam predominantemente do Norte e Nordeste (Penna, 1934). Essa distribuição geográfica prevaleceu até a década de 1950, quando então se iniciaram os programas de controle da leishmaniose visceral como endemia rural do estado do Ceará, apesar de casos esparsos ocorrerem na zona rural de vários outros estados (Alencar, 1961). Anos mais tarde a doença propagou-se às Regiões Norte (Roraima), Centro-Oeste e Sudeste do país.

Na década de 1960, casos urbanos ocorreram na cidade de Santarém (PA) (Alencar, Pessoa \& Costa, 1962). Em fins da década de 1970 e início de 1980, no rastro da mobilidade de grupos sociais, fugindo das secas do Nordeste brasileiro, que levam à fome com possível queda de resistência imunológica humana e canina, a endemia começa a aparecer na periferia de grandes cidades como Rio de Janeiro (RJ), Corumbá (MS), Teresina (PI), Aracaju (SE), Natal (RN), São Luís (MA), Fortaleza (CE), simultaneamente; e, no fim da década de 1980, a urbanização plena da endemia se caracteriza em Teresina (PI), e depois em Belo Horizonte e Montes Claros (MG), Camaçari (BA) e Recife (PE). Na segunda metade dos anos 90, surge a LV já urbanizada em Campo Grande (MS), Palmas (TO) e Araçatuba (SP), associada a intercâmbios comerciais entre produtores rurais.

Até 2008 a Região Sul era considerada indene de LV humana e canina. Em novembro desse mesmo ano apareceu o primeiro caso suspeito em cão, no município de São Borja (RS) (fronteira com a Argentina), e em janeiro de 2009 confirmou-se o primeiro caso humano (Brasil, 2010c). Em 2010, a LV canina foi detectada em Florianópolis (SC) (Estado de Santa Catarina, 2010).

\section{IMPLICAÇÕeS EPIDEMIOLÓGICAS dA URBANIZAÇÃo da LeISHMANIA (L.) CHAGASI}

A leishmaniose visceral, em franco processo de urbanização, está associada à adaptação da Lu. longipalpis às condições peridomésticas de áreas degradadas, sem saneamento e habitadas por animais domésticos como aves e por 
vezes suínos, fontes de alimento para esses insetos hematófagos e geradores de resíduos orgânicos que servem de criadouros aos mesmos insetos, além do cão, este com o agravante de, quando infectado, constituir fonte de infecção para os vetores. A enzootia canina, nas áreas de implantação recente, precede a ocorrência da doença humana, sendo estimada uma relação de vinte casos caninos para cada caso humano (Brasil, 2006; Monteiro, Lacerda \& Arias, 1994).

Pelo fato de a urbanização da LV ser um fenômeno relativamente novo, pouco se conhece sobre a epidemiologia dos focos urbanos. As relações entre os componentes da cadeia de transmissão no cenário urbano são mais complexas e variadas que no ambiente rural clássico. Assim, à maior densidade de pessoas vivendo no contexto peculiar dos aglomerados urbanos de baixo nível de desenvolvimento social - com problemas de moradia, falta de saneamento básico, subnutrição sobretudo de crianças, dependências químicas entre adultos, baixa acessibilidade ao sistema de saúde e à educação, e outros - se associam a maior proximidade dos animais reservatórios, e mesmo de pacientes como possíveis fontes de infecção, e a adaptação dos vetores com suas variantes genéticas aos ambientes modificados, ao que se soma a insuficiência e descontinuidade das ações de controle e as prováveis mudanças climáticas e ambientais que podem ter papel de relevo.

Por sua vez, a persistência dos movimentos migratórios familiares rural-urbanos à procura de locais com maior potencial econômico, principalmente quando dentro das mesmas regiões - em que se podem fazer acompanhar de seus animais domésticos, notadamente o cão eventualmente infectado -, continuam levando as famílias a se instalar nas periferias das cidades. E ali, tornam-se suscetíveis se existir o vetor.

O vetor também poderia ser introduzido por transporte rodoviário e ferroviário, proveniente de zonas endêmicas, junto com resíduos orgânicos como fezes de animais e restos de cereais contendo ovos, larvas ou pupas de $L u$. longipalpis, os quais também poderiam estar presentes em adubo para fertilização do solo, jardins e vasos ornamentais; e o alado, ainda, poderia abrigar-se em veículos de transporte de grandes animais (Marzochi \& Marzochi, 1997).

Em populações urbanas as infecções subclínicas humanas tendem a criar novas situações de riscos: possibilidade de transmissão por doação de sangue e órgãos; entre usuários de drogas endovenosas (Marzochi et al., 1993); evolução à doença induzida por imunossupressão medicamentosa ou associada à Aids (quando ambos os agravos se superpõem endemicamente) (Marzochi \& Marzochi, 1994; Costa et al., 2000; Michel et al., 2011). Em presença da coinfecção com Aids, varia o padrão clínico da LV com resposta irregular ao tratamento, grande tendência a recidivas, e maior letalidade, e do diagnóstico com redução do nível de anticorpos e aumento da parasitemia (Brasil, 2006). É esperada a tendência de aumento de casos de coinfecção Leishmania/HIV em áreas urbanas do Brasil. Estudo de 7.556 notificações de LV mostrou 278 casos de coinfecção por HIV, com 3,1\% em 2007 e 4,2\% em 2008, predominando em homens $(78,1 \%)$ e adultos entre 20 e 49 anos $(77,7 \%)$, com letalidade de $23,9 \%$ em maiores de 50 anos e distribuição geográfica de $7,2 \%$ dos casos na Região Norte, $38,1 \%$ no Nordeste, $16,2 \%$ no Centro-Oeste, $38,1 \%$ no Sudeste e $1,1 \%$ no Sul (Sousa-Gomes et al., 2011).

\section{OS CONTEXTOS DE TRANSMISSÃO DAS LEISHMANIOSES: UMA SISTEMATIZAÇÃO VISANDO AO CONTROLE}

A interação com os focos enzoóticos e com os diferentes graus de modificações antropogênicas podem transformar o homem em: hospedeiro acidental; principal ou único hospedeiro; um entre vários hospedeiros em uma estável anfixenose; ou exposto ao aumento do risco de transmissão em consequência da rápida multiplicação de vetores e reservatórios. Cada um desses quatro tipos de interação pode ocorrer em vários cenários ecológicos e afetar a população humana, que exibe uma diversidade de condições culturais e socioeconômicas (Alexander \& Maroli, 2003).

As estratégias de controle dependem tanto do tipo de transmissão observado em cada região particular, como também dos antecedentes migratórios de grupos humanos nas comunidades envolvidas. As ações de controle devem ser específicas conforme as situações ecoepidemiológicas de cada local ou região, sendo fundamental a identificação do maior número 
de casos suspeitos, diagnóstico e tratamento dos casos confirmados, identificação do agente biológico circulante na área, conhecimento dos locais de transmissão, das espécies de vetores e dos possíveis reservatórios (domésticos, sinantrópicos ou comensais, e silvestres), e, sobretudo, redução do contato homem-vetor, por meio de medidas específicas, com base nos padrões de transmissão. Ressalta-se, na LT, que o grande número de vetores, reservatórios e agentes biológicos se reduz à medida que a transmissão caminha do ambiente silvestre ao urbano (ver Quadro 1).

Na cadeia de transmissão das leishmanioses o elo a ser 'eliminado' para a redução dessas doenças é o vetor, sendo o controle químico a medida mais objetiva atualmente disponível, ainda que insuficiente e complexa.

De forma geral, parece bem aceito pela população o controle de vetores por inseticidas, e especificamente de flebotomíneos (Dye, 1996).

As experiências controladas e mais bem-sucedidas de inseticidas contra flebotomíneos, no mundo e no Brasil, foram desenvolvidas com o uso do diclorodifeniltricloroetano (DDT), composto organoclorado, em razão de sua elevada efetividade pela ação residual em habitações humanas e abrigos de animais, com efeitos localizados e bem delimitados. Iniciaram-se a partir de 1944 contra Lu. verrucarum, em áreas de bartonelose no Peru (Hertig \& Fairchild, 1948) e, no Brasil, na Amazônia em 1945, no combate à malária (D’amato, Torres \& Malm, 2002), e em 1947, contra a Lu. intermedia em área de LT no Rio de Janeiro (Nery-Guimarães \& Bustamante, 1954), seguindo-se contra a Lu. longipalpis em áreas de LV no Nordeste (Alencar, 1961, Deane, Deane \& Alencar, 1955; Sherlock \& Almeida, 1970) e Sudeste (Magalhães et al., 1980). Somente na Índia detectou-se resistência ao DDT, em três espécies de flebotomíneos (Ph. papatasi, Ph. argentipes e Sergentomyia shorti) (Alexander \& Maroli, 2003).

Também grande impacto contra mosquitos anofelinos e drástica redução da malária, no mundo, verificou-se nas décadas de 1950 e 1960 com o uso desse inseticida, embora, mais recentemente, refiram-se evidências de tolerância ou resistência nesses vetores (Alexander \& Maroli, 2003). A partir de 1971, medidas restritivas foram sendo impostas contra o uso do DDT e outros organoclorados, como o BHC utilizado no controle da doença de Chagas, por evidências de graves implicações em seres humanos, animais e meio ambiente (Bouwman, van den Berg \& Kylin, 2011), sendo contestadas por alguns (Edwards, 2004).

Embora praticamente banido pela Convenção de Estocolmo (Unep, 2002), e não mais permitido o DDT na maioria dos países (WHO, 2001), substituído principalmente pelos piretroides sintéticos e outras abordagens ecologicamente indicadas, sua alta efetividade e as necessidades de controle de doenças de transmissão vetorial ante seus graves efeitos adversos permanece polêmica (Bouwman, van den Berg \& Kylin, 2011). A OMS permite sua produção e uso no controle da malária, desde que sob sua supervisão, quando localmente seguro e efetivo e as alternativas não sejam possíveis (WHO, 2007). Para esse fim, cresce em países africanos o uso do DDT e coincidentemente se reduz a transmissão da malária, o que, porém, é atribuído a outros métodos não químicos associados às estratégias de controle integrado, "aumentando a sustentabilidade dos esforços de controle e ajudando a alcançar os objetivos de eliminação da malária” (van den Berg, 2009).

Os piretroides foram introduzidos no mercado em 1976 e, embora mais caros por unidade de peso que os outros praguicidas, têm sido bastante empregados na área da saúde e na agricultura. Para erradicação de vetores ou insetos domiciliares, seu uso está restrito aos aplicadores profissionais, sendo mais utilizados a cipermetrina e a deltametrina (UFRJ, 2012).

No Brasil, os organoclorados DDT e BHC foram utilizados até 1992, e os piretroides, introduzidos em 1989. Porém, enquanto os efeitos do DDT contra insetos vetores perduram até nove meses, os piretroides atuam por períodos muito variáveis, entre dias, semanas, meses (Alexander \& Maroli, 2003), em média de três meses (Brasil, 2010b), sendo pouco efetivos no ambiente extradomiciliar (Falcão et al., 1991; Gontijo \& Melo, 2004) e - possivelmente por isso - sejam mais 
efetivos no ambiente urbano que no rural (Alexander \& Maroli, 2003). No entanto, apresentam baixa a moderada toxicidade para mamíferos, baixa volatilidade e elevada ação inseticida, sendo úteis também contra mosquitos, pulgas e percevejos (Curtis, 1990). Suas propriedades físicas e químicas superiores também garantem maior estabilidade à luz e ao calor (UFRJ, 2012).

o piretro é um inseticida natural obtido da trituração das flores de algumas plantas do gênero Chrysanthemum (Pyrethrum) e espécie cinerariaefolium, um dos mais antigos inseticidas conhecidos pelo homem. A síntese do ácido crisantêmico abriu novos caminhos para a obtenção de piretroides sintéticos, obtidos com base em estudos que modificaram a estrutura química das piretrinas naturais, alcançando muito mais vantagens. Contudo, ainda podem causar intoxicações em indivíduos potencialmente expostos às suas diversas apresentações (em espirais, sprays ou vaporizadores).

Em cães, a utilização de coleiras impregnadas com deltametrina impede a picada por ação repelente e inseticida com duração de até seis meses. No Brasil, foi testada em áreas de Lu. longipalpis (LV) e Lu. migonei (LT), tendo se obtido cerca de 50\% de proteção (David, 2001). No Mediterrâneo e Oriente Médio, apresenta grande eficácia em áreas de LV (mais de $80 \%$ de proteção), onde o vetor, Ph. Perniciosus, é mais cinofílico e a transmissão se dá apenas no verão, enquanto em território brasileiro Lu. longipalpis tem hábitos mais ecléticos e a transmissão ocorre praticamente durante todo o ano (Deane, 1956).

O controle químico vetorial requer: dispor-se de diferentes formulações de inseticidas para alternância ou a substituição, quando indicada; treinamento diferenciado de pessoal para uso de equipamentos de segurança destinados à borrifação do interior das casas e dos abrigos de animais e para orientação aos moradores; domínio de técnicas de monitoramento e interpretação de indicadores de avaliação do inseticida; dispor-se de suprimentos de insumos com qualidade controlada e quantidade adequada para a continuidade de sua aplicação e avaliação (Alexander \& Maroli, 2003).

\section{Padrões de transmissão na leishmaniose tegumentar}

Objetivando contribuir para a especificação das abordagens de controle, Marzochi e Marzochi (1997) as correlacionam com os diferentes padrões epidemiológicos de transmissão definidos principalmente pelos ambientes de infecção do vetor (ver Quadro 1). Quaisquer que sejam esses padrões, são medidas básicas a vigilância clínica, laboratorial e notificação dos casos, além do tratamento dos pacientes (WHO, 2010). E, portanto, a educação com informações sobre o contexto de desenvolvimento da doença e a acessibilidade à atenção à saúde.

- Transmissão silvestre: intraflorestal - adquirida no interior da mata, como observada caracteristicamente na Amazônia durante incursões na selva por exposições ocupacionais, treinamentos militares, incidentais, sob forma de surtos ou casos isolados, acometendo prioritariamente adultos masculinos; periflorestal - em áreas situadas dentro do raio de voo de vetores silvestres, de desmatamentos e instalação de povoados rurais, ou de assentamentos com urbanização recente, quando as cidades se expandem em direção à floresta (como no crescimento da cidade de Manaus, ocupando áreas antes florestais), em que insetos infectados nos reservatórios silvestres transmitem a infecção humana fora do ambiente florestal.

Como alternativas de controle, nas áreas de transmissão silvestre-intraflorestal, onde apenas uma vacina humana seria efetiva, se disponível, uma vez que o combate aos insetos vetores e reservatórios silvestres é inviável, são recomendáveis cuidados individuais como uso de repelentes e proteção por roupas, e, sobretudo, atentar para lesões de pele compatíveis com LT. O uso de repelentes químicos como a dietiltoluamida (Deet) confere ação protetora por até quatro horas na pele ou em roupas, limitado a apenas situação temporária de risco. Nas áreas de transmissão silvestre-periflorestal, além das medidas mencionadas antes, é recomendada a construção de moradias distantes, 
mais de quatrocentos metros, dos limites da floresta, além do controle dos vetores nas casas por meio da aspersão de inseticidas nas paredes externas e internas, uso de mosquiteiros de malha fina impregnados de inseticidas piretroides, telagem de portas e janelas, atentando-se para a proteção das casas e pessoas contra os vetores nos horários de crepúsculo e noturno. Repelentes para insetos como essências de citronela, linalol, geraniol, eucalipto e óleo de Neem indiano podem ser utilizados e até produzidos pela população, aplicados em áreas desprotegidas da pele e mesmo em roupas (Alexander \& Maroli, 2003). Nessas áreas endêmicas a vacinação humana, se disponível, estaria indicada como rotina.

- Transmissão rural: em áreas agropastoris, porém de colonização próxima a matas primárias e residuais extraamazônicas, podendo ser rural-periflorestal - como provavelmente foi implantada, no início do século XX, por migrantes da região amazônica com persistência parasitária clínica ou subclínica, que desmataram áreas da mata atlântica (onde somente existiriam os vetores, possivelmente sem reservatórios naturais) e se estabeleceram no oeste paulista, com a provável introdução antropogênica do parasito -, transmitida a outro homem e a animais sinantrópicos e silvestres, encadeando novas fontes de infecção para os vetores silvestres (fenômeno certamente repetido em outras áreas) e produzindo grandes surtos em assentamentos humanos, com predomínio no sexo masculino; ou ruralperidomiciliar - como ocorre em algumas áreas do Nordeste, Sudeste e Centro-Oeste -, em que a transmissão se dá no peridomicílio onde se desenvolvem atividades agrícolas, e onde se encontram os criadores dos flebotomíneos adaptados, animais domésticos e sinantrópicos, predominando a ocorrência esporádica em ambos os sexos, com surtos sazonais dependentes da flutuação da densidade populacional dos vetores.

Nas áreas de transmissão rural está indicado o controle de vetores com inseticidas de ação residual nos domicílios e abrigos dos animais domésticos, além do combate aos roedores sinantrópicos nos depósitos de produtos agrícolas. Tanto os abrigos de animais como esses depósitos devem ser construídos longe dos domicílios. A remoção de resíduos orgânicos, com manutenção de limpeza em torno do domicílio, deve ser recomendada. Quando disponível, estaria indicada a vacinação da população humana e dos animais domésticos, sobretudo no ambiente rural-peridomiciliar, de rotina em área endêmica.

- Transmissão periurbana - em áreas semiurbanizadas com algumas características rurais, tendo como fonte de infecção suspeita para o vetor, adaptado ao peridomicílio, os animais domésticos (cães e equinos, principalmente) e também os sinantrópicos, e ainda o próprio homem, como se admite na Região Sudeste e em algumas localidades do estado do Ceará (Região Nordeste), podendo a transmissão ser peridomiciliar ou mesmo dentro do domicílio por invasão do vetor, ocorrendo em todas as idades e em ambos os sexos, esporádica ou endemicamente.

- Transmissão urbana - em áreas mais centrais de cidades, pode ocorrer como casos esporádicos, acometendo todas as idades e ambos os sexos, no peridomicílio ou domicílio, admitindo-se o cão ou o homem como fonte de infecção, com criadouros do vetor em parques, praças e terrenos arborizados.

Nessa forma de transmissão, em geral esporádica, não há conduta previsível como rotina para o controle de vetores e reservatórios. Tampouco a vacinação humana e canina, se disponível, estaria indicada como rotina.

Seria recomendável triagem diagnóstica de LT em doadores de sangue e órgãos.

\section{Padrões de transmissão da leishmaniose visceral}

A distribuição e dinâmica populacional do vetor, a Lu. longipalpis, assume papel relevante na LV por ser praticamente o único incriminado, elo essencial entre os indivíduos infectantes e suscetíveis. Por sua raridade em áreas florestais, a transmissão silvestre não ocorre. Definem-se três situações de transmissão (Marzochi \& Marzochi, 1997) (ver Quadro 1): 
- Transmissão rural-peridomiciliar (Nordeste e Sudeste) - era a mais frequente e continua relevante no Nordeste, sobretudo em crianças de ambos os sexos, envolvendo como reservatórios principalmente o cão, mas também animais sinantrópicos como a raposa e marsupiais. Os quintais, galinheiros, chiqueiros e outros abrigos de animais são colonizados pela Lu. longipalpis, sendo a cobertura vegetal propícia ao seu desenvolvimento.

- Transmissão periurbana-peridomiciliar (Nordeste, Centro-Oeste e Sudeste) - nas áreas de instalação recente surge em adultos, com predomínio do sexo masculino, e progressivamente prevalecendo em crianças, sendo o cão o mais importante reservatório, com envolvimento eventual de sinantrópicos marsupiais, sem excluir o homem como fonte de infecção; além disso, o vetor também coloniza os abrigos de animais, principalmente galinheiros e canis, em áreas arborizadas.

- Transmissão urbana-domiciliar (Nordeste, Centro-Oeste e Sudeste) - evento mais recente, porém crescente, podendo ocorrer em todas as idades, com predomínio em crianças e em ambos os sexos, tendo o cão como reservatório, mas em que o homem pode também atuar como fonte de infecção. A produção de criadouros do vetor pode não ter as características habituais, e pode ser importante a proximidade de áreas públicas arborizadas em graus variáveis.

Nessas três formas de transmissão, está indicada a busca ativa de casos suspeitos em áreas endêmicas para tratamento precoce, a identificação dos cães doentes ou sorologicamente positivos e ainda a eutanásia dos mesmos, o controle de vetores - com inseticida - nos domicílios e abrigos de animais, associadamente ao saneamento ambiental. A vigilância epidemiológica por meio do georreferenciamento das áreas de ocorrência dos casos humanos e caninos de LV e da Lu. longipalpis torna-se necessária, objetivando racionalizar o uso de inseticidas residuais. Quando disponível, a vacinação humana e canina estaria indicada nas três formas de transmissão, em áreas endêmicas.

Principalmente no controle da LV, periurbana e urbana, seria recomendável considerar a triagem diagnóstica em doadores de sangue e órgãos.

Quanto à dinâmica epidemiológica da LV, Costa e colaboradores (1990) definiram para a Região Meio-Norte (Piauí e Maranhão) os seguintes padrões:

- Endêmico-epidêmico - associado à presença de casos humanos em ambientes rurais, apresentando o cão e a raposa como reservatórios e o fenômeno das secas acompanhando a migração de pessoas e animais para outras áreas.

- Epidêmico - associado à precariedade das condições de vida nas periferias urbanas, propiciando a eclosão de surtos pela proliferação do vetor, abundância de fontes alimentares, proximidade de criadouros e circulação do agente etiológico em cães e pessoas infectadas.

- Epidêmico rural dos vales e dos rios - principalmente no Nordeste, onde nas escassas coleções de água acumulamse reservatórios domésticos (cães) e silvestres (raposas e marsupiais), além dos animais domésticos infectados e suscetíveis, propiciando o aparecimento de casos de LV humana. A maior suscetibilidade das crianças é explicada pela relativa imaturidade imunológica, agravada pela desnutrição comum em áreas endêmicas (dieta pobre em proteínas, vitamina A, ferro e zinco), além de maior exposição ao vetor no peridomicílio. O envolvimento do adulto tem também significante papel na epidemiologia da LV, igualmente com apresentação de todas as manifestações clínicas (forma leve ou oligossintomática, moderada e grave) a partir da infecção inaparente ou subclínica.

\section{Medidas complementares de controle das leishmanioses}

Devem ser aplicadas a áreas de transmissão endêmica.

No controle da LT de transmissão periurbana (associada a L. (V.) braziliensis), e, sobretudo, da LV de transmissão periurbana e urbana, deveriam ser avaliados e afastados esses diagnósticos nos doadores de sangue e de órgãos de tais procedências. 
Tanto na LT como na LV, exceto na transmissão da LT silvestre, deve ser enfatizado o saneamento ambiental como medida exequível, sendo relevante a participação da comunidade. Busca-se, assim, evitar a formação de criadouros e atração de animais comensais - potenciais reservatórios - pela remoção de lixo orgânico, fezes secas de animais e vegetais em decomposição, mantendo-se o mais limpa possível a área em torno do domicílio.

A eliminação de cães doentes na LT não é recomendada, exceto quando esses animais evoluem para o agravamento das lesões cutâneas e para o surgimento de lesões mucosas com infecções secundárias, o que, consequentemente, trará mais sofrimento (Brasil, 2010a).

Recomenda-se à população o controle de cães errantes, a posse responsável de animais, o uso de telas em canis individuais ou coletivos e também coleiras impregnadas com deltametrina a 4\%. É contraindicado o tratamento de animais com LT ou LV, infectados ou doentes, com drogas de uso humano, a fim de se evitar resistência do parasito (Brasil, 2006).

Quanto aos vetores, nenhum método isoladamente é sustentável para controlar a população de flebotomíneos. o controle integrado pela combinação de diferentes métodos adequados a cada situação epidemiológica e local, é considerado uma alternativa ao controle químico (van den Berg, 2009).

\section{SITUAÇÃO DE TRANSMISSÃO E O CONTROLE DAS LEISHMANIOSES DEFINIDOS PELO MINISTÉRIO DA SAÚDE}

Na LT, o Ministério da Saúde (MS) considera os seguintes padrões epidemiológicos:

- Silvestre - quando a transmissão ocorre em área de vegetação primária; fundamentalmente uma zoonose de animais silvestres que pode acometer o ser humano quando este entra em contato com o ambiente silvestre onde esteja ocorrendo a enzootia;

- Ocupacional ou de lazer - quando a transmissão está associada à exploração desordenada da floresta e à derrubada de matas para construção de estradas, usinas hidrelétricas, instalação de povoados, extração de madeira, desenvolvimento de atividades agropecuárias, treinamentos militares ou a ecoturismo;

- Rural e periurbano - em áreas de colonização, encontra-se relacionada ao processo migratório, ocupação de encostas e aglomerados em centros urbanos associados a matas secundárias ou residuais (Brasil, 2010a).

Na LV, o Ministério da Saúde considera os padrões rural e urbano.

A operacionalização detalhada do controle da LT e da LV encontra-se definida pelos respectivos Manuais de Controle editados pelo próprio MS.

\section{Orientações do Ministério da Saúde dirigidas para o controle químico de vetores nas leishmanioses}

O controle químico por meio da utilização de inseticidas de ação residual é a medida de controle vetorial recomendada no âmbito da proteção coletiva. Tal medida é dirigida apenas para o inseto adulto. A indicação do controle químico deverá ser determinada pelas análises conjuntas dos dados epidemiológicos e entomológicos de cada localidade. Não há indicação do controle químico para ambiente silvestre.

Os produtos mais empregados atualmente no controle dos vetores são: a cipermetrina, na formulação pó molhável (PM) e a deltametrina, em suspensão concentrada (SC), usados nas doses, respectivamente, de $125 \mathrm{mg}$ i.a. $/ \mathrm{m}^{2}$ e de $25 \mathrm{mg}$ i.a/ $\mathrm{m}^{2}$.

A borrifação deve ser feita nas paredes internas e externas do domicílio, incluindo o teto, quando a altura deste for de até três metros. Nos abrigos de animais ou anexos, quando os mesmos forem feitos com superfícies de proteção (parede) e possuam cobertura superior (teto). 
Para aplicação do inseticida, são indicados equipamentos de compressão constante (25-55 lbs). o bico indicado para uso em saúde pública é o Tee Jet 8002E, que proporciona uma vazão de $757 \mathrm{~mL} /$ minuto e deposição uniforme nas laterais do leque de aplicação. Em decorrência da erosão, os bicos que apresentarem uma vazão maior que 900 $\mathrm{mL} / \mathrm{minu}$ to deverão ser descartados.

Os agentes deverão usar equipamentos de proteção individual (EPI), indicados para aplicação de inseticida.

A avaliação das ações de controle químico é de fundamental importância para verificar o impacto das mesmas, devendo ser avaliada a persistência do inseticida nas superfícies tratadas e a efetividade do produto em relação à mortalidade do vetor. Essa atividade deverá ser executada pela Secretaria Estadual de Saúde (SES).

O método utilizado para tal tipo de avaliação foi padronizado pela Organização Mundial da Saúde (WHO, 1970). No entanto, por se tratar de uma atividade específica, essa atribuição deve ser de competência dos estados, quando os mesmos reunirem as condições necessárias.

No que refere às ações de vigilância e controle vetorial, caberá ao MS garantir o fornecimento de inseticidas para os estados e municípios, às SES a aquisição e distribuição de EPIs quando indicado, e aos municípios os pulverizadores, conforme determina a portaria n. 1.172, de 15 de junho de 2004 .

Caberá às SES, por meio do núcleo de entomologia ou setor afim, a execução da atividade de vigilância entomológica, tendo o município como colaborador. Nesse sentido, o estado se responsabilizará pela capacitação dos recursos humanos, assessoria técnica para definição de estratégias e de áreas a serem trabalhadas e o acompanhamento da execução das ações de controle químico. Também caberá ao estado a realização das provas de persistência do inseticida nas superfícies tratadas, quando da borrifação, e a efetividade do produto em relação à mortalidade do vetor. Caberá ao município apoiar o estado nas atividades de coletas e identificação de flebotomíneos, bem como na execução das atividades de borrifação quando indicadas.

Os defensivos químicos para combater os insetos transmissores de doenças são considerados insumos estratégicos, e o seu fornecimento para os estados e municípios está garantido pelo MS, conforme determinado na portaria n. 1.399, de 15 de dezembro de 1999.

Segundo indicações obtidas em pesquisas operacionais, realizadas pelo MS, o efeito residual dos piretroides em superfícies de parede tem duração aproximada de três meses (excetuando-se as superfícies de madeira, nas quais esse efeito poderá ser mais duradouro).

Os cuidados no manuseio, transporte e aplicação de praguicidas no controle de vetores, bem como os EPIs, estão descritos no Manual de Controle de Vetores - "Procedimentos de Segurança”, da Fundação Nacional de Saúde, 2001.

ORIENTAÇÕES DIRIGIDAS PARA 0 CONTROLE QUímICO DE VETORES NA LEISHMANIOSE TEGUMENTAR

O controle químico dirige-se para áreas com:

- ocorrência de mais de um caso humano de LT num período máximo de seis meses do início dos sintomas, em áreas novas ou em surto, associadamente a evidências de que a transmissão venha ocorrendo no ambiente domiciliar - isto é, de que haja a adaptação das espécies L. intermedia, L. pessoai, L. whitmani, L. migonei e $L$. fischeri ao ambiente domiciliar;

- ocorrência de casos humanos de LT na faixa etária inferior a 10 anos, num período máximo de seis meses do início dos sintomas entre a ocorrência de um caso e outro, associadamente a evidências de que a transmissão venha ocorrendo no ambiente domiciliar - isto é, de que haja a adaptação das espécies L. intermedia, L. pessoai, L. whitmani, L. migonei e L. fischeri ao ambiente domiciliar. 
A área a ser borrifada deverá compreender um raio inicial de 500 metros em torno dos domicílios onde ocorreram os casos humanos. Em áreas rurais em que os domicílios estejam muito dispersos, tal distância deverá ser ampliada para um quilômetro. Quando esses domicílios estiverem próximos à mata, o raio de um quilômetro deverá ser obedecido excluindo-se as áreas da mata (WHO, 1990).

Em áreas de surto de LT, é recomendado que o controle químico tenha aplicação imediata, entendendo-se que um surto é caracterizado pela ocorrência de mais de um caso em uma mesma área delimitada, num período de seis meses, ou quando o número de casos for superior ao número anualmente detectado em determinada localidade. O ciclo deverá ocorrer no período que antecede as chuvas ou imediatamente após, período este favorável ao aumento da densidade vetorial. A aplicação de um novo ciclo dependerá da ocorrência de novos casos na mesma área e da presença de qualquer espécie suspeita ou incriminada como vetora no intradomicílio.

\section{ORIENTAÇ̃̃ES DIRIGIDAS PARA 0 CONTROLE QUÍMICO DE VETORES NA LEISHMANIOSE VISCERAL}

As recomendações propostas para cada área estão descritas conforme a classificação epidemiológica, sendo importante salientar que as ações de controle deverão sempre ser realizadas de forma integrada.

O controle químico é recomendado em áreas com registro do primeiro caso autóctone de LV humano, imediatamente após a investigação entomológica.

Em áreas com transmissão moderada e intensa, se a curva de sazonalidade do vetor for conhecida, a aplicação do inseticida de ação residual deverá ser realizada no período do ano em que se verifica o aumento da densidade vetorial. Caso contrário, o primeiro ciclo de tratamento deverá ser efetuado ao final do período chuvoso e o segundo, três a quatro meses após o primeiro ciclo.

Entende-se por ciclo de borrifação o período necessário para cobrir a área delimitada a ser borrifada no menor espaço de tempo.

Em áreas com surto de LV, uma vez avaliada e delimitada a área para o controle químico, deverá ser cumprido imediatamente um ciclo de tratamento com inseticida de ação residual. A programação de novo ciclo de aplicação do inseticida deverá ser de acordo com a curva de sazonalidade do vetor. Se conhecida, a aplicação do inseticida deverá ser executada no período do ano em que se verifica o aumento da densidade vetorial. Caso contrário, o primeiro ciclo de tratamento deverá ser efetuado ao final do período chuvoso e três a quatro meses após o primeiro ciclo. Sendo assim, é recomendado que nas áreas selecionadas para controle químico, de acordo com a classificação epidemiológica, deverão ser feitos dois ciclos de borrifação durante o ano, com intervalo de três a quatro meses. 0 início do ciclo deverá seguir as orientações já descritas.

Na zona rural, o controle químico será efetivado em todos os domicílios da localidade onde ocorreu a transmissão. $\mathrm{Na}$ zona urbana, para o controle deverá ser considerada a área previamente delimitada conforme classificação epidemiológica.

\section{Orientações dirigidas para o controle do reservatório canino na leishmaniose tegumentar e visceral}

\section{LEISHMANIOSE TEGUMENTAR}

Não são recomendadas ações objetivando o controle de animais silvestres e nem ações destinadas ao controle de animais domésticos. E a eutanásia será indicada somente quando os animais doentes evoluírem para o agravamento das lesões cutâneas, com surgimento de lesões mucosas e infecções secundárias que poderão conduzir o animal ao sofrimento. 
O tratamento de animais doentes com drogas utilizadas para o tratamento de casos humanos não é uma medida aceita para o controle da LT, pois poderá conduzir ao risco de selecionar parasitos resistentes.

\section{LEISHMANIOSE VISCERAL}

A prática da eutanásia canina é recomendada a todos os animais sororreagentes ou parasitológico positivos, com base nos inquéritos caninos, amostrais ou censitários, conforme os critérios definidos pelo Ministério da Saúde. Para a realização da eutanásia deve-se ter como base a resolução n. 714, de 29 de junho de 2002, do Conselho Federal de Medicina Veterinária (CFMV), que dispõe sobre os procedimentos e métodos de eutanásia em animais e dá outras providências.

Orientações relacionadas aos cadáveres dos animais estão previstas na resolução RDC, n. 33, de 25 de fevereiro de 2003, da Agência Nacional de Vigilância Sanitária (Anvisa).

As ações relacionadas aos inquéritos de avaliação de infecção canina são específicas para cada área epidemiológica - Áreas sem casos e Áreas com casos - que se subdividem em Áreas com primeiro caso de LV humana; Áreas de transmissão esporádica; Áreas de transmissão moderada e intensa; Áreas com surto.

o detalhamento dessas ações se encontra no Manual de Vigilância e Controle da Leishmaniose Visceral, 2006 (Brasil, 2006).

\section{Atividades de educação em saúde na leishmaniose tegumentar e visceral}

As atividades de educação em saúde devem estar inseridas em todos os serviços que desenvolvam as ações de vigilância e controle, requerendo o envolvimento efetivo das equipes multiprofissionais e multi-institucionais, com vistas ao trabalho articulado nas diferentes unidades de prestação de serviços. Tais atividades deverão ser:

- Divulgação à população sobre a ocorrência de casos na localidade, orientando para o reconhecimento de sinais clínicos e a procura dos serviços para o diagnóstico e tratamento, quando houver caso suspeito.

- Adoção de medidas preventivas, considerando o conhecimento da doença, atitudes e práticas da população, relacionadas às condições de vida e trabalho das pessoas.

- Desenvolvimento de atividades de educação em saúde na comunidade.

- Capacitação das equipes dos Programas de Agentes Comunitários de Saúde (Pacs), Saúde da Família (PSF), Vigilâncias Ambiental e Epidemiológica e de outros profissionais, bem como de áreas afins, visando ao diagnóstico precoce e tratamento adequado, e à incorporação das atividades de educação em saúde dentro de um processo de educação continuada.

- Estabelecimento de parcerias interinstitucionais, visando à implementação das ações de interesse sanitário, principalmente a limpeza pública e o destino adequado de lixo orgânico.

- Implantação de programa de educação em saúde, desenvolvendo atividades de informação, educação e comunicação em âmbito local, regional e municipal.

\section{DESAFIOS PARA O CONTROLE DAS LEISHMANIOSES NO BRASIL}

O caráter focal e diferenciado de transmissão das leishmanioses tegumentar e visceral impede uma melhor comparação entre os coeficientes de incidência das mesmas (Marzochi \& Marzochi, 1994). Entretanto, ambas continuam em expansão pelas condições de ordem social e ambiental que se mantêm, contribuindo para seu reaparecimento e o surgimento de diferentes perfis epidemiológicos dessas afecções e expondo ampla parcela da população nas diferentes 
regiões do Brasil. A tais condições vêm somar-se a falta de elementos de grande impacto no combate a ambas as endemias, como a imunização, para a prevenção da infecção no homem e no animal, e a disponibilidade de inseticidas de longa ação residual para o controle dos vetores nas áreas de transmissão rural, periurbana e urbana, que, porém, é a única ferramenta de ação direta contra os flebotomíneos em uso.

O controle químico das leishmanioses merece discussão aprofundada, com base em experiências e estudos sobre efeitos adversos e benefícios da aplicação de inseticidas nos domicílios e seus anexos. Uma associação temporal entre a suspensão do uso de DDT para o controle da malária a partir da década de 1970 e o reaparecimento dos casos de LT de transmissão peridomiciliar e domiciliar, evidenciado na Região Sudeste, parece indicar esse benefício. Deane (1956) considerou que a aplicação do DDT nas paredes do domicílio e anexos reduz drasticamente a transmissão de LV. Por equivalência, afirma-se que o reaparecimento da malária na América do Sul deve-se ao fato de os países terem deixado de utilizar esse inseticida nos programas de controle, sendo que os dois únicos países onde a malária não reapareceu foram Equador e Venezuela, onde o DDT não foi proibido (D'Amato, Torres \& Malm, 2002). Alguns malariologistas argumentam que sua aplicação dentro de residências não é prejudicial à saúde humana (D’Amato, Torres \& Malm, 2002).

No entanto, há uma gama de efeitos adversos muito graves relacionáveis ao uso do DDT, sobretudo na lavoura, onde era feito abusivamente, aspergido até por avião, ou diretamente em grandes quantidades por agricultores, eles próprios sem equipamentos de proteção. Verificou-se contaminação ambiental, da biota e de ecossistemas marinhos e de água doce (D’Amato, Torres \& Malm, 2002).

A contaminação humana e animal, pelo DDT, dá-se por via digestiva ou respiratória. São citados, na intoxicação aguda, cefaleia, vertigem, parestesia da língua, lábios e membros inferiores, desorientação, hiperexcitabilidade, convulsões, insuficiência respiratória, depressão central grave, coma e até morte, dependendo da dose e tempo de exposição; nas intoxicações crônicas, neuropatias periféricas, paralisias, discrasias sanguíneas, lesões hepáticas, renais e arritmias; clorácnes também podem ocorrer. Além disso, o longo efeito residual no meio ambiente (meiavida de 15 anos nas regiões temperadas e de três a seis meses em regiões tropicais), agregação à cadeia alimentar, acúmulo no tecido adiposo humano e de animais e eliminação pelo leite materno, são associáveis a outros efeitos adversos como câncer de mama, diabete, imunotoxicidade, perda e malformação fetal, infertilidade, leucemia, câncer de pâncreas, déficit de desenvolvimento neurológico, entre outros admitidos (Bouwman, van den Berg \& Kylin, 2011). Contudo, a maioria desses últimos efeitos é contestada (Edwards, 2004).

Por tais razões, foi abolido o uso do DDT na larga maioria dos países, com qualquer fim, a partir de 1970. Em 1985 foi proibido no Brasil seu uso na agricultura; e a partir de 1991 deixou de ser usado no controle da malária (D’Amato, Torres \& Malm, 2002). Porém, em 1995, a OMS declara que o DDT pode ser usado contra a malária - contanto que sob sua supervisão - desde que dentro das casas, com os cuidados indicados, e avaliados custo e benefício, incluindo aquisição de resistência e inseticidas alternativos.

Atualmente, no controle de vetores, em nosso país, os inseticidas químicos são restritos ao grupo dos piretroides, que teriam excelente ação direta sobre os flebotomíneos, porém com efeito residual pouco seguro e ainda menor nos anexos das casas (de poucos dias a seis meses; com média de três meses, segundo o Ministério da Saúde). Seus efeitos adversos podem ser dermatites, desde eritema, vesículas ou bolhas com prurido intenso, edema, queimação e parestesia; irritação nos olhos; alergia respiratória, desde rinite a broncoespasmo e choque anafilático, e pneumonite se aspirado. Tem a grande vantagem de não se acumular em tecidos e seus metabólitos são inativos, sendo de rápida eliminação urinária (UFRJ, 2012).

Entretanto, potencialmente, qualquer inseticida pode levar ao desenvolvimento de resistência dos insetos e a algum tipo ou grau de toxicidade humana e animal, requerendo cuidados especiais e vigilância permanente em sua aplicação e acompanhamento. 
Boas perspectivas do controle vetorial ainda estão a depender do desenvolvimento de novas formulações de inseticidas sintéticos com grande ação residual e eficácia específica para insetos hematófagos como potenciais vetores de doenças, de mínima toxicidade para o homem, animais e o ambiente em geral.

Contudo, valendo para qualquer inseticida, principalmente os de menor ação residual, sua eficácia será prejudicada sempre que o processo de aplicação não obedecer a um planejamento severo no aspecto operacional, com continuidade e avaliação de desenvolvimento de resistência dos insetos, na dependência da valorização da saúde humana, animal e ambiental, considerando investimentos e ações integradas tendo por base a educação.

Em nossa opinião, a principal razão dos insucessos observados em diferentes regiões do país tem sido a falta de continuidade de medidas em conjunto, mesmo das tradicionalmente preconizadas, adaptadas a cada situação e local de ocorrência (Marzochi \& Marzochi, 1997; Nunes et al., 2010).

Outras medidas, como drogas de ação de repelência ou de ação inseticida sistêmica deveriam ser avaliadas, a exemplo da ivermectina, já utilizada na prevenção da dirofilariose canina para evitar a infecção em cães (Marzochi \& Marzochi, 1994; Kassem, Tewfick \& El Sawat, 2001).

Para o diagnóstico tanto da LV como da LT são requeridos o desenvolvimento de métodos práticos e sensíveis que possam ser utilizados pelos profissionais da saúde em locais onde essas doenças ocorram, seja pela pesquisa de DNA por PCR das diferentes espécies de leishmânias, ou por anticorpos específicos mediante métodos dotados de grande sensibilidade e especificidade, tais como os imunocromatográficos com antígenos recombinantes com aplicação no homem e no animal.

Quanto ao tratamento humano, impóe-se o desenvolvimento de drogas seguras e efetivas que possam ser administradas oralmente nas infecções por $L$. (V.) braziliensis e L. (L.) chagasi, ou de uso tópico nas infecções por $L$. (V.) guyanensis e outras espécies dermotrópicas. Para cães (e outros animais domésticos), drogas capazes de curá-los ao negativar os exames parasitológicos, até hoje inexistentes, também seriam essenciais ao controle e para poupá-los da morte pela eutanásia ou pela própria doença. Trata-se de aspectos relevantes, não só na LV, em áreas endêmicas.

Em áreas de transmissão urbana e periurbana, paralelamente às formas clínicas cresce a frequência de infecções subclínicas ou inaparentes decorrentes da permanente exposição do homem às leishmânias dermotrópicas e viscerotrópicas, denunciadas nas áreas endêmicas pelas elevadas taxas de positividade da IDRM. Essas taxas são indicadores não só de presença do agente biológico circulante da LT ou da LV, além de risco de doença em novos suscetíveis que se incorporam - seja em humanos (crianças, novos moradores), seja em animais. Constituem também um novo problema associado à circulação crescente do vírus HIV superposta nessas áreas, transformando as leishmanioses em potenciais parasitoses oportunistas (Marzochi, 1992). Portanto, não se deve ignorar, nessas endemias, o predomínio dos portadores assintomáticos de leishmânia dermotrópica ou viscerotrópica como potenciais fontes de infecção - natural, acidental (uso de drogas injetáveis) ou iatrogênica (doação de sangue ou órgãos) -, propiciando o surgimento de LT ou de LV - e sob formas mais graves em imunodeprimidos -, e/ou como receptores do HIV suscitando o desenvolvimento clínico de ambas as doenças. Assim, deve ser avaliada a indicação de testes diagnósticos de leishmanioses na rotina dos processos de doação de sangue e/ou de órgãos e em pessoas a serem submetidas à imunossupressão.

\section{Aspectos específicos da leishmaniose tegumentar}

A grande complexidade epidemiológica da LT resulta em maior desafio tanto para a prevenção como para o devido controle dos vários agentes etiológicos, vetores, fontes de infecção e ambientes, de modo que ainda não existe adequado consenso sobre indicadores a serem adotados e medidas recomendáveis em cada situação e local de transmissão (Marzochi \& Marzochi, 1994; Gomes \& Neves, 1998). 
Especialmente quanto ao diagnóstico, todos os testes imunológicos são incapazes de distinguir infecções antigas de recentes, e muitas vezes de confirmar o diagnóstico clínico, com resultados limítrofes altamente frequentes. Quanto à IDRM, ainda mais usada na suspeição de LT, é paradoxalmente mais conclusiva quando o resultado é negativo (ausência de infecção passada ou recente) em pacientes de área endêmica, onde a permanente possibilidade de exposição a picadas infectantes explica elevadas taxas de positividade, certamente por infecções subclínicas. Tal fato pode prejudicar a acurácia do teste como meio de diagnóstico, sendo o diagnóstico de certeza relativamente complexo por requerer a demonstração do parasito ou seu DNA.

As leishmanioses cutâneas são as candidatas mais promissoras ao desenvolvimento de vacinas, tendo em vista que a 'leishmanização', que induz a produção de resistência natural pela inoculação do agente em outras áreas do corpo, causando uma ulceração benigna e autorresolutiva, sugere que uma efetiva imunidade pode ser gerada (Davies et al., 2003). Na LT, a vacinação humana seria prioritária para grupos de mais elevado risco de transmissão silvestre e rural. Em áreas de transmissão periurbana e urbana, menos frequente e com grande população envolvida, mas pouco caracterizada geograficamente, essa vacinação teria menos impacto na morbidade, além de insatisfatório custo-benefício. Contudo, a caracterização dos "circuitos de transmissão" (Sabroza, 2002) pode ter relevante papel na política de prevenção e controle, por definir espacialmente a população de maior risco.

Impõe-se também a busca de imunização canina contra LT visando à prevenção da infecção e doença, assim como da possibilidade da transmissão.

Para que medidas mais eficazes de prevenção e controle sejam desenvolvidas, é necessário um acúmulo maior de conhecimentos sobre a identificação das diferentes espécies de leishmânias dermotrópicas, de flebotomíneos e de reservatórios ou fontes secundárias de infecção envolvidas. Para isso, quanto aos flebotomíneos, o conhecimento da dinâmica populacional, dispersão, grau de zoofilia e antropofilia, infecção natural, fontes alimentares e demais aspectos biológicos dos mesmos são de extrema importância. O emprego do xenodiagnóstico pode melhor sugerir possíveis reservatórios da doença, incluindo o homem e o cão, doente ou subclínico, caracterizando o tipo de transmissão e definindo as medidas a serem adotadas.

\section{Aspectos específicos da leishmaniose visceral}

Apesar de o Programa de Vigilância e Controle da LV, no Brasil, ter como principal objetivo a redução de casos e de óbitos, o número de ocorrências tem aumentado em todas as regiões, com a média de letalidade mantendo-se em torno de 6\% (2001-2010), porém, com expressivas diferenças regionais - 5,1\% no Nordeste para 9,2\% no Sudeste, em 2010 (Brasil, 2010c). O maior desafio na prevenção e controle da LV no país decorre da adaptação da L. longipalpis aos ambientes urbanos a partir da década de 1980 (Marzochi \& Marzochi, 1994).

Não há dúvida de que as ações de controle devem ter como principal alvo a redução ou eliminação do inseto vetor peridomiciliado, pelas implicações envolvidas na eliminação dos reservatórios caninos, ainda preconizada, e pela importância menor admitida com relação ao hospedeiro humano, que deve ser sujeito de busca ativa, sempre que possível, para o diagnóstico e tratamento precoces. A estratégia de eliminação dos cães tem produzido resultados conflitantes sobretudo quando adotada separadamente do controle vetorial (Ashford et al., 1998), o qual tem sido considerado mais efetivo que outras medidas (Deane, 1956; Alencar, 1961; Costa, 2011).

Embora o cão e o homem, além de suscetíveis, poderem se tornar, ao adoecer, fontes secundárias de infecção, e o cão atue como a principal fonte de infecção para homem e para outro cão (Deane \& Deane, 1955), estudo entre cães sororreagentes revelou que, dos $40 \%$ que apresentavam sinais clínicos da doença, e que foram acompanhados no período de um ano, $88 \%$ evoluíram ao óbito e $8 \%$ permaneceram estáveis; e entre os 60\% ‘assintomáticos', após um ano 
de observação, 52\% apresentaram negativação sorológica, 12\% continuaram estáveis, 18\% tornaram-se doentes e 18\% morreram ao final do período (Pozio et al., 1981). Lamentavelmente, metade dos cães soropositivos assintomáticos, mas com indicação de eutanásia, podem se tornar soronegativos, sendo difícil de definir se por falso-positividade ao teste ou por cura espontânea. No entanto, sabemos que animais assintomáticos, mas positivos à sorologia, albergam Leishmania na pele aparentemente sã (Madeira et al., 2004; Marzochi et al., 1985).

Outra questão, portanto, relaciona-se aos testes sorológicos realizados para diagnóstico da infecção canina e indicação da eutanásia. A sorologia é um método indireto de avaliar a infecção, não definindo o grau de parasitismo, a presença de doença ou o potencial de transmissão do cão para o inseto vetor, ocorrendo ainda uma proporção de resultados falso-positivos que pode variar de $5 \%$ a $10 \%$, dependendo dos testes adotados (Fabiano Figueiredo informação pessoal). Além disso, os cães retirados são habitualmente substituídos por cães mais jovens, mais suscetíveis à infecção natural. Os testes clássicos, reação de imunofluorescência indireta (Rifi) e ensaio imunoenzimático (Elisa), disponibilizados pelo Ministério da Saúde, podem apresentar reações cruzadas com as infecções caninas por $L$. (V.) braziliensis, cujas endemias se superpõem no Nordeste, Sudeste e Sul do Brasil, assim como pelo Trypanosoma cruzi e o recém-descoberto Trypanosoma caninum, cuja distribuição geográfica de ambos parece ser bastante ampla (Alves et al., 2012; Madeira et al., 2004, 2009).

Atualmente, para triagem de cães suspeitos nos inquéritos, dispõe-se de método imunocromatográfico, o DualPath Plataform (DPP®). De leitura rápida - com antígenos recombinantes rK26 e rK39 de elevada sensibilidade e especificidade (Grimaldi et al., 2012; Alves et al., 2012). No entanto, a retirada dos animais positivos, para eutanásia, só deve ser feita após confirmação pelo Elisa.

A eliminação do cão infectado ainda é considerada fundamental para o controle, pela observação de que a enzootia canina precede a endemia e contribui para sua manutenção e propagação, sobretudo não havendo tratamento canino esterilizante para a Leishmania, com absoluta contraindicação de drogas de uso humano pela possível indução à resistência do parasito, e nem vacina que o impeça de ser fonte de infecção. No entanto, em algumas áreas de LV urbana e periurbana, o cão não parece desempenhar papel de relevo no risco da infecção humana, como observado em Teresina, Piauí (Costa, Pereira \& Araujo, 1990; Amendoeira, Marzochi \& Pereira, 1989) e em Pancas, no Espírito Santo (Dietze et al., 1991). Contudo, no ambiente urbano, a maior densidade populacional humana, assim como a proximidade entre as residências e a intensa circulação de cães dificultam a demonstração de associação entre a infecção canina e a humana. Já no ambiente rural, tal associação parece muito mais forte, por conta da formação de aglomerados habitacionais com maior distanciamento geográfico. Entretanto, estudo teórico, baseado em modelos matemáticos de transmissão da LV para humanos, indica que a eliminação de cães tem o pior desempenho quando comparada com outras estratégias de controle, como uso de inseticidas, vacinação dos cães e melhoria das condições nutricionais das crianças (Dye, 1996). Além disso, no ambiente urbano, a permanência residual de cães infectados antes e após os inquéritos caninos, pela excessiva demora de retirada dos mesmos, associadamente à resistência dos proprietários à eutanásia dos cães positivos, torna essa medida pouco efetiva e pode levar à rejeição das demais condutas de controle pela população (Marzochi \& Marzochi, 1997).

A imunoprofilaxia da população canina, por meio de uma vacina eficaz anti-Leishmania (evitando a infeç̧ão) ou 'antiflebotomíneo' (atuando sobre componentes da saliva do vetor), poderia redundar em importante medida complementar de proteção à população humana nas áreas de risco (Marzochi \& Marzochi, 1997). As vacinas caninas atualmente disponíveis no mercado não demonstraram efetividade, uma vez que os cães vacinados de áreas endêmicas se infectam, apresentando Leishmania na pele. Do ponto de vista do controle pode ser mais um agravante, pois, ao não evitar a infecção e a doença se manifestar de forma mais branda, permanece o cão vacinado como fonte da infecção; além do que, agrada aos proprietários, remunera os veterinários e confere lucro aos laboratórios produtores. Já há, pelo menos, três formulações (duas brasileiras: Leishmune® - a partir de fração glicoproteica de L. chagasi, 
contendo um ligante fucose-manose (FML) - e Leish-Tec ${ }^{\circledR}$ - antígeno recombinante de L. chagasi; e uma europeia CaniLeish ${ }^{\circledR}$ - de proteínas excretadas e secretadas de L. infantum. As duas formulações comerciais de origem nacional tiveram suas comercializações autorizadas pelo Ministério da Agricultura, Pecuária e Abastecimento (Mapa), mas não recomendadas para uso em campanhas de saúde pública pelo Ministério da Saúde (Brasil, 2010c). Para os cães imunizados com as vacinas atuais, a recomendação do MS é de que, caso apresentem nos inquéritos caninos sorologia positiva, sejam retirados e submetidos à eutanásia (Brasil, 2010c).

o papel específico do cão ou relativo a outros elementos (humanos, outros animais domésticos, sinantrópicos e silvestres) no controle da LV suscita questões a serem devidamente avaliadas: presença dos cães nos primeiros estágios da infecção, eventualmente soronegativos, e dos outros assintomáticos soropositivos, que podem ser igualmente infectantes para os vetores; presença de outras fontes de infecção, como marsupiais e raposas - que passam da condição de hábitos silvestres para sinantrópicos -, além do próprio homem infectado ou doente; sensibilidade inadequada dos testes de diagnóstico para a identificação de cães infectantes; substituição dos cães infectados retirados, por outros, suscetíveis; grande espaço de tempo decorrido entre o diagnóstico e a retirada dos cães infectados; elevada prevalência da infecção canina, na ausência de tratamento e de vacinas eficazes (Marzochi et al., 2009; Gontijo \& Melo, 2004; Costa \& Vieira, 2001; Werneck et al., 2008; Courtenay et al., 2002b).

Para a LV humana, a possibilidade de obtenção de uma vacina eficaz parece ser mais remota que na tegumentar.

Pelo potencial de urbanização da LV, grandes contingentes populacionais podem se tornar cada vez mais vulneráveis ao risco de adoecer e/ou vir a ser fonte de infecção e participar de novos mecanismos da transmissão, além do natural (Costa et al., 2000; Michel et al., 2011).

Pelas dificuldades de evitar a doença, torna-se fundamental o diagnóstico precoce. A incorporação da busca ativa de casos de LV na rotina das atividades da equipe de Saúde da Família é vital para a prevenção dos óbitos. São suspeitos os adultos ou crianças com febre contínua ou variável por período superior a 14 dias, com ou sem outras manifestações, os quais devem ser encaminhados a serviço de saúde para esclarecimento diagnóstico, principalmente em locais com notificação de caso humano ou canino. A atuação do médico-veterinário na atenção básica à saúde e em especial nos Núcleos de Apoio à Saúde da Família (Nasf) deveria ser incluída, considerando-se a importância de zoonoses endêmicas no país.

\section{CONCLUSÕES}

Deve ser considerado como desafio permanente para o controle das leishmanioses a ação do homem sobre o meio ambiente, capaz de produzir o aparecimento de uma fauna adaptada ao espaço ocupado pelas atividades humanas. Essa fauna deve envolver espécies de animais domésticos e comensais sinantrópicos em associação a espécies de flebotomíneos em elevada densidade, nos ambientes alterados, os quais lhes oferecem abrigo e alimento em maior abundância que nos ambientes naturais, criando, com isso, o potencial contexto de transmissão (Marzochi \& Marzochi, 1994). Outro desafio é a efetuação de todo o conjunto de medidas de prevenção indicadas com continuidade e avaliação. Devem ser enfatizadas as ações intersetoriais que envolvem aspectos políticos e sociais para a saúde. Além destas, garantir controle ambiental, planejamento urbano, saneamento, educação e atenção à saúde, considerando o crescimento das populações - sobretudo nas periferias das cidades.

Impõem-se investimentos financeiros adequados ao serviço e à pesquisa objetivando estudos de novas abordagens gerenciais de prevenção e controle, pelo desenvolvimento de técnicas inovadoras, metodologicamente avaliadas, que integrem níveis biomédicos e sociais e considerem a participação das comunidades envolvidas. Tais abordagens devem ter como focos principais a melhoria do sistema de saúde, e neste as vigilâncias clínica, epidemiológica e sanitária, 
que deverão atuar para o georreferenciamento dos casos, reservatórios e vetores; para o diagnóstico e o tratamento precoces dos pacientes, com inclusão sistemática da busca ativa; para a continuidade e análises de métodos de assistência e controle (operacionalização de processos, desempenho de inseticidas e drogas terapêuticas, inquéritos epidemiológicos, entre outros), além da melhoria da educação para os profissionais da saúde e para a população.

\section{REFERÊNCIAS}

ALENCAR, J. Profilaxia do calazar no Ceará, Brasil. Revista do Instituto de Medicina Tropical de São Paulo, 3: 175-180, 1961.

ALENCAR, J.; PESSOA, E. \& COSTA, O. Calazar em Santarém, Estado do Pará. Revista Brasileira de Malariologia e Doenças Tropicais, 14: 371-377, 1962.

ALEXANDER, B. \& MAROLI, M. Control of phlebotomine sandflies. Medical and Veterinary Entomology, 17(1): 1-18, 2003.

ALTAMIRANO-ENCISO, A. J. et al. On the origin and spread of cutaneous and mucosal leishmaniasis, based on pre- and postColombian historical source. História, Ciências, Saúde-Manguinhos, 10(3): 852-882, 2003.

ALVES, A. et al. Evaluation of serological cros-reactivity betwen canine visceral leishmaniasis and natural infection by Trypanosoma caninum. Research in Veterinary Science, 93(3): 1.329-1.333, 2012.

AMENDOEIRA, M. R. R.; MARZOCHI, M. C. A. \& PEREIRA, H. F. Relação entre a infecção humana e a canina pela Leishmania donovani chagasi em área endêmica de leishmaniose visceral - Teresina, Piauí. Revista da Sociedade Brasileira de Medicina Tropical, 22: 32, 1989.

ARAGÃo, H. B. Leishmaniose tegumentar e sua transmissão pelos phlebótomos. Memórias do Instituto Oswaldo Cruz, 20: 177-185, 1927.

ASHFORD, D. A. et al. Studies on control of visceral leishmaniasis: impact of dog control on canine and human visceral leishmaniasis in Jacobina, Bahia, Brazil. The American Journal of Tropical Medicine and Hygiene, 59(1): 53-57, 1998.

BARBOSA, G. M. et al. Epidemiological aspects of canine American tegumentary leishmaniasis in the Municipality of Paraty, State of Rio de Janeiro, Brazil. Cadernos de Saúde Pública, 15(3): 641-646, 1999.

BEZERRA, H. S. S. et al. Experimental infection of Lutzomyia migonei (França, 1924) with Leishmania braziliensis in experimentally infected dogs. Acta Parasitologica Turcica, 21, supl. 1: 70, 1997.

BOUWMAN, H.; VAN DEN BERG, H. \& KYLIN, H. DDT and malaria prevention: addressing the paradox. Environmental Health Perspectives, 119(6): 744-747, 2011.

BRANDÃO-FILHO, S. P. et al. Epidemiological surveys confirm an increasing burden of cutaneous leishmaniasis in north-east Brazil. Transactions of the Royal Society of Tropical Medicine and Hygiene, 93(5): 488-494, 1999.

BRANDÃo-FILHO, S. P. et al. Wild and synanthropic hosts of Leishmania (Viannia) braziliensis in the endemic cutaneous leishmaniasis locality of Amaraji, Pernambuco State, Brazil. Transactions of the Royal Society of Tropical Medicine and Hygiene, 97(3): 291-296, 2003.

BRASIL. Ministério da Saúde. Secretaria de Vigilância em Saúde. Departamento de Vigilância Epidemiológica. Manual de Vigilância e Controle da Leishmaniose Visceral. Brasília: Ministério da Saúde, 2006. Disponível em: <http://portal.saude. gov.br/portal/arquivos/pdf/manual_leish_visceral2006.pdf>. Acesso em: 27 abr. 2012.

BRASIL. Ministério da Saúde. Secretaria de Vigilância em Saúde. Departamento de Vigilância Epidemiológica. Manual de Vigilância da Leishmaniose Tegumentar Americana. 2. ed. Brasília: Secretaria de Vigilância em Saúde, 2010a.

BRASIL. Leishmaniose tegumentar americana, 2010b. Disponível em: < http://portal.saude.gov.br/portal/saude/profissional/ area.cfm?id_area $=1560>$. Acesso em: 27 abr. 2012.

BRASIL. Leishmaniose visceral, 2010c. Disponível em: <http://portal.saude.gov.br/portal/saude/profissional/area.cfm?id_ area $=1561>$. Acesso em: 27 abr. 2012 
CASTELLUCCI, L. et al. Familial aggregation of mucosal leishmaniasis in northeast Brazil. The American Journal of Tropical Medicine and Hygiene, 73(1): 69-73, 2005.

CERQUEIRA, A. \& VASCONCELOS, A. A leishmaniose nesta capital. Boletim Sanitário, 1: 35, 1922.

COSTA, C. H. N. How effective is dog culling in controlling zoonotic visceral leishmaniasis? a critical evaluation of the science, politics and ethics behind this public health policy. Revista da Sociedade Brasileira de Medicina Tropical, 44(2): 232-242, 2011.

COSTA, C. H. N. \& VIEIRA, J. B. F. Mudanças no controle da leishmaniose visceral no Brasil. Revista da Sociedade Brasileira de Medicina Tropical, 34(2): 223-228, 2001.

COSTA, C. H. N.; PEREIRA, H. F. \& ARAUJO, M. V. Epidemia de leishmaniose visceral no Estado do Piauí, Brasil. Revista de Saúde Pública, 24(5): 361-372, 1990.

COSTA, C. H. N. et al. Competence of the human host as a reservoir for Leishmania chagasi. The Journal of Infectious Diseases, 182 (3): 997-1000, 2000.

COURTENAY, O. et al. Low infectiousness of a wildlife host of Leishmania infantum: the crab-eating fox is not important for transmission. Parasitology, 125(5): 407-414, 2002a.

COURTENAY, O. et al. Infectiousness in a cohort of Brazilian dogs: why culling fails to control visceral leishmaniasis in areas of high transmission. The Journal of Infectious Diseases, 186(9): 1.314-1.320, 2002b.

COUTINHO, S. G.; PIRMEZ, C. \& CRUZ, A. M. Parasitological and immunological follow-up of American tegumentary leishmaniasis patients. Transactions of the Royal Society of Tropical Medicine and Hygiene, 96, supl. 1: S173-S178, 2002.

CUNHA, J. C. L.; LIMA, J. W. O. \& POMPEU, M. M. L. Transmissão domiciliar de leishmaniose tegumentar e associação entre leishmaniose humana e canina, durante uma epidemia na Serra de Baturité, no estado de Ceará, Brasil. Revista Brasileira de Epidemiologia, 9: 425-435, 2006.

CUPOLILLO, E. et al. Genetic polymorphism and molecular epidemiology of Leishmania (Viannia) braziliensis from different hosts and geographic areas in Brazil. Journal of Clinical Microbiology, 41(7): 3.126-3.132, 2003.

CURTIS, C. F. Pyrethroid impregnation of bed nets and curtains against malaria mosquitoes. Pesticide Outlook, 1: 8-11, 1990.

D'AMATO, C.; TORRES, J. P. M. \& MALM, O. DDT (dicloro difenil tricloroetano): toxicidade e contaminação ambiental - uma revisão. Química Nova, 25(6a): 995-1.002, 2002.

DAVID, J. R. et al. Deltamethrin-impregnated dog collars have a potent anti-feeding and insecticidal effect on Lutzomyia longipalpis and Lutzomyia migonei. Memórias do Instituto Oswaldo Cruz, 96(6): 839-847, 2001.

DAVIES, C. R. et al. Leishmaniasis: new approaches to disease control. BMJ, 326(7.385): 377-382, 2003.

DEANE, L. M. Leishmaniose Visceral no Brasil: estudo sobre reservatórios e transmissores realizados no Estado do Ceará. Rio de Janeiro: Serviço Nacional de Educação Sanitária, 1956.

DEANE, L. M.; DEANE, M. P. \& ALENCAR, J. E. Observações sobre o combate ao Phlebotomus longipalpis pela dedetização domiciliária em focos endêmicos de calazar, Ceará. Revista Brasileira de Malariologia e Doenças Tropicais, 7: 131-141, 1955.

DE SOUZA, M. A. et al. Visceral leishmaniasis in Rio de Janeiro. 1. Phlebotomineae from an endemic area of indigenous human cases. Memórias do Instituto Oswaldo Cruz, 76(2): 161-168, 1981.

DEANE, M. P. \& DEANE, L. M. Observações preliminares sobre a importância comparativa do homem, do cão e da raposa (Licalopex vetulus) como reservatórios de Leishmania donovani em áreas endêmicas de Calazar no Ceará. O Hospital, 48: 61-70, 1955.

DIETZE, R. et al. Leishmaniose visceral no Espírito Santo: tentativa de controle da infecção humana através da eliminação de cães. Revista da Sociedade Brasileira de Medicina Tropical, 24: 105, 1991.

D'UTRA E SILVA, O. Sobre a leishmaniose tegumentar e seu tratamento. Memórias do Instituto Oswaldo Cruz, 7: 213-248, 1915.

DYE, C. The logic of visceral leishmaniasis control. The American Journal of Tropical Medicine and Hygiene, 55(2): 125-130, 1996. 
EDWARDS, G. E. DDT: a case study in scientific fraud. Journal of American Physicians and Surgeons, 9(3): 83-88, 2004.

ESTADO DE SANTA CATARINA. Secretaria de Estado da Saúde, Diretoria de Vigilância Epidemiológica. Gerência de Controle de Zoonoses. Nota técnica n. 007/2010/DIVE/SES, 2010. Disponível em: <www.dive.sc.gov.br/conteudos/zoonoses/ Noticias/2010/Nota_Tecnica_LVC_Fpolis.pdf>. Acesso em: 23 abr. 2012.

FAGUNDES, A. et al. First encounter of subclinical human Leishmania (Viannia) infection in State of Rio Grande do Sul, Brazil. Memórias do Instituto Oswaldo Cruz, 102(8): 1.003-1.005, 2007.

FALCÃO, A. L. et al. Effect of deltamethrin spraying on the sandfly populations in a focus of American cutaneous leishmaniasis. Memórias do Instituto Oswaldo Cruz, 86(4): 399-404, 1991.

FALQUETO, A. et al. Participation of the dog in the cycle of transmission of cutaneous leishmaniasis in the municipality of Viana, State of Espirito Santo, Brazil. Memórias do Instituto Oswaldo Cruz, 81(2): 155-163, 1986.

FOLLADOR, I. et al. Epidemiologic and immunologic findings for the subclinical form of Leishmania braziliensis infection. Clinical Infectious Diseases, 34(11): E54-E58, 2002.

GOMES, A. C. \& NEVES, V. L. Strategy and perspectives for the control of cutaneous leishmaniasis in the state of Sao Paulo. Revista da Sociedade Brasileira de Medicina Tropical, 31(6): 553-558, 1998.

GOMES, R. F. et al. Leishmania (Viannia) braziliensis: genetic relationships between strains isolated from different areas of Brazil as revealed by DNA fingerprinting and RAPD. Experimental Parasitology, 80(4): 681-687, 1995.

GONTIJO, C. M. F. \& MELO, M. N. Leishmaniose visceral no Brasil: quadro atual, desafios e perspectivas. Revista Brasileira de Epidemiologia, 3: 338-349, 2004.

GRIMALDI JR., G. et al. Evaluation of a novel chromatographic immunoassay based on Dual-Path Platform technology (DPP(R) CVL rapid test) for the serodiagnosis of canine visceral leishmaniasis. Transactions of the Royal Society of Tropical Medicine and Hygiene, 106(1): 54-59, 2012.

GUEVARA, P. et al. Presence of Leishmania braziliensis in blood samples from cured patients or at different stages of immunotherapy. Clinical and Diagnostic Laboratory Immunology, 1(4): 385-389, 1994.

HERTIG, M. \& FAIRCHILD, G. B. The control of Phlebotomus in Peru with DDT. The American Journal of Tropical Medicine and Hygiene, 28: 207-230, 1948.

ISHIKAWA, E. A. et al. Genetic variation in populations of Leishmania species in Brazil. Transactions of the Royal Society of Tropical Medicine and Hygiene, 96, supl. 1: S111-S121, 2002.

KASSEM, H. A.; TEWFICK, M. K. \& EL SAWAF, B. M. Evaluation of avermectins as sandfly control agents. Annals of Tropical Medicine and Parasitology, 95(4): 405-411, 2001.

LAINSON, R. \& RANGEL, E. F. Lutzomyia longipalpis and the eco-epidemiology of American visceral leishmaniasis, with particular reference to Brazil: a review. Memórias do Instituto Oswaldo Cruz, 100(8): 811-827, 2005.

LAINSON, R. \& SHAW, J. J. Evolution, classification and geographical distribution. In: PETERS, W. \& KILLICK-KENDRIC, K. (Eds.). The Leishmaniases in Biology and Medicine. London: Academic Press, 1993.

LAINSON, R. et al. The dermal leishmaniases of Brazil, with special reference to the eco-epidemiology of the disease in Amazonia. Memórias do Instituto Oswaldo Cruz, 89(3): 435-443, 1994.

LEWIS, D. J. The biology of Phlebotomidae in relation to leishmaniases. Annual Review of Entomology, 19: 363-384, 1974.

LOPES, U. G. et al. Schizodeme and zymodeme characterization of Leishmania in the investigation of foci of visceral and cutaneous leishmaniasis. The Journal of Parasitology, 70(1): 89-98, 1984.

MADEIRA, M. F. et al. Identification of Leishmania (Leishmania) chagasi isolated from healthy skin of symptomatic and asymptomatic dogs seropositive for leishmaniasis in the municipality of Rio de Janeiro, Brazil. The Brazilian Journal of Infectious Diseases, 8(6): 440-444, 2004.

MADEIRA, M. F. et al. Trypanosoma caninum n. sp. (Protozoa: Kinetoplastida) isolated from intact skin of a domestic dog (Canis familiaris) captured in Rio de Janeiro, Brazil. Parasitology, 136(4): 411-423, 2009. 
MAGALHÃES, P. A. et al. Kala-azar in the Rio Doce, Minas Gerais area. Results of prophylactic measures. Revista do Instituto de Medicina Tropical de São Paulo, 22(4): 197-202, 1980.

MARCONDES, C. B. A redescription of Lutzomyia (Nyssomyia) intermedia (Lutz \& Neiva, 1912), and resurrection of L. neivai (Pinto, 1926) (Diptera, Psychodidae, Phlebotominae). Memórias do Instituto Oswaldo Cruz, 91: 457-462, 1996.

MARZOCHI, K. B. F. et al. Prospective evaluation of human visceral leishmaniasis after treatment in Rio de Janeiro, 19791993. In: BRANDÃO FILHO, S. (Ed.). Research and Control of Human Leishmaniasis in Brazil. Recife: Centro de Pesquisas Aggeu Magalhães, Fundação Oswaldo Cruz, 1993.

MARZOCHI, M. C. A. Leishmanioses no Brasil: as leishmanioses tegumentares. Jornal Brasileiro de Medicina, 63: 82-104, 1992.

MARZOCHI, M. C. A. \& MARZOCHI, K. B. Tegumentary and visceral leishmaniases in Brazil: emerging anthropozoonosis and possibilities for their control. Cadernos de Saúde Pública, 10, supl. 2: 359-375, 1994.

MARZOCHI, M. C. A. \& MARZOCHI, K. B. F. Leishmanioses em áreas urbanas. Revista da Sociedade Brasileira de Medicina Tropical, 30: 162-164, 1997.

MARZOCHI, M. C. A.; MARZOCHI, K. B. F. \& SCHUBACH, A. Leishmaniose visceral americana (calazar americano ou neotropical). In: CIMERMAN, B. \& CIMERMAN, S. (Eds.). Parasitologia Humana e seus Fundamentos Gerais. São Paulo: Atheneu, 1999.

MARZOCHI, M. C. A.; SCHUBACH, A. \& MARZOCHI, K. B. F. Leishmaniose tegumentar americana. In: CIMERMAN, B. \& CIMERMAN, S. (Eds.). Parasitologia Humana e seus Fundamentos Gerais. São Paulo: Atheneu, 1999.

MARZOCHI, M. C. A. et al. Carcinogênese hepática no norte do Paraná e uso indiscriminado de defensivos agrícolas. Ciência \& Cultura (SBPC), 28(8): 893-901, 1976.

MARZOCHI, M. C. A. et al. Leishmaniose visceral canina no Rio de Janeiro - Brasil. Cadernos de Saúde Pública, 1(4): 432-446, 1985.

MARZOCHI, M. C. A. et al. Leishmaniose tegumentar americana por Leishmania (Viannia) braziliensis em Município da Região Serrana do Estado do Rio de Janeiro. Revista da Sociedade Brasileira de Medicina Tropical, 24, supl. II: 100, 1991.

MARZOCHI, M. C. et al. Visceral leishmaniasis in Rio de Janeiro, Brazil: eco-epidemiological aspects and control. Revista da Sociedade Brasileira de Medicina Tropical, 42(5): 570-580, 2009.

MENDONÇA, M. G. et al. Persistence of leishmania parasites in scars after clinical cure of American cutaneous leishmaniasis: is there a sterile cure? The Journal of Infectious Diseases, 189(6): 1.018-1.023, 2004.

MICHEL, G. et al. Importance of worldwide asymptomatic carriers of Leishmania infantum (L. chagasi) in human. Acta Tropica, 119(2-3): 69-75, 2011.

MONTEIRO, P. S.; LACERDA, M. M. \& ARIAS, J. R. Controle da leishmaniose visceral no Brasil. Revista da Sociedade Brasileira de Medicina Tropical, 27, supl. III: 67-72, 1994.

MONTEIRO, W. M. et al. Population mobility and production of American tegumentary leishmaniasis in the State of Parana, southern Brazil. Revista da Sociedade Brasileira de Medicina Tropical, 42(5): 509-514, 2009.

MONTOYA-LERMA, J. et al. Further evidence of humans as source of Leishmania viannia for sandflies. Memórias do Instituto Oswaldo Cruz, 93(6): 735-736, 1998.

NERY-GUIMARÃES, F. B. \& BUSTAMANTE, F. M. A aplicação domiciliária do DDT como base da profilaxia das leishmanioses. Estudo de um foco de leishmaniose muco-cutânea cinco anos depois da aspersão periódica com aquele inseticida. Revista Brasileira de Malariologia e Doenças Tropicais, 6: 127-130, 1954.

NUNES, C. M. et al. Relationship between dog culling and incidence of human visceral leishmaniasis in an endemic area. Veterinary Parasitology, 170(1-2): 131-133, 2010.

OLIVEIRA, C. C. et al. Changing epidemiology of American cutaneous leishmaniasis (ACL) in Brazil: a disease of the urbanrural interface. Acta Tropica, 90(2): 155-162, 2004. 
OLIVEIRA CAMERA, P. et al. Haematogenous dissemination of Leishmania (Viannia) braziliensis in human American tegumentary leishmaniasis. Transactions of the Royal Society of Tropical Medicine and Hygiene, 100(12): 1.112-1.117, 2006.

OLIVEIRA-NETO, M. P. et al. An outbreak of American cutaneous leishmaniasis (Leishmania braziliensis braziliensis) in a periurban area of Rio de Janeiro city, Brazil: clinical and epidemiological studies. Memórias do Instituto Oswaldo Cruz, 83(4): 427-435, 1988.

ORSINI, O. Leishmaniose em Minas. Brasil Médico, 54: 762-766, 1940.

PACHECO, R. S. et al. Epidemiological and genotypical mapping of human Leishmania Viannia) braziliensis in Paraguay. The Journal of Protozoology Research, 9: 76-87, 1999.

PASSOS, V. M. et al. Epidemiological aspects of American cutaneous leishmaniasis in a periurban area of the metropolitan region of Belo Horizonte, Minas Gerais, Brazil. Memórias do Instituto Oswaldo Cruz, 88(1): 103-110, 1993.

PENNA, H. A. Leishmaniose visceral no Brasil. Brasil Médico, 48: 949-950, 1934.

PESSÔA, S. B. \& BARRETTO, M. P. Leishmaniose Tegumentar Americana. Rio de Janeiro: Ministério da Saúde e Educação, Serviço de Documentação, 1948.

PESSOA, S. B. Problemas Brasileiros de Higiene Rural. São Paulo: Universidade de São Paulo, 1949.

PIRMEZ, C.; MARZOCHI, M. C. \& COUTINHO, S. G. Experimental canine mucocutaneous leishmaniasis (Leishmania braziliensis braziliensis). Memórias do Instituto Oswaldo Cruz, 83(2): 145-151, 1988.

POZIO, E. et al. Leishmaniasis in Tuscany (Italy): VI. Canine leishmaniasis in the focus of Monte Argentario (Grosseto). Acta Tropica, 38(4): 383-393, 1981.

QUINNELL, R. J.; DYE, C. \& SHAW, J. J. Host preferences of the phlebotomine sandfly Lutzomyia longipalpis in Amazonian Brazil. Medical and Veterinary Entomology, 6(3): 195-200, 1992.

RABELLO, E. Contribuição ao estudo da leishmaniose tegumentar no Brasil. História e sinonímia. Annaes Brasileiros de Dermatologia e Syphilographia, 1: 3-29, 1925.

RANGEL, E. F. \& LAINSON, R. Flebotomíneos do Brasil. Rio de Janeiro: Editora Fiocruz, 2003.

REITHINGER, R. et al. Domestic dog ownership: a risk factor for human infection with Leishmania (Viannia) species. Transactions of the Royal Society of Tropical Medicine and Hygiene, 97(2): 141-145, 2003.

ROJAS, E. \& SCORZA, J. V. Xenodiagnosis using Lutzomyia youngi in Venezuelan cases of cutaneous leishmaniasis due to Leishmania braziliensis. Memórias do Instituto Oswaldo Cruz, 84(1): 29-34, 1989.

SABRoZA, P. C. O Domicílio como Fator de Risco na Leishmaniose Tegumentar Americana: estudo epidemiológico em Jacarepaguá, município do Rio de Janeiro, 1981. Dissertação de Mestrado, Rio de Janeiro: Escola Nacional de Saúde Pública, Fundação Oswaldo Cruz.

SABROZA, P. C. Vigilância e monitoramento da Leishmaniose Tegumentar Americana em unidades territoriais - Brasil, 1994-2001. Boletim Eletrônico Epidemiológico, 2002. Disponível em: <http://portal.saude.gov.br/portal/arquivos/pdf/ ano02_n05_ve_lta_br.pdf>. Acesso em: 23 abr. 2012.

SALOMON, O. D. et al. Epidemiological aspects of cutaneous leishmaniasis in the Iguazu falls area of Argentina. Acta Tropica, 109(1): 5-11, 2009.

SANTOS, E. G. et al. Epidemiological survey on canine population with the use of immunoleish skin test in endemic areas of human American cutaneous leishmaniasis in the state of Rio de Janeiro, Brazil. Revista do Instituto de Medicina Tropical de São Paulo, 40(1): 41-47, 1998.

SANTOS, G. P. et al. Prevalence of canine infection from endemic areas of American cutaneous leishmaniasis in Paracambi District, Rio de Janeiro State, between 1992 and 1993. Revista da Sociedade Brasileira de Medicina Tropical, 38(2): 161$166,2005$.

SCHUBACH, A. et al. Detection of Leishmania DNA by polymerase chain reaction in scars of treated human patients. The Journal of Infectious Diseases, 178(3): 911-914, 1998a. 
SCHUBACH, A. et al. Cutaneous scars in American tegumentary leishmaniasis patients: a site of Leishmania (Viannia) braziliensis persistence and viability eleven years after antimonial therapy and clinical cure. The American Journal of Tropical Medicine and Hygiene, 58(6): 824-827, 1998b.

SHERLOCK, I. A. Notas sobre a transmissão da leishmaniose visceral no Brasil. Revista Brasileira de Malariologia e Doenças Tropicais, 16: 19-26, 1964.

SHERLOCK, I. A. \& ALMEIDA, S. P. Observações sôbre calazar em Jacobina, Bahia. V. Resultados de medidas profiláticas. Revista Brasileira de Malariologia e Doenças Tropicais, 22(1): 175-182, 1970.

SILVEIRA, F. T.; LAINSON, R. \& CORBETT, C. E. Clinical and immunopathological spectrum of American cutaneous leishmaniasis with special reference to the disease in Amazonian Brazil: a review. Memórias do Instituto Oswaldo Cruz, 99(3): 239-251, 2004.

SILVEIRA, F. T. et al. Sensitivity of the culture of circulating leukocytes in the detection of Leishmania in the peripheral blood of patients with tegumentary leishmaniasis. Revista da Sociedade Brasileira de Medicina Tropical, 22(3): 143-146, 1989.

SOUSA-GOMES, M. L. et al. Coinfecção Leishmania-HIV no Brasil: aspectos epidemiológicos, clínicos e laboratoriais. Epidemiologia e Serviços de Saúde, 20: 519-526, 2011.

SOUZA, M. B. et al. Absence of Lutzomyia longipalpis in some endemic visceral leishmaniasis areas in Rio de Janeiro municipality. Cadernos de Saúde Pública, 19(6): 1.881-1.885, 2003.

TAKAOKA, S. Estudo topographico sobre a prevenção contra a 'leishmaniose americana'. Boletim da Sociedade de Medicina \& Cirurgia de São Paulo, 11: 32-47, 1928.

TITUS, R. G. \& RIBEIRO, J. M. Salivary gland lysates from the sand fly Lutzomyia longipalpis enhance Leishmania infectivity. Science, 239(4.845): 1.306-1.308, 1988.

TRAVI, B. L.; TABARES, C. J. \& CADENA, H. Leishmania (Viannia) braziliensis infection in two Colombian dogs: a note on infectivity for sand flies and response to treatment. Biomedica, 26, supl. 1:249-253, 2006.

UNITED NATIONS ENVIRONMENT PROGRAMME. Stockholm Convention on Persistent Organic Pollutants (POPS). Geneva: Unep/Chemicals, 2002.

UNIVERSIDADE FEDERAL DO RIO DE JANEIRO (UFRJ). Inseticidas piretróides, 2012. Disponível em: <http://ltc.nutes.ufrj. br/toxicologia/mXII.piret.htm >. Acesso em: 19 abr. 2012.

VALE, E. C. S. \& FURTADO, T. Tegumentary leishmanisis in Brazil: a historical review related to the origin, expansion and etiology. Anais Brasileiros de Dermatologia, 80: 421-428, 2005.

VAN DEN BERG, H. Global Status of DDT and its alternatives for use in vector control to prevent disease. Environmental Health Perspectives, 117(11): 1.656-1.663, 2009.

VASCONCELOS, I. A. B. et al. Reservoir hosts of L. b. Braziliensis in a peculiar coastal-sited focus of cutaneous leishmaniasis in Ceara state. Memórias do Instituto Oswaldo Cruz, 82, supl. 1: 200, 1987.

VERGEL, C. et al. Evidence for Leishmania (viannia) parasites in the skin and blood of patients before and after treatment. The Journal of Infectious Diseases, 194(4): 503-511, 2006.

VILLAR, J. R. A. Leishmaniasis Tegumentar Americana en la Region Oriental del Paraguay: localidade de Limoy, Naipi y Pancholo Departamentos de Alto Parana y San Pedro, 1993. Dissertação de Mestrado, Rio de Janeiro: Escola Nacional de Saúde Pública, Fundação Oswaldo Cruz.

WARD, R. D. et al. Reproductive isolation between different forms of Lutzomyia longipalpis (Lutz \& Neiva), (Diptera: Psychodidae), the vector of Leishmania donovani chagasi Cunha \& Chagas and its significance to kala-azar distribution in South America. Memórias do Instituto Oswaldo Cruz, 78(3): 269-280, 1983.

WERNECK, G. L. et al. Avaliação da efetividade das estratégias de controle da leishmaniose visceral na cidade de Teresina, Estado do Piauí, Brasil: resultado do inquérito inicial - 2004. 2008. Epidemiologia e Servicos de Saúde, 17(2): 87-86, 2008. 
WORLD HEALTH ORGANIZATION (WHO). Insecticide resistance and vector control, 1970. (WHO Technical Report Series)

WORLD HEALTH ORGANIZATION (WHO). Control of Leishmaniases: report of a WHO Expert Committee. Geneva: World Health Organization, 1990.

WORLD HEALTH ORGANIZATION(WHO) \& WATER, SANITATION AND HEALTH TEAM. Action Plan for the Reduction of Reliance on DDT in Disease Vector Control. Geneva: World Health Organization, 2001. Disponível em: <www.who.int/ water_sanitation_health/resources/ddt.pdf>. Acesso em: 23 abr. 2012.

WORLD HEALTH ORGANIZATION(WHO). The Use of DDT in Malaria Vector Control. Geneva: World Health Organization, 2007.

WORLD HEALTH ORGANIZATION (WHO). Control of the leishmaniases, 2010. (WHO Tecnical Report Series) 


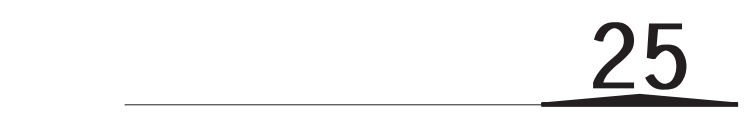

\title{
Vacinas nas Leishmanioses
}

Paula Mello De Luca

\begin{abstract}
A s leishmanioses formam um grupo de doenças endêmicas em 88 países e em quase todos os estados brasileiros. - São causadas por uma ampla variedade de espécies de Leishmania, cada uma delas adaptada a uma ecologia particular e ao parasitismo de diferentes espécies animais (Grimaldi \& Tesh, 1993). Isso faz com que medidas de controle direcionadas contra vetores e reservatórios tenham eficácia limitada. Diante dessas dificuldades, uma potencial solução para o controle da doença seria o desenvolvimento de uma vacina humana, havendo um consenso de que essa seria a estratégia mais abrangente, eficaz e segura, e com a melhor relação custo/benefício, para o controle de tais endemias (Modabber, 1995). No caso mais específico da leishmaniose visceral nas Américas e Mediterrâneo, o caráter zoonótico da doença, tendo o cão doméstico como reservatório, estimula o estudo não só de preparações vacinais humanas, mas também o do desenvolvimento de uma vacina canina.
\end{abstract}

Em geral, as vacinas contra leishmaniose podem ser divididas em três principais categorias: parasitos vivos, incluindo os geneticamente modificados; vacinas de primeira geração: compostas por parasitos inteiros mortos e/ ou extratos não caracterizados de antígenos do parasito, apresentando sérias limitações para sua padronização; e vacinas de segunda geração, que envolvem a utilização da tecnologia de DNA recombinante para a obtenção de produtos padronizados e estáveis, como por exemplo, as vacinas de DNA e as proteínas recombinantes.

Após ser extensamente estudada em modelos experimentais, uma vacina candidata deve seguir quatro fases de estudos clínicos até que seja liberada para uso humano. Na fase I, segurança e imunogenicidade são estudadas em comparação com um grupo placebo. Estudos de fase II avaliam imunogenicidade e melhor esquema vacinal quanto à dose, número de aplicações e vias de inoculação. Um estudo de fase III tem como objetivo avaliar a eficácia vacinal na infecção natural. Somente após ser aprovada nessas três fases, a preparação pode ser registrada e industrializada. Posteriormente, estudos de fase IV são conduzidos em um grande número de indivíduos (dez mil a cem mil) em campanhas nacionais de imunização.

Neste capítulo, abordaremos pontos relevantes relacionados ao estudo e desenvolvimento de candidatos vacinais contra as leishmanioses americanas, além de realizar um levantamento dos principais antígenos estudados que demonstraram ser imunogênicos/protetores em modelos experimentais e/ou apresentaram algum grau de eficácia em diferentes fases de ensaios clínicos. 


\section{ALGUMAS DIFICULDADES ENVOLVENDO 0 DESENVOLVIMENTO DE VACINAS CONTRA AS LEISHMANIOSES AMERICANAS}

Uma vacina ideal contra leishmanioses deve apresentar vários atributos: segurança; acessibilidade para as populações sob risco; indução de resposta CD4 e CD8 de longa duração; ser eficiente contra espécies causadoras das formas tegumentares e visceral; estabilidade à temperatura ambiente, para ser levada ao campo sem necessidade de refrigeração; ter potencial profilático e terapêutico (Kedzierski, Zhu \& Handman, 2006). Embora os atributos relacionados ao custo-benefício e à segurança possam ser obtidos, a indução e manutenção de uma resposta imune eficaz contra o parasito, assim como a proteção cruzada, são objetivos mais difíceis de serem alcançados.

Atualmente, a estratégia para o desenvolvimento de uma vacina eficaz contra determinada doença envolve o entendimento dos mecanismos imunológicos relacionados à cura na infecção natural. Por meio dessa abordagem seria possível delinear perfis de resposta que se correlacionem com indução de proteção. No caso particular das leishmanioses, tal tipo de abordagem tem demonstrado ser tarefa de extrema complexidade. Apesar da existência de um número cada vez maior de informações relativas à genética e à biologia do parasito, assim como sobre a imunologia experimental e clínica dessas doenças (Khamesipour et al., 2006), um dos maiores desafios continua sendo a tradução dos dados do modelo animal para a doença humana e a transição do laboratório para o campo (Kedzierski, Zhu \& Handman, 2006).

Nesse sentido, vários grupos vêm se dedicando ao estudo de modelos experimentais filogeneticamente mais próximos ao homem, dando-se preferência aos primatas não humanos do Velho Mundo (Marques-da-Cunha, 1944; Lainson \& Shaw, 1977; Lainson \& Bray, 1966; Amaral et al., 1996; Teva et al., 2003; Porrozzi et al., 2006; Souza-Lemos et al., 2008). Esses animais apresentam evolução clínica muito semelhante à doença humana (tanto nas leishmanioses do Velho Mundo como nas do Novo Mundo), sendo uma importante ferramenta não só para se estudar a imunopatologia da doença, como também para o estudo de antígenos candidatos vacinais (Amaral et al., 2002; Grimaldi Jr., 2008). Infelizmente, torna-se necessária uma dispendiosa e complexa estrutura para manutenção dos animais em condições aceitas pelos comitês de ética em pesquisa, o que inviabiliza sua utilização em países com menos recursos.

O conhecimento de que a resposta do tipo 1 (pró-inflamatória) e o IFN- $\gamma$ são essenciais para o controle da infecção por Leishmania tem sido confirmado por estudos experimentais e clínicos. No entanto, uma resposta Th1 exacerbada é observada na forma mucosa (Bacellar et al., 2002) e está relacionada a lesões maiores e crônicas na forma cutânea da doença (Antonelli et al., 2005). A resposta polarizada de linfócitos CD4, observada no modelo murino, também não é tão evidente na infecção humana, e a importância da interleucina (IL) 4 (IL-4) como principal citocina mediadora da suscetibilidade à infecção por Leishmania não é facilmente conciliável com os dados provenientes dos estudos clínicos (Sacks \& Anderson, 2004). Nas formas mais graves de leishmaniose humana associadas à inibição da resposta Th1, tais como a leishmaniose visceral (LV) e a cutânea difusa, a principal citocina associada à patologia e a imunossupressão não é a IL-4, mas a IL-10 (Ghalib et al., 1993; Holaday et al., 1993; Akuffo et al., 1997; Caldas et al., 2005; Nylén et al., 2007).

Diferenças no tipo de citocinas produzidas pelas células CD4+ também parecem ter implicações profundas na sua capacidade de mediar uma resposta efetora ou levar ao desenvolvimento de uma memória duradoura, tendo sido demonstrado que células $\mathrm{CD}^{+}$que produzem exclusivamente IFN- $\gamma$ têm baixa capacidade de se tornarem células de memória, enquanto o oposto ocorre com células que produzem IFN- $\gamma$ em associação a IL-2 ou células que produzem apenas IL-2 (Wu et al., 2002; Hayashi et al., 2002; Seder \& Ahmed, 2003; Foulds, Wu \& Seder, 2006; Seder, Darrah \& Roederer, 2008).

No caso específico das leishmanioses, o desenvolvimento de uma resposta imune protetora de longa duração, após imunização com antígenos de Leishmania e CpG ODN, foi associada à indução de células T CD4+ multifuncionais (produtoras de IFN- $\gamma$ e IL2 ou IFN- $\gamma$, IL2 e TNF- $\alpha$ simultaneamente) (Rhee et al., 2002; Darrah et al., 2007). Com 
relação ao desenvolvimento de células T CD4 + de memória central (MC) ou memória efetora (ME), estudos no modelo murino sugerem que a presença constante de parasitos vivos é imprescindível para a manutenção de células CD4 ME, mas pode não ser necessária para a manutenção de células CD4 MC (Seder \& Sacks, 2004; Zaph et al., 2004; Scott, 2005; Scott et al., 2004). Dessa forma, tanto a eficácia quanto a durabilidade da resposta imune celular induzida por vacinas compostas por extratos brutos do parasito ou por antígenos molecularmente definidos podem ser grandemente aumentadas utilizando-se adjuvantes que favoreçam o desenvolvimento de células T CD4+ MC. Por esse motivo, o desenvolvimento de adjuvantes seguros e eficientes para uso humano, envolvidos com indução de resposta imune celular, tornou-se uma necessidade imediata.

Após a descrição dos receptores Toll-like (TLR) humanos, em fins da década de 1990 (Medzhitov, PrestonHurlburt \& Janeway, 1997), em associação com o conceito de que a resposta imune adaptativa depende do nível e da especificidade dos 'sinais de perigo' (os ditos padrões moleculares associados a patógenos, ou pathogen-associated molecular patterns - PAMPs) percebidos pelas células do sistema imune inato após infecção ou vacinação (Iwasaki \& Medzhitov, 2004; Bianchi, 2007), várias moléculas ligantes para TLR têm sido descritas e avaliadas como possíveis adjuvantes (Lahiri, Das \& Chakravortty, 2008). A presença tanto do antígeno como de um ligante para TLR parece ser necessária para que uma perfeita apresentação e ativação do linfócito T antígeno específico seja alcançada (Blander \& Medzhetov, 2006; Yarovinsky et al., 2006).

Grande parte do esforço mundial para o desenvolvimento de vacinas contra leishmaniose envolve a identificação de antígenos de superfície de L. major (espécie causadora de leishmaniose tegumentar no Velho Mundo). Contudo, as diferenças marcantes entre a clínica, epidemiologia e resposta imune na infecção por $L$. major e as espécies americanas suscita alguns problemas que precisam ser solucionados.

Conforme dito anteriormente, um dos pré-requisitos para uma vacina ideal contra leishmaniose seria sua eficácia contra mais de uma espécie do parasito. Essa tem sido uma questão difícil de ser contornada, já que um alto grau de variabilidade é observado na imunidade cruzada não só entre as Leishmanias do Velho e do Novo Mundo como nas espécies do Novo Mundo entre si, tanto em humanos como em modelos experimentais (Lainson \& Shaw, 1977; Lainson \& Bray, 1966; Porrozzi et al., 2004). Além disso, a vacinação com antígenos de uma determinada espécie do parasito nem sempre confere proteção contra a infecção por uma espécie diferente (Tonui \& Titus, 2007). E mais: alguns antígenos protetores apresentam contrapartidas conservadas entre as espécies de mamíferos, levando assim ao problema de reações autoimunes. Contudo, o sequenciamento do genoma de L. major, L. infantum e L. braziliensis, e provavelmente de outras espécies do parasito em um futuro próximo, abre a perspectiva de se selecionar genes específicos do parasito possivelmente associados às diferentes apresentações clínicas da doença e à identificação de antígenos conservados ou espécie específicos, que consigam incorporar uma vacina multivalente pan-Leishmania.

Também a grande maioria dos estudos experimentais utiliza a infecção murina com L. major, mas a doença observada em cepas de camundongos inbred é muito diferente entre as diferentes espécies do parasito. Enquanto camundongos C57BL/6 e C3H são resistentes à infecção por L. major, desenvolvem lesões crônicas quando infectados com L. amazonensis e lesões autolimitadas quando infectados com L. braziliensis. Já camundongos BALB/C são suscetíveis à infecção tanto por L. major quanto por L. amazonensis, mas desenvolvem doença autolimitada quando infectados com L. braziliensis. Pouca informação tem sido gerada com relação a espécies causadoras das leishmanioses americanas. Embora alguns trabalhos tenham sido publicados utilizando-se a infecção de camundongos com L. braziliensis e L. amazonensis, os protocolos são heterogêneos com relação ao tipo de parasito utilizado (promastigotas de fase estacionária ou metacíclicas) e à via de inoculação (subcutânea ou intradérmica), o que dificulta a comparação dos resultados obtidos (McMahon-Prattt \& Alexander, 2004).

Apesar dessas deficiências no conhecimento da resposta imune e principalmente na disponibilidade de modelos experimentais nas leishmanioses americanas, muitos grupos de pesquisa têm se dedicado ao estudo de vacinas 
candidatas, utilizando como base as informações obtidas nos modelos de infecção por L. major e nos estudos de imunopatologia das diferentes formas clínicas na leishmaniose humana.

\section{VACINAS COMPOSTAS POR PARASITOS VIVOS}

O conhecimento ancestral, no oeste e no sudoeste asiático, de que a cura de uma lesão de leishmaniose cutânea confere proteção contra uma nova infecção por L. major, levou à prática da primeira tentativa de vacinação contra leishmaniose de que se tem conhecimento: a leishmanização. Aplicando o conceito originado da variolização (a primeira tentativa de vacinação humana historicamente comprovada), consistia em inocular material obtido de lesões ativas em áreas não expostas do corpo de indivíduos saudáveis, na intenção de causar uma lesão que se curaria espontaneamente e protegeria contra o aparecimento de lesões múltiplas na face e outras áreas expostas do corpo. Posteriormente, o material de lesão foi substituído pela utilização de parasitos obtidos em meio de cultura axênico. Foi amplamente utilizada em Israel na década de 1970 e no Irã na década de 1980, em um programa de vacinação com cobertura de mais de dois milhões de indivíduos durante a guerra Irã-Iraque. Em Israel, sua prática foi interrompida em razão da perda de virulência do parasito após múltiplas passagens em cultivo e a relatos de diminuição da resposta contra a vacina tríplice bacteriana (DTP) em crianças. Depois, também foi abandonada no Irã após o aparecimento de um pequeno número de lesões maiores do que o usual e resistentes ao tratamento antimonial (Nadim et al., 1983).

Atualmente, alguns autores vêm sugerindo a utilização da leishmanização como desafio em ensaios clínicos de fase 3 (proteção), alegando que o custo dos ensaios seria menor e o procedimento garantiria que todos os participantes do estudo seriam expostos ao parasito (Khamesipour et al., 2005). Apesar de essa metodologia ser uma alternativa possível no caso da leishmaniose cutânea do Velho Mundo, não seria uma alternativa ética como vacina nem como desafio em ensaios clínicos contra as leishmanioses americanas, em razão da possibilidade do aparecimento de formas graves da doença, como a leishmaniose mucosa e difusa. Motivo semelhante impediria seu emprego na leishmaniose visceral.

A utilização de parasitos atenuados ou sensíveis a drogas (por manipulação genética, atenuação química, múltiplas passagens em cultura ou radiação) surge como alternativa de aperfeiçoar a prática da leishmanização, possibilitando sua padronização e utilização como vacina ou como desafio em ensaios clínicos, porém, com exceção dos mutantes obtidos por ruptura gênica ou gene knock-out, ainda assim existiria grande possibilidade de reversão para um fenótipo virulento (Silvestre, Cordeiro-da-Silva \& Ouaissi, 2008; Toledo et. al., 2009). Entretanto, essas alternativas não abrandariam o principal problema que acompanha o desenvolvimento de uma vacina viva contra as leishmanioses, que seria sua conservação para utilização no campo.

\section{VACINAS DE PRIMEIRA GERAÇÃO}

O estudo das vacinas compostas por parasitos mortos originou-se, no Brasil, na década de 1940. Essa vacina era composta por promastigotas mortas de 18 cepas de Leishmania, obtendo-se uma eficácia protetora de 80\% (Pessoa \& Pestana, 1941). A partir da década de 1970, uma nova vacina foi desenvolvida e passou a ser estudada por Mayrink e colaboradores. Essa outra vacina era inicialmente composta por promastigotas mortas de cinco cepas de espécies dermotrópicas de Leishmania, isoladas no Brasil, tendo sido extensamente estudada (Mayrink et al., 1979, 1985; Antunes et al., 1986; Nascimento et al., 1990; Mendonça et al., 1995). A preparação demonstrou ser segura e induzir a uma resposta imune contra o parasito, caracterizada pela positividade do teste de Montenegro em cerca de $70 \%$ a 100\% dos indivíduos vacinados, e pela indução de uma resposta imune contra espécies dermotrópicas de Leishmania mediada por linfócitos T produtores de IFN- $\gamma$ e predomínio do fenótipo T CD8+ (Mayrink et al., 1979, 1985; Antunes et al., 1986; Nascimento et al., 1990; Mendonça et al., 1995). 
Em um estudo de fase 3, a vacina foi capaz de proteger contra infecção por Leishmania 70\% dos indivíduos imunizados que apresentaram teste de Montenegro positivo após a vacinação (cerca de 70\% do total de indivíduos imunizados) (Mayrink et al., 1979). Apesar dos resultados promissores, essa preparação foi abandonada por apresentar problemas relacionados a sua padronização. Uma vacina mais simplificada, composta apenas por promastigotas mortas da cepa de L. amazonensis (IFLA/BR/67/PH8) que compunha a preparação original, passou a ser estudada, demonstrando ser segura (Marzochi et al., 1998; De Luca et al., 1999, 2001) e induzir uma resposta semelhante àquela induzida pela vacina de cinco cepas (De Luca et al., 1999, 2001). A preparação, denominada de Leishvacin ${ }$, foi testada em ensaios clínicos de fase 3 na Colômbia e no Equador (Armijos et al., 2003, 2004; Vélez et al., 2000, 2005). De maneira geral, revelou-se segura e imunogênica, mas não conferiu proteção contra a infecção. Como a maioria dos casos da doença nesses países é relacionada a outras espécies do parasito que não a L. amazonensis, uma possível explicação para o fato seria a possibilidade de a vacina proteger apenas contra a infecção com o parasito homólogo.

Apesar de resultados controversos no que se refere a sua capacidade profilática, principalmente em razão de problemas relacionados ao desenho experimental dos ensaios clínicos e à diminuição no número de casos da doença nas áreas de estudo, o potencial da Leishvacin ${ }^{\circledR}$ de cinco cepas ou de uma única cepa de Leishmania como vacina terapêutica vem sendo bem explorado, tendo-se obtido resultados excelentes em pacientes resistentes a terapêutica usual com antimonial pentavalente (Mayrink et al., 1992, 2006; Silveira \& Mayrink, 1993; Da-Cruz et al., 1999; Machado-Pinto et al., 2002). Preparações semelhantes têm sido testadas na Venezuela em ensaios de imunoterapia, com resultados encorajadores (Cabrera et al., 2000; Convit et al., 2003, 2004).

Vacinas compostas por parasitos mortos também já foram testadas contra leishmaniose visceral canina, com indução de proteção observada em um ensaio conduzido no Irã utilizando-se promastigotas de L. major precipitadas com sais de alumínio (alum) (Mohebali et al., 2004). De modo contrário, uma preparação semelhante, formulada com promastigotas de L. braziliensis e BCG, não foi capaz de induzir proteção contra a doença canina no Brasil (Mayrink et al., 1996). Atualmente, uma vacina contendo promastigotas mortas de L. amazonensis e de L. braziliensis, com BCG, vem sendo testada e se revelou segura e imunogênica em cães, induzindo forte resposta celular (Giunchetti et al., 2008).

Apesar do número extremamente elevado de estudos com vacinas de primeira geração, não só nas Américas, como no Velho Mundo, com muitos resultados positivos, tais preparações estão muito longe de serem liberadas para produção e utilização em larga escala, principalmente em virtude de problemas relacionados a sua padronização e estabilidade. Por esse motivo, alguns grupos de pesquisa brasileiros estudam a possibilidade de seleção de frações antigênicas ou mesmo de antígenos definidos, presentes na Leishvacin ${ }^{\circledR}$, que possam ser utilizados em uma futura vacina (profilática ou terapêutica) mais bem definida contra a leishmaniose tegumentar ou em um futuro teste diagnóstico (Fernandes et al., 1997; Cardoso et al., 2003; Telino et al., 2006).

\section{VACINAS DE SEGUNDA GERAÇÃO}

A utilização de antígenos purificados de cultura de parasitos surgiu como a primeira alternativa de vacina de segunda geração contra as leishmanioses. Várias proteínas e glicofosfolipídeos foram isolados e testados com relação ao seu potencial imunogênico nas leishmanioses, mas em razão das dificuldades relativas a sua obtenção em larga escala, muitos antígenos obtidos dessa forma nunca foram utilizados em ensaios clínicos de fases 2 ou 3.

\section{FML e NH36}

Uma exceção é a preparação glicoproteica enriquecida obtida de promastigotas de cultura de L. donovani, chamada Ligante de Fucose-Manose (FML), antigênica para células humanas (Palatnik-de-Sousa et al., 1995) e caninas (Cabrera 
et al., 1999). A formulação contendo FML e a saponina QS21 foi aprovada em estudos clínicos de fases 1, 2 e 3 na leishmaniose visceral canina e se tornou a vacina Leishmune ${ }^{\circledR}$, licenciada para uso no Brasil desde 2004 (Silva et al., 2000; Borja-Cabrera et al., 2002; Nogueira et al., 2005; Parra et al., 2007). Além de ser considerada uma vacina profilática, tem sido estudada como uma possibilidade na terapêutica da leishmaniose visceral canina (Borja-Cabrera et al., 2004; Santos et al., 2007) e demonstrou atuar como vacina bloqueadora de transmissão, já que a resposta de anticorpos IgG2 observada nos animais imunizados foi capaz de induzir uma inibição de $80 \%$ na ligação das promastigotas de L. donovani e L. chagasi ao intestino médio de vetores in vitro, além de inibir 79,3\% da infecção dos vetores in vivo (Saraiva et al., 2006).

Recentemente, uma glicoproteína de 36-kDa isolada do complexo FML (a hidrolase nucleosídica NH36) - um marcador de doença humana - conferiu proteção contra a leishmaniose visceral e cutânea no modelo murino, quando testada na forma de proteína recombinante ou vacina de DNA (Aguilar-Be et al., 2005). Atualmente, a vacina de DNA contendo o gene de NH36 está sendo testada contra leishmaniose visceral canina (Palatnik-de-Sousa et al., 2008).

Outros dois antígenos inicialmente obtidos por purificação e extensamente estudados até hoje são: o lipofosfoglicano (ou LPG), um glicoconjugado expresso na superfície de amastigotas e promastigotas (McConville \& Blackwell, 1991; Moody et al., 1993) e que tem importante papel na interação do parasito com macrófagos e na especificidade da associação Leishmania-vetor (Turco \& Descoteaux, 1992; Kelleher et al., 1995; Sacks et al., 1994); e a glicoproteína 63 (ou leishmanolisina), uma metaloprotease abundantemente expressa na superfície de promastigotas de Leishmania que se liga ao receptor de complemento 3 (CR3), levando à internalização do parasito pelos macrófagos (Russell \& Wright, 1988).

\section{LPG e KMP-11}

No início da década de 1990 demonstrou-se que a resposta de células T humanas atribuída ao LPG devia-se, na verdade, a contaminantes proteicos presentes nas preparações do glicolipídeo (Mendonça, Russell \& Coutinho, 1991). A verificação da presença dessa proteína de 11 kDa na superfície de vários cinetoplastídeos justificou sua denominação atual, kinetoplastid membrane protein 11 (KMP-11) (Tolson et al., 1994). Por um lado, genes que codificam KMP-11 em várias espécies de Leishmania têm sido clonados, demostrando alto grau de homologia entre suas sequências, tendo sido observado uma proteção contra $L$. donovani no modelo hamster através de vacinação com DNA codificando KMP-11, que induziu uma resposta mista de citocinas Th1/Th2 (Basu et al., 2005). Por outro lado, no que se refere à resposta de células humanas, KMP-11 tem apresentado baixa capacidade de induzir produção de IFN- $\gamma$ e um alto poder estimulador da produção de IL-10 (Carvalho et al., 2003, 2005). Apesar da resposta Th1 ser responsável pelo controle da infecção (Sacks \& Anderson, 2004), sua exacerbação pode levar à patologia, cujo exemplo mais extremo, no caso das leishmanioses, são as lesões mucosas secundárias da LTA (Bacellar et al., 2002). O mapeamento de epitopos responsáveis por respostas celulares bem caracterizadas na molécula de KMP-11 pode favorecer o desenvolvimento de antígenos sintéticos ou recombinantes com potencial imunoprofilático, imunoterápico ou diagnóstico para as leishmanioses.

\section{gp63 ou leishmanolisina}

A imunização com gp63 nativa, obtida de L. major, foi capaz de conferir proteção contra a infecção por L. major e L. mexicana em camundongos, quando incorporada em lipossomas (Russell \& Alexander, 1988) e utilizando diferentes adjuvantes e vias de inoculação (Rivier et al., 1999). Porém, a proteína recombinante expressa em Escherichia coli não foi capaz de induzir proteção em camundongos contra a infecção por L. major (Handman, Button \& McMaster, 1990), ou induziu apenas uma proteção parcial em macacos (Olobo et al., 1995). Uma resposta protetora foi obtida utilizando-se a proteína vetorizada em BCG (Connell et al., 1993; Abdelhak et al., 1995) e 
Salmonella atenuada (Yang et al., 1990; Xu et al., 1995; McSorley et al., 1995; McSorley et al., 1997; González et al., 1998), mas a imunização com vacina de DNA codificando a proteína induziu apenas proteção parcial e transitória contra L. major (Xu \& Liew, 1995; Ahmed et al., 2004) e L. mexicana (Dumonteil et al., 2000, 2003).

A utilização de gp63 recombinante, em conjunto com IL-12, não foi capaz de proteger camundongos contra a infecção por L. major (Tonui et al., 2004). Por sua vez, a imunização com células transfectadas expressando gp63, em conjunto com CD40L (um potente indutor da produção de IL-12), foi capaz de proteger parcialmente camundongos contra a infecção por L. amazonensis (Chen, Darrah \& Mosser, 2001). No que se refere à antigenicidade da gp63 para células humanas, resultados variáveis, mas em sua maioria negativos (Jaffe, Rachamim \& Sarfstein, 1990; Kemp et al., 1991; Kurtzhals et al., 1994; Mendonça, Russell \& Coutinho, 1991, Russo et al., 1991), levaram a uma diminuição no número de grupos de pesquisa trabalhando com esse antígeno como candidato vacinal. No entanto, em virtude de seu potencial imunogênico em camundongos, ainda é muito utilizada em estudos de avaliação de novos adjuvantes como CpG ODN.

Tomados em conjunto, tais dados fazem da gp63 um bom de exemplo de como um mesmo antígeno candidato pode induzir diferentes respostas na dependência de sua natureza (nativo, recombinante, vacina de DNA, expresso em células transfectadas e outros), via de inoculação (intramuscular, intradérmico, subcutâneo e outros), ou do tipo de adjuvante utilizado (IL-12, CpG, MPL e outros).

\section{P36/LACK}

É provável que a proteína p36/LACK seja um dos únicos antígenos candidatos a uma vacina de segunda geração contra leishmaniose a ser descoberto através de um protocolo racional: um clone de célula T CD4+ protetor foi utilizado como sonda em uma biblioteca de cDNA, para identificar uma proteína de L. major que possui homologia com receptores intracelulares para proteína quinase $\mathrm{C}$ ativada (RACK), denominada Leishmania analogue of the receptor for activated protein kinase $C$ (LACK).

Apesar de aparentemente ser a proteína responsável pela indução da produção inicial de IL-4, observada em camundongos BALB/C após infecção por L. major (Launois et al., 1997; Julia \& Glaichenhaus, 1999), a proteína LACK recombinante, denominada p36, foi capaz de conferir proteção contra L. major em camundongos BALB/C suscetíveis, quando administrada junto com IL-12 (Mougneau et al., 1995), embora tal proteção seja de curta duração (Gurunathan et al., 1998). Ainda que seja uma molécula extremamente conservada entre as espécies de Leishmania, a imunização com DNA codificando o antígeno LACK foi capaz de induzir proteção parcial contra a infecção por L. major em camundongos BALB/c (Gurunathan et al., 1997), mas não protegeu contra a infecção por L. mexicana (Dumonteil et al., 2003), L. braziliensis (Salay et al., 2007), L. donovani, L. infantum (Melby et al., 2001; Rodríguez-Cortés et al., 2007) e L. chagasi (Marques-da-Silva et al., 2005).

Tais resultados apontam para a possibilidade de um único antígeno não ser capaz de induzir uma resposta imune ampla que contemple possíveis diferenças nas respostas necessárias, para indução de proteção entre os diferentes tipos de leishmaniose cutânea e na leishmaniose visceral. Entretanto, em estudos mais recentes utilizando-se protocolos de prime-boost com vacina de DNA e vírus Vaccinia ou Salmonella enterica expressando o antígeno LACK, observou-se a indução de proteção parcial ou completa contra leishmaniose visceral canina (Gonzalo et al., 2002; Ramiro et al., 2003; Lange et al., 2004; Ramos et al., 2008, 2009). Isso confirmou o benefício potencial dos protocolos de primeboost no sentido de diversificar a resposta induzida por uma molécula candidata, tornando-a mais imunogênica e capaz de induzir proteção contra as diferentes formas clínicas de leishmaniose.

Por fim, a imunização intranasal, com plasmídeos codificando o antígeno LACK, demonstrou ser capaz de controlar a infecção por L. amazonensis, L. major e L. infantum, sugerindo que a via intranasal pode induzir imunidade contra o parasito (Pinto et al., 2004; Gomes et al., 2007). 


\section{Cisteína-proteases}

Antígenos expressos em amastigotas são provavelmente muito importantes no desenvolvimento de uma vacina contra leishmaniose, já que essa é a forma do parasito encontrada no hospedeiro mamífero, sendo um importante alvo da resposta imune. As cisteínas-proteases catepsina L-like (CPs) pertencem à superfamília da papaína e são vistas como bons candidatos vacinais, uma vez que são altamente imunogênicas e importantes na interação parasito/ hospedeiro (Wolfram et al., 1995; Rafati et al., 2003). Três diferentes classes de CPs foram identificadas: tipo 1 ou CPB, tipo II ou CPA e tipo III ou CPC. Tanto CPA como CPB demonstraram ser reconhecidas pelo sistema imune de mamíferos, como verificado pela sua reatividade no soro de pacientes com leishmaniose cutânea ativa ou curados (Rafati et al., 2001). Entretanto, apenas a CPB recombinante foi capaz de induzir proteção parcial contra a infecção por L. major com indução de células CD8+ e produção de IFN- $\gamma$ (Rafati et al., 2002). Contudo, a imunização com DNA só foi eficiente quando foram utilizados em conjunto plasmídeos codificando para as duas proteínas (CPA e CPB) (Rafati et al., 2001). Além disso, de maneira semelhante ao que ocorre com o antígeno LACK, protocolos de prime-boost utilizando a imunização com os plasmídeos CPA e CPB, seguida de uma dose de proteína recombinante em adjuvante incompleto de Freund, levaram a uma proteção ótima contra a leishmaniose visceral no modelo murino (Rafati, Zahedifard \& Nazgouee, 2006; Rafati et al., 2008).

Confirmando tais dados, um protocolo de prime-boost de DNA e proteína recombinante, em associação com CpG ODN e Montanide ${ }^{\circledR} 720$, também foi capaz de proteger camundongos e cães contra a infecção experimental por $L$. infantum (Rafati, Zahedifard \& Nazgouee, 2006; Rafati et al., 2005). Posteriormente, um protocolo de prime-boost semelhante protegeu camundongos contra a infecção por $L$. infantum utilizando-se como imunógeno a CP tipo III (CPC) (Khoshgoo et al., 2008).

Apesar do grande número de trabalhos envolvendo o potencial imunogênico das CPs na infecção por L. major, muito pouco se sabe sobre essas proteínas nas espécies de Leishmania do Novo Mundo. Uma cisteína-protease de $L$. pifanoi (denominada A2) foi capaz de induzir proteção parcial contra a infecção homóloga no modelo experimental murino (Soong et al., 1995), porém mostrou ser fracamente reconhecido por células de pacientes com leishmaniose cutânea (Silveira et al., 1998; Coutinho et al., 1996).

Mais recentemente, uma cisteína-proteinase de $24 \mathrm{kDa}$ isolada de L. amazonensis (Lacys24) foi capaz de induzir proteção parcial contra a infecção homóloga em camundongos BALB/c, após imunização com a proteína recombinante e adjuvante completo de Freund (Fedeli et al., 2010). Algumas cisteínas-proteases de L. braziliensis já foram descritas (Rebello et al., 2009; Lanfranco et al., 2008; Alves, Marzochi \& Giovanni-de-Simone, 1993), contudo nenhum ensaio de proteção foi publicado até o momento.

\section{Antígenos de superfície de amastigotas}

Outros antígenos de amastigota, candidatos a vacina contra leishmaniose, são as proteínas de membrana P4 e P8, que demonstraram conferir proteção contra a infecção por L. pifanoi em camundongos (Soong et al., 1995) e foram reconhecidas por células mononucleares de sangue periférico de pacientes infectados com L. braziliensis, induzindo uma resposta de células CD4+ com perfil Th1 (Coutinho et al., 1996; Haberer et al., 1998). A proteína P4 é uma nuclease presente em todas as espécies de Leishmania (Kar et al., 2000). A proteção induzida pela proteína P4 no modelo murino foi correlacionada com a indução de uma resposta de células CD4 + Th1, com a produção de IFN- $\gamma$, TNF e MIF (Kar, Metz \& McMahon-Pratt, 2005), e a imunização com vacina de DNA codificando para os genes da proteína P4 de L. amazonensis e IL-12 conferiu proteção contra a infecção por L. amazonensis e proteção parcial contra a infecção por L. major em camundongos BALB/c (Campbel et al., 2003). A função da proteína P8 ainda é desconhecida. Além de proteger contra a infecção por L. pifanoi no modelo murino, foi capaz de induzir respostas in vitro em células de pacientes infectados 
com L. braziliensis (Coutinho et al., 1996; Haberer et al., 1998) e L. amazonensis (Silveira et al., 1998) e ainda de cães infectados com L. infantum (Carrillo et al., 2007), com indução de uma resposta Th1 em todos os estudos.

\section{Múltiplos antígenos}

Uma das estratégias que podem ser empregadas para o desenvolvimento de uma vacina contra leishmaniose, a qual seja capaz de conferir proteção para as diferentes espécies do parasito responsáveis pela doença no homem, seria o estudo de uma vacina composta por múltiplos antígenos. Nesse sentido, uma vacina contendo uma poliproteína (ou polipeptídeo) formada pela fusão de epitopos múltiplos seria menos custosa, em termos de manufaturamento, que uma preparação composta por várias proteínas recombinantes. O melhor exemplo desse tipo de vacina seria a proteína trifusão Leish-111f, constituída pelos antígenos homologue of eukaryotic thiol-specific antioxidant (TSA) e stress inducible protein 1 (STI1), de L. major, e a proteína elongation and initiation factor (LeIF), de L. braziliensis.

Tais proteínas são expressas nas formas amastigota e promastigota de várias espécies do gênero Leishmania. Tanto TSA quanto STI1 são reconhecidos por células T de pacientes curados e já demonstraram induzir proteção no modelo murino ou em primatas não humanos, quando utilizadas separadamente ou combinadas (Webb et al., 1996, 1998; Campos-Neto et al., 2001, 2002; Méndez et al., 2001). Além do mais, o antígeno LelF tem a capacidade de induzir a produção de IL-12 e IL-18 por monócitos e fibroblastos humanos (Probst et al., 1997; Sheiky et al., 1995, 1998).

A imunização com a proteína Leish-111f recombinante com IL-12, MPL-SE ou com CpG ODN como adjuvante, ou ainda na forma de vacina de DNA, foi capaz de conferir proteção contra a infecção por L. major no modelo murino (Coler et al., 2002; Skeiky et al., 2002; Rhee et al., 2002). Além do mais, a poliproteína demonstrou ser reconhecida por células mononucleares isoladas do sangue periférico de pacientes com leishmaniose cutânea e mucosa, no Brasil e no Peru (Ghalib \& Modabber, 2007).

Após ser testada em conjunto com inúmeros adjuvantes em ensaios de proteção no modelo murino, o adjuvante MPL monofosforilipídeo A (MPLA) isolado de Salmonella minnesota) foi selecionado para estudos subsequentes em humanos. O MPL é uma agonista de TLR4 e demonstrou ser uma solução aquosa segura que já foi utilizada como adjuvante em várias formulações humanas, incluindo as vacinas para herpes simplex e hepatite B. A formulação contendo a proteína recombinante com MPL-SE - emulsão estável óleo/água usando esqualeno sintético - foi liberada para uso humano. Em recente estudo na Colômbia, ela demonstrou ser segura e imunogênica, tornando-se a primeira vacina de segunda geração contra leishmaniose testada em seres humanos (Vélez et al., 2009).

\section{Antígenos da saliva de flebotomíneos}

Durante a tentativa de alimentação no hospedeiro vertebrado os flebotomíneos injetam, juntamente com as formas promastigotas, uma pequena quantidade de saliva contendo um grande número de moléculas farmacologicamente ativas, capazes de interferir na resposta imune do hospedeiro. A saliva de Lu. longipalpis inibe a produção de IL-10 e de TNF- $\alpha$ e induz a produção de IL-6, IL-8 e IL-12p40 por monócitos e células dendríticas humanas (Costa et al., 2004). O efeito imunomodulador do extrato de glândula salivar de diferentes espécies de flebotomíneos também foi observado na infecção experimental de camundongos com L. major, L. braziliensis e L. amazonensis (Titus \& Ribeiro, 1988; Samuelson et al., 1991; Norsworthy et al., 2004; Bezerra \& Teixeira, 2001). A exposição prévia de camundongos com saliva foi capaz de proteger contra uma infecção subsequente com L. major (Kamhawi et al., 2000). Porém, de maneira oposta, a exposição com saliva de Lu. intermedia, o principal vetor de L. braziliensis, agravou a infecção por esse parasito em camundongos BALB/c (Moura et al., 2007), indicando possíveis diferenças na composição e nos efeitos imunomodulatórios de antígenos presentes na saliva de diferentes espécies de flebotomíneos. Diferenças nos 
efeitos imunomodulatórios induzidos pelas glândulas salivares de flebotomíneos selvagens, ou criados em laboratório, também foram observadas (Laurenti et al., 2009; Ben Hadj Ahmed et al., 2010).

Vários antígenos de saliva de Lu. longipalpis (Maxadilan, LJM19 etc.) e de Phlebotomus papatasi (PpSP15, PpSP42 e PpSP44) já foram isolados, clonados e testados em modelos experimentais. Foi proposto que a resposta imune induzida contra a proteína Maxadilan, um peptídeo vasodilator capaz de inibir a produção de IFN- $\gamma$ e induzir a produção de IL-6 em células mononucleares humanas (Rogers \& Titus, 2003), neutraliza a exacerbação da infecção por L. major (Morris et al., 2001). A imunização com PsP15 protege camundongos selvagens e deficientes em linfócitos B, proteção esta associada à indução de hipersensibilidade tardia contra a proteína (Valenzuela et al., 2001). Contrariamente, observou-se um efeito agravador das lesões após a imunização com a proteína PpSP44 (Oliveira et al., 2008). A imunização com plasmídeo codificando para a proteína LJM19 induziu proteção contra a inoculação intradérmica concomitante de L. chagasi e homogenato de glândula salivar de Lu. longipalpis no modelo hamster (Gomes et al., 2008). A proteção observada também foi associada ao desenvolvimento de hipersensibilidade tardia contra saliva e presença de IFN- $\gamma$ no sítio de picada dos flebotomíneos. Por sua vez, em um estudo mais recente, utilizando-se um painel de plasmídeos codificando para 35 proteínas isoladas da saliva de Lu. longipalpis, a imunização de cães com LJM19 induziu uma fraca resposta imune mediada por células, enquanto a imunização com LJL143 ou LJM17 induziu forte resposta TH1 (Collin et al., 2009).

As diferenças observadas entre as proteínas que induzem resposta em modelos distintos (como a resposta contra LJM19) podem estar relacionadas com restrições impostas pelo repertório de moléculas MHC classe II, presentes nas diferentes classes animais. Esse seria um dos casos em que os estudos em modelo experimental podem não ser comprovados, quando transportados para o sistema imune humano.

\section{Vacinas vetorizadas (vírus e bactérias como vetores)}

Uma alternativa extremamente interessante no desenvolvimento de vacinas de segunda geração contra leishmaniose seria a utilização de vírus ou de bactérias recombinantes como vetores vivos, expressando antígenos do parasito. A imunização com organismos vivos sabidamente induz uma resposta celular mais intensa e eficiente do que a induzida por antígenos mortos e purificados, o que é uma característica significativa quando se busca uma vacina contra um parasito intracelular. Apesar disso, poucos antígenos de Leishmania já foram clonados seguindo essa estratégia, alguns em bactérias como BCG (Connell et al., 1993; Abdelhak et al., 1995; Streit et al., 2000) e Salmonella (Yang et al., 1990; Xu et al., 1995), e outros em alguns tipos virais (Antonelli et al., 2005; Gonzalo et al., 2002; Ramiro et al., 2003; McMahon-Pratt et al., 1993; Carson et al., 2009; Resende et al., 2008; Ramos et al., 2008; Stober et al., 2007; Pérez-Jiménez et al., 2006; Dondji et al., 2005).

Um vetor ideal deve: estimular uma resposta imune forte e de longa duração, capaz de proteger contra a infecção em questão; ser capaz de suportar a introdução de sequências externas ao seu genoma; tolerar esses insertos por muito tempo sem 'expulsar' a sequência introduzida; e, obviamente, não causar doença na população. Do ponto de vista clínico, seria extremamente interessante se tal vacina fosse administrada em uma única dose em indivíduos com nenhuma ou muito pouca imunidade preexistente contra o vetor (Van, 2005). A utilização de vírus ou bactérias de cepas vacinais já liberadas para uso humano (como o BCG e o vírus amarílico vacinal) seria vantajosa, no intuito de se desenvolver uma vacina polivalente capaz de imunizar contra agentes patogênicos bem distintos. Toda essa combinação de fatores é praticamente impossível de ser alcançada e, dessa forma, a escolha de um vetor vem sempre acompanhada de pontos positivos e pontos negativos, os quais precisam ser identificados e ponderados. Os prós e contras da utilização dos principais vetores bacterianos e virais são analisados a seguir. 
- Vaccinia - Poxviridae é uma família de vírus cuja principal característica reside na capacidade de infectar tanto os animais vertebrados como também os invertebrados. Um dos componentes da família poxvírus é o vírus vaccinia (VACV), o qual, no passado, foi usado com sucesso como vacina para erradicar o vírus da varíola humana. Os poxvírus, sobretudo VACV, estão entre os primeiros vírus animais a serem investigados como vetores de transferência. A expressão de genes recombinantes por VACV foi originalmente demonstrada em 1982 (Mackett, Smith \& Moss, 1982; Panicali \& Paoletti, 1982) e, desde então, tem sido utilizada com sucesso para estudos de biologia molecular, produção e caracterização funcional de proteínas in vitro, assim como no desenvolvimento de vacinas vivas e como ferramentas no estudo de candidatos vacinais (Pastoret, 2003; Moss, 1991; Mackett \& Smith, 1986).

Várias características únicas fazem do vírus VACV um excelente candidato como vetor vacinal: sua estabilidade como vacina liofilizada, ser de baixo custo, fácil produção e administração; a expressão citoplasmática dos genes vacinais; a flexibilidade de empacotamento, permitindo que um amplo tamanho do seu genoma seja deletado para que um DNA estranho seja integrado sem que ocorra perda da infectividade do vírus; e a sua habilidade em induzir resposta humoral e células T citotóxicas contra o antígeno vacinal, com indução de uma resposta imune duradoura após uma única inoculação. Contudo, a existência de complicações severas, observadas especialmente em crianças e indivíduos imunossuprimidos, nas campanhas de erradicação da varíola, inviabiliza a reintrodução do VACV como agente imunizante. Por esse motivo, desenvolveram-se linhagens de vírus VACV atenuados como o modified vaccinia virus Ankara (MVA) e o New York vaccinia virus attenuated from Copenhagen (NYVAC). A grande vantagem dessas linhagens atenuadas é sua segurança, pois, apesar de sua limitada replicação em células humanas e de muitos tipos celulares de mamíferos, tanto MVA como NYVAC apresentam alto nível de expressão gênica e também induzem forte imunidade quando utilizados como vetores vacinais em animais e humanos (Gómez et al., 2008).

$\mathrm{Na}$ prática, a experiência de muitos autores revela que uma segunda dose de vírus recombinante esbarra no problema de imunidade preexistente, em que os anticorpos gerados pela primeira imunização neutralizam os vírus inoculados na segunda dose, o que impede o desenvolvimento de uma resposta imune mais robusta contra o antígeno vacinal. No entanto, a utilização de MVA recombinante em protocolos de prime-boost tem demonstrado resultados promissores para vários antígenos, incluindo os antígenos LACK e TRYP de Leishmania contra leishmaniose visceral canina (Ramiro et al., 2003; Ramos et al., 2008; Pérez-Jiménez et al., 2006).

- Adenovírus - os adenovírus são um grupo de vírus de genoma de DNA dupla hélice que causam uma variedade de doenças no homem, desde infecções subclínicas até infecções do trato respiratório superior e de vários outros órgãos, principalmente em crianças, idosos e indivíduos com sistema imune comprometido. Sua habilidade em infectar diversos tipos celulares constitui uma das razões pelas quais os adenovírus são utilizados como vetores para genes de antígenos vacinais ou com aplicações terapêuticas (Danthinne \& Imperiale, 2000; Patterson et al., 2004). Outro ponto positivo seria sua capacidade de empacotar transgenes de $3 \mathrm{~Kb}$ a $4 \mathrm{~Kb}$ nos vírus com capacidade replicativa, podendo chegar a mais de $10 \mathrm{~Kb}$ nos não replicativos (Patterson et al., 2004). Além disso, a biologia dos adenovírus é muito bem conhecida e as partículas virais podem ser obtidas em altos títulos em culturas de linhagens celulares in vitro.

Embora mais de 51 sorotipos de adenovírus humanos sejam conhecidos, os estudos com adenovírus recombinantes se limitam ao subgrupo C, mais especificamente aos sorotipos 2 (Ad2) e 5 (Ad5). Estudos pré-clínicos e clínicos com esses vetores evidenciaram uma séria limitação ao seu uso em seres humanos: a presença de imunidade preexistente, já que as infecções causadas pelo subgrupo C são endêmicas em diversas regiões do mundo. Anticorpos específicos foram detectados em $97 \%$ dos indivíduos estudados, encontrando-se mais de 50\% com imunidade humoral e celular contra Ad2 e Ad5 (Chirmule et al., 1999). Essa imunidade preexistente ao Ad5 reduz drasticamente a imunogenicidade do vírus vacinal recombinante em modelos animais e em seres humanos. Como o nível de anticorpos neutralizantes contra o vírus é variável na população humana, o grau de indução de imunidade com uma vacina utilizando Ad5 seria extremamente variável e imprevisível. Dessa forma, adenovírus de sorotipos menos prevalentes e mesmo de outras 
espécies animais, como chimpanzés, estão sendo estudados como possíveis vetores vacinais (Bangari \& Mittal, 2006). Outra estratégia para subverter a imunidade preexistente seria a utilização de vírus Ad5 quiméricos, expressando antígenos de superfície de outros sorotipos menos prevalentes como o Ad35 (Xin et al., 2005; Thorner et al., 2006; Roberts et al., 2006; Nanda et al., 2005).

Atualmente existem apenas dois relatos de vacinas contra leishmaniose utilizando-se Ad5 recombinante, sendo que em um deles foi observado que o grau de proteção é inversamente proporcional à dose do vírus recombinante utilizada (Stober et al., 2007; Darrah et al., 2007).

- Vírus Amarílico - o vírus vacinal da febre amarela 17D é uma das vacinas mais bem-sucedidas desenvolvidas até hoje. Dispõe de uma metodologia de produção bem definida e eficiente, induz uma resposta imune humoral e celular de longa duração (Lefeuvre, Marianneau \& Deubel, 2004; Reinhardt et al., 1998; Co et al., 2002), é de baixo custo, utilizado em uma única dose, e tem um rigoroso controle de qualidade, incluindo testes de neurovirulência em macacos. Desde 1945 a encefalite pós-vacinal vem sendo reportada em um a cada vinte milhões de indivíduos imunizados (Van, 2005). Diferentemente dos adenovírus, a existência de pré-imunidade ao vírus 17D não interferiu com a resposta imune induzida pelo vírus 17D recombinante utilizado contra a dengue. Além disso, a aplicação de duas doses da vacina com o vírus quimérico induz uma resposta CD8 contra o vírus 17D, e é capaz de induzir células CD4 e anticorpos neutralizantes contra todos os quatro sorotipos de dengue (Guirakhoo et al., 2006; Guy et al., 2008). Todas essas características tornam extremamente tentador o uso do vírus 17D como um vetor de expressão de antígenos heterólogos, o que leva ao desenvolvimento de uma vacina viva polivalente.

Sendo assim, por que até hoje poucas vacinas foram desenvolvidas utilizando-se o vírus amarílico vacinal, a maioria delas utilizando vírus com genes de outros flavivírus como dengue e encefalite japonesa? $\mathrm{O}$ "calcanhar de Aquiles' do vírus vacinal 17D seria o fato de os vírus RNA, como o caso dos flavivírus, serem pequenos e não tolerarem muito bem a inserção de genes heterólogos. Muitas vezes os vírus recombinantes tornam-se instáveis e 'chutam', literalmente, o gene heterólogo para fora. Por sua vez, sequências pequenas de outros vírus da família Flaviviridae já foram introduzidas com sucesso no vírus 17D e mostraram ser estáveis após inúmeras passagens (Guirakhoo et al., 2006; Guy et al., 2008; Bray \& Lai, 1991; Chambers et al., 1999). Uma forma de se introduzir sequências maiores seria a utilização de construtos bicistrônicos contendo sítios de entrada ribossomais internos (Van, 2005) e a criação de vírus quiméricos, através da substituição dos genes estruturais prM/M/E (Lai \& Monath, 2003)

No caso do desenvolvimento de uma vacina contra protozoários intracelulares, apesar de tantos pontos positivos envolvendo até mesmo o desenvolvimento de uma resposta do tipo celular mediada por linfócitos $\mathrm{T} \operatorname{CD} 8+$, não existe nenhum relato de desenvolvimento de vírus 17D quiméricos expressando antígenos de Leishmania. Há apenas poucos relatos envolvendo a expressão de epitopos da proteína CS de Plasmodium (Bonaldo et al., 2002; Tao et al., 2005; Bojang et al., 2004; Mueller et al., 2005). Como novas metodologias têm sido criadas no sentido de se melhorar a estabilidade dos vírus 17D recombinantes, é possível que em um futuro próximo uma vacina combinada contra leishmaniose e febre amarela seja desenvolvida (Bonaldo et al., 2007).

- BCG - o BCG é uma cepa atenuada derivada do Mycobacterium bovis, após 250 passagens em meio de cultura. É uma vacina viva segura, de baixo custo e relativamente termoestável que pode ser aplicada logo após o nascimento, conferindo proteção de longa duração contra tuberculose severa. Como é um forte imunoestimulante, já vem sendo usado como adjuvante em diversos protocolos de imunização, tendo sido sugerido também que a utilização de BCG recombinantes expressando antígenos heterólogos de outros patógenos poderia induzir resposta imune protetora contra a tuberculose e contra o patógeno em questão, e que uma única aplicação seria suficiente para induzir imunidade celular de longa duração (Lagranderie et al., 1993). O BCG já foi administrado a mais de três bilhões de pessoas no mundo, com muito poucos efeitos colaterais severos, o que seria mais um ponto positivo a favor de sua utilização 
como vetor de antígenos heterólogos. Além do mais, um estudo no modelo murino utilizando BCG recombinante expressando lacZ demonstrou que a imunização prévia com BCG não interfere na resposta imune celular específica a $\beta$-galactosidase - quando a administração do BCG recombinante é realizada com intervalo igual ou superior a três meses, o que sugere que a imunidade preexistente não seria um problema na utilização do BCG como vetor vacinal (Gheorghiu et al., 1994).

Como relatado anteriormente, o BCG já foi utilizado como adjuvante em diversas vacinas humanas contendo $L$. mexicana e L. braziliensis (Convit et al., 2004; Noazin et al., 2008; Castes et al., 1989) em ensaios de imunoproteção e de imunoterapia contra as leishmanioses americanas, mas com resultados inconclusivos. Trabalhos utilizando antígeno autoclavado de L. major (ALM) e BCG como adjuvante também geraram dados inconclusivos, com graus de indução de proteção variáveis ou ausentes quando comparados aos grupos placebo que recebiam exclusivamente BCG (Sharifi et al., 1998; Momeni et al., 1999; Khalil et al., 2000). No entanto, resultados positivos foram obtidos com BCG recombinante expressando gp63 de L. major com indução de imunidade mediada por células e proteção em camundongos (Connell et al., 1993; Abdelhak et al., 1995). BCG recombinante expressando a proteína LCR1 de L. chagasi induziu proteção contra desafio homólogo em camundongos suscetíveis (Carson et al., 2009). Apesar desses resultados encorajadores poucos grupos se dedicaram a tal tipo de abordagem, provavelmente em razão das dificuldades de expressão dos antígenos heterólogos pelo BCG recombinante. Atualmente, várias estratégias já foram desenvolvidas para permitir a expressão controlada e estável de antígenos heterólogos pelo BCG recombinante, e muito possivelmente a tendência é de que novos trabalhos surjam na literatura.

O BCG protege contra as formas severas de tuberculose em crianças, mas tem eficácia variada contra a doença pulmonar em adultos, sendo de consenso geral que, para que um dia a tuberculose possa ser erradicada, é necessário o aprimoramento do BCG. Realizar todo o processo de liberação de uma vacina com BCG recombinante expressando antígenos de Leishmania, para que depois a cepa vacinal da bactéria seja modificada, poderia soar como um trabalho infrutífero para quem busca uma vacina multivalente. Por sua vez, o conhecimento gerado com estudos atuais pode tornar o caminho bem menos tortuoso quando uma nova cepa de BCG vacinal for desenvolvida.

\section{CONCLUSÕES}

A utilização profilática de vacinas é reconhecidamente a medida mais eficiente e de menor custo-benefício no controle das infecções. No caso da leishmaniose, o desenvolvimento de uma vacina tem demonstrado ser tanto um desafio como um objetivo difícil de ser alcançado. Não pela descoberta de moléculas candidatas, uma vez que vários antígenos surgem a cada dia e um número maior ainda deve surgir após o sequenciamento do genoma de diferentes espécies do parasito, mas por inúmeras dificuldades relacionadas ao conhecimento ainda incompleto da patogênese do parasito, da complexa resposta imune necessária para indução de proteção, pela ausência de modelos experimentais adequados - o que tem gerado dados que muitas vezes não são reprodutíveis em humanos - e do conhecimento ainda fragmentado sobre os mecanismos de desenvolvimento de memória imunológica.

As vacinas contra patógenos intracelulares requerem a indução de uma resposta imune mediada por células bem definidas, e não só de anticorpos como na grande maioria das vacinas licenciadas para uso humano até o momento. Além disso, vacinas definidas - como proteínas recombinantes - são muito pouco imunogênicas, necessitando de adjuvantes ou de sistemas de expressão (como vírus ou bactérias recombinantes) para que possam desencadear uma resposta protetora. Os adjuvantes liberados para uso nos dias atuais são potentes indutores de resposta imune humoral. Por esse motivo, o estudo da vacinologia tem se voltado para um novo desafio: desenvolver adjuvantes seguros para uso humano que sejam capazes de potencializar indução de memória celular, tanto CD4 quanto CD8. Nesse contexto, os recentes avanços na imunologia básica, demonstrando os mecanismos pelos quais 
a resposta imune inata pode moldar uma resposta imune adaptativa subsequente, em conjunto com novas técnicas bioquímicas, vêm permitindo o desenvolvimento e o estudo de adjuvantes mais específicos, como os diferentes ligantes de receptores Toll-like (Guy, 2007).

Atualmente, mais de trinta antígenos de Leishmania já foram ou estão sendo testados como candidatos vacinais contra leishmaniose visceral ou tegumentar. Muitos deles são conservados entre as espécies do parasito, mas, conforme descrito neste capítulo, em muitos casos não são capazes de induzir proteção em ensaios clínicos ou não induzem proteção contra todas as espécies do parasito causadoras de doença humana. Quem sabe seja a hora de desviar os esforços da obtenção de novas moléculas candidatas para a avaliação de novas formas de apresentação de antígenos conservados já existentes - que envolveria protocolos de prime-boost e o uso de novos adjuvantes - para que se possa avançar ainda mais no desenvolvimento de um produto capaz de concretizar a ânsia de muitos pesquisadores, tanto no Brasil como no mundo: uma vacina contra leishmaniose que preencha a maioria dos atributos relatados no início deste capítulo.

Por fim, é possível afirmar, sem correr riscos, que os estudos com candidatos vacinais contra leishmanioses em muito contribuíram e têm contribuído para o enriquecimento do conhecimento na área da vacinologia.

\section{REFERÊNCIAS}

ABDELHAK, S. et al. Recombinant BCG expressing the Leishmania surface antigen Gp63 induces protective immunity against Leishmania major infection in BALB/c mice. Microbiology, 141(7): 1.585-1.592, 1995.

AGUILAR-BE, I. et al. Cross-protective efficacy of a prophylactic Leishmania donovani DNA vaccine against visceral and cutaneous murine leishmaniasis. Infection and Immunity, 73(2): 812-819, 2005.

AHMED, S. B. et al. A comparative evaluation of different DNA vaccine candidates against experimental murine leishmaniasis due to L. major. Vaccine, 22: 1.631-1.639, 2004.

AKUFFO, H. et al. Leishmania aethiopica derived from diffuse leishmaniasis patients preferentially induce mRNA for interleukin-10 while those from localized leishmaniasis patients induce interferon-gamma. The Journal of Infectious Diseases, 175: 737-741, 1997.

ALVES, C. R.; MARZOCHI, M. C. \& GIOVANNI-DE-SIMONE, S. Heterogeneity of cysteine proteinases in Leishmania braziliensis and Leishmania major. Brazilian Journal of Medical and Biological Research, 26: 167-171, 1993.

AMARAL, V. F. et al. Leishmania amazonensis: the Asian rhesus macaques (Macaca mulatta) as an experimental model for study of cutaneous leishmaniasis. Experimental Parasitology, 82(1): 34-44, 1996.

AMARAL, V. F. et al. Study of the safety, immunogenicity and efficacy of attenuated and killed Leishmania (Leishmania) major vaccines in a rhesus monkey (Macaca mulatta) model of the human disease. Memórias do Instituto Oswaldo Cruz, 97(7): 1.041-1.048, 2002.

ANTONELLI, L. R. et al. Activated inflammatory T cells correlate with lesion size in human cutaneous leishmaniasis. Immunology Letters, 101: 226-230, 2005.

ANTUNES, C. M. et al. Controlled field trials of a vaccine against New World cutaneous leishmaniasis. International Journal of Epidemiology, 15(4): 572-580, 1986.

ARMIJOS, R. X. et al. Field trial of a vaccine against new world cutaneous leishmaniasis in an at-risk child population: how long does protection last? The Journal of Infectious Diseases, 187: 1.959-1.961, 2003.

ARMIJOS, R. X. et al. Safety, immunogenecity, and efficacy of an autoclaved Leishmania amazonensis vaccine plus BCG adjuvant against New World cutaneous leishmaniasis. Vaccine, 22: 1.320-1.326, 2004.

BACELLAR, O. et al. Up-regulation of Th1-type responses in mucosal leishmaniasis patients. Infection and Immunity, 70(12): 6.734-6.740, 2002. 
BANGARI, D. S. \& MITTAL, S. K. Development of nonhuman adenoviruses as vaccine vectors. Vaccine, 24(7): 849-862, 2006.

BASU, R. et al. Kinetoplastid membrane protein-11 DNA vaccination induces complete protection against both pentavalent antimonial-sensitive and -resistant strains of Leishmania donovani that correlates with inducible nitric oxide synthase activity and IL-4 generation: evidence for mixed Th1- and Th2-like responses in visceral leishmaniasis. The Journal of Immunology, 174: 7.160-7.171, 2005.

BEN HADJ AHMED, S. et al. Differences in the salivary effects of wild-caught versus colonized Phlebotomus papatasi (Diptera: Psychodidae) on the development of zoonotic cutaneous leishmaniasis in BALB/c mice. Journal of Medical Entomology, 47(1): 74-79, 2010.

BEZERRA, H. S. \& TEIXEIRA, M. J. Effect of Lutzomyia whitmani (Diptera: Psychodidae) salivary gland lysates on Leishmania Viannia) braziliensis infection in BALB/cmice. Memórias do Instituto Oswaldo Cruz, 96: 349-351, 2001.

BIANCHI, M. E. DAMPs, PAMPs and alarmins: all we need to know about danger. Journal of Leukocyte Biology, 81: 1-5, 2007.

BLANDER, J. M. \& MEDZHITOV, R. Toll-dependent selection of microbial antigens for presentation by dendritic cells. Nature, 440: 808-812, 2006.

BOJANG, K. A. et al. Efficacy of RTS,S/ ASO2A vaccine against Plasmodium falciparum infection and disease in young African children: a randomized controlled trial. The Lancet, 364: 1.411-1.420, 2004.

BONALDO, M. C. et al. Surface expression of an immunodominant malaria protein B cell epitope by yellow fever virus. Journal of Molecular Biology, 315: 873-885, 2002.

BONALDO, M. C. et al. Construction and characterization of recombinant flaviviruses bearing insertions between E and NS1 genes. Virology Journal, 4: 115, 2007.

BORJA-CABRERA, G. P. et al. Long lasting protection against canine kala-azar using the FML-QuilA saponin vaccine in an endemic area of Brazil (São Gonçalo do Amarante, RN). Vaccine, 20: 3.277-3.284, 2002.

BORJA-CABRERA, G. P. et al. Effective immunotherapy against canine visceral leishmaniasis with the FML-vaccine. Vaccine, 22: 2.234-2.243, 2004.

BRAY, M. \& LAI, C. J. Construction of intertypic chimeric dengue viruses by substitution of structural protein genes. Proceedings of the National Academy of Sciences of the USA, 88: 10.342-10.346, 1991.

CABRERA, G. P. et al. The fucose-mannose ligand-ELISA in the diagnosis and prognosis of canine visceral leishmaniasis in Brazil. The American Journal of Tropical Medicine and Hygiene, 61: 296-301, 1999.

CABRERA, M. et al. Immunotherapy with live BCG plus heat killed Leishmania induces a T helper 1-like response in American cutaneous leishmaniasis patients. Parasite Immunology, 22: 73-79, 2000.

CALDAS, A. et al. Balance of IL-10 and interferon-gamma plasma levels in human visceral leishmaniasis: implications in the pathogenesis. BMC Infectious Diseases, 5: 113, 2005.

CAMPBELL, K. et al. DNA immunization with the gene encoding P4 nuclease of Leishmania amazonensis protects mice against cutaneous Leishmaniasis. Infection and Immunity, 71: 6.270-6.278, 2003.

CAMPOS-NETO, A. et al. Protection against cutaneous leishmaniasis induced by recombinant antigens in murine and nonhuman primate models of the human disease. Infection and Immunity, 69: 4.103-4.108, 2001.

CAMPOS-NETO, A. et al. Vaccination with plasmid DNA encoding TSA/LmSTI1 leishmanial fusion proteins confers protection against Leishmania major infection in susceptible BALB/c mice. Infection and Immunity, 70: 2.828-2.836, 2002.

CARDOSO, S. R. et al. Identification and purification of immunogenic proteins from nonliving promastigote polyvalent Leishmania vaccine (Leishvacin (B). Revista da Sociedade Brasileira de Medicina Tropical, 36(2): 193-199, 2003.

CARRILLO, E. et al. Immunogenicity of the P-8 amastigote antigen in the experimental model of canine visceral leishmaniasis. Vaccine, 25: 1.534-1.543, 2007. 
CARSON, C. et al. A prime/boost DNA/Modified vaccinia virus Ankara vaccine expressing recombinant Leishmania DNA encoding TRYP is safe and immunogenic in outbred dogs, the reservoir of zoonotic visceral leishmaniasis. Vaccine, 27(7): 1.080-1.086, 2009.

CARVALHO, L. P. et al. Characterization of the immune response to Leishmania infantum recombinant antigens. Microbes and Infection, 5: 7-12, 2003.

CARVALHO, L. P. et al. Effect of LACK and KMP11 on IFN-gamma production by peripheral blood mononuclear cells from cutaneous and mucosal leishmaniasis patients. Scandinavian Journal of Immunology, 61: 337-342, 2005.

CASTES, M. et al. Cell-mediated immunity in localized cutaneous leishmaniasis patients before and after treatment with immunotherapy or chemotherapy. Parasite Immunology, 11: 211-222, 1989.

CHAMBERS, T. J. et al. Yellow fever/Japanese encephalitis chimeric viruses: construction and biological properties. Journal of Virology, 73: 3.095-3101, 1999.

CHEN, G.; DARRAH, P. A. \& MOSSER, D. M. Vaccination against the intracellular pathogens Leishmania major and $L$. amazonensis by directing CD40 ligand to macrophages. Infection and Immunity, 69(5): 3.255-3.263, 2001.

CHIRMULE, N. et al. Immune responses to adenovirus and adeno-associated virus in humans. Current Gene Therapy, 6: 1.574-1.583, 1999.

CO, M. D. et al. Human cytotoxic T lymphocyte responses to live attenuated 17D yellow fever vaccine: identification of HLA-B35-restricted CTL epitopes on nonstructural proteins NS1, NS2b, NK3 and the structural protein E. Virology, 293: $151-163,2002$

COLER, R. N. et al. Immunization with a polyprotein vaccine consisting of the T-Cell antigens thiol-specific antioxidant, Leishmania major stress-inducible protein 1, and Leishmania elongation initiation factor protects against leishmaniasis. Infection and Immunity, 70: 4.215-4.225, 2002.

COLLIN, N. et al. Sand fly salivary proteins induce strong cellular immunity in a natural reservoir of visceral leishmaniasis with adverse consequences for Leishmania. PLoS Pathogens, 5(5), 2009.

CONNELL, N. D. et al. Effective immunization against cutaneous leishmaniasis with recombinant bacille Calmette-Guérin expressing the Leishmania surface proteinase gp63. Proceedings of the National Academy of Sciences of the USA, 90: 11.473-11.477, 1993.

CONVIT, J. et al. Immunotherapy of american cutaneous leishmaniasis in Venezuela during the period 1990-99. Transactions of the Royal Society of Tropical Medicine and Hygiene, 97: 469-472, 2003.

CONVIT, J. et al. Therapy of Venezuelan patients with severe mucocutaneous or early lesions of diffuse cutaneous leishmaniasis with a vaccine containing pasteurized Leishmania promastigotes and bacillus Calmette-Guerin: preliminary report. Memórias do Instituto Oswaldo Cruz, 99: 57-62, 2004.

COSTA, D. J. et al.Lutzomyia longipalpis salivary gland homogenate impairs cytokine production and costimulatory molecule expression on human monocytes and dendritic cells. Infection and Immunity, 72(3): 1.298-1.305, 2004.

COUTINHO, S. G. et al. T-cell responsiveness of American cutaneous leishmaniasis patients to purified Leishmania pifanoi amastigote antigens and Leishmania braziliensis promastigote antigens: immunologic patterns associated with cure. Experimental Parasitology, 84: 144-155, 1996.

DA-CRUZ, A. M. et al. Atypical mucocutaneous leishmaniasis caused by Leishmania braziliensis in an acquired immunodeficiency syndrome patient: T-cell responses and remission of lesions associated with antigen immunotherapy. Memórias do Instituto Oswaldo Cruz, 94: 537-542, 1999.

DANTHINNE, X. \& IMPERIALE, M. J. Production of first generationade novirus vectors: a review. Current Gene Therapy, 7 (20): $1.707-1.714,2000$.

DARRAH, P. A. et al. Multifunctional TH1 cells define a correlate of vaccine-mediated protection against Leishmania major. Nature Medicine, 13(7): 843-850, 2007. 
DE LUCA, P. M. et al. Evaluation of the stability and immunogenicity of autoclaved and nonautoclaved preparations of a vaccine against American tegumentary leishmaniasis. Vaccine, 17: 1.179-1.185, 1999.

DE LUCA, P. M. et al. A randomized double-blind placebo-controlled trial to evaluate the immunogenicity of a candidate vaccine against American tegumentary leishmaniasis. Acta Tropica, 80(3): 251-260, 2001.

DONDJI, B. et al. Heterologous prime-boost vaccination with the LACK antigen protects against murine visceral leishmaniasis. Infection and Immunity, 73(8): 5.286-5.289, 2005.

DUMONTEIL, E. et al. Comparative study of DNA vaccine encoding various antigens against Leishmania mexicana. Developments in Biologicals (Basel), 104: 135-141, 2000.

DUMONTEIL, E. et al. DNA vaccines induce partial protection against Leishmania mexicana. Vaccine, 21: 2.161-2.168, 2003.

FEDELI, C. E. et al. Partial protective responses induced by a recombinant cysteine proteinase from Leishmania (Leishmania) amazonensis in a murine model of cutaneous leishmaniasis. Experimental Parasitology, 124: 153-158, 2010.

FERNANDES, A. P. et al. Immune responses induced by a Leishmania (Leishmania) amazonensis recombinant antigen in mice and lymphocytes from vaccinated subjects. Revista do Instituto de Medicina Tropical de São Paulo, 39(2): 71-78, 1997.

FOULDS, K. E.; WU, C. Y. \& SEDER, R. A. Th1 memory: implications for vaccine development. Immunological Reviews, 211: $58-66,2006$.

GHALIB, H. \& MODABBER, F. Consultation meeting on the development of therapeutic vaccines for post kala azar dermal leishmaniasis. Kinetoplastid Biology and Disease, 6: 7, 2007.

GHALIB, H. W. et al. Interleukin 10 production correlates with pathology in human Leishmania donovani infections. The Journal of Clinical Investigation, 92: 324-329, 1993.

GHEORGHIU, M. et al. Mycobacterium bovis BCG priming induces a strong potentiation of the antibody response induces by recombinant BCG expressing a foreign antigen. Infection and Immunity, 62: 4.287-4.295, 1994.

GIUNCHETTI, R. C. et al. Antigenicity of a whole parasite vaccine as promising candidate against canine leishmaniasis. Research in Veterinary Science, 85(1): 106-112, 2008.

GOMES, D. C. et al. Intranasal delivery of naked DNA encoding the LACK antigen leads to protective immunity against visceral leishmaniasis in mice. Vaccine, 25(12): 2.168-2.172, 2007.

GOMES, R. et al. Immunity to a salivary protein of a sand fly vector protects against the fatal outcome of visceral leishmaniasis in a hamster model. Proceedings of the National Academy of Sciences of the USA, 3(105): 7.845-7.850, 2008.

GÓMEZ, C. E. et al. The poxvirus vectors MVA and NYVAC as gene delivery systems for vaccination against infectious diseases and cancer. Current Gene Therapy, 8: 97-120, 2008.

GONZÁLEZ, C. R. et al. Immunogenicity of a Salmonella typhi CVD 908 candidate vaccine strain expressing the major surface protein gp63 of Leishmania mexicana. Vaccine, 16: 1.043-1.052, 1998.

GONZALO, R. M. et al. A heterologous prime-boost regime using DNA and recombinant vaccinia virus expressing the Leishmania infantum P36/LACK antigen protects BALB/c mice from cutaneous leishmaniasis. Vaccine, 20: 1.226-1.231, 2002.

GRIMALDI JR., G. The utility of rhesus monkey (Macaca mulatta) and other non-human primate models for preclinical testing of Leishmania candidate vaccines - a review. Memórias do Instituto Oswaldo Cruz, 103(7): 629-644, 2008.

GRIMALDI JR., G. \& TESH, R. Leishmaniases of the New World: current concepts and implications for future research. Clinical Microbiology Reviews, 6: 230-250, 1993.

GUIRAKHOO, F. et al. Live attenuated chimeric yellow fever dengue type 2 (ChimeriVax-DEN2) vaccine: Phase I clinical trial for safety and immunogenicity: effect of yellow fever pre-immunity in induction of cross neutralizing antibody responses to all 4 dengue serotypes. Human Vaccines, 2(2): 60-67, 2006.

GURUNATHAN, S. et al. Vaccination with DNA encoding the immunodominant LACK parasite antigen confers protective immunity to mice infected with Leishmania major. The Journal of Experimental Medicine, 186: 1.137-1.147, 1997. 
GURUNATHAN, S. et al. Vaccine requirements for sustained cellular immunity to an intracellular parasitic infection. Nature Medicine, 4: 1.409-1.415, 1998.

GUY, B. The perfect mix: recent progress in adjuvant research. Nature Reviews. Microbiology, 5(7): 505-517, 2007.

GUY, B. et al. Cell-mediated immunity induced by chimeric tetravalent dengue vaccine in naive or flavivirus-primed subjects. Vaccine, 26(45): 5.712-5.721, 2008.

HABERER, J. E. et al. Leishmania pifanoi amastigote antigen P-4: epitopes involved in T-cell responsiveness in human cutaneous leishmaniasis. Infection and Immunity, 66: 3.100-3.105, 1998.

HANDMAN, E.; BUTTON, L. L. \& MCMASTER, R. W. Leishmania major: production of recombinant gp63, its antigenicity and immunogenicity in mice. Experimental Parasitology, 70: 427-435, 1990.

HAYASHI, N. et al. Antigen challenge leads to in vivo activation and elimination of highly polarized TH1 memory T cells. Proceedings of the National Academy of Sciences of the USA, 99: 6.187-6.191, 2002.

HOLADAY, B. J. et al. Potential role for interleukin-10 in the immunosuppression associated with kala azar. The Journal of Clinical Investigation, 92: 2.626-2.632, 1993.

IWASAKI, A. \& MEDZHITOV, R. Toll-like receptor control of the adaptive immune responses. Nature Immunology, 5: 987995, 2004.

JAFFE, C. L.; RACHAMIM, N. \& SARFSTEIN, R. Characterization of two proteins from Leishmania donovani and their use for vaccination against visceral leishmaniasis. The Journal of Immunology, 144: 699-706, 1990.

JULIA, V. \& GLAICHENHAUS, N. CD4(+) T cells which react to the Leishmania major LACK antigen rapidly secrete interleukin-4 and are detrimental to the host in resistant B10.D2 mice. Infection and Immunity, 67: 3.641-3.644, 1999.

KAMHAWI, S. et al. Protection against cutaneous leishmaniasis resulting from bites of uninfected sandflies. Science, 17(290): 1.351-1.354, 2000.

KAR, S.; METZ, C. \& MCMAHON-PRATT, D. CD4 + T cells play a dominant role in protection against New World leishmaniasis induced by vaccination with the P-4 amastigote antigen. Infection and Immunity, 73: 3.823-3.827, 2005.

KAR, S. et al. The immunologically protective P-4 antigen of Leishmania amastigotes. A developmentally regulated single strand-specific nuclease associated with the endoplasmic reticulum. Journal of Chemical Biology, 275: 37.789-37.797, 2000.

KEDZIERSKI, L.;ZZHU, Y. \&_HANDMAN, E. Leishmania vaccines: progress and problems. Parasitology, 133, supl: S87-S112, 2006.

KELLEHER, M. et al. Lipophosphoglycan blocks attachment of Leishmania major amastigotes to macrophages. Infection and Immunity, 63: 43-50, 1995.

KEMP, M. et al. Activation of human T lymphocytes by Leishmania lipophosphoglycan. Scand The Journal of Immunology, 33: 219-224, 1991.

KHALIL, E. A. et al. Autoclaved Leishmania major vaccine for prevention of visceral leishmaniasis: a randomised, doubleblind, BCG-controlled trial in Sudan. The Lancet, 4(356): 1.565-1.569, 2000.

KHAMESIPOUR, A. et al. Leishmanization: use of an old method for evaluation of candidate vaccines against leishmaniasis. Vaccine, 23: 3.642-3.648, 2005.

KHAMESIPOUR, A. et al._Leishmaniasis vaccine candidates for development: a global overview. Indian Journal of Medical Research, 123: 423-438, 2006.

KHOSHGOO, N. et al. Cysteine proteinase type III is protective against Leishmania infantum infection in BALB/c mice and highly antigenic in visceral leishmaniasis individuals. Vaccine, 26: 5.822-5.829, 2008.

KURTZHALS, J. A. et al. Dichotomy of the human T cell response to Leishmania antigens. II. Absent or Th2-like response to gp63 and Th1-like response to lipophosphoglycan-associated protein in cells from cured visceral leishmaniasis patients. Clinical and Experimental Immunology, 96: 416-421, 1994. 
LAGRANDERIE, M. et al. Oral immunization with recombinant BCG induces cellular and humoral immune responses against the foreign antigen. Vaccine, 11: 1.283-1.290, 1993.

LAHIRI, A.; DAS, P. \& CHAKRAVORTTY, D. Engagement of TLR signaling as adjuvant: towards smarter vaccine and beyond. Vaccine, 26: 6.777-6.783, 2008.

LAI, C. J. \& MONATH, T. P. Chimeric flaviviruses: novel vaccines against dengue fever, tick-borne encephalitis, and Japanese encephalitis. Advances in Virus Research, 61: 469-509, 2003.

LAINSON, R. \& BRAY, R. S. Studies on the immunology and serology of leishmaniasis. II. Cross-immunity experiments among different forms of American cutaneous leishmaniasis in monkeys. Transactions of the Royal Society of Tropical Medicine and Hygiene, 60(4): 526-532, 1966.

LAINSON, R. \& SHAW, J. J. Leishmaniasis in Brazil: XII. Observations on cross-immunity in monkeys and man infected with Leishmania mexicana mexicana, L. m. amazonensis, L. braziliensis braziliensis, L. b. guyanensis and L. b. panamensis. The Journal of Tropical Medicine and Hygiene, 80(2): 29-35, 1977.

LANFRANCO, M. F. et al. Expression and substrate specificity of a recombinant cysteine proteinase B of Leishmania braziliensis. Molecular and Biochemical Parasitology, 161: 91-100, 2008.

LANGE, U. G. et al. DNA-Salmonella enterica serovar Typhimurium primer-booster vaccination biases towards Thelper 1 responses and enhances protection against Leishmania major infection in mice. Infection and Immunity, 72: 4.9244.928, 2004.

LAUNOIS, P. et al. IL-4 rapidly produced by V beta $4 \mathrm{~V}$ alpha $8 \mathrm{CD} 4+\mathrm{T}$ cells instructs Th2 development and susceptibility to Leishmania major in BALB/c mice. Immunity, 6: 541-549, 1997.

LAURENTI, M. D. et al. Effects of salivary gland homogenate from wild-caught and laboratory-reared Lutzomyia longipalpis on the evolution and immunomodulation of Leishmania (Leishmania) amazonensis infection. Scandinavian Journal of Immunology, 70(4): 389-395, 2009.

LEFEUVRE, A.; MARIANNEAU, P. \& DEUBEL, P. Current assessment of yellow fever and yellow fever vaccine. Current Infectious Disease Reports, 6: 96-104, 2004.

MACHADO-PINTO, J. et al. Immunochemotherapy for cutaneous leishmaniasis: a controlled trial using killed Leishmania (Leishmania) amazonensis vaccine plus antimonial. International Journal of Dermatology, 41: 73-78, 2002.

MACKETT, M. \& SMITH, G. L. Vaccinia virus expression vectors. The Journal of General Virology, 67(10): 2.067-2.082, 1986.

MACKETT, M.; SMITH, G. L. \& MOSS, B. Vaccinia virus: a selectable eukaryotic cloning and expression vector. Proceedings of the National Academy of Sciences of the USA, 79(23): 7.415-7.419, 1982.

MARQUES-DA-CUNHA, A. Infecções experimentais na leishmaniose tegumentar americana. Memórias do Instituto Oswaldo Cruz, 41: 263-282, 1944.

MARQUES-DA-SILVA, E. A. et al. Intramuscular immunization with p36(LACK) DNA vaccine induces IFN-gamma production but does not protect BALB/c mice against Leishmania chagasi intravenous challenge. Parasitology Research, 98: 67-74, 2005.

MARZOCHI, K. B. et al. Phase 1 study of an inactivated vaccine against American tegumentary leishmaniasis in normal volunteers in Brazil. Memórias do Instituto Oswaldo Cruz, 93: 205-212, 1998.

MAYRINK, W. et al. A field trial of a vaccine against American dermal leishmaniasis. Transactions of the Royal Society of Tropical Medicine and Hygiene, 73(4): 385-387, 1979.

MAYRINK, W. et al. An experimental vaccine against American dermal leishmaniasis: experience in the State of Espírito Santo, Brazil. Annals of Tropical Medicine and Parasitology, 79(3): 259-269, 1985.

MAYRINK, W. et al. Immunoterapy as treatment of American cutaneous leishmaniasis: preliminary studies in Brazil. Parasitologia, 34: 159-165, 1992.

MAYRINK, W. et al. Phase I and II open clinical trials of a vaccine against Leishmania chagasi infections in dogs. Memórias do Instituto Oswaldo Cruz, 91: 695-697, 1996. 
MAYRINK, W. et al. Immunotherapy, immunochemotherapy and chemotherapy for American cutaneous leishmaniasis treatment. Revista da Sociedade Brasileira de Medicina Tropical, 39: 14-21, 2006.

McCONVILLE, M. J. \& BLACKWELL, J. M. Developmental changes in the glycosylated phosphatidylinositols of Leishmania donovani. Characterization of the promastigote and amastigote glycolipids. Journal of Chemical Biology, 266: 15.17015.179, 1991.

MCMAHON-PRATT, D. \& ALEXANDER, J. Does the Leishmania major paradigm of pathogenesis and protection hold for New World cutaneous leishmaniases or the visceral disease? Immunological Reviews, 201: 206-224, 2004.

MCMAHON-PRATT, D. et al. Recombinant vaccinia viruses expressing GP-46/M-2 protect against Leishmania infection. Infection and Immunity, 61: 3.351-3.359, 1993.

McSORLEY, S. J.; XU, D. \& LIEW, F. Y. Vaccine efficacy of Salmonella strains expressing glycoprotein 63 with different promoters. Infection and Immunity, 65: 171-178, 1997.

MEDZHITOV, R.; PRESTON-HURLBURT, P. \& JANEWAY JR., C. A. A human homologue of the Drosophila Toll protein signals activation of adaptive immunity. Nature, 388: 394-397, 1997.

MELBY, P. C. et al. Leishmania donovani p36(LACK) DNA vaccine is highly immunogenic but not protective against experimental visceral leishmaniasis. Infection and Immunity, 69: 4.719-4.725, 2001.

MÉNDEZ, S. et al. The potency and durability of DNA- and protein-based vaccines against Leishmania major evaluated using low-dose, intradermal challenge. The Journal of Immunology, 166: 5.122-5.128, 2001.

MENDONÇA, S. C. F.; RUSSELL, D. G. \& COUTINHO, S. G. Analysis of the human T cell responsiveness to purified antigens of Leishmania: lipofosfoglycan (LPG) and glycoprotein 63 (gp63). Clinical and Experimental Immunology, 83: 472-478, 1991.

MENDONÇA, S. C. et al. Characterization of human T lymphocyte-mediated immune responses induced by a vaccine against American tegumentary leishmaniasis. The American Journal of Tropical Medicine and Hygiene, 53(2): 195-201, 1995.

MODABBER, F. Vaccines against leishmaniasis. Annals of Tropical Medicine and Parasitology, 89, supl. 1: 83-88, 1995.

MOHEBALI, M. et al. Double-blind randomized efficacy field trial of alum precipitated autoclaved Leishmania major vaccine mixed with BCG against canine visceral leishmaniasis in Meshkin-Shahr district, I.R. Iran. Vaccine, 22: 4.097-4.100, 2004.

MOMENI, A. Z. et al. A randomised, double-blind, controlled trial of a killed L. major vaccine plus BCG against zoonotic cutaneous leishmaniasis in Iran. Vaccine, 5(17): 466-472, 1999.

MOODY, S. F. et al. The structure of Leishmania major amastigote lipophosphoglycan. Journal of Chemical Biology, 268: 18.457-18.466, 1993.

MORRIS, R. V. et al. Sandfly maxadilan exacerbates infection with Leishmania major and vaccinating against it protects against $L$. major infection. The Journal of Immunology, 167: 5.226-5.230, 2001.

MOSS, B. Vaccinia virus: a tool for research and vaccine development. Science, 252: 1.662-1.667, 1991.

MOUGNEAU, E. et al. Expression cloning of a protective Leishmania antigen. Science, 268: 563-566, 1995.

MOURA, T. R. et al. Enhanced Leishmania braziliensis infection following pre-exposure to sandfly saliva. PLoS Neglected Tropical Diseases, 1: e84, 2007.

MUELLER, A. K. et al. 2004. Genetically modified Plasmodium parasites as a protective experimental malaria vaccine. Nature, 433(7.022): 164-167, 2005.

NADIM, A. et al. Effectiveness of leishmanization in the control of cutaneous leishmaniasis. Bulletin de la Société de Pathologie Exotique et de ses Filiales, 76(4): 377-383, 1983.

NANDA, A. et al. Immunogenicity of recombinant fiber-chimeric adenovirus serotype 35 vector-based vaccines in mice and rhesus monkeys. Journal of Virology, 79(22): 14.161-14.168, 2005.

NASCIMENTO, E. et al. Vaccination of humans against cutaneous leishmaniasis: cellular and humoral immune responses. Infection and Immunity, 58(7): 2.198-2.203, 1990 
NOAZIN, S. et al. First generation leishmaniasis vaccines: a review of field efficacy trials. Vaccine, 9(26): 6.759-6.767, 2008.

NOGUEIRA, F. S. et al. Leishmune vaccine blocks the transmission of canine visceral leishmaniasis: absence of Leishmania parasites in blood, skin and lymph nodes of vaccinated exposed dogs. Vaccine, 23: 4.805-4.810, 2005.

NORSWORTHY, N. B. et al. Sand fly saliva enhances Leishmania amazonensis infection by modulating interleukin-10 production. Infection and Immunity, 72: 1.240-1.247, 2004.

NYLÉN, S. et al. Splenic accumulation of IL-10 mRNA in T cells distinct from $\mathrm{CD}_{4}^{+} \mathrm{CD} 25^{+}$(Foxp3) regulatory T cells in human visceral leishmaniasis. The Journal of Experimental Medicine, 204: 805-817, 2007.

OLIVEIRA, F. et al. Immunity to distinct sand fly salivary proteins primes the anti-Leishmania immune response towards protection or exacerbation of disease. PLoS Neglected Tropical Diseases, 2(4): e226, 2008.

OLOBO, J. O. et al. Vaccination of vervet monkeys against cutaneous leishmaniosis using recombinant Leishmania 'major surface glycoprotein' (gp63). Veterinary Parasitology, 60: 199-212, 1995.

PALATNIK-DE-SOUSA, C. B. et al. Leishmania donovani: titration of antibodies to the fucose-mannose ligand as an aid in diagnosis and prognosis of visceral leishmaniasis. Transactions of the Royal Society of Tropical Medicine and Hygiene, 89: 390-393, 1995.

PALATNIK-DE-SOUSA, C. B. et al. FML vaccine against canine visceral leishmaniasis: from second-generation to synthetic vaccine. Expert Review of Vaccines, 7: 833-851, 2008.

PANICALI, D. \& PAOLETTI, E. Construction of poxviruses as cloning vectors: insertion of the thymidine kinase gene from herpes simplex virus into the DNA of infectious vaccinia virus. Proceedings of the National Academy of Sciences of the USA, 79(16): 4.927-4.931, 1982.

PARRA, L. E. et al. Safety trial using the Leishmune vaccine against canine visceral leishmaniasis in Brazil. Vaccine, 25: 2.180-2.186, 2007.

PASTORET, P. P. \& VANDERPLASSCHEN, A. Poxviruses as vaccine vectors. Comparative Immunology, Microbiology and Infectious Diseases, 26(5-6): 343-355, 2003.

PATTERSON, L. et al. Live adenovirus recombinants as vaccine vectors. In: LEVINE, M. et al. (Eds.). New Generation Vaccines. 3. ed. New York: Marcel Dekker, 2004.

PÉREZ-JIMÉNEZ, E. et al. MVA-LACK as a safe and efficient vector for vaccination against leishmaniasis. Microbes and Infection, 8(3): 810-822, 2006.

PESSOA, S. B. \& PESTANA, B. R. Ensaio sobre vacinação preventiva na leishmaniose tegumentar americana com germes mortos. Arquivos de Higiene e Saúde Pública, 6:141-147, 1941.

PINTO, E. F. et al. Intranasal vaccination against cutaneous leishmaniasis with a particulated leishmanial antigen or DNA encoding LACK. Infection and Immunity, 72: 4.521-4.527, 2004.

PORROZZI, R. et al. Cross-immunity experiments between different species or strains of Leishmania in rhesus macaques (Macaca mulatta). The American Journal of Tropical Medicine and Hygiene, 71(3): 297-305, 2004.

PORROZZI, R. et al. Leishmania infantum induced primary and challenge infections in rhesus monkeys (Macaca mulatta): a primate model for visceral leishmaniasis. Transactions of the Royal Society of Tropical Medicine and Hygiene, 100(10): 926-937, 2006.

PROBST, P. et al. A Leishmania protein that modulates interleukin (IL)-12, IL-10 and tumor necrosis factor-alpha production and expression of B7-1 in human monocyte-derived antigen-presenting cells. European Journal of Immunology, 27: 2.634-2.642, 1997.

RAFATI, S. et al. A protective cocktail vaccine against murine cutaneous leishmaniasis with DNA encoding cysteine proteinases of Leishmania major. Vaccine, 19: 3.369-3.375, 2001.

RAFATI, S. et al. Expression of cysteine proteinase type I and II of Leishmania infantum and their recognition by sera during canine and human visceral leishmaniasis. Experimental Parasitology, 103: 143-151, 2003. 
RAFATI, S. et al. Identification of Leishmania major cysteine proteinases as targets of the immune response in humans. Molecular and Biochemical Parasitology, 113: 35-43, 2001.

RAFATI, S. et al. Recombinant cysteine proteinases-based vaccines against Leishmania major in BALB/C mice: the partial protection relies on interferon gamma producing $\mathrm{CD} 8(+)$ T lymphocyte activation. Vaccine, 20: 2.439-2.447, 2002.

RAFATI, S. et al. Protective vaccination against experimental canine visceral leishmaniasis using a combination of DNA and protein immunization with cysteine proteinases type I and II of L. infantum. Vaccine, 23: 3.716-3.725, 2005.

RAFATI, S. et al. Leishmania infantum: prime boost vaccination with C-terminal extension of cysteine proteinase type I displays both type 1 and 2 immune signatures in BALB/c mice. Experimental Parasitology, 118: 393-401, 2008.

RAFATI, S.; ZAHEDIFARD, F. \& NAZGOUEE, F. Prime-boost vaccination using cysteine proteinases type I and II of Leishmania infantum confers protective immunity in murine visceral leishmaniasis. Vaccine, 24: 2.169-2.175, 2006.

RAMIRO, M. J. et al. Protection in dogs against visceral leishmaniasis caused by Leishmania infantum is achieved by immunization with a heterologous prime-boost regime using DNA and vaccinia recombinant vectors expressing LACK. vaccine, 21: 2.474-2.484, 2003.

RAMOS, I. et al. Antibiotic resistance free plasmid DNA expressing LACK protein leads towards a protective Th1 response against Leishmania infantum infection. Vaccine, 27: 6.695-6.703, 2009.

RAMOS, I. et al. Heterologous prime-boost vaccination with a non-replicative vaccinia recombinant vector expressing LACK confers protection against canine visceral leishmaniasis with a predominant Th1-specific immune response. Vaccine, 26(3): 333-344, 2008.

REBELLO, K. M. et al. Cysteine proteinases from promastigotes of Leishmania (Viannia) braziliensis. Parasitology Research, 106: 95-104, 2009.

REINHARDT, B. et al. Development of viremia and humoral and cellular parameters of immune activation after vaccination with yellow fever virus strain 17D: a model of human flavivirus infection. Journal of Medical Virology, 56: 159-167, 1998.

RESENDE, D. M. et al. Epitope mapping and protective immunity elicited by adenovirus expressing the Leishmania amastigote specific A2 antigen: correlation with IFN-gamma and cytolytic activity by CD8 + T cells. Vaccine, 26(35): 4.585-4.593, 2008.

RHEE, E. G. et al. Vaccination with heat-killed Leishmania antigen or recombinant leishmanial protein and CpG oligodeoxynucleotides induces long-term memory $\mathrm{CD} 4+$ and $\mathrm{CD} 8+\mathrm{T}$ cell responses and protection against Leishmania major infection. The Journal of Experimental Medicine, 195: 1.565-1.573, 2002.

RIVIER, D. et al. Vaccination against Leishmania major in a CBA mouse model of infection: role of adjuvants and mechanism of protection. Parasite Immunology, 21: 461-473, 1999.

ROBERTS, D. M. et al. Hexon-chimaeric adenovirus serotype 5 vectors circumvent pre-existing anti-vector immunity. Nature, 441(7.090): 239-243, 2006.

RODRÍGUEZ-CORTÉS, A. et al. Vaccination with plasmid DNA encoding KMPII, TRYP, LACK and GP63 does not protect dogs against Leishmania infantum experimental challenge. Vaccine, 25: 7.962-7.971, 2007.

ROGERS, K. A. \& TITUS, R. G. Immunomodulatory effects of Maxadilan and Phlebotomus papatasi sand fly salivary gland lysates on human primary in vitro immune responses. Parasite Immunology, 25(3): 127-134, 2003.

RUSSELL, D. G. \& ALEXANDER, J. Effective immunization against cutaneous leishmaniasis with defined membrane antigens reconstituted into liposomes. The Journal of Immunology, 140: 1.274-1.279, 1988.

RUSSELL, D. G. \& WRIGHT, S. D. Complement receptor type 3 (CR3) binds to an Arg-Gly-Asp-containing region of the major surface glycoprotein, gp63, of Leishmania promastigotes. The Journal of Experimental Medicine, 168: 279-292, 1988.

RUSSO, D. M. et al. Human T cell responses to gp63, a surface antigen of Leishmania. The Journal of Immunology, 147: 3.575-3.580, 1991.

SACKS, D. \& ANDERSON, C. Re-examination of the immunosuppressive mechanisms mediating non-cure of Leishmania infection in mice. Immunological Reviews, 201: 225-238, 2004. 
SACKS, D. L. et al. The role of the lipophosphoglycan of Leishmania in vector competence. Parasitology, 108, supl.: S55-S62, 1994.

SALAY, G. et al. Testing of four Leishmania vaccine candidates in a mouse model of infection with Leishmania (Viannia) braziliensis, the main causative agent of cutaneous leishmaniasis in the New World. Clinical and Vaccine Immunology, 14: 1.173-1.181, 2007.

SAMUELSON, J. et al. A mouse model of Leishmania braziliensis braziliensis infection produced by coinjection with sand fly saliva. The Journal of Experimental Medicine, 1(173): 49-54, 1991.

SANTOS, F. N. et al. Immunotherapy against experimental canine visceral leishmaniasis with the saponin enrichedLeishmune vaccine. Vaccine, 25: 6.176-6.190, 2007.

SARAIVA, E. M. et al. The FML-vaccine (Leishmune) against canine visceral leishmaniasis: a transmission blocking vaccine. Vaccine, 24: 2.423-2.431, 2006.

SCOTT, P. et al. The development of effector and memory T cells in cutaneous leishmaniasis: the implications for vaccine development. Immunological Reviews, 201: 318-338, 2004.

SCOTT, P. Immunologic memory in cutaneous leishmaniasis. Cellular Microbiology, 7: 1.707-1.713, 2005.

SEDER, R. A. \& AHMED, R. Similarities and differences in CD4+ and CD8 + effector and memory T cell generation. Nature Immunology, 4: 835-842, 2003.

SEDER, R. A. \& SACKS, D. L. Memory may not need reminding. Nature Medicine, 10: 1.045-1.047, 2004.

SEDER, R. A.; DARRAH, P. A. \& ROEDERER, M. T-cell quality in memory and protection: implications for vaccine design. Nature Reviews. Immunology, 8(4): 247-258, 2008.

SHARIFI, I. et al. Randomised vaccine trial of single dose of killed Leishmania major plus BCG against anthroponotic cutaneous leishmaniasis in Bam, Iran. The Lancet, 23(351): 1.540-1.543, 1998.

SILVA, V. O. et al. A phase III trial of efficacy of the FML-vaccine against canine kala-azar in an endemic area of Brazil (São Gonçalo do Amaranto, RN). Vaccine, 19: 1.082-1.092, 2000.

SILVEIRA, F. T. \& MAYRINK, W. Leishmaniose cutânea difusa no Estado do Pará, Brasil: registro do primeiro caso de cura da doença após associação de quimioterapia com imunoterapia. XXIX Congresso da Sociedade Brasileira de Medicina Tropical. Revista da Sociedade Brasileira de Medicina Tropical, 26, supl.: 229, 1993.

SILVEIRA, F. T. et al. T cell responses to crude and defined leishmanial antigens in patients from the lower Amazon region of Brazil infected with different species of Leishmania of the subgenera Leishmania and Viannia. Parasite Immunology, 20: 19-26, 1998.

SILVESTRE, R.; CORDEIRO-DA-SILVA, A. \& OUAISSI, A. Live attenuated Leishmania vaccines: a potential strategic alternative. Archivum Immunologiae et Therapiae Experimentalis (Warsz), 56: 123-126, 2008.

SKEIKY, Y. A. et al. A recombinant Leishmania antigen that stimulates human peripheral blood mononuclear cells to express a Th1-type cytokine profile and to produce interleukin 12. The Journal of Experimental Medicine, 181: 1.527-1.537, 1995.

SKEIKY, Y. A. et al. LeIF: a recombinant Leishmania protein that induces an IL-12-mediated Th1 cytokine profile. The Journal of Immunology, 161: 6.171-6.179, 1998.

SKEIKY, Y. A. et al. Protective efficacy of a tandemly linked, multi-subunit recombinant leishmanial vaccine (Leish-111f) formulated in MPL adjuvant. Vaccine, 20: 3.292-3.303, 2002.

SOONG, L. et al. Leishmania pifanoi amastigote antigens protect mice against cutaneous leishmaniasis. Infection and Immunity, 63: 3.559-3.566, 1995.

SOUZA-LEMOS, C. et al. Dynamics of immune granuloma formation in a Leishmania braziliensis - induced self-limiting cutaneous infection in the primate Macaca mulatta. The Journal of Pathology, 216(3): 375-386, 2008.

STOBER, C. B. et al. Heterologous priming-boosting with DNA and modified vaccinia virus Ankara expressing tryparedoxin peroxidase promotes long-term memory against Leishmania major in susceptible BALB/c Mice. Infection and Immunity, $75(2): 852-860,2007$. 
STREIT, J. A. et al. BCG expressing LCR1 of Leishmania chagasi induces protective immunity in susceptible mice. Experimental Parasitology, 94: 33-41, 2000.

TAO, D. et al. Yellow fever 17D as a vaccine vector for microbial CTL epitopes: protection in a rodent malaria model. The Journal of Experimental Medicine, 201: 201-209, 2005.

TELINO, E. et al. In vitro responses of human peripheral blood mononuclear cells to whole-cell, particulate and soluble extracts of Leishmania promastigotes. Clinical and Experimental Immunology, 143(2): 338-344, 2006.

TEVA, A. et al. Leishmania (Viannia) braziliensis induced chronic granulomatous cutaneous lesions affecting the nasal mucosa in the rhesus monkey (Macaca mulatta) model. Parasitology, 127(5): 437-447, 2003.

THORNER, A. R. et al. Immunogenicity of heterologous recombinant adenovirus prime-boost vaccine regimens is enhanced by circumventing vector cross-reactivity. Journal of Virology, 80(24): 12.009-12.016, 2006.

TITUS, R. G. \& RIBEIRO, J. M. Salivary gland lysates from the sand fly Lutzomyia longipalpis enhance Leishmania infectivity. Science, 11(239): 1.306-1.308, 1988.

TOLEDO, J. S. et al. Leishmania (Viannia) braziliensis transfectants overexpressing the miniexon gene lose virulence in vivo. Parasitology International, 58: 45-50, 2009.

TOLSON, D. L. et al. The kinetoplastid membrane protein 11 of Leishmania donovani and African trypanosomes is a potent stimulator of T-lymphocyte proliferation. Infection and Immunity, 62: 4.893-4.899, 1994.

TONUI, W. K. \& TITUS, R. G. Cross-protection against Leishmania donovani but not L. braziliensis caused by vaccination with L. major soluble promastigote exogenous antigens in BALB/c mice. The American Journal of Tropical Medicine and Hygiene, 76(3): 579-584, 2007.

TONUI, W. K. et al. Immunization with Leishmania major exogenous antigens protects susceptible BALB/c mice against challenge infection with L. major. Infection and Immunity, 72: 5.654-5.661, 2004.

TURCO, S. J. \& DESCOTEAUX, A. The lipophosphoglycan of Leishmania parasites. Annual Review of Microbiology, 46: 65-94, 1992.

VALENZUELA, J. G. et al. Toward a defined anti-Leishmania vaccine targeting vector antigens: characterization of a protective salivary protein. The Journal of Experimental Medicine, 194: 331-342, 2001.

VAN EPPS, H. L. Broadening the horizons for yellow fever: new uses for an old vaccine. The Journal of Experimental Medicine, 201(2): 165-168, 2005.

VÉLEZ, I. D. et al. Failure of a killed Leishmania amazonensis vaccine against American cutaneous leishmaniasis in Colombia. Transactions of the Royal Society of Tropical Medicine and Hygiene, 99: 593-598, 2005.

VÉLEZ, I. D. et al. Safety and immunogenicity of a defined vaccine for the prevention of cutaneous leishmaniasis. Vaccine, 28: 329-337, 2009.

VÉLEZ, I. D. et al. Safety and immunogenicity of a killed Leishmania (L.) amazonensis vaccine against cutaneous leishmaniasis in Colombia: a randomized controlled trial. Transactions of the Royal Society of Tropical Medicine and Hygiene, 94: 698-703, 2000.

WEBB, J. R. et al. Human and murine immune responses to a novel Leishmania major recombinant protein encoded by members of a multicopy gene family. Infection and Immunity, 66: 3.279-3.289, 1998.

WEBB, J. R. et al. Molecular cloning of a novel protein antigen of Leishmania major that elicits a potent immune response in experimental murine leishmaniasis. The Journal of Immunology, 157: 5.034-5.041, 1996.

WOLFRAM, M. et al. Antigen presentation by Leishmania mexicana infected macrophages: activation of helper T cells specific for amastigote cysteine proteinases requires intracellular killing of the parasites. European Journal of Immunology, 25: 1.094-1.100, 1995.

WU, C. Y. et al. Distinct lineages of TH1 cells have differential capacities for memory cell generation in vivo. Nature Immunology, 3: 852-858, 2002. 
XIN, K. Q. et al. Prime-boost vaccination with plasmid DNA and a chimeric adenovirus type 5 vector with type 35 fiber induces protective immunity against HIV. Current Gene Therapy, 12(24): 1.769-1.777, 2005.

XU, D. \& LIEW, F. Y. Protection against leishmaniasis by injection of DNA encoding a major surface glycoprotein, gp63, of $L$. major. Immunology, 84: 173-176, 1995.

XU, D. et al. Protection against Leishmania major infection in genetically susceptible BALB/c mice by gp63 delivered orally in attenuated Salmonella typhimurium (AroA- AroD-). Immunology, 85: 1-7, 1995.

YANG, D. M. et al. Oral Salmonella typhimurium (AroA-) vaccine expressing a major leishmanial surface protein (gp63) preferentially induces $\mathrm{T}$ helper 1 cells and protective immunity against leishmaniasis. The Journal of Immunology, 145: 2.281-2.285, 1990.

YAROVINSKY, F. et al. Toll-like receptor recognition regulates immunodominance in an antimicrobial CD4+ T cell response. Immunity, 25: 655-664, 2006.

ZAPH, C. et al. Central memory T cells mediate long-term immunity to Leishmania major in the absence of persistent parasites. Nature Medicine, 10(10): 1.104-1.110, 2004. 


\section{6 \\ Abordagens Genômicas, Transcriptômicas e Proteômicas Aplicadas ao Estudo de Leishmania spp.}

Marcelo Alves-Ferreira I Ana Carolina Ramos Guimarães

Patricia Cuervo I José Batista de Jesus

$\mathrm{O}$ desenvolvimento de tecnologias de alto desempenho a partir do fim do século XX, tais como o sequenciamento automático de DNA, análises por microarranjo e análise e identificação de proteínas (genômica, transcriptômica e proteômica) vem produzindo uma grande quantidade de dados, que por sua vez exige a aplicação de abordagens mais complexas para a análise da informação gerada. As tecnologias para a descoberta de novos genes, estudos de expressão e análise funcional foram aplicados a uma vasta gama de organismos, incluindo muitos parasitos humanos. Em muitos casos, os dados estão livremente disponíveis pela Internet em bases de dados especializadas, as quais são continuamente atualizadas mediante novos dados experimentais (Hertz-Fowler \& Hall, 2004). Com base no desenvolvimento dessas novas tecnologias de análise em larga escala, o conhecimento molecular das diferentes espécies de Leishmania teve um grande avanço. Dentro desse contexto, este capítulo revisa a produção de conhecimentos sobre esses protozoários patogênicos em três abordagens: genômica, transcriptômica e proteômica.

\section{GENÔMICA}

Durante os anos de 1993 e 1994, países desenvolvidos e em desenvolvimento, incluindo o Brasil, lideraram a formação de consórcios para iniciar uma série de projetos com o objetivo de mapear e sequenciar os genomas de diversos parasitos. Foi nessa época que se iniciou o programa de sequenciamento de três organismos da ordem Kinetoplastida: Leishmania major, Trypanosoma cruzi e Trypanosoma brucei. Com a publicação dos genomas desses parasitos, o projeto foi denominado Tritryps (Degrave et al., 2001; El-Sayed et al., 2005).

O gênero Leishmania foi representado nessa primeira iniciativa pela espécie L. major cepa Friedlin (Ivens et al., 2005). Após alguns anos, outras espécies desse gênero, como L. infantum, L. braziliensis e L. mexicana, também tiveram seus genomas decifrados. Uma das informações extraídas desses estudos revelou que espécies de Leishmania do Velho Mundo, tais como L. donovani e L. major, têm 36 pares de cromossomos, enquanto as espécies do Novo Mundo apresentam 34 ou 35 pares. No caso de L. mexicana o cromossomo 8 está fusionado com o 29 e o cromossoma 20 com o 36, enquanto em L. braziliensis o cromossomo 20 está fusionado com o 34. 


\section{Projeto genoma de Leishmania major cepa Friedlin}

O genoma de L. major (cepa Friedlin) foi o primeiro a ser sequenciado e serviu como modelo para análises genômicas posteriores. Observou-se que esse genoma tem 32.816 .678 pares de bases (pb) de tamanho (versão 5.2) e seu cariótipo é representado por 36 cromossomos, com uma única sequência contígua (contig) gerada para cada cromossomo. 0 conteúdo total de $\mathrm{G}+\mathrm{C}$ é de $59,7 \%$ e o percentual de sequências codificadoras é de 47,9\%, como resumido na Tabela 1. Os dados de sequência foram obtidos por meio de diferentes abordagens experimentais realizadas em paralelo, como sequenciamento de cosmídeos, shotgun e/ou sequenciamento e montagem de clones BAC (Bacterial Artificial Chromosomes) (Degrave et al., 2001).

Tabela 1 - Características do genoma de L. major

\begin{tabular}{l|c}
\hline Parâmetro & Número \\
\hline Tamanho $(\mathrm{pb})$ & 32.816 .678 \\
\hline Conteúdo G+C (\%) & 59,7 \\
\hline Cromossomos & 36 \\
\hline Sequências contíguas & 36 \\
\hline Percentual codificador & 47,9 \\
\hline
\end{tabular}

Fonte: adaptado de lvens et al., 2005.

Análises computacionais identificaram 911 genes de RNA, 39 pseudogenes e 8.272 genes codificadores de proteínas, dos quais 36\% têm uma função atribuída (Tabela 2). A maioria dos genes de L. major contém ortólogos nos genomas de T. brucei e T. cruzi, sendo 74 grupos gênicos compartilhados exclusivamente com T. brucei, 482 grupos compartilhados com T. cruzi e 6.158 grupos gênicos compartilhados com os dois organismos. Apenas 910 dos genes identificados em L. major são específicos desse organismo (Figura 1 e Tabela 3). A maioria das proteínas espécieespecíficas faz parte de famílias de proteínas de antígenos de superfície e podem estar relacionadas com as diferentes estratégias de sobrevivência e escape do sistema imune do hospedeiro. Alguns genes específicos de Leishmania são responsáveis pelas principais diferenças metabólicas entre L. major e os outros Tritryps, como por exemplo, algumas peptidases, transportadores e componentes da biossíntese de glicoconjugados; porém, a maior parte dos genes ainda não teve uma função atribuída, sendo denominados como hipotéticos. Grande parte dos genes cuja função ainda não foi assinalada estaria, provavelmente, envolvida em processos únicos dos tripanossomatídeos. Genes altamente variáveis que escapam de uma inferência de função baseada em homologia, ou seja, similaridade com outros genes já anotados, também podem fazer parte dos genes sem função atribuída. Além disso, as estruturas das regiões teloméricas são heterogêneas e bastante distintas quando comparadas com as de T. brucei e T. cruzi (El-Sayed et al., 2005).

Tabela 2 - Características dos genes codificadores de proteínas no genoma de L. major

\begin{tabular}{l|c}
\hline Parâmetro & Número \\
\hline Genes & 8.298 \\
\hline Genes com função atribuída $(\%)$ & 36 \\
\hline Pseudogenes & 39 \\
\hline Média do tamanho das CDS $(\mathrm{pb})$ & 1.901 \\
\hline Conteúdo $\mathrm{G}+\mathrm{C}(\%)$ & 62,5 \\
\hline Média do tamanho da região intergênica* $(\mathrm{pb})$ & 2.045 \\
\hline Conteúdo $\mathrm{G}+\mathrm{C}$ da região intergênica* $(\%)$ & 57,3 \\
\hline
\end{tabular}

*A região intergênica compreende a região entre as sequências codificadoras de proteínas. Fonte: adaptado de lvens et al., 2005. 
Figura 1 - Diagrama de Venn representando os grupos gênicos compartilhados pelos Tritryps (LMA = L. major, TBR $=$ T. brucei e TCR $=T$. cruzi)

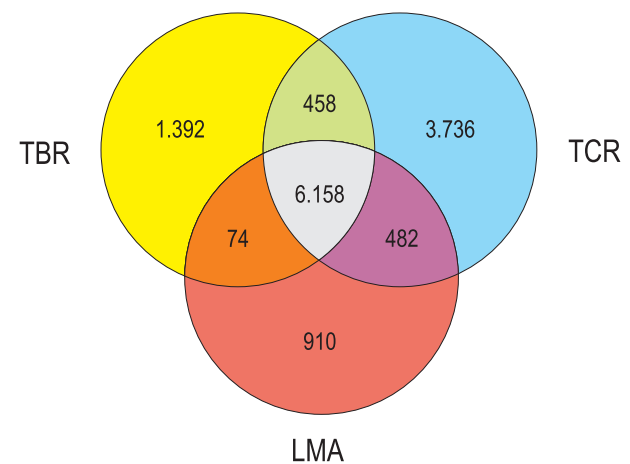

Fonte: adaptado de El-Sayed et al., 2005.

Tabela 3 - Comparação das características gerais dos genomas dos Tritryps

\begin{tabular}{|c|c|c|c|}
\hline Parâmetro & L. major & T. cruzi & T. brucei \\
\hline Tamanho do genoma haploide (Mpb) & $\sim 33$ & 55 & $25^{b}$ \\
\hline Número de cromossomos (por genoma haploide) & 36 & $\sim 28$ & $11^{\mathrm{b}}$ \\
\hline Número de cromossomos (por genoma haploide) & $8.311^{\mathrm{a}}$ & $\sim 12.000$ & $9.068^{c}$ \\
\hline Total de regiões com blocos de sintenia (Mpb) & 30,7 & $\mathrm{NI}$ & 19,9 \\
\hline \multicolumn{4}{|l|}{ a Incluindo 34 pseudogenes. } \\
\hline \multicolumn{4}{|l|}{${ }^{b}$ Aproximado. } \\
\hline \multicolumn{4}{|l|}{ 'Incluindo 904 pseudogenes. } \\
\hline Fonte: adaptado de El-Sayed et al., 2005. & & & \\
\hline
\end{tabular}

Em relação aos genes que codificam para RNAs, identificaram-se os diferentes tipos de RNA no genoma de L. major: RNA transportador ( $t R N A$ ), RNA ribossomal (rRNA), RNA guia de Splice (slRNA), RNA nuclear pequeno (snRNA), RNA nucleolar pequeno (SnoRNA) e RNA de partícula de reconhecimento de sinal (SrpRNA), como demonstrado na Tabela 4. Os Tritryps aparentemente codificam um repertório semelhante de genes de RNA, porém, a organização em $L$. major difere dos outros dois tripanossomatídeos. Os genes que codificam para as subunidades $28 \mathrm{~S}, 18 \mathrm{~S}$ e $5,8 \mathrm{~S}$ do RNA ribossomal de L. major ocorrem em um único arranjo em tandem, enquanto nos outros Tritryp aparecem em loci dispersos em diferentes cromossomos. Em contrapartida, os genes que codificam para as subunidades 5S do RNA ribossomal são encontrados em 11 diferentes loci em vários cromossomos de L. major, e como um arranjo único em T. brucei e T. cruzi. Dos anticódons possíveis, os genomas dos Tritryps são capazes de codificar os mesmos 45 tipos; a diferença está no número de cópias e na localização dentro do genoma (Ivens et al., 2005).

Tabela 4 - Características dos genes codificadores de RNA

\begin{tabular}{l|c}
\hline Parâmetro & Número \\
\hline RNA transportador (tRNA) & 83 \\
\hline RNA ribossomal $(r R N A)^{*}$ & 63 \\
\hline RNA guia de Splice $(s / R N A)^{*}$ & 63 \\
\hline RNA nuclear pequeno (snRNA) & 6 \\
\hline RNA nucleolar pequeno (snoRNA) & 695 \\
\hline RNA partícula de reconhecimento de sinal (srpRNA) & 1 \\
\hline
\end{tabular}

*Valores aproximados.

Fonte: adaptado de Ivens et al., 2005. 
A propósito do conteúdo de genes e arquitetura do genoma, os Tritryps apresentam uma conservação de cerca de 6.200 genes em grandes grupos sintênicos. A comparação dos genomas dos três organismos fornece indícios de uma ancestralidade comum (Tabela 5). Os genomas de L. major e T. brucei têm 110 blocos de sintenia, como descrito em El-Sayed e colaboradores (2005). Mesmo com a grande sintenia existente entre esses organismos, é possível observar inserções, deleções e substituições que podem resultar em diferenças fisiológicas e bioquímicas entre tais parasitos (Degrave et al., 2001; El-Sayed et al., 2005).

Os genomas de T. brucei e T.cruzi contêm elementos transponíveis capazes de se reintegrar no genoma desses organismos. Em contraste, a análise de várias espécies de Leishmania indica uma falta de retroelementos ativos. Nos genomas de L. major e de L. infantum foi possível detectar vestígios de retrotransposons. Porém, detectou-se retrotransposons ativos no genoma de L. braziliensis.

\section{Genômica comparativa entre L. major, L. infantum e L. braziliensis}

As sequências dos genomas L. infantum e L. braziliensis foram obtidas por meio de sequenciamento usando a abordagem de shotgun, com uma cobertura de cinco e seis vezes, respectivamente. Realizou-se uma análise comparativa a fim de alinhar as sequências desses organismos contra as sequências contíguas de referência de L. major (Smith, Peacock \& Cruz, 2007). Embora essas três espécies tenham um conteúdo nucleotídico semelhante (cerca de 33 $\mathrm{Mb}$ ), L. braziliensis é geneticamente mais distinta, como já havia sido observado na diferença do número de cromossomos. A conservação da sintenia, revelada por análises de genômica comparativa entre essas três espécies, sugere que o genoma do Leishmania é altamente estável e não tem sofrido grandes rearranjos durante a especiação (Smith, Peacock \& Cruz, 2007).

Tabela 5 - Comparação das características gerais dos genomas dos Tritryps

\begin{tabular}{l|c|c|c}
\hline Parâmetro & L. major & L. infantum & L. braziliensis \\
\hline Tamanho do genoma haploide (Mpb) & 32,8 & 32,1 & 32,0 \\
\hline Número de cromossomos (por genoma haploide) & 36 & 36 & 35 \\
\hline Conteúdo G+C (\%) & 59,7 & 59,3 & 60,4 \\
\hline Número de genes & 8.298 & 8.154 & 8.153 \\
\hline Número de pseudogenes & 97 & 41 & 161 \\
\hline Região codificadora (\%) & 48 & 44 & 48,5 \\
\hline
\end{tabular}

Fonte: adaptado de Smith, Peacock \& Cruz, 2007.

A comparação entre os genes ortólogos dessas espécies revelou um alto grau de conservação no conteúdo e ordem gênica, mesmo com algumas diferenças no número de cópias de alguns genes. O genoma mais divergente (L. braziliensis) apresenta somente 47 genes que não foram identificados nas outras duas espécies, enquanto L. infantum possui 27 genes específicos e L. major apenas cinco (Figura 2). 
Figura 2 - Diagrama de Venn representando as proteínas preditas específicas e compartilhadas por três espécies de Leishmania (LMA = L. major, $\mathrm{LBR}=$ L. braziliensis e LIN $=$ L. infantum)

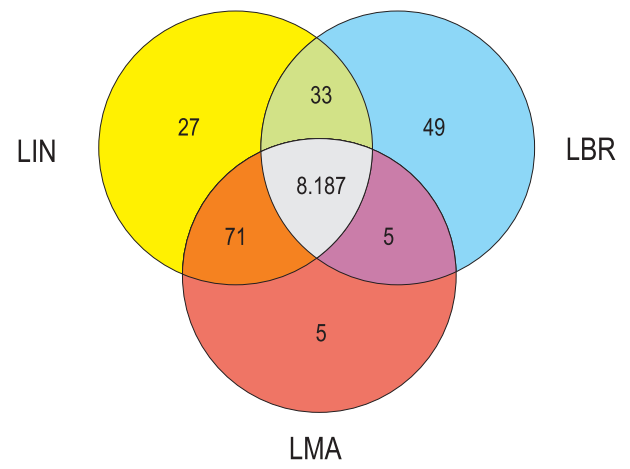

Fonte: adaptado de Smith, Peacock \& Cruz, 2007.

Em uma comparação entre os genomas dos Tritryps, observa-se que a maioria dos genes específicos para cada uma das espécies se localiza nas extremidades dos grupos gênicos ou nas regiões subteloméricas dos cromossomos. Entretanto, a comparação entre as três espécies de Leishmania revelou que a variação gênica não é restrita a essas regiões, estando bem distribuída por todo o genoma. Eventos de inserção, deleção e rearranjos nas sequências gênicas são responsáveis por essa variação, sendo a perda de função por degeneração gênica a mais abundante, correspondendo a cerca de $80 \%$ do total das diferenças entre as espécies. A aquisição de novos genes pode estar relacionada a mecanismos para a adaptação ambiental e para promover a sobrevivência do organismo; adaptações similares relacionadas ao estresse ou a outros estímulos podem levar ao ressurgimento de algumas funções em genes cujas sequências anteriormente foram identificadas como pseudogenes (Smith, Peacock \& Cruz, 2007).

\section{Pós-genômica}

O conhecimento gerado com o sequenciamento dos genomas de diferentes espécies de Leishmania auxilia no entendimento global do fenótipo da doença. Os genes que diferem entre as três espécies são bons candidatos para uma análise funcional para determinar seu papel no estabelecimento da infecção. Contudo, a maioria dos genes espécieespecíficos codifica proteínas com pouca ou nenhuma similaridade com outras sequências de eucariotos, dificultando a inferência de função. Assim, torna-se necessária a utilização de outras metodologias, sejam elas computacionais ou não, combinadas com a análise de fatores genéticos, bioquímicos e imunológicos a fim de determinar suas funções biológicas.

\section{Mineração de dados nos genomas de Leishmania}

O termo 'mineração de dados', uma tradução do termo em inglês data mining, pode ser definido como um processo qualquer em que a informação útil é extraída tendo como base um grande conjunto de dados. No contexto de um projeto genoma, várias etapas envolvem a mineração de dados. Entre elas, pode-se incluir: a deteç̧ão dos 'sinais característicos' presentes nas sequências que estariam relacionadas com as diferentes 'partes' que compõem os genomas, como regiões regulatórias, regiões codificantes, elementos de transposição, sítios de ligação, entre outros. Após a detecção, são definidas as funções de cada região. As ferramentas mais utilizadas na mineração de dados envolvem comparação entre sequências em bancos de dados, sejam eles públicos ou privados (Berriman, 2004).

Várias iniciativas foram empreendidas com o intuito de reunir os dados provenientes dos projetos genomas de diversos organismos. Atualmente, o EuPathDB - Eukaryotic Pathogen Database (<http://EuPathDB.org>) - é um 
banco de dados integrado que abrange os patógenos eucarióticos dos gêneros Cryptosporidium, Giardia, Leishmania, Neospora, Plasmodium, Toxoplasma, Trichomonas e Trypanosoma. Embora cada um desses grupos conte com um banco de dados específico construído sobre a mesma infraestrutura, o EuPathDB é um portal que oferece um ponto de entrada para todos os recursos contidos em cada um desses bancos, com a conveniência de proporcionar buscas baseadas em ontologias preestabelecidas. Além disso, a interface amigável permite ao usuário uma navegação interativa, auxiliando o entendimento dos resultados de cada busca (Aurrecoechea et al., 2010).

\section{TRANSCRIPTÔMICA}

Transcriptômica consiste no conjunto de análises da expressão gênica - por intermédio do estudo qualitativo e quantitativo de diferentes tipos de RNA - de um determinado organismo sob uma condição específica ou na comparação de diferentes condições como, por exemplo, cepas resistentes e não resistentes a determinado fármaco. Ao contrário do genoma que apresenta características comuns nas diferentes formas evolutivas do ciclo de vida, o transcriptoma e o proteoma de parasitos protozoários, como Leishmania spp., apresentam diferenças significativas entre os distintos estágios (amastigotas, promastigotas). Tais diferenças estão associadas à adaptação e sobrevivência dos parasitos aos distintos ambientes que encontram nos hospedeiros vertebrados e invertebrados. Essas adaptações podem envolver regulações específicas, como a expressão de proteínas que permitem escapar da resposta imune do hospedeiro vertebrado ou que evitem a ação de enzimas digestivas do vetor (Peters \& Sacks, 2006).

O conjunto de mRNA transcrito num determinado momento, no parasito, afeta diretamente os níveis de proteínas expressas por essa célula. No caso de Leishmania, assim como nos outros Kinetoplastida, ocorrem os fenômenos de transcrição policistrônica e de processamento de mRNA através do sistema de trans-splicing, os quais aumentam a complexidade dos transcritos gerados e, como consequência, dificultam a análise via mRNA.

Em Leishmania spp., análises transcriptômicas vinham sendo feitas desde antes da publicação dos genomas (Saxena et al., 2003; Akopyants et al., 2004; Almeida et al., 2004) por meio de duas metodologias: amplificação por PCR de fragmentos randômicos de DNA, seguido de fixação dos produtos em lâminas de vidro (Saxena et al., 2003; Akopyants et al., 2004), cobrindo aproximadamente 40\% do genoma; e amplificação de um número limitado de fragmentos randômicos e de fragmentos específicos de cDNA, produzidos a partir de bibliotecas de formas amastigotas e promastigotas, possibilitando assim a identificação de genes expressos de maneira estágio-específica (Almeida et al., 2004). Após a publicação do genoma completo de L. major realizou-se um estudo que possibilitou a identificação de 97,5\% dos genes, utilizando uma técnica de microarranjo de oligonucleotídeo de alta densidade, via síntese por fotolitografia (Holzer, McMaster \& Forney, 2006; Leifso et al., 2007). Posteriormente, em razão do alto grau de similaridade genômica, as lâminas de microarranjo produzidas para L. major foram utilizadas para conduzir estudos em L. mexicana (Holzer, McMaster \& Forney, 2006) e L. donovani (Saxena et al., 2007).

Em distintas espécies de Leishmania, ensaios de microarranjo dirigidos para o estudo de vias específicas têm sido utilizados visando a análise do perfil de expressão gênica em diferentes formas evolutivas (Leifso et al., 2007; Saxena et al., 2007; Quijada, Soto \& Requena, 2005; McNicoll et al., 2006) e no estudo de genes envolvidos em resistência a fármacos (Guimond et al., 2003; Leprohon et al., 2006). A Tabela 6 resume os estudos em transcriptômica utilizando análise por microarranjo nas diferentes espécies de Leishmania (Cohen-Freue et al., 2007). Uma comparação da expressão diferencial de genes em amastigotas e promastigotas de L. major e L. mexicana permitiu a identificação de genes expressos em comum apenas nas formas promastigotas das duas espécies (Cohen-Freue et al., 2007) (Figura 3). 
Tabela 6 - Análise por microarranjo da expressão de mRNA* codificados pelos genomas de diferentes espécies de Leishmania

\begin{tabular}{|c|c|c|c|c|c|c|}
\hline \multirow[t]{2}{*}{ Espécies [referência] } & \multirow[t]{2}{*}{$\begin{array}{c}\text { Tipo de microarranjo de } \\
\text { L. major }\end{array}$} & \multirow[t]{2}{*}{$\begin{array}{l}\text { Número de } \\
\text { sondas }\end{array}$} & \multirow[t]{2}{*}{$\begin{array}{l}\text { Genes únicos } \\
\text { (cobertura do } \\
\text { genoma) }\end{array}$} & \multicolumn{3}{|c|}{$\begin{array}{l}\text { Comparação da expressão diferencial de } \\
\text { mRNA entre promastigotas procíclicos } \\
\text { (\% do total de genes nos arrays) e as } \\
\text { outras formas evolutivas }\end{array}$} \\
\hline & & & & $\begin{array}{c}\text { Promastigotas } \\
\text { metacíclicos }\end{array}$ & $\begin{array}{c}\text { Amastigotas } \\
\text { axênicos }\end{array}$ & $\begin{array}{c}\text { Amastigotas } \\
\text { de lesão }\end{array}$ \\
\hline L. major (Saxena et al., 2003) & DNA genômico & 10.479 & $(\sim 80 \%)$ & 5,1 & & \\
\hline L. major (Akopyants et al., 2004) & DNA genômico & 10.479 & $(\sim 80 \%)$ & 0,8 & & 0,9 \\
\hline L. major (Almeida et al., 2004) & CDNA & 2.734 & $1.843(22 \%)$ & 7,0 & & 13,0 \\
\hline L. donovani (Saxena et al., 2007) & DNA genômico & 10.468 & $3.868(46,2 \%)$ & & 5,5 & \\
\hline L. mexicana (Holzer et al., 2006) & $\begin{array}{l}\text { Oligonucleotídeo com } \\
\text { alta densidade }\end{array}$ & 89.760 & $8.160(97,5 \%)$ & & 0,2 & 3,5 \\
\hline L. major (Leifso et al., 2007) & $\begin{array}{l}\text { Oligonucleotídeo com } \\
\text { alta densidade }\end{array}$ & 89.760 & $8.160(97,5 \%)$ & & & 2,9 \\
\hline
\end{tabular}

* 0 percentual dos genes foi calculado tendo como base um total de 8.370 genes (L. major GeneDB Dataset version 5.1 ; (<www.genedb.org. $>$ ).

Fonte: adaptado de Cohen-Freue et al., 2007.

Figura 3 - Comparação do padrão de expressão gênica diferencial entre L. major e L. mexicana

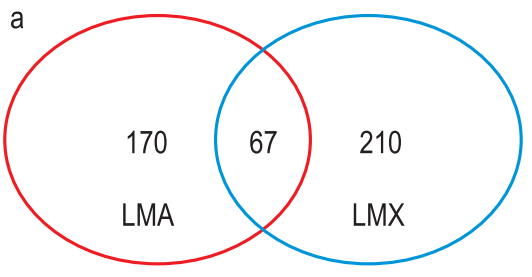

Total

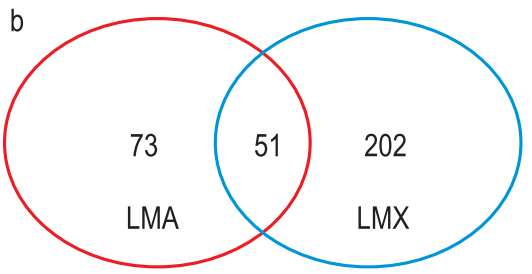

Promastigota

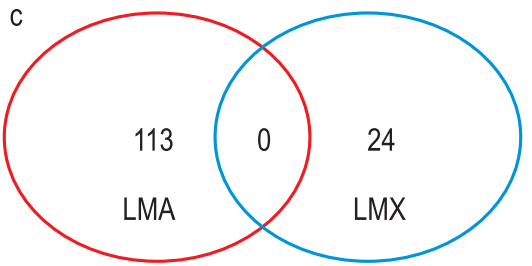

Amastigota

Os diagramas de Venn mostram os números de genes expressos em cada espécie e na intercessão dos círculos estão os genes compartilhados entre essas espécies. Em 'a' estão representados os genes totais identificados; em 'b' estão representados os genes preferencialmente expressos em promastigotas; e em 'c' os genes expressos em amastigotas.

Fonte: adaptado de Cohen-Freue et al., 2007. 
Não obstante existam mecanismos de regulação dos níveis de mRNA, tanto nas distintas formas evolutivas como nas distintas fases de crescimento (Brooks et al., 2001), o perfil do transcriptoma descrito em diferentes espécies ( $L$. major, L. mexicana e L. donovani) demonstrou ser bastante estável (Leifso et al., 2007; Saxena et al., 2007; Duncan et al., 2004). A maioria dos transcritos regulados nos estágios de vida de Leishmania corresponde a proteínas de superfície ou proteínas altamente abundantes, enquanto as enzimas envolvidas no metabolismo central de carbono estão sub-representadas. Uma análise de dados de transcriptoma e proteoma de L. major e L. infantum mostrou que 0 genoma desses parasitos é constitutivamente expresso em amastigotas e promastigotas (Leifso et al., 2007; McConville et al., 2007). Entretanto, as limitações experimentais das técnicas usadas nessa análise podem dificultar a deteç̧ão e identificação das proteínas expressas em baixas concentrações. Dados obtidos utilizando pré-fracionamento com sulfato de amônio de extratos de culturas de L. infantum, utilizando-se amastigotas e promastigotas, revelaram um grande número de modificações nos níveis de expressão estágio-específicos, assim como em relação a modificações pós-traducionais em proteínas de amastigotas (McNicoll et al., 2006).

Recentemente publicaram-se novos trabalhos visando ao estudo da transcriptômica em Leishmania spp., os quais utilizaram diferentes tecnologias. Adaui e colaboradores realizaram uma comparação entre as diferentes formas evolutivas de diferentes isolados clínicos de L. braziliensis pela técnica de PCR em tempo real, utilizando 12 enzimas envolvidas em diferentes funções como no metabolismo redox, e demonstraram que ocorrem modulações diferenciadas tanto entre os diferentes genes quanto entre os isolados clínicos (Adaui et al., 2011). Por sua vez, Alcolea e colaboradores utilizaram a tecnologia de hibridização por microarranjo em L. infantum, porém cobrindo o genoma inteiro, demonstrando alguns dados que corroboram com análises anteriores no que se refere à baixa regulação da expressão entre as formas evolutivas. Em inúmeros genes codificantes para proteínas sem função definida foi preponderante o aumento na expressão dos mesmos em amastigotas e, também, foi demonstrada uma diminuição de 68\% na taxa de redução da expressão nessa forma evolutiva (Alcolea et al., 2010).

\section{Transcriptômica da interação parasito-vetor}

A interação de Leishmania com o vetor determina uma série de modificações bioquímicas e metabólicas, que acarreta mudanças significativas do arsenal proteico desses microrganismos. Tais adaptações têm sido analisadas não só por técnicas de microarranjo, mas também por PCR semiquantitativo, PCR em tempo real e sequenciamento de ESTs (Ramalho-Ortigão et al., 2007; Jochim et al., 2008; Pitaluga et al., 2009).

Demonstrou-se que uma série de proteínas associadas às microvilosidades do trato digestivo do vetor Phlebotomus papatasi, tais como a PpMVP1 e a PpMVP2, assim como as peritrofinas 1 e 2 (PpPer1 e PpPer2) e a quimotripsina PpChym2, apesar de serem expressas somente após o repasto sanguíneo, apresentaram uma significativa redução dos seus transcritos quando da presença de L. major no sangue ingerido (Ramalho-Ortigão, 2007). Em outro sistema, utilizando o vetor $L$. longipalpis e $L$. infantum, foi possível observar também uma redução na expressão de quatro proteínas associadas às microvilosidades (LuloMVP1, 2, 4 e 5), da quimotripsina LuloChym1A, da carboxipeptidase LuloCpepA1, dentre outras. Entretanto, descreveu-se um aumento na expressão de proteínas, tais como da proteína tipo peritrofina LuloPer1, da proteína tipo tripsina Lltryp2 e de uma proteína desconhecida (Jochim et al., 2008).

Outro estudo sequenciou 2.520 ESTs, partindo de bibliotecas de cDNA de intestino médio de Lu. longipalpis, alimentada na ausência ou presença de L. infantum (Pitaluga et al., 2009), tendo-se observado um aumento significativo no percentual de transcritos expressos na biblioteca do vetor infectado. Os transcritos com expressão aumentada estavam correlacionados à defesa/estresse/oxidação ( $7 \%$ contra $4 \%$ obtido da biblioteca não infectada), proteínas ribossomais (16\% contra 13\%), proteínas envolvidas com a mobilização intracelular/citoesqueleto/adesão celular $(4 \%$ contra $1 \%)$ e à transdução de sinais $(5 \%$ contra $2 \%)$. Os dados apresentados nesses dois últimos trabalhos, 
que utilizaram diferentes estratégias/metodologias de análises, evidenciam a importância de se estudar especificamente os diferentes sistemas Leishmania-vetor, para um melhor entendimento da epidemiologia e da dinâmica da doença.

\section{PROTEÔMICA}

A análise global da expressão proteica em parasitos do gênero Leishmania vem destinando-se a identificar e quantificar proteínas específicas expressas em estágios do ciclo biológico, proteínas enriquecidas das distintas frações celulares ou organelas e proteínas envolvidas na imunoestimulação, entre outros. Tais padrões de expressão proteica têm contribuído para a anotação funcional de proteínas e podem permitir o desenho de vacinas e o desenvolvimento de novos medicamentos que tenham como alvo fatores específicos de cada estágio de vida.

Os primeiros estudos em proteômica de Leishmania spp. basearam-se no uso da eletroforese bidimensional (2DE), para detectar proteínas antigênicas presentes em extratos celulares (Handman, Mitchell \& Goding, 1981) e para diferenciar, por meio dos seus padrões de expressão proteica, distintas espécies responsáveis pela LTA (Saravia et al., 1984). Contudo, tais estudos mostraram-se limitados em virtude da impossibilidade de se identificar em larga escala as proteínas de interesse.

A modernização da tecnologia da 2DE e o desenvolvimento de espectrometria de massas (MS), para identificação de proteínas, impulsionaram os estudos proteômicos nesses parasitos. Dessa forma, mapas proteômicos têm sido descritos para várias espécies de Leishmania do Velho e do Novo Mundo (Thiel \& Bruchhaus, 2001; Acestor et al., 2002; El Fakhry, Ouellette \& Papadopoulou, 2002; Gongora et al., 2003; Bente et al., 2003; Drummelsmith et al., 2003; Nugent et al., 2004; Walker et al., 2006a; Brobey et al., 2006; Brobey \& Soong, 2007; Cuervo et al., 2007).

As estratégias usadas para a análise global de proteínas nesses parasitos envolvem a separação por eletroforese em uma e em duas dimensões, seguida pela detecção, excisão e digestão de bandas ou spots proteicos para subsequente identificação pela combinação do perfil de massas peptídicas (PMF, Peptide Mass Fingerprinting) ou pelas massas dos fragmentos peptídicos obtidos por MS em tandem, usando como fontes de ionização electropulverização (ESI, electrospray ionization), ou ainda, laser assistido por uma matriz (Matrix Assisted Laser Desorption-Ionization - MALDI) em combinação com vários analisadores de massas, tais como tempo de voo (Time-Of-Flight - TOF), quadrupolo (Q), Fourier Transform (FT), Orbitrap, ou seus híbridos (Figura 4). Outras abordagens, também muito usadas, acoplam a separação peptídica por cromatografia líquida (LC) uni- ou multidimensional com a análise de massas (LC-MS/MS). 
Figura 4 - Fluxo experimental geral seguido em estudos proteômicos de parasitos do gênero Leishmania

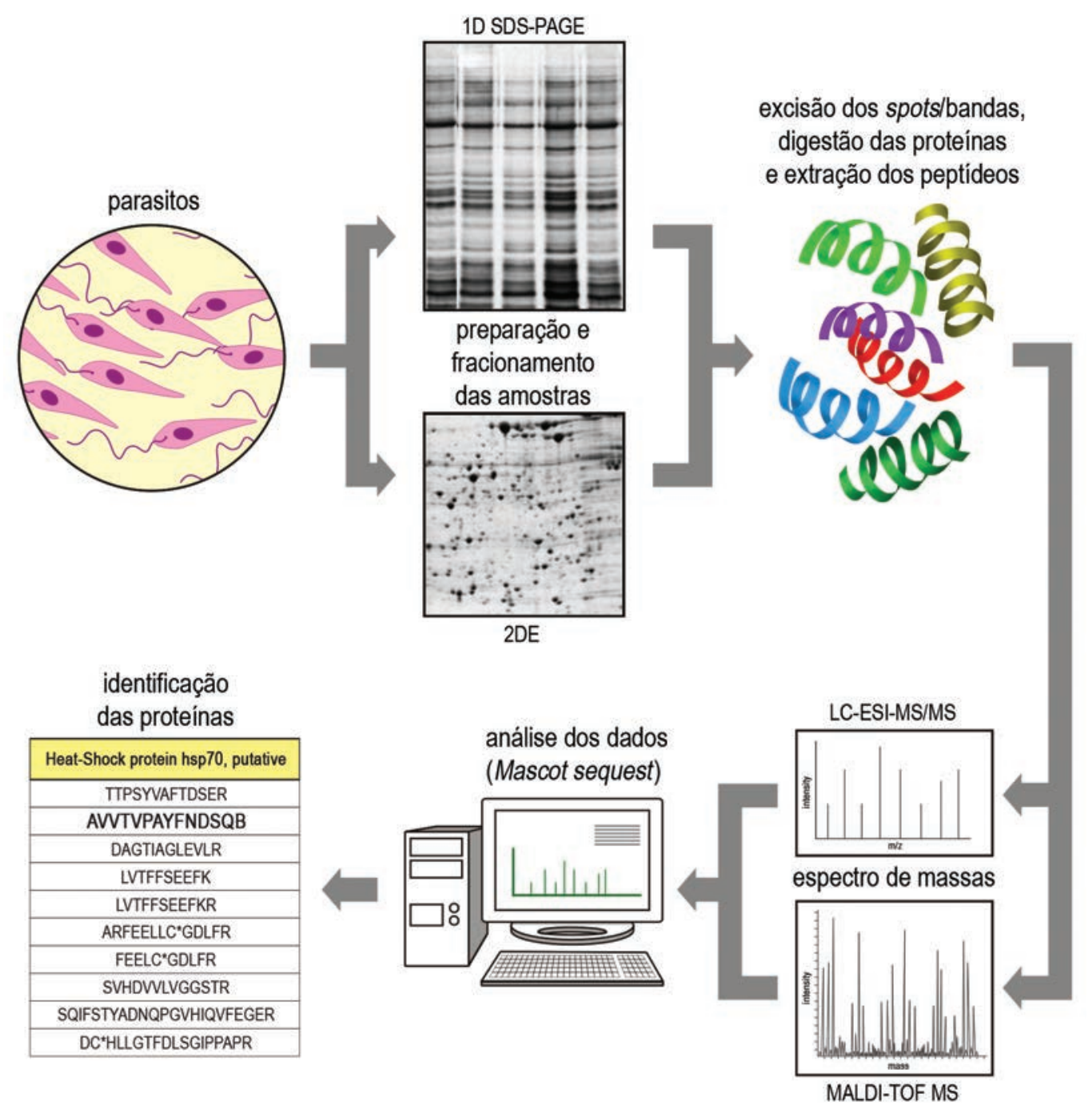

As proteínas são isoladas a partir de um lisado de parasitos e fracionadas por eletroforese em uma ou duas dimensões. Em seguida, as proteínas são clivadas enzimaticamente, em geral com tripsina, para gerar peptídeos. Os peptídeos são separados por um ou por sucessivos passos de cromatografia líquida de alta precisão, e/ou diretamente eluídos numa fonte de ionização (ESI ou MALDI). Os peptídeos protonados entram no espectrômetro de massas e suas massas são apresentadas na forma de um espectro. A seguir, espectros de massa em tandem são produzidos a partir de peptídeos precursores, os quais implicam a fragmentação peptídica por colisão energética com um gás. 0s espectros de MS e de MS/MS são submetidos a buscas contra bases de dados de sequências de proteínas. Finalmente, as proteínas são identificadas pela coincidência das massas experimentais com as massas teóricas dos peptídeos.

\section{Proteômica comparativa dos estágios evolutivos}

O ciclo de vida de Leishmania spp. envolve insetos vetores e distintos hospedeiros vertebrados. A interação desses parasitos com seus dissímeis hospedeiros exige uma rápida adaptação fisiológica, a qual, por sua vez, deve implicar a expressão diferencial de genes em cada ambiente. Nesse cenário, as abordagens proteômicas têm sido ferramentas valiosas para elucidar as alterações na expressão de proteínas durante o ciclo de vida desses parasitos e identificar moléculas específicas de cada estágio. A maioria dos estudos proteômicos das formas evolutivas tem sido conduzida em parasitos do subgênero Leishmania (Leishmania), possivelmente por sua facilidade para cultivo in vitro e pela disponibilidade de informação genômica para esse subgênero. Entretanto, o sequenciamento do genoma de L. (Viannia) 
braziliensis, cuja análise tem revelado a presença de componentes de uma via de interferência de RNA (RNAi) (Peacock et al., 2007), deverá estimular futuros estudos em parasitos do subgênero L. (Viannia) (Smith, Peacock \& Cruz, 2007).

Para os estudos proteômicos comparativos entre promastigotas e amastigotas têm sido usados parasitos axênicos crescidos em condições in vitro que visam simular as condições no intestino do vetor $\left(26^{\circ} \mathrm{C}, \mathrm{pH} 7\right)$ e do fagolisossomo $\left(37^{\circ} \mathrm{C}\right.$, pH 5.5) (Leifso et al., 2007; McNicoll et al., 2006; Thiel \& Bruchhaus, 2001; El Fakhry, Ouellette \& Papadopoulou, 2002; Bente et al., 2003; Nugent et al., 2004; Walker et al., 2006a; Smith, Peacock \& Crz, 2007; Foucher, Papadopoulou \& Ouellette, 2006; Rosenzweig et al., 2008a; Morales et al., 2008; Mojtahedi, Clos \& Kamali-Sarvestani, 2008).

Dentre esses estudos destaca-se o reportado recentemente para L. donovani (Rosenzweig et al., 2008a), no qual foi analisada a cinética de expressão proteica durante a transformação do parasito, tendo como foco principalmente os anos de mudanças metabólicas. Os autores obtiveram $\sim 21 \%(\sim 1.700 / 8.000$ proteínas) de cobertura do proteoma predito de Leishmania e mostraram diferenças quantitativas na expressão de várias proteínas de vias metabólicas centrais. Durante a diferenciação de promastigota para amastigota, enzimas envolvidas no ciclo do ácido tricarboxílico (tri-carboxilic acid - TCA), na respiração mitocondrial, na fosforilação oxidativa, na gluconeogênese glicossomal e na $\beta$-oxidação de ácidos graxos foram superexpressas, ao passo que proteínas glicolíticas citosólicas foram subexpressas (Rosenzweig et al., 2008a).

Os autores também reportaram que tais mudanças na expressão estão acompanhadas por extensiva modificação pós-traducional (post-translational modifications - PTM). Tais resultados indicaram que os parasitos trocam sua fonte de energia de glicose para ácidos graxos, o qual está de acordo com reportes prévios que indicam que o metabolismo de ácidos graxos é mais ativo em amastigotas do que em promastigotas (Coombs, Craft \& Hart, 1982; Hart \& Coombs, 1982). Um estudo proteômico quantitativo em $L$. infantum demonstrou que $72 \%$ das proteínas identificadas são expressas constitutivamente em ambos os estágios de vida do parasito (Leifso et al., 2007). Esses resultados foram corroborados por análises de microarranjos (Leifso et al., 2007; Cohen-Freue et al., 2007). Esse e outros estudos proteômicos em Leishmania demonstram claramente que os níveis de mRNA não refletem os perfis de expressão proteica no parasito, confirmando que mecanismos pós-transcricionais regulam majoritariamente a expressão gênica em Leishmania spp. (Leifso et al., 2007; McNicoll et al., 2006; Brooks et al., 2001; Clayton, 2002; Clayton \& Shapira, 2007; Charest, Zhang \& Matlashewski, 1996; Kelly, Nelson \& McMaster, 2001; Larreta et al., 2004; Purdy, Donelson \& Wilson, 2005).

Em L. mexicana, uma das espécies responsáveis pela leishmaniose cutânea no Novo Mundo, um estudo proteômico comparativo (por meio de uma abordagem 2DE combinada com LC/MS) foi conduzido usando-se promastigotas procíclicos, promastigotas metacíclicos e amastigotas axênicos. Em tal trabalho observou-se expressão diferencial de proteínas entre os três estágios, dentre as quais foram identificadas proteínas implicadas na interação parasitohospedeiro, tais como chaperoninas, fatores de tradução e cisteína-proteinase (Nugent et al., 2004).

Ainda que as formas axênicas exibam muitas das características dos amastigotas intracelulares (Pan et al., 1993; Sereno \& Lemesre, 1997; Puentes et al.; 2000; Gupta, Goyal \& Rastogi, 2001; Sereno et al., 2001a; Debrabant et al., 2004), não se sabe ao certo quão símiles elas são entre si. A propósito disso, recentemente foi reportado um estudo proteômico da diferenciação de L. mexicana usando amastigotas intracelulares (Paape et al., 2008). Amastigotas fluorescentes transgênicos foram extraídos de macrófagos do hospedeiro e comparados com promastigotas. Observouse que amastigotas intracelulares exibem mais proteínas com pI básico do que as promastigotas, além de apresentar um aumento no número de enzimas envolvidas no metabolismo de ácidos graxos, o que reforça os dados observados com amastigotas axênicas de L. donovani (Rosenzweig et al., 2008a). Algumas das proteínas exclusivamente identificadas em amastigotas intracelulares, tais como cisteína-proteinase B, chaperoninas e fatores de tradução foram também reportadas para os amastigotas axênicos (Nugent et al., 2004). Análise in silico dos genes que codificam para proteínas mais abundantes em amastigotas revelou motivos na sequência das regiões 3'-não traduzidas que poderiam 
estar associados a elementos de controle traducional (Paape et al., 2008), apoiando mais uma vez a hipótese de que mecanismos pós-transcricionais regulam a expressão gênica em Leishmania.

Leishmania panamensis é um agente etiológico de leishmaniose cutânea e mucocutânea no Novo Mundo (Martinez et al. ,1991; Osorio, Castillo \& Ochoa, 1998) e é a única espécie do subgênero L. (Viannia) cujo processo de diferenciação tem sido estudado usando abordagens proteômicas (Walker et al., 2006a). Os dados proteômicos sobre a expressão proteica durante a diferenciação, obtidos para várias espécies de Leishmania, são em geral congruentes (Leifso et al., 2007; McNicoll et al., 2006; Thiel \& Bruchhaus, 2001; El Fakhy, Ouellette \& Papadopoulou, 2002; Bente et al., 2003; Nugent et al., 2004; Walker et al., 2006a; Foucher, Papadopoulou \& Ouellette, 2006; Rosenzweig et al., 2008a, 2008b; Mojtahedi, Clos \& Kamali-Sarvestani, 2008; Paape et al., 2008).

Esses estudos suportam a ideia de que promastigotas e amastigotas são altamente adaptados aos seus respectivos ambientes e que os mecanismos subjacentes de tais especificidades adaptativas são provavelmente pós-transcricionais (Rosenzweig et al., 2008a, 2008b). Entretanto, essas análises proteômicas revelaram um baixo número de proteínas (3-9\%) que são diferencialmente expressas entre os estágios, tendo-se em conta o proteoma predito para tais parasitos.

\section{Proteoma subcelular}

Um dos aspectos mais interessantes da proteômica subcelular é a possibilidade de inferir a função das proteínas e a organização celular com base na localização proteica. Esse aspecto é relevante, visto que cerca de $60 \%$ dos genes sequenciados em Leishmania spp. não têm função anotada (Ivens et al., 2005; Peacock et al., 2007). Os proteomas subcelulares são obtidos por purificação seletiva ou enriquecimento específico de organelas ou frações celulares (Dreger, 2003). Fracionamento com digitonina tem sido usado para purificar e enriquecer as frações mitocondrial e citosólica de L. infantum (Foucher, Papadopoulou \& Ouellette, 2006; Hide et al., 2008). Microscopia de fluorescência de proteínas acopladas a GFP corroboraram a localização celular de várias proteínas hipotéticas identificadas em cada fração. Aproximadamente $70 \%$ das proteínas identificadas não tinham sido detectadas em prévios estudos proteômicos globais (Foucher, Papadopoulou \& Ouellette, 2006).

Partindo-se da hipótese de que proteínas importantes para a virulência dos parasitos podem estar na membrana plasmática dos mesmos, desenvolveu-se um estudo para comparar essa fração entre promastigotas procíclicos e promastigotas metacíclicos de L. infantum (sin. L. chagasi) (Yao et al., 2010). As preparações de membrana foram feitas usando-se separação por afinidade com estreptavidina-biotina ou extração com detergente n-octil glicosídeo. Utilizando-se tais abordagens, as frações de membrana plasmática foram enriquecidas cerca de 130X e 250X, respectivamente. Identificação por LC-MS/MS revelou que promastigotas metacíclicos expressam proteínas específicas, ou isoformas destas, tais como cisteína-peptidases e GP63, não detectadas nos procíclicos, que estão envolvidas na virulência dos parasitos (Yao et al., 2010).

Os estudos proteômicos de organelas em Leishmania são relativamente parcos quando comparados aos de proteínas totais. Motivos disso são, provavelmente, as dificuldades na obtenção de frações puras, livres de proteínas contaminantes, bem como o uso de técnicas laboriosas de fracionamento celular. Contudo, novas metodologias vêm sendo utilizadas para o enriquecimento de frações celulares que têm sido consideradas elusivas. Um exemplo dessas metodologias é a eletroforese de fluxo contínuo (FFE, sigla em inglês para free-flow electrophoresis). Essa técnica foi usada para o enriquecimento de proteínas básicas de amastigotas axênicos e promastigotas de L. infantum, tendo revelado $\sim 2400$ proteínas com pH $>7.0$ nos dois estágios (Brotherton et al., 2010). Diferenças discretas na expressão de proteínas básicas entre os estágios também foram reveladas, sendo $\sim 60$ proteínas únicas ou superexpressas nos amastigotas, incluídas proteínas envolvidas na $\beta$-oxidação de ácidos graxos (Brotherton et al., 2010). 


\section{SECRETOMA}

As proteínas secretadas ou liberadas para o meio extracelular pelos parasitos são mediadores-chaves das interações parasito-hospedeiro. Recentemente, os secretomas de L. donovani e L. braziliensis foram caracterizados (Silverman et al., 2008; Cuervo et al., 2009). Esses dois trabalhos são consistentes quando demonstram que apenas algumas das proteínas identificadas na fração secretada apresentam peptídeo sinal de secreção na região aminoterminal, típico das células eucarióticas, e sugerem a existência de mecanismos não convencionais de secreção nesses parasitos, provavelmente baseados em transporte através de vesículas. Ademais, tais estudos indicaram que uma grande porção de proteínas secretadas apresenta funções intracelulares já descritas, revelando a pluralidade funcional e localização múltipla de proteínas em Leishmania, bem como reforçando a ideia de que a fração secretada é uma importante fonte de moléculas efetoras implicadas na interação parasito-hospedeiro (Silverman et al., 2008; Cuervo et al., 2009). Estudos posteriores têm constatado que existe um sistema especializado de secreção de proteínas em Leishmania, baseado em exosomos, que responde por $\sim 50 \%$ da secreção total de proteínas no parasito (Silverman et al., 2010).

\section{MODIFICAÇÕES PÓS-TRADUCIONAIS (PTM)}

Como mencionado, os principais mecanismos de regulação da expressão gênica em Leishmania são póstranscricionais. A modulação pós-transcricional e pós-traducional parece ser governada pela regulação da estabilidade do mRNA, da taxa de iniciação da tradução e do turnover de proteínas. Em adição a esses mecanismos, as PTM parecem ter um papel crítico na estabilidade das proteínas, contribuindo para o controle da expressão gênica. As PTM regulam a função proteica alterando a localização das proteínas, suas interações moleculares ou suas atividades. Dentre as PTM destacam-se a fosforilação, metilação, acetilação, glicosilação, piroglutamilação N-terminal, desamidação e oxidação do triptofano. Análise de sequenciamento de novo de proteínas identificadas no proteoma solúvel de $L$. braziliensis demonstrou que $\sim 20 \%$ das proteínas apresentavam PTM (Cuervo et al., 2007).

Tais modificações foram detectadas em enzimas metabólicas, proteínas envolvidas na replicação do DNA, cisteínapeptidase tipo calpaína, proteínas envolvidas na síntese proteica e na via proteasoma-ubiquitina. A clivagem do resíduo de metionina $\mathrm{N}$-terminal, bem como a acetilação N-terminal, são as modificações mais comuns em proteínas eucarióticas. Essas PTM são importantes para a maturação das proteínas, assim como os resíduos N-acetilados são cruciais para a atividade de proteínas, tais como actina e subunidades do proteasoma (Abe et al., 2000; Polevoda \& Sherman, 2000; Groll et al., 1999). Resíduos de piroglutamato N-terminal, como os identificados em L. braziliensis (Cuervo et al., 2007), poderiam ter a função de reduzir a suscetibilidade das proteínas à degradação por aminopeptidases (Cummins \& O'Connor, 1998).

A desamidação das proteínas tem sido associada a importantes processos biológicos tais como o turnover de proteínas, o desenvolvimento e senilidade molecular (Robinson \& Robinson, 2001; Weintraub \& Manson, 2004). Análise in silico constatou que algumas das enzimas envolvidas nessas PTM, tais como metionina aminopeptidases, deformilase, glutaminil ciclase e acetiltransferases, são codificadas pelo genoma de L. braziliensis (Cuervo et al., 2007). Fosfoproteínas de promastigotas e amastigotas axênicos de $L$. donovani foram purificadas e comparadas, com o intuito de elucidar o papel da fosforilação durante a diferenciação dessa espécie (Morales et al., 2008; Rosenzweig et al., 2008b). As fosfoproteínas identificadas foram classificadas em cinco grupos funcionais: chaperonas, proteínas do citoesqueleto, turnover de proteínas/RNA, sinalização celular, metabolismo e proteínas hipotéticas (Morales et al., 2008; Rosenzweig et al., 2008b). 


\section{INTERAÇÃO PARASITO-HOSPEDEIRO, MARCADORES DE VIRULÊNCIA, ANTÍGENOS PARA DIAGNÓSTICO E IDENTIFICAÇÃO DE POTENCIAIS ALVOS PARA DESENVOLVIMENTO DE VACINAS}

A maioria dos estudos sobre interação parasito-hospedeiro tem-se focado nos antígenos imunogênicos do parasito. Tal interesse dá-se em razão da carência de vacinas para leishmaniose, o que tem levado muitos pesquisadores a investir esforços na busca por proteínas que possam ser usadas para o desenvolvimento racional de vacinas. Nesse sentido, as abordagens proteômicas apresentam uma oportunidade única para detectar marcadores de virulência em Leishmania e em potenciais alvos vacinais.

Os parasitos de subgênero Leishmania (Viannia), em particular L. braziliensis, L. panamensis e L. guyanensis são os agentes etiológicos da leishmaniose mucocutânea nas Américas do Sul e Central. Esses parasitos são capazes de se disseminar (por metástase) a partir da lesão cutânea primária à mucosa nasofaríngea, produzindo desde perfuração do septo nasal até lesões faciais desfigurantes envolvendo o palato, os lábios, a faringe e a traqueia (Osorio, Castillo \& Ochoa, 1998; Saravia et al., 1985; Santrich et al., 1990; Marsden, 1986; Oliveira-Neto et al., 2000; Figueroa et al., 2009).

Em recente trabalho, clones de L. guyanensis expressando distintos fenótipos metastáticos estáveis - parasitos apresentando desde alta capacidade metastática à intermediária e baixa capacidade - foram analisados por 2DE e MS/MS com o intuito de identificar potenciais fatores metastáticos (Walker et al., 2006b). A comparação de seus proteomas revelou que o fator de elongação $1-\beta$ (EF-1 $\beta$ ) e a triparedoxina peroxidase (TXNPX) poderiam estar associados ao fenótipo altamente metastático. Tal associação envolveria alternância na expressão de isoformas das proteínas, em vez de superexpressão ou subexpressão das mesmas. Além do seu papel na síntese de proteínas, o EF$1 \beta$ tem atividades de tripanotiona S-transferase e tripanotiona peroxidase, as quais são importantes na defesa contra o estresse oxidativo (Vickers \& Fairlamb, 2004; Vickers, Wylie \& Fairlamb, 2004).

Não obstante as evidências de que tais proteínas contribuam para a sobrevivência e persistência do parasito in vitro, quando o fenótipo bioquímico foi analisado em isolados clínicos observou-se uma expressão inconsistente desses marcadores. Esse resultado levou os autores a sugerir que as lesões metastáticas são determinadas por múltiplos mecanismos que envolvem tanto a resposta do hospedeiro, quanto determinantes moleculares dos parasitos (Walker et al., 2006b). Estudos posteriores demonstraram que a presença de vírus RNA em cepas de L. guyanensis com distintas capacidades metastáticas pode modular a resposta imune do hospedeiro (Ives et al., 2011). 0 estudo também apontou que a exacerbada resposta inflamatória na leishmaniose mucocutânea está relacionada com a intensidade da carga viral presente no parasito (Ives et al., 2011).

Proteínas imunomodulatórias e proteínas antigênicas têm sido analisadas por abordagens proteômicas em $L$. infantum e L. donovani (Dea-Ayuela, Rama-Iñiguez \& Bolás-Fernández, 2006; Forgber et al., 2006; Gupta et al., 2007; Costa et al., 2011). Tais estudos revelaram que proteínas pertencentes a categorias muito distintas podiam ser antigênicas. Entre estas, foram identificadas propinil carboxilase, transcetolase, gp63, fatores de iniciação, fatores de elongação, subunidades de proteasome, ATPases, subunidades de tubulina, enolase e HSP. Também se observou que a antigenicidade dessas proteínas não se correlaciona com seus níveis de expressão.

Recentemente, uma abordagem imunoproteômica in silico foi usada para identificar proteínas antigênicas em L. major por meio da predição de epítopos reconhecidos por células T (Herrera-Najera et al., 2009). A imunogenicidade de 26 dos melhores candidatos foi avaliada em camundongos BALB/c, comprovando-se a natureza imunogênica de 54\% deles. Observou-se também nesse trabalho que nenhum dos atuais candidatos vacinais ou antígenos conhecidos de L. major foram encontrados entre os principais epítopos preditos. Em vez disso, muitas proteínas constitutivamente expressas, incluindo proteínas hipotéticas e duas proteínas de superfície, foram achadas entre os ‘top' 20 epítopos antigênicos preditos (Bolhassani \& Rafati, 2008). Entre os estudos proteômicos descritos anteriormente, HSP são 
comumente identificadas como proteínas altamente antigênicas e, portanto, promissoras candidatas vacinais em Leishmania. O potencial de proteínas de choque térmico como alvos vacinais foi recentemente revisado (Croft, 2008).

\section{RESISTÊNCIA A MEDICAMENTOS E ALVOS TERAPÊUTICOS}

Na ausência de vacinas, o controle da leishmaniose depende majoritariamente do tratamento quimioterápico (Croft, Sundar \& Fourlamb, 2006). Contudo, os compostos de antimônio pentavalente [Sb(V)], antimoniato de meglumina e estibogluconato de sódio - primeira linha de eleição no tratamento atual de pacientes com leishmaniose (FarautGambarelli et al., 1997) -, que têm sido usados há mais de sessenta anos, apresentam alta toxicidade e severos efeitos secundários que incluem arritmias cardíacas e dano renal. Além disso, pacientes refratários ao tratamento e isolados clinicamente resistentes têm sido reportados em distintas partes do mundo (Lira et al., 1999; Palacios et al., 2001; Sundar, 2001; Abdo et al., 2003; Das et al., 2005; Hadighi et al., 2006; Rojas et al., 2006). Os medicamentos de segunda linha tais como anfotericina B, pentamidina, e o medicamento oral miltefosina apresentam também alta toxicidade, eficácia questionável e resistência cruzada, além de não serem economicamente viáveis para muitos países onde a doença é endêmica (Faraut-Gambarelli et al., 1997; Pérez-Victoria et al., 2006; Seifert et al., 2007; Kumar et al., 2009).

Nesse contexto, faz-se imperativa a elucidação dos mecanismos envolvidos na resistência, bem como a descoberta e validação de novos alvos quimioterápicos. O primeiro reporte sobre análise proteômica, destinado à compreensão dos mecanismos de resistência em Leishmania, utiliza e valida a 2DE para observar a superexpressão de proteínas envolvidas em resistência in vitro de L. major ao $\mathrm{Sb}(\mathrm{V})$ (Drummelsmith et al., 2003). Nesse estudo observou-se aumento na intensidade de spots identificados como tripanotiona (TRYR), uma proteína envolvida na detoxificação do antimônio. A presença de vários spots com distintas intensidades sugere a presença de isoformas, provavelmente originadas a partir de PTM (Drummelsmith et al., 2003). Ademais, esse mesmo trabalho demonstrou que a indução in vitro de resistência ao metotrexate (MTX) em promastigotas de L. major é acompanhada pelo aumento na expressão de pteridina redutase, PTR1, um conhecido mediador primário da resistência ao MTX (Drummelsmith et al., 2003; Papadopoulou, Roy \& Ouellette, 1992; Callahan \& Beverley, 1992).

Trabalhos subsequentes demonstraram que mutantes de L. major resistentes ao MXT apresentam expressão aumentada de proteínas envolvidas em resposta ao estresse tais como chaperoninas, HSP e enolase, bem como a metionina adenosiltransferase, cujo papel na resistência não tinha ainda sido descrito (Drummelsmith et al., 2004). Essa enzima catalisa a síntese de S-adenosilmetionina, cujo aumento de síntese correlaciona-se com o surgimento de resistência ao MXT nessa espécie (Drummelsmith et al., 2004).

Ainda que a resistência in vitro ao antimônio seja parcialmente entendida (Croft, Sundar \& Fairlamb, 2006; Ouellette, Drummelsmith \& Papadopoulou, 2004), os mecanismos da resistência em isolados de campo permanecem obscuros. Com base em evidências prévias que sugeriam que o antimoniato eliminava os parasitos por meio de um processo envolvendo vários eventos da morte celular programada (MCP) (Sereno et al., 2001b; Lee et al., 2002; Sudhandiran \& Shaha, 2003), Vergnes e colaboradores conduziram uma análise proteômica comparativa de isolados de campo de $L$. donovani para identificar proteínas potencialmente envolvidas na resistência ao $\mathrm{Sb}(\mathrm{V})$ (Vergnes et al., 2007). Parasitos naturalmente suscetíveis e resistentes ao $\mathrm{Sb}(\mathrm{V})$ diferiram na expressão de HSP83 e de uma pequena proteína relacionada à calpaína. Essas duas proteínas poderiam estar envolvidas na modulação da suscetibilidade ao $\mathrm{Sb}(\mathrm{V})$ e a outros medicamentos, tais como miltefosina, através da interferência nas vias de MCP induzidas por esses quimioterápicos (Vergnes et al., 2007).

Recente estudo comparando amastigotas axênicos de L. infantum sensíveis e resistentes ao $\mathrm{Sb}(\mathrm{V})$ revelou expressão diminuída da proteína de membrana KMP-11, provavelmente em razão do aumento no turnover da mesma. Deduziu- 
se que tal redução poderia afetar a interação de transportadores tais como aquagliceroporina ou sistemas de efluxo, os quais, por sua vez, aumentariam o bombeio do Sb(III) para fora da célula (El Fadili et al., 2009).

\section{PERSPECTIVAS}

A aplicação de metodologias de análise proteica em larga escala em Leishmania spp. tem provado ser de grande valia para a identificação de grupos específicos de proteínas expressos por cada estágio de desenvolvimento do parasito, como também para a caracterização dos subproteomas e as PTM que as proteínas desses organismos sofrem. A análise proteômica de organelas tem revelado novas proteínas que não haviam sido descritas em análises do proteoma total.

Em paralelo, tais abordagens ressaltam a importância das metodologias de subfracionamento para enriquecer frações proteicas específicas, ampliando o entendimento da biologia do parasito e mudando o paradigma da localização de proteínas nesses organismos. Contudo, a pureza desses subproteomas apresenta ainda um desafio metodológico e requer o emprego de técnicas mais refinadas. A elucidação dos mecanismos de modificação pós-traducional e das PTM per se pode trazer informações relevantes sobre novas vias candidatas para intervenção terapêutica. A descrição e análise das interações proteína-proteína em Leishmania spp. ainda são tímidas e representam um passo crítico para elucidar de forma integrada os mecanismos de virulência e patogenicidade nesses parasitos.

\section{REFERÊNCIAS}

ABDO, M. G. et al. Antimony-resistant Leishmania donovani in eastern Sudan: incidence and in vitro correlation. Eastern Mediterranean Health Journal, 9: 837-843, 2003.

ABE, A. et al. Acetylation at the $\mathrm{N}$-terminus of actin strengthens weak interaction between actin and myosin. Biochemical and Biophysical Research Communications, 268: 14-19, 2000.

ACESTOR, N. et al. Establishing two-dimensional gels for the analysis of Leishmania proteomes. Proteomics, 2: 877-879, 2002.

ADAUI, V. et al. Comparative gene expression analysis throughout the life cycle of Leishmania braziliensis: diversity of expression profiles among clinical isolates. PLoS Neglected Tropical Diseases, 5(5): e1.021, 2011.

AKOPYANTS, N. S. et al. Expression profiling using random genomic DNA microarrays identifies differentially expressed genes associated with three major developmental stages of the protozoan parasite Leishmania major. Molecular and Biochemical Parasitology, 136: 71-86, 2004.

ALCOLEA, P. J. et al. Transcriptomics throughout the life cycle of Leishmania infantum: high down-regulation rate in the amastigote stage. International Journal for Parasitology, 40(13): 1.497-1.516, 2010.

ALMEIDA, R. et al. Expression profiling of the Leishmania life cycle: cDNA arrays identify developmentally regulated genes present but not annotated in the genome. Molecular and Biochemical Parasitology, 136: 87-100, 2004.

AURRECOECHEA, C. et al. EuPathDB: a portal to eukaryotic pathogen databases. Nucleic Acids Research, 38(Database): D415-D419, 2010.

BENTE, M. et al. Developmentally induced changes of the proteome in the protozoan parasite Leishmania donovani. Proteomics, 3: 1.811-1.829, 2003.

BERRIMAN, M. Data mining parasite genomes. Parasitology, 128: S23-S31, 2004.

BOLHASSANI, A. \& RAFATI, S. Heat-shock proteins as powerful weapons in vaccine development. Expert Review of Vaccines, 7: 1.185-1.199, 2008.

BROBEY, R. K. \& SOONG, L. Establishing a liquid-phase IEF in combination with 2-DE for the analysis of Leishmania proteins. Proteomics, 7: 116-120, 2007. 
BROBEY, R. K. et al. Comparative two-dimensional gel electrophoresis maps for promastigotes of Leishmania amazonensis and Leishmania major. Brazilian Journal of Infectious Diseases, 10: 1-6, 2006.

BROOKS, D. R. et al. The stage-regulated expression of Leishmania mexicana CPB cysteine proteases is mediated by an intercistronic sequence element. The Journal of Biological Chemistry, 276: 47.061-47.069, 2001.

BROTHERTON, M. C. et al. Analysis of stage-specific expression of basic proteins in Leishmania infantum. Journal of Proteome Research, 9: 3.842-3.853, 2010.

CALLAHAN, H. L. \& BEVERLEY, S. M. A member of the aldoketo reductase family confers methotrexate resistance in Leishmania. The Journal of Biological Chemistry, 267: 24.165-24.168, 1992.

CHAREST, H.; ZHANG, W. W. \& MATLASHEWSKI, G. The developmental expression of Leishmania donovani A2 amastigotespecific genes is post-transcriptionally mediated and involves elements located in the 3'-untranslated region. The Journal of Biological Chemistry, 271: 17.081-17.090, 1996.

CLAYTON, C. E. Developmental regulation without transcriptional control? From fly to man and back again. The Embo Journal, 21: 1.881-1.888, 2002.

CLAYTON, C. E. \& SHAPIRA, M. Post-transcriptional regulation of gene expression in trypanosomes and leishmanias. Molecular and Biochemical Parasitology, 156: 93-101, 2007.

COHEN-FREUE, G. et al. Global gene expression in Leishmania. International Journal for Parasitology, 37(10): 1.077-1.086, 2007.

COOMBS, G. H.; CRAFT, J. A. \& HART, D. T. A comparative study of Leishmania mexicana amastigotes and promastigotes. Enzyme activities and subcellular locations. Molecular and Biochemical Parasitology, 5: 199-211, 1982.

COSTA, M. M. et al. Analysis of Leishmania chagasi by 2-D difference gel electrophoresis (2-D DIGE) and immunoproteomic: identification of novel candidate antigens for diagnostic tests and vaccine. Journal of Proteome Research, 10: 2.172$2.184,2011$.

CROFT, S. L. Kinetoplastida: new therapeutic strategies. Parasite, 15: 522-527, 2008.

CROFT, S. L.; SUNDAR, S. \& FAIRLAMB, A. H. Drug resistance in leishmaniasis. Clinical Microbiology Reviews, 19: 111-126, 2006.

CUERVO, P. et al. Proteome analysis of Leishmania (Viannia) braziliensis by two-dimensional gel electrophoresis and mass spectrometry. Molecular and Biochemical Parasitology, 154: 6-21, 2007.

CUERVO, P. et al. Proteomic characterization of the released/secreted proteins of Leishmania Viannia) braziliensis promastigotes. Journal of Proteomics, 73: 79-92, 2009.

CUMMINS, P. M. \& O'CONNOR, B. Pyroglutamyl peptidase: an overview of the three known enzymatic forms. Biochimica et Biophysica Acta, 1.429: 1-17, 1998.

DAS, V. N. et al. Magnitude of unresponsiveness to sodium stibogluconate in the treatment of visceral leishmaniasis in Bihar. The National Medical Journal of India, 18: 131-133, 2005.

DEA-AYUELA, M. A.; RAMA-IÑIGUEZ, S. \& BOLÁS-FERNÁNDEZ, F. Proteomic analysis of antigens from Leishmania infantum promastigotes. Proteomics, 6: 4.187-4.194, 2006.

DEBRABANT, A. et al. Generation of Leishmania donovani axenic amastigotes: their growth and biological characteristics. International Journal for Parasitology, 34: 205-217, 2004.

DEGRAVE, W. M. et al. Parasite genome initiatives. International Journal for Parasitology, 31: 532-536, 2001.

DREGER, M. Subcellular proteomics. Mass Spectrometry Reviews, 22: 27-56, 2003.

DRUMMELSMITH, J. et al. Differential protein expression analysis of Leishmania major reveals novel roles for methionine adenosyltransferase and S-adenosylmethionine in methotrexate resistance. The Journal of Biological Chemistry, 279: 33.273-33.280, 2004.

DRUMMELSMITH, J. et al. Proteome mapping of the protozoan parasite Leishmania and application to the study of drug targets and resistance mechanisms. Molecular \& Cellular Proteomics, 2: 146-155, 2003. 
DUNCAN, R. C. et al. The application of gene expression microarray technology to kinetoplastid research. Current Molecular Medicine, 4(6): 611-621, 2004.

EL FADILI, K. et al. Down regulation of KMP-11 in Leishmania infantum axenic antimony resistant amastigotes as revealed by a proteomic screen. Experimental Parasitology, 123: 51-57, 2009.

EL FAKHRY, Y.; OUELLETTE, M. \& PAPADOPOULOU, B. A proteomic approach to identify developmentally regulated proteins in Leishmania infantum. Proteomics, 2: 1.007-1.017, 2002.

EL-SAYED, N. M. et al. Comparative genomics of trypanosomatid parasitic protozoa. Science, 309(5.733): 404-409, 2005.

FARAUT-GAMBARELLI, F. et al. In vitro and in vivo resistance of Leishmania infantum to meglumine antimoniate: a study of 37 strains collected from patients with visceral leishmaniasis. Antimicrobial Agents and Chemotherapy, 41: 827-830, 1997.

FIGUEROA, R. A. et al. Detection of Leishmania in unaffected mucosal tissues of patients with cutaneous leishmaniasis caused by Leishmania (Viannia) species. The Journal of Infectious Diseases, 200: 638-646, 2009.

FORGBER, M. et al. Mapping the antigenicity of the parasites in Leishmania donovani infection by proteome serology. PLoS One, 1: e40, 2006.

FOUCHER, A. L.; PAPADOPOUlOU, B. \& OUELLETTE, M. Prefractionation by digitonin extraction increases representation of the cytosolic and intracellular proteome of Leishmania infantum. Journal of Proteome Research, 5: 1.741-1.750, 2006.

GONGORA, R. et al. Mapping the proteome of Leishmania Viannia parasites using two-dimensional polyacrylamide gel electrophoresis and associated technologies. Biomedica, 23: 153-160, 2003.

GROLL, M. et al. The catalytic sites of 20 S proteasomes and their role in subunit maturation: a mutational and crystallographic study. Proceedings of the National Academy of Sciences of the USA, 96: 10.976-10.983, 1999.

GUIMOND, C. et al. Modulation of gene expression in Leishmania drug resistant mutants as determined by targeted DNA microarrays. Nucleic Acids Research, 31: 5.886-5.896, 2003.

GUPTA, N.; GOYAL, N. \& RASTOGI, A. K. In vitro cultivation and characterization of axenic amastigotes of Leishmania. Trends in Parasitology, 17: 150-153, 2001.

GUPTA, S. K. et al. Proteomic approach for identification and characterization of novel immunostimulatory proteins from soluble antigens of Leishmania donovani promastigotes. Proteomics, 7: 816-823, 2007.

HADIGHI, R. et al. Unresponsiveness to Glucantime treatment in Iranian cutaneous leishmaniasis due to drug-resistant Leishmania tropica parasites. PLoS Medicine, 3: e162, 2006.

HANDMAN, E.; MITCHELL, G. F. \& GODING, J. W. Identification and characterization of protein antigens of Leishmania tropica isolates. The Journal of Immunology, 126: 508-512, 1981.

HART, D. T. \& COOMBS, G. H. Leishmania mexicana: energy metabolism of amastigotes and promastigotes. Experimental Parasitology, 54: 397-409, 1982.

HERRERA-NAJERA, C. et al. Mining the Leishmania genome for novel antigens and vaccine candidates. Proteomics, 9: 1.293$1.301,2009$.

HERTZ-FOWLER, C. \& HALL, N. Parasite genome databases and web-based resources. Methods in Molecular Biology, 270: 45-74, 2004.

HIDE, M. et al. Leishmania infantum: tuning digitonin fractionation for comparative proteomic of the mitochondrial protein content. Parasitology Research, 103: 989-992, 2008.

HOLZER, T. R.; McMASTER, W. R. \& FORNEY, J. D. Expression profiling by whole-genome inter-species microarray hybridization reveals differential gene expression in procyclic promastigotes, lesion-derived amastigotes, and axenic amastigotes in Leishmania mexicana. Molecular and Biochemical Parasitology, 146: 198-218, 2006.

IVENS, A. C. et al. The genome of the kinetoplastid parasite, Leishmania major. Science, 309(5.733): 436-442, 2005.

IVES, A. et al. Leishmania RNA virus controls the severity of mucocutaneous leishmaniasis. Science, 331: 775-778, 2011. 
JOCHIM, R. C. et al. The midgut transcriptome of Lutzomyia longipalpis: comparative analysis of cDNA libraries from sugarfed, blood-fed, post-digested and Leishmania infantum chagasi-infected sand flies. BMC Genomics, 9: 15, 2008.

KELLY, B. L.; NELSON, T. \& McMASTER, W. R. Stage-specific expression in Leishmania conferred by 3' untranslated regions of L. major leishmanolysin genes (GP63). Molecular and Biochemical Parasitology, 116: 101-104, 2001.

KUMAR, D. et al. In vitro susceptibility of field isolates of Leishmania donovani to Miltefosine and amphotericin B: correlation with sodium antimony gluconate susceptibility and implications for treatment in areas of endemicity. Antimicrobial Agents and Chemotherapy, 53: 835-838, 2009.

LARRETA, R. et al. The expression of HSP83 genes in Leishmania infantum is affected by temperature and by stagedifferentiation and is regulated at the levels of mRNA stability and translation. BMC Molecular Biology, 5: 3, 2004.

LEE, N. et al. Programmed cell death in the unicellular protozoan parasite Leishmania. Cell Death and Differentiation, 9: 53-64, 2002 .

LEIFSO, K. et al. Genomic and proteomic expression analysis of Leishmania promastigote and amastigote life stages: the Leishmania genome is constitutively expressed. Molecular and Biochemical Parasitology, 152: 35-46, 2007.

LEPROHON, P. et al. Modulation of Leishmania ABC protein gene expression through life stages and among drug-resistant parasites. Eukaryot Cell, 5: 1.713-1.725, 2006.

LIRA, R. et al. Evidence that the high incidence of treatment failures in Indian kalaazar is due to the emergence of antimonyresistant strains of Leishmania donovani. The Journal of Infectious Diseases, 180: 564-567, 1999.

MARSDEN, P. D. Mucosal leishmaniasis ("espundia” escomel, 1911). Transactions of the Royal Society of Tropical Medicine and Hygiene, 80: 859-876, 1986.

MARTINEZ, J. E. et al. Metastatic capability of Leishmania (Viannia) panamensis and Leishmania (Viannia) guyanensis in golden hamsters. The Journal of Parasitology, 77: 762-768, 1991.

McCONVILLE, M. J. et al. Living in a phagolysosome; metabolism of Leishmania amastigotes. Trends in Parasitology, 2007; $23(8): 368-75$.

McNICOLL, F. et al. A combined proteomic and transcriptomic approach to the study of stage differentiation in Leishmania infantum. Proteomics, 6: 3.567-3.581, 2006.

MOJTAHEDI, Z.; CLOS, J. \& KAMALI-SARVESTANI, E. Leishmania major: identification of developmentally regulated proteins in procyclic and metacyclic promastigotes. Experimental Parasitology, 119: 422-429, 2008.

MORALES, M. A. et al. Phosphoproteomic analysis of Leishmania donovani pro- and amastigote stages. Proteomics, 8: 350363, 2008.

NUGEnT, P. G. et al. Proteomic analysis of Leishmania mexicana differentiation. Molecular and Biochemical Parasitology, 136: 51-62, 2004.

OLIVEIRA-NETO, M. et al. American tegumentary leishmaniosis (ATL) in Rio de Janeiro state, Brazil: main clinical and epidemiologic characteristics. International Journal of Dermatology, 39: 506-514, 2000.

OSORIO, L.; CASTILLO, C. M. \& OCHOA, M. T. Mucosal leishmaniasis due to Leishmania (Viannia) panamensis: clinical characteristics. The American Journal of Tropical Medicine and Hygiene, 59: 49-52, 1998.

OUElletTE, M.; DRUMmElSMith, J. \& PAPADOPOUlOU, B. Leishmaniasis: drugs in the clinic, resistance and new developments. Drug Resistance Updates, 7: 257-266, 2004.

PAAPE, D. et al. Transgenic, fluorescent Leishmania mexicana allow direct analysis of the proteome of intracellular amastigotes. Molecular \& Cellular Proteomics, 7: 1.688-1.701, 2008.

PALACIOS, R. et al. Treatment failure in children in a randomized clinical trial with 10 and 20 days of meglumine antimonate for cutaneous leishmaniasis due to Leishmania viannia species. The American Journal of Tropical Medicine and Hygiene, 64: 187-193, 2001. 
PAN, A. A. et al. Developmental life cycle of Leishmania--cultivation and characterization of cultured extracellular amastigotes. The Journal of Eukaryotic Microbiology, 40: 213-223, 1993.

PAPADOPOULOU, B.; ROY, G. \& OUELLETTE, M. A novel antifolate resistance gene on the amplified $\mathrm{H}$ circle of Leishmania. The Embo Journal, 11: 3.601-3.608, 1992.

PEACOCK, C. S. et al. Comparative genomic analysis of three Leishmania species that cause diverse human disease. Nature Genetics, 39(7): 839-847, 2007.

PÉREZ-VICTORIA, F. J. et al. Mechanisms of experimental resistance of Leishmania to miltefosine: implications for clinical use. Drug Resistance Updates, 9: 26-39, 2006.

PETERS, N. \& SACKS, D. L. Immune privilege in sites of chronic infection: Leishmania and regulatory T-cells. Immunological Reviews, 213: 159-179, 2006.

PITALUGA, A. N. et al. EST sequencing of blood-fed and Leishmania-infected midgut of Lutzomyia longipalpis, the principal visceral leishmaniasis vector in the Americas. Molecular Genetics and Genomics, 282(3): 307-317, 2009.

POLEVODA, B. \& SHERMAN, F. Na-terminal acetylation of eukaryotic proteins. The Journal of Biological Chemistry, 275: 36.479-36.482, 2000 .

PUENTES, F. et al. Cultivation and characterization of stable Leishmania guyanensis complex axenic amastigotes derived from infected U937 cells. The American Journal of Tropical Medicine and Hygiene, 63: 102-110, 2000.

PURDY, J. E. ; DONELSON, J. E. \& WILSON, M. E. Regulation of genes encoding the major surface protease of Leishmania chagasi via mRNA stability. Molecular and Biochemical Parasitology, 142: 88-97, 2005.

QUIJADA, L.; SOTO, M. \& REQUENA, J. M. Genomic DNA macroarrays as a tool for analysis of gene expression in Leishmania. Experimental Parasitology, 111: 64-70, 2005.

RAMALHO-ORTIGÃo, M. et al. Exploring the midgut transcriptome of Phlebotomus papatasi: comparative analysis of expression profiles of sugar-fed, blood-fed and Leishmania-major-infected sandflies. BMC Genomics, 8: 300, 2007.

ROBINSON, N. E. \& ROBINSON, A. B. Molecular clocks. Proceedings of the National Academy of Sciences of the USA, 98: 944-949, 2001.

ROJAS, R. et al. Resistance to antimony and treatment failure in human Leishmania (Viannia) infection. The Journal of Infectious Diseases, 193: 1.375-1.383, 2006.

ROSENZWEIG, D. et al. Retooling Leishmania metabolism: from sand fly gut to human macrophage. Faseb Journal, 22: 590602, 2008 a.

ROSENZWEIG, D. et al. Post-translational modification of cellular proteins during Leishmania donovani differentiation. Proteomics, 8: 1.843-1.850, 2008b.

SANTRICH, C. et al. Mucosal disease caused by Leishmania braziliensis guyanensis. The American Journal of Tropical Medicine and Hygiene, 42: 51-55, 1990.

SARAVIA, N. G. et al. Two-dimensional electrophoresis used to differentiate the causal agents of American tegumentary leishmaniasis. Clinical Chemistry, 30: 2.048-2.052, 1984.

SARAVIA, N. G. et al. Mucocutaneous leishmaniasis in Colombia: Leishmania braziliensis subspecies diversity. The American Journal of Tropical Medicine and Hygiene, 34: 714-720, 1985.

SAXENA, A. et al. Evaluation of differential gene expression in Leishmania major Friedlin procyclics and metacyclics using DNA microarray analysis. Molecular and Biochemical Parasitology, 129: 103-114, 2003.

SAXENA, A. et al. Analysis of the Leishmania donovani transcriptome reveals an ordered progression of transient and permanent changes in gene expression during differentiation. Molecular and Biochemical Parasitology, 152: 53-65, 2007.

SEIFERT, K. et al. Inactivation of the miltefosine transporter, LdMT, causes miltefosine resistance that is conferred to the amastigote stage of Leishmania donovani and persists in vivo. International Journal of Antimicrobial Agents, 30: 229$235,2007$. 
SERENO, D. \& LEMESRE, J.-L. Axenically cultured amastigote forms as an in vitro model for investigation of antileishmanial agents. Antimicrobial Agents and Chemotherapy, 41: 972-976, 1997.

SERENO, D. et al. DNA transformation Leishmania infantum axenic amastigotes and their use in drug screening. Antimicrobial Agents and Chemotherapy, 45: 1.168-1.173, 2001a.

SERENO, D. et al. Antimonial-mediated DNA fragmentation in Leishmania infantum amastigotes. Antimicrobial Agents and Chemotherapy, 45: 2.064-2.069, 2001b.

SILVERMAN, J. M. et al. Proteomic analysis of the secretome of Leishmania donovani. Genome Biology, 9: R35, 2008.

SILVERMAN, J. M. et al. An exosome-based secretion pathway is responsible for protein export from Leishmania and communication with macrophages. Journal of Cell Science, 123: 842-852, 2010.

SMITH, D. F; PEACOCK, C. S. \& CRUZ, A. K. Comparative genomics: from genotype to disease phenotype in the leishmaniases. International Journal for Parasitology, 37(11-3): 1.173-1.186, 2007.

SUDHANDIRAN, G. \& SHAHA, C. Antimonial-induced increase in intracellular $\mathrm{Ca} 2+$ through non-selective cation channels in the host and the parasite is responsible for apoptosis of intracellular Leishmania donovani amastigotes. The Journal of Biological Chemistry, 278: 25.120-25.132, 2003.

SUNDAR, S. Drug resistance in Indian visceral leishmaniasis. Tropical Medicine \& International Health, 6: 849-854, 2001.

THIEL, M. \& BRUCHHAUS, I. Comparative proteome analysis of Leishmania donovani at different stages of transformation from promastigotes to amastigotes. Medical Microbiology and Immunology, 190: 33-36, 2001.

VERGNES, B. et al. A proteomics screen implicates HSP83 and a small kinetoplastid calpain-related protein in drug resistance in Leishmania donovani clinical field isolates by modulating drug-induced programmed cell death. Molecular \& Cellular Proteomics, 6: 88-101, 2007.

VICKERS, T. J. \& FAIRLAMB, A. H. Trypanothione S-transferase activity in a trypanosomatid ribosomal elongation factor1B. The Journal of Biological Chemistry, 279: 27.246-27.256, 2004.

VICKERS, T. J.; WYLIE, S. H. \& FAIRLAMB, A. H. Leishmania major elongation factor 1B complex has trypanothione S-transferase and peroxidase activity. The Journal of Biological Chemistry, 279: 49.003-49.009, 2004.

WALKER, J. et al. Identification of developmentally-regulated proteins in Leishmania panamensis by proteome profiling of promastigotes and axenic amastigotes. Molecular and Biochemical Parasitology, 147: 64-73, 2006a.

WALKER, J. et al. Comparative protein profiling identifies elongation factor-1 beta and tryparedoxin peroxidase as factors associated with metastasis in Leishmania guyanensis. Molecular and Biochemical Parasitology, 145: 254-264, 2006b.

WEINTRAUB, S. J. \& MANSON, S. R. Asparagine deamidation: a regulatory hourglass. Mechanisms of Ageing Development, 125: 255-257, 2004.

YAO, C. et al. Proteomic examination of Leishmania chagasi plasma membrane proteins: Contrast between avirulent and virulent (metacyclic) parasite forms. Proteomics: Clinical Applications, 4: 4-16, 2010. 


\section{Formato: $21 \times 26 \mathrm{~cm}$ \\ Tipologia: Caxton Lt Bt e NewsGoth Cn BT \\ Papel: Print Max $90 \mathrm{~g} / \mathrm{m}^{2}$ (miolo) \\ Cartão Supremo $250 \mathrm{~g} / \mathrm{m}^{2}$ (capa) \\ CTP, impressão e acabamento: Imos Gráfica e Editora Ltda.}

Rio de Janeiro, julho de 2014.

Não encontrando nossos livros em livrarias, contactar a Editora Fiocruz:

Av. Brasil, 4036 - térreo - sala 112 - Manguinhos

21040-361 - Rio de Janeiro - RJ

Tels.: (21) 3882-9039 e 3882-9041

Telefax: (21) 3882-9006

www.fiocruz.br/editora

editora@fiocruz.br 